RENS BOD, JAAP MAAT \& THIJS WESTSTEIJN (EDS.)

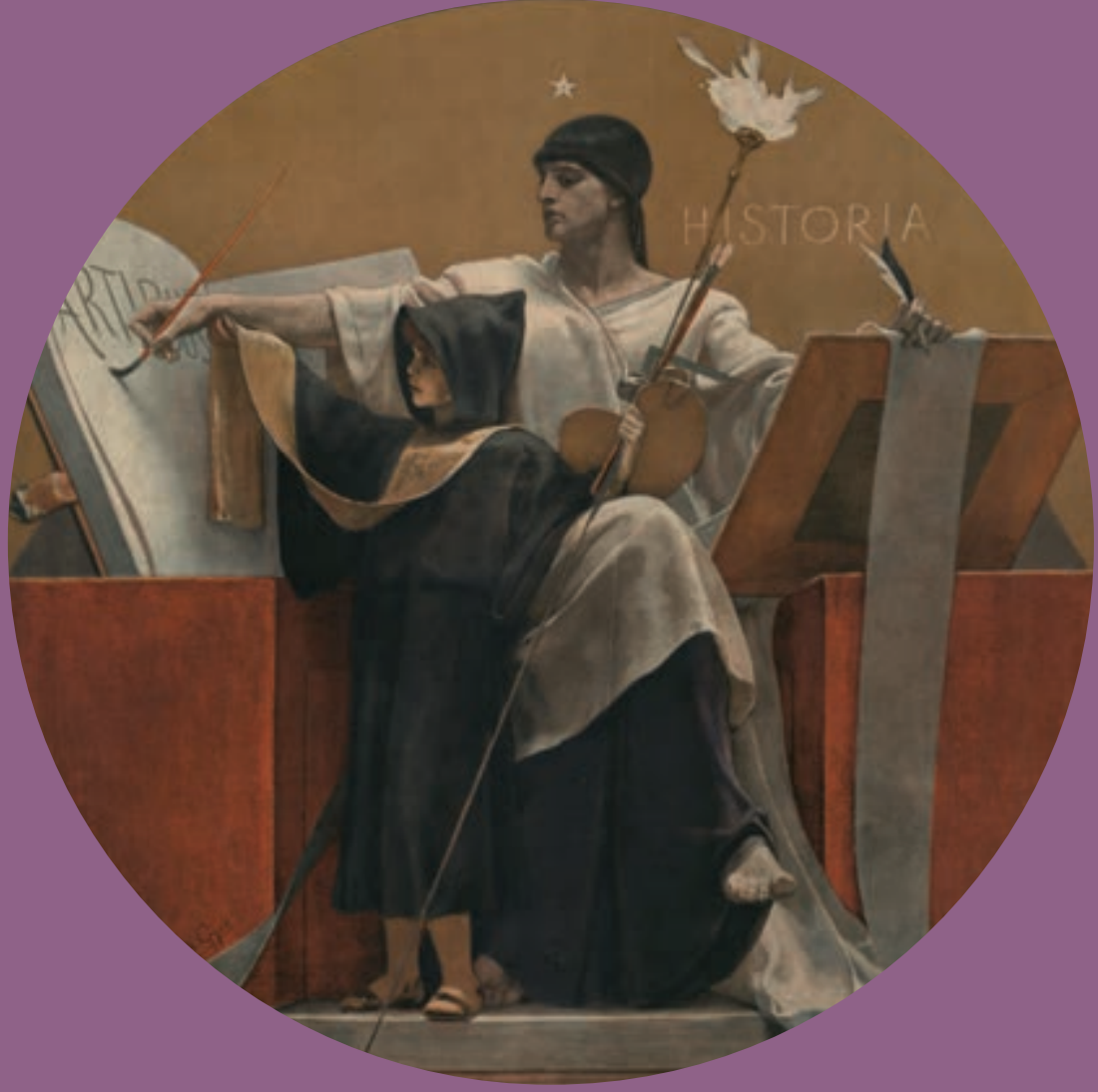

\title{
The MAKING of the HUMANITIES
}

VOLUME III

The Modern Humanities 
THE MAKING OF THE HUMANITIES - VOL. III 



\title{
The Making of the Humanities
}

\author{
Volume III: \\ The Modern Humanities
}

Edited by
Rens Bod,

Jaap Maat and

Thijs Weststeijn 
This book is made possible by a grant from the Netherlands Organization for Scientific Research.

This book is published in print and online through the online OAPEN library (www.oapen,org).

Front cover: Nikolaus Gysis, München 1892 ... VI. internationale Kunstausstellung, 1892, I892, Chromo-lithographed poster, I2I x $68 \mathrm{~cm}$, printed by Chromotypie v. Meisenbach, Riffarth $\&$ Cie (Munich), Bibliothèque nationale de France, Paris, Département Estampes et photographie (inv.nr. EST ENT DO-I). The original oil painting is in a private collection in Athens.

Cover design: Studio Jan de Boer

Lay-out: $\mathrm{V}_{3}$-Services

Amsterdam University Press English-language titles are distributed in the US and Canada by the University of Chicago Press.
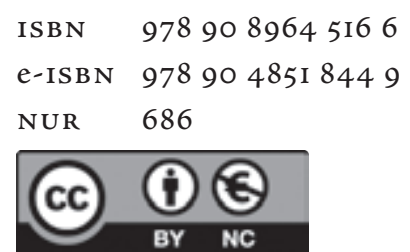

Creative Commons License CC BY NC

(http://creativecommons.org/licenses/by-nc/3.0)

(C) Rens Bod, Jaap Maat, Thijs Weststeijn / Amsterdam University Press B.V., Amsterdam, 2014

Some rights reserved. Without limiting the rights under copyright reserved above, any part of this book may be reproduced, stored in or introduced into a retrieval system, or transmitted, in any form or by any means (electronic, mechanical, photocopying, recording or otherwise).

Every effort has been made to obtain permission to use all copyrighted illustrations reproduced in this book. Nonetheless, whosoever believes to have rights to this material is advised to contact the publisher. 
In memory of John Pickstone (1944-2014) 



\section{Table of Contents}

Introduction: The Making of the Modern Humanities

Rens Bod, JaAp Maat, and Thijs Weststeijn

I The Humanities and the Sciences

I.I Objectivity and Impartiality: Epistemic Virtues in the Humanities Lorraine Daston

I.2 The Natural Sciences and the Humanities in the Seventeenth Century: Not Separate Yet Unequal?

H. Floris Cohen

I.3 The Interaction between Sciences and Humanities in NineteenthCentury Scientific Materialism: A Case Study on Jacob Moleschott's Popularizing Work and Political Activity

Laura Meneghello

I.4 The Best Story of the World: Theology, Geology, and Philip Henry Gosse's Omphalos

Virginia Richter

II The Science of Language

2.I The Wolf in Itself: The Uses of Enchantment in the Development of Modern Linguistics

John E. Joseph

2.2 Soviet Orientalism and Subaltern Linguistics: The Rise and Fall of Marr's Japhetic Theory

Michiel Leezenberg 
2.3 Root and Recursive Patterns in the Czuczor-Fogarasi Dictionary of the Hungarian Language

LÁszló Marácz

\section{Writing History}

3.I A Domestic Culture: The Mise-en-scène of Modern

Historiography

Jo Tollebeek

3.2 History Made More Scholarly and Also More Popular:

A Nineteenth-Century Paradox

Marita Mathijsen

3.3 The Professionalization of the Historical Discipline:

Austrian Scholarly Periodicals, I 840-I900

Christine Ottiner

3.4 Manuals on Historical Method: A Genre of Polemical Reflection on the Aims of Science

Herman Paul

3.5 The Peculiar Maturation of the History of Science

Bart Karstens

IV Classical Studies and Philology

4+I Quellenforschung

GlenN W. Most

4.2 History of Religions in the Making: Franz Cumont (I 868-I947) and the 'Oriental Religions'

Eline Scheerlinck

4.3 'Big Science' in Classics in the Nineteenth Century and the Academicization of Antiquity

Annette M. Baertschi

4.4 New Philology and Ancient Editors: Some Dynamics of

Textual Criticism

Jacqueline Klooster

4.5 What Books Are Made of: Scholarship and Intertextuality in the History of the Humanities

Floris Solleveld 
V Literary and Theater Studies

5.I Furio Jesi and the Culture of the Right

INGRID D. RowLAND

5.2 Scientification and Popularization in the Historiography of

World Literature, I850-I950: A Dutch Case Study

Ton van Kalmthout

5.3 Theater Studies from the Early Twentieth Century to

Contemporary Debates: The Scientific Status of Interdisciplinary-

Oriented Research

Chiara Maria Buglioni

\section{Art History and Archeology}

6.I Embracing World Art: Art History's Universal History and the Making of Image Studies

Birgit Mersmann

6.2 Generic Classification and Habitual Subject Matter

Adi Efal

6.3 The Recognition of Cave Art in the Iberian Peninsula and the Making of Prehistoric Archeology, I 878-1929

José María Lanzarote-Guiral

VII Musicology and Aesthetics

7.I Between Sciences and Humanities: Aesthetics and the EighteenthCentury 'Science of Man'

Maria Semi

7.2 Melting Musics, Fusing Sounds: Stumpf, Hornbostel, and

Comparative Musicology in Berlin

Riccardo Martinelli

7.3 The History of Musical Iconography and the Influence of Art

History: Pictures as Sources and Interpreters of Musical History Alexis Ruccius

\section{East and West}

8.I The Making of Oriental Studies: Its Transnational and Transatlantic Past 
8.2 The Emergence of East Asian Art History in the I920s: Karl With (I89I-I980) and the Problem of Gandhara Julia Orell

8.3 Cross-Cultural Epistemology: How European Sinology Became the Bridge to China's Modern Humanities

Perry JohansSon

\section{Information Science and Digital Humanities}

9.I Historical Roots of Information Sciences and the Making of E-Humanities

Charles van den Heuvel

9.2 Toward a Humanities of the Digital? Reading Search Engines as a Concordance Johanna Sprondel

9.3 A Database, Nationalist Scholarship, and Materialist Epistemology in Netherlandish Philology: The Bibliotheca Neerlandica Manuscripta from Paper to OPAC, I 895-I995 Jan Rock

9.4 Clio's Talkative Daughter Goes Digital: The Interplay between Technology and Oral Accounts as Historical Data Stef Scagliola and Franciska de Jong

9.5 Humanities' New Methods: A Reconnaissance Mission Jan-Willem Romeijn

X Philosophy and the Humanities

I0.I Making the Humanities Scientific: Brentano's Project of Philosophy as Science

Carlo Ierna

I0.2 The Weimar Origins of Political Theory: A Humanities Interdiscipline

David L. Marshall

\section{The Humanities and the Social Sciences}

I I.I Explaining Verstehen: Max Weber's Views on Explanation in the Humanities 
I I.2 Discovering Sexuality: The Status of Literature as Evidence

Robert Deam Tobin

I I.3 The Role of Technomorphic and Sociomorphic Imagery in the Long Struggle for a Humanistic Sociology Marinus Ossewaarde

I .4 Sociology and the Proliferation of Knowledge:

La Condition Humaine

Bram Kempers

I I.5 Inhumanity in the Humanities: On a Rare Consensus in the Human Sciences

Abram de Swaan

XII The Humanities in Society

I2.I The Making and Persisting of Modern German Humanities:

Balancing Acts between Autonomy and Social Relevance

Vincent Gengnagel and Julian Hamann

I2.2 Critique and Theory in the History of the Modern Humanities Paul Jay

\section{Epilogue}

Toward a History of Western Knowledges: Sketching Together the Histories of the Humanities and the Natural Sciences John V. Pickstone

About the Authors

List of Figures

Index 



\title{
Introduction
}

\section{The Making of the Modern Humanities}

\author{
Rens Bod, JaAp MaAt, and Thijs Weststeijn
}

With this third volume of our three-part project on the history of the humanities we have arrived at the modern age. This is the period of discipline formation and academic institutionalization, but it is also the period when the humanities and sciences drew farther apart. While already foreshadowed by Giambattista Vico's famous eighteenth-century distinction between the 'science of the human' and 'science of the natural', Wilhelm Dilthey's distinction between Geisteswissenschaft and Naturwissenschaft was very influential. 'That is, the humanities are deemed to be predicated on understanding (Verstehen), the sciences on explaining (Erklären). The distinction was adopted by philosophers such as Heinrich Rickert, Ernst Cassirer, Hans-Georg Gadamer and it was echoed in C.P. Snow's famous Two Cultures debate. ${ }^{2}$ Although actual practice in the humanities and sciences was quite different from the simple dichotomy between understanding and explaining (see the chapters in this book), the distinction molded the minds of many, and Dilthey's interpretative approach contributed to the current image problem of the humanities. That is, the humanities are no longer seen as the pinnacle of intellectual development but as a luxury pastime with little relevance for society and even less for economy.

While this image problem has been analyzed and rebutted by many, ${ }^{3}$ it is often forgotten that the very distinction between the humanities and the natural sciences is a relatively recent one, and that practices in the sciences and the humanities point at a continuum rather than at a divide between the interpretative and the analytical, and between the subjective and the objective. ${ }^{4}$ More than that, with the current advent of the digital humanities - to which five chapters of this book are devoted - the two fields seem to have come together again in the twenty-first century. Between these two boundary periods - the early nineteenth and the early twenty-first century - there is an immensity of both empirical and interpretative humanistic activities: from art history to linguistics, from musicology to historiography, from philology to archeology, from theater studies to media studies, and 
from literary studies to philosophy. These disciplines deserve an in-depth historical investigation in all respects, especially from a comparative perspective. This is what this book aims to contribute to.

\section{The history of the humanities comes of age}

The current volume is the outcome of the third conference on the history of the humanities, 'The Making of the Humanities III', held in Rome in 20I2. It is also the third volume in the series 'The Making of the Humanities', which follows a chronological order from the studia bumanitatis in the early modern period, through the birth of the Geisteswissenschaften in the early nineteenth century, to the modern humanities in the current era. Thus the first biannual conference on the history of the humanities, held in 2008, dealt with the early modern period (1400-1750). Proceedings were published in The Making of the Humanities, Vol. I: Early Modern Europe (Amsterdam University Press, 2010). The second conference, held in 2010 , focused on the transition of the humanistic disciplines from the early modern period to the modern era, which resulted in the book The Making of the Humanities, Vol. II: From Early Modern to Modern Disciplines (Amsterdam University Press, 2012).

The theme of the third conference was thus a natural continuation of the previous two conferences. But this conference was also different from its predecessors: it included for the first time sessions devoted to the humanities in society and to the relation between the humanities and the social sciences. During the last few years the comparative history of the humanities has proved to be a goldmine: while the history of 'knowledge-making disciplines' usually tends to focus on the history of science, technology, and medicine, it has become increasingly clear how different disciplines in the humanities have set the standard in teaching and research for the social and natural sciences - such can be learned from the contributions of our keynote speakers: Lorraine Daston, John E. Joseph, Glenn Most, John Pickstone, and Jo Tollebeek. Moreover, it has turned out that the humanities had a much more intensive and continuous interaction with the sciences than was previously assumed. If there is any common thread emerging from the chapters of this book, it is the insight that the history of the humanities is not only important as a field of its own, but that it constitutes the missing link in the history of science, or even in the history of knowledge.

There are many other common threads: the historical turn in the early nineteenth century that affected all of the humanities, the search for proper methodologies in the later nineteenth century leading to separate disciplines, the universalist ambitions in the humanities in the early twentieth century (to write 
encompassing overviews of world history, world literature, world art), the postmodern turn in the second half of the twentieth century, and, of course, the turn to the digital in the later twentieth and early twenty-first centuries. The 2012 conference was also different from the previous ones in that it was the first one with parallel sessions. Still, the organizers had to reject almost $70 \%$ of the submissions. From the 167 submitted abstracts, only 50 could be accepted. On the one hand the large number of submissions is a sign that the field is coming of age. On the other hand, it also means that the intimate atmosphere of the previous conferences may not be maintained in the future, as the conference is likely to continue to grow.

This will probably be the last edited volume on "The Making of the Humanities', not because we have arrived at the contemporary era, but because the number of papers is becoming too large to be published in a single edited volume. In sending out all individual papers for review, we are in practice moving toward a journal-like style of publication. For the future, we believe the field will need its own journal where publication is not limited to conference attendees only. In the current time of hardship for scholarship in the humanities, we believe that bringing together all humanities disciplines in one journal will strengthen the position and visibility of the humanities around the globe.

\section{The papers in this book}

Part I dives into the relation between the humanities and sciences. Lorraine Daston argues that the humanities and the sciences - although often framed in terms of oppositions - have intertwined histories at the levels of methods, institutions, ideas and epistemic virtues. She discusses the shared epistemic virtue of objectivity which was preceded by the more ancient epistemic virtue of impartiality. Both virtues have a history, and Daston shows that the notion of historical objectivity became the model for the later scientific objectivity. H. Floris Cohen questions the present-day near-consensus that the modern distinction between the humanities and the sciences was foreign to scholars in the period of the Scientific Revolution. May not such a distinction be found back underneath the surface of at least some of their work? To find out in preliminary fashion, he briefly investigates four select cases: Pascal appears to maintain precisely such a distinction; Descartes appears to posit it in the case of musical theory; Kepler's and Newton's work on biblical chronology turns out to be subtly yet importantly different from their better known work in what we now call the sciences. Laura Meneghello discusses the interaction between the humanities and the natural sciences in the second half of the nineteenth century by analyzing the attitude of scientific materialism - generally considered as one of the most radical movements within positiv- 
ism. By concentrating on the work of Jacob Moleschott (1822-1893), Meneghello argues that scientific materialism was particularly inclusive with respect to the humanities, resulting in an all-encompassing worldview that expanded its limits beyond the sheer divulgation of empirical research. In the last chapter of Part I, Virginia Richter gives a case study of Philip Henry Gosse's (I8IO-I888) Omphalos (1857). She shows how Gosse used rhetorical strategies borrowed from the humanities to make what was for him a scientific argument: just as God had created Adam with a navel, he had created the earth with fossils and all, thus giving the impression not only of the earth's great age but of the mutability of species. Richter argues that Gosse's Omphalos shows the importance of 'nonknowledge' or 'false knowledge' in the formation of scholarly and scientific inquiry.

Part II addresses a number of issues pertaining to the study of language. John E. Joseph analyzes three critical moments in the emergence of modern linguistics: the demise of the concept of the 'genius of a language' in the nineteenth century, the role of sign theory in Saussure's work, and the development of Meillet's work, which resulted in a narrative about mental evolution. Applying a framework proposed by Bruno Latour, Joseph uses these three cases to show that linguistics has never been thoroughly modern, but has always had recourse to various sorts of enchantment in order to establish itself as a science. Michiel Leezenberg investigates the link between nationalism and Orientalism in a paper about the notorious Japhetic theory of Nikolai Marr (I865-I934), which played a prominent part in Soviet linguistics in the first half of the twentieth century. Leezenberg argues that, as the case of Marr's theory shows, the creation of non-Western nationalist theories should not be viewed solely in terms of the colonial exportation of German historical-comparative philology; instead, 'subaltern' forms of knowledge, rooted in local agency, deserve to be explored. László Marácz investigates the context in which the grand project of producing an explanatory, comparative, and etymological dictionary of the Hungarian language took shape in the nineteenth century. Nationalist ambitions were central, as well as Romantic views. In carrying out the work, Gergely Czuczor (I800-I866) and János Fogarasi (I80I-I878) relied on both foreign and local traditions. Although the dictionary was discredited for its alleged outdated approach soon after it was completed, Marácz argues that the dictionary has great merits, and can be used for linguistic research today.

Part III deals with the history of history writing in the modern age. Jo Tollebeek sets the stage by showing that in the decades around 1900, the humanities went through a process of professionalization and academization. In contrast to the natural sciences, however, historians and their colleagues continued to teach in 'lecture rooms' in their private homes. Tollebeek argues that this homely scientific culture strongly contributed to the social, epistemological, and ethical content of the humanities. Marita Mathijsen shows how after the French Revolution 
the writing of history fell into the hands of practitioners of three new kinds: editors, literary authors, and professional historians. New, rigorous standards for authenticity come up, but also popularization in the sense that the past is now opened up to everyone. These two coexisting movements of professionalization and of 'democratization' become particularly manifest as literary authors turn themselves into history writers, all the while historians begin to employ literary techniques. Christine Ottner discusses the influence of scholarly periodicals in the process of academic professionalization and institutionalization. She examines three scholarly journals from the middle of the nineteenth century to the beginning of the twentieth century showing that these not only reflect developments within disciplines, but also actively influence these developments by way of an editorial policy. As part of the making of the historical discipline scholarly periodicals turn out to be very complex elements. Herman Paul examines the impact of ideals of scholarly virtue (such as objectivity, honesty, carefulness) on the development of humanities disciplines. By a study of methodology manuals from history, art history and music history, he argues that these manuals were not merely textbooks on historical criticism, but attempts to codify a certain vision of the historian's scholarly vocation, described in terms of goods to be achieved and to be avoided. Finally, Bart Karstens discusses the history of the history of science. He tries to explain the unstable position of the history of science within the current academic system. Karstens argues that this is due to the tight relation of the history of science to both philosophy of science and the natural sciences themselves. Although alternative models from sociology and anthropology have been used to study science, according to Karstens the study of past science is in a confused state marked by lack of coherence, theoretical anarchy, and uneven attention to the natural sciences and the humanities.

Part IV is devoted to the intertwined traditions of philology and classical scholarship, highlighting how the study of antiquity via its written remnants has informed the systematic analysis of texts in the humanities up to the early twentieth century; it remains relevant today. Glenn W. Most explains how Quellenforschung used to be the basis of explorations of the Greco-Roman world a century ago, whereas nowadays it is practiced by relatively few scholars. By the mid-nineteenth century, Friedrich August Wolf's (1759-I824) philological method was applied to Greek poetry and its extension to philosophy, historiography, and Roman copies of Greek sculptures was the logical next step. Many of the findings of Quellenforschung therefore continue to provide an apparently solid foundation for studies in a variety of disciplines within classical scholarship and beyond, such as historical theology. Eline Scheerlinck addresses the emancipation of the history of religions from its basis in philology and theology. She focuses on the Belgian classicist Franz Cumont (I868-I947), the first to study a specific re- 
ligion (Mithraicism) from the viewpoint of Altertumswissenschaft as a whole, including epigraphical and archeological approaches. He assigned to the Near East a seminal role in the moral and religious evolution of the Roman Empire. Annette M. Baertschi explores how large-scale research projects, launched by the Prussian Academy in the late nineteenth century, made literary and material sources accessible and engendered new forms of organization and collaboration that also impacted the natural sciences: classics, in particular, evolved into an authoritative discipline with subdivisions such as Greek and Latin philology, archeology, ancient history, epigraphy, and papyrology. This development may prove to be analogous to today's 'big data' projects in digital humanities. Jacqueline Klooster points out that Lachmann's philological ideal, aimed at distinguishing the single authoritative version of a text, has been questioned in recent years in reference to medieval textual transmission. She investigates the evidence for ancient variant readings and especially their evaluation by ancient Greek scholars in order to plead for a historically accurate dismissal of the search for the authoritative source. The chapter ties ancient editorial practices and textual transmission to New Philology's observations concerning the status of textual variants. Floris Solleveld, by contrast, focuses on different types of intertextuality to arrive at a new way of analyzing developments in scholarly method in the humanities. He argues that changing patterns of intertextuality (such as editing, extension, compilation, reference, and citation) are revelatory of changing styles of reasoning. Studying practical and conceptual shifts through types of intertextuality therefore opens a new perspective on the relation between scholarly ideals and practices.

Part V, devoted to twentieth-century literature and drama, highlights fundamentally interdisciplinary and transnational approaches. Ingrid D. Rowland foregrounds the versatile historian of literature and religion Furio Jesi (I94I-I980), zooming in on his Cultura di Destra (1979) and its political ideology that harked back to colorful thinkers such as Mircea Eliade (1907-1986) and Julius Evola (1898-1974). Jesi's book comments on the Enlightenment and more recent Fascist past, while also testifying to the author's own role in the politicized Italian 'Years of Lead'. It remains relevant to present-day Italian novelists. Ton van Kalmthout addresses the attempt to write comprehensive histories of 'world literature'. $\mathrm{He}$ explores the development of this historiographical genre in the late nineteenth and early twentieth century, identifying two contrary trends: academization and popularization. The chapter focuses on examples by scholars from the Netherlands, singling out Jan Walch (1879-1946), former professor at the Sorbonne and director of Amsterdam's Theater School. Chiara Maria Buglioni outlines the unique struggle of German theater studies, growing away from literary and historical studies, as well as from ethnology, in the years before the Second World War. Its founders, Max Herrmann (I865-1942) and Artur Kutscher (I878-1960), 
did not define a specific method: Herrmann pointed out the relevance of archeological investigation while Kutscher focused on literary drama and its irrational elements. Many of their problems are still relevant for theater as a multimedial object of inquiry.

Part VI is devoted to the history of art and archeology, focusing on the period around 1900 when new conceptual clarity and disciplinary ambitions arose. Birgit Mersmann associates the making of art history as a universal discipline, based on the understanding of mutual cultural influences and historical transfers, with the German historian Karl Lamprecht (1856-1915). In his wake, texts by Alois Riegl (1898), Oskar Beyer (1923), and Aby Warburg (1923) reached out to disciplines such as universal history and cultural history, which resulted in a reconceptualization of art history's objects, methodology, and geographical framing. This approach adumbrates the current ideal of 'world art studies'. Adi Efal focuses on a specific art-historical concept and its wider application in the humanities: the term 'genre'. Following the scholarship of the Vienna School around 1900, this classification term was superseded by the concept of style as one of the central tools of historicism in the history of art. The chapter argues that genre, as pertaining to the vocabulary of literary history since Aristotle's Poetics, is inherently related to subject matter. The concept of genre furthermore helps to focus historical and analytical attention on an artwork's generation and its diachronic nature. José María Lanzarote-Guiral reveals how the polemic following the discovery of the prehistoric paintings in Altamira (in northern Spain) in 1878 sparked the rise of a discipline. This involved the cross-pollination of the different epistemological traditions of natural science, archeology, and especially anthropology, when Henri Breuil (I877-196I) and Hugo Obermaier (I877-1946) recognized the cave's authenticity in 1902 . The revolutionary insight that 'primitive' men possessed sophisticated symbolic capacities resulted from scholarly exchange across European borders.

Part VII discusses the various attempts of musicologists to incorporate insights from other disciplines, ranging from the natural sciences and psychology to art history. Maria Semi points out how before the birth of the cognitive sciences, natural philosophy had already furnished aesthetics with fundamental notions. She zooms in on Zoonomia (1794-1796), a study of the laws of organic life by Erasmus Darwin (I73I-I8O2), which contained an attempt to define the pleasure received from music in relation to time, repetition, and a melodious succession of notes. A new comprehension of the mind and the body engendered a new way of thinking about the human reaction to art. Riccardo Martinelli begins with the late nineteenth century when comparative musicology became an institutional science. Carl Stumpf (1848-1936), founder of the Phonogramm-Archiv (1906) of non-Western music, developed an empirically oriented investigation of the per- 
ception of sounds. Physiological studies on the sense of touch suggested that two sensations of tone at the same moment tend to mix, which explained the experience of musical consonance. In Stumpf's wake, Erich Hornbostel (1877-1935) focused attention on the eventual 'melting' of Western and non-Western cultures. Alexis Ruccius outlines the history of music iconography as an example of the successful transfer of methods from one discipline to another. In the late nineteenth century, this approach focused merely on reconstructing musical instruments and performance with the aid of images. Only in the igros the Warburg School of art history inquired after the relation between sound and image as an element of the history of ideas, which culminated in Leo Schrade's (1903-1964) analysis of Cluny Abbey.

Part VIII addresses how Western humanities were introduced in Asia and how the confrontation with Asian culture and scholarship affected the humanities in the West. Steffi Marung and Katja Naumann explore how Oriental studies were established in late-nineteenth-century Europe as a transnational endeavor. Around 1900 Russian Oriental studies were internationally in the vanguard. The Petersburg Faculty of Oriental Studies (1855), which included East Asians as scholars, was initially a mainstay for German, French, and English Orientalists. After the 1917 Revolution several leading scholars left the country; some migrating to the US, where the discipline flourished due to the resulting transatlantic networks as exemplified by Serge Elisséeff (1889-1975), who studied in Japan and migrated to Paris before coming to Harvard in I93I. Julia Orell explores how the consolidation of the historical disciplines in Germany engendered the establishment of East Asian art history. The writings of Karl With (I89I-I980) on Japanese and Chinese art from the ig2os reveal some of the methodological issues arising with this new field. His rejection of the Greek-influenced Gandhara sculptures exemplifies how he recognized independent local developments, positing Asia as a counterpart to Europe. At the same time, With associated these developments with the avant-garde art of his own time. Perry Johansson focuses on earlytwentieth-century China as hunting ground for a slew of Western archeological expeditions, marked by the difficult interaction between European scholarship and Chinese politics. He points out how a reaction against foreign attempts to rewrite the Middle Kingdom's history brought about a politics of heritage and history with modern methods. This laid the basis for a reinvention of Chinese tradition that remains relevant today.

Part IX goes into the history of information science and digital humanities well into the twenty-first century. The first contribution by Charles van den Heuvel traces the origins of these disciplines and describes how at the beginning of the computer era, scholars were persuaded to follow the rigorous, often exclusive methods of the natural sciences. Only recently have e-humanities researchers 
pled for the development of holistic methodologies standing in a hermeneutic tradition. Van den Heuvel shows how recent ICT developments also try to incorporate the complexity, ambiguity, and uncertainty of humanities data, methods, and practices leading to a new phase in the making of the humanities, described as Humanities 3.0. Johanna Sprondel examines the history of the concept of concordance. A concordance shows in how many texts any word (or subject) occurs; it may be used to find specific passages, compare different usages, to evaluate relations between words and terms, etc. Sprondel argues that concordance as a genuine concept of the humanities finds its application in Google and other search engines, and that by analyzing these based upon the idea of concordances we can become aware of the changing methods and impacts of the digital. Jan Rock goes into one of the earliest card-file databases on medieval Dutch texts, the Bibliotheca Neerlandica Manuscripta (BNM), set up around 1900 by the Belgian philologist Willem De Vreese (1869-1938) at Ghent. The BNM led to a shift from a materialist approach toward the use of data systems in philology (and nationalistic and scientistic narratives) in the Low Countries and abroad. It contributed to central data systems in philology throughout the twentieth century. Stef Scagliola and Franciska de Jong describe the historiographical development of oral history. After a long period of negligence, oral accounts reemerged as 'reliable' historical sources with the invention of the tape recorder. Affordable technology facilitated the creation of collections around a theme or social group, and in this way supported oral history's ideological agenda of giving voice to the less powerful. Scagliola and De Jong argue that given the multilayered content of audio(visual) oral history accounts, the application of present-day digital tools for searching content and detecting patterns, holds the promise of rich data for multiple disciplines. The final paper by Jan-Willem Romeijn discusses some methodological issues related to the fast growth of empirical and computational methods in the humanities. He argues that confirmation theory - a subdiscipline of philosophy of science - provides useful models for critically evaluating these methods, as it provides a handle on the new notions of evidence that humanities disciplines will need to accommodate. He argues that confirmation theory might thereby help to establish a smoother connection of the humanities with the sciences.

Part X contains two papers discussing the relationship between the humanities and philosophy, each focusing on a specific circle of philosophers. Carlo Ierna explores the idea of philosophy as science in the philosophy of Franz Brentano (1838-1917) and his school. Brentano claimed that the true method of philosophy is none other than that of the natural sciences and claimed a specific field of enquiry for philosophy: mental phenomena defined as phenomena that contain an object intentionally, which are distinct from natural phenomena. This view of philosophy was meant to provide a scientific foundation for the humanities 
independent of the natural sciences, and proved to be a successful research paradigm itself. David L. Marshall revisits the Weimar origins of political theory, and observes hitherto neglected links between Heidegger's 'Dasein', Arendt's 'The Human Condition', Warburg's 'Denkraum' and Benjamin's interest in various sorts of actualization-caught-in-the-midst-of-possibility. Marshall thus reveals a rhetorical core of what could be a rich humanities interdiscipline, in which philosophy, political theory, art history, and literary criticism might all contribute to the analysis of human being as a series of actualizations constituted by possibility.

Part XI is concerned with topics at the interface between the humanities and the social sciences. Jeroen Bouterse discusses the views of Max Weber on how explanation in the humanities differs from that in the natural sciences. Whereas Weber's predecessors Windelband and Rickert tried to safeguard the humanities against the rising scientific psychology by claiming a unique mode of understanding for them, Weber rejected such an approach, arguing that explanation in the humanities should be just as rigorously empirical and objective as in any science, but that it still differed in that its object, human action, is goal-directed and -oriented on values. Robert Deam Tobin reviews the history of the study of sexuality, focusing on the role attributed to evidence from literary sources in theories of sexual identities. Tobin shows that early defenders of male-male love in the I830s relied primarily on literary sources, whereas later in the century both emancipationists and sexologists appealed to natural science. In the early twentieth century, a group of theorists reverted to literature, defending a view of sexuality as fluid and universal, as opposed to the immutable sexual identities supposed by earlier theorists. Marinus Ossewaarde sketches the various imageries that have been instrumental in the shaping of sociology as a discipline. Asserting that in Comtean sociology technomorphic thought patterns were predominant, while with Tocqueville sociomorphic imageries prevailed, Ossewaarde next surveys the history of the field throughout the twentieth century and discusses the changing imageries reflecting the dominant branch of science in a certain period, from nuclear physics to neo-Darwinian biology, which served sometimes as a model, and currently primarily as the object of antagonism for sociologists. Bram Kempers likewise sketches a broad view on the history of sociology, but from the perspective of the great diversity of approaches, rival systems of classification, and ambiguous relations with other social sciences and with the humanities that have characterized the discipline from the beginning. Kempers then traces the development of sociology from Comte and Durkheim, through the interdisciplinary work of Huizinga and the redefinition of the field by Weber and Elias to the present, in which the arts continue to inspire and inform the endeavor to understand the human condition. Rather than to diversity of views, Abram de Swaan draws attention to a consensus in the human sciences - a rare phenomenon. It concerns 
the near unanimous conviction among scholars that the perpetrators of genocide are not distinguishable from other human beings in terms of personality traits. The Eichmann trial in $196 \mathrm{I}$ and the Milgram punishment experiment are typically used in support of the belief that it is the immediate situation, not a certain disposition, that turns people into mass killers. The arguments for this belief are analyzed by De Swaan, and dismantled.

Part XII deals with the position of the humanities in society at large. Vincent Gengnagel and Julian Hamann describe the constant struggle for autonomy that the humanities have been engaged in from the nineteenth century on. Discussing two case studies that exemplify the balancing acts between autonomy and societal as well as academic relevance, they show from a sociological perspective, first, how German historians between I87I and 1945 managed to maintain their own research logic while being politically engaged, and second, that the extensive reforms and the rise of the social sciences in the period after 1945 did not compromise the historians' claim for autonomy. Paul Jay investigates the role that poststructuralist literary, critical, and cultural theory has played in the humanities from 1968 onward, arguing that it would be a mistake to maintain that this type of theory has undermined and marginalized the humanities. On the contrary, it embodies a critical attitude that has always been central to the humanities, and that should be valued and used as an essential part of the mission of the humanities, which is to teach a range of skills in critical thinking.

The volume ends with an Epilogue by John V. Pickstone in which he makes a plea for bringing the histories of the knowledge-making disciplines together - humanities, sciences, medicine, and technology. He shows how the approach put forward in his book Ways of Knowing (2000) can include the humanities, in particular in describing knowledge practices and knowledge revolutions. Drawing from examples from language, history, and philology, Pickstone argues that the common image of humanities disciplines as following the natural sciences is misleading. Instead he argues for a historical frame to include all knowledgemaking disciplines.

\section{Acknowledgements}

Several institutions and people need to be thanked. We are first of all grateful to the Royal Netherlands Institute in Rome (KNIR) for their generous hospitality and support of the 2012 conference. We also greatly thank the other supporting institutions: the Netherlands Organization for Scientific Research (NWO), the Huizinga Institute of Cultural History, and the Institute for Logic, Language and Computation (ILLC) of the University of Amsterdam. We are furthermore 
indebted to Amsterdam University Press for fruitful collaboration for several years and for their fine open access policy. We will unfold our future publication plans at 'The Making of the Humanities IV' conference in Rome (20I4). Last but certainly not least, this volume could not have been completed without the help of external reviewers who generously offered their time and energy. The editors owe a debt of gratitude to Jacques Bos, Petra Brouwer, Floris Cohen, Els Elffers, Gaston Franssen, Toon van Hal, Bart Karstens, Jorrit Kelder, Julia Kursell, Mats Malm, Dirk van Miert, Bram van Oostveldt, Esther Peeren, Jeremia Pelgrom, John Pickstone, Jo Tollebeek, and Miguel-John Versluys.

\section{Notes}

I Wilhelm Dilthey, Einleitung in die Geisteswissenschaften: Versuch einer Grundlegung für das Studium der Gesellschaft und der Geschichte (orig. I 883) (Wiesbaden: Teubner, 1959). For an English translation, see Wilhelm Dilthey, Selected Works, Volume I, translated and edited by Rudolf Makkreel and Frithjof Rodi (Princeton University Press, I99I).

2 Charles Percy Snow, The Two Cultures and the Scientific Revolution (Cambridge University Press, I959).

3 See Jörg-Dieter Gauger and Günther Rüther (eds.), Warum die Geisteswissenschaften Zukunft haben! (Freiburg im Breisgau: Herder, 2007); Martha Nussbaum, Not for Profit: Why Democracy Needs the Humanities (Princeton University Press, 2010); Jonathan Bate (ed.), The Public Value of the Humanities (London: Bloomsbury Academic, 2010); Rens Bod, 'Discoveries in the Humanities That Changed the World', Annuario 53, 2011-2012, Unione Internazionale degli Istituti di Archeologia, Storia e Storia dell'Arte in Roma (Rome: Unione Internazionale degli Istituti, 20II), I89-200; Helen Small, The Value of the Humanities (Oxford University Press, 2013).

4 Rens Bod, A New History of the Humanities: The Search for Principles and Patterns from Antiquity to the Present (Oxford University Press, 2013), $355 \mathrm{ff.}$ 


\section{I \\ The Humanities \\ And The Sciences}
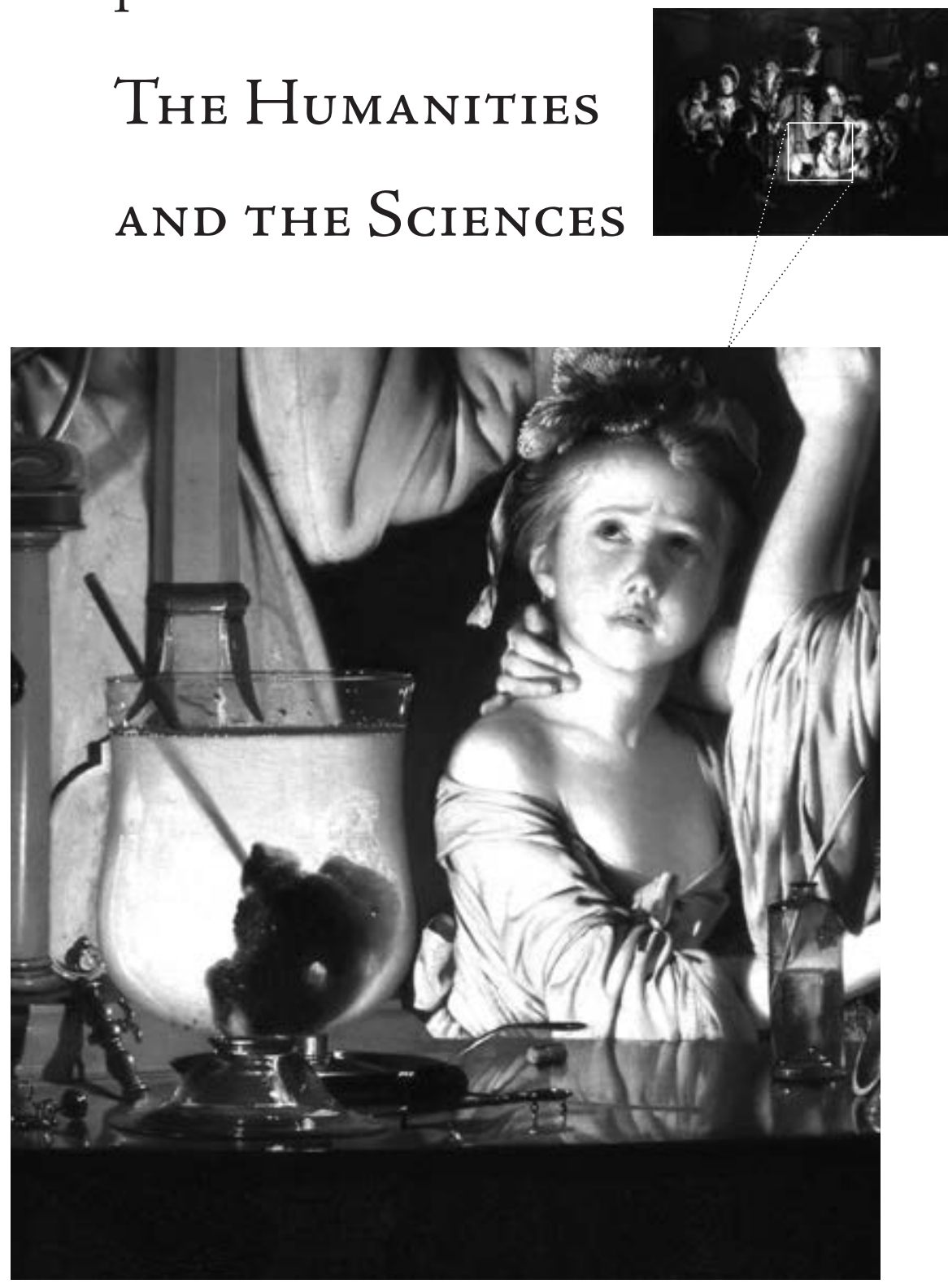



\title{
I.I Objectivity and Impartiality \\ Epistemic Virtues in the Humanities
}

\author{
Lorraine Daston
}

\section{Introduction: Objectivity versus Justice}

For over a century, the relationships between the humanities and the sciences have been largely defined by opposition: Geistes- versus Naturwissenschaften, ideographic versus nomothetic, interpretative versus explanatory, past- versus future-oriented. These oppositions were hammered out in the Festreden of Dilthey, Windelband, Helmholtz, and other leading lights of bellwether German universities and reflected the rising prestige and power of the natural sciences in the final quarter of the nineteenth century. Since then, the history and philosophy of science in most European traditions has been dominated by inquiries into the natural sciences: a comparable history of the humanities is just beginning to be written, and there is as yet no epistemology of the humanities. Yet the histories of the humanities and the sciences have been intertwined since at least the sixteenth century, at multiple levels: methods, institutions, ideas, and also epistemic virtues. Objectivity is one of those shared epistemic virtues. It emerged in both the humanities and the sciences in the nineteenth century. But in at least some of the humanities, it was preceded by a more ancient epistemic virtue: impartiality.

I shall begin with Nietzsche, who put the point of this paper into one lapidary sentence: 'Objektivität und Gerechtigkeit haben nichts miteinander zu tun.' Impartiality is an ancient, judicial value; objectivity is a quite modern scientific value. Nietzsche admired the severity of the just man, who must elevate himself above those who would be judged, but he sneered at the pretensions of the objective historian, der, den ein Moment der Vergangenheit gar nichts angehe [...] das nennt man wohl auch "Objektivität!"!' I call Nietzsche as my star witness because he was at once a sterling product and bitter critic of the new institutions of scholarly teaching and research that forged new epistemic virtues like objectivity in the humanities. ${ }^{3}$ 
In our own time, the words 'impartial' and 'objective' are used almost as synonyms, especially by historians. My aim here is to show that these virtues so dear to historians themselves have histories, which are distinct and not always harmonious. During the nineteenth century, when history became a self-consciously 'objective' science, especially in Germanophone Europe, the tensions between impartiality and objectivity became acute, as Nietzsche realized. In order to throw the differences between the aims of impartiality and objectivity in history into relief, I shall begin with a sketch of how impartiality was preached and practiced by eighteenth-and nineteenth-century historians, especially in the increasingly volatile context of national histories. I then turn to objectivity, arguing that it resided primarily in certain techniques applied to, as well as attitudes toward, the subject matter of history. Both techniques and attitudes come clearly to the fore in the protracted controversy waged among classical philologists and ancient historians over the speeches in Thucydides: did he betray his own methodological principles in reconstructing them so freely? In conclusion, I pose the Nietzschean question as to how the ascetic religion of objectivity took hold of historians in the nineteenth century.

\section{Impartiality}

For the literate eighteenth-century public, the chief utility of history consisted in its true narrations of lives and events presented as guides both moral and practical for readers. On this rhetorical, humanist model, history schooled both judgment and character by exempla. The more ambitious forms of philosophical history also sought out universal generalizations, especially in the realms of politics and human nature. The impartiality of this brand of history was often literally meant: not taking the part of any of the parties whose words and deeds were chronicled in the history. Tacitus's motto was often cited: Sine ira et studio (without anger or zeal). Impartiality by no means implied value neutrality on the part of the historian. On the contrary, the aim of historical impartiality was to reach sound conclusions about moral matters as they were played out in the wars and political conflicts of the past, much as the aim of judicial impartiality was to reach a just verdict in legal matters as presented in criminal and civil cases. ${ }^{4}$ Adam Smith went so far as to make impartiality the basis of all morality: "We endeavor to examine our own conduct as we imagine any other fair and impartial spectator would examine it.' It is in eighteenth-century writings on history and morals that the metaphor of impartiality as perspectival suppleness becomes entrenched: Adam Smith's ethics of impartiality demands that we 'change our position. ${ }^{6}$ 
There was nothing necessarily relativist about these perspectival metaphors of impartiality. So, for example, Edward Gibbon's The Decline and Fall of the Roman Empire (1776-I788) offered a studiously even-handed portrayal of the mores and character of the German barbarians, and much of the liveliness of his descriptions stems from his attempts to see the world from the perspective of the Goths and the Vandals, going far beyond the observations provided by Tacitus:

The languid soul, oppressed with its own weight, anxiously required some new and powerful sensation; and war and danger were the only amusements adequate to its fierce temper. The sound that roused the German to arms was grateful to his ear. It roused him from his uncomfortable lethargy, gave him an active pursuit, and, by strong exercise of the body, and violent emotions of the mind, restored him to a more lively sense of his existence.

But Gibbon's empathic ability to imagine the states of soul of a German warrior by no means implied sympathy, nor did it curb the enlightened historian's judgment on the state of German civilization - or rather, lack thereof:

The Germans, in the age of Tacitus, were unacquainted with the use of letters; and the use of letters is the principle circumstance that distinguishes a civilized people from a herd of savages, incapable of knowledge or reflection. [...] They passed their lives in a state of ignorance and poverty, which it has pleased some declaimers to dignify with the appellation of virtuous simplicity?

I have chosen a passage on the Germans advisedly. The most fiery nineteenthcentury disputes about historical impartiality involved French and German historians who accused one another of fighting today's battles with ammunition from yesterday's history, as often as not encounters between Germanic and Roman peoples in ancient and medieval times. Among the most ferocious of these confrontations was that between two eminent ancient historians, Numa Denis Fustel de Coulanges and Theodor Mommsen, over the nationality of the inhabitants of Alsace-Lorraine in the wake of the Franco-Prussian War. Mommsen, in two letters addressed to a Milanese newspaper in July-August $1870,{ }^{8}$ had argued on the basis of language and race that the Alsatians were of German nationality. In October I870 Fustel replied indignantly:

Mais je m'étonne qu'un historien comme vous affecte d'ignorer que ce n'est ni la race ni la langue qui fait la nationalité [...]. La patrie, c'est ce qu'on aime. Il se peut que l'Alsace soit allemande par la race et par le langage; mais par la nationalité et le sentiment de la patrie elle est française. 
Fustel accused Mommsen and the Prussian army of imposing nationality by conquest. ${ }^{9}$ This was a head-to-head collision over a matter that inflamed nationalist passions on both sides of the Rhine, but hints of the polemic crept into more rarefied historical works on topics apparently quite remote from the Franco-Prussian War. In an 1877 note on whether German law in the fifth century AD permitted a partition of land between Romans and barbarians, Fustel's philological analysis was meticulous, and his conclusion (that the Burgundians had by no means ceded their territories to the invading Germans) hedged with scientific caution. But a remark fraught with relevance for Europe in 1872 , rather than 472 , crept into the final paragraph: 'C'était un système bien commode de dire que les Germains étaient venus en vainqueurs, qu'ils avaient confisqué le sol des vaincus et qu'ils l'avaient partagé au sort. On ne peut plus se contenter de ces généralités vagues et fausses. ${ }^{10}$ And in an 1872 review of a book on the origins of the Germanic empire, ${ }^{\text {II }}$ after upbraiding German historians for their patriotism and French historians for their slavish Germanophilia, Fustel noted with satisfaction that the book under review showed that 'la Germanie, en tant que nation civilisée, est l'oeuvre de Rome et de Gaule [...] le progrès intellectuel, social, moral, ne s'est pas opéré dans la race germanique par un développement interne, et ne fut jamais le fruit d'un travail indigène.. ${ }^{\prime 2}$

Fustel was, of course, aware that such sentiments accorded ill with the vaunted impartiality of history, and yearned for 'ce charme d'impartialité parfaite qui est la chasteté de l'histoire'. But in the very next breath he made it clear that impartial history, 'chaste history', was in his view 'cette vraie science française d'autrefois, cette érudition si calme, si simple, si haute de nos bénédictins, de notre Académie des Inscriptions'. And in any case, whatever one thought of the impartiality of the Benedictine historians, those pure, tranquil times were gone forever. In a bellicose age like his own, even science and learning must don sword and shield. Besides, he could not resist adding, the German historians had begun the mischief by writing in the sign of the Vaterland. For them the science of history (and Fustel was as adamant as his German colleagues in his insistence that it was a science) was not an end in itself but a mean toward promoting national interests.

Fustel was not so wide of the mark when he indicted German historians like Wilhelm von Giesebrecht for strident patriotism in their works. ${ }^{13}$ Once the nation-state became the protagonist of historical narratives, portrayal of the past in the service of present nationalist interests became a constant temptation. The temptation was not irresistible: Leopold von Ranke, for example, had conceived of his Geschichten der romanischen und germanischen Völker (1824) in terms of 'sechs grosse Nationen', the French, Spanish, Italian, German, English, and Scandinavian. But he insisted upon their essential unity (despite the fact that they were constantly at war with one another during the period in question, I494- 
I5I4), and let each nation in turn command center stage in his narrative so long as, in the famous phrase, 'zuweilen die Hand Gottes über ihnen.' ${ }^{14}$ However, the next generation of German historians, although they unanimously embraced the new methods with which the names of Niebuhr and Ranke were narrowly associated, included figures such as Heinrich von Sybel and Georg Gervinus, who explicitly rejected Ranke's doctrine of impartiality. At his public defense of his doctoral dissertation at the Universität Berlin in 1838 , Sybel made 'Cum ira et studio' his motto, and he later criticized his teacher Ranke's studied neutrality as cold, colorless, and perhaps even cowardly.5 Gervinus in his history of German literature also exhorted the science of history to take hold of life with both hands, and saw Machiavelli's greatness as a historian precisely in his political engagement - a position that Ranke criticized as unscientific; Gervinus for his part contended that Ranke's much vaunted impartiality was simply a sign of political impotence. ${ }^{16}$ Friedrich Nietzsche and Heinrich von Treitschke had still stronger words for what they regarded as the self-imposed eunuchry of the Rankean school in matters of impartiality. Yet with the notable exception of Nietzsche, to whom I shall return, all of them, even the political firebrand Treitschke, believed that historical objectivity was essential, one of the glorious achievements of nineteenth-century historiography. This is a position that has bewildered and exasperated their successors. ${ }^{17}$ In the next section I shall try to explain how it was conceivable for these historians to embrace objectivity even as they jettisoned impartiality.

\section{Objectivity}

It would be highly misleading to claim that nineteenth-century historians agreed about the meaning of impartiality or objectivity, much less about the relationships between the two. Just because these words as well as the ideals and practices they represented were so central to the historian's ethos, and therefore so unavoidable in polemics, they admitted of much stretching and shading. I cannot possibly do justice to the spectrum of positions here. Instead, I want to concentrate on core meanings of objectivity that were widely accepted among nineteenth-century historians, however, sharply they may have diverged on more penumbral elements. At the core of this core meaning were the practices of the new-style scientific historian. Although not all - perhaps even none - of these methods was entirely new to Ranke and his students (Fustel thought they'd all been invented by the Benedictines and Mabillon long before), they were nonetheless perceived by most nineteenth-century historians as having finally established their discipline on a firm scientific foundation. On the fringes, as it were, of the core sense of objectivity was the vaguer but nonetheless strongly felt value of scientific restraint, which 
judged precisely how far the evidence at hand could be pushed and refrained from pushing it one whit further.

Gustav Droysen's position as outlined in his influential Grundriss der Historik (1867) is particularly instructive in this context, because he defended historical objectivity while rejecting, on the one hand, historical positivism à la Henry Herbert Buckle (who sought deterministic laws of history based on statistical data) and, on the other hand, historical romance à la Macaulay and Michelet. Droysen dismissed the cult of 'reine Tatsachen' as superstition, the pursuit of deterministic laws in history as wrongheaded, and the faith that history can arrive at unmediated truths about the past as criminally naive. It was the great achievement of 'historische Kritik' since Niebuhr to have shown that historians can only glimpse the past through a glass darkly, through fragmentary sources, every one of which had been stamped with its own partial and partisan perspective. Decoding these perspectives was the essence of Quellenkritik, as Droysen explained it: first, to determine what the sources were about; second, to ascertain with what general 'coloring' they had been impregnated by the reigning conceptions of the time and place; and third, to discern the more individual 'coloring' added by the individual who had written the source. Quellenkritik was the systematic practice of identification, contextualization, and criticism. Nothing about a source was self-evident; it must be read warily, from all angles, against the grain. Anyone who expected historical facts to speak for themselves, or regarded sources as transparent windows upon the past was ipso facto branded a rank amateur - and dangerously subjective to boot, since meaning could then only be projected onto the opaque sources. Even with the aid of Quellenkritik the risks of subjectivism were great, and Droysen recommended further rules to rescue historical interpretation from flights of the imagination. ${ }^{18}$

In the techniques of historical criticism lay the source of historical objectivity. Just as mechanical objectivity in the natural sciences fetishized rigid procedures and protocols, objectivity in history required disciplined respect for methods. The 'objective' truth of the past was forever unattainable, but the methods of the historian - and above all the historian's awareness of the limitations of these methods - qualified scientific history as nonetheless objective. In contrast to art, which must present its subject matter as a smooth, harmonious whole, the empirical sciences, including history, 'haben keine strengere Pflicht, als die Lücken festzustellen, die in den Objekten ihrer Empirie bedingt sind, die Fehler zu kontrollieren, die sich aus ihrer Technik ergeben, die Trageweite der Methoden zu untersuchen'.

The objective historian must not give in to the temptation to generalize prematurely or to edify or entertain at the expense of the hard-won facts that had been dug out of the archives and purified by Quellenkritik. Of course, there was 
no objection to a fine style per se, but Droysen frowned on the perfervid prose of Michelet, who poured his own subjectivity into the past. But such 'subjektive Auffassen' had to be straitened by 'objektive Maße und Kontrollen'. ${ }^{\text {19 }}$ Ranke, whose legendary seminar was the cradle of all these 'objective measures and controls' among the historians, renounced any intention of writing vivid, edifying history: that is the context of his famous declaration that all he wanted to do was 'bloß zeigen, wie es eigentlich gewesen' - even at the price of a narrative that was 'oft hart, abgebrochen, ermüdend'. ${ }^{20}$

If historical objectivity lay in the methods of historical criticism, it is more comprehensible how politically engaged historians like Sybel and Treitschke could simultaneously reject impartiality and affirm objectivity. Both categorically affirmed their allegiance to these methods: if they were not the whole of history, then they were its solid, scientific foundations. Sybel urged the historian to be political and artistic as well as scientific, but while the historian qua writer might give imagination free reign, the historian qua critical researcher had die Pflicht, jede Einwirkung seiner subjektiven Stimmungen zurückzudrängen'. However much he might mock the eunuchs of impartiality for their refusal to put history at the service of life, Treitschke never doubted but that the exacting standards of research in original sources deserved to be called objective, and were the basis for all history worthy of the name. ${ }^{21}$ Ranke's commitment to understand the past in its own terms required literal selflessness, an attempt 'mein Selbst gleichsam auszulöschen.'.2 The objective historians who had learned their handiwork in Ranke's seminar struggled to overcome, not indulge, their own subjectivity. This severity came at the cost of losing the greater part of at least the German reading public, who, Droysen complained, unaccountably 'wollte lesen, nicht studieren.' ${ }^{23}$

\section{Thucydides at the bar}

For historians the patron saint of their discipline had always been Thucydides. It is therefore particularly instructive to observe how Thucydides himself was judged at the bar of objectivity by late-nineteenth- and twentieth-century classicists and historians. Two questions, both revolving around the celebrated Methodensatz in I.22 of the History of the Peloponnesian War, introduced the discussion of historical objectivity into scholarly work on Thucydides: first, to what extent was Thucydides himself consciously aspiring to the standards of objective history; and second, did he hold to these standards, especially in the matter of reporting speeches? The amount of learned ink spilt over the proper rendering of the Methodensatz in modern European languages since c. 1850 makes one chary of quoting any of the translations. Since, however, some general idea of what 
Thucydides said is a precondition for understanding what all the scholarly fuss was about, I hesitantly offer the Loeb translation by Charles Foster Smith of I.22 as a reference point:

As to the speeches that were made by different men, either when they were about to begin the war or when they were already engaged therein, it has been difficult to recall with strict accuracy the words actually spoken, both for me as regards that which I myself heard, and for those who from various other sources have brought me reports. Therefore the speeches are given in the language in which, as it seemed to me, the several speakers would express, on the subjects under consideration, the sentiments most befitting the occasion, though at the same time I have adhered as closely as possible to the general sense of what was actually said. But as to the facts of the occurrences of the war, I have thought it my duty to give them, not as ascertained from any chance informant nor as seemed to me probable, but only after investigating with the greatest possible accuracy [akribeia] each detail, in the case both of the events in which I myself participated and of those regarding which I got my information from others. And the endeavor to ascertain these facts was a laborious task, because those who were eyewitnesses of the several events did not give the same reports about the same things, but reports varying according to their championship of one side or the other, or according to their recollection. ${ }^{24}$

It should be kept in mind that the terminology of objectivity and subjectivity that came to be regularly applied to this passage were themselves still something of a novelty in the mid-nineteenth century, although they became quickly and widely entrenched thereafter. In Franz Wolfgang Ullrich's pioneering work, Beiträge zur Erklärung des Thukydides (1846), which advanced the hypothesis that Thucydides had composed his history in two parts (breaking at V.25), the words 'objective' and 'objectivity' hardly figure. Ullrich consistently rendered Thucydides' own 'akribeia' as 'genaue Sorgfalt'. ${ }^{25}$ However, in later works on how Thucydides had composed his work, and particularly those that treated the question of the authenticity of the speeches he reported, analyses of I.22 were peppered with the vocabulary of objectivity and subjectivity. ${ }^{26}$ Ranke's 'wie es eigentlich gewesen' was arguably a deliberate echo of Thucydides I.22. ${ }^{27}$ The wholesale and, for the most part, unreflecting importation of these modern termini into the analysis of what exactly Thucydides might have meant in I.22 concerning the reporting of deeds and speeches is all the more striking against the background of the meticulous philological analysis of every single word and grammatical construction in the passage. Every semantic shade, every syntactic wrinkle is explored with the pow- 
erful instruments of classical philology by scholars with a princess-and-the-pea sensibility for anachronisms and editorial interpolations. But the framework of objectivity and subjectivity, barely a century old in 1900 , is taken over with hardly a murmur.

In these late-nineteenth-and early-twentieth-century works on Thucydides' historical methods the answer to the first question - To what extent did Thucydides aspire to the standards of historical objectivity? - was usually answered in the affirmative, or simply assumed. So Max Pohlenz, writing in I919, credits Thucydides with 'die erstmalige Festlegung einer objektiven Richtschnur' in the Methodensatz, in welcome contrast to Herodotus's notorious liberties in reporting both deeds and speeches. ${ }^{28}$ August Grosskinsky, in his 1934 Heidelberg dissertation, agreed with this aspect of Pohlenz's interpretation, if in nothing else: Thucydides opposes himself to the 'subjektiven Willkür Herodots', and at least in his reporting of deeds (erga) in the Peloponnesian War had striven toward 'völlige Ausschaltung jeder Subjektivität. ${ }^{29}$ Even classicists who sensed uneasily that Thucydides might not perhaps have subscribed to the modern creed of objectivity felt themselves trapped within its vocabulary. Harald Patzer, in his 1936 Berlin dissertation on what had come to be known as 'die Thukydideische Frage', complained that 'die modernen Begriffe "frei" und "subjektiv"' were responsible for many misunderstandings of 'Thucydides' handling of the speeches, but he was unable to shake free of the accumulated weight of commentary formulated in terms of the opposition between the objectivity or subjectivity of the speeches. ${ }^{30}$

Indeed, one of the principal reasons why the second question - to what extent did Thucydides hold to the standards of historical objectivity, especially in his reporting of the speeches - was elevated to 'die Thukydideische Frage' was because the subjective/objective distinction had become ineluctable for historians by the turn of the twentieth century. There may have been murmurings already in antiquity about Thucydides having put words in the mouth of the speech makers, ${ }^{31}$ but his worth and integrity as a historian was rarely at stake. Nor were his methods objects of intense scrutiny by earlier scholars: I.22 seems to have become the Methodensatz only in the late nineteenth century. The preoccupation with the authenticity of the speeches and the objectivity of his methods - even the attribution to Thucydides of a methodology-mirrored the concerns of the late-nineteenth-and early-twentieth-century historians and philologists themselves. For my purposes, the answer to the question whether or not Thucydides did indeed invent the speeches and if so, how and to what end, is beside the point: my interest is in the sudden urgency of the question, and its entanglement with the relatively new historical value of objectivity, particularly the objectivity of methods. To put the matter very simply, probably too simply: the struggles of 
the classicists to reconcile Thucydides' towering reputation as an historian (and I have yet to find a single commentator who believed that his reputation was undeserved) with what they had come to regard as 'subjective' practices shows the extent to which objectivity, as opposed to impartiality, dominated the ethos of historians. ${ }^{32}$

\section{A new religion}

The difficulties faced by these and other classical philologists in answering such questions mal posées - Did Thucydides try to be objective? Did he succeed? arise from the mismatch between epistemic values that have different meanings and dictate different practices. Impartiality may not require exact quotations; truth may dispense with Quellenkritik. The mystery of objectivity is how it managed, in a relatively short time, to become so preeminent among the values of the historian that it swallowed up all others. Here once again, Nietzsche supplies a clue.

What Nietzsche detested most about historical objectivity was its air of pious self-deception. His charges of 'superstition' and 'mythology' echo the charges of Protestant reformers against popery, which were turned against religion in general by the Enlightenment philosophes. Nietzsche smelled in the cult of historical objectivity a false faith:

Was, es gäbe keine herrschende Mythologien mehr? Was, die Religionen wären im Aussterben? Seht euch nur die Religion der historischen Macht an, gebt acht auf die Priester der Ideen-Mythologie und ihre zerschundenen Knie! Sind nicht sogar alle Tugenden im Gefolge dieses neuen Glaubens? Oder ist es nicht Selbstlosigkeit, wenn der historische Mensch sich zum objektiven Spiegelglas ausblasen läßt ${ }^{23}$

There remains the puzzle of how the new religion of historical objectivity, if religion it was, won so many converts, and in so short a timespan, since it promised the opposite of immortality. It is a truly Nietzschean problem, since the religion in question carried with it a distinct odor of asceticism, of clenched self-restraint in subordinating eloquence to method and method to the analysis of error. The acolytes of this new and decidedly uncomfortable religion of historical objectivity were almost all formed in the new-style research seminar initiated by the reformed German universities and imitated widely throughout the learned world by the end of the nineteenth century. It was the research seminar that in reality disciplined the disciplines. It was the prime mover behind the multiplication of 
specialist societies and journals. In the seminars students learned that Wissenschaftlichkeit meant method, and method in turn meant the mastery of esoteric techniques through long, arduous application. Whether the technique in question was paleography learned at the Berlin philology seminar or error analysis learned at the Königsberg physics seminar, the craft knowledge imparted by close contact of professors with students resembled nothing so much as an apprenticeship with a master. The glittering noun Wissenschaft spanned associations from the character-firming to the culture-making, but the more sober adjective wissenschaftlich referred almost invariably to the painstaking, abstruse techniques - those very methodical 'methods of research' - that certified a piece of work, be it an experiment or an edition, as objective.

Diligence, attention to minute detail, devotion to technique, an ethos of responsibility and exactitude, and the habits of collective discussion united the seminar-trained physicist with the seminar-trained philologist. All had experienced the gradual transition from the repetition of the known (checking archival sources, producing a chemical reaction) to the unknown; all would have experienced 'ein gegenseitiges Nehmen und Geben zwischen Lehrer und Schülern', and all would have felt, as the philologist Hermann Diels put it, the 'unsichtbare Fäden des Vertrauens zwischen den Teilnehmern eines solchen Thiasos.'34 'Thiasos' has several meanings in ancient Greek, ranging from a Bacchic revel to a troop of warriors, and no doubt Diels, virtuoso Hellenist that he was, played upon all of these shades of meaning in his evocation of the seminar. The center that holds together all the senses of 'Thiasos' is that of belonging to a group of initiates, especially a religious confraternity, and it was in this sense of belonging that one must seek the extraordinary power of the creed of historical objectivity. The new creed of historical objectivity was imbibed and realized in seminars like Ranke's when he took up a chair at the University of Berlin, which met for decades in his own private study in his Giesebrecht apartment, day in, day out, making an exception only for Christmas Eve, when 'the assistants ritually rebelled and stayed home with their families, much to Ranke's dismay. ${ }^{35}$

\section{Conclusionः Intensely disinterested}

One of the most curious features of the history of scientific curiosity is how the most unbridled subjectivity has been transmuted into purest objectivity. Or to put it in other terms, intense interest in the objects of scientific research turns into disinterest in everything else. Disinterest in one's nearest and dearest is only the most extreme form of a pinpoint focus of interest that excludes the rest of 
the universe and concentrates all intellect, emotion, and energy like a powerful, pencil-thin laser beam on one spot. This indifference to $99.9 \%$ of the rest of the universe, both human and natural, is often equated with disinterestedness or even objectivity.

Distraction, absent-mindedness, and disinterest are the obverse of an interest of laserlike focus and intensity. It is disinterest only because it is eccentric: the sage, scholar, and scientist choose to neglect what interests the vast majority of other people in favor of their own enthralling preoccupations. Their tranquility and incorruptibility with respect to the worldly rewards of fame and fortune, to the homely comforts of being firmly situated in time and place, and even to the egoism of an individuated self does not stem from temptations met and stalwartly resisted - they do not struggle like St. Anthony in the desert against the familiar demons of human desire, because their desires have been deflected into other channels and their attention diverted to other objects. All economies of attention are profoundly moralized. To attend to one thing is ipso facto to neglect another. Moreover, attention not only signals value; it creates value in its favored objects, which draw their aficionados, amateurs, devotees the etymologies of all these words highly suggestive - deeper and deeper into obsession.

Obsession is the least sociable of states. Only in the last hundred years or so have monomaniacal scientific pursuits been imagined in the context, rather than at the expense of a community. Collective research is a familiar feature of laboratory and field sciences, but 'Big Science' was pioneered by scholars in the humanities, especially in classical philology and history. It was the physicists and chemists who self-consciously imitated the seminar model of teaching advanced students in philology at Göttingen and Berlin in the early nineteenth century; it was the members Physikalish-Mathematische Klasse of the Preussische Akademie der Wissenschaften who in the late nineteenth century envied their colleagues in the Philosophisch-Historische Klasse big, collective projects like Theodor Mommsen's Corpus Inscriptionum Latinarum. ${ }^{36}$

Despite their asocial (if not anti-social) associations, objectivity in both the natural and human sciences was instilled and cultivated in the small, face-to-face communities of the seminar, the research group, and the conference. The suppression of the self by the self that constitutes scientific objectivity was peculiarly well-suited to the rhetoric of self-sacrifice in the name of the community - but also to that of ascetic virtuosity that commands admiration and deference. As in the case of the early Christian saints, the asceticism of objectivity demanded an audience, as Nietzsche recognized all too well. 


\section{Notes}

I Friedrich Nietzsche, 'Vom Nutzen und Nachteil der Historie für das Leben' [I 874], in idem, Unzeitgemäße Betrachtungen, ed. Peter Pütz (Berlin: Goldmann Verlag, I992), 75I 48 , on II 2 ,

2 Ibid., II 4.

3 For the definition of 'epistemic virtues' and an account of the development of objectivity in the natural sciences, see Lorraine Daston and Peter Galison, Objectivity (New York: Zone Books, 2007).

4 On parallels between judicial and historical impartiality in early modern English law, see Barbara Shapiro, 'The Concept of Fact: Legal Origins and Cultural Diffusion', Albion 26 (I994), 227-252, esp. 235.

5 Adam Smith, The Theory of Moral Sentiments [1759], ed. D.D. Raphael and A.L. Macfie (Oxford: Oxford University Press, 1976), i io.

$6 \quad$ Ibid., I35.

7 Edward Gibbon, The Decline and Fall of the Roman Empire [I776-I788], introduction by Hugh Trevor-Roper, 3 vols. (London: Everyman, I993), vol, I, 246, 242-243.

8 The Prussian army had been mobilized on July I 5, I870; by August 6, I870, Alsace was overrun by German forces. Theodor Mommsen published two letters to the Milanese newspaper La Perseveranza addressed to the Italian people, 'La Guerra' (Io August I 870) and 'La Pace' (20 August I870); the status of Alsace-Lorraine is discussed in the second letter. See Lothat Wickert, Theodor Mommsen. Eine Biographie, 4 vols. (Frankfurt am Main: Vittorio Klostermann, I959-I980), vol. 4, I70-I79.

9 'LAlsace est-elle allemande ou française?' Réponse à M. Mommsen (professeur à Berlin), Paris, 27 octobre I 870, repr. in François Hartog, Le XIXe siècle et l'bistoire. Le cas Fustel de Coulanges (Paris: Presses Universitaires de France, I988), 376-382, on 378-379.

Io N.D. Fustel de Coulanges, 'Les lois germaniques indiquent-elles un partage des terres entres Barbares et Romains? [I877]' in Nouvelles recherches sur quelques problèmes d'bistoire, ed. Camille Jullian (Paris: Librairie Hachette, I89I), 279-305, on 305.

I I Jules Zeller, Origines de l'Allemagne et de l'Empire germanique (Paris: Didier, I 872).

I2 N.D. Fustel de Coulanges, 'De la manière d'écrire l'histoire en France et en Allemagne depuis cinquante ans', Revue des Deux Mondes (Ier septembre I872), repr. in Hartog, Le XIXe siècle, 382-392, on 39I.

I 3 Ibid., 387; Wilhelm von Giesebrecht, Geschichte der deutschen Kaiserzeit, 6 vols., (I860-95).

I4 Leopold von Ranke, Geschichten der romanischen und germanischen Völker von 1494 bis 1514 [1 824], 2nd ed. (Leipzig: Duncker und Humboldt, I 874), xv-xxx, viii.

I5 Heinrich von Sybel, Über den Stand der neueren deutschen Geschichtsschreibung [I 856], quoted in Wolfgang J. Mommsen, 'Objektivität und Parteilichkeit im historiographischen Werk Sybels und Treitschkes', in Reinhart Koselleck, Wofgang J. Mommsen, and Jörn Rüsen (eds.), Objektivität und Parteilichkeit in der Geschichtswissenschaft (Munich: Deutscher Taschenbuch Verlag, I977), I34-I58, on I 37.

I6 Jörn Rüsen, 'Der Historiker als "Parteimann des Schicksals": Georg Gottfried Gervinus und das Konzept der objektiven Parteilichkeit im deutschen Historismus', in Koselleck et al. (eds.), Objektivität und Parteilichkeit, 77-124, on 80-85.

I7 Wolfgang J. Mommsen, for example, concludes that Sybel was a superficial thinker and Treitschke a divided soul: W.J. Mommsen, 'Objektivität und Parteilichkeit', I 38, I 46-I 47.

I 8 Johann Gustav Droysen, Grundriss der Historik [I 867, final ed. I882], ed. Erich Rothacker (Halle/Saale: Max Niemeyer Verlag, I925), 5, I8-I9. 
Ibid., 8I, 84.

Ranke, Geschichten, vii-viii.

W.J. Mommsen, 'Objektivität und Parteilichkeit', I40, I 56.

Leopold Ranke, 'Vorwort', Englische Geschichte, vornehmlich im 16. und 17. Jahrhundert [I859-I868], quoted in Rudolf Vierhaus, 'Rankes Begriff der historischen Objektivität', in Koselleck et al. (eds.), Objektivität und Parteilichkeit, 63-76, on 63.

Droysen, Grundriss, 79.

Thucydides, History of the Peloponnesian War, 4 vols, trans. Charles Forster Smith (Cambridge, MA: Harvard University Press, [I919] I99I), Loeb Classical Library, I.22, $38-4 \mathrm{I}$.

Franz Wolfgang Ullrich, Beiträge zur Erklärung des Thukydides (Hamburg: Perthes-Besser \& Mauke, I846), e.g., I28-I30.

Or rather, Objektivität and Subjektivität, since most of the seminal works on this issue were in German. For an overview of the literature, see O. Luschnat, 'Thukydides', Paulys Realencyclopädie der classischen Altertumswissenschaft, neue Bearbeitung, Suppl. I 2 (Stuttgart: Druckenmüller, I970), cols. I085-I354; William C. West III, A Bibliography on the Speeches in Thucydides, I873-1970', in Philip A. Stadter (ed.), The Speeches in Thucydides (Chapel Hill: University of North Carolina Press, I973), I24-I66. On the issues of composition and the authenticity of the speeches, key background works include: E. Meyer, Thukydides und die Entstehung der wissenschaftlichen Geschichtsschreibung (Vienna: Fromme, I9I3), E. Schwartz, Das Geschichtswerk des Thukydides (Bonn: Cohen, I9I9), and W. Schadewaldt, Die Geschichtsschreibung des Thukydides: Ein Versuch (Berlin: Wiedemann, I929).

7 Konrad Repgen, 'Über Rankes Diktum von I 824: “Bloss sagen, wie es eigentlich gewesen”, Historisches Jabrbuch Io2 (I982), 439-449.

M. Pohlenz, 'Thukydidesstudien', Nachrichten von der Gesellschaft der Wissenschaften zu Göttingen, Philologische-bistorische Klasse (Berlin: Weidmannsche Verlag, I919), 56-82, 95-I 38; quoted in August Grosskinsky, Das Programm des Thukydides, Neue Deutsche Forschungen, Abteilung Philologie, vol. 3 (Berlin: Junker u. Dünnhaupt, 1936), 26-27.

Grosskinsky, Programm, 35, 45.

Harald Patzer, Das Problem der Geschichtsschreibung des Thukydides und die Thukydideische Frage, Neue Deutsche Forschung. Abteilung Klassische Philologie. Bd. 6 Berlin: Junker und Dünnhaupt, I937), 36-37.

3 I Dionysius of Halicarnassus, On Thucydides, ed. and trans. W. Kendrick Pritchett (Berkeley: University of California Press, I975), chs. 34-49, 26-49. However, Dionysius is overwhelmingly concerned with rhetorical style and diction in the speeches, not with their accuracy as verbatim records of what was actually said. He criticizes Thucydides not for putting words in the mouths of speakers but for putting the wrong words in, for example, the text of the Athenian emissaries in the Melian dialogue: 'Words like these were appropriate to oriental monarchs addressing Greeks, but unfit to be spoken by Athenians to the Greeks whom they liberated from the Medes, to wit, that justice is the normal conduct of equals to one another, but violence is [the law] of the strong against the weak' (ch. 39, 3I; cp. ch. 4I, 33).

More recently, some Thucydides specialists have expressed doubt as to whether 'objectivity' is an applicable category: see especially Jacqueline de Romilly, 'Die Objektivität in der griechischen Geschichtsschreibung, in Werner Becker and Kurt Hübner (eds.), Objektivität in den Natur- und Geisteswissenschaften (Hamburg: Hoffmann u. Campe, I976), $4 \mathrm{I}-5 \mathrm{I}$, on 46 . 
33 Nietzsche, 'Vom Nutzen', I 27.

34 Diels, 'Organisation', 653-654.

35 Kaspar Eskildssen, 'Leopold Ranke, la passion de la critique et le séminaire d'histoire', in Christian Jacob (ed.), Lieux de savoir: Espaces ey communautés (Paris: Albin Michel, 2007), $462-482$.

36 R. Steven Turner, 'The Prussian Universities and the Concept of Research', Internationales Archiv für Sozialgeschichte der deutschen Literatur 5 (1980), 68-93; David Cahan, 'The Institutional Revolution in German Physics, I865-I914', Historical Studies in the Physical Sciences I5 (1985), I-66; Kathryn M. Olesko, Physics as a Calling: Discipline and Practice in the Königsberg Seminar for Physics (Ithaca, NY: Cornell University Press, I 991); William Clark, Academic Charisma and the Origins of the Research University (Chicago: University of Chicago Press, 2006); Conrad Grau, Die Preußische Akademie der Wissenschaften zu Berlin (Berlin: Spektrum Verlag, I993), 195; Rüdiger vom Bruch, 'Mommsen und Harnack. Die Geburt von Big Science aus den Geisteswissenschaften', in Alexander Demandt, Andreas Goltz, and Heinrich Schlange-Schöningen (eds.), Theodor Mommsen. Wissenschaft und Politik im 19. Jahrbundert (Berlin: Walter de Gruyter, 2005), I 2 I-I4I. 



\title{
I.2 The Natural Sciences and the Humanities in the Seventeenth Century
} Not Separate Yet Unequal?

\author{
H. Floris Cohen
}

When scientists in our day meddle with the humanities, the outcomes are not always uplifting. Sometimes they are, as when art historians and chemists supplement each other's expertise quite nicely in establishing or disproving the authenticity of some famous painting. In my own discipline, the history of science, the contributions scientists make are rarely so productive, unless (as, for instance, with Thomas Kuhn) they turn themselves into professional historians. Professional scientists with a layman's interest in history certainly tend to display a deep-seated emotional involvement in past manifestations of their own presentday concerns. But the flip side of their praiseworthy engagement is most often a rather upsetting naiveté. Armed with a few facts of questionable reliability, even the most history-conscious scientists tend to lack even the most elementary idea of how historians are for good, long-established reasons wont to deal with past facts. Clearly, to them the sciences and the humanities are quite distinct, or even insuperably different, areas of scholarship.

So much for science/humanities interactions in my professional experience. The remainder of the present chapter is about similar interactions in the past, or, more precisely, during the founding period of modern science some three to four centuries ago. I shall examine a few cases where certain subjects that were later to be reckoned among the humanities were taken up at some depth by scholars who at a later age were to count unambiguously as scientists. In examining four selected crossover cases, my primary concern is with the rigorous distinction between the sciences and the humanities that we are used to maintain at present. Rens Bod, Eric Jorink, and others have taught us that, with due reservations even for the present day, it is certainly pointless to make such a distinction for any period prior to the late nineteenth century. ${ }^{1}$ My question is: Do my four chosen authors (in chronological order, Johannes Kepler, René Descartes, Blaise Pascal, and Isaac Newton) agree with Rens and Eric? Or do they perhaps prove these learned gentlemen wrong, in that they do make pre- 
cisely such a distinction, either in principle or, if not that, then at least in their actual practice?

What, indeed, about the performance of these four great men of the Scientific Revolution in (to them) foreign territory? Do we find Kepler or Newton operating differently when pursuing their chronological than their astronomical studies, or not? And what about the quality of their performance? Do they operate with the disdain of professional standards on display with those history-minded scientists of today? Or did the more humanities-focused participants in then current debates perceive these apparent intruders as (by and large) their equals? Also, how do we, in looking back, judge the quality of their performance? Was Newton as great a chronologist as he was in the domains for which we still rightly celebrate him?

A clear-cut instance of a positive answer to my first question, about whether or not a principal distinction was being made at the time between science-like and humanities-like pursuits in the period of the Scientific Revolution, is provided by Blaise Pascal. In a programmatic fragment dating from c. 1647 and posthumously entitled 'Préface pour le Traité du Vide' ('Preface for the Treatise on the Void') he lists on the one hand the disciplines of history, geography, law, languages, and theology. On the other hand you have geometry, arithmetic, music, physics, medicine, and architecture. His enumeration is not meant to be exhaustive in either case, yet I am not omitting any of those he does list. Now by what criterion does Pascal distinguish the one category from the other? Knowledge in domains of the former kind, so he argues, can be attained only by consulting books, whereas the latter 'fall under the senses or under reasoning.' If, so he continues, you want to know who was the first king of France, or where geographers place the first meridian, you are necessarily bound by authority, in that you must look up writings by authors, whereas if you want to find out about, for instance, void spaces you cannot fall back upon available writings on the subject - you must make experiments and then reason upon the outcomes thereof.

Consequently (so Pascal keeps arguing) innovation is quite possible and, indeed, indispensable in fields of the latter kind, whereas with the former their very point is to stick to what we have. Consequently, the Jesuits (Pascal's archenemies) have it doubly wrong. In theology, they introduce all kinds of innovations where these do not belong, in that they go way beyond the sole repository of religious truth, Scripture and the Church Fathers. But these self-same Jesuits oppose new, experimental findings about (for instance) the void, as contradicting the received wisdom of the ancients. By way of another consequence that Pascal draws from his distinction, the perfection of disciplines of the former, humanities-oriented kind lies in the past, whereas the latter can only attain perfection in an as yet unknown future. In short, the humanities are unlike the 
sciences in that only the latter, guided by experimental reasoning, are capable of attaining progress. ${ }^{3}$

It may look surprising that, in his listing of sciences capable of such progress, Pascal takes up 'music'. In this connection he meant not so much the practice of music as, rather, the mathematical-physical theorizing that underlies it. Indeed, my next case of a humanities/sciences distinction being made during the Scientific Revolution concerns thoughts about musical theory of a thinker Pascal abhorred only slightly less than he did the Jesuits, to wit, his older acquaintance René Descartes. The grounds for Pascal's abhorrence (scholarly, not personal) reside in what he diagnosed as Descartes' know-all pretensions, his claim to have hit once and for all upon the one indubitably true system of all knowledge that we can possibly attain of the natural world and how it operates. Take a typical line from Descartes like the following, near the end of Discours de la méthode:

Making my mind pass once again over all objects which at any time have presented themselves to my senses, I venture to say that I have never come across any thing which I could not explain adequately enough by means of the Principles I had found. ${ }^{4}$

'Explain', for sure! Descartes (I am addressing him here in his philosopher's role, not as a highly innovative mathematical scientist) was not out to discover any new phenomena. ${ }^{5}$ His concern was rather to give these their rightful place in his grand scheme of things, necessarily true because he had derived it from indubitably secure first principles. Whenever his faithful correspondent back in Paris, Marin Mersenne, who was in the business of making empirical discoveries, confronted Descartes with his latest, Descartes' preponderant, nay, his sole concern was to make the new phenomenon fit in with his natural philosophy of particles in motion. However, in one exceptional case Descartes did not go along. ${ }^{6}$ The subject, part of the contemporary science of music, was degrees of consonance - a concern, not only of Mersenne, but of Galileo, Kepler, Beeckman, and other pioneers, too. Most agreed that the phenomenon of consonance (that is, the sweet, near-blending quality of certain musical notes sounding together) is due to how often the notes that make up a musical interval coincide. Musical sound, so they came to realize, is produced by the vibrations of a string put in motion, and each musical interval is marked by a specific ratio of vibrational frequency, as $I: 2$ for the octave, $2: 3$ for the fifth, etc. (in modern terms, standard A is 440 Hertz, hence, the A one octave higher is 880 Hertz). In Mersenne's view it followed that, the more often two strings co-vibrate, the more consonant are the intervals thus produced. With the octave, vibrations coincide every I $x_{2}=$ second time, with the fifth every $2 \times 3=$ sixth time, and so on. This yields a neat scale of degrees of 
consonance, from the unison $I: I$ to the minor sixth $5: 8$. How, then, could it be that musical practice fails in several regards to conform to this mathematical-physical rule of descending consonance?

Confronted by Mersenne with the scale and with the question, Descartes felt comfortable only with one portion thereof - the portion that we would nowadays call 'scientific'. The scale of degrees of consonance that seems to follow inexorably from Mersenne's coincidence account of consonance, so Descartes retorted, is indeed right as far as it goes. Only, it does not go very far:

Concerning the sweetness of the consonances two things should be distinguished: namely, what renders them simpler and more accordant, and what renders them more agreeable to the ear. Now, as to what renders them more agreeable, that depends on the places where they are employed; and there are places where even diminished fifths and other dissonances are more agreeable than consonances, so that one could not determine absolutely that one consonance is more agreeable than another. [...] One can say absolutely which consonances are the most simple and the most accordant ones; for that depends only on how often their sounds unite, and how closely they approach the nature of the unison; so that one can say absolutely that the fourth is more accordant than the major third, while ordinarily it is not so agreeable, just as the cassia is definitely sweeter than olives, but not so agreeable to our taste?

What we appear to have here, then, is (once again) a clear-cut sciences/humanities dichotomy. Descartes perceptively distinguishes between the 'science' aspect of musical consonance, which is a matter of ratios of vibrational frequencies, and the aspect of artistic analysis, concerned with the actual context of an actual musical piece in which musical intervals are bound to serve in multiple ways that, at the very least, do not correspond in a one-to-one manner with what mathematical-physical analysis leads us to predict.

To be sure, Descartes was enabled to making the distinction in the first place, not out of some a priori urge to distinguish the sciences from the humanities so much as, rather, due to the extraordinary feature of his natural philosophy just discussed - his emphatic claim to indubitable certainty. The consequence of his highly staked claim (of his all-or-nothing style of philosophizing, really), was that all those matters he did not feel certain about ought to be banished to the outer darkness reserved for topics at the other side of the certainty/uncertainty divide. As in another context he acknowledged himself, he was barely able, when listening to a piece of music, to distinguish a fifth from an octave, or judge whether someone had correctly sung ut re mi fa sol la, let alone do it himself. In 
sum, then, Descartes' urge to distinguish between the sciences and the humanities side of scholarly life coincided with what he felt subjectively certain of, and what not.

My final topic concerns the discipline of chronology. What I have picked up on the subject I owe (of course) to Anthony Grafton, ${ }^{8}$ further to Franz Hammer, coeditor of Johannes Kepler's Gesammelte Werke, ${ }^{9}$ and to Isaac Newton's biographer Richard S. Westfall. ${ }^{10}$ The subject of greatest fascination to Kepler, second only to his all-time favorite, the science of the heavens, was the year of nativity - How many years before Christ was Jesus actually born? The seemingly obvious answer - 'Well, none at all, of course' - was by the early seventeenth century greatly in doubt, as many students of the matter had already questioned the accuracy of the sixth-century monk who created our Christian 'Anno Domini' calendar. But by how many years had this learned monk been wrong?

At the time when Kepler was drawn into the question by a patron who sought his help in fixing dates of Roman history by means of heavenly events like lunar and solar eclipses or planetary conjunctions, Joseph Just Scaliger was busily turning himself into the great authority on this and all other topics that come up in what in his hands became the academic discipline of chronology. Kepler quickly threw himself into the Europe-wide debates that followed upon the appearance of Scaliger's two big books on the subject. Kepler's first publication came as an appendix to his treatise on the New Star, the nova, of I604, and it took shape as an argument to antedate Jesus' birth by one more year than Scaliger had established for it, to wit, the year 6 rather than 5 BC. Two astronomical considerations guided Kepler's determination. One was a lunar eclipse mentioned by Flavius Josephus as occurring on the eve of the death of King Herod (the year of Herod's demise was one important tidbit in the stew of Bible passages, ancient calendar rules, passing remarks by the yes or no reliable historian Flavius Josephus, and other contemporary facts and factoids that together made up the riddle of the nativity). Kepler realized, as Scaliger had, too, that in years around I BC not one but two lunar eclipses qualified, but on astronomical grounds not considered by Scaliger he settled on the one that led to 4 BC for Herod's death and, hence, to $6 \mathrm{BC}$ for Jesus' birth. Kepler thus left the Magi some io months for making up their minds upon spotting the Star of Bethlehem finally to set out on their voyage to the crib of God's Son.

Actually, the Star of Bethlehem provided the other piece of evidence for Jesus' birth in $6 \mathrm{BC}$ that Kepler dropped into the current debate. He connected the Star to the I604 nova he was writing about, by means of a series of Saturn-Jupiter conjunctions that happened to accompany both these spectacular heavenly events. It is a very technical argument, such as only an expert astronomer could produce, and together with the lunar eclipse just ahead of King Herod's death it made 
Kepler settle for good on 6 BC, the year (by the way) still accepted today partly on other grounds.

Kepler did more than just drop $6 \mathrm{BC}$ and his arguments for it into an ongoing debate - he actually joined it. Expert chronologists of both Catholic and Protestant denominations, some of whom he knew personally, challenged his conclusions, and he met their not so much astronomical as, rather, historical arguments on their own ground. For instance, he argued at length for the reliability of Flavius Josephus's book on Jewish history in view of its consistency both with the text itself and with other contemporary Roman authors. In short, Kepler turned himself into an expert historian, taking part in the chronological debate with the research methods and the criteria for authenticity then current in the field. Thus he gained the respect of many among those who, together with Kepler, took the late Scaliger's vast scholarship to heart.

Can we say the same thing about Isaac Newton's concerns with chronology? No, we cannot, as hardly a word of his even more extensive writings on the subject was published during his lifetime. Nor is this by accident - Newton kept quite deliberately silent about the vast scholarship he, too, had amassed in chronology. He came to the subject due to the theological studies he engaged in as a consequence of the obligation that rested upon every Fellow of Trinity College at Cambridge to be ordained within seven years of appointment to the fellowship. A few years ahead of that deadline, so as to acquaint himself with the theological background to the solemn oath he would in due time have to swear, Newton threw himself with his customary methodical thoroughness into the writings of the church fathers - not only Augustine or Eusebius but just about all of them. In those hefty tomes he made an unsettling discovery. In course of the debates over Christian dogma that had raged all over the fourth to sixth centuries, people had been deceived, words had been twisted, texts had been corrupted, so as to peddle and eventually get turned into dogma a pernicious, wholly unbiblical notion that of the Trinity. The two Bible verse which proclaim the consubstantial unity of God the Father, God the Son, and God the Holy Spirit appeared to Newton to be fourth-century forgeries, produced by Athanasius, Bishop of Alexandria, in his ongoing battle with Arius, priest in the same city. Newton relived these millennium-old ecclesiastical battles as if he took part in them, himself. In a sense he did. In short order he took the part of Arius, rejected for good the Holy and Undivided Trinity on which he was presently to swear an oath in the very college of that name. He knew well that if he made his heretical views known he would be kicked out of Cambridge University forthwith. He chose not to take the mantle of another prophet out to combat corruption, but to keep silent, all his life. Somehow he managed to wriggle out of ordination, and he kept pursuing his theological studies in private for the rest of his life. 
Chronology was definitely part of those studies. The only books he wrote that appeared during his lifetime are, of course, Principia and Opticks, but within a year of his death a third, his Chronology of Ancient Kingdoms Amended saw the light of day. As Westfall has shown, one should not take this work at face value, as Newton had deliberately robbed his entire chronology of its own thrust. The true point of this book, which he took great care to keep out of it, is rather to be found in a much earlier manuscript of fully heretical, part late-Arian part early deist tenor, known after its incipit as 'Theologiae gentilis origines philosophicae' ('The Philosophical Origins of Gentile Theology'). "' There is an original, wholly rational religion, with at its center celebration of God's absolute predominance over the cosmos by means of a fire that represents the sun with the planets orbiting it. This religion, 'then which nothing can be more rational', was instituted after the Flood by Noah, and spread over the length and breadth of the ancient world by Noah's three sons. Due to the depravities of the human heart, this rational religion has found itself corrupted time and again. Ever so often God sends a prophet, Abraham, Moses, Jesus, to bring religion back to its pristine purity, but then corruption sets in all over again, as in the fourth century with Athanasius.

Religion just rational, Christ just a prophet - all this did not just smack of heresy, it constituted heresy in Newton's own time, and he knew it. His private time-reckoning in the 'Origines' testifies to it, too - in view of the role accorded Noah and his sons Newton acquired an interest in curtailing time as much as he possibly could. That is why he availed himself, among many other tricks of the trade, of a subterfuge that was already around for some time. Facing as Scaliger had the inconveniently lengthy chain of pharaohs in Manetho's authoritative listing, Gerard Vossius departed from Scaliger in shortening the chain by declaring without a shred of evidence several early Egyptian dynasties to be not consecutive but parallel. Why Newton followed Vossius in this regard, then, becomes clear, not from his orthodox-looking book on chronology itself but from his far earlier, profoundly heretical 'Origines'.

It is time to draw from the foregoing some conclusions. There are, of course, many more pertinent cases to examine than the four I have just sketched in their barest outlines, such as, for instance, Galileo's literary criticism or Bacon's Essays or (a vast enterprise in itself) numerous writings by the incredibly versatile Leibniz. So whatever responses I shall now give to the questions I announced at the start of the present chapter can be no more than very provisional.

Two of our protagonists made a principled distinction. Pascal did so in general terms, Descartes in one specific case only. Descartes' distinction, stemming as it did from the ideal of indubitable certainty paramount to all his philosophizing, seems to correspond by and large to his famous dualism of res extensa (extended 
stuff) and res cogitans (thinking stuff). Pascal's distinction, much like the one so often maintained at present, is between disciplines that draw on authoritative, extant texts, and those that build forth upon experimental reasoning. In contrast, neither Kepler nor Newton seems to bother to make any distinction in principle, so the question is whether it may nonetheless be found back in their actual practice. To a large extent the answer is 'yes'. When doing chronology, both men are chronologists with the chronologists. Kepler took a full, well-respected part in current debates. So, but inevitably posthumously, did Newton's thoroughly selfemasculated views on the subject.

Even so, both men contributed something uniquely their own to the field as well, something that derives from their work in domains we now call scientific. Kepler's solution to the problem of nativity, albeit defended in terms of then current history writing, resulted from his pursuing in depth questions raised by lunar eclipses and past and present planetary conjunctions. Astronomy was hardly foreign to the field of chronology as Scaliger restructured it, only, Kepler was on surer ground and thought more deeply about its possible uses. With Newton the contribution of his science to his chronology, or more generally speaking to the theology which determined the entire thrust of his chronology, is more complex. Just like Kepler, he enriched his efforts in chronology with astronomical details foreign to other practitioners, such as his usage of the precession of the equinoxes for calculating the exact year of the expedition of the Argonauts as a baseline for Greek history. More importantly, Newton's conception of human history stemmed in the last resort from his personal conception of the Deity, that is, from an idea expressed as well in the second edition of his Principia - God's absolute dominion over nature as over human history.

No full-blown distinction between the 'humanities' and the 'science' side of things is called for, then, in either case - in the period of the Scientific Revolution the two interpenetrate to some extent. This applies a fortiori to both Kepler's and Newton's working habits. Kepler brought to his chronological investigation the same style of enthusiastic outbursts alternated with doggedly pursued exactitude that we encounter in his astronomical work. Newton's theological efforts are just as thoroughly and methodically undertaken, just as much built upon vast, carefully accumulated learning as is true of his work on the calculus, on orbital motion, and on light and color.

Still, interpenetration goes only so far. Kepler's unique achievement in the domain of planetary theory rests in good part on his willingness to throw the results of the most painstaking theorizing and calculating in the wastebasket when a timely empirical check showed these results to be wrong within available limits of accurate measurement - the rightly famous eight minutes of arc discrepancy between a parameter theoretically predicted and actually measured. No such will- 
ingness seems to mark Kepler's work in chronology. He arrives at a well-reasoned conclusion, and he sticks to it. Not that, as a rule, the discipline of chronology left room for clear-cut empirical refutation - one could always twist the evidence to one's own, always theologically determined advantage. So it is with Newton. In Principia, he went out of his way to establish an exact match between abstract orbits derived geometrically and planetary orbits observed physically, not hesitating along the way to subject ideas dear to him to the strictest scrutiny and if need be reject them without more ado. In The Chronology of Ancient Kingdoms Amended he availed himself without apparent qualms of Vossius' gambit at the service of a fully preset conclusion - the relatively short amount of time available for Noah's sons in spreading true, rational religion before its first corruption. This conclusion in its turn followed inexorably from his highly personal, deeply felt conception of what a truly rational religion amounts to.

So a final conclusion to my preliminary investigation seems to be this. At the 'science' side of things, as distinguished along Pascal's lines from the 'humanities' side of things, impartiality in the sense of a certain readiness to subject one's dearest conclusions to rigorous testing, albeit difficult always, is easier to attain with the former than with the latter. In the humanities, notably, of course, in the theological concerns always present in all seventeenth-century thinking, values dear to the human heart could not, as they still cannot, fail to determine the overall setup and course of an investigation to a far larger extent than in the sciences of the natural world. By and large, Pascal had it right.

\section{Notes}

I Rens Bod made the point throughout his De vergeten wetenschappen. Een geschiedenis van de bumaniora. (Amsterdam: Bert Bakker, 2010), translated since as A New History of the Humanities (Oxford University Press, 2013). Eric Jorink did so in his Het Boeck der Natuere. Nederlandse geleerden en de wonderen van Gods Schepping 1575-1715 (Leiden: Primavera Pers, 2006), translated as: Reading the Book of Nature in the Dutch Golden Age, 1575-1715 (Leiden: Brill, 2010).

2 Blaise Pascal,'Préface pour le Traité du Vide', first line of the seventh paragraph:'des sujets qui tombent sous le sens ou sous le raisonnement'.

3 To be sure, Pascal does not literally use the term 'progress', but the entire point of his next paragraph is the steady advance of the sciences since their inception with the Greeks.

4 René Descartes, Oeuvres 6, 64 (Discours de la méthode: part 6): 'repassant mon esprit sur tous les objets qui s'estoient jamais presentez a mes sens, i'ose bien dire que ie n'y ay remarqué aucune chose que ie ne peusse assez commodement expliquer par les Principes que i'avois trouvez'.

5 In my How Modern Science Came into the World: Four Civilizations, One 17th-Century Breakthrough (Amsterdam University Press, 2010), I take great pains to maintain this distinction, which was quite in keeping with the (up to mid-seventeenth-century) tradi- 
tional, almost watertight separation between mathematical science and natural philosophy in the sense of a closed system of speculative thought.

6 I have treated the matter at some length in my Quantifying Music: The Science of Music at the First Stage of the Scientific Revolution, 1580-1650 (Dordrecht: Reidel, I984), I69-I72.

7 René Descartes to Marin Mersenne, October I63I: 'Touchant la douceur des consonances, il y a deus choses a distinguer: a sçavoir, ce qui les rend plus simples et accordantes, 8 ce qui les rend plus agreables a l'oreille. Or, pour ce qui les rend plus agreables, cela depend des lieus ou elles sont employées; $\&$ il se trouve des lieus ou mesme les fausses quintes $\&$ autres dissonances sont plus agreables que les consonances, de sorte qu'on ne sçauroit determiner absolument qu'une consonance soit plus agreable que l'autre. [...] Mais on peut dire absolument quelles consonances sont les plus simples $\&$ plus accordantes; car cela ne depent que de ce que leurs sons s'unissent davantage l'un avec l'autre, \& qu'elles approchent plus de la nature de l'unison; en sorte qu'on peut dire absolument que la quarte est plus accordante que la tierce maieur[e], encore que pour l'ordinaire elle ne soit pas si agreable, comme la casse est bien plus douce que les olives, mais non pas si agreable a nostre gout'.

8 Anthony Grafton, 'Joseph Scaliger and Historical Chronology: The Rise and Fall of a Discipline', History and Theory I4.2 (I975), I56-I 85.

9 Franz Hammer's extensive 'Nachberichte' in volumes I and 5 of Johannes Kepler's Gesammelte Werke.

Io Richard S. Westfall, Never at Rest: A Biography of Isaac Newton (Cambridge University Press, I980).

I I This is the one work by Newton on which Westfall developed views that go substantially beyond Never at Rest. See R.S. Westfall, 'Isaac Newton's Theologiae Gentilis Origines Philosophicae', in W.W. Wagar (ed.), The Secular Mind: Transformations of Faith in Modern Europe (New York/London: Holmes \& Meier, I982), I5-34. 


\title{
I.3 The Interaction between Sciences and Humanities in Nineteenth-Century Scientific Materialism
}

\author{
A Case Study on Jacob Moleschott's Popularizing \\ Work and Political Activity
}

\section{Laura Meneghello}

Positivism is normally understood as favoring separation of the humanities and the natural sciences, rather than interaction between them. This is because, around the I850s, the modern scientific method seemed to provoke a progressive demarcation between the exact sciences and other disciplines. I would like to question this assumption by analyzing the attitude of Jacob Moleschott's scientific materialism - which has typically been interpreted as one of the most radical movements within Positivism - vis-à-vis the humanities.

Moleschott was born in 's-Hertogenbosch in 1822 and died in Rome in I893. He had a very international, that is to say, European career: he studied medicine in Heidelberg and was Privatdozent at the University of Heidelberg, later taught at the University of Zürich and was finally appointed Professor of Physiology at the University of Turin in I86I. He became Senator of the newly established Italian Kingdom in 1876 and Professor at 'La Sapienza' in Rome in I878.

Together with Carl Vogt (I8I7-I895) and Ludwig Büchner (I824-I899), Moleschott is considered to be one of the most representative materialist scientists in the nineteenth century. However, Moleschott's engagement in cultural politics was unique among the materialists: in fact, he was the only one who sketched the position of the sciences and the humanities in the context of a national educational system in such an extensive manner. It is interesting to observe that, in the debates on public education at the Italian Senate in the I880s, the most convinced supporters of the project of a 'Philosophical Faculty' embracing the sciences and the humanities were a physiologist (Moleschott) and a mathematician (Luigi Cremona [1830-1903]).

Moleschott's conception of science aimed at including, rather than excluding, ethical, religious and broader cultural and philosophical issues. Via Moleschott, materialism can be interpreted as focusing neither on a rigid demarcation between the natural sciences and the other disciplines, nor on the definition of a strict criterion for 'scientificity' to which every discipline must conform, but 
rather on the absorption of the humanities within the framework of materialist science.

The figure and the work of Jacob Moleschott are excellent models for examining the construction of the modern conceptions of both the sciences and the humanities in the second half of the nineteenth century. Even though his thought has been mostly interpreted as reductionist and strongly empiricist, ${ }^{2}$ not yet studied source material shows that, rather than strictly separating the domain of the natural sciences from any other domain, Moleschott's materialism constituted an all-encompassing worldview that sought to expand the influence of materialism beyond the sheer divulgation of empirical research. Having been a member of the Senate and an important personality in both the public and cultural life of his times, Moleschott is an illuminating example of the 'inclusiveness' of scientific materialism: he contributed both in theory and in practice to the convergence of the sciences and humanities.

In order to examine the relation between the empirical sciences and the other disciplines (in particular, between the natural sciences and the humanities), let us turn to a number of speeches by Moleschott: the first is a speech delivered at the University of Turin in 1867 for the beginning of his sixth course on experimental physiology at that university, entitled 'Della causalità nella biologia'. The others were held at the Senate between November 29, I886, and February 5, I887, on the occasion of a discussion about the national educational system, as well as one held on June 2I, I884, about the procedure for appointing new professors. These Senate speeches give a clear example of the intertwinement between epistemological and socio-political issues in materialism; moreover, they are unique in sketching and explaining precisely how the 'unity of science' - a key concept in Moleschott's thought ${ }^{3}$ - would function in the concrete context of national institutions.

\section{The interaction between arts and sciences: The idea of 'humanity' and the role of history}

That history should not be opposed but should rather be strictly related to nature is one of the central concepts of the introductory lecture Moleschott gave for his course in experimental physiology at the University of Turin in 1867 , called 'On Causality in Biology'. Here the relation between materialist science and the humanities is explicitly declared to be one of nonexclusion, since it is clearly stated that 'poetry does not exclude positivism, in the same way as the latter one is not opposed to the former." As a whole, this speech approaches the theme of the interaction between various disciplines not just abstractly, but also in the form 
of the concrete collaboration between natural scientists ('naturalists') and representatives of what we would call 'humanities' (a term which is, however, never mentioned in this speech nor elsewhere in Moleschott's work) and 'arts': 'poets' and 'naturalists' are said to have helped each other in the understanding of the necessary laws governing knowledge, so that now scholars of 'moral disciplines, linguistics, history, [and] social sciences agree with scientists in the application of that method, which is necessarily required by the natural, i.e., necessary, development of every thing, ${ }^{5}$

Continuous exchange between 'nature and history', that is, in our contemporary terminology, between the sciences and the humanities, or between nature and culture, is presented as the fundamental element for that 'sublime' and 'most noble' human aspiration which is the 'unity of science. ${ }^{6}$

Moleschott observes that, if the diversity of the respective methods has brought about the formation of two categories, namely that of 'philosophers' and that of 'scientists', the methods now tend toward unification: 'linguistics is for a great part becoming a branch of physiology, following the footprints of natural sciences,'7 where physiologists and philologists 'join their efforts to cultivate it'. At the same time, 'modern historical methods' are said to be the very same methods that 'have been dominant for a long time in the natural sciences', while 'the universal laws of history necessarily emanate from nature. ${ }^{8}$

Even the essence of Darwin's theory seems to be the introduction of a dynamic, diachronic and therefore historical dimension in the study of nature, as Moleschott describes in both the commemoration of Charles Darwin held in Rome in 1882 and the discourse he pronounced at La Sapienza in $1892 .{ }^{9}$ Moleschott transfers Darwin's conception of evolutionary theory beyond natural science and toward history as a discipline, an idea that is rarely found among historians at that time, but was becoming popular among natural scientists and sociologists. ${ }^{10}$

One of the major features of Moleschott's conception of science, above and beyond his ideas about educational politics, was therefore to stress the role of history in the system of knowledge and, consequently, in the concrete organization of the sciences. On the level of epistemology (intended as justification of a claim to knowledge and foundation of a scientific discipline), Moleschott conceives the great revolutions in physics and biology (Mayer's and Darwin's theories) as founding natural science on the study of diachronic development instead of concentrating on its static forms (classification) ${ }^{\mathrm{II}}$; at the same time, in all of his opening lectures at the university Moleschott justifies and explains physiology and biology as disciplinary fields by referring to their own history. On the level of the structuring of the educational system, history occupies a special place: it is precisely the historical approach that, referring to empirical objects such as sources, guarantees the 'scientificity' of a discipline. This is why Moleschott cares so much 
about a transformation of theology into history of religion - a particularly important task in the Kingdom of Italy, which was constituted both territorially and ideologically in opposition to the Catholic Church (represented by the Vatican and by the Habsburg Monarchy).

'Embracing nature and history', ${ }^{12}$ which is described by Moleschott as the ideal task of systematization that leads to the unity of science, also leads to a transformation of both the task and the conception of philosophy: 'a philosopher cannot consider his work as being juxtaposed to that of natural scientists', since 'any philosophy worthy of its name embraces the quintessence of the tree of science', and is even its 'ripest fruit', to cite a recurrent image in Moleschott's representation of the systematization of science. 'It is precisely philosophy, permeated by the unity of the law of necessity, which is itself induced by both natural and historical facts, that has to sublimate them in that universal organism which will be the adequate and therefore beautiful expression of science. This kind of philosophy will demonstrate the natural conditions of historical events, [and] the historical conditions of natural phenomena, always through one and the same method, that is, the experimental and inductive method' ${ }^{13}$

The unifying task of philosophy would still be one of the essential elements of Moleschott's thought twenty-one years later, when, having become a member of the Senate, he would propose a reform of higher education that would take into account the role of philosophy as synthesizing science into an organic unity. That this unity is considered to be beautiful because it is adequate is a clear reference to Hegelianism. However, the 'Philosophical Faculty' as conceived by Moleschott in his Senate speeches does not refer to that 'experimental and inductive method' which, according to the abovementioned university lecture, should be adopted by philosophy; therefore, Moleschott's view in the 1880 os seems to be even more flexible and tolerant vis-à-vis nonempirical sciences. ${ }^{14}$ The system of science as a universal organism is significant if one considers the similarity to the organic conception of nature: Moleschott tried to find a 'natural' system of the sciences, as is also evident from the statement that it is 'the law of necessity' that informs philosophy, giving it unity and beauty.

On the biographical level, we can find the idea of a synthesis of science and what he calls 'humanity' as an ideal in Moleschott's correspondence with the Swiss geologist Edouard Desor. The theme appears quite often in his letters, in particular with reference to the theologian Theodore Parker; Parker is said to uniquely combine science and humanity, thereby unifying them ${ }^{15}$ - where it is clear that 'Humanität' does not indicate general moral principles, but a precise idea of humanistic culture. 'Humanity' as a value thus appears to be a central requirement for scientific research: something that pertains to the natural scientist no less than it pertains to other scholars. 
In other letters, Moleschott refers to Parker's work on the history of religion and to its importance for his own project of writing a book on anthropology, which he never finished. Substituting theology with the history of religion was one of the points of Moleschott's program for a reform of higher education: history, considered 'in its broadest sense', had been presented in the Senate speeches held in I886-I887 as an essential subject in the Philosophical Faculty. Such a 'faculty' was conceived as being propaedeutic to further studies, including the natural sciences and technical subjects, on the model of the German Philosophische Fakultät. It would also have among its tasks a serious examination and discussion of religious issues (again, 'intended in the broadest sense and not as dogmatism'), which constituted an important mission for the government after the suppression of theological faculties, as Moleschott himself observed:

History, which should be taught in those Faculties in the broadest sense, will be required to examine religious issues minutely and conscientiously. According to me, as the Senate knows, this does not mean dogmatic issues, but religion as it is present in the human heart, which everyone wants, in one's own way, to be seriously examined and discussed, according to one's own beliefs or philosophical opinions. ${ }^{16}$

On the political level, this implies a secularization of education; on the epistemological level, it indicates a task that the natural sciences and humanities have in common, namely including the historical perspective while taking into consideration either their object of study (theology becomes history of religion) or the discipline itself (the history and prehistory of physiology and biology is constantly referred to in all of Moleschott's opening lectures). The humanities are thus characterized by Moleschott as sciences having their object of study in the empirical world.

\section{The 'Philosophical Faculty' and the 'Unity of Science'}

Moleschott's Senate discourse on higher education dating from 1887 is structured around the form and function of that 'ground' which unifies all disciplines - or 'the whole of knowledge', as Moleschott says when he directly asks his colleagues at the Senate to judge for themselves about their own fields of knowledge. The latter expression clearly indicates a holistic view of knowledge (which we might compare with his organicist view of nature), while the word 'ground' assumes a very concrete meaning, once we think of it as a necessary presupposition for the growth of vegetation. In fact, Moleschott affirms that the juries for a competition 
in higher education, as well as their respective disciplines, cannot be pigeonholed (literally, 'closed in a box'), since the branches of knowledge are connected and interwoven with each other, and all disciplines, all branches have a common 'trunk':

Knowledge becomes fertile through all disciplines, it develops branches through them, it is interwoven with all of them; every discipline needs the other disciplines in order to refer to them, to develop, to be applied to and through them; in conclusion all disciplines, all branches of the knowable have a common trunk. ${ }^{17}$

The image of the tree, another topos of science-systematization around 1850$1900,{ }^{18}$ here stands for the unity in the complexity which characterizes the 'unity of science' and its concrete actualization, at least as Moleschott maintains it in this discourse on the 'Philosophical Faculty'.

In accordance with the taxonomic aim of the speech, all single disciplines find their place in the scale of knowledge. Physiology is taken as an example in order to explain the all-encompassing nature of knowledge, so that a physiologist, according to Moleschott, must take into consideration also physics, chemistry, natural history, anatomy, as well as pathology (including clinical pathology) and, last but not least, philosophy. In order to indicate the synthesis of disciplines that characterizes materialist science and, in particular, physiology (Moleschott's own special field), he states that a physiologist 'would cease to be a physiologist from that day, in which he forgot that he must be an anthropologist.' ${ }^{19}$

This particular discourse, then, far from being merely political, is also of fundamental importance in order to comprehend why Moleschott decided to write a work entitled 'Anthropologie'. Moleschott's Anthropologie represents exactly this all-encompassing sphere described above, in which all disciplines are bound together and put into relation - gaining universality, but not losing their own specificity. This is evident not only from its structure, but also from its programmatic introduction, where the continuity between organic and inorganic substances is underlined. ${ }^{20}$ In this respect, continuity with Schelling's idea of unity is noticeable: ${ }^{21}$ the materialists did not give up the ideal of unification and of the creation of a system of science; on the contrary, they conceived establishing relations between disciplines and domains as one of the core tasks of science. Furthermore, the interrelation between domains is no longer derived from abstract thought, but presented as a result of the most recent scientific research in the fields of biology, physiology and psychology. It is precisely this set of relations connecting all different disciplines (or, better, all different fields of knowledge) that guarantees the 'unity of science': unity as relation, then, as interconnected structure providing every scientist with a 'general view', a broad perspective on the whole field of 
knowledge. This is the feature, according to Moleschott's speech, of all the 'masters from whom knowledge and power derive'; among these, he mentions Helmholtz, Golgi, Wilhelm Wundt, and his disciple Angelo Mosso. ${ }^{22}$ Significantly, the work of all of these scientists has indeed dealt with a mode of research in which relations between the physical and the psychical are established. Golgi's studies on the nervous system, Helmholtz's experiments on sense-perception, and Wundt as experimental psychologist proposing an integrative approach between mind and body: they all allow for physical and psychical interactions to emerge and therefore also for connection between disciplines, especially physiology with psychology.

\section{Classical culture and the roots of the Tree of Knowledge}

Classical culture was so important to Moleschott that, in the abovementioned Senate speeches, he complains about a lack of 'style' in the writings of students (in the Italian language and, even more, in Latin and ancient Greek) - something which may seem uncommon for a materialist to do. Above all, he complains about the fact that students (at high school, as well as at the university) do not study for the sake of science, but just because they are afraid of not passing the examinations ${ }^{23}$ For Moleschott, if students are not educated according to what one would call a 'classical' model, they will never be mature enough for science (the military metaphor literally meaning that they will never be 'general officers' but just 'soldiers' or in the best case 'corporals'). ${ }^{24}$

It should be noted that technical faculties are also explicitly included in this setting of higher education at university level, with the Philosophical Faculty as their background, since only the contact with 'pure science' like philosophy fosters the progress of all disciplines, including the applied sciences. ${ }^{25}$ The study of classical culture, however, means neither dogmatism nor the absence of experimental method: on the contrary, more time should be dedicated to experimentation in the laboratories and there should be space for self-reflection and critical thinking:

Constantly worried about the nightmare of examinations, the student does not even keep a short half of an hour, during the lecture-period, for his favorite studies, or - which would be even better - to reflect by himself and take some research initiative. It is not just about the psychological harm the student has to undergo because he has to think the whole year long about the examinations he will have to go through at the end of the course. We oblige him to a sterile and servile study, with which, apart from few and rare exceptions, he makes nothing of his own [ideas]. He cannot find any time to go to the laboratories, he cannot find any time to learn how to do 
research. And yet it is one's own research, carried out under the direction of a good teacher, with a rigorous method, during the time of university studies, which will be valuable his whole life long. ${ }^{26}$

The Philosophical Faculty is not seen here as a domain of the humanities in opposition to the natural sciences, but rather as literally 'embracing' all the subjects and giving them a basis, including 'moral sciences, history, literature in its broadest sense, philosophy, including also speculative philosophy, mathematics, all positive sciences, [and] all natural sciences. ${ }^{27}$

The image of 'classical' culture as an all-encompassing theoretical framework for scientific development is constantly present in the speeches about higher education held in I886-I887. For instance, Moleschott's use of the tree metaphor continues to underline the function of the Philosophical Faculty as 'roots' for the other disciplines:

Now, I will briefly tell you my intention. If you have such a Philosophical Faculty joining all pure science one can find in higher education, then you will have what is usually called alma mater studiorum. In such a Faculty, all roots of knowledge would be accessible to everyone who seriously wanted to deepen their field of study. The one who found his first lymph there is prepared to choose to go in the direction of law or medicine, or to become an engineer; but all three of them will continuously have to think, again and again, of the root they found in that great Philosophical Faculty ${ }^{28}$

If the roots of the tree representing the system of knowledge are contained in the Philosophical Faculty, we should ask what the fruits of this tree are. According to Moleschott, 'ethical progress' is 'not less worthy than scientific progress', it is in fact its 'ripest fruit':

Gentlemen of the Senate, I see many 'complete men' in Italy, who join deep knowledge with artistic feeling; scientific meditation has not destroyed the energy of action in them, and there is a discrete number of people who have not left apart the 'cult of the ideal' within their 'positive studies'. Without this, there cannot be any high aspiration, nor guarantee of ethical progress, which is no less worthy than scientific progress, being in fact its ripest and most delicious fruit. ${ }^{29}$

During another discussion at the Senate a couple of weeks later (December I4, I886), Moleschott expresses the idea that one should study natural science and do scientific research for the sake of it, because otherwise there cannot be any 
progress; only if one does not aim at any direct application, do great discoveries occur $^{30}$ After having mentioned a few scientific discoveries such as the telegraph and electricity, which he presents not as products of goal-oriented specific research, but rather as results of profound, general, pure research, he arrives at the point of enumerating among the discoveries led by disinterested research even 'the discovery of man', which he attributes to Socrates as initiator, followed by Spinoza, and finally Renan. Without this discovery, mankind would have never achieved its 'most ideal progresses' and, again, it is the Philosophical Faculty, 'richly nourished' as Moleschott would like it to be, that is presented as the condition of possibility for such 'deep studies', for 'the purest, most general, most profound of scientific studies' leading to these important discoveries, such as that of the mechanical equivalent of heat. ${ }^{31}$

On the basis provided by the Philosophical Faculty, Moleschott thinks that 'the most complete, broadest, richest and widest University in the world' ${ }^{32}$ could originate and grow, and would have as a result the establishment of a secure ground for science to develop in contact with the arts, for technical faculties to be in relation with 'beauty. ${ }^{33}$ What Aeschylus's Prometheus calls the 'pantechnic'

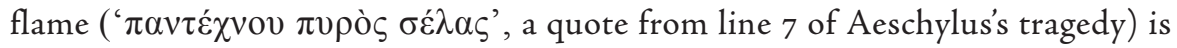
what would embrace the whole of science, knowing how to reach its source and how to spread it throughout the world. ${ }^{34}$

Interestingly, the relationship of Moleschott's materialism to metaphysics is an ambiguous one: metaphysics appears to be not completely excluded, but at the same time is refused as far as its nonempirical objects and methods are concerned, and maintained with respect to its ultimate scopes (as a unifying theory of both science and reality). One of Moleschott's comments regarding his setting of materialist science within the framework of a humanistic tradition, which can only be continued and guaranteed by the Philosophical Faculty, is particularly significant in the context of this discussion. Although some of his colleagues ${ }^{35}$ disagreed with how the Philosophical Faculty should be comprised of so many different disciplines, Moleschott presents this as an advantage, suggesting that it makes possible for each discipline to recognize their own limits. He goes on to write about a physicist and a metaphysician, where he argues that the physicist would 'absorb' a great part of metaphysics, and that this would likely lead to positive results for both sciences. ${ }^{36}$ It has to be noticed that Moleschott literally uses the verb to absorb', which both supports and confirms our interpretation of materialism as an 'inclusive' worldview. It is precisely this absorption and inclusiveness of scientific materialism vis-à-vis nonscientific domains that characterizes the relation between natural sciences and the humanities in late-nineteenth-century positivism.

Natural science thus stands in a reciprocal exchange with nonempirical subjects such as ethics and metaphysics. At the same time, as Moleschott himself 
observed in the abovementioned speech at the University of Turin, during the second half of the nineteenth century an increasing number of disciplines, also in the field of the humanities, started to make claims as to their appropriation and utilization of empirical methods. Moleschott's conception of the system of science appears to be an attempt to connect disciplines and domains in a broader, more comprehensive system, where the relation between materialism and the humanities appears to be open rather than demarcating. The fact that Moleschott aimed at securing an educational structure - which would constitute concretely what he called 'the unity of science', a unity that would be represented by a 'Philosophical Faculty' founded on classical (ancient) culture and philosophy - suggests that materialism was not the rigid, reductionist system that it is often thought to be. Instead, it significantly contributed to assign the humanities a crucial role in the context of Italian higher education.

\section{Notes}

I I would like to thank Dr. Robert Ryder for correcting my English and giving me inspiring feedback on this paper.

2 Compare, e.g., the most recent biography of Moleschott: Giorgio Cosmacini, Il medico materialista: vita e pensiero di Jakob Moleschott (Rome-Bari: Laterza, 2005). For a contrasting view on materialism, see Alessandro Savorelli, 'Jakob Moleschott e la cultura italiana del suo tempo', as well as Laura Meneghello, 'Scientific Materialism and the Conception of Science: A Case-Study Based on the Work of Jacob Moleschott', both in Giornale critico della filosofia italiana VII (fasc. III, 20II), respectively 543-553 and 554-564.

3 Compare especially his university lectures in Jacob Moleschott, Sulla vita umana. Prolusioni e discorsi (1861-1867) (Turin: Loescher, I872).

4 Jacob Moleschott, Della causalità nella biologia. Sesta prolusione al corso di fisiologia sperimentale alla Regia Università di Torino letta dal Professore Jac. Moleschott il di 8 gennaio 1867 (Turin: Loescher, I867), 9. All translations in this article are mine.

5 Ibid.: 'Ora se i poeti ed i naturalisti si sono data la mano nel comprendere ed accettare quella legge della necessità, che è base e condizione assoluta di ogni sapere, non è di certo meraviglioso il vedere come eziandio i cultori delle discipline così dette morali, della linguistica, della storia, delle scienze sociali s'incontrino cogli scienziati nell'applicazione di quel metodo che il naturale, vale a dire il necessario, sviluppo di ogni cosa impreteribilmente ne prescrive'. One should remark that 'naturalists' and 'poets' are much older words than the division between Natur-and Geisteswissenschaften, and that they are not identical with these domains: in fact, it seems that this division was not so clear and accomplished yet, although progressive specialization required the theorization of a 'common ground', a unified system of the sciences.

6 Idem, 3.

7 Idem, 9.

8 Idem, го,

9 Jacob Moleschott, Carlo Roberto Darwin. Commemorazione pronunciata a nome degli studenti dell'Università di Roma nel giorno 25 giugno 1882 (Turin: Loescher, I882) and idem, 
Allocuzione di Jacopo Moleschott pronunciata alla Sapienza di Roma il 16 dicembre 1892 per le feste giubilari in onore di lui, in Per gli amici miei: ricordi autobiografici, trans. by Elsa Patrizi-Moleschott (Palermo-Milan: Sandron, I902), 303-3 I2.

E.g., Ernst Haeckel (I 834-I9I9) and Herbert Spencer (I 820-I903).

In this regard, compare Moleschott, Carlo Roberto Darwin.

Moleschott, Della causalità nella biologia, 3 .

Idem, I I-I 2: Essa è precisamente la filosofia che compenetrandosi dell'unità della legge di necessità, indotta dai fatti, siano naturali siano storici, ha da sublimarli in quell'organismo universale il quale sarà l'espressione adeguata e quindi bella dell'unità della scienza. Tale filosofia dimostrerà le condizioni naturali degli avvenimenti storici, le condizioni storiche dei fenomeni naturali, e ciò coll'aiuto di un unico metodo che sarà mai sempre lo sperimentale ed induttivo' (my emphasis). Here, it has to be noticed that demonstrating the 'historical conditions of natural phenomena' means embedding the study of nature in its cultural background; at the same time, it constitutes a clear example of the transfer of concepts deriving from Darwinism to the theory of knowledge. As can be inferred from the reference to 'the experimental and inductive method', the evolutionary conception of natural history is transferred to history as such.

4 The 'Philosophical Faculty', as it is presented in Moleschott's Senate speeches, does not actually refer to any particular philosophical stream or approach to philosophy: it simply provides a cultural background in the humanities and classical culture. For more details on its function, see below.

Archives de l'État de Neuchâtel, Fonds Edouard Desor, Carton I3, D 55 (Moleschott to Desor, Zürich 2I/09/1859 and 2I/05/I860).

Jacob Moleschott, Discorsi del Senatore Jac. Moleschott pronunziati in Senato nelle tornate del 29 novembre, 14, 15, 16 e 17 dicembre 1886, 20 e 21 gennaio e 5 febbraio 1887. Modificazioni della legge sull' istruzione superiore e Commemorazione del Senatore Francesco Magni (Roma: Forzani e C., Tip. del Senato, I 887), 39-40 (I4/I2/1886).

Jacob Moleschott, Sulla scelta dei professori. Discorso del Senatore Jac. Moleschott pronunziato in Senato nella tornata del 21 gingno 1884 (Roma: Forzani e C., Tip. del Senato, I 884), 6.

Compare Paul Ziche, Wissenschaftslandschaften um 1900: Philosophie, die Wissenschaften und der nichtreduktive Szientismus (Zürich: Chronos, 2008), I78ff.

Moleschott, Sulla scelta dei professori, 6-7.

Jacob Moleschott, 'Einleitung', in Das Wesen des Menschen, 49-50 (manuscript, B V 3, Fondo Speciale Moleschott, Biblioteca Comunale dell'Archiginnasio, Bologna). Now also in Matteo D'Alfonso, 'Lantropologia chimica di Jakob Moleschott', Giornale critico della filosofia italiana VII, fasc. III (20II), 628.

2I Compare Friedrich Wilhelm Joseph Schelling, Einleitung zu seinem Entwurf eines Systems der Naturphilosophie. Oder: Ueber den Begriff der speculativen Physik und die innere Organisation eines Systems dieser Wissenschaft (Jena \& Leipzig, I799).

Moleschott, Sulla scelta dei professori, 7.

Moleschott, Discorsi, I4-I7 (29/I I/I886).

Idem, I 6 .

Idem, 20-22.

Idem, I 7 .

Idem, I 8-I9.

Idem, I9. In the original, the Italian word 'succhi' (meaning 'juice', but also 'lymph', especially in nineteenth-century Italian) should be understood as a continuation of the tree metaphor. 
29 Idem, 32-33.

30 Idem, 35-36 (I 4/I 2/I 886).

3 I Idem, 38 .

32 Idem, 44.

33 Ibid.

34 Ibid.

35 Among the members of the Senate, the critics of the Philosophical Faculty were the Minister of Public Education Michele Coppino (I822-I90I) and the historian Pasquale Villari (I827-I9I7).

36 Idem, 38-39:'A seconda della forza dei due ['il fisico ed il metafisico', L.M.], gioverà al fisico di vedere dove cominci la metafisica, o al metafisico di vedere dove il suo campo finisce. E potrà anche succedere, come è successo, che il fisico assorba larga parte della metafisica, $\mathrm{e}$ potrà fare un bene a tutte e due le scienze' (my emphasis). 


\title{
I.4 The Best Story of the World \\ Theology, Geology, and Philip Henry Gosse's Omphalos
}

\author{
Virginia Richter
}

I

In the first half of the nineteenth century, philological readings of the Scriptures and new approaches in geology - set down, most importantly, in Charles Lyell's Principles of Geology (1830-1833) - uncovered the various strata of the Book of Books and the Book of Nature, respectively. The result of applying the historicalcritical method to the Scriptures was precisely the discovery of its historicity: as philologists and - mainly Protestant - theologians such as Friedrich Schleiermacher and David Friedrich Strauss - whose The Life of Jesus, Critically Examined (1835-1836) was disseminated in Britain in George Eliot's influential translation (1849) - could show, the various books of the Bible had been composed at different points in time and by different authors. ${ }^{\text {'T }}$ The empirical study of geological formations resulted not only in the realization that the age of the earth by far surpassed the six thousand years allotted by the Bible, but also that geological processes were dynamic albeit often infinitesimally slow. ${ }^{2}$ As Lyell stated, 'this planet' could no longer be regarded 'as having remained unaltered since its creation', since modern geologists had 'proved that it had been the theater of reiterated change, and was still the subject of slow but never ending fluctuations., ${ }^{3}$ Neither the earth nor the Scriptures were static, neither had emerged through a single act of creation or revelation; rather, both were the result of slow processes of loss (erosion, textual corruption) and accretion (sedimentation in a geological as well as a philological sense). In a parallel process in the humanities and the sciences, divine authority was undermined by the emergence of new methodologies: the Book of Nature was found to be author-less; natural phenomena emerged under the influence of secondary causes; any reference to a first mover had become dispensable. The authorship of the Book of Books, conversely, now appeared as decentered, not revealed by the Holy Spirit, but composed by various human authors. 
This story of the emergence of the modern disciplines has been told, for example, by Lyell himself, as a linear history of progress:

By degrees, many of the enigmas of the moral and physical world are explained, and, instead of being due to extrinsic and irregular causes, they are found to depend on fixed and invariable laws. The philosopher at last becomes convinced of the undeviating uniformity of secondary causes, and, guided by his faith in this principle, he determines the probability of accounts transmitted to him of former occurrences, and often rejects the fabulous tales of former ages, on the ground of their being irreconcilable with the experience of more enlightened ages. ${ }^{4}$

One of the aims of this paper is to show that the emergence of new methodologies, new epistemic virtues and institutionalized disciplines as we still know them is more complex and contradictory than Lyell's statement suggests. Not only was the relationship between the natural sciences and the humanities much more dialogic than a retrospective construction of the 'two cultures' implies; additionally, the notion of a continuous, progressive advancement of knowledge was challenged by competing efforts to tell a different story about the natural world, a story based on the apparently repudiated view of an unchanging creation. Nineteenth-century historicism was thus questioned by an alternative temporal concept which suggested breaks - caused by divine intervention - in the unidirectional flow of time. ${ }^{5}$ While in retrospect, the 'victors' of this epistemological debate - Charles Lyell, Charles Darwin, Thomas Henry Huxley - can be identified with a high degree of confidence, for their contemporaries the differentiation between 'true' and spurious science was by no means always clear. And even if it was, as in the case of Philip Henry Gosse's theory of 'prochronic creation' discussed below, such interventions were not without effect. At the very least, they forced their opponents to strive for ever better foundations of what they tried to establish as the only valid scientific stance. ${ }^{6}$

Drawing on the work of historians and theorists of knowledge sometimes subsumed under the label New or Comparative Epistemology, ${ }^{7}$ a more heterogeneous, dynamic and recursive picture emerges than the story of linear progress. Ludwik Fleck, one of the founding fathers of this school of thought, describes science as a social practice in terms of a complex web constantly undergoing subtle transformations, in contrast to a view of the history of science in terms of scientific revolutions and epistemic breaks, as suggested by Thomas S. Kuhn and Michel Foucault. What is understood as knowledge in a given historical period and culture, according to Fleck, is not grounded in 'objective facts' or qualities inherent in natural phenomena, but is the result of shared preconceptions and prac- 
tices within a community or, in Fleck's term, a 'thought collective' (Denkkollektiv); in other words, scientific knowledge is socially produced and, in consequence, inseparable from a prevalent 'thought style' (Denkstil) ${ }^{8}$ Crucially, this means that from an internal point of view, from within a thought collective, its own 'knowledge' cannot be discerned as invalid: what knowledge is depends on the particularities of a given thought style. Conversely, other, incompatible thought styles are perceived as 'mysticism': 'Der fremde Gedankenstil mutet als Mystik an, die von ihm verworfenen Fragen werden oft als eben die wichtigsten betrachtet, die Erklärungen als nicht beweisend oder danebengreifend, die Probleme oft als unwichtige oder sinnlose Spielerei,' ${ }^{9}$

Applied to the nineteenth-century debates on geology, the question of divine agency bracketed off by Lyell, and finally laid to rest by Huxley's introduction of 'agnosticism' as the only acceptable stance of the scientist disregarding his personal beliefs, ${ }^{10}$ remains crucial for theologians such as Darwin's critic Samuel Wilberforce. In Fleck's epistemological model, the collective systems of knowledge are relatively stable. They are gradually transformed through intercollective transactions, due to the fact that individuals never belong to only one collective, and through the generative function of language which not only reproduces knowledge but transforms it through processes of transmission and misrecognition; the word serves as 'an intercollective means of transport' (interkollektives Verkehrsgut)." According to Fleck, the transformation of knowledge is neither linear nor directed; it is socially produced and to a degree contingent. Finally, this concept allows us to perceive a-synchronicities within a historical period and culture: while one thought style (for instance, 'mechanical objectivity') will be dominant, and synchronous exchanges between specific thought collectives (for instance, philology and geology) do occur and produce something like a coherent albeit not monolithic epistēme of a period, a-synchronic pockets of seemingly obsolete thought styles (such as the 'delusion as to the age of the world', the biblical six thousand years, denounced by Lyell' ${ }^{12}$ ) can persist and unfold discursive efficacy. For some participants in the debates on modern geology and, later, evolution theory, the belief in the validity of the Scriptures as an explicative framework for natural history continued to persist and was even hitched to a self-declared modern and enlightened notion of proper scientific knowledge. My main example, Philip Henry Gosse's Omphalos (I857), shows the relevance of such a-synchronic pockets in the negotiations of authority, epistemological validity and the discursive rules of scientific communities.

In sum, a notion of knowledge production based on Ludwik Fleck's epistemology allows us to perceive contemporaneous but contradictory narratives as the manifestations of the continuous discursive and pragmatic interactions within the history of knowledge, rather than as a progressive overcoming of obsolete approaches 
by more modern, more scientific ones. Fleck developed his epistemological model on the basis of his own microbiological and medical research. However, as Barbara Hernstein Smith has pointed out, his emphasis on 'conceptual-discursive systems that both enable and constrain the process of cognition, ${ }^{13}$ that is, systems embedded in and effective through language, renders Fleck's model pertinent for a history of knowledge that encompasses the humanities as well as the sciences. In particular, the constitution of the modern disciplines in the nineteenth century is the result of epistemological negotiations across various fields, of the competition to tell the best story about the emergence of the world and the creatures inhabiting it. Importantly, this debate did not take place exclusively within the confines of the natural sciences - which emerged in the modern sense only as a result of this process of intra- and intercollective exchange - but at the intersection between natural history/science, the humanities and individual concerns about faith.

The difference between 'knowledge' and 'mysticism' emerges as the result of an ongoing and often contradictory, nonsynchronous process of practices and negotiations, a process increasingly studied in comparative epistemology. However, from the point of view of the humanities, there remain several desiderata: the history of knowledge is still centered on the natural sciences; the lab is the primary setting of studies in the wake of Fleck, Kuhn and Latour. Other sites of knowledge production - such as the discussion-based seminar, instituted at German universities after Wilhelm von Humboldt's reform of higher education, and soon adopted by American universities - would yield a different picture regarding academic filiation and the formation of thought styles. In addition, reciprocal methodological exchanges between the sciences and the humanities require greater attention. To such an exchange, the humanities can contribute their hermeneutic and philological competence, specifically analytic skills such as the study of metaphors, of rhetorical devices and of linguistic modes, which has already been fruitfully applied to Darwin's works. ${ }^{14}$ It is not by chance that Darwin's style of writing - personal and engaging, narrative and metaphorical, and, as Beer and Levine have shown, deeply influenced by literary patterns - has attracted the attention of literary scholars. Similar studies need to be extended to less accommodating figures, and to fields that lend themselves less easily to narrativization. Last but not least, the history of knowledge needs to become truly comparative. While studies on, for instance, Louis Pasteur have yielded important insights into the workings of science as a network of diverse forces and interests, ${ }^{15}$ the implied concepts of knowledge production and implementation would gain in complexity from a consideration of the humanities. Fleck's intercollective means of transport', language, forges connections between these different fields of enquiry. Ultimately, the making of the sciences cannot be separated from the making of the humanities. 


\section{II}

In the early nineteenth century, the readings of the Book of Books and the Book of Nature are compatible; in both, God's presence is revealed. ${ }^{16}$ A prime example of this, then still unproblematic harmony between theology and science is William Paley's widely read Natural Theology (1802). ${ }^{17}$ Paley's leading metaphor is the watch found in a country lane from which the existence of a watchmaker is necessarily deduced: without an artificer, there would not, could not be a watch. By analogy, the world and human beings, these intricate artifacts, could not exist without a creator. The hypothetical discovery that the watch contains a reproductive mechanism, in analogy to living organisms, would further heighten our belief in and admiration of the artificer:

The conclusion which the first examination of the watch, of its works, construction, and movement suggested, was, that it must have had, for the cause and author of that construction, an artificer, who understood its mechanism, and designed its use. This conclusion is invincible. A second examination presents us with a new discovery. The watch is found, in the course of its movement, to produce another watch, similar to itself [...]. What effect would this discovery have, or ought to have, upon the former inference? What, as hath already been said, but to increase, beyond measure, our admiration of the skill, which had been employed in the formation of such a machine? Or shall it, instead of this, all turn us round to an opposite conclusion, viz. that no art or skill whatever has been concerned in the business, although all other evidences of art and skill remain as they were, and this last and supreme piece of art be now added to the rest? Can this be maintained without absurdity? Yet this is atheism. ${ }^{18}$

Within the thought style represented by Paley, it is not absurd to equate the mechanism of a watch with organic nature. Further, it is not absurd to imagine a watch that is capable of giving birth to baby watches. But it is absurd to imagine a world without a creator. The complexity, harmony and productivity of nature imperatively point to a higher intelligence, a creator and a plan of creation without which there would be only disorder and chaos. The postulate of purely naturalistic explanations of the phenomena, put forward shortly after by Lyell, is for Paley unthinkable. A world without a primary act of creation and without a telos is unthinkable. Atheism is not only wrong but also absurd, or, in Fleck's term, it is 'mysticism.

This self-evident frame of reference was soon to be challenged by the historical criticism of the Bible on the one hand, and by the empirical-inductive methodology in the sciences on the other. Lyell begins the Principles of Geology with 
an overview of the history of his discipline, presented as a directed movement from speculation to the systematic collecting of empirical facts, from 'vision' to consistent method: 'By acting up to these principles with consistency, they in a few years disarmed all prejudice, and rescued the science from the imputation of being a dangerous, or at best a visionary pursuit. ${ }^{19}$ In consequence, geology was established as the leading science, opening up - quite against Lyell's original intention - the temporal and methodological framework for Darwin's transmutation hypothesis. The emergence of a new geology constituted the move from the fantastic to the scientific, from the fabulous tales of medieval travelers to the exact observation of the Enlightenment - or again, from mysticism to true science. What is now rejected as fabulous includes not only stories of unicorns, cynocephali and other unlikely creatures, but also, for example, the story of Noah's flood, shortly before cited as an explanation for the fossils of extinct species. In a relatively short time, the epistemological foundations of the study of the earth and the organisms living on its surface, and preserved as fossils in the different geological strata, had undergone a fundamental change. ${ }^{20}$ However, this does not mean that the transition from natural history, in which the Book of Nature and the Book of Books revealed God's authorship, to natural science, in which these two ways of reading became systematically divorced, went uncontested. One of the most strenuous efforts to keep together what other scientists had put asunder, to reconcile Paley with Lyell, was made by Philip Henry Gosse.

In the I840 and I850s, Gosse was a respected naturalist specializing on littoral flora and fauna, well-known for his books addressed to a popular as well as a learned audience, but also a devout Christian, a member of the particularly strict Plymouth Brethren - a position that was only tenable within the framework of natural theology which justified the study of nature as a way of discovering and praising the harmony of God's creation. ${ }^{21}$ He saw the propositions of Lyellian geology as a contradiction to the superordinate teachings of the Bible: 'the dicta, which its [geology's] votaries rest on as certitudes, are at variance with the simple literal sense of the words of God'.22 In the late 1850 , Gosse belonged to a circle of naturalists who were discretely consulted about Darwin's as yet unpublished hypothesis of evolution through natural selection. This confrontation with evolution theory triggered a deep spiritual crisis. As a way to reconcile the now suddenly incompatible positions that constituted his identity as a Christian and a naturalist, Gosse proposed his theory of 'prochrony' according to which there exist two temporal orders in creation. In diachronic creation, signs of maturation and aging, such as the growth rings of a tree or the wrinkles on a human face, develop in time; they are reliable indicators of the age of an organism or other natural object. Within the diachronic framework, geological formations that require long stretches of time to build up equally reliably point to the age of the earth; here, 
Lyell's principles of uniformitarianism, actualism and the steady-state earth the constant and uninterrupted workings of natural laws - apply. Gosse devotes a sizable chunk of his book (pp. 30-IOI) to a detailed description of the recent advances in geology. It is not his aim to dispute the validity of these observations - he even explicitly confirms that the antediluvian theory is no longer tenable but to offer an alternative hypothesis that would render science again compatible with the simple literal sense of the words of God'.

This hypothesis is prochrony, a temporal order in which natural laws are suspended: signs of maturation come into being at the moment of creation, just as Adam had been created as a grown man on the sixth day of creation. Not born of a woman but formed from clay, Adam still has a navel, the omphalos of Gosse's title. The idea of prochrony is based on an alternative model of time, challenging the prevalent nineteenth-century notion of time as linear and directed, moving uniformly and incessantly from the past to the future. By contrast, life to Gosse is cyclical, and God is free to start the cycle of life at whatever point he chooses; He can create the chick or the egg, and consequently, the existence of a full-grown hen is no proof for the prior existence of an egg. In geology, the material evidence that seemingly points to a long prehistory, and incidentally, the fossil evidence that supports the idea of transmutation, is subject to the law of prochrony: Just as He created Adam as an adult, God may have created an 'old earth', with signs of erosion, fossils and all.

As no direct empirical proof of prochrony is possible, Gosse uses a juridical metaphor to validate his thought experiment. In an imaginary trial, witnesses on both sides are examined; but, of course, there are no living witnesses for the evolutionary party, only circumstantial evidence:

No witness has deposed to actual observation of the processes above enumerated; no one has appeared in court who declares he actually saw the living Pterodactyls flying about, or heard the winds sighing in the tops of the Lepidodendra. [...] Strong as is the evidence, it is not quite so strong as if you had actually seen the living things, and had been conscious of the passing of time while you saw them live. It is only by a process of reasoning that you infer they lived at all. ${ }^{23}$

Gosse indirectly points to an epistemological weakness in Charles Darwin's argumentation that would not escape his critics on the publication of On the Origin of Species two years later. Darwin uses cumulative circumstantial evidence that, according to Gosse and other critics, only suggests that there exists empirical proof of evolution. The actual transition of one species into another could not be conclusively proven until the discovery of the Archaeopteryx and similar intermediary fossils. ${ }^{24}$ The emerging disciplines of paleoarcheology and comparative anatomy drew their 
conclusions on the basis of a fossil record that Darwin himself referred to as incomplete and barely readable: the natural geological record' is a history of the world imperfectly kept, and written in a changing dialect'. ${ }^{25}$ Darwin here takes up the ancient topos of the Book of Nature, but disputes its readability. The study of nature shows how geological and biological 'dialects' are transformed over time. In analogy to the linguistic study of the Indo-European languages, the fossils first discovered in Europe and the Americas, including dinosaurs, cumulatively suggest that extant species had similar but extinct ancestors, and that some species died out without leaving behind similarly formed relatives ${ }^{26}$ The fossils thus tell a different story than the Bible, a contradiction that is acknowledged by Gosse: the records which seem legibly written on His created works do flatly contradict the statements which seem to be plainly expressed in His word. ${ }^{27}$ However, as Gosse argues, two principles are axiomatic: that matter was created, i.e., that the Eternal God [...] called the universe into being out of nothing, ${ }^{28}$ and that the species were created immutable. Consequently, the conclusions drawn from fossils must be a fallacy. The only interpretation which allows us to overcome the discrepancy between the 'stone book' ${ }^{29}$ and the revealed word is precisely the law of prochrony. Taking into account God's unlimited creative power, the unquestioned primary condition of Gosse's argument, fossils do not point to antecedent species; bones are no proof of previous life:

If I could show, to your satisfaction, that a skeleton might have existed; still more, that a skeleton must have existed; still more, if I could prove that myriads of skeletons, precisely like this, must have existed, without ever having formed parts of antecedent living bodies; you would yourself acknowledge that your conclusions were untenable..$^{30}$

Having formulated this hypothesis which is mainly based on the petitioning of the very principles under negotiation (creation and the absence of evolution), Gosse takes us, his readers, by the hand and leads us through the classes of the plants, invertebrates, vertebrata and finally man - who forms a class, and gets a chapter, of his own. Gosse asks the readers to imagine a full-grown exemplar from various species - a sturdy oak, a majestic stag, an adult man - and then, further to imagine that this apparently mature organism has been created on this very day. The oak's year rings, the stag's antlers, the man's wrinkles and grizzled hair, all the signs of growth and aging are prochronic, they have come into being at the moment of creation, on this very day. Unlike the circumstantial evidence of the fossils, these acts of prochronic creation are confirmed by, albeit fictitious, eye-witnesses. We, his implied readers, have seen them with our mind's eye. Better than that, the most eminent witness imaginable, God himself, has deposed His evidence in writing, in the story told in Genesis. 
The rhetorical structure of Gosse's argument consists in an apparently systematic accumulation of hypothetical statements, which through reiteration acquire empirical weight, or so the author hopes. This rhetoric is not dissimilar to Darwin's, who also relies heavily on anecdotal evidence, analogy and seriality. In Darwin's writing, the piling up of examples creates an aura of empiricism without always constituting an impeccable chain of evidence. However, the grammatical trajectory appears to be reversed in the two authors. In Gosse's presentation of arguments we find a constant slippage from the subjunctive to the affirmative, from might to must, as in the example above. Whereas Darwin stresses the tentative and often preliminary nature of his theory formation, but uses this epistemic modesty as a strategy of self-authorization, as can be seen in the opening paragraphs of On the Origin of Species, Gosse strings together his imagined scenes of creation to form declarative statements that finally flow into rhetorical questions:

Who will say that the suggestion, that the strata of the surface of the earth, with their fossil floras and faunas, may possibly belong to a prochronic development of the mighty plan of the life-history of this world - who will dare to say that such a suggestion is a self-evident absurdity?

Of course, everyone dared to say this. Gosse's suggestive declaratives and rhetorical questions failed to convince both his lay readers and his fellow scientists. With the publication of Omphalos, Gosse took up an a-synchronic position in relation to the dominant epistemic virtues of his time, and thus effectively isolated himself from the scientific community of which he had been a respected member, as his son Edmund Gosse describes in his memoirs:

In the course of that dismal winter, as the post began to bring in private letters, few and chilly, and public reviews, many and scornful, my Father looked in vain for the approval of the churches, and in vain for the acquiescence of the scientific societies, and in vain for the gratitude of those 'thousands of thinking persons', which he had rashly assured himself of receiving. ${ }^{32}$

The thought collective that had gathered around Lyell, Darwin, Huxley and the botanist Joseph Hooker from the I840s onward, while internally divided on the question of evolution theory, ${ }^{33}$ were clearly in agreement on the discursive rules that facilitated the distinction between true science and mere speculation. The principle rule, as Huxley was to stipulate later, consisted in the epistemological privileging of naturalism - the observance of natural laws - against received authority including the Bible; in consequence, 'the assertion which outstrips evidence is not only a blunder but a crime. ${ }^{34}$ On the basis of this rule, writers indulging in 
insufficiently founded scientific speculation such as Gosse, Robert Chambers, the author of the evolutionary Vestiges of the Natural History of Creation (I844), or Alfred Russel Wallace, the codiscoverer of natural selection but in his later life an adherent of spiritualism, were excluded from the circle of leading British scientists.

\section{III}

Debates in the 1850 s and 1860 s about the best story in science, the most plausible explanation of the natural world and man's position in it, hinged on what Lorraine Daston and Peter Galison have called 'a distinct code of epistemic virtue, ${ }^{35}$ a code which had changed significantly since the days of natural theology. In order to be perceived as valid, a scientific theory had to adhere to this code, and its author had to position himself accordingly to gain acceptance by the dominant thought collective. If he failed to do so, criticism of his work was correspondingly devastating. In the following review, the author is criticized harshly for his faulty methodology: his theory is fantastic, fabulous, a relapse into the unenlightened times before the rise of modern science. According to the reviewer, the anecdotal procedure and the deviation from established principles of scientific enquiry lead the author straight back into the times of miracles and wonders:

Under such influences man soon goes back to the marvelling stare of childhood at the centaurs and hippogriffs of fancy [...]. The whole world of nature is laid for such a man under a fantastic law of glamour, and he becomes capable of believing anything: to him it is just as probable that Dr. Livingstone will find the next tribe of negroes with their heads growing under their arms as fixed on the summit of the cervical vertebrae; and he is able, with a continually growing neglect of all the facts around him, with equal confidence and equal delusion, to look back to any past and to look on to any future. ${ }^{36}$

This, of course, is not taken from a review of Gosse's Omphalos but of Darwin's Origin of Species, written by one of the most vociferous opponents of evolution theory, Samuel Wilberforce. This quotation is not meant to suggest that the scientific validity of Gosse's theory of prochrony and Darwin's evolution theory is interchangeable. What I have tried to show throughout this paper, however, is that the delimitation between the iterable and the absurd in the history of knowledge depends on a situated logic which is co-emergent with the discursive acts themselves. For Paley, the absurd is something else than for Lyell; for Gosse, it is something else than for Darwin; for Wilberforce, something else than for Huxley. 
From today's perspective, Gosse's theory of prochrony appears as a clear-cut case of bad science. However, as this case study has tried to show, Gosse made every effort to adapt his proposition to the discursive strategies and epistemic virtues of his time: he laid the basis for his argument by recapitulating extensively the findings of geology and paleoarcheology, and by admitting, up to a point, their validity. It is not so much his way of reasoning that departs from the thought style of the Lyell-Darwin-Huxley-Hooker nexus, but his axiomatic premise - God created the world and every living creature as stated in Genesis - and hence, his deduction - God also created the fossils, as fossils - that resulted in the general rejection of his theory. Gosse's attempt to reconcile science with revealed religion was doomed to fail not only because the scientific part of his argument was so outrageous, but because his theology was old-fashioned, or too radical, by the standards of mainstream theologians of his day. By ignoring the philological turn in Bible studies and insisting on a literal reading of the word of God, he broke the connection with the dominant thought collectives in both fields, theology as well as natural science. By insisting that God still matters in scientific theories, Gosse repudiated the agnostic and naturalistic stance proposed by Huxley as the best, and only, stance within the emerging framework of modern disciplines. As a result of his infringement of epistemic codes that had only recently been established, and still believing himself on firm epistemic ground, Gosse positioned himself beyond the pale of 'true science' and was discarded like one of the fossils he had studied on England's beaches.

\section{Notes}

I On the rise of philology and comparative religious studies in the late eighteenth and early nineteenth centuries, see Hans G. Kippenberg, Die Entdeckung der Religionsgeschichte. Religionswissenschaft und Moderne (Munich: C.H. Beck, I997), esp. 60-79; Sascha Müller, Die bistorisch-kritische Methode in den Geistes- und Kulturwissenschaften (Würzburg: Echter, 2010), esp. 45-58; and Joep Leerssen, "The Rise of Philology: The Comparative Method, the Historicist Turn and the Surreptitious Influence of Giambattista Vico', in Rens Bod, Jaap Maat, and Thijs Weststeijn (eds.), The Making of the Humanities, vol. II, 23-35.

2 See Peter Schnyder,'Die Dynamisierung des Statischen. Geologisches Wissen bei Goethe und Stifter', Zeitschrift für Germanistik. Neue Folge I9 (2009), 540-555.

3 Charles Lyell, Principles of Geology: An Attempt to Explain the Former Changes of the Earth's Surface, by Reference to Causes Now in Operation (Cambridge: Cambridge University Press, 2009 [orig. I830]), vol. I, 73.

4 Ibid., 76.

5 Nineteenth-century concepts of linear and cyclical time, and Lyell's position which is more complex than can be sketched here, are discussed in Stephen Jay Gould, Time's Arrow, Time's Cycle: Myth and Metaphor in the Discovery of Geological Time (Cambridge, MA, and London: Harvard University Press, I996), esp. II5-I78. 
6 As Lorraine Daston and Peter Galison have shown in Objectivity (New York: Zone Books, 2007), the dominant scientific stance of the late nineteenth century was 'mechanical objectivity. However, in genres of science writing other than the atlases analyzed by Daston and Galison, a much more personalized and even emotional embodiment of the scientist, and less regulated patterns of scientific practice, can be perceived. This is not least true of Charles Darwin, who combined an empirical scientific style with self-authorization on the grounds of personal credibility; see my analysis of Darwin's appellative style in $O n$ the Origins of Species: Virginia Richter, 'Anschauung des Unsichtbaren. Rhetoriken des Nicht-Wissens im Umfeld des Darwinismus', in Michael Bies and Michael Gamper (eds.), Literatur und Nicht-Wissen. Historische Konstellationen in Literatur und Wissenschaft, 17501930 (Berlin: Diaphanes, 2012), 359-377. Darwin's 'literariness', a style of writing that entails a stance different from the objectivity postulated by Daston and Galison, has been analyzed by: George Levine, Darwin: The Writer (Oxford: Oxford University Press, 20I I). This has become a vast field that cannot be surveyed in full here. Some of the most important contributions to New Epistemology include: Bruno Latour, We Have Never Been Modern (Cambridge, MA: Harvard University Press, I993 [French original I99I]); Barbara Herrnstein Smith, Scandalous Knowledge: Science, Truth and the Human (Durham, NC: Duke University Press, 2006); Isabelle Stengers, The Invention of Modern Science (Minneapolis and London: University of Minnesota Press, 2000 [French original I993]). 8 Ludwik Fleck, Entstebung und Entwicklung einer wissenschaftlichen Tatsache. Einfübrung in die Lebre vom Denkstil und Denkkollektiv, intro. by Lothar Schäfer and Thomas Schnelle (Frankfurt a. M.: Suhrkamp, I980), esp. 52-70. Fleck was a Polish microbiologist specialising in infectology. He published his epistemological writings in German; Entstebung und Entwicklung was first published in 1935 in Basel. To this day, his work has remained little known in the English-speaking word (the first English translation of his book was published in 1979), but his influence on Thomas S. Kuhn's concept of scientific communities has been acknowledged, rather in passing, by the latter in the preface to The Structure of Scientific Revolutions, 4th ed. (Chicago and London: University of Chicago Press, 20I2), xli. For a fuller discussion, see Babette E. Babich, 'Kuhn's Paradigm as a Parable for the Cold War: Incommensurability and Its Discontents from Fuller's Tale of Harvard to Fleck's Unsung Lvov', Social Epistemology I7.2-3 (2003), 99-I09. Fleck's 'thought styles' are linked to sociologically clearly demarcated 'thought collectives', and in this, they differ from A.C. Crombie's similarly sounding 'styles of scientific thinking', which are more broadly defined methods of scientific inquiry and argumentation within European natural philosophy and related fields. See A.C. Crombie, Styles of Scientific Thinking in the European Tradition: The History of Argument and Explanation Especially in the Mathematical and Biomedical Sciences and Arts, 3 vols. (London: Duckworth, I994). Fleck, Entstebung und Entwicklung, I 43.

Io Thomas Henry Huxley, 'Agnosticism' ( I889), in The Major Prose of Thomas Henry Huxley, ed. Alan Barr (Athens and London: University of Georgia Press, I997), 253-282. Fleck, Entstebung und Entwicklung, I43.

12 Lyell, Principles of Geology, 76.

I3 Smith, Scandalous Knowledge, 5.

I4 Since Gillian Beer's seminal study Darwin's Plots: Evolutionary Narrative in Darwin, George Eliot and Nineteenth-Century Fiction, 3rd ed. (Cambridge: Cambridge University Press, 2009), literary Darwin studies have developed into a vibrant field. Recent booklength publications include George Levine, Darwin and the Novelists: Patterns of Science in Victorian Fiction (Chicago: Chicago University Press, I99I); David Amigoni, Colonies, 
Cults and Evolution: Literature, Science and Culture in Nineteenth-Century Writing (Cambridge: Cambridge University Press, 2007); Gowan Dawson, Darwin, Literature and Victorian Respectability (Cambridge: Cambridge University Press, 2007); Virginia Richter, Literature after Darwin: Human Beasts in Western Fiction, 1859-1939 (New York and Basingstoke: Palgrave Macmillan, 20 I I).

I5 Bruno Latour, The Pasteurization of France (Cambridge, MA: Harvard University Press, I 993).

I6 Peter Harrison analyses the long history of interdependence between these two readings of Nature and the Bible, and in particular the catalytic effect of Protestant biblical scholarship on the study of the natural world; see Harrison, The Bible, Protestantism, and the Rise of Natural Science (Cambridge: Cambridge University Press, I998).

17 For a contextualization of Paley within the history of natural theology, and in relation to the emerging evolutionary concepts of the nineteenth century, see Stuart Peterfreund, Turning Points in Natural Theology from Bacon to Darwin: The Way of the Argument from Design (New York and Basingstoke: Palgrave Macmillan, 201 2).

I 8 William Paley, Natural Theology, or Evidence of the Existence and Attributes of the Deity, Collected from the Appearances of Nature, ed. Matthew D. Eddy and David Knight (Oxford: Oxford University Press, 2008), I5. Emphasis in the original.

I9 Lyell, Principles of Geology, 7 I-72.

20 On the controversies about Lyellian geology, in particular in relation to the then prevalent catastrophism, see Michael Ruse, The Darwinian Revolution: Science Red in Tooth and Claw, 2nd ed. (Chicago and London: University of Chicago Press, I999), 36-48.

2 I On Gosse as a littoral biologist and a representative of natural theology, see Jonathan Smith, Charles Darwin and Victorian Visual Culture (Cambridge: Cambridge University Press, 2006), esp. 79-84.

22 Philip Henry Gosse, Omphalos: An Attempt to Untie the Geological Knot (London: John Van Voorst; Paternoster Row, I 857; repr. Milton Keynes: Nabu, 2010), 4.

23 Ibid., I03-I04.

24 The Archaeopteryx was found in I86I; see Paul Chambers, Bones of Contention: The Archaeopteryx Scandals (London: Murray, 2002).

25 Charles Darwin, The Origin of Species, ed. Gillian Beer (Oxford: Oxford University Press, I996), 25I.

26 On the relevance of fossil discoveries for evolution theory, see Donald A. Prothero, Evolution: What the Fossils Say and Why It Matters (New York: Columbia University Press, 2007), esp. 50-90; on Gosse's Omphalos, Ibid., 8-10.

27 Gosse, Omphalos, 5, emphasis in the original.

28 Ibid., III.

29 Ibid., 6.

30 Ibid., I07.

3 I Ibid., 347, emphasis in the original.

32 Edmund Gosse, Father and Son (I907), ed. Michael Newton (Oxford: Oxford University Press, 2009), 64.

33 See Ruse, The Dawinian Evolution, I37-I42 and 202-228.

34 Thomas Henry Huxley, 'Science and Culture' (I889), in The Major Prose of Thomas Henry Huxley, ed. Alan Barr (Athens and London: University of Georgia Press, I997), 224-238, 233.

35 Daston and Galison, Objectivity, I 8.

36 William Wilberforce, 'Review [of On the Origin of Species]' (I 860), in L.S.B. Leakey, Jack Prost, and Stephanie Prost (eds.), Adam and Ape: A Sourcebook of Discoveries About Early Man (Cambridge, MA: Schenkman Books, I982), 2I-35, 35. 

II
The Science
of Language
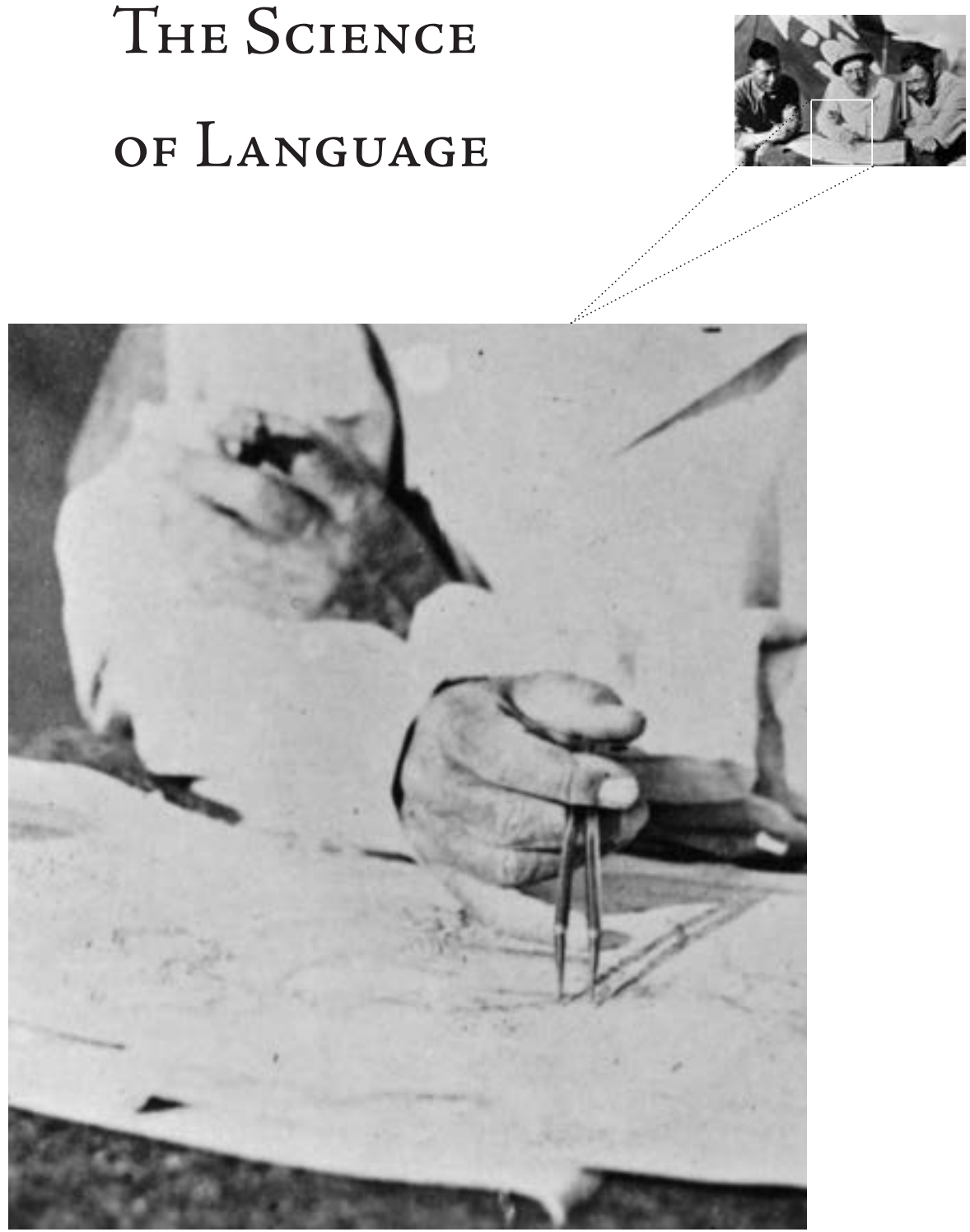



\title{
2.I The Wolf in Itself \\ The Uses of Enchantment in the Development of Modern Linguistics
}

\author{
JoHN E. Joseph
}

\section{Weber's antimodernism and Latour's symmetrical anthropology}

In the School of Philosophy, Psychology and Language Sciences in which I work, the philosophers have no doubt that they are part of the humanities. The psychologists know that they are not; the borderline that matters for them is between the social sciences and medicine. We linguists straddle the humanities and social sciences. A few of us are comfortable on the fence, while others place themselves firmly on this side or that, and generally try to hide their contempt for those on the other.

This may be inevitable, given that language is itself so central both to humanistic studies and to social life. Or the seeming inevitability could be just an ex post facto rationalization. Either way, it is worth zeroing in on some key early moments when the study of language shifted from being firmly rooted in the humanities to staking a claim to be a science, first a natural science, then a social one - and in both cases, a modern one.

In 1917, Max Weber (I864-I920) lamented the fate of our times, with their rationalization, intellectualization and above all, disenchantment of the world'. This indictment of the modern condition was implicitly echoed 75 years later by Bruno Latour:

The antimoderns firmly believe that the West has rationalized and disenchanted the world, [...] that it has definitively transformed the premodern cosmos into a mechanical interaction of pure matters. But instead of seeing these processes as the modernizers do - as glorious, albeit painful, conquests - the antimoderns see the situation as an unparalleled catastrophe. 
He adds that "The postmoderns, always perverse, accept the idea that the situation is indeed catastrophic, but they maintain that it is to be acclaimed rather than bemoaned!" ${ }^{2}$

Latour argues that modernism, antimodernism and postmodernism are all equally grounded in a 'Constitution' which took shape in the seventeenth century, whereby Nature and Society were separated, then gradually made into irreconcilable opposites. By the early nineteenth century this Constitution had become impervious to criticism. It undid the premodern incapacity to tamper with either nature or society, each being conceived as inexorably bound to the other at every point, under the authority of God. But the new 'humanism' gave rise to an 'asymmetry', which Latour considers the true mark of the modern, and the source of its ultimately fatal contradictions. It is asymmetrical because

It overlooks the simultaneous birth of 'nonhumanity' - things, or objects, or beasts - and the equally strange beginning of a crossed-out God, relegated to the sidelines. Modernity arises first from the conjoined creation of those three entities, and then from the masking of the conjoined birth and the separate treatment of the three communities while, underneath, hybrids continue to multiply as an effect of this separate treatment. ${ }^{3}$

Latour designates the 'human' pole as Subject/Society, as though these were conflatable, and repays his reader's willing suspension of disbelief with a grand narrative of modernism as the proliferation of 'hybrids' which mediate between Nature and Subject/Society [Fig. I].

The Constitution denies the existence, even the possibility, of such hybrids, being committed instead to 'purifying' the split. Yet this artificial split has to be mediated. So the Constitution ends up surreptitiously demanding the proliferation of those hybrids it claims to forbid. Such contradictions, far from weakening the Constitution, positioned the moderns as 'invincible':

If you criticize them by saying that Nature is a world constructed by human hands, they will show you that it is transcendent, that science is a mere intermediary allowing access to Nature, and that they keep their hands off. If you tell them that we are free and that our destiny is in our own hands, they will tell you that Society is transcendent and its laws infinitely surpass us. ${ }^{4}$

Because we have never practiced the absolute separation which is preached, Latour says that we have never been modern. Hence the idea of a 'postmodernism' is as absurd as the thought of returning to premodernism. His prescription for a nonmodernism has had less impact than his diagnosis. I'll return to it, but my 


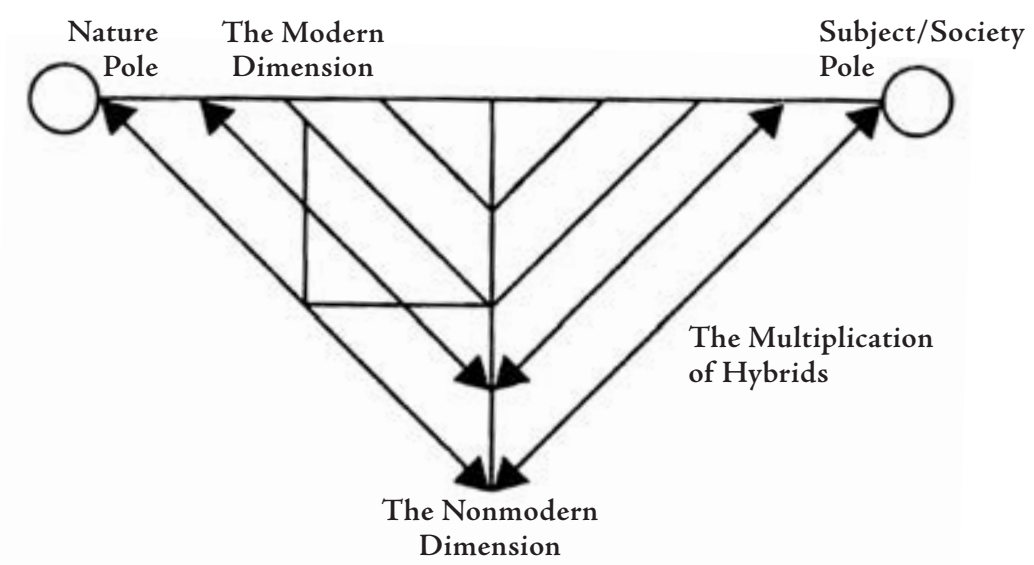

Fig. I: From B. Latour, We Have Never Been Modern (Cambridge, MA, 1993), p. 5 I

central aim is to apply his framework to a set of possibly related critical moments in the emergence of modern linguistics:

- The demise over the course of the nineteenth century of the 'genius of a language', a concept that had arisen two centuries earlier

- How sign theory relates to the linguistic system in the work of Ferdinand de Saussure (1857-1913)

- Why and how the 'social' analysis of language failed to take off for decades after the early work of Saussure's student Antoine Meillet (1866-1936)

\section{The 'genius of a language' as natural and irrational}

Applying Latour's analysis to the post-Renaissance history of linguistics, we have little trouble finding dichotomies that mirror the polarization between Nature and Subject/Society. ${ }^{5}$ One powerful manifestation of the Nature pole was the 'genius of a language', a concept which arose precisely on schedule in the seventeenth century, in a discourse by Dominique Bouhours (I628-I702). ${ }^{6}$ But it was never confined to the Nature pole. Gambarota has chronicled how the genius of a language became a prominent trope in tandem with the modern conception of nationhood, and points to the 'democratizing' impact of this genius, in which all speakers of the language have a share. ${ }^{7}$ Until recent times only a small minority of any European country's population spoke the 'national language'; but just its presence as a written language, and an ideal hovering over dialect usage, drew 
together everyone, not just the elite, into a shared national mind, its defining features matching those of the genius of its language.

It is a classic Latourian example of a superficially modern 'natural' concept that in fact is equally bound up with society and politics. Genius cannot be seen or heard - one can only proclaim particular textual manifestations as being its products. In being only indirectly accessible it is like the 'language system' as we have understood it since Saussure. What differentiates the genius of a language from a prototypical product of Nature is its mediation, not so much with Subject/Society, since all of Latour's 'nonhumans' mediate between the two, as with the enchanted.

The naturalizing of the genius of a language was a crucial first step in establishing what we call 'linguistics', as opposed to the study of language that preceded it. Linguistics begins historically with the erasing of speaking-writing subjects and their willful utterances. The texts with which linguistics worked, and works, are mainly, and ideally, anonymous; if an author is named, we may still use the text, taking it as an expression of the genius of the race that speaks it. That somehow becomes easier the deeper we go into the past, perhaps because a name like Homer or Moses or Panini or Ossian seems as likely to be symbolic of a collective process - a community of practice - as denoting an individual like ourselves.

Language functions as rationality's codification and embodiment, but also its vehicle, and the principal index for judging how rational a given individual is. In our culture, we judge no one as irrational for using language in an unschooled, natural way, except in a social context that demands that it be used in a standard, schooled way. Education is 'prescriptivist' about language, and prescriptivism is counternatural; ${ }^{8}$ it occupies the Society pole in Latour's dichotomy, the Nature pole being that of the spontaneous speech that is more 'native' to us.

Modern linguistics has always refused to engage in prescriptive discourse. It anchors linguistic behavior to natural, physical causes which are always at present only partially understood, but ultimately certain to yield up their secrets. Why physical forces? Because modern views of rationality rest not just on the dyad of Nature and Society but also that of Body and Mind. Put them together, and the body becomes the locus of Nature, the mind that of Rational Subject-Society-God. The 'mind' of linguistics is not the mind of agentive choices, but of the genius of the language, the immutable Saussurean system, the Durkheimian collective consciousness, the Freudian unconscious, the Chomskyan mind/brain where the mind is (merely) what the brain does.

The commitment to forces that cannot (yet) be directly observed, just inferred from what are interpreted as their effects, is a matter of faith. As with religion, some people will say that to base one's actions and commitments on faith rather than on what is directly observable is irrational; others that it is the only rational 
course. Either way, the promise of unseen forces that pose puzzles for us, in the solving of which we will come to uncover those deep, mysterious forces, provides the enchantment of modern linguistics. Call it an enchanted rationality or irrationality: no matter. Enchantment and disenchantment are many-sided concepts. As a translation of Weber's Entzauberung, disenchantment means 'un-magicking', demystifying. Enchantment, however, does not have to mean mystifying, and it has its uses, as shown by another Bruno - not Latour, but Bettelheim. ${ }^{9}$

Outside linguistics, language has its own powers to enchant, but they tend not to be ones linguists want to deal with. They steer clear of anything 'literary'; they keep rhetoric out of bounds; they are even nervous of investigating too deeply into what causes some words and structures to be perceived as good and others as poor. These are just the things that matter in the general cultural discourse about language, which locates rationality in agentive choices based on analytic understanding. In order to have the status of a science, linguists seem to think they must construct the opposite, mirror-image version of rationality from the culture at large. They must become counterrational, refusing to deal with agentive choices, and instead trying to expose heretofore unobservable natural forces and the hidden rationality they project. That gives it a sort of cultishness that enhances its enchantment.

\section{Linguistics and the Nature vs. Subject/Society polarization}

The I860s saw a prominent debate between the Oxford scholar Friedrich Max Müller (1823-1900) and the American William Dwight Whitney (I827-I894) over the question of whether linguistics was a natural science or a historical one, a classic version of Latour's polarization. ${ }^{10}$ For Müller, seeing language as a natural phenomenon was the breakthrough that positioned linguistics at the center of the academic universe. As understanding of language grew, it would provide the keys to unlocking the secrets of the human mind and its evolution. A language was a living thing, an organism, that grew following the same laws as other organisms, such as plants.

For Whitney, on the contrary, languages were human 'institutions'. Language had not grown organically out of the evolution of the vocal apparatus, as Müller thought; rather, the vocal apparatus was chosen, by a combination of chance and convenience - sign language could have developed equally well - and all languages contain elements created by haphazard accident, and ratified through an implicit democratic process among those in the community, who determine which creations will be rejected and which retained.

The naturalist position of Max Müller had been formed through what Latour calls a 'purification', in an attempt to position linguistics among the hard sciences 
as their prestige was suddenly outstripping that of the law, theology and medicine faculties that had traditionally ruled the roost in universities. Whitney, in response, was undertaking a 'hybridization', not denying that language has natural aspects, but rather denying that the natural aspects are primary, and the institutional ones secondary, instead of the reverse.

Saussure wrote that he 'revered' Whitney, whom he first read as a student of Neogrammarian historical linguistics at the University of Leipzig." ally became clear to Saussure that Whitney's characterization of a language as an 'institution' had a flaw. Institutions are planned, designed, changed through decisions taken by powerful individuals, none of which is true of a language. On the Nature-Subject/Society scale, Saussure was a bit to the left of Whitney, though much closer to him than to Müller.

Whitney's institutional conception of language was appealing because of its modernity, as it rejected the irrational dimension of linguistic naturalism. And yet, in a period when science had been constitutionally soldered to the Nature pole, and was increasingly dominant in terms of academic prestige, the claim of linguistics to be a science meant that its precise position was a delicate matter indeed. The Neogrammarians' claim to scientific status was tied to their conception of sound change as mechanical, which is not the same as natural, but somewhere between it and the other end of the spectrum, where the Social clearly mitigates between it and the individual Subject.

By the last decades of the nineteenth century the Enlightenment of a hundred years earlier, while respected, was viewed not as enduring but surpassed. The problem with its approach to language according to Michel Bréal (1832-1915) in his Essai de sémantique (1897), is that

Our forefathers of the school of Condillac, those ideologists who for fifty years served as target to a certain school of criticism, were less far from the truth when they said, in simple and honest fashion, that words are signs. Where they went wrong was when they referred everything to a reasoning reason. ${ }^{12}$

Bréal's condescension toward these 'forefathers' is thick. Their 'reasoning reason' (raison raisonnante) seems a redundant phrase, but is not, for a reason that has to do with the Subject/Society division. There is a reason, a logic, behind every language, but not the reasoning of a willful Subject. It is a social reason, a shared choice that is not chosen but emerges.

That is Saussure's view as well. But Saussure had something in his Genevese educational formation that his French colleagues did not: the grammaire générale tradition. Dating from the seventeenth century, it had, on account of historical 
accidents, endured in Geneva down to the early i870s, forty years longer than in France itself. Saussure had been in one of the last cohorts to have been taught by old men whose courses in logic included general grammar, part of which was the theory of the linguistic sign as the linkage of sound and thought. In the wake of a two-hundred-year discourse about the genius of a language, they were no longer distinguishing sharply between a 'general' grammar and 'particular' grammars, nor were they inclined to assume that universal rationality was equally well embodied in all languages. They did though continue to take language itself as inseparable from rationality. ${ }^{13}$

Reason, genius and related concepts were hybrids in Latour's terms. Saussure could not accept the naturalists' conception of language because of the purification it represented. Linguistics would, for him, have to be a double science, in order to take account of what was in so many respects the dual nature of language: langue and parole, synchrony and diachrony, absolute and relative arbitrariness, mutability and immutability. Neogrammarian doctrine held that phonetic laws operate blindly, with analogy the only explanation permitted for any seeming exceptions. Analogy is a form of reasoning, and it imposes itself on the automatic, instinctive operation of the vocal organs by which sound change is introduced. Those operations are either irrational or rational in a different way from the process of analogy - which itself is still not what Bréal called 'reasoning reason', the rationality of an agentive Subject.

In some of Saussure's last lectures on general linguistics in I9II, he addressed this dual nature head-on. Languages, he said, appear to offer their users a choice, but it is like a forced card, la carte forcée. ${ }^{14}$ This is a conjuror's trick, you fan out a deck of cards and tell an audience member to choose one. As his fingers approach you push out the card you, the conjuror, want chosen, the tiniest fraction of a centimeter, imperceptibly to the audience member's awareness, which you distract by a movement of your free hand. Nearly always the forced card is chosen, though the audience member thinks he has chosen freely.

Conjuring is an interesting form of entertainment. It is a reintroduction of enchantment into our modern rational world, where its reception is different from what it would be in a premodern setting. It reassures us that all enchantment is not in fact vanished, that it is possible even for arch-materialists to experience an amazement akin to a religious experience. Saussure's lectures were - are - themselves enchanting, not least because of the way in which he presents us with paradoxes that are left unresolved, and occasionally an image as powerful as that of the forced card.

That image comes in a discussion of what he terms 'immutability'. On the one hand, language is pervasively mutable, in the sense that all its elements are constantly subject to change. On the other hand, a language is immutable, in that no 
individual can dictate any change to it. Every change begins with an innovation by an individual within speech (parole), but most such innovations are not taken up by the community. Only a very few are socially sanctioned, and it is that sanction that allows a change from parole into the langue - though, since every element of the language system derives its value from its difference vis-à-vis all the other elements, any such change actually brings about a wholly new langue.

\section{The evolution of Meillet}

There is here a force beyond not only human control, but beyond reason. It is not natural, since the elements of language are themselves not naturally determined, but arbitrary. Saussure falls back on the explanation that 'language is a social fact' - quoting an article by his former student, Meillet, in the 1904/1905 volume of the Année sociologique, founded and edited by Émile Durkheim (18581917) ${ }^{15}$ In this period we find Meillet taking pains to stay in line with Durkheim's sociology.

In the same lectures in which he talked about immutability and the forced card, Saussure revisited the arbitrariness of the linguistic sign, introduced in an earlier lecture, to point out that such arbitrariness was in fact limited. ${ }^{16}$ He noted that the evolution from Latin to French saw an enormous shift toward the unmotivated'. For example, 'friend' and 'enemy' in Latin were the transparently related amicus and inimicus; but the French counterparts ami and ennemi are not perceived as related by French speakers. Ennemi has gone back to being absolutely arbitrary'. Saussure takes the strong view that 'The whole process of evolution in a language can be represented as a fluctuation in the overall balance between what is entirely unmotivated and what is relatively motivated'.

Meillet picked up on this idea in an article of the following year, 1912. "The Evolution of Grammatical Forms' is remembered particularly for having introduced the term 'grammaticalization'. Meillet gives examples comparable to Saussure's, which not everyone today would recognize as a case of grammaticalization; for example, proto-Germanic hiu tagu 'this day' grammaticalizing to become Old High German biutu and Modern German heute 'today'. English today is itself an example of this type. ${ }^{17}$

From the perspective both of the analysis of the linguistic signs, and of speakers of German, a more semantically transparent biu tagu has given way to a beute that cannot be analyzed into component parts. There is no absolute logical reason why the one is more 'rational' than the other, but since Condillac the analyzable character of language has been used to explain the development of rational thought - why it has happened in all human groups, and in no nonhuman ones. 
Note again how Saussure said that French ennemi has gone back to being absolutely arbitrary. How does such a 'reversion' happen?

Meillet offers an answer. His first example of 'the passage of autonomous words to the role of grammatical agents, ${ }^{18}$ that is, grammaticalization, is French suis 'am'. It is, he says, autonomous in je suis celui qui suis (I am that I am), and still retains a certain autonomy in je suis chez moi (I am at home). But it 'has almost ceased to be anything other than a grammatical element in je suis malade (I am sick), je suis maudit (I am accursed), and is only a grammatical element in je suis parti (I've departed), je suis allé (I've gone), je me suis promené (I've taken a walk).'.

His choice of words - 'still retains','ceased to be' - clearly implies that originally 'autonomous' elements have over time lost their autonomy and become 'merely' grammatical. Grammaticalization thus meant loss of self-governance, becoming dependent on another element. This involved an intermediate stage in which words become clichés, 'habitual' collocations, on their way to grammaticalization. A word is bleached of its semantic content, becoming functional rather than 'meaningful': more mechanical than rational. Meillet, in exposing irrationality not in the use of language, but within the language system itself, diagnoses a condition that perhaps cannot be eliminated, but can be controlled, through the power of a modern linguistic science that, by facing up to it, does not remain under its power. Exposing this adds to the enchantment of language, with the irrationality it encompasses, and of linguistics, with its power to expose and control the irrational, just as a conjuror appears to do.

A third phase in Meillet's thought begins around 1920 in a shift likely prompted by his reading of Saussure's Cours. ${ }^{20}$ Saussure notes that English gives a more prominent place to the unmotivated than German does, since German indicates grammatical relations through the inflections on nouns and verbs, whereas English does it through position and the use of auxiliaries and prepositions. In this sense, German is more 'grammatical' and inclined toward the motivated, while English is more 'lexical' and inclined toward the radically arbitrary. ${ }^{21}$ This becomes a leading idea in Meillet's later thought. In a coda (dated May 5, 1920) which he added to his 1909 paper 'On the Disappearance of the Simple Preterite Forms' for its republication in I92I, he contrasts Latin with modern English and French:

The essential feature of the morphological structure of Indo-European, and still of Latin, is that the word does not exist independently of the grammatical form: there is no word meaning 'horse', there is a nominative singular equus, a genitive singular equi, an accusative plural equos, etc. and no element signifying 'horse' can be isolated independently of the endings. On the contrary, in the modern type represented by English and, a bit less 
well by French, the word tends to exist independently of any 'morpheme': whatever role it plays in the sentence, in English one says dog and in French chien, where Latin had a series of forms depending on the cases. ${ }^{22}$

Soon he will depart radically from Durkheim and discuss the psychological development of the Indo-European peoples from an early 'concrete' to a more advanced 'abstract' stage. In a paper to the Société de Psychologie in 1922, Meillet stated that

French has an invariable word loup 'wolf', the form of which is always the same, whatever the sentence it appears in, however one envisages the animal [...]. In Latin, on the contrary, there is not really any word that signifies wolf; if you want to say that the wolf has come you would use the form lupus; if you see wolves: lupos [...], etc. No one of these forms can be considered as being the name of the wolf any more than the others. ${ }^{23}$

He goes on to say that 'a Roman was not capable of naming "the wolf in itself", and on the basis of this evidence he makes the very broad extrapolation that "The universal tendency of language, in the course of civilization, has been to give the noun a character more and more independent of all its particular uses. ${ }^{24}$ In the discussion following the paper, Meillet insists further that the development of languages must go from the concrete toward the abstract, and that, consequently, 'The mentality of an Indo-European differs completely from a modern'.

In other words, an Indo-European - indeed, a Roman, much closer to us historically - was not rational in the way that we moderns are. If Romans could not name the wolf in itself, could they think it? From a Saussurean point of view, nothing compels us to answer no; thought is not limited to linguistic signifieds. The notion that the structure of one's language actually limits what one can think is one which modern linguists generally reject as bordering on racism; yet, surprisingly, that appears to be Meillet's answer in this late phase, when he ties the presence or absence of a case-neutral form directly to 'mentality'.

Meillet's 1922 paper to the psychologists would have been very different in 1904. Then he would have upbraided them for not following objective sociological method. Of course, psychoanalysis had a broad cultural effect starting in the I920s, that ultimately made it futile to try to keep scientific research pure of unobservables such as the 'mind'. The first French textbook in psychoanalysis, by Raymond de Saussure (1894-I97I), son of Ferdinand, with an introduction by Sigmund Freud (1856-1939) also dates to $1922 .{ }^{26}$ Established scientists were, for the most part, immune to the enchantment of Freud, which was massive. It took another generation to grow up immersed in it as part of everyday discourse and 
popular culture, to bring it into the mainstream, ${ }^{27}$ though its place within academic psychology has been tenuous.

Linguistics was a 'dry' subject in need of some enchantment in order to garner public interest and institutional support. That makes it less surprising when we find Meillet in 1922 constructing a grand narrative about mental evolution, or Edward Sapir (I884-1939) beginning to write about the influence of language upon thought the following year. The 'Sapir-Whorf hypothesis' suggests that we are none of us so rational as we think, that our rationality is a cultural product, transmitted surreptitiously through our language. Sapir projected synchronically, into the 'primitive', the same nexus of irrationality, enchantment and exoticism as did his fellow anthropologists Margaret Mead (I90I-I978) and Ruth Benedict (I887-I948). Meillet projected it diachronically, into the past.

\section{Conclusion}

Modern linguistics has never been modern. There was a gradual shrinkage in the space allotted to rationality in linguistics, from the eighteenth century, when the field itself has not been defined, to the mid-nineteenth, when it has already become generally associated with language as a 'natural' phenomenon. In reaction Whitney tries to restore the Subject/Society dimension, though never in a way that is contradictory with the Neogrammarian approach, to which he was sympathetic. Even so, he went a step too far for Saussure, who redressed the balance differently, reinstating eighteenth-century sign theory at the heart of a linguistic system that nevertheless escapes the control of any individual Subject. The idea of language as a 'social fact' became a mantra for Meillet and Saussure. By I9I2 Meillet was moving away from social analysis toward 'grammaticalization', a 'natural' process of words and other linguistic elements losing their 'rational' content to become functional. The following decade sees him move still further toward psychological accounts that effectively reinvent the idea of the genius of a language, to show how people's way of thinking evolves over time.

To return finally to Latour, his path forward from modernism would reject the Nature-Society polarization, while retaining the networks of actors, human and nonhuman, which always covertly underlay that polarization. Indeed, he credits the modern Constitution with enabling an unprecedented lengthening of networks and a belief in experimentation, which are among the modern legacies he would retain. He would, however, discard the modern Great Divide between humans and nonhumans, and bring the clandestine practices of mediation into the open. He would keep the postmoderns' reflexivity, constructivism and denaturalization, but not their ironic reflexivity, critical deconstruction or anachronism. 
Above all he would reject the postmodern belief that modernism had actually ever existed in the form which it claimed for itself.

As for antimoderns such as Max Weber, Latour sees 'nothing worth saving' in them. ${ }^{28}$ They too 'consistently believed what the moderns said about themselves', and were for the moderns 'always, in effect, the best of stooges'. ${ }^{29}$ This is not entirely fair. The enchantment whose loss modernism seemed to entail, and that Weber lamented, was the spiritual dimension that seemed to give more meaning to premodern than to modern existence. While Latour rejects the premodern obligation always to link the social and natural orders, he agrees with those who attribute the crisis of meaning in modern life to their purified separation in the so-called free-floating sign. Perhaps. But what would that point toward as the essential task of a nonmodern linguistics? Would it aim at realizing Socrates' dream, recounted in the Cratylus, of seeing how signs link to things? This would represent the perfecting of human thought by Entzauberung, the ultimate unmagicking, replacing our individual interpretations of signs with their 'true' meanings. Actually, that has been the aim of much of linguistics throughout the modern period: it has always been nonmodern and premodern at the same time. For some of us, though, eliminating the element of interpretation, which gives rise to ambiguity and misunderstanding, would not bring the perfection of humankind, but its undoing, replacing us with what are in effect intelligent machines. Misunderstanding and ambiguity are what make us human, and the vision of a world without them may have been Socrates' dream; but then, if Meillet was right, given the similar structure of the Greek and Latin noun systems, Socrates would have been no more able than a Roman to name the wolf in itself, to envisage the creature whose essence is to devour everyone around it.

\section{Notes}

I 'Es ist das Schicksal unserer Zeit, mit der ihr eigenen Rationalisierung und Intellektualisierung, vor allem: Entzauberung der Welt [...]'. Max Weber, Wissenschaft als Beruf (Munich \& Leipzig: Duncker \& Humblot, I919), 36, my translation.

2 Bruno Latour, We Have Never Been Modern, trans. by Catherine Porter (Cambridge, MA: Harvard University Press, I993), I23. Original version, Nous n'avons jamais été modernes: Essai d’anthropologie symétrique (Paris: La Découverte, I99I), I68:'Les antimodernes croient dur comme fer que l'Occident a rationalisé et désenchanté le monde, qu'il a vraiment peuplé le social de monstres froids et rationnels qui satureraient tout l'espace, qu'il a transformé pour de bon le cosmos prémoderne en une interaction mécanique de pures matières. Mais, au lieu d'y voir, comme les modernisateurs, de glorieuses bien que douloureuses conquêtes, les antimodernes y voient une catastrophe sans égale. [...] Les postmodernes, toujours pervers, acceptent l'idée qu'il s'agit bien d'une catastrophe mais affirment qu'il faut s'en réjouir au lieu de s'en lamenter!'. 
3 Latour, We Have Never Been Modern, I3. Original (Nous n'avons jamais été modernes, 23): 'On définit souvent la modernité par l'humanisme, soit pour saluer la naissance de l'homme, soit pour annoncer sa mort. Mais cette habitude même est moderne parce qu'elle reste asymétrique. Elle oublie la naissance conjointe de la 'non-humanité, celle des choses, ou des objets, ou des bêtes, et celle, non moins étrange, d'un Dieu barré, hors jeu. La modernité vient de la création conjointe des trois, puis du recouvrement de cette naissance conjointe et du traitement séparé des trois communautés pendant que, en dessous, les hybrides continuent de se multiplier par l'effet même de ce traitement séparé. C'est cette double séparation qu'il nous faut reconstruire entre le haut et le bas d'une part, entre les humains et les non-humains d'autre part'.

4 Latour, We Have Never Been Modern, 37; Nous n'avons jamais été modernes, 57: 'Si vous les critiquez en disant que la nature est un monde construit de mains d'homme, ils vous montreront qu'elle est transcendante et qu'ils n'y touchent pas. Si vous leur dites que la société est transcendante et que ses lois nous dépasse infiniment, ils vous diront que nous sommes libres et que notre destin est entre nos seules mains'. Porter's translation reverses the clauses in the second sentence.

5 Their poles are always somewhat hybrid, as attempts to 'purify' a natural or conventional account of language have failed ever since Plato's Cratylus. There, Socrates easily shows Hermogenes that individuals are bound to the social force of their language just as much as if it were a creation of nature, and shows Cratylus that, however ideal it would be for languages to signify naturally, we cannot determine whether they do. See John E. Joseph, Limiting the Arbitrary: Linguistic Naturalism and Its Opposites in Plato's Cratylus and Modern Theories of Language (Amsterdam/Philadelphia: John Benjamins, 2000), and 'The Natural: Its Meanings and Functions in the History of Linguistic Thought', in Douglas A. Kibbee (ed.), History of Linguistics 2005: Papers from the Tenth International Conference on the History of the Language Sciences (ICHoLS X), University of Illinois at UrbanaChampaign, 2-5 Sept. 2005 (Amsterdam \& Philadelphia: John Benjamins, 2007), I-23.

6 Dominique Bouhours, SJ, Entretiens d'Ariste et d'Eugène (Paris: chez Sébastien MabreCramoisy, I67I). The concept, like all concepts, has earlier historical roots, but Bouhours's version of it stands at the head of the powerful developments that would take place over the next two centuries.

7 Paola Gambarota, Irresistible Signs: The Genius of Language and Italian Nationalism (Toronto: University of Toronto Press, 20I I).

8 See John E. Joseph, Language and Politics (Edinburgh: Edinburgh University Press, 2006).

9 Bruno Bettelheim, The Uses of Enchantment: The Meaning and Importance of Fairy Tales (New York: Alfred A. Knopf, I976).

Io See Stephen G. Alter, Darwinism and the Linguistic Image: Language, Race, and Natural Theology in the Nineteenth Century (Baltimore \& London: Johns Hopkins University Press, I999), and William Dwight Whitney and the Science of Language (Baltimore \& London: Johns Hopkins University Press, 2005); also John E. Joseph, From Whitney to Chomsky: Essays in the History of American Linguistics (Amsterdam \& Philadelphia: John Benjamins, 2002).

I I See John E. Joseph, Saussure (Oxford \& New York: Oxford University Press, 20 I 2), where all of the points about Saussurean thought discussed in the present paper are treated much more fully.

I2 Michel Bréal, Semantics: Studies in the Science of Meaning (trans. by Mrs. Henry Cust, London: W. Heinemann, I900), 249; original, Essai de sémantique: Science des significations (Paris: Hachette, I897), 277: 'Nos pères de l'école de Condillac, ces idéologues qui ont 
servi de cible, pendant cinquante ans, à une certaine critique, étaient plus près de la vérité quand ils disaient, selon leur manière simple et honnête, que les mots sont des signes. Où ils avaient tort, c'est quand ils rapportaient tout à la raison raisonnante'.

I 3 For a case in point, see John E. Joseph, 'Language Pedagogy and Political-Cognitive Autonomy in Mid-I9th Century Geneva: The Latin Manuals of Louis Longchamp (I802I 874)', Historiographia Linguistica 39 (2012), 259-277.

I4 Ferdinand de Saussure, 'Notes préparatoires pour le cours de linguistique générale I9 IoI9I I', and Émile Constantin, 'Linguistique générale, cours de M. le professeur de Saussure I9ı-I9I I', in Daniele Gambarara and Claudia Mejía Quijano (eds.), Cabiers Ferdinand de Saussure 58 (2005), 7I-290, 238.

I5 Antoine Meillet, 'Comment les mots changent de sens', Année sociologique 9 (I904/5), I-38; repr. in Meillet, Linguistique historique et linguistique générale (Paris: Champion, I92I), vol. I, 23I-27I.

I6 Saussure and Constantin, 'Notes préparatoires/Linguistique générale', 233.

I7 Antoine Meillet, 'L'Évolution des formes grammaticales', Scientia I 2 (I9I 2), 384-400, 392. (repr. in Meillet, Linguistique historique et linguistique générale, vol. I, I30-I48, I38-I39.)

I 8 Ibid., 387 (repr. in Meillet, Linguistique historique, I33). Original: 'le passage de mots autonomes au rôle d'agents grammaticaux' (this and the following excerpts from Meillet are in my translation).

I9 Ibid., 385 (repr. in Meillet, Linguistique historique, I3 I). Original: 'il n'est presque plus qu'un élément grammatical dans: je suis malade, je suis maudit, et il n'est tout à fait qu'un élément grammatical dans: je suis parti, je suis allé, je me suis promené [...]'.

20 Ferdinand de Saussure, Cours de linguistique générale, ed. Charles Bally \& Albert Sechehaye, avec la collaboration d'Albert Riedlinger (Lausanne \& Paris: Payot, I9I6) (2nd ed. I922; further editions essentially unchanged).

2 I Saussure, Cours, 2nd ed. (I922), I83.

22 Antoine Meillet, 'Sur la disparition des formes simples du préterit', Germanische-Romanische Monatsschrift I (I909), 521-526 (repr., including the coda, in Meillet, Linguistique historique et linguistique générale, vol. I, I49-I58, I56-I57). Original: 'Le trait essentiel de la structure morphologique de l'indo-européen, et encore du latin, c'est que le mot n'existe pas indépendamment de la forme grammaticale: il n'y a pas un mot signifiant 'cheval', il y a un nominatif singulier equus, un génitif singulier equi, un accusatif pluriel equos, etc. et l'on ne saurait isoler aucun élément signifiant 'cheval' indépendamment des finales. Au contraire, dans le type moderne représenté par l'anglais, et, un peu moins bien par le français, le mot tend à exister indépendamment de tout 'morphème': quel que soit le rôle joué dans la phrase, on dit en anglais dog et en français chien, là où le latin avait une série de formes suivant les cas'.

23 Antoine Meillet, 'Le caractère concret du mot', Journal de Psychologie Normale et Pathologique 20 (I923), 246ff.; repr. in Meillet, Linguistique historique et linguistique générale (Paris: Champion, I936), vol. 2, 9-I3, I I. Original: 'Le français a un mot 'loup' invariable, dont la forme est toujours la même, quelle que soit la phrase où ce mot figure, quelle que soit la façon dont on envisage l'animal [...]. En latin au contraire, il n'y a à vrai dire aucun mot qui signifie 'loup'; si l'on veut dire que 'le loup est venu', on aura la forme: lupus; si l'on voit des loups: lupos [...], etc. On ne peut pas considérer l'une quelconque de ces formes comme étant le nom du 'loup' plutôt que les autres'.

24 Meillet, Linguistique historique, vol. 2, I3: 'un Romain nétait pas capable de nommer 'le loup en soi. [...] La tendance universelle du langage, au cours de la civilisation, a été de donner au nom un caractère de plus en plus indépendant de tous ses emplois particuliers'. 
25 Ibid., I7: 'La mentalité d'un Indo-Européen diffère tout à fait d'un moderne'.

26 Raymond de Saussure, La méthode psychanalytique, preface by Sigmund Freud (Lausanne: Payot, I922).

27 On the impact of the popular reception of Freud for linguistics, see Joseph, From Whitney to Chomsky, Chapter 9.

28 Latour, We Have Never Been Modern, I 34.

29 Ibid., I34-I 35. 



\title{
2.2 Soviet Orientalism and Subaltern Linguistics
}

The Rise and Fall of Marr's Japhetic Theory

\author{
Michiel Leezenberg
}

One of the attractions of the park surrounding the Villa Borghese in Rome is a group of statues of national poets. Included among them are such obvious examples as the Persian Abulqasim Firdowsi, author of the Shahnâmeh or Book of Kings; the Georgian Shota Rustaveli, who wrote The Man in the Panther Skin (Vepkhistqaosani); and the Montenegran Petar Njegos, writer of The Mountain Wreath (Gorski Vijenac). More surprising, however, is the presence of a statue, unveiled in 2012, of the 'Azerbaijani poet' Nizami Genjewi. Nizami composed all of his poems in Persian, but now he is claimed as the national poet of a country that cultivates an Azeri Turkish rather than a Persian identity. This nationalist reappropriation of a classical poet points to some of the questions to be treated in the present paper: the rise of nationalist ideas in non-European contexts, in this case, the Soviet Caucasus; and the role of the humanities in the creation of these new nationalisms. As will appear below, it was a Georgian-born scholar, the famous linguist and archeologist Nikolaj Marr, who first claimed Nizami as an Azerbaijani poet. Marr will loom large in the following pages, not only in connection with his notorious Japhetic theory, but also in connection with early Soviet nationality policies.

\section{The universalization of the philological humanities}

It has long been claimed that there is an intimate link between the modern humanities and modern nationalism. These modern notions are generally traced to philosophers like Herder and Fichte, linguists and folklore scholars like Wilhelm von Humboldt and the Grimm brothers, and historians like Ranke. ${ }^{\text {I Another }}$ line of argumentation, famously introduced by Edward Said, argues that modern Western Orientalism, i.e., modern philological knowledge of the non-Western world, is a function of the colonizing projects of imperialist Western states. ${ }^{2}$ In 
short, the modern humanities are claimed to be implicated not only in the rise of nationalism or the nation-state, but also in imperialism and modern empires. Here, my main intention is not to appraise or criticize these two theses, but to explore an important if underinvestigated link between them.

To all appearances, the categories of Romantic nationalism and of the philological humanities (like those of the nation and national identity, and the concepts of language and culture, tradition and history in terms of which they are articulated) appear to have gained a virtually worldwide currency. One question to be discussed below is exactly how this vocabulary spread beyond its initial linguistic and cultural confines. For the natural sciences, some plausible suggestions have recently been made: famously, authors like Latour and Shapin and Scheffer have argued that the universalization of the modern Western natural sciences crucially involved the exportation of new instruments like the vacuum pump, and of new facilities like the laboratory. For the modern humanities, however, a similar argument can hardly be given: these generally worked without instruments or laboratory equipment. It can be, and has been, argued that novel forms of education like the seminar and novel spaces like the seminar room - both pioneered by Ranke - contributed to the expansion of modern ways of practicing the humanities across Europe (cf. Jo Tollebeek in this volume, Chapter 3.I); but such accounts do not yet explain how and why modern humanities knowledge reached areas outside Europe, where modern institutions like state-led schools and universities - let alone seminar rooms - were rather slower to materialize.

It is tempting but, as I hope to show, misguided to see the spread of the Romantic-nationalist vocabulary of the philological humanities in terms of the creation of an ideological hegemony of Western concepts; in doing so, one risks ignoring or downplaying both non-Western forms of agency and resistance, and alternative or subaltern forms of Western knowledge. Many accounts of the worldwide effects of the philological humanities, in particular, those standing in the tradition of Said's Orientalism, do in fact proceed from an implicitly or explicitly Gramscian notion of Western ideological or discursive hegemony over non-Western actors; but in doing so, they risk reducing non-Western actors to mere passive recipients of Western ideologies, and thus depriving them of all agency. ${ }^{3}$ Further, they fail to explore the exact processes or mechanisms by which particular Western notions acquired this allegedly hegemonic status.

The intimate if not inherent link between the modern philological humanities and Romantic nationalism is by now well known in the literature; but the link between nationalism and Orientalism has not been explored in comparable detail. As will become clear below, however, the themes of nationalism and empire, and of philology and Orientalism, merge in the case of non-Western national movements. Recently, Stathis Gourgouris and Marc Nichanian have explored 
what they call a hegemonic national and colonial modernity from a Said-inspired postcolonial perspective. As is well known, Said's original thesis of an intimate link between Orientalist knowledge and the colonizing projects of Western states fails to account adequately for German Orientalism, which for most of the nineteenth century developed - and spread abroad - in the absence of any colonizing projects on the part of the German, or rather Prussian, state. ${ }^{4}$ Instead, one might argue that these German orientalist categories were shaped by nationalism rather than colonialism. A question to be pursued further would then be if there are any systematic links between the philological constitution of national selves and the Orientalist constitution of colonial others. Gourgouris and Nichanian address the question of the relation between Orientalism and nationalism for non-Western European national movements (respectively, the modern Greek movement emerging in the Ottoman Empire, and Armenian nationalism arising in both the Ottoman Empire and imperial Russia).5 Such an extension of Said's claims requires, first, that modern German philological Orientalism - despite initial appearances - actually does involve a form of colonialism, and second, that non-Western nationalisms rest on an internalization of these allegedly hegemonic and allegedly colonial categories. Both these claims can in fact be found in these authors. Thus, according to Gourgouris, Wilhelm von Humboldt's famous notion of Bildung, which is traditionally said to instrumentalize classical Greek educational and civilizational ideals for German nationalist purposes, involves not simply the appropriation but also the sublimation of classical Greek ideals. As such, he continues, 'classical Bildung is no less than an explicit and programmatic colonization of the ideal.' Unfortunately, however, Gourgouris largely fails to back this provocative but tantalizingly condensed argument with detailed references or quotations, leaving the impression that the 'colonization' he claims to have found in Humboldt's writings is at best implicit, and rests on a rhetorical association between - or identification of - the notions of appropriation, sublimation and colonization rather than on a detailed textual analysis. Gourgouris' second claim, that the nationalist project of the modern Greeks emerging involved the internalization of this alleged German colonialist sublimation, receives a hardly more elaborate argumentation.

A more detailed development, which applies of Gourgouris's claims, to the creation of a modern Armenian literature and national identity appears in Marc Nichanian's Le deuil de la philologie. Earlier, Nichanian had traced the rise of a modern Armenian literature written in the spoken vernacular, or Ashkharhabar, as opposed both to the written classical language or Grabar which until the early nineteenth century had been the dominant medium for works of literature and learning, and to what he calls the 'civil language', a supraregional variant spoken by eighteenth-century Armenian merchants and, on occasion, printed by the 
Mekhitarist monks in Venice. In his later work, he claims that this linguistic change, and more generally the rise of Armenian nationalism, involves the Orientalist creation of the Armenians as a 'native people', and, as such, an 'internalized Orientalism.7 Extending an argument first made by Foucault, Nichanian argues not only that the invention of the category of literature in the nineteenth century is coeval with the emergence of modern philology, but also that the deployment of modern philology is accompanied by the emergence of the nation as an imaginary form of collective perception, that is, an imagined community in Benedict Anderson's sense. ${ }^{8}$ This claim implies that the process of becoming a nation is less a political than an aesthetic process, as it crucially involves the creation of a modern, national literature. Nichanian adds to this general point that the nationalization of non-European peoples like the Armenians involves the internalization of the categories of European Orientalist philology, in particular that of the native. ${ }^{9}$ Thus, both Gourgouris and Nichanian argue that nationalism among peoples living outside of Western Europe, like the Neohellenism pioneered by Adamantios Korais and the Armenian neo-archeology created by Khatchatur Abovian and Karekin Servantsdiants, involves the interiorization of an 'Orientalist gaze': they involve a perception of the self as 'native', that is, in terms of primitive or primordial (pagan) cultures or traditions that are more typically applied to an Oriental other.

Gourgouris and Nichanian certainly formulate a radical extension of Said's original argument: they wind up virtually identifying Orientalism with philology, and the German national educational ideal of Bildung with a colonizing project. At first blush, this may seem like a reductio ad absurdum of Said's - already contentious - main thesis: taken to its logical conclusions, it would imply that Humboldt is a colonizing imperialist as much as a nationalist, and that the Grimm brothers, in their attempts at recovering and transcribing their own native German culture, were in fact engaged in a colonial project. This claim, however, though extreme, is less far-fetched than it seems: it raises questions concerning the precise relation between nation and empire, and concerning the universalization of (German) Romantic nationalist categories and the role of the various philological disciplines in this process. More specifically, it forces us to look more closely at the relation between the philological construction of a national self and the Orientalist construction of a colonial or domestic other.

\section{Russian and Soviet Orientalism: Marr and Trubetzkoy}

Russia forms a particularly complex case for the nationalism-Orientalism thematic as commonly known. Even in so far as one can qualify the nineteenth-century Russian Empire as imperialist, it complicates the Saidian thesis because of 
the rise of a new Russian self-perception as in important respects non-Western (and thus 'Oriental') during this period; and the Soviet Union that replaced it was explicitly committed to the emancipation of the peoples living in its territories, and supported anti-colonial struggles worldwide. Obviously, I cannot do justice to this vast theme; here, I will only discuss whether and to what extent the philological theories produced in imperial and Soviet times reproduced hegemonic Western categories or can be called an alternative or subaltern' form of knowledge.

It is well known that the Soviet humanities claimed to reject the categories of Western 'bourgeois' scholarship; it is less well known, however, that similar criticisms were already voiced well before the 1917 revolution, by authors who hardly qualify as bolshevists. Thus, Vera Tolz has argued that already in imperial Russia, one can find a critique of Eurocentrism and of the nexus between Orientalist knowledge and imperial power that antedates Edward Said's far more famous Orientalism (1978) by half a century. Tolz adds that Said's work is in fact indirectly indebted to this critique, especially through Soviet-educated intellectuals like the Egyptian Anouar Abdel-Malek. ${ }^{10}$ Russian intellectual life already witnessed important reactions against German cultural influence in the nineteenth century, and more explicitly during the so-called Silver Age (spanning, roughly, the first two decades of the twentieth century); more importantly for the present discussion, this culturally anti-German and Russian nationalist attitude was explicitly linked to a methodological critique of the philological methods that underpinned historical-comparative linguistics as originating in German academia. We find such methodological critiques in two of the most influential linguists of late imperial Russia, Nikolai Trubetzkoy (1890-1938) and Nikolai Jakowlewitch Marr (1865-1934). Surprisingly, these criticisms are not discussed by Nichanian, who generally presents a picture of a smooth and largely uncontested German Romantic-cum-Orientalist hegemony over Armenian national self-awareness; but Marr's work is crucial not only for the Russian and more specifically Soviet experience, but also for the Armenian case: thus, he conducted excavations on the Armenian site of Ani, and published an Old Armenian grammar in 1903.

Trubetzkoy has, of course, become famous as the founder of modern phonology and areal linguistics; but it is less well known that he was also one of the main propagators of Eurasianism, i.e., the idea that Russia occupies a unique cultural space between East and West, and can be reduced to neither. Thus, in 'Europe and Mankind', published in 1920 but already written before World War I and the Russian Revolution, he criticizes Western European or, as he calls it, 'Romano-German' chauvinism, for presenting its cultural particularities as features of universal civilization." with Trubetzkoy's sophisticated linguistic work, but one wonders to what extent 
the notion of a vast nonnational Eurasian space of common cultural experience has shaped Trubetzkoy's more famous ideas about linguistic Sprachbund or areal convergence, which suggest that two geographically adjacent languages may come to share structural features over time. There are indications that these linguistic doctrines have indeed been shaped and informed by a critique of the German chauvinism Trubetzkoy sees implicit in historical-comparative linguistics. Thus, he argues that the hypothetical Proto-Indo-European Ur-language should be treated as a purely linguistic construct, and should not be extrapolated to ethnic or racial developments, as is all too easily done by many of his contemporaries (and, in fact, by many a later author) working on historical comparative linguistics. Moreover, he argues that one should not treat the Indo-European languages in exclusively genetic terms: over time, he argues, languages may start sharing important structural features and thus become members of the same language family. ${ }^{12}$

Marr is as notorious as Trubetzkoy is famous, in particular because of his so-called Japhetic theory, which argues that all of the languages of the Caucasus, whether or not Indo-European, share traces of a distinct family of languages called 'Japhetic.'13 Marr's linguistic doctrines are usually dismissed as crackpot science, or as a linguistic equivalent of Lysenko's attempts to create a truly materialistic genetics, with equally disastrous results. But it would be too easy merely to reject Marr's work as pseudo-scientific, or as just a political abuse of scholarship. Not only should we not project back standards of scientific truth and objectivity that at the time were fiercely contested, it also closes off more radical questions concerning the constitutive role of the philological humanities in the shaping of modern nationalism and the - possibly inherently political category of such apparently neutral analytical concepts like 'language,' culture', or 'tradition'. Some of Marr's criticisms of German philology were in fact founded. Famously, on his first visit to Europe in 1894, Marr met - and soon quarreled with - one of the most famous German scholars of Armenian, Heinrich Hübschmann. ${ }^{14}$ The details of their argument are not known, but it is tempting to see in this confrontation between a German scholar and an unknown native from the fringes of the Russian Empire a clash between a hegemonic German learning and a subaltern non-Western knowledge; in any case, Marr soon after started raising increasingly vocal criticisms of the German chauvinist arrogance and even racism that he found hidden in historical-comparative linguistics. He certainly had a point: as Trubetzkoy had argued independently, late-nineteenth-century German philologists projected linguistic findings onto speculations about the migrations and conquests of an IndoGermanic Herrenvolk and about the supremacy of the Aryan race. ${ }^{15}$

But there were equally cogent theoretical reasons for criticism. Marr developed his Japhetic theory especially on the basis of research into the Georgian and Armenian languages, both of which were problem cases for comparative linguis- 
tics. Thus, the historical-comparative linguistic classification of Armenian as a separate branch of the Indo-European languages left many questions open, and many etymologies unexplained. As an alternative explanation, Marr had argued in his 1903 grammar that the very core of the Armenian language, which arose 'on the soil of historical Armenia', is mixed or, as he calls it, 'bigenetic. ${ }^{16}$ Further, he argued, anticipating his later claims as to the class character of language, that already in classical times, Armenian was divided into a written form used by the (religious) elites and a 'secular', spoken vernacular, and that the modern written language (Askharhabar) was just as old and venerable as the classical Grabar. ${ }^{17}$

Marr's criticism of comparative linguists' tendency to identify languages with nations, and language families with races, certainly makes sense; but as a comparison with Trubetzkoy's Eurasianist and areal views suggests, such criticisms are not necessarily more 'objective' but may themselves presuppose rival ideologies. An open question for further research is to what extent these linguistic and philological theories (including the allegedly neutral and theory-independent 'facts' uncovered by them) were shaped by changing ideologies and practices of language. Trubetzkoy's and Marr's critique of the categories of German-based historical comparative linguistics appears to be driven by an anti-Western Eurasian or Japhetic (and more specifically, anti-German) ideology.

But it was not just, or not simply, anti-comparativist or anti-German considerations that led Marr to develop his Japhetic theory. Basing himself on his archeological excavations as much as on his linguistic research, he criticized the work of more nationalistically inclined Georgian and Armenian scholars, who tended to depict the medieval history of the Caucasus as a purely Christian affair, depriving the contributions of the Muslim presence in the region. Already by the I89os, he had adopted the slogan 'struggle for nationality and against nationalism ${ }^{18}$; later, in a series of 1924 lectures delivered in Baku, Marr argued not only for a greater attention for the Muslim contributions to the history and cultures of the Caucasus, and against the near-exclusive focus on its Christian past by Armenian and Georgian scholars; also, and more specifically, he recommended the study of Nizami as an Azerbaijani rather than a Persian poet: not only was Nizami born in the Azerbaijani city of Genje, he argued, but his Persian-language poetry is also shot through with 'Azerbaijanisms' (azerbaijdzhanizmy); his work therefore merits study as part of the Azerbaijani national heritage. ${ }^{19}$

Despite their ideological affinity, however, the methodological differences between Marr and Trubetzkoy could hardly be greater. Trubetzkoy did not mince his words about Marr: in a letter dated November 6, 1924, he writes that 'a critical review of [Marr's latest] article ought to be done, not by a linguist but by a psychiatrist. ${ }^{20}$ Moreover, he categorically denies that Marr's doctrines mark any methodological innovation, writing that they actually block scientific and social progress: 
[Marr's] 'new linguistic doctrine' is not a bit different from so-called bourgeois linguistics. [...] As a result, Soviet linguistics [...] has lost touch with genuinely progressive and revolutionary trends that are fighting for recognition in Europe and America. ${ }^{21}$

This leaves us with the question to what extent Marr's theories, regardless of their apparent rejection of the concepts and methods of German comparative linguistics, in fact achieve a paradigmatic break with the latter. In its early stages, Marr's Japhetic theory could still be seen as parasitic on German philology, in that it presupposed some of its concepts or etymological methods. It was not until after the October Revolution that Marr explicitly and systematically rejected the identification of languages with ethnic groups, and the explanation of linguistic change in terms of migrations and conquests by peoples. In the same period, he equally discarded the historical-comparative notions of language families and of reconstructed protolanguages. It may be questioned, however, whether even these more radical claims really mark a break with existing philological methods: as noted above, other authors, most notably Trubetzkoy, also argued against the identification of (reconstructed) languages with peoples. Even Marr's apparently novel concepts, or imagery, of 'layers' and 'sediments' bears a close similarity to the more familiar historical-comparative notion of substrates or substrata.

The main problem with Marrian linguistics, and the main difference with, e.g*, Trubetzkoy's views on language contact, is that Marr appears to push back all language mixture and pluralism to a hypothetical stage of linguistic origins (witness his view of Armenian as an originally hybrid language), and thus downplays all change in historic times -, a rather odd move for a theory that presents itself as wholly in agreement with the main tenets of historical materialism. In fact, most of Marr's Marxist ideas, e.g., his conviction that language is a merely superstructural phenomenon, are only late and nonessential additions, rather than supporting members, of his Japhetic theories.

\section{Marr and early Soviet nationality policies}

Marr's linguistic theories gained prominence against the background of early Bolshevik nationality policies. These policies centered on what was called korenizatsiia, or 'nativization', i.e., they aimed at creating new political and cultural elites from among the local populations. ${ }^{22}$ As such, they systematically supported the emancipation of the 'smaller nations' of the Soviet Union, i.e., the communities speaking languages that did not have a long-standing literary civilization. Korenizatsiia policies were directed not only against any Russian chauvinism dis- 
guised as bolshevism, but also against any local chauvinism on the part of the existing elites of the constituent Soviet republics. As such, they directly reflected Stalin's early writings on nationalism. In his famous 'Marxism and the National Question' (1913), Stalin defines nations as requiring, most importantly, a common language, a common territory and a common life. ${ }^{23}$ The mere possession of a common 'philosophical make-up', 'national character' or Volksgeist, he argues against the Romantic-idealist definition of nationhood, is not enough for a group of people to constitute a nation; specifically and explicitly, it is the Jews he has in mind here. He then raises the question of whether one should, or even could, create or 'organize' nations, as some social democrats have proposed. In his opinion, national autonomy should not be based on 'bourgeois' principles of national identity, which he sees as leading to national segregation, and thus as undermining the international unity of the labor movement. Rather, following Lenin, Stalin upholds the right to self-determination as distinct from bourgeois 'national autonomy'; this right, he assumes rather than argues, does not undermine the unity of workers, and will not lead to separatism.

Next, Stalin specifically addresses the nationality question in the Caucasus. The cultural-national autonomy claimed for this region, he argues, presumes developed nationalities with a developed culture and (presumably, written) literature; but how then, should this cultural-national autonomy apply to the smaller nationalities of the Caucasus, like the Mingrelians, the Abkhazians, and the Adjarians, who, as he writes, possess a 'primitive culture' and have no literature of their own? Against the social-democratic propagation of the bourgeois project of national autonomy, he then proposes what he calls the only genuinely progressive solution to the nationality question in the Caucasus: equal rights for all nations regarding schooling and communication, and the prohibition of all national privileges; these, however, can only be achieved by the complete democratization of the country.

In proposing this solution, Stalin not only crucially relies on state power to solve the nationality question; he also explicitly reframes the nationality question within a bolshevist mission civilisatrice. Regional autonomy, he claims, will draw the 'belated nations' into 'the common cultural development' and by allowing them the benefits of 'higher culture', and helps them to avoid small-nation insularity. Note that Stalin employs both 'cultural development' and 'higher culture' in the singular here, apparently assuming that neither has a specifically national, local or otherwise particular character, and tacitly identifying them with a universalist notion of 'civilization' or 'modernity'.

The contradictory character of these views on nationality has often been noted; even more striking, however, is Stalin's relapsing into an idealist vocabulary of 'cultural development' and 'higher culture'. But whatever its intellectual merits, 
Stalin's solution to the nationality question cannot be brushed aside, not only because of its enormous influence on (post)colonial third world nationalisms, but also, and especially, because Stalin got the chance to implement and institutionalize his views in the Soviet Union of the I920s and I930s, once Lenin had appointed him People's Commissar for Nationalities Affairs.

Thus, early Soviet korenizatsiia policies tied in well with Marr's struggle for nationality and against nationalism; but were they actually shaped by it? There is no evidence that Stalin was familiar with the theories of his fellow Georgian Marr before the I920s; but the resemblance with Marr's attitude to nationalism, and the concern with the smaller, non-Christian nationalities of the Caucasus, is striking. Conversely, as noted, it was only in the 1920 s that Marr rephrased his theories in explicitly dialectical terms of class struggle, base and superstructure; but even before this reformulation, Marr's theories had been germane to the emancipation, or creation, of the smaller Muslim nations of the Caucasus, such as the Abkhaz, the Chechens, the Kurds, and to some extent even the Azeris, against the locally dominant Christian Armenian and Georgian nationalities (which, it should be kept in mind, were themselves relatively recent formations shaped in interaction with the rise of Russian nationalism in the nineteenth century).

Marr was certainly not alone in his efforts to create a genuinely Marxist linguistics. Despite the violent power struggle between the bolshevists and their opponents, both the arts and the humanities - not yet as constrained by state power as they would become in subsequent decades - showed a creative outburst during the I920s, with exciting and provocative new ideas developed by both scholars and artists, witness students of literature and folklore like Bakhtin and Propp, and modernist dramaturges, poets and filmmakers like Meyerhold, Mayakovsky and Eisenstein. In linguistics, the I920s saw a significant paradigmatic shift from more historically oriented approaches to language inspired by authors like Wilhelm von Humboldt to the synchronic, structural approach proposed by, in particular, Ferdinand de Saussure; at the same time, various authors started the search for a Marxist alternative to such 'bourgeois' approaches to the study of language. Thus, one Soviet scholar, V.N. Voloshinov, developed a framework that emphasized the materiality of the sign and its priority over consciousness, and formulated a concept of language as class-bound and dialectical in character. Another talented linguist, E.D. Polivanov, called for the creation of a Marxist linguistics that studied language as a collective work activity rather than an individual possession, parallel to (and possibly reducible to) processes of material production. And in a way, the early writings of Volosinov's friend and colleague Mikhail Bakhtin also reflect this wider search for a new account of language and literature that escapes the confines of both German idealism and French structuralism. ${ }^{24}$ In the acerbic polemics of the late 1920 s and early i930s, however, 
claims to Marxist orthodoxy already started to overshadow questions of methodology or empirical adequacy. Thus, for example, Polivanov's cogent, if rather condescending, criticisms of Marr's work were largely ignored.

These increasingly violent debates in linguistics coincided with an acerbic phase of Soviet agrarian policies. In Armenia as elsewhere in the Soviet Union, the collectivization of agriculture met with fierce resistance, and could only be imposed after the forcible intervention of the Red Army. Paired with the korenizatsiia policy, it involved a redefinition of the regional population as a collective of workers and peasants distinguished by 'national cultures', conceived of in terms of primarily oral folkloric traditions. One of the smaller 'folkloric' nations thus created in the I920s was that of the Kurds, in particular in Soviet Armenia. In the I920s, the Soviet Kurds were briefly granted an autonomous region called 'Red Kurdistan' (Kurdistana Sor) in the Laçîn region between Armenia and Azerbaijan; but this region was abolished in 1929. In the same year, a systematic, and quickly successful, alphabetization campaign was mounted among the Kurds of Soviet Armenia, for which a new alphabet was specifically created using the Latin script, and new Kurdish-language textbooks for adult education and elementary schools were published at an astonishing pace, thanks primarily to the indefatigable efforts of the local Kurdish scholar Haciyê Cindî.

Soviet nativization and folklorization policies largely disregarded the earlier literate traditions that some of these peoples knew. Thus, as part of Kurdish nativization, local religious traditions of learning as they had been cultivated in Kurdish medreses were attacked as backward, and the classical Kurdish poetic tradition was largely ignored in the creation of a new, progressive national literature. Considerations of space preclude a fuller discussion, but early Soviet studies of the Kurds clearly aimed at the emancipation, and in a sense even the creation, of the Kurds as a distinct nation defined by its proper language and folkloric traditions. ${ }^{25}$ It is difficult to gauge the actual influence of Marr's doctrines on the shaping of an early Soviet Kurdish national identity; but his ideas fit in well with official policies, and in the I930s became an obligatory feature of scholarly work on Kurdish language and folklore carried out in Leningrad and Moscow. ${ }^{26}$

Thus, early efforts at the nativization of the Soviet Kurds quickly yielded results. The mid-I930s, however, saw major shifts in Soviet nationality policies, which coincided with the start of the Great Terror. Tragically, precisely the loyal party members who had been active in realizing the korenizatsiia policies at the local level were now accused of 'bourgeois chauvinist sentiments', or even of espionage for foreign powers. Thus, in Soviet Armenia, cultural activists like the two pioneers of Kurdish alphabetization, Ereb Shemo and Haciyê Cindî, were imprisoned or deported; elsewhere, Polivanov was arrested and subsequently executed on charges of spying for Japan. 
But although the policy of encouraging smaller nations was replaced by a new Russian-chauvinist policy, Marr's theories maintained their officially sanctioned status. In the I930s and I940s, few if any criticisms of Marr's Japhetic theories were heard, until Josef Stalin personally intervened in the matter in $1950 .{ }^{27}$ Stalin's famous - or notorious - 'Marxism and Problems of Linguistics' may or may not have been written by Stalin himself, but it certainly is not a substantial intervention at the level of linguistic theorizing: it merely offers a number of lay observations about the postrevolutionary Russian language. Remarkably, Stalin's view on language boils down to a form of bourgeois common sense: not only is it idealist, in wholly downplaying or ignoring any material aspects of the linguistic sign; it is also decidedly nondialectical, emphasizing the idea of harmonious language communities over class conflict. Thus, these views actually mark a significant step back with respect to the more innovative Marxist authors of the I920s, like Voloshinov and Polivanov. However, given the personality cult surrounding Stalin and the renewed campaign of intimidation and persecution of artists and intellectuals, which had regained pace after World War II, Stalin's remarks were hailed as a major breakthrough in both the popular and the academic media of the Soviet Union. Countless scholars working in linguistics, ethnography, and archeology joined in the chorus against Marr. The fact that such criticism continued well after Stalin's death in 1953, however, suggests that they did not simply write out of fear of, or political loyalty to, the Soviet leaders ${ }^{28}$

\section{Some Gramscian conclusions}

The above discussion of Marr's anti-philological theories and of the Soviet nativization of the Kurds considerably complicate Gourgouris's and Nichanian's identification of philology and Orientalism, as well as their claim that the creation of non-Western native peoples involves an internalized Orientalism. At the very least, it forces us to explore 'subaltern' forms of knowledge like Marr's and Trubetzkoy's theories alongside the allegedly hegemonic German historical-comparative philology, and to focus on local agency and resistance rather than on the passive 'internalization' of Orientalist ideologies. Thus, the case of the Russian and Soviet humanities - which merits a far more extended and systematic descriptive treatment than I could give here - also raises issues of a more general theoretical interest.

First, it forces us to ask exactly how and why particular categories and theories gained a dominant or hegemonic status. To get an answer to such questions, one should also look at 'subaltern' doctrines like Marr's and at the reasons for their success or failure. Intriguingly, despite its vocal rejection of the main tenets of 
German philological scholarship, Marr himself reproduced crucial conceptual and methodological assumptions of German philology; conversely and ironically, later critics of Marr's work, even when rejecting his Japhetic theories as nonsensical or at best purely speculative, tend to praise his philological work on the grammar of languages like Georgian and Armenian, as well as his archeological work in the Ani area, as valuable and largely correct, and as untainted by his linguistic speculations. In doing so, they tend to reproduce the philological assumption of a foundational and theory-free level of factuality that should precisely be an object of investigation. It is here that arguments like those of Foucault, Gourgouris and Nichanian, if used with caution, can perform valuable services.

Second, it raises questions about language, nationalism, and hegemony. Primarily, of course, the capricious development of Soviet linguistics and Orientalism reflects the destructive - and often murderous - vagaries of Stalin's policies; but theoretically one is led to the deeper problems of the precise role of language in the rise of Soviet and other nationalisms, and of the theoretical status of language in Marxist theory. Regarding the former, one may venture the hypothesis that the public use of vernacular languages, as seen in early Soviet educational campaigns and broadcasting policies, may itself be partly constitutive of national identities. Regarding the latter, one may ask anew exactly where language fits in within Marxist theory: should it be relegated to either the material base or the ideological superstructure, or does it require a more radical reformulation of Marxist cultural theory?

Third, in this context of language, linguistic theory and nationalism, Gramsci's writings on hegemony gain an unexpected relevance. Not only was Gramsci one of the first authors to suggest that a closer attention to cultural factors may force us to rethink the classical Marxist distinction between base and superstructure; but it is also worth recalling that his concept of hegemony is, in origin, inspired by specifically linguistic phenomena: thus, the creation of a hegemonic national language, i.e., a linguistic standard accepted by the population at large, reduces the spoken dialects to a substandard, or subaltern, status. ${ }^{29}$

The above not only suggests that a greater attention to language will affect the Marxist opposition between base and superstructure; it also invites a linguistic turn, so to speak, to questions of ideological hegemony, especially (but not exclusively) as they appear in discussions of Orientalism. The virtually universal spread of vocabularies and methods of the modern European humanities, and their persistence even among apparently rival frameworks like Marr's Japhetic theory, suggests that the kinds of knowledge articulated in the modern philological humanities rest on very particular, and particularly powerful, practices and ideologies of language, which may be implicated less in the spread of any allegedly hegemonic Western philological Orientalism than in the performative power ef- 
fects of the wider patterns of vernacularization that occur during this period..$^{30}$ These power effects remain a topic for theoretical exploration.

Fourth and finally, the Soviet experience provides suggestive material for anyone wishing to study the role of the humanities in the articulation of nationalism and empire. If arguments like Gourgouris's and Nichanian's hold, the Orientalist creation of an (Oriental or domestic) Other may be crucially linked to the nationalist creation of a native self. Perhaps, then, a greater attention to cases like that of the Soviet Union may ultimately lead to a dissolution of 'Orientalism' as a distinct analytical category into a more general theoretical framework formulated in terms of more general analytical notions like new disciplines of philological learning, specifically modern forms of power, and changing practices and ideologies of language. As such, it might even help to explain both the formation and persistence of national identities and the rise and demise of colonial forms of rule.

\section{Notes}

Cf. R. Bauman \& Ch. Briggs, Voices of Modernity (Cambridge: Cambridge University Press, 2002); Joep Leerssen, National Thought in Europe (Amsterdam: Amsterdam University Press, 2007).

2 Edward Said, Orientalism (New York: Pantheon Books, I978).

3 To mention but two examples, both dealing with the alleged spread of hegemonic Western norms of sexuality in the Arab world, see Khalid al-Rouayheb, Before Homosexuality in the Arab World (Chicago: University of Chicago Press, 2005) and Joseph Massad, Desiring Arabs (Chicago: University of Chicago Press, 2007); cf. my discussion of the latter, 'Der Import des westlichen Sexualitätsmodells', Inamo 52 (2008), 20-22.

4 For German Orientalism, see in particular Suzanne L. Marchand, German Orientalism in the Age of Empire: Religion, Race, and Scholarship (Cambridge: Cambridge University Press, 2010). For a brief discussion of earlier criticisms of Said's thesis along these lines, see also my 'The Oriental origins of Orientalism: The Case of Dimitrie Cantemir', in R. Bod et al. (eds.), The Making of the Humanities, Vol. II: From Early Modern to Modern Disciplines (Amsterdam: Amsterdam University Press, 2012), 243-263.

5 Stathis Gourgouris, Dream Nation: Enlightenment, Colonization and the Institution of Modern Greece (Stanford: Stanford University Press, I996); Marc Nichanian, Entre l'art et le témoignage, Littératures arméniennes au xxe siècle, vol. 2: Le deuil de la philologie (Geneva: MêtisPresses, 2007).

6 Gourgouris, Dream Nation, I24; emphasis in original.

7 Nichanian, Le deuil de la philologie, ch. 3, esp. I Io.

8 Ibid., I5-I7; see also Nichanian's earlier Ages et usages de la langue arménienne (Paris: Éditions entente, I989). Foucault, astonishingly perhaps, nowhere in Les mots et les choses or elsewhere discusses either the nationalistic or the colonial projects in which philology in general, and Orientalism in particular, were implicated, except for a brief allusion on p. 303 of that work; I hope to discuss these matters in more detail on some future occasion. Benedict Anderson's oft-cited account of the rise of modern nationalism, Imagined Communities, 2nd ed. (New York and London: Verso Press, I99I), suffers from an overly 
functionalist approach to language, and ignores the literary and philological dimensions of nationalist modernity. See in particular Michael Silverstein,'Whorfianism and the Linguistic Imagination of Nationality', in Kroskrity (ed.), Regimes of Language (Santa Fe, NM: School of American Research Press, 2000), 85-I38.

9 Nichanian, Le deuil de la philologie, I9. For the sake of brevity, I ignore here Nichanian's point, crucial to his own arguments concerning twentieth-century Armenian literature, that the philological reconstruction of the past as irrevocably past is inherently linked to a sense of loss or mourning, but misrecognizes this mourning, in its nationalist project of constituting a native population and culture.

Vera Tolz, Russia's Own Orient: The Politics of Identity and Oriental Studies in the Late Imperial and Early Soviet Periods (Oxford: Oxford University Press, 20I I), esp. Ioo-Ior. Cf. David Schimmelpenninck van der Oye, Russian Orientalism: Asia in the Russian Mind from Peter the Great to the Emigration (New Haven and London: Yale University Press, 20 10). See also Anouar Abdel-Malek, 'Orientalism in Crisis', Diogenes I I (I963), I03-I 40.

I I N.S. Trubetzkoy, Grundzüge der Phonologie (Goettingen: Vandenhoeck \& Ruprecht, I 977 [I939]); for Trubetzkoy's Eurasian views, see his 'Europe and Mankind', in The Legacy of Genghis Khan (Michigan Slavic Publications, I99I), I-64.

N.S. Trubetzkoy, 'Thoughts on the Indo-European Problem', in Studies in General Linguistics and Language Structure (Durham, NC: Duke University Press, 2001), 87-98.

Relatively few of Marr's numerous writings have been translated into Western languages. For a brief statement of the Japhetic theory, see his Der japhetische Kaukasus und das dritte etnische Element im Bildungsprozess der mittelländischen Kultur (Stuttgart: Kohlhammer, I923). For a - very critical - overview of Marr's academic merits as a linguist, see Lawrence Thomas, The Linguistic Theories of N.Ja. Marr (Los Angeles: University of California Press, 1957); see also Thomas Samuelian, The Search for a Marxist Linguistics in the Soviet Union, 1917-1950 (PhD dissertation, University of Pennsylvania, I98I).

I4 Samuelian, The Search for a Marxist Linguistics, I I4.

I5 Cf., e.g., J.P. Mallory, In Search of the Indo-Europeans: Language, Archaeology, and Myth (London: Thames \& Hudson I989), esp. 266-270, for Hübschmann's assumptions about Aryan superiority; cf. Thomas, The Linguistic Theories of N.Ja. Marr, I 8.

I6 N. Ja. Marr, Grammatika drevnearmjanskogo jazyka [Grammar of the Ancient Armenian Language] (Petersburg, I903), xxxi.

I7 Ibid., xxx-xxxi. Nichanian, Le deuil de la philologie, I 3 I, only mentions Marr in passing, erroneously identifying him as 'a Russian'; his overview of the Armenian language ignores Marr altogether, but does mention a likely source of some of Marr's doctrines, viz., Aydenian's thesis of a 'classical' and a 'vernacular' variety of Armenian existing alongside each other ever since the fifth century CE, a claim originally developed in the latter's I 866 Critical Grammar of Modern Armenian (cf. Nichanian, Ages et usages de la langue arménienne, 95).

Cf. Samuelian, The Search for a Marxist Linguistics, I 20.

I9 N.Ja. Marr, 'Ob izuchenii azerbaidzhana' (unpublished lectures, Baku I924), quoted in Tolz, Russia's Own Orient, I52-I53.

20 Quoted in Samuelian, The Search for a Marxist Linguistics, 106. See also Marr's later La langue géorgienne (Paris: Firmin-Didot, I93 I), which is completely free from any Japhetic speculation (reportedly, at the insistence of Marr's French hosts), and is praised as a valid contribution to Georgian philology even today. 
23 J. Stalin, 'Marksizm i natsional'nyy vopros', Prosveshcheniye 3-5 (March-May I9I3). English translation available via URL: http://www.marxists.org/reference/archive/stalin/ works/I913/03.htm.

24 V.N. Volosinov, Marksizm i filosofija jazyk (Leningrad, I930), translated as Marxism and the Philosophy of Language (New York: Seminar Press, I973); E.D. Polivanov, 'The Problem of Marxist Linguistics and the Japhetic Theory', in A.A. Leontov (ed.), E.D. Polivanov: Selected Works: Articles on General Linguistics (The Hague: Mouton, 1974).

25 For an initial overview of Russian and Soviet Kurdology, see my 'Soviet Kurdology and Kurdish Orientalism', in M. Kemper and S. Conemann (eds.), The Heritage of Soviet Oriental Studies (London: Routledge, 2011), 86-102; for a more detailed discussion of developments in I920s and I930s Soviet Armenia, see my 'A People Forgotten by History: Soviet Studies of the Kurds', paper presented at the International Conference on Soviet Iranology, Oxford University, December 2012.

26 Marr wrote relatively little on the Kurds; see in particular his early 'Eshcho o slove Celebi' [Again Concerning the Word Çelebi], Zapiski vostocnogo otdeleniia imp. Russkago arkheologiceskago obscestva 20 (I9II), 99-I5I, a speculative discussion of the etymology of the term çelebi. For a hyperbolic appraisal of Marr's importance for Soviet Kurdish studies, characteristic for its period and published shortly after Marr's death in a special commemorative journal issue, see O. Vil'cevskij, 'N. Ia. Marr i kurdovedenie' [N. Ia. Marr and Kurdology], Yazyk i Myslenie VIII (I937), 209-234.

27 J. Stalin,'Marksizm i voprosy yazyznaniia', Pravda (June 20, 1950). English translation available via URL: http://www.marxists.org/reference/archive/stalin/works/I950/jun/20. htm.

28 Among authors working on the Kurds, one may find critiques of Marr's Japhetic theory later in the I950s and I960s; see, e.g., Q. Kurdoev, 'Kritika oshibocnykh vzgliadov na kurdskii yazyk' [Critique of Erroneous Opinions on the Kurdish Language], Kratkie soobsceniia Instituta vostokovedeniia I2 (I955), 43-6I. See also the discussions of Marr in O. Vil'cevskij, Kurdy: Vvedenie v etniceskuiu istoriiu kurdskogo naroda [The Kurds: Introduction to the Ethnic History of the Kurdish People] (Moscow: Akademija Nauka, I96I), passim.

29 The linguistic origins of the concept of hegemony are discussed in Franco Lo Piparo, Lingua intellettuali egemonia in Gramsci (Rome: Laterza, I979: 103-I45), and more recently in Peter Ives, Language and hegemony in Gramsci (London: Pluto Press, 2004: ch. 2).

30 I explore these wider patterns of vernacularization and their significance in my forthcoming From Coffee House to Nation-State: The Creation of National Languages in the Ottoman Empire. 


\title{
2.3 Root and Recursive Patterns in the Czuczor- Fogarasi Dictionary of the Hungarian Language ${ }^{1}$
}

\author{
LÁSZLó MARÁCZ
}

The first academic Hungarian dictionary A magyar nyelv szótára (The Dictionary of the Hungarian Language) was a monumental work compiled by two members of the Hungarian Academy of Sciences: Gergely Czuczor (1800-1866) and János Fogarasi (I8OI-1878) that was published in six volumes between 1862 and I874 [Figs. 2 and 3]. Rather than just being a list of Hungarian words, Czuczor-Fogarasi's monolingual dictionary (hereafter, the $\mathrm{CzF}$ Dictionary) must be considered a linguistic achievement. It contains IIO,784 entries and is structured according to the agglutinative nature of the Hungarian language since it distinguishes roots and suffixes while also referring to interconnections within the root system. Its importance was recognized by one of the leading German linguists of the second half of the nineteenth century, August Friedrich Pott (1802-1887), who referred in his survey of European linguistics to the $\mathrm{Cz} F$ Dictionary as an outstanding accomplishment on the part of the Hungarian Academy of Sciences. ${ }^{2}$

Czuczor and Fogarasi formulated the following four objectives when writing their dictionary: $(\mathrm{I})$ to make an inventory of Hungarian words and word parts; (2) to determine their grammatical properties; (3) to define their meaning; and (4) to establish the etymology of Hungarian words by comparing the Hungarian roots with those of other languages. The $\mathrm{CzF}$ Dictionary is thus an explanatory, comparative and etymological dictionary all in one. From this point of view it is remarkable that the work has fallen into oblivion. ${ }^{3}$ By uncovering the patterns of the Hungarian lexicon, the $\mathrm{CzF}$ Dictionary provided an interesting step forward in empirical and theoretical approaches to the Hungarian language. In this respect the $\mathrm{CzF}$ Dictionary is also relevant to Rens Bod's project detailing the history of the humanities in according with various patterns and rules. ${ }^{4}$ The present paper will argue that a discussion of the patterns and rules seen in the $\mathrm{Cz} F$ Dictionary can contribute to the richness of such a historiographical project and that there is therefore every reason to include such a dictionary in a history of the humanities based on pattern-seeking research. 


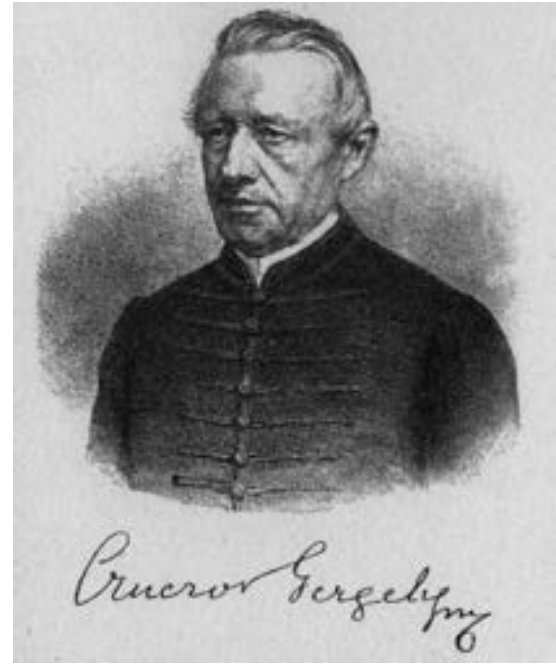

Fig. 2: Gergely Czuczor (1800-I866)

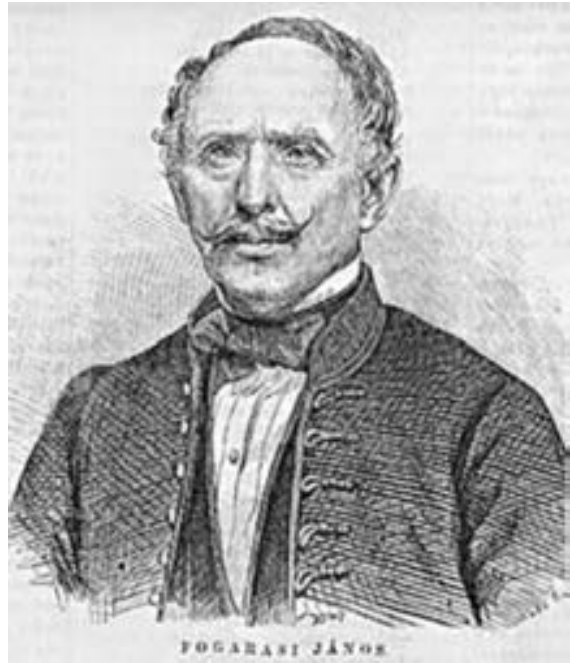

Fig. 3: János Fogarasi (I80I-I878)

The present paper falls into four parts. In the first part, I will discuss the ideas that were responsible for creating a context for the emergence of the academic dictionary project. I shall demonstrate how it was attributable to a mixture of ideas originating from the Enlightenment, state-forming nationalism and Romanticism. The second part of the paper will focus on the incentives behind the lexical project's linguistic research. I will furthermore elaborate on the linguistic traditions the authors relied on when seeking patterns and will argue that both foreign and local traditions played a decisive role. The third part of this paper will give the reader some insight into the nature of the patterns and rules underlying the Hungarian language. Finally, I will assess the discoveries made by Czuczor and Fogarasi. It will be concluded that even if the work on the dictionary is basically empirical it remains a good starting point for pattern-based research into Hungarian lexical structures.

\section{Contextualizing the first Hungarian academic dictionary}

At the end of the eighteenth century the ideals of the Enlightenment also reached Hungary. At first the Hungarian proponents of the Enlightenment were more active in Vienna than in Hungary itself, especially in circles linked to the Hungarian division of the Imperial Guard that was established in 1760 by the Habsburg Empress Maria Theresa. The driving force within the Viennese nobility was György Bessenyei (I747-I8II), a literator and admirer of Voltaire and the French encyclopedists. ${ }^{5}$ 
Bessenyei was convinced, just like his French counterparts, that happiness could only be achieved through the sciences, general access to which was only possible through one's own mother tongue. According to him, no nation had ever gained access to science in the language of another nation. However, toward the end of the eighteenth century the Hungarian language had gained vernacular status, Latin being the only official language in the country until I844 and so Hungarian was not a suitable language for the practicing of science. In his essays, Bessenyei forcefully argued in favor of the renewal and social promotion of the Hungarian language. In $178 \mathrm{I}$ he also launched the idea of establishing a Hungarian academy of sciences. ${ }^{6}$ The ideas of Bessenyei were adopted by a young member of the high aristocracy who also belonged to the Viennese Imperial Guard, Count István Széchenyi (I79I-I860).

The free-thinking Széchenyi and other enlightened Hungarian noblemen strove to modernize Hungary and give it a well-deserved place in the Habsburg Empire. Széchenyi's modernization program focused not only on questions relating to politics and society, but also on putting cultural issues on the agenda. In this cultural program, the Hungarian language occupied a central role. ${ }^{7}$ Széchenyi wanted to secure the same status for the Hungarian language as that enjoyed by other national European languages. Hungarian should become the country's official language and in order to prepare for this official function a Hungarian academy of sciences had to be established, just as Bessenyei had asserted.

In 1825 , Széchenyi enthusiastically put forward his ideas at the Hungarian Diet. ${ }^{8}$ Thanks to his efforts, and financial support, the Hungarian Academy of Sciences was established on November 17, I830. The Academy immediately launched a number of projects relating to the Hungarian language, including the compilation of a grammar, an orthography, bilingual dictionaries and specialist dictionaries establishing scientific and scholarly terminology. In 1844 the Academy board decided to make a 'great' dictionary covering the entire lexicon of the Hungarian language. Two members of the Academy, Gergely Czuczor (1800I866) and János Fogarasi (I80I-I878), were entrusted with this task. Gergely Czuczor was a monk of the Benedictine Order and János Fogarasi worked as a judge in the High Court of Appeal.

Apart from the ideas originating from the Enlightenment and nationalism, the language renewal movement in Hungary was also influenced by Romantic views. Hungarians strongly believed that they were related to ancient Central Asian peoples, like the Huns and Avars who, like the Hungarians themselves, had entered Europe in the ninth century. Széchenyi and his followers were of the opinion that the most important duty of the Hungarians was to gain an identity as a people in Europe that stemmed from Asia:'The Hungarian people, being the only European heterogenic offspring, have no smaller role than to represent the 
unique talents which were hidden in the cradle in Asia, but never grew to fruition. 9 This led researchers to believe that the Hungarian language was an Asiatic language which thus had an impact on the research conducted into the roots of the Hungarian language.

At the time, the West paid little attention to Hungarian political and economic reforms and knew little about the research being undertaken by Széchenyi and his group. There was one exception, however. Besides being a businessman, traveler, liberal politician, government official and governor of Hong Kong between I85I and I859, the British citizen Sir John Bowring (I792-1872) was also a polyglot literator, who supported the emerging national movements in Europe by publishing anthologies of their literature. ${ }^{10}$ Early-nineteenth-century Hungary must have held some special attraction for the British traveler. Indeed, Hungary followed Great Britain in the liberal trend of political and economic reforms that Bowring enthusiastically supported. In addition, Bowring was a member of the Unitarian Church which was one of the Hungarian Protestant churches that played an important role in Hungary's and Transylvania's religious life.

In 1830 , Bowring published a collection of Hungarian poems in English, Poetry of the Magyars, in the foreword of which one reads some notable statements concerning the Hungarian language. ${ }^{\text {II }}$ There Bowring commented on the Hungarian language. In his opinion, the Hungarian language was independent and very old. ${ }^{12}$ Having hardly changed over time, it had retained its Asiatic structure. ${ }^{\mathrm{I} 3}$ Finally, Bowring claimed that the ancient forms of the Hungarian language, that is to say its root words, were composed of simple, monosyllabic lexical elements. These elements enabled the speakers of Hungarian to create an endless number of new lexical elements with the help of affixes. ${ }^{14}$

Bowring's remarks about the Hungarian language are especially worthy of consideration in view of the fact that they elaborate on linguistic theories developed in Hungary itself. In the Poetry of the Magyars, Bowring echoes the opinions that Széchenyi and his group held in the I820s. Bowring's knowledge of the Hungarian language and literature came mostly from Gábor Döbrentei (I786-I85I), the First Secretary of the Hungarian Academy of Sciences with whom he maintained close contact. Döbrentei belonged to Széchenyi's inner circle and was his most influential advisor in the fields of Hungarian language and literature..$^{15}$

The dictionary project of the Hungarian Academy of Sciences was interrupted by the Hungarian Revolution of 1848 . Czuzcor was even incarcerated in Kufstein Prison from 1849 until I85I for his anti-imperial activism. After the crushing of the Hungarian rebellion by the Austrian and Russian armies the Hungarians had to remain under Habsburg rule. Martial law was proclaimed and Hungary started being governed from Vienna. Under this rule, strong Germanizing politics prevailed throughout the country. Moreover, in 1858 , a plan was proposed to 
make German the official language of the Hungarian Academy of Sciences. The Academy's directorate was replaced by scholars who were loyal to the Austrians, like Pál Hunfalvy (1810-I89I), a lawyer who, in I85I, became the chief librarian at the Hungarian Academy of Sciences. His main task was, however, to reorganize the research being conducted into the Hungarian language.

Immediately after his Academy nomination in I85I, Hunfalvy started to attack the dictionary project of Czuzcor and Fogarasi. At an Academy meeting in I85I he argued that from a methodological point of view the dictionary was inadequate and obsolete: 'The sheer cliffs into which language research runs are mainly the meaning of letters and word roots. ${ }^{16}$ Although Czuczor and Fogarasi were allowed to finish their project, which finally went on to be published between 1862 and $\mathrm{i} 874$, the $\mathrm{CzF}$ Dictionary did not play any role in the domain of etymological and historical comparative research into the Hungarian language. ${ }^{17}$

Hunfalvy pushed hard to elaborate on a one-sided genetic relationship between Finnish and Hungarian and cast Czuzcor-Fogarasi's root theory to one side. He entrusted the technical completion of this program to a young German linguist, Josef Budenz (1836-1892) who at the age of twenty-two was invited to go to Budapest to fulfill that task. Budenz was well equipped to do the job. He had read classical languages at the University of Göttingen and had also done comparative Indo-Germanic linguistics and Oriental studies. In I868, when Budenz was made Honorary Professor of Finno-Ugric Linguistics at the University of Budapest, Hungarian genealogical language research suddenly took a completely different turn moving in a direction completely different to what the authors of the Academy Dictionary had had in mind. ${ }^{18}$ Although today's Hungarian linguistics specialists are more positive about the achievements of the $\mathrm{CzF}$ Dictionary and regard it as a standard work in the history of the lexicography of the Hungarian language, internal analysis linked to finding the origin of words is still viewed as something 'anachronistic.' ${ }^{19}$ In this paper, I will argue against this point of view.

\section{Searching for roots}

The direct input regarding the linguistic work on the root dictionary originated from two important traditions. First of all, there were the developments in European linguistics of the end of the eighteenth century. The first to publicize, although certainly not the first to formulate the notion of Sanskrit being the oldest language on earth, the 'mother' of all major Eurasian languages, was the British philologist and scholar on ancient India, Sir William Jones. ${ }^{20}$ Hence, Sanskrit was considered to be the ancient Indo-European language from which all other Indo-European languages derived. Jones' program was taken up in Germany and 
soon intensive research activities in this field began. Throughout the nineteenth century outstanding linguists, such as Franz Bopp (I79I-I867), Jacob Grimm (1785-1863), Max Müller (I823-1900), and August Friedrich Pott elaborated on this research program. ${ }^{21}$ At first German linguists hypothesized that the ancient roots of the German language could be found in Sanskrit with the help of linguistic 'reconstruction'. However, from 1870 onwards the importance of Sanskrit in reconstructing Indo-European gradually declined. ${ }^{22}$

Regardless of the precise results what this research was generally to do was to bring to the surface the different cognate roots connecting the Indo-European languages. ${ }^{23}$ Max Müller, a German philologist and Oriental scholar who lectured at Oxford University, estimated the number of Sanskrit roots to lie at 1700 and considered them to be the most important linguistic components : $^{24}$ "These roots are definite in form and meaning: they are what I called phonetic types, firm in their outline, though still liable to important modifications. ${ }^{25}$ "They are the "specific centres" of language, and without them the science of language would be impossible. ${ }^{26}$ Note that Indo-European research was also driven by notions of Romanticism that were framed in biological metaphors, such as 'language as an organism,' 'mother-daughter languages,' 'family of languages' and other biological metaphors, like 'roots', 'trunks,' 'trees', 'organic groups', etc. ${ }^{27}$

The German research into roots that commenced at the end of the eighteenth and intensified in the early nineteenth century was soon to catch on in Hungary. The first dictionary that was organized along the lines of the 'root' idea was published by the Catholic priest Ferenc Kresznerics (1766-1832) in two-volumes in I 831 and $1832 .{ }^{28}$ He was influenced by the theories of Johann Gottfried Herder (1744-I803) on 'roots' (Stammwörter) expounded in his 'Abhandlung über den Ursprung der Sprache' (1772), as Kresznerics alludes to this influential work terming it a point of reference in the preface to his dictionary. ${ }^{29}$ Kresznerics already started to work on the dictionary in 1808 and his point of departure was that Hungarian is an agglutinative language in which roots can be distinguished from suffixes and other affixes. Hence, under each root entry the total set of 'derivatives', i.e., the roots with all their possible affixes and suffixes are listed. Czuzcor and Fogarasi saw Kresznerics's dictionary as a forerunner, although they went on to considerably elaborate on the subject as will be discussed below. ${ }^{30}$ Much of the nomenclature referred to above in connection with Indo-European research also appears in the context of Czuzcor and Fogarasi's dictionary project.

Apart from the European linguistic impulses that reached Hungary at the beginning of the nineteenth century, especially from Germany, which had taken the lead in linguistics, there was a second more local tradition that was influencing the evolution of Hungarian linguistics in that period. This input was also European-based. 
From the mid-seventeenth century onwards, Hungarian university students had been visiting Western European universities in the course of their academic formation. At that period there were few opportunities for university education in Hungary. The Habsburgs were not eager to actively support the establishment of academic opportunities in the Hungarian kingdom. Hungarian Protestants, who formed an obstacle to the Catholic Counter-Reformation which was supported by the Habsburgs, were excluded from university education in particular. Students with a Protestant background were therefore more or less forced to go abroad for their academic studies. They traveled to Western Europe, where they were welcomed at universities in Protestant countries like the Netherlands, Switzerland and Britain. In the early modern period these universities became centers of peregrination for students from the Hungarian kingdom.

It appears from the publications of the peregrinating Hungarian students that they were familiar with the concept of the 'radix' (root) that was central to the analysis of classical languages like Greek, Latin and Hebrew. Most of these students had studied these languages because they had registered for theological studies. The radix is relevant to the work of the typographer Miklós Tótfalusi Kis ( $1650-1702)$, the translator of the 'Amsterdam Bible', a Hungarian-language edition that was published in Amsterdam in 1685. The Hungarian author Gyula Csernátoni points out that Tótfalusi Kis relied heavily on the 'root' for his Hungarian translation of the Bible: 'When he explains the description of individual words he analyzes them grammatically; he tracks down their roots; and he examines the nature of the suffixes and affixes and gives general rules. ${ }^{31}$ 'The radix is also frequently referred to in the dissertation on ancient Hungarian history of Fóris Ferenc Otrokócsi (1648-1718) that was defended at the University of Franeker in $1693 .{ }^{32}$

György Kalmár (1726-I782), a Hungarian theologian, linguist and poet who, in the second half of the eighteenth century, played an important part in developing Hungarian linguistics based on the radix (root) theory, also followed in this tradition. As a peregrination student, Kalmár visited a number of important centers of academic excellence in Western Europe, such as Universities of Oxford and Leiden. After his peregrination, he continued traveling in Western Europe and built up an extensive network of connections among scholars, including the outstanding German-Swiss scientist Johann Heinrich Lambert (1728-1777) and the Dutch Orientalist and professor at the University of Leiden, Hendrik Albert Schultens (1749-1782). From his linguistic projects, it appears that he was well aware of the importance of the radix or the root when studying language. Note that the 'Semitic' root does not have the same characteristics as the 'Indo-European' root. It remains to be seen how scholars such as Kalmár interpreted these divergent notions. Kalmár's linguistics projects included a proposal for a universal language, a 
hexameter poem and a grammar in Hebrew. ${ }^{33} \mathrm{~A}$ plan for an etymological Hungarian dictionary was also one of his project plans but Kalmár's etymological dictionary was lost. However, we know that it really existed because he refers to it as 'Lexicon Hungaricum' and to its having the explicit character of a root dictionary. ${ }^{34}$

The concept of linguistic roots was clearly an integral part of Hungarian scientific discourse in the early nineteenth century before the issue received further impetus from Germany. The success of the Kresznerics's first attempt to compile a root dictionary was taken up by the newly established Hungarian Academy of Sciences which then passed the project on to Czuzcor and Fogarasi and so the $\mathrm{CzF}$ Dictionary was born.

\section{Patterns in the $\mathrm{CzF}$ Dictionary}

Czuczor and Fogarasi assumed that Hungarian is an agglutinative language in which words display a synthetic structure consisting of a gyök 'root', the basic constituent of the Hungarian lexicon and suffixes attached to it. In order to find the root, a procedure of morphological segmentation comparable to Bopp's Zergliederung had to be first applied. ${ }^{35}$ Roots are those lexical items which, after having been peeled off all the affixes and suffixes from the word structure, cannot be reduced into further segments without losing their well-identified phonetic structure and meaning, ${ }^{36}$ According to Czuzcor and Fogarasi, the Hungarian roots are minimal, monosyllabic lexical elements. Subsets of these roots can also appear as independent words, or 'root words'. The dictionary presents an exhaustive list of the Hungarian roots numbering some 2000 lexical items that display the following basic patterns, including V (19), VC (335), CV (146), and CVC ( 1500$)$. Observe that the tryadic roots form the dominant pattern in Hungarian with 1500 , that is $75 \%$ of the total number of roots.

A number of suffixes can be attached to the basic set of roots to form many new words, to form what are termed derivatives. According to Czuzcor and Fogarasi, the Hungarian language distinguishes around 170 suffixes. Seventy of these are simple and monosyllabic, the rest are a combination of the simple ones yielding complex suffixes. Regularly, the Hungarian root does not change its form when being suffixed. Normally, after isolating the root by taking off the agglutinated material (predominantly suffixes), the root will show a well-identified phonetic structure and meaning in its own right. Compare, for example, some of the derived forms of the root word KÖR 'circle':

(I) KÖR: KÖR 'circle', KÖR-ös 'circular', KÖR-öz 'turn around in circles', KÖR-ny-ék 'environment, neighborhood', KÖR-ny-ez 'surround' 
As can be noted from (I) the root KÖR figures in derived words: 'körös,' 'köröz', 'környék' and 'környez'. Note that the adjectival suffix -ös, the nominal suffix -nyék, and the verbal suffixes $-\ddot{z} z$ and $-e z$ can be attached to the root KÖR or to one of its respective derivatives. The derivatives of the root modify, accentuate, highlight or focus on an aspect of the basic meaning. In most of the cases, however, these meanings, discussed in the $\mathrm{CzF}$ Dictionary only in Hungarian, cannot easily and satisfactorily be translated into English due to the subtle connotations that Hungarian suffixes add to the core meaning.

Czuczor and Fogarasi further observe that by vocalizing the K-R consonant frame with other vowels, like A, E, O, U, and $\ddot{U}$ new $\mathrm{K}-\mathrm{R}$ root alternatives can be generated. With the help of suffixing these structures yield their own set of derivatives. ${ }^{37}$ Compare:

(2) KAR: KAR 'arm', KAR-aj '(pork)chop', KAR-éj 'slice', KAR-ika 'ring', KAR-ima 'brim', KAR-ing 'make small movements in circles'

KER: KER-ek 'rounded', KER-ék 'wheel', KER-ül 'to go around', KER-it 'to ring around', KER-ing 'keep circling around', KER-ge 'bark (tree)'

KOR: KOR-ong 'disk', KOR-ona 'crown', KOR-lát 'fence', KOR-mány 'wheel'

KUR: KUR-kál 'search around'

KÜR: KÜR-t 'horn'

Czuczor and Fogarasi refer to the 'horizontal' groupings as szócsalád 'word family' and collectively to the set of all the cognates with their derived forms as szonemzet, i.e., 'word nation'. Note that in this 'organic' word group a fixed K-R sound pattern corresponds to a conceptual structure, a semantic field covering a line that is curved into itself or a motion that follows such a line'.

The authors of the CzF Dictionary discovered not only interconnected, vocalized root patterns but also connections between roots. These connections result in new clusters of roots used to express a common idea ${ }^{38}$ Compare:

(3) GÖR: GÖR-be 'curvilinear', GÖR-cs 'round, hard knot on tree', GÖR-dül 'roll (intransitive)', GÖR-dit 'roll (a heavy object)', GÖRnyed 'bend (as in old age)', GÖR-hes 'person who is bent, rugged' (4) GUR: GUR-ba used together with GÖR-be as the twin word görbe-gur$b a$ meaning 'curvilinear', GUR-ul 'roll (intransitive)', GUR-it 'roll (a round object smoothly)', GUR-iga 'round, wooden toy for children to play with, they roll it'

(5) GOR: GOR-nyad 'droop' 
(6) GYÜR: GYÜR-ü 'ring', GYÜR-ke 'crust (of bread)', GYÜR-emlik 'crumbled cloths, wrinkles' ('Gy' is the orthographic sign of a palatalized ' $\mathrm{d}$ ' sound, i.e., 'dj' in Hungarian.)

(7) HOR: HOR-og 'hook', HOR-ony 'hollow dent', HOR-gas 'hooked', HOR-gadt 'curved', HOR-paszt 'dent'

Note that ' $\mathrm{K}$ ' in the $\mathrm{K}-\mathrm{R}$ frame is related to the ' $\mathrm{G}$ ' in the $\mathrm{G}-\mathrm{R}$ frame which is then again vocalized with 'Ö', ' $U$ ' and ' $O$ ' to yield various alternatives in (3) to (5); the ' $G$ ' in its turn is related to the 'DJ' in the DJ-R frame and to the ' $\mathrm{H}$ ' in the H-R frame. The plosives ' $\mathrm{K}$, ' $\mathrm{G}$ ' and 'DJ' are related sounds that can be transformed into a fricative ' $\mathrm{H}$ '. Note that such phonetic changes mimic the sound laws of Grimm thereby bearing out the diachronic divergences in Indo-European languages. Czuzcor and Fogarasi did refer to the Grimm brothers' achievements in lexicography but failed to mention their linguistic work. ${ }^{39}$

To conclude, Czuczor and Fogarasi observed the following patterns and rules:

(8)

I. A set of monosyllabic roots and suffixes in Hungarian

2. A rule of vocalization connecting roots

3. Agglutination connecting roots and suffixes

4. Application of (2) and (3) yield recursive patterns

5. Roots can also be connected by 'sound law-types' of rules

6. A close connection between a specific basic sound pattern and a core meaning

\section{Discussion and outlook}

Let us compare the Kresznerics Dictionary with the $\mathrm{CzF}$ Dictionary in order to determine the progress made. The Kresznerics Dictionary is a more empirical and less theoretically inspired dictionary in which only organic groupings are listed. Due to the interconnections Czuzcor-Fogarasi's dictionary has more the structure of a reference dictionary. Under each root entry the interconnections within the dictionary are given as well. This yields a much more coherent structure of sound patterning and core meanings. Kresznerics only operated with 8(I) and $8(3)$. The interconnections within the root system, either by means of vocalization $8(2)$ or through the 'sound law-type rules' $8(5)$ are lacking in his dictionary. As a result, he also missed the important correlation $8(6)$, the relationship between a specific sound structure and a core meaning. Czuzcor and Fogarasi went well beyond the simple concepts of basic primitives and the rule of aggluti- 
nation. Progress was made because Czuzcor and Fogarasi were searching for new patterns and rules. Note that this fits in well with Bod's approach to writing a history of the humanities in terms of patterns. The $\mathrm{CzF}$ dictionary provides clear support for such an approach on the basis of pattern-seeking. ${ }^{40}$

Although in theoretical writings, Czuzcor and Fogarasi operated with levels of abstraction, by giving, for instance, the consonant frames with open positions for vowels, the K-R frame discussed above being a representative example, they displayed a predominantly empiricist attitude. ${ }^{41}$ Nevertheless the patterns and rules detected by Czuzcor and Fogarasi are impressive and open up the possibility for further formalizations, although it must be admitted that some of the rules listed in (8) are not always well understood and require much more research.

Marácz and Montvai is a first attempt to formalize rules like $8(5) .{ }^{42}$ Such rules have to comply with morphophonological and semantic conditions and obey the formation rules restricted on such grounds. Basic roots may be linked if and only if (i) they have a related meaning and (ii) only one of the two basic consonants is replaced, such as ' $G$ ' supplanting ' $K$ ' in KÖR (I) and GUR (4). In this way, it can be guaranteed that the mappings are recoverable. Marácz and Montvai proposed the following context-sensitive rule linking 'minimal pairs' of roots: ${ }^{43}$

(9) Linking of roots: $\mathrm{C}(\mathrm{x}) \_\mathrm{C}(\mathrm{y})>\mathrm{C}(\mathrm{x}) \_\mathrm{C}(\mathrm{z})$ or $\mathrm{C}(\mathrm{z}) \_\mathrm{C}(\mathrm{y})$, in which all roots have a related meaning.

Formalizations like (9) and the embeddings in the theoretical frameworks of the $\mathrm{CzF}$ Dictionary patterns are crucial to making further progress. In recent years, dictionaries have been studied in terms of network theory. There is currently a true explosion of research in this field. What characterizes this research is its interdisciplinary nature and the fact that the study of language networks targets all the different modules of language, including also phonology, morphology and semantic-cognitive structures. ${ }^{44}$

The Czuzcor-Fogarasi Dictionary should be studied in conjunction with these theories of language networks and the basic topic of research in Hungarian and other agglutinative languages should not only operate at word-level but also at root-level. Indeed taking the root as a 'hub' will make it possible to carry out significant lexical-statistical research. Different questions can then be posed relating to, for instance, the functional and distributional load of the individual roots in the Hungarian lexicon and the lexical-statistical distribution and load of individual roots, such as K-R, across languages. Such typological patterns might also have some interesting repercussions for genealogical language research. Czuzcor and Fogarasi started to compare Hungarian roots with the roots of other language families or groups. They were convinced that individual roots cross the 
boundaries of established language families. Czuzcor and Fogarasi were in fact forerunners of the 'one proto-language' approach that figures on the 'nostratic' research agenda. With modern digital resources these and related linguistic puzzles can be elaborated much more easily and effectively than in the time of Czuzcor and Fogarasi.

\section{Notes}

I I am indebted to an anonymous reviewer for critical comments on this paper and valuable suggestions for improvements.

2 See August Friedrich Pott, Zur Litteratur der Sprachenkunde Europas (Leipzig, I 887), 23.

3 In Anna Morpurgo-Davies' recent, authoritative study of the history of linguistics in the nineteenth century there is no reference to this dictionary. See Anna Morpurgo-Davies, Nineteenth-Century Linguistics, vol. 4 of Giulio Lepschy (ed.), History of Linguistics (London, I998).

4 Consider Rens Bod, De vergeten wetenschappen: een geschiedenis van de humaniora (Amsterdam, 20II).

5 Tomasz Kamusella, The Politics of Language and Nationalism in Modern Central Europe (London, 2012), 438.

6 For a more detailed discussion, see László Marácz, 'János Bolyai and Hungarian as the Perfect Language', Octogon Mathematical Magazine i6.IA (April 2008), 4I-56.

7 Kamusella, The Politics of Language and Nationalism in Modern Central Europe, 44I.

$8 \quad$ Ibid., 44I-442.

9 István Széchenyi, $A$ ’ Kelet Népe (Pozsony, I 84I), i6.

Io See Alpita de Jong, Knooppunt Halbertsma: Joast Hiddes Halbertsma (1789-1869) en andere Europese geleerden over het Fries en andere talen, over wetenschap en over de samenleving (Hilversum, 2009), 25, for an overview of his activities in Europe.

I I Sir John Bowring, Poetry of the Magyars, Preceded by a Sketch of the Language and Literature of Hungary and Transylvania (London, I830).

I2 Ibid,vii.

I3 Ibid.,viii.

I4 Ibid., iv.

I5 See László Marácz, 'The Origin of the Hungarian Language', in László Botos (ed.), Selected Studies in Hungarian History (Budapest, 2008), 564-565.

I6 Pál Hunfalvy, 'Kis gyülés', Magyar Akademiai Értesitö (I851), I Io.

I7 László Marácz, Origin of the Hungarian Language, 566-568.

I8 Gyula Décsy, Einführung in die Finnisch-Ugrische Sprachwissenschaft (Wiesbaden, I965), I.

I9 See Ferenc, Bakos, 'Die Lexikographie der uralischen Sprachen I: Ungarisch', in Franz Josef Hausmann, Oskar Reichmann, Herbert Ernst Wiegand and Ladislav Zgusta (eds.), Wörterbücher/Dictionaries/Dictionnaires: Ein internationales Handbuch zur Lexicographie/An International Encyclopedia of Lexicography/Encyclopédie international de lexicographie (Berlin, I99I), vol. 3, 2377.

20 See Peter Rietbergen, Europe: A Cultural History (New York, 2006), 407-408.

2 I There are a number of studies that present an excellent introduction to the development of historical comparative linguistics and the role of German linguists in this research pro- 
gram, including Morpurgo-Davies, Nineteenth-Century Linguistics (an authoritative overview of the topic), Olga Amsterdamska, Schools of Thought: The Development of Linguistics from Bopp to Saussure (Dordrecht, I987), Reinhard Sternemann, 'Franz Bopp und die vergleichende indoeuropäische Sprachwissenschaft: Beobachtungen zum Boppschen Sprachvergleich aus Anlass irriger Interpretationen in der linguistischen Literatur', Innsbrucker Beiträge zur Sprachwissenschaft 33 (I984), and a more recent paper by Bart Karstens, 'Bopp the Builder: Discipline Formation as Hybridization: The Case of Comparative Linguistics', in Rens Bod, Jaap Maat, and Thijs Weststeijn (eds.), The Making of the Humanities, Vol. II: From Early Modern to Modern Disciplines (Amsterdam, 2012), I03-I 27.

See Manfred Mayrhofer, Sanskrit und die Sprache Alteuropas: Zwei Jabrbunderte des Widerspiels von Entdeckungen und Irrtümern (Göttingen, I982), for further discussion.

23 Bart Karstens, Bopp the Builder, ro8.

24 See Max Müller, Lectures on the Science of Language (New York, I 865), 92.

It remains to be seen whether the concept of 'root' in Müller's sense is comparable to the concept of 'radix' that predates nineteenth-century linguistics. See below for the importance of the radix in Hungarian cultural history.

26 Ibid., 33I.

27 See the papers on biological metaphors in nineteenth-century linguistics in Henry $\mathrm{H}$. Hoenigswald and Linda F. Wiener (eds.), Biological Metaphor and Cladistic Classification (Philadelphia, 1987).

28 Ferencz Kresznerics, A magyar szótár gyökérrenddel és deákozattal (Buda, I83I-I832), was actually a bilingual dictionary. All the Latin equivalents of the Hungarian roots and derivatives are listed.

Ibid., xliv, xlv.

See Czuczor-Fogarasi, Vol. VI, végszó, 7.

Gyula Csernátoni, 'Erdély féniksze' (Kolozsvár, I 894), 28.

Fóris Ferenc Otrokócsi, Origines Hungaricae (Franequera, 1693).

33 Georgius Kalmár, Genuina linguae Hebraica grammatical, sive vetus illa sine masoretharum punctis Hebraisandi via (Geneva, I760).

34 József Kelemen, 'Kalmár György szótártervének és szótártöredékének nyomairól', Nyelvtudományi Közlemények LX. Kötet 2 (I958), 439-446.

On Bopp's Zergliederung, see Morpurgo-Davies, Nineteenth-Century Linguistics, I 3 I, 267.

36 Czuzcor-Fogarasi, Vol. 2, I 2 I 5.

37 Gergely Czuczor, 'A magyar nagyszótár ügyében', Akadémiai Értesitö I, no. 4 (I86I), 403445 .

38 This process of accretion where roots differ from each other through one or two additional sounds was also observed by Max Müller for Sanskrit (Science of Language, 330).

See Czuczor-Fogarasi, Vol. VI, végszó, 6.

40 On this issue, see also the progress linked to the pattern-seeking approach of Bart Karstens: 'Recursion, Rhythm and Rhizome: Searching for Patterns in the History of Humanties', Beiträge zur Geschichte der Sprachwissenschaft 2 I (20I I), I56-I57.

Gergely Czuczor, Akadémiai Értesitö, 403-445.

42 See László Marácz and Attila Montvai, 'Quantitative Exploration of the Conceptual and Semantic Structures of Contemporary Hungarian', in László Komlósi, Peter Houtlosser, and Michiel Leezenberg (eds.), Communication and Culture: Argumentative, Cognitive and Linguistic Perspectives (Amsterdam, 2003), I43-I54.

43 See Ibid., I46-I 50, for a detailed discussion of such chains and networks of roots due to transformations. 
44 Here are a few relevant references to give the reader an impression of this: Peter Csermely, Weak Links: Stabilizers of Complex Systems from Proteins to Social Networks (Berlin, 2006), 219; Erzsébet Ravasz and Albert-László Barabási,'Hierarchical Organization in Complex Networks', Physical Review E 67, 026I I 2 (2003), I-7; Christopher T. Kello and Brandon C. Beltz,'Scale-Free Networks in Phonological and Orthographic Wordform Lexicons', in François Pellegrino, Egidio Marsico, Ioana Chitoran, and Christophe Coupé (eds.), Approaches to Phonological Complexity (Berlin, 2009), I 7 I-I90; HaiTao Liu and WenWen Li, 'Language Clusters based on Linguistic Complex Networks', Chinese Science Bulletin 55.30 (October 2010), 3458-3465; Ricard V. Solé, Bernat Corominas-Mutra, Sergi Valverde, and Luc Steels, 'Language Networks: Their Structure, Function and Evolution', Complexity 15.6 (2010), 20-26. 
III

Writing History
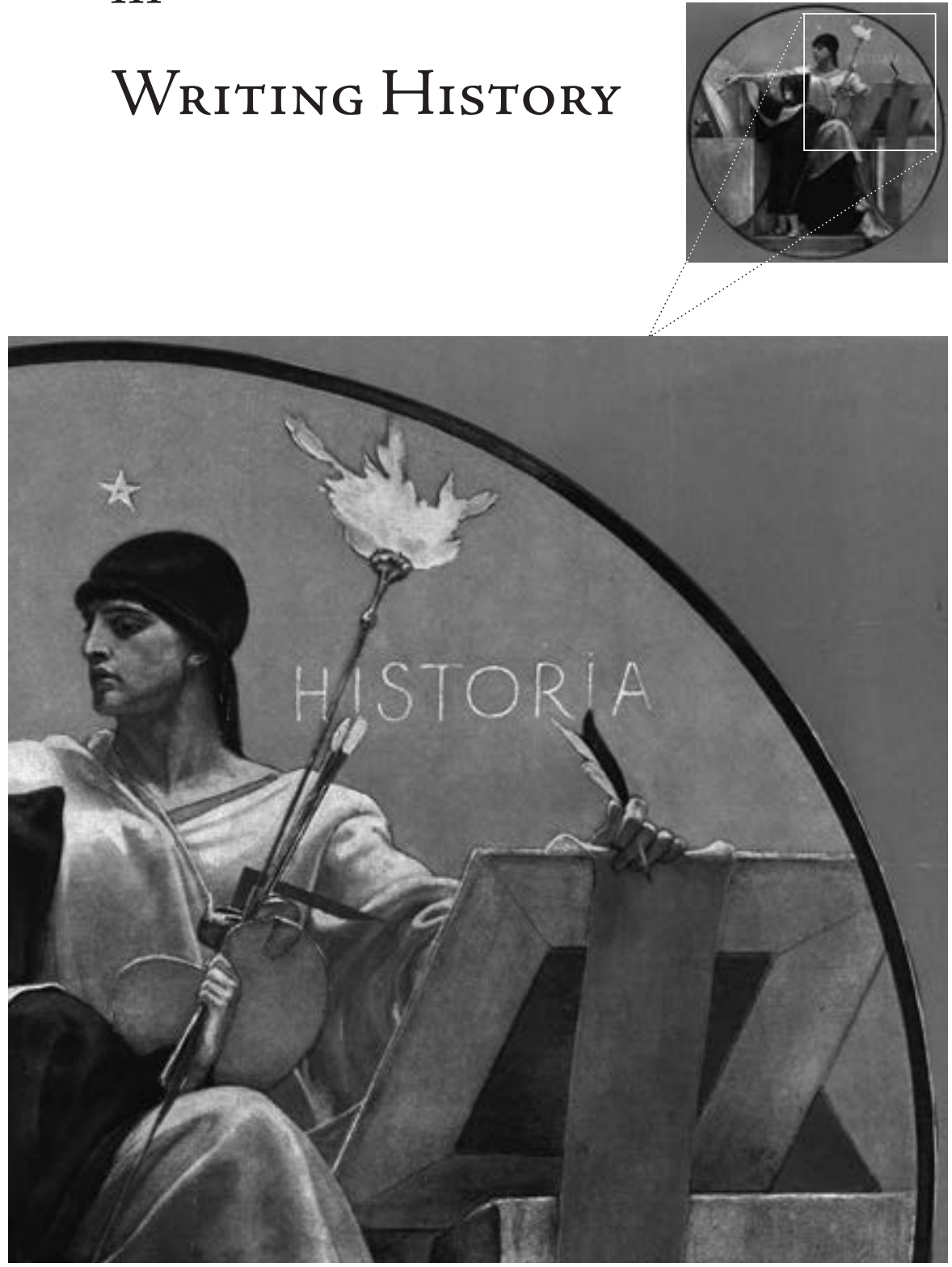



\title{
3+I A Domestic Culture \\ The Mise-en-scène of Modern Historiography
}

\author{
Jo Tollebeek
}

At the conclusion of her autobiographical sketch published a few years ago, the Italian historian Ilaria Porciani, living in Florence but working in Bologna, writes:

Like many Italian historians, I am a commuter. The saying that every Italian academic carries a train timetable could not be truer. The conversations which take place on Eurostars turn out to be a sort of extension of faculty or department meetings and [...] this is usually the right time not only to complain about the new reforms and shortage of money but also to discuss a new book or a project. [...]

But I also think that I have also been a 'passeur' as the French would say: a traveller between different cultural traditions and countries. I have often missed the stability of a single school and a linear track. But I have enjoyed the much richer liberty of diverse approaches.

Since I have spent and spend so much time commuting and travelling, maybe it will not come as a surprise that I started this contribution on a plane and that I have continued to write it - like others of my work - at least partly on trains: so mobile is our historians' workshop nowadays. ${ }^{\mathrm{I}}$

'Self-Portrait of an Italian Historian as a Woman on the Train' thus seems to end in a world of placeless scholarship, where the historian, forever on the move, contemplates reality on the basis of 'the view from nowhere', to borrow the title of Thomas Nagel's well-known book from 1989. In what follows, the mise-enscène of modern historiography will be central, and by extension the culture of the humanities that speaks from this mise-en-scène. Historiography, as we will see, underwent a clear process of self-localization in its first phase of professionalization, between 1870 and I9I4. It was practiced at precisely identifiable places, in workshops with concrete, tangible practices. But just as Porciani's mobile workshop refers to a specific type of historiography - cosmopolitan, eclectic, 
open to innovation - so the workshops of the decades around 1900 also represent specific historiographical ideals. Hence the use of the term 'mise-en-scène': the discipline's locations are not chosen by chance, and are not neutral, but are meaningful sites at which the production of knowledge - in this case historical knowledge - responds to or is supposed to respond to specific ambitions. They are real locations, but also counterlocations, and sometimes virtual locations, too, shaped by dreams whose conversion into reality lies in the future. Their culture defines modern historiography, and mutatis mutandis the other humanities disciplines, too - archeology, art history and musicology, literary studies, philology and linguistics, philosophy and theology. Even the mind has its fixed abode.

Three iconic places will be examined here: the attic room or garret of the university building, the study in the professor's home, and the laboratory. Together, they form the disciplinary landscape in which modern historiography took shape around I900, a 'geography of scientific knowledge', in David Livingstone's formulation. ${ }^{2}$ In these garrets, studies and laboratories, historical research took shape, but what was more, a form of education was created there whose purpose was to make a nouvelle histoire possible. The web of meaning that was woven around these places was extensive: they were about a rejection of showmanship and a yearning for authenticity, about masculine detachment and family involvement, about prestige and progress, and above all about a desire for domesticity and the nostalgia that this ultimately entailed.

\section{The garret: The rhetoric of modesty}

The historical discipline in the late nineteenth century underwent a process of transformation into a science and professionalization: it acquired a method and became a profession. These changes were coupled with academization. This meant that from around 1870 the universities - and no longer the societies, traditional academies or clubs - became the hauts lieux of the historical discipline, and that from then on, the tone in the profession was set by university professors. The situation was similar in the other humanities disciplines, too. It was not just that the number of professors grew in these disciplines: the universities also exerted a greater power of attraction in the subject. In literary studies, for example, writers and critics who not long before had denied the professors any say in literary questions sought to secure a university chair of their own after 1900. At the same time, the university became a place of research: the professors increasingly started to focus on research, specializing and forming research groups or schools. In the natural sciences, this led to a new and powerful paradigm: laboratory science. 
In the historical discipline, this research-oriented development assumed its most explicit form in - as is well-known - the seminar, which claimed a position alongside and opposite the traditional lecture. ${ }^{3}$ In the lecture, an overview of (part of) the past was offered ex cathedra. This form of instruction did not disappear after 1900. It has indeed been pointed out recently how tedious the basis of many of these lectures was: the reading out of the same lecture notes time and time again. ${ }^{4}$ The seminars offered an alternative, however. Here, the students were trained as independent researchers by discussing a specific historical problem together on the basis of a number of documents selected by the professor. They learned what source criticism was and received training of a highly technical nature.

The contrast between these two educational forms was accentuated by locating them in different places. This mise-en-scène was the work of those who championed the further spread of the 'practical classes'. One of these was the Ghent professor Paul Fredericq. This specialist in the history of the Inquisition was to acquire international fame primarily as a result of the reports that he published in the I880s and I89os on his tours of German, French, British and Dutch universities. For Fredericq's European and American readers, these Notes et impressions de voyage were a showcase in which they could see which practices were in the ascendancy in modern historiography. ${ }^{5}$

Fredericq found the traditional lectures most obviously represented in the large auditoria and amphitheaters, with their podiums and lecterns, in the Collège de France in Paris. ${ }^{6}$ These were stately and imposing lecture halls, in keeping with the majestic, sweeping vistas that were presented there. Listeners would walk in and out from hall to hall, just as they went from chapel to chapel in churches. They were not just students - quite the contrary: the majority of the audience for these lectures consisted of tourists, persons of independent means and passersby, noted Fredericq. Nor did he hesitate, in a display of misogyny, to comment that quite a few of the lectures mainly drew women: beaucoup de dames et même un certain nombre de prêtres. ${ }^{7}$ But the Collège de France did not have a monopoly on such practices. In Berlin, Heinrich von Treitschke gave his famous Vorlesungen in the so-called Barakken-Auditorium, which could seat no fewer than seven hundred and fifty listeners (and the hall was too small even so). ${ }^{8}$ In England, where the 'German' seminars did not enjoy much popularity, the lectures to large audiences were laconically justified with a reference to the goal of education: 'We make not books but men'.

How different the situation was with the seminars. They were often held in small rooms in the university library because it was easier to have access to the necessary study material there. Fredericq himself originally chose such a location for his 'practical classes'. But he knew that the premises were often even more cramped. In Paris, he had to climb the stairs of the Sorbonne to finally reach the fourth floor. There, below the roof, the École Pratique des Hautes Études organ- 
ized its seminars, in small, low-ceilinged rooms, presque des mansardes. Fredericq described the chambrettes in detail: how they were packed from top to bottom with books, the dark furniture and simple inkpots, the white porcelain stove, the view of the Sorbonne's peaceful cour, the clock. In 1898 his Ghent colleague, Henri Pirenne, similarly recalled the cours pratique that he had attended under Godefroid Kurth in Liège: a small room on the second floor of the university building, with a stove, a few decrepit benches, one chair. There had been a view of the garden of the École des Mines, with its old machinery, and of the Meuse, 'from which the whistle-blasts of the steamboats rose. ${ }^{\prime \prime}$ Simple but picturesque places, then, where time was forgotten: 'The business was carried out', said Fredericq, 'like all important business: modestly, without any fuss, in a small corner of the university.'

The garret versus the amphitheater - the rhetoric of modesty that permeated the Paris and Liège vignettes revealed a vision of science, didactics, 'epistemological style' (the term is borrowed from Michèle Lamont ${ }^{12}$ ) and ethics. Whereas the lectures were presented as events with all the features of that spectacular amusement for which there was such a taste in the fin-de-siècle, ${ }^{13}$ and where the ultimate aim was pseudo-science, the seminars appeared to be humble contributions to 'true' science: serious work was done there, without disruption by outsiders to that science. The didactics differed just as much: whereas the panoramic overviews were presented in the amphitheaters in a monologue with beguiling rhetoric, knowledge was sought in the garrets in discussions between the professor and the students (although the reality did not always live up to the ideal, with tongue-tied students who could not resist applauding the professor as though they were in an auditorium).

There were still more differences. The proceedings in the amphitheater revealed a hierarchical world in which scientific authority was only conferred on whoever stood on the podium or behind the lectern. In the roof of the university building, by contrast, the professor sat in the middle of his students, not on a raised platform. As a matter of principle, he showed respect for what others had to say, for knowledge was not regarded as a given or as immutable; it originated in discussion, and even the students' work represented fully valid contributions to this. What the students learned there for themselves was not an elaborate method (although this was codified in textbooks toward the end of the nineteenth century ${ }^{14}$ ). Rather, they learned a trade, with skills, ways of doing things and best practices. However, these were guided by certain epistemic virtues: suspicion toward the transmitted documents, criticism, impartiality. At the same time, an ethic was acquired - a bourgeois ethic: science was a matter of self-discipline, steadfastness, character.

The garrets were sites where the historical discipline renewed itself. By stressing the modesty of these places, Fredericq and his allies emphasized the revolutionary character of what was conveyed in the seminars. In the mansardes, on the margin, a break was made with the establishment. 


\section{The study: The rituals of intimacy}

Much of what took place in the university garrets (or in the side-rooms of university libraries) could be found in intensified form in the place that was naturally perceived as more personal: the professor's own home, and the room that was regarded as the heart of that home, the study. For virtually all historians around 1900, the study was still the self-evident place where they carried out their research; despite the academization of the historical discipline, it remained a community of 'home workers'. In fact, the professor's house often had an extensive library and gave its owner the atmosphere that he apparently needed for his work. Anyone who sought routine and regularity could find it there: both the Leiden professor P.J. Blok and Pirenne would withdraw at set times every day into the cabinet de travail of their town house to write their great national history. ${ }^{15}$ Others found peace and quiet in the study of their dwelling located out of town. Johan Huizinga, who was a professor in Groningen, expressed his exultation to a friend after moving out of the town in I9II: 'From my study I can see for miles; all the way to the Himalayas if I wish.' ${ }^{16}$

The study was the Holy of Holies. So it had been for a long time already. When, in around 1500 , a separate museum or studiolo (to quote the Latin terms for the room) was defined in the scholar's house for the first time, its express purpose was to guarantee the scholar a detached existence: the study was a protection against the intrusion of worldly affairs into his life. This was no longer so starkly expressed in the nineteenth century, but the longing for separation was never far away. It could also apply to whole enterprises: the gelebrte Gebilfe of the Monumenta Germaniae Historica, the great German series of editions, worked under the direction of both Georg Heinrich Pertz and Georg Waitz in the director's official home in Berlin; the former even regarded the Monumenta as sein Hausvermögen. ${ }^{17}$

Modern historiography too was thus - from a research viewpoint - still a domestic discipline. This distinguished it (and the other humanities disciplines) from the natural sciences, which in the course of the nineteenth century had generally become laboratory sciences, located outside the home. To be sure, Victorian biographers succeeded in 'domesticating' the heroes of science, such as Isaac Newton: as depicted in their history of science, in some cases they went from being godlike geniuses to domestic figures in dressing gowns, with children playing around them. ${ }^{18}$ But the natural sciences were only really domestic - biology among the Cambridge geneticists around 1900 being a case in point $t^{19}$ - when their research was regarded as too marginal to be eligible for the 'ordinary' infrastructure to be allocated to it, and in such cases women too started to play a more than 'ordinary' role in the design and execution of the 
research. Humanities disciplines such as history were domestic as a matter of principle rather than from necessity; their house, as was said about the professors of Leiden in the late nineteenth century, was their bulwark. ${ }^{20}$ This was not completely self-evident, for since Leopold von Ranke historiography had to a significant extent borrowed its identity as a discipline from the archive work that it performed. This had turned it too into a sometimes adventurous fieldwork discipline. ${ }^{21}$

This domesticity recalls the long history traced out by Gadi Algazi: How could the scholar, who since the late fifteenth century had exchanged his life as a bachelor for a householder's life (a Prozess der 'Familiarisierung'), maintain his status as a scholar ${ }^{22} \mathrm{Or}$, from another perspective: What was the position of the woman - the wife or in some cases the sister - in this constellation? The outcome was usually clear: the woman was, like the maid who was always present in the professor's home, denied access to the study - the Holy of Holies. A wife 'who will never invade my study' was how it was put by the young English historian John Richard Green, preparing for marriage. ${ }^{23}$ So what was expected of the woman? Fredericq, who had remained single and lived with two sisters, associated them with the hearth of his home: the woman created the possibility for the man - for the historian - to work comfortably. ${ }^{24}$ The romantic ateliers in which man and wife worked closely together, as had been the case with Jules Michelet and Athénaïs Mialaret, seemed to have no further place at the end of the nineteenth century. ${ }^{25}$ But the wives of Blok, Pirenne and indeed of Green - his wife was Alice Stopford, who would also publish herself - in fact often did more than tend the hearth: it was not uncommon for them to take on the task of preparing their husband's manuscript for printing. ${ }^{26}$

All of this was connected with the research that the historian performed. However, the professor's house was also a place of instruction in the decades around 1900 - instruction that was far harder to separate from research at that time than was the case later on, as Mauro Moretti has recently emphasized on the basis of, among other sources, Friedrich Meinecke's memoires ${ }^{27}$ In other words, historical instruction also had a domestic character. This was less true of the lectures, although these too were given by some professors at the end of the nineteenth century in their own home - in a specially equipped 'lecture room. ${ }^{28}$ Above all, it was true of the seminars. This was how they had originated in Germany: Ranke, Johann Gustav Droysen and Waitz had set up their historische Uebungen (exercitationes historicae) as private Gesprächszirkel and received the students who attended them in their own Studierzimmer. ${ }^{29}$ Their example was followed: toward the end of the nineteenth century, professors of all descriptions left the library rooms and garrets to hold their seminars in their own homes. In Paris, Gabriel Monod taught students the métier in an apartment - a modest one of course, for 
the same rhetoric applied - which was also referred to as an offshoot of Waitz's seminar. ${ }^{30}$ In Belgium, Kurth and Fredericq now also received students at home. The image arose of a European chain of houses and apartments in which documents were discussed.

In this domestic setting, the seminars gained a specific, domestic character ${ }^{31}$ The number of students admitted to the classes in the professor's house was small. It was a group that regarded itself as the elect, and could experience the sensational proximity of the discipline in the study: on Waitz's desk the proofs of the next volume of the Monumenta lay ready. The room emanated warmth and life. The intimacy was reinforced by the manner in which the study was fitted out for the seminars. The students took their places around a long table, in the halflight, between the packed bookcases. The documents to be discussed - whether originals or copies - lay on the table, together with the most important reference works and several folio editions of sources. In this intimate setting, the discussion got underway, always remaining informal.

Simply by virtue of the place where it occurred, the seminar was a private affair: privatissime, as it was called in Berlin. This privacy was confirmed in many ways. The members of the company became acquainted with the secrets of the craft in weekly sessions (séances) in a private room. They were inducted into the discipline. Religious terms were often employed: they were 'novices', who were 'initiated' (among other things into the rules of source criticism) and underwent a rite de passage. Together, they formed a 'brotherhood', a company that shut itself off from the world. The creation of the group's own history was another element of this: after each meeting, a previously designated member of the group recorded in detail what had been discussed and what had taken place. The scientific work was also combined with forms of sociability: there was drinking and smoking, and a camaraderie arose (of an exclusively masculine character), which could be developed further on excursions. Thus the aspiring historians were also socialized. In a domestic culture, with the professor as role model, they were taught not just techniques, but also values.

Modern historiography was a domestic science, practiced comme en famille, as the metaphor had it. ${ }^{32}$ The setting in which many of the seminars took place also made it possible to understand the image literally: the students came into contact with the professor's family. The boundary between private and public was not drawn sharply. The mere fact that the seminars were arranged in a private house which also acquired public significance through the instruction that was given there created an ambiguity. But if one passed in the professor's house from the study room to the living room, this was a transgression. Nevertheless, such a transgression was not uncommon. After a visit to the study (whether or not in connection with a seminar), a student might be invited into the living room. 
There, he could be introduced to the professor's wife, converse with her or listen to her playing the piano, or dine with other guests. ${ }^{33}$ In this convivial atmosphere, further socialization took place - in a family setting.

Even those who did not have the opportunity to do this could be included in what has been referred to as the professor's 'extended family. ${ }^{34}$ For example, Ranke was a Doktorvater who very explicitly regarded all his students as family members. ${ }^{35}$ The relationship between teacher and pupil could indeed be close to that between father and son. This could be expressed in dramatic ways. When Pirenne lost his favorite pupil Guillaume des Marez in I93I, he said in his funeral address: 'It is monstrous that a father has to survive his son, just as that a professor survives his student'. ${ }^{36}$

In this 'extended family', the professor acted as mentor and patron. He placed his pupils in the professional field (usually in education or the world of archiving), and launched them in their academic career (by opening the doors of the new academic journals to them). As paterfamilias, he also felt responsible if they (or their family members) experienced financial or other adversity. For their part, the protégés were expected to show affection and respect for the paternal professor - and loyalty. They were supposed to belong to their patron's 'party'. That 'party' rarely if ever had a precise organizational structure or an elaborate ideology (on methodological issues, for example). It was unified not around a program, but around a figure. It formed a clan. Clearly, then, communities in modern historiography (and by extension in the humanities in general) did not just arise on rational grounds. It was often a matter of honor and loyalty. This sometimes made the historians a turbulent family. ${ }^{37}$

The image of the family - in a metaphorical sense - was also apt for describing a variety of aspects of discipline- and community-building in historiography (and the humanities). Historiography acquired - like other subjects - fathers of the discipline, usually in a context of national historiography (for example, Robert Fruin became 'the father of Dutch historiography'). ${ }^{38}$ The celebrations of anniversaries or retirements were characterized as 'family celebrations'. The photographs of colleagues from home and abroad that were collected and hung up in the study or in the university building's seminar room in order to demarcate the discipline's space served as 'family portraits'. In the seminars themselves, finally, the students were constantly informed of all kinds of 'family news. ${ }^{39}$ This family atmosphere had also found its way into the laboratories, incidentally. There too, the head of the community could act as a true paterfamilias, family ideals could prevail and suitable photographs in a pantheon could suggest the existence of a family community that extended far outside the laboratory. ${ }^{40}$ 


\section{The laboratory: The representation of modernity}

That the domesticity that was so closely bound up with the humanities, with its complex rituals of intimacy, was also able to become an element of the laboratory culture in the natural sciences, is one thing. But the reverse can be documented even more tellingly: the humanities culture of domesticity was affected by the existing culture of the natural sciences and was weakened by it. Already by the end of the nineteenth century, instruction in the professor's home - both lectures and seminars - was being referred to by the historians themselves as a vieille tradition, an antique usage. ${ }^{41}$

Remaining in the professor's study, for teaching purposes at least, came to be regarded, for various reasons, as an anatopism. The first of these reasons was simple: the growing number of students and the fact that seminar exercises had been made an obligatory part of the historian's training made it harder to receive the students in the professor's private study. A second reason was more subjective in nature: it was the desire to be modern. The proponents of the seminars - who viewed the showpieces in the amphitheaters with horror - felt themselves to be an academic elite, an aristocracy, leading a group of selected pupils. But they also wanted to be an avant-garde, members of a movement in keeping with the spirit of the age. In this progressivist discourse there was no room for antiques usages.

Thus the return to the university buildings was embarked upon. But this time, it was not the mansardes that were sought out. The representation of modernity found its focus in the laboratories in the sciences and medicine, the disciplines that by around 1900 were starting to make an ever stronger mark on the university landscape. An historian such as Fredericq was very familiar with these laboratories: one of his brothers had a brilliant career at the university of Liège in experimental physiology and biochemistry, and moved into a new Institut de Physiologie in the late I880s. These were prestigious institutions. Among the historians (and other practitioners of the humanities), the desire grew for something comparable. In their focus on the practice of historical research, could the seminars not also be seen as laboratories?

Again, it was the German historians who took the lead, just as they had done in the I830s when Ranke had established the first bistorische Uebungen. Now they - or some of them at any rate - called for institutionalized seminars, where with the government's financial support properly equipped rooms could be fitted out for practical instruction in history. The term 'seminar' now began to be used of these institutions rather than of the associated form of instruction. ${ }^{42} \mathrm{It}$ was Heinrich von Sybel, a pupil of Ranke and professor in Munich, who was the first to establish such a 'laboratory': with the Bavarian government's support, 
in 1856 he was able to create a fixed infrastructure for his practical instruction. When he was appointed at Bonn several years later, a seminar was established there, too. But it was above all Carl von Noorden, who between I868 and his death in I883 was successively professor in Greifswald, Marburg, Tübingen, Bonn and Leipzig, that spread the system of 'state seminars'. The most modern complex was built in Leipzig. It comprised five rooms: a study for the professors, a room in which atlases and paleographical and epigraphical albums were kept in drawers, and three rooms for the students, each of whom had his own desk and where the necessary reference works were also available. The complex was open until late in the evening. The professors called in every day to guide the students in their work.

Leipzig became a model, including in the survey presented by Fredericq, who himself attempted to institutionalize his 'practical courses' in Ghent and obtain an annual government subsidy for them. Eventually, through his efforts, a wooden building was erected near the university's Aula several years before the First World War. It was not much. But the optimism did not waver: the ArbeitZimmer as designed by Von Noorden would become the rule in the future, it was said. It was an optimism borne along by a desire for modernity. The German 'state seminars' offered work premises that were hygienic, well heated and well lit (as laboratories). Fredericq contrasted these contemporary rooms in his report with the étroites chambrettes and mansardes misérables in which the students usually lived. But the difference with those other mansardes also claimed attention: the garrets in the roof of the École Pratique des Hautes Études, which were praised for their irreplaceable style in the same Notes et impressions de voyage by Fredericq.

But not everyone was as enthusiastic about the efforts to institutionalize the Uebungen in modern seminars of this kind. Ranke himself refused to give his exercitationes (which he was also unwilling to call'seminars') anywhere other than in his own study. It was his favorite pupil Waitz who, in 1867 , on the occasion of a celebration of his teacher, summed up the points of criticism: in the new seminars, permanent guidance from the professors took away from the pupils any chance of autonomous development, the increase in scale was associated with mediocrity, the financial support provided to the students threatened to make greed a reason for starting such a course of education. Ranke and Waitz only wanted a few students, men with a true vocation, who were not motivated by financial gain. These men of character could only develop in a private education, not in the factories of Von Noorden that were being promoted. It showed how much the critics were living in the past, with a discipline that had not yet been corrupted by an industrial habitus and with historians who had not yet become Beamte. ${ }^{43}$ They clung to their domesticity like the Victorian men described by John Tosh in 
A Man's Place (1999): the 'hardness' of the world of work outside the home made them see their own home as a place of peace, love and comfort, where higher morals held sway, yet everyone could be themselves. ${ }^{44}$ Ranke and Waitz felt alienated from the new educational world - and turned inwards in order to find themselves there alone.

This uneasiness would persist. It carried on for generation after generation. It led to a broad nostalgia for places of science that no longer existed or had been changed beyond recognition, and with these places, it was sadly noted, a scientific culture was disappearing too. The Austrian historian Hans Pirchegger recalled in his autobiography, written in 1950 , how the changes had also reached Marburg, where he had studied. In I895, a new university building had been opened, where the historians and geographers had more space, proper lighting had been introduced and the seminar library had become more accessible. But, Pirchegger added, the old feeling of homeliness - Gemütlichkeit - had never returned. ${ }^{45}$

With the First World War came irreversible changes. The professors' prosperity decreased, as did their status. ${ }^{46}$ Domesticity now completely disappeared from the world of university education, including in the humanities. There was no longer any teaching at home. Examinations formed one exception to this. In some countries and for certain groups, these were still taken in the professor's house. The democratization of education and the advent of the mass university in the I960s would put an end to this too. The old custom of the professor inviting students to tea on a Sunday and receiving them together with his wife had long since vanished. ${ }^{47}$

\section{Epilogue}

In the years 1870-1914, historians sought and found their ideal discipline in university garrets, in studies in private homes and in seminars that were modeled on natural science laboratories. These were not empty places, nor were they undisputed. They played a crucial role in the mise-en-scène of the professional historical discipline, which in this way achieved precise characterization: no showmanship, fed by intimate discussions, a modern setting. This last point pushed the domesticity of the discipline, academized though it was, into the background, at least on the teaching front. Because this remained a remarkable constant: as researchers, the historians continued for many more decades to be 'home workers'. Their study at home remained for them 'the navel of the world'; their room in the university was in fact just a subsidiary office. As a result, public and private remained interconnected in the university world for a long time. ${ }^{48}$ 
But this too came to an end. After the Second World War, the presentism in historiography became more pronounced. The historian was expected to engage in the great social projects that were under construction. ${ }^{49}$ He could be an armchair scholar no longer. The rector of the University of Amsterdam reassured his listeners: the modern professor, it was said in 1948, was no longer 'the absentminded professor, who from his peaceful study would from time to time dispatch a new section of his life's work into the light of day'50 As a result, the study fell into disrepute even as a place of research: it symbolized a private, asocial discipline. Leave that room!, was the insistent advice.

But what could the historian do out in the wide world? 'If he leaves the house of his subject and goes out into the street, the winds of doubt and contradiction confront him, noted an ironic commentator a quarter of a century ago. ${ }^{51}$ For Porciani it was therefore clear: the contemporary historian is a passeur, and in none of the old places does she still feel at home.

\section{Notes}

I I. Porciani, 'Self Portrait of an Italian Historian as a Woman on the Train', in I. Agárdi, B. Waaldijk, and C. Salvaterra (eds.), Making Sense, Crafting History: Practices of Producing Historical Meaning (Pisa, 2010), I52.

2 D.N. Livingstone, Putting Science in Its Place: Geographies of Scientific Knowledge (Chicago, 2003).

3 G. Lingelbach (ed.), Vorlesung, Seminar, Repetitorium. Universitäre geschichtswissenschaftliche Lehre im historischen Vergleich (Munich, 2006). For the origins of the research seminar': W. Clark, Academic Charisma and the Origins of the Research University (Chicago/ London, 2006), I4I-I82.

4 For the procedure at the University of Amsterdam in particular: P.J. Knegtmans, 'Liefde voor de wetenschap. Het negentiende-eeuwse universitaire onderwijs en de scheiding tussen wetenschappelijke vorming en wetenschappelijk beroepsonderwijs', in L.J. Dorsman and P.J. Knegtmans (eds.), Van Lectio tot PowerPoint. Over de geschiedenis van het onderwijs aan de Nederlandse universiteiten (Hilversum, 20 I I), I3-I6.

5 For Fredericq's own efforts in this area: J. Tollebeek, 'Pirenne and Fredericq: Historiographical Ambitions around I900', in M. Boone, C. Billen, and S. Keymeulen (eds.), Henri Pirenne (1862-1935): A Belgian Historian and the Development of Social and Historical Sciences, thematic issue of Belgisch Tijdschrift voor Nieuwste Geschiedenis/Revue belge d'Histoire contemporaine 4I.3-4 (20II), 383-409.

6 For the following, see: J. Tollebeek, Fredericq E Zonen. Een antropologie van de moderne geschiedwetenschap (Amsterdam, 2008), 5 I-58.

7 P. Fredericq, L'enseignement supérieur de l'histoire. Notes et impressions de voyage. Allemagne - France - Ecosse - Angleterre - Hollande - Belgique (Ghent/Paris, I899), 54.

8 See the anecdote in W. Ahrens, Gelebrten-Anekdoten (Berlin/Schöneberg, I9I I), 74-75.

9 Quoted in M. Moretti, 'A New Community of Scholars: The University Professors at Work', in I. Porciani and J. Tollebeek (eds.), Setting the Standards: Institutions, Networks and Communities of National Historiography (Basingstoke, 2012), 298. 
Io H. Pirenne in A Godefroid Kurth, professeur à l'Université de Liège, à l'occasion du XXVme anniversaire de la fondation de son cours pratique d'bistoire (Liège, [I898]), I57.

I I P. Fredericq in A Godefroid Kurth, I74.

I2 M. Lamont, How Professors Think: Inside the Curious World of Academic Judgment (Cambridge, MA/London, 2009), 54 .

I V.R. Schwartz, Spectacular Realities: Early Mass Culture in Fin-de-Siècle Paris (Berkeley/ Los Angeles/London, I999).

I4 See inter alia R. Torstendahl, 'From All-round to Professional Education: How Young Historians Became Members of an Academic Community in the Nineteenth Century', in Een goede historicus? Negentiende-eeuwse idealen en praktijken, special issue of Leidschrift 25.I (2010), I7-3I.

I5 See J. Tollebeek, 'Exegi Monumentum: The Great Syntheses of National History', in Porciani and Tollebeek (eds.), Setting the Standards, I 20-I2 I.

I6 J. Huizinga, Briefwisseling, vol. 1: 1894-1924, ed. L. Hanssen, W.E. Krul, and A. van der Lem (n.p., I989), I2 I, also quoted in Idem, Johan Huizinga. Leven en werk in beelden $\mathcal{E}$ documenten (Amsterdam, I993), I24.

I7 H. Fuhrman, 'Sind eben alles Menschen gewesen'. Gelehrtenleben im 19. und 20. Jahrbundert dargestellt am Beispiel der Monumenta Germaniae Historica und ibrer Mitarbeiter (Munich, 1996), 36-40 and 45-49 (for the gelebrte Gebilfe: 77-90).

I8 See the example in L. Daston and P. Galison, Objectivity (New York, 2010), 2 I6 and 2I8219.

I9 M.L. Richmond, "The "Domestication" of Heredity: The Familial Organization of Geneticists at Cambridge University, I 805-I 9 Io', Journal of the History of Biology 39 (2006), 565-605. W. Otterspeer, De wiekslag van bun geest. De Leidse universiteit in de negentiende eeuw (The Hague, I992), 395-396.

2I K.R. Eskildsen, 'Leopold Ranke's Archival Turn: Location and Evidence in Modern Historiography', Modern Intellectual History 5 (2008), 425-453. See also P. Müller,'Doing Historical Research in the Early Nineteenth Century: Leopold Ranke, the Archive Policy, and the Relazioni of the Venetian Republic', Storia della Storiografia 56 (2009), 8I-103; and, more in general, P. Huistra, H. Paul, and J. Tollebeek (eds.), Historians in the Archive: Changing Historiographical Practices in the Nineteenth Century, special issue of History of the Human Sciences 26.4 (2013), 3-148.

22 Inter alia G. Algazi, 'Scholars in Households: Refiguring the Learned Habitus, I480I550', Science in Context I 6 (2003), 9-42; and Idem, 'Geistesabwesenheit. Gelehrte zu Hause um I 500', Historische Anthropologie. Kultur - Gesellschaft - Alltag I 3 (2005), 325-342.

23 Quoted in B.G. Smith, The Gender of History: Men, Women, and Historical Practice (Cambridge, MA, I998), 79 .

24 See Tollebeek, Fredericq E Zonen, 99-I09.

25 Smith, The Gender of History, 83-I02. For a case study: J. Tollebeek, 'Writing History in the Salon Vert', Storia della Storiografia 46 (2004), 35-40.

26 See, for example, S. Keymeulen and J. Tollebeek, Henri Pirenne, Historian: A Life in Pictures (Leuven, 20I I), 29-30.

27 Moretti, 'A New Community of Scholars', 29I-3I2, especially 293-295. On such memoires: J.D. Popkin, History, Historians, and Autobiography (Chicago / London, 2005).

28 For example, the Leiden professor Robert Fruin did this; see J. Tollebeek, 'Fruin's Aristocracy: Historiographical Practices in the Late Nineteenth Century', in T. van Kalmthout and H. Zuidervaart (eds.), The Practice of Philology in the Netherlands 1800-1900, forthcoming. 
29 Inter alia K.R. Eskildsen, 'Leopold von Ranke, la passion de la critique et le séminaire d'histoire', in C. Jacob (ed.), Lieux de savoir. Espaces et communautés (Paris, 2007), 462 482 .

30 F. Hartog, Le XIXe siècle et l'histoire. Le cas Fustel de Coulanges (Paris, I988), 98.

3 I See Tollebeek, Fredericq E Zonen, 86-99.

32 P. Fredericq, 'Lorigine et les développements des cours pratiques d'histoire en Belgique', in A Godefroid Kurth, 66-67.

33 For a case study see: J. Tollebeek, Mannen van karakter. De wording van de moderne geesteswetenschappen (Amsterdam, 20I I), 40-46.

34 D.R. Kelley, Fortunes of History: Historical Inquiry from Herder to Huizinga (New Haven / London, 2003), I74-I75.

35 W. Weber, Priester der Klio. Historisch-sozialwissenschaftliche Studien zur Herkunft und Karriere deutscher Historiker und zur Geschichte der Geschichtswissenschaft 1800-1970 (Frankfurt am Main/Bern/New York, I984), 216. For the ambiguity of the relationship between the Doktorvater and his (subordinate) pupil, see P. Bourdieu, Homo Academicus (Cambridge/Oxford, I988), 88.

36 B.D. Lyon, 'Guillaume des Marez and Henri Pirenne: A Remarkable Rapport', Belgisch Tijdschrift voor Filologie en Geschiedenis/Revue belge de Philologie et d'Histoire 77 (I999), I076, and C. Billen and M. Boone,'Pirenne in Brussels before I930: Guillaume des Marez and the Relationship between a Master and His Student', in Billen and Keymeulen (eds.), Henri Pirenne (1862-1935), 459.

37 For an example see: J. Tollebeek, 'A Stormy Family: Paul Fredericq and the Formation of an Academic Historical Community in the Nineteenth Century', Storia della Storiografia 53 (2008), 58-72.

38 See inter alia H. Paul, 'Voorbeeld en voorganger. Robert Fruin en Godefroid Kurth als vaders van de geschiedwetenschap', Bijdragen en Mededelingen betreffende de Geschiedenis der Nederlanden/The Low Countries Historical Review I26 (201 I), 30-53, and idem (ed.), Fathers of History: Genealogies of the Historical Discipline, thematic section in Storia della Storiografia 59-60 (2011), 225-293.

39 Tollebeek, Fredericq \& Zonen, 67, I74-I86 and I93-I99.

40 Inter alia, T. van Bosstraeten, 'Dogs and Coca-Cola: Commemorative Practices as Part of Laboratory Culture at the Heymans Institute Ghent, I902-I970', Centaurus 53 (201 I), I-30.

4 I P. Fredericq, Notes et impressions de voyage, 46 and I79.

42 The following sketch is based on Fredericq, Notes et impressions de voyage, 44-47.

43 For this last: M. Daunton, 'Introduction', in idem (ed.), The Organisation of Knowledge in Victorian Britain (Oxford, 2005), I9.

44 J. Tosh, A Man's Place: Masculinity and the Middle-Class Home in Victorian England (London, I999).

45 N. Grass (ed.), Österreichische Geschichtswissenschaft der Gegenwart in Selbstdarstellungen (Innsbruck, I950), vol. I, 79. See also J. Tollebeek and I. Porciani, 'Institutions, Networks and Communities in a European Perspective', in idem and Tollebeek (eds.), Setting the Standards, 9. For the term 'Gemütlichkeit': B. Schmidt-Lauber, Gemütlichkeit. Eine kulturwissenschaftliche Annäherung (Frankfurt am Main/New York, 2003).

46 See the sketch in Moretti,'A New Community of Scholars', 29I-292.

47 See the example in M. Rietveld-van Wingerden, 'Jan Waterink als docent en vernieuwer van universitair onderwijs', in Dorsman and Knegtmans (eds.), Van Lectio tot PowerPoint, I I I-II 3. 
48 K. van Berkel, Academisch leven. Over geschiedenis, karakter en veerkracht van de Nederlandse universiteit (Amsterdam, 2009), 22-27.

49 See inter alia E. Witte, Voor vrede, democratie, wereldburgerschap en Europa. Belgische historici en de naoorlogse politiek-ideologische projecten (1944-1956) (Kapellen, 2009).

50 Quoted in P.B.M. Blaas, Henk Hoetink (1900-1963), een intellectuele biografie. Recht en geschiedenis (Hilversum, 2010), I26.

5I E.H. Kossmann, De Lage Landen 1780-1980. Twee eeuwen Nederland en België (Amsterdam/Brussels, I986), vol. 2, 372-373. 



\title{
3+2 History Made More Scholarly and Also More Popular
}

\author{
A Nineteenth-Century Paradox
}

\author{
Marita Mathijsen
}

The Game of the Goose (Ganzenbord) is the name of a traditional game with dice and pawns still played by many a Dutch family. Its popularity goes back to the Dutch Golden Age. You throw dice to get from field i to the winning field 63 . Along the way you surmount various obstacles - a pit, a thorn bush, or a churchyard may throw you back or get you stuck until somebody else's pawn lands in the same field, thus setting you free again. Some other fields assist your advance, e.g., you may throw a second time and thus keep moving your pawn ahead. I recently discovered a nineteenth-century variety of the Game of the Goose with pictures of historical events that determine both the obstacles and the chances for quick advance. If you move ahead to the picture for 1789 , 'Beginning of the Revolution', you must start the game all over again. If, by contrast, you land on the year 656 , 'Conversion of the Heathen', you receive a reward. This peculiar family game of I8I6 makes it crystal clear that history has become common property; it has been tailor-made without more ado for the historical aim it is meant to serve. ${ }^{1}$ We have here just one particular consequence of the changes that have meanwhile taken place in people's conception of the past. Ordinary people have learned to deal with history. This in its turn is a consequence of history having turned public. It is as if in the nineteenth century history has moved from the closed spaces of society halls and stately rooms of well-educated noblemen to the living room, no longer necessarily stately but just run-of-the-mill. History has become part of collective memory, thus stepping into public space.

Until far into the eighteenth century history is private cultural property, both materially and immaterially so. It may be present in public space, as with early buildings or ruins, but there is no sense of an added quality of historical patrimony. These are just early buildings, which may or may not be in actual use for some specific purpose. History is present in collective memory only where the locals look back upon something extraordinarily impressive, as, for instance, a large natural disaster. For the rest, the past is in the hands of specialists, of lawyers, 
of political and church authorities. It is being examined by narrowly confined, scholarly circles, united in societies or connected with the academy. Or history is being cultivated in the circles of amateur antiquarians, who are likewise united in societies, partly the same as those of the scholars. The boundaries between amateur and scholar, then, are not very strictly drawn. No chairs for the recent history of the fatherland do yet exist; in the academy everything is still directed toward antiquity and its classic texts. ${ }^{2}$

By the mid-eighteenth century, views of history begin to alter all over Europe. I shall distinguish between, and address successively, investigators of history of three different kinds, all of whom contributed to this large-scale development in their own way. Next, I show that these men began to tread other, so far unexamined historical territory, thus attracting another kind of audience. So we encounter trespasses wherever we look - of disciplines, of target audiences, and of objects of study.

We cannot assign a precise birthday to when this new vision of the past emerges. But it is easy to establish that an orientation toward history is growing everywhere. So much is certain that two editions of medieval poetry, which hit the British market almost simultaneously, have greatly furthered the breakthrough of history toward a large audience. In 1765 James Macpherson published his collected Ossian poetry, or rather Ossian forgery. Ossian became popular all over Europe, and even though some doubt about authenticity arose at once, belief in Ossian proved near-unassailable. In the Netherlands we may even speak of dual mystification. Willem Bilderdijk, the leading Romantic poet of his time, translated Ossian for the Dutch market, all the while asserting that his own translation was closer to the - imagined - original Gaelic documents, as he had allegedly consulted them in person! True, Derick Thomson demonstrated in 1952 that Macpherson really recorded authentic, orally transmitted songs and really inspected early texts, yet it remains true that the largest part of Ossian's work stems from Macpherson's own pen. ${ }^{3}$

Equally important is the definitely authentic collection of early ballads that Bishop Thomas Percy published in the same year 1765 under the title Reliques of Ancient English Poetry. The bishop had found a medieval folio manuscript in a friend's kitchen, where the maid used it to kindle the fire. He took it home, edited the ballads in a fairly rigid manner, supplemented them with a few from other sources, and had them published.

The seed of the semi-forger, Macpherson, and of the sincere amateur, Percy, spread over all of Europe. Now an interest arises in vernacular editions, and a scholarly editing discipline emerges, in which the attainments of classical philology are extended toward its vernacular counterpart. But they also influence the historical turn in literary fiction - between c. 1780 and c. 1840 one finds hardly 
an author anywhere in Europe who has not written a historical romance, play, or novel. Percy's ballads and Macpherson's Ossian have an impact on all historically oriented poets and novelists of Romanticism, from Goethe to Bilderdijk, from Coleridge to Walter Scott, from Lamartine to Victor Hugo.

Another revolution in the scholarly pursuit of history that may be dated to the period is less tightly connected to the Ossian/Percy hype. This particular revolution has more to do with Enlightenment thinking and with new standards being set for the sciences. In what follows I shall show how editors, literary authors, and historians explored new pathways at the end of the eighteenth and the beginning of the nineteenth century, with enduring results over the entire nineteenth century up to and including our own time.

\section{Scholarly standards for history writing, and an appeal to the imagination}

The emergence of scholarly standards for history writing Europe-wide is marked by Wilhelm von Humboldt's establishing in I8Io a university in Berlin. From all over Germany he attracted interesting historians. His prime showpiece was Barthold Niebuhr, a specialist in Roman history who immersed himself in the Reformation. Niebuhr wanted to write objective history: 'I seek to denude of all its foreign components a skeleton of fossil bones carelessly scraped together. ${ }^{4} \mathrm{He}$ was succeeded by Theodor Mommsen, who focused on reliable text editions all the while his primary end was to turn history into fine stories - a goal he attained so eminently that early in the twentieth century the effort even earned him the Nobel Prize for Literature.

The no less well-known historian Leopold von Ranke was also a professor at Berlin University. Ranke was concerned above all with establishing rigorous scholarly methods for the writing of history, which entailed a critical examination of the sources. As a born storyteller he managed to engage large groups of readers. He consequently regarded historiography as a profession halfway between the arts and the sciences. Strict methods should not stand in the way of the historian pleasing his readers in an aesthetic sense, too. ${ }^{5}$

The striving for objectivity demonstrated by Niebuhr, Ranke, and like-minded scholars made its way all over Europe. Lorraine Daston has pointed out that it is rather an anachronism to use the term 'objectivity' for the early nineteenth century ${ }^{6}{ }^{2}$ stick to the term nonetheless, in the sense of a striving for reliability. The requirement of objectivity became ever more compelling, and standards for a solid education in history kept being raised. Most universities had departments for ancient history but none for the history of their own country. These came 
into being in course of the nineteenth century. In the Netherlands this happened fairly late; the first chair in the History of the Fatherland (a term still in use today) dates from I83I. In France, a curriculum for archivists was set up in I82I. All over Europe source editions appeared, as indispensable groundwork for reliable historiography. France produced a series entitled Collection de Documents inédits sur l'bistoire de la France. German historians found each other in a series of medieval source editions entitled Monumenta Germaniae Historica, with for nationalist-Romantic epigraph Sanctus amor patriae dat animum - 'a holy love of the fatherland grants us the true spirit'.

This new way of writing history is linked up quite closely with a higher-profile innovation in historiography - the Romantic variety. Thomas Macaulay described his objective thus: "The perfect historian is he in whose work the character and spirit of an age is exhibited in miniature.? A historian such as Ranke, then, takes part in both currents: he insists on scholarly reliability but also wants to ascertain the real meaning and significance of past facts.

Around the I820s the 'nouvelle histoire' starts with authors like Prosper Amable Barante, Augustin Thierry, and Jules Michelet, all of whom come up against their eighteenth-century predecessors. Thierry goes even farther than the others. He accuses them of impoverishing the past - life and inspiration are lacking in their narratives. Also, their accounts fail to narrate the true history, which is one of citizens and their striving for liberty. The new history writing ought to be not conventional, not rhetorical, not solemn, but in constant motion. No one phrased these principles in finer words than Alfred de Vigny, who wrote that history is a novel, with the people for its author. ${ }^{8}$

A Romantic historian saw the past as a rhythmical alternation of periods of flourishing and of decay, with huge crises possibly occurring in between. They derived this insight, surely from the classics, but more specifically from the eighteenth-century Italian philosopher Giambattista Vico, whom Michelet translated into French. Johann Gottfried von Herder provided German history with a similar cycle. In this manner the French Revolution acquired a place in history, as it now became possible to compare it with earlier historical crises, such as barbarian invasions of the Migration Period (fourth to eighth centuries). The new historian to describe these processes was compared with Champollion, who deciphered Egyptian hieroglyphs. ${ }^{9}$

It was in line with such aims that Barante engaged in battle with the novelist Walter Scott - it should be possible to tell a captivating historical narrative without using fiction. Thierry insisted that the historian should set himself up as a judge of the past - an ideal of neutrality was not for him! He also pleaded for the writing of history, not only about all classes of society, but also for them, that is, for popularization. The most famous of all French Romantic historians, Jules 
Michelet, regarded his craft as literary writing of a special kind. His nationalism and the attention he paid to oppressed parties can still be detected in current thinking about French history.

In other countries, too, Romantic historians gained a firm foothold, which differed for each nationality. We already saw that in Germany the objective school of historians also counted in its ranks storytellers like Mommsen or Ranke - objectivity in a neat dress. England had its own great narrators, like Thomas Carlyle, who wrote with a passionate intensity hitherto unknown in historical writing, and Thomas Macaulay, in such splendid command of the rhetoric of the blackand-white story. In an essay entitled 'History' (1828) Macaulay voiced his annoyance over contemporary historiography:

While our historians are practicing all the arts of controversy, they miserably neglect the art of narration, the art of interesting the affections and presenting pictures to the imagination. [...] A history in which every particular incident may be true, may on the whole be false. ${ }^{10}$

He pointed out that official historians were given to filling hundreds of folios with state events, making no mention whatever of changes in customs and morals, of poverty and wealth, which have such an outstanding influence on humanity's sense of life.

So we are watching here a dual process of simultaneous exclusion and widening. In the universities history is turned into a scholarly craft, thus establishing itself as an academic discipline of a small number of practicians writing for small, specialized audiences. At the same time the Romantic historians attract a new, large public in their effort to draw the writing of history out of closed into public space. In so doing they widen the fields of history: no longer histories of princes and their wars but the history of common people, their customs and their ways of life.

\section{Editors as historians}

We have already seen that philologists were at the very forefront of the new interest in the past. Their numbers increase quickly, due among other things to the circumstance that during the French Revolution many medieval manuscripts come into public possession. With these editors, too, we witness a heightening of scholarly standards. But here, too, there is at the same time a noticeable movement toward larger audiences and toward other, more popular sources from the past. In the eighteenth century already, Herder was out to collect popular songs 
- an effort continued by Achim von Arnim and Clemens Brentano in a similar collection entitled Des Knaben Wunderhorn. Wilhelm and Jakob Grimm also swim with this current of attention paid to the people and its collective character. They collect fairy tales, chase medieval manuscripts, and set high standards for the scholarly reliability of their publications. On the basis of the attainments of classical philology, their friend Karl Lachmann, a philologist at the University of Berlin, develops a scholarly method for editions in the vernacular - a method which once again spreads all over Europe. Just as with the historians, there are among the editors men who aim for a large audience and who know how to play it. Other editors aim for scholarly specialization, thus narrowing the market. These two pathways merge with the Grimm brothers - fairy tales for the people, scholarly editions for the academy. ${ }^{\text {II }}$ This is true likewise for editions of medieval texts. Popular editions of texts like the Nibelungenlied, simple and cheap, may appear at the same time as scholarly editions of the same text, but now furnished with variant readings and with comments meant for fellow scholars. Widening takes place here as well. Previously the attention of philologists was directed primarily toward classic texts in Greek or Latin, or upon medieval chronicles in the vernacular, but now narrative texts in the vernacular may likewise boast scholarly attention.

\section{Literary authors as history writers}

Artists, too, felt at liberty to occupy themselves with history. Eighteenth-century experts had formed a closed world - a phenomenon to repeat itself when, by the end of the nineteenth, professionalization becomes predominant. But in between, during the first half of the nineteenth century, the most prominent historians are artists in search of a large audience. Authors like Walter Scott or Victor Hugo, or the painter Géricault, may well have contributed even more to people's historical awareness than, say, Ranke or Thierry.

Particularly remarkable is how literary fiction manages to colonize history. In one sense this is, of course, nothing new - seventeenth-century drama often used historical matter, and medieval tales frequently went back to the past as well. What is novel, is the expansion toward new genres, to the history of the fatherland, and also the massive scale on which all this takes place. Here Walter Scott is the pivot - both in his poetry and in his novels he breaks new ground, soon to be covered all over Europe. Narrative history, notably about the Middle Ages, becomes popular on a scale without any precedent.

Not that popularization, as also the move toward imaginative genres, fails to meet with objections of a theoretical nature. Journal articles point at the histori- 
cal novel as a hybrid genre, it has been called 'history in ballroom garb, ${ }^{, 2}$ and serious historians fear that readers' tastes will be corrupted by just imagined history, so that public interest in their objective history will wane. These risks look rather overdone in retrospect - it is impossible to find an era when there was a larger interest in history and when more novel functions for it were being developed than precisely the nineteenth century. Literary authors themselves argued that their imagination and their imitation of 'couleur locale' might well yield a better picture of an era than historians are able to produce.

In short, literary authors are responsible for history really turning into a popular possession. The professionalization of the historians might have led to history withdrawing further into the sphere of the academy. That this did not happen, is due to the evocative force of literary authors who, on a massive scale, began to write historical novels, drama, and poetry.

\section{Transgression and expansion}

I have now pointed at students of history of three kinds - the editors, who become true scholars but also seek to popularize; the historians, who professionalize and seek objectivity all the while taking a stance as romantic users of their historical imagination; finally, those literary authors who jump on board of the ship of history. Quite remarkably, these three distinct categories are often united in one person. Walter Scott was an editor, a historian, and a literary author, and hardly a failure in any of these respects. The same is true of Goethe, of Willem Bilderdijk, and of other leading public moralists. No problem is involved here in their own view - their border transgression requires no passport.

Disciplines are being transgressed, then, not only inside the humanities but also from the outside, as we need hardly doubt that the new standards for the cultivation of history by editors and historians have been influenced by innovations in the exact sciences of the Enlightenment. Take an editor like Lachmann, who constructed his stemma hypothesis in a manner deliberately similar to William Jones' language family tree, but possibly inspired as well by the analysis of earth strata in new fields like geology or paleontology.

The object of study is not only transcended, it is also expanded. If history ceases to consider nothing but battles and political events, there is much new history to be written. This is more than history from a novel point of view, it is also the writing of a history of a people, of its habits, its customs, its morals. This is what Macaulay meant when addressing the fake objectivity of official history writing: 
The circumstances which have most influence on the happiness of mankind, the changes of manners and morals, the transition of communities from poverty to wealth, from ignorance to knowledge, from ferocity to humanity - these are, for the most part, noiseless revolutions. Their progress is rarely indicated by what historians are pleased to call important events. They are not achieved by armies, or enacted by senates. They are sanctioned by no treaties, and recorded in no archives. ${ }^{13}$

Indeed, so he argues, historians extol political victories, even though these have as a rule worked out miserably for the population at large.

The Netherlands were at the forefront of such expanded attention to the fate of the people, with a considerable impact upon authors abroad. Between 1749 and I759 the amateur historian Jan Wagenaar published a twenty-one-volume History of the Fatherland, which was all about the past of the Dutch people and its struggle for liberation. As such, Wagenaar was far ahead of French historians when these, too, took up the theme of liberation. Abbreviated German translations of Wagenaar's tomes were read by both Goethe and Schiller. The latter used it for his drama Don Karlos (1787). In course of the nineteenth century popular culture habitually received a place in offical histories. ${ }^{\mathrm{I}}$ In the Netherlands the schoolmaster Jan ter Gouw retold in the second half of the century the history of the Dutch Golden Age, viewed from the perspective of everyday life of the common people, with attention being paid to toys, games, habits, the kitchen, signposts, expressions.

\section{Urgency}

We return to Europe and to the background of this all-round fascination with history. Its urgency is closely tied up with the rise of nationalism. Processes of nation formation needed history, and history flourished due to the demand that came from these very processes. Each emerging nation at the time sought to legitimize itself by an appeal to the past, be it mythologized or genuine. Large groups of people acquired a sense of history, as a large variety of media kept instilling in them the idea that history belonged to themselves. The public at large came under the spell of history through a process of ongoing appropriation.

Paradoxically enough, the urgency of history was stimulated likewise by an awareness that past and present are not of one and the same guise. A sudden breakthrough of a sense of history may also induce a feeling of estrangement. According to Reinhart Koselleck, around 1800 the experience of a unity of present and past gets lost, due to the very upheavals of the French Revolution. ${ }^{\text {I5 }}$ 
The past is different, and it requires an expert approach in that particular quality. It is no longer immediately applicable, so he argues, and thus it becomes a contemplative scholarly discipline. Peter Fritzsche, too, regards the Revolution as a trauma, due to which the past is no longer experienced as being one's own. ${ }^{16}$

In I828 Macaulay made another interesting comparison. He saw the reader of history as a traveler to regions yet unknown:

The effect of historical reading is analogous, in many respects, to that produced by foreign travel. The student, like the tourist, is transported into a new state of society. He sees new fashions. He hears new modes of expression. His mind is enlarged by contemplating the wide diversities of laws, of morals, and of manners. ${ }^{17}$

This, then, is what Koselleck meant with his 'estrangement', and this very strangeness of history makes its ongoing appropriation such an intriguing feat, as also appears from a fascinating study by David Lowenthal, The Past Is a Foreign Country. ${ }^{18}$

The effects of the explosive interest in history are reflected in the book market and in the diversity of ways in which history is being published. The Netherlands saw numerous editions of Wagenaar's work: straightforward reprints of his twenty-one-volume History, school books based thereon, versions for children, versions for less educated grown-ups, short versions, illustrated luxury editions, versions in question-and-answer format. Moreover, in various countries abbreviated translations saw the light of day. ${ }^{19}$ When we examine the print histories of all great European historians, we see the same thing. In addition, the print runs of historical novels are larger than would ever have been thought possible. The same goes for books for children filled with historical matter, also for history journals, surveys, and illustrated histories for a large audience. Pertinent statistics show a vastly enlarged interest in history.

Even so, the fields of tension remain the same. On the one hand, there is professionalization and academization, hence, a curtailment of the massive spread of history. On the other hand, there is the democratization of the past, with its expansion of the reading public in level and in age. Every practitioner of history in the nineteenth century seems to have doubts about his proper role. The academic historian wonders whether he may appropriate for his own ends the tools of the literary author, whereas the latter wants to be a historian as well. The dilemma is with us still. 


\section{Notes}

I Nieuw Historie spel van Nederland (Amsterdam: H. Moolenijzer, I 8 I 5). Collection Historisch Museum Deventer (1974-0044).

2 The hypotheses developed in this chapter sum up conclusions attained in my recent book Historiezucht (Nijmegen: Vantilt, 2013).

3 See Dafyld Moore (ed.), Ossian and Ossianism (London: Routledge, 2004), vols. I-4.

4 As quoted in Reginald De Schryver, Historiografie. Vijfentwintig eeuwen geschiedschrijving van West-Europa (Leuven, Assen: Universitaire Pers, Van Gorcum, I990), I84.

5 For this survey of historiographical change I have used De Schryver, Historiografie, and Frederick C. Beiser, The German Historicist Tradition (Oxford: Oxford University Press, 20I I). Further: Jo Tollebeek, De illusionisten. Geschiedenis en cultuur in de Franse Romantiek (Leuven: Universitaire Pers, 2000); Jo Tollebeek, Georgi Verbeeck and Tom Verschaffel (red.), De lectuur van het verleden. Opstellen over de geschiedenis van de geschiedschrijving aangeboden aan Reginald de Schryver (Leuven: Universitaire Pers, I998); Hayden White, The Historical Imagination in Nineteenth-Century Europe (Baltimore, London: John Hopkins University Press, I973); Daniël Woolf et al. (eds.), The Oxford History of Historical Writing, Vol. 4: 1800-1945 (Oxford: Oxford University Press, 20 I I).

6 See p. 27-4I in this volume.

7 Thomas Babington Macaulay, 'History', in Critical and Miscellaneous Essays (Philadelphia: Caney \& Hart, I 84I), vol. I, I92.

8 See Tollebeek, De illusionisten, 56, 64.

9 See among others Joep Leerssen, National Thought in Europe: A Cultural History (Amsterdam: Amsterdam University Press, 2006), and idem, 'Literary Historicism: Romanticism, Philologists, and the Presence of the Past', Modern Language Quarterly 65 (2004), $22 \mathrm{I}-243$.

Io Macaulay, 'History', I 88-I90.

I I See among others Joep Leerssen, De bronnen van het vaderland. Taal, literatuur en de afbakening van Nederland, 1806-1890 (Nijmegen: Vantilt, 2006); idem, 'Literary Historicism'; Marita Mathijsen, 'Stages in the Development of Dutch Literary Historicism', in Dirk van Hulle and Joep Leerssen (eds.), Editing the Nation's Memory: Textual Scholarship and Nation-Building in Nineteenth-Century Europe (Amsterdam, New York: Rodopi, 2008), 287-303.

I2 I take the expression from the title of a study about critics of historical novels by J. van der Wiel, De geschiedenis in balkostuum. De bistorische roman in de Nederlandse literaire kritiek (1808-1874) (Leuven, Apeldoorn: Garant, I999). This title is borrowed in its turn from a certain book review that appeared in the nineteenth century.

I3 Macaulay, 'History', I90.

I4 See Anne-Marie Thiesse, 'Modernising the Past: The Life of the Gauls under the French Republic', in Lotte Jensen, Joep Leerssen, and Marita Mathijsen (eds.), Free Access to the Past: Romanticism, Cultural Heritage and the Nation (Leiden, Boston: Brill, 2010), 43-54; Anne-Marie Thiesse, La création des identités nationales. Europe XVIIIe-XXe siècle (Paris: Éditions du Seuil, I999).

I5 Reinhart Koselleck, Futures Past: On the Semantics of Historical Time (Cambridge: MIT Press, I985). About Koselleck, see also, among others, 'TOR', De opstand van de intellectuelen. De Franse revolutie als avant-première van de moderne cultuur (Amsterdam, Kapellen: Pelckmans, 1989), and N.C.F. van Sas, De metamorfose van Nederland. Van oude orde naar moderniteit, 1750-1900 (Amsterdam: Amsterdam University Press, 2004). 
I6 Peter Fritzsche,'The Melancholy of History: Disenchantment and the Possibility of Narrative after the French Revolution', in Lotte Jensen, Joep Leerssen, and Marita Mathijsen (eds.), Free Access to the Past: Romanticism, Cultural Heritage and the Nation (Leiden, Boston: Brill, 20I0), 3-20; Peter Fritzsche, Stranded in the Present: Modern Time and the Melancholy of History (Cambridge, MA: Harvard University Press, 2004).

I7 Macaulay, 'History', I9I.

I 8 D. Lowenthal, The Past Is a Foreign Country (Cambridge: Cambridge University Press, I985).

I9 For Wagenaar's influence, see: L.H.M. Wessels, Bron, waarbeid en de verandering der tijden. Jan Wagenaar (1709-17730), een historiografische studie. Hollandse Historische Reeks 27 (The Hague: Stichting Hollandse Historische Reeks, [1997]). 



\title{
3+3 The Professionalization of the Historical Discipline
}

\author{
Austrian Scholarly Periodicals, 1840-1900
}

\section{Christine Ottwer}

\section{Introduction}

Scholarly periodicals are important pacemakers and trendsetters in the process of academic professionalization and institutionalization: they not only reflect developments within scientific disciplines or their relationship to other scientific fields, they also influence such developments decisively by way of an active editorial policy. ${ }^{.}$Already in the course of the eighteenth century many journals dealing with 'historical' issues had been founded, i.e., treating genealogical, numismatic, and statistical contents. ${ }^{2}$ Most of them were media of education which intended to spread and discuss established ideas within a circle of educated readers. ${ }^{3}$ At that time and also during the early years of the nineteenth century, before the distinction between 'amateur' and 'professional' historian became clear-cut and complete, scholars working in the historical field did interest themselves in local history periodicals. ${ }^{4}$ Yet by the middle of the nineteenth century the 'periodical' in general had become a medium explicitly meant to address a specialized audience. ${ }^{5}$

As part of a multinational process, numerous such periodicals have been established since the middle of the nineteenth century. Despite many structural differences and challenges, most of them have to be seen against the nationalpolitical backdrop of this time as well as in the context of the then increasing professionalization of the discipline. ${ }^{6}$

This paper attempts to elucidate historical methods and patterns of professionalization in Austria between the I840s and 1900 by means of an analysis of three case studies corresponding to three scholarly journals: Der österreichische Geschichtsforscher, the Archiv für Österreichische Geschichte, and, finally, the Mitteilungen des Instituts für Österreichische Geschichtsforschung. The reason for the selection of these three examples is that they all reflect typical characteristics of Austrian historical research in this period. First of all we have to face the prob- 
lem of an 'Austrian' history in connection with a national representation within the heterogeneous, multinational Habsburg Monarchy. ${ }^{7}$ On the one hand, this question has always been closely related to the issue of the model effect German historical undertakings and enterprises had on Austrian works. ${ }^{8}$ On the other hand, we find numerous attempts of dealing with the history of the Gesamtstaat - which means the entity of the Habsburg Monarchy not only as a complex of various more or less independent lands, but based on a common identity for the entire state. ${ }^{9}$ Furthermore, we have to take into consideration the development of specific philological methods for collecting, preparing, and editing historical sources. In Austria, efforts like these were parts of a longer tradition: following the examples set by the Bollandists and Maurists, some monks in the archives and libraries of various Austrian monasteries and abbeys had been organizing big historical source collections and editions during the eighteenth and early nineteenth century. ${ }^{\mathrm{IO}}$ All in all these trends already anticipated the constitutive significance of the archive in nineteenth-century historiography. ${ }^{\text {II }}$

\section{A historical repertory: Der österreichische Geschichtsforscher}

Our first case study deals with the journal Der österreichische Geschichtsforscher, a short-lived periodical, published around $1840 .{ }^{12}$ It originated from a private initiative by Joseph Chmel, a very ambitious archivist of the Habsburg Privy House Archive in Vienna. While serving as a priest in an Abbey in Upper Austria, Chmel became acquainted with intensive studies on sources in the archive and the library of the monastery. ${ }^{13}$ A self-educated historian, he developed a deep passion for medieval historical sources and for patriotic history. ${ }^{14}$ He regarded his journal as a historical repertory for the writings of the widely dispersed historians of the entire Habsburg Monarchy. Information stemming from manuscripts, charters and books was provided as a guide to find material dispersed to the same degree. He believed that the historical sources of Vienna and other parts of the Monarchy should make it possible to write a complete and truthful history'. In the periodical, Chmel gave researchers clear instructions as to how to achieve this aim: 'Der österreichische Geschichtsforscher must deliver solid building materials and should start building from below.' ${ }^{15}$

The periodical certainly failed in its purpose of being an aid for historians to become acquainted with yet unknown sources: its structure and contents were very heterogeneous and therefore the material was not very easy to handle for contemporary readers. Each volume consisted of three numbers, which included - without any chronological or thematic limitation - charters for an Austrian Codex Diplomaticus as well as materials related to Austrian financial history, numis- 
matics, sphragistics, heraldry, diplomatic affairs, and other matters of historical interest. At the beginning most contributions were authored by Chmel himself, who wanted to give publicity to some of the documents he had found during his previous travels to various archives. ${ }^{16}$

When Chmel was planning the first volume, he had no idea which principles he should apply to arrange his material, which various scholars sent to him in great numbers every day. ${ }^{17}$ For this reason, the arrangement of the periodical exactly mirrors the 'confused state of the documents' prevailing in the archives. ${ }^{18}$ Theodor von Sickel, the founder of modern diplomatics (critical document research), ${ }^{19}$ copied some documents in an Italian archive for Chmel, long before he started his career at the Viennese university. And even Sickel laconically stated that 'the chaos of his own work' corresponded to the disorder of the archive. ${ }^{20}$

As editor of the periodical, Chmel accepted the manuscripts of his collaborators without any changes, as he freely admitted. ${ }^{21}$ In many cases no hints of the origin and the transmission of the edited texts were given. ${ }^{22}$ Specific information on cartularies or archival signatures was often not provided to the reader. The form of presentation comprised excerpts of manuscripts, texts of 'Regesta' as well as complete texts. Basically the Geschichtsforscher represented a mere collection of materials, only now and then interrupted by smaller treatises. ${ }^{23}$

Each number of the periodical was accompanied by an appendix in which the editor offered bibliographical information as well as information on studies and projects undertaken or planned by numerous researchers in the lands of the Habsburg Monarchy. ${ }^{24}$ These appendices enable us to become acquainted with Chmel's extensive network of correspondents and collaborators: these were mainly colleagues like librarians and archivists, but also civil servants in filing departments and teachers in secondary schools who were also active as researchers. Chmel's private correspondence bears witness to lively contacts with researchers in various parts of the Monarchy, especially in Moravia and Bohemia, among others with František Palacký, historiographer of the Bohemian Estates. ${ }^{25}$ This is in accordance with the general findings of present-day scholars, that the connection between the Habsburgs' German hereditary lands and Bohemia was much more fundamental and enduring in intellectual terms than its connection to Hungary or Galicia ${ }^{26}$ It is interesting that Chmel fervently recommended the translation of some late medieval letters published in Palackýs Archiv Český - yet not into German, but into Latin, 'for the good of the historical researchers of all nations. ${ }^{27}$

In his Geschichtsforscher, Chmel gives the impression of being the focal point of historical research in 'Austria', whose history he constantly equates with that of the Gesamtstaat. Nevertheless, his periodical remained thematically restricted 
mainly to Lower and Upper Austria. After its second volume, the journal Geschichtsforscher was given up: its circulation was low, and public interest in a periodical of this kind was yet lacking in Austria ${ }^{28}$ Nevertheless numerous contributions had been sent in to Chmel as editor - and also his own journeys had made him realize that the mass of material stored in the archives was enormous ${ }^{29}$ But for Chmel himself it was nearly impossible to critically select the material that should be published: he preferred to have everything printed and wanted everybody to help him in this respect. ${ }^{30}$

\section{A printed archive: The Archiv für Österreichische Geschichte}

Nevertheless, the basic conception of the Geschichtsforscher proved to be trendsetting. This leads us to the second case study dedicated to a journal published not by a private person, but by the Imperial Academy of Sciences in Vienna, which was founded in 1847 , on the eve of the Revolution. ${ }^{31}$ As one of its first members the above-mentioned archivist Joseph Chmel influenced significantly the design and orientation of its first publications. He initiated the formation of the Historische Kommission, a department for Historical Research within the Imperial Academy, which should prepare, organize and publish editions of certain sources and also a specific historical journal. According to its title, Archiv für Österreichische Geschichte, the journal, first published in 1848, was meant to be a 'printed' archive to make historical material available and accessible to all researchers in the Habsburg lands. At the same time these researchers themselves should participate in this historical 'source collection program'. Parallel to the Archiv the sources of the individual crown lands were to be separately published in series of larger editions - as so-called Fontes rerum Austriacarum, Bohemicarum, Hungaricarum, Polonicarum and Italicarum. As acknowledged model for both, the Archiv and the Fontes, served a German enterprise: the popular Monumenta Germaniae Historica. ${ }^{32}$

In the Austrian enterprise, the different meanings of 'Austria' became visible: on the one hand historical sources of the whole Austrian Monarchy had to be edited, on the other hand the Res Austriacae should be only one part of a total of five and were supposed to represent the German hereditary lands. ${ }^{33}$ In combination with the Fontes the journal Archiv was conceived as a collection of source material; but the Archiv also provided smaller historical treatises. Its main function was to prepare the groundwork for a big comprehensive history of the Austrian Empire (Österreichischer Kaiserstaat), which was revitalized after 1848. Apart from purely historical items the periodical was open also for historical-geographical, topographical, archeological and linguistic studies. ${ }^{34}$ 
It is significant that the Archiv soon was regarded as a methodologically standardized journal and therefore was declared to be an 'academic publication., ${ }^{35}$ Yet, the conceptual policy paper of 1848 had welcomed all 'friends of patriotic history', without maintaining any professional differentiation. ${ }^{36}$ For this reason the journal represents an interesting interface between dilettante and increasingly professional claims.

In contrast with the practice of the predecessor Der österreichische Geschichtsforscher, the Imperial Academy established an editorial staff that had to review the articles and editions before publication. It certainly is instructive to take a look at the reports and the persons who were doing this work. Most of them were members of the Historische Kommission and therefore closely related to the Academy, i.e., as full members. One of the first persons responsible for reviewing the incoming manuscripts was a specialist in German studies, Theodor von Karajan, who held a leading position as a court librarian. ${ }^{37}$ Apart from him, leading archivists, such as the above-mentioned Joseph Chmel as well as Alfred von Arneth, the future director of the Privy House Archive, were busy writing reviews and reports. ${ }^{38}$

In many cases the publication process was a lengthy procedure, including much communication between the authors and contributors and the members of the editorial staff. It is worth mentioning some of the individual approaches and arguments for accepting or declining a publication: Chmel, for example, wanted to ensure that really 'new' and yet unprinted source material was going to be published. For this reason, he often compared the editions with material kept in his own archive, and his final decision was predicated on this comparison. ${ }^{39}$ His colleague Karajan often was unsatisfied with the stylistic competence of some scholars who sent in their treatises. Moreover, he was not interested in any cooperation with 'all friends of history', because in his view the 'academic' publications by all means should be for 'professionals' and not for 'amateurs' or 'laymen. ${ }^{40}$ As a specialist in Austrian eighteenth-century history, Arneth felt that the journal did not treat this period adequately enough, which led him to approve the publication of an edition of materials from this century despite serious methodological defects. ${ }^{41}$ Most of the reviewers insisted on the relevance of the chosen source material for the political history of the Habsburg crown lands. But even here we find interesting exceptions: sometimes historical sources without any political significance were published if they concerned the history of very remote parts of the Monarchy. ${ }^{42}$

In spite of some attempts to represent the historical research of the Monarchy as a whole, all in all the periodical did not succeed in fulfilling these self-imposed requirements. Even internal communications within the editorial staff very soon designated the Archiv as a 'German' periodical. ${ }^{43}$ Indeed, the majority of the re- 
viewers and contributors originated from the German hereditary lands. ${ }^{44}$ However, there was an increasing personal and professional interconnection between the Academy and the rising universities, especially with that of Vienna, where the Institut für Österreichische Geschichtsforschung played a prominent role in the methodological standardization of the historical discipline. ${ }^{45}$ Since the I870s more professional historians can be found among the reviewers as well as among the contributors of the Archiv. As a consequence, the lengthy review procedure was shortened: From 1875 onwards it was not considered necessary anymore to write reports on treatises or editions, which already 'at first sight' did not deserve to be published. A short oral report was supposed to be sufficient to decline a submitted manuscript. None other than the above-mentioned historian Theodor Sickel, professor at the University of Vienna and member of the Historische Kommission since 1872 , had made this proposal. ${ }^{46}$ The research standards that requested the use and quotation of 'original' sources from the contributors were finally taken for granted.

However, the proportions of historical treatises and mere editions of sources within the Archiv were continuously changing: during its first decades the treatises accounted for around 46\%, whereas between 1895 and 1900 the percentage rose to $67 \%{ }^{47}$ Of course, these treatises were firmly based on historical source material and archival studies as well. This remained a characteristic feature of the periodical; but the process of professionalization also becomes evident when looking at the structure of the annotations and indices. Especially since the I89os there were not only archival references and signatures but also numerous references to secondary literature. ${ }^{48}$

\section{Promoting professional auxiliary sciences of history: The Mitteilungen des Instituts für Österreichische Geschichtsforschung}

In I880 the Institut für Österreichische Geschichtsforschung, located at the University of Vienna, began publishing its Mitteilungen, ${ }^{49}$ our third case study. It was the first scholarly historical periodical in Austria to survive to the present and is still one of Austria's most important journals in this field. In addition to the methodological efforts of the Archiv, the new journal Mitteilungen was specifically designed for promoting certain historical disciplines: its initiators, first and foremost Theodor Sickel, mainly aimed at introducing auxiliary specializations in history, such as paleography, diplomatics, and archival science to the scientific community. These disciplines had been continually developed and taught at the Institut for the previous twenty-five years, i.e., since its foundation in 1854 . However, according to the publisher's advertisement the journal should be as universal 
as possible and was not restricted to a certain historical epoch or discipline: legal history was meant to be presented as well as art history, cultural history, and Christian archeology..$^{50}$

But in contrast to the aforementioned Archiv, the Mitteilungen provided critical treatises and articles in the field of the auxiliary sciences of history rather than mere source editions. According to Theodor Sickel, all the peers and colleagues who had been working in this research area were supposed to benefit from this new journal: It was meant to 'glue together' scholars interested in the auxiliary sciences of history. ${ }^{51}$ Therefore the periodical can also be seen as a professional collaborative project. Its aim was that the community and solidarity of professors, readers, lecturers, and current and former students of the institute would be underlined and strengthened. Many of the contributors of the Mitteilungen stood in close personal and functional relation to the institute where they were teaching or had been taught in the above-mentioned historical skills. It is interesting to see that this network of historians, which had been constituted during the time of the Monarchy, remained existent even after the First World War. ${ }^{52}$ A lot of contributors also held positions as lecturers or professors at renowned, especially German universities. This is why it might not have been necessary to 'peer review' the articles sent in for the Mitteilungen. Its editors just selected one colleague from among the Institute's members to do the editorial work and to communicate with the authors. ${ }^{53}$

Around 1880 similar historical periodicals were founded, i.e., in France, Italy, England, Belgium and the United States. ${ }^{54}$ Twenty years earlier the Historische Zeitschrift in Germany had already marked the transition from a journal addressed to an educated public to a scholarly historical periodical..$^{55}$ When founding the Austrian Mitteilungen its first protagonists criticized the lack of a corresponding historical periodical for southern Germany and Austria. In the eyes of the Austrian professors and scholars, the Archiv of the Imperial Academy in Vienna had an excellent reputation; however, the complicated publication procedure did not meet the actual demands any more, which were aiming at a more timely publication process. ${ }^{56}$ Apart from that, and this is a significant structural detail, the Archiv did not contain book reviews or brief notices about specialized historical literature. By contrast, the new Mitteilungen emphasized the importance of extensive book reviews and reports on historical literature. These parts of the periodical contributed greatly to standardization: the attempts to exclude contributions which were not accepted for scientific reasons combined with the attempts to establish a professional solidarity within the academic environment. ${ }^{57}$ The editors of the Mitteilungen paid particular attention to this part of the journal for another reason as well: they wanted specialists to report regularly about the research results in the non-German parts of Austria-Hungary. Thus, 
the periodical offered extensive reports, e.g., on the Monumenta Historiae Hungarica or on the source publications of the Academies of Sciences in Kraków and Zagreb. The reviewers compared these editions to the standards represented by the Viennese Institute, and they also dealt with the problem of using the national languages in the introductions and annotations of the editions. In particular, the Hungarian publications were strongly criticized for using the Hungarian language instead of Latin. ${ }^{58}$

In any case the structure of the Mitteilungen enabled the periodical to respond rather quickly to new subdisciplines and trends such as economic and social history around 1900.59 The growth and diversity of historical knowledge became part of the scholarly exchange by the inclusion of longer and smaller articles, book reviews and research reports. The photographical reproduction and the method of using facsimile editions for paleographic studies, as it was done in the teaching courses at the Institute, found their way into the journal. This approach soon was taken up by related disciplines such as musicology and art history. There were corresponding articles and reports on similar undertakings dedicated to photographical reproductions not only within the Habsburg Monarchy or in Germany, but also in France and Italy. ${ }^{60}$ Despite its concentration on historical research in Germany and 'Austria', the periodical tried hard to become more international.

\section{Conclusion}

To sum up: around 1840 Der Österreichische Geschichtsforscher had an antiquarian slant and consisted of a mere collection of various historical sources. Its primary aim was just to promote historical and archival research in general within the Habsburg 'Gesamtstaat'. Not only promotion and advancement, but also standardization was demanded by the Archiv für Österreichische Geschichte, edited by the Imperial Academy of Sciences in Vienna since I848. In order to achieve this, the Academy established its own staff for reviewing the incoming articles and source editions. The increasing personal interconnection between the Academy and the university made the distinction between 'amateur' and 'professional' historian more pronounced. Our last case study, the periodical Mitteilungen des Instituts für Österreichische Geschichtsforschung, founded in 1880 , was already a university cooperative enterprise. Its main purpose was to promote the auxiliary sciences of history. In the context of German historical research at the end of the nineteenth century, the journal also offered interesting attempts to distinguish itself by special 'Austrian' literary supplements and book reviews, which also tried to include the research results 
of the eastern and southern lands of the Habsburg Monarchy. The structure of the Mitteilungen as a whole strongly correlated with other national scholarly historical periodicals and facilitated rapid reactions to new developments in the historical field.

The case studies reveal changing professional as well as political approaches in combination with the quest for methodological standardization. As part of the 'making of' the historical discipline scholarly periodicals should therefore be regarded as important elements in the very complex academic process.

\section{Notes}

I Matthias Middell, 'Vom allgemeinhistorischen Journal zur spezialisierten Liste im HNet. Gedanken zur Geschichte der Zeitschriften als Elementen der Institutionalisierung moderner Geschichtswissenschaft', in idem (ed.), Historische Zeitschriften im internationalen Vergleich, Geschichtswissenschaft und Geschichtskultur im 20. Jahrbundert, vol. 2, (Leipzig, I999), 7-31, esp. 22.

2 Horst Walter Blanke, 'Verwissenschaftlichung und Aufklärung. Historische Zeitschriften im I8. Jahrhundert', in idem (ed.), Dimensionen der Historik: Geschichtstheorie, Wissenschaftsgeschichte und Geschichtskultur heute. Jörn Rüsen zum 60. Geburtstag (Cologne/ Vienna, I998), 237-253, esp. 240-243 and 25I.

3 Ute Schneider, 'Die Funktion wissenschaftlicher Rezensionszeitschriften im Kommunikationsprozeß der Gelehrten', in Ulrich Johannes Schneider (ed.), Kultur der Kommunikation. Die europäische Gelehrtenrepublik im Zeitalter von Leibnitz und Lessing, Wolfenbüttler Forschungen, vol. Io9 (Wiesbaden, 2005), 279-29I; Thomas Habel, Gelebrte Journale und Zeitungen der Aufklärung. Zur Entstehung, Entwicklung und Erschließung deutschsprachiger Rezensionszeitschriften des 18. Jahrbunderts. Presse und Geschichte - Neue Beiträge, vol. 17 (Bremen, 2007).

4 Margaret F. Stieg, The Origin and Development of Scholarly Historical Periodicals (Tuscaloosa, AL, I986), 9 .

5 Charles B. Osborn, 'The Place of the Journal in the Scholarly Communications System', Library Resources and Technical Services 28.4 (I984), 315-324, esp. 318; Sigrid Stöckel, 'Verwissenschaftlichung der Gesellschaft - Vergesellschaftung von Wissenschaft', in Sigrid Stöckel et al. (eds.), Das Medium Wissenschaftszeitschrift seit dem 19. Jahrbundert: Verwissenschaftlichung der Gesellschaft - Vergesellschaftung von Wissenschaft, Wissenschaft, Politik und Gesellschaft, vol. 5 (Stuttgart, 2009), 9-23.

6 In general, see Georg G. Iggers, 'The Professionalization of Historical Studies and the Guiding Assumptions of Modern Historical Thought', in Lloyd S. Kramer and Sarah Maza (eds.), A Companion to Western Historical Thought (Oxford, 2006), 225-242.

7 Gerald Stourzh, 'Der Umfang der österreichischen Geschichte', in Herwig Wolfram and Walter Pohl (eds.), Probleme der Geschichte Österreichs und ibrer Darstellung. Veröffentlichungen der Kommission für die Geschichte Österreichs, vol. I8 (Vienna, I99I), 3-27; Ernst Bruckmüller, 'Österreichbegriff und Österreich-Bewusstsein in der Franzisko-Josephinischen Epoche', in Richard G. Plaschka et al. (eds.), Was heißt Österreich? Inhalt und Umfang des Österreichbegriffs vom 10. Jahrbundert bis heute. Archiv für Österreichische Geschichte, 136 (Vienna, I995), 255-288. 
8 Monika Glettler, 'Die Bewertung des Faktors Deutschland in der österreichischen Historiographie', in Michael Gehler et al. (eds.), Ungleiche Partner? Österreich und Deutschland in ibrer gegenseitigen Wabrnebmung. Historische Analysen und Vergleiche aus dem 19. und 20. Jahrbundert, Historische Mitteilungen im Auftrage der Ranke-Gesellschaft, Beiheft I5 (Stuttgart, I996), 55-72, esp. 58.

9 Karl Vocelka,'Die Habsburgermonarchie als Gegenstand und Aufgabe der österreichischen Geschichtsforschung', in Martin Scheutz and Arno Strohmeyer (eds.), Was heißt 'österreichische' Geschichte? Wiener Schriften zur Geschichte der Neuzeit, vol. 6 (Innsbruck, 2008), 37-50, esp. 43 f.

Io Thomas Wallnig, 'Ordensgeschichte als Kulturgeschichte? Wissenschaftshistorische Überlegungen zur Historizität in der benediktinischen Geschichtsforschung des I8. Jahrhunderts', in Thomas Wallnig et al. (eds.), Europäische Geschichtskulturen um 1700 zwischen Gelehrsamkeit, Politik und Konfession (Berlin/Boston, 2012), I93-2I2; an older benchmark is David Knowles, Great Historical Enterprises: Problems in Monastic History (London, I963).

I I Pieter Huistra, "The Documents of Feith: The Centralization of the Archive in Nineteenth-Century Historiography', in Rens Bod, Jaap Maat, Thijs Weststeijn (eds.), The Making of the Humanities, vol. II: From Early Modern to Modern Disciplines (Amsterdam, 2012), 357-375.

I2 Der österreichische Geschichtsforscher, ed. Joseph Chmel, 2 vols. (Vienna, I838/I84II 842).

I3 Christine Ottner, 'Joseph Chmel und Johann Friedrich Böhmer: Die Anfänge der Regesta Imperii im Spannungsfeld von Freundschaft und Wissenschaft', in Karel Hruza and Paul Herold (eds.), Wege zur Urkunde - Wege der Urkunde - Wege der Forschung. Beiträge zur europäischen Diplomatik des Mittelalters, Forschungen zur Kaiser- und Papstgeschichte des Mittelalters. Beihefte zu J.F. Böhmer, Regesta Imperii 24 (Vienna-Cologne, 2005), 259-293.

I4 Alphons Lhotsky, 'Joseph Chmel zum hundertsten Todestage', Anzeiger der philosophischbistorischen Klasse der österreichischen Akademie der Wissenschaften 95.23 (I958), 32 I-347; Joseph Chmel,'Bericht ueber eine im Jahre I83 I unternommene kleine Reise zum Behufe der oesterr(eichischen) Geschichts-Quellen-Sammlung', Oesterreichische Zeitschrift für Geschichts-und Staatskunde 2.93 (I836), 369-37I.

I5 Der Österreichische Geschichtsforscher (see n. I2), vol. I, iii-viii (my translation).

I6 Chmel, 'Bericht ueber eine Reise'. (see n. I4)

I7 Archiv des Stiftes St. Florian (hereafter: AStF), Letters of and to Joseph Chmel, Chmel to Johann Friedrich Böhmer, I83 I October I4.

I8 Der Österreichische Geschichtsforscher (see n. I2), vol. I, ii (my translation).

I9 Daniela Saxer, 'Archival Objects in Motion: Historians' Appropriation of Sources in Nineteenth-Century Austria and Switzerland', Archival Science Io (2010), 315-33I, at 3 I 8; for Sickel's career, see esp. Alphons Lhotsky, Geschichte des Instituts für österreichische Geschichtsforschung 1854-1954, Mitteilungen des Instituts für Österreichische Geschichtsforschung, supplemental vol. I7 (Graz/Cologne, I954), $45 \mathrm{ff}$.

20 AStF, Letters of and to Joseph Chmel, Theodor Sickel to Chmel, I854 November I (my translation).

2I Der Österreichische Geschichtsforscher (see n. I2), vol. I, 566.

22 See, for example, Anton Emmert, 'Monumenta Tirolensia', Der Österreichische Geschichtsforscher (see n. I2), vol. I, 566-585.

23 Theodor Georg von Karajan, 'Ueber Banteidinge', Der österreichische Geschichtsforscher (see n. I2), vol. 2, II3-I32. 
24 Der österreichische Geschichtsforscher (see n. I2), vol. I, I66f., 397-399; see Notizenblatt in vol. I, after 2oI: i-xxvii, esp. xxvi-xxvii.

25 Chmel was not only in contact with František Palacký, but also with Moravian archivists and historians; see AStF, Letters of and to Joseph Chmel: Peter von Chlumecky to Joseph Chmel (2o letters between I 852 and I 858); AStF, Beda Dudik to Joseph Chmel (2 I letters between I 849 and I 857); for Palacký, see Jiř́ Kořalka, František Palacký (1798-1876). Der Historiker der Tschechen im österreichischen Vielvölkerstaat, Studien zur Geschichte der Österreichisch-Ungarischen Monarchie, vol. 30 (Vienna, 2007).

26 David S. Luft, 'Austrian Intellectual History and Bohemia', The Austrian History Yearbook 38 (2007), I08-I2I, esp. II2.

27 Joseph Chmel, 'Bericht über den historischen Verein für Innerösterreich und über Palackýs Archiv Český, Sitzungsberichte der philosophisch-historischen Klasse der Kaiserlichen Akademie der Wissenschaften 3 (I849), 407-425, at 422f. (my translation).

28 Engelbert Mühlbacher, Die literarischen Leistungen des Stiftes St. Florian bis zur Mitte des 19. Jahrbunderts (Innsbruck, I905), 294.

29 Joseph Chmel, 'Bericht über den Fortgang einiger akademischer Unternehmungen, namentlich der Monumenta Habsburgica', in Sitzungsberichte (see n. 27), 22 (Vienna, I 856), 29-90, at 32 .

30 Johannes Janssen (ed.), Johann Friedrich Böhmer's Briefe, vol. I (Freiburg im Breisgau, I868), Johann Friedrich Böhmer to Christoph Friedrich Stälin, I 848 August I5, 5 I6.

3I Richard Meister, Geschichte der Akademie der Wissenschaften in Wien 1847-1947 (Vienna, I947), 42-47.

32 Christine Ottner, 'Zwischen Wiener Localanstalt und Centralpunct der Monarchie: Einzugsbereich und erste Geschichtsforschungsunternehmen der kaiserlichen Akademie der Wissenschaften', Anzeiger der philosophisch-historischen Klasse der Österreichischen Akademie der Wissenschaften I43.I (2008), I 7 I-I96, at I85.

33 Stourzh, Umfang, 8.

34 [Joseph Chmel], 'Vorwort', in Archiv für Kunde österreichischer Geschichtsquellen (since I 865: Archiv für österreichische Geschichte, hereafter: $A O ̈ G$ ), I (I 848), iii-xi.

35 Archiv der Österreichischen Akademie der Wissenschaften, Historische Kommission (hereafter: AÖAW, HK), Karton I, Alte Akten I85I-I869, Nr. I55, Joseph Bergmann, Letter to the Academy, I 862 June I 8.

36 [Joseph Chmel], 'Vorwort', iv; AÖAW, Allgemeine Akten, Aktenzahl ad 1042 ex I85I, Joseph Chmel, Nachricht, I85 I October I.

37 For all the members of the Historische Kommission, see Gudrun Pischinger, Geschichtsministerium oder Verlagsanstalt? Eine Funktionsanalyse der Historischen Kommission der kaiserlichen Akademie der Wissenschaften in Wien 1847 bis 1877 (PhD thesis, Graz, 200I), 26If.

38 Already in 1852 Arneth was called on to write a review on an article; AÖAW, HK, Karton 2, Protokolle der Sitzungen I 85 I - I 870, I 852 January 26, fol. I Iv. In I 853 Arneth became a member of the Historische Kommission and in 1868 director of the Privy House Archive in Vienna; Richard Meister, 'Das Haus-, Hof- und Staatsarchiv und die Akademie der Wissenschaften', Sitzungsberichte der philosophisch-historischen Klasse der Österreichischen Akademie der Wissenschaften 226.3 (I949), 3-82, at 57, 65f.

39 AÖAW, HK, Karton I, Nr. 24, AZ I I 9 ex I 852, Theodor von Karajan and Joseph Chmel, I 852 March I.

40 AÖAW, HK, Karton I, Nr. 7, AZ 1038 ex I850, Theodor von Karajan, Report, I85 I November 9; AÖAW, HK, K I, Alte Akten I85I-I869, Nr. 93, AZ 352 ex I855, Theodor 
von Karajan, Report, I 855 October 3I; ibid., Nr. 3, Theodor von Karajan, Review, I85I November (sine die).

AÖAW, HK, Karton I, Alte Akten I85I-I869, Nr. I94, sine Aktenzahl, Alfred von Arneth, Report, I 866 April 23.

AÖAW, HK, Karton I, Alte Akten I85I-I869, Nr. 218, Joseph Fiedler, Report, I868 November 2.

43 AÖAW, HK, Karton I, Alte Akten I85I-I869, Nr. 79, sine Aktenzahl, exped. July 24 I 854, Theodor von Karajan, Letter (Concept), I 854 July 24.

44 Pischinger, Geschichtsministerium, I67-I69.

45 Daniela Saxer, 'Vermittlungsweisen des Quellenblicks im Geschichtsunterricht an den Universitäten Wien und Zürich (I833-I9I4)', in Gabriele Lingelbach (ed.), Vorlesung, Seminar, Repetitorium. Universitäre geschichtswissenschaftliche Lebre im bistorischen Vergleich (Munich, 2006), 2I-57, at $28 \mathrm{ff}$.

46 AÖAW, HK, Karton 2, Sitzungsprotokolle der HK, Meeting I 875 November 24.

47 Christine Ottner, 'Für den Mann vom Fache. Redaktion und Standardisierung Historischer Publikationen der Kaiserlichen Akademie der Wissenschaften', in idem et al (eds.), Geschichtsforschung in Deutschland und Österreich im 19. Jahrbundert. Ideen - Akteure Institutionen, Pallas Athene. Beiträge zur Universitäts- und Wissenschaftsgeschichte, vol. 48 (Stuttgart, 2014), 243-265.

48 See, for example, the treatise: Adolf Beer, 'Die österreichische Handelspolitik unter Maria Theresia und Josef II', AÖG 86 (I899), I-204.

49 Abbreviated as MIÖG (= Mitteilungen des Instituts für Österreichische Geschichtsforschung).

50 Institut für Österreichische Geschichtsforschung (hereafter: IÖG), Bestand MIÖG, Karton MIÖG-Akten, Mappe 2, Faszikel 2, Konvolut: Vorverhandlungen, Promemoria der Wagner'schen Universitätsbuchhandlung, I 878 May 25.

5I Theodor Sickel, 'Das k.k. Institut für österreichische Geschichtsforschung', MIÖG I (I 880), I-I 8, esp. I7f. (my translation).

52 Martin Scheutz, 'Turba ist ein ganz gemeiner Kerl! Rezensionen als Ehrdiskurs am Beispiel der MIÖG (I920-I939)', MIÖG I2I (2013), 63-8I, at 7 I.

53 Alphons Lhotsky, Geschichte des Instituts für österreichische Geschichtsforschung, I56-I58, 26I.

54 See the corresponding articles in Middell (ed.), Historische Zeitschriften im internationalen Vergleich (see n. I); for Belgium: Jo Tollebeek, 'Voorgeschiedenis en vormverandering. Historische Tijdschriften in België, I870-1922', Revue Belge de Pbilologie et d'Histoire 76 (I998), 847-870, esp. 853f.

55 Martin Nissen, 'Wissenschaft für gebildete Kreise. Zum Entstehungskontext der Historischen Zeitschrift', Das Medium Wissenschaftszeitschrift seit dem 19. Jahrbundert (see n. 5 ), 25-44.

56 IÖG, Bestand MIÖG, Karton MIÖG-Akten, Mappe I: Buchhandlungen, etc., Fasz. I, Engelbert Mühlbacher, Promemoria, I879 October 22.

57 Lutz Raphael,'Organisational Frameworks of University Life and Their Impact on Historiographical Pratice', in Rolf Torstendahl and Irmline Veit-Brause (eds.), History-Making: The Intellectual and Social Formation of a Discipline, Konferenser, vol. 37 (Stockholm, I996), I5I-I67, esp. I57.

58 Christine Ottner, 'Zwischen Referat und Rezension. Strukturelle, fachliche und politische Aspekte in den Literaturberichten der MIÖG (I880-I900)', MIÖG I2 I (20I3), 4062, esp. 55-57. 
59 Pavel Koláŕ, 'Nährboden fachlicher Innovation? Verfassungs- und Wirtschaftsgeschichte im Seminarunterricht an der Berliner, Wiener und Prager Deutschen Universität im Zeitalter des universitären Großbetriebs (I900-1930)', in Vorlesung, Seminar, Repetitorium (see n. 45), 89-I28, esp. I09-I I6.

60 Just to give an example: Guido Adler, '[Review:] Paléographie musicale: les principaux manuscrits de chant grégorien, ambrosien, mozarabe, gallican publiés en fac-similés phototypiques, vol. I, ed. Benediktinerpatres in Solesmes (Solesmes I 889)', MIÖG I I (I 890), 327-328. 



\title{
3.4 Manuals on Historical Method A Genre of Polemical Reflection on the Aims of Science
}

\author{
Herman Paul
}

\section{Introduction}

Manuals on historical method from around 1900 are like neoscholastic philosophy textbooks: books that are supposed to be so dull and dreary that only few scholars dare venture into them. Although methodology manuals were once a flourishing genre, especially in the late nineteenth and early twentieth centuries, when such emerging academic disciplines as history, art history, and church history were in need of methodological signposts and boundary markers, the hundreds of pages that these manuals typically devote to the minutiae of internal and external source criticism now read like neoscholastic meditations on the analogia entis. At least, that is the impression offered by the spare secondary literature on such late nineteenth-century methodology books as Ernst Bernheim's Lebrbuch der bistorischen Methode (1889) and the Introduction aux études historiques (1898) by Charles-Victor Langlois and Charles Seignobos. If these manuals are not openly criticized for their positivist-inspired epistemologies, ${ }^{1}$ they are portrayed at best as dry, didactic means for codifying and conveying the methodological standards of newly established humanities disciplines. ${ }^{2}$

This, however, is to overlook that methodology books could serve as cannons or swords in heated debates over the aims of historical scholarship. Virtually unnoticed in the literature so far is that manuals on historical method could serve as polemical interventions in debates on the nature and implications of a scholar's vocation. This is true for historical manuals - think of Charles De Smedt's Principes de la critique historique (1883), or Edward Augustus Freeman's The Methods of Historical Study (1886) - but especially also for manuals in fields plagued by insoluble disagreement over the need for scholarly asceticism with regard to religious beliefs, aesthetic taste, or moral judgment. Reading Hans Tietze's Die Methode der Kunstgeschichte (1913) and Guido Adler's Methode der Musikgeschichte (1919), for instance, does not amount to entering a classroom where students are being 
initiated into the methodological foundations of their discipline; it amounts to entering a battlefield. For whatever their titles may suggest, these manuals did not merely deal with methods, that is, etymologically speaking, with a scholar's 'ways' or 'paths', but also in particular with the goals to which such roads supposedly led. The books engaged in debate over ends at least as much as over means.

If this is true, historians of the humanities may want to dust off these methodology manuals, for instance, if they are interested in what Lorraine Daston calls the persona of the scholar, ${ }^{3}$ or what I call the 'scholarly self', that is, the habits, virtues, and character traits that were considered as distinguishing good scholars from less gifted ones. ${ }^{4}$ Why did late-nineteenth-century humanities scholars often fail to reach agreement on the qualities of the wissenschaftliche Persönlichkeit? Why did they often have rather different expectations of the scholar's moral and intellectual character? Part of the answer is that these scholars did not quite agree on the aims that habits, virtues, and character traits were supposed to serve. What counted as scholarly virtues and vices depended, among other things, on the goods that scholars were supposed to pursue - that is, on the 'aims of science' (or, more broadly, the 'aims of scholarship') as debated in the pages of such methodology manuals as Tietze's Die Methode der Kunstgeschichte and Adler's Methode der Musikgeschichte. ${ }^{6}$

So, what I shall argue, with these two books from early twentieth-century Vienna as my case studies, is that manuals on historical method, uninspiring as they may seem, offer in fact some fascinating insight into disciplinary polemics over the most fundamental of all questions: What is the goal our discipline must serve?

\section{The Viennese context}

Both Tietze (I880-I954) and Adler (I855-I94I) were firmly rooted in that vibrant center of intellectual, cultural, and political life that was Vienna in the I9Ios. Although both men had spent more than a decade in Prague - Tietze as a child, Adler on his first professorial chair - they had made the Austrian-Hungarian capital their home during their studies in Vienna and established themselves in Viennese upper-middle-class circles by marrying into local merchant families. Moreover, both Tietze and Adler belonged to one of those Viennese 'schools' or 'circles' that set their stamp on early-twentieth-century art, philosophy, and scholarship. As a former student of Franz Wickhoff, Alois Riegl, and Julius von Schlosser, and as Privatdozent in art history at the University of Vienna, Tietze belonged to the third generation of the 'Viennese School of Art History'. Adler, on his turn, had exchanged his professoriate in Prague for the chair of his former 
teacher Eduard Hanslick in Vienna in 1898. The 'Second Viennese School' to which Adler is often said to belong was not a historical school, but a group of avant-garde composers and musicians, the best-known members of which included Arnold Schönberg, Alban Berg, and Anton Webern. Academically, however, Adler was expected to do for music history what the Viennese School of Art History was doing for the history of the visual arts: raising the level of scholarship so as to meet the strictest demands of modern, critical, source-based historical studies. As one of the members of the search committee responsible for Adler's appointment had put it in 1896: 'Without question, the university, as an abode of learned research, has above all the right and the need to assure that the study of music history is undertaken by the faculty according to the same methods as those used in every other historical discipline. ${ }^{8}$

One wonders, though: How easily could 'learned research' be reconciled with deep fascination for Schönberg? To what extent was joyous immersion in Vienna's cultural life compatible with the scholarly asceticism preached by advocates of scientific history? Both Tietze and Adler worked in academic contexts that put a premium on sharp lines of division between scholarly research and aesthetic appreciation of art. Moriz Thausing, for example, one of Tietze's most influential predecessors in the Viennese School of Art History, had advocated a type of art history from which aesthetic criteria had been rigorously banned. ${ }^{9}$ This positivist legacy had been carried on by Tietze's teachers, Wickhoff, who had put all his cards on rigorous source criticism, and Riegl, whose was reported to have said that the best art historian is a person without personal taste. ${ }^{10}$ Tietze, however, had a taste for art: he greatly enjoyed expressionist art and supported such young painters as Oskar Kokoschka (whose double portrait of the Tietzes, painted in 1909, testifies to their close relationship). ${ }^{11}$

Similar tensions between the historical and the aesthetic existed in the emerging field of music history, where the German Bach biographer Philipp Spitta represented that end of the spectrum most committed to positivist Musikwissenschaft, while Hanslick, Adler's predecessor and prolific music critic, was a specimen of the opposite style. No one doubted that after Hanslick's retirement, in 1895, the university longed for a Spitta-type of musicologist. As one Viennese observer put it, in a letter to Johannes Brahms: 'Since work in the field of music history has, under Spitta's magnificent influence, seen an upswing and an expansion that was almost unimaginable twenty-five years ago, today one expects a completely different kind of knowledge from someone who occupies a pulpit like the one on which Hanslick stood. ${ }^{12}$ That the university expected Adler to be a kind of second Spitta was hardly surprising. Not only did Adler know Spitta very well - they had, for example, cofounded the Vierteljahrsschrift für Musikwissenschaft - but he had also aligned himself closely with Spitta's positivist program, 
most notably in his 1885 article, 'Umfang, Methode und Ziel der Musikwissenschaft. ${ }^{13}$ One wonders, however, how carefully the Viennese search committee had read the last few pages of this manifesto, in which Adler, contrary to his positivist inclinations, had charged music historians with the responsibility of helping, stimulating, and encouraging composers and musicians - a task that Spitta would have rejected as truly unscientific. And what did the committee know about Adler's fascination, not only for Schönberg, but also for Gustav Mahler and Richard Wagner, or about his life-long wrestling with Friedrich Nietzsche's question on the use of history for life? ${ }^{14}$

All this is to suggest that Tietze and Adler lived in a world ridden with tensions: tensions between the historical and the aesthetic, between scholarship and art, as well as between Viennese cultural life and a university proud to be at the forefront of positivist science. Tietze and Adler, each in their own way, not merely encountered these tensions; they embodied them and tried to cope with them.

\section{The aims of science}

Tietze's and Adler's methodology books are book-length proposals for working out such tensions. This is perhaps not immediately apparent. Both manuals have lengthy chapters on the auxiliary sciences of history. Both spend a significant number of pages on source criticism - the watchword of those committed to what Franz Schulz called a 'philological ethos' in the nineteenth-century humanities. ${ }^{15}$ In this respect, the books fairly closely resemble Ernst Bernheim's Lebrbuch der bistorischen Methode, which is perhaps the prime example of a methodology book that codified a broadly shared set of methods in a more or less student-friendly format. Tietze's Methode even imitated the structure of Bernheim's Lebrbuch and relied on it in matters of source criticism. ${ }^{16}$

Unlike Bernheim, however, Tietze and Adler were not in a position to codify a set of widely shared methods. Although Bernheim, a historian of medieval Europe, had also risked his neck, perhaps especially by choosing sides in such methodological disputes as those revolving around Dietrich Schäfer and Karl Lamprecht, ${ }^{17}$ his book was conventional in the sense one expects a methodology manual to be. It offered a state-of-the-art description of methods used by a majority of historians, working in the tradition of Leopold von Ranke, who consequently felt little difficulty in recognizing the patterns laid out in Bernheim's manual. Such conventions, however, did not, or not to the same degree, exist in Tietze's and Adler's fields of study. Even if they exaggerated in their complaints about an 'almost endless number of approaches', about an 'anarchy that threatens the kernel of our discipline', or, in military language, about a 'fight', a Krieg bis aufs 
Messer, with 'contending parties' that treated each other like 'enemies', ${ }^{18}$ Tietze and Adler made controversial choices with every step they took. Was it appropriate, for example, to recommend a student of Mozart's Requiem to subject the autograph manuscript to external source criticism? Or would such a technical examination of the Requiem manuscript miss the whole point of studying this sublime piece of music, as a more aesthetically inclined musicologist might argue ${ }^{19}$

Strikingly, when Tietze and Adler spoke about methods, they presented these as conditioned by the aims of scholarship. They highlighted the indissoluble ties between the methods that Mozart scholars chose to employ and the aims their scholarship served. Adler, for instance, regularly employed topographical metaphors in arguing that methods are like 'roads' leading to a 'goal'. What kind of roads scholars have to travel, depends on the Zweck or Ziel they want to reach. Scholars must therefore be 'goal-oriented' (zweckgemäß) and, consequently, employ purposive (zweckentsprechende) methods. ${ }^{20}$ For Tietze, too, methods were always means to an end. Especially in the opening pages of his book, he spoke in one and the same breath about 'goal and method' (Zweck und Method), 'method and tasks' (Methode und Aufgaben), 'task and working manner' (Aufgabe und Arbeitsweise), and 'method and purpose' (Methode und Absicht). Apparently, what it meant for scholars to work methodically was to be goal-oriented, or unfailingly dedicated to, the 'distinctive knowledge aims' (eigentümlichen Erkenntniszielen) of their discipline. ${ }^{21}$

This explains why Tietze and Adler reflected at least as much on the aims, goals, and purposes of scholarship as on their methods and means. Confronted with a diversity of approaches in their respective fields, they felt this 'chaos' was not so much a lack of methodological unanimity, but rather a divergence of views on the very goals that art historians or music historians were supposed to serve. Accordingly, the key word in their manuals was not method, but task, aim, goal (Aufgabe, Ziel, Zweck) or, more emphatically, 'main task' (Hauptaufgabe). ${ }^{22}$ Especially Adler continuously reminded his readers of the distinctive Aufgabe or Hauptaufgabe der Musikgeschichte, arguing that music history could grow to maturity only if its practitioners stayed focused on its proper aim (resisting the lures of such unscientific goals as aesthetic pleasure and education of the general public). ${ }^{23}$

One might argue, of course, that the language of aims is inevitable in methodology books, especially if such manuals also practice the genre of encyclopedia by providing a map of the discipline and its constituent parts. Even Bernheim devoted a section to the 'nature and task of historical scholarship', while returning to the 'goal of historical scholarship' and the 'fundamental tasks of our science' whenever he dealt with such 'temptations' as artistic writing and romantic evocation of the past. ${ }^{24}$ Likewise, Langlois and Seignobos, in France, could not do without the 
language of aims when they portrayed historians as traveling on a road toward the goal of their profession: establishing true facts about the past. ${ }^{25}$ However, while Bernheim, Langlois, and Seignobos could more or less expect their readers to agree with what they defined as the goal of their profession, given that deviant views mostly came from outside the mainstream of the historical discipline, Tietze and Adler saw themselves confronted with opposition from within the ranks of their profession. When they set out to define 'the office of art history,' ${ }^{26}$ they were not articulating a broadly accepted position, but taking sides in a fierce debate about the scholar's vocation.

\section{A lead for the future}

Unsurprisingly, then, both Tietze and Adler presented their views on the aims of science in contrastive terms, that is, in explicit dissociation from alternative views on the goods that historical scholarship was supposed to pursue. Typical is, for example, Adler's phrase 'that the task of music history is not the exploration of artistic beauty [das Kunstschönen] in music, but knowledge of the development of music. ${ }^{27}$ If this formulation already conveyed Adler's desire to steer away from Hanslick, ${ }^{28}$ or more generally from all types of musicology in which aesthetic judgment took precedence over sober scientific analysis, it took only a couple of pages before the author had also dissociated himself from such colleagues as the Leipzig musicologist Hugo Riemann. He blamed Riemann, the editor of a multivolume Handbuch der Musikgeschichte (1904-1913), for collecting facts and toying with little problems without even trying to integrate these into an evolutionary history of musical styles that, in Adler's view, would best serve the aim of music history, which he defined as 'the study and exposition of the development [Entwicklungsganges] of musical products. ${ }^{29}$ The historicist trope of development', then, provided Adler with a solution for the tensions mentioned earlier. If the aim of music history was the detection of Entwicklung in musical styles, then music historians could, on the one hand, engage in what Adler called 'scientific' and 'objective' analysis of patterns and trends - a task to which much of the Methode was devoted. ${ }^{30}$ However, by doing so, music historians could also, on the other hand, provide current-day artists (composers such as Schönberg) with valuable clues as to where contemporary music came from and how it might be developed further - a role that Adler emphasized especially in his nonacademic publications. ${ }^{31}$

Although Tietze, twenty-five years Adler's junior, presented a less articulated view on the aims of art history, his Methode nonetheless employed similar contrastive language. One front was Riegl's dream of the art historian as a man without qualities, which Tietze rejected as incompatible with the hermeneutic 
insight, derived from Wilhelm Dilthey, that art historians are always products of their times, voicing concerns and studying problems that inevitably reflect their own zeitgeist. ${ }^{32}$ 'Objectivity', therefore, was a word to be used only with caution and significant qualification: history is always being written by human beings of flesh and blood. ${ }^{33}$ Another methodological quarrel followed right out of this hermeneutical understanding of historical interpretation. Over against an arthistorical tradition that sought to identify lawlike patterns of stylistic change, Tietze firmly defended individual human agency, which he defined as the most decisive factor' in stylistic evolution. ${ }^{34}$ Given that this went right against such influential art historians as Heinrich Wölfflin, in Munich, ${ }^{35}$ it was evident that Tietze did not merely summarize or codify the views of others, but staked out a position of his own.

Given the divergence of views existing among music and art historians, it comes as no surprise that Tietze and especially Adler not only used contrastive language, but also wrote conditionally, about the gains to be obtained if just everyone agreed with their proposals, and in the future tense about the joyous day when scholars would eventually close the ranks and devote themselves jointly to research along the lines proposed in their books. How great would be the benefits if we could just 'unite ourselves' in methodological respect, Adler exclaimed. 'We would only need to agree on the way of applying style criteria and, in the first place, become fully aware of our own treatment methods. ${ }^{36}$ Near the end of his book, however, in a self-reflective passage on the possibility for this manual to offer a lead for the future', Adler admitted that this could take some time: 'Almost all pages of this book point to new territory [Neuland] of music historical research, which has yet to be conquered. ${ }^{37}$ Music history, in other words, had not yet reached a stage of shared paradigms: unanimity on the aims and methods of the discipline did not yet exist. ${ }^{38}$

Judging by its reception history, Adler's volume did not suffer too much from this disagreement in the field. Even though critical voices were not lacking, ${ }^{39}$ Adler's approach resonated strongly among many of those, in Europe as well as overseas, who tried to establish musicology as a scholarly discipline. "What a university should teach the student of music has been set forth in The Method of Music History (1919) by Prof. Dr. Guido Adler of Vienna, dean of European musicologists', stated an American admirer in $1925 .{ }^{41}$ Ten years later, that same American musicologist repeated his praise by hailing Adler as the first to draw a ground-plan for the structure of musical research', which had meanwhile been 'universally adopted.' 'His disciples, far and wide, are teaching his theories'.42 One of these pupils, Wilhelm Fischer, even identified so thoroughly with Adler's program that he could not think of 'serious [ernstzunebmenden] musical historical publications' that did not adopt the methods laid down in Adler's book. ${ }^{43}$ 
If the Methode nonetheless did not achieve a status comparable to, for instance, Bernheim's Lebrbuch, this was due to at least three factors. One is the modest size of the musicological discipline, another the fact that the Methode was not exactly designed as an introductory textbook, and a third the circumstance that the manual quickly became overshadowed by Adler's Handbuch der Musikgeschichte (1924), ${ }^{44}$ a thousand-plus-page tome that came to serve as 'the textbook for Austrian musicology students in the 1920 s and $30 s^{\prime}{ }^{45}$ This, I note in passing, is another challenge for the view that methodology manuals were primarily written for educational purposes. While Adler's Methode cleared the ground, ambitiously and polemically, it was left to the Handbuch to survey the field in a more tranquil, encyclopedic, and student-friendly manner. ${ }^{46}$

Whereas Adler had therefore little reason to complain, Tietze's manual met with fierce criticism. Although it was favorably reviewed by the French art historian Louis Réau, ${ }^{47}$ most German-language reviews were unsparingly critical. They bemoaned not only the loose organization and inconvenient structure of the book, but especially also Tietze's alignment with Bernheim, which was perceived as repudiating the distinctiveness of the discipline and/or as testifying to an old-fashioned, source-oriented conception of art history. Tietze's progressive Viennese colleague, Joseph Strzygowski, for example, responded with dismay that Tietze seemed to want to bring the field back to pre-I890 standards. ${ }^{48}$ Erich Rothacker was slightly more sympathetic, but deeply puzzled by Tietze's rather underdeveloped hermeneutics: How could he possibly combine a romantic notion of human individuality with a positivist conception of science ${ }^{49}$ Wölfflin's former student Richard Hamann explained at length why Tietze's rejection of laws in art history was fundamentally mistaken..$^{50}$ And as if this was not enough, the Heidelberg art historian Carl Neumann, committed to a more aesthetically oriented type of art history, rebuked Tietze for rejecting aesthetic quality as a relevant category of art-historical interpretation. ${ }^{51}$

What these criticisms illustrate is not merely that Tietze was rather ineffective in proposing a hermeneutical conception of art history (so that it was left to another Viennese colleague, Tietze's fiend Max Dvořák, to advocate more successfully for a Kunstgeschichte als Geisteswissenschaft).52 More important for our present purpose is that almost all the reviewers treated the book not as a textbook, but as a piece of polemic, as a proposal or a stance in a debate over the nature and tasks of art history. They commented on Tietze's 'standpoint,, ${ }^{53}$ assessed his 'polemics, ${ }^{54}$ and, in Hamann's case, took the book as an occasion to write a reply more than forty pages long. Tietze's book figured, as it might have been intended to figure, in debates over what Tietze would later call the 'fundamental questions' and 'fundamental problems' of art history. ${ }^{55}$ It served, not as a repository of disciplinary wisdom, but as a stimulus to debate over the aims that art history was supposed to pursue. 


\section{Conclusion}

Speaking about Bernheim's Lebrbuch, Peter Novick once suggested that methodology books of this kind were 'probably more cited than read'.56 This may well have been the case, perhaps especially for those manuals, like Bernheim's, that could be prescribed in university courses because of their extensive treatment of nearly everything that historians could possibly wish to know about methods. It would be wrong, however, to assume that all manuals on historical method from around 1900 were encyclopedic surveys of methodological do's and don't's, just as it would be inaccurate to assume that all manuals were primarily written for educational purposes. In this paper, I have tried to argue that Tietze's and Adler's manuals challenge even some further clichés about the genre. These books did not codify an agreed-upon body of methods. They were neither dry-as-dust nor specimen of the fact-oriented sort of positivism epitomized by Langlois and Seignobos. Instead, these manuals were designed as polemical interventions in a debate over the proper aims of science. They dwelled on the scholar's professional vocation at least as much as on details of source criticism. Moreover, they did not hesitate to do so in critical dissociation from alternative views on the aims of historical scholarship, in sometimes militantly polemical prose.

Accordingly, it is the genre of methodology manuals, as represented by Tietze and Adler, in which one may find some explicitly formulated answers to the question raised in the introduction of this paper: Why did late-nineteenth-century humanities scholars disagree so often about the virtues, habits, and character traits typical of a good, responsible, conscientious scholar? The gist of these answers is that scholars had different expectations of what counted as professional scholarly conduct, mainly (though not only) because they disagreed on the goals their work was supposed to serve. In fields fraught with moral, religious, and/or aesthetic sensibilities - that is, throughout the late-nineteenth-century humanities, even if these sensibilities were more contested in some fields than in others - the aims of science were a fundamental issue in disciplinary controversies. They were fundamental, indeed, because these aims determined so much of what scholars associated with professional academic conduct, varying from methodological sophistication to technical skill and epistemic virtuousness. This explains, finally, why the genre of methodology manuals served more than educational purposes. Judging by Tietze's and Adler's contributions, manuals on historical method could be swords or cannons in heated conflicts over the aims of historical scholarship. ${ }^{57}$ 


\section{Notes}

I Hans Schleier,'Ranke in the Manuals on Historical Methods of Droysen, Lorenz, and Bernheim', in Georg G. Iggers and James M. Powell (eds.), Leopold von Ranke and the Shaping of the Historical Discipline (Syracuse, NY: Syracuse University Press, I990), I I I-I23; Philippe Carrard, 'Disciplining Clio: The Rhetoric of Positivism', Clio 24 (I995), I89-204.

2 Jeremy D. Popkin, History, Historians, and Autobiography (Chicago and London: University of Chicago Press, 2005), I6; Rolf Torstendahl,'Historical Professionalism: A Changing Product of Communities within the Discipline', Storia della Storiografia 56 (2009), 3-26, at I0-I I.

3 Lorraine Daston, 'Die wissenschaftliche Persona: Arbeit und Berufung', in Theresa Wobbe (ed.), Zwischen Vorderbühne und Hinterbühne: Beiträge zum Wandel der Geschlechterbeziehungen in der Wissenschaft vom 17. Jahrhundert bis zur Gegenwart (Bielefeld: Transcript Verlag, 2003), I I0-I36; Lorraine Daston and H. Otto Sibum, 'Introduction: Scientific Personae and Their Histories', Science in Context I 6 (2003), I-8.

4 Herman Paul, 'The Scholarly Self: Ideals of Intellectual Virtue in Nineteenth-Century Leiden', in Rens Bod, Jaap Maat, and Thijs Weststeijn (eds.), The Making of the Humanities: From Early Modern to Modern Disciplines (Amsterdam: Amsterdam University Press, 20I2), 397-4II.

5 Jo Tollebeek, Men of Character: The Emergence of the Modern Humanities (Wassenaar: Netherlands Institute for Advanced Study in the Humanities and Social Sciences, 20 I I).

6 I borrow the expression 'aims of science' from Larry Laudan, Science and Values: The Aims of Science and Their Role in Scientific Debate (Berkeley; London; Los Angeles: University of California Press, I984).

7 For biographical details, see Ernst Lachnit, Die Wiener Schule der Kunstgeschichte und die Kunst ibrer Zeit: Zum Verhältnis von Methode und Forschungsgegenstand am Beginn der Moderne (Vienna; Cologne; Weimar: Böhlau, 2005), 98- I ro; Almut Krapf-Weiler, 'Daten zur Biographie', in Hans Tietze, Lebendige Kunstwissenschaft: Texte 1910-1954, ed. Almut KrapfWeiler (Vienna: Schlebrügge, 2007), 308-3 I5; Gabriele Johanna Eder, 'Einleitung,' in Eder, Alexius Meinong und Guido Adler: Eine Freundschaft in Briefen (Amsterdam; Atlanta, GA: Rodopi, I995), 3-52; idem, 'Guido Adler: Grenzgänger zwischen Musikwissenschaft und Kulturleben', in Theophil Antonicek and Gernot Gruber (eds.), Musikwissenschaft als Kulturwissenschaft damals und heute: Internationales Symposion (1989) zum Jubiläum der Institutsgründung an der Universität Wien vor 100 Jahren (Tutzing: Hans Schneider, 2005), I0I-I 23.

8 Quoted in Kevin C. Karnes, Music, Criticism, and the Challenge of History: Shaping Modern Musical Thought in Late Nineteenth-Century Vienna (New York and Oxford: Oxford University Press, 2008), 23.

9 M. Thausing, 'Die Stellung der Kunstgeschichte als Wissenschaft: Aus einer Antrittsvorlesung an der Wiener Universität im October I873', in Thausing, Wiener Kunstbriefe (Leipzig: E.A. Seemann, I884), I-20.

Io Cited in Max Dvořák, 'Alois Riegl', in Dvořák, Gesammelte Aufsätze zur Kunstgeschichte (Munich: R. Piper \& Co., I929), 280-298, there 285.

I I Catherine M. Soussloff, The Subject in Art: Portraiture and the Birth of the Modern (Durham; London: Duke University Press, 2006), 6I-82.

I2 Quoted in Karnes, Music, 24.

I 3 Guido Adler, 'Umfang, Methode und Ziel der Musikwissenschaft', Vierteljahrsschrift für Musikwissenschaft I (I885), 5-20. Cf. Philipp Spitta, 'Kunstwissenschaft und Kunst', in Spitta, Zur Musik: Sechzehn Aufsätze (Berlin: Gebrüder Paetel, I892), I-I4. 
Karnes, Music, I33-I 58 .

Franz Schultz, 'Die Entwicklung der Literaturwissenschaft von Herder bis Wilhelm Scherer', in Philosophie der Literaturwissenschaft, ed. Emil Ermatinger (Berlin: Junker \& Dünnhaupt, I930), I-42, at 37.

See, e.g., Hans Tietze, Die Methode der Kunstgeschichte: Ein Versuch (Leipzig: E.A. Seemann, I9I3), vi, I87, 240, 257, 288-289, 293, 298, 308, 3 I6.

Mircea Ogrin, Ernst Bernheim (1850-1942): Historiker und Wissenschaftspolitiker im Kaiserreich und in der Weimarer Republik (Stuttgart: Franz Steiner, 201 2), 44-57; Hans Schleier, 'Ernst Bernheims Historik in seinem "Lehrbuch der historischen Methode", in Wolfgang Küttler (ed.), Das lange 19. Jahrbundert: Personen, Ereignisse, Ideen, Umwälzungen: Ernst Engelberg zum 9o. Geburtstag (Berlin: Trafo, I999), 275-292.

Guido Adler, Methode der Musikgeschichte (Leipzig: Breitkopf \& Härtel, 1919), 2; Tietze, Methode, v, 4, 6, 3. All translations are mine.

Adler, Methode, 4-5.

Ibid., 2, I I 0, 59, 67, 63 .

Tietze, Methode, 2, 7, I7 I.

E.g., ibid., I05, I07, I I0, II 3, II6, I23, I26, I65, I66, I 76.

E.g., Adler, Methode, 6, 9, I0, I3, I5, I92.

Ernst Bernheim, Lehrbuch der historischen Methode: Mit Nachweis der wichtigsten Quellen und Hülfsmittel zum Studium der Geschichte (Leipzig: Duncker \& Humblot, I889), 90-96, 523,528 .

C.-V. Langlois and C. Seignobos, Introduction aux études historiques (Paris: Hechette \& Cie., I 898$), 44$.

Tietze, Methode, 132 .

Adler, Methode, I 3 .

On Adler's difficult relation with Hanslick, see Gabriele Johanna Eder,'Eduard Hanslick und Guido Adler: Aspekte einer menschlichen und wissenschaftlichen Beziehung', in Martin Seiler and Friedrich Stadler (eds.), Kunst, Kunsttheorie und Kunstforschung im wissenschaftlichen Diskurs: In memoriam Kurt Blaukopf (1914-1999) (Vienna: ÖBV \& HPT, 2000), I07-I 42.

Adler, Methode, 23, 9. Riemann, in turn, had dissociated himself from Adler in, for example, Hugo Riemann, Handbuch der Musikgeschichte, vol. II/ 2 (Leipzig: Breitkopf \& Härtel, I922), $\mathrm{v}$-vi. On the relation between these two musicologists, see Barbara Boisits,'Hugo Riemann Guido Adler: Zwei Konzepte von Musikwissenschaft vor dem Hintergrund geisteswissenschaftlicher Methodendiskussionen um I900', in Klaus Mehner and Tatjana Böhme-Mehner (eds.), Hugo Riemann (1849-1919): Musikwissenschaftler mit Universalanspruch (Cologne; Weimar; Vienna: Böhlau, 200I), I7-29; Alexander Rehding, Hugo Niemann and the Birth of Modern Musical Thought (Cambridge: Cambridge University Press, 2003), I38-I49.

Barbara Boisits, 'Historismus und Musikwissenschaft um I900: Guido Adlers Begründung der Musikwissenschaft im Zeichen des Historismus', Archiv für Kulturgeschichte 82 (2000), 377-389; Barbara Boisits, 'Kulturwissenschaftliche Ansätze in Adlers Begriff von Musikwissenschaft', in Antonicek and Gruber, Musikwissenschaft als Kulturwissenschaft, I25-I39.

Karnes, Music, I5I-I 58 .

For Dilthey's influence on Tietze, see Riccardo Marchi, 'Hans Tietze e la storia dell'arte come scienza dello spirito nella Vienna del primo Novecento', Arte Lombarda i Io/ I I I (I994), 55-66.

Tietze, Methode, 455-466.

Ibid., 454.

Marchi, 'Hans Tietze and Art History', 20. 
36 Adler, Methode, 2I.

37 Ibid., I93.

38 These formulations reflect, of course, a progressivist narrative of disciplinary development according to which Adler's generation stood only at the threshold' of scientific research (e.g., ibid., 26, I57, I92).

39 See Alfred Schnerich's review in the Neue Zeitschrift für Musik 87 (I920), 40.

40 See the reviews signed by J. M. and A. W., respectively, in Literarisches Zentralblatt für Deutschland 73 (1922), 39-40 and Musica Divina II (1923), 22-23.

4I Carl Engel, 'Views and Reviews', The Musical Quarterly II (I925), 617-629, there 620.

42 Carl Engel,'Views and Reviews', The Musical Quarterly 2I (I935), 484-49I, there 485.

43 Wilhelm Fischer, 'Guido Adlers “Methode der Musikgeschichte", Zeitschrift für Musikwissenschaft 7 (I924), 500-503, at 503 .

44 Guido Adler (ed.), Handbuch der Musikgeschichte (Frankfurt am Main: Frankfurter Verlags-Anstalt, I924).

45 John Charles Koslovsky, From Sinn und Wesen to Structural Hearing: The Development of Felix Salzer's Ideas in Interwar Vienna and Their Transmission in the Postwar United States (PhD dissertation, University of Rochester, 2009), 72.

46 Fischer, 'Guido Adlers Methode', 50 .

47 Louis Réau, 'Un théoricien de l'histoire de l'art: Hans Tietze', Revue de Synthèse Historiques 28 (I9I4), 45-50, esp. 50 .

48 Josef Strzygowski, Die Krisis der Geisteswissenschaften, vorgeführt am Beispiele der Forschung über bildende Kunst: Ein gründsätzlicher Rabmenversuch (Vienna: Anton Schroll \& Co., I923), 55 .

49 Erich Rothacker, 'Literatur', Repertorium für Kunstwissenschaft 4I (I9I9), I68- I86, there I77.

50 R. Hamann, 'Die Methode der Kunstgeschichte und die allgemeine Kunstwissenschaft', Monatshefte für Kunstwissenschaft 9 (I9I6), 64-78, I03-I I4, I4I-I54.

5I Carl Neumann, 'Zur Theorie der Geschichte und Kunstgeschichte', Historische Zeitschrift I 6 (I9I6), 484-494, esp. 490-493.

52 Max Dvořák, Kunstgeschichte als Geistesgeschichte: Studien zur abendländischen Kunstentwicklung (Munich: R. Piper \& Co., I924).

53 Rothacker, 'Literatur', I76.

54 Ibid., I79, I80; Neumann, 'Theorie', 485; Hamann, 'Methode', 64.

55 Hans Tietze, 'Geisteswissenschaftliche Kunstgeschichte', in Johannes Jahn (ed.), Die Kunstwissenschaft der Gegenwart in Selbstdarstellungen (Leipzig: Felix Meiner, I924), I 83I98, at I83.

56 Peter Novick, That Noble Dream: The 'Objectivity Question' and the American Historical Profession (Cambridge: Cambridge University Press, 1988), 38.

57 Research for this chapter was funded by the Netherlands Organization for Scientific Research (NWO). 


\title{
3.5 The Peculiar Maturation of the History of Science $^{\mathrm{I}}$
}

\author{
Bart Karstens
}

\section{Introduction}

This paper takes as its topic how the history of science, as a separate field of study, came into being in the early twentieth century and how it developed thereafter. The first signs of the institutionalization of the field as an academic discipline were the first international conference on the history of science held adjacent to the World Exhibition in Paris in 1900, the start of the journal Isis in 1912, and the founding of the History of Science Society in 1924. This journal and the society still occupy a prominent position in the field today. The period also saw the first chairs, textbooks and specialized courses in the history of science come about. To be sure, before the twentieth-century works on the history of science were written. As a matter of fact historians operating in the first half of the twentieth century reacted to the philosophically informed views on the historical development of science of, for example, Comte, Whewell, Mach, and Duhem. ${ }^{2}$ Nothing ever starts in a void. Yet in the nineteenth century nothing resembling a modern academic specialization came about. ${ }^{3}$ For this reason I have chosen the early twentieth century as a starting point of this overview of the development of the field.

Historiography of science is now a respected academic discipline all over the globe. Still, the field has not been institutionalized in a uniform way, for example, as a clearly recognized subdiscipline of the study of history. Historians of science are often not employed by institutes of history but either appear as isolated figures, scattered over the various faculties and institutes of universities, or are bundled in separate HPS (History and Philosophy of Science) or STS (Science, Technology and Society) institutions, quite often with strong ties to philosophy or sociology. The uneasy institutional status of the field is a symptom of profound differences in view on why and how the history of science should be studied. Among historians there is considerable difference of opinion on the purposes and aims of the field, what kinds of knowledge it should produce, by 
what methods this knowledge should be arrived at, etc. One goal of this paper is to demonstrate where these differences come from. The paper starts with a sketch of the aims and goals that the first generation of professional historians of science set themselves. Their work, and the conscious reflection on this work, resulted in the formulation of a number of challenges for the new discipline. During and after the I960s a thorough change in orientation in the field came about. A description of these changes is provided in this paper. We will then be in a position to consider the peculiar aspects of the maturation of the history of science and analyze the most important driving forces behind this process.

The output of scholarly research in the field clearly reflects the major reorientations after the I960s. Yet other orientations, sometimes even opposite to the mainstream, continue to exist. The resulting picture of the current status of the field therefore is one of disorder. The variety in approaches to the history of science can, to some extent, be viewed as a healthy form of pluralism. Yet there is also an aspect of unhealthy 'anarchy' because fruitful exchanges of thought about the relative worth of the approaches, the possible compatibility of assumptions, etc., are rather scarce. ${ }^{4}$ This signals the need for reform. In the final section of the paper I argue that a road toward more unity in historiography of science can be found if two things are taken seriously. First, the recognition that the strong ties of the field to the natural sciences and to philosophy were not accidental. Aiming to gain complete independence from these 'parent' disciplines must therefore be considered as a wrong-headed project. Second, the recognition that the challenges to the profession that were already formulated by the first generation of professional historians of science are still relevant today. It is with respect to these challenges that a new balance must be struck. These considerations show how the study of the history of a discipline can be relevant to the operations of that very discipline in the present.

\section{Aims of the field in the first phase of professionalization}

The central figure in the first phase of the institutionalization of history of science was George Sarton (1884-1956). Sarton was of Belgian origin but gained recognition as a professor at Harvard University. Sarton taught history of science there for many decades. Among his students were important later scholars in science studies, such as I.B. Cohen and Robert K. Merton. He was also instrumental in Alexandre Koyrës move to the US, where he became highly influential. Sarton set up the journal Isis and was its editor-in-chief for many years. He was also involved in the creation of the History of Science Society. Sarton's role in the institutionalization of the discipline is widely recognized. Of interest here are the 
programmatic essays he wrote about the relevance of the field, not just to the rest of the academic system but to society as a whole, and the way it should be studied and taught to students. The arguments and motivations he gave for a thorough study of the history of science by way of a specialized academic discipline form an interrelated whole that is worthwhile to unravel. Sarton's views will also be compared to the views of his contemporaries; this comparison yields a good picture of the prevailing ideas with respect to the study of past science during the first phase of its professionalization.

Sarton saw science as the only human activity in which progress had been achieved. According to him the progressive force of science also had profound effects on society, especially in modern times. It was through science that the improvement of living conditions became possible and science also showed the way to improve the organization of society. Furthermore Sarton saw the striving for pure knowledge as a moral quest. Good scientific research was a disinterested search for the truth and this attitude brought about the most outstanding achievements the human mind was capable of.

For all these reasons Sarton argued that the scientific enterprise had to be dealt with great care. If science fell into the wrong hands, or if it were practiced in the wrong way, this could only be harmful to society. A mistaken approach to science was not just a symptom of a bad regime: it could well be conducive to wrong political systems. ${ }^{5}$ Another danger was that scientists could start to overrate themselves and the importance of their contributions. Such hubris needed a check at all times. In premodern days people were kept in check by a clear social hierarchy: the church or the nobility. In modern times such social hierarchies, and the institutions connected to them, have only a marginal hold on people. Thus other forms of (institutional) control were needed.

Now Sarton firmly believed that modern historical consciousness could replace the older forms of social control if it was embedded in a spirit of 'new humanism. The old humanism had known three categories: the natural, the human and the superhuman. The superhuman was thought to be the highest category, the natural to be the lowest. It followed that the study of man was also more important than the study of nature. This needed to be changed, according to Sarton. In his 'new humanism' the superhuman category disappeared and the study of man gained equal status with the study of nature. Only the combination of study of both fields could save humanity from the so-called technocrats: scientists who had become specialists in their own fields, who had no respect for the humanities and a total lack of appreciation of the unity of science. According to Sarton the role for the history of science in bringing this new humanism about was crucial: 'Between the old humanist and the scientist, there is but one bridge, the history of science, and the construction of that bridge is the main cultural need of our time. ${ }^{6}$ 
Why was the history of science needed for this? Why not just concentrate on the products of modern science? Sarton answered this question by pointing to the complementary tasks of science and the historiography of science. For him there was no difference in principle between these fields. Both science and the study of its history worked toward the same goals, namely the acquisition of knowledge. It is only that the tasks of historians and scientists were different. Whereas the scientist investigates nature and comes up with experimental and theoretical results, the historian should act as a critic of the products of the scientist, like art critics value the work of artists. Sarton thought that: 'There can be no real understanding of science, that is, there can be no science, without continuous criticism of it." This continuous criticism is the most important check on the dangers involved in the growth of knowledge and technology. On top of debates held within the scientific community, the historian was in a position to deliver such permanent criticism because he or she possessed the scholarship to place the products of the scientist and the debates held in scientific communities in a larger perspective and evaluate the new contribution with respect to the foregoing tradition. In this way historical understanding and current scientific research met and only a professional historiography of science could provide the needed bridge.

Apart from being a critic, the historian should also act as a guardian. One of the main tasks of historiography of science was to establish the good tradition and do away with things that do not belong to it such as superstitions, undeserved privileges, (willful) error, etc. This good tradition was not a story of immutability. Tradition for Sarton was a dynamic force, not an endless repetition of the same behavior. He saw the good tradition as a sequence of the right steps. Only when this good tradition was safely protected could new discoveries and new claims to knowledge be assessed properly. The historian must thus be evaluative with respect to the past and present but not in the simplistic sense that everything in the past that contradicts present-day knowledge should be considered as bad science. Science progresses toward the truth but this road is difficult and almost every scientific theory so far has proven to be open for revision. The methods by which this constant revision is possible are thus of central importance to the whole endeavor.

It was equally important that the historian highlighted the human dimension in this process. Historians had to concentrate on the nonlinear development of science. Gathering knowledge about the world was a difficult process, which required a lot of effort. In the long run, with the benefit of hindsight, it is possible to see patterns and logical sequences but when focused on shorter time spans great struggles can be seen, hard work, wandering down wrong paths, periods of puzzlement and conflicts with others, victories and losses, etc. Clearly it was one of the historian's tasks to highlight these struggles in narratives about the past. 
'New humanism' thus also meant that the human effort that had to be put in to unravel nature's mysteries gained the highest respect: 'The New Humanist is of all men the one who is most conscious of his traditions and of the traditions of mankind. He admires the wonders of science but the greatest wonder of all he reflects is that man revealed them.'

Finally, historians of science should become, perhaps somewhat paradoxically, specialists in generalization, and obtain long-term views lending unity to all scientific efforts. The general picture should act as an antidote to today's delusions and create the right attitude to science by sorting effects of moderation, patience and, most importantly, humility. Scientists are after the truth and their theories are converging toward it but they need to bear in mind that their ideas are continuously subject to revision. Knowledge of the history of science can help to critically evaluate present scientific ideas. Thus acquaintance with the history of science could have the following benefits: be an inspiration for current scientists, act as a check on claims of originality, lend a scientific attitude to further scientists' investigations and provide useful morals for present-day research.

In education the historian had to teach what science was about, its function and methods, its psychological and sociological implications, its deep humanity and its importance for the purification of thought and the integration of culture. In order to do all this a historian of science had to be an expert in history, have a good command of the state of the art in the sciences of both his or her own day and the past, be able to interpret past sources well (Sarton was also an empiricist), and also be a good writer and an able teacher.

Taken together, and especially in an age of rapid discipline formation, the task was obviously impossible for a single scholar to perform. This is precisely the reason why Sarton put so much effort in the institutionalization of the field. The unearthing of the sources and the interpretations of all episodes of the history of science for the most part still needed to commence. A great number of people was needed to perform such an abundance of detailed research projects. Good communication channels and an institutional platform for bringing all this knowledge together, passing it over to future generations and eventually build syntheses out of them, was therefore absolutely necessary. Otherwise historiography of science could never perform the important tasks Sarton had placed on it. And since these tasks were for him of crucial importance to the well-being of mankind as a whole, he devoted much energy to the legitimatization of the study of history of science as a separate discipline and the institutionalization of the field in the academic world.

According to Kragh, Sarton's program was never carried out in practice. ${ }^{9}$ There is, however, serious reason to doubt this. First the well-known historian of science A. Rupert Hall noticed a great influence of Sarton's ideas in Cam- 
bridge at the onset of professional historiography of science there. He writes: 'the broad notion of the literate scientific culture, at once rigorous and humane, agnostic and experimental, which Sarton called the New Humanism had become widespread during the first half of the century' ${ }^{\prime \circ}$ Apart from such direct references the similarities between Sarton's programmatic writings and the work of other historians such as Alexandre Koyré (I892-1964), E.A. Burtt (I892-1989) and E.J. Dijksterhuis (1892-I965) are striking. These historians did not write lengthy programmatic essays but were all occupied with establishing the good tradition, with the issue of humanism and with the philosophical dimension of science.

In the writings of both Koyré and Burtt we find the view of science as the most successful movement of thought history so far records. But in both we also find comments on the downside of the progress that modern science brought, not unlike Max Weber's ideas on the disenchantment of the world. According to Burtt the dominance of modern science in Western culture had led to a downgrading of the human spirit. It was the central task of philosophy 'to reinstate man with his high spiritual claims' ${ }^{\text {II }}$ rather than let him become a mere entity reducible to the atomic categories of modern science. The remedy for this, according to Burtt, was to reconnect science in each historical period to the philosophical or metaphysical ideas that reigned supreme in these periods. The quest for scientific knowledge could be properly understood only in connection to these philosophical schemes. Hence the title of Burtt's work, The Metaphysical Foundations of Modern Physical Science (1924). The fear of dehumanization is expressed in different terms than in the work of Sarton, who considered the scientific process dangerous, not in itself, but only if the control of science fell into the wrong hands. Yet the remedy both come up with is strikingly similar: a firm connection between the sciences and the humanities is needed in order to benefit most from the advancement in scientific knowledge.

Koyrés ideas, although slightly different again, can easily be compared to the views of Burtt and Sarton. Like Burtt, Koyré too argued for the importance of studying philosophical schemes of the past. For him general mental frameworks could not be separated from scientific research: in every period scientific thought must be related to the 'thinking cap' prevalent in the period. In effect this can be seen as the start of contextualism in historiography of science. ${ }^{12}$ What made the seventeenth-century breakthrough in science possible for Koyré was a change from Aristotelianism to Neoplatonism. The latter brought with it the idea that reality was to be captured in mathematical terms. From a world of 'more or less' people started to live in a universe of precision. It was chiefly Galileo who brought this revolution about. For Koyré, Galileo's approach to science was basically the right one. ${ }^{13}$ 
The praise for Neoplatonism was shared by Dijksterhuis, who launched the idea of a mechanization of the world picture, which was in fact a mathematization of the world picture. ${ }^{14}$ A considerable difference of opinion with Koyré was that Dijksterhuis did not consider reality as fundamentally mathematical. He saw mathematics as a way of describing that gets us as close to reality as we can. Yet they both had a decidedly anti-positivist attitude, as can also be read off from Koyré's slogan that 'good physics is done a priori'. Thus there was a great difference with Sarton, who very much wanted to align history of science to the positivist project in philosophy. Yet what is most important for the present purposes is to see that they all tried, in very different ways to be sure, to relate the study of past science in one way or another to philosophy, thereby finding a way to distinguish the good tradition in science from the bad.

Cohen has summed up Koyrés achievements in the following way:

Let there be no mistake about it: Koyré had a most powerful message. It had all the strengths of a unitary account in which, through the magnetic action of the core conception, a huge number of hitherto unrelated historical facts were now arranged, like so many iron filings, along neat lines of force. $^{15}$

That core conception was the Scientific Revolution. In Sartonian spirit Koyrés unitary account combined the search for the right place of the human aspect in the development of science, the aim to distinguish the good tradition from the bad, and an attempt to secure a fundamental place for philosophy in writing of the history of science. The similarities in outlook on the goals and aims of the new profession are striking. The execution of them led to a number of challenges that, as will be argued, have remained pressing, especially for the study of past science in our day.

\section{Challenges to the profession}

Gradually historians started to doubt the value of sketching 'big pictures' of the history of science because these appeared to be centered too much on the present instead of the past. Therefore stories of the good tradition, spanning long periods of time, possibly held together with unifying concepts, are nowadays invariably set aside as 'Whiggism'. In general one speaks of Whig history when the historical process is accounted for with present outcomes in mind. This lends the historical process a form of necessity and for this reason presentist schemes for the organization of historical narratives are mostly rejected. Next to presentism three other 
Whiggish 'sins' can be associated with history of science, namely judgmentalism, triumphalism and internalism.

All these four aspects of Whiggism apply to the historiography of science that was produced until roughly the I 960 s. It was presentist in the sense that historians sought to establish the string of ideas that had led to the present-day state of scientific knowledge. It was also presentist in its objectives: to keep contemporary developments of science in check by historical awareness. It was judgmental in the sense that studying the history of science led to inferences about what the correct way of doing science was. It was triumphalist as science was seen as potentially beneficial to mankind and achievements in science, especially during and after the Scientific Revolution, were seen as the highest achievements of mankind. It was internalist in the sense that an influence of the so-called 'external' factors, such as social, economic, political and cultural factors, on the course of science was hardly recognized. Although a start of contextualism can be witnessed, this contextualism applies only to the wider mental, spiritual or philosophical context, and certainly not to the socio-cultural context.

It comes as no surprise, then, that historians who did begin to put emphasis on an analysis of the socio-cultural context in order to understand past science set aside the work of their predecessors as Whiggish. A recent example is Steven Shapin, who sees in Sarton no more than a triumphalist. He explains this triumphalism by Sarton's institutional aims. The high achievements of the past were a good selling point for the study of history. When historiography of science had become a recognized discipline in the university system, Shapin argues, there was no longer any need for exaggeration and a process of 'lowering the tone' could begin ${ }^{16}$ There is maybe some truth in this analysis but in general I believe it can be harmful to brush off the older historiography of science as Whiggish with the implication that the work, as well as the incentives behind this work, can be considered irrelevant. In this way one loses sight of important motivations to engage in historical study of the past and equally important deliberations on the discipline's aims and the prospects of and problems in achieving these aims.

The first generation of professional historians of science certainly was not naively Whiggish. There was keen appreciation of the struggles of past scientists and their modes of thinking. Not everything that must be considered wrong from the standards of present-day science was simply rejected as uninteresting or as bad science. Being an important link in the chain toward the present was the most important criterion to assess the science of the past. Progress was also not seen as a linear, gradual and smooth process, as an extreme Whig account of past science would have it. However, dividing the concept of Whig history into four aspects, presentism, judgmentalism, progressivism/triumphalism and 
internalism, allows for a more balanced approach to 'Whiggism'. It is quite well possible that interpretations of these aspects can be formulated without turning them into a 'Whiggish sin'. It is, for example, not difficult to see that any form of historiography contains a degree of presentism, for the simple reason that the historian can never fully shake off his or her own rootedness in place and time. Moreover with the rejection of Whig history talk of progress has been abandoned in historiography of science. One can, with Elzinga, wonder whether this effect of the use of the notion of Whig history is desirable: "The reproach has become a shibboleth, which is placed in position against anyone who claims that science is in progress at all, ${ }^{17}$

It is indeed important to recognize that the term 'Whig history' with reference to the historiography of science only came in use from the 1970 s onwards. ${ }^{18}$ If one searches the word in the Isis database one sees references to the term increase dramatically only from the 1980 s onwards. This suggests that the usage of the term has played a role in the legitimatization of new approaches to past science (see the next section). Dismissing former approaches as naively Whiggish then appears also to have been a rhetorical strategy. This strategy leaves all kinds of questions unaddressed. If triumphalism was needed to legitimize the field, the question why the historiography of science was needed as a separate academic field is still open. Why were the concerns with humanism so strongly present in many scholars? And if the present was thought so important, why was a study of the history of science needed? Why not just devote all effort to present-day science? Only by zooming in on the 'unitary' accounts of scholars like Sarton and Koyré can we find answers to such questions. The uptake of this paper is that a number of challenges to the profession that can be extracted from this, have lost none of their relevance today. These challenges have in common that they are all about striking a right balance between generalism and specialism.

The first of three challenges is the tension between the universalist aspirations of historiography of science and the increase in specialization in the natural sciences. How to satisfy the aim of maintaining a general overview of the whole development of science if it becomes so enormously complex? Even groups of historians cannot keep up with the specialism required to understand what is going on in all the separate disciplines and subdisciplines. ${ }^{19}$ The issue of unity between past and present is at stake here as well as the issue of unity between science and history of science which Sarton, in particular, envisaged as complementary endeavors. A gap in expertise was already felt pressing before World War II. The continuing relevance of the problem can, however, be seen in the so-called 'Science Wars' in the I99os. In this period historians or sociologists of science were blamed by natural scientists for not having a clue about what they were talking 
about in terms of the content of scientific theories. On the other hand natural scientists were blamed for ignoring the impact of contextual factors on the course of science. Both camps argued that the other camp was, through fundamental ignorance, not in a position to offer serious critique, analysis or interpretation of past and present science. The way these 'Science Wars' were conducted strikes one as not very fruitful and the debate in the end was quite inconclusive. ${ }^{20}$ Sarton's worst fear of a separation between the sciences and the humanities appeared to have come about!

The second challenge involves the tension between the generalist attitude of the historian and the need to stay close to the sources. For Sarton generalization (the creation of larger historical syntheses) over detailed case studies was justified only after work on the primary sources had been done. Since in later generations the number of relevant factors to consider expanded dramatically (see the next section) the number of sources to take into account expanded as well. A decidedly empirical attitude then blocks the way to setting up a grand historical narrative about science. Sarton could still maintain a relatively simple conception of the good tradition and how to account for it, but such a thing is no longer possible today. The question the field has yet to answer satisfactorily is what the proper level of generalization is and how to connect this to detailed studies of source material tied to historical localities.

A final point of tension is the relation between philosophy of science and historiography of science. Next to the natural sciences, philosophy of science must be considered as the mother discipline of the historiography of science. Clearly during the first period of professionalization the ties to philosophy were quite strong. In Sarton there was an emphasis on positivism; others sought to connect past science to its metaphysical backgrounds and held the turn to Neoplatonism in high esteem. Moreover all historians were involved in the philosophical project of setting up criteria for what good science consists of and this model of good science was surely meant to be context independent. Philosophical thinking led to overarching normative models of science. Historical research was done in order to demonstrate or test such philosophical models. Today most historians abhor such historiography and the implication is that philosophy is mostly kept at a distance. Yet weakening the ties to the natural sciences and to philosophy of science did not lead to independent historical scholarship as ties to the social sciences such as sociology and anthropology were set in place. In the next two sections this profound change in orientation will be addressed and analyzed. We will then be in a position to assess the significance of the three challenges to the profession as it is currently practiced. 


\section{Changes to the profession}

After World War II attention for the study of the history of science grew considerably. In the US chairs were created at the insistence of not only university policy makers but also general politicians. ${ }^{21}$ Yet according to Kuhn professionalization in historical scholarship proceeded slowly. In a tribute paper to commemorate Sarton, Kuhn offered some valuable insights into the status of the field of the historiography of science in the 1950s. In hindsight he felt the field offered an amateurish sight. There were regular meetings of the History of Science Society but these were relatively small conferences, sometimes even held at the home of one of the members of the society. Moreover, Kuhn himself was appointed lecturer in the history of science while having had no training in that field whatsoever. He observed that such a thing would be impossible in the I980s. Kuhn did not express any nostalgic feelings about this period and claimed that, in spite of all the efforts before, the professionalization of the discipline started only when his generation set out to work..$^{22}$

This much-needed increase in historical sophistication occurred against the background of changing perspectives on the benefits of science for mankind. Science was also seen as standing at the root of many negative things such as dehumanization and alienation, pollution and dramatic forms of warfare. Perhaps the gain in scientific knowledge did not automatically lead to improvements in human life. Perhaps scientific progress was a myth. To address the fear of loss of control it was necessary to lower the tone of science. ${ }^{23}$ Because it put science on a high pedestal, making it something sacred and inaccessible, the universalist ideology was seen to be part of the problem and not part of the solution as the older generation had thought. The concern with improving society, that was clearly present from the beginning of the process of professionalization, remained, but became articulated in a completely different way as new approaches to (past) science came into being.

These new approaches invariably started to stress the contingent aspects of the historical process. The main idea became to understand past science on its own terms. Kuhn's notion of the paradigm demonstrates the shift in attention well. ${ }^{24}$ In its most common interpretation a scientific paradigm is a 'closed' system consisting of theories, methods of research and standards of evaluation, but also of a set of values, principles and background assumptions. This set is informed by the social and cultural factors dominant in a given period and/or place. All aspects together determine what normal science is within the paradigm. When a shift occurs to a new paradigm Kuhn argued that no cumulative process of increase of knowledge should be assumed, as the perspective on things, even on the most fundamental concepts like time and space, could 
change dramatically. Thus the next paradigm should be understood on its own terms again, and so on. ${ }^{25}$

Older science students were aware that reality was not easily mirrored in scientific theories but they did not imagine that the relationship could be so complex with a multitude of contextual factors operating on it. ${ }^{26}$ Yet even Kuhn's model of science as moving from paradigm to paradigm can nowadays appear as a bit old-fashioned. A paradigm for Kuhn could last very long, for example, the Newtonian paradigm that held sway from roughly I700 to I900. Moreover within a period of normal science the focus on scientific ideas is still quite dominant. Sociologists and historians after Kuhn found all this too schematic and too abstract. ${ }^{27}$ They argued that research should focus on concrete local circumstances and the concrete interaction of people and things. Ideas were not just floating in the air but their emergence and acceptance or rejection should be understood in terms of these interactions. The maturation process of the history of science has therefore been one of increasing localization.

This process can be captured in two ways. It can be viewed as a process of increasing naturalization of the study of past science. By 'naturalization' I mean here the approach to explain science in causal terms. This can be done on the following levels: social interaction, man-nature interaction, psychological processing and historical factors. ${ }^{28}$ It depends on the specific approach to past science which form of causal interaction is given the most dominant explanatory force. The naturalist approach is opposed to the formal approach to the study of science, which aims to establish a logical succession in the historical process of theory replacement and seeks to identify relations in the total body of scientific knowledge by the use of formal logic. The formal approach has close ties to philosophy and has been increasingly rejected in favor of naturalist projects in history of science. Fields apt to serve such projects are the social sciences and also the study of history, broadly speaking.

Another way to capture the change in orientation in the study of past science is in terms of symmetry. The principle of symmetry, introduced to the study of science by sociologist David Bloor in 1976, orders us to study both true and false claims to knowledge in the same manner, i.e., symmetrically. For Bloor it is not the case that 'good' science can be explained by reference to a set of rational or formal rules and deviations from good science by reference to 'disturbing' social factors. Instead all acceptance and rejection of theories should according to him be explained by reference to the same type of factors, namely social factors. There may be other factors in play but social factors (meant in the widest sense possible) ultimately determine the course of science, for example, in the settling of scientific controversies. ${ }^{29}$ Norms of rationality cannot be used to explain past science but acceptance of norms becomes itself a topic of investigation. The rationale of 
this approach is to gain a better grasp of the decision-making processes in science. A deeper understanding of these social processes would yield more control over the scientific enterprise and possibly minimize harmful effects to society. Note that the distinction between 'internal' and 'external' is given up. In any historical context acceptance and rejection of knowledge claims is inextricably mixed up with all the societal factors present in that context. ${ }^{30}$

It has proven possible to erase more boundaries and expand the reach of the symmetry principle. ${ }^{31}$ Such generalized principles of symmetry declare even more things as topics of investigation, instead of using them as explanatory resources. In other words, analytical concepts and models are increasingly replaced in favor of a purely descriptive approach of rigidly following the actors, perhaps not far remote from the old Rankean spirit of 'bloss zeigen wie es eigentlich gewesen'. ${ }^{32}$

What these programmatic changes have meant for the research agenda of historians of science has been brought together by Golinski in a useful survey. ${ }^{33}$ The following themes dominate this agenda: study of scientific and experimental practices (practical turn), focus on material circumstances, instruments and objects (material turn), focus on linguistic practice, discourse analysis, communication, representation (linguistic turn), attention to the places of research (geographical turn), the institutionalization process of universities, scientific disciplines, etc., the interaction of science and the public and the self-fashioning of scientists. To this list a number of socially oriented topics such as relations of trust and authority among scientists, relations between science and politics and the interwovenness of economic and scientific developments can be added (social turn). Golinski argues that this list of topics has become what mainstream historiography of science is occupied with. I agree with this and add that this continues to be so to this day. As a Belgian historian recently put it: 'It is widely accepted among historians of science that the production of knowledge is first and foremost a localized process $[\ldots]$, the localized setting plays a crucial role in understanding its conceptual and epistemic features. ${ }^{34}$

\section{A peculiar process of maturation}

It is strange that the development in approaches to historiography of science has ended in a form of Rankean historicism, the model general professional historiography started out with at the beginning of the nineteenth century, but that has long become obsolete. ${ }^{35}$ How can we account for this? Behind the process of naturalization of the study of past science two driving forces can be discerned. Lorraine Daston once said that 'all epistemology is born in fear'. These two driving forces can both be seen as being born in fear. The first force I call the striving 
for liberation. By liberation I mean the freeing of dogmas, norms and standards, Eurocentrism, Westernization, elitism, etc. There is a moral component in this. In presenting the development of science, both in terms of its knowledge claims and in terms of its institutions, as a highly contingent process and in denying that there exist transcendental norms with which all scientific activities and products can be judged, space is created to treat all actions and motives of past historical actors with equal respect. Further, stepping back from the modernist progressive project creates room for a critical engagement with this project, which staunch adherents of modernism are not willing to undertake. All this relates to a fear of objectivism: the dehumanizing force of science that destroys essential aspects of man's life - something that bothered Burtt and Koyré. Perhaps it is ultimately a Romantic fear, as one of the points of Romanticism was to free the individual from the mechanistic and deterministic schemes that Enlightenment thinking had produced.

The second driving force I have called the striving for exactness. An empiricist attitude of being as exact as possible in explications of past science shows itself in the approach to investigate concrete causal relations. Pointing toward 'influences' of persons, ideas or movements on scientists is not enough but must be made concrete by identifying patterns of interaction. This approach has gradually gained the upper hand in the historiography of science. Grand narratives or large-scale comparisons are eschewed because they are regarded as speculative. This is the scientific side of the abolishment of a priori analytical concepts, or philosophically informed interpretive models of past science. Historians do not want to be reproached for being unscientific and therefore they insist on the most exact proof they can get. This fear of being unscientific relates to a more general fear of subjectivism. Once progressive ideals and transcendental standards are given up there is nothing to go by and hence the door is open for subjective speculation. Only an insistence on proof of concrete causal interactions can keep this door closed.

The two fears are clearly different as one leads to a striving for less determination whereas the other leads to a striving for more determination. Yet strangely both lead to the same direction in historiography of science. Both lead to a localist and descriptivist type of historiography. ${ }^{36}$ This becomes understandable if the striving for liberation is interpreted as an avoidance of prescriptivism. To let the past speak without fitting it into all kinds of straitjackets is not incompatible with an empiricist attitude of deriving theories from facts and being wary of too much theoretical speculation.

A conscious estrangement of philosophy and the natural sciences has occurred in connection. Historians of science no longer wanted to work in service of these disciplines and claimed independence instead. This, however, has proven more easily said than done. Interpretative models from the social sciences have started 
to exert a strong influence on the field and cannot easily be passed by. And if the return to a naive historicism is the price that needs to be paid to become a fully recognized historical subdiscipline then this price is surely too high. ${ }^{37} \mathrm{I}$ am drawn to the conclusion that to gain complete independence for historiography of science is a mistaken goal. It belongs to the peculiarities of historiography of science that it really is a discipline that stands on a bridge between the natural sciences and the humanities. The subject matter historians of science have to deal with, the products of the sciences, together with the humanistic methods of studying and interpreting the past dictate this. Trying to gain independence by cutting off the bridge from the banks would be self-destructive. In light of this conclusion, and in light of the analysis of the developments in the approach to past science in mainstream historiography of science, the three challenges to the profession formulated above require renewed attention.

\section{Back to the challenges}

In the development of approaches to the history of science the common aim has been to loosen the ties to the natural sciences and to philosophy. This enterprise has been driven by lofty ethical and scientific ideals but the end result of the process is nonetheless unsatisfactory. We were drawn to the conclusion that the relation between historiography of science and its 'parent' disciplines has to be taken seriously. The challenge then is not to gain independence by cutting ties with these disciplines but to reconceptualize the relations between historiography of science, philosophy and the natural sciences. This challenge fits in remarkably well with the three challenges formulated above of striking the right balance between generalism and specialism. On all scores, the history of science has started to lean over to specialism. The danger of this is that the field is losing its relevance.

The first challenge was to address the tension between maintaining a universal picture of scientific development and the dramatic increase in specialization in the sciences. To place all the developments into the larger picture is very hard to do since it runs against the problem that highly specialized knowledge is needed for that. This is not something historians of science can easily acquire. The solution that has been followed by historians of science is to break off the past from the present and focus on past science, forbidding the use of present-day scientific knowledge in historical explication. This approach can, however, backfire, even when the aim is just gaining a better understanding of specific historical episodes. Although this has to be handled with great care, it can be argued that modern ideas about phenomena with which past scientists also struggled can help in explicating past science. ${ }^{38}$ In order to make proper use of modern scientific knowl- 
edge in accounts of past science cooperation needs to be sought with present-day scientists. Scientists can benefit from this cooperation too as historical scholarship can be of aid in present-day research. ${ }^{39}$

The second challenge was to come up with a proper level of generalization. The prevalent empiricism in the historiography of science nowadays blocks generalization very quickly. The problem with a full empiricism, in which almost anything is declared a topic that requires explanation, is, however, that selective criteria of what is relevant in the past fail us. To describe everything is not only impossible - the past is far too complex for that - but also undesirable. It would be just a reproduction of the past without any gains or insight. One can wonder what purpose the description of all the interactions between actors in the past serves since there is no longer a clear research agenda behind it. ${ }^{40}$ Although historical scholarship has markedly improved over the years, in the end the two forces driving the process have overshot their goals. They put restrictions on the tools of analysis historians of science are allowed to use and these restrictions lead to unwelcome consequences. The challenge is to retreat a few steps without relinquishing the abundance of insight that the symmetrical approaches to past science have brought. How to achieve this is one of the harder questions as it is very easy to slide back into Whig history or to the re-instantiation of normative philosophical models of science that do not square very well with the actual course of history.

Yet philosophy is indispensable for finding the way forward. Thomas Kuhn observed that particularly in periods of acknowledged crisis, scientists have turned to philosophical analysis as a device for unlocking the riddles of their field'. ${ }^{4}$ This holds for historians of science as well, who still have to unlock the riddle of the connection between the general and the specific. This brings us to the third challenge: How can we envisage the relation between the historical (specific, concrete) and the philosophical (general, abstract) study of science?

It is good to recognize that in spite of all the rhetoric philosophy has never been cut out completely in the science studies. As a matter of fact, the shift in orientation toward past science was supported by philosophical arguments and new approaches were founded upon philosophical ideas. For example, the ideas of the later Wittgenstein on rule following, language games, life forms and 'meaning is use' or Quine's naturalist epistemology and his holistic approach to scientific knowledge have played a profound role. ${ }^{42}$ Philosophy has thus been out only on the surface. Philosophical debates about science have continued and 'symmetrists' have amply taken part in them. ${ }^{43}$

All this is an indication that the role of philosophy in any approach to the study of science is indispensable. To satisfy the need for a new analytical framework one has to turn to philosophy. Historians no longer have to be afraid that 
philosophers do not recognize the value of their work. Historical winds have blown hard enough through the ranks of philosophy for philosophers to recognize an important role for history in their models of science. Clear examples are projects in normative naturalism (Laudan, Rouse, Mayo), specific formulations of the analogy between science and evolutionary theory and new developments in thinking about the concept of error. ${ }^{44}$ Such projects, however, have not found their way into the community of historians of science yet. Perhaps reaching out to them still requires shrugging off stereotyped images of philosophy and Whiggism in the community of historians of science.

Another option would be to seriously investigate the merits of comparative historiography for the history of science. The suggestion is very logical because comparisons bring about a connection between what is specific and what is general. When two particular historical localities are compared, what is present in both automatically becomes more general whereas what is present in only one context remains specific. Both findings can be valuable for historical explanation. Yet setting up a comparative framework for the historiography of science is not an easy task since the general intuition needs to be articulated in more specific terms with respect to the level of comparison, the suitable units of comparison, the steering role of prior analysis and the manner in which the results of comparative investigations need to be evaluated. Also comparativism has received a bad press among historians of science because of the projects of Needham and Zilsel that started out before World War II, which are mostly seen as just another version of Eurocentrism. So serious scruples need to be overcome. ${ }^{45}$

Whatever the next turn in the historiography of science will be, a general perspective is involved in any approach to past science. Different approaches to the history of science can lead to different views of what science actually is. The whole enterprise then is profoundly philosophical, just as every really good historiography is. A conscious use of this insight may help to restore some of the old aims of the field: to be general, to be critical, to act as a bridge between the sciences and the humanities, to channel progress into the right direction and to contribute to the improvement of society.

\section{Notes}

I This work is part of the research program 'Philosophical Foundations of the Historiography of Science' financed by the Netherlands Organization for Scientific Research (NWO). I thank my colleagues in the program at Leiden University for their valuable comments and suggestions.

2 See Helge Kragh, An Introduction to the Historiography of Science (Cambridge, I987); George Sarton, A Guide to the History of Science: A First Guide for the Study of the History of 
Science with Introductory Essays on Science and Tradition (Waltham, I952). Contributions to historiography of science by Whewell, Duhem, and Mach are discussed in $\mathrm{H}$. Floris Cohen, The Scientific Revolution: A Historiographical Inquiry (Chicago, 1994), 24-53.

For example, none of the best-known historians of the period such as George Sarton, Alexandre Koyré, Lynn Thorndike, Edwin Burtt, Eduard Dijksterhuis, or even Thomas Kuhn was educated as a specialist in history of science, or even in history in the case of most of these.

4 I am in agreement here with Nicholas Jardine who perceives 'theoretical anarchy' in the field in N. Jardine, 'Sammlung, Wissenschaft, Kulturgeschichte', in A. te Heesen and E.C. Spary (eds.), Sammeln als Wissen. Das Sammeln und seine wissenschaftsgeschichtliche Bedeutung (Göttingen, 200I), I99-22 I.

5 Sarton opposed both communist and fascist systems. After the war he saw his opinions confirmed when the horrifying scientific experiments of the Nazis became known. He also went as far as to say that Hegel was not well versed in science, because he had declared in his dissertation that the number of planets could not exceed seven on principle, and thus it was not a coincidence that his dialectic philosophy led via Marx to communist ideologies: G. Sarton, A Guide to the History of Science, 2nd lecture.

6 George Sarton, The History of Science and the New Humanism (New York, I93I), 72. The plea for 'new humanism' is much less quoted but essentially very similar to C.P. Snow, The Two Cultures and the Scientific Revolution (Cambridge, I959). Even the political concern with totalitarian systems is similar: Sarton wrote against fascism and Snow warned against communism. The similarity is also noted by $\mathrm{H}$. Floris Cohen, 'De wetenschapsrevolutie van de $\mathrm{I} 7^{\mathrm{e}}$ eeuw en de eenheid van het wetenschappelijk denken', in W.W. Mijnhardt and B. Theunissen (eds.), De Twee Culturen. De eenheid van kennis en haar teloorgang (Amsterdam, 1988). In The Two Cultures there is, however, no reference to Sarton at all.

7 Sarton, A Guide to the History of Science, I 4.

8 Ibid.,I3.

9 Kragh, Introduction, I9.

Io A. Rupert Hall, 'Beginnings at Cambridge', Isis (I984), 22-25.

I I E.A. Burtt, The Metaphysical Foundations of Modern Science (New York, I 954 [I 924 ]), 25.

I2 As pointed out in Cohen, The Scientific Revolution. The idea of 'thinking cap' was further developed by Thomas Kuhn into the notion of paradigm.

I 3 See A. Koyré, Études Galiléennes (Paris, I939).

I4 E.J. Dijksterhuis, The Mechanization of the World Picture (I950).

I5 Cohen, The Scientific Revolution, 79.

I6 Steven Shapin, Never Pure: Historical Studies of Science as if It Was Produced by People with Bodies, Situated in Time, Space, Culture, and Society, and Struggling for Credibility and Authority (Baltimore, 2010), 3-14: 'Lowering the tone in the history of science'.

I7 A. Elzinga, 'Wetenschapsgeschiedenis van overzee. Congresverslag', Skript 8 (I987), 263270, esp. 267.

I 8 In Nicholas Jardine, 'Whigs and Stories: Herbert Butterfield and the Historiography of Science', History of Science 4I.2 (2003), I25-I 40, the first usages of the term are traced.

I9 As Floris Cohen pointed out to me lack of scientific background is perhaps the most profound reason why 'mainstream' historians en masse leave out science as an important determining factor of the history of mankind.

20 In the collection of essays in both N. Koertge (ed.), A House Built on Sand: Exposing Postmodernist Myths about Science (Oxford, I998) and Ullica Segerstråle (ed.), Beyond the Science Wars: The Missing Discourse about Science and Society (New York, 2000), an 
attempt is made to strike a balance after the storm had died down. The former is still quite belligerent, while the explorations to move beyond the 'wars' in the latter remain somewhat inconclusive.

2I James B. Conant was one of the main driving forces behind this process as mentioned in Robert S. Westman, 'Two Cultures or One? A Second Look at Kuhn's The Copernican Revolution', Isis 85 (I994), 79-I I 5. Kuhn also mentioned the profound impact of scientific findings on the course of the war as a motivation to increase attention for history of science. A useful survey is also J. W. Dauben, M.L. Gleason, and G.E. Smith,'Seven Decades of History of Science: I. Bernhard Cohen, I9I4-2003, Second Editor of Isis', Isis Ioo- Io I (2009), 4-35.

22 Thomas S. Kuhn, 'Professionalization Recollected in Tranquility', Isis 75.I (I984), 29-32.

23 That this fear is widespread can, for example, be seen in the recurrent topos of the mad and bad scientist in film and literature.

24 Thomas S. Kuhn, The Structure of Scientific Revolutions (Chicago, I962).

25 This message was radicalized in Feyerabend's well-known Against Method: Outline of an Anarchistic Theory of Knowledge (I975). Instead of Kuhn I could also have chosen other examples of new approaches to science using new analytical concepts to study the specifics of historical contexts, such as Robert K. Merton, who came with a sociology of institutions and Stephen Toulmin, who developed a study of scientific disciplines as ecological 'niches' via an analogy with the theory of evolution.

26 In fact the whole mirror metaphor was cast aside in favor of constructivist points of view. See especially Richard Rorty, Philosophy and the Mirror of Nature (Princeton, 1979).

27 Note that Kuhn himself changed his position, but in the opposite direction. On the problem of incommensurability of paradigms he proposed that with respect to a number of virtues, such as simplicity, accuracy and scope, interparadigmatic comparisons were possible thus offering an alternative standard of progress.

28 For naturalism in relation to the study of (past) science, see Philip Kitcher,'The Naturalists Return', Philosophical Review Ior.I (I992), 53-II4.

29 David Bloor, Knowledge and Social Imagery (London, 1976).

30 According to Steven Shapin, 'Discipline and Bounding: The History and Sociology of Science as Seen through the Externalism-Internalism Debate', History of Science 30 (I992), this message still awaited full recognition in historiography of science as late as I992.

3I One of the most important generalizations of symmetry can be found in Bruno Latour, We Have Never Been Modern (Boston, 199I). For an overview of generalizations, see D. Pels, 'The Politics of Symmetry', Social Studies of Science 26.2 (I996), 277-304.

32 The same observation can be found in J.M. Kuukkanen, 'The Missing Narrativist Turn in the Historiography of Science', History and Theory 5I.3 (2012), 340-363.

33 J. Golinski, Making Natural Knowledge: Constructivism and the History of Science (Chicago and London, 2005).

34 Geert van Paemel, 'Introduction: Networks and Institutions in the Circulation of Knowledge', Studium 4.4 (201 I), I93-I94.

35 See G.G. Iggers, Historiography in the 2oth Century: From Scientific Objectivity to the Postmodern Challenge, 2nd ed. (Middletown, 2005).

36 Note that the network model of Bruno Latour, based on generalized symmetry, offers a global perspective in which localities are connected to each other. Yet this is allowed only if these localities can be related through concrete interaction of actors. Therefore the global in Latour remains local no matter how big the network eventually becomes. 
37 It is therefore not surprising that attempts to declare oneself independent have not been very convincing. Examples: Paul Forman, 'Independence, Not Transcendence, for the Historian of Science', Isis 827 I (I99I), 7I-86, is a late cry to finally get rid of Whiggism. Jardine, 'Sammlung, Wissenschaft, Kulturgeschichte', calls for an end to theoretical anarchy by choosing one model of interpretation, namely the ideas of Norbert Elias on the civilization process. Historians of science should cooperate with other cultural historians in bringing the full understanding of this process about. Yet, Elias was a sociologist and the dominant model then would still be sociological. Hasok Chang, 'We Have Never Been Whiggish (About Phlogiston)', Centaurus 5I (2009), 239-264, calls for an independent judgmentalism for history of science but it remains unclear what this judgmentalism should be based on.

38 An example is given by the puzzling number of measurements of the ratio of the electron's mass and charge carried out by J.J. Thompson. If modern knowledge is used, these measurements can be understood much better. Argument taken from Stephen Weinberg, 'Sokal's Hoax', The New York Review of Books XLIII-I 3 (I996), I I-I 5.

39 Hasok Chang has argued that the history of science can have complementary functions to science because important lines of research may have become forgotten that can still be relevant for present-day research. The historian can reopen such forgotten lines of research. It is different in its formulation but this way of thinking is clearly in Sartonian spirit. Hasok Chang,'History and Philosophy of Science as a Continuation of Science by Other Means', Science and Education 8 (1999), 4I3-425.

40 Ken Alder, 'The History of Science, or, an Oxymoronic Theory of Relativistic Objectivity', in Lloyd Kramer and Sarah Maza (eds.), A Companion to Western Historical Thought (London, 2002), 297-3I8, warns that the history of science can no longer perform its critical functions. Nicholas Jardine has expressed the same worry: "[S]hould the history of science lose the critical functions Butterfield assigned to it, it would become pointless' (Nicholas Jardine, 'Whigs and Stories', I36).

4I Thomas S. Kuhn, The Structure of Scientific Revolutions (Chicago: University of Chicago Press, I962), 88.

42 See, for example, David Bloor, Wittgenstein: A Social Theory of Knowledge (New York: Macmillan, I983), or Bloor, Wittgenstein: Rules and Institutions (Florence, KY: Routledge, I997).

43 This holds especially for Bloor and Latour.

44 For the last, see Giora Hon, Jutta Schickore, and Friedrich Steinle (eds.), Going Amiss in Experimental Research (New York: Springer, 2009).

45 One reviewer suggested that the comparative approach could be the primary resource for the improvements sought in the paper. I am very sympathetic to this suggestion and working on a dissertation at the University of Leiden, in the 'Philosophical Foundations of the Historiography of Science' project, that will contain a discussion on comparativism. The trouble is that the approach has never been articulated very well and has turned into a fringe phenomenon. Almost all contributions to comparative historiography of science are brought together in Lewis Pyenson, 'Comparative History of Science', History of Science 40.I (2002), I-33. The most important theoretical explorations stem from the social sciences and from the I980s: Charles Tilly, Big Structures, Large Processes, Huge Comparisons (New York: Russell Sage Foundation, 1984), Charles Ragin, The Comparative Method: Moving Beyond Qualitative and Quantitative Strategies (Los Angeles: University of California Press, 1987). More recent short papers offering valuable suggestions are by Chris Lorenz, 'Comparative Historiography: Problems and Perspectives', History and 
Theory 38 (1999), 25-39, and Margaret C. Jacob, 'Science Studies after Social Construction: The Turn toward the Comparative and the Global', in Victoria Bonnell and Lynn Hunt (eds.), Beyond the Cultural Turn: New Directions in the Study of Society and Culture (Berkeley: University of California Press, 1999). All this is not much but the tide may be turning as a number of possibly groundbreaking books explicitly based on the comparative approach have recently appeared: G.E.R. Lloyd, Disciplines in the Making: Cross-Cultural Perspectives on Elites, Learning and Innovation (Oxford, 2009), H. Floris Cohen, How Modern Science Came into the World: Four Civilizations, One 17th-Century Breakthrough (Amsterdam, 2010), Rens Bod, A New History of the Humanities (Oxford, 2013). 


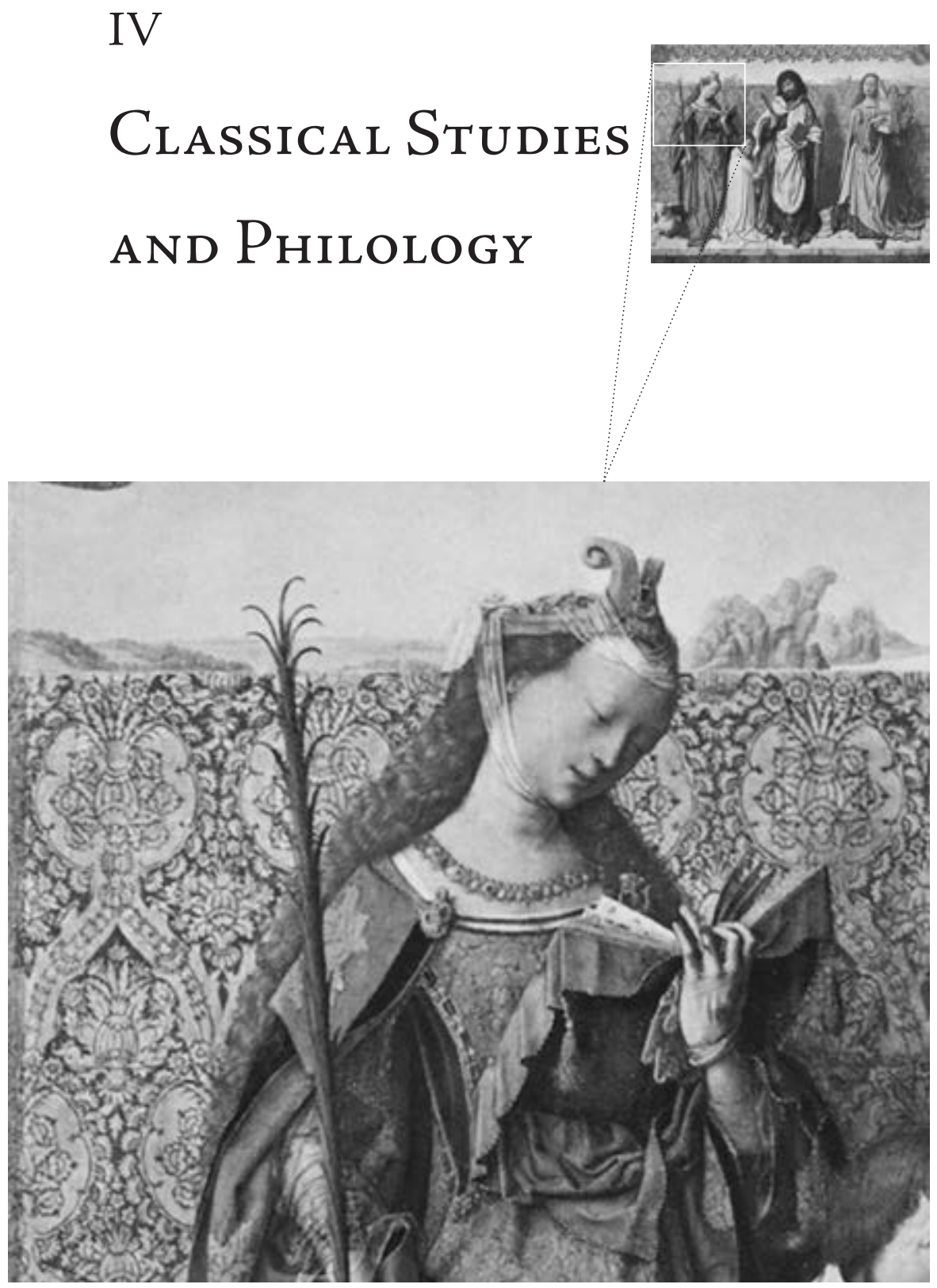



\title{
4+I Quellenforschung
}

\author{
GLenN W. Most
}

A century ago, one of the most important modes of research in the professional study of Greco-Roman antiquity as well as in a number of other fields was a recently developed specialty called by its admirers (back then it had no opponents) 'Quellenforschung'. By decomposing the compilatory handbooks produced by the erudition of late antiquity into their various sources and establishing the relations of dependence among them, the adepts of this method sought to trace back reports about a variety of aspects of the ancient world - primarily philosophy and history, but also religion, law, sculpture, and other matters to their earliest origins. They were convinced that they would thereby place themselves in a position to assess with greater precision the reliability of those reports and would hence be able to make claims of greater validity about those aspects of antiquity.

Nowadays, Quellenforschung is not dead, but it seems moribund. It has moved from the fashionable center of classical studies to the swamps at their periphery; it is practiced by relatively few scholars and seems to be ignored, if not held in suspicion or contempt, by most. Yet, until recently at least, many of the results experts in this field obtained a century ago or more have continued to provide a seemingly solid foundation for studies in a wide variety of disciplines within classical scholarship and beyond it in related and dependent areas of research for which classical scholarship seems itself to have functioned not only as a model but also as a source. Why this has been the case deserves analysis and reflection, and not only because of the implications of these developments for these disciplines themselves.

What are the Quellen of Quellenforschung? The notion that authors use sources is neither novel nor exciting. Derrida was not - indeed, on principle could not possibly have been - the first to proclaim citationality as a fundamental feature of language, nor to point to the countless paradoxes and problems that arise from it. For every way that an author can use a source - indicating 
it clearly, blurring the limits of who said what, citing it verbatim or paraphrasing or distorting or even inventing it, pretending to have used it when he did not, pretending not to have used it when he did, misunderstanding it slightly or greatly or completely, deliberately or inadvertently - can cause difficulties for those readers who want to know not only what is being said, but also and especially just who it is who is saying it. ${ }^{2}$ In premodern times, these difficulties were greatly exacerbated by the absence of such generally agreed upon, unambiguous typographical signals as single and double quotation marks, ' $\mathrm{x}$, " $\mathrm{x}$ ", « $\mathrm{x}$ », etc. ${ }^{3}$ Thus, in the 'Introductory Remarks' to his Guide for the Perplexed, Moses Maimonides writes,

There are seven causes of inconsistencies and contradictions to be met with in a literary work. The first cause arises from the fact that the author collects the opinions of various men, each differing from the other, but neglects to mention the name of the author of any particular opinion. In such a work contradictions or inconsistencies must occur, since any two statements may belong to two different authors. [...] Inconsistencies occurring in the Mishnah and Boraitot are traceable to the first cause. You meet frequently in the Gemara with passages like the following: 'Does not the beginning of the passage contradict the end? No; the beginning is the dictum of a certain Rabbi; the end that of another'; or 'Rabbi (Jehuda ha-Nasi) approved of the opinion of a certain rabbi in one case and gave it therefore anonymously, and having accepted that of another rabbi in the other case he introduced that view without naming the authority'; or 'Who is the author of this anonymous dictum? Rabbi A'. 'Who is that author of that paragraph in the Mishnah? Rabbi B'. Instances of this kind are innumerable. ${ }^{4}$

But if sources and confusions are anthropological universals, the search for ancient sources is a cultural phenomenon which has gone in and out of fashion and Quellenforschung in particular is a specific scholarly technique with its own history quite limited in space and time - if not with legally valid certificates of birth and death, then at least with a roughly dateable rise and fall.

One deep-seated psychological basis for the search for earliest sources is the conviction, already widespread in antiquity, that the best wisdom is a dead one. If (as many old men who think themselves wise suppose) old men are wiser than young men, then perhaps old cultures are wiser than young cultures, too. Herodotus and Plato were impressed by how much more ancient Egyptian culture was than Greek, and were not the only classical Greek authors to pass on to their Greek readers various stories about Greek institutions whose sources lay in a primeval barbarian past (and which, depending upon the point of view, were 
therefore either legitimized or delegitimized). In the cosmopolitan, rootless Hellenistic period, the compensatory demand for the ailta ('causes, origins') was satisfied both by Greek poets and scholars and by foreigners who supplied more or less authentic versions of ancient barbarian wisdom, Egyptian, Phoenician, Babylonian, and so on. But it was above all during late antiquity that Chaldaean oracles, Orphic poems, Hermetic revelations, Pythagorean speculations, and other genuinely preserved or, more often, piously forged texts satisfied a need, concentrated in but by no means limited to the Stoic and especially Neoplatonist philosophers, for primitive sources of a wisdom uncontaminated by (and hence redemptive of) quotidian realities.

A direct affinity links this attitude with that of the Renaissance Neoplatonists, who, when they rediscovered Plato in the fifteenth century, read him through the lens of his late ancient commentators and inherited their antiquarian tastes, magnified now by the further historical distance. Pico della Mirandola, for example, uses a surprisingly sophisticated source analysis both constructively - in the nine hundred theses for which his oration De dignitate hominum was intended as a preface and which, derived from the comparison of surviving ancient philosophical texts, represented what these had in common and must presumably therefore have served as their ultimate sources - and critically - in his last work, an unfinished polemic against astrology in which he tried to demonstrate that this was not after all a science by investigating its origins and reducing it to its sources. Some other Italian humanists, above all Politian, made significant contributions in this field, but it seems thereafter not to have been immediately taken up in general but instead, with some exceptions like the study of Roman law, to have lapsed as a dominant mode of historical research for about two centuries. It was not until the Pyrrhonian skeptics of the latter seventeenth century that the general distrust of historical documentation and the search for new methods for validating and especially for falsifying ancient claims brought the question of the lost sources for extant documents to the forefront of scholarly consciousness.

It is in this context, and above all in the theological scholarship of the eighteenth century, that both of the two ultimate Quellen of nineteenth-century German Quellenforschung are to be found. For in fact Quellenforschung is methodologically a Siamese twin, whose two interdependent halves have rather different characteristics and pedigrees.

On the one hand, Quellenforschung seeks to break apart the transmitted ancient texts that their authors went to so much trouble to weld together out of the various sources they consulted. Such an analysis, which we may term 'deconstructive', attentively examines the text for any evidence of errors or inconsistencies - self-contradictions, variations in language or style, anachronisms, 
etc. - which could suggest that different parts might have derived from different sources; yet at the same time it retains a conviction of the great value of that text despite its evident defects (for otherwise investigating it will lead not to analyzing its sources but simply to repudiating its authority). Precisely this fragile combination of rational analysis and stubborn faith is a characteristic feature of some religious traditions based upon a sacred text; and it was above all in the Hebrew Bible that the Enlightenment found ample opportunity to exercise its skills in this variety of source criticism. ${ }^{5}$ By careful analysis of textual anomalies ${ }^{6}$ Spinoza was able to demonstrate that the Pentateuch could not possibly have been written by Moses, but only by someone else who had lived much later, perhaps Esra; he thereby in effect replaced the notion of a unified text created all at once in a single act of divine afflatus by the image of a lengthy historical development involving contributions and modifications by human authors from different periods who were pursuing different interests. So too, Spinoza analyzed the Book of Daniel into one part (Chapters I-7) derived in the Maccabaean period from Chaldaean writings and another (Chapters 8-I2) written by Daniel himself; he suggested that some later editor must have put these parts together and published them. ${ }^{7}$ But it was above all Henning Bernhard Witter and Jean Astruc, who in the early eighteenth century argued that the Pentateuch is a heterogeneous compilation. Astruc's analysis of the text into Moses' three sources - 'mémoire A' (which calls God 'Elohim'), 'mémoire B' (which uses the term 'Jehova'), and an additional 'mémoire $C$ ' (further subdivided into 8 rubrics) - was at first dismissed by such scholars as Johann David Michaelis, but by the last quarter of the eighteenth century had won acceptance, especially by the Göttingen specialist for the Hebrew Bible, Johann Gottfried Eichhorn. It was in turn Eichhorn's work which went on to serve as a model for Friedrich August Wolf's Prolegomena ad Homerum of 1795 , in which the discrepancies and anomalies of the transmitted Homeric text were taken as evidence that it had been compiled out of earlier, originally independent songs and had acquired its present form in the course of centuries of transmission and modification. ${ }^{8}$ Wolf's authoritative transference of deconstructive source criticism from the founding text of the theologians to that of the philologists ensured that the method of Quellenforschung would become canonical for nineteenth-century German classical scholarship.

But this method is only one of the two sources involved: for Quellenforschung not only tries to tear apart existing texts but also to reconstruct lost ones. How can one be sure that some passage in a surviving ancient text $B$ was not invented by that text's author but was taken over by him from some other earlier text $A$ ? Obviously, matters seem simple if text A is still available to us, so that we can determine that the two passages in question are identical. ${ }^{9}$ But suppose that text $\mathrm{A}$ 
has been lost. The standard technique of philological Quellenforschung involves comparing that surviving passage in one text $\mathrm{B}$ with some other similar passage in another surviving text $\mathrm{B}^{\mathrm{r}}$ (and with similar passages in surviving texts $\mathrm{B}^{2}, \mathrm{~B}^{3}$, etc. if available) and arguing that since ( $\mathrm{I}$ ) the similarity between these passages in $\mathrm{B}$ and in $\mathrm{B}^{\mathrm{r}}$ (and $\mathrm{B}^{\mathrm{n}}$ ) is too great to be explained by chance and (2) the two surviving texts seem to be independent of one another in the sense that neither of them was the direct cause of the other, they must consequently both derive from some third text A, earlier than both of them but subsequently lost, which can be reconstructed on the basis of this comparison. This is the 'reconstructive', synthetic method of Quellenforschung, and it explains why so many works of late-nineteenth-century German scholarship bear an uncanny visual resemblance to the menus in Chinese restaurants: the page is divided into two (or in some cases three or even more) narrower columns, printed in parallel with one another; and the reader is invited, if not to choose one item from Column $A$ and one from Column B, then at least to be convinced by the apparent evidence of the similarity of the various columns that there must have been a lost progenitor responsible for both. Here too the source for the technique is to be found in theological scholarship - but this time, concerning not the Hebrew Bible but the Christian New Testament. For the life and teachings of Jesus were validated by not just one, but four canonical Gospels; and these inevitably were very similar to one another in some regards, rather different in others. Ultimately, the Chinese menus of German Quellenforschung go back to the synoptic harmonies of the Gospels: early modern theologians printed the four Gospels in parallel columns, placing reports of the same events next to one another and balancing solitary reports in one or more Gospels by blank spaces in the others. Their intent was to prove the miraculous preestablished harmony of the Gospels and to create a divinely sanctioned mega-text in which all the individual reports could supplement one another: where two reports agreed, they corroborated one another reciprocally; where one was silent, divine providence had ensured that another would speak. But in the course of the eighteenth century, the same printing technique came increasingly to produce quite a different effect upon its readers: differences between the Gospels began to look like discrepancies, and similarities came to seem less the work of divine wisdom than the product of shared earlier human sources. Already in 176I Johann August Ernesti had asserted in his Institutio interpretis Novi Testamenti that the primary purpose of the interpreter of the New Testament, as of any other text, was to determine the original intention of its human author. By the end of the eighteenth century, New Testament scholars like Ritschl had begun the hunt for the lost sources of our Gospels - after all, were not their human authors even closer to the holy events they described than any text that had reached us? 
The relationship between theology and classics continued to remain often quite close through the nineteenth century. But the fact that the apparent results of source criticism inevitably raised unsettling questions for dogmatic theology meant that it was not until toward the end of the nineteenth century that the historical-critical method could come to dominate biblical studies; and it is only nowadays that most academic scholars, at least, are fully convinced of the historically composite, derivative nature of both the Hebrew Bible and the Christian New Testament. By contrast, Wolf's transference of the method to the field of ancient pagan literature meant that it could flourish there in a theologically neutral atmosphere: in classical studies Wolf's treatise was immediately hailed as epoch-making and served as a model for numerous other studies. The Homeric epics were the first and most prestigious test case: their analysis into the smaller, earlier songs that were thought to have been their direct sources occupied many of the finest minds of nineteenth-and early-twentieth-century German classical scholarship. But in the early decades of the nineteenth century this particular variant of source criticism was applied not only to Homer but to many other problems as well: for example, by Lobeck and K.O. Müller to the analysis of the ancient reports concerning Greek religion and by Friedrich Welcker to the reconstruction of the history of Sappho's reputation in antiquity and of the lost masterpieces of Athenian tragedy. Toward the middle of the century, Karl Lehrs programmatically adopted and refined Wolf's method and applied it to the field of ancient scholarship on Greek poetry; its application to other subdisciplines of ancient scholarship, such as Greek philosophy or historiography or Roman copies of Greek sculptures, was only the logical next step.

In these fields, much of the work that was done by the practitioners of Quellenforschung has proven to be of enduring value. But consideration of even the more successful examples of this method suggests not only how it was conceived by its adepts and why it seemed so attractive to generations of philologists - but also why in the end it could not help but achieve results which were rarely more than possible and all too often were simply arbitrary. The wave of popularity of this particular mode of source criticism, which began at the turn of the nineteenth century and started to crest in the second half of that same century, was already subsiding in the first half of the twentieth century. Why?

Quellenforschung was not only a specifically nineteenth-century German variant of the age-old scholarly technique of source criticism; it was also a peculiarly philological variant of a much more widespread development in nineteenthcentury culture, the historicization of science. Like historical linguistics, historical geology, evolutionary biology, and a number of other contemporary sciences, Quellenforschung sought to bring order into a disparate and inconsistent mass of data by telling a genealogical narrative about the various steps by which 
these data had gradually come about. Post hoc, propter hoc: the hypothesized diachronic, causal relations were thought to guarantee scientific validity even in the absence of any conclusive corroboratory evidence for the actual existence of the postulated origins and phases of development. Quellenforschung was thus part of a wider cultural movement that sought to translate questions of identity into ones of origin, and we can explain part of its fascination in terms of this larger context. But a seduction more specific to the particular discipline of classical philology is likely also to have been at work. Part of what attracted many classicists to Quellenforschung was, I would suggest, precisely what was in fact wrong with Quellenforschung - its evident similarity to the genealogical method of the study of the relations of dependence and affiliation among the manuscripts which transmit an ancient author. The similarity is manifest, but in fact it was misleading, and it necessarily limited the validity of any results this method could obtain.

The genealogical method of textual constitution is a modern response to a fundamental problem textual scholars have always faced: what to do when one manuscript contradicts another one in its reading in a certain passage. Already in the Renaissance, some scholars like Politian had recognized that in order to assess the value of a manuscript's readings it is important to try to determine what other manuscript it was copied from (its 'parent') and with which others it could be associated in order to be classified into a group of manuscripts sharing the same derivation ('families'). ${ }^{10}$ But it was in eighteenth-century New Testament studies that such a recognition first attained not only philological, but also theological urgency, and it is in this field that the implications of such sporadic insights first began to be worked out systematically - thus Johann Albrecht Bengel postulated as early as 1734 what he called a tabula genealogica of all the New Testament manuscripts. ${ }^{\text {IT }}$ Throughout the early nineteenth century, German scholars gradually developed a philological technique for establishing such relations which climaxed in what was called Lachmann's method, since it was Karl Lachmann's edition of Lucretius (1850) which made the method famous by reconstructing, on the basis of the errors and contradictions among the surviving manuscripts of the poet, a highly detailed image of the hypothetical archetype which was their source. But already in the decades preceding that edition much of the conception and terminology was already familiar - for example, Friedrich Ritschl, wrote in his notebooks in I837 in Italy that his aim was to produce einen förmlichen genealogischen Stammbaum über die Abstammung und Verwandtschaft aller Väter, Söhne, Brüder, Enkel und Neffen in der großen Plautinischen Manuscriptenfamilie.. ${ }^{\text {I2 }}$

Lachmann's method was widely hailed as the technique which permitted German Classical philology to establish itself as a reliable scientific enterprise; 
and there can be little doubt that Quellenforschung derived a great deal of its attraction from its parasitic similarity to that technique - indeed, often it was unmistakably, if at times perhaps unconsciously, modeled upon it. Like Lachmann's method, Quellenforschung too provide a set of procedures for resolving contradictions and inconcinnities, this time not between the textual readings of various manuscripts, but instead in the informational content supplied within and among various ancient works, and it inquired not into how manuscripts were copied from and related to one another, but instead into how one text copied its information from another (its source) and was related to other texts. Both methods combined an analytic procedure, attentively examining the extant documents for contradictions or discrepancies that could be used as evidence for different lines of derivation, with a synthetic one, hypothesizing shared common ancestors when comparison between two extant documents revealed similarities that were too marked to be ascribable to mere chance. Both methods attempted to harmonize chronologically a synchronic plurality of logically discrepant propositions, by transposing them into a diachronic genealogical narrative in which a number of individually coherent positions could be projected onto the same number of different speakers operating at different moments along the same temporal axis.

But a moment's reflection suffices to suggest how implausible the assumptions underlying the applications of the principles of the criticism of textual variants to those of the criticism of sources really are. What author could possibly be as sleepy and as lazy as scholars imagined a late ancient compiler to be? Even if that were possible, why should that mean that he used only one main source rather than five or ten? Why should anyone go to the trouble of transcribing so completely some other man's published and available work, and then publish it as though it were his own? Whom could he hope to fool? Would not anyone with the intelligence and energy to conceal the evidence for his plagiarism so thoroughly have preferred to deploy his capabilities in a more constructive and creative way? Might not the later author have had different sources available to him at different stages of his production of his text, or differing versions of the same sources? Might he not have used different methods in dealing with different sources, trusting some more, modifying others, correcting here and conflating there? Does it make sense to assume that any extant author must be purely mechanical and receptive, and that only ones that are entirely lost could have been creative and productive?

Such questions could easily be multiplied further, but the point should already be clear: that the only reason for making these presuppositions is not that they have been independently, empirically verified beforehand, but rather that it is only if they are admitted as premises that a certain kind of scholarly 
procedure, which is attractive for other reasons, can be undertaken. But, in consequence, the results of Quellenforschung are not so much entirely false, nor certainly entirely true, as rather all too often just arbitrary. Until the sands of Egypt or the monastery libraries of Asia Minor finally yield up manuscripts that provide direct testimony of one of the postulated early sources of transmitted late ancient compilations, we shall never be able to test the results of the reconstructions of modern Quellenforschung - and this has not happened yet nor would any but the most incautious or wealthy wager that it will happen any time soon. ${ }^{13}$ This is no doubt one reason why the impetus toward this line of research gradually petered out, but it is not hard to think of other reasons as well. Where it was possible to attain relatively secure results, these were obtained fairly quickly; in most other cases the arbitrariness of the procedure and the fragility of the results became inescapably obvious; the sheer quantity of the texts that best lent themselves to this kind of analysis (largely late ancient prose compilations of earlier scholarship) was finite to begin with and eventually became depleted; the interests of many philologists shifted away from causal explanations of diachronic processes toward literary interpretations of synchronic structures; the effect of Quellenforschung was all too often to make the texts we actually possess seem not more interesting than we had thought beforehand, but much less interesting; and a wider skepticism set in, particularly after the nineteenth century, concerning the ultimate value of genealogical explanation as a whole, in this as in other fields.

In the end, what is perhaps most surprising is that Quellenforschung lasted as long as it $\operatorname{did} .^{14}$ Its survival was assisted by a combination of inertia, corporate solidarity, methodological naïveté, a concentration upon individual results rather than upon general premises, and the seductive paradigm of Lachmann's method. Whatever results it obtained, its adherence to a set of unquestioned assumptions about how ancient scholars might have worked impeded for a long time detailed and pragmatic research into a much more important and interesting question: how ancient scholars actually did work, and, more generally, how the cultures of authors and readers have differed from period to period in history and from place to place in the world. That the presuppositions of Quellenforschung do not bear close examination and that its results were all too often possible but arbitrary certainly does not mean that everything it produced can simply be rejected as false. We all depend upon the results of Quellenforschung and make use of them in our own work, with greater or lesser degree of anxiety. I myself am currently preparing a new edition of the early Greek philosophers; and not a day goes by in which I do not employ the results and the techniques of Quellenforschung. Unfortunately, even if much of the work this method produced is likely to have been quite correct, we shall almost certainly never be in a position to tell just which 
parts, or why. Hence scholars today have little choice but to continue to make use of the Quellenforschung of their predecessors - but with caution and doubt, and with the painful awareness that they are building not upon solid rock, but upon a swamp.

\section{Notes}

I This paper represents a shorter and provisional version of a longer article to appear in its definitive form under the title 'The Rise and Fall of Quellenforschung' in a forthcoming festschrift.

2 On various aspects of this general problem, see Glenn Most and Thomas Fries,' Die Quellen von Nietzsches Rhetorik-Vorlesungen', in T. Borsche, F. Gerratana, and A. Venturelli (eds.), Centauren-Geburten. Wissenschaft, Kunst und Philosophie beim jungen Nietzsche. Monographien und Texte zur Nietzsche-Forschung, 27 (Berlin, I994), 17-46.

3 The full history of the development of these conventions seems not yet to have been written. It would certainly cast an interesting light upon fundamental issues of identity, authority, and textuality, as well as upon the development of the concepts of copyright and legal ownership of intellectual products.

4 Moses Maimonides, The Guide for the Perplexed, trans. M. Friedländer, 2nd ed. (New York, I956).

5 A helpful general survey is provided by Hans-Joachim Kraus, Geschichte der historischkritischen Erforschung des Alten Testaments (Neukirchen-Vluyn, 1956; 2nd ed., I969 [cited here]; 4th ed., I988).

6 Dtn. 31.9; Gen. I2.6; Dtn. 3.I4; Num. I2.3, 31.4; Dtn. 33.I. See Kraus, Geschichte der bistorisch-kritischen Erforschung, 62. Still useful is Leo Strauss, Die Religionskritik Spinozas als Grund seiner Bibelwissenschaft (Berlin, 1930). See especially Piet Steenbakkers, 'Spinoza in the History of Biblical Scholarship', in R. Bod, J. Maat, and T. Weststeijn (eds.), The Making of the Humanities, Vol. I: Early Modern Europe (Amsterdam, 2010), 31 3-326.

7 Spinoza, Tractatus theologico-politicus c. X $\$ \$$ Igff. See Kraus, Geschichte der historischkritischen Erforschung, 63.

8 See Anthony Grafton, Glenn W. Most, and James E.G. Zetzel, "Introduction," in F.A. Wolf, Prolegomena to Homer (1795), trans. A. Grafton, G.W. Most, and J.E.G. Zetzel (Princeton, 1985).

9 Yet even here uncertainties can arise. Are the relative datings of the two texts secure? Can we be certain that the one text was not copied from the other one? Might the passage have been introduced from the one text into the other during the course of the latter's transmission? What is the exact length beyond which textual coincidence cannot reasonably be ascribed to chance?

Io Cf. S. Timpanaro, La genesi del metodo del Lachmann, corrected 3rd ed. (Padua, I985); English translation as The Genesis of Lachmann's Method, ed. and trans. G.W. Most (Chicago, 2005).

I I J.A. Bengel, Apparatus criticus ad Novum Testamentum, ed. 2 (Tübingen, I763), I 8 (first published as an appendix to the text of the Novum Testamentum Graecum [Tübingen I734]). Cf. Timpanaro, La genesi del metodo del Lachmann, 24-25. 
I2 Cited by Timpanaro, La genesi del metodo del Lachmann, 53 n. Io, from O. Ribbeck, F.W. Ritschl (Leipzig, I879), I.201.

I3 In the case of manuscript transmission, it has sometimes been thought that later papyri discoveries might definitively confirm or refute Lachmannian reconstructions of the archetype of surviving manuscripts, or conjectural emendations. But this is mistaken. In fact what papyri supply is nothing more than ancient, usually late ancient variants, witnesses to one of the ancient streams of transmission rather than the true original form of the text. They do not decide the question but offer further evidence that can strengthen or weaken hypotheses arrived at independently.

I4 Here the contrast with the situation in textual criticism is instructive. Lachmann's method has survived despite the doubts expressed about it from various quarters, and it flourishes in our own day, usually formalized and often computerized, among scholars who sometimes describe themselves as Neo-Lachmannians. Evidently, whatever its problems, the model was less problematic than the imitation. 



\title{
4.2 History of Religions in the Making Franz Cumont (1868-1947) and the 'Oriental Religions'
}

\author{
ELINE SCHEERLINCK ${ }^{1}$
}

As is the case for many of his colleagues within the humanities, it is hard to pin one label on Franz Cumont (1868-1947). His work moves at the crossroads of history of religions, classical philology, ancient history, archeology and Orientalism. However, Cumont employed this multidisciplinarity in such a way as to make him a pioneer within the developing field of history of religions at the turn of the nineteenth century. In what follows I will focus mainly on Cumont as a historian of religion and on the renewing role which he played in the development of the history of religions as an independent academic discipline. Cumont created a new methodological model for the study of ancient religions. Moreover, Cumont's focus on the Oriental influence on Greek and Roman religion was a symptom of his original yet nuanced ideas on the role of the ancient Near East within the history of Western culture, in particular Western religions and (pseudo)sciences such as astrology and magic.

\section{A new method for Mithras}

At the end of the nineteenth century some students of ancient religion had grown to be dissatisfied with the methodology which had dominated the field until then. In the previous decades, the study of religion had been approached from a purely philological perspective. One of the founding fathers of the comparative study of religions, Oxford professor Friedrich Max Müller (1823-1900), was a comparative philologist, who traced the evolution from a primordial monotheism to polytheism by studying the names of the gods in the so-called Semitic and Indo-European languages. ${ }^{2}$ According to Max Müller, divinities came into existence through epitheta which were originally given to the one god. It is clear that, to the comparative mythologist, 'the history of religions was a history of language. ${ }^{3}$ However, Max Müller was also responsible for the edition and translation 
to English of different ancient Eastern religious texts, from, e.g., Zoroastrianism and Confucianism. These 'Sacred Books of the East', were published by Oxford University Press in fifty volumes from I879 until I9ıo, a few decades later than Max Müller's earlier theoretical work. ${ }^{4}$ This collecting and editing of texts fits in well with the methodological climate of history of religions at that time. The popularity of the approach of comparative mythology had started to teem toward the last decade of the nineteenth century, as scholars criticized its generalizing claims which were not satisfyingly based on documents. A more positivist methodology for the history of religions asserted itself: the methods of the academic discipline of history were to be applied to the history of religions: to collect the data, classify and analyze them were the historian of religions' priorities. Synthesizing and generalizing ideas were to be formulated in a later stage. ${ }^{5}$ This was the viewpoint of, e.g., Jules Toutain (I865-I96I) (cf. infra) and Maurice Vernes (I845-I923). Vernes was the founder of the Revue de l'histoire des religions in 1880 and director of the 'V section: Sciences religieuses', established in I885, at the École Pratique des Hautes Études in Paris. ${ }^{6}$ These are two important examples which show how, in the last quarter of the nineteenth century, a history of religions independent from theology, was institutionalized. ${ }^{7}$

What was the role or place of Franz Cumont within this development? Although Cumont studied comparative grammar with Charles Michel (1853-1929) in Ghent and comparative mythology with Hermann Usener (1834-1905, cf. infra) in Bonn, as a historian of religion he was not a comparatist. ${ }^{8}$ He did not pay much attention to the subjects to which students of comparative mythology or religion were generally drawn, such as the origin of religion or parallels between religions which had never been in contact. However, Hermann Usener's ideas would have a lasting influence on the Belgian scholar, ${ }^{9}$ as he was most probably responsible for Cumont's open mind when it came to other cultures of the Mediterranean (cf. infra). ${ }^{\circ 0}$ However, Cumont's approach would certainly not be entirely his teacher Usener's, who in 1893 published Götternamen, a major work in the tradition of comparative mythology. ${ }^{\text {II }}$

That Franz Cumont provided the history of religions with a model for the study of ancient religions was affirmed by his contemporaries ( $\mathrm{cf}_{*}$ infra) as well as it is the consensus within the academic community today. ${ }^{12} \mathrm{He}$ famously did this with his work on Mithras. 'L'Homme de Mithra'13 developed his interest in the Persian god during his study period in Germany and Austria (I887-1890), when he wrote essays on the topic and went on a first journey of exploration in Hungary and Romania, in search of inscriptions and other ancient remnants that would attest the presence of the cult of Mithras. ${ }^{14}$ In the following years, $\mathrm{Cu}$ mont collected, assisted by his international network of correspondents, Mithraic monuments from all over Europe, ${ }^{15}$ after which he published the two monumental 
volumes of Textes et monuments figurés relatifs aux mystères de Mithra (TMMM) in 1896 and $1899 .{ }^{16}$ Instead of focusing on language, names, texts and myths, $\mathrm{Cu}$ mont thus examined this one specific ancient religion in the Greco-Roman world from the viewpoint of the entire Altertumswissenschaft. In TMMM, which established him as a world authority in the study of ancient religions, Cumont took account of all literary texts in Greek, Latin and Oriental languages, particularly Armenian. Moreover, he included all inscriptions and all figurative archeological monuments, such as statues or the typically subterranean and cavelike Mithraic temples. ${ }^{17}$ In 1910 Jules Toutain wrote an article in the Revue de synthèse historique on the progress of the discipline of history of religions in the previous decades. ${ }^{18}$ Applauding Cumont's TMMM as a perfect example, as a model even, of the historical method, he compared it in a positive way to the new comparative approach within the study of religions, connected with anthropology, which we find in the work of influential scholars such as James Frazer (I854-I94I) and William Robertson Smith (1846-I894). ${ }^{\text {I9 }}$ Toutain contrasts Cumont's inductive method with the deductive, 'arbitrary' approach of the comparative school:

Souci constant de ne recourir, pour expliquer le caractère et le succès des mystères mithriaques, quà des idées ou des faits recueillis soit dans la civilisation iranienne soit dans la civilisation gréco-romaine des premiers siècles de l'empire; usage de la méthode inductive, à l'exclusion de toute comparaison arbitraire, de toute déduction purement logique; clarté de la pensée, maîtrise de l'expression toujours adéquate, par sa précision même, à l'idée de l'auteur toutes ces qualités donnent au grand ouvrage de M. Cumont une valeur hors pair. ${ }^{20}$

\section{Between Hellenomania and Panbabylonism}

Cumont's preference for a Near Eastern god for his first important study of ancient religion is another aspect of the classicist's pioneering role. After this groundbreaking work on Mithras, the scholar broadened his outlook to other mystery cults who found their origin in the Near East. In his most important work, Les religions orientales dans le paganisme romain, he described mystery cults from Asia Minor, Egypt, Syria and Persia, and the pseudosciences astrology and magic, in terms of their impact on the Roman West. ${ }^{21}$ In this work, Cumont argued that these cults, as a group, completely destroyed the Roman state religion. Moreover, in his evolutionist take on the religious history of late antiquity, the 'Oriental' religions constitute an intermediary step, paving the way for Christianity. ${ }^{22}$ Thus, again rather exceptionally, Cumont assigned to the Near East an active and positive role in the moral and religious evolution of the Roman Empire. ${ }^{23}$ By emphasizing the role of these 'Oriental' religions within the Roman religious 
landscape, Cumont presented an interpretation of late antique religious evolution that was new in the field of history of religions, which tended to focus on Judaism as the precursor of Christianity. ${ }^{24}$ While Cumont acknowledges the similarities between the mystery cults and Christianity, he does not aim to explain them. ${ }^{25}$

These issues were also tackled by contemporary scholars. In Germany, Richard Reitzenstein (I86I-193I) discussed the 'Hellenistischen Mysterien-religionen' and their influence on Christianity. ${ }^{26}$ Reitzenstein was an exponent of the Religionsgeschichtliche Schule, a group of scholars from the University of Göttingen, for example, Hermann Gunkel (I862-I932), Otto Gruppe (I85I-I92I) and Adolf Deissmann (1866-1937), who challenged the originality of Christianity by studying it in its historical, Oriental context. ${ }^{27}$ For example, Deissmann compared the Greek of early Christian literature with popular Greek language in the papyri from Egypt, where, e.g., the Oxyrynchus cache was found in $1897 *^{28}$ This significant development in the history of the study of Christianity and ancient religions was connected with the heightened political interest of Europe in the East during the second half of the nineteenth century, which brought with it an intensification of archeological excavations and scientific missions in the Orient. Scholars could make use of a profusion of new documents, the knowledge of ancient languages and writing systems increased enormously, remnants of ancient civilizations were unearthed. This meant also that some subjects, such as the classical civilizations of Greece and Rome and the history of Christianity, could be studied in a broader context. These subjects, both crucial for the formation of European identity, were until then studied as fairly isolated phenomena and the new approach challenged their supposed originality and/or superiority. As for Greece, nineteenth-century German Hellenists were studying it as an autonomous culture, rejecting the possibility of substantial foreign influence on the idealized Greeks. ${ }^{29}$ One of the most influential exponents of this tradition and a founding father of classical philology, Hellenist Ulrich von Wilamowitz-Moellendorf (I848-I93I) could consider the ancient civilizations of the Middle East as:

the peoples and states of the Semites and the Egyptians which had been decaying for centuries and which, in spite of the antiquity of their culture, were unable to contribute anything to the Hellenes other than a few manual skills, costumes, and implements of bad taste, antiquated ornaments, repulsive fetishes for even more repulsive fake divinities..$^{30}$

Marchand has argued that the Religious Historical School which we discussed above belonged to what she called the 'furious Orientalists', a generation of German scholars characterized by a focus on the Oriental material which had been excavated and deciphered mostly by previous generations and by a tendency to 
use this material to decentralize Greek culture but also Judaism within the history of religions, whereby anti-Semitism not seldom lurked around the corner. ${ }^{31}$ In many respects, Cumont was affiliated to these 'furious Orientalists': by considering the Oriental mystery cults to be the predecessors of Christianity, the latter was, although implicitly, compared with the former and robbed of its originality. Moreover, Cumont accorded great importance to the archeological material unearthed in the Middle East. ${ }^{32}$ In 1893 Cumont gave the opening lecture of the course of Greek history at Ghent University. ${ }^{33} \mathrm{He}$ discussed the recent progress in that domain, and the causes thereof:

La première des causes et la plus éloignée, c'est cette merveilleuse découverte de l'ancien Orient, qui dans le domaine historique restera certainement le titre scientifique le plus brillant du XIXe siècle. [...] Ce coup de théâtre a exercé une influence énorme sur l'histoire grecque: [...] mais notre conception générale du rôle de la race grecque en a été profondément modifiée. Pour la première fois nous la voyons agir dans son milieu, nous savons ce qui exista avant elle, il nous est permis de contempler la toile de fond devant laquelle se déroule le drame hellénique. Il n'est plus possible de supposer aujourd'hui, comme on faisait complaisamment autrefois, que la Grèce ait tout ou presque tout tiré de son propre fonds. Elle a été pendant longtemps, fort longtemps, à l'école de l'Orient. ${ }^{34}$

Cumont deems the archeological discovery of the ancient Orient responsible for a very decisive change in how Greek history should be approached in his days, questioning the originality of Greek culture and affirming the influence of the Near East. Throughout his whole career, the East-West interaction in the ancient world - mainly but not exclusively, as we will discuss further on, in the Hellenistic and Roman periods - was the major theme in Cumont's scholarly work. Martin Bernal, who accused generations of classicists and ancient historians of Eurocentrism and racism, actually cites Cumont as an example of a scholar who did acknowledge the influence of the Middle East on ancient Greek science. ${ }^{35}$ We can compare Cumont's words from the citation above with another opening lecture, given one year later, in I894, by Egyptologist Henri Édouard Naville (1844-1926) president of the International Orientalist Congress in Geneva, held in 1894 :

J'en demande pardon aux hellénistes de l'école d'Ottfried Müller, le caractère absolument autochtone de la civilisation hellénique, ce point de vue qu'il défendit avec opiniâtreté me semble avoir reçu un rude coup; et au risque de paraître me faire l'écho de ce que l'illustre helléniste allemand 
appellerait les idées préconçues d'un orientaliste, je n'hésite pas à dire qu'aujourd'hui on ne peut plus séparer la Grèce de l'Orient; et que ce que nous avons à rechercher, c'est la part qui revient à l'un et à l'autre dans ce merveilleux ensemble qu'on nomme la civilisation grecque. ${ }^{36}$

In that year, the Orientalist Congress organized for the first time a section 'Grèce et Orient', where specialists of antiquity, such as the Hellenist and papyrologist Jules Nicole (I842-I92I) and the archeologist and Hellenist Georges Perrot (I8321914) presented studies based on both Greek sources and Oriental documents. The section was a great success, according to the French archeologist and allround classicist Théodore Reinach (I860-1928), who invited Cumont to speak at the next congress in Paris, held in $1897 .{ }^{37}$

On the other hand, Cumont also reacted against some scholars' tendencies to overestimate Oriental influence on Western culture. ${ }^{38}$ In Marchand's categorization, the 'furious Orientalists' also comprise the so-called Panbabylonists, who argued that Babylonian astrology was the origin of all art and all mythology - Hugo Winckler (1863-1913), Peter Jensen (I86I-1936) and Alfred Jeremias (1864-1935). ${ }^{39}$ In I9Io Cumont writes a letter to his former teacher Hermann Diels, a specialist in Greek philosophy and literature and congratulates him on his work on Oriental literature and its influence on Greek culture. ${ }^{40}$ In this letter Cumont's professes his interest in the issue of Babylonian influence on the West and denounces the likes of 'scatterbrain' Jeremias for having confused it with their 'aberrations': 'Tout ce qui peut éclaircir la question des emprunts faits par l'Occident à Babylone m'intéresse particulièrement. Il est déplorable que des brouillons comme Jeremias l'aient troublées par leurs aberrations'. ${ }^{41}$ In fact, in those years Cumont was indeed working on the interconnections between Greek and Mesopotamian astronomy and astrology. In I9II, Cumont traveled to Sweden and the United States, giving lectures on 'Astrology and Religion among the Greeks and Romans', which were published one year later in the 'American lectures on the history of religions' series ${ }^{42}$ At the beginning of his first lecture, Cumont briefly summarized the theories of the Panbabylonists, after which he evaluates them. During a lecture or in an academic publication, Cumont, of course, had not the same liberty of speech as in his private correspondence with Hermann Diels, but in this passage Cumont clearly showed where he thought the errors of the Panbabylonists lay:

Now of this system it may be said that what is true in it is not new, and what is new is not true. That Babylon was the mother of astronomy, starworship, and astrology, that thence these sciences and these beliefs spread over the world, is a fact already told us by the ancients, and the course of 
these lectures will prove it clearly. But the mistake of the Pan-Babylonists, whose wide generalizations rest on the narrowest and flimsiest of bases, lies in the fact that they have transferred to the nebulous origins of history conceptions which were not developed at the beginning but quite at the end of Babylonian civilization. ${ }^{43}$

While according to the 'Babylonian mirage' of the Panbabylonists the Babylonian astronomy was established in the fifth millennium BCE, Cumont argued that on the basis of the sources available, the Mesopotamian cuneiform tablets which were recently deciphered, astronomy was only instituted in those regions in the first millennium BCE. ${ }^{44}$ In the second chapter of Astrology and Religion, 'Babylon and Greece', Cumont did not fail to pay the Mesopotamian astronomers the respect which was due to them, as he, e.g., discussed how certain astronomical discoveries, which had hitherto been attributed to the Greeks, were in fact to be ascribed to the Babylonians. ${ }^{45}$ To compare, in a 1920 letter to the Orientalist Giorgio Levi della Vida (1986-1967), Cumont praised the abilities and accomplishments of the Babylonian astronomers.

Après tout, ce sont des Sémites qui ont été les grands initiateurs en astronomie; je veux bien qu'ils aient étudié la marche des corps célestes dans un but pratique, pour y chercher des présages, mais ils ont poursuivi leurs recherches avec une précision, une patience sagace, qui seraient méritoires même chez des savants modernes et ils ont tiré avec une logique rigoureuse les résultats de leurs observations. ${ }^{46}$

In the course of 'Babylon and Greece', Cumont discussed how the Greeks, in different periods of their history, came into contact with and adopted Babylonian astronomy and star worship. On the other hand, to explain the apparent disinterest of the Greek philosophers in Chaldean astrology until the fourth century BCE, Cumont appealed to the rational, critical and logical Volksgeist of the Greeks, rather in the vein of the philhellenic tradition which he refuted.

The insatiable curiosity of the Greeks, then, did not ignore astrology, but their sober genius rejected its hazardous doctrines, and their keen critical sense was able to distinguish the scientific data observed by the Babylonians from the erroneous conclusions which they derived from them. It is to their everlasting honour that, amid the tangle of precise observations and superstitious fancies which made up the priestly lore of the East, they discovered and utilized the serious elements, while neglecting the rubbish. ${ }^{47}$ 
Apparently, Cumont's admiration for the ancient Near East did not diminish his appreciation for the Greeks and their intellectual abilities, which he, at least in this passage, seems to deem superior to those of the Orientals.

In this paper we have examined in which ways Franz Cumont was a pioneer in the development of the field of history of religion around the turn of the nineteenth century. Not only did he introduce a new model for the study of ancient religions, he also played an important part in the European academic debates on the influence of the ancient East on Western culture, particularly regarding religion and (pseudo)science. These debates, which have recurred at intervals during the history of the Western humanities, were renewed at the end of the nineteenth century, thanks to the accumulation of new sources from the ancient Near East. Moving at the crossroads of classics, Orientalism and history of religions, Franz Cumont belonged to a new generation of scholars who went against the grain of an academic tradition which treated Christianity and Greek civilization as autonomous and wholly original cultural phenomena. Although Cumont's approach is also nuanced, as he attacks the far-fetched conclusions of the Panbabylonists, throughout his whole career he would call attention to the Eastern influence on the West. Moreover, he considered this influence a positive one: the East, whether it be in the form of Middle Eastern mystery cults, or in the form of Babylonian astronomy and sidereal theology, was a decisive and constructive actor in the moral and intellectual development of the West.

\section{Notes}

I The author was able to write this paper at Ghent University with the support of the Research Foundation Flanders, which is funding the research project 'Orientalism and Franz Cumont: His Views on East and West in the Context of Classical Studies in the Late Nineteenth and Early Twentieth Century' (Flanders Research Foundation, project G.o194.09; supervision: Danny Praet). I thank Danny Praet for his numerous and most precious suggestions.

2 Maurice Olender, The Languages of Paradise: Race, Religion, and Philology in the Nineteenth Century, trans. Arthur Goldhammer (Cambridge, MA: Harvard University Press, 2008; first published in Paris by Éditions du Seuil in I989), 82-92. Volkhard Krech, Wissenschaft und Religion. Studien zur Geschichte der Religionsforschung in Deutschland 1871 bis 1933, Religion und Aufklärung 8 (Tübingen: Mohr Siebeck, 2002), Io I-I02. Cf. also H. Klimkeit, 'Friedrich Max Müller (I823-I900)', in Axel Michaels (ed.), Klassiker der Religionswissenschaft. Von Friedrich Schleiermacher bis Mircea Eliade (Munich: Beck, 1997), 29-40.

3 Friedrich Max Müller, Lectures on the Science of Language (London: Longmans, Green \& Co., I87I), vol. 2, 467, also cited in Olender, The Languages of Paradise, 84. Cf. also Lourens van den Bosch, Friedrich Max Muller: A Life Devoted to the Humanities (Leiden: Brill, 2002), xvi-xviii. 
4 Max Müller had started the work on these series in I875: H. Klimkeit, 'Friedrich Max Müller (I823-1900)', in A. Michaels (ed.), Klassiker der Religionswissenschaft. Von Friedrich Schleiermacher bis Mircea Eliade (Munich: Beck, I997), 3 I.

5 François Laplanche, 'L'histoire des religions en France au début du XXe siècle', Mélanges de l'École Française. Italie et Méditerannée (MEFRIM) I I I (I999), 623-634, esp. 626-627.

6 Jules Toutain, Les cultes païens dans l'Empire romain. 1. Les provinces latines, 3 vols. (Paris: Leroux, 1907-1920). In the second volume of this work, es cultes orientaux, Toutain presents a very different picture of the importance of the Orient mystery cults in the Roman West than Cumont had done in his Religions orientales dans le paganisme romain in 1906 (cf. n. 2I and n. 22). Cumont studied in I89I-I 892 at the IV Section 'Sciences historiques et philologiques': Patrick Cabanel, 'Les sciences religieuses en Europe et la formation de Franz Cumont', MEFRIM II I (I999), 6I I-62I, at 6II.

7 Patrick Cabanel, 'Les sciences religieuses en Europe et la formation de Franz Cumont', MEFRIM III (I999), 6II-62I. After the generation of the great founders, this period is characterized by institutionalization: chairs, series: e.g., first chair in Europe: Holland (Tiele?). First chair in France: Albert Réville at the Collège de France in I880. Belgium knew its first 'cours libre d'Histoire des Religions' in I 884 and it was taught by Eugène Goblet d'Alviella (I846-I925). In England Max Müller started the Hibbert Lectures (I 878), while in France the industrialist Émile Guimet founded the 'Annales du Musée Guimet: Bibliothèque de Vulgarisation'.

8 Aline Rousselle, 'Franz Cumont et la science de son temps. Introduction', MEFRIM i I I (I999), 50I-506, at 504.

9 As would his academic experiences in Germany and Austria in general. Cf. C. Bonnet, Le 'grand atelier de la science'. Franz Cumont et l'Altertumswissenschaft. Des études universitaires à la fin de la Ie Guerre mondiale (1888-1923), BHIR Studies over oude filologie, archeologie en geschiedenis vol. XLI (Turnhout: Brepols, 2005).

Io Bonnet, Le 'grand atelier de la science', vol. I, r04. E.g., in his work on flood myths, Usener compares accounts in Middle Eastern and Indian texts to Greek flood myths: Hermann Usener, Die Sintfluthsagen untersucht (Bonn: Cohen, I 899).

I I Hermann Usener, Götternamen. Versuch einer Lebre von der religiösen Begriffsbildung (Bonn: Cohen, I896).

I2 Richard Gordon, 'Franz Cumont and the Doctrines of Mithraism', in John Hinnells (ed.), Mithraic Studies (Manchester: Manchester University Press, I975), 215-248, esp. 215 n. 2; Robert Turcan, 'Franz Cumont, un fondateur', Kernos II (I998), 235-244. It is, however, important to note here that, while Cumont was an influential historian of religion who certainly kept abreast of the theoretical and methodological developments within his fields of research, he never explicitly professed himself to belong to a certain school and never intended to lead one. Cf. André Motte, 'La notion de syncrétisme dans l'oeuvre de Franz Cumont', in André Motte and Corinne Bonnet (eds.), Les syncrétismes religieux dans le monde méditerrannéen antique (Brussels/Rome: Institut Historique Belge de Rome, I999), 2I-42, in particular 28-29.

I 3 Georges Radet, in Revue des Études Anciennes I5 (I9I3), 233, quoted by Nicole Belayche (ed.), Les Mystères de Mithra. Introduction historiographique. Première partie (Turnhout: Brepols, forthcoming), xiii.

I4 Bonnet, Le 'grand atelier de la science', I, 96 n. I43. Mihai Popescu, 'Quand Franz Cumont cherchait Mithra en Dacie. Remarques sur les voyages du savant d'après la correspondance conservée à l'Academia Belgica de Rome', Ephemeris Dacoromana I I (2000), 2 I-5I. Cf. Franz Cumont, 'Revidierte und neugefundene Inschriften aus Dacien', Archaeologisch- 
Epigrafische Mittheilungen aus Oesterreich-Ungarn I4 (I89I), I08-II3. In I889 he wrote a dissertation entitled 'Sur la propagation des mystères de Mithra', with which he won a travel scholarship awarded by the Belgian Ministry of National Education, in Berlin he wrote the essay 'L'introduction du culte de Mithra en Occident', which was annotated by Theodor Mommsen (I8I7-I903) and which will be published as an appendix to the Bibliotheca Cumontiana edition of Les Mystères de Mithra, edited by Nicole Belayche. On the influence of Cumont's German teachers on his Mithras research, cf., e.g., Corinne Bonnet, 'La formation de Franz Cumont d'après sa correspondance (I 885-I892)', Kernos II (I998), 245-264, esp. 249.

I5 Franz Cumont, 'Catalogue sommaire des monuments figurés relatifs au culte de Mithra', Revue Archéologique 20 (1892), 306-322; Franz Cumont, 'Catalogue sommaire des monuments relatifs au culte de Mithra', Revue Archéologique 2I (I893), 40-54.

I6 Franz Cumont, Textes et monuments figurés relatifs aux mystères de Mithra, 2 vols. (Brussels: H. Lamertin, I 896-99). In I900, Cumont published Les mystères de Mithra, which constituted in fact the conclusions drawn from his research in the two volumes of TMMM. Cumont's theories on Mithras have been heavily criticized (cf., Gordon, 'Franz Cumont and the Doctrines of Mithraism'). Recent research refutes Cumont's view that the cult of Mithras as it was attested in Rome originated in Persia, a view which he cherished since I 893 at least (Bonnet, Le 'grand atelier de la science', I, I76).

I7 The publication of source material in collective volumes was an important aspect of $\mathrm{Cu}$ mont's scientific practice - cf., the Catalogus Codicum Astrologorum Graecorum (Io vols.), of which he was the instigator and editor of several volumes, the Catalogue des manuscrits alchimiques grecs, of which he was on the editorial board, and the volume of inscriptions encountered on his journey of archeological exploration in Turkey: F. Cumont, J.G.C. Anderson, and H. Grégoire, Studia Pontica III. Recueil des inscriptions grecques et latines du Pont et de l'Arménie. Studia Pontica, vol. 3 (Brussels: H. Lamertin, I9ro).

I 8 Jules Toutain, 'L'histoire des religions de la Grèce et de Rome au début du XXe siècle', Revue de Synthèse Historique (1910), 73-100.

I9 James Frazer, The Golden Bough: A Study in Magic and Religion (London: Macmillan, I890) (third edition I906-19I5 in I 2 vols., of which vols. 5-6 on Cumont's 'Oriental gods' 'Attis, Adonis and Osiris'), first abridged edition 1922 in I vol.); William Robertson Smith, Lectures on the Religion of the Semites: First Series: The Fundamental Institutions (Edinburgh: Adam and Charles Black, I889). Robertson Smith's work promoted, as did Cumont's work on the 'religions orientales' ( $\mathrm{cf}$. infra) a view, now contested, of homogeneity of local cults in the classical Near East: Ted Kaizer, 'Introduction', in Ted Kaizer (ed.), The Variety of Local Religious Life in the Near East in the Hellenistic and Roman Periods (Leiden: Brill, 2008), I-36, at I8.

20 Toutain, 'L'histoire des religions', 88.

2 I Franz Cumont, Les religions orientales dans le paganisme romain (Paris: Leroux, I906; 4th and last edition Paris, Librairie orientaliste Paul Geuthner, I929), with several editions in four languages: French (1906, I909, 1928, 1929), English (in the United States: I9I I, I956), German (I9I0, I9I I, I93I), and Italian (I9I3, I967). Cumont's classic was reedited, with extensive introduction, in 2006 by Corinne Bonnet and Françoise Van Haeperen, as part of the Bibliotheca Cumontiana. Cumont's work was continued by Maarten Vermaseren, who in I96I founded the series 'Études préliminaires aux religions orientales dans l'empire romain', now 'Religions of the Graeco-Roman World', still published by Brill.

22 Although Cumont used epigraphical and archeological material as sources, Jules Toutain's conviction that Cumont's literary bias led him to overestimate the influence of the Orient 
mystery cults (Toutain, Les cultes païens, passim, and Bonnet and Van Haeperen, 'Introduction historiographique' in Les religions orientales, lix-lx) is shared by recent scholarship, which ascribes Cumont's vision of a battle between the 'Orient religions' and Christianity to the influence of polemical tendencies within some of his sources, such as the Christian authors. Bonnet and Van Haeperen, 'Introduction historiographique' in Les religions orientales, xxxix. Cf. also Corinne Bonnet, 'Lempire et ses religions. Un regard actuel sur la polémique Cumont-Toutain concernant la diffusion des religions orientales', in H. Cancik and J. Rüpke (eds.), Die Religion des Imperium Romanum (Tübingen: Mohr Siebeck, 2009), 55-74. Moreover, the academic community nowadays finds fault with the category of 'Orient religions' as it presumes homogeneity where the recent research focuses more on their differences than their similarities. Reflections on Cumont's work from the viewpoint of present-day research are assembled in Corinne Bonnet, Jörg Rüpke and Paolo Scarpi (eds.), Religions orientales-culti misterici. Neue Perspektive-nouvelles perspectives-prospettive nuove (Stuttgart: Franz Steiner Verlag, 2006). Cf. also James Rives, 'Graeco-Roman Religion in the Roman Empire: Old Assumptions and New Approaches', Currents in Biblical Research 8 (2010), 240-299.

23 On Cumont's teleological take on the history of religion and the influence of Hegelian dialectics, cf. Danny Praet, 'Wird rein durch Feuer, Wasser, Luft und Erden. Teleologie, universalisme en de symboliek van de elementen in de godsdienst-filosofie van Franz Cumont', in Tom Claes (ed.), Door denken en doen: essays bij het werk van Ronald Commers (Ghent: Academia Press, 20 I 2), I77-219; Danny Praet,'Franz Cumont, the Oriental Religions, and Christianity in the Roman Empire: A Hegelian View on the Evolution of Religion, Politics, and Science', in Todd Gooch, Dawn De Vries, and Arie Molendijk (eds.), Papers of the Nineteenth-Century Theology Group 20I I, XLII, I33-I58, and also Danny Praet, 'Les liens entre philosophie et religion dans quelques Scripta Minora de Franz Cumont', in Corinne Bonnet, Carlo Ossola and John Scheid (eds.), Rome et ses religions: culte, morale, spiritualité. En relisant Lux Perpetua de Franz Cumont, Suppl. Mythos vol. I (Caltanissetta: Sciascia Editore, 2010), 97-I Io; and Annelies Lannoy, 'Les masses vulgaires et les intelligences élevées. Les agents de la vie religeuse dans Lux Perpetua et leur interaction', in Bonnet et al. (eds.), Rome et ses religions, 63-8I.

24 Guy Stroumsa, A New Science: The Discovery of Religion in the Age of Reason (Cambridge, MA: Harvard University Press, 2010), I64.

25 Annelies Lannoy, Het christelijke mysterie. De relatie tussen het vroege christendom en de heidense mysterieculten in het denken van Alfred Loisy en Franz Cumont, in de context van de modernistische crisis (PhD dissertation, Ghent, 20I2).

26 Richard Reitzenstein, Die bellenistischen Mysterienreligionen: ibre Grundgedanken und Wirkungen (Leipzig: Teubner, I910; 3rd ed., 1927).

27 Volkhard Krech, Wissenschaft und Religion. Studien zur Geschichte der Religionsforschung in Deutschland 1871 bis 1933, Religion und Aufklärung 8 (Tübingen: Mohr Siebeck, 2002), I23-I 26.

28 Adolf Deissmann, Licht vom Osten: Das Neue Testament und die neuentdeckten Texte aus dem hellenistisch-römischen Welt (Tübingen: Mohr Siebeck Verlag, I908).

29 Suzanne Marchand, 'From Liberalism to Neoromanticism: Albrecht Dieterich, Richard Reitzenstein and the Religious Turn in Fin-de-Siècle German Classical Studies', in Martin Ruehl and Ingo Gildenhard (eds.), Out of Arcadia, British Institute of Classical Studies Supplement, vol. 79 (London, 2003), I 3 I. Cf. also Bonnet, Le 'grand atelier de la science', I, 73. 30 Ulrich von Wilamowitz-Moellendorf, Homerische Untersuchungen (I884), 215. I cite the English translation by Margaret E. Pinder and Walter Burkert in Walter Burkert, The 
Orientalizing Revolution: Near Eastern Influence on Greek Culture in the Early Archaic Age (Cambridge, MA: Harvard University Press, I995), 2-3.

3I Suzanne Marchand, 'Philhellenism and the Furor Orientalis', Modern Intellectual History I (2004), 33I-358, esp. 364-353; Suzanne Marchand, German Orientalism in the Age of Empire: Religion, Race and Scholarship (Cambridge: Cambridge University Press, 2009), 2I2-25I.

32 Cumont's own archeological activities in the Middle East are discussed in Ève Gran Aymerich, 'Franz Cumont et l'archéologie française', Mélanges de l'École française de Rome. Italie et Méditerranée (MEFRIM) I I I (I999), 525-539; Pierre Leriche and Justine Gaborit, 'Franz Cumont, homme de terrain', MEFRIM I I I (I999), 647-666.

33 He taught several courses there from I 892 until I910. Cf. Corinne Bonnet, La correspondance scientifique de Franz Cumont (Brussels/Rome: Belgisch Historisch Instituut Rome, I997), I-67.

34 F. Cumont, 'Les progrès récents de l'histoire grecque', Revue de l'instruction publique en Belgique 36 (I893), 9-I9 (citations I0-II).

35 Martin Bernal, Black Athena: The Afroasiatic Roots of Classical Civilization: Volume I: The Fabrication of Ancient Greece, 1785-1985 (London: Vintage, I99I, first published London: Free Association Books, 1987), I37: 'Cumont's argument presents a serious problem to the Aryan Model because it means either that Plato's ideas coincided with the Hermetic Oriental-Egyptian ones or that they came from Egypt, as the Ancient Model maintained'. Bernal comments on Cumont's L'Égypte des astrologues (Brussels: Vromant \& Co., I937), 22-23.

36 In Actes du dixième Congrès international des orientalistes. Session de Genève 1894. Première partie: comptes rendus des séances (Leiden: Brill, I897).

37 T. Reinach to F. Cumont on 24 July I 897, AB, Archivi Cumont, letter no. I I 5 I. There is no lecture by Cumont published in the proceedings of the various Congrès des Orientalistes, but in a letter addressed to Cumont by Paul Perdrizet (I870-1938) we have an indication that he spoke at the conference in Paris: the archeologist refers to a communication given by Cumont on that occasion, on the 'propagation du mazdéisme et les Yézidés' (Perdrizet to F. Cumont, 22 June I903, AB, Archivi Cumont, letter no. 3050).

38 Moreover, Cumont's publications nor private correspondence testify to anti-Semitism from his part. He helped the Italian Orientalist Giorgio Levi della Vida find work in the United States when the latter had to flee racial persecution in I939: cf. Mongolus Syrio salutem optimam dat. La correspondance entre Mikbaïl Rostovtzeff et Franz Cumont (Paris: De Boccard, 2007), I66-167, and Bonnet, La correspondance scientifique de Franz Cumont, 270-273. However, Cumont was al but free from ethnic and racial stereotypes, cf., e.g., Eline Scheerlinck,'Franz Cumont's Syrian Tour: A Belgian Archaeologist in the Ottoman Empire', Revue Belge de Philologie et d'Histoire 9I (2013), and Eline Scheerlinck, Danny Praet, and Sarah Rey, 'Racial Theories on the Spread of the Oriental Religions and the Transformation of the Later Roman Empire: Franz Cumont and his Contemporaries', in preparation.

39 Marchand, 'Philhellenism and the Furor Orientalis', 33I-358, esp. 34I-346; Marchand, German Orientalism, 212-25I.

40 Hermann Diels, Orientalische Fabeln in griechischen Gewande (Berlin, I910).

4I Cumont to Diels, I9I0. The correspondence between Cumont and Diels was published in Bonnet, Le 'grand atelier de la science', II, IO-I33.

42 Franz Cumont, Astrology and Religion among the Greeks and Romans (New York: Putnam's Sons, I9I2). Cf. F. Cumont, 'Comment les Grecs connurent les tables lunaires des Chal- 
déens', in Florilegium Melchior de Vogüé (Paris, I910), I59-I65; and F. Cumont, 'Babylon und die griechische Astronomie', NJA 28 (I9I I), I-Io.

43 Cumont, Astrology and Religion, 4.

44 Ibid., 6-I4 ('Babylonian mirage': 5). Cumont uses the work of F.X. Kugler, SJ, Die Babylonische Mondrechnung (Freiburg, 1900), and ibid., Sternkunde und Sterndienst in Babel (Münster, 1907-I924).

45 Cumont, 'Babylon und die griechische Astronomie', 6-io.

46 Cumont to Levi della Vida, I 3 November 1920, published with commentary in Bonnet, La correspondance scientifique de Franz Cumont, 517-518.

47 Cumont, Astrology and Religion, 53. 



\title{
4+3 'Big Science' in Classics in the Nineteenth Century and the Academicization of Antiquity
}

\author{
ANNETTE M. BAERTSCHI
}

The digital revolution of the past years has profoundly changed higher education and the academic world in general. Not only has 'much of the teaching and learning apparatus moved online, thus effectuating new forms of classroom instruction, but the computational technologies and methodologies' available today have also 'transformed research practices in every discipline.' The digital humanities in particular have created exciting new tools, which have attracted a lot of attention within the scholarly community and received positive media coverage. ${ }^{2}$ This in turn has boosted public interest in humanities research, especially in relation to new technologies that 'facilitate insights into history, language, art and culture that human researchers might never have been able to glean on their own. ${ }^{\prime}$ With considerable grants being awarded to such projects - the sums allotted can range from $\$ 50,000$ to $\$ 250,000$ - some even see in them the new frontier that will restore government support of, and funding for the humanities and secure their survival within academia in the current era of 'cuts'. While it remains to be seen whether this will be the case, it is certainly true that the humanities have been able to reclaim some of their lost territory thanks to digital initiatives, which showed how technology and computational research methods can be fruitfully applied to the study of literature, history, and the arts.

Needless to say, there is a wide variety of activities and projects usually subsumed under the umbrella term 'digital humanities', ranging from online archiving of texts and artifacts to digital mapping and the creation of ${ }_{3} \mathrm{D}$ models of cities and monuments to the use of geographic information systems. ${ }^{4}$ In terms of goal and methodology, however, these projects all share the compilation and continuous updating of massive databases, which are made publicly available for computer-assisted analysis by scientists and other users. Moreover, they rely heavily on interdisciplinary as well as international collaboration with colleagues and institutions inside and outside of academia. In other words, they are truly communal enterprises, making use of contributions from a global circle of 
experts, since modern technology allows scholars to communicate easily with distant partners across the world and thus to expand their communities beyond the physical borders.

Interestingly, " $[\mathrm{t}]$ his "methodological moment" [...] is similar to the late nineteenth and early twentieth centuries, when scholars were preoccupied with collating and cataloging the flood of information brought about by revolutions in communication, transportation and science. The practical issues of discipline building, of assembling an annotated bibliography, of defining the research agenda' together with new critical editions of the materials discovered 'were the main work of a great number of scholars.' ${ }^{5}$ In this paper, I will look at the emergence of large-scale collective research projects in Classical Studies that were launched by the Prussian Academy of Sciences in Berlin in the last third of the nineteenth century and greatly added to the international renown of the German Altertumswissenschaft. I will argue that these projects not only made specific ancient primary sources, both literary and material, accessible for the first time, but also established new forms of institutional organization and scholarly collaboration, which became standard for academic enterprises in the humanities and the sciences. In addition, I will discuss the impact that this type of Großwissenschaft or 'Big Science,, as it was commonly referred to, had on Classics as a discipline as well as on the perception of antiquity and the status of its study within academia. Finally, I will explore some of the parallels than can be drawn to current digital humanities projects and scholarship.

First, however, I would like to give a brief overview of the development of Classical Studies in the first half of the nineteenth century, which in turn will explain the focus on Berlin in this contribution, and then also clarify the meaning and use of the term 'Big Science'.

As is well known, the founder of the modern Altertumswissenschaft is Friedrich August Wolf (I759-I824), who insisted on enrolling as a student of philology, not theology, at the University of Göttingen against the explicit advice of his teacher Christian Gottlob Heyne (I729-I8I2) and then became a professor at the University of Halle (1783) before joining the newly founded University of Berlin in I8Io after the University of Halle had been closed (1806-I807). Wolf transformed Classical Studies by defining them as a purely historical science and advocating a new critical approach to ancient texts based on strict objectivity. This agenda had already informed his most successful, but also deeply polarizing work, Prolegomena ad Homerum (1795), in which he argued that the texts we know as the Iliad and the Odyssey were not the work of a single poet but the products of centuries of ancient song that had been given their final form by the textual critics of Hellenistic Alexandria. Furthermore, Wolf introduced an innovative form of teaching in Halle, the philological seminar (1787).? Imitating Heyne's model 
in Göttingen, but deliberately distancing himself from his teacher by excluding students of theology, Wolf's seminar was no longer simply devoted to preparing participants for a career as schoolteachers. Rather, it was designed as a forum in which those interested in becoming classical scholars could gain experience in conducting original research. In other words, the main goal of the seminar was to instruct students in the method(s) of the discipline, not to teach them a closed body of knowledge.8 In light of this it is not surprising that Wilhelm von Humboldt (1767-1835), a life-long friend of Wolf since 1792, was keen on appointing him as a professor at his new university, which distinguished itself from others precisely by demanding the unity of research and teaching and whose internal organization by departments reflected the seminar principle of discipline-specific training. ${ }^{9}$

Wolf explained and justified the new historical approach to antiquity in his programmatic treatise Darstellung der Alterthumswissenschaft nach Begriff, Umfang, Zweck und Werth (1807), which is rightly regarded as the founding document of modern Classical Studies. He declared the aim of philology to be the knowledge of human nature in antiquity, which comes from the observation of an organically developed, significant national culture, founded on study of the ancient remains.' ${ }^{10}$ Given that 'national culture' could manifest itself as much in texts as in works of art and other material remains he encouraged his students to master the various subdisciplines of Classics from philosophy of language, hermeneutics and criticism to geography, history, chronology, and numismatics and to 'fuse them in a single interdisciplinary "science of antiquity".".

Similarly, August Boeckh (1785-1867), a former student of Wolf, who in I8II was appointed as professor eloquentiae et poeseos at the University of Berlin, ${ }^{12} \mathrm{de}-$ fined Classical Studies as a comprehensive, historically and philosophically based science of the ancient world. Boeckh had also studied with Friedrich Schleiermacher (1768-1834) at Halle, and it was the latter's influence that led him to characterize philology as Erkenntniss des Erkannten ${ }^{13}$ ('knowledge of what is known') in his posthumously edited and published Encyklopädie und Methodologie der philologischen Wissenschaften (1877). The work was based on a lecture series which Boeckh held twenty-six times at the University of Berlin and in which he developed a general hermeneutics for the humanities. For in contrast to Wolf, Boeckh was less intent on establishing the absolute supremacy of Greek (and Roman) culture, arguing that studies of Hebrew, Indic, Chinese, and other Oriental philology possessed the same fundamental importance. ${ }^{14}$ The only reason to accord a privileged position to classical antiquity was that it was the foundation of all European culture. ${ }^{15}$ Das Erkannte ('what is known') in Boeckh's memorable formula Erkenntniss des Erkannten denoted any form of cultural production, not only texts, but also artifacts, institutions, practices, and places, ${ }^{16}$ since for him 
philology was one with history: 'That which is produced historically is a product of the mind which has been translated into action. ${ }^{17}$ Consequently, he stipulated that the philology of antiquity contains ... as material of knowledge the entire historical evidence of antiquity.'18

In keeping with this approach Boeckh urged his students to consider 'all genres in which classical civilization had been transmitted', as Wolf had done, and in particular to combine the study of literature "with an overall view of social "realities" based on empirical foundations. ${ }^{19}$ His early masterpiece, Die Staatshaushaltung der Athener (1817), is a representative example of this type of classical scholarship, offering an exhaustive survey of the Athenian economy in the classical period. Boeckh broke new ground by drawing heavily on epigraphic sources for his work and subsequently suggested the collection of all Greek inscriptions by the Prussian Academy of Sciences resulting in the impressive Corpus inscriptionum Graecarum (1825-1860), of which he edited the first two volumes.

Boeckh was a prolific scholar and published numerous works on a range of topics in line with his universal conception of Classical Studies as a science for antiquity as a whole. ${ }^{20}$ Equally impressive are his achievements as an academic administrator: He served five times as rector and six times as dean of the University of Berlin, regularly defending academic freedom in his speeches against political control and instrumentalization. Furthermore, from I834 through I86I he was the secretary (Secretar) of the Philosophical Class of the Prussian Academy of Sciences (he had been a member since 1814) and initiated its transition from a mere society of the learned to a sponsor of large-scale research projects. In addition, he was an external or corresponding member of numerous other academies as well as a member of the German Archaeological Institutes in Rome, Athens, and Cairo, while also serving as the permanent director of the philological and the pedagogical seminar at the university. ${ }^{21}$ From his arrival in Berlin in I8II to his retirement in 1867 Boeckh counted no less than I,602 participants in his seminar, many of whom became well-known scholars. ${ }^{22}$ It is thus safe to say that Boeckh dominated and shaped Classical Studies in Berlin like no other in the first half of the nineteenth century $y^{23}$ and set the standards for the discipline, which by now had reached the status of a fully developed profession instead of simply being 'an intermediary stage on the way to higher office. ${ }^{24}$ As a consequence, all German universities began to introduce philological seminars leading to an unprecedented rise both in quantity and quality of works devoted to classical antiquity..$^{25}$

In particular, in the field of classical editing based on the methodological principles championed by Karl Lachmann (1793-185I) a new era set in. While the first printed texts relied only on a few manuscripts of often dubious quality and subsequent editions equally failed systematically to incorporate new variant 
readings and conjectures, the new approach developed by New Testament critics at the end of the eighteenth century and then adopted by classical scholars attempted to collate all the manuscripts available and then to group them into families and identify the genealogical relationships among them ${ }^{26}$ This allowed scholars not only to distinguish which textual versions 'possessed independent authority and which were purely derivative, ${ }^{27}$ but also to reconstruct the lost archetype on the basis of common readings in the main families. Lachmann refined the so-called stemmatic method by splitting the editorial process into recensio (examination of the manuscript evidence) and emendatio (correction of errors) in order to restore the surviving texts as closely as possible to their original form. ${ }^{28}$ His many editions, especially that of Lucretius, had a lasting influence on his contemporaries and shaped textual scholarship throughout the nineteenth century (and beyond).

At the same time, classical scholars embraced Boeckh's holistic approach and situated the ancient literary sources within their wider historical and cultural context, combining rigorous philological criticism with socio-political analysis ${ }^{29}$

According to Grafton,"not all of this work was original either in conception or in execution". Rather, "German classicists continued to rely on the Latin monographs and commentaries written by French and Dutch inhabitants of the sixteenth- and seventeenth-century Republic of Letters.". ${ }^{\circ}$

For instance, Johann Georg Graevius' Thesaurus antiquitatum Romanarum (1694-1699) and Jacob Gronovius' Thesaurus Graecarum antiquitatum (1697-1702), both of which also considered material evidence and included printed images, remained important resources. Similarly, Jan Gruter's epochal collection of ancient inscriptions (Inscriptiones antiquae [1602]) was still in use. ${ }^{31}$ The modern Altertumswissenschaft in the first half of the nineteenth century thus drew in many ways on the contributions of the antiquarians and 'polyhistors' in the preceding centuries sharing their goal to consolidate and enlarge the textual and material foundations for the study of antiquity. ${ }^{32}$ Moreover, most of these efforts were carried out by outstanding individuals who were toiling away in solitude, often for years, with little institutional or financial support or cross-disciplinary fertilization. This changed with the advent of 'Big Science' in Classical Studies, which established a new framework for scholarly activity based on collaboration and facilitated by public funding.

The term 'Big Science' was coined when, in the aftermath of World War II, a new form of research facility was established, the government-sponsored laboratory, employing hundreds, if not thousands of scientists and technicians. ${ }^{33}$ These national laboratories were a legacy left by the so-called Manhattan Project, the international research and development program led by the United States that had produced the first atomic bomb during World War II. For this reason, most 
people view 'Big Science' as a specific characteristic of nuclear research in the second half of the twentieth century ${ }^{34}$ and associate the term with large-scale projects that are funded by national governments or groups of governments and have enormous budgets ('Big Budgets') as well as large numbers of staff ('Big Staffs'). In addition, these projects often use massive machines as their main research tool ('Big Machines'), which require both significant financial and human resources to build and maintain, and concentrate their scientific work in large research centers ('Big Laboratories')..$^{35}$

But as historians of science have pointed out, 'Big Science' is not limited to national laboratories and nuclear research nor can it simply be measured by quantitative criteria. ${ }^{36}$ Rather, 'Big Science' is characterized more broadly by collaborative research, a large team of coworkers, and multidisciplinarity, since expertise in several academic fields is usually required; furthermore, by a steady flow of publications, (inter)national connections, specialized working methods, and last, but certainly not least, public funding. ${ }^{37}$ The earliest examples of this type of enterprise emerged in the last third of the nineteenth century and introduced a new era of scientific organization and scholarly collaboration, with not the sciences but the humanities, and in particular Classical Studies, paving the way. ${ }^{38}$

In fact, the beginning of 'Big Science' in Classics can be dated precisely: ${ }^{39} \mathrm{On}$ April 27, I858 Theodor Mommsen (I817-1903) was elected as an ordinary member of the Prussian Academy of Sciences in Berlin after having been a corresponding member since $1853 .{ }^{40}$ In his inaugural address, he demonstrated using the example of the Corpus inscriptionum Latinarum, which he had founded in 1853, how scientific research had to be structured in the future in order to organize and preserve what he called the Archive der Vergangenheit.$^{41} \mathrm{He}$ explained that German and foreign scholars had to work together in government-funded projects and that the traditional but ineffective fragmentation of work in Classical Studies at the Prussian Academy had to be replaced with an interdisciplinary collaboration of historians, philologists, and jurists. ${ }^{42}$

In the following decades of his membership at the Prussian Academy, in which he held the position of secretary (Secretar) from I874 to I895, Mommsen consistently and successfully put his vision into practice by founding or initiating numerous large-scale research projects, some of which exist to the present day, such as the aforementioned Corpus inscriptionum Latinarum and the Prosopographia Imperii Romani, founded in $1874 .{ }^{43} \mathrm{He}$ also established and chaired several scientific committees, among them the committee for the edition of the correspondence of the Roman orator Fronto (c. 95-I66 CE) and the committee for the edition of the Codex Theodosianus (collected and published between 429-438 CE), collaborated with the German Archaeological Institute and played an important role in the publication of the Monumenta Germaniae Historica. 
Finally, in 1893 , he designed the by-laws for the Thesaurus Linguae Latinae, the ambitious enterprise of the newly formed cartel of the German Academies of Arts and Sciences. ${ }^{44}$

Through his work and the resulting collections and editions of ancient primary sources Mommsen put classical scholarship on a new foundation. He demanded categorically that all ancient evidence, and not just the textual documents, be systematically collected, cataloged, indexed, and subsequently published, since the entire legacy of Greek and Roman antiquity (cognitio totius antiquitatis) ${ }^{45}$ had to be taken into consideration. Furthermore, he insisted that the strict philological method be applied to any text in order to guarantee authenticity, ${ }^{46}$ as the largescale projects undertaken by the Prussian Academy were 'directed toward providing the materials to permit an unprejudiced historical understanding' of the ancient world. ${ }^{47}$ In short, he combined the practice inherited from Wolf, Boeckh, and Lachmann - source criticism - 'with a new agenda - the ideal of totality for the purpose of constructing a new vision of antiquity and of Roman history especially.48 In so doing, Mommsen perpetuated Boeckh's conception of Classical Studies as a comprehensive and interdisciplinary science of antiquity, but reconfigured and re-organized academic activity following industrial and military models ${ }^{49} \mathrm{He}$ created a new structural framework for classical scholarship by establishing 'Big Science' at the Prussian Academy and successfully implemented 'the principle of a factory-like division of labor', while also securing the necessary financial and political support. ${ }^{50}$

Mommsen's pioneering efforts were continued by his successor as secretary of the Prussian Academy, Hermann Diels (1848-1922), best known for his epochmaking edition of the Fragments of the Presocratics (first edition 1903, sixth edition, revised by Walther Kranz, 1952), which to this day provides an indispensable textual basis for the study of early Greek philosophy. Diels was put in charge of the edition of the Commentaria in Aristotelem Graeca, of which twenty-six volumes were published from I882 through I909, with Diels himself contributing the two volumes of Simplicius' commentary on Aristoteles' Physics and proofreading all the others. In 1907, Diels also founded the Corpus Medicorum Graecorum/ Latinorum, which only recently has been completed. Similarly, in I89I, the theologian and prominent church historian Adolf von Harnack (I85I-1930) started to edit the Greek church fathers together with Mommsen; the project was first called Die griechischen christlichen Schriftsteller der ersten drei Jabrhunderte and after 1945 renamed Griechische Christliche Schriftsteller (completed 2010).51 Other long-term enterprises followed, for instance, the Wörterbuch der ägyptischen Sprache, initiated by Adolf Erman in 1897, of which thirteen volumes appeared between 1926 and 1963 and which found a continuation in the current Altägyptisches Wörterbuch. 
All these monumental projects boosted the international reputation of the German Altertumswissenschaft and served as methodological and organizational paradigm for 'Big Science' in other disciplines and countries, especially in England, France, and Italy. ${ }^{52}$ At the same time, the institutionalization of 'Big Science' had far-reaching consequences both for the Prussian Academy of Sciences and for Classical Studies as a discipline. The former had been founded in 1700 by the Prussian prince-elector Frederick III, the later Frederick I of Prussia, upon the advice of the German philosopher and mathematician Gottfried Leibniz (I646I7I6). Despite its original conceptualization as a general society of the learned, it had been primarily an association of dignitaries in the eighteenth and nineteenth centuries, organized by disciplines and providing a forum for specialized scholarly discourse..$^{53}$ Mommsen restructured the Prussian Academy in the course of his appointment as secretary and transformed it into a large-scale research institution, redefining its function as a sponsor for the new type of collaborative, government-funded, and interdisciplinary academic enterprises that he had initiated.54 Simultaneously, the Academy began to play a major role in education, since the various projects and committees in Classical Studies provided an opportunity for recruiting and training young academics. For even though the unity of research and teaching at the new University of Berlin allowed promising students to participate in the scholarly discussion, it was at the Academy that they truly gained firsthand practical experience carrying out specific work assignments. ${ }^{55}$

Even more fundamental were the changes that Classical Studies as a discipline experienced following the introduction of 'Big Science'. Since Mommsen demanded that the entire legacy of classical antiquity be taken into account, all literary and material remains - texts of all sorts, inscriptions, papyri, coins, archaeological objects, etc. - were collected, organized, and edited in the aim to capture the Greco-Roman culture in its very essence as well as in its individual forms and expressions', as Wilamowitz later wrote. ${ }^{56}$ This led to an enormous expansion of the ancient source material and a multitude of highly specialized research projects requiring specific techniques and scholarly expertise, which in turn accelerated the division of Classical Studies into discrete disciplines such as Greek and Latin Philology, Classical Archeology, Ancient History, Epigraphy, Papyrology, etc. ${ }^{57}$ The emergence of independent fields of study, however, resulted in the abandonment of the conception of Altertumswissenschaft as a systematic and all-encompassing science of the ancient world. Moreover, the notion of classical antiquity as an overarching cognitive ideal was given up and replaced with the specific paradigm(s) of knowledge in the different subdisciplines. ${ }^{58}$

Simultaneously, the professionalization of Classical Studies effectuated by 'Big Science' and, as a consequence, the academicization of antiquity deprived the ancient world both of the exceptional status and the normative function that 
it had had in previous centuries. ${ }^{59}$ Most scholars in the eighteenth and nineteenth centuries had no doubt about the exemplary nature, or at least the profound cultural importance of classical antiquity, and especially that of the Greeks. ${ }^{60}$ But the definition of Classical Studies as a purely historical science led to a consistent de-idealization of antiquity, even if policy makers in higher education clung to the neohumanist appreciation of the absolute primacy of Greek and Roman culture. Mommsen and his contemporaries did not reflect much on the theoretical assumptions and premises of their work nor did they continue earlier efforts to develop a philosophy of science or a universal methodology, as August Boeckh had done. Rather, they focused on the organization of research now that 'Big Science' in Classical Studies had been institutionalized and had produced tremendous results. ${ }^{6{ }^{6}}$ Faith in progress and optimism about the power of scholarship marked the professionalized and diversified study of antiquity in universities and academies. ${ }^{62}$

Toward the end of the nineteenth century, however, the positivistic and historicist investigation of the past ${ }^{\prime 63}$ as represented by the collective research enterprises of the Prussian Academy increasingly met resistance. They were considered uncreative, unproductive, and inadequately theorized, concerned only with the amassing of material without accounting for the necessity and function of such collections or asking about their relevance for real life ${ }^{64}$ Even Mommsen felt that his own scholarly achievement had been relativized and that he had turned into a servant of science. ${ }^{65}$ Similarly, Ulrich von Wilamowitz-Moellendorff (I848-1931), his son-in-law and later president of the Prussian Academy (from 1902 onward) as well as director of the Inscriptiones Graecae, wrote at the beginning of his monograph on ancient Greek lyric: 'My heart is truly more attached to the poets than to the inscriptions; but the Academy has made me the leader of the Inscriptiones Graecae, and duty comes before inclination. ${ }^{66}$

While there is much to learn from the rise and fall of 'Big Science' in Classical Studies at the turn of the past century, it may be particularly timely to look back at the new type of research project established by Theodor Mommsen in light of current digital humanities initiatives, since there are some interesting parallels. This is not to say that the digital humanities are to be seen as modern successors of the academic enterprises at the Prussian Academy of Sciences, but rather that the history of the latter symbolizing a pretheoretical age can provide a useful perspective on present-day activities in an academic landscape that thinks of itself as post-theory (though of course not un-theoretical) ${ }^{6}{ }^{67}$ In addition, it needs to be pointed out that despite all justified criticism of nineteenth-century 'Big Science' for its exclusive focus on collecting, cataloging, and publishing, not for its cataloging, and publishing all surviving texts and objects from classical antiquity, 'any sustained attempt to work with the body of older scholarship is likely to make it clear that there are advantages in having a usable documentary basis 
for Classical Studies'. ${ }^{68}$ The research projects launched by the Prussian Academy provided the fundamental tools for the study of Greco-Roman culture and civilization on which scholars rely to this day, even if it is necessary to examine them critically and to transcend 'the intellectual limitations of the positivist legacy' ${ }^{69}$

Tellingly, Classics was one of the first humanities disciplines to adopt computing approaches and to develop technological tools for the study of antiquity, just as in the nineteenth century Mommsen's vision of Altertumswissenschaft initiated the transition to 'Big Science.' The Thesaurus Linguae Graecae, for instance, was founded as early as 1972 and has since then collected and digitized most extant texts written in Greek from Homer to the fall of Constantinople in I453 CE. Similarly, the text collections of the Packard Humanities Institute, established in 1987, and the Perseus Digital Library Project, also under development since 1987, have set the trend. Finally, the collaborators of Rome Reborn, one of the pioneering ${ }_{3} \mathrm{D}$ digital projects, have been working on their model since 1997, with the first version made public in 2007.

All these digital humanities projects in Classical Studies - and the same goes for other fields - are collective enterprises, regularly involving several institutions as well as numerous individual scholars from various disciplines and countries (not to mention experts from outside academia) and thus share the same form of research organization as the long-term projects of the Prussian Academy of Sciences. ${ }^{70}$ Furthermore, they usually provide opportunities for students and young academics to participate in, and contribute to the respective research activity, thus offering further, often highly specialized training and professional experience similar to their counterparts in the nineteenth century.

However, the digital humanities not only invite comparison with 'Big Science' at the Prussian Academy in terms of organizational structure, international and multidisciplinary collaboration, and - of course - public funding, but also with regard to goal, scope, and methodology. To remain in the field of Classical Studies, the digital projects mentioned above all aim at making the literary and material remains of classical antiquity available to present-day scholars and students in order to advance (and enrich) knowledge, improve research conditions in various disciplines, and open up new avenues for scientific inquiry. The Perseus Digital Library Project defines its objectives even more broadly and states that 'our mission is to make the full record of humanity - linguistic sources, physical artifacts, historical spaces - as intellectually accessible as possible to every human being, regardless of linguistic or cultural background' ${ }^{71}$ This clearly evokes Mommsen's demand to consider the entire legacy of the Greek and Roman world and to make it available in large critical editions. Similarly, most contemporary digital humanities projects are primarily engaged with the collection of vast amounts of data and other evidence just like the large-scale academic enterprises Mommsen founded or sponsored. 
To be sure, the actual processes look very different today; moreover, modern digital technology offers unprecedented opportunities especially for the visual representation of both texts and objects, thus allowing for new forms of study. For instance, electronic editions can not only produce faithful facsimiles of manuscripts or papyri, but also document the entire textual history of a work, since technical applications like color coding, layering, and moving images can effectively display multiple versions, which in a traditional print edition would result in a hopelessly confusing labyrinth of variants. ${ }^{72}$ Likewise, digital commentaries can do justice to the evolving reading habits in recent years due to the influence of such tools as the hyperlink (or pop-up information), immediate search, or the scrolling page, and include material which the limited space of a printed book does not permit or not as fully as desirable.

While contemporary technological progress thus holds much potential, many scholars remain concerned about what actual new insights can be gained from the ever-growing number of databases and online libraries of digitized sources. More specifically, they fear that quantification comes at the expense of interpretation and that people 'forget [that] the digital media are means and not ends', as a wellknown historian of science recently put it. ${ }^{73}$ For databases ' [...] do not tell stories; they do not have a beginning or end; in fact, they do not have any development, thematically, formally, or otherwise that would organize their elements into a sequence. Instead, they are collections of individual items, with every item possessing the same significance as any other' ${ }^{\prime 74}$ Similarly, critics of nineteenth-century 'Big Science' in Classical Studies complained about the unreflected amassing of evidence without consideration of its actual meaning both in the original context and for our understanding of classical antiquity. In light of this, it seems all the more pressing to start thinking about how the new media alter our practices of reading, analysis, and interpretation, how they change our conception of the liberal arts and the production, exchange, and dissemination of knowledge, and in which new direction(s) research should be pushed.

\section{Notes}

I Alan Liu \& William G. Thomas, 'Humanities in the Digital Age', Inside Higher Education, October I, 20I2.

2 See, for instance, the series of articles published in The New York Times between November 2010 and July 20 I I by Patricia Cohen:'Humanities 2.0: Digital Keys for Unlocking the Humanities' Riches', The New York Times, November I6, 2010; 'Humanities 2.0: Analyzing Literature by Words and Numbers', The New York Times, December 3, 2010; 'Humanities 2.0: In 500 Billion Words, New Window on Culture', The New York Times, December 16, 2010; 'Humanities 2.0: Scholars Recruit Public for Project', The New York 
Times, December 27, 20 I0; 'Humanities 2.0: Giving Literature Virtual Life', The New York Times, March 2I, 20I I; 'Humanities 2.0: Digital Maps Are Giving Scholars the Historical Lay of the Land', The New York Times, July 26, 20 I I.

3 Steve Kolowich, 'The Promise of Digital Humanities', Inside Higher Education, September 28, $201 \mathrm{II}$.

4 A few examples are: Digital Mappaemundi (Drew University): URL: http://dm.drew. edu/dmproject; Mapping Gothic France (Columbia University, Vassar College), URL: www.mappinggothicfrance.org; Mapping Soweto (Hamilton College), URL: www.dhinitiative.org/projects/mappingsoweto; The Princeton Dante Project (Princeton University), URL: www.princeton.edu/dante; Railroads and the Making of Modern America (University of Nebraska, Lincoln), URL: railroads.unl.edu; Rome Reborn (University of Virginia), URL: www.romereborn.virginia.edu; Seattle Civil Rights and Labor History Project (University of Washington), URL: depts.washington.edu/civilr; The Shakespeare Quartos Archive (Bodleian Library, Folger Shakespeare Library, Maryland Institute for Technology in the Humanities), URL: www.quartos.org; The Spatial History Lab (Stanford University), URL: www.stanford.edu/group/spatialhistory; Virtual Jamestown (Virginia Polytechnic Institute, University of Virginia), URL: www.virtualjamestown.org.

5 Tom Scheinfeldt, Managing Director of the Center for History and New Media at George Mason University, in Patricia Cohen, 'Humanities 2.0: Digital Keys for Unlocking the Humanities' Riches', The New York Times, November I6, 20 Io.

6 The term was introduced by Theodor Mommsen: cf. 'Antwort an Harnack, 3. Juli I 890', Sitzungsberichte der Königlich Preußischen Akademie der Wissenschaften (I890), 79I-793, repr. in Theodor Mommsen, Reden und Aufsätze, ed. Otto Hirschfeld (Berlin: Weidmannsche Buchhandlung, 1905), 208-210, at 209.

7 On the history of the seminar as an academic institution including its social function, cf. Ian F. McNeely and Lisa Wolverton, Reinventing Knowledge. From Alexandria to the Internet (New York/London: W.W. Norton \& Company, 2008), I66-I85.

8 Anthony Grafton, 'Polyhistor into Philolog: Notes on the Transformation of German Classical Scholarship, I 780-I 850', History of Universities 3 (I983), I59-I92, at I64.

9 Cf. Martin Holtermann, 'Philologisches Seminar', in Der Neue Pauly. Enzyklopädie der Antike. Rezeptions- und Wissenschaftsgeschichte, vol. I5.2: Pae-Sch (Stuttgart/Weimar: Verlag J.B. Metzler, 2002), 327-331, at 329.

Io Friedrich August Wolf, Darstellung der Alterthumswissenschaft nach Begriff, Umfang, Zweck und Werth (Berlin: Realschulbuchhandlung, I 807), repr. with an afterword by Johannes Irmscher (Weinheim: VCH, I986), I24-I25: Es ist aber dieses Ziel kein anderes als die Kenntniß der alterthümlichen Menschheit selbst, welche Kenntniß aus der durch das Studium der alten Ueberreste bedingten Beobachtung einer organisch entwickelten bedeutungsvollen National-Bildung hervorgeht'. Translation from Anthony Grafton, Defenders of the Text: The Traditions of Scholarship in an Age of Science, 1450-1800 (Cambridge, MA/London: Harvard University Press, I99I), 2 I6.

I I Anthony Grafton, 'Wolf, Friedrich August', in Anthony Grafton, Glenn W. Most, and Salvatore Settis (eds.), The Classical Tradition (Cambridge, MA/London: The Belknap Press of Harvard University Press, 2010), 987-989, at 988.

I2 By contrast, Wolf had transferred to Berlin as Professor Litt<erarum $>$ Ant<iquarum $>$ from the University of Halle and, despite earning an extremely high salary, was deeply offended by the higher academic status of his former pupil. Cf. Walter Rüegg, 'Theology and the Arts', in Walter Rüegg (ed.), A History of the University in Europe. Vol. 3: Universities in the Nineteenth and Early Twentieth Centuries (1800-1945) (Cambridge: Cambridge Uni- 
versity Press, 2004), 393-458, at 420. Cf. also Thomas Poiss, 'Die unendliche Aufgabe. August Boeckh als Begründer des Philologischen Seminars', in Annette M. Baertschi and Colin G. King (eds.), Die modernen Väter der Antike. Die Entwicklung der Altertumswissenschaften an Akademie und Universität im Berlin des 19. Jahrbunderts (Berlin: de Gruyter Verlag, 2009), 45-69, at 5I-53.

I3 August Boeckh, Encyklopädie und Methodologie der philologischen Wissenschaften, ed. Ernst Bratuschek (Leipzig: Teubner Verlag, I877), I I.

I4 Wilfried Nippel, 'Böckh, August', in Anthony Grafton, Glenn W. Most, and Salvatore Settis (eds.), The Classical Tradition (Cambridge, MA/London: The Belknap Press of Harvard University Press, 2010), I 3 I.

I5 Boeckh, Encyklopädie, 2 I.

I6 Poiss, 'Die unendliche Aufgabe', 65. Cf. Axel Horstmann, Antike Theoria und moderne Wissenschaft. August Boeckhs Konzeption der Philologie (Frankfurt am Main: Peter Lang Verlag, I982); Frithjof Rodi, 'Erkenntnis des Erkannten. August Boeckhs Grundformel der hermeneutischen Wissenschaften', in Frithjof Rodi, Erkenntnis des Erkannten. Zur Hermeneutik des 19. und 20. Jahrbunderts (Frankfurt am Main: Suhrkamp Verlag, 1990), 70-88.

I7 Boeckh, Encyklopädie, II:'Das geschichtlich Producirte ist ein Geistiges, welches in That übergegangen ist'. Translation from Rüegg, 'Theology and the Arts', 422.

I 8 Boeckh, Encyklopädie, 56:'Die Philologie des Alterthums enthält ... als Stoff der Erkenntniss die gesammte historische Erscheinung des Alterthums'.

I9 Nippel, 'Böckh, August', I 3 I. For the (in)famous controversy between Boeckh and Gottfried Hermann (I772-I 848), the former defining Classical Studies as a broad, multidisciplinary science, the latter as narrow philology with main focus on grammar and textual criticism, cf. Poiss, 'Die unendliche Aufgabe', 6I -62, and Wilfried Nippel,'Philologenstreit und Schulpolitik: Zur Kontroverse zwischen Gottfried Hermann und August Böckh', in Wolfgang Küttler, Jörn Rüsen, and Ernst Schulin (eds.), Geschichtsdiskurs. Vol. 3: Die Epoche der Historisierung (Frankfurt am Main: Fischer Verlag, I997), 244-253.

20 Worth mentioning here are especially his edition of Pindar (I8II-I8I9), complete with an (epoch-making) treatise on meters, an edition of the ancient scholia, a Latin translation, and a commentary, his Metrologische Untersuchungen über Gewichte, Münzfüße, und Maße des Alterthums in ihrem Zusammenhange (I 838), as well as his edition of Sophocles' Antigone, accompanied by a poetical translation and two interpretive essays (I843).

2 I Poiss, 'Die unendliche Aufgabe', 49.

22 Cf. Karl Otfried Müller, Georg Friedrich Schömann, Moritz Meier, Eduard Gerhard, Ludwig Döderlein, Friedrich Adolf Trendelenburg, Christian Konrad Spengel, Johann Gustav Droysen, Ludwig Preller, Richard Lepsius, Otto Jahn, Hermann Bonitz, Ernst and Georg Curtius. Poiss, 'Die unendliche Aufgabe', 54.

23 Max Lenz, Geschichte der Königlichen Friedrich-Wilhelms-Universität zu Berlin (Halle/ Saale: Buchhandlung des Waisenhauses, I9 I0), Vol. 2.I, 499-500.

24 Rüegg,'Theology and the Arts', 424. This is reflected in the foundation of professional organizations such as the Association of German Philologists and Schoolmen (I837), later enlarged to the Association of German Philologists, Schoolmen, and Orientalists (I 844), and the publication of the first specialized journals in Classical Philology, for instance, Das Rheinische Museum für Philologie (I827-), Philologus (I846-), Hermes (I866-), Philologische Wochenschrift (I88I-I944), from I884-1920 called Berliner Philologische Wochenschrift, cf. Rüegg, 'Theology and the Arts', 424-425.

25 For the leading role that Germany played cf. the following remark in a review essay of Greek dictionaries in The London Quarterly Review 5I (I834), I44-I45: 'In the study of 
the dead languages in general, but more particularly of the Greek and Latin, the Germans have taken the lead, not only of us, but of all the rest of Europe, and have gained such a decided ascendancy, that their neighbours appear to have given up all hope of rivaling them, and are satisfied to follow as mere servile imitators of their triumphant career' (Rüegg, 'Theology and the Arts', 423).

Richard Tarrant, 'Lachmann, Karl', in Anthony Grafton, Glenn W. Most, and Salvatore Settis (eds.), The Classical Tradition (Cambridge, MA/London: The Belknap Press of Harvard University Press, 2010), 506-507, at 506. Important figures in the development of the new method include Johann August Ernesti, Immanuel Bekker, Johan Nicolai Madvig, Karl Gottlob Zumpt, Hermann Sauppe, Johann Caspar von Orelli, and Friedrich Ritschl.

28 Ibid.

29 Cf., for instance, Karl Otfried Müller, Die Dorier (1 824) or also Barthold Georg Niebuhr's Römische Geschichte (I8II-I8I2).

30 Grafton,'Polyhistor into Philolog', I78.

3 I Ibid.

32 Cf. Rudolf Pfeiffer, History of Classical Scholarship, from 1300 to 1850 (Oxford: Clarendon Press, I976), I29. Cf. also Grafton, 'Polyhistor into Philolog', I 78.

The following is based on Rüdiger vom Bruch,'Mommsen und Harnack: Die Geburt von Big Science aus den Geisteswissenschaften', in Alexander Demandt, Andreas Goltz, and Heinrich Schlange-Schöningen (eds.), Theodor Mommsen. Wissenschaft und Politik im 19. Jahrbundert (Berlin: de Gruyter Verlag, 2005), I2I-I4I, at I26. In the United Stated some national laboratories were already founded before and during the war, for instance, the Lawrence Berkeley National Laboratory, the Los Alamos National Laboratory, and the Oak Ridge National Laboratory. The popularization of the term 'Big Science' is usually attributed to an article, published in I96I, by Alvin M. Weinberg, then director of the Oak Ridge National Laboratory, cf. Alvin M. Weinberg, 'Impact of Large-Scale Science on the United States', Science I 34 (I96I), I6I-I64. Cf. also Alvin M. Weinberg, Reflections on Big Science (Cambridge, MA/London: Massachusetts Institute of Technology Press, I967).

34 Vom Bruch, 'Mommsen und Harnack', I26 and I38 n. I5 with further bibliographical references.

35 For a brief summary of the general characteristics of 'Big Science' cf. Carlos Spoerhase, 'Big humanities: 'Größe' und 'Großforschung' als Kategorien geisteswissenschaftlicher Selbstbeobachtung', Geschichte der Germanistik 37/38 (2010), I7; cf. also William J. Kinsella, 'Big Science', in Arne Hessenbruch (ed.), Reader's Guide to the History of Science (London/Chicago: Routledge, 2000), 79-80.

36 For this reason, as Derek J. de Solla Price emphasized, the Uraniborg, the observatory instituted by Tycho Brahe in the sixteenth century, cannot be regarded as a precursor to 'Big Science', even though it had large resources at its disposal and made use of huge astronomical instruments, cf. Derek J. de Solla Price, Little Science, Big Science (New York/London: Columbia University Press, I963), 4. Similarly, Lawrence Bedash rejected the notion of 'Big Science' being exclusively determined by the magnitude and scope of a project, cf. Lawrence Bedash, 'The Origins of Big Science: Rutherford at McGill', in Mario Bunge and William R. Shea (eds.), Rutherford and Physics at the Turn of the Century (New York: Dawson and Science History Publications, 1979), 29-4I. Cf. also Vom Bruch,'Mommsen und Harnack', I 27 with further references.

Vom Bruch, 'Mommsen und Harnack', I 27. 
Ibid., $\mathrm{I} 24$ and $\mathrm{I} 28$.

The following account is based on Stefan Rebenich, 'Vom Nutzen und Nachteil der Großwissenschaft. Altertumswissenschaftliche Unternehmungen an der Berliner Akademie und Universität im I9. Jahrhundert', in Annette M. Baertschi and Colin G. King (eds.), Die modernen Väter der Antike. Die Entwicklung der Altertumswissenschaften an Akademie und Universität im Berlin des 19. Jahrhunderts (Berlin: de Gruyter Verlag, 2009), 397-42I, at 398-403 and 407-4I3.

In I86I, he also became a professor of Roman history at the University of Berlin, where he taught until 1887 .

I Theodor Mommsen, 'Antrittsrede, 8. Juli I 858', Monatsberichte der Königlich Preußischen Akademie der Wissenschaften (1858), 393-395, repr. in Theodor Mommsen, Reden und Aufsätze, ed. Otto Hirschfeld (Berlin: Weidmannsche Buchhandlung, I905), 35-38, at 37. Mommsen, 'Antrittsrede', 35-36.

Other projects that Mommsen either inaugurated or sponsored were the Corpus Nummorum (Griechisches Münzwerk, founded in the I880s), the Vocabularium Iurisprudentiae Romanae (founded in I 886), a comprehensive collection of the ancient papyri, a catalog of all surviving information regarding imperial Roman military history, and - together with Adolf von Harnack - the edition of the Greek church fathers (Die griechischen christlichen Schriftsteller der ersten drei Jabrbunderte, founded in I89I). Cf. Rebenich, 'Vom Nutzen und Nachteil der Großwissenschaft', 402.

Vom Bruch, 'Mommsen und Harnack', I 33.

Ulrich von Wilamowitz-Moellendorff,'Der griechische Unterricht auf dem Gymnasium [ı1о]', repr. in Ulrich von Wilamowitz-Moellendorff, Kleine Schriften. Vol. VI: Philologiegeschichte, Pädagogik und Verschiedenes, Nachlese zu den Bänden I und II, Nachtrag zur Bibliographie (Berlin: Weidmannsche Buchhandlung, I972), 77-89, at 77.

6 Rebenich, 'Vom Nutzen und Nachteil der Großwissenschaft', 407-408. For this reason, Mommsen declared the direct examination of the monuments and objects themselves the condicio sine qua non for the critical edition of inscriptions including their measurement and the evaluation of the larger archaeological and epigraphic context, while August Boeckh did not require autopsy believing that printed texts and copies were sufficient.

7 Glenn W. Most, Review of Stefan Rebenich, Theodor Mommsen und Adolf Harnack. Wissenschaft und Politik im Berlin des ausgebenden 19. Jahrbunderts. Mit einem Anhang: Edition und Kommentierung des Briefwechsels (Berlin/New York: de Gruyter Verlag, I997), The Classical Review 5I (200I), 37I-373, at 37I.

48 Stefan Rebenich, 'Mommsen, Theodor', in Anthony Grafton, Glenn W. Most, and Salvatore Settis (eds.), The Classical Tradition (Cambridge, MA/London: The Belknap Press of Harvard University Press, 2010), 598-599, at 599.

49 Rebenich,'Vom Nutzen und Nachteil der Großwissenschaft', 408-409. The term 'Großwissenschaft' has been coined in analogy to 'Großstaat' and 'Großindustrie', cf. Theodor Mommsen, 'Antwort an Harnack, 3. Juli I 89o', Sitzungsberichte der Königlich Preußischen Akademie der Wissenschaften (I890), 791-793, repr. in Theodor Mommsen, Reden und Aufsätze, ed. Otto Hirschfeld (Berlin: Weidmannsche Buchhandlung, I905), 208-2 I0, at 209.

Rebenich, 'Mommsen, Theodor', 599. For Mommsen's special relationship with the main functionary of the Ministry of Education at the time, Friedrich Althoff, cf. Rebenich, 'Vom Nutzen und Nachteil der Großwissenschaft', 403-407. Cf. also Stefan Rebenich, Theodor Mommsen und Adolf Harnack. Wissenschaft und Politik im Berlin des ausgebenden 19. Jahrbunderts. Mit einem Anbang: Edition und Kommentierung des Briefwechsels (Berlin/ New York: de Gruyter Verlag, I997). 
5I Since I90I, Harnack was also involved in the Prosopographia Imperii Romani saec. IV.V.VI, a sequel of Mommsen's Prosopographia Imperi Romani.

52 Rebenich, 'Vom Nutzen und Nachteil der Großwissenschaft', 403.

53 Vom Bruch,'Mommsen und Harnack', I 23. Since I 830 the Prussian Academy was divided into a Philosophical-Historical and a Physical-Mathematical Class; before there were two humanities and two sciences classes.

54 Cf., for instance, his first speech as 'Secretar' in I 874, 'Rede am Leibnizschen Gedächtnistage', Monatsberichte der Königlich Preußischen Akademie der Wissenschaften (I874), 449-458, repr. in Theodor Mommsen, Reden und Aufsätze, ed. Otto Hirschfeld (Berlin: Weidmannsche Buchhandlung, I905), 39-49, esp. 46-47: Alle die wissenschaftlichen Aufgaben, welche die Kräfte des einzelnen Mannes und der lebensfähigen Association übersteigen, vor allem die überall grundlegende Arbeit der Sammlung und der Sichtung des wissenschaftlichen Materials muß der Staat auf sich nehmen, wie sich der Reihe nach die Geldmittel und die geeigneten Personen und Gelegenheiten darbieten. Dazu aber bedarf es eines Vermittlers, und das rechte Organ des Staats für diese Vermittlung ist die Akademie. He also helped revising the by-laws of the Prussian Academy so that they would meet the requirements of the modernized research organization, cf. Rebenich, 'Vom Nutzen und Nachteil der Großwissenschaft', 399.

55 Rebenich, 'Vom Nutzen und Nachteil der Großwissenschaft', 40I-402 and 4I4. Cf. also Rebenich, Theodor Mommsen und Adolf Harnack, 2 I0-223, and Stefan Rebenich, Theodor Mommsen. Eine Biographie (Munich: Beck Verlag, 2002), I58-164.

56 Ulrich von Wilamowitz-Moellendorff, 'Geschichte der Philologie', in Alfred Gercke and Eduard Norden (eds.), Einleitung in die Altertumswissenschaft (Leipzig/Berlin: Teubner Verlag, I927), Vol. I.I, I-80, at I.

57 Rebenich, 'Vom Nutzen und Nachteil der Großwissenschaft', 4I I.

58 Annette M. Baertschi and Colin G. King,'Einleitung', in Annette M. Baertschi and Colin G. King (eds.), Die modernen Väter der Antike. Die Entwicklung der Altertumswissenschaften an Akademie und Universität im Berlin des 19. Jahrbunderts (Berlin: de Gruyter Verlag, 2009), 3-22, esp. I 8. Cf. also Rebenich, 'Vom Nutzen und Nachteil der Großwissenschaft', 4I I-4I2.

59 Rebenich, ibid., 4II-4I2.

60 Rüegg,'Theology and the Arts', 423.

6I Rebenich, 'Vom Nutzen und Nachteil der Großwissenschaft', 4 Io.

62 Stefan Rebenich, 'Historicism', in Anthony Grafton, Glenn W. Most, and Salvatore Settis (eds.), The Classical Tradition (Cambridge, MA/London: The Belknap Press of Harvard University Press, 2010), 440-44I, at 440.

63 Most, Review, 37I.

64 Rebenich, 'Vom Nutzen und Nachteil der Großwissenschaft', 4I 2.

65 Cf. Theodor Mommsen, 'Ansprache am Leibnizschen Gedächtnistage, 4. Juli I 895', Sitzungsberichte der Königlich Preußischen Akademie der Wissenschaften (I 895), 733-735, repr. in Theodor Mommsen, Reden und Aufsätze, ed. Otto Hirschfeld (Berlin: Weidmannsche Buchhandlung, I905), I96-198: 'Die Wissenschaft allerdings schreitet unaufhaltsam und gewaltig vorwärts; aber dem aufsteigenden Riesenbau gegenüber erscheint der einzelne Arbeiter immer kleiner und geringer. [...] Unser Werk lobt keinen Meister und keines Meisters Auge erfreut sich an ihm; denn es hat keinen Meister und wir sind alle nur Gesellen. [...] Wir klagen nicht und beklagen uns nicht: die Blume verblüht, die Frucht muss treiben. Aber die Besten von uns empfinden, dass wir Fachmänner geworden sind'.

66 Ulrich von Wilamowitz-Moellendorff, Sappho und Simonides. Untersuchungen über griechische Lyriker (Berlin: Weidmannsche Buchhandlung, I9I3), I-2: 'Mein Herz hängt wahr- 
lich mehr an den Dichtern als an den Inschriften; aber die Akademie hat mir die Leitung der Inscriptiones Graecae übertragen, und Pflicht geht vor Neigung.' For a detailed analysis of Wilamowitz as both collaborator and initiator of 'Big Science' at the Prussian Academy cf. Martin Hose, “.... und Pflicht geht vor Neigung”: Ulrich von WilamowitzMoellendorff und das Leiden am Großbetrieb der Wissenschaft', in Annette M. Baertschi and Colin G. King (eds.), Die modernen Väter der Antike. Die Entwicklung der Altertumswissenschaften an Akademie und Universität im Berlin des 19. Jabrhunderts (Berlin: de Gruyter Verlag, 2009), 445-480.

67 Constanze Güthenke, Review Essay, 'Shop Talk: Reception Studies and Recent Work in the History of Scholarship', Classical Receptions Journal I (2009), I04-I I 5, at I09.

68 Alice A. Donohue, Review of Suzanne Marchand, Down from Olympus. Archaeology and Philhellenism in Germany, 1750-1970 (Princeton: Princeton University Press, I996) in Bryn Mawr Classical Review, October I3, 1997.

69 Ibid.

70 Rome Reborn, for instance, is a collaboration between the Virtual World Heritage Laboratory of the University of Virginia (VWHL), the UCLA Experiential Technology Center (ETC), the Reverse Engineering (INDACO) Lab at the Politecnico di Milano, the Ausonius Institute of the CNRS and the University of Bordeaux III, and the University of Caen.

7I Perseus Digital Library Project Homepage, URL: http://www.perseus.tufts.edu/hopper/research. For a similar agenda cf. also the recently announced Open Philology Project by the Humboldt Chair of Digital Humanities at the University of Leipzig, URL: http:// sites.tufts.edu/perseusupdates/2013/04/04/the-open-philology-project-and-humboldtchair-of-digital-humanities-at-leipzig/. While Perseus' main focus is - and always has been - on the ancient world, the project associates have also created digital collections of other humanities resources, for instance, on the American Civil War and the English Renaissance, thus enlarging the original scope in order 'to demonstrate the commonalities between Classics and other disciplines in the humanities and beyond'.

72 On the advantages of digital philology vis-à-vis 'old' and 'new' philological practices and in particular on its impact on stemmatology cf. Tara L. Andrews, 'The Third Way: Philology and Critical Edition in the Digital Age', Variants: The Journal of the European Society for Textual Scholarship ro (2013), 6I-76. Cf. also Lou Burnard, Katherine O'Brien O'Keefe, and John Unsworth (eds.), Eletronic Textual Editing (New York: Modern Language Association of America, 2006), and Marilyn Deegan and Kathryn Sutherland (eds.), Text Editing, Print and the Digital World (Farnham: Ashgate Publishing, 2009).

73 Anthony Grafton, historian at Princeton University, in Patricia Cohen, 'Humanities 2.0: Digital Keys for Unlocking the Humanities' Riches', The New York Times, November 16, 2010.

74 Lev Manovich, The Language of New Media (Cambridge, MA/London: Massachusetts Institute of Technology Press, 200I), 2 I 8. 



\title{
4.4 New Philology and Ancient Editors \\ Some Dynamics of Textual Criticism
}

\author{
JACQueline KLoOSTER
}

\section{Introduction}

This paper discusses the place of New Philology in the history of textual criticism of ancient texts. In particular, I will look at the benefits and drawbacks of applying this approach to the textual edition of ancient Greek poetry, by comparing modern editing techniques with what we know about their ancient transmission and editing techniques.

\section{Modes of textual criticism}

In his monograph on textual criticism, Paul Maas makes clear the problem that everyone who seriously wishes to study ancient texts inevitably comes across:

We have no autograph manuscripts of the Greek and Roman classical writers and no copies which have been collated with the originals; the manuscripts we possess derive from the originals through an unknown number of intermediate copies, and are consequentially of questionable trustworthiness. The business of textual criticism is to produce a text as close as possible to the original (constitutio textus).

Although textual criticism has a history of at least 2300 years, it is mainly in the eighteenth and nineteenth centuries that the study of texts and manuscript traditions gets a theoretical underpinning. To determine or reconstruct what an author wrote, three modes of textual criticism can be distinguished, which show some overlap in method. ${ }^{2}$ Of these methods, the first is that of eclectic criticism, where the editor determines, based on the evidence of contrasts between various witnesses of one text what the most plausible reading should be, without 
necessarily singling out one manuscript as being most reliable. The comparison between manuscripts in this process makes it akin to the second method, copytext editing. ${ }^{3}$ In this second procedure first a single most trustworthy manuscript (the base text), often but not always the oldest testimony at hand, is selected and compared to other copies, after which errors in the base text are remedied with the help of these other witnesses. This has been the dominant method until the nineteenth century.

Finally, the most rigorous is that known as stemmatology, in which, on the basis of comparison of the surviving manuscript evidence (recensio) a family tree of surviving manuscripts is reconstructed in order to determine what the archetype of a text hypothetically looked like. This paradigm, known as Lachmann's method, ${ }^{4}$ was first developed in the nineteenth century for the textual criticism of medieval literary texts and New Testament studies, but later applied successfully by Karl Lachmann, most famously in his edition of Lucretius's De Rerum Natura. Thence it became a staple of classical philology. The steps followed in this process are the following:

Recensio (also selectio): Sorting through and collating the surviving manuscript evidence (and the creation of a stemma or cladorama)

Examinatio: An attempt to establish the earliest possible version of a text (the reconstruction of a (hyp)archetype)

emendatio: Correcting the text when none of the surviving manuscripts appears to preserve the correct reading; this may include making a conjecture ${ }^{5}$

The procedure results in a text edition with a critical apparatus (in which editorial decisions, conjectures and variae lectiones are noted) and a stemma codicum. This method is still employed and is usually justified by pointing out that it is essential to possess as much knowledge as possible of the assumed original text in order to study factual content in a responsible way (e.g., if one wishes to know whether a certain general in Thucydides is called Philippides or Pheidippides), but also if one wishes to reach decisions on matters of style and linguistics.

Stemmatology generally involves a strong evaluative element: some manuscripts or readings are dubbed 'inferior', others 'superior'; one speaks of 'corruption' or 'contamination' of manuscripts when a scribe has not followed a single tradition, but combined two. It should moreover be noted that despite its aura of scientific objectivity, several objections have been raised against this mode of text constitution. ${ }^{6}$ For instance, the assumption that scribes only alter texts by mistake is a famous misconception (they may, of course, ameliorate them). Likewise, the idea that commonality of error implies common origin, is only defendable in cases where the text critic is able to identify the error, i.e., where the error is 
recognizable as such - which it may not always be. Another problem (raised by Joseph Bedier in the nineteenth century) was that the method clearly favored bipartite stemmata, whereas in many cases alternative, more complex, family trees were imaginable. Despite these attacks on the alleged rigor and scientific soundness of the method, the stemmatic approach has remained the dominant way of constituting medieval and classical texts.

Meanwhile, in the wake of sociological studies in historical research in the first half of the twentieth century, a systematic interest in the Sitz im Leben of texts and their bearers came more and more to the foreground in literary, and also, finally, philological studies. Awareness of the historical context of the production of a text was an already Rankean procedure, ${ }^{7}$ but it took a long time before existing practices translated into something like the program suggested by the label of 'New Philology' as a discipline. It was in the I970s that this discipline was finally developed by James Lockhart, in the wake of a second development in historical study, namely anthropology, particularly the anthropological approach of ethnologists studying the written and oral cultures or Meso-America. ${ }^{8}$

To return to the topic of text editing classical and medieval texts, it was in 1989, informed by insights from these quarters that the French medievalist Bernard Cerquiglini, in his book Éloge de la Variante: critique de la philologie, polemically stated that the stemmatic method really amounts to a fallacy in the case of medieval poetry in the vulgar languages. His argument was taken up in 1990 (in the journal Speculum) by a group of American medievalists, who proposed that 'New Philology' was indeed what was called for: an approach that recognizes the specific nature of this poetry, namely its oral transmission alongside the written records. Because of its orality, poetry of this type is more flexible than texts that are both conceived and transmitted in written form. This explains the high number of variants in the manuscripts of poets like the medieval Walther von der Vogelweide. Typically, these variants take the shape of (I) different text order, (2) different wording, and (3) sizeable omissions (or additions of text passages). ${ }^{9}$

These variants cannot be considered 'mistakes' of transcription, nor should they be regarded as inferior interpolations'. Rather, they are manifestations of the text that are all equally valuable and authentic. Apart from this, the SpeculumNew Philologists promoted so-called multitextual or multiform editions, which allow the reader to see at a glance the numerous variants, without trying to establish a stemmalike model.

It may be noted that such multiform editions are not entirely new as a concept, in the sense that earlier so-called variorum editions had already been produced (in which various manuscript readings were placed side by side in an edition, and accompanied by the notes of various scholars). ${ }^{\circ}$ Even a critical apparatus has potential elements of the multiform, in that it records various traditions. The 
most important conceptual difference between this and the multiform is that stemmatology aims mainly at constituting a hypothetical archetype, and pays less attention to the later manuscript traditions.

Although, certainly in the world of medieval and classical textual criticism, traditional and New Philology seemed destined to become polemically opposed disciplines, a kind of synthesis and some degree of mutual adaptation has now in many cases been reached."

A number of classicists have recently argued that this New Philological way of editing should also be fully applied to the text criticism of archaic Greek poetry, because here we are also dealing with oral transmission mixed with written records. Of course, an awareness of the Sitz im Leben of ancient texts was well established in Altertumswissenschaften almost from their beginning, but the curious fact remained that this was not always taken into account in editing practices, as I have tried to make clear in the above. In the rest of this paper I will focus on the question what the theoretical benefits and problems with a New Philological approach to editing might be in the case of Greek poetry. ${ }^{12}$

\section{New Philology and archaic Greek poetry: Which genres?}

Clearly, some genres in ancient Greek poetry more readily lend themselves to a New Philologist editorial approach than others. A genre like Pindaric choral victory ode, for instance, is so complex in metrical structure, thought and wording that any possibility of a truly fluid state of the text (resulting from improvisation and a dominant oral transmission) needs to be dismissed. Pindaric lyric poetry was heavily scripted and was moreover 'protected' by its complex metrical structure (with its close metrical responsions) from interpolations. In cases like this, there must have been a single authentic text (allowing perhaps a reworking by the author for reperformance), ${ }^{13}$ and editors may well strive to approximate it as closely as possible.

Homeric or other epic poetry (and to a lesser extent early elegy), on the other hand, originates from long traditions of oral transmission, and hence employs a relatively simple metrical scheme, a specific vocabulary, the repetition of typical scenes and formulaic verses, which facilitate improvisation, and hence justifies a New Philologist approach.

Or rather, it should be noted that the oral nature of Homeric poetry has been recognized since at least Friedrich Wolf (1759-1824), and has developed into a field of study wholly sui generis (the famous Homeric Question), but nevertheless presents noteworthy parallels and overlaps with the approaches of New Philology, although until recently, multiform editions were not available. 
An interesting field between these two extremes is monodic lyric (i.e., poetry sung by an individual to the accompaniment of a lyre), exemplified by the songs of Sappho or Alcaeus. This type of poetry seems to result from single authorship, rather than from an improvisational tradition. Hence, here we might perhaps ultimately postulate an, albeit elusive, original text. In length, Sappho's songs are, of course, no comparison with either Pindaric lyric, or Homeric epic. Moreover, monodic lyric is mainly a performative and therefore oral art. It does not possess the complex structures of Pindaric choral lyric. These last two features would have encouraged textual variation by oral repetition and improvisation to a greater extent than Pindaric lyric allows.

In the following, I look at Homeric epic in order to identify the parallels in the approaches of orality studies and New Philology, and will then turn toward the field of monodic lyric, to see what the benefits and drawbacks of New Philology are in this latter genre.

\section{Homer}

Homer illustrates the paradox of the 'oral text' perfectly. Since the work of Lord and Parry, ${ }^{14}$ the oral nature of Homeric poetry, which had already been postulated by Wolf in 1795 , has been generally accepted, though not perhaps in the extreme form Wolf envisaged. This entails acceptance of the fact that it is impossible to reconstruct a single authoritative version of these poems, because each oral performance would have been - however slightly - different, and would have constituted an original in its own right.

Nevertheless, while paying lip service to this creed, some editors still treat their editions of Homer as though they could in fact reconstruct a single authoritative text. ${ }^{15}$ The projected archetype of this version is presumed to have been written down or dictated at some early point (some say the seventh century BC), and from it all later written copies are believed to derive. ${ }^{16}$ While, of course, there may have been a single, earliest written down version of the Homeric epics, the subsequent continuation of the oral performances by rhapsodes, and the written versions that resulted from these performances, ensure that the postulation of such a version has a different status from what is usually subsumed under the header of 'authoritative text'.

Quotations in ancient authors and remarks in the scholia attest to the very early existence of alternative versions, as Wolf already noticed. The scholia to the Venetus Marcianus codex (A, the so-called Viermänner Kommentar) attest that in antiquity, from very early onward, i.e., in sixth century, various texts of Homer circulated in editions either named after their city of origin (ekdoseis kata poleis, 
from places as widely apart as Marseille, Argos and Sidon) or their editor (ekdoseis kat' andra, of which the earliest known is that of Antimachus, c. 404 BC); these may well have been transcriptions of different oral traditions. Indeed, it has been estimated that when the Alexandrian scholars in the Hellenistic era created their editions of Homer, they may have had as many as 400 different versions of the Homeric poems available. ${ }^{17}$

Since the nineteenth century we also possess the amazing testimony of the numerous Ptolemaic Homer papyri (third to first century BC). What makes these 'wild' or 'eccentric papyri' so intriguing are the notorious 'plus lines', extra lines, sometimes amounting up to $33 \%$ of a single fragment. These lines do not appear in the witnesses later than $150 \mathrm{BC}$, i.e., not in the so-called 'vulgate' versions on which our text of Homer is based. Moreover, the lines are so numerous and blend so organically into the surrounding text that they cannot be discounted as 'mistakes' or random interpolations: they are variants, examples of different traditions. ${ }^{18}$ In this sense they resemble the medieval traditions of the songs of Walther von der Vogelweide mentioned above.

The date of 150 BC appears to have been a watershed, presumably somehow related to Aristarchus's edition of the Homeric epics. ${ }^{19}$ The model of an authoritative archetype from the seventh century leading to a more or less consistent manuscript tradition can hardly be correct therefore, and should not inform modern editions of Homer. A number of scholars in fact now insist that the multitextuality of the tradition should be acknowledged and made visible in digital editions, and this is currently being worked on at the Homer multitext website of the Harvard Center for Hellenic Studies. The resemblance to the editing ideals of some radical New Philologists is clear. One might wonder what such choices mean for the time-honored distinction between aoidoi (creative singers, 'poets') and rhapsodoi, the singers of traditional tales, which they embellish but do not create wholesale: if all versions of the text are put on a same level, then, theoretically, the difference between these categories diminishes or even disappears.

Without wishing to discredit this line of investigation, it remains a rather striking thought that New Philology editing and its aims (i.e., to show that there is not a single retrievable Homer text, and to celebrate the variants of the tradition) theoretically seem to run counter not only to 'traditional' philology, but also to recognizable currents in the philological approaches throughout antiquity.

Consider the following: the ancient Greeks apparently wished to put one name to the author of the Iliad and the Odyssey - the blind bard Homer; in order to make him a more tangible character, they provided him with several biographies. It is also clear that from a very early point onwards general opin- 
ion held that only Iliad and Odyssey were authentic (together with the now lost comic poem Margites) as distinct from the largely anonymous later socalled 'cyclical' epics. ${ }^{\circ}$ We moreover hear (although this is nowadays generally considered a legend) that as early as the sixth century BC there was an attempt to standardize, protect and privilege a certain version of Homeric epic, in Athens, the so-called Peisistratean recension. Even if this story may be a later fabrication, ${ }^{21}$ the fact that textual editions were made as early as $404 \mathrm{BC}$ by individual scholar-poets like Antimachus points toward the wish to privilege one form of the text. At the same time, these ongoing attempts at standardization demonstrate if anything how difficult it must have been to standardize Homer's text.

The most systematic attempt at standardization took place in the Hellenistic era, the great age of Greek scholarship, when Zenodotus, Aristophanes of Byzantium and Aristarchus produced their so-called diorthoseis (emended versions), ekdoseis (editions, presumably mainly for scholarly consultation), and bypomnemata (commentaries). This undertaking points toward the attempt to reach some authentic core of Homeric material, distinct from later accretions. Scholarly opinions differ on how the Homeric critics actually went about these editions, but clearly they did not yet possess the refined stemmatological method. It seems most likely that their attempts were more similar to the copyediting style of textual criticism. From what we can retrieve from the scholia, they apparently selected a single manuscript (presumably an old one they considered to be reliable) and clarified by means of marginal signs (like the famous obelos) whether they thought the text at the passage in question was authentic or not. They did not cut from or add to the text; their separate commentaries (bypomnemata) presumably explained their editorial choices. The idea of 'what was fitting' for Homer (to prepon) often played an important role in their decisions about authenticity. ${ }^{22}$ Indeed, the common sense idea that Homer should be clarified out of his own texts (Homeros ex Homerou safenizein) informs Aristarchus's critical choices. ${ }^{23}$

It may be noted that not many of the suggestions of the Alexandrian editors made it into the vulgate, but it does seem likely that the vulgate represents the reliable text they chose to work with. ${ }^{24}$ What needs consideration, then, is the fact that throughout antiquity, next to the unstable improvisational oral transmissions, a tendency toward a single, authentic text has also always played an important role in the Homeric tradition. Indeed, without it, we might not even have any Homer to speak of. 


\section{Monodic lyric}

Let us now briefly turn to monodic lyric. This is a challenging field because it lies between the two extremes of improvisational oral epic and extensively scripted Pindaric lyric. To begin with, the material is multifarious. The few fragments we have of Sappho, Ibycus and Alcaeus are very different from, e.g., the voluminous collection known as the Theognidea, which comprises a nucleus of poems that appear to be by a certain Theognis of Megara (sixth century BC), ${ }^{25}$ and much traditional symposium-related material besides, which we also encounter in other elegists. For this reason, and also because of the fact that elegy and monodic song presumably served different purposes, one would probably need different theoretical approaches in the editing of such texts.

Also, concentrating for the purposes of this paper, for instance, on the case of Sappho, ${ }^{26}$ the obvious challenge presents itself that we have far less material; there is not, as with Homer, a vulgate against which we can compare 'variant versions'. For all we know, fragments of Sappho's poetry of which we now possess a single version might otherwise have been 'variants'. Besides, as in the case of Homer, we have very little reliable knowledge of the composition and early transmission of these texts although some guesses may be made on the basis of circumstantial evidence.

First, and perhaps most importantly, we do not know whether Sappho actually existed as a historical person, even if it seems highly likely, perhaps more so than in Homer's case. Secondly, it is unclear how Sappho's poetry was composed: in writing? It may have been, or it may have been dictated or written down soon afterwards. And how and where was it first preserved? In the cases of other early authors, such as Alcaeus, we hear of author copies of texts that are deposited in temples (for safekeeping, but presumably also to enable eventual transcription). ${ }^{27}$ And what form did these early texts take? Were they poetry collections written on papyrus, or other materials, and if so, was there a definite order to these collections? Did the order of the poems matter, and was it decided on by the author herself?

With regard to the early transmission scholars struggle with the same amount of uncertainties: how was Sappho's poetry first transmitted beyond her own circle, and when did this begin? Quotations in other early texts make it clear that Sappho's poetry was known outside of Lesbos from as early as the sixth century onwards. Her songs may well have traveled orally: there is a record for learning these songs from hearing them. ${ }^{28}$ One, regrettably late, and therefore not entirely trustworthy, anecdote relates how Solon asked his nephew to teach him a song by Sappho, which he overheard the boy singing. ${ }^{29}$ Testimonies like these apart, it is certain that written copies (serving as scripts for performance, as aide-mémoire for the singer) were also involved right from the start and throughout..$^{30}$ As An- 
drew Ford argues, the scribes of these very early texts, however, presumably did not strive with scholarly rigor for an authoritative version of the poem. Rather, texts were means toward an end: the oral performance. Only in the Alexandrian era, again, do we find an attempt at standardization of Sappho's works.

This explains why the written record shows that Sappho's texts were transmitted in widely different versions, both on a word level, and on the level of strophes or actual poems, that is to say their ordering, and inclusion or omission of texts. The following example, taken from a forthcoming article by André Lardinois, ${ }^{31}$ illustrates this well:

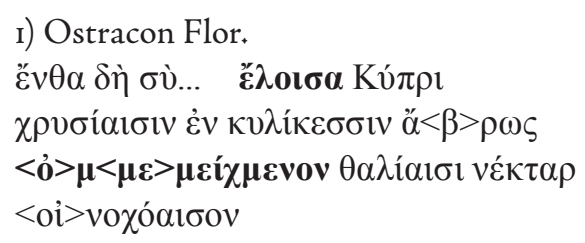

I) Ostracon Flor.

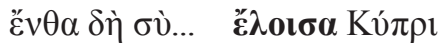

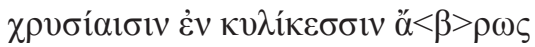

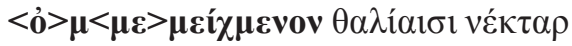

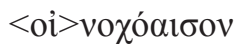

Where you, having taken up (wreaths?), Cypris,

pour nectar gracefully

in golden cups

mingled with the festivities.

2) Athenaeus iI.463e

... $\dot{\boldsymbol{\varepsilon}} \boldsymbol{\lambda} \boldsymbol{\theta} \dot{\boldsymbol{\varepsilon}}, \mathrm{Kú} \pi \rho 1$,

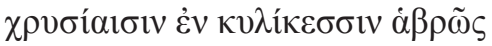

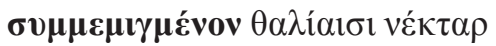

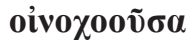

\author{
... Come, Cypris, \\ pouring nectar gracefully \\ in golden cups \\ mingled with the festivities.
}

Of course, if we would consider a digital multitext edition of Sappho, such variants are all part of the transmission history. However, assuming that there was - different perhaps from the case of Homer - a poet called Sappho and that she composed her songs in writing, when we edit her songs in different versions, we are really recording different stages in the later transmission. But there may have been, again, differently from Homer, originally, a single authoritative written text. This is a fundamentally different point of departure. It is, of course, also clear that such a hypothetical text must forever remain elusive. In this sense the way in 
which Sappho's poetry was transmitted does come close to some of the medieval poems by Walther von der Vogelweide.

In Sappho's case there appears not to have been a pervasive attempt at standardization such as we saw in the case of Homer. This may be due to lack of surviving evidence, but other explanations are readily conceivable. It might, for instance, point to the fact that the material was not so wildly prone to variants as the Homeric epics, or, equally importantly perhaps, was not considered to be of the same Panhellenic cultural importance as Homer's epics.

As noted, the first real attempt at producing an authoritative and standardized text of Sappho's poetry is attested, again, with the age of the great Alexandrian scholars, who made editions of her works. In this case we may ask: what texts did they possess for Sappho? The Alexandrian edition of Sappho's poetry is said to have amounted to nine books of poems (i.e., nine scrolls of papyrus), so there must have been quite some (written) material around.

A final intriguing piece of information related to Alexandrian editing concerns the Hellenistic scholar-poet Callimachus and his Pinakes, a (now lost) I20-scroll catalogue of authors kept in the Alexandrian Library, and their works ordered according to genre. This catalogue seems to have listed not only incipits of the works of these authors, but also the number of verses they contained..$^{22}$ This raises the question what Callimachus would have done with poetry collections, like Sappho's: did he list the incipits of all poems on the scroll (thus preserving or establishing an 'authentic' ordering), ${ }^{33}$ or just the incipit of the first poem?

The information that he wrote down the total number of verses is even more fascinating, because this suggests that there was a more or less 'definite' version of the work in question. This verse total could then serve as a kind of safeguarding of this version. Of course, we have no way of knowing how Callimachus determined the correct number of lines.

\section{By way of conclusion}

New Philology editing seems a fully justified approach to forms of Greek poetry that find their origin in oral improvisation, like epic and elegy. In the case of Greek monodic lyric too, it seems a viable idea to produce, e.g., a website showing all available variants of a text, in order to enable readers to see synchronically and diachronically what evidence there is for any given poem. This will certainly provide a more realistic image of the history of such texts and their users than a traditional text edition with a necessarily limited apparatus criticus. Yet, it must be kept in mind that an author's copy may well have once existed, even if it is now and has probably been for the longest time even in antiquity - ultimately elusive. 
Also, we do well to recognize that alongside the unstable and often unorganized transmission of texts in antiquity there existed an important tendency that did focus on authorship, authenticity and standardized texts, and to which, in great part, we probably owe the actual survival of these texts. It is an interesting paradox that this tendency toward standardization should be included in the multiform-oriented approaches of New Philology, and that the rigorous and scientifically inspired nineteenth-century stemmatological approach too could and indeed should be accounted for in the new, historicizing digital text editions, which record the life of a text in all its facets. Contextualization, anthropology and awareness of the Sitz im Leben of texts become central to textual criticism, a discipline that entered the twentieth century with a much more closely circumscribed, philologically centered outlook, and which was all about determining whether a reading was inferior or superior.

\section{Notes}

I Maas, Textual Criticism, trans. B. Flower (Oxford, I958), I.

2 Standard works on the history of textual criticism are J.E. Sandys, A History of Classical Scholarship (Cambridge, I92 I); R. Pfeiffer, History of Classical Scholarship (Oxford, I968); L. Reynolds and N.G. Wilson, Scribes and Scholars: A Guide to the Transmission of Greek and Latin Literature (Oxford, I968); E.J. Kenney, The Classical Text: Aspects of Editing in the Ages of the Printed Book (London, 1974); A. Harris's translation of Ulrich von Wilamowitz-Moellendorff's History of Classical Scholarship (Baltimore, I982); A. Grafton, Joseph Scaliger: A Study in the History of Classical Scholarship I: Textual Criticism and Exegesis (Oxford, I983); A. Grafton and M. Williams, Christianity and the Transformation of the Book: Origen, Eusebius, and the Library of Caesarea (Cambridge, MA: Harvard University Press, 2006).

3 The name of this method was given by Ronald Kerrow in his I904 edition of Thomas Nashe's works, but the method had been in use for a long time, it forms the basis for, e.g., Erasmus's famous edition of the New Testament in Latin.

4 Although it had been developed by others, Lachmann was the first to make it famous. See Sebastiano Timpanaro, La genesi del metodo di Lachmann (Florence: Le Monnier, I963), first translated in German in 1963, second revised edition I97I, later translated and edited by Glenn Most, The Genesis of Lachmann's Method (Chicago, 2005).

5 See Maas, Textual Criticism, I. The wording here is adapted from G.D. Bird, Multitextuality in the Homeric Iliad: The Witness of the Ptolemaic Papyri (Cambridge, MA, 2010), I-2.

6 Cf. Reynolds and Wilson, Scribes and Scholars, I92-I94.

7 Indeed, already in the sixteenth century, with the rise of antiquarianism, consciousness grew as to the context in which ancient texts, notably the Old and New Testaments were made: for whom, under which circumstances, with what kind of cultural presuppositions, etc. Antiquarians had a growing awareness of the material history of the circulation of texts and their transmission. This adumbrated such studies as those of Friedrich Wolf c.s., on which more below. 
M. Restall, 'A History of the New Philology and the New Philology in History', Latin American Review 38.I (2003), II 3-I34.

9 Cf. T. Bein, "Schlechte Handschriften", "critische Ausgaben", "ausgezeichnete copisten": Über die Bedeutung der Materialität für Edition und Interpretation am Beispiel von Ton 36/36a Walthers von der Vogelweide', in Materialität in der Editionswissenschaft, ed. M. Schubert (Berlin, 2010), 267-274.

Io Nicolaas Heinsius's edition of Claudian (I66I) is a good example.

I I See, e.g., Variance and the Politics of Textual Criticism, in K. Busby (ed.), Towards a Synthesis? Essays on the New Philology (Amsterdam, I993), 29-45.

I 2 I have left out the discussion of ancient prose. Although prose was (also) a performative genre in antiquity, it is nevertheless a text type that is less readily available for improvisation or misquotation, albeit on different grounds. Prose became an artistic text type much later than poetry in ancient Greece, and it arose more or less together with the rise and spread of writing. It was, moreover, certainly in the classical period, not performed in the same kind of social contexts as poetry (i.e., at the symposium or the religious festival), due to its generally more technical nature.

I 3 It is assumed that Pindar's patrons received the text, probably with the musical accompaniment in written form as well, in order to enable such (private) reperformances. But, as is the case with so much about ancient transmission, this is not entirely certain.

I4 A.B. Lord, The Singer of Tales (Cambridge, MA, I 960); Epic Singers and Oral Tradition (Ithaca, NY, 199I); The Singer Resumes the Tale, ed. M. Lord (Ithaca, NY, I994); M. Parry, The Making of Homeric Verse: The Collected Papers of Milman Parry, ed. A. Parry (Oxford, I97 I).

I5 G.S. Kirk, The Iliad of Homer, Vol. 1, Books 1-4 (Cambridge, I985), R. Janko, The Iliad: A Commentary (Vol. IV, Books 13-16), ed. G.S. Kirk (Cambridge, I992), as cited by Bird, Multitextuality in the Homeric Iliad, 4I n. 64.

I6 Useful graph in Bird, Multitextuality in the Homeric Iliad, 4I. He posits his own model on page 43 .

I7 E. Pöhlmann, Einführung in die Überlieferungsgeschichte und in die Textkritik der antiken Literatur (Darmstadt, 1994), 36.

I 8 G. Nagy, Homer's Text and Language (Champaign, IL, 2004). See on the wild papyri: Bird, Multitextuality in the Homeric Iliad.

I9 Bird, Multitextuality in the Homeric Iliad, 75-78.

20 At least as early as Aristotle, as the Poetica attests, i.e., fourth century BC.

2 I Sources for this story include the scholia to the second-century BC grammarian Dionysius Thrax, and some late Lives of Homer.

22 On the editing techniques of the Hellenistic scholars, see, e.g., Pfeiffer, History of Classical Scholarship; Reynolds and Wilson, Scribes and Scholars; Pöhlmann, Einführung in die Überlieferungsgeschichte; R. Nünlist, The Ancient Critic at Work (Cambridge, 2009).

23 See Pfeiffer, History of Classical Scholarship, 229.

24 See for numbers: Pöhlmann, Einführung in die Überlieferungsgeschichte, 36-37.

25 On the problematic Theognidean corpus, see, e.g., M.L. West, Iambi et elegi Graeci. Vol. 2, 2nd. rev. ed. (Oxford, I992).

26 The case of Sappho has been discussed in the light of New Philology by A. Lardinois, 'The New Sappho Poem (P. Koln 2 I 35 I and 2 I 376), Key to the Old Fragments', in Greene and Skinner (eds.), The New Sappho on Old Age (Cambridge, MA, 2009), 4I-57, and idem, New Philology and the Classics.

27 We know of an edition of Alcaeus's poetry, which was kept in the Apollo temple at Delos (IDel I 400, 70). 
28 Testimonia in E.M. Voigt, Sappho et Alcaeus, fragmenta (Amsterdam, I97 I [1963]).

29 Sappho, Test. Io Voigt = Stobaeus Anth.3.29.58.

30 A. Ford, 'From Letters to Literature: Reading the Song Culture of Classical Greece', in H. Yunis (ed.), Written Texts and the Rise of the Literate Culture in Ancient Greece (Cambridge, MA, 2003), I5-37.

3I In: The Reception of Greek Lyric Poetry 60oBC-40oAD: Transmission, Canonization, and Paratext. Proceedings of the Network for the Study of Archaic and Classical Greek Song, Vol. 3. eds. B. Currie \& I. Rutherford. Leiden: Brill, 2016.

32 Pöhlmann, Einfübrung in die Überlieferungsgeschichte, 25, cf. also Pfeiffer, History of Classical Scholarship, I6I, on the Pinakes.

33 Cf. the Vienna Papyrus (P. Vindob. G 40611), of the third century, which contains a list of about 240 epigram incipits. 



\title{
4.5 What Books Are Made of \\ Scholarship and Intertextuality in the History of the Humanities
}

\author{
Floris Solleveld
}

\section{Introduction: Paper castles}

In 1866 Alfred Blot, a history teacher at the Collège Stanislas, published a reedition of Louis de Beaufort's 1738 Dissertation sur l'Incertitude des Cinq Premiers Siècles de l'Histoire Romaine [Fig. 4]. Out of print for more than a century, the main virtue of Beaufort's work was to show systematically how little we know about the mythical past. The gist of Beaufort's argument is that most of the early Roman historical record and monuments perished in the sack of the city by the Gauls in 387 or $390 \mathrm{BCE}$, and that of the two main sources we have today, Dionysius of Halicarnassus is overly credulous and Livy knows that he is working with unreliable legend but has nothing else to fill the gaps. The book then proceeds to list inconsistencies in early Roman history, for 500 pages.

In support of his new edition, Blot cites two authorities in his introduction, Michelet and Hyppolite Taine. Both describe Beaufort, in strikingly similar terms, as 'the first true reformer', who 'deserves to be reprinted', the man who destroyed the idealized past in order to make space for proper historiography - in short, a French precursor to Niebuhr and Mommsen. Niebuhr, for that matter, in the foreword to his Römische Geschichte, makes a somewhat grudging acknowledgement toward Beaufort as the only predecessor in early Roman history whose work makes sense, but puts him down as 'mehr Gewährsmann als Vorgänger', someone whose sound judgment has proved reliable rather than someone who actually contributed substantial work. This is not entirely fair as Beaufort proceeded, thirty years later, to publish a two-volume Plan Géneral of the Roman Republic, for which the Dissertation self-avowedly prepared ground; but as far as the Dissertation is concerned one is tempted to agree with Niebuhr. Beaufort's contribution is indeed entirely negative in terms of facts, though it does propound new arguments.

Blot's edition and its argument about the origins of source criticism make a nice case of how text is made of earlier text. There are at least six layers of that: 


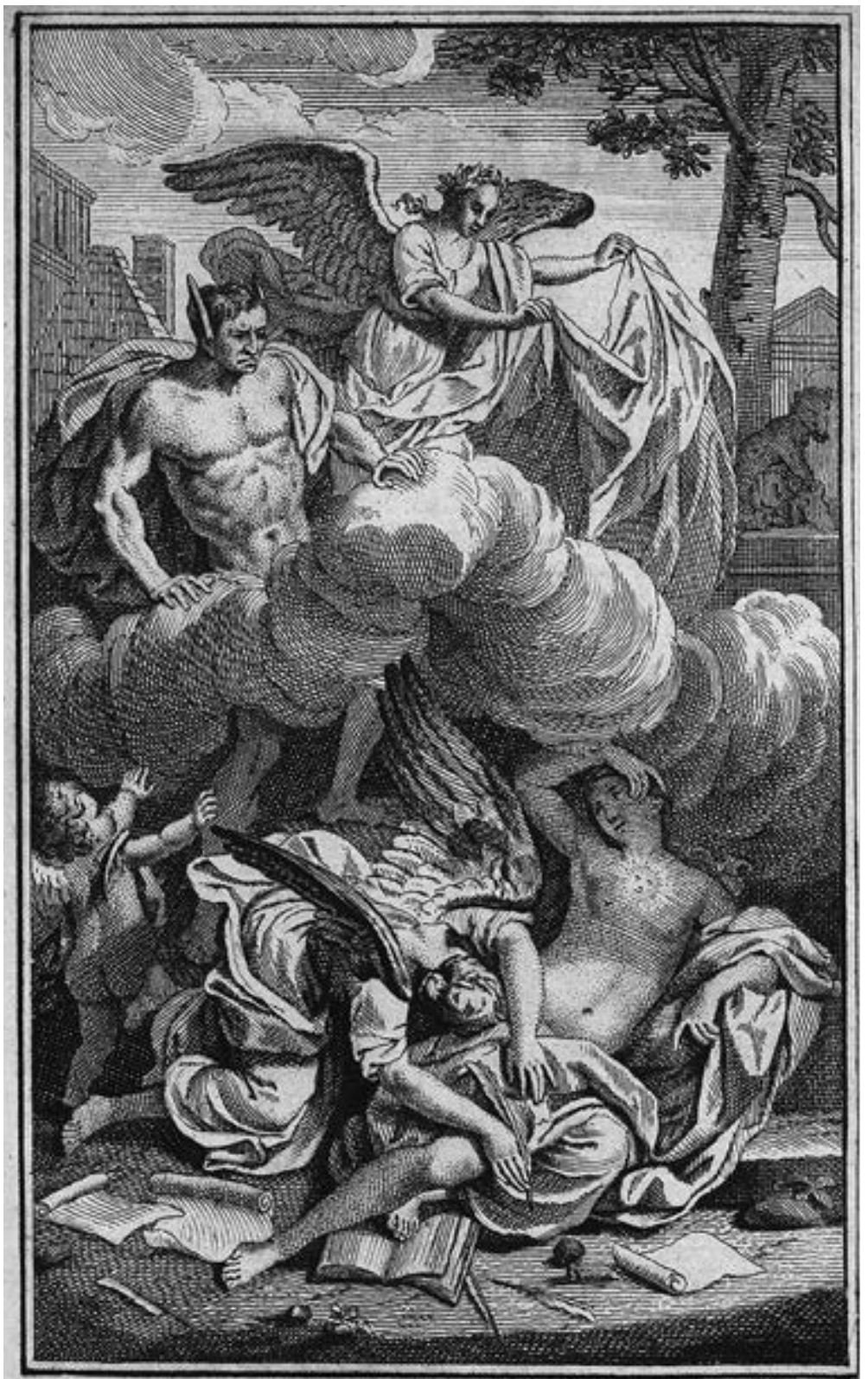

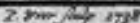

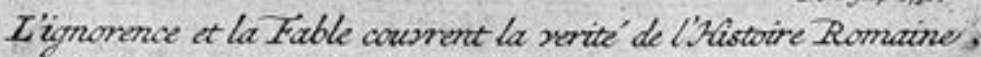

Fig. 4: P. Yver, frontispiece to Louis de Beaufort, Dissertation sur l'incertitude des cinq premiers siècles de l'bistoire romaine (Utrecht, 1738), engraving (C University Library, University of Amsterdam, Special Collections) 
the ancient Roman records, now lost; the work of Roman and Greek historians, partly preserved; early modern comments on those histories; the Dissertation; its reception; and finally, the schoolmaster's foreword. (Moreover, Blot's edition includes Beaufort's response to 'l'écrit d'un certain Allemand' that had doubted the originality of his work and even accused him of plagiarism. ${ }^{\mathrm{I}}$ What is relevant here is the ways in which these text are linked: already in the ten pages of the introduction, we see different kinds of quotation, allusion, comparison, reformulation and criticism at work. Highlighting Beaufort's originality and his contribution to classical scholarship requires in itself a whole network of such links.

This illustrates the duplicity inherent in all scholarship concerned with text, not just historiography but also philology and language study: of building and destroying paper castles at the same time, so that one arrives at the underlying fact. At the end of the paper trail is a very concrete event: the sack of Rome by the Gauls in 387/390 BCE, before which nothing can be known with certainty. Beaufort merits canonization, according to Blot, Taine and Michelet, precisely because of his destructive work so that others can build. Beaufort says it with a frontispiece: Ignorance and Fable Cover the Truth of Roman History.

\section{Reproduction and innovation}

My aim in this article is to argue for the study of types of intertextuality as a means for mapping developments in the humanities. The basic idea is simple. Scholarly work is, in many ways, a compound of earlier text. Very little, at least in the humanities, is the report of direct observation or firsthand experience. In August Boeckh's dictum, philology (in a very inclusive sense) is die Erkenntnis des Erkannten, the recognition of what has been recognized. The question, then, is: to what extent does research in the humanities add significant new information? And how do the means of information management change?

Intertextuality is not mere replication. Or rather, replication is just the simplest form of intertextuality; we have already seen more sophisticated types such as comparison, continuation, emendation, comment and critique. Rather than being the opposite of adding significant new insight, intertextuality is the precondition of it: only by building upon previous work, by accumulation as well as rejection, is progress in the humanities possible. Still, from Descartes and Bacon onwards, historians and philologists have been accused of building paper castles, of heaping together stacks of useless antiquarian facts and comments on footnotes - and every generation of scholars has since been occupied with defending its practice, putting it on new footing, presenting new ways of doing 'scienza nuova', writing proper history, and time and again announcing a 'crisis in the humanities'. 
The notion of intertextuality, stemming from literary studies, has until recently rarely been applied to the history of scholarship, or to the history of ideas at large. ${ }^{2}$ According to the principle of 'guilt by association', this may well be because it stems from literary studies. There has, however, been substantial previous work in intellectual history on the notion of 'influence, ${ }^{3}$ the paper trail of 'core concepts, ${ }^{4}$ information management, ${ }^{5}$ the history of the footnote, ${ }^{6}$ and, more recently, digital humanities scholarship on textual borrowing. ${ }^{7}$ This article aligns with the latter rather than the former. My main interest in intertextuality is in how bits of source text are embedded into the argument of the target text, and what this reveals about changes in scholarly practice. Although there is an obvious similarity between my analysis of 'types of intertextuality' and the five 'types of transtextuality' identified by Genette, ${ }^{8}$ and the six 'levels of intertextuality' distinguished by Bazermann, ${ }^{9}$ their concern is ultimately with authorship, whereas mine is with information management.

In this article I will be offering a typology of different types of intertextuality with some examples from the history of scholarship. The aim behind this typology is to find a way of assessing changes in scholarly practice while short-stepping discussions of epistemology, ideology, or worldview, without recourse to such notions as 'hermeneutics', 'narrative,' 'discourse', and 'context'. This perspective, obviously, is internalist; it only takes into view what scholars were doing in, not what they were doing by writing a particular text. However, intertextuality includes the replication, reformulation and extension of arguments, the reuse and redefinition of concepts by which scholars define themselves, and models and examples they follow; as well as the selection and arrangement of this material. All this requires a more substantive analysis for which the mere study of intertextuality only supplies the raw data; which is why, in conclusion, I will propose an integrated approach in which types of intertextuality are one element.

\section{Types of intertextuality}

The typology offered here is essentially open and informal: it can be extended with further types, and there is a certain overlap between types. Some elements in the typology - those dealing with literal replication - can and have been the object of computational research: given the availability of a substantial digitized corpus, it is relatively easy to do queries over word or word-pair matches and distribution of terms. With other types, such as paraphrase, model-following, critique and borrowing or continuing arguments, that depends on whether sources are stated. But for each type, the issue is not just how often it is done but also how it is done. 
The typology should at least include the following:

Quotation, paraphrase, reference, samples, excerpts, summaries, editing, translation, comparison, continuation, following models, borrowing concepts, borrowing arguments, critique, comment, emendation, plagiarism.

In table I below, these are listed according to how they use the source text, what role the source text plays in the target text, and what else is distinctive of this or that type.

Table 1: Types of Intertextuality

\begin{tabular}{|c|c|c|c|}
\hline Type & Use of the source text & Role in the target text & Specific function or features \\
\hline Quotation & $\begin{array}{l}\text { literal reproduction of the } \\
\text { source text }\end{array}$ & $\begin{array}{l}\text { embedded in the } \\
\text { argument of the target } \\
\text { text }\end{array}$ & $\begin{array}{c}\text { often a status marker that } \\
\text { attributes authority to } \\
\text { what is cited }\end{array}$ \\
\hline Paraphrase & $\begin{array}{l}\text { a reformulation of (the } \\
\text { crucial information from) } \\
\text { the source text }\end{array}$ & $\begin{array}{l}\text { integrated into the target } \\
\text { text, often interspersed } \\
\text { with quotes }\end{array}$ & $\begin{array}{l}\text { more interpretive than } \\
\text { quoting; requires further } \\
\text { support by references, } \\
\text { unless the content is } \\
\text { assumed to be 'common } \\
\text { knowledge' }\end{array}$ \\
\hline Reference & $\begin{array}{l}\text { pointing to a source text } \\
\text { for some information, } \\
\text { quote, or paraphrase }\end{array}$ & $\begin{array}{l}\text { supplies additional } \\
\text { information that does not } \\
\text { fit into the main text }\end{array}$ & $\begin{array}{l}\text { represented by a symbol } \\
\text { or abbreviation }\end{array}$ \\
\hline Samples & $\begin{array}{c}\text { reproduce source text, but } \\
\text { it's not the content that } \\
\text { matters }\end{array}$ & $\begin{array}{l}\text { functions as an } \\
\text { illustration of something } \\
\text { asserted in the target text }\end{array}$ & $\begin{array}{l}\text { crucial for dictionaries } \\
\text { and linguistic proofs }\end{array}$ \\
\hline Excerpts & $\begin{array}{l}\text { a type of'longer } \\
\text { quotation' which presents } \\
\text { the source text in its own } \\
\text { right }\end{array}$ & $\begin{array}{l}\text { independent bit of text, } \\
\text { referred to in the main } \\
\text { text or part of a larger } \\
\text { compilation of excerpts }\end{array}$ & $\begin{array}{l}\text { often used in compendia, } \\
\text { chrestomathies, etc. }\end{array}$ \\
\hline Summaries & $\begin{array}{l}\text { a 'longer paraphrase' } \\
\text { which abbreviates } \\
\text { the source text into a } \\
\text { (supposed) semantic } \\
\text { equivalent of the relevant } \\
\text { information }\end{array}$ & $\begin{array}{l}\text { either integrated or } \\
\text { referred to in the main } \\
\text { text; if integrated into } \\
\text { a novel argument, the } \\
\text { summary also contains } \\
\text { comment and/or critique }\end{array}$ & $\begin{array}{c}\text { a way of applying } \\
\text { Ockham's razor through } \\
\text { selection }\end{array}$ \\
\hline
\end{tabular}




\begin{tabular}{|c|c|c|c|}
\hline Type & Use of the source text & Role in the target text & Specific function or features \\
\hline Editing & $\begin{array}{l}\text { reproduces the source } \\
\text { text in full, after a } \\
\text { critical examination and } \\
\text { comparison of different } \\
\text { (printed/manuscript) } \\
\text { versions }\end{array}$ & $\begin{array}{l}\text { target text becomes } \\
\text { a fuller, more correct } \\
\text { version of the source text }\end{array}$ & $\begin{array}{l}\text { extends the source } \\
\text { text with comments/ } \\
\text { emendations/ } \\
\text { corrections/multiple } \\
\text { versions }\end{array}$ \\
\hline Translation & $\begin{array}{c}\text { replaces the source text } \\
\text { by a (supposed) semantic } \\
\text { equivalent in a different } \\
\text { language }\end{array}$ & $\begin{array}{c}\text { translation }=\text { the target } \\
\text { text }\end{array}$ & $\begin{array}{l}\text { translation involves } \\
\text { a reformulation or } \\
\text { introduction of novel/ } \\
\text { alien concepts }\end{array}$ \\
\hline Comparison & $\begin{array}{c}\text { presents source texts } \\
\text { (versions/translations) } \\
\text { side-by-side as a tool for } \\
\text { analysis }\end{array}$ & $\begin{array}{c}\text { comparison supports a } \\
\text { generalization/selection/ } \\
\text { preferred reading }\end{array}$ & $\begin{array}{l}\text { leads to specific kinds of } \\
\text { layout: double columns, } \\
\text { tables, glosses, etc. }\end{array}$ \\
\hline Continuation & $\begin{array}{l}\text { 'updates' the source text } \\
\text { with emendations and } \\
\text { extensions }\end{array}$ & $\begin{array}{l}\text { source text is literally } \\
\text { copied as a model for } \\
\text { presenting information }\end{array}$ & $\begin{array}{l}\text { target text generally } \\
\text { makes no claim of original } \\
\text { authorship, unless the } \\
\text { divergence is substantial }\end{array}$ \\
\hline Models & $\begin{array}{l}\text { target text does not } \\
\text { reproduce source text } \\
\text { or content as such but } \\
\text { follows its example }\end{array}$ & $\begin{array}{l}\text { source text functions } \\
\text { as an guide for how to } \\
\text { structure and present } \\
\text { one's material }\end{array}$ & $\begin{array}{l}\text { operates on a second or } \\
\text { 'meta-intertextual' level }\end{array}$ \\
\hline Concepts & $\begin{array}{l}\text { borrows a specific } \\
\text { (abstract) term drawing } \\
\text { upon its previous } \\
\text { associations, implications } \\
\text { and definitions }\end{array}$ & $\begin{array}{l}\text { employs a previously } \\
\text { defined concept in a novel } \\
\text { argument; alternatively, } \\
\text { it introduces a new } \\
\text { though related term or } \\
\text { description }\end{array}$ & $\begin{array}{l}\text { equivalence of concepts } \\
\text { cannot be established } \\
\text { unambiguously, even if } \\
\text { the same term is used }\end{array}$ \\
\hline Arguments & $\begin{array}{l}\text { rarely ever reproduced } \\
\text { from the source text } \\
\text { in exact terms, but } \\
\text { rather paraphrased and } \\
\text { commented upon }\end{array}$ & $\begin{array}{l}\text { structures the target } \\
\text { text through extended } \\
\text { argument }\end{array}$ & $\begin{array}{l}\text { arguments (unlike } \\
\text { proofs) are essentially } \\
\text { open and contestible; } \\
\text { equivalence cannot } \\
\text { be established } \\
\text { unambiguously }\end{array}$ \\
\hline Critique & $\begin{array}{l}\text { either extends or } \\
\text { reformulates the source } \\
\text { text, drawing out false } \\
\text { implications or noting } \\
\text { contradictions with other } \\
\text { source material }\end{array}$ & $\begin{array}{l}\text { statements or arguments } \\
\text { from the source text are } \\
\text { corrected or ruled out as } \\
\text { false (often in support } \\
\text { of the argument of the } \\
\text { target text) }\end{array}$ & $\begin{array}{l}\text { functions both as a } \\
\text { selection mechanism for } \\
\text { novel insight, a step to } \\
\text { new ideas through the } \\
\text { rejection of old ones, and } \\
\text { an expression of scholarly } \\
\text { morals and standards }\end{array}$ \\
\hline
\end{tabular}




\begin{tabular}{|c|c|c|c|}
\hline Type & Use of the source text & Role in the target text & Specific function or features \\
\hline Comment & $\begin{array}{l}\text { extends the source text } \\
\text { with elucidation or } \\
\text { significant additional } \\
\text { information }\end{array}$ & $\begin{array}{c}\text { embeds a quote or } \\
\text { paraphrase }\end{array}$ & $\begin{array}{c}\text { when comment raises } \\
\text { questions, it overlaps with } \\
\text { critique }\end{array}$ \\
\hline Emendation & $\begin{array}{l}\text { fills lacunae in the source } \\
\text { text with additional } \\
\text { information }\end{array}$ & $\begin{array}{l}\text { target text becomes } \\
\text { a fuller, more correct } \\
\text { version of the source text }\end{array}$ & \\
\hline Plagiarism & $\begin{array}{l}\text { reproducing the source } \\
\text { text or its significant new } \\
\text { information without } \\
\text { mentioning the source }\end{array}$ & $\begin{array}{l}\text { presenting the source } \\
\text { text or its content as a } \\
\text { new text }\end{array}$ & $\begin{array}{c}\text { makes a false claim of } \\
\text { original authorship, or } \\
\text { disregards considerations } \\
\text { of authorship }\end{array}$ \\
\hline
\end{tabular}

Several things can be concluded from this list. First, that the different types not merely overlap but also combine: a comment upon the source text contains a quote or paraphrase, concepts are borrowed as words but also through the continuation of arguments, quotes and paraphrases are marked with a reference. Second, that although the list is not strictly hierarchical, there are different levels on which intertextuality operates: there is the basic level of reproducing text; the more interpretive level of reproducing content; the meta-level of concepts, arguments, and the structure of a text; and the supra-level of models and critique. This is only an analytical distinction: these levels do not exist as different layers in the text. Third, that some types are alike in what they do to the source text, and others in how they function in the target text. Accordingly, there are two possible subdivisions within this typology.

One can distinguish three categories in 'what is done to the source text':

Replication: quotes, references, samples, excerpts, plagiarism

Reformulation: summaries, arguments, concepts, critique, comparison, translation

Extension: editing, continuation, model-following, comment, emendation

Equally, one can distinguish three ways in which the source text functions in the target text. There are ways in which the source text is embedded in a line of argument, ways in which the source text or its content is presented in its own right, and there are ways in which the source text plays a structuring role, in which the target text is built around it: 
Embedding: quotes, references, arguments, paraphrase, concepts, plagiarism, translation

Presenting: summaries, samples, excerpts, comparison, editing, emendation

Structuring: continuation, models, critique, arguments, concepts

The division between embedded source text and being structured around the source text is one of degree: comments and critique can be an element of a larger text as well as an entire new text, and concepts and arguments affect the content and structure of the text they are embedded in. These higher-level types of intertextuality are on the whole more difficult to pin down; if there is no lower-level marker (say, a quote, a reference, an allusion, or word matches) then there is only a subjective judgment on similarity and possible influences. ${ }^{\text {IO }}$

Table 2: Subdivisions

\begin{tabular}{|c|c|c|c|}
\hline \multirow[t]{2}{*}{ Use of the source text } & \multicolumn{3}{|c|}{ Function in the target text } \\
\hline & Embedding & Presenting & Structuring \\
\hline Replication & $\begin{array}{c}\text { quotes, references, } \\
\text { plagiarism }\end{array}$ & samples, excerpts & \\
\hline Reformulation & $\begin{array}{l}\text { paraphrase, arguments, } \\
\text { concepts, critique }\end{array}$ & summaries, translation & $\begin{array}{l}\text { critique, concepts, } \\
\text { arguments }\end{array}$ \\
\hline Extension & emendation, comment & editing & $\begin{array}{l}\text { continuation, model- } \\
\text { following }\end{array}$ \\
\hline
\end{tabular}

One could include more elements in this typology. For instance, there is arrangement or collation, and also parody (which is not a very common scholarly device, but it happens). Even forging is to a large extent an intertextual construct. Equally, I'm not sure whether coagulation - that is, combining things - should be a separate category. But the resultant picture of what we as scholars do most of the time is clear enough: we read, pen in hand, and then we write. Like the typology, this may sound like stating the obvious. But the most obvious conclusion of all is that you don't structure a text by simply replicating it.

\section{Shifting patterns}

Within the scope of this article, it is impossible to give detailed examples for each type; 'I but the Beaufort/Blot example serves to show that, at least in the percep- 
tion of eighteenth- and nineteenth-century scholars, there was indeed a shift in the uses of source text. As Glenn Most argues elsewhere in this volume, we are so used now to smoothened narratives in scholarly publications that we are surprised to see how openly early modern works display their building blocks. This is particularly true for the genre of compendia, which is now restricted to welldefined types of lexicon but had a much wider scope in the early modern period. Some examples are below.

Equally, there is a shift in citation strategies from representative to epistemic uses; that is, in the early modern period, authorities are often quoted because they are authorities, even when the actual information is drawn from elsewhere. As recent articles by Edelstein and by Horton, Olson, Roe et al. have shown, ${ }^{\mathrm{I} 2}$ the Encyclopédie predominantly quotes classical and seventeenth-century authors, while shamelessly plundering passages from Montesquieu (68I), Voltaire (528), Moréri's Grand Dictionnaire Historique (2606), and the Dictionnaire de Trévoux (II,430). These figures also serve to illustrate different attitudes toward plagiarism.

The great shift in model-following is toward disciplinary models: Ranke and Niebuhr in history, and Bopp and Grimm in linguistics are key examples. Their influence in this regard is not so much in the content of what they write as in the example they give of how to write, and how to be a scholar. In this, they are unlike earlier models like Montesquieu and Gibbon, Condillac and Port-Royal: they are not examples of a genre, such as Histoire Philosophique and Grammaire Générale, but of a profession. ${ }^{13}$

As stated in the previous section, intertextuality takes place on different levels: reproducing text; reproducing content; the meta-level of concepts and structure; and the supra-level of models and critique. The next section will provide examples of intertextuality on all these levels: the uses of samples, excerpts and summaries in compendia; the methodological problems in tracking arguments and concepts; and the uses of criticism as a means of fact-checking. Accordingly, these are examples of how content is organized, presented, and scrutinized, and the role that intertextuality plays in this. How these different aspects can be combined in an integrated approach will be addressed in the final section.

\section{Examples}

\section{Compendia}

Toward the end of his life, German lexicographer Johann Christoph Adelung published the first volume of Mithridates, oder allgemeine Sprachenkunde mit dem Vaterunser als Sprachprobe. The title says it all: in four volumes, Mitbridates presents all (c.500) known languages with the Lord's Prayer as standard sample. 
Why the Paternoster? Because that was the first text that Jesuit missionaries would translate; which is where approx. half the samples come from. Obviously, in these samples, it's not their content that matters, but their uniformity.

One of Adelung's avowed aims, in this overview, is to avoid all kind of partiality and speculation:

Ich habe keine Lieblingsmeinung, keine Hypothese zum Grunde zu legen, sondern ging unmittelbar von dem aus, was ist, ohne mich um das zu kümmern, was seyn kann, oder was seyn sollte. Ich leite nicht alle Sprachen von einer her; Noah's Arche ist mir eine verschlossene Burg, und Babylons Schutt bleibt von mir völlig in seiner Ruhe. ${ }^{14}$

Compare that with the following. In his two-volume Histoire des Navigations aux Terres Australes (1755), Charles de Brosses explicitly disavows the ambition to wield 'la plume de l'historien' ${ }^{15}$ in flowery storytelling. Rather, for the sake of objectivity, De Brosses offers a lengthy digest of all the known voyages to the southern seas. He reproduces and translates journals and travel literature from the past two centuries, sometimes commenting on the reliability of the sources and judiciously selecting, but never quite interfering with the original accounts.

This, indeed, is 'applying Ockham's razor': De Brosses' own comments are sparse, but he sifts the information so that the reader is in a position to compare and draw out the relevant information without going through fifty-three books. (Together, this makes a 'compound argument' for further exploration in the South Seas; the English translation indeed motivated Captain Cook's expeditions.) With summaries, the information can be condensed even further than with excerpts: instead of reproducing the most relevant passages, one can reformulate the relevant information in the shortest possible way. However, such reformulation also means a substantial loss in transparency.

Johann Gottfried Eichhorn's Geschichte der Litteratur von ibrem Anfang bis auf die neuesten Zeiten (1805-I8I2) is a late example of a compendium of the whole of fiction and nonfiction from the West as well as the Rest. One could see it as an early 'history of the humanities', though it's actually rather a 'handbook in encyclopedia', intended primarily for students but also aimed at the general educated public. In the first three volumes, Eichhorn presents an overview of the arts and sciences of each period, divided by genre and subgenre, ordered by country or region. In the next three volumes, he treats the history of Schöne Redekunsten, Sprachwissenschaft, and theology. The text is divided into paragraphs dealing with each specific field (as in 'Political Sciences in Sweden, I650-I810,' vol. 3, 86I-863). At the end of each paragraph, he provides references for further reading. 
These compendia are entirely built upon previous text: nothing in them could count as 'original research'. Partly textbooks, partly reference works, they belong to a previous age in information management. Eichhorn devotes the first 130 pages of the first volume to speculation about the arts and sciences until 1483 BCE (that is, before Moses), true to the conventions of historia litteraria that require him to start at zero. Still, by sheer virtue of completeness, these works are excellent indicators of the state of knowledge at the time of writing: Eichhorn points in a footnote to the forthcoming work of Adelung, Adelung's posthumous editor and continuator Vater makes abundant use of Alexander von Humboldt's reports from Southern America, and De Brosses may have a mistaken belief in a 'great southern continent' as a counterweight to the Eurasian land mass, but he very acutely points out a knowledge gap. Most striking is an observation in Adelung's foreword: 'Nur aus der Vergleichung der Wurzelsylben lässt sich die Verwandtschaft und Verschiedenheit der Sprachen beurtheylen ${ }^{16}$ - a quite more precise statement than William Jones' famous remark on the Sanskrit language.

\section{Concepts and arguments}

Hans Aarsleff, in his collection of essays From Locke to Saussure, argues against the 'standard account' of the history of linguistics by pointing out that intellectual debts cannot be inferred from references, nor even from the lending of certain concepts, but only by identifying similarities in arguments in which these concepts are employed. The problem is that this kind of similarity between arguments is much more subjective than references or word matches: it requires interpretation, or even rational reconstruction.

Dietrich Busse levies a similar kind of methodological critique in Historische Semantik: Analyse eines Programms. Busse describes the lexicon Geschichtliche Grundbegriffe and related works by Reinhart Koselleck and Jürgen Kocka as a 'mountain ridge tour' (Gratwanderung) along canonical figures. ${ }^{17}$ The approach of Geschichtliche Grundbegriffe, according to Busse, is insufficient as an account of the development of 'core concepts'; to get a full grasp of how a term was used in discourse and what an author was doing in using it, one would need to know how common a certain term was in a certain period and who else were using it to what ends.

In 1987, this was an impossible demand in terms of scale - Geschichtliche Grundbegriffe already fills eight big volumes. In the digital age, this has become easier. Although the degree to which books and journals have been digitized varies, one could now more easily do a corpus search for the earliest occurrences and the frequency of specific words in a certain period. However, this does not yet solve the problem noted by Aarsleff; the results of such queries still need to be assessed (not merely filtered) by human readers. 
Both through rational reconstruction and through tracking references, the search for where a certain concept or argument derives from tends to be quite canon-confirming. Concepts are generally associated with a small set of authors who (re)defined it, and they are wound up with arguments in strands of reasoning which require lengthy formulation. The lengthiest reconstruction of intellectual debts to date, Pocock's multivolume work on Gibbon's Decline and Fall, reads like a 'Who's who?' of Enlightenment philosophy and historiography in spite of its contextualist approach. This does not mean that the history of concepts can only be a Big Man history; rather, one can also view the standard authors as shorthand for a certain thought complex, as nodes in the organization of knowledge.

\section{Critique}

The greatest shift that takes place in criticism is probably the professionalization of it: that is, the degree to which a work of scholarship is judged as a contribution to expert knowledge. Thus, during the nineteenth century, criticism increasingly becomes a way of distinguishing experts from amateurs - a distinction that was more diffuse during the early modern period. However, that is not in itself a change in the intertextual format of it - though the more professional criticism also tends to be more argumentative rather than simply listing mistakes and inconsistencies.

What sets critique apart from other types of intertextuality is its power to pierce through paper: more than any other kind of reformulation or extension it connects the source text to the outside world. This is apparent in the Beaufort example. An even more telling example is the nineteenth-century historiography of the French Revolution. The Revolution did not only bring about a drastic shift in historiographic perspective (one for which classical antiquity no longer provided a model, and in which social, economic and ideological factors became impossible to ignore), but histories of the Revolution were also particularly vulnerable as they were liable to incite public debate and drew on recent and sometimes living sources. Particularly noteworthy is a case previously discussed in Ann Rigney's The Rhetoric of Historical Representation: Nettement's critique of Lamartine's Histoire des Girondins.

Alphonse de Lamartine's Histoire des Girondins became an instant bestseller upon its appearance in 1847 . In the avertissement, he stated his procedure: 'We don't request faith on word. Indeed we haven't supplied footnotes, citations and pièces justificatives, but there is not one assertion which is not authorized by authentic memories, be they unpublished memoirs, correspondence or oral communication. ${ }^{18}$ As Lamartine's work presents a romanticized picture of the Revolution in which the heroes and villains are united by the larger historical drama, and as he fills the gaps with what one would charitably call 'narrative imagination', it is 
unsurprising that his conservative adversaries did not take this for granted. One of them, the Catholic journalist and historian Alfred Nettement, published an announcement inviting critical responses.

This provided the basis for Nettement's Etudes Critiques sur les Girondins (1848). A large part of the book consists of letters and excerpts from letters, mainly from nobles, notables, and clerics: pages 64-160 are entirely filled with them, other letters are quoted and alluded to throughout. Some correspondents complain against Lamartine soiling their families' good name; one argues, more convincingly, that his grandfather was not guillotined at all; still others produce written counterevidence or give a point-by-point reading of events of which they were an eyewitness. A rather uneven lot, these 'rectifications historiques' still serve their purpose in throwing doubt on Lamartine's reliability as a historian.

Not that Nettement fared any better: in his own Histoire de la Conquête d'Alger (I856) he did not take the trouble of asking any Algerians how they felt about the matter. On the whole, his Etudes Critiques are entirely dependent in content and outline on the book they wish to discredit. The argument developed throughout 500 pages of pedantry is that freethinking leads to terror and that any attempt at 'rehabilitation' of the Revolution should therefore be dispelled. It is interesting to note what Nettement did next: in the same year (1848) he published a new edition of Bossuet's Discours sur l'Histoire Universelle as an example for modern historians of how history should be written - that is, in a theological frame. As this was the book that Voltaire's Essai sur les Moeurs famously set out to outdo, Nettement's statement will have been read by at least some of his readers as 'taking back Voltaire., ${ }^{19}$

\section{Conclusion: An integrated approach}

What the above examples show is that intertextuality goes further than providing 'building blocks'. Rather, the typology contributes to a history of the humanities in terms of information management and the organization of knowledge. More specifically, intertextuality is part of how information is turned into knowledge. That process is in no way reducible to intertextuality, but it requires a constant reassembly of facts and concepts precisely in virtue of being creative and selfcorrective. ${ }^{20}$ The typology and the above examples show different ways in which content is collected and selected; but they also show that it must be organized, presented, and scrutinized.

An integrated approach, accordingly, should take into account: (I) What counts as a 'fact', how is an argument built from the source material? (2) How are these findings presented (rhetorically, visually) and ordered? (3) How is fact- 
checking done, what counts as valid/relevant/good scholarship? and (4) Where does the content come from and what is added to it? As a grid for answering question 4 , the typology developed here is one step toward developing such an integrated approach.

These questions correspond to four broad categories of analysis: (I) styles of reasoning, (2) forms of presentation, (3) ways of criticism, and (4) types of intertextuality. ${ }^{2 \mathrm{I}}$ These are, to some extent, overlapping categories. Criticism is itself a type of intertextuality, different styles of reasoning are manifest in different forms of presentation, and the form of presentation generally depends upon a model - that is, something borrowed. The overlap is excusable as it is precisely the interrelation between these categories that connects scholarly ideals and scholarly practice. The terms by which scholars define themselves and their practice, the criticism they give, the models they follow are not a 'top layer' of ideology, they are part of the intertextual fabric.

\section{Notes}

I Louis de Beaufort, Dissertation sur l'Incertitude des Cinq Premiers Siècles de l'Histoire Romaine, ed. A. Blot (Paris: Maillet, I866), 30I-326. The accusation of plagiarism is addressed on page $320 f f$. The German was Christoph Saxe (I7I4-I 806).

2 A key example is Ann Rigney, The Rhetoric of Historical Representation: Three Narrative Histories of the French Revolution (Cambridge: Cambridge University Press, I990), chapter I. More explicitly geared toward methodology is Robert Darnton,'Discourse and Diffusion', Contributions to the History of Concepts I.I (2005), 2 I-28.

3 Quentin Skinner, 'The Limits of Historical Explanations', Pbilosophy 4I.I57 (I966); 'Meaning and Understanding in the History of Ideas', in J. Tully (ed.), Meaning and Context: Quentin Skinner and His Critics (London: Polity, I988).

4 Reinhart Koselleck, Otto Brunner, and Werner Conze (eds.), Geschichtliche Grundbegriffe: Historisches Lexicon zur politisch-sozialen Sprache in Deutschland (Stuttgart: KlettCotta, I972-1997); Rolf Reichardt et al. (eds.), Handbuch politisch-sozialer Grundbegriffe in Frankreich, 1680-1820 (Munich: Oldenbourg, 1985ff.).

5 Ann Blair, Too Much to Know: Managing Scholarly Information before the Information Age (New Haven: Yale University Press, 2010).

6 Anthony Grafton, The Footnote: A Curious History (Cambridge, MA: Harvard University Press, I997).

7 Dan Edelstein, 'Humanism, L'Esprit Philosophique, and the Encyclopédie', Republics of Letters: A Journal for the Study of Knowledge, Politics, and the Arts I.I (2009), URL: http:// rofl.stanford.edu/node/27 (accessed 4 March 2013); Russell Horton, Mark Olsen, and Glenn Roe,'Something Borrowed: Sequence Alignment and the Identification of Similar Passages in Large Text Collections', Digital Studies/Le champ numérique 2.I, URL: http:// www.digitalstudies.org/ojs/index.php/digital_studies/article/view/I90/235 (accessed 4 March 2013); ibid. et al.,'Plundering Philosophers: Identifying Sources of the Encyclopédie', Journal of the Association for History and Computing I3.I (2010), URL: http://hdl. handle.net/2027/spo.33104I0.0013.107 (accessed 4 March 2013). 
8 Gérard Génette, Palimpsestes: La littérature au second degree (Paris: Éditions du Seuil I982), 7-I7.

9 Charles Bazerman, 'Intertextuality: How Texts Rely on Other Texts', in C. Bazerman and P. Prior (eds.), What Writing Does and How It Does It: An Introduction to AnalyzingTexts and Textual Practices (Mahwah, NJ: Erlbaum, 2004).

Io Such judgments are an essential building blocks of histories like Meinecke, Die Entstehung des Historismus, and Aarsleff, From Locke to Saussure. Their judgments on similarities and influences may well be correct, but they require a great deal of reformulation in order to (re)construct patterns in the history of historiography and linguistics.

I I An earlier version of this paper consisting mainly of such examples is on my blog, URL: http://florisotto.blogspot.nl/2012/05/scholarly-intertextuality-in-I 8th.html (accessed 4 March 2013).

I2 Edelstein, 'Humanism, L'Esprit Philosophique, and the Encyclopédie'; Horton, Olsen, and Roe, 'Something Borrowed'.

I3 For Montesquieu and Gibbon as paradigmatic examples of modern historiography, see Hugh Trevor-Roper, History and the Enlightenment (Oxford: Oxford University Press, 2007).

I4 Johann Christoph Adelung, Mithridates oder alllgemeine Sprachenkunde mit dem Vater Unser als Sprachprobe (Berlin: Voss, I 806), vol. I, xi.

I5 Charles de Brosses, Histoire des Navigations aux Terres Australes, 2 vols (Paris: Durand, I766), vol. I, xi.

I6 Adelung, Mithridates, xiii. Adelung's discussion of East Asian and Semitic languages, though, shows that he neither understands isolating languages nor bisyllabic roots, describing the former as an impediment on abstract thought and the latter as a random and untenable theory' (p. 30I).

I7 Dietrich Busse, Historische Semantik: Analyse eines Programms (Stuttgart: Klett-Cotta, I987), 66ff.

I 8 Alphonse de Lamartine, Histoire des Girondins (Paris: Furne/Coquebert, I 847), vol. I, i-ii.

I9 Apart from Blot's edition of Beaufort, and Nettement's edition of Bossuet, there are other, more successful examples of such programmatic republications. Michelet's first work was in fact a translation of Vico's Scienza Nuova, while his friend Quinet was translating Herder's Ideen, both at the instigation of Victor Cousin, himself a cultural broker for German Idealist philosophy in France. Later, editing Schleiermacher's work and correspondence was crucial for Dilthey's program of defining the Geisteswissenschaften.

20 Wilfrid Sellars once described science as 'rational not because it has a foundation but because it is a self-correcting enterprise' ('Empiricism and the Philosophy of Mind', in Science, Perception and Reality (London: Routledge $\&$ Kegan Paul, I963), ch. 8, \$38). That is precisely what the typology highlights.

2 I The term 'styles of reasoning' is borrowed from Ian Hacking, 'Language, Truth and Reason' (I980) and 'Style for Historians and Philosophers' (I99I) in Historical Ontology (Cambridge, MA, and London: Harvard University Press, 2002). The nearest example for 'forms of presentation' is Lorraine Daston and Peter Galison, Objectivity (New York: Zone Books, 2007). 



\section{V \\ LITERARY AND \\ Theater Studies}
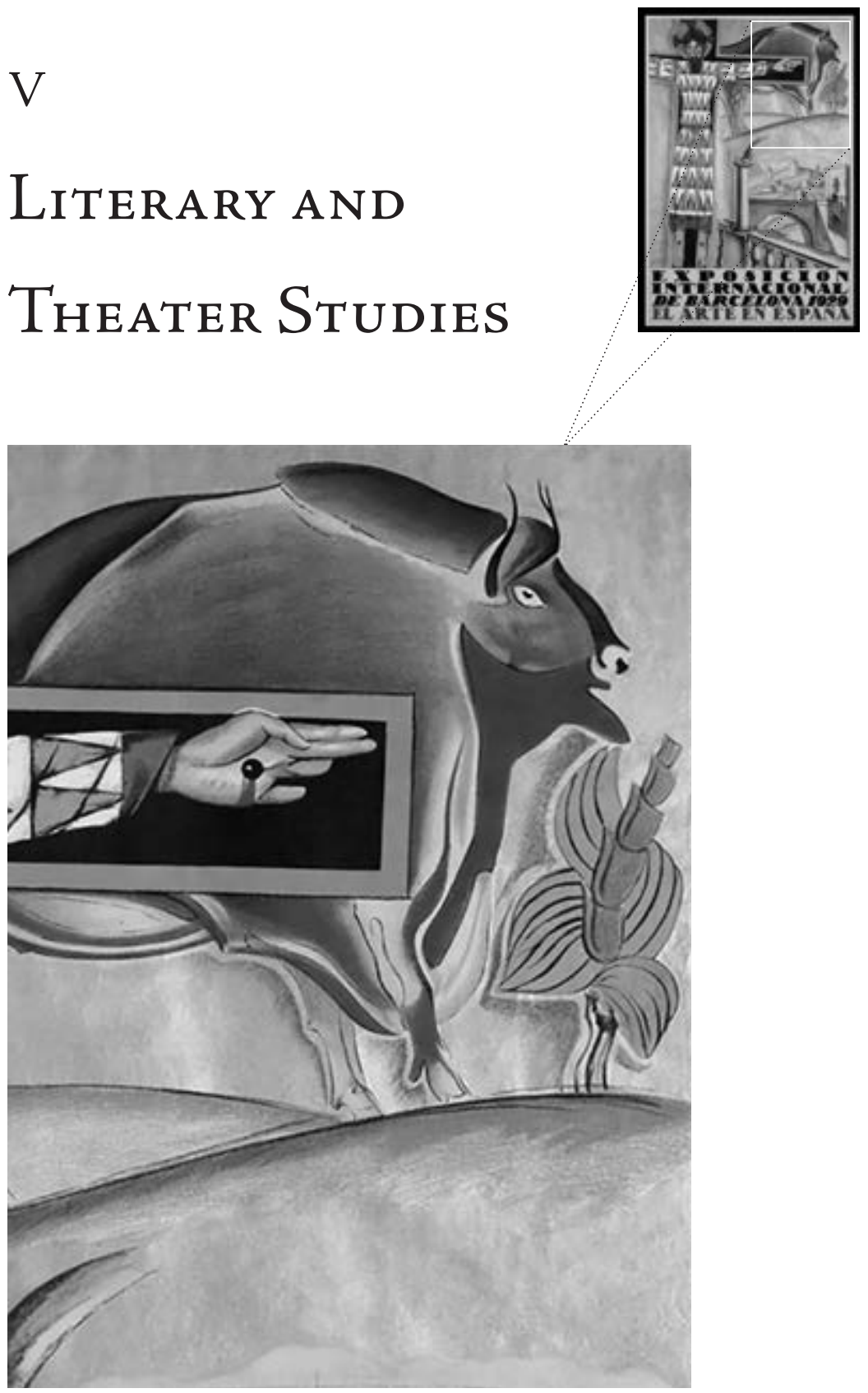



\title{
5+I Furio Jesi and the Culture of the Right
}

\author{
INGRID D. RowLAND
}

On the night of June I6, I980, Furio Jesi, Italian scholar, critic, poet, novelist, actor and political activist, died in his home, suffocated by an accidental gas leak from the water heater. ${ }^{1}$ He had turned thirty-nine only a month before, but his curriculum vitae was already long enough for several people twice his age: he had written nearly twenty monographs on subjects including Egyptology, mythology, German literature, and Hebrew mysticism, as well as newspaper articles, novels, translations, poetry, and a spate of unpublished manuscripts. In 1979, typically, he had produced two books, Materiali mitologici (Mythological Materials: Myth and Anthropology in Central European Culture) and Cultura di destra (Right-wing Culture), a study focused on the twentieth century, with special emphasis on Italy. Republished in 20II with the encouragement of the Wu Ming writer's cooperative, Cultura di destra has lost none of its originality. And though Furio Jesi may have died when Silvio Berlusconi was no more than an aspiring tycoon in the $\mathrm{Mi}$ lanese provinces, many of his observations about the connection between middleclass culture, pulp culture and right-wing culture still apply three decades later, with Berlusconi himself as a prime example. ${ }^{2}$

Cultura di destra used relatively plain language with biting wit at a time when florid rhetoric in a whole spectrum of styles was the norm for left, right, literati, bureaucrats, academics, and terrorists. Photographs of its author, most of them taken in his thirties, almost always show Furio Jesi grinning broadly, long-haired, bearded, cigarette in hand, radiating energy and humor amid a pile of books and papers; in the Sixties, when he was in his twenties, already married and the father of two, he is short-haired, clean-shaven, and deeply serious.

Furio Jesi was a complicated man, with a complicated background. Although his parents belonged to Turin's large Jewish community, he was a nonbeliever and did not practice religion of any kind. Furthermore, his father, Bruno, had been granted honorary Aryan status for heroic service as a Fascist cavalry officer in Ethiopia in World War II. ${ }^{3}$ In 1943, when Furio was two, Bruno Jesi died of the 
injuries he had sustained in combat in Africa. ${ }^{4}$ The boy grew up with his mother, Vanna Chiron, an art historian, and his maternal aunt and uncle, in a house filled with books, artworks, and archeological artifacts. ${ }^{5}$ The setting ensured that he was both prodigiously well read and prodigiously precocious. By the time Furio Jesi reached his teens, he had begun to publish scholarly articles; he completed his first book, Tales and Legends of Ancient Rome, at the age of fifteen, and his second, Egyptian Pottery, at seventeen. ${ }^{6}$ He abandoned formal schooling before finishing the liceo and traveled instead. After time spent as a researcher in Brussels and Hildesheim, he returned to Turin in 1969, where he combined editorial work with journalism, theater, and activity on behalf of the Communist labor union, the CGIL. His publications on German culture and his translations of German authors earned him a professorship of German at the University of Palermo in 1976, and then a chair in the same field at the University of Genoa in 1979. Disillusioned with the pressures of city life (at a moment when Italian cities were literal battlegrounds between left and right), he and his family withdrew to live in the countryside outside Genoa, and it was in this rural refuge that he died unexpectedly of carbon monoxide poisoning on a summer night in 1980 .

Myth, culture, and anthropology were recurrent keywords in Jesi's writing, as they were in the writing of many of his contemporaries; these were words that captured the Zeitgeist. So did the word 'politics', in all its ramifications. But Jesi ultimately came to mistrust large words of indefinable content, and Cultura di destra presents the most sustained evidence for that mistrust. Although he does not explicitly address the paradox, Jesi seems to be perfectly conscious that the words 'Cultura' and 'destra' themselves ran the risk of being large, empty abstractions.

Despite his bourgeois background and upbringing in Piedmont, the most historically bourgeois of Italy's regions, Jesi's own political convictions leaned powerfully leftward, at the moment in Italian history that would later be known as the anni di piombo (Years of Lead); lead for their distance from any glimmer of a Golden Age, lead for the bullets that flew so freely in every direction from left, right, Mafia, and central state, lead for the weight of gray despair that had followed so brutally on Italy's hopeful prosperity of the 1960s. ${ }^{7}$ Cultura di destra arrived in bookshops shortly after one of the defining events of those leaden years, the kidnapping, fifty-five-day imprisonment, and murder of former Prime Minister Aldo Moro at the hands of the radically left-wing Red Brigades in the spring of $1978 . .^{8}$ But the author of Italy's first sustained study of rightist culture did not live to see the most dramatic gesture ascribed to Italy's radical right. Two months after Jesi's death, on August 2, 1980, a bomb would rip through Bologna's central train station, killing eighty-three people. ${ }^{9}$ Two members of a group called the $\mathrm{Nu}$ clei Armati Rivoluzionari were eventually sentenced to life imprisonment for that atrocity. ${ }^{10}$ But there had been earlier random bombings over the course of more 
than a decade, all of them aimed to kill and injure civilians, most of them to this day never formally ascribed to a perpetrator, though the impetus evidently came from the right." There had been left-wing fire-bombings as well: the most terrible killed two brothers in a working-class Roman suburb when their apartment was set on fire one April night in 1973; their father served as secretary for a local section of the neo-Fascist MSI. As neighbors, family, and firefighters watched, twentytwo-year-old Virgilio Mattei burned to death at a window in a desperate attempt to shield his ten-year-old brother Stefano from the flames. ${ }^{\mathrm{I2}}$ Another left-wing bomb in 1978 scarred a future president of Italy's parliament, Gianfranco Fini. ${ }^{13}$ For a country still traumatized by its memories of World War II, this near civil war between left and right in the 'Years of Lead' not only revived old hostilities, it also pulled the conflict into a new generation, a generation of young people who often seemed to be at war with their elders as much as with traditional political adversaries. It was in the middle of this terrifying new world of old battles that Furio Jesi published the last and most controversial of his many books.

The title Cultura di destra played knowingly on the ambiguity of the term 'culture. In its short, dense chapters, Jesi dealt both with culture in the anthropological sense (what the American archeologist Lewis Binford had then begun to call 'lifeways' with reference to prehistoric peoples) and culture in the more restricted fine-arts sense implicit, for example, in institutions like the national Ministry of Archaeological and Cultural Property. ${ }^{14}$ Jesi defined rightist culture as a culture of 'ideas without words' (a phrase drawn from Oswald Spengler's Decline of the West), abstractions so overused that they had lost their meaning: Myth, Fatherland, Jack the Ripper - the anecdotal inclusion of the Victorian serial killer in a list of lofty principles is a typical Jesi touch. But Jack, as he points out, is an unknown and therefore has an unknown meaning, as inherently empty a phrase as 'patriotism' - or, though Jesi does not say so explicitly, 'dictatorship of the proletariat. ${ }^{15}$ He does warn his readers, however, that left and right are not always so easy to distinguish, no matter how polarized postwar Italy seemed to be by the battle between Fascists and Communists:

Most of the cultural heritage, even of those who have no desire to be on the right, is a cultural residue of the right. In past centuries, the culture that has been preserved and transmitted is above all the culture of the wealthy and powerful, or more accurately, it has not been, except minimally, the culture of the weak and poor. It is useless and irrational to be scandalized by the presence of these residues, but it is also necessary to try to find out where they come from. [...] Left-wing speech is dense with 'ideas without words', including the most incendiary left, and in this respect it is related to its institutional adversaries. ${ }^{16}$ 
In this passage, Jesi shows both his left-wing sympathies (history has seldom been written by the weak and the poor) and his growing skepticism about all mass movements ('Left-wing speech is dense with "ideas without words"). As a younger man, he was more certain of his convictions. In 1968, at the age of twenty-six, he broke off a four-year friendship with the older Hungarian scholar Karl Kerenyi when Kerenyi reproved him for simplifying his arguments in a typical 'Italo-Communist' fashion; Jesi's bristling reply, to a man who had lived through the Communist occupation of Hungary, never received an answer. ${ }^{17}$ The young man had caught the older man's point: that Jesi's thinking was clever but immature, and he reacted by growing up. Although they never corresponded again, Furio Jesi delivered the eulogy at Kerenyi's funeral in $1974 .^{18}$

In the ensuing quarter century, scholars have done precisely what Jesi suggests doing in the passage cited above from Cultura di destra, namely, devoting their attention to less privileged strata of society, motivated by some of the same concerns he himself expresses in hopes that overlooked voices should be heard at last. This research has shown that on the whole, the poor and weak have usually been just as conservative as the rich and powerful, with the same general tendency to hold fast to whatever has favored their survival in a harsh world. The poor and powerless are not, in fact, inherently leftist, or communist; they are often fiercely attached to their traditional ways, as another Italian scholar of phenomenal erudition, Torinese Jewish heritage, and left-wing convictions had begun to show in these same years. By the time Cultura di destra emerged from the press in 1979, Carlo Ginzburg had completed two famous studies of peasant culture in northern Italy: I benandanti (1966; translated in English as The Night Battles), which argued that a group of northern Italian peasants preserved the remnants of ancient, pre-Christian cults, and Il formaggio e $i$ vermi (The Cheese and the Worms [1976]), which examined the case of a sixteenth-century Friulian miller named Menocchio, whose smattering of education made him a truly creative thinker about religion and cosmology, and thus brought him to the attention of the Inquisition. Ginzburg derived Menocchio's peculiar ideas about cosmology from peasant myth, passed by 'oral transmission from generation to generation', and he treated the beliefs of the Benandanti, a group of peasants distinguished by having been born with a caul, as a similar survival of an immemorial culture preserved by the less privileged strata of human society. Although his political and scholarly orientation were, and are, firmly situated on the left, certain aspects of Ginsburg's argument fit comfortably into Jesi's category of destra, such as the attempt to root historical phenomena in a kind of folk mythology, not to mention the peasants' inclination to preserve immemorial custom, conservative in the most genuine sense of the word. This tendency to loose inclusiveness is one of the inherent problems with Jesi's use of destra as a diagnostic term. 
But the problematic nature of the term destra runs to more than its inclusiveness. Jesi's warnings about the 'incendiary left' alert his readers to a phenomenon that has become much better documented in the years since his death: there were Italian terrorists who played both sides of the political spectrum, more excited by a life of lawlessness, violence, and peremptory authority than by any specific ideology of right or left. ${ }^{19}$ For these individuals, Jesi's description of rightist culture as a compendium of 'ideas without words' and a 'religion of death' applies to the forces that drove both extremes, as well as Italian organized crime. But given the fact that the far-right movements of Fascism and National Socialism began as left-wing socialism, the problem may have more to do with 'right' and 'left' as analytical categories.

For his analysis of the 'religion of death', Jesi found Italian Fascism too involved in theatrical display to provide a good example, too involved, as he writes, with life, ${ }^{20}$ He therefore focused his discussion on other Fascist movements in Europe: the German SS, the Spanish Legionaries of Francisco Franco, and the Romanian Iron Guard, where he found his most revealing example in Mircea Eliade, the Romanian historian of religion who had held a distinguished professorship at the University of Chicago since the end of World War II. In I973 Jesi had edited an Italian translation of Eliade's book on yoga, Yoga: Immortality and Freedom, for publication. ${ }^{21}$

In 1972, however, a Romanian-language periodical published in Israel, Toladot, produced extracts from Eliade's extensive diaries to show that shortly after his return from India in 1931, this famous student of yoga, shamanism, and world religion had become a fervent supporter of the Iron Guard, or Legion of St. Michael, the Romanian paramilitary organization that combined Orthodox Christianity with Fascist authoritarianism. ${ }^{22}$ Drawing on this evidence, first in an encyclopedia entry on 'Myth' from 1973, and then, more extensively, in Cultura di destra, Jesi showed Eliade as obsessed with an Orthodox Christian version of the 'religion of death'. His discussion in the latter book begins with Eliade's use of a Romanian folktale about Master Manole, a man who cannot build a house until he has immured his wife inside it, in what Eliade himself called a 'foundation sacrifice', a practice that goes back to antiquity, and seems, for example, to be attested in recent excavations of archeological sites like the Roman Forum and Etruscan Tarquinia. ${ }^{23}$

From the idea of foundational sacrifice, Jesi turns to the Iron Guard's rhetoric of sacrifice in battle as a necessary step toward building a new Christian world order and compares this rhetoric with Eliade's own writings about religion and human redemption.

In order to last [Eliade writes], a building must be animated: that is it must receive both a life and a soul. The transfer of the soul is not possible except by means of a sacrifice; in other words, by means of a violent death. Like- 
wise, sacrifices of human victims are performed to ensure the success of an activity, or the historical duration of a spiritual undertaking. ${ }^{24}$

In journal entries that range from the I920s to the 1950 , Eliade often wrote about the withdrawal of a Supreme Being from the world, and how religions had been invented to fill the void left by that withdrawal; this is the basic premise of his famous book on shamanism, and of his four-volume History of Religions. ${ }^{25}$

From these remarks Jesi argues that in the final analysis the Jews, as the chosen people of God, provided the Iron Guard and the National Socialists with the perfect foundation sacrifice for their religion of death. Yet the very idea of God's withdrawal, Jesi notes, is also fundamental to early modern Jewish mysticism; he notes that Eliade even applies the Kabbalistic term tzimtzum, 'withdrawal' or 'contraction' to this phenomenon of God's departure:

Eliade says, "Myths and "religions" [...] are the result of the void left in the world because of God's withdrawal'. The Kabbalah [of Isaac Luria] affirms that 'God, in order to guarantee the possibility of the world's existence, needed to create a place that was emptied of his being, from which $\mathrm{He}$ therefore withdrew himself', ${ }^{26}$

Jesi here suggests, in short, that Eliade has taken his scheme of divine withdrawal, ultimately to be compensated by the Holocaust, from a Jewish source. Like his exchanges with Kerenyi a decade earlier, his exposition of Eliade seems to reveal enthusiastic admiration for an elder scholar that has turned to disillusionment, expressed along narrowly defined political lines, but also reflective of something larger. Jesi suggested more than once that all scholarly work was autobiographical, and in these troubled relationships with scholarly father figures, admired and then viewed critically as rightists, it is not hard to see the Jewish father who is Fascist, Aryan, and as absent from his son's life as the God who has withdrawn from the world by contracting into himself.

Jesi was not the only follower of Eliade to struggle with this legacy. The assertions of Cultura di destra greatly upset both the elder historian himself and his international following, especially the Romanian student of religion who eventually followed Eliade to Chicago and became his literary executor, Ioan Culianu. ${ }^{27}$ In 1987, a year after Eliade's death, Culianu confided to a colleague that his mentor 'had never been an anti-Semite, or a member of the Iron Guard, or a proNazi. But I understand anyway that he was closer to the I[ron] G[uard] than I might have liked to think. ${ }^{28}$ Culianu's mysterious assassination on the University of Chicago campus in I99I further complicated reaching any clear assessment of Eliade's legacy by removing his most evident intellectual heir ${ }^{29}$ 
It is clear in any case that Eliade was close to the Iron Guard in the late I930s, whether through naïve patriotism, as Culianu eventually concluded, or through the more complicated mystical impulse that Jesi outlined in Cultura di destra. If Jesi himself had lived longer, he may well have analyzed Eliade's career somewhat differently as historical events turned many of his fellow Italian Communists into social democrats. Culianu, somewhat defensively (of both Eliade and himself) explained his mentor's Legionary sympathies by a particular historical situation in Romania; what is particularly compelling about Jesi's account is its immersion in a particular situation within the history of religion, or at least of mysticism, rather than the history of politics. ${ }^{30}$

Jesi's change of heart about Mircea Eliade was not an isolated phenomenon among young historians of religion. At the very same time, the brilliant German classicist Walter Burkert, ten years older than Jesi, was beginning to rethink his own pioneering book on sacrificial ritual, Homo Necans (1972). ${ }^{31}$ Deeply influenced by the work of an older Swiss scholar, Karl Meuli, and captivated by Meuli's vividly imaginative descriptions of ritual life in prehistoric human society, Burkert had gradually come to realize how extensively those accounts might have reflected Meuli's contemporary political sympathies rather than ancient realities. ${ }^{32}$ To a conspicuous extent, in fact, the history of religion in the early to mid-twentieth century was written by scholars who leaned to the political right and helped to create what Jesi would term a 'mythological machine' of prototypes and archetypes - not only Eliade and Meuli, but also figures like the French Indo-Europeanists Georges Dumézil and Émile Benveniste and the American Joseph Campbell. ${ }^{33}$ Their students, on the other hand, often came from a completely different political background, like Jesi himself, or Burkert, or the Swede Jesper Svenbro, or the American Gregory Nagy. Not every attitude these historians of religion shared, including the conviction that the world was in a state of decline and the longing for an imagined past, was necessarily political; many of the notoriously cranky Joseph Campbell's most biting statements, for example, were expressions of curmudgeonly temper rather than ideological conviction.

The Eastern European mystical currents that Jesi brought into play in his discussion of European Fascism had already figured largely in another of his books, Mitologie intorno all'Illuminismo (1972; Enlightenment Mythologies). ${ }^{34}$ This volume's title promised to upset the image of the eighteenth-century Enlightenment as a triumph of reason, much as the Irish scholar E.R. Dodds had upset the image of ancient Greece as a paradise of reason with his lectures published as The Greeks and the Irrational (1962). ${ }^{35}$ In Mitologie, Jesi treated, among other themes, the eighteenth-century messianic Jewish movements that followed Shabbatai Zevi and Joseph Frank, figures to whom he returned in Cultura di destra. In 
one sense, Shabbatai Zevi and Joseph Frank, as Jewish saviors, represented the perfect fulfillment of their contemporaries' hopes for a new order. But rather than immolating themselves as sacrificial victims, Zevi eventually converted to Islam and Frank to Christianity. Jesi tries to explain their actions within his scheme of foundational self-immolation, but it seems more likely that both men were acting out of a practical instinct for self-preservation:

Extensive research has been carried out on Shabbatai Zevi; it turns out that this 'holy sinner' who had presented himself as an 'apostate messiah' committed 'evil acts' but when the inspiration ceased 'he behaved like an entirely ordinary man, and regretted the strange actions he had committed'. In this sense of guilt he made plain the tragedy of his condition: the Law that he broke had to be broken in order to establish the Law of the new kingdom, but it was still the Law. ${ }^{36}$

Jesi's discussion of Zevi and Frank comes just after his exposé of Mircea Eliade's sympathies with the Iron Guard, suggesting that on some level he may suspect that Eliade's case, too, is probably impossible to confine within a scheme of sacrificial mysticism, or, for that matter, of consistent human behavior. Eliade, Zevi, and Frank lived in troubled times; so did Furio Jesi, but he was less exposed to physical risk than these three men who changed their beliefs to fit their surroundings.

Clearly, Furio Jesi himself was powerfully attracted to the same histories, myths, and fantasies as the scholars he analyzed. By the time he reached the age of thirty, however, he had begun to see these histories and myths as invented stories rather than archetypal realities, and this skeptical detachment led to another important theme of Cultura di destra: the conclusion that myths and historical pasts had been invented ex post facto by people who needed such stories to justify their own actions or their own position in the world. Like his elder contemporary Walter Burkert, Furio Jesi was beginning to face the full extent to which the remote past was simply unknowable.

Furthermore, as a nonbeliever in matters of religion, he had also come to disbelieve in myth per se - in good left-wing materialist fashion, he began to write about 'mythological materials', a phrase that also appears in the title of his penultimate book, published a few months before Cultura di destra. For the forgers of rightist culture, he would argue in a 1979 interview, 'ideas without words' and 'mythological materials' provided 'a kind of homogenized pulp that can be modeled and held to a shape in the most expedient way'. ${ }^{37}$

When Jesi traced the fate of 'ideas without words' in Italian popular culture, he did so as a pioneer. The second long essay of Cultura di destra examines Italian 
neo-Fascism in an effort to understand the ideology of right-wing terrorism (one year before the crowning act of right-wing terrorism in Italy, the bombing of the Bologna train station). Jesi notes first that Italian Fascism is distinctive because the persistence of the Catholic Church and the aristocracy have resulted in a relatively small middle class, which is largely secular and liberal in its attitudes rather than taken by mystical or occult movements:

The modern Italian bourgeoisie, especially the petit and middling bourgeoisie, has never had a particular propensity for esoterica and Knights of the Holy Grail. A bit of occultism - but in small doses and certainly much smaller than those absorbed, for example, by the German or French bourgeoisie - a bit of Freemasonry (and that not for the petit bourgeoisie), but this, too, secularized often as not, is much more anticlerical, liberal, and inspired by Unification rather than by 'secret centers'.

Within his contemporary Italian context, Jesi identifies two kinds of neo-Fascism: 'fierce-faced Fascism' and 'Fascism in a suit', the former typical of the rg7os heirs of the violent, black-shirted squadristi who brought Mussolini to power, and the latter their more socially acceptable sympathizers, who combined two categories invidious to Jesi's own political stance: Fascist and bourgeois. ${ }^{38} \mathrm{Jesi}$ warns his readers, however, that these two categories of neo-Fascist are interchangeable: the mildest of Fascists-in-a-suit still keeps a black leather jacket in his closet (as a later Minister of Justice in Silvio Berlusconi's 'center-right' governments, former MSI member Ignazio La Russa, would demonstrate by his sartorial choices in office and out).

Typical of Italian Fascism, Jesi argues, is the figure of Julius Evola, the ideologue both for Mussolini and for postwar neo-Fascism:

Julius Evola is a person with whom no one as yet has reckoned thoroughly. It is not enough, in fact, to declare him so filthy a racist that it is revolting to touch him (which is true) and so jejune that it is a waste of time paying attention to him (which is not true). But [...] to examine him as a significant cultural personality does not at all mean ascribing to him merits and stature of any consequence. ${ }^{39}$

Evola wrote in a visionary vein, but the real soul of Italian Fascism and its later successor, Jesi argues, is to be found in popular culture (it was Mussolini, after all, who created a Ministry of Popular Culture, the notorious 'Minculpop'). He discusses openly Fascist writers like the eccentric, flamboyant Gabriele D'Annunzio, and compares D'Annunzio's eroticism and hothouse prose with that of the pop- 
ular romance novelist Amalia Liana Negretti Odescalchi Cambiasi, to whom D'Annunzio himself suggested the pen name Liala 'so that she would always have a wing (ala) in her name' - the aristocratic Liala's long-time lover was an aviator killed in 1926.

Despite her own noble origins, Liala was overwhelmingly popular with women of every class, who felt that she 'spoke to them in their own language'. Jesi attacks that apparent fellow-felling relentlessly. Liala's romances, obsessed with the minute description of interior decor, boats, airplanes, clothing, and fast cars, were written, he contended, in a language:

that does not ask to be 'understood' in any sense, if 'understand' implies any sort of exercise of reason. It is the language of package vacations organized by those in power for those who lack it, so that the vacation will mean the cessation of all effort ${ }^{40}$

Jesi also devoted a sardonic paragraph of his analysis of luxury to the man he called the 'little marquis (marchesino) of racing cars', by whom he meant Luca Cordero di Montezemolo, the future head of Ferrari, whose vanity the rumpled scholar captured mercilessly. ${ }^{4}$ (Jesi's right-wing adversaries borrowed the term marchesino immediately to describe Communist leader Enrico Berlinguer, who was, in fact, a Sardinian aristocrat.)

Liala, Jesi notes, dwells on the icons, the 'ideas without words' that denote luxury (a word that means both 'luxury' and 'lust' in Italian), by dwelling lovingly on the physical trappings of a wealth that most of her readers would never enjoy. Until the later stages of her career, when changing sexual mores changed the plots of romance novels, she also devoted extensive space in her novels to the preservation of female virginity (Liala lived from I897 to 1985). Through the same emphasis on extravagant consumption, the same appeal to the desire for the physical trappings of what would soon be called benessere, 'well-being' (but meaning luxury), Silvio Berlusconi would soon create his own cultura di destra, first in the media and then in politics.

Clearly, on some level Jesi acknowledged the overwhelmingly visual emphasis of Fascist culture, but did so without using his own experience in art, archeology and art history to develop an argument about visual media and ideas without words' - for this still young, and inveterately bookish man, Cultura continued to mean literary culture.

Thus Jesi misses some of the importance of Giorgio Almirante, the charismatic head of the MSI, the postwar heir to the Fascist Party. The son of two actors, Almirante used his face and gestures as a medium in the way that Mussolini had before him. But Almirante's physicality was not simply a matter of empty 'ideas 
without words': often, he let his presence speak on his behalf in a way that gave him enormous authority with his rank and file. When he appeared at the funeral of Communist Party secretary Enrico Berlinguer, his meaning was perfectly clear right across the political spectrum. ${ }^{42}$

Some of Almirante's followers caught on to this aspect of his conduct. In his study of gentrification in a Roman working-class neighborhood, anthropologist Michael Herzfeld noticed that the people who were physically present to protect the long-time residents from pressures to move and eviction notices belonged to Alleanza Nazionale, the party that succeeded Almirante's MSI and renounced Fascism for a position they defined as center-right; whereas former Communists, become eager capitalists, were driving the process of gentrification as eagerly as more traditional, business-minded conservatives. ${ }^{43}$

Inspired though it may have been by a certain amount of standard Communist rhetoric about the perils of capitalism, Jesi's picture of an Italy lulled into thoughtlessness by the obsessive, empty-minded consumption of luxuries and empty symbols seems as apposite in the sunset years of Silvio Berlusconi is it did in the 'Years of Lead', no longer quite 'Fascism in a suit' but an evident descendant of the 'luxurious' branch of the same rightist culture.

Jesi also evokes a terrifying vision of the right-wing sage, but it is really the picture of any self-styled authority, and a warning to himself as much as to his readers:

The sage [saggio] is the author of an essay [saggio]; mythological masks that he adopts and outcomes to which he is exposed, mythological materials that he manages and outcomes he claims to have sensed in advance, at the same time become myths and outcomes that envelop his work. He runs the risk, by assuming that mask and managing those materials, of identifying himself with his knowledge-by-composition to the point that he falls headlong, before his own May 5 [the date of Napoleon's death in exile], into a 'There has never been anyone like Napoleon'. But he also believes that he has been offered the opportunity to wear down, by a procedure related to Romantic irony or Jewish assimilationism, mechanisms and materials, museum pieces, that he promises to himself that he will reduce, by consuming them, under the stimulus of his own inspiration, to a transparency sufficient to counterbalance the opaque density he has conferred on his own face by assuming the features of a pundit. ${ }^{44}$

Interestingly, the only moving image to survive of Furio Jesi is a brief appearance in a television documentary by Ferdinand Braudel on the meaning of Europe. Here, Jesi, long-haired and bearded, appears through the fog of the Po Valley, 
crunching his way across a snowy field, wrapped in a shaggy lambskin coat with a broad collar, talking about the myth of Europa and Mediterranean solar cults. The ice and fog make him mysterious and remote, though his voice is warm and his way of speaking is ironic and conversational. Is he opaque or transparent, scholar or prophet? He is certainly an artist.

In many ways, Cultura di destra represents Furio Jesi's coming of age as a scholar; in this, his last book, he succeeds in putting his vast trove of knowledge into a series of coherent patterns, without denying the complexity and mutability of individual human beings, or of their society. Unlike Burkert, he did not live long enough to rethink his own ideas, and to some extent they remain bound to his own time and the black-and-white contrasts of early, schematic formulations. Italian politics, in those days, was divided into three broad categories. Just over half the country's population tended to favor conservative and Catholic positions, but a substantial minority, about one-third of the citizenry, favored a strictly secular socialist or social-democratic state. After the eclipse of Fascism at the end of World War II, these two positions solidified in the Christian Democratic Party (DC), working in overt concert with the Roman Catholic Church, and the Italian Communist Party (PCI), insistent on its independence but strongly tied to the Soviet Union. A smaller contingent, some twenty percent, maintained its Fascist loyalties, crystallized in the Italian Social Movement (MSI). All these parties dissolved abruptly in the early I99os, but the people involved have gone away much more slowly, and so have their basic conflicts.

But there are also differences between today's Italy and the Italy of Cultura di destra. Culture in the I970s, in any sense of that word, was still largely a faceto-face activity, from the smoke-filled cinema clubs to street theater to opera; television was state-run, in black and white, but capable, like radio, of extraordinary quality. ${ }^{45}$ Contacts were physical rather than virtual, including the constant clashes of right and left on Italian streets. Large segments of the official state apparatus were still shot through with Fascist sympathizers; this is why it has proven so difficult to prosecute right-wing terrorists and why an Italian military court could refuse to prosecute the Nazi war criminal Erich Priebke as late as 1996. At the same time, to please the Roman Church and the United States, Communists continued to be categorically excluded from government. ${ }^{46}$ The grip of the Christian Democratic Party on Italy seemed destined to last in saecula saeculorum.

It all changed, of course, and sometimes with startling rapidity. The Berlin Wall came down in 1989, the Christian Democrats and the Socialists came down in a hail of corruption charges in 1992 and 1993, the old Fascists died and the one-time Communists turned into Democrats of the Left, then simply 
Democrats, and took the roles once denied to them: Prime Minister, Senator, Deputy, President of Italy. Former neo-Fascists from the MSI followed suit, holding offices like President of Parliament and Mayor of Rome. Between 1992 and 20I2, a perpetually smiling little plutocrat named Silvio Berlusconi bought the right wing of the Italian political system with a combination of money, television, newspapers, and a constant cry of anti-Communism. ${ }^{47}$ The Polish cardinal who had just been elected pope when Jesi died, John Paul II, would reign for another quarter century, ushering in a new Catholic cultura di destra that fostered secretive, ideological organizations like Opus Dei and the Legionaries of Christ at the expense of more traditional religious orders, most notably the Jesuits. (Now changing again with the election of the Jesuit Pope Francis I.)

Yet Cultura di destra still provides a trenchant analysis of many phenomena in today's Italy, its hard-core right, its Catholic right, and its center right, of which there are, by now, several different manifestations, even though the spirit of Jesi's enterprise remains very much the spirit of the late ig7os.

That spirit emerges on film as vividly as it does in the written word, and not only in Jesi's spectral appearance in the snow. In the sodden October of 1978, as the young author put the finishing touches on Cultura di destra, the English film director Joseph Losey began to shoot a cinematic version of Mozart's Don Giovanni in Vicenza near Venice, amid the buildings of the Renaissance architect Andrea Palladio ${ }^{48}$ One of the first images in the film, which came out in the spring of 1979, is a quotation from the Prison Diaries of Italian Communist leader Antonio Gramsci: 'The crisis consists precisely in the fact that the old is dying and the new cannot be born; in this interregnum a great variety of morbid symptoms appear. ${ }^{\prime} 9$ Gramsci was referring to the beginnings of Fascism; for Losey, who had collided with McCarthyism in the United States, the citation was a way of emphasizing the revolutionary qualities of Mozart's opera, the story of a libertine composed and produced in the years between the American and the French Revolutions. Losey's stroke of genius was to sense the same revolutionary vibrations in Palladio's sixteenth-century architecture, which may look placid in plan and photograph, but in real space is strange, disquieting, charged with elemental force..$^{50}$ Losey's Don Giovanni, Ruggero Raimondi, was born, like Furio Jesi, in I94I, and in many ways his performance embodies the same conflicts, myths, and violent upsets that Jesi explores in his work. ${ }^{51}$ Both Cultura di destra and Don Giovanni, in other words, are sublime creatures of their time, a dreadful time in many ways, but a time that in retrospect seems rooted and real in ways that our virtual world no longer does. 


\section{Notes}

I Giovanni Proietti, 'Jesi, Furio', in Dizionario Biografico degli Italiani 62 (2004).

2 See, for example, Cesare Medail, 'Che razza di destra?', Corriere della Sera, 24 January I993; Marco Filoni, 'Cosè la cultura di destra?’, Il Fatto Quotidiano, i9 April 2or I; Raffaele Liucci, 'L'intellettuale e il suo “colore” politico', Il Fatto Quotidiano, ig April 20 I I. See Marco Belpoliti and Enrico Manera, Furio Jesi, Riga 3 I (November) (Milan: Marcos y Marcos, 2010), I3.

$4 \quad$ Ibid.

5 Vanna Chiron, a teacher in the liceo and author of books for young adults, eventually married the physicist Gian Carlo Wick and moved to the United States, returning to Turin after Wick's death. For the atmosphere in the Jesi household, see Anna Strumia, 'Omaggio Torinese a Furio Iesi, indagatore disincantato del mito', 25 September 2003, Bollettino dell'Associazione Ex-Alunni del Liceo Alfieri (Turin, 2003), I I.

6 Furio Jesi and Vanna Chiron, Racconti e leggende dell'antica Roma (Turin: Editrice S.A.I.E., 1956); Furio Jesi and Pierre Gilbert, La ceramica egizia dalle origini al termine dell'età tinita (Turin: Editrice S.A.I.E., I958).

7 In a vast bibliography, see, for example, Guido Crainz, Il paese reale: dall'assassinio di Moro all'Italia di oggi (Rome: Donzelli, 20I3); Mario Calabresi, Spingendo la notte più in là (Milan: Mondadori, 2007).

8 Leonardo Sciascia, Laffaire Moro (Palermo: Sellerio, I978); Sergio Flamigni, La tela del ragno. Il delitto Moro, rev. ed. (Milan: Kaos Edizioni, 2003); Richard Drake, The Aldo Moro Murder Case (Cambridge, MA: Harvard University Press, I995).

9 Luca Telese, Cuori Neri (Milan: Sperling \& Kupfer, 2006), 684-700.

Io Enrico Deaglio, Patria, 1978-2008 (Milan: Il Saggiatore, 2009), 93-94; Crainz, Il paese reale, 56-57.

I I Crainz, Il paese reale, 47-6I.

I2 Telese, Cuori Neri, 63-I I9.

I3 Ibid., 2I4-262.

I4 Lewis R. Binford and Sally R. Binford, New Perspectives in Archeology (Chicago: Aldine Press, I968).

I5 Furio Jesi, Cultura di destra (Rome: Garzanti, I979); new edition, ed. Andrea Cavalletti, Cultura di destra. Con tre inediti e un'intervista (Rome: Nottetempo, 20 I I), I68. See also ibid., 48-49.

I6 Jesi, Cultura di destra, 26.

I 7 The correspondence was published by Antonio Cavalletti as Furio Jesi-Karl Kerenyi, Demone e mito. Carteggio 1964-1968 (Macerata: Quodlibet, I999).

I8 Manera, Furio Jesi, 48-54.

I9 The kidnapping of the Neapolitan Christian Democrat Ciro Cirillo in I980 eventually involved the far left, the far right, and organized crime in the form of the Nuova Camorra Organizzata of Raffaele Cutolo. Rita Di Giovacchino, Il libro nero della Prima Repubblica (Rome: Fazi, 2003), I66-I67; Crainz, Il paese reale, I I9-I20.

20 Jesi, Cultura di destra, 54.

2 I Mircea Eliade, Lo Yoga, immortalità e libertà, trans. Giorgio Pagliaro, ed. Furio Jesi (Milan: Rizzoli, 1973).

22 'Dosarul Mircea Eliade', Toladot. Buletinul Istitutului Dr. J. Niemirower, Jerusalem, I (January-March 1972), 24-26; presented in Italian in Alfonso Maria Di Nola, 'Mircea 
Eliade e l'antisemitismo', La rassegna mensile d'Israel, 43:I-2 (I977), I2-I5; Cultura di destra, 64-78.

23 Andrea Carandini, Roma il primo giorno (Bari and Rome: Laterza, 2009); Maria Bonghi Jovino and Cristina Chiaramonti Trerè, Tarquinia: Testimonianze archeologiche e ricostruzione storica, scavi sistematici nell'abitato, campagne 1982-1988 (Rome: 'L'Erma' di Bretschneider, I997). Jesi, Cultura di destra, 77.

25 Mircea Eliade, Shamanism: Archaic Techniques of Ecstasy (Princeton: Princeton University Press, [195I] 2004).

26 Jesi, Cultura di destra, 7I.

27 Liviu Bordaş, 'Ioan Petru Culianu, Mircea Eliade, and Felix Culpa', in Mihaela Gligor, ed. Mircea Eliade between the History of Religions and the Fall into History (Cluj: Presa Universitară Clujeană, 20I2), 68-I 78 .

28 Ioan Culianu, letter to Mac L. Ricketts, May I3, I987, published in Bordaş, 'Ioan Petru Culianu', I29-I 30.

29 See Ted Anton, Eros, Magic, and the Murder of Professor Culianu (Evanston, IL: Northwestern University Press, 1997).

30 Pierre-E. Lacoque, 'Mircea Eliade Remembered', McGill Journal of Education 22:2 (I987), I I7-I30; Marcello De Martino, Mircea Eliade Esoterico (Rome: Settimo Sigillo, 20 I I).

3I Walter Burkert, Homo Necans: Interpretationen altgriechischen Opferriten und Mythen (Berlin: De Gruyter, 1972).

32 Burkert's only analytical study of Meuli is in Japanese. This information comes from a private conversation.

33 See, e.g., Carlo Ginzburg, 'Germanic Mythology and Nazism: Thoughts on an Old Book by Georges Dumézil', in Clues, Myths, and the Historical Method (Baltimore: Johns Hopkins University Press, I990), I26-I 45.

34 Furio Jesi, Mitologie intorno al illuminismo (Milan: Edizioni di Comunità, 1973).

35 E.R. Dodds, The Greeks and the Irrational (Berkeley: University of California Press, I95I). See also idem, Missing Persons: An Autobiography (Oxford: Oxford University Press, I977).

36 Jesi, Cultura di destra, 74 .

37 'Una sorta di pappa omogeneizzata che si può modellare e mantenere in forma nel modo più utile', from an interview in 1979 with L'Espresso.

38 Cuori neri, xi-26 and passim.

39 Jesi, Cultura di destra, I42. See also Francesco Cassata, A destra del fascismo: Profilo politico di Julius Evola (Turin: Bollati Boringhieri, 2003).

40 Jesi, Cultura di destra, 168.

4 I Ibid., I76-I78.

42 Cuori neri, xviii.

43 Michael Herzfeld, Evicted from Eternity: The Restructuring of Modern Rome (Chicago: University of Chicago Press, 2009), I92-196, 293-302. Herzfeld notes the opportunism of both sides in the debate about gentrification.

44 Jesi, Cultura di destra, 46.

45 Crainz, Il paese reale, 24, I95-2 I 2.

46 See, for example, Richard N. Gardner, Mission Italy: On the Front Lines of the Cold War, with a foreword by Zbigniew Brzezinski (New York: Rowman and Littlefield, 2005).

47 Crainz, Il paese reale; Enrico Deaglio, Patria, 1978-2008; Alexander Stille, The Sack of Rome: Media + Money + Power = Silvio Berlusconi (Harmondsworth: Penguin, 2007); Paul Ginsborg, Berlusconi (Turin: Einaudi, 2003). 
48 For a discussion of Losey's career, see Paul Buhle and Dave Wagner,'The Lucid Outsider: Joseph Losey', in Hide in Plain Sight: The Hollywood Blacklistees in Film and Television, 1950-2002 (New York: Palgrave Macmillan, 2003), 21 5-246.

49 Antonio Gramsci, Quaderni dal carcere, 3, 3II. Translation from Zygmunt Bauman, 'Times of Interregnum', Ethics and Global Politics 5.I (2012), 49-56.

50 Ingrid D. Rowland,'The Passions of Palladio', The New York Review of Books, December I7, 2009.

5I Giorgio dell'Arti and Massimo Parrini, Cataologo dei Viventi; 6589 italiani notevoli (Milan: Marsilio, 2009), available online through Corriere della Sera at URL: http://www. cinquantamila.it/storyTellerThread.php?threadId=RAIMONDI+Ruggero. 


\title{
$5+2$ Scientification and Popularization in the Historiography of World Literature, I850-1950
}

\author{
A Dutch Case Study ${ }^{1}$
}

\author{
Ton van Kalmthout
}

\section{Introduction}

In 1827 , in one of his best known quotations, Goethe said:

I am more and more convinced [...] that poetry is the universal possession of mankind, revealing itself everywhere, and at all times, in hundreds and hundreds of men. [...] National literature is now a rather unmeaning term; the epoch of World literature is at hand, and everyone must strive to hasten its approach. ${ }^{2}$

In Europe, interest in other cultures had began to grow in the course of the eighteenth century, a development connected with the expansion of the notion of 'culture' at the time. Formerly, it had been used exclusively in relation to individuals, but around 1800 it had also become applicable to collectives or even to the whole of humanity. ${ }^{3}$ The growing interest in foreign cultures seems to have been intensified by at least two factors. Firstly, a growing concern with preserving national character and national identity automatically focused attention on other nations. A nation could profile itself in comparison and in competition with other nations, which could also serve as a touchstone or as a source of inspiration. Secondly, the Enlightenment advocated the idea that all men are equal and that they all take part in a nation-transcending brotherhood, the human race. And since the spiritual life of a single nation was supposed to manifest itself in its national literature, the spiritual life of all mankind could be read in a transnational literature, in world literature.

In the quotation above, Goethe appears to have brought the term Weltliteratur into wider circulation, primarily to denote the international dissemination of literary art, including non-Western literature. ${ }^{4}$ However, the meaning he attributed to the concept of Weltiteratur did not immediately elicit a widespread response. 
A much more businesslike and pragmatic notion of world literature was more common in the nineteenth century. It was seen as the sum of all literary works brought into circulation by all nations or by mankind in general over the course of time, or at least its undisputed highlights, such as the masterpieces by Dante, Shakespeare and Goethe. Viewed in this way, these international figures did not belong solely to the Italians, the English, or the Germans. Given the fact that their works were the spiritual heritage of the entire human race, they were also owned by other nations.

Since the nineteenth century, several literary histories have been written with the aim of describing the literary heritage of more than one nation or even of all mankind in a single comprehensive historical account. I want to explore the development of this historiographical genre in the second half of the nineteenth and the first half of the twentieth century using a number of Dutch examples. ${ }^{5}$ In the Netherlands, the genre is part of a tradition established in the preceding period. I will follow two lines of evolution, which I shall refer to as (I) academization or scientification and (2) popularization or democratization. Both lines come together in a transnational literary history published during World War II.

But now, back to Goethe's era. While he was developing his cosmopolitan concept of literature, a young man named Willem de Clercq was writing a unique literary history. ${ }^{6}$ In the winter of $1820 / 21$, the Royal Netherlands Institute of Arts and Sciences had announced a competition for a treatise on the following topical issue: 'What influence has foreign literature, especially Italian, Spanish, French and German literature, had on Dutch language and literature from the beginning of the fifteenth century to the present day?"7 De Clercq submitted his manuscript after only a few months. In extended and printed form it would number more than three hundred pages. ${ }^{8}$

His answer to the question was unique, and not simply because it was the only answer submitted. It pleased the Academy so much that it awarded De Clercq a gold medal. De Clercq had established a reputation at a single stroke. His book would continue to command the admiration of readers and, in the Netherlands, it even became famous as the first comprehensive comparative literary history ever written. ${ }^{9}$ At any rate, its author can be regarded as one of the pioneers of comparative literature. This field of study, inspired by emerging disciplines such as comparative linguistics, would flourish in the second half of the nineteenth and the first half of the twentieth century. In this process of discipline formation, the two tendencies mentioned above - scientification and democratization - can be distinguished, tendencies I want to highlight here on the basis of a number of Dutch books written in the tradition established by De Clercq. 


\section{Scientification}

In the Netherlands, history teacher Willem Doorenbos and the somewhat younger professor of Dutch Gerrit Kalff represent the scientification tendency. Unlike De Clercq, they both completed a university degree during which they acquired modern scientific views. In their generation the new scientific paradigm of historism emerged in the comparatist's thinking. Just like any other man of science he was expected to describe and explain literary phenomena - from the smallest details to entire literatures - by collecting empirically observable facts and assessing them impartially. To this end, these phenomena must be compared and causally related to each another, as Kalff - the most important theoretician in this field in the Netherlands - prescribed around 1900. A literary work, for instance, might be explained by the life of its author and by other factors influencing its properties.

According to Kalff there were several ways to obtain a picture of the literary art of a large number of nations. Different national literatures could simply be placed side by side, highlighting perhaps their points of contact or other relationships. Kalff himself, however, inspired by comparatists like Posnett (I886) and $\operatorname{Ker}(1896),{ }^{10}$ preferred an approach which fully abandoned the national pattern, concentrating, for instance, on literary currents or literary contents occurring internationally. As such, Kalff distanced himself from a compiling approach. Doorenbos had used this approach in his Handleiding tot de geschiedenis der letterkunde (Guide to the History of Literature), published in 1870 . This book examined Indian, Hebrew, Greek, Roman, Arab, Persian, medieval Christian, Castilian and Germanic literature in succession, as well as Italian, French, Spanish, English, German and Dutch literature.

Books like these and a growing number of partial studies by other authors show us that comparative literature took root in the course of the nineteenth century. ${ }^{\text {II }}$ Kalff provisionally completed a Dutch academic and nation-transcending literary history in 1923-1924, publishing his two-volume Westeuropeesche letterkunde (Western European Literature). ${ }^{12}$ In this book, he attempted to abandon the national point of view completely. His foreword to volume I describes his aim: 'Starting from the supposition that, during the Middle Ages, the nations of Western Europe more or less formed a unity in faith, civilization, art and other respects, I have tried to show the revelation of this unity in literature. ${ }^{13}$ In the course of his life, Kalff had repeatedly defended extremely nationalistic ideas. Westeuropeesche letterkunde, however, proved that he was also able to apply a pan-European perspective which would, he believed, reconcile nations. ${ }^{14}$ This is apparent from the broad perspective of both volumes which, incidentally, present a cultural history based on literary examples rather than a literary history in the narrower sense. The 
first volume opens with an introduction about the genesis of nations and states, about the church versus the secular world, about the Renaissance and the role of clergymen and laymen. Chapter I deals with the three medieval estates, Chapter 2 with wise, amorous and foolish narratives, and Chapter 3 examines art, artists and their public. The first chapter of Volume 2 continues with the Reformation and Counter-Reformation, Chapter 2 discusses several genres of the Renaissance, Chapter 3 examines literary currents, and Chapter 4, finally, covers genres and writers like Spencer and Cervantes who also influenced the course of literature.

\section{Popularization}

Besides academization, comparative literary historiography included a popularscientific tendency, representing a form of middlebrow culture: easily digestible, tailored to a mass audience of consumers for whom high culture was not accessible as a matter of course, but who wished to gain access to it. ${ }^{15}$ One representative of this new kind of historiography was Steven Margadant, an educated author, but not a trained philologist. ${ }^{16}$ Margadant opted for a less academic route. He studied mathematics and physics at the University of Leyden, but while teaching these subjects ${ }^{17}$ he also developed as a classicist. In the I930s, he edited a number of popular scientific magazines. Two of his books were typically intended for a middlebrow audience: De wereldlitteratuur (World Literature) (1930) and Twintigduizend citaten, aphorismen en spreekwoorden (Twenty Thousand Quotations, Aphorisms and Proverbs) (1935).

Margadant never precisely explained the intentions behind his book on world literature. However, it must have had the same aim as the successful German book that served as his model: Paul Wiegler's Geschichte der Weltliteratur (History of World Literature) of $1914{ }^{18}$ Wiegler declared that he wanted to bring the reader closer to the cultural wealth of the poetry and prose of the leading nations. ${ }^{19} \mathrm{His}$ book presented only the main outlines, leaving aside the ballast of details useful for specialists. It only discussed writers who, according to Wiegler, still accorded with the perceptions of modern people, or who had lived a remarkable life. This must have been Margadant's point of view too. His book had twenty-five chapters, beginning with the literary art of the Egyptians, Babylonians and Assyrians, of the Indians, Jews, Greeks and Romans. It continued with early Christian literature, Persian and Arab literature, the literature of the age of chivalry and of the Teutons. Then, several European literatures were examined in turn in each period. Margadant finished with the literature of East Asia. In his book, he acts explicitly as a guide surveying the whole. High literature was his standard and there was no place for folklore, even if it was artistic. Characteristically, how- 
ever, Margadant did consider less valued popular poetry and he did not reject wholesale the mechanistic production of literature as practiced in the writing workshops of Alexandre Dumas, père, and Eugène Scribe. Margadant took into account the tastes and abilities of the widest possible readership. And that was not all he did to broaden his appeal.

The price of De wereldlitteratuur - eight guilders and seventy-five cents - was fairly low, ${ }^{20}$ certainly given its attractive design, with almost six hundred pages on large-format heavy paper. It was bound in a stylish cover and according to the title page it contained no fewer than two hundred illustrations. It lacked a bibliography, but anyone in need of enrichment could turn to the in-depth passages which alternated with the main text in a smaller font. Margadant's writing style focused first and foremost on accessibility, drawing the reader on. ${ }^{21}$ He also tried to hold the reader's attention with juicy anecdotes. Pietro Aretino was presented as the first journalist ever to use blackmail and as the most feared man of his time, leading a life of debauchery, surviving an assault and using his pen to write threatening and begging letters, satires and pornographic texts. Nevertheless, Margadant himself appeared to share the values of the common citizen, taking a conservative and anti-revolutionary position. This is also clear from his exclusively Eurocentric perspective. If literature did not meet Western standards, Margadant was not interested. He made literary life more familiar for his compatriots, in particular, by referring occasionally to their homeland.

Did Margadant really reach his intended audience? This is not clear; data on the matter are scarce. The weekly magazine De Groene Amsterdammer (The Green Amsterdam Weekly) and, in particular, the quality newspaper Het Vaderland (The Nation) gave the book a negative reception. ${ }^{22}$ The latter review induced Margadant to respond and his publisher Kruseman to place an advertisement in which a series of positive reviews were printed to counterbalance the Vaderland review. ${ }^{23}$ Another response came from Jan Walch, a professor of Dutch in Paris who had formerly written appreciative reviews of Westeuropeesche letterkunde by Kalff, ${ }^{24}$ his former teacher and $\mathrm{PhD}$ supervisor. Walch had been willing to provide an introduction for Margadant's book, which was, of course, positive. ${ }^{25} \mathrm{How}$ ever, some principled remarks preceded his friendly words, in which he distanced himself from the kind of historiography championed by Margadant. Referring to the results comparative literature had achieved by then, Walch concluded that different approaches had arisen in the field. The one he himself preferred proved that he was a pupil of Kalff. More than Margadant had realized, Walch advocated a cultural-historical approach. He thought a literary historian should not take as his basis the insights and tastes of his own time. He had to empathize with other cultures and periods and to use a scientific method focused on establishing causal historical relations: 
The historian must, with receptivity to all that is human and with real scientific love for truth, try to understand the coherence of what he notices as emerged in the wide scope of space and time. It has all grown from the bottom of the human heart, and who truly doesn't want to deem something human strange will, by understanding, be able to approach the essence of all this; often, he must also consider other sides of the history of mankind political, economic, philosophical history - in a given period and in a given region in order to achieve an insight why art had to form and to elaborate its performances in a particular manner then and there. ${ }^{26}$

Apart from sympathy and scientific sense, the literary historian should have the aesthetic sensibility needed to assess the value of verbal art. Furthermore, he should be able to distinguish textual relations: 'He has to register influences, the more or less immediate connections, between works of art of a particular period and between these artefacts and nonartistic phenomena, ${ }^{27}$ With these requirements Walch declared his rejection of the prevailing inclination of some of his colleagues to confine themselves to aesthetic appreciation and to focus on their own time. According to Walch, this inclination was caused by the rise of a social class which, although not elevated in traditions and not educated in the humanities, may and can assert itself culturally. ${ }^{28}$ Walch adjured that this did not imply a negative judgment about democratized society. At the same time, however, he felt that democratization had developed to the detriment of historical awareness and tradition. ${ }^{29}$ Some ten years later, Walch would himself write a history of world literature.

\section{Jan Walch's book on world literature}

Before Walch had been appointed professor in Paris, he made a career as a teacher of Dutch, as a journalist on several quality newspapers and as a Privatdozent of theater history at the University of Leiden. He also came to the fore as a playwright and a prose writer, and he published a handbook on Dutch literary history. After a thirteen-year professorship in Paris, Walch returned to the Netherlands in 1939 in order to become director of the Theater School in Amsterdam. ${ }^{30} \mathrm{He}$ set about writing Het boek der wereldlitteratuur (The Book of World Literature), which appeared in 1943. The book considers the Greeks, Latin literature, early Christianity in literature, the courtly love lyric, humanism and the Renaissance, and, finally, the nineteenth century. It does not therefore examine literature nation by nation, but rather period by period. Walch did not include a programmatic introduction like the one he had written for Margadant's book. Neverthe- 
less, he gave out signals that he advocated a scientifically sound, cultural history approach, revealing the correlation between literary works and the context from which they originated. A representation of medieval mystics as overwrought people, Walch says, is not typical of the Middle Ages. ${ }^{31}$ And studying a particular period will require one to delve into what was believed and thought at the time. However, despite this basic scientific attitude, the book also displays quite a few features that can be characterized as middlebrow. It is in these features that the two tendencies in comparative literature I have discussed - scientification and democratization - meet.

According to his introduction, Walch wrote the book for readers who appreciated an interesting novel and who were obviously striving for a general literary education. ${ }^{32}$ How did Walch try to satisfy this desire? To begin with, he published his book as a course in the popular science series of the 'Universiteit voor Zelfstudie' ['University for Self-Study']. Walch, who according to 's-Gravesande remained a journalist under all conditions, was undeniably determined to share his literary expertise with nonspecialists in clear language. ${ }^{33} \mathrm{He}$ set the tone at the beginning with a definition of world literature:

Having read a book that touched you or made you laugh, did you ever think about the fact that hundreds of generations at hundreds of thousands of places in the world experienced the same emotions by reading or [...] by hearing someone reading aloud?

This book will examine this phenomenon, this thing that has given reading pleasure through the ages: world literature. ${ }^{34}$

Sometimes Walch's literary history is quite emphatically didactic, for instance, where he provides lined pages for a personal table of contents. New to the genre of the history of world literature, but proven in education, was Walch's illustration method, alternating his historical narrative with a large number of annotated sample texts translated or adapted for a Dutch readership. That is why his book is also an anthology. Often even book titles were translated, apparently for readers who were not familiar with modern European languages. And Walch also uses several captivating strategies to hold the attention of the students of the University of Self-Study.

Just like Margadant, Walch sometimes uses anecdotes. At the beginning of his book he promises a historical narrative which will be anything but dry; 'it's often more romantic than a novel. And it is: a true "story". ${ }^{5}$ Lope de Vega, for instance, was an extremely remarkable man: 'His life was infinitely more adventurous - and less noble - than the life of Cervantes. In all things he was excessive!'36 He blackmailed his beloved and was banned, he abducted a woman and 
he joined the Spanish Armada, he had love affairs and fought duels, he married a lady and became a priest after her death, again taking many lovers. Another strategy Walch used to captivate his audience was to present himself as a guide, just like Margadant - a guide on a jaunty stroll, a saunter through the world of literature. Again and again Walch takes a moment to draw the attention of his fellow walkers to the most beautiful places, not least in the final words of the book:

We have completed a long walk through the literature of Europe. We have not seen everything; I hope my readers, like myself, are not tourists who want to see everything, that they are content to be able to admire some beautiful things. [...] This journey has at least yielded a series of clues as to what is worth considering further. If it has brought my readers to such a further consideration of some of the indicated works, it will bring joy and gratitude to the compiler of this book. ${ }^{37}$

It is no mistake that Walch refers to the literature of Europe rather than world literature. Despite the title of his book - Het boek der wereldlitteratuur - he again takes as his basis a strictly Eurocentric frame of reference. Non-European literature is almost entirely disregarded. For Walch, world literature is European literature. Moreover, Dutch literature gets preferential treatment. Even if it is poorer quality, Walch believes it is interesting for his readers because it comes from 'our own country' and because Dutch examples are more instructive for his readers than others.

Sometimes Walch responds to the current socio-political situation - a final way to conform to the views of his audience. In 1943, it was determined for largely by the German occupation of the Netherlands. Reading what Walch wrote about classical literature, one can detect hidden references to the modern era. The imperialistic Roman nation (read: Germany) is presented as having overridden Greece (read: the occupied countries). ${ }^{38}$ However, Walch's message is that, in the end, brute force will lose the battle to the spiritual civilization of the conquered. It was not for nothing that as early as 194I a leading national-socialist newspaper called him a cowardly servant of the Jews. ${ }^{39}$ In any case, his attitude toward the Germans could hardly be described as submissive. This is also apparent from the fact that he did not omit Heinrich Heine, whose books had recently been burnt in Germany:

He was a Jew by birth, he converted to Christianity, but this had no profound effect on his emotional life. [...] His Deutschland, ein Wintermärchen is also witty, full of scoffing at his homeland in which his love for his country nevertheless repeatedly breaks through. ${ }^{40}$ 


\section{Conclusion}

Comprehensive histories of world literature written by an individual author have already been out of fashion for more than half a century. ${ }^{41}$ However, investigating a number of Dutch examples shows that, alongside the traditional nationally oriented literary historiography, an international sister discipline developed in the course of the nineteenth and twentieth centuries. ${ }^{42}$ An academic variant of this historiography developed from compiling national literatures to generalizing literary phenomena. Meanwhile, a popular scientific variant arising from the latter more or less retained the compilation approach. This middlebrow literary historiography can be regarded as a kind of postschool literary education. Initially, it was in the hands of authors with no academic literary training, who were, however, accustomed to writing for a nonspecialist audience. Jan Walch, versatile as he was, tried to combine both subgenres, ending up in the field of popular science.

Paradoxically, the historiography of world literature has often been motivated by nationalistic considerations, or has developed according to national patterns. Unlike Goethe's intentions in referring to Weltliteratur, his contemporary De Clercq, for example, had a nation-building intention: by researching systematically which foreign influences made themselves felt in Dutch literary history, he tried to denote the uniqueness of Dutch literature and hence the Dutch national character. The more comparative literary historians had to address a large audience, trying to conform to its way of thinking and its social context, the more they opted for such a nationalistic view. Furthermore, world literature was invariably considered from a Eurocentric angle. ${ }^{43}$ Although receptiveness to foreign literature can be identified at various levels in intellectual circles, the middlebrow audience in particular seems to have been internationally minded to only a limited extent, even less so in the past than in our own time. A time in which - as Erich Auerbach observed, adapting Goethe - our philological homeland is no longer the nation, but the earth. ${ }^{44}$

\section{Notes}

I In writing this contribution I made grateful use of data gathered by Brenda Heeringa, MA, during her internship and her research for her Master's thesis at the Huygens Institute for the History of the Netherlands in The Hague. I am also obliged to Prof. M.H. Schenkeveld for her comments on an earlier version, which appeared in Dutch with slightly different emphases and details: Ton van Kalmthout, 'Verschillende fragmenten tot een geheel verenigd. Nederlandse geschiedschrijving over de wereldliteratuur, I 824I944', in Zdenka Hrnčírová et al. (eds.), Praagse perspectieven. Handelingen van het colloquium van de sectie Nederlands van de Karelsuniversiteit te Praag op donderdag 22 en vrijdag 23 maart 2012 (Prague, 20I2), 27-52. 
2 Translation from Johann Peter Eckermann, Conversations of Goethe, Translated by John Oxenford, 1906 ([s.1.], 2006), consulted via URL: http://www.hxa.name/books/ecog/ Eckermann-ConversationsOfGoethe-1827.html. Original quote: 'Ich sehe immer mehr [...] daß die Poesie ein Gemeingut der Menschheit ist, und daß sie überall und zu allen Zeiten in hunderten und aber hunderten von Menschen hervortritt. [...] National-Literatur will jetzt nicht viel sagen, die Epoche der Welt-Literatur ist an der Zeit und jeder muß jetzt dazu wirken, diese Epoche zu beschleunigen', Johann Peter Eckermann, Gespräche mit Goethe in den letzten Jahren seines Lebens, Herausgegeben von Christoph Michel unter Mitwirkung von Hans Grüters (Frankfurt am Main, I999), 224-225.

3 On this expanding concept of culture: Remieg Aerts, 'Prometheus en Pandora. Een inleiding tot cultuurkritiek en cultuurpessimisme', in Remieg Aerts and Klaas van Berkel (eds.), De pijn van Prometheus. Essays over cultuurkritiek en cultuurpessimisme (Groningen: Historische Uitgeverij, I996), I0-66, esp. 2I-25.

4 For Goethe's interpretation of the term and its further history, see Hendrik Birus, 'Goethes Idee der Weltliteratur. Eine historische Vergegenwärtigung', in Manfred Schmeling (ed.), Weltliteratur heute. Konzepte und Perspektiven (Würzburg I995), 5-28; John Pizer, The Idea of World Literature: History and Pedagogical Practice ([Baton Rouge, LA], 2006); Peter Goßens, Weltliteratur. Modelle transnationaler Literaturwabrnebmung im 19. Jahrbundert (Stuttgart/Weimar, 20II); and John Pizer, 'Johann Wolfgang von Goethe. Origins and Relevance of Weltliteratur', in Theo D'haen, David Damrosch, and Djelal Kadir (eds.), The Routledge Companion to World Literature (London/New York, [20I 2]), 3-II.

5 According to Theo D'haen, The Routledge Concise History of World Literature (London/ New York, 20I2), I7, histories of world literature 'knew a great vogue especially in the Scandinavian countries, the Netherlands, and Britain, and also in the United States'. See on the genre in general also J.C. Brandt Corstius, 'Writing Histories of World Literature', Yearbook of Comparative and General Literature I2 (I963), 5-I4, and Anders Petterson, 'The Possibility of Global Literary History', in Suthira Duangsamosorn et al. (eds.), ReImagining Language and Literature for the 21st Century: Selected Proceedings of the XXII International Congress of FILLM Held at Assumption University, Bangkok, Thailand, from 19-23 August 2002 (Amsterdam/New York, 2005), who mention quite a few examples. The best known include John Dunlop, The History of Fiction, Being a Critical Account of the Most Celebrated Prose Works of Fiction from the Earliest Greek Romances to the Novels of the Present Age, 3 vols. (London, I8I4); Karl Rosenkranz, Handbuch einer Allgemeinen Geschichte der Poesie, 3 vols. (Halle, I 832-I833); Henry Hallam, Introduction to the Literature of Europe in the Fifteenth, Sixteenth, and Seventeenth Centuries, 4 vols. (Paris, I837-I839); Johannes Scherr, Allgemeine Geschichte der Literatur von den ältesten Zeiten bis auf die Gegenwart. Ein Handbuch für alle Gebildeten (Stuttgart, I85I); G. Brandes, Hovedstrømninger $i$ det 19de Aarbundredes Litteratur. Forelasninger holdte ved Kjøbenhavns Universitet $i$ efteraarshalvaaret 1871-1879, 5 vols. (Kjøbenhavn, I 872-1 882); Otto von Leixner, Illustrierte Geschichte der fremden Literaturen. Das Schrifttum altorientalischen und altklassischen sowie die neueren Völker, 2 vols. (Leipzig, I882); Adolf Stern, Geschichte der Weltlitteratur in übersichtlicher Darstellung (Stuttgart, I888); Alexander Baumgartner, Geschichte der Weltliteratur (Freiburg im Breisgau, I 897-I9I2); [G.E.B.] Saintsbury, Periods of European Literature: A Complete and Continuous History of the Subject, 2I vols. (Edinburgh, I899I923); Otto Hauser, Weltgeschichte der Literatur, 2 vols. (Leipzig, I9 Io); and Paul Wiegler, Geschichte der Weltliteratur. Dichtung fremder Völker (Berlin, I9I4). The last is discussed further below. Based on Von Leixner's book, Der wereld letterkunde, voor Nederlanders bewerkt [World Literature Adapted for the Dutch] by P.A.M. Boele van Hensbroek is a 
Dutch history of world literature; it is discussed separately in Van Kalmthout, 'Verschillende fragmenten'.

6 On De Clercq see, for example: I. da Costa, Herinneringen uit het leven en den omgang van Willem de Clercq, medegedeeld in de Maatschappij tot Nut van 't Algemeen (Amsterdam, I 850), and [P.D.] Chantepie de la Saussaye, 'CLERCQ (Willem de)', in P.C. Molhuysen and P.J. Blok (eds.), Nieuw Nederlandsch biografisch woordenboek, vol. 3 (Leiden, I9I4), 236-240.

7 Original quote: 'welken invloed heeft vreemde letterkunde, inzonderheid de Italiaansche, Spaansche, Fransche en Duitsche, gehad op de Nederlandsche taal- en letterkunde, sints het begin der I 5 e eeuw tot op onze dagen?'

8 On the creation of De Clercq's Verhandeling: A. Pierson, Willem de Clercq naar zijn dagboek, met medewerking van De Clercqs jongste kleindochter, 2 dln. (Haarlem, I 889), I 45I 46 and I56. See also J.C. Brandt Corstius, 'Willem de Clercq als literatuurhistoricus en comparatist', Verslagen en Mededelingen Koninklijke Vlaamse Academie voor Taal- en Letterkunde, nieuwe reeks, I-4 (I96I), 48 I-504; M.H. Schenkeveld, Willem de Clercq en de literatuur (Groningen, 1962), 75-122, and W. van den Berg, De ontwikkeling van de term 'romantisch' en zijn varianten in Nederland tot 1840 (Assen, 1973), 295-304. I have quoted the 1826 reprint.

9 See, for example, J. te Winkel, De ontwikkelingsgang der Nederlandsche letterkunde, reprint (Haarlem, 1925), vol. 4, 453; Gerard Brom, Geschiedschrijvers van onze letterkunde (Amsterdam, I944), 3 I; G.P.M. Knuvelder, Handboek tot de geschiedenis der Nederlandse letterkunde (Den Bosch, I973), vol. 3, 344-345; [W.J.C. Buitendijk], 'Clercq, Willem de', in G.J. van Bork and P.J. Verkruijsse (eds.), De Nederlandse en Vlaamse auteurs van middeleeuwen tot heden met inbegrip van de Friese auteurs (Weesp, I985), I 39-I 40.

Io Hutcheson Macaylay Posnett, Comparative Literature (London, I886); W.P. Ker, Epic and Romance: Essays on Medieval Literature (London, I 897).

I I For a more detailed account of the emergence of comparative literature in the Netherlands: Ton van Kalmthout, 'Beam of a Many-Coloured Spectrum: Comparative Literature in the Second Half of the Nineteenth Century' (forthcoming). D'haen, Concise History, 47-73, gives an overview of the international emergence of the discipline over the past two centuries.

I 2 G. Kalff, Westeuropeesche letterkunde, 2 vols. (Groningen/The Hague, I923-I924).

I3 'Uitgaande van de onderstelling, dat de volken van West-Europa gedurende de Middeleeuwen in geloof, beschaving, kunst en andere opzichten min of meer een eenheid vormden, heb ik getracht de openbaring dier eenheid in de literatuur te doen zien' (p. iv).

I4 L.H. Maas, Pro Patria. Werken, leven en streven van Gerrit Kalff 1856-1923 (Hilversum, I998), 248-250.

I5 See for defintions of the middlebrow concept the Middlebrow Network website, URL: http://www.middlebrow-network.com.

I6 See Ben van Eysselsteijn, 'Steven Willem Floris Margadant (22 Nov. I 887,'s-Gravenhage, I 5 Maart 1946)', Jaarboek van de Maatschappij der Nederlandse Letterkunde te Leiden, 19461947 (1948), 93-94, for biographical details.

I7 For details of his appointment as a teacher of mathematics, see Verslag van den staat der booge-en lagere scholen [Report on the State of the Universities and Schools] (I9I5-I9I6), I40-I4I, (I9I6-I9I7), I39, and (I9I7-I9I8), I96, consulted via URL: www.statengeneraaldigitaal.nl.

I 8 The publisher ordered a translation from Margadant. After the second chapter, however, he went his own way, only using Wiegler's book as a source of data. According to Mar- 
gadant himself his book could not even be called a free adaptation; S.W.F. Margadant, De wereldlitteratuur. Geschiedenis der letteren (The Hague, I930), ix, xi. Wiegler, Geschichte, vii.

It was also available bound in linen for $\mathrm{fl}$. 10.75 and in quilted leather for fl. I 8.75 (prospectus in the archives of the Kruseman publishing house, The Hague, Amsterdam University Library). In the Dutch East Indies the book cost fl. I2.35 (advertisement placed by the booksellers Visser \& Co in Nieuws van den Dag voor Nederlandsch Indië, 9 January 1930). Margadant, Wereldlitteratuur, ix, xi.

J. Westerwoudt, review of Margadant, Wereldlitteratuur, in De Groene Amsterdammer, I I Jan. I930, I7; N.N.,'De wereldlitteratuur in een notendop', review of Margadant, Wereldlitteratuur 1930, in Het Vaderland, 5 March 1930.

[S.W.F.] Margadant, 'Wereldlitteratuur', in Het Vaderland, 7 March I930; advertisement placed by the Kruseman publishing house, The Hague, in Het Vaderland, I I March 1930.

J.L. Walch, review of Kalff, Westeuropeesche letterkunde, in Groot Nederland 2I (I923), vol. 2, 506-509; Jan Walch, 'Vergelijkende litteratuurgeschiedenis', Het Vaderland, 28 July I923; Jan Walch, 'Een nagelaten geschrift van Prof. Dr. G. Kalff', Het Vaderland, 28 June I925.

Margadant, Wereldlitteratuur, ix-x.

'[D] e geschiedschrijver moet, met ontvankelijkheid voor al wat menschelijk is en met de echte wetenschappelijke liefde tot de waarheid, trachten den samenhang te begrijpen van wat hij daar als onder zich, in de wijde strekking van ruimte en tijd, ziet gegroeid. Het is alles gewassen [sic] uit den bodem van het menschelijk hart, en wie waarlijk niets menschelijks zich vreemd wil achten, zal in het begrip tot het wezen van dit alles vermogen te naderen; [dan] zal hij ook dikwijls andere zijden van de levensgeschiedenis der menschheid - staatkundige, economische, filozofische geschiedenis - in een bepaald tijdvak en onder een bepaalde hemelstreek moeten bezien om tot het inzicht te komen, waarom tóén en dáár de kunst juist op die bepaalde wijze haar voorstellingen moest vormen en uitwerken' (Walch in Margadant, Wereldlitteratuur, v-vi).

'Hij zal de invloeden, het minder en meer onmiddellijk verband hebben vast te leggen tusschen de kunstwerken van dien tijd onderling en tusschen deze en andere dan kunstverschijnselen' (Ibid., vii).

'[D]e opkomst eener klasse, die niet opgevoed in traditiën en niet geschoold door de humaniora, toch zich in-zake cultuur mag en kan laten gelden' (Ibid., viii-ix).

Walch in Margadant, Wereldlitteratuur, vii-ix.

Biographical details about Walch are taken from G.H.'s-Gravesande,'Johannes Lodewijk Walch ('s-Gravenhage, 2 Januari I 879 - Amsterdam, I2 December I946)', Jaarboek van de Maatschappij der Nederlandsche Letterkunde te Leiden, 1947-1949 (I95 I), I 88-I93.

Walch, Het boek der wereldlitteratuur (The Hague, [I943]), 2 I I.

Ibid., I I.

's-Gravesande, 'Johannes Lodewijk Walch', I9I.

'Wanneer u een boek hebt gelezen, dat u heeft ontroert of heeft doen schateren [...], hebt $\mathrm{u}$ er dan weleens over nagedacht, dat honderden geslachten van mensen op honderdduizenden plaatsen van de aardbol aandoeningen van zodanige of van verwante aard hebben ervaren, óók door het lezen, of [...] door het horen voorlezen? / In dit boek wordt daar iets van verteld: van wat, de eeuwen door, lees-genot gaf: van de wereldlitteratuur' (Jan L. Walch, Wereldlitteratuur, I I.

5 Original quote: '[...] het is vaak romantischer dan een roman. En het is: een ware "geschiedenis"', Walch, Wereldlitteratuur, I I. 
36 'Zijn leven was nog oneindig avontuurlijker - en minder nobel - dan dat van Cervantes. Alles is even buitensporig aan hem!', ibid., 202.

37 'We hebben een lange wandeling door de litteratuur van Europa volbracht. Alles hebben we niet gezien; ik hoop dat mijn lezers, evenmin als ik zelf, [niet] tot die toeristen behoren, die alles zien willen; en dat ze tevreden zijn, wanneer ze enige mooie dingen hebben kunnen bewonderen. [...] Mocht deze tocht die althans een reeks aanwijzingen opleverde van wat de moeite van nadere beschouwing waard is, mijn lezers tot zulk een nadere beschouwing van enkele der aangeduide werken hebben gebracht, dan zal dit den samensteller van dit boek tot vreugde en dankbaarheid stemmen', ibid., 590 .

38 Cf. ibid., 75, 98, I07 en I22. Walch constructs a similar contrast between the Teutons and the Gauls (p. Ioo). Cf. also: 'En dan overstromen de barbaarse Germanen Italië' (p. I 20; 'And then, the barbaric Teutons overwhelm Italy').

39 'De walgelijke taal en houding van prof.dr. Jan L. Walch. De directeur van onze eenige Tooneelschool laat zich in de kaart kijken', in Volk en Vaderland, 3 October 194I, 7. This anonymously published article by August Heyting rejects Walch because of his essay 'Het nationaal-socialisme', in Het Vaderland, I6 May I933. Here, it was printed in Walch's personal column 'Scherven van gisteren', written under the pseudonym of Krammer.

'Hij was Jood van geboorte, ging tot het christendom over, maar zonder dat dit op zijn gevoelsleven een belangrijke invloed had. [...]/[...] Geestig is ook zijn Deutschland, ein Wintermärchen, vol spot met zijn vaderland, waardoor toch telkens de liefde heenbreekt', Walch, Wereldlitteratuur, 582 .

4I See Brandt Corstius, 'Writing Histories', and J.C. Brandt Corstius, 'Literatuurgeschiedschrijving en literatuurwetenschap', in Handelingen van het XXIXe Vlaams Filologencongres, Antwerpen 16-18 april 1973, [z.p. z.j.], 55-63; Sophie Levie, 'Literatuurgeschiedschrijving', in Peter Zeeman (ed.), Literatuur en context. Een inleiding in de literatuurwetenschap ([Heerlen/Nijmegen], 1991), 252-253, 266. After the Second World War, however, several new attempts were made in the Netherlands.

42 The discipline has been taught less successfully in secondary schools. See Ton van Kalmthout, 'The Most Universal, Beautiful and Enthralling: The Teaching of Comparative Literature in the Netherlands, ca. I880-1940', in T.J. Broos et al. (eds.), The Low Countries - Crossroads of Cultures (Münster, 2006), 217-229.

43 See also D'haen, Routledge Concise History, 5-46.

44 In his essay 'Philologie der Weltliteratur', in Erich Auerbach, Gesammelte Aufsätze zur Romanischen Pbilologie (Bern/Munich, I967), 3 Io. 



\title{
5+3 Theater Studies from the Early Twentieth Century to Contemporary Debates
}

\author{
The Scientific Status of Interdisciplinary-Oriented \\ Research
}

\section{Chiara Maria Buglioni}

The complexity of theory pales by comparison to the abundant wealth of theatrical experiments in our times. Many of these are having some success, whether research into space, body expression, rereadings of classics, or the fundamental relationship between actor and spectator. But beware those who proclaim the death of staging or history, the disappearance of theater, a return to the evidence of the text or the incontestable supremacy of the actor, for underlying such statements is often a rejection of reflection and meaning, a return to a critical obscurantism with sinister echoes. In these times of ideological uncertainty, as the humanist heritage is liquidated between two fire sales of concepts too soon shop-soiled, of hermeneutical gadgets and flashy postmodern devices, a process of historical and structural reflection seems ever more necessary to stave off the vertigo of theoretical relativism and aestheticism.

No other discipline within the humanities has had to struggle with its own interdisciplinary character as much as theater research in Europe. The fathers of the new-born scholarship Theaterwissenschaft were mainly concerned with distinguishing theater from other forms of art and with asserting its right as an independent field of enquiry. The need to define a specific methodological approach, however, was not taken into account. This initial lack in the creation of the scientific discipline has influenced the controversial development of theater studies and has caused frequent identity crises.

The new challenge within theater studies is called the integrated approach. ${ }^{2}$ From the mid-8os, under the condition of postmodernity, which reflects the collapse of categories and the blurring of traditional genres, theater research has pursued the analysis of every aspect and form of the theatrical medium, rejecting the conventional boundaries highly specialized scholarship has imposed since the foundation of the discipline. What is more, the focus of the discipline has witnessed a gradual shift from theater, an aesthetic object, but also an audience- 
based activity and an institution, to all kinds of cultural and social performances, to be read as a semiotic process. This way, theater scholars are called on to share the knowledge of many fields of enquiry and to discover the potential points of contact theatrical events have with other disciplines. Nonetheless, such interdisciplinary-oriented research tends to superficiality rather than to scientific enterprises through the cooperation with other fields; ultimately, it is willing to analyze every small pseudo-theatrical incident in daily life, without carrying any contribution to the history of the humanities, rather than to limit its object and to display the contents and results of its investigations in a systematic way. The theoretical quarrels among opposing factions such as hermeneutical scholars, historians, semioticians, poststructuralist thinkers and performance practitioners have now been sublimated into an all-embracing methodology, in a sometimes confusing multitude of definitions, practices and procedures that makes theater lovers wonder why theater studies fears to deal with theater art. Theater scholars are constantly repeating that theater studies is not an omnicomprehensive cultural scholarship, else no precise, specific questions could be raised, discussed and solved. ${ }^{3}$ However, they all flinch from delimiting the boundaries of their discipline: since an exhaustive definition of aesthetic experience is hard to find, the difference between artistic performance and nonartistic performance seems to be inexistent. If it is true that all the humanities are interwoven, the nature and substance of a single scholarship can nevertheless be endangered by a denial of its particular object of investigation and of its own methodology, which should build its own framework for research instead of resorting to predetermined categories.

This essay questions the assumption that a certain methodological polytheism - of heterogeneous tools and skills - is the proper answer to the scientific status of theater studies and that the eclectic nature of the discipline corresponds to its strength. Through an historical overview of theater studies as interdisciplinaryoriented research, the article aims at demonstrating how the self-imposed lack of definitions and methodological stances, as well as the irresistible urge to assess the discipline within the mainstream of other humanities and social sciences, is just a way to avoid fundamental issues. It is hence necessary to clarify the author's position with respect to the object 'theater'. The point of departure is not the classical, Eurocentric concept of theater as performance of dramatic texts, but as theatrical performance, live art, communicative event in which the aleatory component is always mediated by the performer(s)' choice - the so-called 'planned uncertainty' -, by the audience's expectations and the relative stability of theatrical contexts. As Willmar Sauter rightly asserts, the artistic level is one of the constituent elements of theatrical performance: 'The artistic level of communication is built on coded actions, and each theatrical genre has a specific set of expressive strategies. ${ }^{4}$ The subject matter of theater studies should be therefore 
its relation to the aesthetic and the performance as art form and as social/cultural behavior: the discipline should rediscover the aesthetic properties of theater and make them an integral part of its enquiry.

\section{A young discipline fighting for independence and recognition}

The autonomous status of theater research was undermined at the very beginning of its career, when the pathfinders of the German Theaterwissenschaft called for the recognition of a theatrical art to be analyzed separately from literary studies, but ignored to distinguish their work in terms of methodology. Curiously, the German name contains the word 'science', which linked the newborn academic subject to a broad cultural process through which Dilthey's Geisteswissenschaften tried to attain the same scientific status of the natural sciences. Wilhelmine Germany was characterized by two connected trends: on the one hand, the relationship between society and theater changed, since the latter lost its educational role; on the other hand, new disciplines found their way into the highly conservative university system - for example, archeology, the history of art, and musicology. In the fervid shift toward modernity, some scholars focused their attention on the fin-de-siècle theatrical revolution. The demand for performances was increasing and, consequently, the number of public and private houses tripled after the passing of the trade laws in 1869 , which had allowed public establishments to open without legal restrictions. As for drama and staging, the first moves toward a director's theater were to be seen at the Meiningen Court Theater or in the work of other pioneers such as Richard Wagner, Max Reinhardt and Georg Fuchs, who arrested the so-called literalization of theater. New avant-garde movements likewise tried to overcome the impasse of a standardized theater by experimenting with stage effects and illusions, space and audience involvement: this was the period of Edward Gordon Craig and Adolphe Appia. The public at large grew increasingly interested in theater, and, partly as a result, theater criticism grew out of the field of literary criticism. Another relevant circumstance is the appearance of theater societies (Gesellschaften) and theater associations (Vereine) which both allowed the staging of innovative theatrical forms in close circuits and helped the establishment of theater departments in the German universities. ${ }^{5}$

In 1900 Max Herrmann (1865-1942) delivered the first lectures and tutorials in Theaterwissenschaft at the University of Berlin, and nine years later Artur Kutscher (1878-1960) did the same in Munich. The universities of Kiel and Cologne followed in 1918 and 1920 respectively, under the aegis of the literary historian Eugen Wolff (1863-1929) at the former and Carl Niessen (1890-1969) at the latter. In 1923 Herrmann was able to establish his 'Theaterwissenschaftliches 
Institut an der Universität Berlin', but Kutscher never did witness the realization of his dream; the department of Theaterwissenschaft, in fact, was established the Ludwig-Maximilians-Universität only in $1974{ }^{6}$ The main concern of these scholars was to prove that the art of theater could not be reduced to a mere manifestation of the dramatic text. As an object composed of different elements, it needed an independent discipline. Herrmann's first observation refers to the spatial dynamics of theater. In order to interpret theater, which is primarily a spatial art, scholars have to know in detail about both the actual theatrical space and the way it is used and transformed by theatrical practitioners. Placed precisely within its space, a drama can be fully translated into mimic, gestural communication, and proxemic action. Literary studies cannot grasp the phenomenon of theater because its tools are simply insufficient - they are limited, that is, to abstract speculations. When, in 1919, Herrmann outlined the essential subjects to be taught in the new department of theater studies, he expounded his idea of theater as a spatial art to be studied from a practical point of view. The syllabus follows three strands: theater history, theater aesthetic and theater legislation. Beside a general study of the art of theater as well as a study of dramatics, staging, acting, costumes, lighting and sets, theater students must have practical notions (for example, about theater administration or censorship) and must apply their knowledge through exercises. For this reason, a small revolving stage is placed inside the institute. As far as the question of method is concerned, Herrmann has to deal with the transience of theatrical performance. In this respect, although theater studies is to be subtracted from the hegemony of history and literary studies, these disciplines can all the same supply scholars with the tools needed to work out the problems connected with an evanescent performance; ${ }^{8}$ what is more, the historical methodology was the only one acknowledged in the early twentieth century for scholarly pursuits. Max Herrmann provided the first systematic approach to theater history by supplying us with a model called 'reconstruction'. As a theater historian, the creator of Theaterwissenschaft in Berlin applies strategies developed by archeology to document single elements of a mise-en-scène, rather than a whole, unique performance. ${ }^{9}$ The final goal is to understand the practice and staging of a particular form of theater, such as the theater of the Meistersingers of Nuremberg, and to place it within the wider context of German theater: "Theater studies is the vital lesson from the past connected to the teachings of contemporary theater.' ${ }^{\text {Io }}$ Granted that Herrmann's field of interest is not the historical past tout court, but the relationship between the conditions of previous performances and those of modern theater, all the same he avoids studying contemporary forms of theater. ${ }^{\text {II }}$

At Munich University, on the contrary, Kutscher arouses his students' curiosity in extremely contemporary manifestations of theater by organizing evening debates and performances with famous playwrights and artists. He reinforces 
the dichotomy of theory and practice in theater studies as he prompts students to experiment on the stage and with dramatic texts. However, he, too, does not deal systematically with contemporary performances: the literary drama is always analyzed with the tools of poetics, since Kutscher's main concern is the diachronic enquiry into theatrical expression. He tries to explain the interrelation of complex and primitive modes of performance by identifying their original source: mime. This is the way through which human bodies express themselves. It is innate in human beings, but theater studies must limit its attention to the deliberate, noninstinctive use of the body as a means of expression. This way of controlling and showing 'tensions, emotions and life-nexuses' can be subsumed under the concept 'play.' ${ }^{12}$ The play instinct is the basic instinct of mankind, since it combines the use of the imagination with an awareness of one's own strengths. Starting from the speculations of Hermann Reich and Hugo Dinger, Kutscher argues that theatrical art differs from literature in its mimic character. ${ }^{13}$ Theater, he says, communicates above all through space and movement. Kutscher develops a theory of mime whose aim is to explain why literary studies are unable to define theater. Carl Niessen reelaborates this theory, trying to stress the importance mimesis - as representational instinct - has for the definition of mime, but he shares Kutscher's scope: the desire to demonstrate that theater comes from instincts which transcend culture and time, rather than from dramatic forms linked to ritual acts. Herrmann and Kutscher have a different idea of theater and, consequently, a different methodological approach. The Munich scholar overlooks the need for a specific set of working methods, so much so that he claims:

The term Theaterwissenschaft or, at the beginning, Theaterwissenschaften, was coined by myself, since I was convinced that theater, as the object of a discipline within the Humanities, grants and requires method of its own. What kind of method should that be? [... Mime must be the core of theater studies. [...] Its method comprises everything that belongs to science as such and that can be grasped with scientific tools. ${ }^{14}$

What emerges from this tautological phrase is the impossibility of detaching theater studies from philological and historical principles in the academic context, the so-called 'science'. Kutscher considers the risks of such a mixing-up of methods, ${ }^{15}$ but he wants to enrich theatrical analyses with reflections coming from other fields. He is the first theater scholar to consider anthropology and ethnology as important aids for the newborn discipline, to open up the scholarship to other branches of knowledge. ${ }^{16}$ Since social sciences were underestimated in the German university system at that time, he didn't dare get rid of the study of literature and history. 
Max Herrmann and Artur Kutscher, as well as Carl Niessen, overlooked the actual dilemma of Theaterwissenschaft, namely the relationship of its many-sided object of study with extremely different factors and domains. The pioneers of German theater research were, in fact, the first scholars to favor the subdivision of the discipline, through the application of methods borrowed from other fields or through the claim that theater research actually needs no specific methodology. Even if they challenged the traditional approach to the theatrical phenomenon based on the textual study, they were unable to choose between historical, literary-critical, and anthropological analyses.

\section{Approaches to theater studies: Relationships to the other humanities}

Although the path-breaking discipline defined itself through the epistemological 'passage from the object-dramatic text to the object-performance, ${ }^{17}$ it is clear that its founders could not overcome the conflict with literary studies. Herrmann and Kutscher had a philological curriculum, as they had both qualified as professors of German literature. What is more, they were convinced of the supremacy of the poetic text within the theatrical performance. Herrmann defended any playwrights' work against a director's free interpretation of the text - he believed the author's intention should always be preserved in the way the text was staged ${ }^{18}-$ and Kutscher described the main property of drama as 'ennobled' mime, because it masters the poetic text on a mimic basis. Lastly, the inner quality of theater history must be borne in mind, as it is based on actual documentary records, and thus on texts. Herrmann himself believed the art of theater could speak directly to the present through its sources, and these sources are, first and foremost, literary ones. Drama-based theater studies takes as its legitimation this original commitment to the written text, and as a result hermeneutical analyses and philological speculation on texts dominated the discipline till the late ig6os. As a 'method of interpreting text and performance', hermeneutics attempts to seek out the relationship between the theatrical work and the outside world, thereby falling within the area of dramatic criticism. ${ }^{19}$ However, what must be underlined here is that Herrmann's and Kutscher's different approaches to the theater, combined with a similar kind of uncertainty about methodology, led to two parallel approaches to theater studies.

On the one hand, the positivist foundations of the discipline influenced theater historians, who had to struggle first with 'vulgar positivism' and then with its 'more subtle reappearance' ${ }^{20}$; the former includes the methodological assumption that it is possible to achieve the objective reconstruction of truths based 
on facts, while residual positivism is based on the belief that facts can remain neutral and analyses can be impartial. On the other hand, the theory of theater as mime survived because theories of cultural evolution tried to place cultural events on evolutionary ladders and origin theories explained how the legitimate theater (fifth-century Attic tragedy and comedy) had derived from a 'Primal Ritual'. The common element of hermeneutical, historical and evolutionary-anthropological perspectives is, then, the search for unprovable signs that Richard Schechner deplores in older approaches to the theater. ${ }^{21}$ According to him, these 'vertical' theoretical approaches force theater into a literary context in which it does not belong. The opposite development of theater studies, a development that explores 'horizontal relationships', can be seen in semiotics and performance studies. Despite the fact that these fields of enquiry - which are not simply a discipline, nor properly a method (as Keir Elam would say ${ }^{22}$ ) - are linked to different concepts of theater, it is possible to unite them in an attempt to work on all the phenomena involved in performance with a unified set of approaches. After an initial period, characterized by the textual analyses of theatrical performances (the I970s to the early I980s), theater semioticians are now engaged in ordering inputs from various fields of investigation in a meta-disciplinary frame by using semiotic principles. The main object of study is therefore the 'theatrical relationship' during the creative process (hence the relationship between playwright and director, director and actors, etc.) and in its result (the relationship between performance and spectator). The poles of this relationship are the actor and the spectator, 'which are conceived as interdependent entities, but also as active subjects, provided with a relative mutual autonomy. ${ }^{23}$ This definition emphasizes the spectator-response as a partial, creative independence with respect to the performance, and aims at denying the deconstructive claim for boundless spectator's autonomy. Semiotics has been linked to reception theories or corrected by phenomenological reflections about direct experiential aspects of the performance. Problems concerning taxonomy and methods are, however, far from being solved. Critiques of theater semiotics have always involved the process of transferring linguistic terms and metaphors to theater - which is a polyphonic system, not merely a verbal phenomenon - and the oversystematization of its concepts. As far as phenomenological theater theories is concerned, they also express the needless attempt to define theater:

$[A]$ ny specialized vocabulary or set of terms does not exhaust the phenomenon it is intended to describe (performance, theater, art), but simply 'fixes' it from one possible angle of intentionality or expressiveness; for the phenomenon is always nameless and multiform before a vocabulary traps it in one of its manifestations. [...] We can only seek the essential nature of performability, not a taxonomy of performable objects or behaviors. ${ }^{24}$ 
On the other side of theatrical investigation, cultural studies and avant-garde artistic practices have favored, in the US, the emergence of performance studies. Taking important tools from social sciences in the late ig6os and from ethnology and anthropology in the early I970s, the father of performance theory and poetics, Richard Schechner, declares that theater belongs among 'public performance activities of humans', along with ritual, play, games, sports, dance and music. ${ }^{25}$ With the word 'performance' Schechner limits Erwin Goffman's idea of a mode of behavior that qualifies any human activity and coins the classical definition: 'a performance is an activity done by an individual or group in the presence of and for another individual or group. ${ }^{26}$ The field of performance studies immediately defines itself in opposition to the American theatrical theory - which was at its foundation concerned with drama; however, its development has followed the traces of the different approaches to theater studies in existence in the I940s: the Midwestern and Northwestern traditions entailed an oral interpretation-and communication-oriented approach to theater studies as a part of the broader School of Speech, while on the East Coast scholars focused on theater as a physical event and stressed the importance of the material conditions of each performance. After Schechner, performance research at New York University aims at developing an interdisciplinary faculty, by stressing the fundamental role of dialogue with specialists from different disciplines and cultures.

In 1992, Schechner reformulates the theory he has been developing for decades and declares a paradigm shift from theater - or written drama - to performance. In so doing, the performance practitioner and theorist follows two rationales: 'Theater Studies lacked the scope to engage with increasingly "performative" as well as "intercultural" Western societies, or performances beyond; and it addressed a redundant form. ${ }^{27}$ Meanwhile, Phillip Zarrilli's definition of performance as an arena for the constant process of negotiating experiences and meanings that constitute culture' ${ }^{28}$ clearly emphasizes the pragmatic interest of his - and others' - performance theory as well as his intercultural perspective. Theater studies has become one element of the new paradigm of performance. On the whole, in performance studies attention is shifted away from the traditional aesthetic to the universal, intercultural basis for the relationship between social and aesthetic drama. ${ }^{29}$ Through an arbitrary metaphorical gesture, performance studies has claimed epistemological superiority over theater studies, ignoring the fact that theater is also an aesthetic, artistic object of enquiry and pursuing the wider democratic scope of including identities marginalized by so-called highbrow culture, with its canonical texts and institutional contexts. If we think of Jon McKenzie's recent statements, in which he argues that the twenty-first century is the very 'age of global performance, ${ }^{30}$ thus an age in which everything is performance, in which every human activity is dominated 
by a 'formation of power and knowledge, ${ }^{31}$ and in which performances largely contribute to the process of globalization, the absence of interest for artistic and theatrical performance is evident. According to McKenzie, cultural specialists should analyze not only the discursive discipline of performance studies and its respective colegitimating object of study (cultural performance), but also the paradigms of performance management and techno-performance with their objects (organizational performance and technological performance), in order to embrace, understand, and use performance as a tool to transform society. Jill Dolan rightly evokes a model of exchange between theater and other disciplines, 'rather than one in which the performative evacuates theater stud-

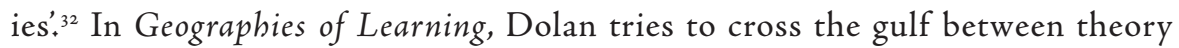
and practice, so that, in Chapter 4 , she argues for a new alignment of the objects of investigation and for a new methodology that can transform theater studies into a lively discipline. She proposes 'borrowing back' concepts and metaphors historically developed by theater studies which have been lifted by other disciplines in recent times. The idea is certainly suggestive, but no explanations have been offered to show how precise methodological characteristics could structure this process of reappropriation and retranslation. An interesting aspect is the theoretical affinity Marvin Carlson sees between Jill Dolan's studies and Erika Fischer-Lichte's continental perspective on the field of theater and performance research. ${ }^{33}$

Again in Germany, the discussion about performance studies has been received in the late 1980 s and is directly connected with Fischer-Lichte's later work. As she herself recalls, the focus of her interest quite spontaneously shifted to the performative aspect of theater performances and other cultural performances ${ }^{\prime 34}$ in an epoch marked by the new metaphor 'culture as performance'. Her attempt to connect the performance studies discourse to the birth of theater studies in Germany and to present the contemporary evolution of the discipline as already foreseen and theorized in Max Herrmann's concept of theater unravels the desire to remark Germany's hegemonic position in the field of theater/ performance studies, against the so-called 'US/UK PS empire. ${ }^{35}$ There is no doubt that Herrmann understood theater as an event, as festive play and, therefore, as performative art ${ }^{1}{ }^{36}$ nonetheless he was exclusively interested in events or performances which allowed particular aesthetic experience and which were broadly considered works of art. His research interest was not any kind of cultural performance', as Fischer-Lichte now defines the object of enquiry of theater studies ${ }^{37}$ Rightly enough, Carlson observes that Fischer-Lichte draws her examples almost exclusively from what might be called the artistic tradition of theater and performance art, instead of ranging broadly through other examples of social and cultural performance as an American theorist might do ${ }^{\prime}{ }^{38}$ an aspect that 
shows the divergence between her approach based on the aesthetic side of live art and the will to place German theater studies at the core of the Anglo-Saxon performance studies debate. ${ }^{39}$

If theater studies has been questioned at theoretical and methodological level by gender theories, cultural studies, postcolonial analyses, and communication models, there is a need for the discipline to take up a position with respect to its research aims and the procedures of other fields. The attempt to redefine itself must not be blamed as an old-fashioned urge to categorize knowledge and to preclude any historical and cultural development of the discipline.

\section{Epilogue}

From the time of its foundations in Germany, the main concern of theater studies has been to organize the tools and methods deriving from historical, semiotic, anthropological and other areas of scholarship. The multimedia theatrical phenomenon, in the way it works out in practice, and in terms of its determining factors, meanings and response is the actual object of enquiry, but the existence of so many theater concepts and borrowed tools makes the scholars' path perilous. Even though theater as an overall reality can only be analyzed by privileging single perspectives - in terms of spatial art, expressive art, dramatic art, communicative art, performative art, representational art and so on - the essence of theater is left aside. In the preface to his new 'theatrology' in I988, De Marinis warned theater experts that interdisciplinary eclecticism constantly endangers the efforts of theater scholars, forcing them to use concepts that are imprecise and foreign to the field in a somewhat confused fashion. ${ }^{40}$ Twentyfour years later, in 2012, Andreas Kotte concludes his reference book Theaterwissenschaft in a similar way. In the epilogue he asserts: 'Creating new theater concepts is legitimate from a scientific point of view, but acknowledging many of them the same validity brings the charge of relativism. ${ }^{41}$ At the present time, conferring scientific status on theater studies, as an autonomous Human Science, is still extremely problematic and the discipline unity is constantly threatened by its scholars' uncertainty about descriptive research goals and methods. A fusion of theories and approaches could be reached through the claim of the peculiarity of theater studies: its analysis of theater as a performative artistic event. Only the clear, courageous definition of its subject matter and of its own investigative framework would ensure the survival of theater studies as an academic discipline. 


\section{Notes}

I Patrice Pavis, 'Preface', in Dictionary of the Theatre: Terms, Concepts, and Analysis, trans. Christine Shantz (Toronto, ON: University of Toronto Press, I998), x.

2 Thus the incorporation of intercultural and interdisciplinary perspectives on drama, music theatre, dance, puppet theatre and performance art' (Christopher Balme, Cambridge Introduction to Theatre Studies [Cambridge: Cambridge University Press, 2008], xii).

3 For an emblematic example, see Erika Fischer-Lichte, Theaterwissenschaft (Tübingen, Basel: A. Franke Verlag, 2010), 248.

4 Willmar Sauter, 'Approaching the Theatrical Event: The Influence of Semiotics and Hermeneutics on European Theatre Studies', Theatre Research International 22.I, supplementary issue (I997), 4-I3, esp. II. See also Jacqueline Martin's and William Sauter's definition of 'communicative theatrical event': 'We define communicative theatrical event as the relation between presentation and perception. Theatrical presentation describes the world of the stage, both in its real sense and its signification of a fictional world. Theatrical perception presupposes a spectator to be present and reacting emotionally and intellectually to the presentation' (Jacqueline Martin and William Sauter, Understanding Theatre: Performance Analysis in Theory and Practice [Stockholm: Almqvist \& Wiksel International, I995], ro).

5 On the role that the 'Gesellschaft der Freunde und Förderer des theaterwissenschaftlichen Instituts an der Universität Berlin', the 'Gesellschaft für Theatergeschichte, E.V'. and the 'Vereinigung künstlerischer Bühnenvorstände, E.V. played for the new-born theater department in Berlin, see Bruno Satori-Neumann (ed.), Theaterwissenschaftliche Blätter. Fachorgan für die Wissenschaft, Kunst, Technik und Kultur des Theaters (Besano-Verlagsgesellschaft m. b. H., Berlin, I5. März I925 - Heft Nr. I), 4. In Munich, consider the connection between 'Neuer Verein' and the topics of Kutscher's seminars.

6 On the development of theater departments in Germany, Austria and Switzerland, see Helmar Klier, 'Theaterwissenschaft und Universität', in Klier (ed.), Theaterwissenschaft im deutschsprachigen Raum (Darmstadt: Wissenschaftliche Buchgesellschaft, I98I), 327343 .

7 Satori-Neumann, Theaterwissenschaftliche Blätter, 5.

8 In the introduction to his Forschungen zur deutschen Theatergeschichte des Mittelalters und der Renaissance (Berlin: Weidmann, I9I4), Herrmann states clearly that the tools to investigate the materials connected to a particular form of theater and to re-create its whole structure are the ones used by historical and philological criticism.

9 See Stefan Corssen, Max Herrmann und die Anfünge der Theaterwissenschaft (Tübingen: Niemeyer, 1998), for an insightful analysis of Max Herrmann's approach to theater studies.

ıo Max Herrmann, 'Über die Aufgaben eines theaterwissenschaftlichen Institutes' (transcription of Herrmann's lecture held on June 27, 1920), Theaterwissenschaft im deutschsprachigen Raum (198I), I8. All translations in this article are my own, unless otherwise stated.

I I A quick look at the scientific publications from the so-called 'Herrmann's school' should be enough to exclude any direct interest in contemporary theatrical forms or in cultural performances. See Satori-Neumann, Theaterwissenschaftliche Blätter (Zum I4. Mai 1925 - Heft Nr. 5), 72-84.

Artur Kutscher, Die Elemente des Theaters (Düsseldorf: Pflugschar Verlag, 1932), 8.

'The character of mime distinguishes any dramatic art from literature', Ibid., I I 8. 
I4 Kutscher, Stilkunde des Theaters (Düsseldorf: Pflugschar Verlag, I936), I94-I95.

"The incompatibility of methods and the risk of confusing them are clear. By no means can theater studies be reduced to the field of German philology', Ibid., I 98.

I6 Carl Niessen developed this idea even further and regarded theater studies as a branch of cultural history.

Marco De Marinis, Capire il teatro. Lineamenti di una nuova teatrologia (Firenze: La Casa Usher, I988), 8.

I8 See Corssen, Max Herrmann, I62.

I9 Pavis, 'Preface', I68.

20 Janelle Reinelt and Joseph R. Roach (eds.), Critical Theory and Performance (Ann Arbor: University of Michigan Press, I992), 293-294.

2 I Richard Schechner,'Approaches to Theory/Criticism' (I966). Here quoted from Essays on Performance Theory (New York: Drama Book, 1977), 27-28.

22 Keir Elam, The Semiotics of Theatre and Drama (London/New York: Methuen, I980), I.

23 De Marinis, Capire il teatro, Io.

24 Bert O. States, 'Performance as Metaphor', Theatre Journal 48.I (I996), I-26, esp. 20. This position on the importance of clear definitions is not univocally supported among phenomenological scholars. See, for instance, Wilshire's manifold attempts to define theater art in Bruce Wilshire, Role Playing and Identity: The Limits of Theatre as Metaphor (Bloomington: Indiana University Press, I982).

25 Schechner, 'Approaches to Theory/Criticism', 6.

26 Ibid., 30.

27 Simon Shepherd and Mick Wallis. Drama/Theatre/Performance (London/New York: Routledge, 2004), I52.

28 Phillip B. Zarrilli, 'For Whom Is the King a King? Issues of Intercultural Production, Perception, and Reception in a Kathakali King Lear', in Reinelt and Roach (eds.), Critical Theory and Performance, I6-40, esp. I6.

29 In the essay 'Selective Inattention' (1976), Schechner drew upon Victor Turner's model of the 'social drama' sketched in Schism and Continuity, 2nd ed. (New York: PAJ Publications, 1992). The two had also cooperated on a workshop with The Performance Group, exploring the same relationship.

30 Jon McKenzie, 'Performance and Global Transference', The Drama Review 45.3 (2001), 6.

3 I Ibid., 7.

32 Jill Dolan, Geographies of Learning: Theory and Practice, Activism and Performance (Middletown, CT: Wesleyan University Press, 2000), 67.

33 Marvin Carlson, 'Introduction: Perspectives on Performance: Germany and America', in Erika Fischer-Lichte, The Transformative Power of Performance: A New Aesthetics (London and New York: Routledge, 2008), I-Io.

34 Erika Fischer-Lichte,'The Theatre Journal Auto//Archive: Erika Fischer-Lichte', Theatre Journal 57.3 (2005), 567.

35 J. McKenzie, 'Is Performance Studies Imperialist?', The Drama Review 50.4 (2006), 5- 8, esp. 6.

36 Fischer-Lichte, 'From Text to Performance: The Rise of Theatre Studies as an Academic Discipline in Germany', Theatre Research International 24.2 (I999), I68-I78, esp. I73.

Fischer-Lichte, Theaterwissenschaft, 243.

38 Carlson, 'Introduction', 4. 
39 It must be noticed here that the only Performance Studies International conference held in Europe was at Mainz University in March 200I. On that occasion the "Zentrum für Performance Studien' in Germany was founded; the European-leading role of Germany in the field of performance studies has therefore been institutionalized.

40 De Marinis, Capire il teatro, 9.

4I Andreas Kotte, Theaterwissenschaft: eine Einführung, 2nd rev. ed. (Köln: Böhlau, 20I2), 3 I 3 . 

VI

Art History

And Archeology
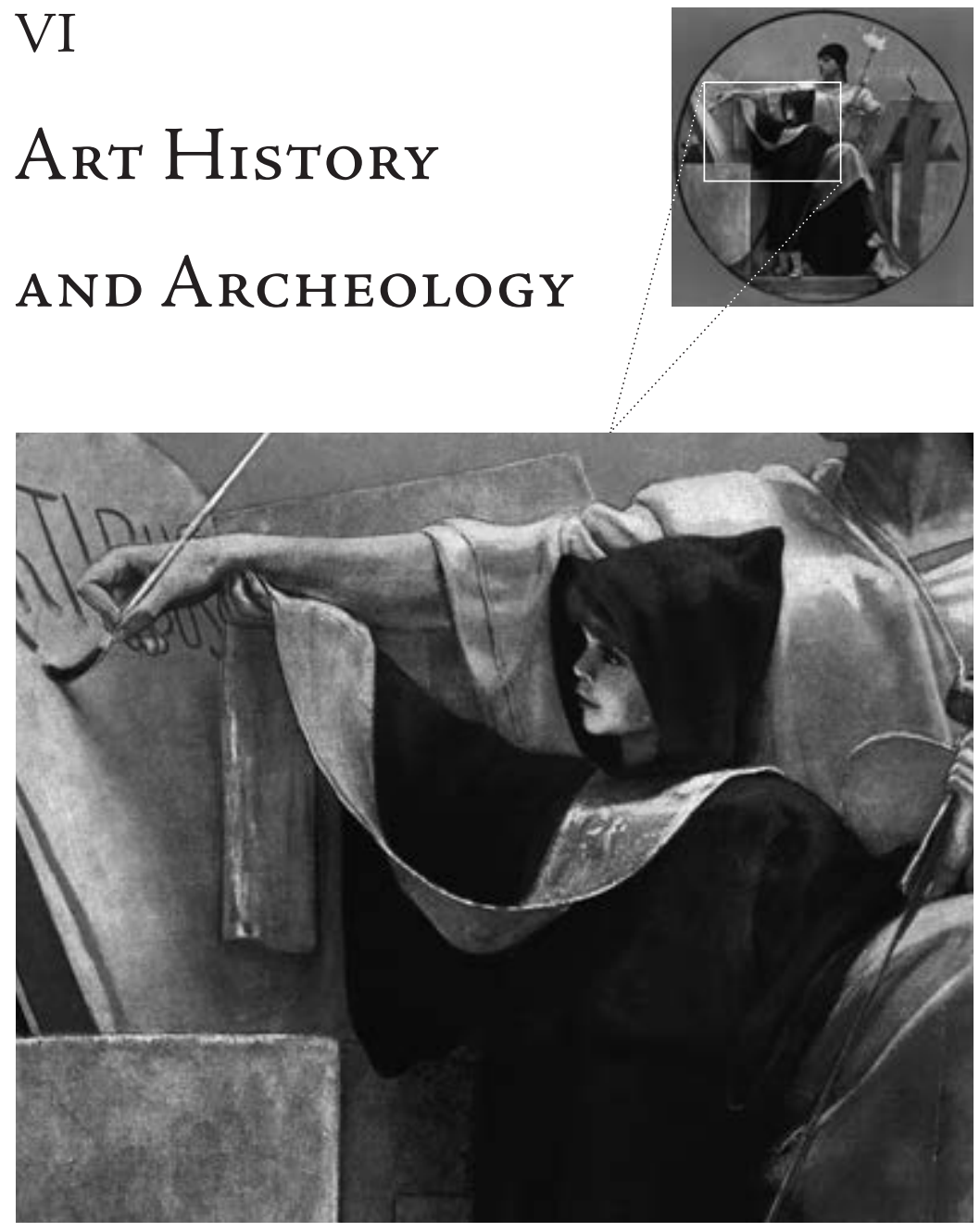



\title{
6.I Embracing World Art \\ Art History's Universal History and the Making of Image Studies
}

\author{
Birgit Mersmann
}

Within the realm of modernizing the humanities, the aspiration of art history to transform into a universal discipline and modern science manifests itself as a cultural, anthropological, and spatial orientation toward world art and universal history. The ground for this modern shift was prepared by the universalization of art as based on the concept of mutual cultural influences and historical transfers. At the turn from the nineteenth to the twentieth century, art history joined forces with subbranches of history such as universal history and cultural history. Through these interdisciplinary linkages, it also opened to a new self-definition and revaluation as image history.

The primary objective of this paper is to closely examine how cross-disciplinary fertilizations between universal history (or world history), cultural history, and art history have resulted in a reconceptualization of art history, its study objects, methodology, and geographical framing. For this purpose, it will focus on three areas of reconfiguration, as they manifested themselves in the German and partly Austrian debate on the notion of universal history: (I) the new definition of art history as universal history and world history performed in the scholarly work of the art historians Alois Riegl and Oskar Beyer, (2) the redefinition of universal history as cultural history, as proposed by the historian Karl Lamprecht, and (3) the reconceptualization of art history as a cultural history of images, that was implemented by the art historian Aby Warburg.

\section{Art history and universal historyः New linkages}

Historically, the Austrian art historian Alois Riegl opened the debate on art history as universal history. He formulated a critique of the academic discipline of art history which, in its essential features, anticipated Oskar Beyer's critical diagnosis of art history's inappropriate philological constitution and West-cen- 
teredness made twenty-five years later. In Kunstgeschichte und Universalgeschichte (1898), Riegl turned against the critical-historical method, the pedantry of source study and the hyperspecialization practiced by most contemporary art historians. At the same time, he asserted to recognize an ongoing change in the field of art history, characterized by a move from art history as connoisseurship (Kunstgelebrtentum) to a full-fledged science. This scientific transformation is acknowledged as a process of modernization. Riegl observes a displacement of what he calls an 'individual history or art' (Individualgeschichte der Kunst) by a reawakening interest in a universal history of art:

The tendency of specialized history of the past 30 to 40 years appears to be replaced by a new universal trend. The researchers of preceding generations have comprehended each art-historical manifestation as an individual one which, produced by particular causes, expressed only very peculiar effects. [...] The most advanced 'modernists' among art historians [...] stress the fact that art-historical manifestations are not only separated by individual features, but also connected by common characteristics. ${ }^{\mathrm{I}}$

The intention behind the universal extension of art is a bringing together of temporally and spatially distant art periods for comparison. In order to better understand the new linkages between art history and universal history, a closer historical look at the cultural reinterpretation of universal history has to be taken.

\section{Universal history as cultural history:} A new concept and methodology of historical research

The redefinition of universal history as cultural history was integral part of the so-called 'method dispute' (Methodenstreit) in the historical sciences at the end of the nineteenth century. This is reflected in two influential methods-centered studies on universal and cultural history by Karl Lamprecht: (I) Die kulturhistorische Methode (Berlin, I900); (2) Zur universalgeschichtlichen Methodenbildung (Leipzig, 1909).

Until the turn from the nineteenth to the twentieth century, 'world' history and 'universal' history were almost interchangeable concepts. The purpose of assessing world history was to recognize the universal elements in the history of humankind. In the course of the method dispute, it became clear that the controversy was mostly sparked by determining the universal component (or components) in the concept of world history. The most articulated confrontation line ran between (a) universality in world history as political history, and (b) univer- 
sality in world history as cultural history. Whereas in the first category of worldhistorical search for universal patterns that give meaning to all of human history, peoples 'without culture' were excluded as study objects due to their a-historicity, in the second search category the prehistory of man as well as the cultures of early civilizations were included. This also meant that culture-oriented world historians welcomed the usage of visual artifacts as prehistorical sources.

Among the most prominent proponents of the first universalistic fraction of world historians, one finds the German historian Leopold von Ranke. His World History (Weltgeschichte) in nine volumes (I88I-1986) presented human history as a civilizational history of progression and higher development from Egypt via the Middle East, Greece and Rome into the Germanic Middle Ages, culminating in the Christian nation-states of modern Europe. This Rankean tradition and orientation of writing world history was carried on by his pupil Theodor Lindner. In his Weltgeschichte seit der Völkerwanderung (9 volumes, 1906-1916), non-Western peoples were part of the historical account, but they only served to highlight the superiority and universality of Western culture. The main argument for this assertion was that the most human culture is the most universal: 'West European culture, the crowning of Indo-European culture, strikes us as the most human.'

The foundation of universal history as world history of culture took off with Kurt Breysig's history of humanity (Die Geschichte der Menschbeit: Die Völker ewiger Urzeit. Die Amerikaner des Westens und des Nordens [1907]). New about this record of world history was the explicit interest in problems of ethnology as linked with the issue of universality. Breysig had a clear institutional vision for implementing his world-historical research agenda. He attempted to establish an interdisciplinary institute for comparative historical research at the Humboldt University in Berlin, but he failed due to the resistance from respected historians active in the university's historical department. It was only Karl Lamprecht who, following Breysig's path and vision, finally succeeded in establishing an interdisciplinary historical 'Institute for Cultural and Universal History' (Institut für Kultur- und Universalgeschichte) at the University of Leipzig in 1909, which was officially supported by the King of Saxony. The institute still exists today, although it was renamed as the 'Global and European Studies Institute' (GESI), thus evidencing its far-reaching mission of modernizing and at the same time globalizing historical studies. ${ }^{3}$

Regarding these changes and subdisciplinary differentiations in the emerging field of universal history, the crucial methodological question to be addressed is: What were the cultural and art-historical implications of Karl Lamprecht's universal-historical method? Most effectively, Lamprecht actuated a cultural paradigm shift in the historical sciences and its methods. This one is instigated by a 
critique of how contemporary universal history is pursued methodologically. The fundamental criticism is mainly directed against the philosophy of history, following the deductive method in its application to a metaphysical concept of history, and the particular history, following the inductive, historical-critical method of source criticism. For Lamprecht, the new methodological challenge for historical studies lay in embedding the universal-historical method into a broader framework of cultural history.

Universal history was considered to be a process of renaissances and receptions. Because these movements are cultural-historical phenomena, the core of universal history was defined by cultural history. The formation of universal history presupposes a 'double' comparative approach in order to transgress the fragmentation of isolated history writings. It should involve two phases of comparative studies: (I) a comparison of the historical development of particular subfields of history (political history, constitutional history, economic history, social history, religious history, art history) across different nations, ideally all of them, and (2) an international, cross-cultural comparison of national histories, their overall developments.

Departing from the subfields of historical development, Lamprecht comes to the conclusion that intellectual and mental history in contrast to material history aspires most closely to world-historical significance, and that, among it, art history entails the highest potential of universality, as its products (that is, artifacts) are reflections of the cognitive and mental capacity of imagination (Phantasietätigkeit). For this reason, he recommends art history - in particular, the examination of plastic and graphic arts - as a primary field of study for establishing a universal history. The main argument for art's universality is twofold in Lamprecht. Firstly, he stresses the production side by reasoning that human artistic creativity is a universal phenomenon. All peoples on earth have created artifacts, thereby providing evidence that the human as image maker is an anthropological constant throughout history and beyond historical writing. Secondly, his argument draws upon the reception side. Scientists have universal access to visually shaped and crafted material worldwide. Given the option of direct contact and experience, they can study these object as unmediated forms of cultural representation and historical tradition. These two aspects of art's universality imply the visual interpretation of cultural history, thus launching two types of visual studies: (I) visual history as historical study of visual monuments, and (2) visual (culture) studies as the study of activities and forms of visualization. Both branches offer a combination of studies in material and mental culture, as emphasized by Lamprecht.

But where to start from, when applying the universal-historical method to art history? In the vein of Lamprecht's approach, the main point of departure for studying visual imagination in the field of artistic creation was the ornament. The 
first contribution to a universal art history of ornamental style, using Lamprecht's newly introduced universal-historical method, was a dissertation by Werner von Hörschelmann on the development of ancient Chinese ornament (Die Entwicklung der alt-chinesischen Ornamentik [Leipzig, 1907]) submitted at the Institute of Cultural and Universal History in Leipzig. That Chinese art history with its long-standing tradition became the first case study for proving universal art history gives a clear indication that a new world horizon of art was about to form at the beginning of the twentieth century.

\section{Cultural history of images: The emergence of image studies in the work of Aby Warburg}

The tremendous impact of Lamprecht's model of universal cultural history on the reconceptualization of the discipline of art history in the German-speaking countries is most pronouncedly reflected in the work of Aby Warburg, although this influence has never been studied to the full extent of its significance. ${ }^{4}$ As Aby Warburg studied cultural history with Karl Lamprecht at the University of Bonn as one important component of his studies in art history, history, and archeology, a direct link of influence is obviously given. Foremost, it was Lamprecht's universalhistorical method that gained influence in the field of art history and contributed to reshape its methodology. The change in art history's methodology is a repercussion of the historical method dispute fiercely led in the historical sciences in the i89os. The methods controversy was carried out between Leopold von Ranke as proponent of the descriptive historical method and Karl Lamprecht as advocate of a new genetic approach to historical studies. Warburg's introduction of iconology as a new cultural-scientific method of art history that transcends the motif- and content-based analysis of iconography adheres to the concept of Lamprecht's universal cultural history. Ascending to the 'Warburg method' in art history's reception, it had a big impact on the redefinition of art history as universal cultural history.

One of the most effective [methods and schools of art history] (and one of the few to have been somewhat self-analytical) is iconology - or the Warburg method, after its promulgator. [...] This method in simple essence is to study the work of art as a carrier of the interests of its culture and its social myths. ${ }^{5}$

In proposing iconology as a new art-historical method, new emphasis was put on studying art works as activities of the human mind (and soul) and transmitters of culture and society. 
The strong influence of Lamprecht's universal-historical method formation on Warburg is also reflected in the interdisciplinary modeling of Warburg's Kulturwissenschaftliche Bibliothek (Library for the Study of Culture) after the agenda of the Leipzig Institute for Cultural and Universal History. Warburg himself had defined his Kulturwissenschaftliche Bibliothek as the 'Institut für methodologische Grenzüberschreitung' (Institute for the Crossing of Methodological Frontiers). The crossing of methodological frontiers, implemented by a new library system of ordering scientific books according to the interdisciplinary principle of 'good neighborship', intended a traversing of usually separated disciplinary frameworks and methodologies, including the interlacing of scientifically segregated historical epochs from antiquity to modernity. Warburg's interdisciplinary relocation of the field of art history aimed at the widening of the art horizon in time and space. He strove for its embedding into cultural history, universal history, and image history. In line with Lamprecht's assumption that the course of universal history is constituted by processes of renaissances and receptions as dominant cultural-historical manifestations and thus coincides with cultural history, ${ }^{6} \mathrm{War}$ burg redefined art history as cultural history, therein including the formation of cultural memory through the transmission of images. Cultural history of art thus aspires to build an organum of remembrance of 'images past'. At this point of the Warburgian mental, psychic and cognitive refunctionalization of art history, image history joins forces with cultural history.

The particular concern about the psychological dimension of art and culture as well as the 'modern' idea of culture as a whole way of life is nurtured by Lamprecht's psychologization of historical studies. Lamprecht distinguished between two concepts of history: (a) an individual-psychological understanding of history, in his view identical with traditional political historiography, and (b) a socio-psychological understanding of history congruent with cultural history. Accordingly, cultural history is interpreted as history of human socialization. For Lamprecht, the socio-psychological or cultural factor is the actual causal factor of historical development. It becomes visible as diapason, the overall habitus of an epoch or era, accumulatively formed by the transmission of cultural conditions cast into traditions. ${ }^{7}$ Cultural development follows the law of the 'historical resultant', a principle Lamprecht adopts from Wilhelm Wundt. ${ }^{8}$ The appropriation of the cultural past does not only take shape as an addition of individual factors, but as a processing of a socio-psychological or cultural overage or surplus, resulting in the advancement of culture and a reshaping of the diapason of a society:

$[\mathrm{R}]$ egarding the organic unity of each socio-psychic life of a given time, the transformations are not restricted solely to the economic and social life, they rather affect the complete advanced intellectual life: as observed, it 
adapts the effects as quickly that, through spontaneous energy, it further develops them much faster than the development on the topsoil of the economic life and the societal stratification would allow. ${ }^{9}$

The universal element inherent in cultural history is constituted by a profound developing potency, reoccurring in all forms of human community buildings so that it naturally establishes a nexus between different cultural eras:

The most deepest and lowest causes can only be grasped as particular processes of the one developing potency, which manifests itself throughout the history of all large-scale human communities, [...] as movements of the specific potency of the human-social and finally also the human-individual soul, in as much as this one is inscribed into the general chronology and the particular development of its social environment. ${ }^{\text {IO }}$

The triangular modeling of the relation between art, culture, and the image in the work of Aby Warburg is strongly influenced by Lamprecht's thoughts on the universal-historical formation of culture, his acknowledgement of the human collective consciousness. This can be seen from Warburg's cultural-historical reconceptualization of the principal functions and meanings of art, culture, and the image as medial and symbolic transfer unit. Culture is defined as 'historical sum of all efforts made by man to overcome his fear." The artwork is comprehended as a pathetic representation of the dialectic between expressive energies of the past and rational orientations of the present. The image is understood as engram of culture and (re)collection of mnemonic energies. At the same time (and this does not stand in contradiction to its definition as 'pathos formula'), it is considered as a document of historical evidence. Warburg's concept of the historical 'survival' or 'afterlife of images', that is, particular visual forms of human expression which are transmitted throughout history via their motional potency, is closely connected to the idea of socio-psychological overflow, the surplus value of the historical resultant.

\section{The universalist concept of modern world art history}

In the European history of art-historical studies, the development of a modern world art history as based on the idea of universal history was most prominently conceptualized in German-speaking academia by the Dresden art historian Oskar Beyer in his book Welt-Kunst. Von einer Umwertung der Kunstgeschichte (Dresden 1923). Although the book has not been extremely influential at the time 
of its publication, it was recently rediscovered in the context of the revival of world art studies as one of the earliest conceptual attempts to transform classical Western art history into modern world art history. ${ }^{12}$ The transvaluation of art history (Umwertung der Kunstgeschichte) explicitly stated in the book title refers to the modernization of art history as academic discipline, its content, scope, and methodology. The essay's direction of impact is inspired by the French tradition of the 'Quérelles des Anciens et Modernes', virulent at the turn from the seventeenth to the eighteenth century. By transposing the controversy into the new modern era at the turn from the nineteenth to the twentieth century, it formulates a criticism of the old, classical model of art history, its concepts and methods, and suggests a new modern art history in the shape of world art history.

The crucial elements claimed by Beyer in Welt-Kunst for modernizing art history are contemporaneity and dehistorization. Both factors are coupled, as the relevance of the present and its significance for the future implies a devaluation of the past: 'The new research will no longer deal with the past of art, with art "history", but [... ] ultimately always with art contemporaneities. ${ }^{13}$ The devaluation of the historical dimension is tantamount to the dephilologization of art history:

For this reason, we may reckon that the study of art [Kunstwissenschaft] will increasingly lose its historical character, as the aspect of history turns out to be unsignificant with regard to the numerous new works flooding in; the historical interest shall only be an auxiliary agent, because in principle it has nothing to do with the spirit of art..$^{14}$

Parallel to the devalorization of the historicizing component, a revalorization of space takes shape. This spatial turn is to be understood as a process of de-and reterritorialization of art history, the geographical extension of European/Western art history to world art history:

We may expect that the history of art will transform into a comparative research on style $[\ldots]$. Its function would be to help understand the individual domains of style of the world art arena [Weltkunstkreis] from within themselves, their spiritual form, to characterize them in the most intense plasticity, and to extend all of them onto one and the same plane of knowledge so that they can be surveyed as on a topographical map: Where do things belonging together exist, where do historical lines of connection run, where to find typical parallel phenomena, and where those elements that are incompatible by essence? ${ }^{\text {I5 }}$ 
This geospatial shift in the perspectivization of art history is paired with a new interest in visual art as material culture and, as a consequence, a reorientation toward a focus on objects as opposed to the fixation on the artist as ingenious originator. The revaluation of the art object itself and its critical reflection, supported by the argument of unmediated access and the advantage of a direct visual-perceptual experience, effectuates a move away from art philology, as rooted in the art-historiographical tradition of Vasari's Lives of the Artists (Le vite), toward art philosophy as a new self-reflective approach to the study of art. In the same line and in coalition with the advancement of the natural sciences, art history argues for a comprehensive scientification of its discipline, including its methodological framework. As a result, art history is redefined in Beyer's world art project either as kunsthistorische Wissenschaft (art-historical science) or even Kunstwissenschaft (art science), thereby signaling that the long-standing burden of history or historiography is thrown overboard and that art history can no longer be confined to the role of an 'auxiliary agent' for the historical sciences.

The endeavor of scientifically modernizing the classical discipline of art history is acted out by means of a harsh criticism toward the existing tradition of art history and its scholars. The whole first chapter of Beyer's book on Welt-Kunst stands under the agenda of 'unmasking' (Entlarvung). It reveals the state-of-the arts conditionality of art history as single-sided and inadequate. The main point of critique refers to the so-called 'historical dogma', the idea of a continuous progress and higher development of art (creation), culminating in the appraisal of peak stages. Contrary to this teleological, progress-oriented historical dogma, Beyer pronounces himself for a revaluation of early stages of art design, articulating interest in stylistic transformations as a reflection of changing needs of expression in a particular culture and society. By doing so, he advocates a more pronounced cultural approach to art history, moving from what he calls a 'conviction of art' (Kunstüberzeugung) to a 'conviction of culture' (Kulturüberzeugung). ${ }^{16}$ In addition to the criticism of the historical dogma, Beyer pounces on the 'antique dogma' as the basis of classical art history. The idea of art as representational form, as imitation of nature, is refused because of its extreme limitation.

The same critique of constriction is also applied to the individualistic and biographistic approach of classical art history, the celebration of technical virtuosity ruled by the principle of 'art for art's sake'. The reproach is that art is valued as the individual product of a unique and creative personality, but not as a product of community, including a particular culture. According to Beyer, the attention of new world art studies should be directed toward the 'communitarian work of art' (Werk der Gemeinschaft), and not any more to the 'artwork of individualistic isolation' (Werk der Vereinzelung). Consequently, folk art and popular art are 
strongly upvalued; they take center stage as agents and determinants of universal art history. In the same string of argumentation, universal history is conceived of as a counter model to individual history, the latter being equated with the exceptional, particular status of Western art and art history. It is exactly the idea of an individual history of art, for centuries dominant in the Western hemisphere of the art world, that has to be overcome in order to open the way to the constitution of a universal history of art.

Bundling all of these points for change, foremost the geospatial and sociocultural turn, it becomes clear that Beyer's critique of what is usually designated as classical art history points to the limitations of the European/Western concept of art and art history. It is the confrontation with the new world horizon of art that pushes classical European art history beyond its long-standing conceptual and methodological boundaries. The inclusion of the new world horizon anticipates art history in a global perspective. The reorientation of art history follows the trends and transformations in historical research prevailing in those days, namely the study of world history as universal history. Accordingly, art history is located between world art history and universal art history. The primary goal of Beyer's transvaluation of art history is the extension of its geographical scope. Art history must transcend its regional boundaries and cultural-historical bonds, thus opening spaces for its transition to world art history.

When assessing the limits of art-historical research of his time and former periods, Beyer comes to the conclusion that art history mostly suffers from a strong nationalism. He criticizes the national art historiography in Europe, its reduction to German and Italian art, and, as a countermove, calls for a truly European art history. New research emphasis is put on both, the internationalization and regionalization of art and art history. At the same time, so-called European or Western art history is considered to be exceptional, that is solely representative for the particular, but not for the universal. By aiming at the new horizon of world art and art history, Beyer also practices a strategy of provincializing European art history. Western art history in its disposition of the early twentieth century is not (or in the logic of his argumentation: not yet) universal, or universally applicable, although it claims the universality of its modern condition. The global modernization of art history, as pursued by Beyer, thus resonates with the questioning of the Western concept of art and art history, its 'universalist' consensus.

The universal dimension of art history can only lie in the universal perspective of a world horizon of art. The narrow-mindedness of the 'old' traditional art-historical perspective shall be superseded by an open-minded wide-angle perspective of a new future-oriented art history with a high viewpoint that allows to make the 'vastness of world art manifestations' visible. In this sense, world art history enacts a shift from a micro-historical to a macro-structural perspective. 
In principle, Beyer follows Lamprecht's approach of universal history as culture-comparative history. According to this position, the universal in art coincides with the spiritual (form) in art. It can only be grasped by means of a comparative research on style. One of the consequences of this universal, spiritual turn is that art history is remodeled, even upgraded, into a truly 'spiritual' science (Geisteswissenschaft). The scientification of art history, in particular its spiritualization, takes shape under the growing influence of the natural sciences:

As a recently created university discipline, the study of art history had to demonstrate its 'scientific' dimension in comparison with other human sciences - and it had to fulfill the requirements of a 'science', primarily expressed as holistic explanatory models and laws [...]. Simultaneously, art history had to secure an independent profile in order to contrast itself to the discipline of history, which had provided the most important methodological model of the positivist Kunstgeschichte in the tradition of Rumohr. [...] Probably the most decisive attempt to solve this dilemma on the part of Kunstwissenschaft involved an orientation towards the natural sciences, initially based on their classification systems. ${ }^{17}$

The transformation from Kunstgeschichte to Kunstwissenschaft signifies a switch from a historical (auxiliary) science to a full-fledged science of mind, a Geisteswissenschaft in the Wundtian sense wherein the spiritual component is prevalent. Parallel to this reorientation, Beyer envisages a new type of art historian, the so-called Kunstdenker (art thinker), who stands in for the change of mind, the scientific advancement of art history from an art-historical philology to a proper art philosophy, qualified for higher knowledge. The remodeling of art history into a genuine Geisteswissenschaft, a philosophical science of art, is oriented toward the integration of the human sciences. It aims at understanding the human mind by looking at worldwide human artistic creativity, its forms and structures of expression, and by defining art forms and styles as 'living forms' of cultural and societal life. Because the creation of art is reacknowledged as a human capacity and social phenomenon, it calls for a transdisciplinary brotherhood of researchers. Here, the preference of universal/world art history for the study of collective art (Gemeinschaftskunst) is transferred to the idea of an international community of art researchers contributing to the formation of a universal history of world art. From the viewpoint of Beyer, this transformation of art history into a spiritual human and social science is already on its way. The transvaluation of European/Western art from representational art (Darstellungskunst) to expressive art (Ausdruckskunst) under the influence of world art/non-Western art is understood as a clear signal that the reorientation of classical art history toward world art history has begun. 


\section{Modern global humanities and the making of image studies}

The shift in historical studies toward universal history had a lasting effect on the redefinition of art history as modern science. The cultural-scientific approach, including psychophysical and anthropological elements, to the study of art revealed the image as a new and autonomous category of investigation. This held true for both of the here discussed reform projects of art history, the ones by Beyer and Warburg, although they undoubtedly differ largely in their incentive and design. In postulating world art history, Beyer relied on artistic expression as human activity. He set the agenda for a universal history and theory of creative imaging, focusing on the interrelations between conceptions of the world and image concepts, in short: between world pictures and pictorial worlds. One central drawback inherent to this universalistic conceptualization of world art history is that it does not allow thinking beyond the category of style. Universal art history is - also in terms of methodology - restricted to a comparative analysis of style; hence, it cannot reach the status of a genuine image history or even image science. Moreover, it adheres to the modern idea of the universal as spiritual, coming dangerously close to the folkish, nationalistic ideology of the given period.

Also Warburg is in search of the universal image of mankind and humanity that transcends the individual work of art. This is why he develops interest in the return of the image, the renaissance or survival of the image. By definition, the universal image is both at once, an image of remembrance and an image of expression, an internalized and externalized, mental and physical image. Because of the new valorization of the mediating qualities of images, their emotional and translational potency, Warburg took a pioneering role in not only transforming art history into image and media history, ${ }^{18}$ but also reshaping it as universal art history.

Certain parallels in reorientation between the making of the modern science of art history around 1900 and the attempts of making art history into a global discipline around 2000 can be detected. These manifest themselves in two different shapes: firstly as transposition from world art history to world art studies $^{19}$ and from Western art history to global art histor $y^{20}$ and secondly as a move from art history to image studies (Bildwissenschaften) and visual culture studies. Although the impact direction and main interest in transcending the historical, cultural, and methodological limitations of Western art history and plunging into the exploration of visual creativity and visual imagery appear to resemble each other with regard to the science-led renewal of art history during the time periods of around 1900 and 2000 , the goals, conceptions, and implications of modern world art history strongly differ from those of contemporary global art history. Whereas the hegemony of Western modernism with its universal ideology still 
prevails in world art history, global art history endeavors to deconstruct it by revealing the alter-modernities of a purported postmodern and postcolonial era. This is one of the reasons why the art historian Hans Belting has strictly warned against identifying world art history with global art history:

World Art History cannot serve as a synonym [for Global Art History], as it is a history of world art and as such presents even a double problem: on the one hand the notion of world art, as an art concept with a questionable universalism, and on the other hand the notion of history that implies the even more questionable assumption that world art, in its utter diversity, allows for a common history in terms of art history. ${ }^{21}$

In particular the last sentence constitutes a direct link to the here discussed attempts at creating a universal art history. Drawing on the pitfall of the universal, Belting views globalism as

almost an antithesis to universalism because it decentralizes a unified and uni-directional world view and allows for 'multiple modernities'. [...] This also means that in the arts, the notion 'modern' becomes a historical definition and accordingly loses the authority of a universal model ${ }_{+}^{22}$

A full critical assessment of what these differences mean for the concatenation between modern and global studies of art history is strongly required, but it lies beyond the purpose of this paper. The arguments brought forward here intended to suggest that the early-twentieth-century German projects to make art history into a purportedly 'modern' science present an important historical foundation, but also a critical lesson for future attempts at methodologically and theoretically reconceptualizing art history in the contemporary global context.

\section{Notes}

I Alois Riegl, 'Kunstgeschichte und Universalgeschichte', in Festgaben zu Ehren May Büdingers von seinen Freunden und Schülern (Innsbruck, I898), 454. English translation by the author.

2 Cf. after Roger Chickering, Karl Lamprecht: A German Academic Life (1856-1915) (Atlantic Highlands, NJ: Humanities Press, I993), 336.

3 For detailed information about the history of the Leipzig Institute for Cultural and Universal History from its foundation up to the present, see Matthias Middell, Weltgeschichtsschreibung im Zeitalter der Verfachlichung und Professionalisierung. Das Leipziger Institut für Kultur- und Universalgeschichte 1890-1990, Von der Vergleichenden Kulturgeschichte zur Revolutionskomparatistik, Bd. I: Das Institut unter der Leitung von Karl Lamprecht 
(Leipzig: Akademieverlag, 2005). For the successor institution, that is, the Global and European Studies Institute at Leipzig, see URL: http://www.uni-leipzig.de/ gesi/home/.

4 An exception to this is Kathryn Brush, 'Aby Warburg and the Cultural Historian Karl Lamprecht', in Richard Woodfield (ed.), Art History as Cultural History: Warburg's Projects (Amsterdam: G + B Arts International, 2001), 65-92.

5 Panofsky quoted in Creighton Gilbert (ed.), Renaissance Art (New York: Harper, I970), XVI.

6 Karl Lamprecht, Zur universalgeschichtlichen Methodenbildung (Leipzig: Teubner, 1909), 634 .

7 The term 'diapason' is introduced by Karl Lamprecht in ibid., 'Was ist Kulturgeschichte? Beitrag zu einer empirischen Historik', in Herbert Schönebaum (ed.), Karl Lamprecht. Ausgewäblte Schriften zur Wirtschafts- und Kulturgeschichte und zur Theorie der Geschichtswissenschaft (Aalen: Scientia, I974), 309. It means a general sociopsychical disposition of human culture and society as causal factor of historical development and is also referred to as 'Gesamtwille, Gesamtgefühl, ein Gesamtkomplex von Vorstellungen und Begriffen' (ibid., 264), which unifies the material and spiritual culture of an epoch to one organic whole. Based on the idea of diapason, Lamprecht conceives of historical change and development as intensification of the sociopsychical life. This is expressed in his periodization theory of five historical cultural epochs: symbolism, typism, conventionalism, individualism, and subjectivism.

8 The law of the historical resultant has been developed by Wilhelm Wundt in his Logik. Eine Untersuchung der Prinzipien der Erkenntnis und der Methoden wissenschaftlicher Forschung, Vol. 3, Logik der Geisteswissenschaften (Stuttgart: Ferdinand Enke, 1908), where he discusses the logic and the principles of the historical sciences (see in particular Section 2: 400-442). Embedded into his overall psychophysiological empirical approach to the humanities, it is related to the formation of psychological cognitive processes in a long-term historical perspective. Each psychic and mental activity from intuition over conceptions to complex decisions and powerful actions contains a surplus value with respect to its constituting elements. As the 'resultant' entails a qualitative growth, it has also been defined by Wundt as 'creative resultant'. In his treatise 'Was ist Kulturgeschichte?' Lamprecht draws upon the psychological science model of Wundt as proposed in Logik, arguing that psychology as 'exact science of the laws of spiritual life' (Lamprecht, Was ist Kulturgeschichte?, 272) would be the 'foundation of all historical sciences' (Ibid., 259). By adopting the principle of the historical resultant from Wundt, he attempts to explain the qualitative higher development of human culture, society, economy, and science which, in a feedback loop, induces the cultural-historical universalization of mental and cognitive operations.

9 Karl Lamprecht, Deutsche Geschichte, Ergänzungsband zur jüngsten deutschen Vergangenheit, Bd. 2.I Wirtschaftsleben, soziale Entwicklung (Berlin: Gaernter, I9I2), 472. English translation by the author.

Io Karl Lamprecht, Moderne Geschichtswissenschaft. Fünf Vorträge von Karl Lamprecht (Berlin: Weimannsche Buchhandlung, I909), I7. English translation by the author.

I I Cf. after Jan Assmann, 'Collective Memory and Cultural Identity', New German Critique 65 (I995), I30.

I2 See Susanne Leeb, 'Weltkunstgeschichte und Universalismusbegriffe: I900/2010', Kritische Berichte (2012), I3-25, and Ulrich Pfisterer, 'Origins and Principles of World Art History - I900 (and 2000)', in Kitty Zijlmans and Wilfried van Damme (eds.), World Art Studies: Exploring Concepts and Approaches (Amsterdam: Valiz, 2008), 69-85. 
I3 Oskar Beyer, Welt-Kunst. Von der Umwertung der Kunstgeschichte (Dresden, SibyllenVerlag, I923), I93.

I4 Ibid., 65.

I5 Ibid.

I6 Ibid., 28.

I7 Pfisterer, 'Origins and Principles of World Art History', 7 I-72.

I8 Compare Thomas Hensel's book Wie aus der Kunstgeschichte eine Bildwissenschaft wurde. Aby Warburgs Graphien (Berlin: Akademie Verlag, 20II).

I9 For a new contemporary conceptualization of world art studies as transdisciplinary undertaking involving anthropological, psychological, evolutionary, creative, and neuroscientific studies, see Kitty Zijlmans and Wilfried van Damme (eds.), World Art Studies: Exploring Concepts and Approaches (Amsterdam: Valiz, 2008), in particular the first chapter 'Introducing World Art Studies' (23-6I).

20 For the contested discourse on global art history, see James Elkins (ed.), Is Art History Global? (New York, London: Routledge, 2007).

2I Hans Belting, 'Contemporary Art as Global Art: A Critical Estimate', in Hans Belting and Andrea Buddensieg (eds.), The Global Art World: Audiences, Markets, and Museums (Ostfildern: Hatje Cantz, 2009), 45.

22 Hans Belting, 'Contemporary Art and the Museum in the Global Age', in Peter Weibel and Andrea Buddensieg (eds.), Contemporary Art and the Museum: A Global Perspective (Ostfildern: Hatje Cantz, 2007), 22. 



\title{
6.2 Generic Classification and Habitual Subject Matter
}

\author{
Adi Efal
}

One of the operations included in philological inquiries is the restoration of etymologies, built up of linguistic units enduring through ages, languages, meanings, usages and contexts. ${ }^{2}$ The following essay attempts a possible deployment of an etymology of the lingual unit 'genre'. Our trail will be guided by two stations in the long and extended history of this etymon: First, the Aristotelian origins of the etymon 'genre' are reconsidered; second, attention is given to the presence of the same etymon in the vocabulary of modern art criticism. Working within a comparative framework, this essay tries to create a trail between literary artistic and philosophical discourses. In all three domains, 'genre' appears as a classificatory instrument, and it is as a classificatory instrument that genre is addressed here. In the second anthology of 'The Making of the Humanities', Mats Malm portrayed the chart of relations between literary genre theory, rhetorical motives and emotional figures, as well as demonstrated the affinities between literary genre theory and theory of painting. ${ }^{3}$ The present essay joins this trail and tries to ponder about the methodic tenor and relevancy of generic classification to the humanities.

\section{Genre: Critics and defenders}

Henri Bergson blamed generic classification for causing situations of imprecision: 'Imprecision is, usually, the inclusion of a thing in a genre too wide." This articulation takes part in the general critical attitude toward generic classification, a criticism launched throughout the twentieth century across the humanities. Numerous authors, many of them motivated by vitalist tendencies, such as Walter Benjamin, ${ }^{5}$ Erich Auerbach, ${ }^{6}$ Mikhail Bakhtin, ${ }^{7}$ Jean-François Lyotard ${ }^{8}$ and Jacques Derrida ${ }^{9}$ interrogated the complexities of generic classifications. Their interrogations entail several problems regarding the concept of genre: the generic 
method of classification is considered as too wide, too rigid, too hierarchic or too essentialist. In his Ursprung des Deutsches Trauerspiel, Benjamin, drawing his argument from Benedetto Croce's criticism of the schematic deduction of literary genres, preferred to promote the importance of the 'idea' of a work rather than sticking to generic systems of classifications, as

It is [...] precisely the more significant works, in as much as they are not the original, and so to speak, ideal embodiments of the genre, which fall outside the limits of genre. A major work will either establish the genre or abolish it, and the perfect work will do both. ${ }^{\text {I }}$

More recently, Derrida questioned the validity of the classical rigid dictum: 'genres are not to be mixed', a dictum demanding a strict separation between the genres. Derrida described the disciplinary rigidity forced by the generic regime thus:

As soon as the word 'genre' is sounded, as soon as it is heard, as soon as one attempts to conceive it, a limit is drawn. And when a limit is established, norms and interdictions are not far behind. 'Do', 'Do not' says 'genre', the word 'genre', the figure, the voice or the law of genre.

Thus, as soon as genre announces itself, one must respect a norm. One must not cross a line of demarcation, one must not risk impurity, anomaly or monstrosity. ${ }^{\text {II }}$

This deconstructive criticism expresses unease with the rigid differentiations that are enforced by generic classifications. Indeed, the organization of the humanist disciplines embodies generic rationality and its effective method of classification according to subject matters and themes, a classification according to "what is at stake', i.e., the subject matter of the inquiry. Twentieth-century critics of genre promoted mixing between genres, making the genres interpenetrate both within the disciplinary discourses and between them. Within the twentieth-century landscape of genre criticism, the moderate, favorable position of Gérard Genette stands as an exception. ${ }^{12}$ Both in his 'Introduction de l'architexte' and more so in his 'Des Genres et des OEuvres', Genette conceived of generic rationality as a challenge, and his poetics, in fact, involves elaborations of the conceptual and terminological potential of generic rationality. Genette notes: 'To the question, "Can one love a genre?", the proper answer may be this other question: "Can one really love anything else?"'13

The experiment in this present essay is to follow Genette's approach to generic rationality, and to defend the place of the concept of genre as a methodic in- 
strument in the humanities. This does not mean that the concept of 'genre' must retain all its traditional coordinates, yet it does mean that the broader concept of genre as it was furnished by Aristotle could still be used as an Archimedean point for enquiries within the humanities. The compact review of the trails of usage of the concept of genre that is suggested here supports the conclusion that something did change in the modern period in the application of the concept of genre, something which has to do with its original Aristotelian roots. That is to say: In modern times, i.e., from the eighteenth century onwards, a change occurred within the hierarchic structure of genres, leading to the situation in which the 'lower' genres have been gradually regarded as a primary reality from which subject matter is to be drawn. Therefore, in modern times genre has been not so much a system as a problem, a task, perhaps yet to be accomplished.

\section{Literary genres and their Aristotelian origins}

Though the origin of literary 'genre theory' is to be found in Aristotle's Poetics what was later to be known as 'generic differentiation' has its origins in the Aristotelian differentiation between poetic forms (eide), not genres. It is rather in his logical, metaphysical and biological writings that the concept of genre (genos) plays a central role. ${ }^{14}$ In the Poetics Aristotle differentiated between the central forms of poietic mimesis: epic, tragedy and comedy, and only the last two were considered by him as dramatic, as they imitate an action in a direct manner, told from the point of view of the characters themselves. ${ }^{15}$

This basic differentiation established the long and canonic tradition of literary 'genre theory', consisting of a system of classification of kinds of literature; ${ }^{16}$ the generic distinction between tragedy and comedy is based on the subject matter that the work imitates. And though, as Genette demonstrated, the long history of genre theory largely deviated from the Aristotelian designations, ${ }^{17}$ yet, the basic Aristotelian alleged 'generic' differentiation of the Poetics was retained: it is the one drawing a distinction between tragedy, which is a mimesis of a 'serious', good praxis, performed by good or noble, that is to say 'better' characters, and comedy, which imitates ridiculous, laughable deeds, performed by 'lesser' characters. ${ }^{18}$ This distinction entails a hierarchy, distinguishing between that which is imbued with importance and tenor, and that which is considered as minor, insignificant and habitual. The generic literary distinction between tragic and comic subject matter was still being maintained in literary seventeenth-century neoclassical discourse. During the second half of the seventeenth century, the vocabulary of generic classification was transferred to the discourse of the plastic arts. This passage was carried out by the development of artistic theory 
in the academies. In his preface to the Conférences de l'académie royale de peinture et de sculpture, ${ }^{19}$ André Félibien used the literary hierarchy of genres in order to discuss painting and sculpture, constructing a hierarchy of subject matter, which begins from still-life and landscape (the lowest genres), continues to portraiture, and culminates in history and theological painting, which were taken to be as the higher, respectable genres. ${ }^{20}$ Yet artistic discourse in the eighteenth century entailed a notable deviation in the etymon's trail, to which our trail now turns.

\section{Peintres de genre and habitual subject matter}

Artistic vocabulary in the eighteenth century had to follow contemporary changes in the conditions of production of artistic works. As early as in the seventeenth century, mostly in the Netherlands, a notable school of painting developed, having its sources in earlier Dutch painting and 'Caravaggism'. This class of paintings is characterized by subject matter which are admittedly nonheroic and nonhistorical, but rather belong to everyday life, describing human habitudes, many times accentuating moral frailty. In France, one should note the paintings of the Le Nain brothers, who worked in the same thematic framework and were known and influential in their own times. The paintings of this 'kind' were referred to initially by the Italian-driven derogatory term Bambochades, ${ }^{21}$ meaning laughable, fake, or even deformed. The word 'genre' was not used in the seventeenth-century Netherlands to describe what was later to be referred to by this word. ${ }^{22}$ Only in the eighteenth century does one start to find in French art criticism the use of the term peinture de genre to refer to the above class of painting. Therefore, the term 'peinture de genre' was a retroactive term, serving French authors of the eighteenth century to refer and to define seventeenth-century (mostly Dutch) paintings and to affiliate these with their own present-day painterly production. This new encompassing category of 'genre painting', as Wolfgang Stechow specified, 'embraced the minor categories [les genres] of painting, such as landscape, still life and everyday scenes. ${ }^{23}$

Localizing precisely the original eighteenth-century textual usage of the term peinture de genre (genre painting), or peintre de genre (genre painter) is a complicated task. The term is clearly to be found in Diderot's art criticism, though he referred to it as an already commonly used term. Notwithstanding, the expression 'peinture de genre' does not make an explicit category in earlier eighteenth-century French art criticism, such as those by Roger de Piles, l’Abbé Dubos or La Font de Saint-Yenne. One could find in these texts the usage of the word 'genre' referring to 'kinds' in general, for example, as in the expressions: 'le genre de Peinture la plus considerable ${ }^{24}$; 'différents genres de la poésie, ${ }^{25}$ or 'en aucun genre. ${ }^{26}$ In all these expressions, 'genre' does not explicitly refer to the specific class of painting mentioned above. 
The use of the term 'peinture de genre' is a peculiar one, in which the word 'genre' refers to subject matter located at the very bottom of generic hierarchy, or falling outside it altogether. Slightly prior to Diderot's art criticism, one could find the term 'peinture de genre' in the seventh volume of the Encyclopédie, edited by Diderot and by d'Alembert in I757, in the article 'Genre (Peinture)', written by Claude-Henri Watelet. ${ }^{27}$ Hence, one may narrow the localization of the formation of the specific classification 'Genre painting' to around I750. The formation of this term is synchronous with the beginning of the Salon exhibitions (from I746 onwards) and the development of public discourse surrounding them. This cultural process included the development of the practices of the amateurs, collecting affordable paintings, an occupation demanding new categories of classification and reference to paintings that were unclassifiable according to pregiven iconographical, canonical systems of subject matter ${ }^{28}$

Thereafter, one finds in the writings of Diderot the term 'peintres de genre' as an independent expression. Here is Diderot's definition:

One calls genre painters [peintres de genre], without distinction [indistinctement], those who busy themselves with flowers, fruits, animals, woods, forests, mountains, as well as those who borrow their scenes from common and domestic life [de la vie commune et domestique]; Teniers, Wouwermans, Greuze, Chardin, Loutherbourg and even Vernet are genre painters. ${ }^{29}$

For Diderot, the term peinture de genre refers to those seventeenth- and eighteenth-century painters depicting all subject matter which is not historical or theological. In fact, the above definition appears in the place were Diderot discusses a terminological dyad which is relevant to our trail of inquiry: it is the dyad of genre painting versus history painting. ${ }^{30}$ In the framework of this discussion $\mathrm{Di}$ derot explicitly recalls the classical literary generic model when noting that ' $i] \mathrm{t}$ is the quarrel between prose and poetry, between history and epic poem, between heroic tragedy and bourgeois tragedy, between bourgeois tragedy and gay comedy' ${ }^{31}$ Thus Diderot implicitly suggests the following scheme, which amounts to a philological trail of sorts:

$$
\begin{aligned}
& \text { Prose } \rightarrow \text { history } \rightarrow \text { heroic tragedy } \rightarrow \text { bourgeois tragedy } \\
& \text { versus } \\
& \text { Poetry } \rightarrow \text { epic poem } \rightarrow \text { bourgeois tragedy } \rightarrow \text { gay comedy }
\end{aligned}
$$

Genre painters are occupied with habitual themes, those considered as comic in the Aristotelian sense, and therefore are classified according to the specific sort of 'things' depicted in their painting, rather than by the 'history' they recount. 
Diderot protected the status of genre paintings, and even affiliated these with the work of philosophy. According to Diderot, both practices, genre painting and philosophical investigations, seek to represent the 'true'. ${ }^{32}$

It was the proliferation of the unclassified subject matter of mundane, habitual reality, correlative to the widening of the art public, that lead to the eighteenthcentury usage of the concept of genre, and which, according to Diderot, coincided with the task of philosophical thinking. Diderot used the term 'peinture de genre' in a framework of a critical polemic against historical painting which adheres to the classical, Aristotelian academic hierarchy of genres which was still retained, as noted above, by the French academy of the seventeenth century.

The term peinture de genre continued to be effective also in the following century, when artistic theory and discourse proliferated, with the writing and teaching of the history of art. ${ }^{33}$ In Germany, the term became accepted during the nineteenth century; around 1830 one can find the term Die Genre-malerei in the art-historical surveys of Karl Schnasse and Franz Kugler. ${ }^{34}$ Moreover, genre painting served as a model for the 'Realist' nineteenth-century critics and authors ${ }^{35}$

Though seeming to entail a deviation from classical hierarchies of genres, the modern concept of peinture de genre continued to lean on the Aristotelian differentiation between the tragic and the comic, the serious and the habitual. The change particular to the modern period since the eighteenth century is that habitual subject matter has been gradually given a central role to be equaled and sometimes surpassing in importance historical and theological subject matter.

Still, the use of the concept of 'genre painting' in artistic vocabulary stands as a philological riddle: Must one, as Jakob Burckhardt did i874, refer to this term of 'genre painting' as merely 'accidental' or arbitrary? ${ }^{26}$ In my opinion the history of the etymon 'genre', and its affiliation with habitual subject matter is not accidental but rather informative. Moreover, it points to the capacity of the concept of genre to continue to serve as a methodical tool in the humanities. This suggestion could be enhanced by a return to the Aristotelian meaning of the term genos. Indeed a long tradition of transmission exists between Aristotle's thought regarding the genos and the various definitions of genre theory in modernity. Regarding the twentieth century's criticisms of 'genre', which I mentioned at the outset, one may ask: is genre classification, as its twentieth-century prosecutors argued, indeed a stiff grill of separations, that is inadequate to account for the complexity and singularity of historical reality? Perhaps genre could rather be viewed as a methodic mechanism enabling a localization, or definition of a work, be it provisory or transitory? All generic classification places a work within a preexisting diachronic line of types, corresponding primarily to the work's subject matter. Now let us take a brief look at the Aristotelian beginning of generic classification. 


\section{Generic classification and genre as the 'matter' of forms}

The insistence of the methodic centrality of the concept of 'genre' could be viewed as one of the central suggestions of the Aristotelian orientation throughout the centuries. The genos was placed by Aristotle as a complementary and supplementary concept to the Platonic eidos. Instead of forms, Aristotle posed the genera as the primary means of classification. For Aristotle, the form (eidos) is a subdivision within the genos, a subdivision which is the outcome of a specific difference (diaphora) found within the genre. Hence: a genre + a specific difference supply, within a certain inquiry, what Aristotle refers to as the eidos, or the form of a thing in question. Genres include all actualized differences as a potentiality; and one achieves the definition, or the form, of a thing when recognizing both the latter's genre and the specific difference. Thus one cannot achieve an understanding of a thing's form without passing through an understanding of its genre.

The concept of genos, translated also as 'kind' or as 'race', comes up throughout Aristotle's works: In the Categories, the two Analytics, in the Topics, in the biological writings, in the Metaphysics, the Poetics and in the Rhetoric.

Here is the definition Aristotle gives to the genos in his Metaphysics Delta: ${ }^{37}$

The term genus, then, is used in all these senses: (a) in respect of continuous generation of the same type ( $\varepsilon i \delta o v \varsigma$ ); (b) in respect of the first mover of the same type as the thing which it moves; (c) in the sense of material. For that which the differentia or quality belongs to is the substrate, which we call material (vँ $\lambda \eta v)$.

This Aristotelian definition is applicable to the literary classification of genres. Indeed, Richard McKirahan has recently demonstrated a continuity and coherence between Aristotle's logical and metaphysical definitions of the genos, and his definitions of various forms of literature in the Poetics.$^{38}$ Genres are, in Aristotle's definition as well as in literary genre theory, recognized to exist in several exemplars during a certain period. And the generic series exhibits repetitions, articulations and variations of the genos. Indeed, a relation of hierarchy exists between genre and forms. Genos is to Form, what matter (byle) is to shape (morphe): Genos is a 'matter' from which specific forms are generated, released or distinguished; Genos is the byle of definitions, a reservoir of potential forms. ${ }^{39}$ Due to this basic layering, a generic system of classification must be, to some extent, a hierarchical one. ${ }^{40}$ In literary generic classical classifications, it is the subject matter of the work that determines its stylistic form, and the generic type supports and sustains, and in that sense entails the various realizations as potencies; and the same is also true of the genos in the original Aristotelian definition, 
which is denoted as a kind of matter regarding forms; it is a yet to be determined potentiality, as a matter from which forms and their differences are to be realized. ${ }^{41}$ The genera are epistemological instruments enabling saying something about something else, an operation which is one of the most basic impulses of humanist inquiries. Naturally, generic rationality demands a certain amount of discipline: According to Aristotle, locating an inquiry within a certain genre is necessary for any proof process, and one should abstain from moving from genre to genre in the same demonstration. ${ }^{42}$ The two following sections examine what continuity can be demonstrated between the eighteenth-century transfiguration of the concept of 'genre' regarding painting and a modern epistemological understanding of 'genre'.

\section{Genre painting and the subject matter of modern art}

Genre painting, as was demonstrated above, is essentially related to the comic 'genre' of artworks, imitating subject matters belonging to habitual reality, not exactly still-life, not landscape either, but rather minor human scenes located on the background of history, devoid of ideal nobleness. The rise of the comic through the new classification of 'genre' could be comprehended as the decisive change modern art, at least in literary and artistic discourse, has brought to the history of our etymon.

In the nineteenth century, 'genre painting' became prominent. From Gustave Courbet's Realism, through Édouard Manet's Impressionism, up to Édouard Vuillard's Post-Symbolism, a large part of nineteenth-century avant-garde painting could not be thematically and stylistically understood without a recourse to the classification of 'genre painting' [Fig. 5]. Therefore, the concept of 'genre' should be considered as a key player in establishing the paradigm of modern art. ${ }^{43}$ Hence modern art and its associated discourse could be understood as a development within the long tradition of transfiguration of the Aristotelian literary 'genre' theory. And in the twentieth century it was physical, material reality itself that became primary and central, ${ }^{44}$ so that abstract art, dedicated to the articulation of physical characters of space, color, materiality, and corporeal gestures, could be included in the story that is deployed here, driven as it is by the movement toward the 'comic' through the concept of 'genre' in the arts. To the claim that one cannot use thematic generic classification regarding nonfigurative, 'abstract' art, one could reply that an artwork does not have to be figurative in order to be considered within a certain genre; the type of subject matter of the work can still, in most cases, be deciphered. ${ }^{45}$ On the other hand, clearly classical canonic iconographies, ancient as well as Christian, have been found in modern 


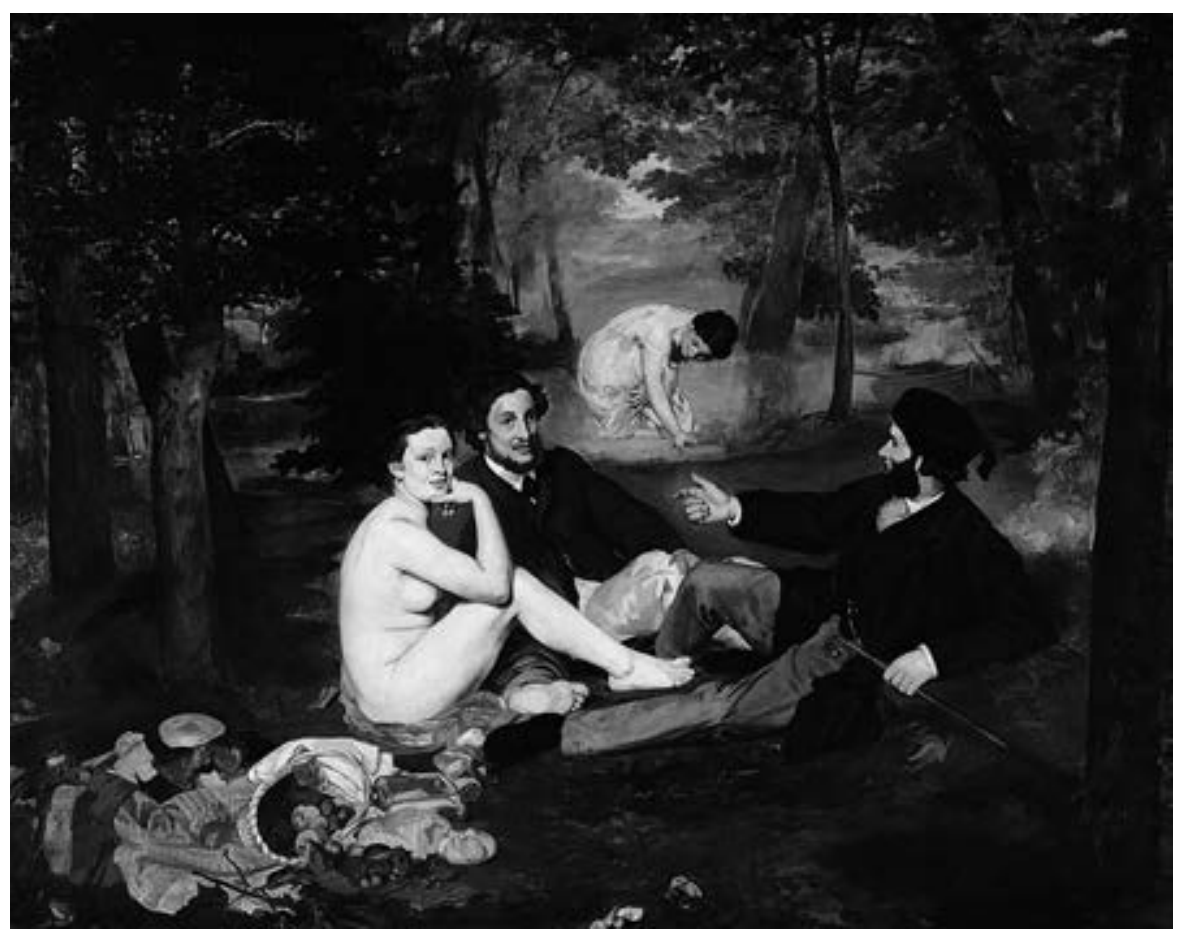

Fig. 5: Édouard Manet, Le Déjeuner sur l'herbe, I862-1863, oil on canvas, 208 x $265.5 \mathrm{~cm}$,

Musée d'Orsay, Paris

times as too narrow and anachronistic to supply the exhaustive subject matter from which possible forms could be drawn. It is therefore physical reality as such, from its materials to habitual life in the city or the home, that make the modern, encompassing 'genre' of art. This was anticipated by the formation of 'genre painting' in the eighteenth century, and exemplified by philological rationality in the twentieth century, to which we now turn.

\section{Genre and philological habitude}

We arrive now at the last station of our trail, gathering the various threads together, and considering their relevance to humanist inquiries at large. ${ }^{46}$ The modern use of the concept of genre in artistic discourse, epitomized by the concept of 'genre painting', is not by sheer coincidence related to habitual subjects. Indeed, Diderot's use of the term clarifies an aspect of the Aristotelian genos and its application, which hasn't been clear in previous usages of the term in traditional liter- 
ary genre theory. It highlights the fact that generic examination is essentially and consistently occupied (I) with definitions and (2) with a hierarchical distinction between the comic and the tragic, or between the habitual and the heroic. Generic investigation considers human work as a result of serial repetition of types, and therefore as a constant process of distinction between the habitual, repeating 'comic' details, and the tragic deviations from the generic web. A generic problem always involves the demand for a definition. It comes up when one seeks to define 'what's that' in a situation where some figure is not automatically classifiable under accepted iconographies. In the twentieth century, in the history of art, Erwin Panofsky practiced such a generic, thematic history; occasionally he referred to this kind of inquiry as iconology ${ }^{47}$ Iconology, as it was practiced by Panofsky and before him by Warburg, breaks the matter of history into themes and distinguishes genres of classification inside those which already exist; it locates a work, through the definition of its theme, within the already existing schemes of generic categories. In that sense, it is less interested in history as such.

A late-modern kind of generic inquiry, taking both Aristotle and Diderot into account, would understand historical reality as a result of habitual repetition and variation, not as tragic historicity. History would then be considered to be woven out of repetition and rehearsal of generic themes and types. The task of a genreoriented study of art would then consist in locating a work, or some detail of a work, within a classificatory thematic category, which should be demonstrated to exist in a continuous trail of repetition across a certain segment of history. Generic classification locates a work within a genre, yet a one which would not be too wide (see Bergson's complaint mentioned at the outset) but rather as wide and as weighty as the work in question can carry. Leo Spitzer attested to the tragic-comic nature of philological inquiry, in his 1948 introduction to Linguistics and Literary History:

[T] he philological, the inductive way, seeks to show significance in the apparently futile. [...] Philology, which deals with the all-too-human, [...] the attempt to discover significance in the detail, the habit of taking a detail of language as seriously as the meaning of a work of art - or, in other words, the attitude which sees all manifestations of man as equally serious - this is an outgrowth of the pre-established firm conviction, the 'axiom', of the philologian, that details are not an inchoate chance aggregation of dispersed material through which no light shines. ${ }^{48}$

A generic investigation demands from the researcher to rethink and rehabilitate his own habituated system of classifications, thus carrying a potential for new forms to be generated on the charts of history. 


\section{Notes}

I My gratitude goes to the Gerda Henkel Stiftung, supporting my work in 2012-20I4. I am thankful to Rens Bod, Mats Malm, David L. Marshall, Johanna Sprondel, Elijah Millgram, and Thijs Weststeijn for helpful comments.

2 Leo Spitzer, Linguistics and Literary History (Princeton: Princeton University Press, I948), 4 ff.

3 Mats Malm, 'The Role of Emotions in the Development of Artistic Theory and the System of Literary Genres', in Rens Bod, Jaap Maat, and Thijs Weststeijm (eds.), The Making of the Humanities, Vol. II: From Early Modern to Modern Disciplines (Amsterdam: Amsterdam University Press, 2012), 267-282.

4 My translation. Henri Bergson, 'Introduction I', La pensée et le mouvant (Paris: Presses Universitaires de France, 2009), 23: 'Car l'imprécision est d'ordinaire l'inclusion d'une chose dans un genre trop vaste.'

5 Walter Benjamin, The Origin of German Tragic Drama, trans. John Osborn (London: Verso, 2003), 43-44, drawing on Benedetto Croce, Grundriß der Ästhetik. Vier Vorlesungen (I9I3), Gesammelte philosophische Schriften, vol. 2/2 (Tübingen Verlag I929), 4 off.

6 Erich Auerbach,'Romantik und Realismus (I933),,Über die ernste Nachahmung des Alltaglichen (1937)' in Martin Treml and Karlheinz Barck (eds.), Erich Auerbach, Geschichte und Aktualität eines europäischen Philologen (Berlin: Kulturverlag Kadmos, 2007), 426465 .

7 Mikhail Bakhtin, 'The Problem of Speech Genres', Speech Genres, and Other Late Essays, trans. Vern W. McGee, ed. Caryl Emerson and Michael Holquist (Austin: University of Texas Press, I986), 60-102.

8 Jean-François Lyotard, The Differend: Phrases in Dispute, trans. Georges Van den Abbeele (Minneapolis: University of Minnesota Press, I988), I 29-I 38.

9 Jacques Derrida, 'The Law of Genre', trans. Avital Ronell, Critical Inquiry 7.I (Autumn I980), 55-8I.

Io Benjamin, Origin, 44.

I I Derrida, 'Law of Genre', 55.

I2 Gérard Genette, Fiction et Diction, précédé de Introduction de l'architexte (Paris: Seuil, 2004 [1979]), 9-82; Gérard Genette, The Architext: An Introduction, trans. Jane E. Lewin (Berkeley/Los Angeles/Oxford: University of California Press, I992); Gérard Genette, Des Genres et des OEuvres (Paris: Seuil, 20I2).

I 3 My translation. Genette, Genres et OEuvres, I 50.

I4 See Otfried Höffe (ed.), 'Genos/Gattung', Aristoteles Lexikon (Stuttgart: Alfred Kröner Verlag, 2005), 232-236.

I5 Aristotle, The Poetics, with Longinus, On the Sublime, and Demetrius, On Style, trans. Stephen Halliwell (London and New York: Loeb Classical Library, 2005), 28ff. (I $447 a 2-$ I449bir).

Tzvetan Todorov and Gérard Genette (eds.), Théorie des genres (Paris: Seuil Essais, I986).

Genette, Architexte, 39-7I (VI-X); Genette, 'Architext', $36 \mathrm{ff}$.

Aristotle, Poetics, 8-I I (I448a I-7); Gérard Genette, 'Architexte', I9.

I9 Elisabeth Lavezzi, La scène de genre dans les Salons de Diderot (Paris: Hermann, 2009), 33; André Félibien, Préfaces au Conférences, Les Conférences de l'Académie royale de peinture et de sculpture, ed. Alain Mérot (Paris: ENSBA, I966), 50-51.

20 Lavezzi, Scène de genre, 43.

2 I Ibid., 35 . 
22 Wolfgang Stechow and Christopher Comer, 'The History of the Term Genre', Allen Memorial Art Museum Bulletin 33.2 (I975-I976), 92.

23 Ibid., 89.

24 Roger de Piles, Cours de peinture par principes (I708) (Paris: Gallimard, I989), 3I (A searchable version is to be found in Gallica database).

25 Abbé Du Bos, Réflexions critiques sur la poésie et sur la peinture (I7Ig) (Paris: Ensba, I993), 2 I.

26 La Font de Saint-Yenne, 'Sentiments sur quelques ouvrages de peinture, sculpture et gravure (c. I753)', OEuvre critique, ed. Etienne Jollet (Paris: Ensba, 200I), 28I.

27 Lavezzi, Scène de genre, 3I, I2 I n. 42.

28 See Helena Zmijewska, La critique des Salons en France du temps de Diderot (1759-1789) (Warsaw: Wydawnictwa Uniwersytetu Warsawskiego, 1980); Albert Dresdner, Die Entstebung der Kunstkritik (Amsterdam and Dresden: Verlag der Kunst, 200I), 21 5-266.

29 I quote the English translation from Stechow and Comer, 'History of Genre', 89-90. The French text is to be found in Denis Diderot, Essais sur la peinture (Paris: Fr. Buisson, I795), 90-9I. A searchable version of this edition could be found on the Gallica database.

30 Diderot, Essais sur la peinture, 84-9I.

3 I My translation from Diderot, Essais sur la peinture, 90: 'C'est la querelle de la prose et de la poésie, de l'histoire et du poëme épique, de la tragédie héroïque et de la tragédie bourgeoise, de la tragédie bourgeoise et de la comédie gaie'.

32 Ibid., I76,

33 See Axel Hémery (ed.), Petits théâtres de l'intime, La peinture de genre française entre révolution et restauration, Exh. Cat. (Toulouse: Musée des Augustines, 20I I).

34 Stechow and Comer, 'History of Genre', 92; Franz Kugler, Handbuch der Geschichte der Malerei (Berlin: Duncker I837), I87.

35 See Peter Demetz, 'Defence of Dutch Painting and the Theory of Realism', Comparative Literature I5.2 (Spring I963), 97-I I5.

36 Stechow and Comer, 'History of Genre', 89 n. 2 ('[...] zu diesem zufälligen Namen [...]').

37 Aristotle, Metaphysics Books I-IX, trans. Hugh Tredennick (Cambridge, MA, and London: Harvard University Press), 284-285 (1024b5-10).

38 Richard McKirahan, 'The Place of the Posterior Analytics in Aristotle's Thought, with Particular Reference to the Poetics, in J.H. Lesher (ed.), From Inquiry to Demonstrative Knowledge: New Essays on Aristotle's Posterior Analytics (Alberta: Academic Publishing, 2010), 75-105.

39 Marjorie Grene, 'Is Genus to Species as Matter to Form? Aristotle and Taxonomy', Synthese 28.I (September I974), 5I-69.

40 See Andrei Cornea, 'Umberto Echo's Encyclopedia vs. Porphyry's Tree', Laval théologique et philosophique 65.2 (2009), 301-320.

4I Michael-Thomas Liske, Aristoteles und der aristotelische Essentialismus: Individuum, Art, Gattung (Freiburg-Munich: Karl Alber Verlag, I985), 397, 429; Höffe, 'genos', 234-235.

42 Aristotle, Posterior Analytics, trans. Hugh Tredennick, with Topica, trans. E.S. Forster (Cambridge, MA, and London: Harvard University Press, I960), 6I (75a39); I3I (84b I5-I9).

43 Stephen Bann, 'Questions of Genre in Early Nineteenth-Century French Painting', New Literary History 34.3 (Summer 2003), 50 I-5II.

44 See Kay Heymer, Susanne Rennert, and Beat Wismer (eds.), Le grand geste! Informel und abstrakter Expressionismus 1946-1964, Exh. Cat. (Düsseldorf: Museum Kunst Palast, 20I0). 
45 Günter Bandmann, 'Bemerkungen zu einer Ikonologie des Materials', Städel-Jahrbuch 2 (1969), 75-I oo; Thomas Raff, Die Sprache der Materialien: Anleitung zu einer Ikonologie der Werkstoffe, Kunstwissenschaftliche Studien 6I (Munich: Dt. Kunstverlag, 1994).

46 For a similar attitude, see Ralph Cohen, 'History and Genre', New Literary History 7I.2 (Winter I986), 203-2I8.

47 Erwin Panofsky, 'Iconography and Iconology: An Introduction to the Study of Renaissance Art', in Meaning in the Visual Arts (New York: Doubleday Anchor, I955), 26-55.

48 Spitzer, Linguistics and Literary History, 23-24. 



\title{
6.3 The Recognition of Cave Art in the Iberian Peninsula and the Making of Prehistoric Archeology, 1878-1929
}

\author{
José María Lanzarote-Guiral
}

In May I92I, the Exhibition of Spanish Prebistoric Art (Exposición de arte prebistórico español) opened its doors in Madrid. Hosted by the National Library and inaugurated by King Alphonse XIII, the exhibition presented prehistoric cave art as the first chapter of the Spanish art tradition, placing the peninsula at the cultural origins of Western civilization. This exhibition was conceived of to showcase the work undertaken by Spanish scholars in this field since 1902, when cave art was recognized as such by the international scientific community. Moreover, the organizers did not miss the chance to highlight that it was 'foreign' prehistorians, particularly French ones, who had first denied the authenticity of those figurative representations discovered in a Spanish cave in 1878. Inspired by an essentialist conception of national history, this exhibition contributed to define a constructed object of study, 'Spanish prehistoric art', which was elevated to the status of national heritage and played a strong role for national identity definition from then on.

In order to better understand the role of cave art research in the making of prehistoric archeology I shall deconstruct this hybrid object: What was the intellectual and social process that led to the definition of 'Spanish prehistoric art'? And in order to answer this question, this paper is concerned with the process of configuration of scientific categories and it is divided in two main sections. The first one analyzes the construction of the concept 'prehistoric art' between 1878 and 1902, paying particular attention to the Altamira affair, namely the discovery, early rejection and definitive recognition of the first prehistoric decorated cave. In a chronological continuity, the second part is devoted to the social and intellectual making of Spanish prehistory in the first decades of the twentieth century. As I shall demonstrate, this process is marked by a strong drive for the nationalization of humanities and sciences fostered by state initiative, which materialized in the creation of research institutions and the organization of public exhibitions. 
In analyzing this process, this paper reflects the role of cultural transfers across European borders in the shaping of cognate disciplines such as prehistory, anthropology and art history. It also analyzes from a comparative perspective the contribution of those different fields of study to the making of 'national heritage'. Combining these approaches, I use the case of prehistoric cave art to argue in favor of a histoire croisée of the humanities. ${ }^{1}$

\section{The question of cave art and the making of prehistory}

The origins of prehistory as a field of study are marked by two dates; after its 'birth' commonly designated as dating from I859, when a critical sector of the scientific community arrived at a consensus on the deep antiquity of humanity, ${ }^{2}$ in 1867 the new field of study was presented in Paris at the Exposition Universelle. Inbetween those two dates a community of 'prehistorians' began to form and become aware of itself through the creation of institutions such as museums for vernacular antiquities, specialized periodicals and a stable pattern of international congresses. Borrowing methods and theoretical grounding from natural and historical sciences, those self-proclaimed prehistorians established the foundations of a new discipline. ${ }^{3}$ Due to its relevance for the question of human origins, prehistory was suspected of heterodoxy and associated with evolutionary anthropology; it became enmeshed in philosophical, social and political debates, particularly on the role of science and religion in society. All these elements were present in the controversy about Altamira representations that emerged in the late I870s.

The cave of Altamira was discovered in 1878 by Marcelino Sanz de Sautuola (1831-1888), a local erudite scholar from Santander in Northern Spain. The cave contained depictions of cold faunal species such as European bison, which were technically remarkable; they were naturalistic, in some cases adapted to the irregular surface of the rock adding a three-dimensional effect and had been executed with a combination of colors, a range of pigments using carbon and ochre. The similarity of these representations with the engravings on stratigraphically dated Paleolithic objects that Sanz de Sautuola had seen in Paris at the Exposition Universelle in $\mathrm{I} 878$, led him to conclude that the paintings also dated back to the Stone Age. ${ }^{4}$

Subsequently Sanz de Sautuola informed the scientific institutions in Spain about his discovery and he got the support of Juan de Vilanova (I82I-1893), chair of geology at the University of Madrid. In line with his Catholic beliefs and creationist standpoint, Vilanova considered the representations as the first examples of fine art produced by men, and therefore the proof that humanity was created by God with full intellectual and spiritual capacities. Vilanova decided to present 
the new discovery to the international community at the International Congress of Prehistoric Anthropology and Archaeology to be celebrated in September $\mathrm{I} 880$ in Lisbon. However, the Altamira paintings met with skepticism from the majority of the congressmen and the discussion on this cave was set aside in favor of other debates, such as the question of the Tertiary man.

In the following years, Vilanova tried to raise the issue in several scientific meetings, but again he met with skepticism. Finally, an article published in the pages of Matériaux, the leading journal in the field, at the time directed by Émile Cartailhac (1845-1922), settled the question: the paintings could not date back to the Paleolithic, so they had to be a forgery. ${ }^{5}$ As he revealed years later, Cartailhac followed the advice of his mentor, the leader of the materialist school within French anthropology, Gabriel de Mortillet (I82I-I898), who suspected that Altamira's paintings had been planted by Spanish Creationist scholars in order to trick French prehistorians. In the hands of De Mortillet, prehistory became a weapon of social combat, as it was brandished in an attempt to reduce the influence of religious ideas in society and advance the cause of materialist philosophy. ${ }^{6}$

Moreover, this rejection can be explained by a combination of scientific and social factors. First of all, De Mortillet's interpretations were influenced by unilinear evolutionary anthropology, which led him to think that prehistoric men, as modern 'primitive peoples', did not possess symbolic thinking and therefore were not capable of producing fine art. Secondly, even for those scholars who did not share his viewpoint, the idea of prehistoric art was hard to conceive of, even if some prehistoric objects that had been found in caves did have naturalistic representations. These were considered just ornamental depictions on tools at best, comparable to 'crafts' but not to high forms of fine art. In the eyes of nineteenth-century specialists, Altamira representations were either 'art' for their technical proficiency or 'prehistoric' for their location and what they represented, but could not be both; the combination of those categories at the time was unthinkable. ${ }^{7}$

In 1870 the French scientific divulgator Louis Figuier (I8I9-I894) had published a plate titled 'The Forerunners of Raphael and Michelangelo' [Fig. 6]; almost as a caricature, even if it was not intended as such, the illustrator ÉmileAntoine Bayard (I837-I89I) presents two sitting sculptors carving statuettes, whereas a third standing figure is drawing a reindeer on a rock slab. Interestingly, this figure fits the stereotype of the artist in Western tradition as a painter in front of the easel. This was the way most nineteenth-century scholars thought of art: as a noble activity, born out of genius and creativity and formally based on mimesis. Neither this illustration, born from the imagination of a nineteenthcentury scientific divulgator and a contemporary artist (which was soon to be 


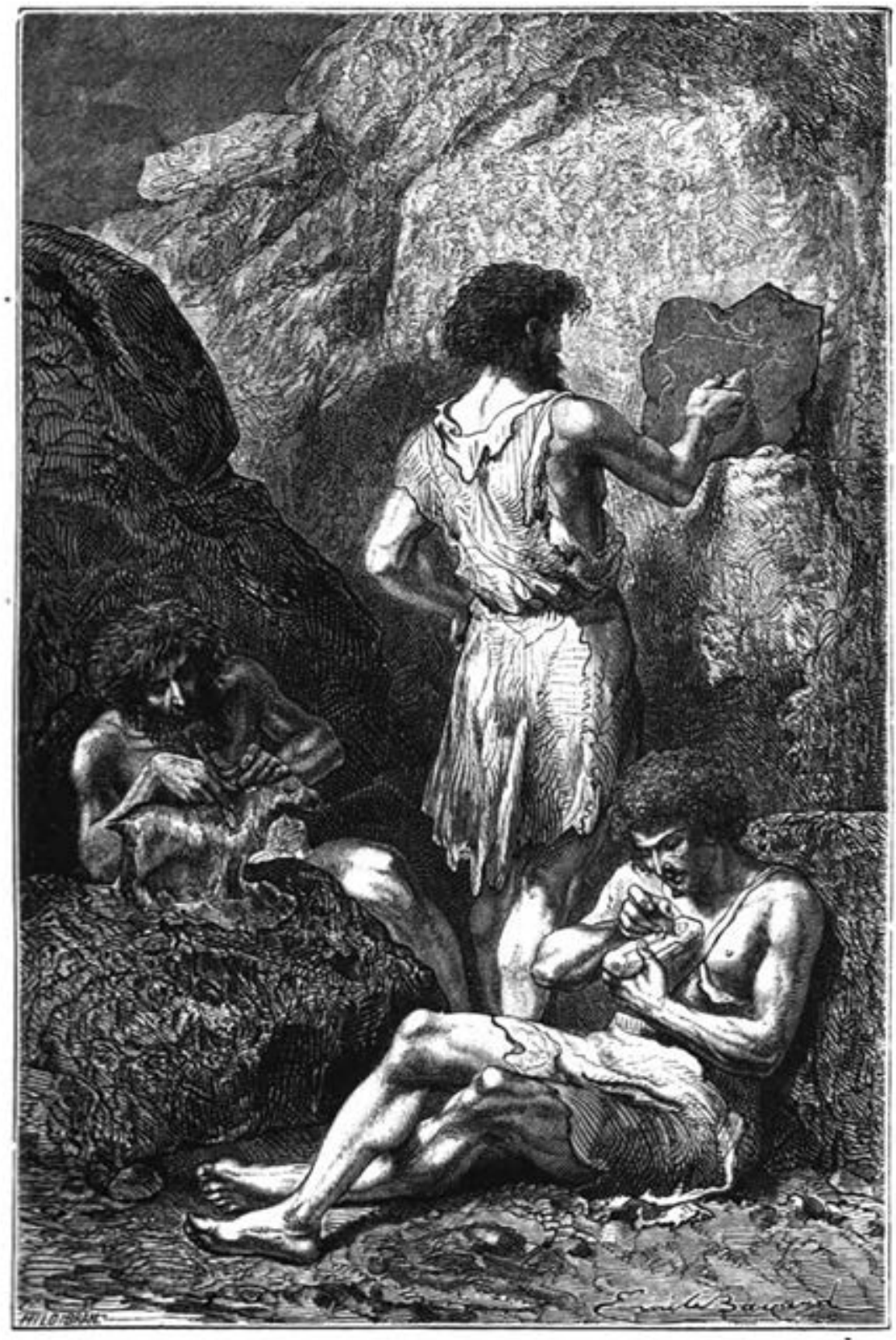

Fig. 6: Émile-Antoine Bayard, The Forerunners of Raphaël and Michelangelo, or the Birth of the Arts of Drawing and Sculpture in the Reindeer Age, engraving from Louis Figuier, L'Homme primitif (Paris, 1870 , first edition) 
contested by the leading prehistorians of the time), nor the depictions from the Altamira cave, met with the idea that the scholars of the time could expect from the 'primitive' men of prehistory. ${ }^{8}$

The Altamira affair was settled for some years until new decorated caves were discovered in France, starting in I885. Little by little the consensus was challenged, and finally in 1902 Cartailhac, one of the scholars that had most prominently denied the authenticity of Altamira, pronounced his mea culpa. ${ }^{9}$ His change in opinion was grounded in the redefinition of prehistory's social and scientific credentials, and the shift in its epistemological paradigm after the turn of the century. The unilinear evolutionism cherished by the materialist school was gradually substituted by the cultural-history paradigm, which led to an acknowledgement of regional differences within the archeological record. ${ }^{10}$ This, coupled with new approaches in the history of religion, led to a reappraisal of the intellectual and symbolic capacities of modern 'primitive' (and prehistoric) populations. ${ }^{\text {II }}$ Moreover, new ideas in art theory led to the appreciation of ornamental arts on the one hand, and to a renewed interest in the expressive force of primitive art manifestations on the other. ${ }^{\mathrm{I}}$ Finally, in the last decade of the nineteenth century, prehistory was gradually defused from its revolutionary potential; in trying to avoid what they considered partisan uses of knowledge, a new generation of scholars, among them some Catholic priests, strove to transform prehistory into a 'neutral' scientific field. ${ }^{13}$ And some of them converged in the study of prehistoric art, transformed after 1902 in one of the most promising fields within the discipline.

In the autumn of 1902 Cartailhac and the young Catholic priest Henri Breuil (I877-196I) visited Altamira, which they called the 'Sistine Chapel' of prehistoric times. Four years later, and thanks to the support of Prince Albert I of Monaco (I848-I922), they undertook the publication of a lavishly illustrated monograph on Altamira, the first of a series devoted to the principal decorated caves that were being discovered in France and Spain. ${ }^{14}$ From an epistemological point of view, this monograph inaugurated the religious interpretation of prehistoric art. They applied the ideas of Salomon Reinach (I858-1932), who translated the work of British social anthropologists as well as those of contemporary German art historians. ${ }^{15}$ This interpretation was pursued and developed by Breuil throughout his career, which culminated with the publication of Four Hundred Centuries of Cave Art, ${ }^{16}$ in which he provided a general account of the evolution of prehistoric art. In this work he accepted the magical interpretation of cave art proposed by the Henri Begouën (I863-1956); according to whom, prehistoric art was symbolic and had to be interpreted as the evidence of a religious practice, linked to propitiatory ceremonies for hunting. ${ }^{17}$ Breuil also introduced religious vocabulary to describe the decorated caves, such as 'cathedral' (cathédrale), 'sanctuary' (sanctuaire), or 'shrine' (camarin) [Fig. 7]. 


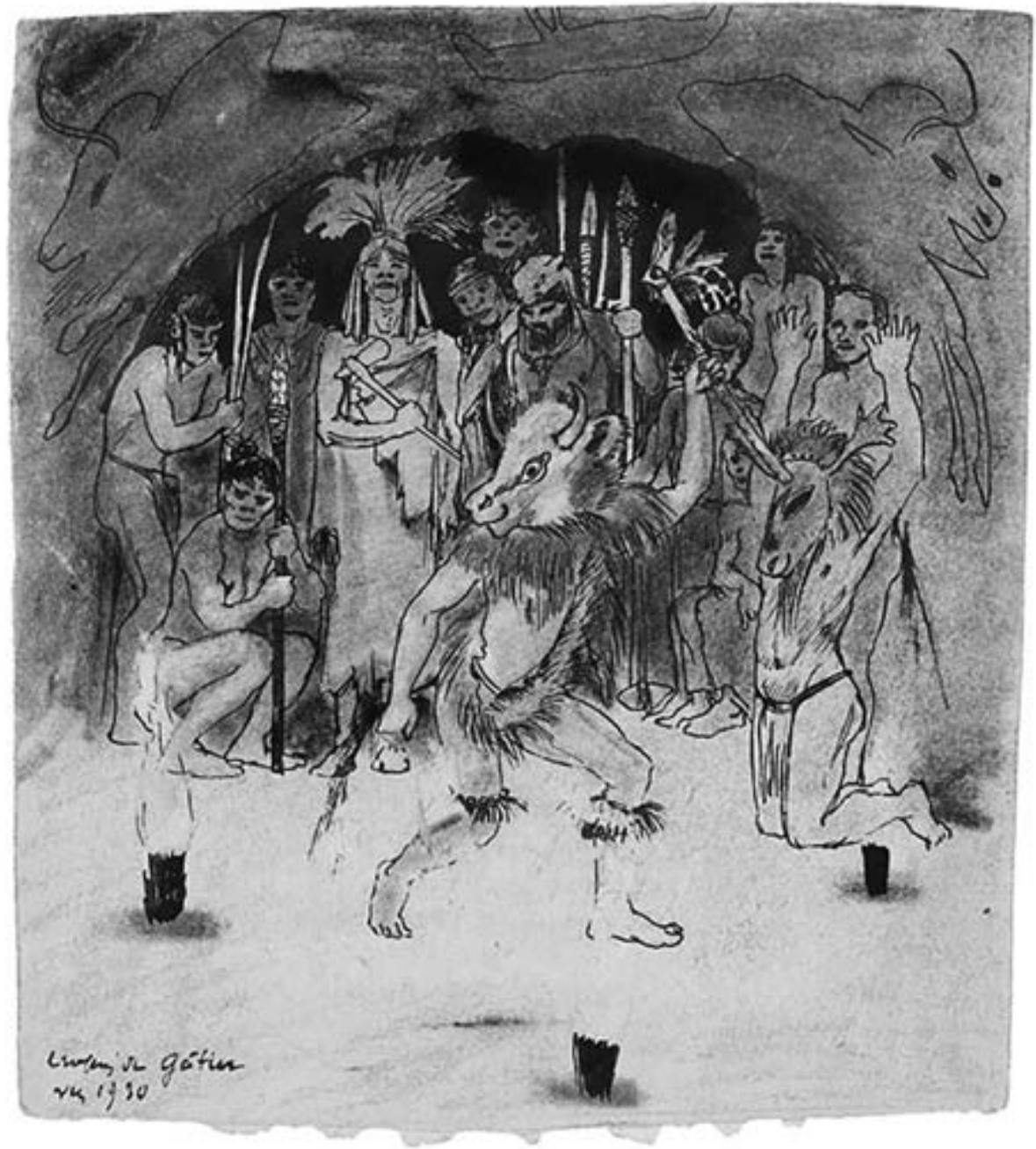

Fig. 7: Pierre Gatier, Prehistoric Ceremony in a Decorated Cave, Related to Henri Breuil's Magic Interpretation of Prehistoric Cave Art, c. 1930, drawing, Bibliothèque Centrale du Muséum d'Histoire Naturelle, Paris (Fonds Breuil-Boyle, Br. 22). Reproduced in Noël Coye, Ed., Sur les chemins de la prébistoire : L'abbé Breuil du Périgord à l'Afrique du Sud. (Paris, 2006): 17I).

Breuil spent a life of dedication to the study of prehistory in the Institute of $\mathrm{Hu}$ man Paleontology (Institute de Paléontologie Humaine; IPH), established in Paris in I9Io by the Prince of Monaco. The new research center was formally linked to the National Museum of Natural History (Muséum Nationale d'Histoire Naturelle; $\mathrm{MNHN}){ }^{18}$ Along with Breuil, the IPH enrolled as professor another rising scholar in the field of prehistory: the German Hugo Obermaier (1877-1946); both were 
trained naturalists, and both were Catholic priests. Their career is to be understood as a process of rearming of Catholicism in science that started in the last decade of the nineteenth century. If their research had to be negotiated in terms of their double allegiance to both the principles of science and the dogmas of faith, the IPH allowed both of them to become leading prehistorians of their time. ${ }^{19}$

The new institution aimed at studying the origins of humanity and more particularly prehistoric cave art, and from the very beginning both professors set out to explore Spanish territory. While Breuil traveled all over the Iberian Peninsula in search of new art stations, Obermaier's activities concentrated on the excavation of El Castillo cave, situated not far from Altamira. El Castillo was considered as one of the best Paleolithic sites of Europe, due to its very complete stratigraphic sequence, and also due to the association it presented of an outstandingly decorated cave and an archeological site. ${ }^{20}$

Even if the IPH was reputed as an international institution, it was also deeply rooted in French scientific structures. Indeed its creation implied a decisive move toward the institutionalization of prehistory and its professionalization by means of centralization in Paris. In this sense, the IPH opposed the large community of French amateur archeologists, scattered across the whole country and organized since 1904 in the French Prehistoric Society (Société Préhistorique Française; $\mathrm{SPF})$. The excavation activities of a German-speaking Swiss scholar, Otto Hauser (1874-1932) in the prehistoric sites of the Dordogne, and the selling of human fossils and prehistoric artifacts, including artworks such as the Venus of Laussel, to German museums, confirmed the division between the two ways of conceiving prehistoric research. Alarmed by what they considered as the looting of the 'underground national archives', official French scholars asked their government for a law on excavations to curtail the 'freedom of excavation' that the amateurs of the SPF proclaimed. Even if the law failed, the claims of those official scholars to control the field were satisfied, at least to some extent, with the creation of the IPH. After 1900, prehistory, up to then a scientific activity mostly in the hands of private entrepreneurial excavators, started to fall within a different domain, that of national heritage. ${ }^{21}$

\section{Searching for the origins of Spanish art}

Since their first missions in Spain, the professors of the IPH encountered a country immersed in an intense process of renovation of its scientific structures, influenced by the consequences of the 1898 colonial crisis. After the military defeat in the Spanish-American War and the subsequent loss of the last colonies, Spanish intellectuals had insistently demanded an official effort to redraft scientific policy, 
oriented toward the 'regeneration' of the country. In this wave of renovation the idea of 'Europeanizing' Spain became central, implying the emulation of scientific achievements of the leading European imperial nations. This policy led to the reform of the university system and to the creation of new institutions, such as the Board for the Extension of Studies (Junta para la Ampliación de Estudios; JAE) in 1907. This well-funded superstructure for advanced research was made up of different centers and it promoted academic exchange by awarding scholarships to both students and professors to undertake studies abroad. ${ }^{22}$

This trend of renovation affected sciences and humanities alike. The study of human sciences was promoted in the Center of Historical Studies (Centro de Estudios Históricos; CEH), created in I9Io, and made up of different sections concerned with philology, history and archeology ${ }_{*}^{23}$ Art history was promoted within the latter section by Manuel Gómez Moreno (1870-1970) and Elías Tormo (1869-1957), two scholars who became instrumental in the consolidation of art history as a fully fledged academic discipline in Spain. Their work focused on the characterization of the Spanish school of painting and was marked by a process of strong nationalization; in line with the Spanish elaborations of Karl Krausse's German idealism in the second half of the nineteenth century, they considered fine art as the emanation of the 'national spirit. ${ }^{24}$ At the same time, they were also influenced by Unamuno's concept of 'intrabistoria', or the idea that the national essence was to be found in the people, translating in a renewed interest in vernacular manifestations of crafts and folklore.

This was not at all contradictory with the desired 'Europeanization'; as Unamuno put it, 'Spain is waiting to be discovered, and only Europeanized Spaniards will discover it. ${ }^{25}$ Spanish tradition and Europeanization were thus two sides of the same coin in the drive for modernization. Given the high relevance that art history had for national identity in Spain (as in other European countries), ${ }^{26}$ it is not surprising that competing nationalist projects within the state, such as the Catalan, fostered with similar strength the study of artistic manifestation that spoke of the 'primitive' origins of the nation. For instance, since the turn of the century, Romanesque art from Catalonia and neighboring areas was extensively collected and studied by the economic and cultural elite of Barcelona, which also fostered a parallel drive in the institutionalization of research in archeology and art history. ${ }^{27}$

Situated in between the sciences of culture and those of nature, the study of prehistoric cave art did not fall within the province of the $\mathrm{CEH}$ but in that of a new institution, the Commission of Prehistoric and Paleontological Research (Comisión de Investigaciones Prehistóricas y Paleontológicas; CIPP). This was created in Madrid in 1912 under the initiative of Eduardo Hernández-Pacheco, chair of geology at the Universidad Central, who had just benefited from a scholarship to visit the Muséum in Paris, at the precise moment in which the IPH 
started its activities. Upon his return, he proposed the creation of an institution within the National Museum of Natural Sciences (Museo Nacional de Ciencias Naturales; MNCN), ${ }^{28}$ which mirrored the organization and the research objectives of the Parisian Institut: the study of archeological sites and cave art from the Quaternary. ${ }^{29}$

Hernández-Pacheco became the academic director (jefe de estudios) of the new center, whereas a 'grand amateur' of archeology, Enrique de Aguilera y Gamboa, Marquis of Cerralbo (I845-I922) was chosen as the president. As the leader of the Traditionalist Party, Cerralbo was also a key political figure. In fact, the marquis was welcomed at the JAE, which was accused of being ideologically dominated by progressive thinkers, as his participation evinced that the JAE's scientific and patriotic goals went beyond specific political choices. Moreover, by using his position as senator, Cerralbo had contributed largely to the drafting of the Archeological Excavations Act (Ley de Excavaciones Arqueológicas), passed in I9II. This legal text defined a protectionist framework for the practice of archeology and limited the right of non-Spanish citizens to become owners of the discoveries or to export them. In this manner, the law was a crucial step in the definition of prehistoric and paleontological remains as Spanish national heritage. ${ }^{30}$

The passing of the Excavations Act in I9II and the creation of the CIPP in I9I2 are the expression of a desire to regulate archeological activity and to create scientific structures for its development. Furthermore, its members justified their existence as a defensive effort against 'foreign science'. In this way, Spanish prehistorians used the rhetoric of nationalism to legitimate their discipline and to consolidate their academic position vis-à-vis the archeologists who came from abroad. This strategy paid off in a context of high sensitivity toward what some called 'scientific imperialism', in the aftermath of the colonial crisis, as it had also worked in the French case with the Hauser affair, in the context of rising antiGermanic feelings. Singling out 'foreigners' as the antagonist allowed the creation of a group identity, surpassing the social or ideological cleavages between those who constituted the emerging prehistorian community in Spain, whether noblemen or commoners, official scholars or amateurs, conservative or liberal.

For all these reasons, Spanish scholars perceived the IPH's activities with a mixture of admiration (for its scientific proficiency and economic means) and mistrust (for their leading role at an international level). If at the outset the relationship between IPH and CIPP was cordial - there were some attempts to establish formal links between them - the discord finally came to a head in I9I3 as a personal dispute between researchers. The break between the institutions deepened in the context of the First World War, when, archeological activities by IPH scholars ceased or were severely reduced: Breuil was drafted into the French army, and combined his work as researcher with propaganda activities in Spain 
in favor of the Allies. In turn, Obermaier, a German citizen working in a French institution, lost his position. When the war broke out in summer 1914, he was digging in El Castillo; invited to join the CIPP by Hernández-Pacheco, from then onwards his career developed within Spanish research structures.

The war provided neutral Spain with a chance to catch up with Europe in scientific terms; as a result, Spanish prehistorians could affirm their leadership, while fostering the definitive shaping of prehistory as a patriotic discipline. ${ }^{3 \mathrm{I}}$ Speaking in front of the Spanish Association for the Advancement of Sciences (Asociación Española para el Progreso de las Ciencias) in 1915, Hernández-Pacheco exposed the results of the last years' effort to investigate 'Spanish prehistory and paleontology'. In his intervention, Hernández-Pacheco established a narrative in which the shortcomings of the nineteenth century were contrasted against the 'rebirth of national science' in the twentieth, and claimed a protagonist role for Spain in the field of prehistory on account of the fact that it 'constitutes the world's museum of prehistoric art'. He did not miss the opportunity to recall that the artifacts discovered in the excavations led by the IPH had been taken to Paris, and accused its researchers of conquering the Peninsula for the benefit of 'French science' by the physical and intellectual appropriation of its past. He concluded affirming that the archive of the primitive civilizations, which fortunately for Spanish science, belongs to our homeland, and which, as Spaniards and cultivated people, we ought to preserve and study. ${ }^{32}$

Those ideas were staged in I92I at the Exhibition of Spanish Prehistoric Art, already mentioned at the beginning of this chapter [Fig. 8]. The exhibition was organized by the CIPP with the support of the aristocratic members of the Spanish Society of Art Amateurs (Sociedad española de amigos del arte), including the aforementioned Professor Elías Tormo. The annual exhibition organized by this Society at the National Library every spring since I9I2 was a social event in Madrid and fostered the appraisal of lesser known kinds of Spanish arts and crafts. Much less acknowledged though was the contribution of the Parisian IPH, although the exhibition featured a good number of sketches of cave art depictions that had been carried out by Breuil, and that were loaned by this institution. Not surprisingly the exhibition was conceived of by Hernández-Pacheco as a showcase of the achievements of the Spanish CIPP and only recognized the achievements of 'foreign scholars' with reservations:

[T] he study of those remote paintings was done, chiefly, by Spaniards; in some cases they were on their own, and, although the material means were scarce, they excelled in enthusiasm and ideals, in the wish to discover the unknown and the wonderful, and in the determination to study these astonishing monuments; in some other cases the research was conducted in 


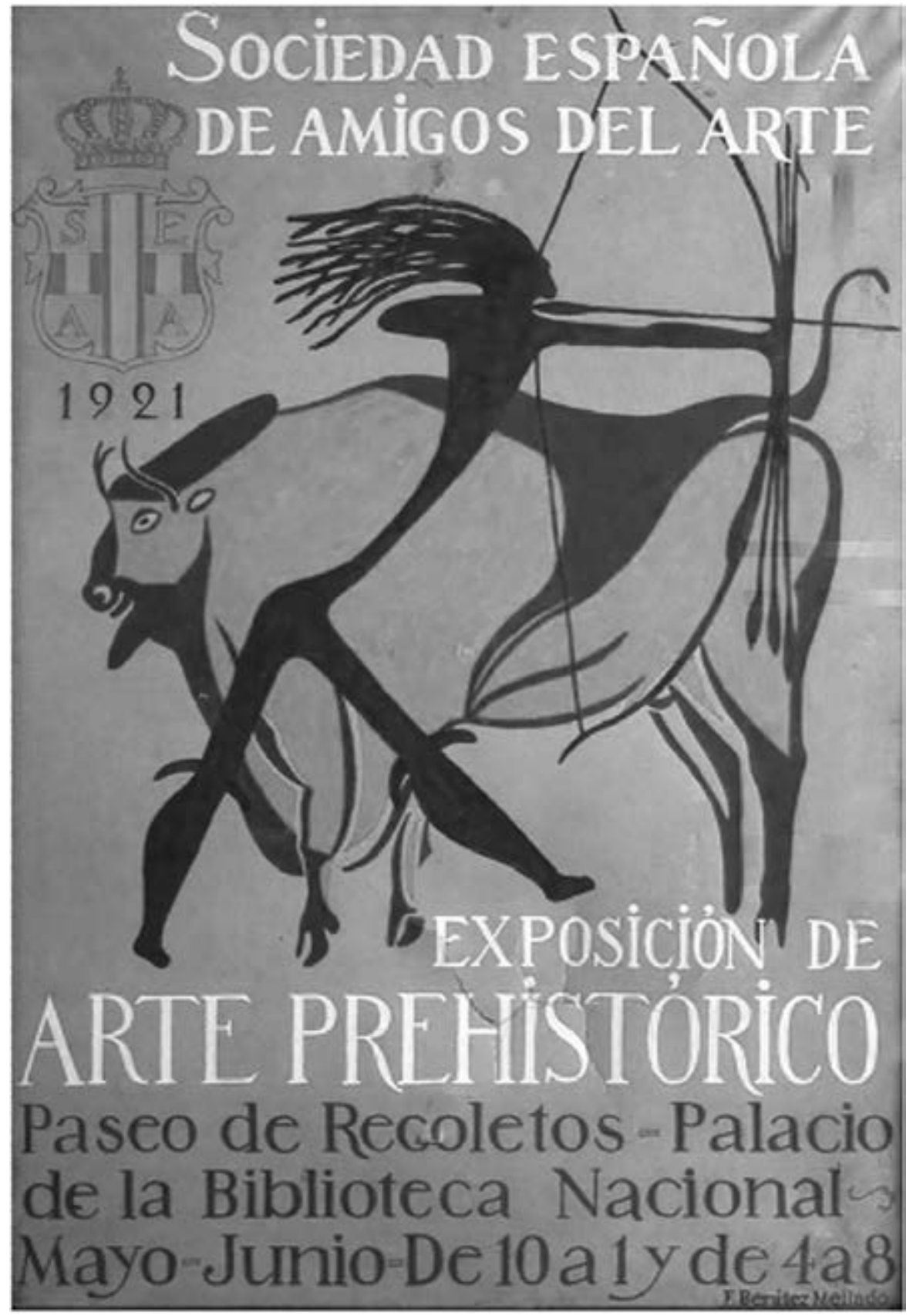

Fig. 8: Francisco Benítez Mellado, printed poster for the Exbibition of Spanish Prehistoric art (Exposición de arte prehistórico español), May-June 192I, Madrid 
partnership with foreign researchers, which excelled in material means and set out on the scientific conquest of the oldest artistic manifestations of primitive humanity. ${ }^{33}$

Hernández-Pacheco not only expressed the idea that the foreign scholars had conquered the Peninsula scientifically thanks to their material means, but he also insisted on the intellectual honesty that had guided their Spanish counterparts. For this reason, the exhibition paid tribute to the Spanish 'pioneers' that had contributed to the discovery and recognition of prehistoric art in the nineteenth century, Sanz de Sautuola and Vilanova. The display was inspired by a long history of national unity, and avoided dealing with sensitive issues such as the ongoing scientific debate on the ethnic division of the Peninsula in prehistoric times.

The collaboration of the two institutions at the exhibition was possible due to the mediation of Obermaier. As a member of the CIPP, he had researched intensively on the geology and prehistory of the Iberian Peninsula during the years of the war. In his monograph El Hombre Fósil (1916), he drew on his previous knowledge and digging experience in Central Europe and France to insert the prehistory of Spain into that of the Continent. ${ }^{34}$ Even if his relations with Hernández-Pacheco deteriorated to the point that he quit the CIPP, by the end of the First World War, Obermaier had developed close ties with aristocratic patrons and members of the Spanish intelligentsia, particularly those who admired the achievements of German science. Finally, in 1922 he was given the first chair of prehistory in Spain at the University of Madrid.

His designation was not achieved without resistance, notably by Hernández-Pacheco, who held a chair in the Faculty of Sciences and impeded the creation of a new position in this faculty. Thanks to the support of Elías Tormo, dean of the Humanities Faculty, Obermaier's chair was established in the latter under the name 'Primitive History of Man' (Historia Primitiva del Hombre). This confirmed the disciplinary shift of prehistory from natural sciences to humanities that the study of cave art, among other factors, had fostered. Obermaier acquired Spanish citizenship in 1926, and became the authority on the Peninsula's Stone Age at home and abroad until 1936, when the Spanish Civil War again forced him into exile. After 1922 cave art became an important subject in his career and he conducted research on Altamira at a time when decorated caves started to become, not just national monuments, but also touristic

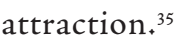

A poster from Barcelona's 1929 Universal Exhibition gives a graphic synthesis of the process of configuration of 'Spanish national art', while also paying tribute to the host city [Fig. 9]: the composition is made up of a bison from Altamira, 


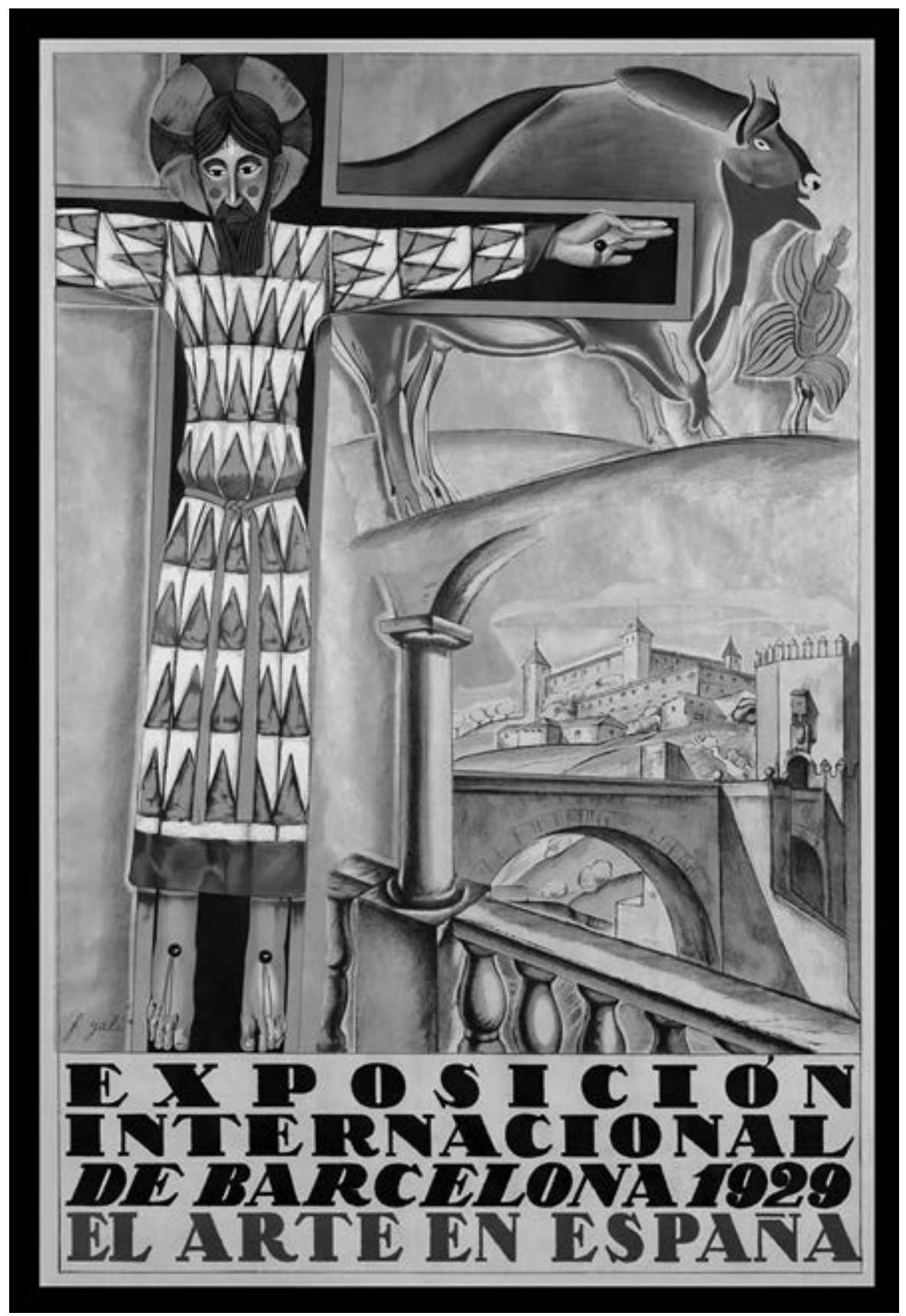

Fig. 9: Francesc d'Assís Galí i Fabra, printed poster for the International Exbibition of Barcelona(Exposición internacional de Barcelona), Barcelona, May I929-January 1930 
a Romanesque sculpture of Christ on the Cross of Catalan provenance and the imperial city of Toledo in the background. In it, the primitive art of prehistory and the 'primitive' art of medieval times are brought together to illustrate the cultural origins of modern Spain. Prehistoric artifacts and artworks figured in the exhibition titled España Primitiva, which was one of the sections of the larger exhibition El Arte en España on display at the National Palace, the symbolic core of the event. If the main exhibition was curated by Gómez Moreno, the so-called 'Primitive section' was curated by Pere Bosch Gimpera (I89I-1974), leading Catalan archeologist of his time, who defined the objects exposed there as 'the first foundation of the Spanish civilization, in which are to be found the roots of many of the phenomena that later on made up the cultural values that Spain has created for the world'. ${ }^{36}$

\section{Conclusion}

The making of prehistoric archeology in Europe in the nineteenth and the twentieth centuries resulted from a complex interplay of scientific, social and economic interests, and was inspired by both academic internationalism and the constraints of the nation-state building process. For this reason, the alleged 'scientific colonialism' performed by European scholars in Spain appears as a narrative construct of those Spanish prehistorians who strove to consolidate their field by means of legal regulations, institutions and the conversion of archeological artifacts and sites into national heritage. Furthermore, those scholars, in alliance with leading art historians, transformed prehistoric cave art into a mighty element for national definition; in doing so, they contributed to a historiography that praised Spain's painting tradition as one of its most relevant contributions to Western civilization, which compensated for what was perceived of as a less decisive achievement in scientific terms.

In the first decades of the twentieth century, a time when the rhetoric of the 'discovery' invaded cultural and political language, the 'invention' of painting by the primitive men of prehistory, the discovery of the Americas by the Castilians at the end of the medieval period or the discovery of prehistoric art by Spanish researchers in the nineteenth centuries, were all historical processes interpreted as elements in the same essentialist national history based on the achievements of talented individuals, a narrative that was to provide a source of pride and an example for the regeneration of the country by the new generations. 


\section{Notes}

I These arguments are developed in my PhD dissertation: Prehistoria Patria: National Identities and Europeanisation in the Construction of Prehistoric Archaeology in Spain (18601936), defended at the European University Institute in Florence in January 20 I 2.

2 Chris Evans (ed.), 'Celebrating the Annus Mirabilis', special section of Antiquity: A Quarterly Review of Archaeology 83 (2009), 458-46I; Claude Blanckaert, 'Les trois glorieuses de I 859 [Broca, Boucher de Perthes, Darwin] et la genèse du concept de races historiques', Bulletins et Mémoires de la Société d'anthropologie de Paris 22.1-2 (2010), 3-16; Arnaud Hurel and Noël Coye (eds.), Dans l'épaisseur du temps: Archéologues et géologues inventent la préhistoire (Paris: MNHN, 20I I).

3 José María Lanzarote Guiral,'Le naturaliste, l'archéologue et l'anthropologue: De l'origine de la préhistoire en Espagne (I862-I880)', Bulletin du Musée d’anthropologie prébistorique de Monaco 53 (2013), 29-4I.

4 Marcelino Sanz de Sautuola, Breves apuntes sobre algunos objetos prebistoricos de la provincia de Santander (Santander: Telésforo Martínez, I880).

5 Éduard Harlé, 'La grotte d'Altamira, près de Santander, Espagne (avec une planche)', Matériaux pour l'Histoire Naturelle et Primitive de l'Homme I6 (I88I), 275-283.

6 Michael Hammond, 'Anthropology as a Weapon of Social Combat in Late-NineteenthCentury France', Journal of the History of the Behavioral Sciences I6.2 (I980), I I 8-I 32.

7 Nathalie Richard, 'De l'art ludique à l'art magique: Interprétations de l'art pariétal au XIXe siècle', Bulletin de la Société prébistorique française 90.I (I993), 60-68; Oscar Moro Abadía and Manuel Ramón González Morales, 'Presente-pasado. Definición y usos de una categoría historiográfica en historia de la ciencia: El arte prehistórico como paradigma', Complutum 16 (2005), 59-72.

8 Following the advice of the prehistorian Adrien d'Arcelin, Figuier introduced changes in the plates for the second edition of his work. See Noël Coye, N. La prébistoire en parole et en acte. Méthodes et enjeux de la pratique archéologique, 1830-1950 (Paris: L’Harmattan, I998), I63-I68; Claude Blanckaert. 'Les bases de la civilisation: lectures de "L'homme primitif" de Louis Figuier (I870)', Bulletin de la Société prébistorique française 90.I (I993), 3 I-49.

9 Émile Cartailhac, 'Les cavernes ornées de dessins. La grotte d'Altamira, Espagne. Mea culpa d'un sceptique', L'Anthropologie I 3 (I902), 348-354.

Io See B.G. Trigger, A History of Archaeological Thought (Cambridge: Cambridge University Press, 2006; ist ed. in I989); M. Díaz-Andreu García, A World History of NineteenthCentury Archaeology: Nationalism, Colonialism, and the Past (Oxford: Oxford University Press, 2007).

I I Marc-Antoine Kaeser 'The First Establishment of Prehistoric Science: The Shortcomings of Autonomy', in J. Callmer et al., Die Anfänge der ur-und frühgeschichtlichen Archäologie als akademisches Fach (1890-1930) im europäischen Vergleich (Berlin: Marie Leidorf, 2006), I 49-I60.

I 2 Sally Price, Primitive Art in Civilized Places (Chicago: University of Chicago Press, 200I); Ernst H. Gombrich, The Preference for the Primitive: Episodes in the History of Western Taste and Art (London: Phaidon, 2002); B. de l'Estoile, Le goût des autres. De l'exposition coloniale aux arts premiers (Paris: Flammarion, 2007).

I 3 Fanny Defrance-Jublot, 'Question laïque et légitimité scientifique en préhistoire: La revue L'Anthropologie (I 890-1910)', Vingtième Siècle. Revue d'bistoire 87.3 (2005), 73-84.

I4 Émile Cartailhac and Henri Breuil, La caverne d'Altamira à Santillana, près de Santander (Espagne) (Monaco: Imprimérie de Monaco, 1906). 
I5 Salomon Reinach, 'Lart et la magie', L'Anthropologie I4 (I903), 257-266; Eduardo Palacio Pérez, 'The Origins of the Concept of Palaeolithic Art: Theoretical Roots of an Idea', Journal of Archaeological Method and Theory (2012), 682-7I4.

I6 Henri Breuil and Fernand Windels, Four Hundred Centuries of Cave Art (London: Zwemmer, I952).

I7 Henri Bégouën, 'The Magic Origin of Prehistoric Art', Antiquity 3.9 (I929), 5-I9.

I 8 Henri de Lumley and Arnaud Hurel, Cent ans de prébistoire: L'Institut de Paléontologie Humaine (Paris: CNRS, 20II).

I9 Eduardo Ripoll Perelló, El abate Henri Breuil (1877-1961) (Madrid: UNED, I994); Noël Coye (ed.), Sur les chemins de la préhistoire: L'abbé Breuil du Périgord à l’Afrique du Sud. (Paris: Somogy, 2006); Arnaud Hurel, L'abbé Breuil. La vie et les travaux du 'Pape de la Préhistoire' (Paris: CNRS, 20II).

20 José María Lanzarote Guiral, 'La stratigraphie d'une vie consacrée à la préhistoire. L'abbé Hugo Obermaier, sa chaire de l'Institut de paléontologie humaine et les fouilles du Castillo', in Henri de Lumley and Arnaud Hurel, Cent ans de prébistoire. L'Institut de Paléontologie Humaine (Paris: CNRS, 201 I), 65-82.

2I Arnaud Hurel, La France préhistorienne de 1789 à 1941 (Paris: CNRS, 2007), chapter 5: I 49-I 77 .

22 Edward I. Fox, La invención de España: nacionalismo liberal e identidad nacional (Madrid: Cátedra, 1997); Carlos Forcadell (ed.), Nacionalismo e bistoria. (Zaragoza: Institución Fernándo el Católico, I998); Javier Varela, La novela de España: los intelectuales y el problema español (Madrid: Taurus, I999). Juan Sisinio Pérez Garzón (ed.), La gestión de la memoria: la historia de España al servicio del poder (Barcelona: Crítica, 2000); José Alvarez Junco, Mater dolorosa: la idea de España en el siglo XIX (Madrid: Taurus, 200I); Eric Storm, La perspectiva del progreso. Pensamiento politico en la España del cambio de siglo (1890-1914) (Madrid: Biblioteca Nueva 2001).

23 José María López Sánchez, Heterodoxos españoles. El Centro de Estudios Históricos, 19101936 (Madrid, Marcial Pons-CSIC, 2006).

24 Karl C. Krause, Compendio de Estética. Traducción de Francisco Giner de los Ríos (Sevilla: Jironés y Orduña, I 874). See María Rosario Caballero Carrillo, Inicios de la historia del arte en España: La Institución Libre de Enseñanza (1876-1936) (Madrid: CSIC, 2002).

25 'España está por descubrir y solo los españoles europeizados podrán hacerlo'. Miguel de Unamuno, En torno al casticismo (Madrid: Fernando Fé, I902).

26 Michela Passini, La fabrique de l'art national: Le nationalisme et les origines de l'histoire de l'art en France et en Allemagne (1870-1933) (Paris: Maison des Sciences de l'Homme, 2013).

27 B. Bassegoda i Hugas, Colleccionistes, colleccions i museus: episodis de la història del patrimoni artistic de Catalunya (Barcelona: Universitat Autònoma de Barcelona, 2007).

28 Santos Casado de Otaola, Naturaleza patria. Ciencia y sentimiento de la naturaleza en la España del Regeneracionismo (Madrid: Marcial Pons, 20 Io). Luis Enrique Otero Carvajal and José María López Sánchez, La lucha por la modernidad: las ciencias naturales y la Junta para Ampliación de Estudios (Madrid: CSIC, 20I2).

29 Marcos de la Rasilla Vives, 'La Comisión de Investigaciones Paleontológicas y Prehistóricas (I9I2-I939): algunas consideraciones sobre su andadura y su economía', Zona arqueológica 4.4 (2004), 402-407.

30 Marco de la Rasilla Vives and David Santamaría Álvarez, 'La institucionalización de la arqueología prehistórica en España durante el primer tercio del siglo XX', Revista de historiografía 5 (2006), I I 2 -I 33 . 
3I José María Lanzarote Guiral, 'Dangerous Intruders or Beneficial Influence? The Role of the Institut de Paléontologie Humaine in the Development of Prehistoric Archaeology in Spain (1900-1936)', Complutum 24 (2013), special issue: 'Speaking Materials: Sources for the History of Archaeology', ed. Oscar Moro Abadía and Christoph Huth, 33-42.

32 '[...] es el archivo de las primitivas civilizaciones, el cual, para suerte de la Ciencia española, poseemos en nuestra Patria y que, como españoles y pueblo culto, estamos en deber de conservar y estudiar'. Eduardo Hernández-Pacheco,'Estado Actual de las Investigaciones en España respecto a la paleontología y prehistoria', Actas del V Congreso de la Asociación para el Progreso de las Ciencias, Valladolid, 1915 (Madrid, I9I5), II7-I76, at I49.

33 '[...] el estudio de tan remotas pinturas ha sido hecho, en su mayor parte, por españoles, unas veces solos y aunque escasos de medios materiales, sobrados de entusiasmos y de ideales, de deseos por descubrir lo desconocido y maravilloso, y de constancia para estudiar lo relativo a tan sorprendentes monumentos; otras veces el estudio se hizo en alianza con investigadores extranjeros que sobrados de facilidades materiales, acudieron a la conquista científica del conocimiento de las más antiguas manifestaciones artísticas de la humanidad primitiva'. Eduardo Hernández-Pacheco, 'Exposición de Arte Prehistórico Español', Arte Español 5.7 (I92I), 315-339, at 316.

34 Hugo Obermaier, El Hombre Fósil. Memorias de la Comisión de Investigaciones Paleontológicas y Prehistóricas, 9 (Madrid: JAE, I9I6).

35 Henri Breuil and Hugo Obermaier, La cueva de Altamira en Santillana del Mar (Madrid: Tip. de Archivos, I935).

36 ' [... la base primera de la civilización española, en la que tienen su remota raigambre muchos fenómenos que después han constituido los grandes valores culturales que España ha creado para el mundo'. Pere Bosch Gimpera, introduction to El Arte en España: guía de la sección España primitiva del museo del Palacio Nacional (Barcelona: Herma, I929), 5. 

VII

Musicology

And Aesthetics
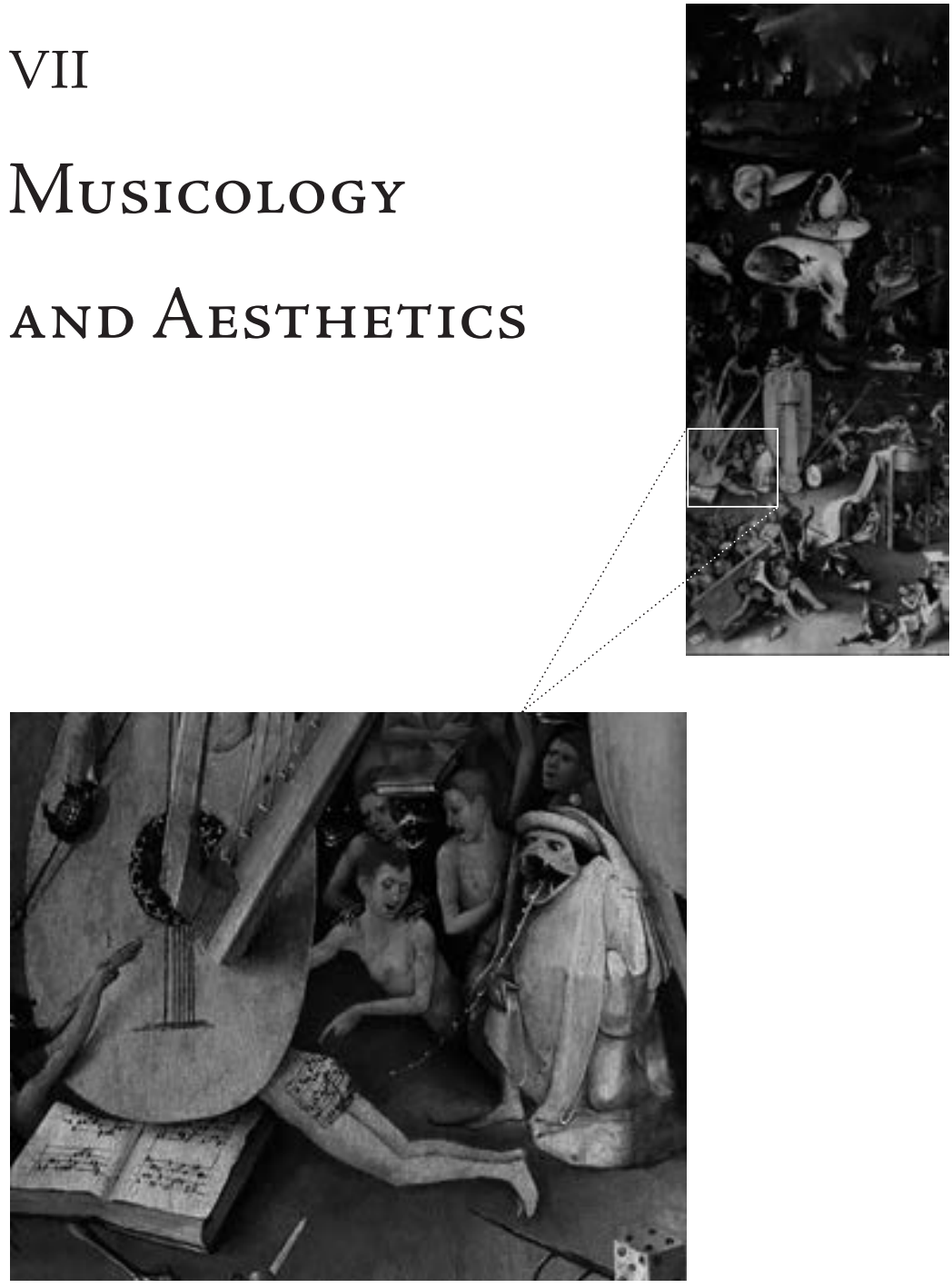



\title{
7+I Between Sciences and Humanities Aesthetics and the Eighteenth-Century 'Science of Man'
}

\author{
Maria Semi
}

\section{Introduction}

The sciences and the humanities have a long tradition of cultural crossings and reciprocal influences; this interwoven history, however, has been first somehow minimized and downplayed during the nineteenth century, and then simply slipped into a far corner of our memories - feeding on contemporary hyperspecialization and high disciplinary boundaries - until recent scholarly work evidenced how our narrow contemporary perspective was compromising a thorough understanding of the modern era. Positivism and the professionalization of academic disciplines brought about a very critical attitude toward the intellectual syncretism of the foregoing centuries. This had several consequences as, as well described by Richard Olson,

nineteenth-century practitioners of the human and social sciences virtually stopped reading and giving serious consideration to their eighteenth-century predecessors, taking literally the Comtian notion that knowledge of the human interactions in society attained the status of positive knowledge only in the nineteenth century. In this perception, they were cutting themselves off from their roots in a way that has persisted into the late twentieth century.

One of the many topics that surely suffered much from this historical denial and repression is the eighteenth-century notion of a 'science of man' (sic), a project which aimed at a global view and interpretation of man, considered as a sensible being. ${ }^{2}$ The topic I wish here to tackle is how aesthetic questions raised by the new 'science of man' studies of the eighteenth century were used both from a scientific and a humanistic perspective to enrich the reasoning on mankind. In this article I wish to show in particular, through the example of two eighteenth- 
century British authors, the significance that aesthetic issues held in the project of the science of man, and also show what rendered aesthetics - during the eighteenth century in Britain - an ideal bridge between the sciences and the humanities.

The change of man's image between the seventeenth and the eighteenth century 'from homme machine to homme sensible', following Moravia, ${ }^{3}$ and so the call into question of the iatromechanical model to describe man, brought about an interest for a scientific enquiry of sensibility and sensitivity. In this context sciences and humanities converged naturally, finding their focus on the same object, mankind, and thus exchanging ideas, lexicon, and mutually enriching each other. 'Aesthetics' as such did not exist in eighteenth-century Britain. However, I will use this term by the same reasoning Gary Hatfield used for the term 'psychology', which declined to our purpose would sound like this: if we agree that 'aesthetics' may be defined as the science of perception, then we can consider the questions pertaining to this discipline as part of what the early modern period called 'natural science' or 'natural philosophy'. Before the birth of the so-called cognitive sciences, much of the subject matter of aesthetics could be found in the realm of natural philosophy, where the interest in man's intellectual pleasures could find some basic and fundamental notions about the workings of that complex being which is man. Even if during the eighteenth century in Britain the word 'aesthetics' was not used, its subject matter was actively pursued in a way that was soon to be lost in the - eminently German - development of nineteenth-century aesthetics: 'aesthetics' was practiced in a way more consistent with one of the definitions Alexander Baumgarten gave it: a 'science of sensitive cognition' (cognitio sensitiva), which proved fully consistent with the British empiricist tradition. According to many important figures of that period (such as Hutcheson, Hume, Reid, Smith, Hartley, etc.) the interpretation of the artistic principle of imitation, or the understanding of the pleasure mankind experiences thanks to the works of art, passes through the examination of the mental faculties of man (the science of mind), but also of his body, as we will see in Hartley's case and his theory of vibrations. Thus, the eighteenth century bears witness to a particularly fruitful interaction between natural philosophers and humanists in the field of the art appreciation: new understanding of the functioning of the human mind (for example, the discovery by Locke of the principle of the association of ideas), and of the human body (the role played by nerves) was used to develop a new way of thinking about the arts, their perception, and how they affected man.

In the sketch I wish to outline here, perception finds itself in a specific position: right at the crossroads between body and mind, it also represents a possible bridge between the sciences and the humanities, between the supposed 
objectivity people usually associate with the word 'science', and the subjectivity of sensation. Between the seventeenth and the eighteenth centuries, with the development of experimental science and of the philosophy of mind, perception gains a foreground status, as sensation is considered the cornerstone upon which we build our ideas, which we afterwards connect together through the principle of association. Philosophers (both 'plain', and natural philosophers) focus on the connection between what we perceive and what we think or believe; they are interested in the bodily and mental processes that govern thought. Thus analysis of the brain's functioning becomes the starting point of theories as disparate as Adam Smith's theory of moral sentiments, Hume's theory of human belief, or David Hartley's theory of intellectual pleasures. Aesthetics enters the scene at this point as during the period we are referring to the issue of 'taste' was much debated, and it often cropped up in contexts that we would nowadays find awkward. It so happens, for example, that in an essay devoted to the constitution of man, such as Hartley's, we find an extensive discussion on the intellectual pleasures of the imagination (elicited by appreciation of the Fine Arts). It also occurred that one could find in John Gregory's A Comparative View of the State and Faculties of Man, with Those of the Animal World (1765) a chapter on the foundation of taste in music, or that the arts were discussed in an aesthetic context 'as they affect the mind', as witnessed by the title of James Beattie's essay 'On Poetry and Music, as They Affect the Mind' (1776). These are just a few examples which I bring here in order to emphasis that in a century, the eighteenth, which sought to develop a theory of man, humanities and sciences could (and had to) communicate at large, because the study of man as a whole needed both perspectives. Besides, even today the studies on perception show that human perception is always the result of both a quantitative and objective stimulus, which can be scientifically described (e.g., for the perception of sound, we can talk about the sound waves in terms of frequency, amplitude, etc.), and our mental elaboration of the stimulus, which communicates a different sensation to each and every man.

\section{Two examples: Hartley's and Darwin's theories of pleasure given by the arts}

David Hartley (1705-1757) was educated at Jesus College (Cambridge) where he studied medicine. His principal work is Observations on Man, His Frame, His Duty, and His Expectations, published in 1749, where he expounds his theory of vibrations and associations. As effectively resumed by Barbara Bowen Oberg: 
Hartley conceived of vibrations as movements backwards and forwards of the infinitesimally small particles, first of the nerves and then of the brain. Their movements were initiated by the impression of external objects upon any of the five senses. Excited and supported by the ether, these vibrations seemed at times for Hartley to become identical with pure sensation. And the nerves, spinal marrow, and medullary substance of the brain served as the instruments of sensation. Hartley alternated between the detailed inquiry of the neurologist puzzling out the working of the brain and the nervous system, and the task of a more traditional British empiricist philosopher tracing the progress from sensation to idea. Vibrations, the physical movement, and association, the mental phenomenon, were both important to him. ${ }^{5}$

Now, this treatise devoted to the topic of the progress from sensation to idea and to the explanation of the voluntary and involuntary movements of our body in terms of vibrations and nerves impulses, not only leads to a discussion on the 'Six classes of intellectual pleasure and pain', but was in fact occasioned by the desire to explain the idea that 'it was possible to deduce all intellectual pleasures and pains from association principles, ${ }^{6}$ an idea that Hartley derived from the dissertation of Reverend Gay of Sidney Sussex College, Concerning the Fundamental Principle of Virtue or Morality (1730). In his treatise, Hartley includes a chapter on 'The Pleasures and Pain of Imagination', which is further divided into 'The Beauties of the Works of Art', 'The Pleasures Arising from Music, Painting, and Poetry,' 'The Pleasures Arising from the Study of the Sciences,' 'Wit and Humour', etc. Hartley is interested in demonstrating how intellectual pleasures and pains are generated by way of association: a mechanism which has the peculiarity of being used by each and every man, but with different results. Speaking of association, Hartley writes that:

The influence of association over our ideas, opinions, and affections, is so great and obvious, as scarcely to have escaped the notice of any writer who has treated of these, though the word association, in the particular sense here affixed to it, was first brought into use by Mr. Locke. But all that has been delivered by the Ancients and the Moderns, concerning the power of habit, custom, example, education, authority, party-prejudice, the manner of learning the manual and liberal arts, etc. goes upon this doctrine as its foundation?

The influence of the associationists' theories on the topic of taste in eighteenthcentury Britain is a matter that is impossible to overestimate: Francis Hutcheson, Edmund Burke, Lord Kames, Hogarth, Alexander Gerard, and Archibald Alison 
all wrote treatises in which the theory of association was used, albeit differently, to discuss taste. This theory was always combined with theories of sensation and perception, as it was in the end the association elicited by perception which gave birth to pleasurable and painful ideas. Of these, every form of intellectual pleasure was to be examined, or, as it was often called, every form of 'pleasure of the imagination.' What is at work here is in fact an example of a fruitful communication of knowledge. Men of letters such as Kames and artists such as Hogarth read philosophical and medical treatises, in order to find material that was useful to their own considerations. Association, for example, provided one of the best means to develop theories that would respond to the challenge of the multiplicity of individual tastes, without obliging theorists to renounce the existence of something as a 'standard of taste'. There may in fact be a sort of objectivity in matters of taste, granted by factors such as unity and variety, symmetry, or the perception of quantitative relations. But the influence of experience and thus the diversity of associations, which these same objective factors generate in the human mind, could easily explain why it is so difficult to agree upon matters of taste. But the usefulness of this communication can also be seen the other way round, as matters pertaining to aesthetics gave topics and real 'case studies' to men of science, guiding their research through the questions they raised. This can be seen, for example, in those medical treatises which took interest in awkward 'musical phenomena' like the cure of the tarantula bite, or in all the medical uses of music which we nowadays call 'music therapy'.

The second example I wish to bring comes from a very well known book of the late eighteenth century: Erasmus Darwin's Zoonomia (I794-I796). In the preface to the book Darwin states his intentions, and explains that his aim is to describe animal life by an analytical method in order to give birth to a theory founded on nature that would display the laws of organic life. This theory, according to Darwin, would - among many other advantages - be useful to men in the perspective of the 'knowledge of themselves' ${ }^{\prime}$ : medical and moral interest are here bound. But what has Darwin's classification of the classes of motion to do with aesthetics? The answer lies in a section of Darwin's work, the 22nd, entitled: 'Of Propensity to Motion, Repetition and Imitation' [Fig. Io].

Darwin gives in this part of his work his interpretation of the pleasure which we receive from music in relation to time, repetition and a melodious succession of notes. He connects the analysis of these phenomena to the principles at the core of his theory of animal causation. The repetition of some stimulus at uniform intervals of time is agreeably perceived by our body 'because the sensorial power of association [...] is combined with the sensorial power of irritation ${ }^{10}$; that is, in common language, the acquired habit assists the power of the stimulus', thus: 

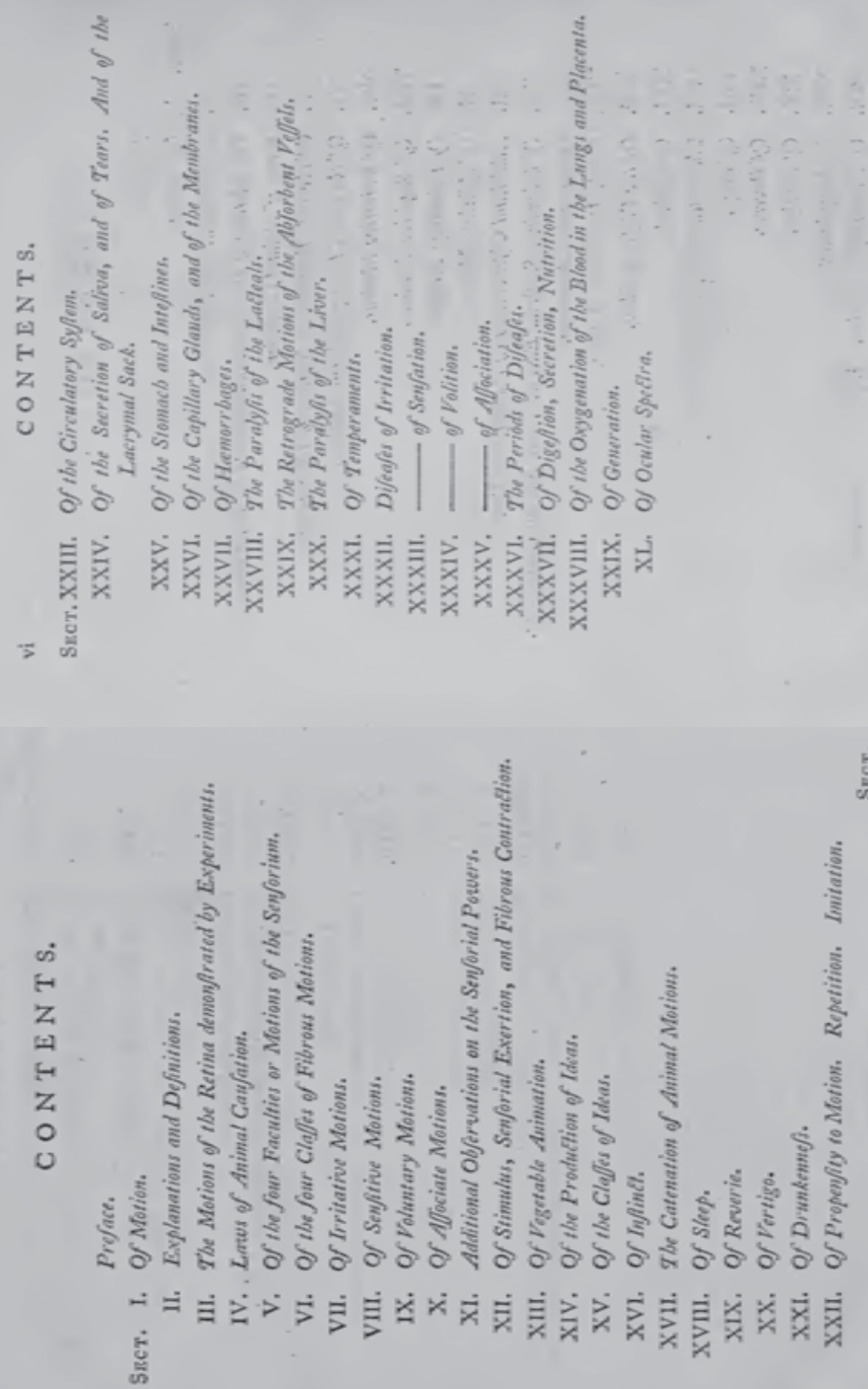

Fig. IO: Erasmus Darwin, Zoonomia; or, The Laws of Organic Life (London, 1794) 
To the facility and distinctness, with which we hear sounds at repeated intervals, we owe the pleasure, which we receive from musical time, and from poetic time. [...] There is no variety of notes referable to the gamut in the beating of the drum, yet if it be performed in musical time, it is agreeable to our ears; and therefore this pleasurable sensation must be owing to the repetition of the divisions of the sounds at certain intervals of time, or musical bars. Whether these times or bars are distinguished by a pause, or by an emphasis, or accent, certain it is, that this distinction is perpetually repeated; otherwise the ear could not determine instantly, whether the successions of sound were in common or in triple time. ${ }^{\text {II }}$

The four classes of motion belonging to life identified by Darwin (irritative, sensitive, voluntary, associate) and object of his treatise are used to explain why our body responds to music and rhythm in a way - similar to the one developed by Hartley - that considers both physical stimuli (irritation of fibers) and mental associations:

[B] esides these little circles of musical time, there are the greater returning periods, and the still more distant choruses, which, like the rimes at the ends of verses, owe their beauty to repetition; that is, to the facility and distinctness with which we perceive sounds, which we expect to perceive, or have perceived before; or in the language of this work, to the greater ease and energy with which our organ is excited by the combined sensorial powers of association and irritation, than by the latter singly. A certain uniformity or repetition of parts enters the very composition of harmony. Thus two octaves nearest to each other in the scale commence their vibrations together after every second vibration of the higher one. And where the first, third, and fifth compose a chord the vibrations concur or coincide frequently, though less to than in the two octaves. It is probable that these chords bear some analogy to a mixture of three alternate colours in the sun's spectrum separated by a prism. The pleasure we receive from a melodious succession of notes referable to the gamut is derived from another source, viz. to the pandiculation or counteraction of antagonist fibres. [...] If to these be added our early associations of agreeable ideas with certain proportions of sound, I suppose, from these three sources springs all the delight of music, so celebrated by ancient authors, and so enthusiastically cultivated at present. ${ }^{12}$

So we have a purely physical pleasure, in the case of harmony's perception, which is dependent on the coincidence of vibrations, caused by the principle of irritation; a pleasure given by rhythm, due to the pleasure we derive from repetition; and fi- 
nally the power of association grants us the third kind of pleasure, where our early musical experiences melt together with new ones, influencing their perception.

As we have seen these scientific discourses touch some particular fields related to the humanities, and especially the field of aesthetics - intended as the study of perception and particularly the perception related to arts - together with others I have not here dealt with (first of all morals). This communication between sciences and humanities, which is not a characteristic of the eighteenth century alone, gains in the British context a particular significance as it partakes in the project of a 'science of man' and brings about a new way of looking at mankind and its history. The eighteenth century sees 'the first explicit inclusion of humans in a comprehensive classification of natural organisms ${ }^{13}$ - which appeared in Linneus's Systema Naturae sive Regna Tria (1735) - in the same century Lord Monboddo looks at orangutans as specimens of precivilized men, 'living experiments' such as accounts of wild children were used to develop a historical account of human nature developed in a series of stages: thus physical, anthropological, linguistic enquiries all contribute to the forging of a conjectural history and an actual 'theory' of mankind.

It must be said that, although I have drawn all my examples from scientific works, the fruitful communication between sciences and humanities can also be seen the other way round. That is: not only did the arts foster the sciences with many an interesting question and case study, but the sciences themselves gave back to the arts words, ideas, theories. One of the primary ideas related to science, the idea of the 'experiment', and the lexicon of sciences are to be found in eighteenth-century literature and painting: let's just think about Joseph Wright of Derby's An Experiment on a Bird in the Air Pump, or A Philosopher Giving a Lecture on the Orrery in Which a Lamp Is Put in Place of the Sun, where the painter depicts a man of science explaining and demonstrating physical or astronomical theories, Swift's many descriptions of the functions of the brain as, for example, when in Gulliver's Travels (chap. 6) he describes a new system of government which should intervene when 'Parties in a State are violent' and that evoke an operation to be performed on a damaged brain, ${ }^{14}$ or again, many of the exhilarating scenes in Sterne's Tristram Shandy, as, for example, when he tries to explain Uncle Toby's confused reasoning by means of Locke's theories [Fig. II]. Further examples of this use of scientific or philosophical language or theories in the domain of art can also be found in the poetical works of Wordsworth, which have been read this way by Noel Jackson in his interesting Science and Sensation in Romantic Poetry, ${ }^{15}$ and also in musical treatises and histories, as I have tried to show in a former work. ${ }^{16}$ 


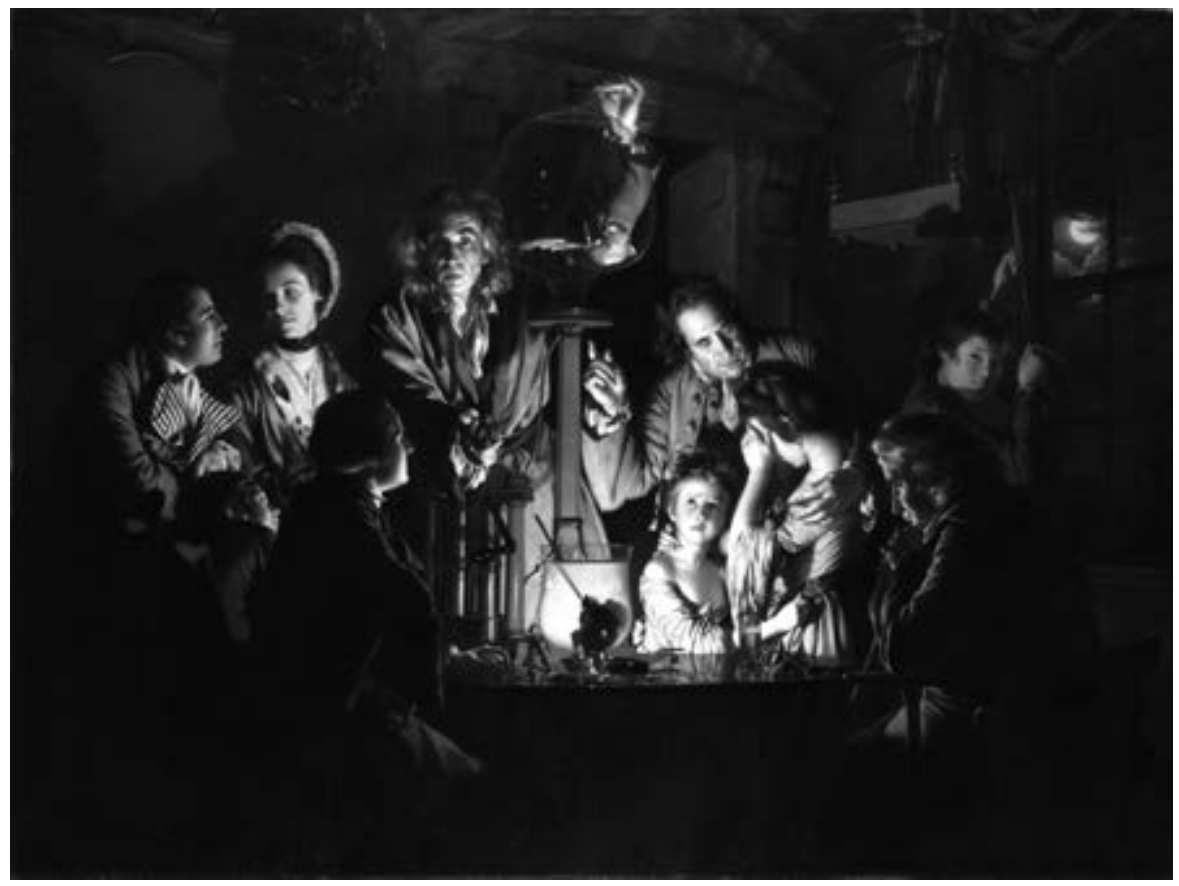

Fig. II. Joseph Wright of Derby, An Experiment on a Bird in the Air Pump, I768, oil on canvas, I $83 \times 244 \mathrm{~cm}$, National Gallery, London

\section{Conclusion}

These examples should give our theme a lot of topics for consideration. I will here conclude by singling out just two of them. First of all: the inquiry on mankind needed and still needs the perspective of humanists and scientists alike. The history of aesthetics, intended primarily in this context as the science of perception, furnishes many good examples of this need, and of the fruitful outcomes of this collaboration. When we deal with topics as 'taste', the beautiful or the sublime (just to name some of the most discussed topics of the eighteenth century), we speak both of external objects of appreciation, and of the feeling excited by these objects (works of art, natural scenes, etc.). This means we need to examine, study and describe the external objects as well as to examine, study and describe our feelings, and then try to understand how these two are connected. As man is made up of flesh, bones and mind, in order to understand the phenomena in which he is involved, we need - as was done in the eighteenth century, but obviously with research tools adapted to the twenty-first century - to consider all these aspects together. From this point of view, the eighteenth- 
century attempt to establish a 'science of man' can be considered a very ambitious project.

In the last decades many important researchers have devoted themselves to the study of the 'science of man $^{\text {'17 }}$ and brought back to life a whole world, whose light is appealing to us precisely because of its syncretism and capability to pursue some great humanistic ideals, which our actual environment does not seem able to think any longer, let alone to pursue actively. Much of this rediscovery of the project of a 'science of man' is due to a debate occasioned by Michel Foucault and by his well-known - and much discussed - work The Order of Things. ${ }^{18}$ In the final part of this work Foucault states that:

no philosophy, no political or moral option, no empirical science of any kind, no observation of the human body, no analysis of sensation, imagination, or the passions had ever encountered in the seventeenth or eighteenth century, anything like man; for man did not exist (any more than life, or language, or labour); and the human sciences did not appear when, as a result of some pressing rationalism, some unresolved scientific problem, some practical concern, it was decided to include man (willy-nilly, and with a greater or lesser degree of success) among the objects of science - among which it has perhaps not been proved even yet that it is absolutely possible to class him; they appeared when man constituted himself in Western culture as both that which must be conceived of and that which is to be known. ${ }^{19}$

The perspective promoted by the French philosopher was questioned by many scholars, among whom the figure of Jürgen Habermas stands out prominently, with his critique of Foucault's thought in his The Philosophical Discourse of Modernity. ${ }^{20}$ The secondary literature I here refer to in the footnotes contributes to the questioning of Foucault's interpretation of the eighteenth century by giving detailed analysis of how natural history, the study of language, medicine, conjectural history, the science of mind all converged into a project of a science of man'. My contribution, however modestly, inserts itself in this context, and I hope to have shown that the two crossed questions proposed to us by the organizers of the series of conferences on the "The Making of the Humanities' - i.e., what can we say about the 'making of the humanities', and how, in this context, should we examine the relationship between the 'sciences' and the 'humanities' - find an interesting case study precisely in the 'science of man' of the eighteenth century. 


\section{Notes}

I Richard Olson, 'The Human Sciences', in Roy Porter (ed.), The Cambridge History of Science, Vol. 4: Eighteenth-Century Science (Cambridge: Cambridge University Press, 2003), 436-462, at 462 .

2 David Hume uses the expression 'science of man' in his Treatise of Human Nature (New York: Dover, 2003), x: "Tis evident, that all the sciences have a relation, greater or less, to human nature; and that, however wide any of them may seem to run from it, they still return back by one passage or another. Even Mathematics, Natural Philosophy and Natural Religion are in some measure dependent on the science of Man'.

3 Sergio Moravia,'From Homme Machine to Homme Sensible: Changing Eighteenth-Century Models of Man's Image', Journal of the History of Ideas 39.I (I978), 45-60.

4 Gary Hatfield, 'Remaking the Science of Mind: Psychology as Natural Science', in Christopher Fox, Roy Porter, and Robert Wokler (eds.), Inventing Human Science (Berkeley: University of California Press, I995), I 84-23 I: "Let us agree that "psychology" may be defined as the science of the mind or of mental phenomena, and the subject matter of this science includes sense perception, imagination, memory, understanding or reasoning, feeling, and will. If we then interpret the term "natural science" (or "natural philosophy") as it was understood in the early modern period, psychology considered as a natural science already had a long history as the eighteenth century began' (p. I 84).

5 Barbara Bowen Oberg, 'David Hartley and the Association of Ideas', Journal of the History of Ideas 37 (I976), 44I-454, at 443.

6 Robert B. Glassman and Hugh W. Buckingham, 'David Hartley's Neural Vibrations and Psychological Association', in H. Whitaker et al. (eds.), Brain, Mind and Medicine: Neuroscience in the 18th Century (New York: Springer, 2007), 177-190.

7 Hartley, Observations, 42.

8 See Martin Kallich, The Association of Ideas and Critical Theory in England (The Hague: Mouton, I970).

9 Erasmus Darwin, Zoonomia; or, The Laws of Organic Life (London, I794; 2nd expanded ed., I 796): '[T] he purport of the following pages is an endeavor to reduce the facts belonging to ANIMAL LIFE into classes, orders, genera, and species; and, by comparing them with each other, to unravel the theory of diseases [...]. A theory founded upon nature, that should bind together the scattered facts of medical knowledge, and converge into one point of view the laws of organic life, would thus on many accounts contribute to the interest of society. It would capacitate men of moderate abilities to practice the art of healing with real advantage to the public; it would enable every one of literary acquirements to distinguish the genuine disciples of medicine from those of boastful effrontery, or of wily address; and would teach mankind in some important situations the knowledge of themselves'.

Irritation is defined by Darwin as an exertion or change of some extreme part of the sensorium residing in the muscles or organs of sense, in consequence of the appulses of external bodies' and an exertion of the spirit of animation exciting the fibres into contraction'. The concept of 'irritability' was first developed by Francis Glisson in his De naturae substantiae energetica (1672).

I I Ibid., 25I.

I2 Ibid., 252 .

I3 Olson, 'The Human Sciences', 450.

I4 Marjorie Perlman Lorch, 'Explorations of the Brain, Mind and Medicine in the writings of Jonathan Swift', in Whitaker et al. (eds.), Brain, Mind and Medicine, 345-352. 
I5 Noel Jackson, Science and Sensation in Romantic Poetry (Cambridge: Cambridge University Press, 2008).

I6 Maria Semi, Music as a Science of Mankind in Eighteenth-Century Britain (Farnham: Ashgate, 20I2).

I7 See, for example, Sergio Moravia, La scienza dell'uomo nel Settecento (Bari: Laterza, I970); John Christie, 'The Human Sciences: Origins and Histories', History of the Human Sciences 6 (I993), I-I 2; Fox, Porter, and Wokler, Inventing Human Science; Olson, 'The Human Sciences'; Peter Jones (ed.), The 'Science of Man' in the Scottish Enlightenment: Hume, Reid, and Their Contemporaries (Edinburgh: Edinburgh University Press, I989).

I 8 See David R. Hiley, 'Foucault and the Question of Enlightenment', Philosophy and Social Criticism II (I985-I986), 63-83.

I9 Michel Foucault, The Order of Things (London/New York: Routledge, 2002) (orig. Paris: Gallimard, I966), 376.

20 See, for example, James Schmidt, 'Habermas and Foucault', in M. Passerin d'Entrèves and S. Benhabib (eds.), Habermas and the Unfinished Project of Modernity (Cambridge, MA: MIT Press, I997), I47-I7I; S. Ashenden and D. Owen (eds.), Foucault contra Habermas (London: Sage, 1999). 


\title{
7.2 Melting Musics, Fusing Sounds \\ Stumpf, Hornbostel, and Comparative Musicology in Berlin
}

\author{
Riccardo Martinelli
}

\section{Naturalism and musical otherness}

Observations on the peculiarities that distinguish the music of various populations always raised the interest of philosophers and musicians. Ancient Greeks used to assign ethnic names such as Doric, Phrygian, Lydian, etc., to their different scales, but curiosity as to the variety of the exotic musical systems remarkably increased in the modern age. Geographic discoveries face the Europeans with puzzling forms of musical otherness, and some attention begins to be paid to the repertory of the domestic barbarians living in the countryside of cultivated Europe. ${ }^{I}$ Yet, it is only by the beginning of the twentieth century that a systematic discipline with genuine scientific ambitions eventually begins its process of institutional recognition under the name of comparative musicology. ${ }^{2}$

A major role in this process is played by Carl Stumpf and his pupil Erich Moritz von Hornbostel, who initiated the so-called Berlin School of vergleichende Musikwissenschaft [Fig. 12]. ${ }^{3}$ As they clearly recognized, technological progress has an important part in this development. Until then, the study of exotic music had relied upon the haphazard and amateurish transcriptions into the Western notational system made by missionary fathers or musically educated travelers. The possibility of recording music on Edison phonographic cylinders permanently changed this state of affairs. ${ }^{4}$ Primitive as they may appear today, phonographic recordings allow preservation, promote objectivity and provide a general idea of timbre and other performative characteristics of the recorded items.

Yet, intellectual factors must be also considered in the development of comparative musicology. As I shall argue, Stumpf's attitude toward the phenomena of music perception are among them. With his theory of 'tonal fusion', Stumpf demonstrates an anti-naturalistic and yet scientifically minded attitude, which he consciously opposes to Hermann Helmholtz's physiological explanation of the true foundations of music. In my view, Stumpf's rejection of Helmholtz's natural- 


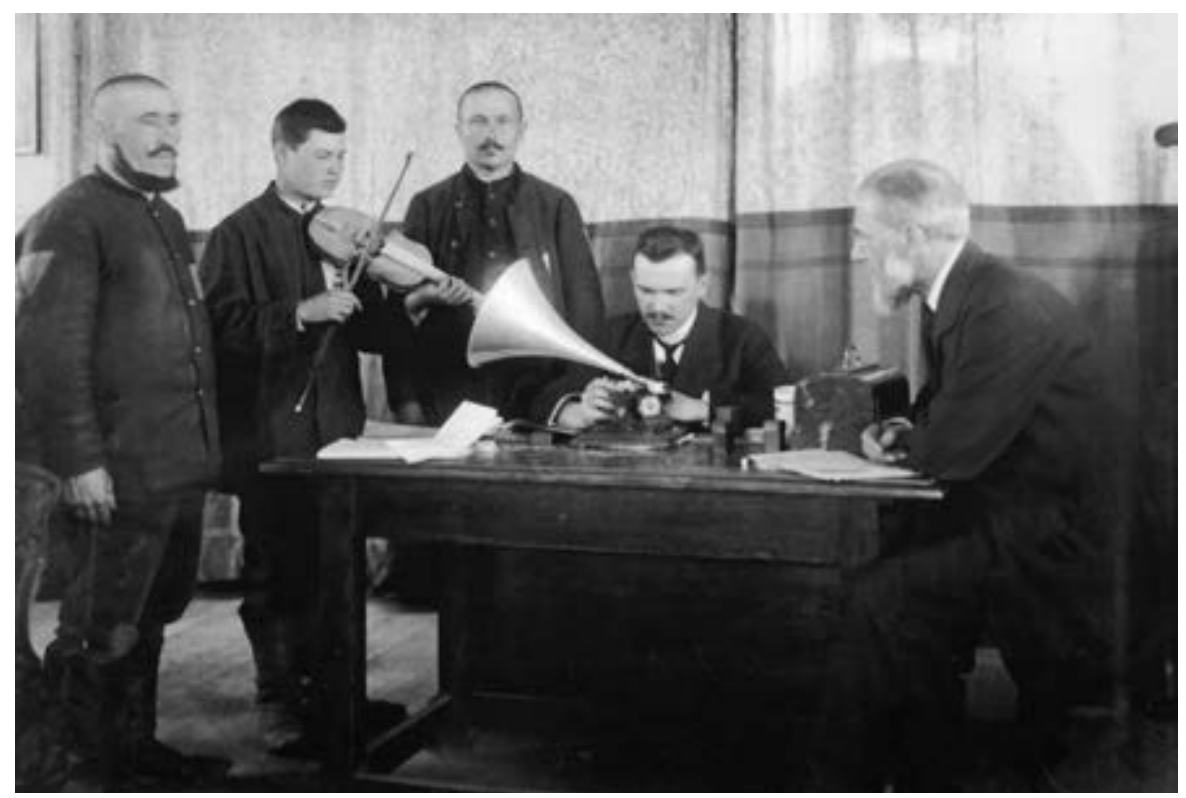

Fig. 12. Georg Schünemann and Carl Stumpf Recording Tatar Singers, 1916, photo, The Sound Archive of Humboldt University, Berlin (HZK Bilddokument ID8249,

Sammlungszugehörigkeit Lautarchiv, Inventar-Nr. Sign. Pn. 1003/5)

ism explains and justifies his interest toward extra-European and folk music as legitimate and autonomous objects of scientific study.

A short definition of what 'naturalism' means in this context is now appropriate. Naturalism is probably the mainstream in the history of philosophy of music, from the Pythagoreans to Zarlino, Rameau, Euler, Helmholtz and many others. Despite obvious differences, these thinkers share the general view that a convincing explanation of music should insist on the nature of sound, its mathematical or physical properties, whose structures are somehow reflected into musical facts by virtue - at least for modern naturalists - of the physiological structure of the ear. Helmholtz himself stresses the continuity between Pythagoras' 'enigma', as he says, and with Rameau, d'Alembert and Tartini, and his own solutions. ${ }^{5}$

Although this definition of naturalism may appear rather loose and generic, it will serve its relatively modest present scope. It should be noted, in fact, that naturalism allows and sometimes suggests an objective criterion for the classification of musical systems. In other terms, a frequent corollary (sometimes explicit, sometimes not) of naturalism is that Western tonal music satisfies the requirements of a 'perfect' musical system much better than any other form of music. This does not necessarily mean that naturalists ignore, dismiss or despise other forms of music. They aren't necessarily more Eurocentric than their adversaries 
or the average of their times. Helmholtz, who has a good knowledge of exotic musical systems, insists that the path toward perfect intonation has still to be accomplished even within Western tonal music. ${ }^{6}$ But naturalists sometimes incline to underestimate the differences among musical systems, perhaps in the ecumenical attempt of including all forms of music within their paradigm. Jean-Philippe Rameau, for instance, is deeply convinced that every people of the world actually uses tonal triads, at least in a melodic disposition, and that the savages sing using our same intervals or, as he says, 'aussi juste que nous.7 In his time, Jean-Jacques Rousseau had been able to distinguish the differences between musical systems with more precision; in Helmholtz's time, it was Stumpf who recognized them most clearly and felt the need for an independent science devoted to that subject.

\section{The Berlin School}

Stumpf's anti-naturalistic philosophical assumptions, then, have had a strong influence upon the origins of comparative musicology in Berlin. This link has been often neglected in literature, and surely not by accident. For opposite reasons, both musicologists and historians of philosophy often pay little attention to these marginal areas. The more so in the case of Stumpf, whose work is still nowadays relatively underestimated. ${ }^{8}$ Let us begin with a brief sketch of his life and work. Born in 1848 , young Carl Stumpf plans to devote himself half-professionally to music until he meets Franz Brentano, whose impressive intellectual figure leads him to philosophy. Stumpf later studies with Hermann Lotze in Göttingen, where he also attends Wilhelm Weber's lessons on physics. In I873 Stumpf begins his academic career: he is appointed professor in Würzburg, then in Prague, Halle, Munich and finally in Berlin, where he resides from I894 until his death in 1936. Erkenntnislehre, his two-volume work published posthumously, demonstrates that Stumpf, who retired in the I920s, remained an active thinker and writer until the last days of his long life. ${ }^{9}$

Although Stumpf follows Brentano's phenomenological (more precisely: descriptive) program in psychology, he also diverges from him in many aspects. Most notably, he has a deeper commitment in experimentation and in empirical science. Stumpf devotes a considerable amount of his time in the investigation of sound perception. He publishes his results in 1883 and in 1890 in two volumes entitled Tonpsychologie (Psychology of Sound)..$^{10}$ In Berlin, as a teacher and head of the Institute for Psychology, Stumpf has an important part in the birth of Gestalt psychology. Actually, the theories of Wertheimer, Koffka, and Köhler diverge from many of Stumpf's ideas; yet, his attitude toward phenomenological observation and experimental activity undoubtedly influences the Gestaltists' 


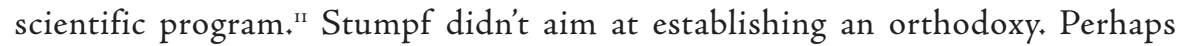
for this reason, the Berlin group (also including Kurt Lewin and, for a while, Robert Musil) respected him deeply, as manifested by the celebratory issue of the journal Psychologische Forschung on his 75 th anniversary. ${ }^{12} \mathrm{Had}$ not the Nazis dispersed the human and scientific heritage of the Berlin School, Stumpf's pioneering work in many fields of research would have been more widely remembered and recognized.

As far as ethnomusicology (as one would currently say) is concerned, Stumpf begins his career in Halle in I885 with a study on the songs of a North American Indian tribe. ${ }^{13}$ At that time Stumpf doesn't have a phonograph yet: his first recording occurs in Berlin, in $1900 .{ }^{14}$ In the same year, Stumpf sets up the Phonographic Archive (Phonogramm-Archiv), a collection of Edison cylinders whose direction is taken up by Hornbostel from 1905 to 1933. A Phonographic Archive aiming at recording both musical and spoken linguistic items had already been established in Vienna in 1899 . Yet the Berlin collection, focused on music, became the largest and most important in the world from this point of view. Stumpf and Hornbostel prompted their Berlin colleagues involved in expeditions to record music and songs of the visited countries. During the First World War, Stumpf could record songs of war prisoners from all over the world; a program of exchanges with Franz Boas also enriched the archive with many more cylinders and later also gramophone recordings. ${ }^{15}$

\section{Mixed sensations: Stumpf on tonal fusion}

In which sense, then, did Stumpf's philosophical stance influence and foster his interest toward exotic and folk music? Let us first consider Stumpf's key concept of 'tonal fusion' (Tonverschmelzung) as illustrated in the second volume of his Tonpsychologie. According to Stumpf, the basis of consonance lies in a tendency of the perceived tones to 'fuse together'. The more two given tones do so, the more they are perceived as consonant. Musical consonance is then the surface of a deeper psychological phenomenon, i.e., fusion. The definition given by Stumpf is the following:

Fusion is that relationship of two sense-perceived elements in which they form not a mere sum but rather a whole. The result of this relationship is that with greater levels of fusion the overall impression, under otherwise identical circumstances, approaches closer and closer to the one of a single perception, and becomes increasingly difficult to break down. ${ }^{16}$ 
As Wolfgang Köhler later recognized, Stumpf's speaking of the 'whole' in this passage represents a step forward in the direction of Gestalt theory.7 More significantly, however, Stumpf's ideas must be read in the light of ancient philosophical theories and their nineteenth-century developments. In the treatise concerning sensation in the Parva naturalia, Aristotle notes that mixed sensations, if compared with pure ones, are less easily perceived. This happens, for instance, in the case of wine or honey, but also for colors and sounds..$^{18}$ In Stumpf's times, these ideas of Aristotle's had been experimentally confirmed by the physiologist Ernst Heinrich Weber, to whom Stumpf had been introduced by his brother Wilhelm Weber, who was his teacher in physics. ${ }^{19}$ In a famous series of experiences concerning the sense of touch, which later also inspired Gustav Theodor Fechner's psychophysics, Ernst H. Weber had demonstrated that weighing two given bodies successively, with the same hand, improves our ability to discern the differences. By contrast, the simultaneous evaluation with both hands easily misleads us. In this case, Weber argues, the two sensations tend to 'mix' and then to confound the subject. ${ }^{20}$

Stumpf, who explicitly quotes Ernst H. Weber, ${ }^{21}$ does little more than applying this well-tested model to tonal perception. The two simultaneous sensations of tone (Tonempfundungen) mix and thus mislead the subject, who believes he is hearing one single tone. Thus, this error is the key to the whole phenomenon. According to Stumpf, systematic errors are of utmost importance in psychology, since they show how the perceptual system actually works. ${ }^{22}$ Stumpf experimentally determines five degrees of tonal fusion: the octave, the fifth, the fourth, the thirds and sixths (major and minor) and all the remaining intervals. ${ }^{23}$ However, we don't need to provide further details here. Despite being harshly criticized, ${ }^{24}$ Stumpf's idea of tonal fusion seems to still be attractive to psychologists and musicologists. ${ }^{25}$

It is remarkable that Stumpf consciously conceived tonal fusion as an alternative to the prevailing naturalistic approach of Hermann Helmholtz. In his Lebre von den Tonempfindungen (1863), Helmholtz offers an innovative and convincing explanation of musical perception. He shows that a complete set of fibers of different lengths that are located in the inner ear correspond to each audio frequency. ${ }^{26}$ Helmholtz draws on the classical comparison between the inner ear apparatus and a piano, whose strings are set free to resonate. Consonance thus originates from the physical and mathematical affinity of sounds. Many scholars, including, most notably, Ernst Mach, found this explanation partially inadequate: Helmholtz's liberality in admitting single resonating fibers and the correspondent specific nervous 'energies' seemed excessive. ${ }^{27}$ However, whereas Mach aims at correcting and ameliorating Helmholtz's theory, with tonal fusion Stumpf offers a radical alternative to it, thus diverging from the mainstream of his time. ${ }^{28}$ 
A remarkable consequence of Stumpf's researches is that music becomes possible through a sort of illusion, a failure of the perceptive system. Far from faithfully grasping the acoustic world by virtue of the analysis of sounds performed in the inner ear, music originates for Stumpf from a perpetual filter, which is permanently imposed upon human hearing. Tonal fusion is the scientific measure of this inertial force. As previously noted, Weber had shown the way human sensibility works: on the basis of his experimental work, he could ascertain the appropriate function (curve) for each sensory field. Similarly, Stumpf's experiments on fusion show the way human sensibility works whenever a multiplicity (Mebrheit) of simultaneous tones is involved. ${ }^{29}$ These aspects are capital to Stumpf's phenomenological approach, and help distinguishing it more clearly from naturalism..$^{30}$ Whereas in his opinion tonal fusion introduces a gap between sound as natural phenomenon and the perception of music, naturalists like Helmholtz tend to see a smooth transition from sound perception to the appreciation of music with its aesthetic content, suggesting that our ears provide us with a faithful picture of what is going on in the acoustic world. For Stumpf, by contrast, music becomes possible just because we (partly) fail to perceive the physical reality of acoustics as it is. As we all know, other forms of art, including cinema, are likewise based upon an illusion, a deception of the visual system which is unable to distinguish single frames in quick succession - as the Gestalt theorists knew very well. But music, with its sometimes almost inebriating effect, is perhaps more reminiscent of the Aristotelian example of a blended wine, whose mixing flavors would be irremediably lost for a merely analytical sense of taste.

\section{Stumpf as ethnomusicologist}

We have now a better overall view, enabling us to appreciate Stumpf's interest in exotic music and to interpret it correctly. As early as 1883 , in the preface to the first volume of Tonpsychologie, ${ }^{31}$ Stumpf includes the comparison of peoples and times' among the auxiliary methods of general psychology, and observes that their integration succeeds particularly in psychology of music. Two years later, in I885, in the above-mentioned study on North American Indians, Stumpf underlines the value of comparative research not only for the purposes of historical investigation, but also for those of psychology in general and for aesthetics..$^{32}$ Conversely, Stumpf stresses the importance of music for anthropology: a common patrimony of music systems or songs can bear witness of the common origin of distant human groups. In September 1900, in Berlin, Stumpf studies and records a royal orchestra coming from Siam (Thailand). Stumpf provides a detailed and accurate report on musical instruments, their tuning, the performed music and 
reports some experiences on some of the most gifted musicians' musical ear. This allows him to confirm Alexander Ellis's hypothesis that the musical scale adopted by Siamese musicians consists of seven equal intervals within an octave. Stumpf ends this exemplary essay with some methodological remarks. The utility of compared musicology for 'general ethnology and the history of humankind' is surely out of question; yet, Stumpf insists, it also represents a fruitful task for the psychologist or the aesthetics scholar who is ready to abandon the 'parlor of scholars' (Gelehrtenstube) and the method of self-observation, and wishes to 'widen his horizon by means of an objective study of human thinking and feeling [Denkens und Füblens] in other times and spaces., ${ }^{33}$ The more so, Stumpf concludes, since these forms of music presently die off as a result of the Europeans' cultural pressure: it is time to collect and to preserve them. His foundation of the Archive in the same year serves precisely to this scientific scope.

In I9Io, together with Hornbostel, Stumpf exposes his ideas and results to his colleagues at the Fourth Congress on Experimental Psychology of Innsbruck. He contrasts the old Herbartian introspective method with the open-mindedness of Theodor Waitz, a philosopher and psychologist who turned to ethnological research and wrote the monumental Anthropologie der Naturvölker. ${ }^{34}$ Psychology should open its doors to ethnological research and reconnect them with experimentation: both disciplines will profit from this process. The ideal path from tonal fusion to ethnomusicology is justified within the frame of a clearly stated and frequently reaffirmed scientific program. ${ }^{35}$

\section{Hornbostel: Music and culture}

Stumpf's younger friend and follower as director of the Archive, Erich Hornbostel, echoes these general ideas. Given his further achievements, he actually deserves Jaap Kunst's definition of 'facile princeps among all those who have made of ethnomusicology the chosen subject of their study'. ${ }^{36}$ Whereas Stumpf is permanently engaged in many different undertakings and academic commitments, Hornbostel intensively and primarily attends to comparative musicology, partly in cooperation with Otto Abraham and Georg Schünemann. Together with Curt Sachs, he devoted much effort to the study, the collection and the classification of musical instruments. ${ }^{37}$ With his friend Max Wertheimer, who himself studies the music of the primitive Weddas of Ceylon, Hornbostel especially investigates the psychological problem of perceiving the sound direction..$^{38}$

In an essay from i9io, Hornbostel underlines the close relation of musicology, ethnology and psychology. ${ }^{39}$ In analyzing the causes of the widespread intellectual resistance against comparative methods, Hornbostel keenly observes that 
many researchers are still convinced that music is everywhere a 'natural universal language' which deserves much more attention than any of its 'dialects'. Moreover, many are convinced that the so-called 'savages' are not able to bring out anything but 'noise and ugly uproar', which one should reasonably compare to animal cries and not to our music. Hornbostel is then much more explicit than Stumpf in his criticism of naturalism and of its Eurocentric implications.

Also in his case, a robust set of theoretic assumptions forms the background of his interest in comparative musicology. Rather than adopting Stumpf's tonal fusion, Hornbostel eventually develops an original theory of auditory perception of his own. His theses and results have been often criticized by psychologists and musicologists. In any case, Hornbostel is much closer than Stumpf to the Gestaltists' ideas. He pays special attention to two themes: the unity of senses and the holistic aspects of music perception:

What is essential in the sensuous-perceptible is not that which separates the senses from one another, but that which unites them: unites them among themselves, unites them with the entire (even with the non-sensuous) experience in ourselves, and with all the external world that there is to be experienced. ${ }^{40}$

Even more decidedly than Stumpf, Hornbostel thus rejects naturalism and conceives of music as cultural phenomenon. He also provides a gestalt-oriented interpretation of cultural phenomena. In his view, sensible and intellectual gestalts form a net, whose knots are joined together in different manners or 'styles' within different cultures. The musicologist aiming at reconstructing and interpreting styles should consider each element - a melodic or harmonic construct, a rhythmic figure, and so on - as a part in this net of interwoven 'wholes'. Some elements come from the composer's personality, some other from the historical and cultural context he belongs to. Surely not by chance, in this 1930 essay Hornbostel adds some conclusions concerning melting cultures and races: '[T] he crossing of races originates new races; the fusing of cultures (Kulturverschmelzung) leads to new cultures. In both cases, new styles arise. This generates something totally new, not a "hybrid"'.4

Three years later, identified by the Nazis as a 'half-Jew' (Halbjude), Hornbostel was relieved of his post and had to leave Germany, sharing the destiny of many other members of the Berlin School. He first moved to Switzerland and to the United States, and eventually reached Cambridge where he died two years later, at the age of fifty-seven. Needless to say, Hornbostel's interests and views were radically opposed to the plan to restore the supremacy of a purely German art over degenerate music. The Archive was transferred and went through difficult 
times. After the postwar recovery of its material legacy of wax cylinders, it is time to reconsider the virtuous link of philosophical ideas and scientific practice which gave rise to that enterprise.

\section{Notes}

I See Philip V. Bohlman, The Study of Folk Music in the Modern World (Bloomington: Indiana University Press, I988).

2 On this history and its many problems, including the definition of the discipline as comparative musicology or ethnomusicology, see Bruno Nettl, Music in Primitive Culture (Cambridge, MA: Harvard University Press, I956); Idem, The Study of Ethnomusicology: Twenty-Nine Issues and Concepts (Urbana: University of Illinois Press, I983), Idem, Nettl's Elephant: On the History of Ethnomusicology (Urbana: University of Illinois Press, 20I 2); Alan Merriam, The Anthropology of Music (Evanston, ILL: Northwestern University Press, 1956); Bruno Nettl and Philip V. Bohlham (eds.), Comparative Musicology and Anthropology of Music: Essays on the History of Ethnomusicology (Chicago: University of Chicago Press, I99I).

3 Dieter Christensen, 'Erich M. von Hornbostel, Carl Stumpf, and the Institutionalization of Comparative Musicology', in Arthur Simon (ed.), Das Berliner Phonogramm-Archiv 1900-2000 - Sammlungen der traditionellen Musik der Welt/The Berlin Phonogramm-Archiv 1900-2000: Collections of Traditional Music of the World (Berlin: Verlag für Wissenschaft und Bildung, 2000), I4I-I 50 .

4 Erika Brady, A Spiral Way: How the Phonograph Changed Ethnography (Jackson: University Press of Mississippi), I999, where Stumpf is yet never quoted, and Hornbostel only once.

5 Hermann von Helmholtz, Die Lebre von den Tonempfindungen als physiologische Grundlage für die Theorie der Musik, trans. Alexander J. Ellis, On the Sensations of Tone as a Physiological Basis for the Theory of Music (London, New York: Longmans, Green, and Co., I 885; repr. New York: Dover, I954), 229.

6 Helmholtz, On the Sensations of Tone, 514, 522.

7 Jean-Philippe Rameau, Code de Musique pratique, ou, Méthodes pour apprendre la musique [...]. Avec des nouvelles réflexions sur le principe sonore (Paris: Imprimerie Royale, I760), 216.

8 However, Stumpf's work is getting more and more attention among scholars. See the translation of his Die Anfänge der Musik (I9I I): Carl Stumpf, The Origins of Music, ed. by David Trippett (Oxford: Oxford University Press, 20I2), in a volume also including Stumpf's Selbstdarstellung (I924): 'Carl Stumpf: A Self-Portrait', I 89-252) and two introductory essays by Helga de la Motte-Haber ('Carl Stumpf: Impulses toward a Cognitive Theory of Musical Evolution', 3-I6) and David Trippet ('Carl Stumpf: A Reclutant Revolutionary', I 7-29). See also Nadia Moro, Estetica trascendentale in musica. La psicologia del suono di J.F. Herbart e C. Stumpf (Milano: Mimesis, 2012). Historians of psychology have also begun to recognize Stumpf's pioneering role. See H. Sprung, Carl Stumpf. Eine Biographie. Von der Philosophie zur experimentellen Psychologie (Munich-Vienna: Profil, 2006).

9 Carl Stumpf, Erkenntnislehre, ed. Felix Stumpf, 2 vols. (Leipzigः Barth, I939-I940).

Io Carl Stumpf, Tonpsychologie, 2 vols. (Lepizig: Hirzel, I883-I 890, repr. Amsterdam: Bonset I965). 
I I See Mitchell G. Ash, Gestalt Psychology in German Culture, 1890-1967: Holism and the Quest for Objectivity (Cambridge: Cambridge University Press, I995), 28-4I and passim.

Festschrift Carl Stumpf zum 75. Geburtstag in Dankbarkeit und Verehrung gewidmet, special issue of Psychologische Forschung 4 (1923).

I 3 Carl Stumpf, 'Lieder der Bellakula-Indianer', Vierteljahrsschrift für Musikwissenschaft 2 (I 886), 405-426. See Martin Müller, 'Carl Stumpf auf dem Wege zur vergleichenden Musikpsychologie', in Margret Kaiser El-Safti and Matthias Ballod (eds.), Musik und Sprache. Zur Phänomenologie von Carl Stumpf (Würzburg: Königshausen \& Neumann, 2003), 2 II-223.

I4 Carl Stumpf,'Tonsystemen und Musik der Siamesen', Beiträge zur Akustik und Musikwissenschaft 3 (I90I), 69-I38.

I5 Simon (ed.), Das Berliner Phonogramm-Archiv, passim. The book contains documents and informations concerning the history of the Archive from its foundation to recent times.

I6 Stumpf, Tonpsychologie, vol. 2, I28.

I7 Wolfgang Köhler, Die physischen Gestalten in Ruhe und im stationären Zustand. Eine naturphilosophische Untersuchung (Braunschweig: Vieweg \& Sohn, I920), 34.

I8 Aristotle, Sens., vii, 447a I7-I 8, in Parva naturalia, ed. David Ross (Oxford: Oxford at the Clarendon Press, I995).

I9 Carl Stumpf, Selbstdarstellung, trans. Thomas Hodge and Susanne Langer, in Carl Murchison (ed.), History of Psychology in Autobiography (Worcester, MA: Clark University Press, I930), vol. I, 389-44I.

20 Ernst Heinrich Weber, Die Lehre vom Tastsinne und Gemeingefühle, auf Versuche gegründet (Braunschweig: Vieweg, I 850), 85-86.

2 I Stumpf, Tonpsychologie, vol. 2, 6I.

22 Ibid., vol. I, vii.

23 Ibid., vol. 2, I35.

24 Christian Allesch, 'Zur Rezeption von Carl Stumpfs Tonpsychologie', in Kaiser-El-Safti and Ballod (eds.), Musik und Sprache. Zur Phänomenologie von Karl Stumpf, 225-236.

25 See, e.g., David Huron,'Tonal Consonance versus Tonal Fusion in Polyphonic Sonorities', Music Perception 9 (I99I), I 35.

26 Helmholtz, On the Sensations of Tone, passim.

27 Ernst Mach, Die Analyse der Empfindungen und das Verbältnis des Physischen zum Psychischen, trans. C.M. Williams, The Analysis of Sensations and the Relation of the Physical to the Psychical (New York: Dover, I959), 276.

28 See also Riccardo Martinelli, 'Brentano and Stumpf on Tonal Fusion', in Denis Fisette and Guillaume Fréchette (eds.), Themes from Brentano (Amsterdam: Rodopi, forthcoming 2013).

29 Notwithstanding this attitude, Stumpf does not aim at any 'psychophysics' of sounds: his goal is to measure 'sense-judgments' (Sinnesurteile), not sensations. In this sense, his Tonpsychologie is defined as a 'doctrine of the measurement of judgments' (messende Urteilslehre). Stumpf, Tonpsychologie, vol. I, 54. See Alexandra Hui, The Psychophysical Ear: Musical Experiments, Experimental Sounds, 1840-1910 (Cambridge, MA: MIT Press, 20I3); unfortunately, haven't yet been able to consult this book.

30 On Stumpf's phenomenology and its divergence from Husserl's, see Robin R. Rollinger, 'Stumpf on Phenomena and Phenomenology', Brentano Studien 9 (200I), I49-I66.

3 I Stumpf, Tonpsychologie, vol. I, vi.

32 Stumpf,'Lieder der Bellakula-Indianer', 89.

33 Stumpf,'Tonsystemen und Musik der Siamesen', I67. 
34 Carl Stumpf and Erich Moritz von Hornbostel, 'Über die Bedeutung ethnologischer Untersuchungen für die Psychologie und Ästhetik der Tonkunst', in Friedrich Schumann (ed.), Bericht über den IV Kongress für experimentelle Psychologie (Leipzig: Barth, I9II), 256-259. See Theodor Waitz, Anthropologie der Naturvölker, vol. I, Über die Einheit des Menschengeschlechtes und den Naturzustand des Menschen (Leipzig: Fleischer, I 859).

35 A strong connection of comparative musicology with psychology clearly emerges. 'Early musical ethnology does not begin as musicology': Sebastian Klotz, 'Hornbostels Nadelkurven', in Sebastian Klotz (ed.), Vom tönenden Wirbel menschlichen Tuns. Erich M. von Hornbostel als Gestaltpsychologe, Archivar und Musikwissenschatfler (Milow: SchibriVerlag, I998), I93.

36 Jaap Kunst, Ethnomusicology: A Study of Its Nature, Its Problems, Methods and Representative Personalities (The Hague: Nijhoff, I974), i 8.

37 Erich von Hornbostel and Curt Sachs, 'Systematik der Musikinstrumente. Ein Versuch', Zeitschrift für Ethnologie 46 (I9I4), 553-590.

38 Erich von Hornbostel and Max Wertheimer, 'Über die Wahrnehmung der Schallrichtung', Sitzungsberichte der Preussischen Akademie der Wissenschaften 20 (I920), 388-396. For a bibliography of Hornbostel's writings, see Erich Moritz von Hornbostel, Tonart und Ethos: Aufsätze zur Musikethnologie und Musikpsychologie (Lepizig: Reclam, 1986), 369377 .

39 Erich von Hornbostel, 'Über vergleichende akustische und musikpsychologische Untersuchungen', Zeitschrift für angewandte Psychologie und psychologische Sammelforschung 3 (I910), 465 .

40 Erich von Hornbostel, 'Die Einheit der Sinne', trans. Elizabeth Koffka and Warren Vinton,'The Unity of the Senses', Psyche 7 (I927), 87.

4I Erich von Hornbostel, 'Gestaltpsychologisches zur Stilkritik', in Studien zur Musikgeschichte. Festschrift für Guido Adler zum 75. Geburtstag (Vienna: Universal, I93), I4. 



\title{
7+3 The History of Musical Iconography and the Influence of Art History
}

\author{
Pictures as Sources and Interpreters of Musical History
}

\author{
Alexis Ruccius
}

\section{Introduction}

Musical iconography is a prime example of a research field that emerged through the affiliation of two disciplines from the humanities. Over a period of 150 years, musicologists had already turned to art works in search of visual evidence to guide in the reconstruction of musical instruments and historical performance practices. Understood as being fundamentally representational in nature, pictures were used as reliable historical sources, by Julius Rühlmann or Hugo Leichtentritt, for example. In the twentieth century, under the influence of the Warburg School, this field of study expanded into an independent research field known as 'musical iconography'. Aiming at more that the mere reconstruction of historical instruments, the ideological content of musical representations now came into focus. Pictures were analyzed as artifacts capable of revealing insights into the history of ideas, for instance, a period's understanding of music. With the introduction of iconography and iconology into the discipline, the connection between musicology and art history became firmly established. ${ }^{I}$ The core methods of musical iconography derive both from musicology (musical theory and organology) and from art history (iconography and iconology). Musical iconography is hence founded upon an interdisciplinary relationship between these two humanities subjects.

This interrelation is emphasized by most definitions for 'musical iconography', the last part of which is composed of graphein, the Greek term for 'describing', and eikón, meaning 'picture. ${ }^{2}$ In 1984, Reinhold Hammerstein (1910-2010) defined musical iconography as a field in which two disciplines merge: musicology and art history. In his words, it is a sector marked by the relationship between the world of beholding and that of hearing in general., ${ }^{3}$ In 1997, Tilmann Seebaß (1939-), editor of the first journal of musical iconography, Imago Musicae, summed up the difficulties of the field as follows: 
Musical iconography requires both art-historical and musicological expertise. Whoever doesn't possess both will encounter analytical difficulties, be it because he misjudges the idiosyncrasies of the visual medium, or because he lacks the necessary organological, terminological, or socio-historical knowledge. ${ }^{4}$

Seebaß therefore concluded that one should follow the intrinsic clues of the artwork by applying the methods and expertise of musicology and art history. Otherwise, he warned, the artwork's meaning could not be fully grasped.

At the time of its emergence, the eventual title of the research field, 'musical iconography', had not yet been coined. One of its later subsectors, the reconstruction of musical instruments and historical performance practices with the help of visual representations, in fact evolved within the research field of organology. With the development of the term 'Musikwissenschaft' (musicology) and the establishment of the first professorships for music in I826 in Germany, studies dealing with musical iconography became increasingly common in organology. ${ }^{5}$ For instance, in Guido Adler's classification of musicological subdisciplines of I885, they are listed in the historical block under the section 'History of Musical Instruments. ${ }^{6}$ The introduction of the composite term 'musical iconography' signalizes the gradual institutionalization of the subject. It was first used in 1922 by William Barclay Squire in reference to a collection of musicians' portraits. ${ }^{7}$ In 1954, Albert G. Hess applied the term to a collection of pictures that was meant to function as an 'important documentary source' for performance practice and instrument reconstruction. ${ }^{8}$ Since 1971, the year in which the Répertoire international d'iconographie musicale was founded as the first institution devoted explicitly to musical iconography, the term has been more broadly defined to also include iconographical and iconological studies. ${ }^{9}$

\section{Establishment under the umbrella of organology: Pictures as sources}

Julius Rühlmann (1816-I877) devoted himself to the reconstruction of bow instruments with the aim of reacquiring the musical knowledge of a period and performing historical pieces in the original manner. ${ }^{10}$ In his posthumously published Geschichte der Bogeninstrumente (I882), he depicted bows and bridges of string instruments, which he had copied from historical manuscripts, prints, and paintings. For example, he virtually took the bow of a fiddling angel from Raphael's Coronation of the Virgin (1502-1504) out of its hand in order to use it as a historical source in his book, where he depicted it in isolation from its original context 


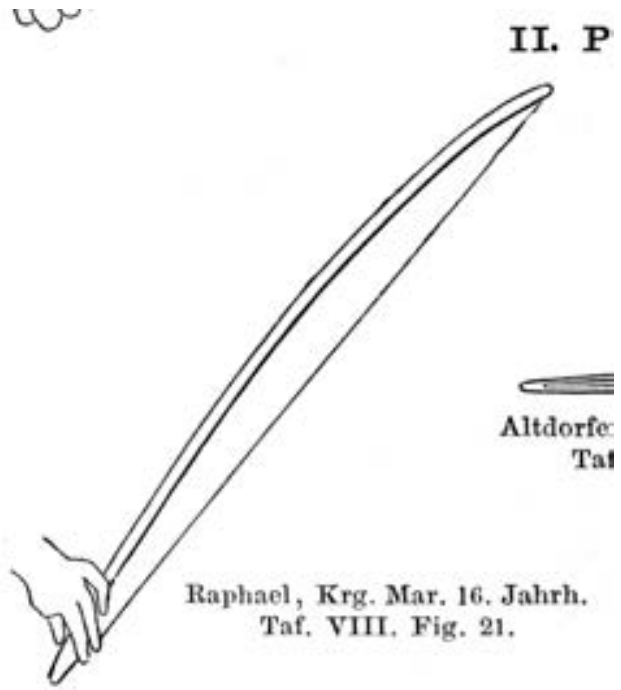

Fig. 13. From Julius Rühlmann, Geschichte der Bogeninstrumente (Braunschweig I882), p. 144 (detail)

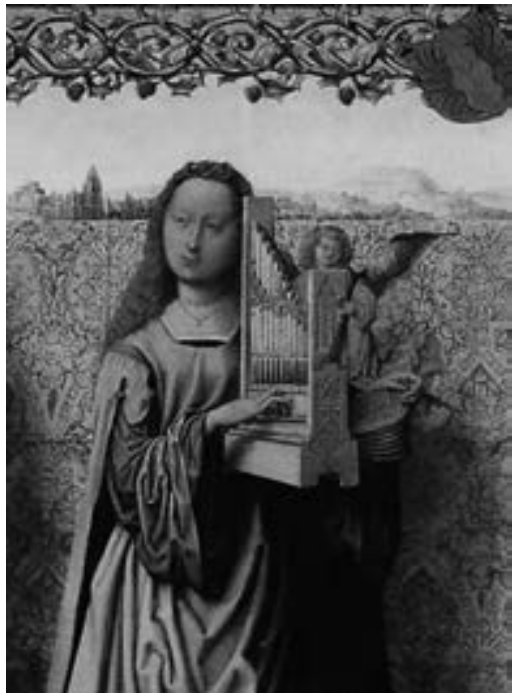

Fig. 14. Master of the Bartholomew Altar, Bartholomew Altar, c.1500-1510, oil on oak, $129 \times 16 \mathrm{I} \mathrm{cm}$, Alte Pinakothek, Munich, Nr. II863 (central panel, detail with Saint Cecilia)

[Fig. 13]. Rühlmann concentrated his efforts strictly on the form and its development. 'In the second period, we observe that the strongly arched shape of the stick has been maintained, but already shows signs of a frog and a head. The latter begins to develop from the other two forms in the fifteenth century." By means of this extraction from visual sources, Rühlmann tried to gain insight into the construction of musical instruments in different centuries and to trace their formal development. In doing so, he interpreted pictures as blueprints for his reconstructions.

Taking an approach similar to Rühlmann's, Hugo Leichtentritt (1874-195I) attempted to reconstruct historical performance practices. In his article 'Was lehren uns die Bildwerke des I4.-I7. Jahrhunderts über die Instrumentalmusik ihrer Zeit?' (1906), he analyzed paintings, prints, and manuscripts. Leichtentritt lists a large number of artworks and comments on them. For instance, he describes the depiction of St. Cecilia on the Bartholomew Altar (around 150I-1503). With her right hand, she plays a portative, while she presses the bellow with her left to elicit a sound from the organ pipes [Fig. 14]. According to Leichtentritt, the painting proves the existence of a transitional period between the solo song performances of the twelfth century and the accompanied songs of the seventeenth century. ${ }^{12}$ Leichtentritt interpreted the picture as a reliable historical source, just 
like Rühlmann had done, using the artwork as a blueprint for a historical performance practice.

However, in Rühlmann's as well as in Leichtentritt's publications, the strength of the image shimmers through. A double page in Rühlmann's book shows bridges of various string instruments [Fig. I5 below]. Rühlmann identified a series of stylistic periods and categorized the bridge shapes according to their alleged developmental stages. The climax of this evolution in form is Stradivari's bridge [Fig. I5, lower right].

The final perfection is only achieved in a seventh period of the bridge, at the beginning of the seventeenth century [...]. [T] he high point, which could not be superseded, is [reached] with Ant. Stradivari [...]. The latter has hence remained the exemplary [style] and is still in use today. ${ }^{\mathrm{13}}$

Rühlmann's study of the different shapes of musical instruments was guided by the assumption that paintings, prints, and manuscripts depicted them naturalistically. The musical instruments themselves he considered independent works of art belonging to certain styles. Rühlmann established a sequence that allegedly revealed the evolutionary development of form and thereby historically confirmed the unique sound of a Stradivari. The instrument makers became artists designing instrument shapes. In Leichtentritt's essay, a first iconographical approach appears rather incidentally. He surmises that the depictions of St. Cecilia result from a misinterpretation of the biblical text. Despite the sound of the roaring organ, she sang a song in her heart, a song to God'. ${ }^{14}$ Leichtentritt points to the possibility that the text was understood'as if she [St. Cecilia] [indeed] sang to the sound of the organ.' ${ }^{15}$ Thus Leichtentritt offered a first reading of the painting that transcended a mere reconstruction of performance practice and understood the painting itself as an interpreter.

\section{Iconography as the driving force of institutionalization: Pictures as interpreters}

By integrating the iconographical and iconological method of the scholars in the circle around Aby Warburg (I866-I929), musical iconography began to develop into an independent discipline. ${ }^{16}$ Pictures were understood as interpreters. An analysis in this broader sense investigates the relationship between sound and image, conceived as an entity in the history of thought as related to music. Leo Schrade's (1903-1964) Die Darstellung der Töne an den Kapitellen der Abteikirche zu Cluni (1929) must be considered a milestone in this regard. In the 

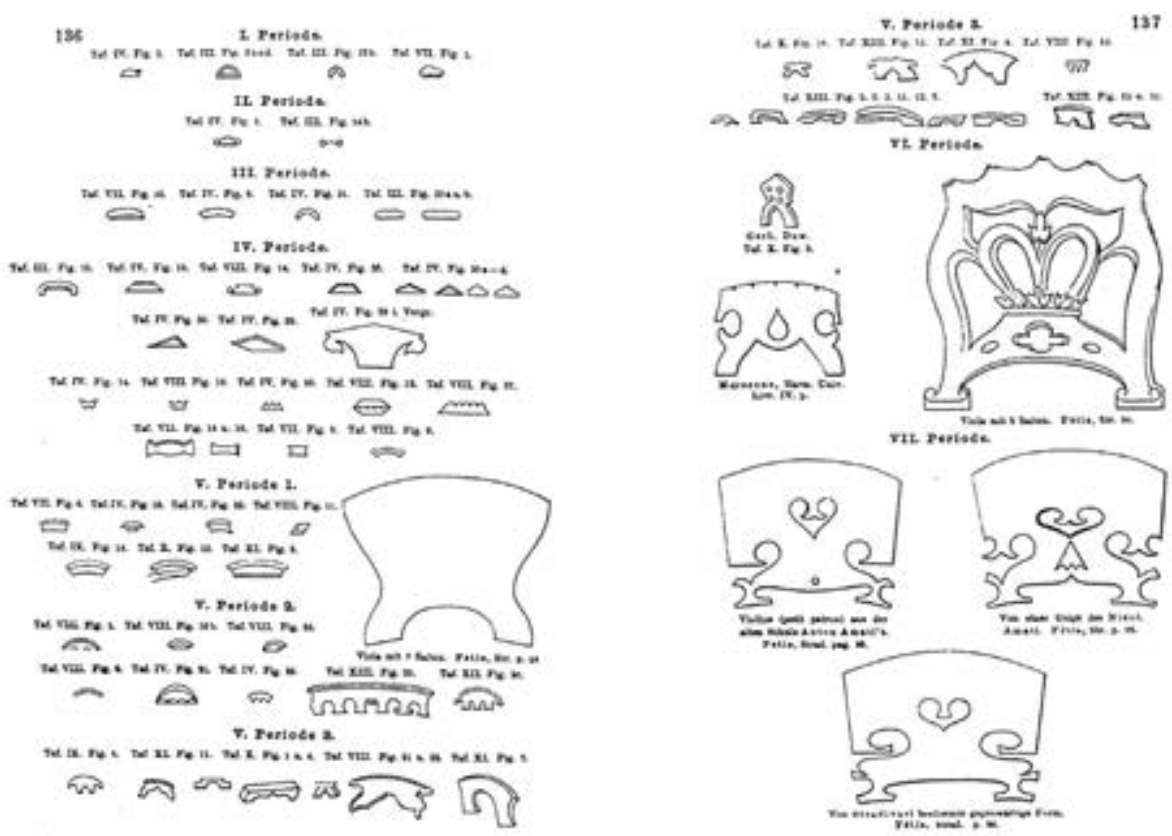

Fig. 15. From Julius Rühlmann, Geschichte der Bogeninstrumente (Braunschweig, I882), p. 138-139

Cluny Abby, two capitals show figurative representations of the church modes. According to Schrade, this was not only a way of visualizing the modes. He understood them as a symbol of the conception of music prevalent at the time of their origin. For this reason, he not only dealt intensively with musical theory but also with its forms of representation and their symbolic content. The second mode, for example, is depicted as a female figure [Fig. I6]; she is playing the cymbals, while her body is leaning slightly to the left. Schrade claims that this is meant to represent the vexationes, which symbolize the melodia anfracta. According to contemporary musical theory, this would imply a melody in the second church mode, which, as Guido of Arezzo noted, contains leaps (anfractis). ${ }^{17}$ By applying his expertise in musical theory, Schrade convincingly interpreted the posture of the female figure as a figura anfracta. Schrade's essay revealed the argumentative force of an analysis that unites musicological and art-historical methods. Receiving its impetus from iconography and iconology, his essay gave the impulse for other scholars, like Willibald Gurlitt (1938) or Reinhold Hammerstein (1959), ${ }^{18}$ which lead to the institutionalization of the research field in I97 I with the foundation of the Répertoire international d'iconographie musicale, and Imago Musicae, the first periodical dedicated entirely to music iconography. 
One of the first major music-iconographical works to be broadly received in art history, thus achieving a reflux of theory from musicology into art history, was Hammerstein's 1974 book, Diabolus in musica. ${ }^{19}$ The climax of the book is his analysis of the Musicians' Hell by Hieronymus Bosch. The right wing of Bosch's triptych The Garden of Earthly Delights (around 1500) shows a gigantic lute with six strings standing on a music book [Fig. 17]. A harp is stuck into the side of the lute and a naked man is hanging in its strings as if crucified. Another man is bound to the neck of the lute, with his hands on his back. Bosch enlarged the musical instruments to use them as instruments of torture. The motif of the Musicians' Hell was commonly ascribed to Bosch's imagination. ${ }^{20}$ Hammerstein, however, was able to relate the motifs to existing models and traditions, while he at the same time succeeded in accentuating Bosch's personal reinterpretation. The harp, for instance, was at the time considered a heavenly instrument; by misappropriating the harp as an instrument of torture, Bosch not only used contemporary musical concepts as a basis for his painting, but also introduced his own interpretation. According to Hammerstein, Bosch's musical scenes are 'accusations and part of a call for penitence in times of deep arousal and skepticism, expressions of a crumbling belief in any kind of prestabilized harmony of the world' ${ }^{21}$ Hammerstein understood the picture as an independent entity and as an interpreter of the musical conceptions of a historical period. The

attempt to introduce the iconography of music [...] as an independent research field into musicology [...] is motivated by the conviction that relevant evidence from the visual arts does not possess a mere accessory, adorning, and illustrative character for the music historian, but that, correctly understood, it conveys essential and novel facts with regard to music and the musical conceptions of a period. ${ }^{22}$

By this time, pictures had become established as idiosyncratic interpreters in the discipline of musicology, thanks to the advances made in musical iconography.

Today this field has continued to be a prolific part of the present discussions, like the question about the exchange between cultures. ${ }^{23}$ The case history of musical iconography shows that, at the time when the humanities emerged, an exchange between two disciplines produced a new and independent field of study. The immanent strength of pictures was a main driving force behind the research field's foundation. Musical iconography helped scholars to fruitfully analyze artifacts from a fresh perspective and with a broader horizon, allowing them to describe the pictures more exactly, contextualize them within a certain cultural sphere, and thus produce more substantiated interpretations by means of combining musicological expertise with an art-historical approach. 


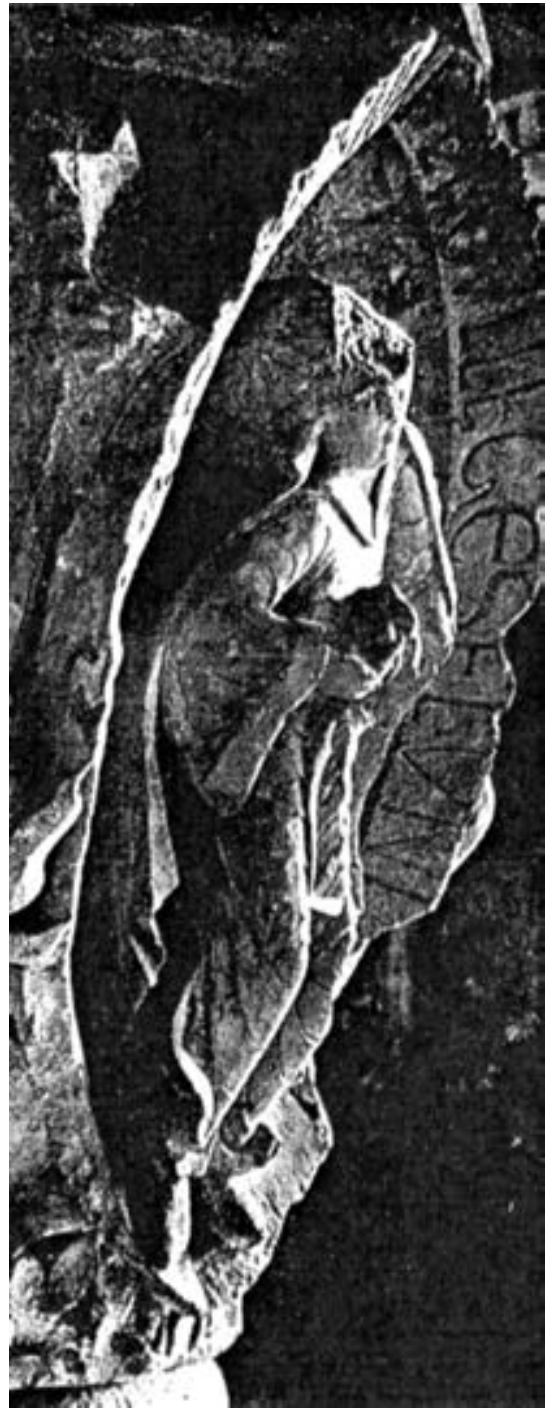

Fig. 16. From Leo Schrade, Die Darstellung der Töne an den Kapitellen der Abteikirche zu Cluni (1929), Fig. 2b

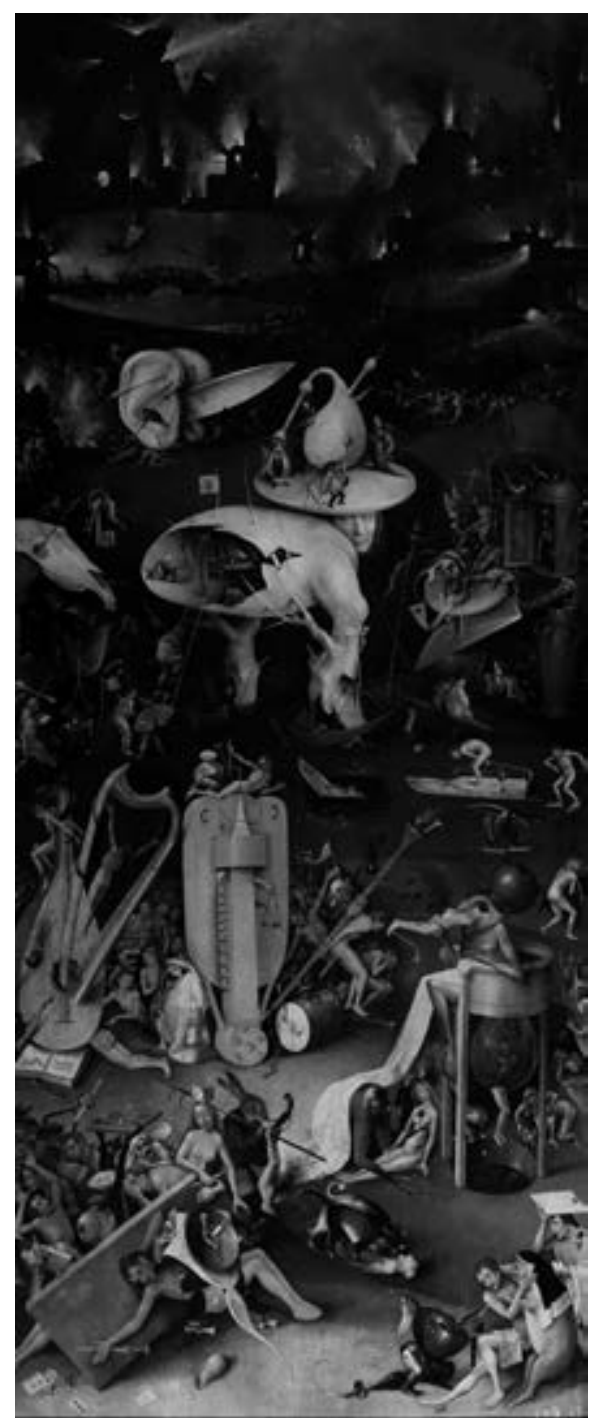

Fig. 17. Hieronymus Bosch, The Garden of Earthly Delights, c. 1500, oil on panel, 220 x $389 \mathrm{~cm}$, Museo del Prado, Madrid (right panel, detail) 


\section{Notes}

I Tilman Seebaß, 'Musikikonographie', in Ludwig Finscher (ed.), Musik in Geschichte und Gegenwart, vol. 6: Sachteil (Kassel/Stuttgart: Bärenreiter/Metzler, I997), I3I9-I343, I 32 I.

2 Ibid., I319-I320.

3 Reinhold Hammerstein, 'Musik und bildende Kunst. Zur Theorie und Geschichte ihrer Beziehungen', in Imago Musicae: International Yearbook of Musical Iconography I (I984), I-28, I,

4 'Die Musikikonographie erfordert zu gleichen Teilen kunstwissenschaftlichen und musikologischen Sachverstand. Wer nicht beides besitzt, gerät in analytische Schwierigkeiten, sei es, daß er die Eigengesetzlichkeit des bildnerischen Mediums nicht anerkennt, sei es, $\mathrm{da} ß \mathrm{ihm}$ das instrumentenkundliche, terminologische oder sozialgeschichtliche Fachwissen fehlt'. Seebaß, Musikikonographie, I32 I.

5 The term 'Musikwissenschaft' (musicology) was used for the first time by Johann Bernhard Logier. The first professorships for music were established in Bonn (I 826, Heinrich Carl Breidenstein) and in Berlin (I830, Adolf Bernhard Marx). Rainer Cadenbach, Andreas Jaschinski, Heinz von Loesch, and Dorothea Mielke-Gerdes, 'Musikwissenschaft', in Ludwig Finscher (ed.), Musik in Geschichte und Gegenwart, vol. 6: Sachteil (Kassel/ Stuttgart: Bärenreiter/Metzler, I997), I789-I834, I80I-I802.

6 'Geschichte der musikalischen Instrumente'. Guido Adler, 'Umfang, Methode und Ziel der Musikwissenschaft', Vierteljahrsschrift für Musikwissenschaft I.I (I 885), 5-20.

7 William Barclay Squire, 'Musical Iconography', Bulletin de la Société Union musicologique 2 (I922), 33-36, 34 .

8 Albert G. Hess, 'The Cataloging of Music in the Visual Arts', Notes I I.4 (I954), 527-542, 527-528.

9 Seebaß, Musikikonographie, I322. For information on the founding date: Répertoire international d'iconographie musical, About Association RIdIM, URL: http://www.ridim.org/ association.php.

Io Julius Rühlmann, Geschichte der Bogeninstrumente (Braunschweig: Friedrich Vieweg und Sohn, I882), 2, vi.

II 'In der zweiten Periode sehen wir die hochgeschwungene Form der Stange beibehalten, aber bereits mit Ansatz zu Frosch und Kopf versehen. Dieselbe beginnt im I5. Jahrhundert aus den zwei anderen Formen sich zu entwickeln'. Ibid., I47.

I2 Hugo Leichtentritt, 'Was lehren uns die Bildwerke des I4.-I7. Jahrhunderts über die Instrumentalmusik ihrer Zeit?', Sammelbände der Internationalen Musikgesellschaft 7.3 (I906), 315-364, 322.

I 3 'Die endliche Vollkommenheit in einer siebenten Periode des Steges wird jedoch erst zu Anfang des 17. Jahrhunderts [...] herbeigeführt. [...] zum Glanzpunkt, der nicht übertroffen werden konnte, bei Ant. Stradivari [...]. Dieser letztere ist denn auch der mustergültige geblieben und noch heute in Gebrauch'. Rühlmann, Bogeninstrumente, I4I.

I ' '...] stimmte sie in ihrem Herzen einen Gesang zu Gott an'. Leichtentritt, Bildwerke, 349 .

I5 '[...] als ob sie beim Klange der Orgel sang'. Ibid.

I6 Seebaß, Musikikonographie, I32I.

I7 Leo Schrade, 'Die Darstellung der Töne an den Kapitellen der Abteikirche zu Cluni', Deutsche Vierteljahrsschrift für Literaturwissenschaft und Geistesgeschichte 7 (1929), 229266,243 . 
I 8 Willibald Gurlitt, 'Die Musik in Raffaels Heiliger Caecilia', Jabrbuch der Musikbibliothek Peters 45 (1938), 84-97. Reinhold Hammerstein, 'Instrumenta Hieronymi', Archiv für Musikwissenschaft I 6 (I959), I I 7-I 34.

I9 Reinhold Hammerstein, Diabolus in Musica. Studien zur Ikonographie der Musik im Mittelalter (Bern: Francke, I974). For example, cited in Hans Belting, Hieronymus Bosch. Garten der Lüste (Munich: Prestel, 2002), I 24; Stefan Trinks, Antike und Avantgarde. Skulptur am Jakobsweg im 11. Jahrbundert. Jaca. León. Santiago (Berlin: Akademie Verlag, 20I2), 383 .

20 Ibid., 105.

2 I 'Boschs Musikszenen [...] sind Anklage und Teil des Aufrufs zur Buße in einer bis in die Tiefe erregten und skeptisch gewordenen Zeit, Ausdruck eines brüchig gewordenen Glaubens an eine irgendwie geartete prästabilierte Harmonie der Welt'. Ibid., I I 9.

22 '[Das] Bemühen, die Ikonographie der Musik [...] als eigene Forschungsrichtung in die Musikwissenschaft einzubringen [...] liegt die Überzeugung zugrunde, daß die einschlägigen Zeugnisse der bildenden Kunst für den Musikhistoriker nicht nur akzessorischen, schmückenden und illustrierenden Charakter besitzen, sondern daß sie, recht verstanden, Wesentliches und Eigenes über Musik und Musikanschauung einer Epoche auszusagen vermögen'. Ibid., 5 .

23 I I th Symposium of the ICTM Study Group on the Iconography of the Performing Arts, 'Images of Music Making and Cultural Exchange between the East and the West', held at the China Conservatory of Music, Beijing, 26-3I October 20I2, URL: http://rcmi. gc.cuny.edu/wp-content/uploads/20I2-Beijing-conference.pdf. 



\section{VIII}

East and West

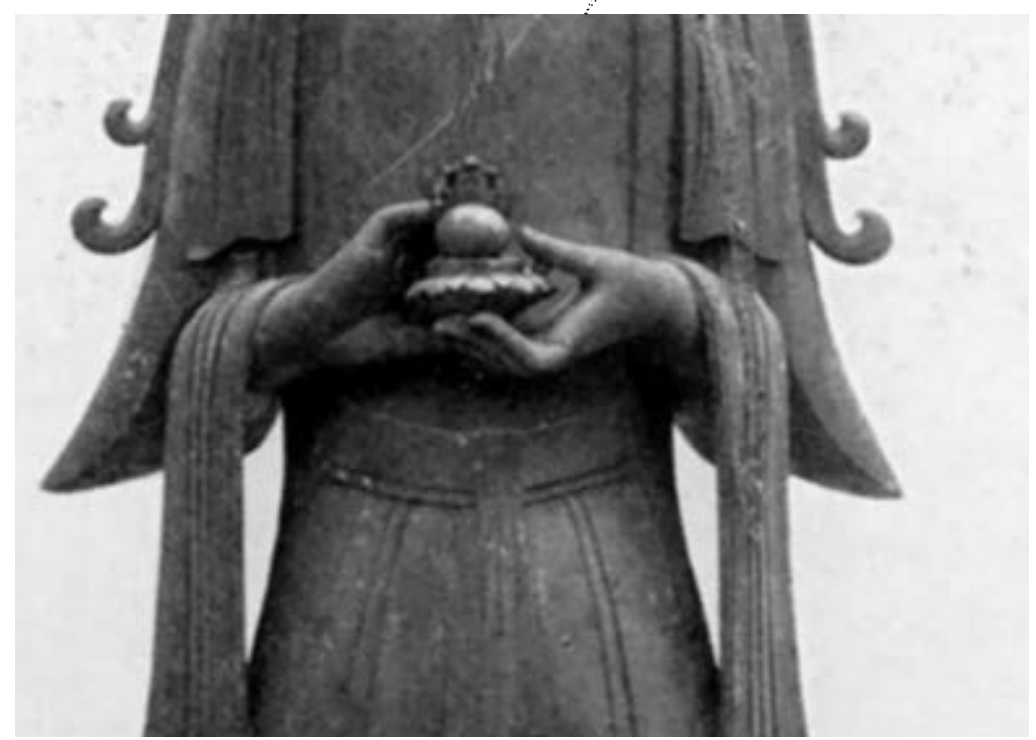





\title{
8.I The Making of Oriental Studies \\ Its Transnational and Transatlantic Past ${ }^{1}$
}

\author{
Steffi Marung and Katja Naumann
}

While some disciplines of the humanities struggle with a seemingly waning attention, both within academia as well as at the interface with politics and society, the opposite is the case for the fields falling under the rubric of regional studies or Oriental studies. There are increasing efforts to come to terms with its past, including its intellectual shape, its institutional position, and its political baggage. Likewise, new visions of Oriental studies are drafted that better suit the needs of our time. Although much ink has been spilled over the challenges of the latter attempt, less has been done on the intellectual traditions. Still, there is a growing body of research that seeks to historicize the field.

Two predispositions, however, impede such efforts at providing historical context. First, this research is as yet markedly West-centric; by and large the focus is on Germany, France, and Great Britain, as well as partly on the Netherlands, Belgium, and Austria. ${ }^{2}$ Second, a nationalizing perspective dominates. Single historical developments often stand disconnected side by side. When shared patterns are highlighted, then this is being done without asking for common origins. ${ }^{3}$ Both tendencies originate from the period of profound nationalism in which modern academia with its disciplinary divisions was created. Throughout the twentieth century, both inclinations were fueled, particularly during and following the Cold War that some interpreted as the victory of the West with the vanishing of the Second World. The degree to which the current state of the art reproduces these earlier world orders is remarkable. Two serious flaws accompany the scholarship: a disregard that Oriental studies existed also outside of Western Europe and the United States, maybe even to a larger degree, and the failure to address the international dimension of the field.

Without doubt, the field of Oriental studies was established in the eighteenth century by a network of scholars from various countries who shared a cosmopolitan outlook and were embedded in the international Republic of Letters. In the nineteenth century, mutual observation and exchange were promoted, which came 
with the global competition that the various academic systems were engaged in. This global history, however, is much richer and reaches far beyond the nineteenth century. Concepts and organizational structures were also borrowed and appropriated later owing to the fact that the founding fathers and their successors lived transnational careers in a cross-boundary community of Orientalists. Colleagues abroad were known personally as their research projects served as mutual and constant reference points. These contacts had sweeping effects. With the knowledge and methods of these traveling scholars, intercultural experience and sensitivity for cultural differences circulated among different expanses of academia.

We argue that an international dimension was a core feature of the discipline when it was created, which was not lost in the twentieth century. To illustrate this, we will sketch the landscapes in which Oriental studies scholars in the Soviet Union and the US undertook their research, focusing on the period between the I920s and I960s and on the entanglements between both. With the juxtaposition of these cases, we want to question the strikingly similar judgment of both fields: Soviet Oriental studies are generally presented as isolated from international trends while its US-American counterpart is also said to have been inward looking and parochial, stemming from vain self-interest. If one takes a closer look, however, one finds an astonishing history of interaction that mirrors the new global order after World War I, namely the rise of the US as a global power, the establishment of the Soviet Union as a competing model for social and political organization, and the incipient decolonization. Russian Oriental studies had been internationally leading, especially for scholars from the United States, up until the late igios. But even after the October Revolution and the Bolshevik reorganization of the higher education system, the discipline did not turn inwards. Its international scale changed in the patterns of its architecture without losing its significance. Soviet scholarship became important for others, for example, scholars from East-Central Europe and from what came to be known as the Third World. US-American Oriental studies have a similarly surprising past. In fact they originated largely abroad, with 'abroad' meaning Russia and countries further east rather than Germany and France. We believe that recalling this transatlantic or trans-Pacific history, in fact a global history, of Oriental scholarship is worthwhile as it helps to decentralize it and to contextualize its 'Western' variant.

\section{Soviet Orientalists}

For a long time Soviet Oriental studies were treated marginally within Western research agendas, although this is fortunately changing thanks to several recent excellent studies on the topic. ${ }^{4}$ Still, they appear somewhat peculiarly in comparison to 
its Western counterparts. This is due to Russia's close entanglement with the 'East', which did not necessarily represent its 'other' ${ }^{6}$ but rather a part of its 'self', This resulted early on in an intense commitment to Oriental studies, which pushed Russian Orientalists to criticize Western claims of superiority over the Orient and positively appreciate its contributions to Russian history. Furthermore, scholars from the 'Orient' were also integrated into the academic system. With Russia's unique geopolitical location, the Orient reached from Northern and Eastern Africa to the Middle East, Central, Eastern, Southern and South East Asia, while the equivalent Western conception of the Orient centered on the Middle East. ${ }^{8}$

In the second half of the nineteenth century, Russian Oriental studies were in some respect avant-garde. Its disciplinary breadth included history, philology, geography, literature, religion and philosophy, a constellation quite innovative for nineteenth-century Oriental studies. However, the Russian Orientalists also remained firmly rooted in philology, as were their German and Austrian counterparts. At the same time they systematically integrated other humanities disciplines into their approaches, in particular history, ethnology, cultural studies, and religious studies. Reflecting this setup, the St. Petersburg Faculty of Oriental Languages, founded in 1855, remained a unique academic institution until the beginning of the twentieth century - unrivaled, as thanks to its size and breadth it covered the whole 'Orient' from Islamic societies in Central Asia to Buddhist nations in East Asia.

A stronger interdisciplinary cooperation between the humanities and the social sciences was institutionally enforced in the early 1920 s under new political conditions, for instance, when the St. Petersburg Faculty for Oriental Languages was reorganized in I92I and, after it had to merge with the Department of History and Philology and the Department of Law, became a Section of Ethnology and Linguistics in the Social Science Department. ${ }^{9}$ In this manner, what has been described as an academic innovation of area studies in the US after the Second World War, namely the inclusion of and subsequent focus on the social sciences, had been implemented in the Soviet Union two decades earlier, even though this was a project conducted by the political elites, not one driven by internal academic motives. Russian Orientalists who migrated to the US during the 1920 s carried their experiences of such an interdisciplinary cooperation with them, thereby making an impact on developments in their host country. This often underestimated transfer will be examined more closely below, focusing on the example of Serge Elisséeff.

As a highly transnational endeavor from its early beginnings in the eighteenth century - with a considerable import of German scholars into the Russian acad-

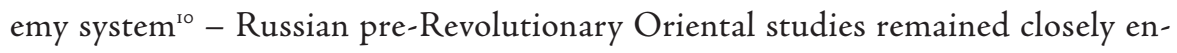
tangled with the Western academic community both through mutual study visits 
as well as through a network of international academic organizations. Its excellent reputation was particularly epitomized by the Arabist Viktor Romanovič Rozen, dean of the St. Petersburg Faculty of Oriental Studies from I893 to 1902, who remained influential after I9I7 like many of his colleagues and pupils, such as Vasilij Vladimirovič Bartol'd, Sergej Fedorovič Ol'denburg and Nikolaj Jakovlevič Marr.

The above-mentioned marginality of Russian Oriental studies may suggest that the October Revolution of I9I7 erased these transnational and international networks, and led to the disappearance of its traditions behind the Iron Curtain. On the contrary we argue that Soviet scholars continued to be profoundly international, yet their preferences and strategies changed. A more relevant caesura with regard to the scholars' outward orientation emerges in mid-1920s when Stalin's distrust against everything 'foreign' infected large sections of Soviet society. ${ }^{\text {II }}$ To substantiate this claim, preliminary results of an investigation into patterns of transnational and international networks of Soviet Orientalists after I9I7 will be presented. A quantitative analysis shall provide first observations, complemented with exemplary accounts and biographies.

For the quantitative analysis, the regularly updated biographical encyclopedias edited by Sofia Miliband were evaluated, the latest edition appearing in $2008^{12}$ These comprise approximately 3000 Soviet Orientalists, mainly those active after 1917. Focus was placed on the generations that graduated in the decades up until 1953, i.e., immediately after the October Revolution, during the Second World War and under Stalin's regime. Of these a sample of two hundred persons was analyzed in more detail. The period after 1953 demanded separate attention as the domestic and global context changed dramatically - both in the production of knowledge about the world as well as in the contacts with it. ${ }^{13}$

The analysis (Table I) reveals a clear tendency: $95 \%$ of the 200 scholars in focus had experiences abroad, as teachers, researchers and members of international scientific organizations, or involved in activities outside academia as journalists, diplomats, or staff members of Soviet companies. The career paths rarely followed either the academic track or the 'practice' one; rather these two aspects were often intertwined. Most of the scholars went abroad after their studies, usually in Leningrad or Moscow, and mostly turned to the regions of their specialization. They went as scholars or consultants, collected information for the government or helped building institutions in the higher education sector in Asia and Africa. The older pattern of going abroad for studies to England, France and Germany almost disappeared. Under these new circumstances basic education was achieved at home, while research and practical projects were developed afterwards in the regions of specialization. Western European institutions no longer appeared as the source for gaining necessary expertise, although this pattern did not vanish completely. 
Table 1 Careers of Soviet Orientalists

\begin{tabular}{lcc}
\hline Orientalists & Number & Percentage \\
\hline graduating after 1917 with experience abroad & 60 & $32 \%$ \\
\hline thereof during their studies & 3 & $5 \%$ \\
\hline thereof after their studies & 55 & $92 \%$ \\
\hline thereof in the region of their specialization & 42 & $70 \%$ \\
\hline thereof outside the region of their specialization & 20 & $33 \%$ \\
\hline both within and without & I0 & $17 \%$ \\
\hline Total sample: & 190 & \\
\hline
\end{tabular}

The new geography of these contacts was shaped by a clear preference for the 'Far East' and South Asia, particularly for China and India [Fig. I8]. Second ranked the Middle East and Central Asia, reflecting the Soviet interest in its 'near abroad'. For diplomats as well as researchers, Turkey and Iran were the most frequent destinations. ${ }^{14}$

A certain continuity in the scholars' international orientation can be traced; however, their stays abroad had been postponed to later stages in the academic career. Furthermore, the linkages with the areas of specialization were strengthened; international research and travel were no longer directed toward Western Europe but to the regions of academic interest. In this regard, the profound reshaping of society under Bolshevik rule was tangible. A more radical caesura in academic careers was nevertheless the Second World War in combination with the Stalinist purges of the late r93os. While the generation born in the decades of the I920s and graduating in the late I940s/early I950s represents more than $50 \%$ in the investigated sample, those born in the first decade of the century and graduating in the second half of the 1920s/early 1930s account for only $15 \%$, and the cohort born between 1910 and 1919, graduating in the mid-and early 1940s, amounts to just $7 \%$.

Certainly the quantitative analysis can only provide a general impression of much more complex patterns, which have varied considerably for individual scholars. The cohort taken into account here reflects diverse backgrounds and career paths. The first Soviet Orientalists were manifold with regard to their temperaments and interests as they followed diverse paths into the discipline and conceived of their subject differently. This shall be illustrated with three exemplary figures, reflecting divergent career patterns, strategies of internationalization and interaction with their region of expertise.

The Sinologist Vasilij Mikhailovich Alekseev ${ }^{15}$ embodies the passage from the czarist to the Soviet regime. Born in I88I, graduating in 1902 from the Faculty of Eastern Languages in St. Petersburg, he not only studied in England, France and 


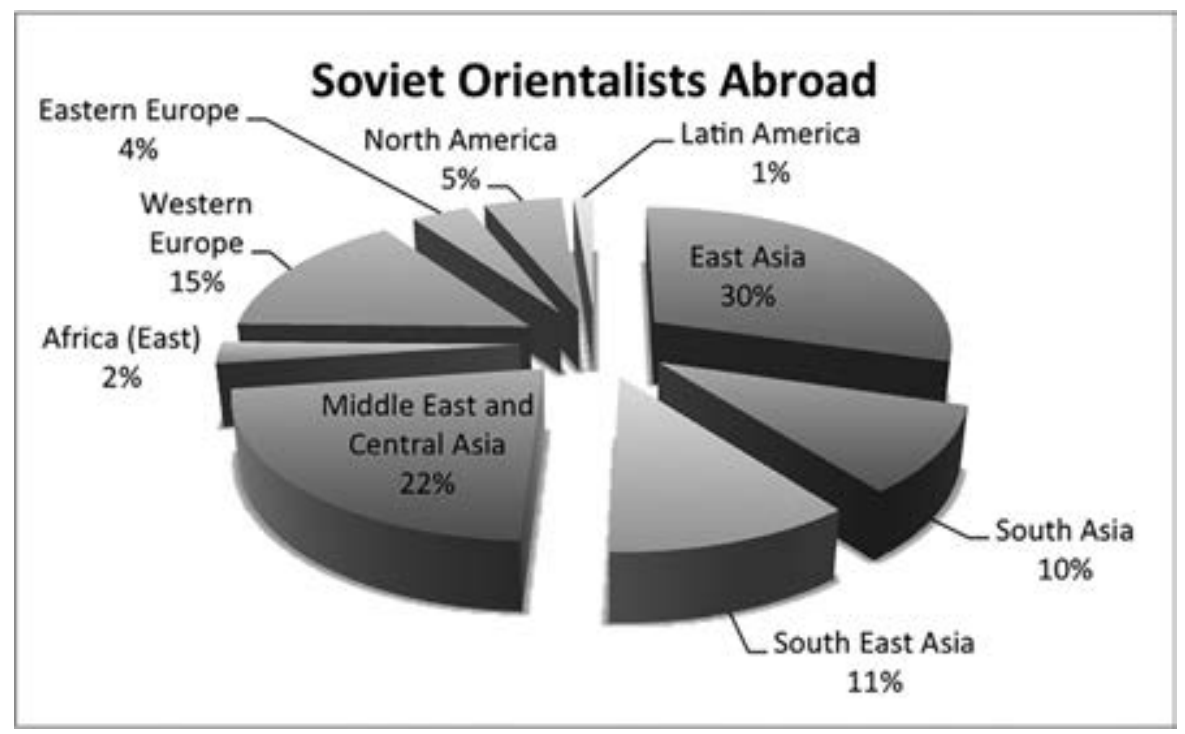

Fig. 18. Soviet Orientalists Abroad

Germany, but since 1906 also in China for a three-year research trip. Specializing in Chinese literature, he promoted cooperation between historiography, philology, literature, and other disciplines to develop a nuanced concept of Chinese culture and society. ${ }^{16}$ This conception seemed to have been congruent with the views of the new political elite, which helped Alekseev pursue his career successfully as a professor at the newly founded Faculty for Oriental Studies at Leningrad University from 1918 onward and a full member of the Academy of Sciences from 1929. Up until the mid-rgeos he held lectures in France, England and China, and became a member of the American Academy for Political and Social Sciences in Philadelphia in 1923. During Stalin's Great Purges, when some members of his research team were executed or deported, he went underground, restarting his career in the I940s. Thus for him, the Stalinist purges as well as the subsequent campaign against 'cosmopolitanism' marked a more considerable caesura than $1917^{17}$

While Alekseev, educated in czarist Russia, represented the old academic elite, Dmitrij Alekseevičh Ol'derogge was a part of an intermediate generation. ${ }^{18}$ Born in 1903 into a noble Russian family of German origin, he started a military career in his youth and was recruited into the Red Army after 1917. After the Civil War he completed ethnological and linguistic studies at Petrograd University in 1925. In 1926/1927 he was sent to Germany to study with the renowned German Orientalist Diedrich Westerman, where he was commissioned to gather information about German ethnographic museums to improve the collections in Leningrad. As one of the first to teach African languages in the Soviet Union, he became 
the 'patriarch' of Soviet African studies. Since 1946 he held the chair of African studies at the Faculty of Oriental Studies at Leningrad University and enjoyed a venerable reputation not only in the Soviet Union - as a corresponding member of the Soviet Academy of Sciences since 1960 - but also in the West. This was reflected in his memberships of international academic organizations, for example, in Great Britain, France, Poland, and the German Democratic Republic. Ol'derogge navigated the dangerous watersheds of the October Revolution as well as the Stalinist purges and his reputation transformed from a purported 'bourgeois' into one of the founders of the new Soviet disciplines. The strength of his international networks east and west of the closing Iron Curtain made him a decisive mediator in the international academic community.

Ivan Izosimovičh Potekhin was the same age as Ol'derogge but born into a farmer's family in Siberia. ${ }^{19}$ He joined the Communist Party in I92I and was sent to Leningrad University in 1930 where he dedicated himself with Ol'derogge to African studies. He became a teacher at the Communist University of the Toilers of the East (KUTV) in 1932 where he got in close contact with anti-colonial African elites. Since 1960, as the first director of the newly founded Africa Institute of the Academy of Sciences, he traveled frequently to African and Western countries, including the US, Italy, and the United Kingdom, promoting the academic agenda of Soviet African studies. Potekhin represents a generation that, on the one hand, profited considerably from the newly opened opportunities for upward social mobility, but, on the other hand, faced hardship during the Stalinist years. Combining both political and academic paths, his international career started at home' at KUTV with students coming from Africa and Asia.

\section{Oriental studies in the United States}

The general interpretation, mentioned at the beginning, that US-American Oriental studies were by and large parochial, needs some qualification, first of all because it is based on two convictions that do not stand closer inspection.

First, the origins of academic studies of the 'non-Western' world as we know it today are often dated to the end of the Second World War. 'Non-Western' cultures and societies became firmly anchored in higher education and research with the establishment of area studies - designating a particular concept of Oriental or regional studies established in the mid-I940s in order to distinguish between, on the one hand, the traditional disciplines (Sinology, Indology, etc*) that predominately analyzed languages, literatures, and ancient histories and, on the other, newly conceptualized interdisciplinary fields such as Chinese or South Asian studies which were more focused on the present, interested in the nineteenth 
and twentieth centuries, and combined philological-historical approaches with questions and methods from the social sciences, especially economics, political science, and sociology.

Second, the geo-political context of the Cold War is usually emphasized in the development after 1945, which served the argument that Oriental studies and area studies were in essence instruments to 'know the enemy', particularly with regard to research on Russia. Such studies also related to inquiries of non-Western cultures as they were regarded as eminently important for winning hearts and minds in these regions in the ideological competition with the Soviet Union. ${ }^{20}$

While not denying the relevance of the political context, we argue that this is only half the story. Postwar Oriental studies were firmly rooted in a tradition of studying the world that dates back to end of the nineteenth century, which only accelerated after World War I. The I89os saw the opening of 'Departments of Semitic Languages and Cultures', the foundation of anthropology and archeology. Well before the First World War, the three strands - philological, ethnographical, and archeological research - had a small but safe base in US academia. Their position would expand in the 1920 s, within the university and through the creation of research institutes like the well-known Oriental Institute in Chicago. ${ }^{21}$

Although the founding phase of Oriental studies was shaped by the characteristics of the US-American higher education system, it was part of a broader trend to investigate the world. Academic studies of foreign cultures began in many places at that time. Accordingly, American scholars examining foreign societies traveled, exchanged knowledge, and borrowed organizational patterns. They were strongly linked to scholarship from abroad and the geography of their careers spanned large distances. This state of affairs persisted in the second half of the twentieth century, albeit under different circumstances, as was the case in Russia following the October Revolution. This is evident in the biographies of leading figures of the field. The two we chose to present are especially illuminating in terms of their transatlantic linkages.

In the late 1920s, Oriental studies in the US was in the middle of a process of differentiation. After Indology had taken shape, Far East (or Asian) studies was given contours out of which China and Japan studies were crafted. In parallel, Byzantine studies, which at first was regionally and temporally concerned with the Eastern Roman Empire, was later broadened to include the Caucasus and Western Asia. The Second World War initiated another expansion of the field, now as Middle Eastern studies. ${ }^{22}$ Among the main actors of this period were Serge Elisséeff and Robert B. Blake.

Elisséeff is often portrayed as the first professional Japanologist in the US. Indeed he helped to build Japanese studies both at his home university (Harvard) and beyond by introducing the study of living Asian languages and bringing Rus- 
sian and French research traditions to the US, from which the US Oriental studies gained its intellectual shape. It is telling that his work was also appreciated in the Soviet Union. ${ }^{23}$

Born in St. Petersburg in I889, Elisséeff had witnessed the Russo-Japanese War as a young adult, which stimulated his interest in the East. Even before he passed his A-level studies, he introduced himself to Sergej Ol'denburg, the doyen of Russian Oriental studies at that time. ${ }^{24}$ After Ol'denburg suggested studying in Japan, Elisséeff went to Berlin to study with Eduard Sachs and soon after to Tokyo Imperial University. When he returned to St. Petersburg in 1914 he was familiar with the German and Japanese state of the art, allowing him to easily pass the exam to become a Privatdozent at the St. Petersburg Imperial University. He immediately returned to Japan to work on his dissertation, which he defended in Tokyo in 1917. Shortly after he had returned home, the Russian Revolution changed what could have become a decent academic career at home. His family lost almost all its property and he his position at the university, which was instantly restricted. It is interesting that his colleagues Ol'derrogge and Alekseev did not meet the same fate. For some, I9I7 meant a break for their scholarly work, for others the interruption came later.

The few opportunities to publish, together with a job at the Oriental Library of the Russian Academy of Sciences, did not provide enough money to live on and so in 1920 Elisséeff left for Paris. The move was challenging, but he soon secured a teaching post at the Sorbonne and established connections with the Japanese embassy, the Musée Guimet, and the International Committee for Intellectual Property of the League of Nations. In these years he met and worked with many of the leading French Sinologists, among others Henri Maspero, Antoine Meillet and Paul Pelliot. These contacts paid off. In 1930 he was appointed Maitre de Conference at the École des Hautes Études; two years later he advanced to become director of the Oriental division. While it looked as if he had settled within French academia, a visit to Harvard University in I93I proved to be consequential. In Cambridge, the newly founded Harvard Yenching Institute - an independent institute for humanistic and social science research on China, continental Asia, and Japan, in which scholars from the Bejing-based Yenching University and their Harvard colleagues collaborated - was in need of a director. Initially it was hoped to have Pelliot take the position; however, he suggested his younger colleague Elisséeff, who accepted the double invitation to run the institute and to teach as a professor at the Department of Semitic Languages. Both positions provided the social and financial space of manoeuvre to establish the barely existing study of China and Japan at Harvard. Being able to use the internal mechanisms of a university for his own ambitions, Elisséeff accomplished much in a short time. In 1936 he founded the Harvard Journal of Asiatic History and the year after the Department of Far Eastern Languages. 
Within a decade he had gathered the resources to establish nine university research and teaching positions, publish a book series, hold international congresses, and to build a well-organized library. The results of these activities went well beyond Cambridge. The doctoral program he created trained many of the later East Asianists, while the American Association of Asian Studies owes its existence also to him. When he retired in 1956, Chinese and Japanese studies had a firm and stable place at Harvard and within US-American academia. Besides his organizational influence, he had an intellectual impact that was decisively shaped by his education in Russia and Japan as well as his research in France.

Similarly, Byzantine studies came into being through the hands of someone profoundly influenced by Russian scholarship. Robert B. Blake, born in I886, went to Freiburg and Berlin to prepare his dissertation, where his teacher, Eduard Meyer, encouraged him to go to St. Petersburg to study under Michael Rostovtzeff. ${ }^{25}$ Russian Byzantine scholars were seen at that time as internationally leading in the field. Deeply impressed by the wide range of courses offered at the Faculty of Oriental Studies at St. Petersburg Imperial University, where one could learn all important languages of the Near and Far East, Blake resolved to build up a similar program at home. During his time at St. Petersburg, he tried to gain as much knowledge as he could in ancient history and Byzantine studies, and learned Arab, Armenian and Georgian. Fascinated by the history of the Caucasus, he focused his dissertation to the region. For administrative purposes, he returned to the US to defend the thesis, but since the conditions for further research were much better in Russia, shortly after he returned to St. Petersburg, passed the exam to be a university lecturer and gained a travel stipend from the Russian Academy of Sciences to do archival work in Tbilisi. His plans were interrupted by the Russian Revolution as well, which prevented him from returning to St. Petersburg. He successfully applied for a chair in church history at Tbilisi State University. He taught and studied there for five years before returning to the US, to Harvard, where he took up his initial idea in establishing Byzantine studies similar to and at the same level as the discipline in Russia. ${ }^{26}$

In the first years he was involved in creating East-Asian studies together with Elisséeff, but he also invested tremendous efforts in institutionalizing his own field of expertise. For example, the establishment of the first chair of Central Asian history in the History Department was largely due to his merit. ${ }^{27}$

Elisséeff and Blake do not account for the development of the whole field, but the biographies of their colleagues - Harley F. MacNair in Chicago, Martin C. Wilbur at Columbia University, and Edwin Reischauer in Cambridge - also display a lot of international experience and connections. ${ }^{28}$ These were of a dif- 
ferent kind, though, since the strong linkages between US-American and Russian Oriental studies are typical for the founding period only. Later on, Russia lost its position as the prime training place and intellectual frame of reference for US scholars. Their international orientation, however, persisted. Oriental studies practiced in the regions of expertise itself became the main reference point, especially after the Second World War. Telling in this regard are several surveys on area studies conducted in the I960s and I970s. More than 50\% of area studies specialists had worked at least two years in the region they were investigating. More than a third had stayed for three years, and no less than a fifth drew from the experience of five years of living and researching in the 'non-Western' world. ${ }^{29}$ 'This again could not but leave an imprint on their research, on how they approached their subjects and which questions they asked. The knowledge they produced was profoundly shaped by encounters they made during their stays abroad and by the material they collected there. Returning home they brought new insights, hitherto unknown research concepts, and unfamiliar arguments the US. Ideas and intellectual traditions thus traveled from Asia, Latin America, the Middle East, and Africa to North America; cultural transfer shaped and changed Oriental studies at all the places involved. That did not prevent interpretations that are nowadays highly problematic - for example, the claims of the modernization theory - but these became increasingly questionable, an unease which culminated in current reconsiderations of the intellectual and political underpinnings of area studies mentioned at the beginning.

\section{Conclusion}

The disciplines of Oriental studies in the US and in the Soviet Union have a transnational and transatlantic past. In the development of both fields, a profoundly international dimension was a core feature, lasting well beyond the Russian Revolution into the early years of the Cold War. Along the way and due to the changing circumstances, patterns and strategies of involving the wider world took shape. With the progress of decolonization and the heating up of the Cold War, relations with the regions that were investigated were fostered while the entanglement across the Atlantic was cut off for the time being. These developments are one layer in the changing geography of the field's connectivity. It has as yet been scarcely explored.

There is still few systematic and comparative research regarding the non-Western humanities, let alone about transfers from 'East' and South' to the 'West', and even less from 'East' to 'East' and 'South' to 'South'. While, for instance, Russian Orientalists obviously observed their Western counterparts and considered how to be 
part of, or compete with, this academic community, at the same time they integrated learned 'native' scholars into the Russian and later Soviet academic systems. Here, a transfer in the opposite direction must be assumed; yet this remains, for now, a question for further investigation. The presence of 'native' scholars in the respective academic systems might be an excellent starting point for such a line of scrutiny; the encounters of Russian and US scholars with their 'native' counterparts during their fieldwork travels might be another. One could then trace in more detail how the 'Orient' was studied in various parts of the world and how concepts and ideas developed in Asia or Latin America influenced the disciplines in Europe and North America. One could compare the specific interdisciplinary composition of Oriental studies across the continents, i.e., how the approaches of philology, history, and the social sciences were combined and balanced. And one could follow the respective rhythms of intellectual shifts. After all, what was conceived, constructed, and researched as the 'Orient' changed and differed depending on where scholars and their own societies positioned themselves. The first steps that we have taken here on the path toward the global history of Oriental studies show, if anything, how much the usual national and 'Western'-centric accounts leave out.

\section{Notes}

'Transatlantic' usually denotes the space constituted by Western Europe and the US, but we refer here to a broader notion that includes Russia/the Soviet Union.

2 Suzanne L. Marchand, German Orientalism in the Age of Empire: Religion, Race, and Scholarship (Washington, DC/Cambridge: German Historical Institute/Cambridge University Press, 2009); Ursula Wokoeck, German Orientalism: The Study of the Middle East and Islam from 1800-1945 (London: Routledge, 2009); Zachary Lockman, Contending Visions of the Middle East: The History and Politics of Orientalism (Cambridge: Cambridge University Press, 2005); Sabine Mangold, Eine 'weltbürgerliche Wissenschaft': Die deutsche Orientalistik im 19. Jabrhundert (Stuttgart: Steiner, 2004); Robert Irwin, Dangerous Knowledge: Orientalism and Its Discontents (Woodstock: Overlook Press, 2006); Burkhardt Schnepel, Gunnar Brands, and Hanne Schönig (eds.), Orient - Orientalistik - Orientalismus (Bielefeld: Transcript, 20II); Wolfdieter Bihl, Orientalistik an der Universität Wien. Forschungen zwischen Maghreb und Ost- und Südasien (Vienna: Böhlau, 2009); Christian Cannuyer, Nadine Cherpion, and Claude Vandersleyen, Regards sur l'Orientalisme Belge (Brussels: Sicieté Belge d'Etudes Orientales, 20I2); Clifford Edmund Bosworth, A Century of British Orientalists, 1902-2001 (Oxford: Oxford University Press, 2001); Youssef Courbage and Manfred Kropp (eds.), Penser l'Orient. Traditions et Actualité des Orientalismes Français et Allemand (Beyrouth: Institut Francais du Proche-Orient, 2005); Pascale Rabault-Feuerhahn, L'Archive des Origines: Sanskrit, Philologie, Anthropologie dans L'Allemagne du XIXe siècle (Paris: Edition du Cerf, 2008).

3 An exception is Andreas Eckert, 'Area Studies and the Writing of Non-European History in Europe', in Matthias Middell and Lluis Roura (eds.), Transnational Challenges to National History Writing (Basingstoke: Palgrave Macmillan, 2013), I40-I63. 
4 Vera Tolz, Russia's Own Orient: The Politics of Identity and Oriental Studies in the Late Imperial and Early Soviet Periods (Oxford: Oxford University Press, 20I I); David Schimmelpenninck van der Oye, Russian Orientalism: Asia in the Russian Mind from Peter the Great to the Emigration (New Haven: Yale University Press, 2010), Michael Kemper and Stephan Conerman (eds.), The Heritage of Soviet Oriental Studies (London: Routledge, 20 I I).

5 Cf. also Eva-Maria Stolberg, Sibirien: Russlands 'Wilder Osten'. Mythos und soziale Realität im 19. und 20. Jahrbundert (Stuttgart: Steiner, 2009).

6 See: Edward Said, Orientalism (New York: Pantheon Books, I978). Cf. also Iver B. Neumann, Uses of the Other: The East in European Identity Formation (Minneapolis: University of Minneapolis Press, 1999).

7 Tolz, Russia's Own Orient, convincingly demonstrates this.

8 Thomas Scheffler, 'Fertile Crescent, Orient, Middle East: The Changing Mental Maps of Southwest Asia', European Review of History/Revue européenne d'Histoire ro (2003), 253-272; Martin W. Lewis and Karen E. Wigen, The Myth of Continents: A Critique of Metageography (Berkeley: University of California Press, 1997).

9 Mikhail Rodionov, 'Profiles under Pressure: Orientalists in Petrograd/Leningrad, I9 I 8I956', in Michael Kemper and Stephan Conerman (eds.), The Heritage of Soviet Oriental Studies, 47-57, spec. 50.

Io Cf. Tolz, Russia's Own Orient.

I I Sheila Fitzpatrick, The Russian Revolution, 3rd ed. (New York: Oxford University Press, 2008); Sheila Fitzpatrick, Everyday Stalinism: Ordinary Life in Extraordinary Times: Soviet Russia in the 1930s (Oxford: Oxford University Press, I999).

I2 Sofija D. Miliband, Biobibliograficheskiy slovar' sovetskich vostokovedov (Moscow: Nauka, I975), later editions 1995 and 2008.

I 3 Odd Arne Westad, The Global Cold War: Third World Interventions and the Making of Our Times (Cambridge: Cambridge University Press, 2007).

I4 Alexej Vassiliev, Russian Policy in the Middle East: From Messianism to Pragmatism (Reading: Ithaca Press, I993); Mikhail Volodarsky, The Soviet Union and Its Southern Neighbours: Iran and Afghanistan 1971-1933 (Ilford: Cass, I994).

I5 Cf. Vasilij M. Alekseev, Nauka o Vostoke. Stat'i i dokumenty (Moscow: Nauka, I982); Miliband, Biobibliograficheskiy slovar'; website of the University of Massachusetts, URL: http://www.umass.edu/wsp/sinology/persons/alexeev.html.

I6 Alekseev himself combined literary and historical studies in particular, cf., e.g., Vasiliy Michailovich Alekseev, 'Otrazheniye borby s zavoyevatelyami v istorii u literaturye Kitaya' [The Represeantation of the Fight with Conquerors in Chinese Literature and History], Izvestnik AN SSSR 4/5 (I945), I87-I99.

I7 The persecutions and purges during Stalin's reign had paradoxical effects on Russian/ Soviet Orientalists both as a group as well as as individuals (which is true for other groups in the Soviet society, too), as Alekseev's biography demonstrates. Those educated during czarist times in particular were suspected of being 'bourgeois cosmopolites', and thereby enemies of the new regimes and Stalin's Russification policy. Many were persecuted, exiled, or executed. Yet, this characterization needs to be cautiously placed in a historical context. While it is true for the I930s, in the I920s, Russian/Soviet Orientalists played an important role as experts and mediators for Stalin's 'korenizatsiia' policy in Central Asia, in particular. However, a decade later, this same circumstance was interpreted by the Stalinist regime as assistance to national counterrevolution and cited as an argument for punishment. In the I 990 s again, after the dissolution of the Soviet Union, the affirmative role that Russian Orientalists played in the early nation-building of Central Asian societ- 
ies turned them into national heroes of the newly founded states. Cf. Rodionov, 'Profiles under Pressure', and Michael Kemper, 'Introduction: Integrating Soviet Oriental Studies', in Michael Kemper and Stephan Conerman (eds.), The Heritage of Soviet Oriental Studies, I-25, and for detailed empirical evidence: Yaroslav Vasilkov and Marina Sorokina, Lyudi i sud'by. Biobibliograficheskiy slovar' vostokovedov-zhertv politicheskogo terrora v sovetskii period (1917-1991) (Saint Petersburg: Petersburgskoe Vostokovedenie, 2003).

Cf. Apollon Davidson, Stanovlenie otecchestvenoy afrikanistiki: 1920-e nacchalo 1960-e g-y (Moscow: Nauka, 2003); Miliband, Biobibliograficheskiy slovar'; and Wikipedia, URL: http://ru.wikipedia.org/wiki/Ольдерогге,_Дмитрий_Алексеевич (accessed 24 June 20I4).

I9 Cf. Davidson, Stanovlenie otecchestvenoy afrikanistiki; Miliband, Biobibliograficheskiy slovar'; Wikipedia, URL: http://ru.wikipedia.org/wiki/Потехин,_Иван_Изосимович; and the Free Dictionary, URL: http://encyclopedia2.thefreedictionary.com/Ivan+Izosimovich +Potekhin (accessed 24 June 2014).

20 David C. Engerman, Know Your Enemy: The Rise and Fall of America's Soviet Experts (Oxford: Oxford University Press, 2009); Bruce Cumings, 'Boundary Displacement: The State, the Foundations, and Area Studies during and after the Cold War', in Masao Miyoshi and Harry D. Harootunian (eds.), Learning Places: The Afterlives of Area Studies (Durham: Duke University Press, 2002), 26I-302; Mark T. Berger, Under Northern Eyes: Latin American Studies and US Hegemony in the Americas, 1898-1990 (Bloomington: Indiana University Press, 1995). The criticism of instrumental usage has caused a massive defence of the academic merits of area studies: David Szanton (ed.), The Politics of Knowledge: Area Studies and the Disciplines (Berkeley: University of California Press, 2004).

2 I Bruce Kuklick, Puritans in Babylon: The Ancient Near East and American Intellectual Life, 1880-1930 (Princeton: Princeton University Press, I 996), Vincent L. Rafael,'The Cultures of Area Studies in the United States', Social Text 4I (I994), 9I-I I I.

22 Since Middle Eastern studies were oriented toward the study of modern times, the traditional Byzantine studies were set apart again. On the development of Middle Eastern studies in historical perspective, see Roderic H. Davidson, 'Where Is the Middle East?', Foreign Affairs 38/4 (I960), 665-675.

23 See a letter by Alekseev, in which he mentions Eliséeff as one of the most competent scholars who emigrated: 'Otzyv o N.A. Nevskom', 27 July 1922, published in Alekseev, Nauka o Vostoke, 88f.

24 E.O. Reischauer, 'Serge Elisséeff', Harvard Journal of Asiatic Studies 20.I-2 (I957), I-35.

25 S. Elisséeff, 'Robert Pierpont Blake (I886-I950)', Harvard Journal of Asiatic Studies I4.I-2 (I95I), vii-xiii; S. Fan, 'To Educate China in the Humanities and Produce China Knowledge in the United States: The Founding of the Harvard-Yenching Institute, I924I928,' Journal of American-East Asian Relations I6 (2009), 4.

26 Although there are no personal documents directly mentioning this ambition, he was a student of Archibald Coolidge who, like almost nobody else, established 'non-Western' studies at Harvard University and who taught his students how a scholarly field can be institutionalized, with the clear aim that they would continue what he had started: R.F. Byrnes, Awakening American Education to the World: The Role of Archibald Coolidge, 18661928 (Notre Dame, IN: University of Notre Dame Press, I982).

27 The first to be appointed, Richard F. Frye, had been taught by Blake. His ability to accumulate money changed Harvard further. In 1958 he persuaded the father of one of his students to donate a sum with which the Aga Khan Professorship in Iranian Studies was established, the first of its kind in the US. 
28 Maurice T. Price, 'Harley Fransworth MacNair (I89I-I947)', Far Eastern Quarterly 8.I (1948), 45-63; C. Martin Wilbur, China in My Life: A Historian's Own History (Armonk, NY: Sharpe, 1996), G.R. Packard, Edwin O. Reischauer and the American Discovery of Japan (New York: Columbia University Press, 2010).

29 Richard D. Lambert, Language and Area Studies Review (Philadelphia: The American Academy of Political and Social Sciences, I973), 53. This was paralleled by another process: The fellowship programs of the large philanthropic foundations, like Rockefeller and Ford, as well as millions of dollars provided by the US government, brought scholars from 'non-Western' countries to the US in order to internationalize their own academia and thereby change its outlook. See the annual reports of the Rockefeller Foundation, which detail the grantee of the fellowship programs, and the history of the National Defense Education Act: Wayne J. Urban, More Than Science and Sputnik: The National Defense Education Act of 1958 (Tuscaloosa: University of Alabama Press, 2010). 



\title{
8.2 The Emergence of East Asian Art History in the I920s
}

\author{
Karl With (1891-1980) and the Problem of Gandhara
}

Julia Orell

\section{East Asian art and art history}

Late-nineteenth-and early-twentieth-century Europe saw an increasing interest in non-European art from Africa, Pre-Columbian America, Asia, the Pacific Islands and elsewhere. Private collectors and museums eagerly collected, exhibited, and published such works, often in competition with each other in the context of colonization. ${ }^{\mathrm{I}}$ In addition to museums and collectors, artists developed a great interest in non-European art and artifacts since at least the mid-nineteenth century, ranging from Japanese woodcut prints to African masks, often summarized under the problematic category of primitivism. The academic discipline of art history, however, was slow in responding to the broadening range of images and objects that became available for study. In German-language academic art history, the late nineteenth and early twentieth century was a formative period with regard to the field's methodological foundations, with major centers at the universities in Berlin, Hamburg, Munich, Basel, and Vienna among others. ${ }^{2}$ Non-European art and artifacts rarely made their way into academic art-historical research; the newly emerging specialists in these fields were philologists, ethnologists, and archeologists in addition to museum curators, collectors, and private scholars. ${ }^{3}$ One case in East Asian art was Otto Kümmel (1847-1952), who was appointed curator of the newly established Department of East Asian Art at the Berlin Museums in 1906. His academic background was in classical philology and archeology before he started to familiarize himself with East Asian art, learned Japanese, and became one of the most influential figures in German art history of East Asia in the early twentieth century. ${ }^{4}$

It was at the Vienna Department of Art History, where Josef Strzygowski (1862-194I) established the Section for East Asian Art History in I9I2 - the first institution where research in East Asian art history was officially conducted and supported. Karl With (189I-I980), whose scholarship will be the focus of this es- 
say, was among the first of Strzygowski's students in East Asian art and finished his dissertation on Japanese Buddhist sculpture in 1919. ${ }^{5}$ His work in the early I920 presents an interesting case study to explore the emergence of East Asian art history as an academic field: With combined an art-historical academic training, that lead to his specialization in Asian art, with ideas about art as a universal language that circulated among artists, collectors, and intellectuals at the time. This paper explores With's scholarship in relation to that of his adviser Josef Strzygowski and takes into account With's work for the private collectors Karl Ernst Osthaus (1874-1921) and Eduard von der Heydt (I882-1964).

\section{Josef Strzygowski and non-European art}

In the preface to Karl With's dissertation, Josef Strzygowski claimed that the 'East Asian section in the Department of Art History at the University of Vienna was founded in 1912, though with very limited means. ${ }^{6}$ While Strzygowski may have exaggerated when he called the activities at his department pertaining to East Asian art a section or program (Abteilung), the statement illustrates his ambition to open up art history to non-European art. ${ }^{7}$ In a short pamphlet, The Art History Department at the University of Vienna (1913), Strzygowski outlined the structure and activities in more detail ${ }^{8}$ In order to account for the artistic creations of all mankind as a whole', art history needed to expand its focus eastward and to free itself from the historical-philological method. The department was thus to be divided into the three sections (I) History, (2) Systematics, (3) Neighbor disciplines (such as ethnology, prehistory, and human geography) and the first, historical section was further subdivided by region: (I) Austria, (2) Western Europe, (3) Eastern Europe, (4) West Asia, and (5) East Asia (including India, Central Asia, China, Japan, South and South-East Asia).

With regard to the current activities of the East Asian group, Strzygowski reported that one member had been dispatched to the Museum of East Asian Art in Cologne to work on cataloguing the collection, two members had traveled to Japan, ${ }^{9}$ a seminar on Indian art had taken place, and a group was studying Japanese Yamato-e painting. Strzygowski's expansion eastward attracted many students, some of whom would go on to pursue distinguished academic careers.

Only recently has the role of Strzygowski in the formation of non-European art history come to the attention of art historians in relation to current debates about 'global art history'. ${ }^{\circ}$ After having been more or less expelled from the history of art history after the Second World War because of his racist ideologies and support of the Nazi regime, Stzrygowski's work has been reevaluated in the past two decades. Besides acknowledging his contribution to broadening art history's 
geographical scope of inquiry - primarily with regard to the art of late antiquity, early Christian and Islamic art in Eastern Europe and the Near East - the lingering attraction of some of his ideas and their dangers have been pointed out as well: Jas Elsner has addressed the importance of Strzygowski's book Rome or Orient (Rom oder Orient [190I]) and its methodological kinship with the much more appreciated Alois Riegl, whose Late Roman Art Industry (Spätrömische Kunstindustrie) was also published in 190I. "Johann Konrad Eberlein has depicted Strzygowski as the ultimate modern art historian and has drawn attention to what he perceives to be current threats to the discipline of art history that are manifest in Strzygowski's work, among them a thinking in terms of continents as an early form of globalization, the opening of disciplinary boundaries, assumptions about the spread of cultural streams as if they were independent entities, and a false belief to be free from ideologies by using scientific concepts. ${ }^{12}$ Yet other scholars have addressed Strzygowski's involvement with anthropology, including the French avant-garde journal Documents, ${ }^{13}$ and the impact of his work on emerging national art histories, especially in Eastern Europe. ${ }^{14}$

Strzygowski's motivation to extend the scope of his scholarship to include Asia, especially East Asia, should be understood as part of his anti-humanist and anti-historical-philological project that had begun with his attack on the privileging of Roman-Greek antiquity in art-historical narratives, as well as of methods largely relying on textual sources. ${ }^{15}$ Asia became part of this project, in order to counter prevailing assumptions that classical antiquity, or the influence of the Mediterranean, had extended as far as India, China, and Japan. Instead, the study of Asian art should, according to Strzygowski,

force us to finally bridge the gaps between East and West and between South and North and to realize that the center of dispersing power is not to be found in the Mediterranean alone, but that the movement instead generates from a number of sources and a great number of canals that connect these original streams. ${ }^{16}$

While arguing for independent artistic developments in Asia, Strzygowski was at the same time eager to prove the existence of a different kind of relationship between the arts of Europe and Asia based on shared racial heritage. His narrative aimed at foregrounding the achievements of 'Northern man' (Nordmensch) and to point out a common Indo-Germanic basis for Eurasia in these achievements. Strzygowski believed that there was an 'Aryan axis' - he alternatively called it the 'Indo-Germanic axis' - that connected Central Europe with the Caucasus and the Caspian Sea, reaching further to Central Asia, Iran, and India. As Susanne Leeb has pointed out, Strzygowski thus followed popular myths about the common 
Indo-Germanic heritage of large parts of Europe and Asia. ${ }^{17}$ It appears obvious that Strzygowski took on doctoral students to study South Asian, Central Asian, and East Asian art in order to further his own agenda and to supply him with materials and arguments in his attack on mainstream art history.

\section{Karl With's career in art history, work for private collectors, and museums}

According to Karl With's own memory, his first fascination with Asian art arose when he received a collection of photographs of the Javanese Buddhist monument Borobudur, which lead him to explore Asian art in museums and to consider studying it academically. An anecdote from With's autobiography illustrates that pursuing this interest was not easily to be realized at the time. Albert Grünwedel (1856-1935), curator for India at the Ethnological Museum in Berlin, rejected With: 'When I asked his advice how to go about studying Indian art, he jumped up from behind his desk, shouted at me that he would throw me out if I would ever again dare to speak of Hindu sculptures as works of art ${ }^{\prime}{ }^{18}$ After failing to find a professor in Germany, With was recommended to Josef Strzygowksi, who accepted him as his student.

With had studied art history in Freiburg, Munich, and Berlin before he came to Vienna in I9I2, and had also been connected to artistic circles in Munich and Berlin as well as to private collectors who combined an interest in the European avant-garde with a predilection for non-European art. Karl With would never focus on East Asian art alone but retained a strong interest in contemporary art and design that would continue to shape his career after he left Vienna. Among With's early mentors was the prominent collector Karl Ernst Osthaus, for whom he first worked in the summer of I9II. Osthaus's collection, which would become the basis for the Folkwang Museum in Hagen (and later in Essen), included works by artists such as Vincent van Gogh, Paul Cézanne, Paul Gauguin, Henri Matisse, Aristide Maillol, Christian Rohlf, and Emil Nolde, but also Persian miniatures, ancient Egyptian sculpture, Chinese ceramics, Japanese Noh masks, and African sculpture. ${ }^{19}$ Through his contact with Osthaus, With met many artists, such as the architect and designer Henry van Velde, and he accompanied Osthaus to Paris in 1912. Here, With would encounter art dealers of Asian art and was first introduced to Victor Goboulev, a Russian aristocrat and collector of Asian art who recommended him to Strzygowski. After having finished and published his dissertation, With worked for Osthaus's newly founded Folkwang Publishing House and was editor of the series Asia's Spirit, Art, and Life (Geist, Kunst, und Leben in Asien). He then became the director of the Folkwang Museum from I9I9 
to I92I - still a work in progress at the time - for which he organized two exhibitions after Osthaus's death in I92I. At that time, he had also started to work for Baron Eduard von der Heydt, a banker and collector of European avant-garde art, who had begun to build a collection of Asian and African works. ${ }^{20}$ With first catalogued parts of Von der Heydt's Asian art collection, mostly East and South-East Asian Buddhist sculpture, in 1923. ${ }^{21}$ The early I920s were With's most productive time as a scholar of Asian and East Asian art but he also published on contemporary European art, such as a small booklet on Marc Chagall. ${ }^{22}$ In 1925 he started working in Cologne, first as lecturer at and later as director of the Werkschule (School for Applied Arts and Design), and starting in 1928 also as director of the Kunstgewerbe-Museum (Museum for Applied Arts), where he developed a new concept for exhibiting the collection. ${ }^{23}$ His focus shifted away from East Asian art at that time and his publications on Asia decreased. After the Nazis came to power in 1933, With lost his positions and after a few years he went to Switzerland, where he worked again on Von der Heydt's collection while staying at his estate on Monte Verità in Ascona. He emigrated to the US in I939, where he became professor of art history at the University of California, Los Angeles, in 1950, after some years as a lecturer and working for a variety of museums. Here he built up the art history program and developed the so-called integrated art course'. East Asian art did not play a prominent role in his later career, but at UCLA he continued to promote a very broad notion of art history, not only in geographical terms but also by including design, film, and other subjects that were not widely acknowledged to belong to the discipline.

\section{With's dissertation on Japanese Buddhist art under Strzygowski}

After having begun his studies in Vienna under Josef Strzygowski, Karl With had the opportunity to undertake research in Japan during a trip in 1913-1914 that was financed by his fellow student, Oskar Vonwiller. ${ }^{24}$ During his stay in Japan, he focused on exploring Buddhist sculpture in temples and museum collections and assembled rich photographic documentation that would serve as the basis for his dissertation. The completion of the dissertation was delayed when the First World War broke out and With was drafted to serve in the German army. After the war he returned to Vienna and completed the dissertation, which was published in two volumes as Buddhist Sculpture in Japan until the Beginning of the Eighth Century in 1919. ${ }^{25}$

The dissertation focuses on a rather limited time period of roughly a century and a limited region, in order to provide, in With's own words, 'the detailed stylistic analysis that is indispensable for a sincere understanding' and to 'foreground the material itself by showing it as comprehensively as possible and to represent it 
photographically in a way that allows an adequate perception. ${ }^{26}$ The photographic documentation was indeed the very core of the published dissertation and the primary reason for its success: the separate volume of illustrations includes more than 200 photographs of sculptures dating from the seventh to the early eighth century, housed in temples in the Nara and Kyōto region - among them Hōryūji, Daigo-ji, and Kōryū-ji - but also from several museum collections such as the Ueno-Museum in Tokyo. With's photographs isolate the individual sculptures from their surroundings and usually show at least a frontal and a side view, as in the example of the famous Yumedono Kannon in Hōryū-ji temple [Fig. I9 left and Fig. 20 right]. ${ }^{27}$ Often, he adds photos of further points of view and of details, as if dissecting the sculptures photographically.

The text volume of the dissertation is, as announced in the introduction, an attempt to carefully describe the formal properties of the individual sculptures, to compare them with each other, and to thus group them according to stylistic categories and to trace stylistic developments over time. For the example of the Yumedono Kannon, With describes formal properties characteristic for the Tori style $^{28}$ : basic geometric forms of oval and triangle as the underlying structure and the creation of a silhouette that is developed out of a two-dimensional plane and thus dissolves the core of the sculpture. Such a formalist approach and categorizations are dominant throughout the dissertation and not unusual for the time. To apply this approach to a relatively short time frame of Japanese Buddhist art, however, must have challenged prevailing essentialist views about Buddhist art or East Asian art more generally. Rather than attempting to explain what Japanese Buddhist art was in essence, With treated his subject with the same attention to detail and historical change that had previously been afforded to European art.

Contextual considerations, such as about Buddhism in Japan, the ritual function of the sculptures, or their architectural framing, are hardly considered in With's dissertation except for some general points mentioned in the introduction. Neither does he consider iconographic issues nor the different materials and techniques, such as bronze, wood, or lacquer, even though these did, at least partially, determine formal features. While one may detect a reference to Strzygowski's method in these choices, i.e., disregard for textual sources and historical context, With acknowledges the lack of iconographical analysis and consideration of materials as shortcomings. ${ }^{29}$ In addition, he points out that he did not follow Strzygowski's systematic method, because he considered it dangerous 'to approach a foreign inventory of art by using a strict, systematic terminology that is primarily formed and evaluated based on the appearances of Western European $\operatorname{art}^{1}{ }^{30}$ At the same time, With explicitly situated his work within the framework established by Strzygowski for the study of East Asian art by emphasizing the 


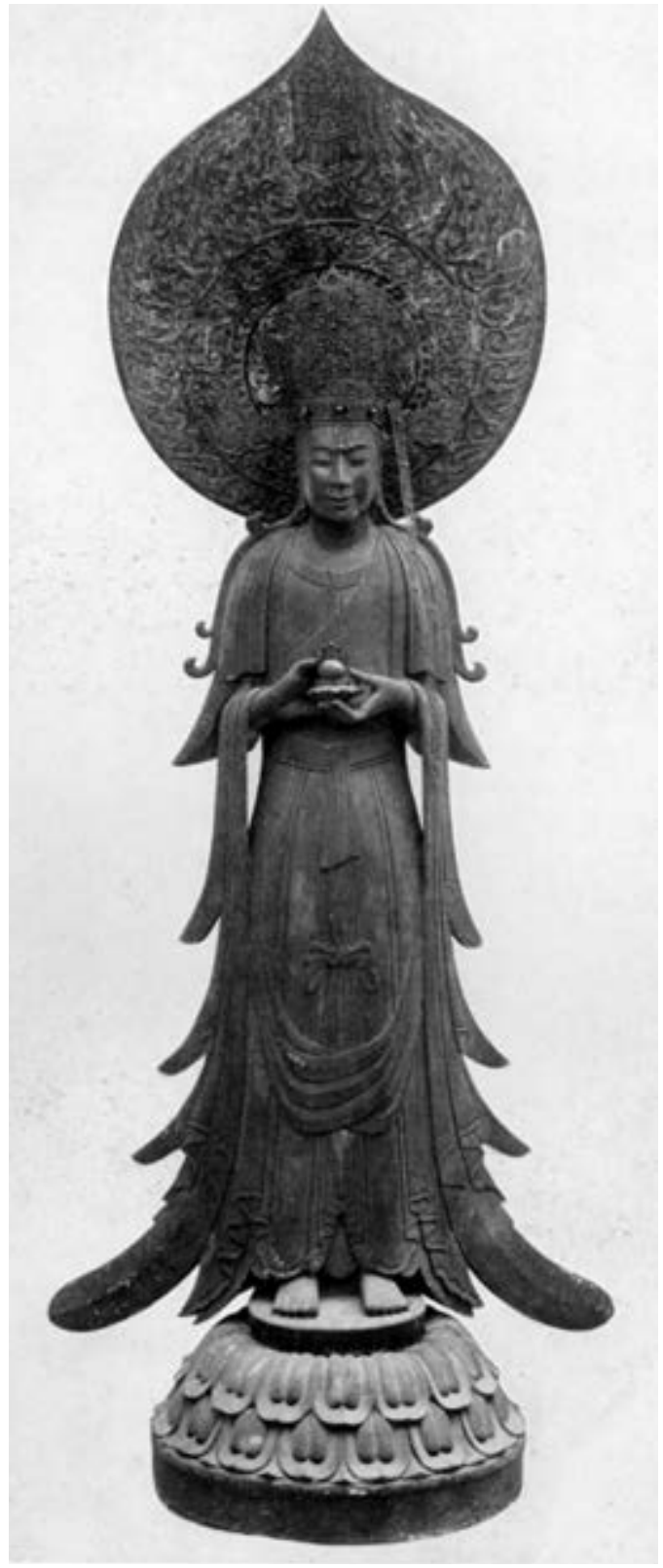

Fig. 19. Yumedono Kannon, first half of the seventh century, wood and gilt lacquer, height: $178.8 \mathrm{~cm}$, Horyu-ji, Nara prefecture (frontal view); after Karl With, Buddhistische Plastik in Japan (Vienna, 1919), vol. 2, plate I5

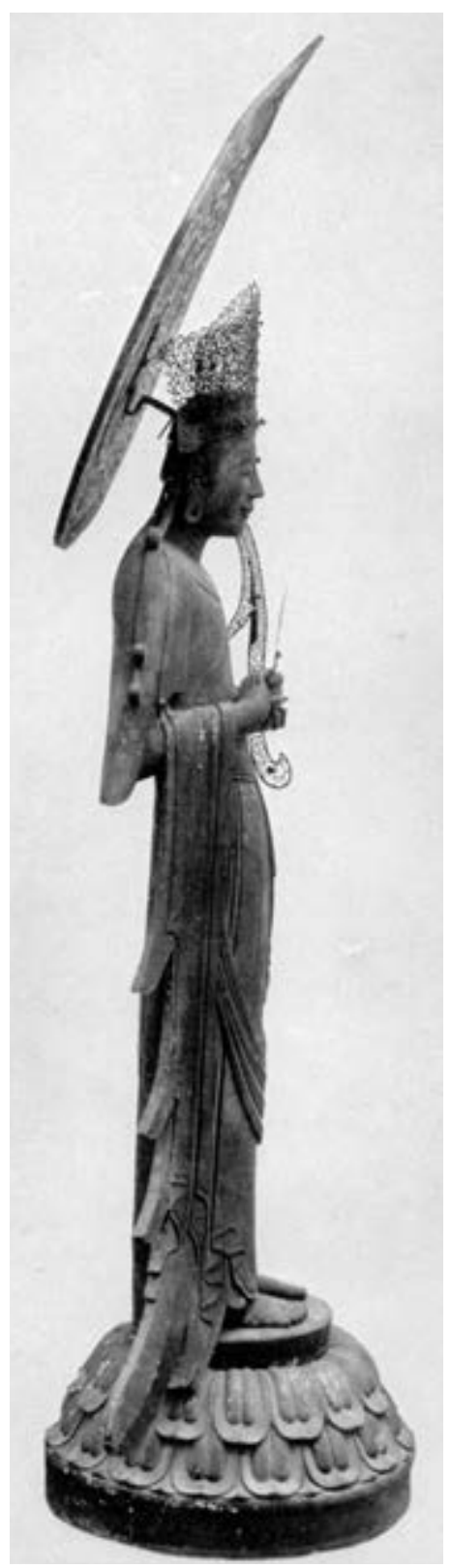

Fig. 20. Yumedono Kannon (see fig. I8) (side view); after Karl With, Buddhistische Plastik in Japan (Vienna, I9I9), vol. 2, plate I6 
importance of 'scientific art research' (wissenschaftliche Kunstforschung, i.e., Strzygowski's term for his systematic approach):

It was of decisive significance (for scientific art research) to free itself from the tyranny of a one-sidedly conceived idea of development that understood the forms of archaic art production only as the primitive precondition for an art shaped according to natural observation. To recognize that in this case it was a fundamentally different drive to make art [Kunstwollen], and not just one single, continuous developmental scheme, it [i.e., scientific art research] lay the basis for research that was able to encompass the entire field of artistic expression and to understand its laws. It will contribute especially to broadening Western European consciousness toward a truly human one. ${ }^{31}$

While With's work did not support Strzygowski in furthering his arguments about racial connections across Eurasia, he did emphasize the independence of developments in Japanese art and defended formal features that may not conform to European ideas of naturalism as being artistically superior. Strzygowski highly valued With's work, as can be seen in his evaluation of the dissertation, where he states that:

With has collected early Japanese sculpture since the appearance of Buddhism and offers through individual photographs insights that we hardly had for Italian art. After having overcome the influences from India, China and Korea, Japan rises to great prosperity under the great masters of the Suiko and Hakuho periods, and With attempts to grasp these developments by examining the essence of the individual artworks. ${ }^{32}$

Strzygowski would also take up With's work later on, especially in his The Visual Arts of Asia (Asiens Bildende Kunst [1930]), probably his most ambitious publication in terms of the historical and geographical range of materials covered. He includes some examples from With's dissertation, e.g., to point out that Japanese art was equivalent in its achievements to the art of Central Europe: '[T]here existed at the time in Japan the same movement of art for art's sake as in, for example, Quattrocento Italy' and that certain formal features appear 'as if in East Asia there was a movement in artistic creation that was scientifically grounded, similar to the so-called Gothic and Early Renaissance in Italy. ${ }^{33}$

To prove the independence of East Asian art and its formal developments is the point in which Strzygowski's and With's arguments come together most closely. More concretely, this independence is identified as an independence from the art of Gandhara, i.e., Buddhist art from what is today northern Pakistan and 
eastern Afghanistan during the first to fifth centuries with obvious Hellenistic influences. It is tempting to link the two scholars' insistence on the independence of Indian, Chinese, and Japanese art to the emerging national art histories that opposed colonial narratives. For instance, in the I920s Ananda Coomaraswarmy was developing similar, yet much more detailed and historically sound arguments about Indian Buddhist art predating Gandharan examples in his well-known study 'The Origin of the Buddha Image' (1927), which highlighted indigenous traditions as opposed to Hellenistic models. ${ }^{34}$ Yet neither Strzygowski nor With were interested in arguments about national independence or indigenous artistic achievements; instead their main aim was the rejection of Hellenistic influences, though their reasons differed.

\section{The problem of Gandhara}

Gandharan sculpture first became known to a wider audience in Central Europe during the Vienna World Exposition in 1873. The works suggested that Indian and, by implication, Asian Buddhist art, derived from Greek models, yet without having achieved their ideal standards. Gandhara posed a problem to Strzygowski, because it seemed to confirm a far-reaching dependence on Hellenistic influences throughout Asia. This, of course, opposed his narrative that downplayed the importance of Greek and Roman art and Gandhara became an instance in Strzygowski's 'struggle against Rome':

Just like Rome, supposedly the giving party everywhere in the Occident, so Hellas supposedly takes on the same role everywhere in Asia. The falsity of such an assumption is not recognized, because artistic research sits comfortably in its European nest and has not freed itself from the assumptions of historical research. ${ }^{35}$

The dismissal of Gandharan art and the emphasis on autochthonous developments in Buddhist sculpture of China and Japan became an important part of Karl With's research as well, although his motivation differed from Strzygowski's, as will be pointed out below.

With's dissertation displays a striking rhetoric of purity and independence, especially if one considers his otherwise formalist approach. To return the example of the Yumedono Kannon introduced above, With ends his formal analysis with a surprising, almost abrupt, statement that this sculpture presented a counterpoint to Gandharan Buddhist art. According to With, Gandharan art, despite its abstractions, remained always bound to a Southern sensuality and to a naturalistic notion 
and materiality. The Yumedono Kannon demonstrated in With's understanding that the Japanese Tori style was indebted to an early Chinese 'national' style that was already fully independent from Indian models. With argues that even if one was to accept that early Chinese and Japanese sculptors 'had indeed derived their forms from Gandharan works, then we can only admire their forceful, artistic will that transformed such provincial, naturalistic works into a new and deepened expression appropriate to the Buddhist spirit. ${ }^{36}$ Several threads of a larger argument are combined in this statement. First of all, Gandharan art is dismissed as Southern, provincial, sensual, and naturalistic, i.e., With considers geography in relation to form and questions naturalism as the end to formal developments in sculpture. Secondly, With does not neglect the influence of Gandhara on Chinese and Japanese Buddhist art, but argues that Chinese Buddhist sculpture freed itself from it and developed a 'national style' that would then be further refined in Japan. Thirdly, the Chinese and Japanese examples that became independent from Gandhara display in With's view a more properly Buddhist approach to sculpture.

The first point takes up Strzygowski's division between Southern naturalism and Northern idealism in art. Whereas Strzygowski further linked these properties of artworks to racial categories in juxtaposing Semitic naturalism with Aryan idealism, With did not subscribe to these ideas. Instead, he sought to reevaluate an observed lack of naturalism in Buddhist sculpture to religious concepts of transcendence. The second point about the development of a Chinese national style can be illustrated by the comparison of two Buddha heads from Eduard von der Heydt's collection. According to With's analysis, one of the heads still belonged to the late phase of a declining art with formal features close to 'Central Asian composite art' (zentralasiatische Mischkunst) [Fig. 2I]. Its characteristics are naturalistic, curly hair; irregular lower-eye contours; weak and bloated cheeks; a sensual heaviness in the lower part of the face disproportional to the narrow forehead; and a generally saturated and sedate expression. ${ }^{37}$ The second Buddha head is dated only slightly later, to the mid-fifth century and shows in With's narrative how rapidly China purged foreign forms and found its own style during the Wei Dynasty (386-534 AD) [Fig. 22]..$^{38}$ Characteristic for this 'sincere Wei style' are the massive, rectangular head; simple lines; and the frontal, architectonic structure. Further following With, the head's expression is solemn, oriented inward, nonsensual and at the same time sculpturally alive, displaying a mysterious smile. It thus fulfills With's requirements for transcendental monumental sculpture in the Chinese national style. ${ }^{39}$

This comparison already hints at the third point, namely that the Chinese national style and subsequent Japanese examples were more properly Buddhist than their Gandharan predecessors. With states this explicitly in the same catalogue of Von der Heydt's collection: 


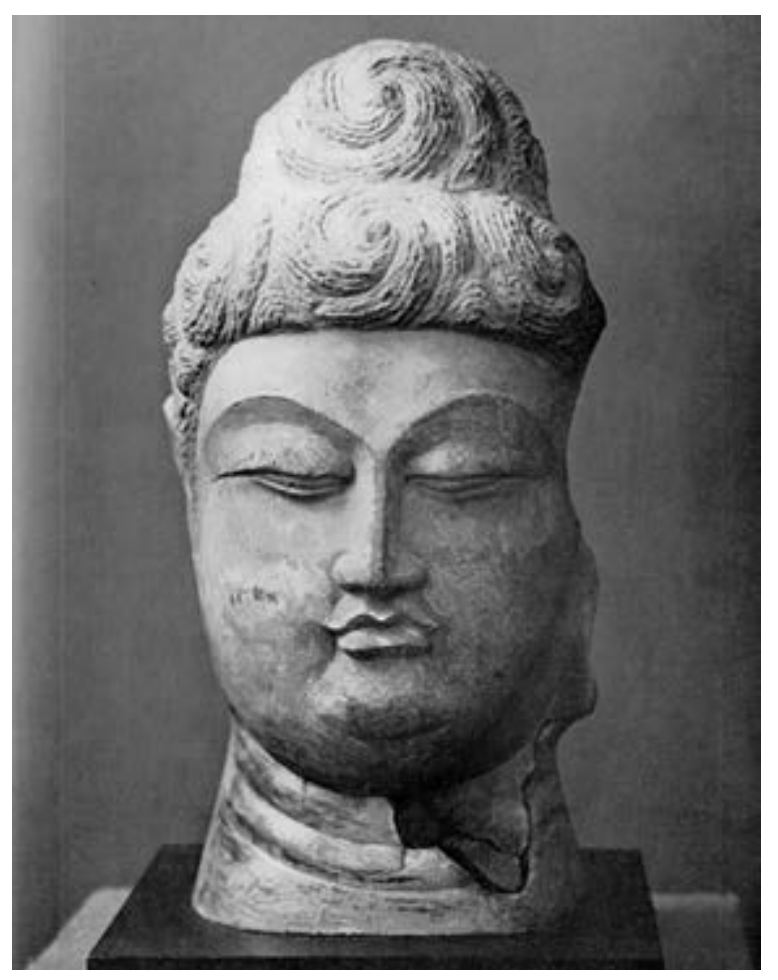

Fig. 21. Head of a Buddha, c. $500 \mathrm{AD}$, limestone, previously collection Von der Heydt; after Karl With, Bildwerke Ost- und Südasiens der Sammlung Yiyuan (Basel, 1924), plate 20

The province of Gandhara, however, formed the center of a late Hellenistic provincial art that made use of Buddhist motifs while completely ignoring the Buddhist spirit. This art is characterized by an unpleasant decline, or, alternatively put, a dependent composite art. Its weak and bloated, bodily and individualized forms have nothing to do with the transcendental spirit of Buddhism. ${ }^{40}$

In his work on Buddhist art, Karl With was searching for a spirituality that he understood as emerging from the dialectics of transcendence and body. If Buddhism was based on a transcendent concept of god and thus required an artistic form that departed from the empirical world, sculptors had to resolve an inherent contradiction caused by the focus on the historical Buddha and the human figure. Gandharan art had not been able to do this, according to With, as it adhered to naturalistic principles of representation in the Hellenistic tradition. The Chinese national style, however, had developed a fully sculptural form that rendered the physical presence of the Buddha while embodying transcendence in less naturalistic, basic three-dimensional forms. In With's account, formal features in Chi- 


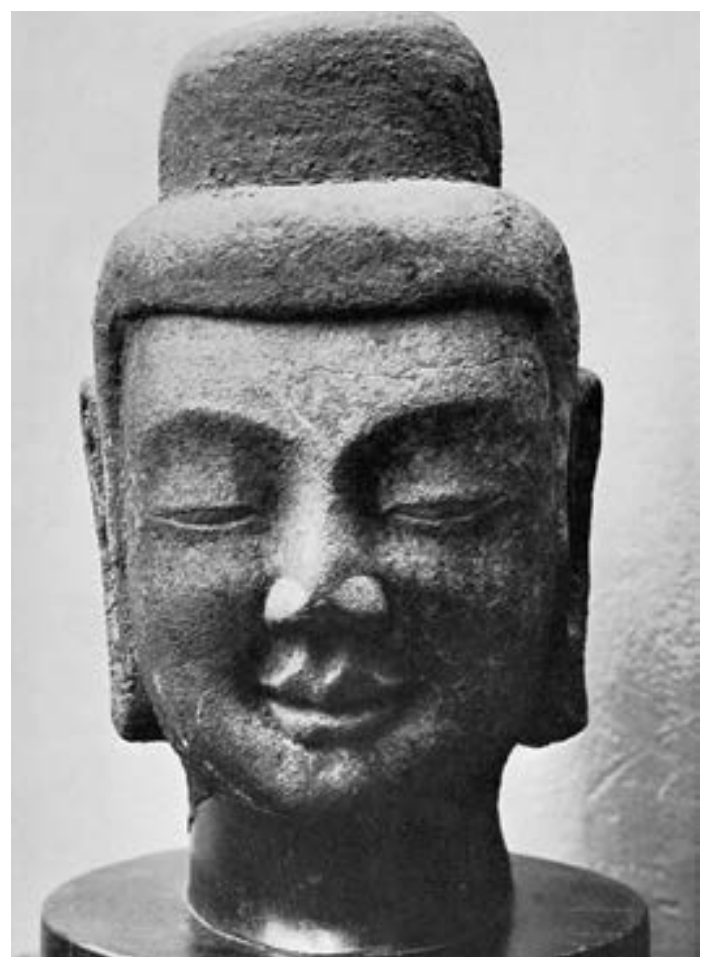

Fig. 22: Head of a Buddha, Wei Dynasty (fifth century AD), sandstone, previously collection Von der Heydt; after Karl With, Bildwerke Ost- und Südasiens der Sammlung Yiyuan (Basel, 1924), plate 22

nese and Japanese Buddhist sculpture are thus tied to religious concepts, and both are shown to depart from Gandharan models.

With's argument was not confined to Asian Buddhist art. Instead, he related it to the artistic and intellectual concerns of his own time when he repeatedly pointed out that only now the appreciation of Buddhist art had become possible:

It was only the search of the soul of our own age, it was the artistic longing that urges away from constrictions or chaos toward a clarity of sculptural greatness, it was only the cosmopolitan attitude that opened the paths to appreciate the genius of sculptural creation in China. ${ }^{4 \mathrm{I}}$

These ideas relate to the concept of ars una - that there is only one art - as promoted by With's mentors Osthaus and Von der Heydt, as visible in their homes and exhibitions that displayed European avant-garde art in dialogue with nonEuropean art [Fig. 23].

The connection that Karl With saw between Asian Buddhist art and the soulsearching' of his own time demands further exploration, extending to the role 


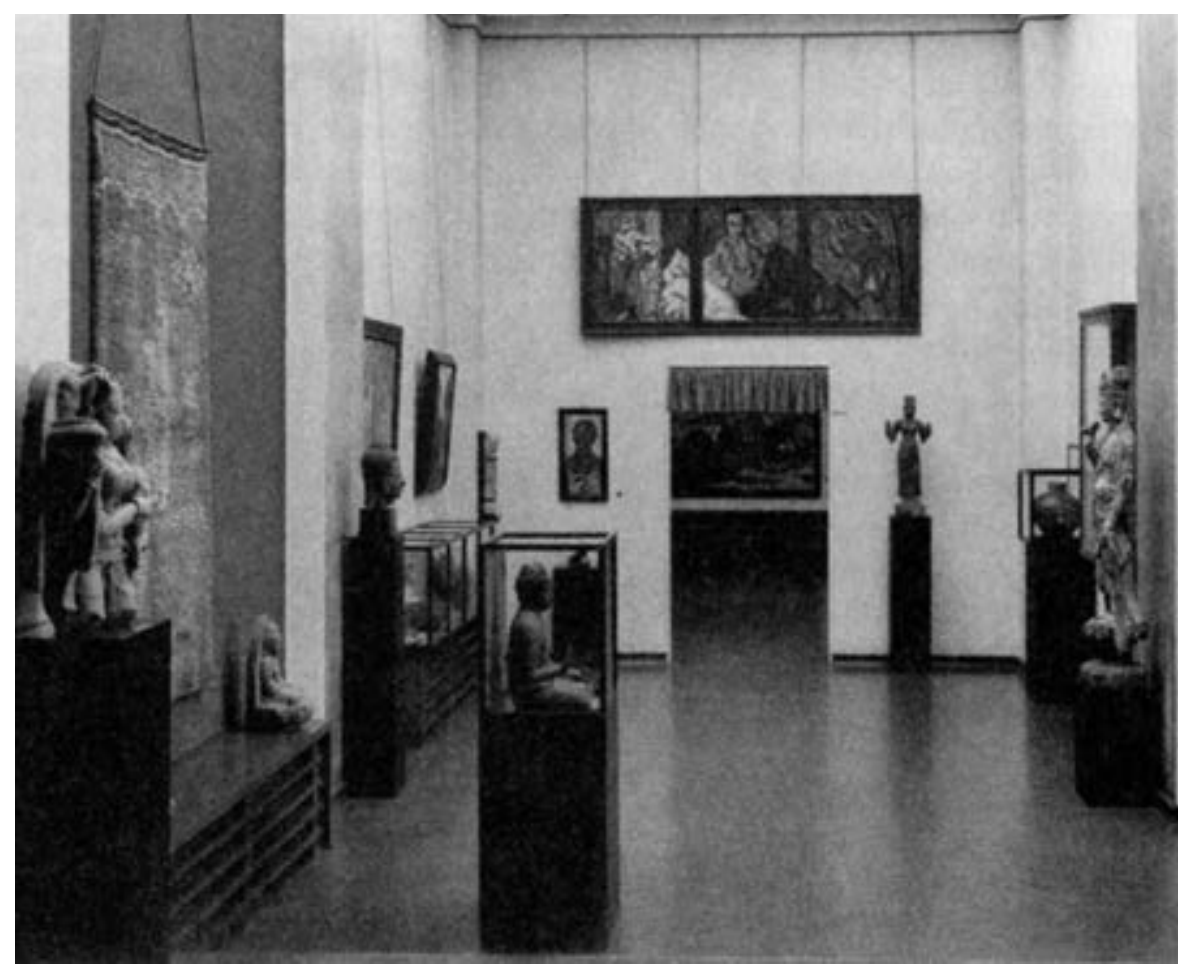

Fig. 23: Albert Renger-Patzsch, Second hall in the Folkwang Museum, Essen, view into the big gallery with paintings by Paula Modersohn-Becker and Erich Heckel, with Franz Marc's "Grazing Horses IV" and with non-European sculptures and objects, around 1930 (C Museum Folkwang Essen)

that Buddhist art played in European collections and to the more general spiritual interest in Buddhism and other world religions among scholars and intellectuals at the time. One connection between ancient Asian Buddhist art and early twentieth-century avant-garde sculpture that With himself made by way of terminology, appears with regard to his favorite contemporary sculptor Moissey Kogan (1879-1943), a friend from his student days in Munich and a protégé of Karl Ernst Osthaus [Fig. 24]. In an article on the occasion of an exhibition of Kogan's work in Germany, With summarizes the effect of Kogan's sculpture as a 'silent transcendence'. ${ }^{42}$ This implies a formal and spiritual relation between the transcendental forms of Buddhist art that he found in Chinese and Japanese Buddhist sculpture and what he referred to as the urge toward the clarity of sculptural greatness' of his own time. 


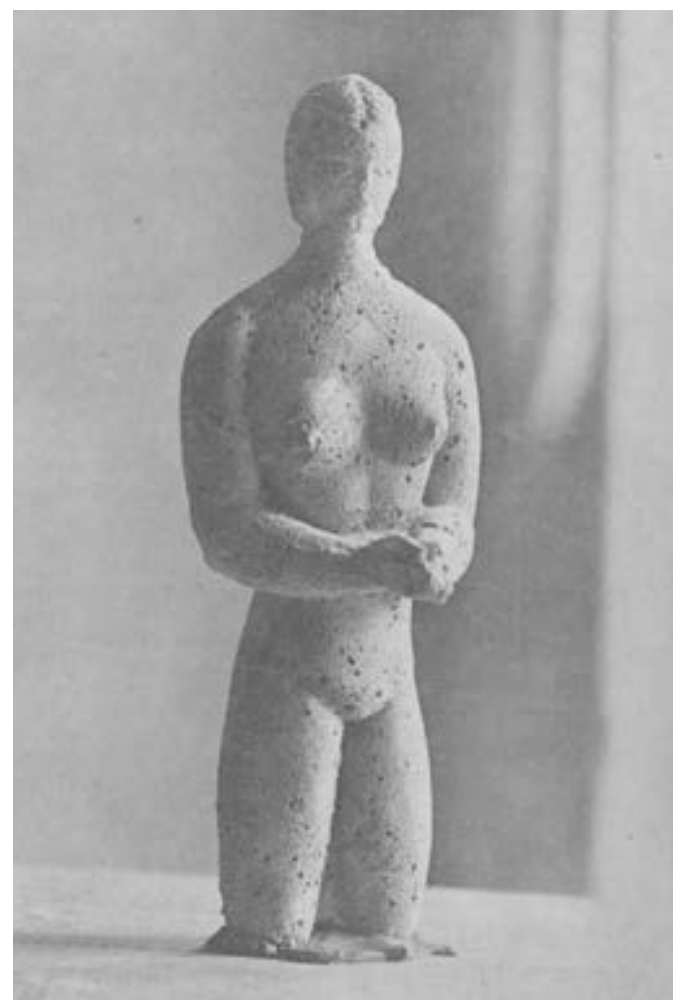

Fig. 24: Moissey Kogan, Female Figure; after Karl With,'Kogan besucht Deutschland', Das Kunstblatt 6.II (1922)

\section{Notes}

I For instance, colonial powers sent out expeditions to Central Asia to excavate ancient sites and to bring back artifacts. Among these were several German expeditions starting in I902, lead by Alfred Grünwedel and Albert von Le Coq to Turfan. The British government sent Sir Aurel Stein to Dunhuang in 1907, and shortly thereafter he was followed by the French Paul Pelliot. Earlier, the Swedish government had sent Sven Hedin in I 896 and again in I 899 to excavations in the Taklamakan desert. On the discovery of the Dunhuang caves by Western explorers See, e.g., Roderick Whitfield, Cave Temples of Mogao: Art and History on the Silk Road (Los Angeles: Getty Conservation Institute and the Getty Museum, 2000). For a non-academic account, see Peter Hopkirk, Foreign Devils on the Silk Road: The Search for the Lost Cities and Treasures of Chinese Central Asia (London: Murray, I980).

2 To name just a few of the scholars active at the time, whose work is still widely read and taught in historiography courses: Heinrich Wölfflin (I864-I945), who taught in Berlin, Munich, Basel, and Zurich; Aby Warburg (I 866-I929), who was active in Hamburg until his death; the Vienna school of art history with Alois Riegl (I858-1905), Franz Wickhoff (I 853-I909), and others; and Erwin Panofsky (I892-I986), who taught in Hamburg until he emigrated to the United States. 
3 A few exceptions were art historians initially trained in European art who then shifted their focus to East Asian art, such as Otto Fischer (I886-I948). He wrote his dissertation on Northern European painting under Heinrich Wölfflin in 1907 and subsequently focused on East Asian art with a Habilitation on Chinese landscape painting in I9I2. Fischer contributed the volume on the arts of India, China, and Japan to the PropyläenKunstgeschichte in 1928 - marking a point when Asian art had arrived in the art-historical canon of German art history.

4 For the history of the East Asian art department at the Berlin Museums see, e.g., Lothar Ledderose, 'Collecting Chinese Painting in Berlin', in Ming Wilson and John Caley (eds.), Europe Studies China: Papers from an International Conference on the History of European Sinology (London: Han-Shan Tang Books, 1995), I75-201. For biographical information on Otto Kümmel, see, e.g., Hartmut Walravens, Bibliographien zur ostasiatischen Kunstgeschichte in Deutschland 3: Otto Kümmel (Hamburg: C. Bell, 1985).

5 Karl With, Buddhistische Plastik in Japan bis in den Beginn des 8. Jabrbunderts (Vienna: Anton Schroll \& Co., I9I9). Besides Karl With, there were many better-known students of Strzygowski working on Asian and East Asian art, who would continue their careers in these fields. Among them were Stella Kramrisch (I 896-I993), who finished her dissertation on Indian art in Vienna in I9I9 and would become professor in Calcutta and later curator at the Philadelphia Museum of Art and professor at the University of Pennsylvania. Alfred Salmony (I890-I958), who studied in Vienna in I9I9-I920, was a specialist in Chinese art, who worked at the Museum for East Asian Art in Cologne and became professor at the Institute of Fine Arts at New York University after his emigration.

6 'Die ostasiatische Abteilung des Kunsthistorischen Instituts der Universität Wien wurde I9I 2 gegründet, freilich mit sehr beschränkten Mitteln'. Karl With, Buddhistische Plastik in Japan bis in den Beginn des 8. Jahrbunderts (Vienna: Anton Schroll \& Co., I9I9), vol. I, 7 .

7 Strzygowski provides a short list of materials and activities of his new East Asian section: a collection of photographs of Indian monuments donated by the collector Victor Goboulev, another collection of photographs of Javanese monuments donated by Karl With, the Japanese art journal Kokka provided by Otto Kümmel in Berlin, and a research trip undertaken by With together with Oskar Vonwiller to Japan, China, Java/Indonesia, and Egypt in I9I 3 that would result in With's dissertation and from which he brought back more photographs as well as Japanese woodblock prints. Further mentioned is that With taught a seminar on early East Asian Buddhist sculpture in I9I4 based on these materials. Josef Strzygowski, 'Das Kunsthistorische Institut der Wiener Universität', Die Geisteswissenschaften I.I (I9I3/I4), I2-I6.

9 These members were, as pointed out above, Karl With and Oskar Vonwiller. Vonwiller was financing the journey. For an account, see With's autobiography: Karl With, Autobiography of Ideas: Lebenserinnerungen eines außergewöhnlichen Kunstgelebrten (Memoirs of an Extraordinary Art Scholar), ed. Roland Jaeger (Berlin: Mann, I997), 67-85.

Io For instance, Christopher Wood has addressed Strzygowski's 'global map of art history' and warns against the danger of repeating Strzygowski's mistakes, not because they were rooted in the racist and imperialist ideologies of the nineteenth century but rather because of their implicit 'idealist fallacy' that privileged a visual comparative approach to artifacts of uncertain date and origin without documentation in textual sources in order to draw conclusions about the people who had (supposedly) produced them. See Christopher Wood, 'Strzygowski und Riegl in den Vereinigten Staaten', Wiener Jahrbuch für Kunstgeschichte 53 (2004), 225 and $23 \mathrm{I}$. 
I I Jas Elsner,'The Birth of Late Antiquity: Riegl and Strzygowski in I90 I', Art History 25.3 (June 2002), 358-379.

I2 Johann Konrad Ebelerlein. 'Josef Strzygowski: Gedanken über die Zeitlosigkeit eines Typus', in Lukas Madersbacher and Thomas Steppan (eds.), De re artificiosa. Festschrift für Paul von Naredi-Rainer zu seinem 6o. Geburtstag (Regensburg: Schnell und Steiner, 20 I0), 8I-93.

I 3 Julia Kelly, 'Discipline and Indiscipline: The Ethnographies of Documents', Papers of Surrealism 7 (2007). For a general account of anthropological perspectives in early world art history and Strzygowski's involvement, see Susanne Leeb, Die Kunst der Anderen. Weltkunst und die anthropologische Konfiguration der Moderne (Frankfurt, Oder: Universitätsbibliothek der Europa-Universität Viadrina Frankfurt, 2013), 239-243. Online resource: http://opus.kobv.de/euv/volltexte/2013/80/ (accessed 6 November 2013).

I4 Ernö Marosi, 'Josef Strzygowski als Entwerfer von nationalen Kunstgeschichten', in Ruth Heftrig et al. (eds.), Kunstgeschichten im 'Dritten Reich'. Theorien, Methoden, Praktiken (Berlin: Akademie Verlag, 2008), I03-II3.

I5 For an analysis of these aspects in Strzygowski's scholarship, see Suzanne L. Marchand, 'The Rhetoric of Artifacts and the Decline of Classical Humanism: The Case of Josef Strzygowski', History and Theory 33 (I994), I06-I 30.

i6 '[D]aß sie uns zwingen, endlich einmal die Brücke zwischen Ost und West, Süd und Nord zu schlagen und uns bewußt zu werden, daß das Ausbreitungszentrum der Kraft nicht nur am Mittelmeere liegt, die Bewegung vielmehr von mehreren Quellpunkten und sehr vielen diese originellen Ströme verbindenden Kanälen ausgeht'. Josef Strzygowski, 'Ostasien im Rahmen der vergleichenden Kunstforschung, Ostasiatische Zeitschrift 2.I (I9I3), 8.

I7 Leeb, Die Kunst der Anderen, 240. In addition, Strzygowski clearly articulated the political implications of these views for his own time, when he declared that German dreams of world domination were simply an expression of a repressed former racial bond with the world. See Josef Strzygowski, Die Bildende Kunst des Ostens. Ein Überblick über die für Europa bedeutungsvollen Hauptströmungen (Leipzig: Verlag von Dr. Werner Klinkhardt, I9I6), 7 I.

I 8 With, Autobiography of Ideas, 60.

I9 On the history of the Folkwang Museum and its collection, see Hartwig Fischer (ed.), 'Das schönste Museum der Welt' - Museum Folkwang bis 1933: Essays zur Geschichte des Museum Folkwang (Göttingen: Steidl, 20 го).

20 On von der Heydt see, e.g., the most recent publication: Eberhard Illner et al. (eds.), Eduard von der Heydt. Kunstsammler Bankier Mäzen (Munich, London, and New York: Prestel, 2013). On his collection of non-European art, see Sabine Fehlemann (ed.), Asien, Afrika, Amerika und Ozeanien. Eduard von der Heydt als Sammler aussereuropäischer Kunst (Wuppertal: Von der Heydt Museum, 2002).

2 I Karl With, Bildwerke Ost- und Südasiens aus der Sammlung Yi Yuan (Basel: Schwabe \& Co., I924).

22 Karl With, Marc Chagall (Leipzig: Klinkhardt \& Biermann, 1923). For a complete list of With's publications, see Karl With, Autobiography of Ideas, 389-400.

23 This aspect of With's career is currently explored by Marie Yasunaga in her dissertation at the University of Tokyo which focuses on Karl Ernst Osthaus' and Karl With's exhibition concepts and aesthetics in relation to their respective interests in non-Western art.

24 The trip to Japan and the return journey via China, Indonesia, and Egypt is described in With, Autobiography of Ideas, 67-85.

25 Karl With, Buddhistische Plastik in Japan bis in den Beginn des 8. Jahrbunderts (Vienna: Anton Schroll \& Co., I9I9). The dissertation is dedicated to Karl Ernst Osthaus and Oskar Vonwiller. The publication was an unexpected success, primarily because of the 
photographic documentation of sculptures previously unavailable in European publications, and a second and third one-volume edition with a shortened text came out in I920 and 1922 .

'[J]ene stilistische Kleinarbeit (zu ergänzen), die unerlässlich für ein aufrichtiges Verstehen ist [...]. Dafür versucht sie das Material selbst in den Vordergrund zu stellen und in möglichster Vollständigkeit aufzuzeigen und photographisch so wiederzugehen, dass eine gewissermassen adäquate Vorstellung möglich wird' (With, Buddhistische Plastik in Japan, I I).

27 This sculpture - like many others studied by With - is today listed as a National Treasure and believed to be the oldest extant wooden sculpture in Japan. The Yumedono Kannon was 'discovered' by the American scholar Ernest Fenellosa, who worked for the Japanese government, in I884. Before, it had been covered up in the temple and is until today usually hidden from view and only revealed on specific holidays. For Ernest Fennellosa's discovery, see his Epochs of Chinese and Japanese Art: An Outline History of East Asiatic Design (London and New York: Heinemann and Stokes, I9I3), vol. 2, 50. For more recent research on the sculpture, see, e.g., Lucie R. Weinstein, 'The Yumedono Kannon: Problems in Seventh-Century Sculpture', Archives of Asian Art 42 (I989), 25-48.

28 The term 'Tori style', after the sculptor Tori Busshi (active late sixth to early seventh century), was not invented by With and is still used today to identify features of Japanese sculpture related to Chinese Northern Wei Dynasty (386-534 AD) Buddhist sculpture. Interestingly, similar categories of stylistic categorization are still applied, for instance, when describing Tori-style bodhisattvas that are 'frontally oriented, have slender bodies, oval faces, and drapery that terminates in a zigzag pattern on both sides of the skirt' (Weinstein,'The Yumedono Kannon', 30).

With, Buddhistische Plastik in Japan, vol. I, I98.

30 ' $[E]$ s schien mir gefährlich mit einer festgelegten, systematischen Terminologie, die doch zum wesentlichen an den Erscheinungen der westeuropäischen Kunst ausgebildet und bewertet ist, an einen fremdländischen Kunstbestand heran zu treten..., (ibid., vol. I, I99).

3 I 'Es war für sie (die wissenschaftliche Kunstforschung) von entscheidender Bedeutung, dass sie sich von der Tyrannie des einseitig aufgefaßten Entwicklungsgedankens freimachte, der in den Formen archaischen Kunstschaffens nur die primitiven Vorstufen für eine im Sinne der natürlichen Anschauung gebildete Kunst sah. Mit der Erkenntnis, daß es sich hier um ein prinzipiell anders geartetes Kunstwollen und nicht nur um eine einzige durchlaufende Entwicklungsreihe handle, legte sie den Grund für eine Forschung, die das Gesamtgebiet künstlerischer Äußerungen zu umfassen und in ihrer Gesetzmäßigkeit zu erkennen im Stande ist. Sie wird vornehmlich dazu beitragen, das westeuropäische Bewußtsein zu einem wahrhaft menschlichen zu erweitern' (ibid., Io).

'With hat die frühjapanische Plastik seit dem Auftreten des Buddhismus gesammelt und bietet durch seine Einzelaufnahmen einen Einblick, wie wir ihn bisher kaum für die italienische Kunst kannten. Nach Ueberwindung der Einflüsse von Indien, China und Korea her schwingt sich Japan unter grossen Meistern der Suiko- und Hakuho-Periode zu einer grossen Blüte auf, der With durch Untersuchung der Wesensart der einzelnen Kunstwerke beizukommen sucht'. The original evaluation of With's dissertation signed by both Strzygowski and Max Dvořák is available online from the University of Vienna, URL: http://www.univie.ac.at/geschichtegesichtet/images/vertreibung/With/_MG_3247.jpg (Accessed I November 2012).

33 '[D]ass damals in Japan die gleiche Bewegung, Kunst um der Kunst willen, bestanden hat, wie etwas in Italien im Quattrocento [...] als wenn in Ostasien in der Zeit seiner Blüte 
eine ähnliche, geradezu auf wissenschaftliche Begründung des künstlerischen Schaffens losgehende Bewegung bestanden hätte wie in der sogenannten Gotik und Frührenaissance in Italien' (Strzygowksi, Asiens Bildende Kunst, 69 and 70).

34 Ananda K. Coomaraswamy, 'The Origin of the Budhha Image', Art Bulletin 9.4 (June I927), 287-329.

35 'Wie im Abendlande überall Rom der gebende Teil sein soll, so in Asien überall Hellas. Die Verkehrtheit einer solchen Annahme wird nur deshalb nicht empfunden, weil die Kunstforschung behaglich in ihrem europäischen Neste hockt, und sich nicht von den Anschauungen der Geschichte freimacht'. Josef Strzygowski, Die Krisis der Geisteswissenschaften, vorgeführt am Beispiele der Forschung über bildende Kunst: Ein grundsätzlicher Rahmenversuch (Vienna: Schroll, I923), 3 17. Strzygowski had brought up similar ideas earlier; an almost identical sentence can, for instance, be found in Josef Strzygowski, 'Ostasien im Rahmen der vergleichenden Kunstforschung', Ostasiatische Zeitschrift 2.I (I9I3), 6.

36 '[I]hre Formen wirklich von den Gandhara Bildwerken abgeleitet hätten, so können wir nur ihren mächtigen, künstlerischen Willen bewundern, der jene provinziellen wirklichkeitsnahen Bildwerke auf einen neuen, dem buddhistischen Geiste entsprechenden und vertiefteren Ausdruck gebracht haben' (With, Buddbistische Plastik in Japan, 48). Similar statements can be found throughout With's work on Buddhist art from the early I920s, for instance, in an article on Chinese sculpture in the municipal gallery in Frankfurt (today's Liebighaus), where he accuses previous scholarship of having falsely chased the 'ghost' of Greek and other influences in Asian sculpture instead of devoting itself to the independent values of a foreign aesthetic and spirit. See Karl With, 'Chinesische Plastik in der Frankfurter Städtischen Galerie', Städel-Jahrbuch I (I92I), 6.

37 Karl With, Bildwerke Ost-und Südasiens aus der Sammlung Yi Yuan (Basel: Schwabe \& Co., I924), I4-I5 and 46.

38 Ibid., I5 and 46-47.

39 Ibid. It should, however, be noted that Northern Wei Buddhist sculpture, identified by With as the epitome of a Chinese national style, was produced under a non-Chinese dynasty ruled by the Tuoba, a Turkic nomadic tribe that had united a large part of Northern China under its rule. I do not know whether With was aware of this, but if he was, then his use of the term 'national' does not carry racial or ethnic but instead regional or cultural connotations. Ibid., I 4 .

4I 'Erst das Suchen unserer eigenen Zeitseele, die aus Enge oder Chaos zur Klarheit plastischer Größe drängende künstlerische Sehnsucht, erst die weltbürgerliche Einstellung fand die Wege, die Genialität plastischen Schaffens in China zu würdigen' (With, 'Chinesische Plastik in der Frankfurter Städtischen Galerie', 6).

Karl With, 'Kogan besucht Deutschland', Das Kunstblatt 6, I I (I922). 


\title{
8.3 Cross-Cultural Epistemology How European Sinology Became the Bridge to China's Modern Humanities
}

\author{
Perry Johansson
}

\section{Introduction}

European sinology since Matteo Ricci (1552-1610), founder of the Jesuit mission in China, was occupied with interpreting the Chinese classics, unpacking the learned worldview of the elite that adhered to them. ${ }^{1}$ However, the Swedish explorer Sven Hedin's late-nineteenth-century rediscovery of ancient hidden cities buried along the Silk Road unleashed a new wave of sinology [Fig. 25]. The magnificent collections of Silk Road material that Paul Pelliot, Aurel Stein, and Albert Grünwedel then plundered provided European scholars with previously unknown source material that the Chinese themselves could not easily consult. Hedin's find sparked a modern direction in sinology and inspired Western sinologists to travel east for more discoveries. In the same time it sent Chinese scholars going the opposite direction.

For a thousand years the Chinese examination system created scholars for service in the administration of the empire. The knowledge required prescribed a hierarchically ordered world based on relations and personal virtue. But in the early twentieth century the sudden fall of this two-thousand-year-old imperial system also brought the demise of this regime of knowledge. Before 1905, when the examination system was abolished, radical intellectuals had been involved in a tug of war with conservative scholars. With the May Fourth Movement political demands became clearly coupled with a cultural politics that wanted to displace everything old and Chinese. Scholars like Lu Xun and Hu Shi elevated the culture and language of the people, reforms that helped the Chinese to imagine the nation in a more Western manner. ${ }^{2}$ The reforms would, of course, also radically challenge the formerly exclusive position of the educated elite. With this process arrived the formation of a modern humanities based on a secular scientific study of man - academic disciplines similar to those in existence already in the West. 


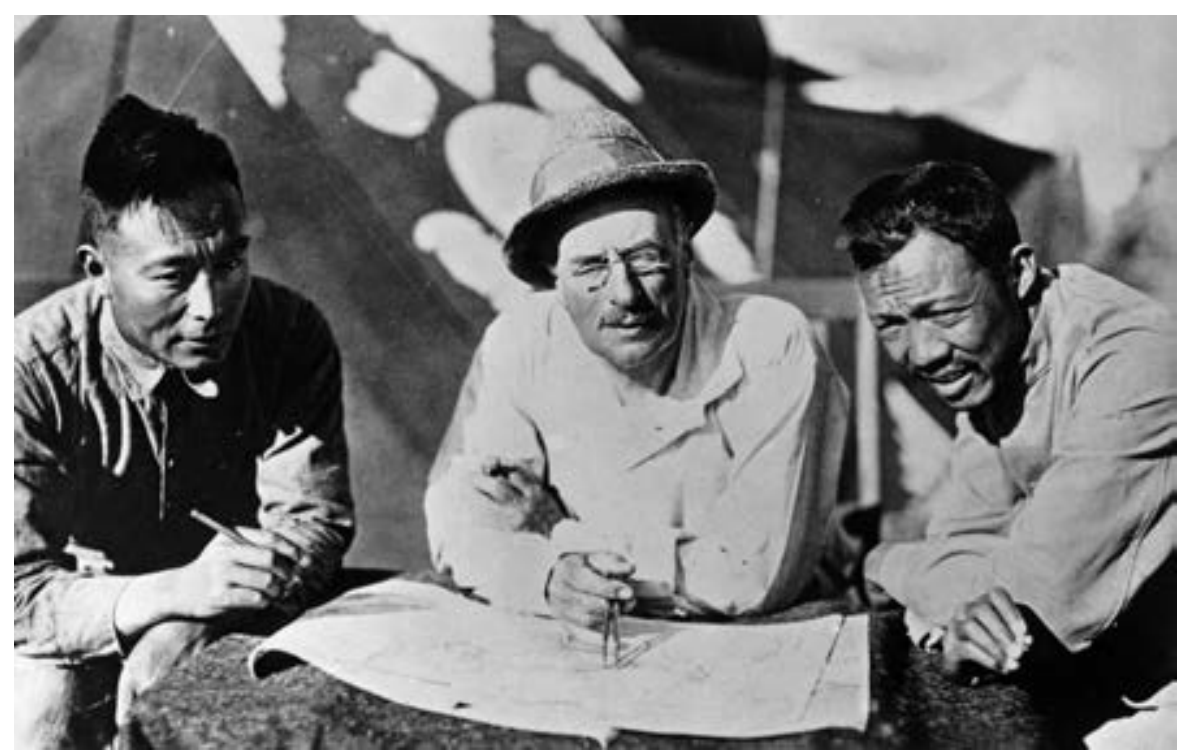

Fig. 25: Leaders of the Sino-Swedish Expedition studying a map (c. 1927-28): Xu Bingchang (also known as Xu Xusheng), professor of history and archaeology at Peking University (left), Sven Hedin, the Swedish explorer (center), and Yuan Fuli, a geologist (right). Photo at a private collection / The Bridgeman Art Library

That many Chinese intellectuals under pressure of Western imperialism disavowed their history and tradition is understandable; but it had its dire effect on cultural heritage. The material archive of the Chinese state - the treasures, libraries, and document collections relating to the previous six hundred years of Ming and Qing rule - came under serious threat. Antique porcelain and other valuables were pawned for providing money to run the imperial household and then sold off at auctions. ${ }^{3}$ Eunuchs stole priceless treasures from within the vermilion walls while the last emperor himself smuggled out precious imperial objects. ${ }^{4}$ Even the Inner Chancery archives of the Ming and Qing dynasties were threatened. These priceless documents were stolen, sold, even used as scrap papers, until first the antiquarian, Luo Zhenyu, and then the historian $\mathrm{Fu}$ Sinian intervened.5 In these precarious times neither politicians nor intellectuals could see the value of documents that were pertaining to the history of dynastic rule. The empire had become the abject Other for the Chinese modernizers and in 1928 a member of the Republican government even tried to pass a bill to 'Abolish the Palace Museum and sell or auction off all of the objects in the former palace in lots. ${ }^{6}$ The proposal was hotly debated and a committee was set up to deal with what was regarded as the 'illicit property' of the former imperial house. ${ }^{7}$ 
The New Culture Movement that raged from the years of the failed republic to the mid-I920s wanted to get rid of old China. Scholars like Gu Jiegang consequently tried to deconstruct the Chinese master narrative. But things were about to change. With the catchphrase of zhengli guogu or 'reorganizing the national past' a countermovement to this iconoclasm appeared. Thus China's history became significant again for the intellectuals. To reconnect with older scholarly traditions, national studies (guoxue) institutes were established at a number of universities in the early 1920 s. This ambivalent manner of both discarding and reviving the tradition is reflected also in its treatment of European sinology.

This article evaluates the role of Western sinology for the incorporation of the methodology and institutional practices of academic humanities in China. Because of a certain politics of knowledge this connection has been occluded. With American dominance in the Cold War this sinology with its tradition of philology and immersion in other cultures was supplanted with a social scienceoriented area studies. ${ }^{8}$ For China studies the question of modernization was highlighted. First the idea was that the Western challenge set China on the path to modernization. ${ }^{9}$ The Vietnam War ushered in a reaction, bringing forward a similarly binary but China-centric approach seeking the roots of modernization in internal Chinese factors. ${ }^{10}$ Postcolonial scholarship now instead focuses on the circulation of ideas and practices inside such a colonial modernity and breaks down the binaries into a more fluid reality of cross-fertilization of ideas and approaches. ${ }^{\text {II }}$ However, postcolonial writers have simultaneously shared the Cold War social sciences scholarly movements' critique of sinology, discarding it as simply part of a Western Orientalist project; racist and biased..$^{12}$ In reality sinology served as an important epistemological bridge between cultures. European sinology was the cross-cultural space where an indigenous Asian cultural tradition could fuse with Western scientific standards, then be safely repatriated and put to service in the project of providing cultural legitimacy to a rejuvenated Chinese state.

In the following we will trace how a Chinese anxiety concerning foreign incursions escorted appreciation of the groundbreaking sinological research coming from Europe. We will then outline how this challenge was met with 'national studies' research centers and with scholarly organizations protesting against Western research expeditions in China. Finally we will discuss the implementing of laws on archeology and the export of antiques, as well as the significance of the Academia Sinica's Institute of History and Philology (IHP) in returning to the Chinese scholars their lost prestige. 


\section{From European sinology to national studies}

As Europeans during the disorderly I920s were pursuing scholarly aims in the Far East young Chinese scholars were going the other way. Japan was geographically and culturally their closest choice but in the interwar era many also studied in Europe. Berlin had a thousand Chinese students in 1924; coming there not solely out of scholarly considerations but because inflation made living on a Chinesecurrency scholarship relatively cheap. Others, like Liu Fu and Xu Xusheng, went to Paris, which at the time was the world's capital for sinology.

Some of these students were to become important Chinese historians. Although starting out with natural sciences while studying in Europe they often drifted toward sinology and other areas of Oriental studies. The historian Yao Congwu studied with the sinologists Otto Franke and Eric Haenisch and also worked at the Oriental Institute in Bonn. ${ }^{13}$ Another remarkable historian, Chen Yinke, cooperated with the Orientalists Friedrich W.K. Mueller. Back in China, Chen became associated with the French sinologist Paul Pelliot while learning more Sanskrit from Baron Stael von Holstein. ${ }^{14}$ Fu Sinian, the most important of the Chinese scholars in shaping the modern humanities in China, also assisted Western sinologists. He had set out to study psychology in London but ended up studying Tibetan in Berlin. Together with Chen Yinke, Fu Sinian also took several courses with the German sinologist Herbert Franke. Eventually, just like his compatriots Chen Yinke and Yao Congwu, he returned to China as a historian. ${ }^{15}$ So why were these Chinese scholars drawn to study sinology while in Europe?

The first decades of the twentieth century saw the zenith of European colonialism. With the many Western dominions in India and East Asia, Oriental studies flourished. European powers needed more knowledge about the foreign countries they were set to administer and therefore universities in the European capitals founded new positions in Asian languages and culture. The archeological sources, libraries, and archives brought from various Asian dominions helped to bring about a revival in Oriental studies. Surprisingly then, the Western metropolises of a Paris, London, and Berlin became centers for studying the East. The Asian scholars who came there looking for the essence of Western learning were simultaneously exposed to the forefront of scholarship about their own countries, cultures and civilizations.

While studying abroad many of the Chinese scholars, of course, found out how good European sinology had become. In contrast to the financially poor and institutionally isolated Chinese scholars, European sinologist had modern methods and were supported by their universities and museums at home. During the chaotic period between the fall of the empire and the full-scale Japanese invasion, Westerners also gained access to Chinese source materials. Collecting new source 
materials and reinterpreting China's past the European sinologists became a formidable threat to native scholars committed to a nationalist cause.

The Chinese scholars finally banded together to protest against this situation. They were, however, not just opposed to Westerners conducting research in China and of their spiriting away of historical and other artifacts from the country. They were also dismayed by the treatment they received from their own government. The main reason for setting up the National Scientific Union, for example, was certainly to a large extent the dire situation of Chinese researchers themselves. Xu Xusheng describes the situation for him and his fellow scholars in the mid-rg2os:

Not only did no one support them, but they were even hindered from doing research. At the same time, foreigners came and with their superior resources, took what they wanted of our research material! They forcefully removed from our country limitless amounts of rare items. If this were not stopped, then the future of our ability to undertake national studies [ guoxue] would suffer inconceivable damage. ${ }^{16}$

The interest Westerners paid to China's history had an unforeseen effect. The New Culture Movement at first strove to get rid of the Chinese tradition. Now appeared a culturalist revival, a return to the purported core of China's civilization and a desire to rethink what actually made up this Chinese nation under threat of foreign aggression. An effort of zhengli guogu, of 'ordering' or 'setting right' of the country's past, was launched. It appears paradoxical at first that many of the radical iconoclasts of the May Fourth Movement were involved in this project. But as Hu Shi, head of the Qinghua National Studies Institute, explains, the zhengli guogu movement wanted to do research like the Western sinologists and the Japanese sinologists [zhinaxue] who had learned from the West.'. ${ }^{17}$

It was the radical anarchist turned educational reformer, Cai Yuanpei, who set up the first institute for guoxue research. Right after he took position as head of China's first university he turned to the old scholar and mentor of the last emperor, Luo Zhenyu for advice. Luo's only suggestion was to establish an institute for the research of antiques $(g u w u)$ aimed at halting the exportation of ancient books and antiquities out of China ${ }^{18}$ Two years later, in 1922 , Cai established the first Chinese research institute ever, and it was exactly the kind of institute for national studies that Luo had requested.

The Beijing University School of National Studies that Cai Yuanpei set up was constructed around five areas. While one concerned the important archives of the Ming and Qing dynasties, all the others were on subjects where European sinologists had recently proved very successful: First was linguistics, where Bernhard Karlgren's research on Chinese historical phonology - via ancient rhyme books and modern dialect studies - was already legendary. Second was archeol- 
ogy, where Johan Gunnar Andersson had recently made the decisive discovery of the first ever known Chinese Stone Age culture. Ethnography and folk songs, in which the Frenchman Marcel Granet had excelled, became the other two fields researched in the Beijing University School of National Studies. ${ }^{19}$

This dependence on European sinology also shines through in naming practices. In translations, the center as well as its scholarly journal is denoted with the term 'sinology'. The front page of their bulletin thus featured, below the name in Chinese, the subtitle Bulletin de l'institut de sinologie. The Beijing University School of National Studies moreover relied heavily on the assistance on European sinologists and Western institutes of Oriental studies. All except one of the advisory scholars of the institute were foreigners. Their bulletin furthermore ran a large number of path-breaking works of European sinology in Chinese translation. ${ }^{20}$

Another famous New Culture figure, Hu Shi became the director of the second-most important of these guoxue centers: the Qinghua College Institute of National Learning. Just like the Beijing University School of National Studies, this institute was run by people returning from Europe with high hopes of the nationalist movement. Avant-garde institutions like these two in Beijing were thus staffed by a small number of foreign-educated, elite intellectuals with the mission to create the China scholars of tomorrow.

In reality then, modern Chinese humanities came about - via European sinology - in the form of guoxue, or 'national studies'. The first classes that Chen Yinke taught at the Qinghua College Institute of National Learning were on Buddhist Sanskrit texts and a bibliographical course on Western sinology. The first class in phonology that linguist Qian Xuantong gave at the Beijing University School of National Studies, in 1922 when the school was founded, relied on translations of Bernhard Karlgren's research. ${ }^{21}$

Facing the competition from Europe, what had originally been an iconoclast movement returned to its own semi-sacred historical traditions. So it was that when research and education institutes in national studies had been set up in China even such anti-classicist scholar as Fu Sinian decided to come back home. ${ }^{22}$ His return would prove decisive for the delivery of the new Chinese humanities through the creation of the Institute of Philology and History at the newly founded Academia Sinica. ${ }^{23}$ Its first priority was to challenge the foreigners.

\section{The Chinese humanities}

One of the most important singular events in what would lead to the creation of the Academia Sinica, must have been the 1920 discovery of a Chinese Stone Age culture by Johan Gunnar Andersson [Fig. 26]. ${ }^{24}$ Based on scientific meth- 


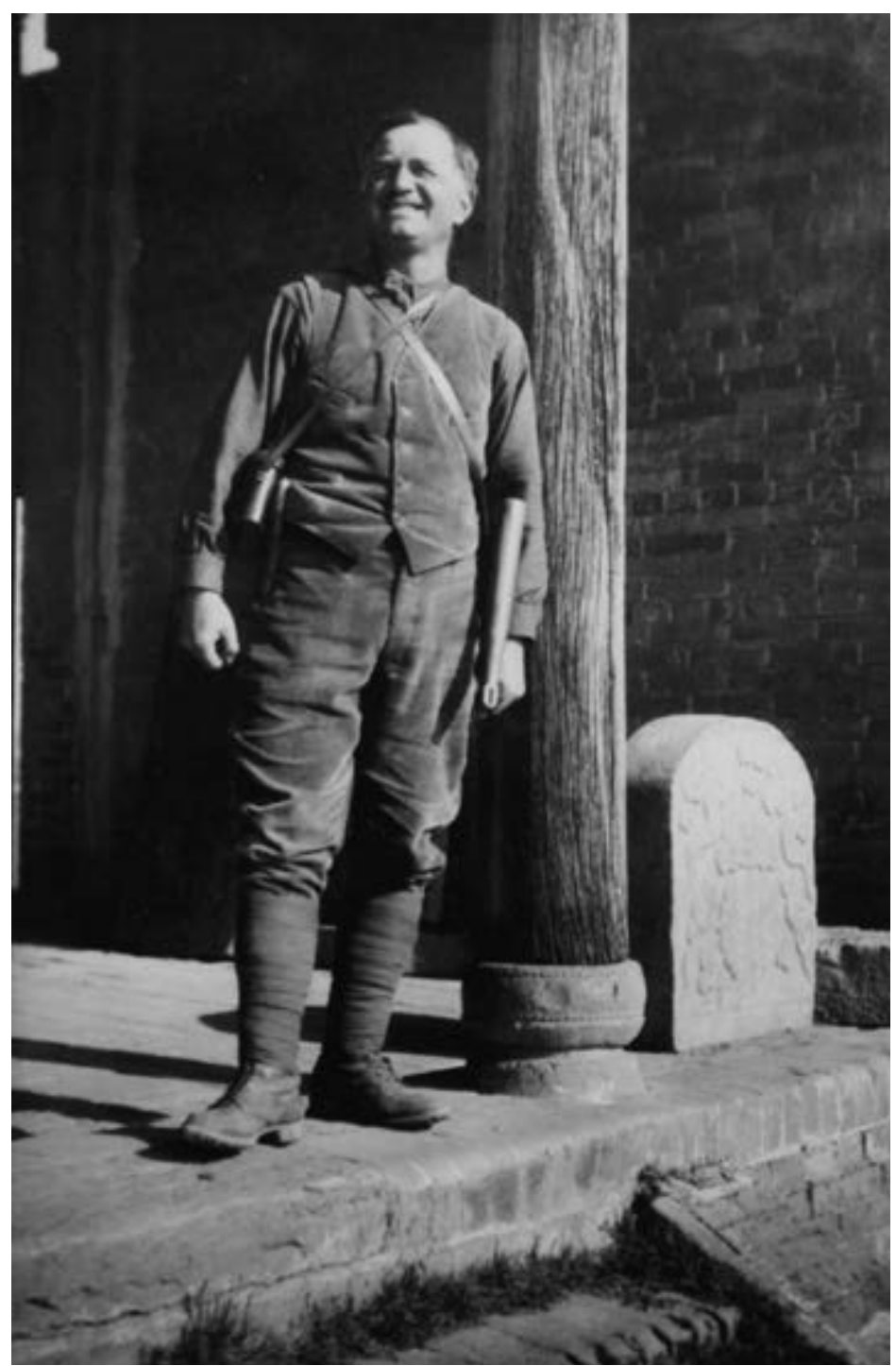

Fig. 26: Johan Gunnar Andersson in China, 1920, photo, East Asian Museum, Stockholm

ods and the search for new source material, this archeological discovery promised an 'underground twenty-four dynastic histories' to some and the possibility to finally reorganize China's early history to others. ${ }^{25}$ But at the same time Andersson's theory that the Chinese had come from the west greatly disturbed Chinese scholars. ${ }^{26}$ They themselves lacked the unique new sources that Western scholars 
like Andersson possessed and could not easily dispute anything. Therefore they were helpless in front of new theories on their own civilization that scholars like Andersson brought forward.

A second, very important event in the prehistory of the Academia Sinica came with the expedition Sven Hedin and German Lufthansa tried to launch in early 1927. The Beijing University School of National Studies led a number of Chinese scholarly and culture organizations in protests against what they suspected to be an attempt to expatriate more source material related to China's history. They finally managed to force Hedin to finance the inclusion of a number of Chinese scholars in his ten-year project. For the Chinese, this became a traveling university where for the first time indigenous scholars could learn fieldwork, which in turn gave the budding Chinese scientific community a great sense of confidence. ${ }^{27}$

Only months after the protests against Hedin's expedition, a Chinese research academy was also established. The former president of Beijing University, Cai Yuanpei, was chosen as the first director of this Academia Sinica. Cai had, as we remember, earlier set up the Beijing University School of National Studies. As all this was taking place, Fu Sinian was directing a department for history and philology at the nationalist stronghold of the Sun Yatsen University. Hearing about the Academia Sinica, Fu traveled to Shanghai to see Cai, advising him to include also an Institute for Philology and History. ${ }^{28} \mathrm{Fu}$ Sinian had initially been against guoxue on the grounds that it was too concerned with textual exegesis. But as has been argued in recent scholarship, Fu was also strongly impressed by Parisian sinology. ${ }^{29}$ Although he regarded the greater part of the Western sinologists as charlatans, he highly admired scholars like Paul Pelliot and Bernhard Karlgren. ${ }^{30}$

When Fu Sinian selected his Academia Sinica staff for an Institute of History and Philology they were all from Beijing University's and Qinghua College's Institutes for National Learning. So not only were the research areas that $\mathrm{Fu}$ Sinian choose for his section of the Academia Sinica the same as those of guoxue institutions, but the Institute of History and Philology was actually made up of people from such backgrounds as well. Chen Yinke thus took position as head of the History section and Zhao Yuanren the Philology section. Both were from the Beijing University School of National Studies. Li Ji, who came to head the important Archaeology section had worked with the American sinologist Carl Whiting Bishop but also taught at the Beijing University School of National Studies.

Under Fu Sinian's leadership and with generous funds provided by the Nanjing government, the Institute of History and Philology became a renewed, betterfunded version of the Beijing University School of National Studies. In contrast to its predecessor it was able to launch the kind of source-gathering scientific explorations that had earlier been the prerogative of Western and Japanese research 
institutions. In the distraught times Chinese scholarship found itself in the ideas of positivism and Quellenkritik had turned into an obsessive occupation with the sources themselves. Fu Sinian had been influenced by Rankean Quellenkritik as well as positivist ideas when he spent most of his time in Berlin studying Ernst Mach. He carried this reverence for the sources when he returned home and Fu's directorship at the Academia Sinica was all about securing new sources. ${ }^{3 \mathrm{I}}$ With the IHP of the Chinese Academy up and running, Fu Sinian managed to secure funding to enable Chinese scholars to compete with Western sinologists for access to new source material. But a second step was needed in order to limit the Europeans' freedom to scour China for material. The Chinese scholars needed to get exclusive right to collect materials in order to research their own cultural heritage.

Fu Sinian openly connected the faith of the Chinese nation with how well Chinese historians could win back the momentum by controlling the source material. ${ }^{32}$ If the Chinese scholars did not control the sources - which for Fu and most positivist Western historians at the time was history - then the West with its modern scientific methods and its hold on new sources, would reinterpret China's history to their own liking. ${ }^{33} \mathrm{Fu}$ Sinian expressed the fear of such a situation in the very program declaration of the Institute for History and Philology he was running for the Academia Sinica. Thus the introduction of the first issue of their Bulletin of the Institute of History and Philology reads:

China is rich in sources on history and philology but the way Europeans strive to have them they might soon be difficult to access for us. Despite this we have just been sitting with arms crossed watching them getting ruined and disappear in front of our eyes. We are certainly not happy with this situation. We are certainly not appreciating how, not just any material sources, but scholarly source material is being brought out, sometimes even stolen by the Europeans. We decided to engage some fresh approaches to deal with this problem, and to secure source material. We have therefore set up this Research Institute for History and Philology. ${ }^{34}$

The young and newly trained archeologist Li Ji shared the concerns of Xu Xusheng and Fu Sinian about how Europeans were acquiring precious Chinese source material. However, with his experience of working together with the Smithsonian and Carl Whiting Bishop, he centered in on the organized Western collecting of material from China. In his memoirs Li Ji thus writes the following on the foreign research organizations that had arrived in Beijing during the feeble rule of the Beiyang Army: 
Forceful as they were, these organizations became increasingly unrestrained. With the sole exception of the Geological Survey these enterprises were all run by foreign research organizations. These foreigners were all richly supported, financially and materially, and they had acquired new and accurate methods. Not only did they go after and remove, bit by bit, specimens for the natural sciences but also historical, archeological, and other source material related to the human sciences fell prey to their eager attention. Determinedly, they stormed China, to investigate our language, measure our bodies, excavate our as-yet-unearthed antiques, and examine our traditional customs. These 'scholarly sources' are day after day 'brought out, sometimes even stolen by the Europeans'! ${ }^{35}$

In the contract that the protesting Chinese academics had forced the explorer Sven Hedin to sign, it was stated that all archeological and other material should stay in China to be studied by the Chinese. ${ }^{36}$ This was an important first step for the repatriation of sinology. When Chiang Kai-shek and the Kuomintang Army regained control of China and set up a government in Nanjing, a state organization for protecting cultural heritage was also established. ${ }^{37}$ Named the Central Commission for the Preservation of Antiquities, it proved quite efficient in dealing with some of the well-known plunderers like Sir Aurel Stein, but many problems remained with foreign buyers, Chinese tomb raiders, and local attempts at excavation. ${ }^{38} \mathrm{Li} \mathrm{Ji}$ 's idea of coming to grips with the remaining problems was to lobby for a new law about cultural heritage and archeology. From the late I92os he worked hard to bring about regulations to this effect, and in 1930 the 'Legislative Yuan' passed such a decree. ${ }^{39}$ The 'Law on Protecting Antiquities' covered historical and archeological artifacts plus fossil remains of plants and species, and it made clear that 'everything buried in the earth, including those parts that protrude from the earth, entirely belongs to the state. ${ }^{40}$

\section{Conclusion}

Early-twentieth-century European sinology engaged with the Chinese tradition but in a context of modern academic humanities and furthermore based their scholarship on new sources found inside China. In this way it came to play an indispensable role in the establishment of a postimperial discipline of 'national studies'. The national studies institutes of China were staffed with people returning from abroad and they relied on European advisers. These institutes also published the works of European sinologists for use in their teaching. The Beijing Institute of National Studies was therefore not only the first modern research in- 
stitute in China, but from it - via European sinology - also arose the modern humanities as an academic discipline. It could thus be argued that modern humanities in China were not formed directly by the integration of Western learning in the form of academic disciplines like history, philosophy linguistics, etc. Instead, it built upon, and then challenged, a European sinology, which was already in itself a mix of Western and Chinese scholarship.

$\mathrm{Fu}$ Sinian imagined that the European sinologists had begun to despise the Chinese scholars, and therefore decided that his institute would become worldleading in Chinese studies. ${ }^{41} \mathrm{He}$ furthermore argued that although the Westerners, together with Japan, excelled in Orientalist studies, the Chinese themselves, if only they could control and monopolize the sources, had a chance to reach the foreigners' level and even control research in history, philology, and linguistics. ${ }^{42}$ The IHP under Fu became the synthesis of, on the one hand, a modernist iconoclastic positivism and then, on the other, the more classicist zhengli guogu movement. The IHP's focus was on restoring the ties with the past plus protecting Chinese historical remains, and interpretations, from Western dominance. It had for the first time also at its disposal the resources and the will to carry out scientific expeditions for new source material. Thus, with Li Ji in the lead, the IHP undertook the Anyang excavations, rejecting the doubting the old' claims of $\mathrm{Gu}$ Jiegang, proving there had been a Shang Dynasty after all. Other archeological projects that were undertaken disputed Andersson's theory of the western origin of the Chinese civilization.

With China under the threat of being carved up by the aggressive imperialist powers of the day its very history and cultural identity was at risk of expatriation. Source material had been shipped away en masse to Europe where Western sinologists were now chipping away at tradition to create a revised version of Chinese history. National studies was a first step in countering this trend and out of it grew the IHP. It has been argued that IHP, with its Anyang excavations, was the most successful section of the Academia Sinica. ${ }^{43}$ It brought back to the Chinese a national narrative based on a long unbroken history and cultural uniqueness. The IHP also launched modern humanities in China, modeled on European academic disciplines. Not least importantly, it had taken up the challenge of Western sinology, and won. The Chinese scholars had put laws in place claiming the state as the owner of archeological and other sources relevant to writing China's history. The indigenous scholarship had at the same time modernized into a row of academic disciplines in the humanities, that soon began competing with and surpassing European sinology. No longer was China under threat of being represented scientifically by a West in sole possession of crucial source material. In 1932, after only four years in existence, Fu Sinian could therefore proudly report back to Cai Yuanpei that the IHP had achieved results that outdid that of the formerly 'superior' European sinologists. ${ }^{44}$ 


\section{Notes}

I See David B. Honey, Incense at the Altar: Pioneering Sinologists and the Development of Classical Chinese Philology (New Haven: American Oriental Society, 200I), for a concise history of European sinology.

2 See Henrietta Harrison, China: Inventing the Nation (New York: Bloomsbury USA, 200I) for a survey on the role of culture in China's nation-building.

3 Much ended up in the hands of Sir Percival David, who then donated it to museums in London.

4 These castrated palace servants of course had a unique access to the enormous amount of riches served inside the walls of the Forbidden City.

5 They bought up specimen and lobbied for preservation of the archives respectively. See Edward Wang, Inventing China through History: The May Fourth Approach to Historiography (Albany, NY: SUNY Press, 200I), I25; and Chen Yiai, Zhongguo xiandai xueshu yanjiu jigoude xingqi (Nanchang: Jiangxi jiaoyu chubanshe, 2002), I08-Io.

6 Geremie Barme, The Forbidden City (Cambridge, MA: Harvard University Press, 2008), I33.

7 For more on this story, see Wu Ying, Gugong chenmeng lu (Beijing: Zijin cheng chubanshe, 2005), I 48 -I 55 .

8 See Harry Harootunian, 'Postcolonialism's Unconscious/Area Studies Desire', Postcolonial Studies 2.2 (I999), I27-I47.

9 Especially influential was Joseph Levenson's Confucian China and Its Modern Fate (Berkeley: University of California Press, I958-I965), and John K. Fairbank, Trade and Diplomacy on the China Coast: The Opening of the Treaty Ports, 1842-1854 (Stanford: Stanford University Press, I953).

Io See Paul Cohen, Discovering History in China: American Historical Writing on the Recent Chinese Past (New York: Columbia University Press, I984) for more on this.

I I This short article is not the place to recapitulate that discussion in any detail. Readers are recommended the introduction to a very interesting study on the importance of the public survey for imaging the nation in China. Tong Lam, A Passion for Facts: Social Surveys and the Construction of the Chinese Nation-State, 1900-1949 (Berkeley: University of California Press, 201 I).

I 2 From Edward Said's seminal study Orientalism (New York, 1978).

I 3 Wang, Inventing China, 93-96.

I4 Ibid., I92.

I5 Wang Fan-shen, Fu Ssu-Nien: An Intellectual Biography (PhD dissertation, Princeton University I993), 96.

I6 Xu Xusheng, Xu Xusheng xiyou riji [A Diary of Xu Xusheng's Travels to the West] (Yinchuan: Ningxia renmin chubanshe, 2000), 2. This situation was actually so bad that when the leading national studies scholar, the reputable Wang Guowei, committed suicide, Fu Sinian blamed his death on the poor research conditions indigenous scholars had to put up with (see Chen Yiai, Zhongguo xiandai xueshu yanjiu, 76). Another guoxue scholar, Chen Yinke instead saw Wang Guowei's suicide as a proper way to mourn the shattering of the old symbolic universe and the social position it used to bring Chinese scholars. See Wen-Hsin Yeh, The Alienated Academy: Culture and Politics in Republican China, 19191937 (Cambridge, MA: Harvard University Press, I990), 46.

I7 Chen Hongbo, Zhongguo kexue kaoguxue de xingqi (Guilin: Guangxi shifan daxue chubanshe, 20II), I IO.

I8 See Chen Yiai, Zhongguo xiandai xueshu yanjiu, 76. 
I9 Marcel Granet's studies on kinship in China influenced, among others, also the renowned anthropologist Claude Lévi-Strauss.

20 See Chen Yiai, Zhongguo xiandai xueshu yanjiu, 83. Paul Pelliot and Bernhard Karlgren had three articles each in the few issues published between 1922 and 1927.

2I Ibid., I 32. For more on Bernhard Karlgren, see Perry Johansson, Saluting the Yellow Emperor: A Swedish Case of Sinography (Leiden \& Boston: Brill, 20I2), and Göran Malmqvist's biography, Bernhard Karlgren: Portrait of a Scholar (Bethlehem, PA: Lehigh University Press, 2010).

22 See Wang Fansen, Fu Ssu-nien: A Life in Chinese History and Politics (Cambridge: Cambridge University Press, 2000), and Wang, Inventing China.

23 Zhongyang yanjiu yuan, or 'The Chinese Central Research Institute', thus came to present itself as related to European sinology by using 'Sinica' instead of 'Chinese' in its name.

24 On Johan Gunnar Andersson, see Johansson, Saluting the Yellow Emperor, and Magnus Fiskesjö \& Chen Xingcan, China before China: John Gunnar Andersson, Ding Wenjiang, and the Discovery of China's Prehistory, Monograph I5 (Stockholm: Museum of Far Eastern Antiquities, 2004).

25 These matching the canonical written histories of the twenty-four dynasties of rulers.

26 See Fiskesjö and Chen, China before China; Johansson, Saluting the Yellow Emperor, or Chen Hongbo, Zhongguo kexue kaogu, 58.

27 See Johansson, Saluting the Yellow Emperor, or Chen Aiyi, Zhongguo xiandai xueshu yanjiu jigou de xingqi [The Rise of China's Modern Academic and Research Institutions] (Beijing: Jiangxi Education Press, 2002), for more on this.

28 Chen Hongbo, Zhongguo kexue kaogu, 95.

29 Ibid., I04, and also in Wang Fansen, Fu Ssu-nien.

30 Ibid., I Iо. Chen groups Bernhard Karlgren together with Parisian sinology in general. While Karlgren had spent a year in Paris he was actually a Swedish-trained scholar in comparative phonology from Uppsala University. See Johansson, Saluting the Yellow Emperor, and Malmquist, Bernhard Karlgren.

3 I Fu later became known by the maxim, 'No sources, no history'. See Wang Fansen, Fu Ssunien. However, his slogan, originally inspired of course from the French historian Charles Seignobos, has been mistranslated. Wu shiliao ji wu shixue should rather be 'No historical sources, no study of history'.

32 See Perry Johansson, 'Discovering History in China: War, Sinology, Sources', in Bettina Braun and Judith Becker (eds.), Die Begegnung mit Fremden in ibrer Bedeutung für das Geschichtsbewußtsein (Göttingen: Vandenhoeck \& Ruprecht, 20II) for more.

33 See Edward Wang, Inventing China, or Wang Fansen, Fu Ssu-nien, for a lengthier discussion on Fu Sinian and his ideas on sources and Western sinology.

34 Fu Sinian, 'Lishi yuyan yanjiusuo gongzuo zhi zhiqu' [Aspirations and Objectives for the Work of the Institute of History and Philology], Lishi yuyan yanjiusuo jikan [The Bulletin of the Institute of History and Philology] I (I928). The mid-war era also experienced Chinese tomb raiders and Western collectors buying looted items. The Institute of History and Philology's archeologist Li Ji encountered these people when he excavated the Shang capital at Anyang. See Li Ji, Anyang (Seattle: University of Washington Press, I977), ro.

$35 \mathrm{Li} \mathrm{Ji,} \mathrm{Gan} \mathrm{jiu} \mathrm{lu} \mathrm{[Impressions} \mathrm{from} \mathrm{the} \mathrm{Past]} \mathrm{(Taibei:} \mathrm{Zhuanji} \mathrm{wenxue} \mathrm{chubanshe,} \mathrm{1967),}$ 74. Li Ji here refers to a text by Fu Sinian, hence the quotation marks.

36 The Chinese themselves did not, Li Ji writes, recognize the value of the things foreigners were bringing out under the guise of science. It was not until the I920s, as we have seen, 
that a sense of national ownership started to take shape around the cultural heritage of China. The modern nation was still young. Only ten years earlier had the empire been toppled and the old order replaced by a republic. It would have to wait until I 924 before even the most important treasure, the belongings of the former imperial family, was taken care of properly by the state. For more on this, see Jeanette Shambaugh Elliot and David L. Shambaugh, The Odyssey of China's Imperial Art Treasure (Seattle: University of Washington Press, 2005).

37 But that did not solve all other problems. Li Ji grumbles in an article in Dongfang Zazbi in 1934 about the displaced Chinese love of antiquity. Although, he writes, the Chinese have a long tradition of loving the old ( $h a o g u$ ) they do not, like the Europeans and the Americans - and, yes, 'even the Japanese' - know to preserve their antiquities. The trend of the last few years, he complains, was that the Chinese had been destroying archeological sites in a scale far surpassing that in any other nation. The lucrative market in antiquities was such a temptation that, many people, even scholars and those who advocated the protection of Chinese culture, became customers. He adds that people would be surprised if they knew about some of the cases he himself was familiar with. Li Ji, 'Zhongguo kaoguxue zhi guoqu yu weilai' [The Past and Future of Chinese Archeology], Dongfang Zazhi (I934).

38 See Karl Ernest Meyer and Shareen Blair Brysac, Tournament of Shadows: The Great Game and the Race for Empire in Central Asia (New York: Basic Books, 2006) for a description of how Langdon Warner and Aurel Stein were hindered in their respective attempts to plunder.

39 The Legislative Yuan is the parliament of the Republic of China.

$40 \mathrm{Li}$ Ji, "Guwu baocun fa" yubu hou suo yinqide diyige wenti' [The First Problem Encountered after the 'Law on Protecting Antiquities' Was First Promulgated], in Kaogu suotan (Hubei Publishing House, I997), 238.

4I Edward Wang, Inventing China, I25.

42 Fu Sinian, Lishi yuyan yanjiusuo gongzuo zhi zhiqu.

43 Wang Fansen, Fu Ssu-nien, 70. That the IHP was the most successful part of an Academia Sinica including all the sciences says something about the significance of the humanities in this period of China's history.

44 Ibid., 93 n. I70. 
IX

INFORMATION

Science And

Digital

Humanities
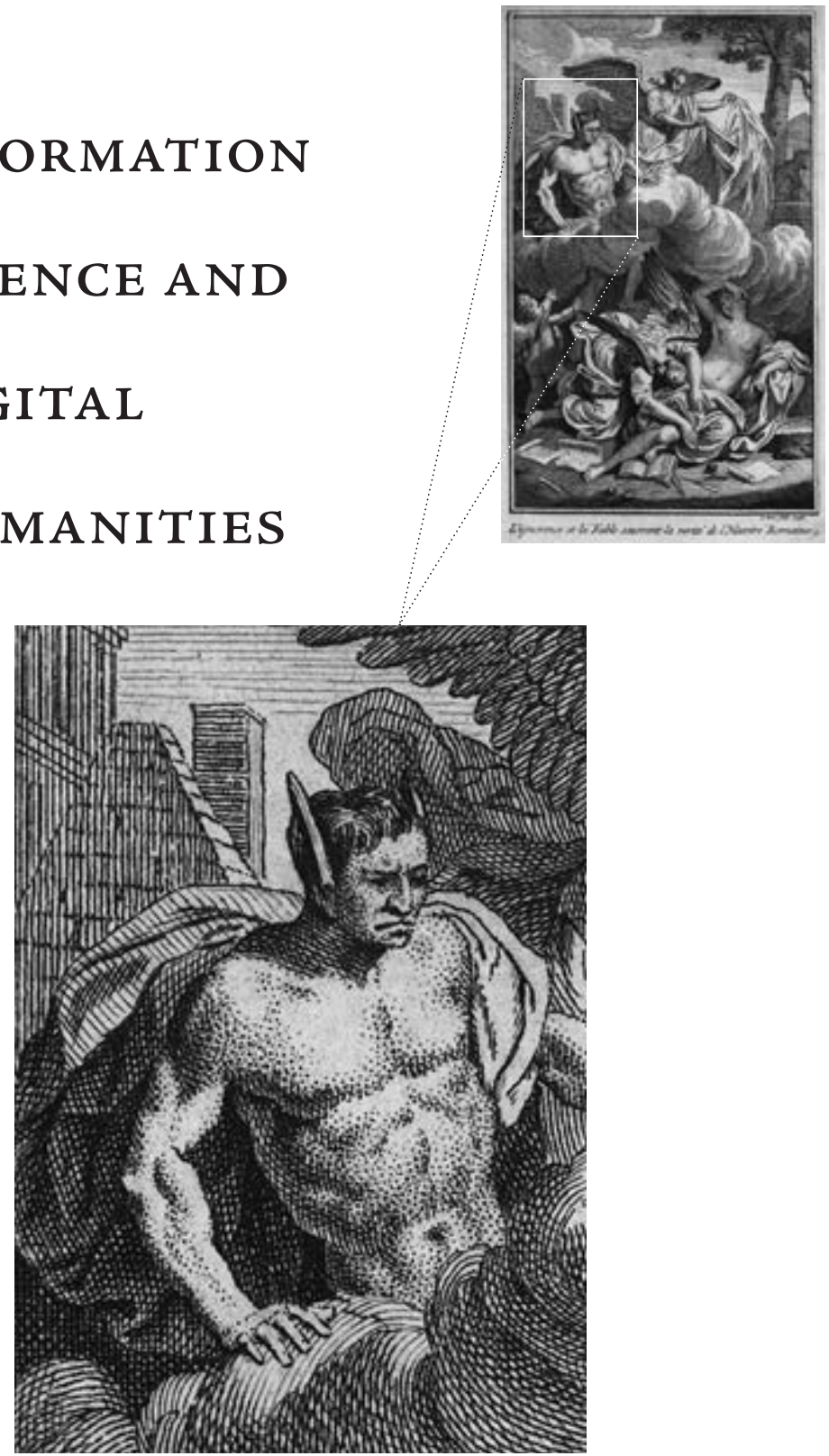



\title{
9.I Historical Roots of Information Sciences and the Making of E-Humanities
}

\author{
Charles van den Heuvel
}

\section{Introduction: The making of library and information sciences}

Information scientist Christine Borgman in Scholarship in the Digital Age distinguishes between data used by natural scientists, social scientists and humanities scholars and discusses the implications hereof for their research practices. The analysis of these practices in combination with information technology must in her view result in an infrastructure for digital scholarship to facilitate distributed, collaborative, multidisciplinary research and learning that relies on large volumes of digital resources. ${ }^{1}$ The distinction in data that Borgman mentioned has been used as one of the arguments to explain why scholars in the humanities and social sciences make less use of digital infrastructures and tools than those in the natural sciences. ${ }^{2}$ However, the roots of library and information sciences that emerged as disciplines from the end of the nineteenth century onward can be found in the humanities and social sciences. Whereas there is a vast bibliography of the history of information science and technology, only recently a research project was set up to uncover the history of computing in the humanities by interviewing prominent members of this scholarly community. ${ }^{3}$ However, a systematic study of the e-humanities, similar to one of the humanities by Rens Bod or in 'The Making of the Humanities' series of which this publication makes part, still lacks. ${ }^{4}$ It goes beyond the scope of this chapter to write such a study. This chapter focuses on shifts in the relation between the history of the information sciences and of the e-humanities and their common roots.

One of the first historiographical accounts of library science by Henry Evelyn Bliss opens with the line: 'This book should be of interest, we think, to educators, and philosophical readers who recognize the intellectual and the social values of what is termed the organization of knowledge, ${ }^{5}$ And according to the well-known American philosopher, psychologist, and pedagogue John Dewey, 
who wrote the introduction to this historiography: 'It includes questions of psychology concerned with effective, growing assimilation of knowledge and the logical and philosophical questions involved in the problem of unity, interrelations and classifications of science. ${ }^{6}$ We will demonstrate how in library science by the end of the nineteenth century multidimensional representations of knowledge rooted in humanist disciplines were gradually reduced and translated into more pragmatic terms to serve information retrieval. Furthermore, the impact of methods of the information sciences on the humanities will be discussed. Finally, the renewed interest in the information science and in software development for more inclusive hermeneutic approaches of the humanities will be briefly addressed.

\section{Classification of the sciences}

From Bliss's historiographical study it becomes clear that the development of library science at the end of the nineteenth century was shaped by three interrelated debates: debates on the classification of the sciences, on evolution and on atomist theory. ${ }^{7}$ For our analysis of changes in the relationships between the library and information sciences on the one hand and the humanities on the other, we just will briefly touch upon the classification of the sciences. The debate on the classification of the sciences goes back much further in history, but it got a new impetus in nineteenth-century philosophy in reactions to the statements of the positivist thinker Auguste Comte. Comte came up with a hierarchy of sciences, that historically were depending on each other, running from mathematics, astronomy, physics, chemistry, and biology to a new discipline, social physics (sociology), of which he is considered to be one of the founding fathers. Critics such as Herbert Spencer opposed to such a linear and historical sequential representation of the evolution of sciences and argued that sciences are so complex that the relationships can only be explained in a multidimensional way. ${ }^{8}$ The discussion on the evolution of the sciences stood in a wider context of the nineteenth-century debate on (biological and organic) evolution. Studies in the emerging discipline of psychology (Baine, Wundt, Fouillée, Bergson) tried to include the evolution of mental order and explored the internal dimension or 'psyche' of man.

Here, we introduce one of the pioneers of modern knowledge organization, the Belgian Paul Otlet (1868-1940), whose work stands in tradition of positivism and who was a close follower of the ideas of Herbert Spencer and Albert Fouillée. Moreover, the case of Otlet is interesting because it allows us to follow the increasing impact of the natural sciences in library science and classification 
at the beginning of the twentieth century, in which the focus from knowledge organization and classification based on philosophical arguments gradually shifted toward information retrieval based on mathematical logic.

\section{Paul Otlet: \\ Knowledge organization of ideas and retrieval of facts}

Paul Otlet (1868-1940) wanted to bring all the knowledge of the world together in order to create a better society, or in his own words a universal civilization. Aware of the enormous increase of information, he proposed to replace the system of many duplicates of books by microfilms that could be distributed from one central office, The Mundaneum, combining a World Library, a World Museum, a World Archive, World University and a World Headquarters for International Organizations, to smaller units in a global network of documentation. The book in codex form would be gradually replaced by other media, in his time especially radio, that expressed ideas more conveniently. Otlet suggested that scholars all over the word extracted the most valuable information in books and other documents on bibliographic cards. To this end he, and his colleague Henri La Fontaine (1854-1943), founded in I895 an International Office (later Institute) of Bibliography. Its first aim was to create a bibliographic database, the Universal Bibliographical Repertory. It grew from about 400,000 entries in 1895 to II,000,000 in 1914 and was soon augmented by a Universal Iconographic Repertory and an Encyclopedic Repertory of Dossiers. ${ }^{9}$ To order these databases, Otlet, together with La Fontaine, developed on the basis of Melvil Dewey's (I85I-I93I) famous Dewey Decimal Classification (DDC), the Universal Decimal Classification (UDC). Similar to Dewey's classification, the UDC divided all knowledge into ten main classes, numbered from 0-9, instead of using alphabetical orders or letter symbols. This way problems related to semantic differences between natural languages could be avoided. Whereas Dewey had developed his classification as a practical book-shelving system, Otlet and La Fontaine saw it as a way to understand and communicate scientific knowledge: The UDC could form a kind of universal language of numerical codes,

a veritable new language whose [figures] translate ideas absolutely common to the entire scientific world and express them in universally understood signs - numbers. In this twofold way the Decimal Classification actually constitutes an international scientific language, a complete system of symbolization for science. ${ }^{10}$ 
Different from DDC, the ten classes of the UDC had more subdivisions which orders could be changed. Moreover, by using auxiliary signs various relations between concepts could be expressed. The result was a nonlinear classificatory language. In his article 'On the Structure of Classification Numbers,' Otlet wrote that: 'Classification numbers will [...] be complex numerical expressions made up of different factors whose respective meanings when juxtaposed will express a complex idea after the fashion of compound words in spoken languages." ${ }_{+}$

In several studies Otlet has been put forward as a forerunner of the World Wide Web. His reseau universel de documentation that aimed at connecting all knowledge institutions on a global level has been compared to the Internet, his ideas about knowledge production by scholars to that network has been compared to Web 2.0 and his interpretation of the UDC as a multidimensional, nonlinear classificatory language has been compared to hypertext. ${ }^{12}$ There are indeed similarities, but Otlet's ideas on knowledge organization can be better understood within the context of positivism, neoscholasticism, and encyclopedism, which he used in a typical nineteenth-century eclectic way. In Paris he studied the modern philosophies of the Comtean Positivists and was particularly interested in the Synthetic Philosophy of Spencer and Fouillée's synthetic principle of idée-force. In his diary Otlet wrote in I889: 'I believe in the great principles of positivism and evolution: the formation by evolution of things - the relativism of knowledge and the historical formation of concepts. ${ }^{13}$

However, despite the fact that Otlet's views on knowledge organization and classification are deeply rooted in the nineteenth-century paradigms of the universe of knowledge and the order of sciences, they also express his will to go beyond their metaphorical meaning and to use the sciences as active instruments to order information. Although Otlet adhered as most classificationists of his time to a certain hierarchical order of the sciences - ranging in his case from the general science of being, ontology, to the science of divinity, theology - his interest herein was not just philosophical or theoretical, but foremost instrumental. This becomes clear from Otlet's very early work Something on Bibliography (I89I-I892) in which he outlines models for bibliographies of law and the social sciences and explains that methods from the natural sciences can be useful for fact finding and formulating scientific laws:

The views of natural scientists on the constitution of man and the world, on the laws of their organization and development, are no less extensive or less imaginative than those of economists and sociologists. But the difference between them is that in the natural sciences speculation and interpretation are secondary and are hardly ever made a-priori. [...] The results of the natural sciences are grounded in millions of carefully observed, analysed, and catalogued facts. ${ }^{14}$ 
In fact Otlet sees in the empirical approach of the natural sciences a means to restore in the future the old scholastic ideal of a vast synthesis of universal knowledge, experience of the human reason and the proper principles of faith that he deemed not possible anymore:

The famous Summa of Saint Thomas should be mentioned here as an example. It sets forth a complete exposition of all the questions which the philosophers of the Middle Ages posed and formulated and answered for each question according to the state of knowledge then. Summae are no longer possible. The a priori is too far in the past and the empirical method has not yet produced enough facts for us to attempt today a new and definitive synthesis. ${ }^{15}$

Otlet tried to produce sufficient facts by the involvement of scholars and mechanical extraction of information from multimedia documents. Scholars would work together, assisted by machines, to carry out the complementary operations of analysis and synthesis by means of which these elements could be extracted, recorded on cards, ordered and recombined mechanically. His view of processing information led Otlet to formulate what he called the 'Monographic Principle' according to which documents are dissected into their informative elements. Otlet's search for the smallest particles of knowledge must be seen in relation to developments in the sciences at the end of the nineteenth century and the beginning of the twentieth century. He stood in direct contact with the Nobel Prize winner for chemistry, Wilhelm Ostwald, famous for his atomist debate on the substance of the universe with Ludwig Boltzman. Otlet's Monographical Principle was in fact based on Ostwald's Monographieprinzip, which the latter had described as 'the principle of the independent preservation of smaller pieces of thought.' ${ }^{16}$

According to Otlet, the form of book did not correspond with the one of ideas. The book was just was just a container of ideas that might be conveyed more efficiently. ${ }^{17}$ He envisioned the emergence of a future format of the book in which 'each intellectual element, in corresponding to a physical element, will create a structure such that any combination of ideas, notions and facts will be possible., ${ }^{18}$ Mechanical operations do not only play a role in flexible (re)ordering knowledge, but as well in the retrieval of what we call nowadays data:

Documentation is not limited to recording information but will allow its automatic retrieval at any moment it is required; [documentation is] a vast intellectual mechanism designed to capture and condense fragmentary and scattered information and to disseminate it wherever it is needed. ${ }^{19}$ 
Otlet realized that the reconceptualization of the book also had implications for his classification. In effect, the replacement of the book by a database of cards required new ways of linking related information chunks (or facets) that were dispersed over various cards. The possible links were complex and could in Otlet's view only be organized in multidimensional orders. A poster of April I9I6 with the title Elements de schématique reveals how Otlet is experimenting with processes of dissecting books and of multidimensional classification to create a semi-mechanical, rotating polygonal card system. ${ }^{20}$

Otlet is thus describing a new process of flexible information search and retrieval that allows for multiple points of contact between cards and the information inscribed on them, which for him are encoded in the notation and combinatorial processes of the UDC as a nonlinear, multidimensional classificatory language. However, there was also the realization that the sheer amount of possible combinations hindered information retrieval and that the complexity of thought could never be completely captured. ${ }^{21}$

\section{Dimension reduction: Multidimensional thought and one-dimensional search}

Otlet's experiments with information retrieval in multidimensional displays of polygonal cards revealed the complexity of search in a nonlinear way. The Indian mathematician Ranganathan, developer of the Colon Classification, another multidimensional faceted classification system, described the problem as follows:

Thought is multi-dimensional. But we are one-dimensional beings - that is, we still prefer all things to be handled to be arranged in one-dimension. [...] This means that classification is essentially a transformation of a manydimensional universe into a uni-dimensional, uni-directional one. The machine tools are expected to perform this transformation. ${ }^{22}$

The solution to this problem was dimension reduction. In his manuscript"Theorie schématique de la Classification' of I4 December 1908, Otlet describes and visualizes the multidimensional reduction of the content of books to one line [Fig. 27].

Otlet was well aware that the reduction of dimensions had implications for his synthesis. An unpublished manuscript from 1927 in the archives of the Mundaneum in Mons (Belgium) reveals that Otlet was studying the implications of notions of events in time and space (and in space-time) in the work of the philosophers/mathematicians Samuel Alexander, Bertrand Russell and Alfred 


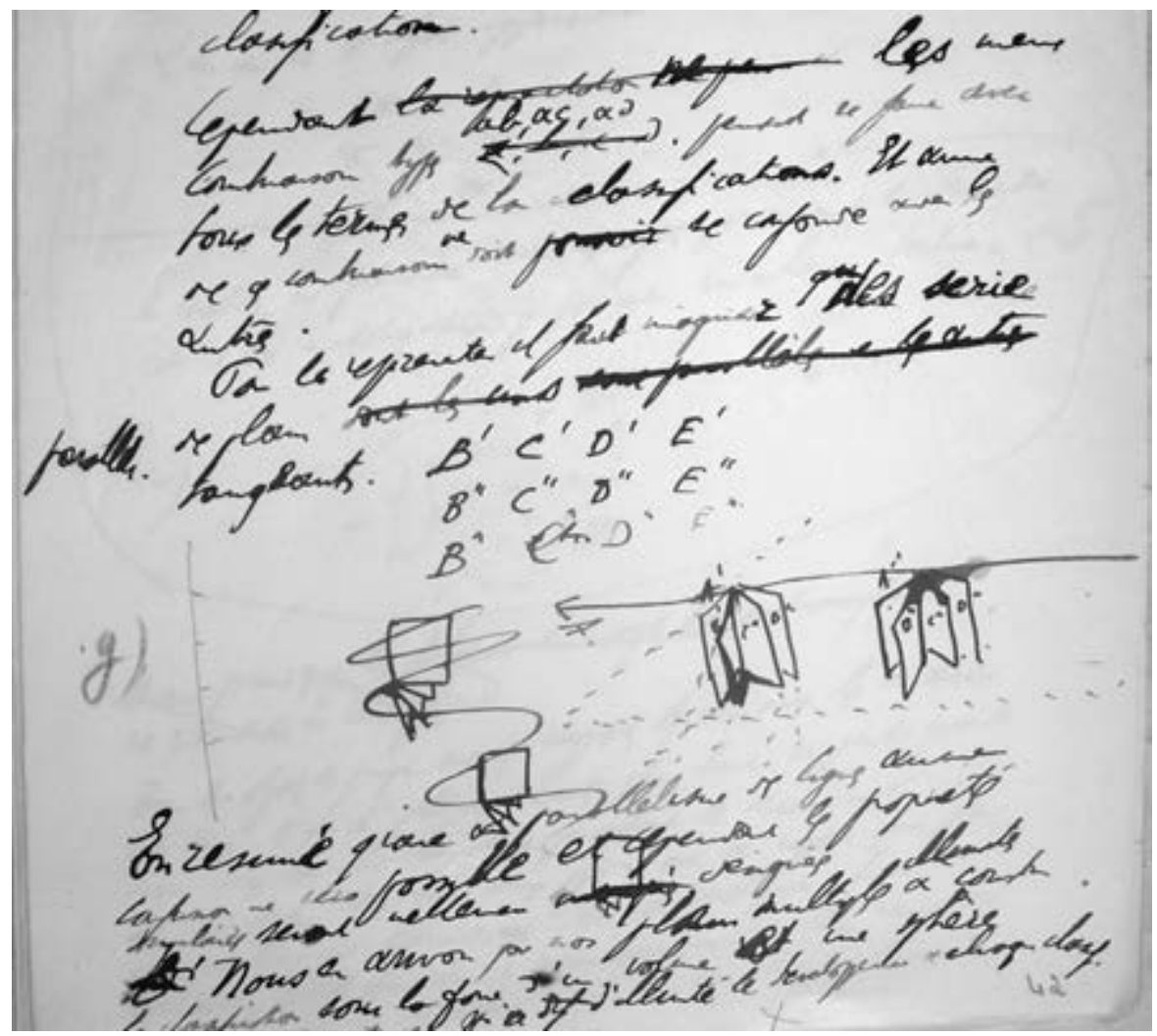

Fig. 27: Visualization from Paul Otlet's manuscript Theorie schématique de la classification, I4

December 1908

North Whitehead for a synthesis of the knowledge. It was clear to him that the universe of ideas and the universe of documents could not be fully integrated yet in one synthetic classification. ${ }^{23}$ This might be the reason why Otlet outlined in 1928 a kind of shadow classification of knowledge'Structure and Classification of Knowledge: General Considerations and Synoptic Table' in which he differentiated between objects, beings, ideas and facts. The distinction between the universe of ideas and of documents becomes apparent when he describes the purpose of the table. Otlet does not want to include this classification of knowledge in the UDC, or 'documentary classification' as he calls it in this context, but it could be used in 'preparation of its revision. ${ }^{24}$

Despite the fact that Otlet realized that vast developments in the sciences hindered a synthesis of knowledge, he never gave up his universalist ideals. In fact, he believed that the sciences, in particular mathematics, would not just be 
instrumental to reach higher levels of abstractions, but would become:'a producer of concepts that allow us to reason about unperceivable objects and that will spiritualize us unceasingly and free us from our senses, to get higher and further. ${ }^{25}$ In short, Otlet was not just interested in mathematical methods of dimension reduction to cope with the complexity of his knowledge representations, but believed that one day mathematics would liberate the human spirit in order to create an universal civilization.

\section{Denial of philosophical conceptions of classification}

The most important biographer of Paul Otlet, Boyd Rayward, rightly warned not to overestimate the influence of philosophy on Otlet's work. ${ }^{26}$ Otlet was certainly no philosopher and very eclectic in the combination of theories and ideas. However, he strongly believed in the need to understand the principles of science underlying his classification to come to a synthesis of knowledge. From that perspective, the explicitly nonphilosophical interpretation of the UDC by one of Otlet's closest collaborators and leading experts of this classification comes somehow as a surprise. ${ }^{27}$ In his article 'UDC, What It Is and What It Is Not', Frits Donker Duyvis (I894-I96I) argued that Otlet had been eager to give full credit to Dewey as the source of the UDC, but that he had changed it fundamentally. Those changes to the concept of DDC implied according to Donker Duyvis that no philosophical or scientific system could longer be recognized as underpinning the UDC'. ${ }^{28}$ In fact, Donker Duyvis ignored that important characteristics of this classification of knowledge, such as universality, multidimensionality, hierarchy, dynamics were not just practical, but were underpinned by theoretical, sometimes philosophical arguments, based on Otlet's views on universalist thought and the unity of the sciences. Otlet, as we observed, had studied the texts of Comte and Spencer on the hierarchical order and evolution of sciences; he had studied the ideas of Russell and Whitehead on events in time and space and had tried to assess their implications for a synthesis of universal knowledge.

The denial of the philosophical argument and the reduction of conceptualizations of human thought to one dimensional, linear methods in information retrieval became more and more apparent in library science, but was also criticized. The early guru of human computer interaction Joseph Licklider observed in his Libraries of the Future that most studies of topological and metric space analogies (for the greater part written in the domain of information retrieval) had focused so far on linear methods, and 'have little or no consensus even about the dimensionality, much less about the identities of the dimensions, of any such thing as "information space" or "semantic space" or the "space of knowledge". ${ }_{29}$ 
This dimension reduction in the information sciences did not only affect library and information sciences, but would also have an impact on the humanities, especially when computer-assisted methods were introduced, and philosophical arguments gradually made place for more pragmatic ones.

\section{Dimension reduction in the humanities}

After the computer had proved its capacity in the sciences to analyze large quantities of information and to make complex calculations in a couple of seconds, it also gradually made its way in those disciplines in the humanities that were looking for meaningful patterns in texts or were trying to support their observations with quantitative and statistical methods. The Jesuit priest Roberto Busa, convinced IBM's director Thomas J. Watson in 1949 to produce a machine readable corpus and concordance, the Index Thomisticus, of the work of St. Thomas Aquinas that could be searched using punch cards. ${ }^{30}$ This way the pioneer of computational linguistics fulfilled to some extent the old dream of the pioneer of knowledge organization, Paul Otlet, to create a machine-readable Summae on cards. In history, quantitative and statistical methods were especially used in historic-demographic research and socio-economic history.

Historiographical accounts of these disciplines that became known as historic informatics or cliometrics often open with a famous quote from a 1968 essay by the French historian Emmanuel Le Roy Ladurie: 'Dans ce domain au moins l'historien de demain sera progammeur ou il ne sera plus. ${ }^{31}$ Although many promoters of the digital humanities indeed claim nowadays that practitioners in these disciplines should be trained in xml code and other software languages, Le Roy Ladurie's prediction did not come true. Right from the start of the use of computers for quantitative research in history there was severe resistance. The well-known historian Carl Bridenbaugh, for instance, formulated in his presidential address to the American Historical Association in 1963 his dislike of quantitative approaches in history: "The finest historians will not be those who succumb to the dehumanizing methods of social sciences. [...] Nor will the historian worship at the shrine of that Bitch goddess, QUANTIFICATION'.32 But twenty years later even a supporter of computerassisted history, Bernard Bailyn, lamented the fact that historians had forsaken the general goals of history for 'severely vision-limiting' technical problem solving. ${ }^{33}$

Resistance of historians against the use of computers was followed by pleas of practitioners of computer-assisted historical research not to resist any longer against the hard methodologies of the sciences. This development is, for instance, recognizable in changing attitudes toward the use of geographical information systems in historical research. Kemp and Mostern proposed that users of Geo- 
graphic Information Systems (GIS) in historical research followed the example of environmental modeling by asking scholars to change their methods to suit technology, rather than making the technology work for them.' ${ }^{34}$ Jack Owens turned the question regarding the demands of technology around by asking, 'What do historians want from GIS?', but still recommended that historians experiment with the use of algorithms and fuzzy logic. By doing so, they would acquire more rigor in their methods to handle the ambiguity and uncertainty in historical records. ${ }^{35}$ In a more recent study on the use of GIS in future humanities scholarship, David Bodenhamer seeks for the enhancement of this technology with spatial multimedia and gaming tools. Such changes in technology would allow: 'for an open postmodern scholarship, an alternate construction of history and culture that embraces multiplicity, simultaneity, complexity, and subjectivity. ${ }^{36}$ Book artist and digital humanities expert Johanna Drucker suggests that humanist scholars give up the visualization techniques borrowed from the natural and social sciences all together and develop their own graphic language. ${ }^{37}$

\section{Epilogue: Digital hermeneutics and the making of e-humanities}

Technology-driven quantitative methods of computational humanities are more and more complemented by computer-assisted qualitative approaches that are inclusive and embrace complexity, subjectivity, ambiguity and uncertainty as typical characteristics of humanities research. After historic informatics and cliometrics with their statistical and quantitative methods, we are entering a phase in digital history with a comprehensive approach that is labeled as digital hermeneutics. It is hardly surprising that this shift is supported by digital historians as becomes clear from the digital-born initiative: Writing History in the Digital Age. ${ }^{38} \mathrm{How}-$ ever, digital hermeneutics does not only belong to the domain of the e-humanities or e-history; it is also making its way into the theory and practice of information and communications technology. One of the most important advocates of digital hermeneutics, the information scientist Rafael Capurro, tries to raise the attention of IT researchers for hermeneutics, which in his view has both theoretical and practical relevance. Digital hermeneutics answers, according to Capurro,

to the call of the digital by making explicit its ontological presuppositions. As a philosophic discipline it does not place itself outside history but tries to understand the factual present situation in which human existence and human thinking is located. It looks for a radicalization of the process of self-understanding of human societies that interact with natural and technical networks and construct complex hybrid living systems. ${ }^{39}$ 
It is probably this complex understanding of human societies that drive large companies to include the inclusive, hermeneutic approaches in their software designs. Steve Jobs wrote: "[T]echnology alone is not enough. It is technology married with the liberal arts, married with humanities, that yields us the result that makes our hearts sing." 40

And IBM started recently a collaboration with the Royal Netherlands Academy of Arts and Sciences (KNAW), the University of Amsterdam and the VU University Amsterdam for the creation of a Center for Humanities and Technology (CHAT) that "combines a set of major challenges in the fields of digital humanities and cognitive computing into an ambitious public-private research agenda. Its goal, briefly put, is to develop a new generation of computer technology that is able to truly 'understand' products of the human mind, and past and present human activities." ${ }^{41}$

To conclude, classificationists and other early practitioners of library and information sciences had rooted their theories in the humanities and social sciences. When technical information retrieval methods became predominant, philosophical and social arguments became less prominent or were even silenced. Humanities scholars collaborating with information and communications specialists, especially in the early computer era, were gently persuaded to follow the rigorous, often exclusive methods from the sciences. Only recently have e-humanities researchers questioned reductionist approaches of the sciences and pleaded for the development of holistic methodologies standing in a hermeneutic tradition in ehumanities research. At the same time large players in ICT development try to incorporate the complexity, ambiguity and uncertainty of humanities data, methods, and practices in their software designs. Both will contribute to the use of digital methods and new interpretations in the humanities. It is a prelude of a new phase in the making of the humanities, recently described as Humanities $3.0 .4^{42}$

\section{Notes}

I Christine Borgman, Scholarship in the Digital Age: Information, Infrastructure and the Internet (Cambridge, MA, London: MIT Press, 2007), 3 I and I79-226.

2 See, for instance, American Council of Learned Societies Commission on Cyberinfrastructure for the Humanities and Social Sciences, Our Cultural Commonwealth (2006). Available at URL: http://www.acls.org/cyberinfrastructure/OurCulturalCommonwealth.pdf.

3 Julianne Nyhan and Anne Welsh, "Uncovering the "Hidden Histories" of Computing in the Humanities, I949-I980: Findings and Reflections on the Pilot Project', in Digital Humanities 2013: Conference Abstracts University of Nebraska-Lincoln, 16-17 July 2013 (Center for Digital Research in the Humanities, 2013), 326-329. Available online at URL: http:// dh2or 3.unl.edu. 
4 Rens Bod, A New History of the Humanities: The Search for Principles and Patterns from Antiquity to the Present (Oxford: Oxford University Press, 2013).

5 Henry Evelyn Bliss, The Organization of Knowledge and the System of the Sciences (New York: H. Holt and Co., I929), preface, xi.

6 Ibid., introduction, vii.

7 For relations between library and information science and atomist theory, see Charles van den Heuvel and Richard Smiraglia, 'Concepts as Particles: Metaphors for the Universe of Knowledge', in C. Gnoli and F. Mazzocchi (eds.), Paradigms and Conceptual Systems in Knowledge Organization: Proceedings of the Eleventh International ISKO Conference, 23-26 February 2010 (Rome, 2010), 50-56; Richard Smiraglia and Charles van den Heuvel, 'Interactions between Elementary Structures in Universes of Knowledge', in Proceedings of the International UDC Seminar Classification and Ontology: Formal Approaches and Access to Knowledge (The Hague, 20II), 25-40.

8 Herbert Spencer, The Classification of the Sciences: Which Are Added Reasons for Dissenting from the Philosophy of M. Comte (New York: D. Appleton and Co., I864), 26.

9 W. Boyd Rayward (ed.), International Organisation and Dissemination of Knowledge: Selected Essays of Paul Otlet (Amsterdam, New York, Oxford, Tokyo: Elsevier, I990), 3-4.

Henri La Fontaine and Paul Otlet, 'Creation of a Universal Bibliographic Repertory: A Preliminary Note, 34', in W. Boyd Rayward (ed.), International Organisation and Dissemination of Knowledge: Selected Essays of Paul Otlet (Amsterdam, New York, Oxford, Tokyo: Elsevier, 1990), 25-50. Originally published as 'Création d'un Répertoire Bibliographique Universel: note préliminaire', IBB Bulletin I (I895-I 896), I 5-38.

I I Paul Otlet, 'On the Structure of Classification Numbers', in W. Boyd Rayward (ed.), International Organisation and Dissemination of Knowledge: Selected Essays of Paul Otlet (Amsterdam, New York, Oxford, Tokyo: Elsevier, I990), 51-62, esp. 52. Originally published as 'Sur la structure des nombres classificateurs', IIB Bulletin 1 (I 895-I896), 244-249.

I2 W. Boyd Rayward, 'Visions of Xanadu and Hypertext', Journal of the American Society for Information Science 45 (I994), 235-50; C. van den Heuvel, 'Building Society, Constructing Knowledge, Weaving the Web: Otlet's Visualizations of a Global Information Society and His Concept of a Universal Civilization', in W. Boyd Rayward (ed.), European Modernism and the Information Society (London: Ashgate Publishers, 2008), I27-I53; Charles van den Heuvel, 'Web 2.0 and the Semantic Web in Research from a Historical Perspective: The Designs of Paul Otlet (I868-I944) for Telecommunication and Machine Readable Documentation to Organize Research and Society', Knowledge Organization 36.4 (2009), 21 4-226. W. Boyd Rayward, The Universe of Information: The Work of Paul Otlet for Documentation and International Organisation, FID 520 (Moscow: VINITI, I975), 20.

I4 Paul Otlet, 'Something about Bibliography', in W. Boyd Rayward (ed.), International Organisation and Dissemination of Knowledge: Selected Essays of Paul Otlet (Amsterdam, New York, Oxford, Tokyo: Elsevier, I990), I I-24, esp. I I. Originally published as 'Un peu de bibliographie', Palais (I89I-I892), 254-27I.

I5 Paul Otlet, 'Something on Bibliography', I8.

I6 Thomas Hapke, Wilhelm Ostwald,'The 'Brücke', and Connections to Other Bibliographic Activities at the Beginning of the Twentieth Century', in M.E. Bowden, T. Bellardo Hahn, and R.V. Williams (eds.), Proceedings of the 1998 Conference on the History and Heritage of Science Information Systems (Medford, NY: Information Today), I 39-I47.

I7 Paul Otlet, 'La Fonction et les Transformation du Livre. Résumé de la Conférence faite à la Maison du Livre (I4 Novembre I908)', Publication XI (Bruxelles: Musée du Livre, I909), 23. 
Paul Otlet, 'L'Avenir du Livre et de la Bibliographie', IIB Bulletin I6 (I9II), 275-296, esp. 29I.

Paul Otlet, 'Documentation', IIB Bulletin I2 (I907), I I.

Charles van den Heuvel, 'Multidimensional Classifications: Past and Future Conceptualizations and Visualizations', Knowledge Organization 39.6 (2012), 446-460.

Compare: 'Indeed there is divergence, inexactness, and incompleteness. [...] The Mind does no know everything, language does no express everything and the document does not register everything. But they intend to do, or should to do so' (Paul Otlet, Monde. Essai d'Universalisme. Connaissance du Mode. Sentiment du Monde. Action organisée et Plan du monde [Brussels: Editiones Mundaneum I935], xxii).

Shiyali R. Ranganathan, 'Colon Classification and Its Approach to Documentation', in J.H. Shera and M.E. Egan (eds.), Bibliographic Organization: Papers Presented before the Fifteenth Annual Conference of the Graduate Library School, July 24-29, 1950 (Chicago: University of Chicago Press, I95I), 94-105, esp. 96.

Mons, Mundaneum, EUM Farde 9 N 63, 'Relations fondamentales', 9 April 1928.

The Hague, National Library, Archives of FID, Box 95, 'Andere classificatiesystemen', MD 25.49, Paul Otlet Note 2197.

Otlet, Monde, 3 I.

Rayward, The Universe of Information, 27.

Charles van den Heuvel, "The Dutch Connection: Donker Duyvis and Perceptions of American and European Decimal Classification Systems in the First Half of the Twentieth Century', in T. Carbo and T. Bellardo Hahn (eds.), International Perspectives on the History of Information Science and Technology: Proceedings of the ASISET 2012 Preconference on the History of ASISET and Information Science and Technology (Medford, NJ: Information Today, 20I2), I74-I86.

8 Frits Donker Duyvis, 'The UDC: What It Is and What It Is Not', Review of Documentation I 8.2 (I95I), 99-I05: esp. I00.

Joseph C.R. Licklider, 'Council on Library Resources: Bolt, Beranek and Newman Inc., in Licklider, Libraries of the Future (Cambridge, MA: MIT Press, I965), 77.

Tony McEnery and Andrew Wilson, Corpus Linguistics: An Introduction, 2nd ed. (Edinburgh: Edinburgh University Press, 200I), 20.

Emmanuel Le Roy Ladurie, Nouvel Observateur, 8 May 1968.

Carl Bridenbaugh, URL: http://www.historians.org/info/AHA_History/cbridenbaugh. htm. Quantification in capitals by Bridenbaugh.

Bernard Bailyn, 'Annual Meeting American Historical Association'. For these quotes of Bridenbaugh and Bailyn I am indebted to Jan Kok, Radboud University Nijmegen, Netherlands.

4 Karen K. Kemp and Ruth A. Mostern, First COSIT Workshop on Spatial Vagueness, Uncertainty and Granularity (Ogunquit, ME, 200I), I, available at URL: http://www. geokemp.net/papers/svug.pdf. It is important to note that such statements about the need to adapt historical research to the methodology of the 'hard' sciences must be seen in context of that period and that the authors might have different opinions nowadays on, for instance, the role of technology.

35 Jack B. Owens, 'What Historians Want from GIS', ArcNews 29.2 (2007), 4-6; Jack B. Owens, 'Towards a Geographically-Integrated, Connected World History: Employing Geographic Information Systems (GIS)', History Compass 5.6 (2007), 20I4-2040.

36 David Bodenhamer, 'The Potential of Spatial Humanities', in D.J. Bodenhamer, J. Corrigan, and T.M. Harris (eds.), The Spatial Humanities: GIS and the Future of Humanities Scholarship (Bloomington: Indiana University Press, 2010), 28. 
37 Johanna Drucker, 'Humanities Approaches to Graphical Display', Digital Humanities Quarterly 5.I (Winter 20II), URL: http://digitalhumanities.org/dhq/ $\mathrm{vol} / 5 / \mathrm{I} / 00009 \mathrm{I} / 00009 \mathrm{I} \cdot \mathrm{html}$.

38 Frederick W. Gibbs and Trevor J. Owens, "The Hermeneutics of Data and Historical Writing', in J. Dougherty and K. Nawrotzku (eds.), Writing History in the Digital Age (20II). URL: http://writinghistory.trincoll.edu/data/hermeneutics-of-data-and-historical-writing-gibbs-owens/.

39 See for these quotes: Rafael Capurro, 'Digital Hermeneutics: An Outline' (2010). Available at URL: http://www.capurro.de/digitalhermeneutics.html. For the implementation of digital hermeneutics in humanities and cultural heritage, see, for instance, Chiel van den Akker, Susan Legêne, Marieke van Erp, Lora Aroyo, Roxane Segers, Lourens van der Meij, Jacco van Ossenbruggen, Guus Schreiber, Bob Wielinga, Johan Oomen, and Geertje Jacobs, 'Agora Digital Hermeneutics: Online Understanding of Cultural Heritage', Proceedings of the 3rd International Conference on Web Science (WebSci'11) (Koblenz, 201 I). Available at URL: http://www.cs.vu.nl/ guus/papers/AkkerI Ia.pdf.

40 Walter Isaacson, Steve Jobs (New York: Simon \& Schuster, 20 I I), 527.

4I Sally Wyatt (KNAW) and David Millen (IBM) (eds.), Meaning and Perspectives in the Digital Humanities. A White Paper for the establishment of a Center for Humanities and Technology (CHAT), (Amsterdam: KNAW, IBM, University of Amsterdam, VU University Amsterdam, 2014), 5.

42 Rens Bod, Het einde van de geesteswetenschappen 1.o. Oration: University of Amsterdam, 14 December 2012. URL: http://www.oratiereeks.nl/upload/pdf/PDF-I433Weboratie_ Rens_Bod_-_def.pdf. 


\title{
9.2 Toward a Humanities of the Digital? Reading Search Engines as a Concordance
}

\author{
JoHANNA SPRONDEL
}

\section{Introduction}

In their seminal paper 'The Verbal Concordance to the Scriptures' from 1974, R.H. and M.A. Rouse characterize concordances to the scriptures to be not only one of the earliest but probably the most important [technical aid], because its system of reference, its method of compilation and its successful application of complete alphabetization were used by generations of later tool-makers.' ${ }^{\prime}$ To what extent this holds true for more recent inventions, such search engines, and more specifically web search engines, is the question I shall address in this paper: Can we consider Google \& Co. as concordance?

I will begin by examining the term 'concordance' (I), the use of which has increasingly broadened over the last centuries. Deriving from the Latin concordare (to agree, be united, harmonize), the implications of 'concordance' moved from Samuel Johnson's definition 'a book which shows in how many texts of Scripture any word occurs ${ }^{2}$ toward a more extensive meaning. Today, the term is commonly used in disciplines such as law, politics, cosmology, genetics, mathematics, psychology, medicine, linguistics, and grammar. I shall concentrate on the implications of the term following from Johnson's abovequoted definition and what we would commonly refer to as a concordance in philology, theology and literary studies. What unites all these usages throughout the disciplines, however, is a sense of harmonization, reflecting the term's Latin roots with respect to content, interests, ideas, data or methods. ${ }^{3}$ In a second step, I will focus on search engines (2). Although the history of computerized search engines is a recent one, I will show how the pattern of search, the harmonization of information, and the idea behind search engines is on the one hand congruent with that of concordances, while on the other hand it significantly differs from the latter (3) and will conclude with some brief remarks on how, nevertheless, comparisons like this might give us insights 
on the understanding of digital developments and should encourage a critical comparison of practices (4).

\section{Concordance and the idea of harmony}

Johnson's definition may be seen as an abbreviation of what we find in Alexander Cruden's preface to the first complete and perhaps best-known concordance to the Holy Scriptures in English, published in $1737,{ }^{4}$ where he defines the term as

an Index to the Bible, wherein all the words used through the inspired writings are ranged alphabetically, and the various places where they occur are referred to, to assist us in finding out passages, and comparing the several significations of the same word. ${ }^{5}$

This definition characterizes the function as well as the capacity of a concordance, also hinting at the incentive that made many authors write concordances. While we can see the finding of a passage by using a concordance as a direct function of it, it is the indirect function - the comparison and interpretation of different applications of a word - that makes concordances an indispensable instrument for textual criticism in numerous fields of research and, as Rouse and Rouse remarked, a source for numerous systematic and methodological approaches. To understand the core meaning of the term, it seems advisable to approach it from an historical perspective. ${ }^{6}$ The term concordance was first introduced into the English language in $1387^{7}$ when John of Trevisa translated Ranulf Higden's Polychronicon (1327 or 1343).

[Innocent IV] putte honest and noble persones in pe cardinales see pat were voyde. He made cardynal frere Hewe of pe ordre of Prechoures, pat expownede al pe bible, and made a greet concordaunce uppon pe bible (VIII. 235)

These lines refer to what is assumed to be the first known concordance: most likely around 1244, a word index to the Vulgate, named Concordantiae Sacrorum Bibliorum was completed that began under the instructions of Hugh of SaintCher (Frere Hewe). After providing a critical edition of the Bible (Sacra Biblia recognita et emendata, around $\mathrm{I}_{236}$ ) and planning to write a commentary on the same, ${ }^{8}$ Hugh realized that an index of the words occurring and the places of their occurrence was required to compare different passages and to see whether the 
meaning of the words altered in these. ${ }^{9}$ He produced a sheer word index, an index verborum: a concordance of the simplest kind.

To understand the implications of the term concordance though, it is noteworthy that John of Trevisa not only translates, but coins the term concordance in a way that points to 'biblical criticism. ${ }^{10}$ In order to understand why, we need to look at what John of 'Trevisa translates as 'concordance': Ranulf Higden writes 'et magnas super bibliam concordancias compilavit', what we might translate as 'and he has brought together many agreements all over the Bible'. A single concordancia, a medieval formation of the participle concordare (to agree), is to be seen as a bundle of two or more passages where the same word appears in Scripture, making the plural a collection of these bundles in a book. And in this broad sense the term had in fact been used before, e.g., for the lists Langton prepared in his glosses and that he named concordantia. ${ }^{\text {II }}$ But differing from what the plural 'magnas [...] concordancias' might suggest, John of Trevisa explicitly speaks of a single agreement, turning Hugh's Concordantiae Sacrorum Bibliorum into a certain concordance.

Being merely a list of the words in the Bible with references to their location, when Hugh completed his work in 1244, John of Trevisa's interpretation of the term would have seemed somewhat inept. But when John completed the translation of Hidgen's work in 1397, the Concordantiae Sacrorum Bibliorum had indeed become a concordance, mainly owing to the work of three English monks who had not only revised and added quotes of the passages in question to the references of the work of Hugh but had basically produced a new concordance the Concordantiae Anglicanae - that was nevertheless commonly received as a second edition' of Hugh's work. Furthermore: John of Trevisa, knowingly or not, boarded a 'hermeneutic-semantic' train that, for example, changed the title of Gratian's Decretum from Concordia discordantium canonum into Concordantia discordantium canonum. ${ }^{\mathrm{I}}$ And it is idea that Cruden identifies as the gist of a concordance that moved more and more into the focus: 'interpreting Scripture, namely [... comparing one Scripture with another.' ${ }^{13}$

Starting with Hugh of Saint-Cher's work, concordances to the Bible, both verbal and topical but also marginal, became increasingly common and were produced in almost every language considered 'franca'. Along with this came a broader acknowledgement and awareness of the functions and possibilities that a concordance offered: a 'key to the knowledge of the scripture ${ }^{14}$ and a 'higher truth', an idea that is reflected throughout the history of concordances and perhaps in the most allegorical way by Isaac Nathan ben Kalonymus, who in the fifteenth century made a Hebrew Concordance of the Bible that he called not 'Concordance' but Meïr Netib, which is Hebrew for 'Light to the Path'. ${ }^{15}$ In the introduction (Petibat Meïr Netib) Nathan explains that a Hebrew concordance was long 
due to allow the Jewish to benefit from a system that made the central text of a whole culture (the Holy Scripture) and its information easier accessible and thus easier interpretable. He also explains that he chose to do a Hebrew concordance in order to be able to argue with his Christian adversaries more easily. ${ }^{16}$

Moreover, a reflection upon the method, its choice, and a justification of which words were chosen became part of most introductions. A critical and guiding summary is given by Kenneth McKenzie in his considerations upon concordances on the works of Petrarch and Dante:

[I]t must be borne in mind that the editor is not presenting the results of an investigation, but a work which will be referred to, whether incidentally or systematically, for certain information; hence he should keep his own personal judgment as much as possible in the background, and should arrange the material in the most natural and practical way. In a word, the arrangement most convenient for practical use is the most scholarly. The editor should then introduce no system of classification except on a universally accepted basis, such as the order of the alphabet, or, as the case may be, the actual order of occurrence in the text. ${ }^{17}$

I shall not further depict the development of concordances in detail here, since the focus of this paper lies on the concept, method and idea behind concordances rather than on their historical development. It goes without saying that Johannes Gutenberg's innovation around the year 1439 not only radically changed the 'book market' but also allowed concordances to be more widely spread, letting them be present in many churches - often ad usum communem - most monasteries and surely fostering exegesis. And in the course of political and social development of that time and especially during the Enlightenment, when the litterae bumaniores became increasingly popular, it was suggested that not only Scripture should enjoy the privilege of being furnished with a concordance. Over two centuries the emphasis shifted more and more from clerical writings to other types of literature, and the conviction grew that not only the Bible and religious texts were books in which every word counted.

But while this widening of the 'canon' of works supplied with concordances is mostly of interest in terms of a change in the history of ideas, one might say that the next milestone in terms of the practices of composing a concordance is to be seen in the advent of computing and especially latent semantic indexing, developed by the French mathematician Jean-Paul Benzécri. Making a concordance became significantly easier, and works as well as authors that until then had not been recorded were provided with a concordance, ${ }^{18}$ but, of course, the 'classics' were among those who first were digitized and consequently furnished with con- 
cordances in the late I960s. ${ }^{19}$ Scholars were quick to agree that digital concordances offered a tremendous gain, and their multiple applicability surfaced with the turn in the so-called 'Dead Sea Scrolls controversy': Scholars were granted only limited access to the scrolls discovered in 1947. In I99I, Michael Abegg used a complete concordance of all Scrolls from the 1950 s that lists every usage of every word appearing in the scrolls, including the words that flank it on either side and the name of the scroll where it appeared. By an invert use of this concordance, Abegg reconstructed the parts that, until then, had remained unpublished, programming his computer to identify overlaps of 'word strings', and to assemble these into larger groupings. ${ }^{20} \mathrm{~A}$ work that would have taken Hugh and his monks years to complete, once the passages were entered into the computer, took Abegg's Mac SE 'less than I5 minutes', as he explained.

As a preliminary conclusion, we may sum up the key characteristics of a concordance in the following way: A concordance - and as the ideal type we shall define a complete concordance - is, first of all, a tool that enables us (a) to search for the occurrences of words or subjects in a text. It thereby allows us (b) easier access to works. To support this, a concordance should (c) be based upon a system of classification on a universally accepted basis. We may use the results of our search (d) to identify certain passages and even writings. Also they grant us (the user) the possibility (e) to compare, upon this basis, dispositions of words and then (f) to interpret the latter or even a whole work. Thus a concordance should (g) be objective and neutral. As for the subject matter of concordances, we may furthermore note that concordances mostly exist for (h) major works or major authors of a culture.

\section{Searching the Webः Index, corpus and engine ${ }^{21}$}

The history of web search engines began in 1990, when the World Wide Web still consisted of a manageable amount of websites. A simple directory would then serve all purposes and the content of pages could be searched manually. With an ever-growing number of websites, documents, pictures and other data sets available online, search engines were needed that not only displayed all pages available, but also their specific content, making the latter a concern of the search. Furthermore, with the growth of the overall amount of data, searches that would fit the request of the user became more important, while also the time needed for an individual search became an issue (which is, for example, why a Boolean search that would list every single occurrence of a word turned out to be no longer manageable). ${ }^{22}$ Also sign-n-grams ${ }^{23}$ are no longer a basis in web-based search engines, 
which they were earlier and still are, for instance, in archives where manuscripts are scanned and converted to digital documents by OCR. We therefore have to face the fact that the results of a query may be detailed, but are never a complete record of what could be found - and what we find varies widely, also due to a highly unstable corpus.

Web-based search engines such as Google, Yahoo!, Bing and others used today operate in three steps - web crawling, indexing, and searching - and only in the last of these steps is the user involved directly. These operations, to put it simply, rely on two basic concepts: an (inverted) index ${ }^{24}$ and an algorithm. The World Wide Web is crawled regularly, that is, it is systematically browsed, and whatever the crawler (a,k.a. the spider) finds is stored in an index. While the inverted index is a record of all words existing in all documents available with a notation of their location, the algorithm takes care of these being interpreted in a relevant and (for the user) satisfactory way once a search is placed. This user query then results in a list of search results, the so-called hits, that are sorted following numerous heuristic factors, described in the case of Google by the term PageRank ${ }^{25}$; one might mention stochastic factors like the proximity of words searched and the number of their occurrence in a document or website, the number of links that refer to documents or websites available, the number of clicks a website or document has received so far (documented in a 'query log'), but also an estimation of the relevance of the site as a whole and other criteria, to most of which we remain ignorant. The aim of a search engine is to make results available as fast as possible and, at the same time, to match the query as close as possible, thereby following the 'principle of least astonishment' (POLA/PLA). The POLA is based on the idea that users already have a certain knowledge of what they are searching (otherwise they would not search for $\mathrm{it}^{26}$ ) and therefore a search result should meet their expectations, which is one of the reasons why data of the users' queries is saved and introduced as a factor to future queries.

The fulfillment of these aims demands several preconditions and concessions. One is the availability of an index server that keeps at hand all the information needed, so that the search engine does not have to search the World Wide Web itself for the information queried again and again but can fall back on a stored index. Considering that the World Wide Web is a constantly growing, neither already nor yet complete and thus unstable corpus, the problem of information stored on the server expiring or not being available is obvious. Another problem consists in limitations. Beyond the fact that a search result never covers every incidence of the word queried for, the words searched for are not necessarily identical to the actual keywords entered in the query: firstly, 'stop-words' (in, on, of, the, single numbers or letters and more $)^{27}$ are ignored, i.e., not indexed; secondly, search engines rely on a so-called 'similar words match', based on the linguistic 
method of stemming ${ }^{28}$ Stemming is the (computer-)linguistic term for reducing (inflected) words to their stems or root forms and searching for these as well as for all its possible inflections and even derivative morphemes; e.g., the stem of 'children' would be 'child', possible results therefore might include 'children', 'childish', 'childlike' but might also include 'childless' or 'childe' and are stored on a 'lookup table' on the server. This not only implies a search for words beyond their grammatical setting but also leads to a broadening of the results that treats the different inflections and derivative morphemes synonymously. ${ }^{29}$ In contrast to a search engine working with a closed set of data that refers to a limited indexed corpus and therefore limits the field of results to the possible words, a stemming algorithm that is introduced to a corpus like the World Wide Web tends to be either over- or understemming words, ${ }^{30}$ owing to the fact that the algorithm does not necessarily retain stem words in the semantic relation to inflected word in its index.

Finally, it should be mentioned that search engines do depend on the user. Not only does a search engine save the queries of users and the choices they made from the results offered and learns from this. Also the correct use of operators by users leads to more detailed and exact results and therefore alters future results, helping the search engine to interpret (I) the user's query and (2) the index in the light desired by the user. ${ }^{31}$

We may thus note the following key features for web-based search engines: Web-based search engines pursue the goal to (a) search the World Wide Web for a keyword or a set of keywords. They thereby (b) put the material available into an order. The search is (c) based on an index that is produced by the crawlers that are part of the system of the search engine itself. The way the (d) index is searched and results are given relies on an algorithm that is not fully known to the user. Therefore (e) the user is not searching the index himself, recurring to his own means and criteria of interpretation, but $(f)$ the search engine is an agent. Keywords are furthermore (g) limited and (h) altered due to stemming and other processes. Search engines tackle (i) a constantly changing corpus but are (j) able to 'learn', i.e., to implement information gathered from earlier search processes.

\section{Same but different: \\ Retrieving knowledge, scraping information and sorting data}

Against this background, and the two sets of key features in particular, several parallels can be drawn between concordances and search engines. First of all, we may state that the World Wide Web is, although it is not a major single work of 
our culture, the most present medium of our times. If we understand the World Wide Web as a (possibly unstable) corpus, it would therefore deserve, we may argue, a concordance, 'a book which shows in how many texts of scripture any word occurs', to return to Johnson's definition once again. As a matter of fact, the search engines that compile data since the I990s (and in the way we know today since approximately the year 2000) surely allow us an easier access to works or information by enabling us to search for the occurrences of words or subjects, for the material available on the World Wide Web. As frequently proven, web-based search engines enable us to identify passages and even writings by entering keywords. ${ }^{32}$ So they in many ways serve as a form of concordance already, allowing the user to use the results for further purposes, such as interpretation. Thus if we take into account what, on a surface level, search engines do, it appears that they are a concordance of the World Wide Web. If, furthermore, we consider that from the material available on the World Wide Web, most existent concordances and many others could be compiled by using search engines, it seems that we may even consider web-based search engines the concordance par excellence. Or, at least, a highly potential concordance.

Having said this, it is just as vital to point out the profound differences between concordances and search engines, some of which become clear if one considers the operating methods of both, others if one looks at the idea underlying their concept. Many of these differences might be seen marginal in everyday usage; however, when we ponder the question whether a search engine may be referred to as a concordance, these aspects require scrutiny.

I shall start with the limitations applied to the actual content of the query itself and the problems that arise from it. As pointed out earlier, search engines, by means of stemming or of not indexing stop-words, modify the search to improve its results. Unless put into inverted commas, the keyword is altered through stemming or even ignored when being a stop-word. Now, considering that one of the denotations of a concordance - and in fact the incentive for the very first one - was that the different usage of words throughout a work could be compared, we recognize this as a central disagreement between the two concepts. The same holds for the tackling of stop-words. Articles, particles, conjunctions and other small but often-used words would surely downsize the relevance of the results of a search-engine search. But historically, as we have seen before, and also semantically, they are essential. ${ }^{33}$ Moreover, it would be erroneous to think that a search engine allows us to search strings that are not presorted in a 'lexematic' or even 'semantic' way. Yet again: if a concordance is an instrument for interpretation and answering questions on the text or the content underlying it rather then about it, the precision as much as the complete and equal representation of a corpus must be considered essential. 
As for the resorting to an index listing all words and the pages on which they occur, we touch on another problem that leads us beyond the materiality of the search engine or the concordance itself, approaching the actual idea that is behind a concordance. We might state that the index that is retrieved by a crawler and resorted to by the search engine when a user conducts a query can be understood as a concordance. But we have to be aware of the fact that this turns the search engine itself into a kind of intermediary between the index/data and the user (who enters the query). The task of this intermediary agent is then to interpret the query as well as the matches in the index, which at times - as with any intermediary agent - can be a challenge. In fact, it can be so in multiple ways: firstly, the bigger and more open to changes a corpus, the broader are its results and the more it is likely, in comparison to a search in a concordance that is applied to a single corpus or a limited field, to come up with numerous results that might not fit the query. While the 'user' of a traditional concordance might, for example, just search for the word 'honor' and its occurrences in Troilus and Cressida using a concordance of Shakespeare's complete works, the user of a search engine is depending on the search engine to interpret his query in that intention and to show her twenty-two appearances of the word - instead of an interpretation on the question of honor in the play, which is all that 'my' Google offers me for the first thirty-eight results. In fact, this makes obvious, again, the problem of displaying information that can be found in the text or the content underlying it as opposed to information about it. At the same time, an engine that corresponds to a large, ever-changing corpus is supplied with an algorithm that evaluates the user's picks, and learns. So can the user: every search engine can be optimized by the user's effort to learn how to use operators correctly and therefore get more detailed and exact search results. So overall search results can be 'improved' - which is, of course, not the case in a concordance, but there would be no need for it anyway, assuming it was sufficiently assembled and the canon established. And it would furthermore not be in the interest of a concordance to represent previous searches and filter the results in favor of these.

Secondly, the interpreting intermediary agent can be bribed, which neither the concordance nor its author nor its user are likely to be. The objective and universally transparent and understandable criteria mentioned before dictate a concordance to be sorted in an alphabetic order. The order of the listing of the passages would then be defined by the position of the occurrence in the book, etc. In web-based search engines, this is not the case. However, the intermediary agent may try to interpret the query and the index on a neutral basis, so the index is constantly under attack by external parties who try to improve their own presence in the search result rankings, due to the fact that the higher an entry is listed the more often it is clicked by a user. ${ }^{34}$ Search engine optimization (SEO) is a flourishing area of business. Therefore, in this respect as well, search engines 
do not seem to be objective scholarly concordances but highly hierarchical ones. This, in a way, makes their use much less deliberate than we might wish it to be. Although this is only one aspect, it seems to be a substantial one.

From what has been said it also becomes clear that a web-based search engine not only does not distinguish between primary sources and works that are already an interpretation, but Google's latest developments, the so-called 'knowledge graph', goes even one step further by actually conveying the user that this is 'the truth': Offered as an extra search result, displayed in an emphasized way this search result seems immune to interpretation - an idea that stands in opposition to the concept of a concordance.

\section{The potential of reading search engines as a concordance}

As of June 30, 20I2, the number of World Wide Web users was calculated to be $2,405,518,376$, which at that point equaled $34.3 \%$ of the overall population of the world. $67.7 \%$ of the online population were physically living in Asia, Europe, or North America, in the latter with almost $80 \%$ coverage in the population. ${ }^{35}$ Given the fact that the indexed web contains at least 14.48 billion pages ${ }^{36}$ today and is continuously growing, it may appear that we are looking at an infinite, unsorted, unmanageable, and, even more important, not understandable amount of information. Thus it is hardly surprising that a search engine, namely Google, is by far the most visited website in global rankings, receiving over 2,000,000 queries per minute, ${ }^{37}$ suggesting the impression that most of the world's population is hardly able to imagine using the World Wide Web without using search engines - maybe simply because they are overwhelmed by the amount of data and information available.

Such an interpretation in the face of new technologies has been dramatically declared by authors such as Neil Postman. The dissemination of information, according to Postman, is nowadays (and this still holds today) no longer the problem; instead, he argues, the problem today is 'how to transform information into knowledge, and how to transform knowledge into wisdom, ${ }^{\prime 3}$ knowledge being defined as

organized information - information that is embedded in some context; information that has a purpose, that leads one to seek further information in order to understand something about the world. Without organized information, we may know something of the world, but very little about it. When one has knowledge, one knows how to make sense of information, knows how to relate information to one's life, and, especially, knows when information is irrelevant. ${ }^{39}$ 
Besides brooding fears among scholars of vanishing paper work, libraries and corpora ${ }^{40}$ the biggest problem that I see, however, seems to be connected to the 'users' and a losing of the ability to make sense of what is left when there is 'just' data - or even information - and concerns understanding and making sense of information and turning it into knowledge. Applications as the 'knowledge graph' are actually supporting the approach that a search engine as an agent can supply information that seemingly lies beyond interpretation. That users accept this as factual knowledge might be a consequence of an increasing lack of procedural knowledge on how to retrieve, and critically review, the information provided; for example, by applying long-learned practices of research and interpretation. But it may just as well be a lack of awareness that the results we are offered by web-based search engines such as Google are neither objective nor based on a fully transparent methodological approach. Moreover, there may be a lack of awareness of the fact that the search engine is already offering an interpretation of the listings found in an index: The search results represent a statistical harmonization rather than a harmonization reflecting the meaning or the content as a concordance would. Again, a simple example might come from Shakespeare: In his play Troilus and Cressida the word 'lord' comes up a hundred times, the word 'honor' twenty-two times, 'love' appears fifty times, but 'hierarchy' is not used once. As a result, it seems, the index in a concordance would possibly categorize the play as being mainly about a lord (or lords), about the experience of love, somewhat less about honor, and not at all involving hierarchy - an inaccurate assessment to be sure.

Without doubt, the World Wide Web is an outcome of the technologies that are as well a representation as an expression of our current culture. Of course, it is one of the basic ideas of cultural studies and the social sciences that the change of culture and society are connected to the change of technologies (Innis, Benjamin). Media are no longer only instruments to spread or to bear information but 'apparatuses' (Benjamin), 'codes' (Flusser), 'dispositivs' (Foucault), 'extensions' (McLuhan), or Aufschreibesysteme (Kittler), to mention but a few approaches, and thus are themselves sources of cultural, scientific and social practice whose influence we can not ignore but approach in a way that valuates them as such. Criticism geared toward the digital humanities and the practices of the digital age' is mostly concerned with its methods, its phenomenological and psychological impact, and the focus that is put on pure data rather than what one might call content; finally, many scholars question its reliability and sustainability (most prominently by Fish, Fitzpatrick and Ramsay). So far, however, neither the critics nor the champions of the field have exhaustively addressed the possibility that the effects of the digital technologies on the humanities and scholarship more generally their new 'learned practices' and 'habits', can be considered as no- 
table features able to reflect the changes and impacts themselves. Precisely this, to compare the practices of the 'traditional' humanities to those of the 'digital' humanities in order to better understand the shifts and changes that the transition from one to the other produces, is an approach I think valuable if we want to grasp not only developments in a 'digital age' but also a 'making of the humanities' as we experience it today. Rather than merely celebrating out or criticizing the assumed potential of a great renewal that can counter the often presumed 'crisis of the humanities', the task might be to produce a genealogy of methods and their media. To me it seems promising to not only assume an 'exceptional promise for the renewal of humanistic scholarship [...] enabled by networked, digital environments' ${ }^{41}$ but to approach new technologies using older ideas and concepts ${ }^{42}$ now hidden behind them in order to see both of them in a different light: Models and practices such as, for instance, concordance, but also, for example, source criticism have lost nothing of their significance. And they correspond to practices and techniques on the Web and in digital technologies (such as search engines, the Text Encoding Initiative (TEI), topic models, stylometrics, to mention but a few); at the same time, however, they can serve to make problems and derivatives in methodologies and interpretations of both, the digital humanities and the humanities, transparent. Turning around the convoluted project of the digital humanities and ask for a new 'humanities of the digital',43 comparing practices of the humanities with the altered forms that result from the mingling with digital practices and the influence of multifaceted technological innovations seems promising, also to analyze concepts of knowledge and understanding in the 'digital age'.

My claim would be to approach new technologies using the idea behind, for example, a concordance as a vehicle. We may surely consider the results as bundles that have been nicely brought together, each with a title and indication of the source, the webpage - 'Google, qui magnas super World Wide Webem concordancias compilavit', we may say - but only to continue, putting the results into a relation to our query and interpreting and scrutinizing these bundles as carefully as we would the indices of Frere Hewe, Cruden and others; and from there, turn to the passages displayed and again start to search for meaning. Because that, the Erkenntnis des Erkannten (in the words of August Boeckh), will always be on us, the users.

\section{Notes}

I R.H. and M.A. Rouse: 'The Verbal Concordance to the Scriptures', Archivum fratrum praedicatorum 44 (I974), 5-30, esp. 5.

2 Samuel Johnson, 'Concordance', A Dictionary of the English Language (Heidelberg, I 828), vol. I, 209. This is understood as the first definition of the term in a dictionary, given in I755. Note that a concordance is not a dictionary, but a dictionary is a type of concor- 
dance. Johnson's referring to the '(Holy) Scripture' is owed to the circumstance that the first word concordances were made for the Bible, which was the only book considered true throughout and thus worthy. Other writings that may be called early concordances (though mostly in the sense of a 'harmony' of numerous writings mainly of interest to textual criticism) are the Concordantiae Morales (attributed to Antony of Padua, possibly around I225), the Concordia discordantium canonum (Gratian, most likely around II40) and Origen's Hexapla, an extensive comparative study of various translations of the Old Testament, compiled in the 3 rd century. There were also concordances for other central religious writings, such as the Qu'ran, the Torah or ancient Chinese texts. This paper, however, focuses on the European tradition.

3 This broadening of an already broad applicability of 'concordance' started around the time of the raise of the 'Geisteswissenschaften' in the late I 8th century. Unfortunately, to my knowledge, as of today there is no comprehensive study of the idea of concordances through the ages and disciplines.

4 Earlier, John Marbeck had completed a concordance, though this must be seen as a index verborum: John Marbeck, A Concordace, That Is to Saie, a Work Wherein by the Ordre of the Letters of the A.B.C. Ye Maie Redely Finde any Words Conteigned in the Whole Bible (London, I550). (Alternate spellings are Marbecke or Merbecke.)

5 Alexander Cruden, A Complete Concordance to the Holy Scriptures of the Old and New Testament, or, A Dictionary and Alphabetical Index to the Bible (London, I837, orig. I737), Preface.

6 For the history of concordances I am indebted to several introductions to concordances, particularly to Bindseil, Bruder, Cruden, Mandelkern, Mengenot, Rouse and Rouse, who provide an overview of this wide but surprisingly understudied topic.

7 Oxford English Dictionary: 'Concordance.' To my knowledge, the term was not used in this sense in any other language before that; French uses it in diplomatic vocabulary, starting in II90, and in this meaning the term later also occurs in English. Cf.: Denis Diderot, 'Concord', Encyclopédie (Paris, I75 I), vol. I.

8 Later released under the title Postillae in universa Biblia iuxta quadruplicem sensum literalem, allegoricum, moralem, anagogicum.

9 Heinrich Ernst Bindseil, Concordantiarum Homericarum specimen, cum Prolegomenis in quibus concordantiae biblicae recensetur (Halle, I867), vif (Prolegomena).

Io John of Trevisa here translates a passage in which Higden reflects upon the reign of Pope Innocence IV, mentioning a certain 'frere Hewe', who was made a Cardinal Priest by Innocence IV. However, it seems that this coining of the term 'concordance' in the context of what we may today understand as 'biblical criticism' can be considered a by-product that only in retrospect receives a deeper meaning. Hugh of Saint-Cher's role in clerical politics under the reign of Innocence IV was surely considered his greatest achievement throughout the Middle Ages, which is why Ranulf Higden mentions him in the Polychronicon. The sentence "pat expownede al pe bible, and made a greet concordaunce uppon pe bible' in my opinion is mainly a predication of Hugh of Saint-Cher. In a similar way this information is treated in the Memoriale potestatum Regiensium, '[...] dominus Ugo Cardinalis, $[. .$.$] qui doctor eximius doctrina sana et prælucida totam Bibliam postillavit;$ Concordantiarum Biblix primus auctor fuit'. Cf. Du Cange et al., Glossarium medice et infimce latinitatis (Niort, I883-I887).

I I Beryl Smalley, The Study of the Bible in the Middle Ages (Notre Dame, IN: University of Notre Dame Press, I964), 24I.

I2 In his synoptic harmony from around I I 40, Gratian brought works of potentially contradictory contents into accordance, thus the title Concordia discordantium canonum. 
I 3 Cruden, Concordance to the Holy Scriptures, preface.

I4 There is good reason why verbal indexes and concordances, for example, on the works of Homer (I656), were givens names such as Clavis Homerica.

I5 The cover page of the first edition read 'Yaïr Natib' (It/He Will Light the Path, after Job 4I. 24, the description of Leviathan [A. V. 32]).

I6 This is a common motivation. John of Regusa, for instance, president of the Council of Basel from I43I to I449, when getting into a quarrel over the particles nisi, ex and per, realized that these were not part of any concordance so far and tasked John of Segovia with the Concordantiae biblicae vocum indeclinabilium (Basel, I476), cf. Bindseil, Concordantiarum Homericarum specimen, xii, which also shows that detailed information on texts was becoming more and more essential.

I7 Kenneth McKenzie,'Means and End in Making a Concordance, with Special Reference to Dante and Petrarch', Annual Reports of the Dante Society 25 (I906), I9-46, esp. 29.

I 8 With Marshall McLuhan and others we may argue that this led to a turn in editing comparable with that of Gutenberg's invention. Cf. Marshall McLuhan, The Gutenberg Galaxy: The Making of Typographic Man (Toronto, 1962).

I9 Sometimes these attempts were rather overdoing, as has to be stated. Spevak's concordance on Shakespeare that was compiled by an IBM 7094, for instance, takes into account every single word of Shakespeare's works. Not only does this concordance fail to compile different spellings of the same word in one entry, but in fact it also shows all entries for so-called stop-words such as 'a' and 'the', urging Frank Kermode to close his I 969 review in The New York Times close with the line: '[W] shall learn, inter alia, what proportion of the poet's total vocabulary is claimed by such words as love, black, power, and will. But his favorite word will, I predict, turn out to be the' (Frank Kermode, 'The IBM Shakespeare', The New York Review of Books, January 30, 1969).

20 For a summary of the case, see Ron Grossman, 'Computer Generates Bootleg Copy of Dead Sea Scrolls: Official Committee Has Refused to Publish Its Translations of Texts', The Seattle Times, September 4, I99I.

2 I Note that 'search engine' is an umbrella term covering numerous types: web-based search engines, selection-based search, meta search engines, desktop search tools, search engines within applications and with limited corpora, and web portals or vertical market websites offering a search facility for their online databases. This paper focuses on web-based search engines, i.e., specific software codes, designed to retrieve information from the World Wide Web, regardless of their origin. Examples of these are Yahoo!, Soso, Bing, or Google. Again, individual web search engines work differently, mostly with different algorithms. I have chosen Google as a case study for two reasons: (I) Google is by far the most frequently visited website in global rankings, and therefore also the most frequently used web-based search engine. Cf. URL: http://www.alexa.com/topsites; and (2) despite the fact that details of the algorithm itself are being kept secret, the basic idea of how Google works is accessible and well documented.

22 For a brief characterization of the differences between search engines in light of their history, see Kuyoro Shade O et al., 'Trends in Web-Based-Search Engine', International Journal of Emerging Trends in Computing and Information Sciences 3.3 (June 2012), 942 948.

23 Not to be confused with Google's service 'Ngram Viewer' that is not only limited to the Google Books corpus but also tackles words as grams.

24 The terminology is somewhat confusing, since this is what one would refer to as an index or even concordance from the aforementioned. 'Inverted' refers to the following: in com- 
puter science an 'index' lists the documents and from there accesses the words/signs in it. An inverted index lists the words/signs and the documents available from there. A term referring to a paper written by the Google founders Lawrence Page and Sergey Brin, URL: http://infolab.stanford.edu/pub/papers/google.pdf. The idea of search being lead by the idea of knowing what should be found is a common place in the history of ideas, see, e.g., Martin Heidegger, Phenomenology of Religion, $\$ 9, \mathrm{~h}$ ('What does it mean to search').

27 URL: http://www.link-assistant.com/seo-stop-words.html provides an exhaustive, though seemingly rather exaggerated list.

28 Most prominent stemmer implementations are the algorithms developed by J.B. Lovins, 'Development of a Stemming Algorithm', Mechanical Translation and Computational Linguistics I I (I968), 22-3I, and M.F. Porter, 'An Algorithm for Suffix Stripping', Program 3 (I980), I30-I 37 .

29 To be clear on this: Google does not list synonyms.

30 Overstemming means that words of the same stem but a possibly different field of reference are brought together; understemming denotes the case where words have a different stem but a similar semantic concept.

3I Cf: Martin Feuz et al.,'Personal Web Searching in the Age of Semantic Capitalism: Diagnosing the Mechanisms of Personalization', First Monday I6.2 (20II), URL: http:// firstmonday.org/htbin/cgiwrap/bin/ojs/index.php/fm/article/view/3344.

32 At least those that are available and searchable online. One may see the various plagiarism affairs of the past years as an example, e.g., http://de.guttenplag.wikia.com/wiki/ Tools,_um_Plagiate_aufzusp\%C $3 \%$ BCren.

33 For a possible reading of the value of semantic detachment, cf. Boris Groys, Google: Words beyond Grammar (Ostfildern, 20II). Groys argues that Google is the incarnation of a philosophical machine because it detaches words from their grammatical limitations, thus crossing boundaries beyond deconstructivism.

34 URL: http://searchenginewatch.com/article/2049695/Top-Google-Result-Gets-36.4of-Clicks-Study.

35 URL: http://www.internetworldstats.com/stats.htm.

36 URL: http://www.worldwidewebsize.com/.

37 URL: http://www.alexa.com/topsites.

38 Neil Postman, Building a Bridge to the 18th Century: How the Past Can Improve Our Future (Westminster, I999), 98.

39 Ibid.,93.

40 Cf. Anthony Grafton, Codex in Crisis (New York, 2008), who clearly represents a more optimistic position than many other scholars in the humanities and whose fear of the loss of what we may see as a certain 'reader and reading attitude' I fully share. Anne Burdick et al., Digital_Humanities (Cambridge, 2012), 7 .

42 For a comprehensive study on methods of information management in ancient and medieval Europe, see Ann M. Blair, Too Much to Know: Managing Scholarly Information before the Modern Age (New Haven, 201 I).

43 Johanna Sprondel, Towards a Humanities of the Digital. In preparation. 



\title{
9.3 A Database, Nationalist Scholarship, and Materialist Epistemology in Netherlandish Philology
}

\author{
The Bibliotheca Neerlandica Manuscripta from \\ Paper to OPAC, $1895-1995$
}

JAN Rock

The history of digital humanities may seem relatively short. The study of culture, history and humanity appears to have been affected by digital culture and networked computers for only about two decades. That is why usually not the past, but the future of digital humanities is discussed, conversation being flavored with possibilities and promises: greater convenience for scholarly labor, and increased speed in the consultation of data, the massive accessibility of which would enable the humanities to deal with their scientific arrears.

Yet already in 1902, similar ideas incited the Belgian philologist Willem De Vreese to address the Royal Flemish Academy of Language and Literature in Ghent. He questioned the competence of most vernacular philologists in reading old types and hands. 'Of course I do not intend to maintain', he said to his fellow members,

that there would be no students of Dutch who can read Middle Dutch manuscripts. Enough of them are seasoned, as we all know. But their knowledge is a personal matter, that stands or falls with them, that perishes along with them, so that the prerequisite of an established science lacks, namely the handing down of a certain amount of knowledge to a next generation, for them to build on it. ${ }^{2}$

De Vreese formulated an ambition equally simple as naïve: he wanted to transform the competence of reading old Netherlandish texts into proper scholarship, an ambition which could only be realized by an intergenerational tradition of knowledge. In order to secure such a tradition, he proposed a documentary instrument: a Bibliotheca Neerlandica Manuscripta. ${ }^{3} \mathrm{He}$ conceived it as a card file 
system containing descriptions of all medieval manuscripts in Netherlandish, to be collected and indexed by himself (and his family, as became clear later on). De Vreese expected his data collection to be particularly useful for training reading skills with original excerpts, but also for writing a history of medieval scribal culture in the Low Countries. In short, just like the most renowned German historians, De Vreese was convinced that having the Quellen at hand in the personal, even intimate setting of a seminar would improve objectivity in philological studies. ${ }^{4} \mathrm{He}$ acknowledged the advantages of a data collection, both practical and scientific, as much as other scholars of his time $e^{5}$ as much as most scholars nowadays when they speak of digital data collections.

The discursive parallel between today's expectations for digital humanities and De Vreese's ideals of improved apprenticeship and assured objectivity is more than just the fiddling of some historian. There is more to say in favor of the Bibliotheca as a single historical case study. In his 1902 address, De Vreese referred to paleographic collections and manuals from abroad, to make clear what Netherlandish philology was missing. He mentioned publications from the I870s onwards: those by Léopold Delisle and the École des Chartes, the Facsimiles by the Palaeographical Society (I873-I883), a Bilderatlas (1887) by Gustav Könnecke and Schrifttafeln (1874-1878) by Wilhelm Arndt, and Magda Enneccerus's glittering Die ältesten deutschen Sprach-Denkmäler in Lichtdrucken herausgegeben (I897). His own discipline on the contrary was served by only one 'small work' (werkje), dating back to I8I8, and by scattered facsimiles in scholarly text editions, which were mostly 'unserviceable, because they are processed independently neither from the draughtsman's greater or lesser degree of skilfulness and from his imagination, nor from the publisher's intended purpose. ${ }^{6}$ With this enumeration, De Vreese not only pointed at a documentary gap in Netherlandish philology, he also implicitly stressed the merits of his planned Bibliotheca. For unlike the models from abroad, his own paleographical study instrument would not be a book, but, as a modular collection accessible through indexes, an innovation in international paleography.

Later on, the Bibliotheca's history appeared as no less pioneering: the data collection was digitized as early as the beginning of the I990s and it was made accessible through a computer network in 1995 . So this case began its public life in 1902 and reaches as far as the breakthrough year of multimedia in personal computing and of the Internet. That is why the last three paragraphs of this article consist of a short history of the Bibliotheca. It starts with De Vreese's initial collecting activity against the backdrop of major questions in the history of Netherlandish philology; it passes on to his death in 1938 , after which the Bibliotheca was transferred to Leiden University Library and became publicly accessible; and finally, the Bibliotheca's digitization serves as the closing episode. 
The case of the Bibliotheca thus proves to be more than merely a discursive parallel; it is relevant for a historical view on digital humanities because of its innovative forms. Its modular and searchable data organization in fact makes it a database, and as such an early manifestation of what would become, according to new media scholar Lev Manovich, the 'symbolic form' of computer age information culture in the late twentieth century. ${ }^{7}$ That is why in the first paragraph the Bibliotheca, both in its paper and its numerical versions, is interpreted as a database according to the characteristics which Manovich considers distinctive for 'new media' (in The Language of New Media [200I], only recently confirmed as one of the 'very few books on new media worth reading'). ${ }^{8}$ This interpretation will provide the sightlines for the following historical paragraphs. It foregrounds the public 'narratives of value's which De Vreese and the successive keepers of his Bibliotheca attributed to the collection, throughout different periods and different contexts of information culture, scholarly organization and politics. By doing so, this article illustrates that phenomena similar to new forms in digital humanities can be traced back to even before 1995, and that digital humanities can be studied from a historical perspective, by taking into account continuities as much as discontinuities and promises for the future.

\section{A paper database between new and old media}

Willem De Vreese's Bibliotheca Neerlandica Manuscripta was innovative in three ways which Manovich in The Language of New Media calls distinctive for 'new media': its discrete representation of data, its multimedial character, and its random accessibility through search indexes. In this paragraph some of Manovich's insights in the functioning of 'new media' are applied to the Bibliotheca, in order to bring some new medial aspects of its history to the surface.

In fact, the Bibliotheca could have served Manovich well as an example in his study, where he chose to discuss cinema as the prehistory of 'new media'. Not only does cinema more or less fit the Bibliotheca chronologically, starting at the end of the nineteenth century, with the igros as a 'classical' decade which set its language and forms for a century to come. ${ }^{10}$ The Bibliotheca, as a scholarshipfocused piece of information technology, also fits Manovich's assertion that new media need not be studied as part of the fields of technology or economy, but as part of culture and the humanities. He describes cultural practices and patterns in new media in their relation to other manifestations of a broader 'information culture. ${ }^{\text {II }}$ He even explicitly parallels his record of the transformation of old media into new ones with Thomas Kuhn's study of scientific paradigms. ${ }^{12}$ The case of the Bibliotheca can be studied as a cultural history of informa- 
tion too, as a history not only of local productions of knowledge or as 'ways of knowing' (Pickstone), but also as a cultural history of information storage and communication.

Such a cultural-historical study of the Bibliotheca will also confirm Manovich's blurry distinction between 'modern media' and 'new media'. ${ }^{13}$ Manovich found modern cinema to be an early form of new media, because some of its features became associated with computerized culture forms later on. ${ }^{\mathrm{I}}$ Cinematic technology translates the continuities of everyday experience into a sequence of discrete elements, i.e., each frame of the film. Cinema also merged individual media into one multimedial object - in this respect being as 'new' as medieval illuminated manuscripts - while nineteenth-century cinematic machines already provided access to the discrete and multimedial representation of reality in nonlinear ways, thus making randomized access possible. All three features - discrete representation, multimedia, and random access - apply to the Bibliotheca on paper, too: it reduced the continuum of culture and reality to discrete elements, not only inevitable linguistic ones such as sentences, words and sounds, but also elements from the 'bibliographic code' of medieval texts ${ }^{15}$ - their authors, copyists, illuminations, bindings, and depositories. These bindings appeared in the collection in pictural form as well: the Bibliotheca contained a collection of facsimiles, samples of copyists' hands, photographs and rubbings of bindings. All these descriptions were searchable through different indexes on authors, titles, keywords, copyists, incipits, owners, themes, and motives of the stamps on the bindings. It is clear that the card files of the Bibliotheca share their randomly accessible, multimedial, and discrete characteristics with the 'new' forms of cinema and computers, and evidently more so when the Bibliotheca was digitized in the early I990s. Its data were no longer only discrete, but now also numerically represented, and hence suitable for automated handling. In short, a philological database can be considered as a partial form of new media, similar to Manovich's interpretation of cinema.

How can such an interpretation of an old paper database provide us with a meaningful account of its history? First, Manovich's opposition between the database and the narrative as cultural forms, in computerized culture as much as in the cases of cinema, the novel, and language in general, can be helpful. ${ }^{16}$ Since the Bibliotheca was conceived as a collection of paper card files and indexes and later on was turned into a 'new' database with logarithmic retrieval options, it had no narrative form apart from the search routes of librarians and individual philologists. Yet, its conception and its later use were closely related to powerful narratives, legitimizing the data project in different scholarly and political ways. Secondly, Manovich describes (following Benjamin and Virilio) the ongoing replacement of physical objects with interchangeable and mobile signs. ${ }^{17}$ This process is accompanied by efforts to create a reality effect, using virtual technologies 
in such a way that they become universal conventions, obscuring the process of replacement itself. Again, this process is manifest in the case of new media, but no less in the case of the Bibliotheca. De Vreese's scholarly teaching and gathering of objective evidence aimed exactly at such a replacement: in order to write a history of Netherlandish paleography, he wanted to have all paleographical data collected in one room. He himself would make several philological journeys throughout Europe during his lifetime, but only in order to confine his subsequent efforts to a simple consultation of the Bibliotheca. However, the Nachleben of his Bibliotheca proves that De Vreese's ambition of replacing visits to libraries and archives with his own descriptions had an epistemological sting to it. Along with the Bibliotheca's oppositional place between various narratives, this sting will prove to be a key issue in the history of the Bibliotheca Neerlandica Manuscripta.

\section{The database in national thought and philological epistemology (1895-1938)}

The following short history of the Bibliotheca Neerlandica Manuscripta is based on existing historical accounts, most of which were published by its keepers much later, all of them specialists in bibliography, codicology and paleography and as such the database's intended users. Invariably, they identify the Bibliotheca as a useful instrument in philological study and as the brainchild of De Vreese. They praise its author in the most romantic ways: the database was his 'life's work' (levenswerk), expressing his 'grandmastership' (grootmeesterschap), ${ }^{18}$ even proving the creator to be 'a man of genius' (een geniaal mensch). ${ }^{19}$ The Bibliotheca itself has been called 'a unique collection of material' (een unieke materiaalverzameling), 'a true gold mine' (een ware goudmijn), ${ }^{20}$ the merits of which become apparent when one takes into account the historical context: it was a documentation system which was relatively advanced in scope considering the period in which it was developed'. ${ }^{21}$ Jos Biemans, curator of Western manuscripts at Leiden University Library in 1987, stressed its importance for future scholarly developments: he concluded that De Vreese in fact has [... ] provided the study of Middle Dutch codicology with an entire new, modern foundation. ${ }^{22}$ In short, historical accounts of the Bibliotheca have hitherto searched for its historical significance in De Vreese's almost prophetical views on the future of academic disciplines.

It is, of course, a myth that De Vreese was able to foresee later developments in his discipline and in information culture; he only dealt with scholarly concerns of his own time and of previous decades. The historical significance of the Bibliotheca indeed has to be looked for in the long-term history of vernacular philology in the Low Countries. In his 1902 address to the Flemish Academy, De Vreese 
made clear that his database had to attain some of the goals that Netherlandish philology had been pursuing for decades, even centuries. He too wanted philological scholarship to have societal effects within a frame of national thought, and his database too had to meet the materialist epistemological requirements which had been extant in Netherlandish vernacular philology since the late sixteenth century.

It is particularly meaningful that De Vreese presented his plans at the Royal Flemish Academy of Language and Literature in Ghent. He had participated in its establishment a few years earlier, and would later on become its director. In his view - which he expressed more than once - the Academy not only had to facilitate the work of Netherlandish philology, but also improve the status of the Dutch language, literature and culture within the Belgian state. ${ }^{23}$ De Vreese indeed employed nationalistic frames to legitimize his own and his fellow members' study of old Netherlandish language and literature: the Academy had to be at the intersection of scholarly and social advancement of the Dutch language and its users. At the same time his contribution to the Academy attested his conviction that scholarship needed an infrastructure similar to that of learned societies. This ideal of nationalistic scholarship in learned societies was not new at all and not restricted to the Netherlands. The study of national literatures had always been practiced out of concern for the supposed singularity of local culture and by means of scholarly meetings and correspondence, public competitions and in closed libraries. ${ }^{24}$ That was - obviously - true for the nineteenth century, with well-known national philologists like Jan Frans Willems in Belgium and Willem Jonckbloet in the Netherlands, but also in the preceding centuries, as demonstrated by the Society of Dutch Literature in Leiden, established in 1766 , and the Royal Academy in Brussels, established in $1772 .{ }^{25}$ Before these, in the eighteenth and seventeenth centuries, individual scholars had defended the vernacular language and literature along with the Dutch Republic. One can think of Balthasar Huydecoper and Jan Wagenaar, but also of Hugo Grotius, and Petrus Scriverius and Janus Dousa at Leiden University. From this long-term perspective, De Vreese and his plans appear as the Belgian variant of a much older alliance of philological vernacular scholarship and national ambitions. Considering his plans to use the Bibliotheca for writing a history of scribal culture in the Low Countries, it becomes clear that the database not only contributed to an ideal scholarly training, but also had to support a nationalist narrative of history.

The persistent influence of earlier scholarly contexts is also clear in De Vreese's concerns about the epistemological looseness of his discipline. In fact, such concerns were the raison d'être of his Bibliotheca. Its 'desirability, yes the urgent necessity' emerged in De Vreese's opinion from the lack of a trustworthy factual basis. 
Literary histories had been written, according to him, on the arbitrary base of literary value. A Middle Dutch dictionary was being compiled, based on questionable text editions - although 'it is time for us, I believe', as he spoke to the Academy,

to bring across to ourselves that the vast majority of our text editions is no longer of use, because they do not give us what is in the manuscripts. Socalled critical editions, in which the so-called grammatical errors made by copyists are said to have been corrected, present the image of an imaginary language, just like those in which the author's original text is said to have been determined, often do not present more than an imaginary text. All of that is nothing but aesthetic dilettantism, totally unsuitable for linguistic research. ${ }^{26}$

Serious scholarship distinguished itself from 'aesthetic dilettantism' in its attachment to the original manuscript, which guaranteed the original form of literary works and old words. In contrast, the philological instruments of his own time, mostly in book form, did not even meet the minimal requirements of scholarship, because the data they provided did not correspond with the sources.

Such epistemological complaints were old. Original manuscripts, with material evidence of their age, had been the sole epistemological guarantee in Netherlandish philology for decades. This had been demonstrated by some cases of forged medieval texts, in particular the supposedly thirteenth-century chronicle of Count Dirk of Holland by Klaas Kolijn, which had deceived scholars during most of the eighteenth century and which was still mentioned in philological debates during the nineteenth century. ${ }^{27}$ Only one generation before De Vreese, the supposedly early medieval Frisian chronicle Oera Linda had made its appearance in the circles of Eelco Verwijs, one of his teachers in lexicography. ${ }^{28}$ In the case of Kolijn, the absence of an old manuscript meant the disclosure of the text as a forgery; in the case of Oera Linda the opposite was true: the fact that the old text showed up on parchment was puzzling. Both cases indicate how even before De Vreese's complaints, philological knowledge could rely only on an accessible old manuscript. This simple epistemological demand was the philological equivalent of the material proof that antiquarians had been mobilizing all over Europe against historical Pyrrhonism from the seventeenth century onwards. ${ }^{29}$ That is why in the early nineteenth century all of the scholarly societies started setting up collections of medieval manuscripts, and libraries with trustworthy, material evidence readily accessible to their members. That is also why scholarly text editions were made: they supposedly gave access to old manuscripts through print. Again, De Vreese's plan for the Bibliotheca, based on epistemological distrust, appears as 
an equivalent of earlier concerns about reliable access to old texts. In short, the Bibliotheca Neerlandica Manuscripta was a new stick to chase a quarreling twin from the philologist's study, the twin of accessibility and reliability of old textual material that would not leave. ${ }^{30}$

However, there was something new. De Vreese's Bibliotheca was not a collection of physical manuscripts themselves, like in the learned societies' libraries, nor of representations of only textual elements, like in previous scholarly editions. The Bibliotheca contained descriptions and facsimiles, and no material or textual objects, but mere data on such objects. It is in this way that the Bibliotheca indeed was a 'modern' database in Manovich's terms: it replaced objects with signs. The epistemological impact of this process did not remain unnoticed, since one of the later keepers of the Bibliotheca remembered that during De Vreese's life his "See my Bibliotheca Neerlandica Manuscripta" had the effect of a pronouncement. ${ }^{31}$ Did the appearance of a philological database without physical links to material evidence, indeed mean an epistemological shift away from the centuries-old materialistic epistemology, toward one in which virtual collections could serve as a base for knowledge as reliable as the original material? As every shift in history, this one too was not linear and uncontested, as the vicissitudes of the Bibliotheca after De Vreese illustrate.

\section{The database in Leiden, a scholarly metropolis (1939)}

In 1939, the Bibliotheca was sold by De Vreese's widow to the state of the Netherlands, which deposited it at the University Library in Leiden, to be taken care of by the curator of manuscripts and his assistants. The first one was Gerard Isaäc Lieftinck, appointed curator shortly after the acquisition of the Bibliotheca. Lieftinck recognized its value and shared some ideals with De Vreese, although he had seen that during the last years of his life De Vreese actually has become a solitary man, as if entrenched in his fort, his vast arsenal of data, from which he could always draw and from which he derived his great authority. ${ }^{32}$ After his death, the Bibliotheca revealed its 'weak side' (zwakke zijde). ${ }^{33}$ Browsing the card files, Lieftinck discovered that some of the descriptions were not written by De Vreese himself."There are also many records, especially tables of contents, which are not from De Vreese's own hand, maybe from students or from officials at the libraries in question'. It gave reason for concern: 'Because one does not know who drew them up and since some of them were corrected in later times by De Vreese himself, there is every reason not to trust these data too much. ${ }^{34}$ Lieftinck, like other philologists for centuries, did not think the evident benefits of easily accessible philological data to outweigh their reliability. 
Lieftinck started to select and correct descriptions in the Bibliotheca and he substantially enlarged its collections of photographs and copies. These were no minor interventions, but - so he assured his colleagues at a congress for librarians - history has proven that as a curator at Leiden University Library, he was in the right place to do so. 'Owing to the rich book collection of the Maatschappij der Nederlandsche Letterkunde, which the [University] Library holds within its walls and the Academy's venerable tradition as a cradle of Netherlandish philology, Leiden actually has been a middle point already from way back'. And it was the right place too for a reordered, corrected, and expanded Bibliotheca, according to his own ambitions: 'Such a valuable, internationally orientated apparatus as the [Bibliotheca Neerlandica Manuscripta] might turn Leiden definitively into a metropolis of Middle Dutch linguistics. ${ }^{35}$ At Leiden, the Bibliotheca could make Netherlandish philology an international field of study. Lieftinck thus transformed De Vreese's equally scholarly and national aspirations for the Bibliotheca at the Flemish Academy into an image of Leiden as a scholarly metropolis. This image did justice to both the city's century-old philological fame the Dutch nation was proud of, and the international orientation of academic scholarship in his own time. Like other historians and intellectuals did in these decades, Lieftinck formulated a variant of the nationalist narrative to incorporate international cultural horizons. ${ }^{36}$ According to him, the Bibliotheca would become truly metropolitan when it was accessible to scholars from the Netherlands and the rest of the world, and when its data were reliable.

\section{An automated database (I99I-1995)}

From 199I onwards, the Bibliotheca was digitized at Leiden University Library. It was in particular André Bouwman who spoke in public about the plans and proceedings at conferences for medievalists. Whereas Lieftinck focused on the shortcomings of the Bibliotheca's reliability, Bouwman's discontentment concerned in the first place its accessibility. He depicted the database as a collection of 'tens of thousands of index cards' (tienduizenden fiches), 'put away in card-index boxes' (weggestoken in kaartenbakken), the consultation of which was only possible in Leiden 'and is rather complicated' (en is tamelijk ingewikkeld). ${ }^{37}$ And most of all: the 'separate card-indexes left cross-references a feature to be desired' ${ }^{38}$ Bouwman gave the impression that the database not only was hard to access itself, but that its modular structure in fact even complicated knowledge about the physical manuscripts - thus negating the creator's intentions. But Bouwman saw new possibilities in digital times: 'It became increasingly clear that only the computer would be able to bring relief, if at least some conditions are fulfilled', ${ }^{39}$ 
These conditions exactly met the shortcomings of the paper database Bouwman himself had diagnosed: it would have to be user friendly, and accessible through electronic data traffic routes' (via elektronische dataverkeerswegen toegankelijk).40 It would have to present 'better sorted information' (beter geordende informatie), ${ }^{41}$ using standardized authority records and descriptions, and the photographs and rubbings too would have to be digitized. At the same time, an electronic system for data input would have to be implemented. In I99I, the semi-governmental Netherlands Organization for Scientific Research (NWO) acknowledged the Bibliotheca as a 'Center of Expertise', making it possible to be subsidized for this digitizing project. The work was carried out in collaboration with PICA, a cataloguing system of Dutch scientific libraries. It became accessible in 1995 as part of the Leiden University Library's online catalogue (OPAC), which could be consulted through a Dutch library network, through a Telnet connection, or on the 'World Wide Web [... ] using a WWW navigator." ${ }^{42}$ Access to the database started at a screen with seventeen search keys, such as 'HSG', 'DAT', 'HTI', 'AUT', or 'MAT', or by starting a search action 'from any screen, by filling in ' $z$ [search key] [search term]', if necessary truncated'. ${ }^{43}$ All such codes could be consulted in 'the extended helptexts. ${ }^{44}$ In short, Bouwman stressed in many ways the increased accessibility of philological data in the Bibliotheca, now called e-BNM.

Besides that, Bouwman was optimistic about the changes made to the database structure. The Bibliotheca would still consist of modular descriptions of medieval manuscripts with references to literature, made accessible through search indexes, but they were once more reordered, on persons, corporations, and keywords. New information was added too, based on published library catalogues. The new indexes also figured uniform descriptions, thus putting and end to the arbitrariness in the paper database ('the key words of course [have to be] edited absolutely uniformly' [de trefwoorden [moeten] natuurlijk volstrekt uniform geredigeerd worden]), ${ }^{45}$ and they were completed with authority records and families consisting of cross-linking descriptions. Bouwman was clear about their importance: they were not just new, elaborated entries to the descriptions. The numerical uniform descriptions made the Bibliotheca electronic; the cross-references made the authority records 'the nervous system of the electronic database' ${ }^{46}$ and each of them even a 'crystallization point of knowledge' (kristallisatiepunt van kennis). ${ }^{47}$ Automated searches and links between numerical data on philological objects gave the Bibliotheca a new function: it was no longer a didactic tool for reading old texts, nor the instrument for scholars in a learned society, nor a record of the nation's forgotten scribal culture, it now renewed scholarship itself. Bouwman replaced De Vreese's and Lieftinck's narrative of national scholarship with a technical discourse on knowledge production (with by times anthropomorphic 
metaphors). For him, the digitized Bibliotheca was in the first place exactly that: a new scholarly instrument, 'an electronic database [which] may contribute to the development of new strategies in scholarship. ${ }^{48}$

Was there in Bouwman's computer optimism any trace left of the centuriesold materialist epistemology and the framing nationalist narrative? At least in his public statements, Bouwman remained remarkably silent on both subjects. The Netherlands and Leiden appear to be nothing more than the accidental setting for scholarly innovations, not to be mentioned explicitly, not even in Lieftinck's metropolitan way. For the Bibliotheca's reliability he did not refer to the traditional guarantees offered by physical manuscripts; he did not present the digitization as a new reditus ad fontibus. He seemed to consider its reliability guaranteed by the academic institutions involved. Data for input came from published library catalogues - notwithstanding Lieftinck's doubts; the work done by collaborators of the University Library was unquestioned; access to the database was guaranteed by the OPAC network; and most of all, the Bibliotheca as a whole was certified by NWO. One could say that the Bibliotheca became not only a 'new' database in the sense of a discrete and multimedial, cross-referring, automatedly and randomly accessible set of data, but also in the sense that its reliability was attested by institutions of present-day science production.

\section{Conclusion}

What does this single history of a philological database from the Low Countries, interpreted as a discrete, multimedial and randomly accessible form of data organization, demonstrate? In the first place that the Bibliotheca was more than a simple instrument to hand down philological knowledge to a next generation. From its creation by De Vreese in Ghent onwards, it materialized some of his scientistic and nationalistic aspirations, just as the Flemish Academy did. The Bibliotheca continued to materialize varying aspirations at Leiden University Library. The database thus had varying relations to successive institutional contexts and powerful narratives, which gave the database meaning and legitimized it. That was initially the case on a documentary level: the Bibliotheca had to serve De Vreese in writing a cultural history of the Low Countries in the Middle Ages based on the developments in scribal culture, in other words a historical narrative based on paleographical data. It was also the case on a political level, since the Bibliotheca had to be integrated into the Flemish Academy, established to realize equally scholarly and national progress through the study of old Netherlandish language and literature. As such, the initial organizational infrastructure for the Bibliotheca included it in the historical and political nar- 
rative of the Flemish Movement. Yet, although the database had important relations to such narratives, it remained a genre of informational culture of its own, and because of that, it survived independently from the foundational narratives and was given a place in other wide views, such as scientific internationalism in the interwar era and optimism about the computer age at the close of the twentieth century.

Apart from a changing decor of narratives, the history of this database makes clear that the old tension between the epistemological ideals of accessible and reliable data remained high in both modern and digitized philological information cultures. De Vreese aspired to replace the physical consultation of libraries and archives all over the world with a search action in his database. Doubts about the reliability of the data arose, however. Such doubts had proven to be of great influence in the earlier history of Netherlandish philology, and had resulted in materialistic requirements for scholarly certitude. Nevertheless, the database's material base seemed to have become undiscussed in the age of its digitization at modern scientific institutions. The history of the Bibliotheca thus makes clear that fundamental aspects of a database in both its paper and digitized form, such as its epistemological basis or its connection to political narratives, can survive several decades and remain unchanged or can be forgotten along the way, when they are silenced permanently.

\section{Notes}

I A word of thanks to Paul Bijl for his help at the very outset of this study.

2 'Het is natuurlijk de bedoeling niet te beweren, dat er [...] geen Neerlandici zijn, die Middelnederlandsche handschriften kunnen lezen. Er zijn er genoeg die daarin doorkneed zijn, we weten het allen. Maar hunne kennis is iets persoonlijks, dat met hen staat of valt, dat met hen te gronde gaat, zoodat het eerste vereischte om van een gevestigde wetenschap te kunnen spreken, ontbreekt, $\mathrm{nl}$. dat een zekere hoeveelheid kennis aan een volgend geslacht wordt overgeleverd, om daarop voort te bouwen' (Willem de Vreese, Over eene Bibliotheca Neerlandica Manuscripta [Ghent: Siffer, I903], 209).

3 On the Bibliotheca in general, see Petrus Josephus Henricus Vermeeren, De Bibliotheca Neerlandica Manuscripta van Willem De Vreese (Utrecht: De Lanteern, I953), and R. van Dijk, "Titus Brandsma en de bestemming van de Bibliotheca Neerlandica Manuscripta van Willem De Vreese', Ons Geestelijk Erf 72-3 (I998), 273-292 and 73-I (I999), 40-72.

4 L. Daston, 'Objectivity and the Escape from Perspective', Social Studies of Science 22.4 (I992), 597-6I 8; Daston, this volume (Chap. I.I); Tollebeek, this volume (Chap. 3.I).

5 Baertschi, this volume (Chap. 4.4.).

6 '[O]nbruikbaar, omdat ze vervaardigd zijn met procédés die niet onafhankelijk zijn van de mindere of meerdere vaardigheid van den teekenaar en van diens verbeelding, noch van het doel, door de uitgevers beoogd' (De Vreese, Over eene Bibliotheca, 208). 
7 L. Manovich, The Language of New Media (Cambridge, MA/London: The MIT Press, 200I), 219, after Erwin Panofsky.

8 A.R. Galloway, 'What Is New Media? Ten Years after the Language of New Media', Criticism 53.3 (20II), 377-384, esp. 377 .

9 As used by K.L. Rumbold, 'From Access to Creativity: Shakespeare Institutions, New Media, and the Language of Cultural Value', Shakespeare Quarterly 61.3 (2010), 313-336. Manovich, The Language of New Media, 7-8.

I I Ibid., I0-I 3 .

I2 Ibid., 8 .

I3 Ibid., 28 .

I I Ibid., 50-5I.

I5 After Jerome McGann: G. Bornstein, Material Modernism: The Politics of the Page (Cambridge: Cambridge University Press, 200I), 7.

I6 Manovich, The Language of New Media, 225-233.

I7 Ibid., I73-I74.

I8 J. Biemans, 'Over de Bibliotheca Neerlandica Manuscripta van Willem De Vreese. Drie bijdragen aan de geschiedenis van de medio-neerlandistiek en de Middelnederlandse handschriftenkunde', Tijdschrift voor Nederlandse Taal- en Letterkunde I05 (I989), 249280, esp. 249 and passim; J. Biemans, 'De Bibliotheca Neerlandica Manuscripta: reorganisatie en voortzetting van een documentatie-apparaat', in A.J. Geurts (ed.), Ontsluiting van middeleeuwse handschriften in de Nederlanden. Verslag van studiedagen gehouden te Nijmegen, 30-31 maart 1984 (Nijmegen: Alfa, 1987), 47-67, esp. 53.

I9 G. Lieftinck, De Bibliotheca Neerlandica Manuscripta in de Universiteits-Bibliotheek te Leiden. Voordracht, gehouden op het Bibliotheek-Congres te Rotterdam, 7 Juni 1939 (S.1.: s.n., I939), 3 .

20 Biemans, 'Over de Bibliotheca', 25 I; Lieftinck, Voordracht, 5.

2 I G. Warnar and T. Bouwman, "The Bibliotheca Neerlandica Manuscripta as an Electronic Database: Achievements and Expectations', in R. Schlusemann, J.M.M. Hermans, and M. Hoogvliet (eds.), Sources for the History of Medieval Books and Libraries (Groningen, I999), 339-352, esp. 339.

22 'In feite heeft hij de studie van de Middelnederlandse handschriftenkunde van een geheel nieuw, modern fundament voorzien' (Biemans, 'De Bibliotheca', 53; identical in Biemans, 'Over de Bibliotheca', 25I).

23 W. Rombauts, De Koninklijke Vlaamse Academie voor Taal-en Letterkunde (1886-1914). Haar geschiedenis en haar rol in het Vlaamse cultuurleven, VIe reeks I Io, 2 vols. (Ghent: Secretariaat van de Koninklijke Academie voor Nederlandse Taal- en Letterkunde, I979I98I).

24 W. Mijnhardt, Tot heil van 't menschdom. Culturele genootschappen in Nederland, 1750-1815. Nieuwe Nederlandse bijdragen tot de geschiedenis der geneeskunde en der natuurwetenschappen (Amsterdam: Rodopi, I988); and C. Singeling, Gezellige schrijvers. Aspecten van letterkundige genootschappelijkheid in Nederland, 1750-1800 (Amsterdam: Rodopi, I99I).

25 F. Kosmann, Opkomst en voortgang van de Maatschappij der Nederlandse Letterkunde te Leiden. Geschiedenis van een initiatief (Leiden: Brill, I966); and R. Honings, Geleerdheids zetel, Hollands roem! Het literaire leven in Leiden 1760-1860 (Leiden: Primavera Pers, 20 I I); T. Verschaffel, De hoed en de hond. Geschiedschrijving in de Zuidelijke Nederlanden 17151794 (Hilversum: Verloren, I998).

26 ' $[\mathrm{H}]$ et wordt tijd, geloof $\mathrm{ik}$, dat wij er ons van doordringen dat de overgroote meerderheid onzer tekstuitgaven niet langer bruikbaar is, omdat ze ons niet geven wat in de hand- 
schriften staat. Zoogenaamd critische uitgaven, waarin de zoogenaamde fouten tegen de grammatica door afschrijvers gemaakt, heeten verbeterd te zijn, geven een beeld van een denkbeeldige taal, evenals die, waarin de oorspronkelijke tekst van een schrijver heet vastgesteld te zijn, dikwijls niet veel meer geven dan een denkbeeldigen tekst. Dat alles is niet veel anders dan aesthetische liefhebberij, voor het taalkundig onderzoek totaal ongeschikt' (De Vreese, Over eene Bibliotheca, 2 I8).

27 J. Burgers, 'De constructie van het verleden. De Hollandse visie op de Middeleeuwen van de zestiende tot de achttiende eeuw en de centrale plaats daarin van de Rijmkroniek van Melis Stoke', in Joep Leerssen and Marita Mathijsen (eds.), Oerteksten. Nationalisme, edities en canonvorming (Amsterdam: Instituut voor Cultuur en Geschiedenis, 2002), 59-68; R. de Bonth, 'Een oud man of een jonge bedrieger. Balthazar Huydecoper en de rijmkroniek van Klaas Kolijn'. Madoc 7.I (I993), 36-46; M. van Lieburg, 'Reinier De Graaf (I674I7I7) en de rijmkroniek van Klaas Kolijn', Documentatieblad 37 (I997), 4-25.

28 G. Jensma, De gemaskerde God. François HaverSchmidt en het Oera Linda-boek (Zutphen: Walburg Pers, 2004).

29 A. Momigliani, 'Ancient History and the Antiquarian', in Studies in Historiography (London: Weidenfeld and Nicolson, I966), I-39; A. Grafton, Bring Out Your Dead: The Past as Revelation (Cambridge, MA/London: Harvard University Press, 200I).

More in J. Rock, Papieren monumenten. Filologie en nationalisme in de Lage Landen, 15911863 (Nijmegen: Vantilt [in production]).

3I 'Het "Zie mijne Bibliotheca Neerlandica Manuscripta” werkte als een machtspreuk' [Lieftinck, Voordracht, 5].

32 ' $[\mathrm{T}]$ och een eenzame is geworden, als verschanst in zijn fort, zijn enorm arsenaal van gegevens, waaruit hij steeds kon putten en waaraan hij zijn groot gezag ontleende' [ibid., 4].

33 G.I. Lieftinck, 'De Bibliotheca Neerlandica Manuscripta', Het boek 26.4 (I940/I942), 365368, esp. 366.

34 'Er zijn ook vele aanteekeningen, vooral inhoudsopgaven, die niet zijn van de hand van De Vreese zelf, misschien van studenten of van ambtenaren van de betreffende bibliotheken. [...] Omdat men niet weet wie ze opstelden en daar sommige ervan in later tijd door De Vreese zelf gecorrigeerd werden, is er alle reden om die gegevens niet al te zeer te vertrouwen' (ibid., 366).

'Door de rijke boekerij van de Maatschappij der Nederlandsche Letterkunde, die de Bibliotheek binnen haar muren herbergt en de eerwaardige traditie van de Academie als bakermat van de Nederlandsche philologie, is Leiden toch al van oudsher een middelpunt. [...] Een zoo rijk, international georiënteerd apparaat als de B.N.M. zou Leiden definitief kunnen maken tot metropool der Middelnederlandsche taalwetenschap' (ibid., 365).

J. Tollebeek, 'The Hyphen of National Culture: The Paradox of National Distinctiveness in Belgium and the Netherlands, I860-I91 8', European Review I 8.2 (2010), 207-225.

37 A. Bouwman, 'De Bibliotheca Neerlandica Manuscripta: van kaartenbak tot database', in J.M.M. Hermans and K. van der Hoek (eds.), Boeken in de late Middeleeuwen: verslag van de Groningse Codicologendagen 1992 (Groningen, I994), 30I-3 I2, esp. 30 I.

Warnar/Bouwman. 'The Bibliotheca Neerlandica Manuscripta', 340.

39 'Het werd steeds duidelijker dat alleen de computer uitkomst zou kunnen bieden, indien althans aan enkele voorwaarden wordt voldaan' (Bouwman, 'Van kaartenbak tot database', 30I).

40 Ibid., 30I.

4 I Ibid., 30I.

42 Warnar/Bouwman, 'The Bibliotheca Neerlandica Manuscripta', 352. 
43 Ibid., 344.

44 Ibid., 345.

45 Bouwman, 'Van kaartenbak tot database', 309.

46 Warnar/Bouwman, 'The Bibliotheca Neerlandica Manuscripta', 343.

47 Bouwman, 'Van kaartenbak tot database', 307.

48 Warnar/Bouwman, 'The Bibliotheca Neerlandica Manuscripta', 350. 



\title{
9.4 Clio's Talkative Daughter Goes Digital \\ The Interplay between Technology and Oral \\ Accounts as Historical Data
}

\author{
Stef Scagliola and Franciska de Jong
}

\section{Introduction}

The introduction of the recording device at the beginning of the twentieth century not only marked a major transition in communication technology, but also paved the way for a revaluation of the oral account in Western historiography. With the rise of early civilizations and the introduction of writing tools it had lost its central role in the transfer of meaning and identity. Centuries later, the spread of literacy and the invention of the printing press stimulated the consolidation and appreciation of historical sources in textual form. Given the weight of this strong focus on text, the invention of a device that could capture and reproduce the human voice directly can be truly regarded as revolutionary. Most important, in the context of historical sources, is that accounts could now be stored and preserved in their original form: as sound. This development laid the ground for the practice that is referred to as 'oral history'. Another series of transitions, decisive for the accessibility and contextualization of oral narratives, set in with the 'digital turn' at the end of the twentieth century. The purpose of this paper is to offer an overview of these transitions by showing how the interplay between technology and social-cultural change influenced the creation and appreciation of oral history interviews as sources of knowledge. What can be observed is a shift in appreciation of what is regarded as the most truthful and characteristic representation of the oral account: the original sound recording or the transcribed interview.

Although the term 'oral history' has various meanings, most scholars agree that its purpose is to create spoken accounts on personal history in an interview setting. A distinction can be made between collecting interviews to answer a specific research question, and documenting the experiences of a person as an archival effort with future listeners in mind. ${ }^{\mathrm{I}}$ The first approach, with strong roots in Europe, bears a strong resemblance to academic practices in the social sciences, 
and draws on a long tradition of investigative journalism. The second places oral history in the archival realm, and is strongly rooted in a tradition of nation-building, in which the state initiates projects that stimulate public involvement in the creation of shared cultural heritage. Researchers in the United States were the pioneers in using the method of oral history for this purpose. ${ }^{2}$

The paper starts off with a description of the change in status of oral sources in the late nineteenth century and the parallel technological innovation. The next stage presented is the early evolution of the practice of interviewing in relation to bearing witness to crises and conflict in the first half of the twentieth century. Then the emergence of the postwar social movement is described and its central role in developing a pluralist perspective on history by giving voice to minority groups through collecting life stories and making them public. The following section discusses the impact of the digital turn and the introduction of the Internet on historical culture in general and on oral history in particular. The final section deals with the potential of information and communications technology (ICT) for the accessibility and analysis of digital oral history.

\section{Text defeats spoken word}

Contrary to what one would expect, oral sources were regarded as quite reliable until the professionalization of history as an academic discipline was heralded by the nineteenth-century Rankean school of historicism. Ranke and his disciples confined the search for historical sources almost exclusively to written documents that were found in archives produced by the state and other institutions, ${ }^{3}$ and that were attributed the desired level of objectivity. They thereby rejected oral sources as a valuable asset of the historiographical paradigm, disregarding that, of course, many textual sources are the product of a sequence of witnessing, discussing, and passing on historical evidence to future generations. ${ }^{4}$

The retrospective oral accounts of sieges and battles documented by Herodotus and Thucydides, the founding fathers of history, are a clear illustration of the oral origin of many written sources. At the same time the opposing positions of these Greek pioneers show how timeless the debate is on how to weigh the quality and validity of oral accounts. Herodotus would include myths, rumors and tales in his documentation on the Persian Wars and relied on oral accounts of events that had happened long before his time. He would sometimes offer different versions of an account and ask the reader to choose. Thucydides, in contrast, did not regard himself as a 'storyteller', and based his accounts almost entirely on facts that he himself had witnessed or been told from firsthand witnesses and recorded: 
And with regard to my factual reporting of the events of the war I have made it a principle not to write down the first story that came my way, and not even to be guided by my own general impressions; either I was present myself at the events which I have described or else I heard them from eyewitnesses whose reports I have checked with as much thoroughness as possible. (History I, 22)

Thucydides acknowledged the importance of 'pathos' in a narrative as a technique to appeal to an audience. Nevertheless he chose to strive for truth and accuracy, for this would yield history having a long-lasting impact.

The evolving culture of documenting a phenomenon in all its details for the sake of a reliable historical record led to the development of history as an academic discipline with a distinct method of its own in the course of the nineteenth century. ${ }^{6}$ Moving from the pub and the marketplace to the lecture hall, a new class consciousness emerged that made 'ordinary people' less appealing as a historical source. ${ }^{7}$ Combined with the cumulative effect of three centuries of printing, and the central role attributed to historians in the process of nation-building, this profoundly changed the character of the profession. Historians were now trained to analyze what were perceived to be the building stones of academic history: printed and written documents. This came down to using sources that had been generated in the slipstream of the lives and policies of those who were the most influential and powerful. ${ }^{8}$

\section{Capturing the voice}

At the beginning of the twentieth century developments in communication technology and transport increased the pace of interpersonal communication. As the telephone offered the opportunity to discuss issues that would previously have been communicated through letters, the social function of documents changed gradually in the course of the twentieth century. As new generations of historians made it clear that archives contained only a biased selection of hand-picked written sources intended to legitimize or advocate a pursued policy, history based exclusively on the meticulous study of official state documents and diplomatic sources lost some of its standing. ${ }^{9}$

The first scholars to embrace the potential of recording technology were not historians but ethnologists. Already in the second half of the nineteenth century the interest in recovering (and sometimes inventing') cultural traditions such as ceremonies, customs and folktales, had shifted from local amateur historians to professionals. The focus on cultural identity expressed in objects, dresses, lan- 
guage and music makes it easy to understand their interest in capturing sound and images and their pioneering role in modern oral history. ${ }^{\text {10 }}$ The very first recording device, the phonograph, invented by Thomas A. Edison in 1877 , would be taken along as equipment during research expeditions not only by ethnologists and linguists, but also by medical doctors, missionaries and colonial officials. Although expensive until the I920s, these recorders were simple to use and could be easily transported, not being dependent on electrical power. ${ }^{\text {II }}$ It is noteworthy that its use for documenting history was envisioned by Edison himself. In a long list of possible applications he also lists: 'The 'Family Record' - a registry of sayings, reminiscences, etc., by members of a family in their own voices, and of the last words of dying persons. ${ }^{\text {I2 }}$ The conditions for actually applying the phonograph by introducing an affordable version and improving its performance, were created by Chichester Bell and Charles Sumner Tainter, with the introduction of wax cylinders. ${ }^{13}$

As always happens when new technology is introduced, there were reservations. Some writers even feared that the phonograph would be the beginning of the end of writing. An illustration hereof is a cartoon by Albert Robida that portrays Edison as a devil handing over a phonograph to Gutenberg. ${ }^{14}$ The Italian historian Benedetto Croce looked upon it as a folly:

I am convinced that the realism of the phonograph, this cunning attempt to physically grasp the past, will not contribute to the increase of historical knowledge, just as attempts to evoke the atmosphere and impression of a past life do not enrich our knowledge; that very life is dead as a doornail and should be understood, not evoked. ${ }^{15}$

In Croce's view the peculiarities of the voice would distract and entertain, rather than increase the understanding of history. When listening to sound recordings or watching newsreels with speeches of Mussolini or Hitler today, we may be inclined to think that there is a kernel of truth in Croce's observation. Many will find it hard to believe that these demagogues could hold such sway over the masses with their theatrical gestures and shouting voices. However, with only the texts of these speeches, it would be even more difficult to understand their performative power and appeal to the masses. Still, it would take decades for many historians to appreciate that the original sound of spoken words reflects the human experience better than words transmitted in textual format.

The next step in technological innovation in recording human speech was the wire recorder invented by the Danish engineer Valdemar Poulsen in 1877. It would take until the Interbellum before its more successful successor, the tape recorder, was widely introduced. Both devices involve the use of a magnetizable medium that can capture sound waves and turn them into electrical signalss ${ }^{16}$ 


\section{Personal experience with war and crisis}

The dissemination of the practice of documenting and recording interviews should be seen in the light of the emergence of the social sciences as instruments for social engineering in the two World Wars. In this period bureaucratic structures came into existence meant to manage large numbers of conscripts that were sent to the military fronts in other parts of the world. Military personnel were separated from family members and spouses, and on their return had to reintegrate into society together with large numbers of displaced persons. This pressed the social sciences to offer solutions. Besides, the first massive involvement in the circumstances of war by citizens who could write letters to their loved ones led to a culture of giving testimony about extraordinary experiences. While paper was still the main carrier of such testimonies, many memories remained in the minds of the people to be captured only decades later. ${ }^{17}$

An example of a folklorist for whom the context of war created unique opportunities was the German teacher Wilhelm Doegen. Having been granted access to all German prisoner-of-war camps during the First World War, he began to systematically record the languages, music and texts of prisoners from other countries with the intent to create a collection for a future 'Museum of the Sound' ${ }^{\prime 8}$ In the United States the massive draft in 1917-1918 called for an adequate selection mechanism and interviewing became a method for psychological testing. This was repeated during World War II when more than half a million American soldiers were interviewed to document their mental and emotional lives. ${ }^{19}$

The connection between the social sciences and the Armed Forces was paralleled by that between history and soldiers' experiences at the battle fronts in the Second World War. Anticipating the Army's official history of the war, the US government initiated an extensive program that, in each theater of war, brought professional historians together to collect sources. One of these was the drafted journalist S.L.A. Marshall, who introduced the practice of gathering troops shortly after their engagement in battle in order to conduct group interviews. The purposes served by this practice were multifold: providing additional testimonies to military unit journals to improve efficacy of operations, giving participants the opportunity to relate their experiences in battle, and creating a basis for popular monographs to explain the war to wounded soldiers and new recruits. ${ }^{20}$

One of the first war-related projects to record extended interviews from the perspective of victims was initiated right after the end of the war in 1946 by the psychologist David P. Boder, of Latvian Jewish origin. Trained in Germany and Russia and emigrated to the US in 1932, Boder was determined to document the impact of extreme suffering on personality. Using a state-of-the-art wire recorder he traveled to displacement camps all over Europe, interviewing 130 
persons in nine languages. At his return he not only set out transcribing the interviews but also submitted them to analysis, and commented on terms and narratives, with the intent of developing a systematic coding system for the various kinds of trauma. The transfer of knowledge on traumatic experiences to the broader American audience came in 1948, when he published a book, hoping that it would be helpful in advocating on behalf of the refugees for immigration to America. ${ }^{21}$

These pioneers in the archiving of oral sources illustrate the interest in capturing the thoughts and actions of people in extreme circumstances such as war. The focus was primarily on using technology for the purpose of documentation and the derivation of knowledge from the sources as a basis for publishing books. The potential and motivation to convey the material to large audiences was limited.

\section{Pioneers in archives and academia}

The pioneering role of the United States in the establishment of oral history as an archival practice is connected to a policy of social engineering that aimed at forging unity in a multiethnic society in times of crisis ${ }^{22}$ Similar approaches can be found in other Anglo-Saxon immigration societies such as Canada, Australia and New Zealand.

It was Franklin Delano Roosevelt who introduced the Federal Writers' Project as part of the New Deal to support writers and journalists during the Great Depression. Among the many who set out across the country, equipped with pencils and manual typewriters, to compile local and oral histories, were famous names such as John Steinbeck, Saul Bellow and Studs Terkel. Since the interviews were conducted at a time before tape recorders were widely available, writers had to rely on their exhaustive notes and memory to capture each history. ${ }^{23}$ The project led to the collection of more than 10,000 first person narratives, including accounts by the last generation of slaves. ${ }^{24}$ Although much effort was put in creating this archive, only decades later would the full potential of this rich collection be exploited. ${ }^{25}$

An initiative covering the lives of the famous and powerful was the establishment of the Columbia University Oral History Research Office in 1948 by the political scientist Allen Nevins. Nevins took the initiative out of concern for missing important information from the top level of society, as the introduction of the telephone had led to a dramatic decrease in written correspondence among prominent figures in the political, cultural and economic realm. ${ }^{26}$ With his team, he set out to document life histories making use of first-generation wire recorders. It is striking that they treated the material as text, not as sound. In fact, the 
officially catalogued date of the interview was that of publishing the transcript, not the one on which the interview had been conducted. Moreover, just as is usual with manuscripts before publication, the transcripts would be returned to the interviewees to check whether they contained mistakes or potential embarrassing or sensitive references. These were then taken out. The most radical intervention was the destruction of the original tapes, sometimes out of concern that the interviewees would dislike the way they sounded. ${ }^{27}$ This tradition of arranging power to 'speak' for posterity was further institutionalized with the introduction of the 'Presidential Libraries' program in 1961 by the National Archives, that included interviews with the higher ranks of a political administration.

In other parts of the world, and in Europe in particular, the practice of oral history emerged from a long tradition of traveling investigations that would, at the end of the nineteenth century, evolve into academic social research. ${ }^{28}$ For practitioners in this field, the focus was not on the elite, but on those who were poorly represented in written archives. When 'oral history' was introduced as a term for collecting oral accounts of past experiences, for this particular group it was just a new name for something that they had always been doing. What was new and coincided with the postwar political tide of activism, was putting their efforts at the service of history 'from below'. Another fundamental difference with the American archival approach was the social historian's exclusive relationship with the interviewees. While archival projects separated the creation of the interview from the end use, social historians argued that only those who had created the interviews should be responsible for their use and interpretation. This monopoly excluded other researchers from access to valuable sources, leaving the enormous potential for reuse unexploited. In the I960s a heated debate evolved around this issue. During the founding meeting of the US Oral History Association in 1967 the archivist Philip C. Brooks stressed the advantages of the archival approach: 'The person who is collecting a stock of evidence for other researchers to use is almost by definition to be [sic] doing a more objective job than the one who is writing his own book, especially one that has a case to prove. ${ }^{29}$ This stance does not take into consideration that the archival interview cannot anticipate the variety of research questions of future listeners. Of course, for the study of topics pertaining to the recent past, accounts collected in a setting with an exclusive relationship between researcher and interviewee that offer the possibility to probe for certain details, may be preferred over interviews conducted by someone else with a less specific goal or topic list, that have been deposited in an archive. Yet this advantage of direct contact becomes irrelevant with the unavoidable disappearance of generations of eyewitnesses. Oral accounts of the lives of the last American slaves and of the daily routine in the trenches of World War I, can now only be found in archives. 


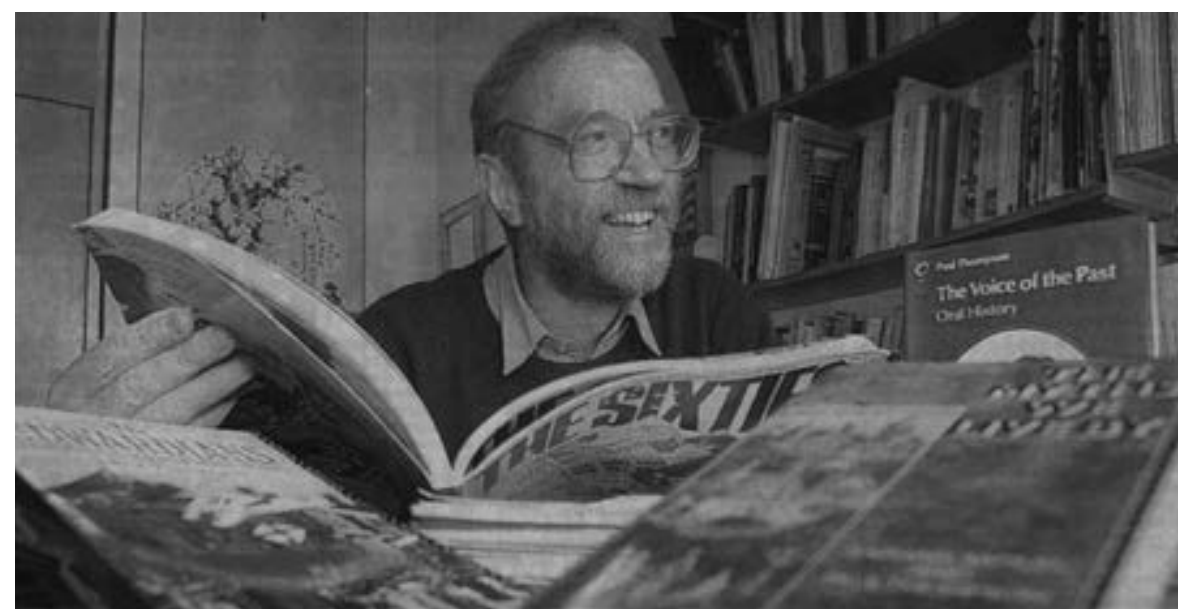

Fig. 28: The British historian Paul Thompson among his books

The scholar to be accredited the pioneering role of facilitating the reuse of life stories is the social historian Paul Thompson, who led the first national oral history project in Great Britain in the early I970s. He collected 537 interviews about family and work with so-called'Edwardians', people living during the reign of King Edward VII between I9OI and I9IO, and opened them up to other scholars. It was a decisive step that paved the path for the archival tradition in Great Britain, which would later be picked up by the Imperial War Museum and the British Library [Fig. 28]..3

Despite the differences between archival and research-generated oral narratives, in both approaches a traditional appreciation of the sources persisted. Out of defense against criticism from positivist historians, oral historians tended to regard their interviews as mere data from which the 'objective' historian extracted facts that could be tested for their accuracy, verifiability and representativeness. ${ }^{31}$ This attempt to gain credibility did not convince the American historian Barbara Tuchman, who lamented that the tape recorder is a monster with the appetite of the tapeworm that facilitates an artificial survival of trivia of appalling proportions. ${ }^{32}$ Her comments seemed to foresee what according to some would be brought about by the digital turn twenty years later.

\section{The memory boom, the cultural turn, and the digital turn}

At the end of the twentieth century a paradigm shift in oral history occurred that was shaped by the interplay of three powerful social, intellectual and technological forces: the popularization and democratization of historical culture, 
the postpositivist appraisal of sources as construction of meaning, and the digital revolution that set in the late 1990 s. $^{33}$

The first manifested itself in the proliferation of the production of personal memory and the interest raised in it. ${ }^{34}$ The combination of affluence, higher education, individualism and mass media fostered an historical culture that was no longer the exclusive domain of professional historians. This not only led to less visible hierarchies of authority but created a strong demand for personalized history, turning identity into a commodity that can be consumed by anyone in leisure time. ${ }^{35}$ The economic component of this new demand created new job opportunities for academically trained historians, but at the same time problematized their professional ethics. This process of democratization could draw on the firmly grounded position of 'history from below' that oral history had already established in the I970s and I980s. ${ }^{36}$

The second change that influenced the practice of oral history was the transformation from the search for information in the narratives into an appraisal of the narratives as constructions of meaning. Instead of objective information on the past they were now considered to be a type of data that merely offered an interpretation of the past conveyed through the agency of memory and language. Subjectivity and memory became key concepts in this new approach and the 'objective observer' was now expected to reflect on his role and influence in the interaction between interviewer and interviewee. This transformation was part of a much larger shift in paradigm, often referred to as the 'linguistic turn' or 'cultural turn', and had the effect that scholarly work in oral history moved from social history to cultural studies. ${ }^{37}$

With this new orientation the speaker's subjectivity, his or her biases, failing memory and distortions, were no longer problematic, but clues to how people make sense of experiences of the past in the present. In the words of a leading theorist on oral history Alessandro Portelli: 'Oral sources tell us not just what people did, but what they wanted to do, what they believed they were doing, and what they now think they did. ${ }^{38}$ Portelli argued for more listening and less reading. In his view the practice of transcription denied the reality of oral sources, by not considering the value of tone, volume, range of sound and rhythm of speech. ${ }^{39}$ The contemplative nature of this line of research reinforced the already existing multidisciplinary potential of oral history connecting it to disciplines such as biographical and literary studies, linguistics, communication and narrative studies, folklore studies and interdisciplinary work exploring the relationship between memory, narrative and personal identity* ${ }^{40}$

The effects of the cultural turn and considerations of the nature and impact of narratives were duplicated with the expansion of digital video recording as an option in the late I990s. In combination with the disseminative power of the digital turn, this led to a third major shift in the practice of oral history. ${ }^{41}$ 
Digitization and the World Wide Web made unlimited reproduction and distribution of oral history transcripts and sound files possible, bringing technological and ethical issues regarding copyright, accessibility and control of data the center of the debates on oral history. ${ }^{42}$ Direct online access to the original spoken narrative became possible, and by adding subtitles, access to videotaped oral history can even be offered across the borders of language. The most compelling illustration of what multilingual video oral history has to offer is the Shoah Visual Archive with video narratives of 52,000 survivors of the Holocaust collected in fifty-six countries in thirty-two languages [Fig. 29 below].43

Although the advantages in terms of massive involvement in online oral history are evident, the wide range of online digital encounters with historical accounts and the diversity of personal narratives to be found online calls for some scholarly guidance in the form of digital source criticism. The boundaries between community engagement, entertainment and carefully designed oral history projects that yield valuable sources for academics are not always clear. Moreover, when an appealing narrative that represents the view of an underprivileged group, although historically inaccurate, gains strong public support, the perspective of historians can lose authority. A critical stance should also be taken with regard to the dominance of state-funded oral history projects on the Web. Contextualization of digital oral sources is therefore vital to understand the current battle between memory and history.

\section{Immediacy and hidden layers}

As indicated, novel means for online access to spoken content have entered the scene, and the emerging techniques for the automated unraveling of the multiple layers encrypted in narratives are likely to enhance the options for exploring the wealth of data that is available in digital format. They come along with other innovations in the (digital) workflow that is now at the disposal of humanist scholars for handling their data. This new encounter of the humanities with technology is nurtured and closely monitored by industrial parties and ICT researchers alike, as they all have something to gain from mastering the complexity inherent to humanities data and practices. ${ }^{44}$ The promise for the oral history community is the development of sophisticated software that can help to search, annotate, analyze, share and present oral histories in novel ways with no limits in terms of space, scale and time.

A number of pioneering initiatives for using the Internet as a stage for presenting oral history were carried out in the past decade. These projects yielded recommendations for how to apply cutting-edge technology to online interview repositories at all conceivable levels: across online collections, within a collection, within a specific interview, or within a specific fragment. 


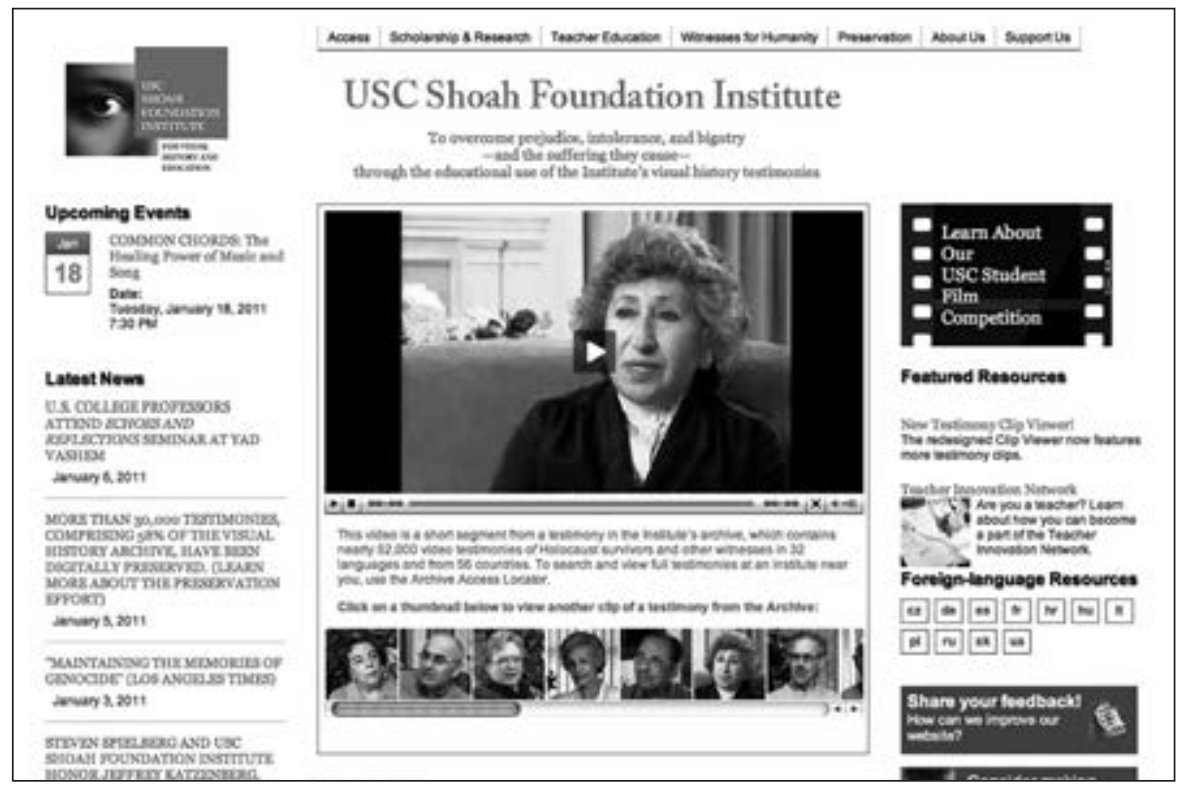

Fig. 29: Home page of the Shoah Foundation Visual Archive

According to Michael Frisch, the paradigm emerging in the application of search technology to digitized oral history, is characterized by 'a postdocumentary sensibility': away from text and sensitive to other dimensions of human expression than language, including the nonverbal and affective layers of speech (visual and nonvisual) and gestures, or in other words: the 'full' story. The nonverbal dimensions are also crucial for the interaction design of online platforms giving access to spoken word content. Audio content may be faceted (not just speech, but also sighs, laughter, hesitations, corrections, etc. ), and video narratives are inherently multifaceted, but user interfaces should also provide visual anchors, such as timelines, related image content and well-designed frameworks for the presentation of metadata and time-coded pointers to search results. Ideally, life stories can be played together with any relevant geographical and chronological context, and without dependency on information elsewhere in cyberspace. Figure 30 (see next page) contains an illustration of the timeline visualization for retrieved fragments in the access portal for a collection of thirty-eight interviews with survivors from Camp Buchenwald. ${ }^{45}$

In addition to tools for search and navigation, analytical tools for the automatic discovery of patterns in oral history data are gradually becoming available for scholarly use. The successful and rapid adoption of such tools in humanities disciplines such as ethnography, literature studies and media studies, calls for the exploration of their usability for oral history. The so-called 'mining' of speech 


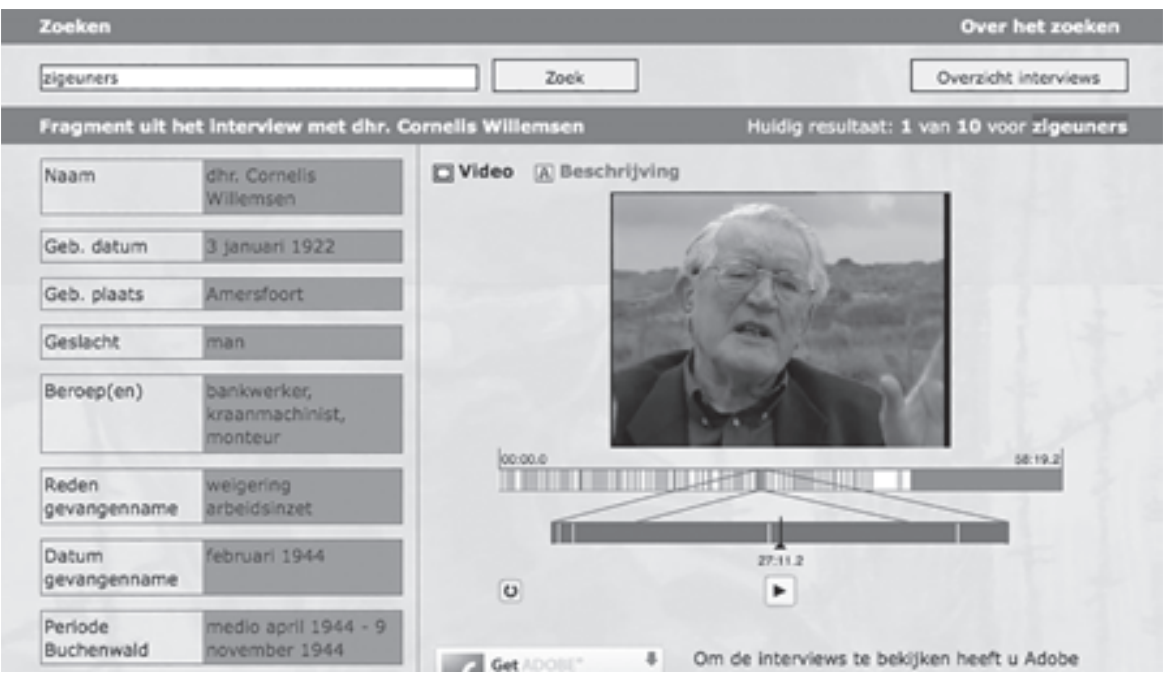

Fig. 30: Timeline visualization of retrieved fragments in the access portal for a collection of thirtyeight interviews with Dutch survivors from Camp Buchenwald, Buchenwald, NIOD Instituut voor Oorlogs-, Holocaust- en Genocidestudies, http://www.buchenwald.nl

data is mostly approached as a special instance of text mining (also known as text analytics), as for spoken word content the textual annotations layers, including metadata and interview transcripts, can be used. ${ }^{46}$ Tools supporting content sharing are specifically relevant from the perspective of archives that deploy some form of crowdsourcing and that invite the general public or dedicated communities of amateurs to help enriching archival content.

How to benefit from the innovations described and illustrated above lies in the hands of scholars who are willing to embrace e-humanities and the challenges of engaging in collaboration with software engineers. ${ }^{47}$ Of course, the innovations have encountered skeptical responses, and in the field of oral history with its rich tradition of debates on how to appreciate new technology, one may expect that there will be recurring calls for rethinking the risks and virtues attributed to the digital humanities. Some of these attributions are expressed through concepts such as 'distant reading' (as opposed to 'close reading').48

The support for search and navigation in speech collections and the tools for pattern detection in spoken audio are likely to reach maturity in the coming years. For oral history this would lead to the paradoxical scenario that transcriptions are fully exploited, while at the same time the potential is created for direct access to oral sources without engaging in transcript reading. This is once again an illustration of the ever shifting balance in the appreciation of the spoken word and transcripts that characterizes the field of oral history. 


\section{Notes}

A. Freund, 'Oral History as Process-Generated Data', Historical Social Research 34.I (2009), 22-48.

R. Grele, 'Oral History as Evidence', in T.L. Charlton, L.E. Myers, and R. Sharpless (eds.), History of Oral History: Foundations and Methodology (Altamira, 2007), 34.

Peter Burke has observed that Leopold von Ranke was less orthodox than his followers; just as Marx was not a Marxist, Ranke was not a Rankean ('Overture the New History, Its Past and Its Future' in Burke (ed.), New Perspectives on Historical Writing [Cambridge, I99I], 3).

Paul Thompson, The Voice of the Past (Oxford: Oxford University Press, 2009), 35.

J. Morris, 'Inimitable Charlatan or the "Father of History"? A Reexamination of Herodotus', URL: http://www.yale.edu/heyzeus/winter2002/herodotus.pdf. Cf.: 'Herodotus as an Ancient Journalist: Reimagining Antiquity's Historians as Journalists', online paper by J. Saltzman, Annenberg School for Communication and Journalism, University of Southern California, Los Angeles, CA, URL: http://ijpc.uscannenberg.org/journal/index.php/ijpcjournal/article/viewFile/22/29. The difference between the two Greek historians is accentuated strongly in order to illustrate that the discussion about the validity of oral sources has a long tradition. According to some classicists a closer reading of their texts makes clear that there are passages in the work of either that do not fit well with this ideal-typical differentiation.

Thompson, The Voice, 34.

Ibid., $5 \mathrm{I}$.

Ibid., 56 .

Just a few examples of new approaches to history are the French Annales movement, with its focus on social structures and mentalities, the interest in micro-histories and egodocuments expressed by historians like Carlo Ginzburg and Leroy Ladurie, and anthropologists like Eric Wolf, who tried to rewrite world history from a subaltern perspective in his magnum opus Europe and the People without History (Berkeley, I982).

Thompson, The Voice, 54.

C. Weber, 'University Collections as Custodians of Oral Heritage: Some Examples from Germany', URL: http://publicus.culture.hu-berlin.de/umac/2004/weber.doc.

2 T.A. Edison, North American Review, June I878, Library of Congress, Motion Picture, Broadcasting and Recorded Sound Division; URL: http://memory.loc.gov/ammem/ edhtml/edcyldr.html.

I 3 Edward B. Moogk and Paul Théberge, 'Recorded Sound Technology and Its Impact', The Canadian Encyclopedia, URL: http://www.thecanadianencyclopedia.com/en/article/ recorded-sound-technology-and-its-impact-emc/; U. Idzikowska, De fonograaf in de Nederlandstalige literatuur rond de eeuwwisseling; een motievenstudie (MA thesis, Ghent University, 2009/20Io), URL: http://lib.ugent.be/fulltxt/RUGor/oor/457/999/RUGoIo0I457999_20II_000I_AC.pdf.

4 Original source unknown. The cartoon is included in J. Weverbergh and I. Hobana, De triomf van de droom (Antwerp-Baarn, I99I), 35, cf. Idzikowska, De fonograaf, I 6.

Benedetto Croce, 'Sentendo parlare un vecchio napoletano del Quattrocento' (orig. I9I3), in Storie e leggende napoletane (Bari: Laterza, I948), I2 I-I22. Cited in Alessandro Casellato, 'Le guerre non finiscono mai. Fonti orali, storiografia, culture di Guerra', in Associazione di Storia Orale, Fonte edite. URL: http://www.aisoitalia.it/wp-content/uploads/ Storia-orale-storiografia-e-cuture-di-guerra.pdf; website: Associazione di Storia Orale 
Italiana: http://www.aisoitalia.it/2008/I2/28/alessandro-casellato/ (translation by Stef Scagliola).

I6 URL: http://www.britannica.com/EBchecked/topic/357264/magnetic-recording.

I7 Casellato, 'Le guerre non finiscono mai'.

I8 S. Ziegler, 'Die akustischen Sammlungen. Historische Tondokumente im PhonogrammArchiv und im Lautarchiv', in Horst Bredekamp and Jochen Brüning (eds.), Theater der Natur und Kunst/Theatrum naturae et artis. Wunderkammern des Wissens (Berlin, 200o).

I9 A. Fontana and J. Frey,'The Art of Science', in N. Denzin, The Handbook of Qualitative Research (Sage, I 994), URL: http://jan.ucc.nau.edu/ pms/cj355/readings/fontana\%26frey. pdf.

20 R. Sharpless, 'The History of Oral History', in T.L. Charlton, L.E. Myers, R. Sharpless (eds.), History of Oral History: Foundations and Methodology (Lanham, MD: AltaMira Press, 2007), I I-I2, See also: S. Everett, Oral History Techniques and Procedures (Washington, DC: Center of Military History, United States Army, I992).

2 I Voices of the Holocaust, Paul V. Galvin Library, Illinois Institute of Technology, URL: http://voices.iit.edu/david_boder.

22 J. Hirsch, Portrait of America: A Cultural History of the Federal Writers' Project (Wilmington: University of North Carolina Press, 2003), I 47-I 48.

23 URL: http://suiteror.com/a/the-federal-writers-project-a-new-deal-initiative-a240803/. The fact that recording devices were only used for a very small part of the project and that the eventual sources were the notes of the interviewers and not the original wordings of the interviewees, does not mean that the accounts should be regarded as a form of journalism. They were created as sources with clear instructions to stay as close as possible to the language of the speakers.

24 Sharpless, 'The History of Oral History', г о. The Oregon Encyclopedia, URL: http://www. oregonencyclopedia.org/entry/view/federal_writers_project_in_oregon/.

25 Hirsch, Portrait of America.

26 Thompson, The Voice, 65.

27 R. Grele, 'Oral History as Evidence', in Sharpless, History of Oral History, 36-37.

28 Grele, 'Oral History', 38.

29 E.I. Dixon and J.V. Mink (eds.), Oral History at Arrowhead: The Proceedings of the First National Colloquim on Oral History (Los Angeles: Oral History Association, I967); Grele, 'Oral History', 39.

30 Thompson, The Edwardians: The Remaking of British Society (Philadelphia: Taylor and Francis, 2005). URL: http://www.esds.ac.uk/qualidata/online/data/edwardians/introduction.asp.

3 I A. Thomson, M. Frisch, and A. Hamilton, 'The Memory and History Debates: Some International Perspectives', Oral History 2.22 (Autumn I994), 33-35.

32 B. Tuchman, 'Distinguishing the Significant from the Insignificant', in D.K. Dunaway and W.K. Baum (eds.), Oral History: An Interdisciplinary Anthology (London/New Delhi, I994), 94-98; Sharpless, 'The History'.

33 R. Perks and A. Thomson, The Oral History Reader (New York, 2006), I.

34 J. Winter,'The Generation of Memory: Reflections on the Memory Boom in Contemporary Historical Studies', Bulletin of the German Historical Institute (Spring 2000), URL: http://www.ghi-dc.org/publications/ghipubs/bu/o27/b27winterframe.html.

35 A.S. Milward, 'Bad Memories', Times Literary Supplement, I4 April 2000, 8.

36 Sharpless, 'History of Oral History', I4.

37 Grele, 'Oral History', 53-54. 
38 A. Portelli, 'What Makes Oral History Different?', in R. Perks and A. Thomson (eds.), The Oral History Reader (New York, 2006), 36.

39 Ibid., 33.

40 V. Yow, Recording Oral History (Altamira, 2005).

4 I Sharpless, 'History of Oral History', 24.

42 Ibid., 27.

43 URL: http://sfi.usc.edu/aboutus.

44 F.M.G. de Jong, 'NLP and the Humanities: The Revival of an Old Liaison', in Proceedings of the 12th Conferencce of the European Chapter of the ACL (Athens, 2008), I0-I5.

45 See URL: http://www.buchenwald.nl/.

46 F.M.G. de Jong, D.W. Oard, W.F.L. Heeren, and R.J.F. Ordelman, 'Access to Recorded Interviews: A Research Agenda', ACM Journal on Computing and Cultural Heritage I.I (2008), 3:1-3:27.

47 F.M.G. de Jong, R.J.F. Ordelman and S. Scagliola,'Audio-Visual Collections and the User Needs of Scholars in the Humanities: A Case for Co-Development', in Proceedings of the 2nd Conference on Supporting Digital Humanities (SDH 2011) (Copenhagen: Centre for Language Technology, 20II).

48 F. Moretti, Graphs, Maps and Trees: Abstract Models for Literary Theory (London: Verso, 2005). 



\title{
9.5 The Humanities' New Methods A Reconnaissance Mission
}

\author{
JAN-WILlem RomeIjN
}

\section{Introduction}

In comparison to the natural and social sciences, the humanities have received comparatively little attention from the analytic philosophy of science. This discipline has been concerned primarily with the sciences narrowly construed. In particular confirmation theory, the systematic study of theory evaluation, shows remarkable lacunas when it comes to the methodology of the humanities. But developments in the humanities and in conformation theory invite us to reconsider this situation. First, due to the fast uptake of empirical and computational methods in several humanities disciplines, the humanities are presently very much in flux, and much more amenable to methodological elucidation. Second, confirmation theory has over the past decade significantly broadened its scope, and made contact with developments in mathematics and computer science. It is in a good position to take on new challenges.

The main idea of this paper is that confirmation theory can help to elucidate the introduction of new methods in humanities scholarship. In the context of this paper, it will not be possible to work out the confirmation-theoretic models in any level of detail. Instead I will discuss an example of the kind of challenges that arise where humanities scholarship is confronted with empirical and computational methods. After some general considerations on the case study itself, I will sketch how we might engage with these challenges by means of confirmation theory. One goal with this is to expand the reach of confirmation theory, thereby contributing to the philosophy of science. But more importantly, I think there is a need within the humanities for a theory about the status and impact of empirical and computational results. I hope this paper can illustrate this need and suggest a possible direction for exploring the issues. 


\section{New methods and missing methodology}

The last two decades have seen the fast growth of a number of new branches in humanities scholarship, centered on the application of empirical and computational methods. We find these new methods in a wide array of humanities' disciplines. They range from linguistics and cognitive musicology, in which researchers simulate language production and musical hearing on a computer, to archeology, museology, philosophy, and the study of religion, in which empirical studies from psychology, ethnography, and sociology are brought to bear on more traditional ways of theorizing. These developments present us with new challenges and opportunities, and invite us to rethink the humanities as a discipline. How do the new methods relate to traditional humanities scholarship? What is the epistemic status of the empirical and computational findings and how do they bear on the theories and models that scholars in the humanities are entertaining? And where should we position the humanities in relation to the social and natural sciences?

The working hypothesis of this paper is that some answers to these questions can be found in the philosophy of science. A quick glance at history suggests that methodological analysis plays an important role in the definition and formation of scientific disciplines. Bacon's Novum Organon set the stage for an experimental science of nature. Popper's Logik der Forschung and Fisher's Statistical Methods for Research Workers have provided the social sciences with a backbone, and even with a criterion of demarcation. For a research area that is undergoing fast changes, like the humanities, a philosophical theory on evidence and the evaluation of theories is likely to be of great value. More specifically, an improved understanding of how the humanities interact with empirical and computational methods will help the humanities to incorporate those methods on their own terms and integrate them with more traditional interpretative approaches.

In view of the pressures on academic research, humanities scholars may well be tempted to resort to methods from sciences whose societal or economic value is more easily established. The loss of scholarly approaches presents a real possibility, and potentially a risk. Moreover, it is not exactly clear what the humanities are supposed to hold on to if they resist this temptation. The disciplines that make up the humanities involve a wide array of methods, approaches, and intellectual sources. While these disciplines recognizably belong to the humanities, it is hard to say exactly what links them. They seem much less unified and homogeneous than the social or the natural sciences. ${ }^{\mathrm{I}}$ In an attempt to remedy this, Bod calls for renewed historical and philosophical attention for the humanities, which he terms the 'forgotten sciences.' ${ }^{2}$ He proposes to counteract the disunity by conceptualizing the humanities as concerned with pattern recognition: patterns in 
music, in discourse, in language, in art, and in history. By itself, this is a very welcome attempt to push the agenda of the humanities. However, for the purposes and concerns of this paper, Bod's proposal is less attractive. Insofar as Bod gives a correct description of the humanities, empirical and computational methods can be integrated relatively easily. The introduction of empirical and computational methods is more likely to lead to tensions where humanities research does not fall under the header of pattern recognition. This paper is focused explicitly on cases in which tensions do arise, and addresses the question of why they arise and how they can be resolved.

Unfortunately, in the current analytical approach to philosophy of science, attention for humanities methodology is scarce. As said, this may be partly due to the orientation of analytic methodologists to the sciences. ${ }^{3}$ In contrast, much of the research in the humanities is carried out by means of scholarly methods: close reading of texts, analysis of concepts, and interpretation of practices. In analytic philosophy of science, insofar as it is concerned with research methods and the justification they lend to scientific theories, these scholarly methods have hardly been targeted. In addition, the absence of an analytic and empiricist methodology for the humanities derives from the eclectic nature of humanities research. The empirical, computational, and other methods used in the humanities are often not home-grown. Rather, they have been taken over from neighboring fields of research, and hence accommodated to the specifics of their domain of application on a case-by-case basis.

More specifically, insofar as researchers from humanities disciplines employ quantitative empirical methods, they mostly rely on the methodology of the social sciences. The study of religion, for example, is routinely informed by psychological and ethnographic research. But the statistical and experimental tools employed for such interdisciplinary work derive by and large from the social sciences. This means that some presuppositions of the methods will be taken over into humanities research, for lack of an alternative methodological backbone. And this may have adverse consequences. For instance, in the social sciences there is little room for the exploratory nature of theorizing - hypotheses are fixed in advance and tested against the collected data - while in the humanities theory formation is deliberately done in tandem with data collection. In the same vein, available methods from the social sciences do not accommodate the possible incompatibility of theoretical concepts with the empiricist conception of measurement and fact. In short, the presuppositions of empirical research methods borrowed from the social sciences sit badly with particular aspects of humanities scholarship.

Of course, the present paper cannot fill these lacunas. The aim is rather to illustrate some methodological challenges with a particular case study, and to 
offer a perspective on a resolution. The case study concerns the confrontation of empirical methods with more traditional scholarly methods from archeology and museology. More precisely, it features a project of the Drents Museum (Assen, The Netherlands), where visitor data is currently being collected and analyzed, with the aim of improving the match between visitor and collection and the management of the museum's collection.

\section{Case study: The Drents Museum}

The Drents Museum has recently obtained an infrastructure to trace visitors in real time, using radio-frequency identification (RFID) technology and an annotated database of its collection. The movements and interests of visitors can be recorded using a simple chip embedded in the museum ticket. ${ }^{4}$ The museum now faces the challenge to provide the conceptual and statistical tools to fully employ this infrastructure, and to bring the resulting information system to bear on the traditional conceptions of collection and visitor. The eventual aim is twofold: to enhance the visitor experience by real-time feedback based on revealed interests, and to improve the management of the collection and the exhibitions.

In its traditional form, a museum displays objects from a heritage collection so that visitors can learn about them. But in the past century this idea had to be modified extensively. Rather than exhibiting things, museums engaged in an 'economy of experience' and underwent so-called 'McDonaldization. 5 Accordingly, museums saw the need to cater to visitors who vary strongly in their intentions, motivations, and attitudes when interacting with heritage collections. Moreover, where the old mode of information transfer is linear and unidirectional - think of a book - the Internet introduces an entirely new mode of operation for visitors. The roles of museum and visitor converge ${ }^{6}$; rather than following a given story line, visitors are predisposed to browse over a network of links, constructing their own narrative as they go along.

These shifts in the conceptions of museum and visitor present major challenges to museum management, which have only partially been met. Curators have learned to develop exhibitions with dramatic timing, latching onto people's interests and natural attention span. Moreover, museums attempt to accommodate the diversity in the interests, motivations, and attitudes of their audience by the use of audio guides and other technological means. However, the information provided in that way is hardly adapted to the nature of the museum visitor, as revealed by her behavior during the visit. Moreover, personalized interaction with the collection typically remains confined to the touchscreen of a PDA, focusing visitors' attention to a handheld device rather than the physical en- 
vironment. And lastly, in all of this the curator remains the sole source for the available story lines.

Ideally, technology and heritage studies can work together to translate the experience of browsing the Web to the individual's physical interaction with cultural heritage, leading to an entirely new conception of viewing and managing heritage collections. The eventual aim is an adaptive information system that presents visitors with selections of derivatives (short texts, films, photos) in conjunction to the objects that hold their attention, and that provides personalized suggestions on how to continue the museum visit. Suggestions and selections can be made in real time, determined by earlier onscreen choices among objects and derivatives, as well as by measurements of the physical movements of visitors. As an example, when seeing a excavated pot, the visitor who has previously looked at stone tools may be pointed to a film on prehistoric cooking and receive a suggestion to see weaponry next, while a visitor who just looked at stone figurines is offered a text on the ornamental styles of pots and be invited to view jewelry from the same period.

Importantly, this is not just a technological challenge. It requires substantive theoretical input from museology and heritage studies. The system yields a wealth of data on visitor behavior. Correctly analyzed and interpreted, these data provide invaluable information to the museum management, e.g., the time visitors spent at different items in the exhibition, the type of additional information that they take interest in, the overall timing of the museum visits, and so on. With this information, the museum can inform key decisions on exhibition management. Moreover, by recording the patterns of choices and interests of the visitors, the information system can enrich the annotated database with semantic structure: robust patterns in visitor behavior will suggest new perspectives on objects in the collection. For instance, if many people whose revealed interest is paintings also look at certain prehistoric items, this may lead to a reconceptualization of these items in aesthetic terms, and their inclusion in a suggested itinerary for art lovers.

In terms of the case study, we can now revisit the challenge outlined in the foregoing. How can we integrate the computational and empirical results with an understanding of the collection based on museology and heritage studies? In the Drents Museum project, the risk is that the information system will be developed independently of the scholarly study of the collection. As an illustration of the larger aims referred to above, the following will zoom in on the task of determining how empirical findings on visitor behavior might square with theoretical ideas about heritage management. 


\section{Exploring the relation between visitor data and heritage studies}

Below we consider the relation between visitor data and museological theory from the point of view of confirmation theory. Of course, this relation is manysided, and in fact impossible to capture in a single confirmation-theoretic model. In this section I first explore a number of perspectives on the relation between visitor data and heritage studies in the Drents Museum project. The main goal with this is to convey the many-sidedness of this relation, and thereby to enrich our understanding of the analysis provided further down.

Let us say that the museum establishes some kind of information or knowledge transfer from collection to visitor. Three influential philosophical viewpoints on knowledge then come to mind: it is interactive, embodied, and dynamic. More precisely, knowledge is a construction emerging from the interaction of a subject or a group with its environment, rather than a neutral representation of that environment. ${ }^{7}$ Second, the nature of knowledge is essentially connected to the physical nature of the interaction between knowing subject and object, or in short, cognition is embodied. And third, knowledge is characterized by dynamic, and not by static qualities. The nature of knowledge is given not by fixed foundations, but by rules about revision in the light of evidence. All these ideas about the nature of knowledge provide a particular perspective on the relation between visitors and cultural heritage, which reflects back on the relation between visitor data and heritage studies.

If those ideas about knowledge seem a bit far-fetched, notice that the infrastructure at the Drents Museum establishes an embodied and dynamic interaction between the museum's collection and the visitors. Consider the interactive museum guide. The traditional structure of knowledge is hierarchical and linear, leading to a conception of knowledge transfer that is unidirectional from source to receiver. But at the Drents Museum the visitor will eventually be able construct her own stories from the collection, by physically browsing it. In the interactive museum guide we can therefore identify the contours of both constructivism and embodied cognition. The former emphasizes the role of the receiver in the constitution of knowledge, while the latter views knowledge as the result of physical interactions with an environment, as opposed to passive recordings thereof. Finally, the idea that knowledge is essentially dynamic is also made concrete. The fact that patterns of visitor may suggest new perspectives on items in the collection makes concrete that the nature of knowledge depends on its dynamics, in this case its interactions with museum visitors, rather than its static foundations in archeological findings and source material.

Among these perspectives, I believe that the constructivist aspects merit special attention. One reason for this is that the constructive nature of the knowledge 
contained in a heritage collection connects naturally to methodological ideas that stem from community-based archeology. Although not universally embraced, many archeologists and historians have started to involve the wider community in their research agenda. ${ }^{9}$ Interaction with the people that have cultural ties to the research topics may in fact help to shape research questions, identify preconceptions, and improve the interpretation of results. ${ }^{\text {Io }}$ In the context of museums, involvement of local communities in archeological research comes down to giving museum visitors, as receivers of archeological research results, a say in the design of exhibitions and in the information they obtain. Indeed, the project at the Drents Museum may stimulate an approach to heritage management that directly involves the general public. ${ }^{\text {II }}$

As a second reason to focus on constructivist ideas, the information system currently installed at the Drents Museum presents unparalleled research opportunities in the area of social epistemology. Within social epistemology the use of computational techniques has seen a sharp increase in the last decade. But the application of these trends in social epistemology to themes from social constructivism has not been properly undertaken. The museum presents a wonderful opportunity to see the process of 'knowledge construction', happening when visitors collectively interact with the collection in the museum, at work. The information system at the museum allows us to follow this process of knowledge construction experimentally, and thereby provides a quantitative, empirical and computational perspective on philosophical ideas of constructivism (e.g., the actor-network theory of Bruno Latour). The Drents Museum offers a rich experimental environment for it.

This constructivist perspective presents interesting avenues for further research. However, in what follows we will first and foremost investigate certain confirmation-theoretic aspects of the relation between data and theory in the museum project or, more precisely, the evidential bearing of visitor data on the scholarly study of the museum collection. To keep matters simple, we will by and large ignore the idea that knowledge about the collection is partly constructed by the interaction of visitors with the collection. This will only feature briefly at the end of the next section.

\section{Fuzzy evidence and incompatible conceptual schemes}

We focus on two aspects of the relation between visitor data and museological theory: the phenomenon of incompatible conceptual schemes and the phenomenon that empirical data may hold fuzzy evidential relations to theory. Before providing a sketch on how confirmation theory might accommodate those aspects, it will be insightful to show their broad relevance to humanities methodology and make 
them more concrete in the case study. At the end of this section I will briefly return to how these aspects relate to a focus on constructivist ideas.

The phenomenon of incompatible schemes can be encountered in any humanities discipline that harbors multiple vocabularies. Consider, for example, the difficult relation between archeological findings as physical objects and as artifacts that served a purpose in prehistoric society and culture. ${ }^{12}$ Establishing this relation requires us to confront the empirical archeological facts, written in a modern and empiricist vocabulary, with ideas from anthropology and cultural theory, written in a language determined by the culture under investigation. Similar confrontations of theoretical frameworks can also be found in the study of religion. Findings from the psychology and the sociology of religion are typically cast in the empirical vocabulary that matches the ontology of quantitative social science, while the content of those findings pertains to experiences and events that are normally recorded in a wholly different vocabulary, e.g., of magic or religion. ${ }^{\mathrm{I}}$

With respect to fuzzy evidence, the key observation is that in the humanities there is often only a weak confirmatory relation between empirical findings and theory. Partly this is because the empirical facts are still amenable to a variety of interpretations, each associated with their own confirmatory value for the empirical facts at issue, and partly this is because the theories may themselves be subject to fuzziness in content, owing to the fact that the theories have not been spelled out in full detail or operate with incompatible conceptual schemes. To date, there is no comprehensive understanding of empirical confirmation in settings where evidence is fuzzy in these ways.

The claim here is not that the themes of incompatible concepts and fuzzy evidence exhaust the problem domain of a confirmation theory for the humanities. However, these themes address genuine theoretical problems that apply widely across the meeting ground of new methods and humanities scholarship. Moreover, they seem particularly relevant for disciplines in the humanities. The confirmatory practice of the natural and social sciences is comparatively straightforward, often consisting of data collection and hypothesis testing against a fixed background of theory and terminology. The humanities, by contrast, employ a wider variety of confirmatory relations, which are often set against an imprecise and contested theoretical background. Conceptual change is more frequent in the humanities than in other disciplines. It is high time that these characteristics of the humanities are brought to the attention of the analytic philosophy of science.

With this more general motivation in place, consider how fuzzy evidence and incompatible schemes show up in the aforementioned museum project, in which we match a museum inventory to empirical facts on typical visitor profiles. The theme of incompatible concepts is immediately recognizable. A direct challenge for museums is to link patterns in visitor data, for instance, expressed in the 
time spent in the vicinity of objects belonging to various categories like paintings, documentation, and archeological findings, to an understanding of the collection, which is typically structured according to different terms: historical periods, cultural significance, origin, owner, and so on. The introduction of new labels and terms in the analysis of visitor data is highly problematic: How do we adapt the analyses in response to, effectively, refinements and alterations of the possible visitor patterns? This concrete problem touches on technical issues, ${ }^{14}$ but also on deep conceptual issues with a wide appeal in epistemology and philosophy of science, concerning language-relativity and theoretical continuity under revisions of conceptual frameworks.

Finally, consider the phenomenon of fuzzy evidence in the museum project. Formal epistemology is already acquainted with the idea that empirical fact does not always relate neatly to the theories that may be supported or falsified by it. A large body of literature researches epistemic update rules in which the empirical facts cannot be described in the straightforward observational terms, e.g., as in Jeffrey updating. In such update rules, the empirical facts are instead described by specific probabilistic constraints that do allow expression in the terms associated with the theory. But the museum project seems to give rise to fuzziness of a different nature. While the visitor data is itself is perfectly clear, its impact on theory is not. Often the theories, which might concern particular cultural or aesthetic relations among items in the collection, will only have a vague empirical content. How do we bring evidence from visitors, whose behavior strings items in the collection together, to bear on these theories? Extant confirmation theory is quiet on this point.

Recall that I deemed the constructivist perspective particularly salient in the project of the Drents Museum. We can now return, albeit only briefly, to constructivism and relate it to the two aspects just outlined. It will be clear that a constructivist mindset means that we cannot preselect a vocabulary as primitive or preferred when it comes to, e.g., an item from a heritage collection. This vocabulary genuinely depends on the person observing the item, in this case the visitor. To integrate all the different visitor experiences in a single data structure and analysis, we will need to make the vocabularies of different visitor types and curators meet. And this is what confirmation-theoretic models of incompatible schemes may help to achieve. Similarly, we might use visitor data for evaluating a claim about the collection. Simultaneously the visitors impact on the way in which the collection is being conceived. And this might in turn affect the content of theoretical claims about it. To accommodate such looping effects, ${ }^{15}$ the confirmatory relations between visitor data and theory has to allow for some degree of fuzziness. 


\section{Some first steps in confirmation theory}

Confirmation theory, a subdiscipline of the philosophy of science, concerns the support that empirical and other evidence provides for scientific hypotheses. The focus lies on logical and mathematical models of scientific inference. Generally speaking, the inferences start in empirical fact and result in general statements, or else predictions on future observations. In other words, the inferences run from data to some form of theory, or else from data to observations that are still to come. Confirmation-theoretic systems of inference have been the subject of academic study for almost a century now, with seminal contributions from Carnap, Reichenbach, Hintikka, Levi, Jeffrey, Skyrms, and numerous more recent authors.

In the last two decades, philosophers of science have become increasingly aware of the fact that scientists use all sorts of nonempirical considerations when choosing between theories: causal structure, simplicity, coherence, novelty, and so on. In response, they have developed a large array of primarily probabilistic models to explicate and clarify the role of nonempirical, or theoretical, considerations. Present-day confirmation theory consists of some lively debates on how to model coherence, variety of evidence, ${ }^{16}$ explanatory force, ${ }^{17}$ on how to detect and exploit causal structure ${ }^{18}$ or analogy, ${ }^{19}$ on how to weigh simplicity against predictive performance when comparing models, ${ }^{20}$ and so on.

One of the messages of this paper is that we can break new and fertile ground for these developments in confirmation by focusing on new methods in humanities scholarship. Applications to humanities scholarship will involve major changes in confirmation theory, requiring us to rethink some of the hard-wired assumptions of current confirmation-theoretic systems. But the potential benefit and impact of improving confirmation theory is enormous. The systematic approach of confirmation theory will help to clarify the intricate relations that obtain between empirical studies and theories, as they appear in humanities disciplines. This will make humanities scholars aware of the dangers and opportunities associated with involving empirical studies in their research. And eventually the research will also inform scientists who hope to involve insights from the humanities in their science, for instance, in the medical humanities.

The general plan is to enrich confirmation theory with ideas from statistical model selection and probabilistic logic. But it will be clear that a full-scale development of new confirmation-theoretic models is not undertaken in this paper. The more modest goal is that fuzzy evidence and incompatible schemes will be related to some promising current developments in confirmation theory. The central development is a change in the conception of theory, and an associated change in the conception of epistemic attitudes toward theory. The 
point of departure for this change is Bayesian confirmation theory. ${ }^{21}$ This type of confirmation theory expresses our epistemic attitudes with regard to theory by degrees of belief, or probability functions, over a language or algebra. Scientific and scholarly theories are supposed to be captured by sharp probability functions over empirical data, expressing that theories make probabilistic, yet fully specific predictions. The key point is that humanities theories are often represented more adequately by structured sets of probability functions over empirical data. ${ }^{22}$ Relative to empirical data and various theoretical criteria, we do not merely choose the best fitting probability function as our best theory. Rather we choose between several sets of such functions, or in statistical parlance, we choose between models. The major advantage of representing the nature and evaluation of theories from the humanities in this way is that it provides more room for accommodating confirmation-theoretic phenomena like incompatible concepts and fuzzy evidence.

Now it might require some explanation that the central ideas here are apparently gleaned from a statistical context. After all, in the humanities, evidence and theory are often not quantitative, let alone statistical in nature. Indeed, I readily concede that some humanities disciplines are primarily informed by methods of interpretation or hermeneutics, ${ }^{23}$ which seem to resist a formal and confirmationtheoretic representation. ${ }^{24}$ Moreover, the rigidity and uniformity of statistical methods seems to be in stark contrast to the plurality of methods that we find in humanities disciplines. And finally, humanities research is often concerned with the unique and specific, and not, as are statistical methods, with the repeatable and generic. However, the goal of involving confirmation theory is certainly not to cover all theory evaluation in the humanities. The proposal is to employ confirmation theory for an assessment of particular approaches within the humanities, namely computational and empirical ones. It is undeniable that some humanities disciplines have recently seen the introduction of such empirical and computational methods. Our challenge is to integrate those new methods with an open eye for the specifics of existing humanities scholarship. And for this task, formal philosophical methods are certainly not far-fetched.

All of this is, of course, a far cry from designing a confirmation theory that fits the specific requirements of the museum project. This is not the place to lay out the probabilistic models in detail, but rather to sketch a development in confirmation theory, and the philosophical and methodological setting in which this development takes shape. The take-home message is simply that confirmation theory can be made applicable to pressing methodological problems in the humanities, and that this breaks new ground for confirmation theory itself. 


\section{Conclusion}

It will be clear from the foregoing that we are only seeing the start of the development of a confirmation theory that can accommodate humanities scholarship as well as methods from the social sciences that have been imported into the humanities. However, at this point it deserves emphasis that such a project is timely, even urgent. It addresses developments that are presently transforming the humanities, and has the potential to be a key contribution to its methodology: it integrates an analytic and empirical mindset into a field formed by traditional scholarly methods, and it establishes a much smoother connection of the humanities with the natural and social sciences. Finally, it will bring an entirely new perspective to the lively philosophical debate on scientific confirmation.

\section{Notes}

I Cf. J. Kagan, The Three Cultures: Natural Sciences, Social Sciences, and the Humanities in the 21st Century (Cambridge: Cambridge University Press, 2009).

2 R. Bod, De vergeten wetenschappen: een geschiedenis van de bumaniora (Amsterdam: Prometheus, 2010).

3 In Dutch, the term for the humanities is 'geesteswetenschappen', literally 'mental sciences'. This term is on a par with terms like 'natuurwetenschappen' (natural sciences) and 'sociale wetenschappen' (social sciences). In English, the humanities and the sciences are unfortunately set apart from each other.

4 More abstractly, the infrastructure assists owners of a collection of artifacts and information items (museums, zoos, town centers, but also shops) in offering these items to the general public. As such, the infrastructure can also be employed for active forms of control in the personal sphere, e.g, attempts by retailers to manipulate consumer behavior. Research in this direction is already well underway and, rather worryingly, mostly not available for the general public. We believe it better to put both research and technical development in the hands of nonprofit organizations that work in Open Source, and that are committed to the common good rather than private interests. To this aim the University of Groningen and the Drents Museum have set up a foundation which ensures that the expertise developed in the project is accessible for everyone, while commercial parties pay for licensed use. The added benefit is that proceeds reaped from the application of the expertise will flow back to the general public, through the funding of research and museums.

5 J. Pine and J. Gilmore, The Experience Economy (Boston: Harvard Business School Press, I999); G. Ritzer, The McDonaldization of Society, 2nd ed. (Los Angeles: Pine Forge Press, 2008).

6 H. Jenkins, Convergence Culture: Where Old and New Media Collide (New York University Press, 2006).

7 H. Collins, 'The Structure of Knowledge', Social Research 60 (I993), 95- I 6.

8 A. Clark, Being There: Putting Brain, Body, and World Together Again (Cambridge, MA: MIT Press, I997). 
9 Cf. S. Greer, R. Harrison, and S. McIntyre-Tamwoy, 'Community-Based Archaeology in Australia', World Archaeology 34.2 (2002), 265-287.

io A. Wylie, 'Philosophy of Archaeology; Philosophy in Archaeology', in S. Turner and M. Risjord (eds.), The Philosophy of Anthropology and Sociology, Handbook of the Philosophy of Science, volume I4 (Amsterdam: Elsevier Science, 2007), 517-549.

I I Unfortunately, the public voice does not always carry universal approval. A poll organized by the public broadcasting company KRO nominated the populist politician Pim Fortuyn (I948-2002) as the 'greatest Dutchman of all times'. Commentators and historians considered this an embarrassing choice.

I2 Cf. Descola, Par-delà nature et culture (Paris: Gallimard, 2005), and Descola, Lécologie des autres. L'anthropologie et la question de la nature (Versailles: Editions Quae, 2008).

I3 A. Taves, 'Bridging Science and Religion: "The More" and "the Less" in William James and Owen Flanagan', Zygon 44.I (2008), 9-I7; and J.J. Kripal, Authors of the Impossible: The Paranormal and the Sacred (University of Chicago Press, 2010).

I4 J.W. Romeijn, 'Theory Change and Bayesian Statistical Inference', Pbilosopby of Science 72.5 (2005), I I 74-II 86.

I5 I. Hacking, The Social Construction of What? (Cambridge, MA: Harvard University Press, 2009).

I6 E.g., C. Howson and P. Urbach, Scientific Reasoning: The Bayesian Approach (Chicago: Open Court, 2006).

I7 P. Lipton, Inference to the Best Explanation (Cambridge University Press, 2004); S. Okasha, 'Van Fraassen's Critique of Inference to the Best Explanation', Studies in History and Philosophy of Science 3I:4 (2000), 69 I-7 I0.

I8 J. Pearl, Causality (Cambridge, MA: MIT Press, 2000); J. Williamson, Bayesian Nets and Causality (Oxford University Press, 2005); J.W. Romeijn and J. Williamson, Intervention and Underdetermination. Manuscript submitted for publication.

I9 J.W. Romeijn, 'Analogical Predictions for Explicit Similarity', Erkenntnis 64 (2006), 253280 .

20 M.R. Forster and E. Sober, 'How to Tell When Simpler, More Unified, or Less Ad Hoc Theories Will Provide More Accurate Predictions', The British Journal for the Philosophy of Science 45 (I994), I-35; I.A. Kieseppä, 'Statistical Model Selection Criteria and the Philosophical Problem of Underdetermination', British Society for the Philosophy of Science 52 (200I), 76I-794.

2 I Howson and Urbach, Scientific Reasoning.

22 J.W. Romeijn and R. van de Schoot,'A Philosophical Foundation of Null, Alternative and Informative Hypotheses', in H. Hoijtink, I. Klugkist, and P. Boelen (eds.), Bayesian Evaluation of Informative Hypotheses (New York: Springer, 2008), 329-357; L. Henderson, J. Goodman, J.B. Tenenbaum, and J. Woodward,'The Structure and Dynamics of Scientific Theories: A Hierarchical Bayesian Perspective', Philosophy of Science 77 (2010), I72-200; R. Haenni, J.W. Romeijn, G. Wheeler, and J. Wiliamson, Probabilistic Logics and Probabilistic Networks (Berlin: Springer, 2010).

23 H.G. Gadamer, Truth and Method, 2nd ed., trans. J. Weinsheimer and D.G. Marshall (New York: Crossroad, I989).

24 Some theorists, e.g., M. Foucault, The Order of Things (London: Pantheon, I970), even argue that the humanities have passed the stage of tabulation and representation. This seems a rather one-sided view of humanities scholarship. 

X

Philosophy

AND THE

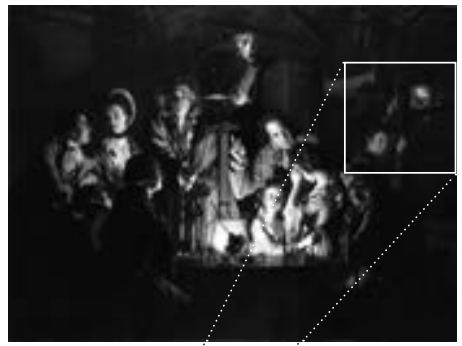

Humanities

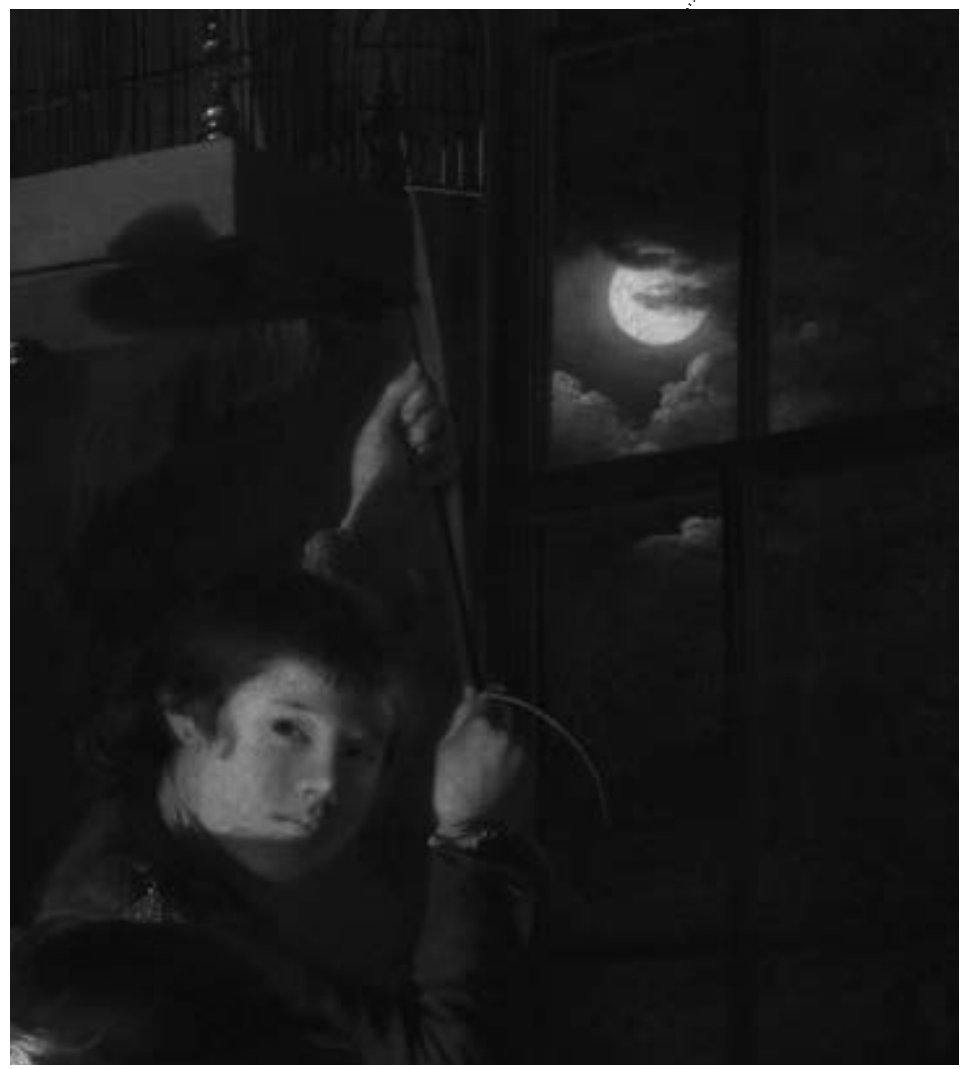





\title{
IO.I Making the Humanities Scientific Brentano's Project of Philosophy as Science
}

\author{
Carlo Ierna
}

During the nineteenth century we witness an extraordinary progress and increasing specialization in the natural sciences as well as the growth and professionalization of universities in Germany. ${ }^{1}$ At the same time, after the deaths of Goethe and Hegel, the epoch of Romanticism and German Idealism had come to an end. ${ }^{2}$ While the sciences diversified and emancipated from their philosophical past, philosophy itself fragmented into competing schools and currents, ${ }^{3}$ and in many respects, precipitated into an existential crisis. ${ }^{4}$ For a long time in the mainstream historiography of philosophy the nineteenth century was considered to harbor only epigones or predecessors. ${ }^{5}$ However, there certainly were central questions specific to the development of philosophy and the humanities in the nineteenth century: What makes science science? What would make philosophy science? What is or should be the relation between the natural sciences and the humanities, the Natur - and the Geisteswissenschaften? The scientific status of philosophy became a mainstream issue at first in nineteenth-century philosophy ${ }^{6}$ and concerned the demarcation of academic and institutional fields as well as the fundamental nature of scientific knowledge as such. Many prominent philosophers and psychologists now argued that philosophy needed to become scientific by taking the natural sciences as a model, ${ }^{7}$ while before the nineteenth century philosophy in general had been regarded as universal science and the sum of all knowledge. During the nineteenth century, scientists did no longer consider themselves to be philosophers and few, if any, philosophers could claim to be able to embrace the depth and breadth of the former 'natural philosophy'. There certainly had been debates about the precise subject, method and demarcation of specific subdisciplines prior to the nineteenth century, but these were still considered as internal to philosophy as an encompassing whole, as the overarching quest for knowledge. Before the nineteenth century, few felt the need to articulate the relation between philosophy and science as if these were two independent enterprises or to argue that philosophy would need to become more scientific. Indeed, prior to 
the nineteenth century most empirical and experimental scientific research was considered to be part of philosophy. ${ }^{8}$ If philosophy was inspired by any models of rigorous science outside itself, those were geometry and mathematics rather than physics or chemistry.

In the second half of the nineteenth century, however, philosophy needed to reestablish its proper role and function: beneath, between or beyond the increasingly diversified natural sciences. What options did philosophy have to become scientific? According to Hegel, philosophy would not really have a domain of its own, but rather a specific method to approach any domain, the method of speculation. ${ }^{9}$ Speculation would yield the concepts that would then determine the objects, not from experience, but a priori ${ }_{+}{ }^{10}$ The focus is on method and the form of reasoning, on building a top-down system that can account for the whole of reality in a holistic manner. ${ }^{\text {II }}$ In the second half of the century, however, the view that philosophy would instead have a domain of its own gained currency. The proper domain of philosophy would not be the physical world outside us, but the internal world of the psyche. ${ }^{\text {I2 }}$ A truly scientific philosophy would have to be based on a natural-scientific experimental psychology. This idea became so popular in Germany toward the end of the nineteenth century that philosophy chairs were increasingly being offered to experimental psychologists, ${ }^{13}$ to the point that when the experimental psychologist Erich Jaensch obtained the chair of philosophy in Marburg in I9I2, replacing the neo-Kantian Herman Cohen, the philosophers vehemently protested and sent around a petition to collect signatures in all German universities containing a 'Declaration against the occupation of philosophical chairs by representatives of experimental psychology', requesting the institution of separate chairs for psychologists and the repristination of philosophical chairs previously assigned to psychologists. ${ }^{14}$

Many experimental psychologists, including Wilhelm Wundt (who is usually credited with founding the first psychological laboratory), ${ }^{15}$ argued that by studying the relations between the external and internal world through experimentation, psycho-physics could establish the essential link between nature and consciousness, and hence ultimately found the humanities on the natural sciences. ${ }^{16}$ The view that the mind can be reduced to the brain remains widespread today not only among the general public, but also within the cognitive sciences and philosophy of mind, leading to claims such as: 'Intentionality is a biological feature of the world, on all fours with digestion or photosynthesis. It is caused by and realized in the brain. ${ }^{17}$ But if the Geisteswissenschaften are in the end founded on the Naturwissenschaften, then what do they actually study? Since we already have a natural science that claims to study the mind and consciousness, i.e., experimental psychology, can the Geisteswissenschaften even claim rightly that they are still studying the Geist? Or is this field restricted to studying merely the products 
and expressions of the mind ? $^{18}$ Do we have to choose between either studying nature with an unscientific, speculative method or 'giving up the ghost' and studying the expressions of a mind that ultimately is just an effect caused by the brain, ${ }^{19}$ effectively becoming a branch of the natural sciences?

Franz Brentano's project of the renewal of philosophy as science presents an interesting solution to this dilemma, by providing the best of both worlds.

It thus turns out that Brentano and Husserl offer us something that we cannot find among the two main streams of contemporary philosophy, generally classified as continental and analytic. Roughly speaking, the continentals reject the very ideal of philosophy as a science and perhaps even science itself, whereas the analytic philosophers do not as a rule allow for any other kind of science besides that which is exemplified in its finest form in physics. It is, to be sure, of great importance not to allow philosophy to decay into the dogmatism, relativism, and mysticism of the continentals. It is, however, of equal importance not to overlook a whole dimension of scientific inquiry. In spite of the many disagreements between Brentano and Husserl, their common concerns may well be the only ones that will ultimately prevail in a genuinely scientific philosophy. ${ }^{20}$

On July I4, I866, Brentano stepped up to the pulpit to defend his thesis that 'the true method of philosophy is none other than that of the natural sciences. ${ }^{21}$ This thesis became the north star of his school, rallying his first students to his flag, ${ }^{22}$ and remained a central and lasting concern for many of them. ${ }^{23}$ This thesis is part of a greater whole and actually follows from another thesis, namely that: 'Philosophy must deny that the sciences can be divided into the speculative and the exact; because if this is not correctly denied, then philosophy itself would have no right to exist. ${ }^{24}$ Here a more general claim is made about the nature of science and philosophy: there is just one kind of science and philosophy is part of it. Philosophy is not done by speculative construction, but by humble, detailed investigation. ${ }^{25}$ As Brentano told his students some years later: 'We are taking the first steps toward the renewal of philosophy as science', not by conjuring up 'proud systems' out of thin air, but by humbly 'cultivating fallow scientific ground'. ${ }^{26}$ Thus Brentano instilled in his students a strong sense of scientific rigor and his students did not consider themselves to practice 'armchair philosophies', but to do science.

There is no doubt anymore that also in philosophical matters no other teacher can be found than experience, and that it is not a matter of revealing the whole of a more complete Weltanschauung as a product of genius, 
but that a philosopher, like any other researcher, can only make progress in his field conquering it step by step. ${ }^{27}$

Brentano explicitly addresses the question whether we are justified in applying the methods of the natural sciences to the problems of the human sciences. First of all, Brentano observes that the natural sciences, in all their variety, do not simply use one single method everywhere. The method always must be appropriate to the object of inquiry. While mechanics uses deduction from first principles and paleontology has historical elements, the ultimate source of knowledge is always experience. Direct experience is decisive.$^{28}$ For Brentano, the true golden age of philosophy lies before us, if we manage to develop a method in analogy to the natural sciences. ${ }^{29}$ This depends on an analysis of experience and hence on the development of a new philosophical psychology as a science of consciousness.

Nowadays, what Brentano himself is probably still best known for is his reintroduction of the concept of intentionality into philosophy:

Every mental phenomenon is characterized by what the Scholastics of the Middle Ages called the intentional (or mental) inexistence of an object, and what we might call, though not wholly unambiguously, reference to a content, direction towards an object [...], or immanent objectivity. Every mental phenomenon includes something as object within itself, although they do not all do so in the same way. In presentation something is presented, in judgement something is affirmed or denied, in love loved, in hate hated, in desire desired and so on. This intentional in-existence is characteristic exclusively of mental phenomena. No physical phenomenon exhibits anything like it. We could, therefore, define mental phenomena by saying that they are those phenomena which contain an object intentionally within themselves. ${ }^{30}$

Intentionality is also at the root of his methodology and of his claim that the true method of philosophy is that of the natural sciences. While philosophy would use the method of natural science, its main domain would not be natural, but mental phenomena: a full-blooded science of the mind that does not require a reduction to the physical in order to be scientific. Brentano defined his psychology as a descriptive science: empirical, but not necessarily experimental; subjective, but not introspective.

While the striving for scientific philosophy is of course something that Brentano and Husserl have in common with other philosophers, such as the logical positivists, it is to be noted that they differ from many of these others 
insofar as they see consciousness as the subject matter of such philosophy. When we speak of science in English, what is primarily meant is natural science. It may accordingly be difficult to understand how Brentano and Husserl could have advocated or advanced scientific philosophy without seeing natural science as its foundation. As difficult as this is for the contemporary Anglo-American understanding, it must time and again be emphasized that consciousness, completely devoid of any sort of physicalistic reduction, is an object of science for Brentano and Husserl. This science, moreover, they regard as absolutely central to all the concerns of philosophy. ${ }^{31}$

Using intentionality as a criterion we can distinguish natural and mental phenomena: physical phenomena and psychical phenomena, or in other words, phenomena of external and internal perception. Physical phenomena would be color, tone, warmth, etc.; psychical phenomena would be the seeing of the color, the hearing of the tone, the feeling of the warmth, etc. Hence, the Geisteswissenschaften would be the sciences that deal primarily with the mind, with consciousness, with its acts, contents, objects and its expressions. This would also include most of the social sciences: 'Clearly social phenomena belong among the mental phenomena, and no other knowledge can be drawn upon as ordering authority but the knowledge of psychical laws, that is, philosophical knowledge'. ${ }^{32}$

While these broadly defined sciences, the Natur- and Geisteswissenschaften, each have their own domain, they are essentially founded on the same empirical method, again broadly understood, based on perception and experience and not on a priori metaphysics or speculation. Sciences are built bottom-up, not topdown. By taking the experience of concrete phenomena as the foundation, Brentano maintains the fundamental unity of science, while making a clear distinction between the sciences of physical and the sciences of psychical phenomena. Indeed, Brentano clearly distinguishes his descriptive psychology from the experimental study of psycho-physics, which he calls genetic psychology. Hence, psychology is not used to found Geist on Natur hierarchically and hence the Geisteswissenschaften keep their autonomy in their own domain.

Psychology is also confronted with another task [besides the formulation of laws that regulate the (causal) coherence of body and soul, which is the task of genetic psychology]: to give clarity about what inner experience shows immediately; hence not a genesis of facts, but at first only a description of the field. This part is not psychophysical, but purely psychological. We must know in advance, what the facts look like: and this is shown by the internal perception of the psychical. When we want to describe this, we summon phenomena through iteration of the physical stimuli; in this sense 
we will also have to discuss the body. Otherwise only internal experience is considered.

This field of psychology I call descriptive. ${ }^{33}$

Descriptive psychology, according to Brentano, identifies three natural basic classes of mental acts: presentations (Vorstellungen), judgments (Urteile) and phenomena of love and hate or emotions (Phänomene der Liebe und des Hasses). ${ }^{34}$ All of these are intentional acts; no presentations without something presented: 'There is no psychical phenomenon which is not consciousness of an object.'. All mental acts would either be presentations or contain presentations in them: judgment and emotions essentially consist in a positive or negative quality added to a presentation. ${ }^{36}$ What is accepted or rejected in a judgment is the existence of what is presented. ${ }^{37}$ Perception, both internal and external, would be simply a case of judgment, where we positively accept the existence of what is given in the presentation. In this sense, internal perception is inherently superior to external perception. We can always doubt the existence of the objects of our external perception, because we cannot exclude that we fall prey to illusions or hallucinations, that we are dreaming, etc. 'Internal perception is actually the only kind of perception in the proper sense, while strictly speaking so-called external perception isn't perception'. ${ }^{38}$ Due to the epistemic privilege of internal perception, Brentano considered his philosophical psychology to be an exact science. In the case of internal perception, I have a direct experience and immediate evidence of my own mental acts when I live through them. In this respect, Brentano sharply distinguishes internal perception from introspection, pointing out that inner perception cannot become introspection or inner observation. ${ }^{39} \mathrm{We}$ are directly conscious of our own mental acts while living through them, without the need for another separate act directed at them that would 'observe' them, since this would introduce an infinite regress.

The science of mental phenomena would then proceed in the same fashion as the natural sciences: perception and description of concrete phenomena, formulation of hypotheses, discussion based on further data, induction of increasingly general laws, deduction of increasingly specific cases, verification or falsification based on concrete experiences. In other words: pick a problem, consider all the possible explanations, reject all the false ones based on concrete counterexamples taken from experience, until in the end the correct theory remains.$^{40}$

In this way, Brentano represents both an exception to and a culmination of the nineteenth-century concerns with philosophy as science, advancing a new paradigm that would make it possible to work in philosophy and the humanities scientifically without making them dependent on the natural sciences. Moreover, his theories and teachings turned out to be quite fruitful and influential in phi- 
losophy and other human sciences thanks to their further development by his students in the School of Brentano.

Brentano's students adapted and spread his theories far and wide, holding important chairs in philosophy at major universities throughout the AustroHungarian Empire and central Europe. Carl Stumpf, Brentano's first student, taught at the universities of Göttingen, Würzburg, Prague, Halle, Munich and finally settled in Berlin, where he established a psychological laboratory and phonogram archive, founding the Berlin School of Gestalt Psychology, influencing, among others, Max Wertheimer, Kurt Koffka and Wolfgang Köhler. Anton Marty spread Brentano's philosophy for more than three decades in Prague, raising the second generation of Brentanists, among others Alfred Kastil and Oskar Kraus, and exerting a significant influence on the development of Prague Linguistics, since Vilem Mathesius studied with him and Roman Jacobson read his works already before coming to Prague. Alexius Meinong became professor in Graz, where he established a psychological laboratory and founded the Graz School of Gestalt psychology, including Stephan Witasek and Vittorio Benussi. Edmund Husserl's works gave rise to the phenomenological movement, which inspired much of what is now called 'continental philosophy' and in various ways influenced existentialism, hermeneutics and French philosophy: Martin Heidegger, Maurice Merleau-Ponty, Jean-Paul Sartre, Emmanuel Levinas, Jacques Derrida, Paul Ricoeur, Alexandre Koyré, Jan Patocka, and Edith Stein, among many others. Kazimierz Twardowski moved back to his homeland Poland, establishing the first Polish psychological laboratory, and became the father of Polish Philosophy, propagating Brentanist ideas as the teacher of Tadeusz Kotarbinski, Jan Lukasiewicz, Stanislaw Lesniewski, Kazimierz Ajdukiewicz. Finally, Christian von Ehrenfels is still best known for his Über 'Gestaltqualitäten' (I890), which contributed to establishing and shaping Gestalt psychology* Other notable figures that studied under Brentano include Thomas Masaryk, Sigmund Freud, and Rudolf Steiner. ${ }^{41}$

The nineteenth-century idea of scientific progress as a collective achievement obtained through collaborative research ${ }^{42}$ led to a division of labor in the School of Brentano. Each of his students chose to mainly concentrate on and work out a philosophical position in a specialized field, either due to Brentano's guidance or following their own interests, applying the Brentanist methods and principles of descriptive psychology to it and working it out as a part of the greater whole: Stumpf, the philosophy of sound and music; Marty, the philosophy of language; Meinong was originally meant to work mainly on the history of philosophy; Husserl started out by formulating a Brentanist philosophy of mathematics and then went on to develop philosophical logic as a general theory of science, before starting his own phenomenological movement; and so on. However, besides these 
various pursuits, Brentano's students were also still concerned with the overall project of the renewal of philosophy as science and, besides their work in epistemology, logic, and philosophy of science, they also discussed the scientific status of philosophy and its relation to other disciplines, both scientifically as well as institutionally, in various programmatic works. ${ }^{43}$

With such an extensive list of notable descendants in such a wide spectrum of fields, one would expect Brentano to be much better known and studied nowadays, but alas this is not the case. His theories spread mostly through his teachings, the division of labor in his School obscured the underlying methodological unity, and the success of the schools and movements founded and influenced by his students overshadowed their common background and shared origin. These factors have led scholars to speak of 'Brentano's invisibility'.44

As we can see from the success and influence of his students and their schools, Brentano's project of renewing philosophy as science has been very fruitful in highly disparate fields. Brentano's ideal of philosophy as science is to all effects, 'a program for scientific research' showing that it is possible to conduct scientific research in the humanities, ${ }^{45}$ that the Geisteswissenschaften can be understood to be indeed full-blooded sciences in their own right: unnatural sciences. ${ }^{46}$

\section{Notes}

I For a coeval testimony and analysis, see Friedrich Paulsen, The German Universities and University Study, trans. Frank Thilly and William G. Elwang (New York: Charles Scribner's Sons, I906), esp. 58: 'The second half [of the nineteenth century] was characterized more by a lateral growth. [...] The accompanying phenomenon was the ever-increasing specialization of the fields of investigation, as illustrated by the constant multiplication of departments and chairs in the universities. Everywhere the number of professorships in the philosophical faculty was as much as doubled and trebled in the course of the century. Berlin began with twelve full professorships. It now has more than fifty in this department'.

2 See Terry Pinkard, German Pbilosophy 1760-1860: The Legacy of Idealism (Cambridge: Cambridge University Press, 2002), 306.

3 Paulsen, The German Universities, 4I 4, speaks of 'anarchy'.

4 Herbert Schnädelbach, Philosophie in Deutschland 1831-1933 (Frankfurt a. M.: Suhrkamp, I983), II, Charles R. Bambach, Heidegger, Dilthey, and the Crisis of Historicism (New York: Cornell University Press, I 995), 2 If., but also see Friedrich Paulsen, Introduction to Philosophy, translated by Frank Thilly (New York: Henry Holt, I 895), 27f. and 37f., who places the blame for the separation between philosophy and science with Kant and German Idealism.

5 About this tendency, see Schnädelbach, Philosophie in Deutschland, r 3.

6 David Sullivan, The Idealists, in Dov M. Gabbay and John Woods (eds.), Handbook of the History of Logic, Volume 4: British Logic in the Nineteenth Century (Amsterdam: North Holland, 2008), 623, also see Bambach, The Crisis of Historicism, 23. 
7 Consider, among others, Hermann von Helmholtz, Richard Avenarius, Rudolf Virchow, Wilhelm Wundt, etc.

8 Paulsen, Introduction to Philosophy, zoff., offers an extensive historical survey as support for the claim that 'Philosophy is the comprehensive sum-total of all true knowledge. The sciences do not exist outside and by the side of it; they are parts of it' (22), and that philosophy has been generally so conceived up to the nineteenth century. Among the examples he adduces, we find of course Aristotle and Plato, but also Bacon and Descartes. According to Paulsen, Kant is the first to break with this traditional conception (27f.), also see Friedrich Paulsen 'Über das Verhältniss der Philosophie zur Wissenschaft', Vierteljabrsschrift für Wissenschaftliche Philosophie I (I877), I7, 33, thus setting the stage for German Idealism and the opposition between philosophy and science in the nineteenth century.

9 The opposition between a speculative and an empirical method was repeatedly and emphatically stressed by Brentano, but my approach here is also based on the account given by Paulsen, Introduction to Philosophy, I $5 \mathrm{f}$.

Io See Thomas E. Wartenberg, 'Hegel's Idealism: The Logic of Conceptuality', in Frederick C. Beiser (ed.), The Cambridge Companion to Hegel (Cambridge: Cambridge University Press, I993), II 5 .

I I See Michael Forster, 'Hegel's Dialectical Method', in Beiser (ed.), The Cambridge Companion to Hegel, I 37.

I 2 Compare with Paulsen, Introduction, I6f., who points out that restricting the domain of philosophy to either knowledge or inner experience would simply reduce philosophy to one of its parts, i.e., logic or ethics.

I 3 Also see Roberto Poli, 'The Brentano Puzzle: An Introduction', in Roberto Poli (ed.), The Brentano Puzzle (London: Ashgate, I998), I.

I4 'Erklärung gegen die Besetzung philosophischer Lehrstühle mit Vertretern der experimentellen Psychologie', published in Logos IV (I9I3), I I4, with more than Ioo signatories. See Martin Kusch Psychologism: A Case Study in the Sociology of Philosopbical Knowledge (London and New York: Routledge, I995), r 86ff., and Mitchell G. Ash,'Academic Politics in the History of Science: Experimental Psychology in Germany, I879-I94I', Central European History I 3.3 (1980), 279-280.

I5 Brentano fruitlessly petitioned the Austro-Hungarian authorities for funding to establish a psychological laboratory in Vienna when he obtained his professorship there. If this had been successful, it would have predated Wundt's by five years. Instead, only in I 894 would the first psychological laboratory in Austria be established in Graz, by Brentano's student Alexius Meinong. See Wolfgang Huemer and Christoph Landerer,'Mathematics, Experience and Laboratories: Herbart's and Brentano's Role in the Rise of Scientific Psychology', History of the Human Sciences 23.72 (2010), 85, and Liliana Albertazzi, Immanent Realism: An Introduction to Brentano (Dordrecht: Springer, 2006), 26.

I6 Wilhelm Wundt, Grundzüge der physiologischen Psychologie (Leipzig: Wilhelm Engelmann, I 874), $4 \mathrm{ff}$.

I7 John Searle, 'The Phenomenological Illusion', in Maria E. Reicher and Johann C. Marek (eds.), Experience and Analysis: Proceedings of the 27th International Wittgenstein Symposium, Kirchberg am Wechsel (Vienna: ÖBV \& HPT, 2005).

I 8 This view is unfortunately and inexplicably also sometimes taken in highly official contexts, such as in the Dutch report Duurzame Geesteswetenschappen (Amsterdam: Amsterdam University Press, 2008) regarding the national plan for the future of the humanities [geesteswetenschappen]' that explicitly identifies the proper domain of the humanities as 
the expressions of the human mind [geest], as representations and interpretations of the world' (1 3 ), which is followed by an explicative footnote that quite unambiguously states that the geesteswetenschappen do not address the human geest itself as an object of research' $(52 \mathrm{n} .3)$, which would then remain the province of psychology.

I9 Or in extremis that it just is our brain. See D.F. Swaab, We Are Our Brains: A Neurobiography of the Brain, from the Womb to Alzheimer's (New York: Spiegel \& Grau, 2014)/Wij zijn ons brein. Van baarmoeder tot alzheimer (Amsterdam: Uitgeverij Contact, 2010); or Wim van de Grind, Natuurlijke Intelligentie (Amsterdam: Nieuwezijds, I997), I6: 'Thought is an adaptive brain-activity'.

20 Robin Rollinger, 'Brentano and Husserl', in Dale Jacquette (ed.), The Cambridge Companion to Brentano (Cambridge: Cambridge University Press, 2004), $27 \mathrm{I}$.

2I Franz Brentano, 'Die Habilitationsthesen', in Franz Brentano, Über die Zukunft der Philosophie, ed. Oskar Kraus (Leipzig: Felix Meiner, 1929), I36-I37.

22 The expression comes from a letter of Carl Stumpf to Brentano from I892, quoted in Oskar Kraus, Franz Brentano. Zur Kenntnis seines Lebens und seiner Lebre (Munich: Beck, I9I9), I9. Also see Carl Stumpf,'Erinnerungen an Franz Brentano', in Kraus, Franz Brentano, 88 .

23 About this thesis, see Dale Jacquette, 'Brentano's Scientific Revolution in Philosophy', The Southern Journal of Philosophy 40 (2002), and Robin Rollinger, Austrian Phenomenology: Brentano, Husserl, Meinong and Others on Mind and Object, Phenomenology E Mind (Frankfurt: Ontos Verlag, 2008), 3.

24 Brentano, 'Die Habilitationsthesen', in Über die Zukunft der Philosophie, I36-I 37.

25 Poli, 'Introduction', in The Brentano Puzzle, 7, and Roberto Poli, 'At the Origin of Analytic Philosophy', Aletheia (I994).

26 Franz Brentano, 'Über Schellings Philosophie', in Über die Zukunft der Philosophie, I 3 I; Wilhelm Baumgartner, 'Nineteenth-Century Würzburg: The Development of the Scientific Approach to Philosophy', in Roberto Poli (ed.), In Itinere: European Cities and the Birth of Modern Scientific Philosophy (Amsterdam: Rodopi, I997), 86.

27 Franz Brentano, 'Über die Gründe der Entmutigung auf philosophischem Gebiete', in Über die Zukunft der Philosophie, 85: 'Kein Zweifel mehr besteht, daß es auch in philosophischen Dingen keine andere Lehrmeisterin geben kann als die Erfahrung, und daß es nicht darauf ankommt, mit einem genialen Wurfe das Ganze einer vollkommeneren Weltanschauung vorzulegen, sondern daß der Philosoph wie jeder andere Forscher nur Schritt für Schritt erobernd auf seinem Gebiete vordringen kann'. All translations, unless otherwise indicated, are my own.

28 Franz Brentano, 'Über die Zukunft der Philosophie', in Über die Zukunft der Philosophie, SII-I 2 .

29 Ibid., 45.

30 Franz Brentano, Psychologie vom empirischen Standpunkte (Leipzig: Duncker \& Humblot, I 874), I I 5; Franz Brentano, Psychology from an Empirical Standpoint, trans. Antos C. Rancurello et al. (London: Routledge, I995), 68.

3 I Rollinger, 'Brentano and Husserl', in Jacquette, Cambridge Companion to Brentano, 27 I.

32 Brentano, 'Über die Gründe der Entmutigung', in Über die Zukunft der Philosophie, 99-1oo 'offenbar gehören die sozialen Erscheinungen zu den psychischen Erscheinungen, und kein anderes Wissen kann hier als ordnende Macht zu Hilfe gerufen werden als die Kenntnis der psychischen Gesetze, also das philosophische Wissen'.

33 Franz Brentano, Manuscript Q io: Descriptive Psychologie (Vienna, WS I887/ I 888): 'Der Psychologie ist aber auch noch eine andere Aufgabe gestellt [außer die des Aufstellens 
der Gesetze, die den (kausalen) Zusammenhang von Leib und Seele regeln, welches die Aufgabe der genetischen Psychologie ist]: Klarheit darüber zu geben, was die innere Erfahrung unmittelbar zeigt; also nicht eine Genesis der Tatsachen, sondern zunächst erst Beschreibung des Gebietes. Dieser Teil ist nicht psychophysisch, sondern rein psychologisch. Vorweg müssen wir wissen, wie die Tatsachen aussehen: und dies zeigt ein innerer Blick ins Psychische. Wollen wir solches beschreiben, so rufen wir Erscheinungen durch Wiederholung der physischen Reize hervor; in dieser Weise wird also auch hier Körperliches zu berücksichtigen sein. Sonst kommt ganz und gar bloß die innere Erfahrung in Betracht. Diesen Kreis der Psychologie nenne ich die deskriptive'.

Brentano, Psychologie, 260; Brentano, Psychology, I 52.

35 Brentano, Psychologie, I 33; Brentano, Psychology, 79. A shorter phrasing of the claim that 'There is no psychical phenomenon which is not consciousness of an object' would be 'Nichts vorstellen is nicht vorstellen', i.e., not presenting anything, is not presenting at all.

Brentano, Psychologie, I04, I I I. Specifically for judgments, see Peter M. Simons, 'Brentano's Reform of Logic', in Topoi 6 (I987), 27.

37 Franz Brentano, Vom Ursprung sittlicher Erkenntnis (Leipzig: Duncker \& Humblot, I889), I6, translated as Franz Brentano, The Origin of the Knowledge of Right and Wrong, trans. Cecil Hague (Westminster: Archibald Constable \& Co., I902), I4.

38 Brentano, Psychologie, I I9: 'Die innere Wahrnehmung [...] ist eigentlich die einzige Wahrnehmung im eigentlichen Sinne des Wortes. [...] Die sogenannte äussere Wahrnehmung ist also strenggenommen nicht eine Wahrnehmung' (Brentano, Psychology, 70). This is what is meant by the expression 'Wahrnebmung ist Falschnebmung', i.e., taking external perception as truthful is to be mistaken.

Brentano, Psychologie, 35; Brentano, Psychology, 22.

40 Compare Brentano, 'Über die Gründe der Entmutigung', in Über die Zukunft der Philosophie, 89-90, 96, and Franz Brentano, Die Vier Phasen der Philosophie (Hamburg: Meiner I968), I8, where he endorses Bacon and Descartes. For a discussion of the development of the method of descriptive psychology in its historical and intellectual context, see Wilhelm Baumgartner, 'Nineteenth-Century Würzburg: The Development of the Scientific Approach to Philosophy', Poznán Studies in the Philosophy of the Sciences and the Humanities 54 (I997), 86, 9I.

4I For further details on the School of Brentano, see Liliana Albertazzi, Massimo Libardi, and Roberto Poli (eds.), The School of Franz Brentano (Dordrecht: Kluwer, 1996), Robin Rollinger, Husserl's Position in the School of Brentano (Dordrecht: Kluwer, I999), Barry Smith, Austrian Philosophy: The Legacy of Franz Brentano (Chicago: Open Court Publishing Company, 1994).

42 Alan Richardson, 'Toward a History of Scientific Philosophy', Perspectives on Science 5.3 (I997), 434 .

43 Consider inter alia Carl Stumpf, Zur Einteilung der Wissenschaften (Berlin: Verlag der Königlichen Akademie der Wissenschaften, 1907), Carl Stumpf, Die Wiedergeburt der Philosophie (Leipzig: Barth, I908), Alexius Meinong Über philosophische Wissenschaft und ihre Propädeutik (Vienna: Alfred Hölder, I885), Alexius Meinong, Über die Stellung der Gegenstandstheorie im System der Wissenschaften (Leipzig: R. Voigtländer, 1907); Edmund Husserl, 'Philosophie als strenge Wissenschaft', Logos I (I9I I).

44 Albertazzi, et al. (eds.), The School of Franz Brentano, 3ff.; Poli, 'Introduction', in Poli (ed.), The Brentano Puzzle; Dallas Willard, 'Who Needs Brentano?', in Poli (ed.), The Brentano Puzzle; Karl Schuhmann, 'Brentano's Impact on Twentieth-Century Philosophy', in Jacquette (ed.), The Cambridge Companion to Brentano, 278. 
45 Liliana Albertazzi, 'Franz Brentano's Psychology Today: A Programme of Empirical and Experimental Metaphysics', Brentano Studien Io (2002/2003), I I 8.

46 'Unnatural' is used here to indicate that the field of science, broadly understood, can be partitioned into the natural sciences and the unnatural sciences, i.e., all those sciences that do not study natural objects. This is not meant to characterize them specifically as opposing the natural sciences, but rather as complementing them. It is also meant to underscore that one cannot use 'sciences' simply and straightforwardly as a synonym of 'natural sciences'. The term 'unnatural' is therefore used as an umbrella term for all scientific disciplines that are not counted among the natural sciences. 


\title{
IO.2 The Weimar Origins of Political Theory
}

\section{A Humanities Interdiscipline}

\author{
David L. Marshall
}

With a frequency that is quite remarkable, contemporary political theorists in the Anglophone world continue to speak of the Weimar Republic as a decisive point of origin for their field of inquiry. Of course, the field has many sources (some modern, some ancient), but 'the Weimar origins of political theory' is a key topos. Thus, in 1988, John Gunnell, perhaps the most relentless scholar on this issue, could write that the contemporary estrangement of political theory from political science is in large measure the product of a quarrel that originated in the challenge to the values of US political science initiated by émigré scholars during the I940s.' The issue was whether political science had to be value-neutral if it was to be counted as a science and whether something essential would be lost if the normative dimension of political inquiry were excluded. Even someone like Sheldon Wolin, who agreed that there was a tension between political science and political theory and yet denied that the Weimar émigrés were setting the agenda, cast his landmark 1969 essay on 'Political Theory as a Vocation' in the form of an homage to a German theoretical initiative forged in the context of Weimar's birth. ${ }^{2}$ And, following the discontinuation of political theory from the graduate program in political science at Penn State in 2007, the science-theory tension, defined in significant ways by Weimar and its afterlife, has become highly controversial once again. ${ }^{3}$

If one were to distill the various articulations of this 'Weimar origins of political theory' topos into the most compact sequence possible, one would emerge with something like the following conceptual narrative - which is oversimple but provisionally useful. Max Weber took the major challenge of modernity to be the increasing hegemony of rule-governed systems, and he then described politics under modern conditions as a kind of conundrum: unable to do without leaders, modern systems had difficulty producing them, because the basic governmental form of modernity - bureaucracy - was something like an attempt to render leadership superfluous. ${ }^{4}$ Carl Schmitt then proceeded to challenge the 
self-sufficiency of posited, rule-governed systems, and he reoriented political science to the study of a sovereignty that distinguished itself by determining when the rule was and was not in force. Thus, according to the well-worn Schmittian sentence, Souverän ist, wer über den Ausnabmezustand entscheidet (Sovereign is he who decides upon the state of exception)..$^{5}$ In turn, Leo Strauss accused Schmitt of falling prey to precisely the logic that Schmitt thought he had been critiquing. That is, liberal pluralism brought Schmittian decisionism into being by undermining tradition. The implication was that romanticizing the decision merely deepened what was for Strauss the central modern political problem - namely, pluralism and its purported corollary, relativism. ${ }^{6}$ Less explicitly but just as compellingly, Hans Baron's discovery of Florentine Bürgerbumanismus in the shadow of Weimar's collapse responded to the charge of relativism by transforming 'decision' into 'action' and by giving action its own - now neo-Aristotelian, now neoCiceronian - value as a form of human flourishing, that is, as a cultivation of 'the virtues of active life' in the polis and in the Stadtstaat. ${ }^{7}$ Probably unaware of Baron, Theodor Adorno proceeded to replace the city-state and its rhetoric with the metropolis and Kierkegaardian aesthetic. Voguish 'existentialism' was a pseudo-politics, Adorno thought, a merely idealist retreat from the vita activa into a world of rentier inwardness. Avant la lettre, one might say, existentialism was not a civic humanism. Engagement did not translate virtì. What one needed, he concluded, was a Phantasie that would not merely think the particular but would in fact act into historico-political concretions by finding the gaps between their characteristics. ${ }^{8}$ Like tangents peeling off a historical arc, these initiatives show us a series of specific conceptual possibilities deriving from (but not bound to) Weimar Germany.

This is a rich and provocative sequence, but when I look at Weimar I see something different, something we have neglected. I see an alternative lineage defined by the sequence: Martin Heidegger, Hannah Arendt, Aby Warburg, and Walter Benjamin. To be sure, these are four more of the usual suspects in the Weimar canon. What I want to emphasize is the sense in which each of these four thinkers was working at the intersection of political theory and rhetorical theory. Only recently has this cluster of interests received a degree of attention. Heidegger lectured on Aristotle's Rhetoric at the University of Marburg in the summer semester of 1924 , and a number of scholars have taken this as an opportunity to think about Weimar's sense of a republic's existence in persuasion. ${ }^{9}$ Even as it is not as well-known as it should be, this work has been invaluable, but I would argue the initiative can be taken further. The particular Heidegger in whom rhetorical and political theory intersected is only one point of departure, one of several that need to be thought together if they are to be thought more fully. What I propose to do in this short piece is sketch the beginnings of an account of the Weimar 
origins of political theory in which rhetoric plays a central role. The larger point - here simply exemplified rather than analyzed or established - is that even after the 'rhetorical renaissance' and before the 'linguistic turn' rhetoric was more than simply an art of persuasion. In fact, rhetoric could be a conceptually rich interdiscipline at the core of the humanities.

The richest point of departure for an account of the Weimar intersection of rhetorical and political theory is Heidegger's summer semester 1924 lecture course on the basic concepts of Aristotelian philosophy. With extreme ingeniousness, Heidegger argued, in effect, that rhetoric had been at the center of the Aristotelian research enterprise. Tracing Grundbegriffe out from Book V of the Metaphysics into the biological and the logical works, he found those basic concepts intersecting in the Rhetoric. 'Today', he complained, 'we have a primitive conception of language or none at all'. In contrast, the Greek sense had been deeply original. And the concrete proof of the originality of this understanding is the Rhetoric, in its entirety.' This being in language was always a being with others in processes of taking up positions counterposed to phenomena, phenomena that were themselves in the process of being delineated. Being in language was an array of faculties understood as possibilities impinging upon the actual: aisthesis was, most basically, a kind of hearing, hören, a being disposed toward; phantasia was a situating of oneself sensuously among objects not present to the senses; pathesis was a kind of conviction, a being held and a holding oneself in a particular position. Rhetoric, on this account, was not an art, not a techne, but rather a dunamis, which in Heidegger's transposition was not a 'faculty' or 'capacity', not a Vermögen, but rather, a Möglichkeit, a possibility - a (my term) 'living-in-themidst-of-the-risks-that. ${ }^{\prime}$ Politics then became something like the most intensive, most encompassing, inseparability of all of these dispositions in the lives of human communities. Indeed, so Heidegger, 'rhetoric makes the claim to be itself politics. ${ }^{12}$ I am claiming that, for Heidegger - for the early Heidegger who was paraphrasing Aristotle - politics was the process in which a community became entangled in its own possibilities.

Thus, when Heidegger spoke of human being as a very particular form of Dasein, he meant that human being was always a being that was rhetorically and politically situated in a particular place and in a particular moment, with contiguities in space and time that extended ahead and behind, into the past and into the future, and with discontinuities made proximate by means of imagination. Orientations to the proximate and to the available-for-use were in fact rhetorical orientations to the relatively immediate environment. The rhetoricians had termed this zero point, this here and now in space and time, kairos - the critical place or moment, the opportunity. And they subordinated much of rhetorical theory to the demands of kairos. Heidegger, in turn, described kairos as the intersection of 
all intersections between past and future, a mean of means. 'The mean', he said, glossing the Aristotelian meson, 'is nothing other than the kairos, the totality of circumstances, the how, when, whither, and about which.' ${ }^{13}$ In any given time and place, the situation would be defined by the coming together of a multiplicity of trajectories. But one's exposure to a trajectory would be necessarily partial. Such an exposure might even be momentary. A political situation, for example, might be defined by a high-resolution photographic image in which one could not detect even the slightest hint of a blur. The political task might be to infer a past for this moment (a cause) and a future (an effect). A series of hypothetical pasts and an array of possible futures thus defined the political situation. And, of course, the collective action would be calibrated to the directionality - that is, the sense of potential threat or opportunity - generated by those inferences.

In Sein und Zeit (1927), there was only one sentence that bore explicit witness to Heidegger's articulation of the centrality of Aristotle's Rhetoric in the lectures of 1924. In \$29, Heidegger noted that Aristotle's Rhetoric must be understood as die erste systematische Hermeneutik der Alltäglichkeit des Miteinanderseins. ${ }^{14}$ Miteinandersein here was not simply 'being-with-another'; it was the sum total of all the sensibilities marking a political, or rather politicizable, community. In turn, this Alltäglichkeit was an 'everydayness' in which the majority of sense experiences went unregistered. That is, the so-called self-forgetfulness of being was habit. It was the inconspicuousness of sense data encountered on a daily basis, and it was the sclerosis of words used too often and too readily. But the inconspicuousness of the present was also a dimming down of past and future, because it was a denial that the here and now was in fact a kairos. In this way, political capacity was a power of representing the present in ways that made it visible, conspicuous.

The one point at which scholars have clearly received the Heideggerean line of inquiry that I am laying out here is the emphasis he placed on Entscheidung, decision. Since at least Christian von Krockow's famous 1958 grouping of Heidegger with Ernst Jünger and Carl Schmitt, we have often folded Heidegger into a kind of generic existential dramatization of the decision. ${ }^{15}$ And from there the road to an ever more merciless decidedness has seemed natural, inevitable even. Or, alternatively, noticing the moments in which Heidegger saw that the fetishization of decision was itself simply a form of Weimar Gerede (idle talk), we say that Heidegger turned, did an about-face, and preached Gelassenbeit (serenity), in place of, or as a redescription of, Entschloßenheit (resolution). But, like the man himself in many ways, we have forgotten how he got to this point, and thus we have forgone an opportunity to think Heidegger's thoughts in a different direction.

To some extent, Hannah Arendt certainly did think Heidegger's thoughts, but in a different direction. Famously, it was the same Athenian world of logos - word and deed and being-with-others in a public realm - that Arendt placed at the 
center of The Human Condition in 1958. And she did so in order to power a theoretical counterattack upon the form of politics ('totalitarianism' was, of course, her word) that Heidegger had, for a time, joined. This was ironic. But the irony was, I think, deeper than we have seen. Arendt's problem was not that she had too much Heidegger. The problem was that she received too little. Or, more precisely, she took too little from the early Heidegger.

Heidegger's analysis of Dasein as a kind of actualization within a contexture of possibilities was heavily invested in a reconceptualization of time. The distances that pushed out from the moment into the past and into the future were primarily temporal distances. There were, it is true, crucial ways in which Heidegger's project also reconceptualized space. And, what is more, Arendt did inherit the Heideggerean concern with the simultaneity of past, present, and future. Nevertheless, there is a real sense in which Arendt transposed Heideggerian interests from time to space. Her doctoral dissertation aimed at a critique of the Christian concept of neighborly love - a kind of geographic disposition. Her habilitation was an analysis of the acts of social distantiation undertaken by and encountered by the nineteenth-century Jewish salonnière Rahel Varnhagen. Her journalistic writings in the I940s were often investigations of the bipolar and multipolar spaces that war and political negotiation brought into existence. And, of course, in The Human Condition, the distinctive human activity of action took place in what Arendt termed 'the space of appearance'.

If one concentrates on the various spaces conceptualized by Arendt in these texts, one discovers that over time her treatments became flatter, more idealized, and less perceptive. Throughout her oeuvre, space was never something that could simply be assumed, and it was always in the process of being opened or closed, but in the early texts - up to 1950 or so - the depictions of spatial fissure and suture had been far more exacting. In the Augustine and Rahel texts, space was the distance at which one held oneself from the world, or it was the distance at which one was held by the world. Where Augustine feared assimilation into the world (as a losing of oneself in the desires of the flesh), Rahel craved assimilation into Prussian society but failed to achieve it. In both cases, Arendt's prime interest was how to describe non-assimilation. Space itself simply was non-assimilation, a combining of the distances established by the non-identity of persons. Elements of her early analytical acuity remained in the later treatments, but ultimately the space of appearance in The Human Condition - despite its conceptual centrality and apparent richness - was Olympian. It was the individual's distinctiveness as 'a who' that dominated. Space was now a venue for performance. And in her characterization of Adolf Eichmann, she wanted to head in precisely the opposite direction: the modern biopolitics of extermination, she argued, had been made possible by Eichmann's absolute indistinctness, by the non-existence of a space 
separating him as 'a conscientious exception' from 'the rule of law'. The late work on judging promised to renew the early investigation of the non-disappearance of the case into the rule together with the specific sensus communis brought thereby into being, but Arendt died before she could complete that book. ${ }^{16}$

In part, the simplifications of the late works were deliberate, politically motivated, and understandable. But they also revealed Arendt's truncated reception of Heidegger's lectures on rhetoric. It was the University of Marburg summer semester 1924 lectures that had constituted the richest cache of terms and tactics for describing the space of distances between possibilities in which human political community existed. Yet Arendt began to study with Heidegger in Marburg only in winter semester 1924-1925. Thus, she heard Heidegger's lectures on Plato's Sophist but did not have the Aristotelian rhetorical background from the Summer Semester lectures. Student notes of Heidegger's lectures, including those on rhetoric, were circulating in Marburg, but we do not know if Arendt ever read them. ${ }^{17}$ I think it unlikely that she worked with the Mitschriften on rhetoric. Certainly, notes attesting to her 1953 reading of Aristotle's Rhetoric (which we find in her Denktagebuch) have none of the explosive conceptual energy characterizing Heidegger's 1924 gloss. ${ }^{18}$ And, in 1972, when Heidegger indicated that he had neither the manuscript nor any copies von der wichtigen Vorlesung SS 1924 über Aristoteles, Rhetorik, Buch II, Arendt could only report that these lectures were unfortunately not among the Nachschriften that had recently surfaced courtesy of Heinz Lichtenstein. ${ }^{19}$ Thus, she was working with an empty category when - in a text on the relationship between philosophy and politics composed in 1954 (and later revised) - she declared that for the Greeks 'rhetoric, the art of persuasion' had been 'the highest, the truly political art.' Rhetoric' for her was only ever a husk word, one that she would use occasionally, without ever really knowing what it might mean. ${ }^{20}$ This is not something to be lamented. It is, I think, an opportunity. It is an opportunity to think Arendt's thoughts anew, from the inside, this time with a richer sense of something that she herself regarded as central.

The movement from Heidegger to Arendt is natural, conventional even. The movement from Arendt to Warburg is not. I propose, however, that we can insert Warburg into the gap that we have discovered in Arendt. Where Arendt spoke of 'the space of appearance', Warburg spoke of Denkraum (thought-space). On the one hand, a matrix of intersecting perspectives. On the other hand, a dislocation between inputs and outputs. Arendt spoke of the fullness of being that could be achieved in political energeia, that is, in the actualization of human being in political action. Warburg too spoke of energeia, but for him it was to be understood in the context of dunamis. That is, actuality was always embedded in possibility. And, for Warburg, this inextricability of stillness from motion was primarily visual. Just so, his great early discovery was that Renaissance art could be under- 
stood as a series of attempts to reinvent ancient approaches to the problem of how to represent motion in static works of art.

It is sometimes tempting to think of Denkraum as something like a space opening up between a thinking subject and a cognized object. This space then begins to look like freedom, indeed, like an enlightened exiting from the state of superstition. In fact, I would argue, it is more accurate (and more useful) to think of the term as marking out gaps between the various qualities constituting a phenomenon being perceived. Not all - indeed, very few (if any) - quality agglomerations of this kind will be definitions of the class of which they are members. Denkraum was the contingency manifested by relationships of non-mutualnecessitation among predicates. Most important, therefore, were those points at which Warburg glossed Denkraum as Hemmung, as a hesitating. ${ }^{21}$ This, one might say, was the zone of imaginative continuation, in which trajectories perceived in or implied by the world were projected into possible futures. Hesitation derived from a multiplicity of possibilities and from an inability to decide. It was as if visual attentiveness, as if seeing something, was a kind of living in a variety of possible futures simultaneously. The space of thought, the Raum of Denken, was thus a space demarcated by the distances between these possible futures.

For Warburg, European cultural history had captured this Denkraum qua hesitation in a variety of ways. It was Medea in Ovid's reworking of Euripides, where she was famously conscious of the possibility of the better even as she was enacting the worse. It was Lorenzo de' Medici in Ghirlandaio's Sassetti Chapel, where he held out his hand in a gesture that stood midway between greeting and holding at bay. And it was Claudius Civilis in Rembrandt's historical painting, where the moment of swearing into a political conspiracy was saturated with individualized foreboding. ${ }^{22}$ The enemy of possibility was necessity. And necessity was indeed Warburg's enemy. In 1917, in his talk on prophecy in the age of Luther, this involved an investigation of the human capacity for prostration before the goddess Fate. In 1923, in his famous talk on Pueblo Indians, this became the depiction of a primitive human tendency to assume that decisive moments were fully determined in the sense that each and every detail in such situations could bear interpretative scrutiny and that all such details were equally telling.

I would argue that, if we place Warburg in a sequence after Arendt, we gain an ability to think Warburg's concepts more politically. And, indeed, the beginnings of such a repositioning are to be found among his papers in London. On my account, the 'Mnemosyne' project, the magnum opus left unfinished when he died in 1929, was a kind of visual training in equipoise. The image tables we find in the Mnemosyne Bilderatlas constitute a series of requests to adopt response-poses to the images on display. Equipoise was a kind of facility in running through response-poses without losing one's affective balance. Political capacity, one might 
continue, was precisely this kind of talent in agile counterposing. And I think that this is why, when he thought about what the phrase restitutio eloquentiae might cover as a title for the Mnemosyne project, Warburg included not only style, pathos, and ethos but also magnanimitas - for magnanimitas was the great early modern political virtue. ${ }^{23}$ It was 'a greatness and capaciousness of soul' that never lost its balance in the political world of multiple and rapidly changing possibilities. And this, Warburg had said, was the defining feature of Lorenzo de' Medici as a politician: affective range. ${ }^{24}$

At the center of Walter Benjamin's work, I claim, there was a core interest in being drawn into a multiplicity of possibilities that was very similar to Warburg's. In fact, one could narrate the sequence of Benjamin's intellectual interests by tracing variants of actualization-caught-in-the-midst-of-possibility: Stillstand, Starre, Zögern, Unentschloßenheit, Entschlußunfähigkeit, Spannung, Schwanken, Spiegelung, Unendlichkeit, Vexierbild, Schwebezustand, Kontrapost, Debatte, Dialektik, Sophistik, Alarmbereitschaft, Geistesgegenwart. These were his terms, and they marked out a zone of core interests. And, indeed, the specific connections between Warburg and Benjamin have been the object of scholarly interest recently - although, at this point, I do not think we have really understood this possible never quite actualized proximity. In 1928, Benjamin had his newly published book on early modern German drama sent to the Kulturwissenschaftliche Bibliothek Warburg, hoping that it might gain him entry into the Warburg Circle in Hamburg. It did not. What was the point of possible connection? Briefly put, it was Dürer's Melencolia I. In the gloss of the Warburgians, this was a depiction of the simultaneity of a gloomy situatedness in the middle of influence and an ingenious perspicacity with regard to the multiple possibilities fanning out from, and structuring, that situation. ${ }^{25}$ The anxiety of influence underwrote creativity. Ingenuity was freedom. And freedom here was being understood as an artifact of the imagination, not the will. For Benjamin, on the other hand, Dürer's image glossed the early modern sovereign as represented in German Trauerspiele. The absolutist concentration of power opened up such an intense world of possibility that the monarch became immobilized at the moment of decision. This was a hyperconsciousness of the consequences, intended and unintended, of every move made - or not made. In this way, ingenuity generated an oversupply of freedom, at which point freedom became debilitating. This, one might say, was Hamlet. ${ }^{26}$

For Warburg, Denkraum had been a way of dislocating oneself from monomanias of sensory input and imaginative continuation, in fear and the like. For Benjamin, Schwebezustand - one of the terms he used for the state of uncertainty deriving from an equilibrium of proximate and incompatible possibilities - was a motif for politicization. Like the Aristotelian Heidegger and the Augustinian Arendt, Benjamin perceived a world around him in which attention, Aufmerksam- 
keit, was continually being overwritten by habit, Gewobnheit. His politics was a politics of politicization. That is, his task was simply deploying Aufmerksamkeit in such a way that the established modes of habit were called into question.

One sees this politics of politicization everywhere in Benjamin. One finds it, for example, in his manifesto for a children's proletarian theater, written in collaboration with Asja Lacis. There, the task of educating the young for revolution became the task of showing children how to understand the statements they heard as implicit requests. And the twist was that one could only respond appropriately to a request if one demonstrated that one's actual response to that request had been but one of several possible responses. ${ }^{27}$ One also finds this politics of politicization in Benjamin's radio plays. The point of broadcasting a pair of petitions for a pay raise in I93I (one inept, the other cunning), for instance, was not to foster better bargaining practices in a working class struggling in the middle of a depression. The point was to highlight the differences between two possibilities in order to reveal not only structures of power in the workplace but also their contingency. ${ }^{28}$

The Heidegger-Arendt-Warburg-Benjamin lineage that I am laying out is not peripheral to Benjamin's main interests. I am claiming that it runs directly through the center of his project. Take the 'Kunstwerk' essay, for instance, the most canonical of Benjamin's canonical texts. What we have there, I would argue, is a sudden and brilliant consciousness of the opportunities provided by new media. It was not that photography and film were for Benjamin intrinsically better media. They did not presage utopian political solutions. The crucial fact was simply that they were new. Film cut through sensory habituation, not because there could be no such thing as visual cliché and not because film could not itself constitute a training for and domestication of the senses, but simply because cinema was novel. New media provided new opportunities for Aufmerksamkeit that is, for an awareness of how things were in the context of how they might be. This, I would argue, was a re-emergence of Kairos - or, as Benjamin termed it, the Zehntelsekunde, the tenth-of-a-second made visible by photography and film in slow-motion. ${ }^{29}$

Given the massive amount of scholarly attention that has been given to the intellectual legacy of the Weimar Republic, it might seem remarkable to propose that we have lost anything - let alone an entire vision of the rhetorico-political as a humanities interdiscipline. What we have lost, I would argue, is a vision of how philosophy, political theory, art history, and literary criticism (as they were instantiated by Heidegger, Arendt, Warburg, and Benjamin) might all participate in the description and analysis of human being as a series of actualizations saturated by - indeed, constituted by - possibility. To be sure, this particular interdiscipline never quite existed in Weimar itself. Ultimately, Heidegger did 
not pursue the Aristotelian-rhetorical version of himself. And Arendt did not follow this line of inquiry on his behalf. Warburg never interpreted his interests in stasis and kinesis through Arendt's analysis of love in Augustine. And, whereas Benjamin did take up Warburgian interests in melancholy, he did not thereby gain entry to the Warburgian community of inquiry in Hamburg. These things could have happened, but they did not. And, although each of these thinkers has been canonized as a titan of twentieth-century thought, we have not yet perceived them as a gestalt. What we have lost, therefore, is the possibility of seeing these thinkers together and the possibility of thinking their projects together. But this is not an irrevocable loss. Unlike political possibilities, intellectual historical possibilities remain possible.

By way of conclusion, a word or two on my presuppositions. When I say that intellectual historical possibilities remain possible, I mean that thoughts can be thought again and anew. A sentence can be thought again in the sense that one can suspend one's disbelief and repeat a sentence in the mode of provisional assertion at the same time as one - to a degree and only with great discipline - contextualizes that sentence within an array of simultaneously asserted sentences. The 'meaning' of these sentences is then to be understood in terms of their inferential consequences. Ultimately, it may be impossible to repeat the coming together of a contexture of sentences in inference with absolute precision. Often, there will have been too many sentences in play at any one time, and only some of them will have been brought together explicitly in the extant historical record. What is more, quarantining a certain set of sentences off from those other sentences that, at any given moment, historians might entertain as assertions is only an imprecise art. One can balt the inferential cross-pollination of sentences only with difficulty (although one can organize it). Nevertheless, the reconstruction and reenactment of inference is possible to a significant degree. In this sense (and to this degree), it is indeed possible to think thoughts 'again'.

Furthermore, one can think a thought anew in the sense that, instead of supposing that one may only contextualize the sentences of a particular author in the middle of other sentences by that same author (or in the middle of sentences all simultaneously authorized by that same author), one can propose more complex historical contextualizations in which, for example, Weimar-era sentences join with other Weimar-era sentences, constituting thereby inferential matrices. In this way, historically sensitive de- and recontextualizations become possible, for, just as one can decontextualize a sentence from Aby Warburg's corpus of writings and recontextualize it in a tissue of Benjaminian sentences, so one can rethink a Weimar sentence, or a contexture of Weimar sentences, in post-1933 and postI945 contexts. Ultimately, one can say, 'presentism' is just another form of historical recontextualization. As in all such cases, one can do this work with great 
historical sensitivity or great historical insensitivity. Perhaps thinking the past in the context of the present is particularly fraught (because of the vividness and insistence of one's actual, and not merely feigned, convictions), but it is not basically different from the general historical work of thinking conceptual afterlives. After all, to think a sentence is to think the range of its potential applications. And time is the great discoverer of potential applications. I conclude, therefore, that, although there will be distinctions between them, the history of thought and thought itself cannot be radically separated..$^{30}$

\section{Notes}

I John G. Gunnell, 'American Political Science, Liberalism, and the Invention of Political Theory', American Political Science Review 82 (I988), 7 I.

2 Sheldon Wolin, 'Political Theory as a Vocation', American Political Science Review 63 (1969), 1062-1082.

3 The Penn State decision has created a good deal of discussion. See, as a point of departure, the symposium on 'Political Theory as a Profession and a Subfield in Political Science?', Political Research Quarterly 63 (2010), 654-701.

4 Max Weber, Political Writings, ed. Peter Lassman and Ronald Spiers (Cambridge: Cambridge University Press, I994), I45, 3 I 3.

5 Carl Schmitt, Politische Theologie: Vier Kapitel zur Lebre von der Souveränität (Munich: Duncker \& Humblot, I922), 9.

6 Leo Strauss, 'Anmerkungen zu Carl Schmitt, Der Begriff des Politischen', Archiv für Sozialwissenschaft und Sozialpolitik 67 (1932), 732-749.

7 Hans Baron, 'Cicero and the Roman Civic Spirit in the Middle Ages and Early Renaissance', Bulletin of the John Rylands Library 22 (I938), 73. See also Hans Baron,'Einleitung', in Leonardo Bruni Aretino: Humanistsche-Philosophische Schriften (Leipzig: B.G. Teubner, I928), $2 \mathrm{I}$.

8 Theodor W. Adorno, Kierkegaard: Konstruktion des Ästhetischen (Tübingen: Mohr, I933).

9 Martin Heidegger, Grundbegriffe der aristotelischen Pbilosophie, ed. Mark Michalski (Frankfurt a. M.: Vittorio Klostermann, 2002); Daniel M. Gross and Ansgar Kemmann (eds.), Heidegger and Rhetoric (Albany: SUNY Press, 2005); Josef Kopperschmidt (ed.), Heidegger über Rhetorik (Munich: Wilhelm Fink, 2009). The frame text is Theodore Kisiel, The Genesis of Heidegger's Being and Time (Berkeley: University of California Press, I993).

Io Heidegger, Grundbegriffe, 6r: '[H] eute haben wir eine primitive oder gar keine Vorstellung von Sprache. Der konkrete Beleg für die Ursprünglichkeit des Sehens ist die ganze Rhetorik'.

I I Ibid., I I 4 ff.

I2 Ibid., I 35: 'Die Rhetorik macht den Anspruch, selbst Politik zu sein'.

I 3 Ibid., I7I: 'Die Mitte ist nichts anderes als der Kaıрos, die Gesamtheit der Umstände, das Wie, Wann, Wozu, und Worüber'.

I4 Martin Heidegger, Sein und Zeit (Frankfurt a. M.: Vittorio Klostermann, I977), I84.

I5 Christian Graf von Krockow, Die Entscheidung: Eine Untersuchung über Ernst Jünger, Carl Schmitt, Martin Heidegger (Stuttgart: Ferdinand Enke, 1958). 
I6 For a more concerted treatment of these issues, compare my 'The Polis and Its Analogues in the Thought of Hannah Arendt', Modern Intellectual History 7 (2010), I23-I49, and 'The Origin and Character of Hannah Arendt's Theory of Judgment', Political Theory 38 (2010), 367-393.

I7 At this juncture, an essential contribution is Theodore Kisiel's 'Rhetorical Protopolitics in Heidegger and Arendt', in Heidegger and Rhetoric, I $3 \mathrm{I}-\mathrm{I} 60$.

I 8 Hannah Arendt, Denktagebuch, ed. Ursula Ludz and Ingeborg Nordmann, 2 vols. (Munich: Piper, 2003), vol. I, 408-420.

I9 Hannah Arendt and Martin Heidegger, Briefe 1925 bis 1975 und andere Zeugnisse, ed. Ursula Ludz (Frankfurt a. M.: Vittorio Klostermann, 2002), 23 I-236.

20 Hannah Arendt, 'Philosophy and Politics', Social Research 57 (I990), 73-74. Jacques Taminiaux, 'The Platonic Roots of Heidegger's Political Thought', European Journal of Political Theory 6 (2007), 24ff.

2I Aby Warburg, 'Bilder aus dem Gebiet der Pueblo-Indianer in Nord-Amerika', in Martin Treml, Sigrid Weigel, and Perdita Ladwig (eds.), Werke in einem Band (Frankfurt a. M.: Suhrkamp, 2010), 56I.

22 Warburg Institute Archive, III.I I.2.I, I05-I06. Aby Warburg, 'Bildniskunst und florentinisches Bürgertum', in Die Erneuerung der heidnischen Antike: Kulturwissenschaftliche Beiträge zur Geschichte der europäischen Renaissance, ed. Gertrud Bing, 2 vols. (Leipzig: B. G. Teubner, I932) vol. I, I02.

23 Warburg Institute Archive, III.I I 3.5.2, 23.

24 Warburg, 'Bildniskunst und florentinisches Bürgertum', I I o: Lorenzo's specificity was 'daß sein seelischer Umfang durch die Schwingungsweite und vor allem durch die Intensität der Schwingungen das Durchschnittsmaß phänomenal überschreitet'.

25 Erwin Panofsky and Fritz Saxl, Dürer's Melencolia I: Eine Quellen-und Typen-Geschichtlichen Untersuchung (Leipzig: B.G. Teubner, 1923), 7I-72.

26 Walter Benjamin, Ursprung des deutschen Trauerspiels, in Gesammelte Schriften, ed. Rolf Tiedemann and Hermann Schweppenhäuser, 7 vols. (Frankfurt a. M.: Suhrkamp, I977), vol. I, 323-335.

27 Walter Benjamin and Asja Lacis, 'Programm eines proletarischen Kindertheaters', in Gesammelte Schriften, vol. 2, 763-769.

28 Walter Benjamin and Wolf Zucker, 'Gehaltserhöhung?! Wo Denken Sie Hin?' in Gesammelte Schriften, vol. 4, 629-640.

29 Walter Benjamin, 'Das Kunstwerk im Zeitalter seiner technischen Reproduzierbarkeit', in Gesammelte Schriften, vol. I, 499.

30 I cannot fully articulate this line of thinking here. For a more sustained explication, see David L. Marshall,'The Implications of Robert Brandom's Inferentialism for Intellectual History', History and Theory 52 (2013), I-3I. 


\title{
XI \\ The Humanities
}

\author{
AND THE
}

Social Sciences
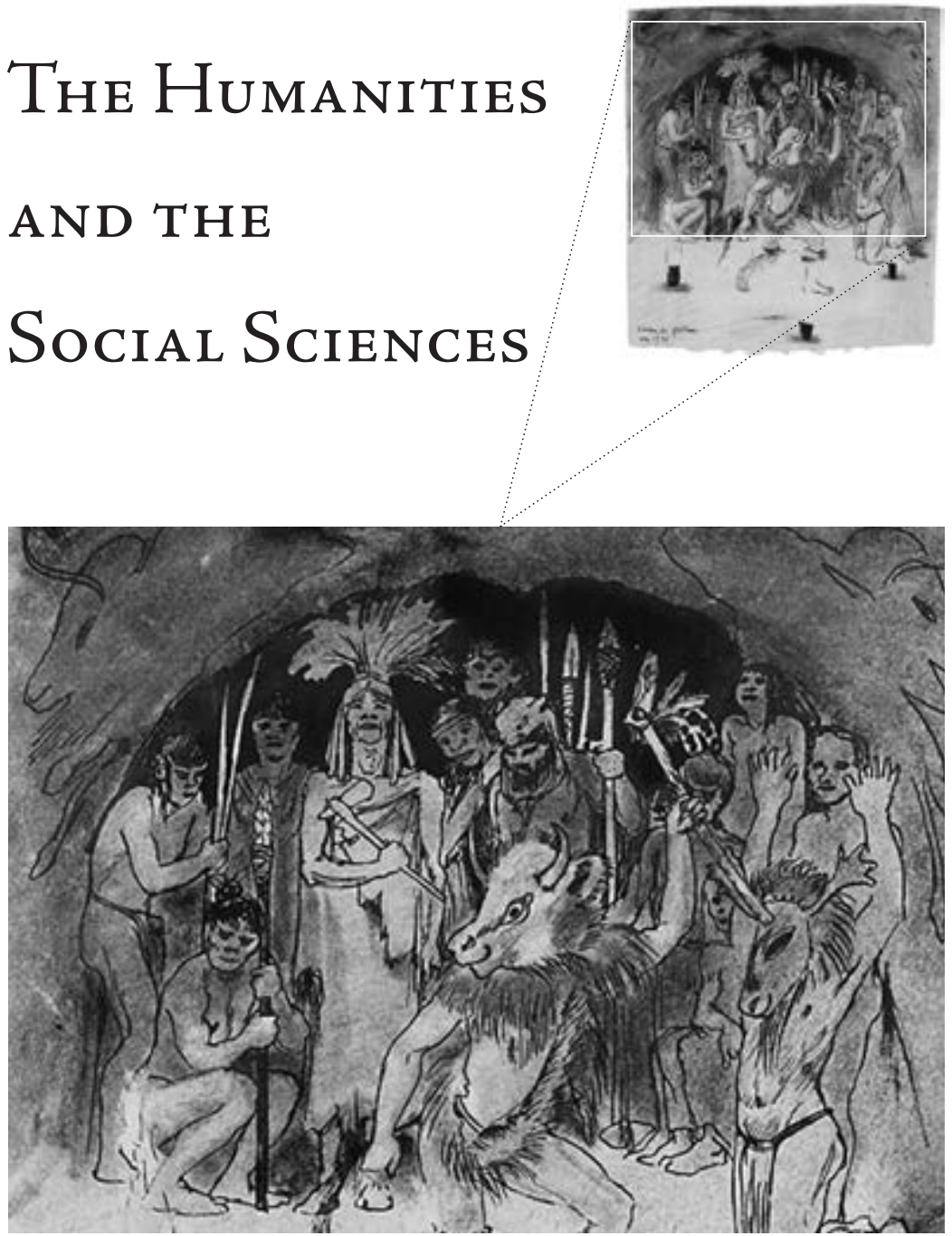



\title{
II+I Explaining Verstehen \\ Max Weber's Views on Explanation in the Humanities
}

\author{
Jeroen Bouterse
}

Max Weber is, of course, famous as one of the founding fathers of sociology. From the perspective of a threefold division of scholarly activity - natural sciences, social sciences, and humanities - it might seem odd to devote focused attention to him in a discussion of the humanities.

However, the distinction between social sciences and humanities itself deserves historical attention: there is obviously some overlap both in the object and in the interests of those clusters of disciplines. They are both interested in what people do and have done, broadly speaking. They probably do so differently, constructing their research object in different ways and using different vocabularies and concepts. But importantly, in Weber's time the vocabularies pertinent to the study of human culture and society were subject to fierce debate. If in this context Weber developed a position that contributed more to twentieth-century social science than to the humanities, this does not mean that his position at the time was only relevant to a social-scientific perspective. These were categories still in the making.

This paper places Weber's formulation of the position of the human sciences in relation to the challenge to their autonomy posed by the rise of psychology as a scientific discipline - a challenge that was not just intellectual but also institutional: the question whether university chairs in philosophy ought to be given to psychologists as well was a live one, for instance. ${ }^{I}$ We will see how experimental psychology backed up its claim to belong the human sciences - and, in fact, to be the foundational human science; and we will see how advocates of humanistically oriented disciplines resisted the intrusion of such a psychology in their domain.

Before turning to Weber, we will look at two other attempts to counter the perceived threat that psychology posed to the autonomy of what can pragmatically be called the humanistic disciplines: by Wilhelm Windelband and Heinrich Rickert. The argument will be that while Windelband and Rickert responded by redefining the humanities as individualizing disciplines separated from the 
search for regularities, Weber developed another way of meeting the challenge, in which interpretation and the search for lawlike patterns could be combined.

\section{Windelband and Rickert: Expelling psychology from the humanities}

There were several traditions in dialogue with which Weber was to develop his project for an interpretive sociology. Of these, the strongest intellectual influence on his own theoretical reasoning was the neo-Kantian school represented chiefly by Wilhelm Windelband and Heinrich Rickert ${ }^{2}$ From them Weber inherited the problem of the status of the 'Geisteswissenschaften', as well as part of the solution: they shared the opinion that the study of human culture should be qualitatively different from that of nature, but that the former was not necessarily inferior to the latter.

Windelband noted that a once plausible distinction between these two - based on a substantive difference between Natur and Geist - had lost its attractiveness, but that there remained a very important logical division within the empirical sciences: that between the search for knowledge of general laws on the one hand, and the search for individual knowledge on the other. This was the difference between 'nomothetic' and 'idiographic' sciences, a difference located not in the studied material itself, but in the treatment of that material. ${ }^{3}$

This logical distinction conveniently implied that psychology could be evicted from the domain of the Geisteswissenschaften, which were now identified as by definition idiographic: psychology was a science of the mind, but its treatment of the material had more in common with the natural sciences in that it, too, sought to formulate general laws: 'the substantive differences are minimal compared to the logical identity which all these disciplines have with respect to the formal nature of their knowledge goals: they are always looking for the laws in events.'

Windelband acknowledged that causal knowledge depended on general statements but that individual personality withstood such a reduction to general categories: it was 'causeless', and therefore 'free'. ${ }^{5}$ This reasoning would run the risk of leaving human action incomprehensible were it not for the possibility of intuitive understanding: only by reliving the past in its fullness could one avoid using the abstract concepts which were (according to Windelband) by definition inappropriate for the understanding of free action. This freedom together with intuitive understanding and the logical distinctness of the idiographic sciences served as barriers keeping 'nomothetic' psychology away from the study of human culture.

This self-definition of the sciences of man with psychology left out was developed further by Rickert. He, too, started from the assumption that the division of the sciences by their subject matter was outdated: the prime example was, 
again, psychology, which happened to occupy itself with 'mental being' instead of physical nature, but which could not therefore claim to be anything else than a natural science. ${ }^{6}$ Psychology, Rickert recognized, might strictly be a Geisteswissenschaft for its subject matter, but it was not therefore a Kulturwissenschaft - and the cultural sciences embraced in practice all objects of the study of religion, law, history, philology, political economy, etc., that is, that of all "humanities" with the exception of psychology'?

Rickert warned that if these disciplines were grouped according to their occupation with human mental life, psychology would become the principal basis of all cultural scholarship, understood in its elevated sense.. Such an intrusion of a discipline so strongly oriented toward the natural sciences was unacceptable. But what, then, were the cultural sciences? Rickert proceeded from the idea that reality was infinitely large and describable in infinitely many ways, and that therefore any attempt to grasp it conceptually had to be simplifying and selective. The nomothetic sciences did this by generalizing, and this was indeed one option. But Windelband's idiographic sciences were originally defined by their ambition to describe a part of historical reality in its totality, which they could in fact never hope to do; so what was their principle of selection?"

Rickert concluded that it must be value-relatedness: the 'essential' was selected on the basis of the values of the historian - and according to Rickert, the attribution of cultural value to historical phenomena or persons was mostly based on their uniqueness, on those aspects that made the phenomenon or person in question a unique historical 'Individuum'. By this supposition, cultural scientific interest was the logical complement to natural scientific interest, which was aimed at the general. ${ }^{10}$ Accordingly, the kind of 'psychology' relevant to the cultural scientist was qualitatively different from that advocated by representatives of scientific psychology.

As historians were occupied to a large extent with the mental life of their actors, it was understandable that they were supposed to be good 'psychologists,", but this had nothing more to do with scientific psychology than had the psychological intuition of artists. ${ }^{12}$ Rickert still distinguished between a general conceptual' grasp of the psyche, and an individual 'intuitive' grasp of it: the distinction between natural and cultural science, in that respect, went together with a distinction between explanation and understanding: Erklären and Verstehen.

We have to distinguish explanation [Erklären] and understanding [Verstehen]. We want to explain the nature of physical being, in so far as we search for its general laws. Mental life in history however we want to understand, as we re-experience it in its individual course. Once this distinction is clear, one will cease to think it self-evident that the historian should practice scientific psychology in order to enhance his 'psychological' understanding, 
and one will not consider the foundation of the historical sciences to lie in any science of the mind. ${ }^{\mathrm{I3}}$

That last remark was in explicit opposition to Wilhelm Wundt, the chief spokesman of scientific psychology, 'who primarily wants', said Rickert in his efforts to refute him, 'to make psychology into the foundation of the humanities.. ${ }^{14}$

He seems not to have exaggerated Wundt's ambition, for indeed a few years earlier, Wundt had defined the status of his scientific psychology in relation to the other disciplines precisely in the way that bothered Rickert so much and to which he was now formulating a coherent response. According to Wundt,

as the science of the universal forms of immediate human experience and their combination in accordance with certain laws, [psychology] is the foundation of the mental sciences. The subject-matter of these sciences is in all cases the activities proceeding from immediate human experiences, and their effects. Since psychology has for its problem the investigation of the forms and laws of these activities, it is at once the most general mental science, and the foundation for all the others, such as philology, history, political economy, jurisprudence, etc. ${ }^{15}$

For Wundt, these latter disciplines were primarily Geisteswissenschaften and thus supposed to sail under the flag of the most fundamental science of the mind; Rickert had now redefined them as Kulturwissenschaften and thus supposedly secured their independence from Wundtian psychology.

\section{Weber and the explicability of human action}

We have seen that both Windelband and Rickert dismissed psychology in part because in their view the kind of knowledge relevant to the idiographic or cultural sciences could not be produced by the generalizing knowledge of psychology. Instead of this generalizing conceptual knowledge, both placed an 'intuitive grasp' or 'reexperiencing' on the foreground. This approach was unattractive to Weber, for whom all science revolved around explanation, as we will see.

Weber wrote his most famous methodological essays after a period of severe mental troubles. The first of these essays was devoted to a critique of two of the most important members of the 'historical school' of political economy, Wilhelm Roscher and Karl Knies. ${ }^{16}$ Of these, the latter two (about Knies) are most important for our current purpose. In Knies' work, Weber found several errors that he considered to be so common that a lengthy general treatment of them was justi- 
fied - to such an extent that most of the dialogue turned out to be with other thinkers than Knies.

Weber frontally attacked Knies' idea that free and purposeful human action was opposed to regularity. Weber connected this wrong opinion to the intuition that human action was in some sense specifically 'creative', as opposed to the mechanical causality of nature - a mistake that Weber identified in Wundt as well and to which he attributed Wundt's overambitious claims on the status of psychology. The notion of creativity was inherently value-laden, Weber maintained, and reading it as something objective (within the domain of an empirical science) suggested that empirical disciplines could deliver value judgments, quod non. Wundt's idea that there could be laws pertaining to the production of value and meaning amounted to this, and was therefore dangerous: psychology should not claim to provide a worldview. ${ }^{17}$

However, Weber's criticism of the uses of psychology extended only to its muddled relation with value judgments, and did not constitute a wholesale dismissal. Indeed, Weber's intention was to improve psychology: 'psychology as an empirical discipline only becomes possible through the elimination of value judgments. ${ }^{18}$ Such a purified scientific psychology was potentially equipped for a fruitful search for causal explanations of whatever it would like to investigate. In fact, Weber openly invited psychology to deliver any explanation of human mental phenomena, provided, of course, that it could justify these explanations. How could he still refuse to acknowledge it as the foundational science for the study of human culture?

There was, of course, the logical argument that individual phenomena could never be deduced from general laws alone, and in another context Weber did use that argument: 'even today the opinion is not completely eradicated that it would be the task of psychology to play a role comparable to mathematics with regard to the individual "humanities". ${ }^{19}$ But, he argued, even if by psychology or another science all possible causal relations had been discovered, in no way could the reality of life be deduced from these "laws" and "factors" [...] since for our knowledge of reality what matters is the constellation in which these (hypothetical!) "factors" $[\ldots]$ are found'. ${ }^{2}$ This observation drew on Windelband's argument that individual reality was always the product of general laws and individual initial conditions, and could therefore not be explained by exclusive reference to these general laws. ${ }^{21}$ However, we may note that this argument guaranteed only a limited amount of disciplinary autonomy for the cultural sciences. For comparison: even a positivist like Hempel would grant this point. ${ }^{22}$ There was more work to be done.

Returning to Knies, Weber coolly dismissed the latter's view of the irrationality of human behavior: 'in "lived" reality there is no question whatsoever of a specific "incalculability" of human action. ${ }^{23}$ Did people not 'take into account' the reactions of others to their own actions? Granted, the actions of others could not 
be predicted with full certainty or in toto, but was not the same true for the weather? ${ }^{24}$ When it came to a phenomenon in its total individuality, certain prediction was impossible - at best it could be said in retrospect that the phenomenon had not occurred in contradiction with the known regularities. ${ }^{25}$

There was a difference between the explanation of human action and that of natural events, Weber said, but it was not that human action was less rational - on the contrary! Human action could not only be understood as 'possible' in relation to general laws, but was also accessible to understanding: 'Verstehen, that is, establishing a concrete "motive" (or a complex of motives) that can be "internally" "reexperienced" and that we can attribute to it with more or less certainty depending on our source material. ${ }^{26}$ Apart from possible, a historical action could be considered teleologically rational, adequately motivated, and as such be understood. "The "interpretability" [Deutbarkeit] here adds to the "calculability" [Berechenbarkeit) when compared to natural phenomena, which cannot be interpreted' ${ }^{27}$ To the extent that a historical person acted irrationally, his behavior could in theory still be explained by psychological laws, but then it was both less understandable and less free. ${ }^{28}$

Human action, then, in so far as it was not regulated by natural laws, was actually more explicable than natural phenomena; moreover, even if it could be consistently related to empirical rules, this in itself would not give us the feeling of having understood it adequately ${ }^{29}$ - 'we will not possess this understanding as long as we do not also have the possibility of inner "replication" [Nachbildung] of this motivation in our imagination. ${ }^{30}$ The kind of knowledge appropriate to human action, then, was closely related to the notion of Versteben, considered as a kind of inner experience.

But, Weber hastened to add in a footnote, 'we will see that one can only speak of "replication" in a very improper sense., ${ }^{31}$ There was a trap that Weber did not want to fall into, and that was that emphasizing the difference between these two kinds of knowledge came close to separating them altogether - to concluding that the 'objectifying' and the 'subjectifying' method had nothing to say to each other. ${ }^{32}$ This was a position that Weber took very seriously, but that he judged to be fundamentally incorrect. In the patient argument against it that covered more than half of his two essays against Knies, Weber maintained that, on the one hand, there was something specific about interpretation that could not in any useful sense be reduced to scientific psychology, and that on the other hand this did not close the door to psychology but instead gave every discipline its proper place. According to this view, scientific psychology would be neither all-powerful nor irrelevant to the understanding of human action.

An opposing view Weber discussed was that of Hugo Münsterberg, who radically separated 'direct "understanding", that is, an empathizing with, reexperienc- 
ing, feeling, appreciating and valuing of "actualities"' ${ }_{33}$ from value-free, analytical knowledge. History, according to him, was a subjectifying discipline whose object and way of knowing had no relation to the methods of objectifying knowledge. ${ }^{34}$ Weber objected that phenomena that could be considered to be irreducible to historical questions were not therefore necessarily out of reach of the objectifying sciences; a psychological analysis of, for example, religious hysteria could very well increase our understanding of a historical phenomenon. ${ }^{35}$

It could also be the case, of course, that the results of experimental psychology did not exceed the understanding that could anyway be reached by common sense - especially the complexity of individuals, in whom an infinity of causal relations was combined, made this plausible. ${ }^{36}$ But in this, again, the mental domain was no different from the physical. Abstract laws could provide valuable insights - or not; and in that respect psychology was (a priori) neither more nor less relevant than any science.

The rules of experience of psycho-pathology and the laws of psycho-physics come into the consideration of history [as a discipline] only in precisely the same sense as physical, meteorological, biological knowledge. That is to say: it is ever dependent on the individual case whether history or political economy has cause to take note of the robust results of a psycho-physical nomothetic science [Gesetzeswissenschaft]. ${ }^{37}$

The notion that psychology had a special status was dismissed, then:

[T] the assertion one sometimes hears, that 'psychology' [... ] would have to be a universally indispensable 'foundational science' for history or political economy, since all historical and economical phenomena go through a 'mental' stage and have to go through one, is, of course, untenable. ${ }^{38}$

One could as well say that acoustics was the foundational science for the historical understanding of political speech. Psychological concepts, rules or statistics in so far as they could not be interpretively understood ought to be treated as simply 'given' - and not therefore irrelevant, but also not satisfying a specific historical interest.

This historical interest Weber defined, like Rickert, in terms of values. Knowledge of reality was knowledge of individual phenomena; but there were infinitely many of those, and any one of them was related to infinitely many causes. ${ }^{39}$ There was nothing in the phenomena itself which could govern the selection of a finite part of these. ${ }^{40}$ 'In this chaos', Weber said, 
order comes only from the circumstance that in every case only a part of individual reality has value and meaning [Interesse und Bedeutung] to us, while only that part stands in relation to the cultural values [Kulturwertideen] with which we approach reality. ${ }^{4 \mathrm{I}}$

Phenomena were of scientific interest in so far as they related to cultural interest - not, of course, in the sense that science was only about valuable phenomena; prostitution, money and religion could all be of equal interest; this simply meant that they were relevant to the cultural interests of the scientist. ${ }^{42}$

\section{Interpretation as explanation}

In Weber's view, interest in the study of cultural (value-related) facts as such was necessarily connected to understandable human action. ${ }^{43}$ This, then, remained the legitimate and unchallenged domain of the historical sciences. That is, if Verstehen was a scientifically legitimate business. Could it be? According to Weber it could, as long as it was disconnected from value judgments, as long as its results were treated as nothing more than intellectual statements, and as long as it served the intellectual goal of causal understanding of actions.

Weber recognized that interpretation (Deutung) could mean both the attribution of value and the understanding of motives, but these meanings had to be kept clearly distinct. ${ }^{44}$ Of science Weber demanded abstinence from value judgments at all times - interpretation as valuing was by definition not a scientific act. Of course, a scholar could in his interpretation of a historical event or person make use of value-related concepts to which he, as a valuing human being, also took a stance - but this was a matter of Wertbeziebung, not Wertung; in service of objectifying knowledge, the use of value-laden concepts was not an act of Stellungnabme, but of Verstehen. ${ }^{45}$

Further, the notion of Verstehen as a kind of 'experience' (Erlebnis) had to be qualified. Too often the claim was made that the 'inner' experience of historical knowledge was in some way more reliable than the kind of experience on which natural scientific knowledge was based; that intuitive reexperiencing was a privileged kind of understanding with special certainty ${ }^{46}$ Instead of embracing this view as an affirmation of the autonomy of the interpretive science, Weber demolished it completely.

Intuition was no prerogative of the historical sciences ${ }^{47}$ - mathematicians could also use their imagination as a starting point, for example. ${ }^{48}$ The point was that one's own inner 'experience' in itself did not constitute understanding of the other - someone who tried to empathize with an acrobat felt neither what the acrobat actually felt, nor what he himself would feel in his place, but something 
with an indefinite relation to this; ${ }^{49}$ and even that feeling was not 'knowledge', for it was something pre-conceptual. In order to become knowledge, it first had to be transformed into an articulate statement.

This process of transformation was required, for even one's own experience could not be reproduced in thinking. ${ }^{50}$ Against the opinion that concepts were restricted to relations between things and that understanding of the individual things themselves was necessarily a-conceptual and therefore artistic and intuitive, Weber placed his view that an empirical science could very well create a Dingbegriff that was not an exhaustive Anschauung but an artificial product of thought - a concept of something individual..$^{51}$ It had to create such artificial concepts, moreover, because only concepts could be elements in statements of which the validity could be judged..$^{52}$

For most importantly, the validity of an interpretation was still only a hypothetical matter which had to be subjected to empirical criticism, "just, from a logical perspective, like the hypotheses of the "natural sciences". ${ }^{53}$ Rationally understandable actions might possess more Evidenz than non-rational events, but this understandability should not be confused with empirical certainty, ${ }^{54}$ which could by definition only be reached by empirical means: 'all "understanding" presupposes (psychologically) "experience" and is (logically) only demonstrable as valid by reference to "experience". 55

In this way, then, understanding was an intellectual business like all others. It had its point of departure indeed in 'co-experience' (inneres Mitmachen) or 'empathy' (Einfüblung), but for the sake of knowledge, this had to be selectively articulated, 'a "co-experience" of teleologically selected elements. ${ }^{56}$ The bridge between indefinite feelings and articulate judgments was constituted by values ${ }^{57}$ - valuerelations defined what was essential and could therefore serve as guides in the construction of historical units:

[T] he 'historical unit' [bistorisches Individuum], even in its special sense of 'personality', can logically only be a 'unity' that is artificially constructed through value-relations, and therefore 'valuing' is the usual psychological stepping-stone for 'intellectual understanding [Verständnis].58

One's own values were instruments in the service of understanding [Versteben], which is here the causal interpretation of the actions of others' ${ }^{59}$

For in its final goal, too, Verstehen resembled the treatment of individual natural phenomena:

the 'interpretive' investigation of motives by the historian is a causal attribution in a logically absolutely identical sense as the causal interpretation of some individual natural phenomenon, for its goal is the identification (at 
least as a hypothesis) of a 'sufficient' condition [Grund], just as this is the only possible goal of the research of complex natural phenomena, if what matters are the individual elements of those phenomena. ${ }^{60}$

Verstehen was not something radically opposite to Erklären, it was a form of it - in the historical sciences an essential one - and was in principle subject to the same procedures as any other kind of explanation within the empirical sciences. ${ }^{61} \mathrm{It}$ was a specific kind of explanation not because it was unscientific (that is, valuing, a-conceptual or noncausal), but because it concerned 'meaningful', value-oriented human action and worked by virtue of the fact that the scholar himself could (by means of his own value-orientation) interpret such meaningful action. ${ }^{62}$

It was an empirical question to what extent specific human action was actually meaningful, and as said before, psychological laws could provide a different kind of causal understanding if (and in so far as) it turned out not to be meaningful. This is best explained by the hypothesis of rationality: interpretation through the categories of "goals" and "means". ${ }^{63}$ Action was most understandable if it was 'teleologically rational': if the scholar could show that it served, given his knowledge of the 'objective' situation, as a means for the actor to reach a valued goal ${ }^{64}$ Of course, people did not always behave completely rationally, so this ideal-typical construction of what would be rational behavior should be compared to empirical evidence, after which it also served to show the causal scope of irrational elements in someone's actions, ${ }^{65}$ which were then open to scientific psychological explanation:

when our historical knowledge is confronted with behavior that is 'irrational' in the sense of 'not interpretable', our need for causal explanation [kausales Bedürfnis] will often have to satisfy itself with a way of 'grasping' [Begreifen] oriented upon the nomological knowledge of, for example, psycho-pathology, or similar sciences. ${ }^{66}$

Versteben and scientific psychology were neither reducible to each other, nor active on incommensurable terrains; they were complementary methods serving the goal of the historical sciences, explaining different kinds of elements within the causal network of one reality.

\section{Conclusion}

In contrast with the views of his neo-Kantian predecessors Windelband and Rickert, who tried to disconnect scientific psychology as a generalizing discipline from the historical or cultural disciplines arguing that their respective modes of 
understanding were incompatible, Weber decided that as sciences, these disciplines were working on the same terrain and could not simply ignore each other. All empirical sciences had in common that they attempted to construct objectively valid knowledge of aspects of reality, and for knowledge to be objectively valid meant for it to be value-free, conceptually articulate and empirically supported - there was no difference here between sciences occupied with the physical and the mental domain, nor was there a difference between generalizing and individualizing sciences. 'Scientific' psychology had to be purified from value-laden or metaphysical concepts, but the same was the case for historical understanding.

For the notion of Verstehen, this meant that in the sense of a subjectifying, valuing, intuitive act it had no place in science. The cultural scholar could, however, identify the motives of agents as causes of their behavior, motives which were connected to value-related concepts, which he in turn could understand because of his own value-relatedness. When his empathic 'feeling' was translated, by means of articulate Wertbeziebung, into definite concepts, and made part of intellectual statements applicable to empirical reality, it could serve the goal of causal explanation of those aspects of reality that were considered relevant, which was the goal of all empirical sciences.

It should serve this goal, moreover, because human action distinguished itself from other events precisely to the extent that it could only be 'understood', not explained by laws. In so far as human action was purposeful, it was best explained by the purpose toward which it was directed - by the values toward which it was oriented; in this case, Verstehen was not only possible, but appropriate.

\section{Notes}

I On the historical relation of experimental psychology to the philosophical tradition, cf. K. Danziger, Constructing the Subject: Historical Origins of Psychological Research (Cambridge, I990), I7-24.

2 The extent of Weber's debt to especially Rickert has been subject to some controversy. I consider the argument by T. Burger, Max Weber's Theory of Concept Formation: History, Laws, and Ideal Types (Durham, NC, 1976) to be right, who sees Weber's ideas on concept formation in the historical sciences as an elaboration of Rickert's theory, but the claim by Oakes (G. Oakes (1988), 'Rickert's value theory and the foundations of Weber's methodology', Sociological theory 6.I: 38-5I) that Weber has to accept Rickert's notion of objective value to be mistaken: for Weber, there is no contradiction between the subjectivity of values and the objectivity of science. A good assessment of Weber's development of Rickert's views is provided by F. Ringer, Max Weber's Methodology: The Unification of the Cultural and Social Sciences (Cambridge, MA; London, I997), 36-62.

3 W. Windelband, Geschichte und Naturwissenschaft (Strasbourg, I 894), esp. 26.

4 ' $[\mathrm{S}]$ achlichen Differenzen treten weit zurück hinter der logischen Gleichheit, welche alle diese Disziplinen hinsichtlich des formalen Charakters ihrer Erkenntnissziele besitzen: 
es sind immer Gesetze des Geschehens, welche sie suchen' (ibid., 24). Translations from the German in this text are mine unless indicated otherwise. Ibid., 39-40.

6 H.J. Rickert, Kulturwissenschaft und Naturwissenschaft: ein Vortrag (Freiburg, I899), I4I6.

7 '[A]lle Objekte der Religionswissenschaft, der Jurisprudenz, der Geschichte, der Philologie, der Nationalökonomie u.s.w., also aller 'Geisteswissenschaften' mit Ausnahme der Psychologie' (ibid., 2I-22).

8 'die vornehmste Basis aller in einem höheren Sinne gefassten Kulturwissenschaft' (ibid.).

9 Ibid., 3I-38.

Io Ibid., 45-47.

II Ibid., 40-4I.

I2 Ibid., 4I.

I 3 'Erklären und Verstehen müssen wir auseinander halten. Erklären wollen wir die Natur des psychischen Seins, indem wir nach seinen allgemeinen Gesetzen suchen, das Seelenleben in der Geschichte aber wollen wir verstehen, indem wir es in seinem individuellen Verlauf nacherleben. Macht man sich diesen Unterschied klar, so wird man es nicht mehr selbstverständlich finden, dass der Historiker zur Ausbildung seines 'psychologischen' Verständnisses wissenschaftliche Psychologie treiben müsse, und wird dann auch in keiner Wissenschaft vom Seelenleben, die mit allgemeinen Begriffen arbeitet, die Grundlage der Geschichtswissenschaften sehen' (Rickert, Kulturwissenschaft und Naturwissenschaft, 42-43).

I4 'der [...] vor Allen die Psychologie zur Grundlage der 'Geisteswissenschaften' machen will' (ibid., 4I-42).

I5 W. Wundt, Outlines of Psychology, trans. C.H. Judd (I 897), I6, cited by D.B. Klein, A History of Scientific Psychology: Its Origins and Philosophical Backgrounds (New York, London, I970), 83 I-832.

i6 M. Weber, 'Roscher und Knies und die logischen Probleme der historischen Nationalökonomie', in M.Weber, Gesammelte Aufsätze zur Wissenschaftslehre (Tübingen I922; orig, I903-I906), I-I45. W. Hennis, 'A Science of Man: Max Weber and the Political Economy of the German Historical School', in W.J. Mommsen and J. Osterhammel (eds.), Max Weber and His Contemporaries (London, Boston, Sydney, I987), 25-58, argues that Weber's later work must be understood primarily as a continuation of the tradition of the historical school, and that his criticism of Roscher and Knies fails to add up to a genuine break with their ideas (esp. ibid., 40-52).

I7 Weber, 'Roscher und Knies', 63.

I 8 'Psychologie wird als empirische Disziplin erst durch Ausschaltung von Werturteilen [...] möglich' (ibid., 57).

I9 'die Ansicht [ist] noch heute nicht ganz verschwunden, dab es eben die Aufgabe der Psychologie sei, eine der Mathematik vergleichbare Rolle für die einzelnen 'Geisteswissenschaften' zu spielen', M. Weber, 'Die Objektivität sozialwissenschaftlicher Erkenntnis', in M. Weber, Soziologie, Weltgeschichtliche Analysen, ed. J. Winckelmann (Stuttgart, I956, orig. I904), I86-262, esp. 215.

20 "liebe sich aber aus jenen "Gesetzen" und "Faktoren" die Wirklichkeit des Lebens jemals deduzieren [...] weil es uns für die Erkenntnis der Wirklichkeit auf die Konstellation ankommt, in der sich jene (hypothetischen!) "Faktoren" [...] vorfinden' (ibid., 216).

2 I Windelband, Geschichte und Naturwissenschaft, 37-39.

22 C.G. Hempel, 'The Function of General Laws in History', Journal of Philosophy 39.2 (I942), 35-48, esp. 36 . 
23 in der "erlebten" Wirklichkeit [ist] von einer spezifischen "Unberechenbarkeit" menschlichen Tuns ganz und gar nichts zu spüren' (Weber, 'Roscher und Knies', 64).

24 Ibid., 64-65.

25 Ibid., 65-67.

26 "Verstehen, d.h. ein “innerlich" "nacherlebbares" konkretes "Motiv" oder einen Komplex von solchen zu ermitteln, dem wir sie, mit einem je nach dem Quellenmaterial verschiedenen hohen Grade von Eindeutigkeit, zurechnen' (ibid., 67).

27 'Die "deutbarkeit" ergibt hier ein Plus von "Berechenbarkeit", verglichen mit den nicht "deutbaren" Naturvorgängen' (ibid., 69).

28 Ibid., 69.

29 Cf. K.-H.Nusser,'Verstehen und Erklären bei Max Weber', Philosophisches Jahrbuch 93 (I986), I42-I 50, esp. I44-I46; also H. Homann, Gesetz und Wirklichkeit in den Sozialwissenschaften. Vom Methodenstreit zum Positivismusstreit (Tübingen, 1989), 261-263, on the indispensability of Verstehen for the understanding of human action. Burger, Max Weber's Theory, I03-I I 3 , qualifies the importance that Weber attached to Verstehen, pointing out that Weber denied its special logical status (indeed, Weber, 'Roscher und Knies', I26-I27, emphasizes that the concepts of which the different sciences make use are logically identical). Weber, 'Roscher und Knies', 70. "wir werden noch sehen, dab man von "Nachbildung" nur in sehr uneigentlichem Sinn reden darf' (ibid., 70, n. 2).

32 Ibid., 7 I.

33 'unmittelbares "Verstehen", d.h. ein Mit- und Nacherleben, Nachfühlen, Würdigen und Bewerten von "Aktualitäten"' (ibid., 74).

34 Ibid., 74-77,

35 Ibid., 77-78.

36 Ibid., 79-80.

37 'Erfahrungssätze der Psychopathologie und Gesetze der Psychophysik kommen für die Geschichte nur genau in dem gleichen Sinn in Betracht, wie physikalische, meteorologische, biologische Erkenntnisse. Das heibt: Es ist ganz und gar Frage des Einzelfalls, ob die Geschichte oder die Nationalökonomie von den feststehenden Ergebnissen einer psychophysischen Gesetzeswissenschaft Notiz zu nehmen Anlab hat' (ibid., 82).

38 'die zuweilen gehörte Behauptung, dab die "Psychologie" [...] um deswillen für die Geschichte oder die Nationalökonomie ganz allgemein unentbehrliche "Grundwissenschaft" sein müsse, weil alle geschichtlichen und ökonomischen Vorgänge ein "psychisches" Stadium durchlaufen, durch ein solches "hindurchgehen" mübten, ist natürlich unhaltbar' (ibid). Weber, Soziologie, 2 I 2.

40 Ibid., 219-220.

4I 'In dieses Chaos bringt nur der Umstand Ordnung, dab in jedem Fall nur ein Teil der individuellen Wirklichkeit für uns Interesse und Bedeutung hat, weil nur er in Beziehung steht zu den Kulturwertideen, mit welchen wir an die Wirklichkeit herantreten' (ibid., 220).

42 Ibid., 223-224.

43 Weber, 'Roscher und Knies', 84.

44 Ibid., 88-89.

45 Ibid., 90-9I.

46 Ibid., I02-I03. Cf. T.E. Huff, Max Weber and the Methodology of the Social Sciences (New Brunswick, London, I984), esp. 46-55, on the subtle relation between reexperiencing and Verstehen as a scientific instrument. 
Weber, 'Roscher und Knies', I I I.

Ibid., 98.

Ibid., 107.

50 Ibid., I п.

5I Ibid., I08-I09. The possibility of a concept of something individual was at the same time an epistemological necessity, as concrete empirical reality could not be 'thought'; cf. Burger, Max Weber's Theory, 59-77. The same considerations would lead Weber to emphasize the importance of ideal constructs: his famous ideal-types selectively highlighted certain well-defined aspects of reality (Weber, Soziologie, 227-238). Weber, 'Roscher und Knies', I I I.

53 'in logisch gleichem Sinn wie die Hypothesen der "Naturwissenschaften"' (ibid., I00-102). 54 Ibid., II7.

55 jedes "Verstehen" setzt (psychologisch) "Erfahrung" voraus und ist (logisch) nur durch Bezugnahme auf "Erfahrung" als geltend demonstrierbar' (ibid., I I 5).

56 'ein “Mitmachen” zweckvoll gewahlter Bestandteile' (ibid., I08).

57 Ibid., I22-I23.

58 "weil das "historische Individuum" auch in der speziellen Bedeutung der "Persönlichkeit" im logischen Sinn nur eine durch Wertbeziehung künstlich hergestellte "Einheit" sein kann, ist "Wertung" die normale psychologische Durchgangsstufe für das "intellektuelle Verständnis"' (ibid., I24).

59 "Mittel in den Dienst des "Verstehens", und das heibt hier: der kausalen Deutung fremden Handelns' (ibid., I 25).

60 'die "deutende" Motivforschung des Historikers ist in absolut dem gleichen logischen Sinn kausale Zurechnung wie die kausale Interpretation irgendeines individuellen Naturvorganges, den ihr Ziel ist die Fest[st]ellung eines "zureichenden" Grundes (mindestens als Hypothese) genau so, wie dies bei komplexen Naturvorgängen, falls es auf deren individuelle Bestandteile ankommt, allein das Ziel der Forschung sein kann' (ibid., I34).

6 I Cf. also M. Heidelberger, 'Von Mill via von Kries to Max Weber: Causality, Explanation, and Understanding', in U. Feest (ed.), Historical Perspectives on Erklären and Verstehen (Dordrecht, 2010), 24I-265, who in this respect locates Weber in the tradition of J.S. Mill, rather than Windelband and Rickert.

62 Ibid., I26.

63 'Deutung mittels der Kategorien "Zweck" und "Mittel”' (ibid., I 26). Cf. F. Ringer, 'Max Weber on Causal Analysis, Interpretation, and Comparison', History and Theory 4I.2 (2002), I63-I78, esp. 92-I20, on the relation between explanation and understanding and the function of hypothetical attribution of rationality.

64 Weber, 'Roscher und Knies', I 27-I29.

65 Ibid., I30-I 3 I.

66 'wo es für unser historisches Erkennen auf ein im Sinne der Undeutbarkeit "irrationales" Verhalten einmal ankommt, da mub freilich unser kausales Bedürfnis regelmäbig sich mit einem an dem nomologischen Wissen etwa der Psychopathologie oder ähnlicher Wissenschaften orientierten "Begreifen” [...] begnügen' (ibid., 67-68). 


\title{
II 2 Discovering Sexuality
}

\section{The Status of Literature as Evidence}

\author{
Robert Deam Tobin
}

Today, the study of sexuality brings together scholars from a wide variety of disciplines - history, politics, literature, religion, the arts, psychology, anthropology, medicine, and biology. At its best, this interdisciplinary work promotes critical self-reflection on disciplinary assumptions about sexuality and the data used to test those assumptions: Is there such a thing as a fixed sexuality and how would one prove its existence? Such questions have arisen ever since the emergence of the concept of 'sexuality' at the end of the eighteenth century. At the beginning of the nineteenth century, theorists regarded humanistic and literary sources as high quality evidence in analyses of sexuality. By the end of the nineteenth century, literary and humanistic sources seemingly took a back seat to biological data. A more nuanced analysis of this shift in the prioritization of evidence reveals, however, that it accompanied a changing emphasis: biological and medical investigations tended to focus on specific and immutable sexualities, understood as pathological, while humanistic studies tended to concentrate on universal and fluid sexualities, often understood as part of a healthy human experience.

Michel Foucault famously declares that the West replaced the ars erotica with a scientia sexualis. ${ }^{1}$ As Anna Katharina Schaffner has documented, science was always already indebted to the arts, at least in the realm of sexuality. ${ }^{2}$ Schaffner's essay focuses on the sexologists, Richard von Krafft-Ebing, Alfred Binet, Havelock Ellis, and Iwan Bloch, all publishing in the late nineteenth and early twentieth centuries. The paradigms structuring the thinking of these specialists in sexuality have roots going back to the early nineteenth century, when the distinction between art and science was just emerging. Activists who advocated for the rights of people who sexually desired members of their own sex worked alongside these sexual scientists; their writings provide additional perspectives on the changing social attitude toward the truth claims of the humanities and the natural sciences in the realm of sexuality. A chronological analysis of the approach taken by these activists and scientists suggests that - at least among edu- 
cated bourgeois European men - literature came to provide a rhetorical home for a resistance to sexual identities, while the natural sciences bolstered faith in those identities.

\section{The I830s: Heinrich Hössli and the truth of literature}

In the I830s, the Swiss milliner Heinrich Hössli published a two-volume defense of male-male love called Eros: Die Männerliebe der Griechen: Ibre Beziebungen zur Geschichte, Erziebung, Literatur und Gesetzgebung aller Zeiten (Eros: The Male Love of the Greeks: Its Relationship to the History, Education, Literature and Legislation of All Ages), which promotes one of the earliest consistent arguments for an innate immutable sexual identity. The horrific execution of François Desgouttes, who was broken at the wheel in 1817 for the murder of his beloved Daniel Hemmeler, deeply shocked Hössli, who understood the murder as a crime of passion. Characteristically, he turned first to a literary author, Heinrich Zschokke, commissioning a short story to explain passionate male-male love, which appeared in I82I under the title, 'Der Eros. ${ }^{3}$ Feeling that the result moralistically cemented readers' prejudices against Greek love, Hössli detested the novella.

Bitterly disappointed, Hössli set to work on his own study. In it, he cites anthropological and historical studies of male-male erotic love, including Christoph Meiners's 1775 essay, 'Betrachtungen über die Männerliebe der Griechen' ('Observations on the Male Love of the Greeks'). ${ }^{4}$ He relies on progressive eighteenthcentury medical authorities, such as Johann Georg Zimmermann and Johann Friedrich Zückert. ${ }^{5}$ He makes use of the most recent scientific materials, quoting a passage on 'Sexualität' from an I835 issue of Rusts Magazin für die gesamte Heilkunde (Rust's Magazine for All the Healing Arts). ${ }^{6}$ At that time, the terms Sexualität, sexualité, and 'sexuality', were new, having been introduced by Carl von Linné to botany, as a way of talking about the sex of plants. The passage Hössli cites continues in this tradition, referring to a person's 'sexuality' as his or her masculinity or femininity. The vocabulary clearly carries a medical, biological and scientific inflection.

Much of Hössli's data, however, comes from more humanistic sources, such as the three-volume study, Venus Urania: Ueber die Natur der Liebe, über ibre Veredlung und Verschönerung (Venus Urania: On the Nature of Love, on Its Refinement and Beautification), published in 1798 by the diplomat and aesthetician Friedrich Wilhelm Basilieus Ramdohr, otherwise known for his critiques of Caspar David Friedrich's paintings. ${ }^{7}$ Hössli cites Wolfgang Menzel's LiteraturBlatt frequently, using that literary journal to access the most recent reviews 
of dramas such as Sigismund Wiese's I836 Die Freunde (The Friends), which seemed overtly sexual to him. For Hössli, literature provides the strongest evidence on human nature:

[T] he oldest, deepest and purest language, the sacred language of higher humanity, the flowery world of man's invisible, his heavenly realm, is literature, poetic language, the glowing and thoughtful observation by the soul of itself and of the great phenomena of nature. ${ }^{8}$

Because for Hössli literary language is the most important source of evidence, he fills his apology for male-male love with passages from the classical literature of Persia, Greece, and Rome, including texts from Sa'di, Hafiz, Anacreon, Lucian, Theocritus, Horace, and Virgil. He regards these texts as voices and witnesses, 'scattered in our literary possessions, in the plantings of humanity', concerned that

when we run into them individually - each separated from the other - in our wanderings in the realm of research and scholarship [Wissenschaft], we kick them into the mud as misunderstood weeds, with the contemptuous, thoughtless, inhuman arrogance of vandals, with derision or with superstitious fear; we don't realize that they are plants of pure humanity, we don't realize that they belong to the psychological investigative records $[z u$ den psychologischen Untersuchungsakten] of so many thousands of the innocently executed. ${ }^{9}$

Hössli's extended botanical metaphor may reflect the tradition of discussing sexuality in terms of plants. In any case, it is significant that he envisions a scholar stumbling across poetry while pursuing Wissenschaft, which is nowadays often translated as 'science'. In Hössli's era, poetry qualifies as a 'psychological investigative record', as good as any psychological, forensic or criminalistic evidence.

\section{Mid-nineteenth-century homosexual emancipationists}

Three decades later, in the 1860 s and I870s, the homosexual emancipationists Karl Heinrich Ulrichs and Karl Maria Kertbeny would steer clear of the literary evidence that Hössli finds so convincing. While Ulrichs commends Hössli on his commitment to the belief in the innateness of male-male desire, he objects to his reliance on literary sources, which in his mind prove very little: 
[T] the innateness of male love is for him [Hössli], as for me, the foundation upon which he bases his justification. Admittedly, this foundation is only asserted by him, not proven. At least, what he offers is no proof: urning love poetry from Greece, Rome, and Persia, etc. These prove only the uncontested fact that male love exists. The entire scientific side [die ganze naturwissenschaftliche Seite] of the subject, namely the muliebrity [of the urning], is not touched. ${ }^{\text {Io }}$

As Ulrichs's critique of his predecessor suggests, this new generation of activists shared a faith in natural science (Naturwissenschaft) to explain sexuality.

The 'muliebrity', or femininity, of the urning is central to Ulrichs's understanding of sexuality. Ulrichs coined the term 'urning' to describe a person with a female soul within a male body (anima muliebris virile corpore inclusa). He also discussed 'urningins', whose male soul resides in a female body. In the tradition of the early botanical meaning of the word 'sexuality', Ulrichs focused on the femininity of men who desire other men and the masculinity of women who desire other women. Because Ulrichs understood urning desire as a product of innate gender inversion, he was predisposed toward biological explanations of sexuality. He was interested, for instance, in finding out the results of blood transfusions between urnings and non-urnings, suspecting that a change of blood would result in at least a temporary change of orientation."

Ulrichs avoided heavy reliance on the classical texts because - pace Hössli they did not support his vision of an innate, immutable sexual identity. Ulrichs was committed to the notion of fixed sexual identities that required society's reconstruction in order to provide for the rights of people who had no other option but to sexually love members of their own sex. The classical texts, however, often suggest considerable malleability in sexual tastes. Privileged men in antiquity might beget heirs with their wives, consort erotically with alluring courtesans, and also fall passionately in love with attractive young men. Ulrichs knew these texts better than Hössli, having been thoroughly trained in the classics. In fact, after he stopped agitating on behalf of urnings in 1879 , he devoted the remainder of his life to the resurrection of Latin. ${ }^{\mathrm{I}}$

Ulrichs's humanist background did not prevent him from having an impact on the legal and medical communities. In I867, his public speech as an urning for urning rights at a conference of German legal experts in Munich did not go well he was booed out of the hall and sodomy remained a crime in Germany for a century afterward. His connections with scientists were more successful, however. Carl Westphal's I869 article 'Die conträre Sexualempfindung' ('Contrary Sexual Feelings or Sexual Inversion'), which Michel Foucault cites as a plausible locus for the birth of the homosexual, ${ }^{13}$ relies heavily on direct quotes from Ulrichs. 
Westphal provides thorough case studies of his two patients, but much of his theoretical discussion of gender inversion comes directly from Ulrichs. ${ }^{14}$ Early British apologists and advocates of same-sex desire knew of him: John Addington Symonds visited him in Italy in the I890s, writing to Edward Carpenter, there is a singular charm about the old man, great sweetness, the remains of refined beauty. ${ }^{15}$ As we shall see, both Richard von Krafft-Ebing (who corresponded with the activist until his death) and Sigmund Freud reference Ulrichs.

In I869, Karl Heinrich Ulrichs's comrade in arms, Karl Maria Kertbeny, became the first person in any language to combine the Greek prefix homo with the Latin term sexus in order to create a word - 'homosexual' - describing a person with a fixed sexual desire for a member of his or her own sex. ${ }^{16} \mathrm{He}$ did so, not in a biological or medical context, but in a legal context, as an activist fighting for the decriminalization of sodomy in the legal codes proposed for the new North German Confederation, which would become the German Empire. In his open letters calling for the decriminalization of sodomy (where the words homosexual and Homosexualität first appear in print), Kertbeny refrains from citing literary sources as evidence concerning the phenomenon he named 'homosexuality'. His arguments are legal, his evidence anthropological. Eventually, his terminology gained prominence when the biologist Gustav Jäger printed a number of Kertbeny's observations about homosexuality in the second edition of his book, Die Entdeckung der Seele (The Discovery of the Soul), which appeared in I880. It would seem that Kertbeny too rejects literary sources as evidence regarding sexuality.

Although Kertbeny's vocabulary became famous through sexological texts, he himself was no medical doctor. Instead, he was an homme de lettres who made a precarious living translating, critiquing and promoting Hungarian literature in German-speaking Europe and beyond, arguing that language and culture evinced the 'national character' of a people. ${ }^{17}$ Although Kertbeny claimed to have'a sharp eye for questions of race, ${ }^{18}$ he seems to have believed that language and culture can express nationality in ways that outweigh biology. Thus, Kertbeny, who was born into a German family with the last name of Benkert, could become 'Hungarian' through his deep knowledge of Hungarian language and literature. Similarly, while Kertbeny did at times rely on biological explanations for same-sex erotic desire, the essays that he sent to Jäger celebrate the cultural legacy of homosexuality, especially as exemplified by more modern poets, artists and scholars, such as Shakespeare, Michelangelo, Winckelmann and Byron.

Ulrichs and Kertbeny were both humanists, deeply devoted to the study of language and literature. Nevertheless, they stepped back from Hössli's reliance on literary sources, in part because they found biological explanations of sexuality more compelling. In both cases, their work was repackaged and widely distributed by medical experts and biologists such as Westphal and Jäger. Under the 
aegis of science, their thinking about sexuality had wide and lasting resonance, which has led to the belief that homosexuality is a purely scientific, biological and medical category. In fact, however, interests in politics, literature and culture motivated the men who first conceptualized homosexuality.

\section{Richard von Krafft-Ebing and the late-nineteenth-century sexologists}

Westphal and Jäger belong to the scientific tradition of sexology that includes Paolo Mantegazza in Italy, Auguste Tardieu in France, Havelock Ellis in England, and Arnold Aletrino in Holland. Probably no sexologist had more impact in spreading a modern vocabulary of sexuality to the most remote corners of the Western world, however, than Richard von Krafft-Ebing, whose Psychopathia Sexualis (1886) informed countless readers of the existence of homosexuals, masochists, sadists and fetishists.

As modern scientists, sexologists relied on empirical data collected in the clinics, rather than literary texts. More than most sexologists, however, Krafft-Ebing devotes time to the question of the value of literary texts as data. While he is remarkably sympathetic to literature, he insists that the poet will not discharge his arduous task adequately without the active cooperation of natural philosophy and, above all, that of medicine, a science which ever seeks to trace all psychological manifestations to their anatomical and physiological sources. ${ }^{\prime 9}$ Biology provides the ultimate answer, even for the poets.

When discussing conditions about the existence of which there can be little doubt in the minds of his readers, it doesn't occur to Krafft-Ebing to mention literary sources. He laments that the pathological love of married women for other men is a phenomenon in the domain of psychopathia sexualis which sadly stands in need of scientific explanation. The author has had the opportunity of observing five cases belonging to this category. ${ }^{20} \mathrm{Krafft}$-Ebing could cite such famous adulterous women as Emma Bovary and Anna Karenina to prove the existence of this phenomenon, but clearly he believes that his readers will not doubt that there are women who love men other than their husbands.

On the other hand, Krafft-Ebing bolsters his arguments concerning homosexuality and masochism with frequent references to literary texts, in case his readership needs more evidence on the existence of the conditions. About homosexuality, he writes: 'That inversion of the sexual instinct is not uncommon is proved, among other things, by the circumstances that it is frequently the subject in novels. The neuropathic foundation of this sexual perversion does not 
escape the writers. ${ }^{21}$ As evidence, he lists several German texts, including Adolf Wilbrandt's Fridolin's heimliche Ehe (Fridolin's Secret Marriage), as well as Petronius's Satyricon. Similarly, brief references to the Bible, ancient Greece, Rome and the Middle Ages serve as 'proofs that congressus intersexualis feminarum took place at all times, the same as it is practiced now-a-days in the harem, in female prisons, brothels and young ladies' seminaries. ${ }^{22}$ Krafft-Ebing adds a series of contemporary novels to this list of historical sources: 'It is a remarkable fact that in fiction, lesbic love is frequently used as the leading theme', whereupon he cites works by Diderot, Balzac, and Flaubert, among others. ${ }^{23}$ Apparently abashed about his reliance on literary sources, Krafft-Ebing often hides his references to them in footnotes. Amusingly, the modern novels about male homosexuals are all German, while those about female homosexuals are all French. In both cases it is clear, however, that he cites them explicitly to prove the widespread frequency and historical invariability of the condition, just as Hössli would.

Similarly, Krafft-Ebing augments his evidence on masochism with literary texts, beginning with those by the author Leopold von Sacher-Masoch, after whom Krafft-Ebing named the condition: 'I feel justified in calling this sexual anomaly 'Masochism', because the author Sacher-Masoch frequently made this perversion, which up to his time was quite unknown to the scientific world as such, the substratum of his writings. ${ }^{24}$ In addition to Sacher-Masoch, KrafftEbing finds evidence for the existence of masochism in classical Indian and Buddhist literature, Russian literature and folktales, Shakespeare, Jacobsen and Zola.

In the cases of both masochism and homosexuality, Krafft-Ebing makes some methodological observations regarding the limitations of literature as data. He believes that generally literary texts sympathize with their subjects. In his foreword, while praising poetry as better than much other pre-scientific work, he also insists on its weaknesses: "The poet [...] is swayed rather by sentiment than by reason, and always treats his subject in a partial fashion. He cannot discern deep shadows, because he is dazed by the blazing light and overcome by the benign heat of the subject. ${ }^{25} \mathrm{Krafft}$-Ebing finds this critique particularly applicable to homosexuality. He brings up classical literary sources in the context of noting that the majority of urnings are happy in their perverse sexual feeling and impulse, and unhappy only in so far as social and legal barriers stand in the way of the satisfaction of their instinct toward their own sex. ${ }^{26}$ Given this acceptance of their situation and lack of interest in a cure, he notes that many urnings cite literature primarily to justify, rather than diagnose, their love. Krafft-Ebing concedes that in much of the classical tradition, homosexuality comes off well: 'From many other places in the classics the impression may be won that Uranic love attained a higher position even than her sister. ${ }^{27}$ (The 
translator's term 'Uranic' is an adjectival form of 'Uranian', a frequently used translation for 'urning')

In the discussion of literature around masochism, Krafft-Ebing takes a slightly different tack - rather than critiquing the literary texts for being too sympathetic with their subjects, he accepts that in this case literary authors frequently delineate the nuances of nonpathological passions, while he as a physician must focus on the pathologically perverse. Thus, in one footnote, he cites a considerable body of literature (including Abbé Prévost's Manon Lescaut, George Sand's Leone Leoni, and Heinrich von Kleist's Käthchen von Heilbronn) dealing with aspects of sexual love that approach masochism, but do not require medical treatment: 'Sexual bondage, of course, plays a role in all literature. Indeed, for the poet, the extraordinary manifestations of the sexual life that are not perverse form a rich and open field'. ${ }^{28}$

Repeatedly, Krafft-Ebing takes pains to distinguish pathological masochism from the normal travails of love. Discussing a text by Otto Zimmermann called Die Wonne der Liebe (The Bliss of Love), Krafft-Ebing criticizes Zimmermann for failing to make this distinction between normal and abnormal pleasure in suffering: 'However, the domain of masochism must be sharply differentiated from the principal subject of that work, which is, that love contains an element of suffering. Unrequited love has always been described as 'sweet, but sorrowful', and poets speak of 'blissful pain' or 'painful bliss'. This must not be confounded, as Zimmermann does, with the manifestations of masochism, any more than should be the characterization of an unyielding lover as 'cruel'. ${ }^{29}$

Krafft-Ebing returns to the topic in one more footnote with a lengthy observation on certain seemingly masochistic expressions that are commonly used to describe love, such as 'slavery,' 'to bear chains,' 'bound,' to hold the whip over', and 'to lie at the feet.' He argues that poets operate according to the logic of masochism when they use such metaphors:

Poetry has always recognized, within the general idea of the passion of love, the element of dependence in the lover, who practices self-sacrifice spontaneously out of necessity. The facts of 'bondage' have also always presented themselves to the poetical imagination. When the poet chooses such expressions as those mentioned, to picture the dependence of the lover in striking similes, he proceeds exactly on the same lines as does the masochist, that is, to intensify the idea of his dependence (his ultimate aim), he creates such situations in reality. ${ }^{30}$

Profoundly, Krafft-Ebing suggests that the poet and the masochist are engaged in similar activities, both relying on established tropes to create a fantasized reality. 
As Schaffner paraphrases this passage, 'the poet expresses symbolically what the pervert enacts literally. ${ }^{31}$ Here too, Krafft-Ebing seems primarily interested in a nonpathological masochism, as his other comments about poetry do not suggest that he believes poetic activity is pathological per se.

Subsequent sexologists and homosexual emancipationists follow in KrafftEbing's footsteps, relying primarily on empirical scientific evidence. Indeed, most spend far less time than Krafft-Ebing considering the potential validity of literary passages as data. Magnus Hirschfeld worked tirelessly on behalf of homosexuals and other sexual minorities, editing one of the first journals devoted to the scientific study of sexuality and homosexuality, Das Jahrbuch für sexuelle Zwischenstufen (Yearbook for Sexual Intermediary Types) (1899-1923) and founding Das wissenschaftlich-humanitäre Komitee (The Scientific-Humanitarian Committee), which advocated for homosexual rights. Importantly, he helped crystallize a homosexual rights canon by reprinting works by and about Hössli, Ulrichs and Kertbeny. Hirschfeld certainly took advantage of the prestige of literary authors, especially from ancient Greece, as indicated by the title of his first book, published in 1898: Sappho und Sokrates, oder Wie erklärt sich die Liebe der Männer und der Frauen zu Personen des eigenen Geschlechtes (Sappho and Socrates, or How Can the Love of Men and Women to Members of Their Own Sex Be Explained). In general, however, Hirschfeld avoided literary texts in favor of case studies that supported his argument for the existence of a biologically based, innate, immutable homosexual orientation.

\section{The masculinists and the early twentieth century}

One group of theorists, however, continued to rely primarily on literary texts as evidence in their analysis of sexuality. Members of this school have been called the 'masculinists' because of their effort to frame male-male sexual desire as a masculine, rather than a gender-inverted, phenomenon. ${ }^{32}$ They embraced precisely those assumptions about emerging sexuality from classical literary texts that the sexologists and emancipationists rejected. When they looked at classical Greek and Latin texts, they saw evidence for the universality and the fluidity of masculine desire for other men.

Foremost among these authors was Adolf Brand, who founded a number of institutions that directly contrasted with Hirschfeld's. Der Eigene (sometimes translated as The Special), a journal for 'masculine culture' that ran from 1896 to 1933, stood in opposition to Hirschfeld's Jahrbuch. Brandt's organization, Die Gemeinschaft der Eigenen (The Community of the Special) split off from the Scientific-Humanitarian Committee in 1903. While the Jahrbuch featured statistical, 
sociological, ethnographic, psychological, biological and medical analyses, Der Eigene consisted primarily of short stories, poems, drawings and photographs. In Der Eigene, Brand uses literature as data to reject the notion that homosexuals constitute a specific, countable, discrete minority. The Gemeinschaft der Eigenen similarly cultivated an approach to sexuality that emphasized literature and the arts, rather than empirical scientific evidence.

John Henry Mackay, who despite his Scottish name lived in Germany and wrote in German, describes this universally fluid sexuality in his literary works, Die Bücher der namenlosen Liebe (The Books of the Nameless Love) (1913) and Der Puppenjunge (The Hustler) (1926). Repeatedly he focuses on young men who prostitute themselves in Berlin, without much concern for their own sexual identity or that of their clients. Mackay denounces the medical establishment, decrying in his 1913 novel, Fenny Skaller, that 'physicians took over this love. For physicians, people are only valuable when they are sick' ${ }^{33}$ Interestingly, Mackay's protagonist Fenny maintains some respect for Krafft-Ebing, and his compendium, Psychopathia Sexualis. Fenny

was still grateful to him, for what it [Psychopathia Sexualis] had told him first of all: that he wasn't alone. But otherwise he was horrified by these shameless revelations of desperate and poor people, these revelations that a narrow-minded, albeit honest, mind had brought together, packed up, registered and labeled in the name of a new science. ${ }^{34}$

Mackay's respect for Krafft-Ebing comes from the physician's airing of samesex desire, while his contempt comes from the pathologizing impulse. He would certainly appreciate Krafft-Ebing's endorsement of literary depictions of 'the extraordinary manifestations of the sexual life that are not perverse'.

Brand's ally, Hans Blüher, author of the scandalous and wildly successful Die Rolle der Erotik in der männlichen Gesellschaft (The Role of Erotics in Masculine Society) (1917-1919), insists that 'in ancient Hellas, it was self-evident for any otherwise woman-loving man that he sometimes took a male youth for the pleasures of love. ${ }^{35}$ Blüher argues that precisely this universal erotic bond between men provides the glue that holds society together. In no way does the sexual love of one man for another impugn the masculinity of either party - in fact, both the lover of men and the male beloved tend to be more masculine than those who eschew such practices. While Blüher does not cite literary sources as frequently as Brand, he does rely heavily on the classical tradition in his arguments. In one essay, Blüher distinguishes between bumanitär (humanitarian) and bumanistisch (humanistic), setting apart his humanistic, artistic and literary approach from the humanitarian approach of more scientific sexological and le- 
gal activists like Hirschfeld and other members of the Scientific-Humanitarian Committee. ${ }^{36}$

Perhaps the clearest evidence for the role of literature in the masculinist writings on sexuality appears in Elisar von Kupffer's collection, Lieblingminne und Freundesliebe in der Weltliteratur (Ardor for Favorites and Love of Friends in World Literature), which was published in 1900. Kupffer was a Baltic German who settled in Minusio, near Monte Verita and Ascona, in the Italian-speaking district of Switzerland, where he wrote dramas and poetry, painted, and erected the Sanctuarium Artis Elisarion, a temple to beauty, which he believed was most purely incorporated in the image of the young man. The Elisarion featured enormous murals showing idyllic scenes of scantily clad young men playing the flute, swinging, playing ball, holding hands, and generally enjoying each other's company. Sometimes called the first anthology of gay literature, Kupffer's collection consists of literary texts from the classical Greeks, Romans and Persians, as well as more modern passages from authors such as Shakespeare, Byron, Platen and Verlaine. Although Kupffer does not see a need to justify his use of literature as evidence, these literary sources are in the service of an argument that male desire for other men is universal and general, not specific to a distinct minority of homosexuals. Moreover, it is masculine and manly, not gender inverted. Kupffer's introduction to the collection is a manifesto for masculinist beliefs, arguing against gender inversion and for the manliness of man-loving men and rejecting the very term 'homosexual' as pathologizing. He dismisses Ulrichs as 'a brave and honorable character, although not really a circumspect thinker', while directly denouncing Krafft-Ebing. Referring to Hirschfeld's organization, he mocks 'humane-scientific circles's ${ }^{37}$ Kupffer's thinking was widely influential in his era: according to Marita Keilson-Lauritz, if one takes Hirschfeld's Jahrbuch and Brand's Der Eigene together, Kupffer is the most frequently cited author in the publications of the time devoted to same-sex relations. ${ }^{38}$

\section{Conclusion}

The sexological emancipatory view of sexual identity took deep root in Western society and has continued to flourish until today. The masculinist humanistic critique of sexual identity has been influential as well, too. A thorough analysis of Sigmund Freud's use of literature as data is not possible here, but it is clear that psychoanalysis remained open to the use of literary sources as evidence for discussions of sexuality long after psychology and psychiatry had move away from this practice. Freud finds Sophocles' Oedipus, Shakespeare's Hamlet and E.T.A. Hoffmann's 'Sandman' to be as valid sources of data about sexuality as 
the case studies that he investigates. Arguably, he treats his case studies as literary texts, open to multiple, at times self-contradictory interpretations. Significantly, Freud stands closer to the masculinists than the sexological emancipationists in many ways. Like the masculinists, he rejects the notion of fixed sexual identities:

Psychoanalytic research decisively opposes the efforts to separate homosexuals as a special sort of group from other people. In studying sexual arousal other than the manifestly announced, psychoanalysis learns that all people are capable of same-sex object choice and have already made such a choice in their unconscious. ${ }^{39}$

He disavows Ulrichs and Krafft-Ebing by name, finding their theories of gender inversion naïve. ${ }^{40}$

Eve Kosofsky Sedgwick asserts that many people in the modern world are comfortable with two, not entirely compatible, conceptions of sexuality: on the one hand, the universalizing notion that everyone - gay or straight - might have a homosexual side; on the other hand, the minoritizing belief that some people really are gay, while others are definitely straight. ${ }^{41}$ The brief overview in this essay suggests that the dichotomy Sedgwick identifies has roots almost as old as the vocabulary of sexuality itself. At least in nineteenth-century Central Europe, the scientific and medical approach increasingly took a minoritizing view of sexual identity, while the humanistic and literary approach increasingly took a universalizing view of sexuality.

\section{Notes}

I Michel Foucault, Histoire de la sexualité I: La volonté de savoir (Paris: Gallimard, I976), 76-78.

2 Anna Katharina Schaffner,'Fiction as Evidence: On the Uses of Literature in NineteenthCentury Sexological Discourse', Comparative Literature Studies 48.2 (201 I), I65-I99.

3 The story, which appeared in Erheiterungen ( I $82 \mathrm{I}$ ), is reprinted in Heinrich Hössli, Eros: Die Männerliebe der Griechen, ihre Beziehungen zur Geschichte, Erziehung, Literatur und Gesetzgebung aller Zeiten, 2 vols. (Glarus I 836 and St. Gallen I838; repr. with additional material in 3 vols., Berlin: rosa Winkel, I996), vol. 3, $201-256$.

4 Christoph Meiners, Vermischte philosophische Schriften, 3 vols. (Leipzig: Weygand, I775), vol. I, 6I-II9. Available online at URL: http://books.google.at/books?id=Iro 9AAAAcAAJ\&pg=PPıo\&hl=de\&source $=$ gbs_selected_pages $\&$ cad $=3 \# \mathrm{v}=$ onepage $\&$ $\mathrm{q} \& \mathrm{f}=$ false.

5 Hössli, Eros, vol. I, I26.

6 Joseph Herrmann Schmidt, 'Ueber die relative Stellung des Oertlichen zum Allgemeinen', Rusts Magazin für die gesammte Heilkunde 45.2 (I835), I66. 
7 Friedrich Wilhelm Basileus Ramdohr, Venus Urania: Ueber die Natur der Liebe, über ibre Veredlung und Verschönerung, 3 parts (Leipzig: Goschen, I798). Available online at URL: http://books.google.at/books?id=KOMAAAAAcAAJ\&pg=PAI \&dq=Ramdohr+Ven us+Urania $\& \mathrm{hl}=\mathrm{de}$.

8 Hössli, Eros, vol. 2, 45. All translations my own, except where noted otherwise.

9 Ibid., vol. 2, 50.

Io Karl Heinrich Ulrichs, Forschungen über das Rätbsel der mannmännlichen Liebe, I 2 vols. in 4 (Berlin: Verlag rosa Winkel, I996), vol. 7, I29.

I I Ibid., vol. 4, xviii.

I2 Hubert Kennedy, Ulrichs: The Life and Work of Karl Heinrich Ulrichs, Pioneer of the Modern Gay Movement (Boston: Alyson, I988), 2 I 4.

I3 Foucault, Histoire de la sexualité, 59.

I4 Carl Friedrich Otto Westphal, 'Die conträre Sexualempfindung, Symptom eines neuropathischen (psychopahtischen) Zustandes', Archiv für Psychiatrie und Nervenkrankheiten 2.I (I869), 73-108.

I5 Kennedy, Ulrichs, 2 I 8.

I6 Karl Maria Kertbeny, ' $\$$ I43 des Preussischen Strafgesetzbuches vom I4. April I85I und seine Aufrechterhaltung als $₫$ I52 im Entwurfe eines Strafgesetzbuches für den Norddeutschen Bund' (Leipzig: Serbe, I869), repr. in Karl Maria Kertbeny, Schriften zur Homosexualitätsforschung, ed. Manfred Herzer (Berlin: rosa Winkel, 2000), 65-I50.

I 7 K.M. Kertbeny, Petöfi's Tod vor dreissig Jahren 1849 (Leipzig: Freidrich, I880), 60.

I8 Kertbeny, Homosexualitätsforschung, 26I.

I9 Richard von Krafft-Ebing, Psychopathia Sexualis, with Special Reference to the Antipathic Sexual Instinct, I2th ed., trans. Franklin S. Klef (New York: Arcade, I998), xxi.

20 Krafft-Ebing, Psychopathia Sexualis, 51.

2 I Krafft-Ebing, Psychopathia Sexualis, 427-428, ft. 92.

22 Ibid., 262.

23 Ibid., 428, ft. 98.

24 Ibid., I 32.

25 Ibid., xxi.

26 Ibid., 224.

27 Ibid., 224.

28 Ibid., 42I, ft. 54.

29 Ibid., 420, ft. 4I.

30 Ibid., $422, \mathrm{ft} .56$.

3I Schaffner, 'Fiction as Evidence', I75.

32 James D. Steakley, The Homosexual Emancipation Movement in Germany (New York: Arno Press, 1975).

33 John Henry Mackay, Die Buecher der namenlosen Liebe von Sagitta, reprint of 2nd edition of 1924 (Berlin: rosa Winkel, I979), 263.

34 Mackay, Die Bücher, 222.

35 Hans Blüher, Die Rolle der Erotik in der männlichen Gesellschaft, 2 vols. (Jena: Diederichs, I9I7-I9I9), vol. I, I69.

36 Hans Blüher, In Medias Res: Grundbemerkungen zum Menschen (Jena: Diederichs, 1919), I.

37 Elisarion von Kupffer, Lieblingminne und Freundesliebe in der Weltliteratur, reprint of the I90o edition with a foreword by Marita Keilson-Lauritz (Berlin: rosa Winkel, I995), 3 . 
38 Marita Keilson-Lauritz, Die Geschichte der eigenen Geschichte: Literatur und Literaturkritik in den Anfängen der Schwulenbewegung (Berlin: rosa Winkel, I997), 290.

39 Sigmund Freud, Gesammelte Werke, ed. Anna Freud (London: Imago, 1942; repr. Frankfurt a/M: Fischer, 1999), vol. 5, 44, ft. I.

40 Ibid., vol. 5, 42.

4I Eve Kosofksy Sedgwick, Epistemology of the Closet (Berkeley: University of California Press, I990), 40. 


\title{
II.3 The Role of Technomorphic and Sociomorphic Imagery in the Long Struggle for a Humanistic Sociology
}

\author{
Marinus OssewaArde
}

Since its inauguration as an academic discipline after the July Revolution, in the 1830 s, sociology has had a lasting ambivalent relationship to the humanities. On the one hand, Auguste Comte, who in I 838 had coined the word 'sociology' in a footnote to the $47^{\text {th }}$ lesson of his Course in Positive Philosophy (1830-1842), introduced the new science as a type of physics, 'social physics', patterned on the model of Newtonian physics. For Comte's contemporary Alexis de Tocqueville, on the other hand, the 'new science' belonged to the humanities, in particular to political philosophy, theology, classical studies, rhetoric and history, inspired by sociological forerunners like Hobbes, Montesquieu and Rousseau. Conflicting views of the relationship between sociology and the humanities and the natural sciences have shaped sociology's development. ${ }^{\text {I }}$ The key issue in the making of sociology, I argue, is the question of how to position sociology in the modern period, that is, in the context of modern civilization. Comte defined this civilization as industrial civilization. Sociology, accordingly, was the science of industrial civilization that theorized and shaped industrial progress. For Tocqueville, civilization was democratic civilization. Sociology was that peculiar branch of the humanities which theorized and shaped democratic progress. Historians of sociology have amply documented the conceptual, methodical and analytical differences that characterize the making of sociology. What has not been narrated yet is the role of mythical imageries in the two sociologies, how myth continues now in the making of the Comtean and Tocquevillian sociologies in the modern period.

Considering the role of myth in sociology is an ambiguous practice. Sociology has often presented itself as a myth-busting enterprise. But since the publication of Max Horkheimer and Theodor Adorno's Dialectic of Enlightenment it has been accepted that science and myth are false opposites. Science has created its own myths, in particular the myth of progress. ${ }^{2}$ More than any other scholar, Ernst Topitsch has reimagined the relationship between science and myth. ${ }^{3}$ Science, 
Topitsch points out, is not a self-sustaining logical process cut off from the welter of imaginative activity which in fact fills most of science. Myths, accordingly, are a part of science; stories, imaginative visions and networks of powerful symbols shape the mental maps that enable scientists, including sociologists of whatever kind, to understand those parts of reality over which reason has only partial control. Scientists, according to Topitsch, attribute mythical imageries, which are analogous to real-world phenomena, to the forms (such as family, state, nation or science), formations (like the emergence of the nuclear family, state formation, nation-building or scientific development), and transformations (the civilization process) that are under investigation. Such analogical reasoning is not necessarily a conscious process, and it is often veiled by the ambiguity of scientific language, yet, mythical imageries are observable in the thought patterns of scientists. ${ }^{4}$

Topitsch distinguishes between three mythical thought patterns - biomorphism, sociomorphism and technomorpism - that seem useful for my purposes of reconstructing the continuation of myths in sociology. Scientists attribute biomorphic imageries of some vital, procreative process, characterized by fertility, sexual energy, birth, growth and death, to account for the origin of the form or for the destination of the formation and transformation. In such pictorial representations no intentions can be attributed to the forms, formations or transformations. Therefore, Topitsch observes, modern scientists rarely attribute biomorphic features to forms. When scientists attribute sociomorphic imageries to forms, the regularities, directives, laws and measures of the forms come to correspond to the norms that govern the world. The idea of the Stoic logos, Providence or Weltgeist are examples of sociomorphic imageries: the cosmic agent can interfere with human affairs either directly or by virtue of the events through which He realizes His will in the form, formation or transformation. In technomorphic thought patterns known technical achievements and craftsman features are attributed to forms, formations and transformations. Forms are imagined as the work of the craftsman. The idea of causality is technomorphic. In Aristotle's theory of causality, the craftsman has the aim (final cause) to produce a form (efficient cause) of a preconceived and designed shape (formal cause) out of some matter (material cause). ${ }^{5}$

In the making of sociology different sociologists have made use of different sociomorphic and technomorphic imageries. In Comtean sociology, technomorphic thought patterns appear predominant. Industrial civilization, with its central institutions of science (Newtonian physics) and technology (the product of physics), is the work of the craftsman. As in Newtonian physics, the technomorphic imagery of causality is key in Comtean sociology, even though Aristotle's theory is highly impoverished: only the efficient cause, the mechanical production of a 
form, matters. Comte attributes technomorphic imageries to sociology itself, in the sense that the new mechanics is invested with craft procedures, such as methodical observation, technique, inventiveness and organization. ${ }^{6}$ The aim of the new science is to know transformation, 'starting from a condition barely superior to that of a society of great apes [...] to the present stage of European civilization.' In his positivism, Comte believes that this transformation is real progress. The rise of industrial civilization is intentional in the sense that the new social forms are scientifically planned and technocratically organized for the benefit of humankind. In the modern period, human misery follows from the obstruction of the transformation by anti-scientific forces, including parliaments and democratic movements and publics. ${ }^{8}$

In Tocquevillian sociology, by contrast, sociomorphic imageries predominate. Democratic civilization, a historical condition characterized by equality of living conditions that enables people to interact in publics (such as townships) and thereby develop democratic habits, is providentially governed and in agreement with natural law. He borrows from Augustinian theology (Tocqueville was inspired by French Augustinian thinkers like Bossuet and Pascal) the idea of Providence, to emphasize that God governed the big transformation in accord with His will. The march of democratic civilization is the unintended result of a series of events, discoveries, inventions, decisions, and actions that, 'every fifty years from the eleventh century on [...] in all the Christian universe', has somehow contributed, 'as blind instruments in the hands of God', to the democratization of social existence. ${ }^{9}$ Democratic forms, formations and transformation (democratization), are treated as problems of interlinkages between the civitas Dei and the civitas terrana. Tocqueville attributes sociomorphic imageries to sociology, in the sense that the new science is invested with a distinctive mindset and habits of the heart that would enable sociologists to grasp the meaning of the historical transformation. The aim of sociology is to grasp the 'secret design of Providence, ${ }^{\text {,o }}$ so that democratic civilization can be prudentially governed in accord with natural law so as to uphold the European values of reason, self-government, rule of law and justice. Human misery follows from the attempt to arrest democratic transformation: 'to wish to stop democracy would then appear to be to struggle against God himself'.

The contrasting views that have been instituted in sociology, and expressed in contrasting pictorial representations of both civilization and sociology, is not only manifest in the founding of sociology as a new scientific form. The entire process of formation and transformation expresses itself in contrasting understandings of 'enlightenment' and mythical imageries. In the 1850 s, Herbert Spencer - 'the English parallel to Comte' as H.G. Wells called him in his famous London School of Economics (LSE) lecture ${ }^{13}$ - develops a more systematic sociology than Comte..$^{14}$ 
Spencer introduces the law of evolution in sociology, defined as the transformation of social forms, as dictating the progress of industrial civilization. Spencer attributes technomorphic features to evolution: transformation follows from the necessity to adapt to changing environments, via free enterprise and individual initiative. Human misery is the result of nonadaption. Human misery follows from the attempt to counteract the elimination of bad habits and reward of unfitness and laziness. When, in the wake of the Civil War, sociology became for the first time institutionalized in the American academy, the technomorphic thought patterns of Comte and Spencer dominated the discipline in the making. These first academic sociologists, including Yale's William Graham Sumner, Chicago's Albion Woodbury Small and Columbia's Franklin Henry Giddings, considered sociology as a new branch of political economy, that is organized for remedying the ills of laissez-faire capitalism. ${ }^{15}$ Similarly, when L.T. Hobhouse came to hold the first sociology chair in the UK, in 1907 at the LSE, his major sociological concern was the place of the mind in governing the evolution of capitalism. ${ }^{16}$ That is, the aim of sociology is to inform enlightened or liberal social reforms for improving the capitalist environment.

In France, Comtean sociology developed in the shadow of the February Revolution, the Franco-Prussian War, and the establishment of the Third Republic. In the 1850 s, Frédéric le Play concludes that industrial civilization is the product of the transformation of family forms, the transition from the extended family into the nuclear family. ${ }^{17}$ In the 1880 s, after the Paris Commune, Gustave le Bon and Gabriel Tarde state that revolutionary crowds of industrial works have come to block the progress of industrial civilization. The aim of their sociology is to uncover the obstacles to industrial civilization: unenlightened crowds are the social forms under sociological investigation. ${ }^{18}$ When in France the first sociology chair is established in 1895 at the University of Bordeaux, Émile Durkheim is appointed to develop sociology as a moral pedagogical science for the Third Republic. ${ }^{19}$ Like Tocqueville, Durkheim attributes sociomorphic features to democratic civilization, which he, in his sociology of civic morals, sees as the transformation (extension) of the consciousness of social forms - a consciousness that was narrowed by capitalist competition. ${ }^{20}$ When Durkheim moved to Paris, a new sociology chair was established at the Sorbonne in 1912, which was to become the leading department of French sociology.

In Germany, sociology developed in the aftermath of the foundation of the German state in 1871. A generation of sociologists including Ferdinand Tönnies, Max Scheler, Georg Simmel, Emil Lederer, Werner Sombart, Max Weber, Alfred Weber, Leopold von Wiese, Robert Michels, Ernst Troeltsch, and Franz Oppenheimer acted as a sociological movement to develop a new German science for a new Germany. ${ }^{21}$ These sociologists grounded sociology in German idealism, as 
well as in the ideas of Friedrich Nietzsche and Karl Marx, in sharp contrast with the materialism of French Comteanism and Anglo-Saxon Spencerianism. For them, sociology is a humanities, a Geisteswissenschaft, committed to Bildung and Kultur. Without exception, German sociologists attributed sociomorphic features to social forms: civilization was the cultural offspring of the mind (Geist). When, after the defeat in the First World War, the first sociology chairs are established in the Weimar Republic, in Frankfurt, Cologne and Munich, the aim of German sociology is clear. German sociology is to safeguard the German mind and its seat (Humboldt University). It is organized for criticizing and negating the nihilistic forces of cultural regress. German sociologists strongly identify cultural regress the attack on the mind - with the principles of industrial civilization, including the division of labor, specialization, standardization, positivism, mechanization, team work, technology, bureaucracy, goal-rationality.

German sociologists in particular recognize that the First World War was a war of industrial civilization. And this civilization had become increasingly organized around oil, energy stations, home electronics and worldwide telecommunications. A new generation of American sociologists, including Chicago's Robert Ezra Park, William I. Thomas, and George Herbert Mead, and Michigan's Charles H. Cooley, most of whom studied in German universities, come to criticize Comte and Spencer. ${ }^{22}$ Cooley, for instance, in a Tocquevillian fashion, criticizes Spencer for setting a low value on classical studies and the Greco-Roman heritage. Manifesting a sociomorphic thought pattern, Cooley insists that 'Greece and Rome are our life-blood'. ${ }^{23}$ In Germany, the Frankfurt School of Social Research, established in 1923, aims to negate the mass society of industrial civilization (including mass technology like the radio) and to promote positive ideals of democratic civilization for the Weimar Republic. ${ }^{24}$ By the I930s, American sociologists no longer conceive of industrial civilization as something that benefits humankind. The Great Depression and the horrific event of 1933, when the Nazis came to power, revealed that the march of industrial civilization had resulted in the transformation of democracy into tyranny, the outbreak of a hightech total war, and the formation of an unprecedented barbarism. In 1939, Columbia sociologist Robert Wilson Lynd, in his Knowledge for What?, notes that 'our contemporary world is losing its confidence in the inevitability of Progress. ${ }^{25}$ Sociologists such as Lynd stress, like Tocqueville, the responsibility of sociology for democratic civilization: the aim of sociology is to combat the forces of totalitarianism.

During the Cold War, the making of sociology in the West was dictated by governments charged with the responsibility of postwar industrial reconstruction. Many new sociology departments were established while reconstruction was taking place. In the UK, former directed of the LSE (1919-1937) William Bev- 
eridge assigns to sociology a central place in the postwar development of the welfare state. Thereby the relationship between sociology and social policy becomes intimate: sociology is now included in the power apparatus of the welfare state. In the UK, social policy sociologists like Thomas Humphrey Marshall and Richard Titmuss are leading the field. In the US, Harvard sociologist Talcott Parsons comes to fill the intellectual space once occupied by Spencer and presents himself as the spokesperson of US sociology. ${ }^{26}$ Parsons enforces the technomorphic imagery of social forms as evolutionary systems in which four functional prerequisites need to be fulfilled: adaptation to changing circumstances, goal-attainment, integration, and the maintenance of solidarity norms. Like Durkheim, Parsons claims that human misery follows from the breakdown of solidarity norms; it is the function of the welfare state, as the liberal apparatus of social reforms, to prevent this. Parsons also attributes technomorphic features to sociology, which he styles as a 'building':

I feel that the real job of founding was done in the generation from about I890 to 1920 . We belong to the second generation, which already has foundations on which to build. But as for the building itself, a post here and there, and a few courses of bricks at the corners, are all that is yet visible above the ground. ${ }^{27}$

Under Cold War conditions, especially after the Manhattan Project ('Atoms for peace'), nuclear physics becomes the predominant science, to the point that the very meaning of the term 'science' is now narrowed down (for instance by the LSE's Karl Popper) to cover only the physical sciences ${ }^{28}$ With the development of the new (post-Newtonian) physics by men like Albert Einstein, Niels Bohr, Werner Heisenberg, Erwin Schrödinger, Max Planck, and Louis de Broglie, Comtean sociology comes to reimagine its relationship to physics and to industrial civilization. In 1944, John von Neumann, who, as a mathematician, participated in the Manhattan Project, introduced the mathematical foundations of quantum mechanics in economics. In Theory of Games and Economic Behavior, written with Princeton economist Oskar Morgenstern, Von Neumann attributes technomorphic features to social forms, to the point that social behavior (motivation, choices, strategies) is styled as machinelike and accordingly can be mathematically formalized. During the Cold War, Comtean sociologists tend to adapt such technomorphism. Comtean sociology is remolded according to the linguistic analogies of the new physics. Chicago's James Samuel Coleman, in his Foundations of Social Theory, published at the end of the Cold War in I990, reformulates the sociological canon in mathematical language, making it fit the techno-scientific era of the Cold War. 
In France, the Sorbonne's Georges Gurvitch develops a new Comtean sociology around the new physics, introducing the post-Newtonian insights into sociology. ${ }^{29}$ The new physics no longer attributes technomorphic features like Copernicus's 'lamp' and Newton's 'clockwork' to nature because it identifies dead matter as a dynamic entity. Einstein's relativity theory has done away with the Newtonian view of space and time as absolutes, so that it may seem that little, if anything, in this world would be really stable and certain. Bohr's quantum theory eliminates the Newtonian dream of being able to control nature through accurate measurement: the dynamics of chaos is the law of nature. For Gurvitch, the dynamics of chaos is the law of nature governing industrial civilization, as the two world wars illustrate. Thermonuclear industrial civilization is a flow of opposing tendencies and unexpected shifts that cannot be domesticated: social forms, formations and transformations are fundamentally chaotic. Not only a new Comteanism but also a new Tocquevillian sociology emerges in French sociology. The Sorbonne's Raymond Aron, in 1965, introduces Tocqueville in the sociological canon as a counterforce to a Comtean sociology that he finds unsuitable for combating totalitarianism in the Cold War era: the Soviet Union incorporates, besides Marxism, old Comteanism as a source of legitimacy for its planned and organized industrial civilization. Industrial civilization in the atomic age assumes a totalitarian character when a people tragically appears incapable of political freedom.

German sociology develops in the shadow of the Shoah in the sense that, during the Cold War, it is mainly concerned with interpreting the rise of totalitarianism and anti-Semitism, the popularity and election of Hitler, the Holocaust and with the real possibility of a nuclear war. For most postwar German sociologists, the sociomorphic imagery of the disastrous dialectic of enlightenment, introduced by Horkheimer and Adorno in 1944, dictates the making of sociology. Arnold Gehlen, in Man in the Age of Technology, originally published in 1949, observes that 'the Enlightenment era appears to us at an end; its premises are dead. Yet its consequences are still with us, in particular a deeply rooted tendency to consider a certain number of things as obvious. ${ }^{30}$ In One Dimensional Man, Herbert Marcuse notes that the progress of civilization invalidates myth (this is almost a definition of progress), but it may also return rational thought to mythological status. ${ }^{31}$ And similarly Norbert Elias, in his final major work, The Germans, notes that modern Europeans cherish the enlightenment myth of progress while they despair about their wars and genocides and the lack of European values (democracy, freedom) in industrial civilization..$^{32}$

In the I950s, Columbia sociologist Charles Wright Mills, like Lynd before him, poses the question 'knowledge for what', only to conclude that Parsons, the leading figure of US sociology, makes 'mainstream sociology' sustain the liber- 
al status quo in the battle with totalitarianism. In The Sociological Imagination, published in 1959, which, together with Horkheimer and Adorno's Dialectic of Enlightenment constitutes the key text of postwar sociology, Mills mocks Parsons for his unquestioning acceptance of the enlightenment, liberal values and the welfare state - a power structure that is, in Mills view, fundamentally undemocratic. Like Tocqueville, Mills promotes the sociomorphic imagery of the 'democratic society of publics' as a pictorial representation of an ideal society that conforms to natural law dictates of reason and freedom..$^{33}$ In The Coming Crisis of Western Sociology (1970), Mills's heir, Alvin Ward Gouldner, gives a final blow to Parsonian sociology, which has grown out of touch with reality since the protest movements of the $1960 s .{ }^{34}$ More than any other sociologist, Gouldner calls for a 'reflexive sociology' in which the ideological commitments of sociologists, and the power structures in which they operate, are contested. Gouldner's call for a reflexive (Socratic) self-examination urges sociologists to live for sociology (not of sociology), in close tension with the social forms they investigate, assuming responsibility for the practical (political) ends that are manifest or latent in the sociology they are making. ${ }^{35}$

When the Cold War is over, neo-Darwinian biology or life sciences gains prestige at the expense of nuclear physics. Instead of the atom, DNA, information and communications technology (ICT), and nano-machines become the key cultural icons. As a consequence, sociologists come to reimagine their relationship to physics, biology and industrial civilization. ${ }^{36}$ Manuel Castells observes that, since the I970s, ICT has come to define a new era, the 'information age' in which constant flows of information through ICT come to restructure industrial civilization. ${ }^{37}$ Anthony Giddens notes that with the advent of bio-industrial civilization, characterized by new biotechnologies like genetic engineering, assisted reproduction, regenerative medicine, stem cell technologies, technological implants, and so forth, humankind has come to live after 'the end of nature..$^{38}$ In this new industrial condition, sociology becomes connected to biology: not only the environment but also the living species are subject to liberal reform. Comtean sociologists have become increasingly aware that sociology's very survival could be imperiled if sociologists fail to connect with neo-Darwinian biology. While during the Cold War, the analogies of nuclear physics had been borrowed, in the information age and in bio-industrial civilization ICT and neo-Darwinian analogies are being embraced. Sociologists now come to attribute technomorphic imageries like networks, DNA and memes to social forms. Coleman had reformulated the sociological enterprise to connect sociology with physics; Cambridge sociologist W.G. Runciman has reformulated sociology so as to relocate the discipline within the neo-Darwinian paradigm. ${ }^{39}$ Social change can be explained as an evolutionary process analogous but not reducible to natural selection. 
No new mainstream sociology develops out of this neo-Darwinian turn. In fact, sociology increasingly comes to develop itself in opposition to the neoDarwinian paradigm, in support of democratic civilization that is once again under threat. Ivan Illich introduces the sociomorphic imagery of a 'biocracy' to pinpoint the power complex of bio-industrial civilization. ${ }^{40}$ In the biocracy, life is fetishized as a new idol, a playground for bio-medical experts who organize themselves to manage the species. In a biocracy, Illich notes, policy focuses on re-engineering organisms, while the environment turns life-threatening due to the industrial production of poisons, toxic emissions, radiations, pestilence, and so forth. In his Risk Society, originally published in 1986, Ulrich Beck explains that such industrial risks, the leftovers of thermonuclear civilization, as well as the new risks of bioengineering, come to define bio-industrial civilization, a catastrophic world. Beck makes it clear that in bio-industrial civilization, no 'respectable research at all' can be conducted because bio-industrial civilization, ruled by biocrats, lacks a strong democratic backbone. The aim of sociology is now to ally with the extra-parliamentary publics of democratic civilization, with the protest movements that are now compelled to cope with the risks manufactured by nuclear physics and the neo-Darwinian engineering sciences. ${ }^{41}$

Furthermore, Michel Foucault notes that the fetishism of life, and the policy concern with health, vitality, hygiene, sanity and fitness, is at the core of the biopolitical strategies of the welfare state that seeks to impose bodily discipline. ${ }^{42}$ As a social form, life is socially constructed in power relationships, by people governed to fit their bodies to the health regimes constructed by the biomedical professions. And such regimes come into force prior to actual birth, for instance, via policies of prenatal screening. In this line of thought, Foucauldian sociologists like Nikolas Rose introduce sociomorphic imageries of life forms under bioindustrial conditions: life is constructed as 'bio-capital' that is a new humanity that is debased and dwindled to a herd animal, a dwarf. Bio-capital means that humanity is being commodified into an investible genetic quality that can be used to acquire resources (including jobs and partners). ${ }^{43}$ Imagined as bio-capital, life becomes a key bio-political site for the management and re-engineering of human bodies in which the emergence of reflexivity at the democratic civilizational level of publics is repressed. Steve Fuller calls for 'a new sociological imagination' needed to uncover the power structures of bio-industrialization in which the production of novel organisms is prioritized over the provision of adequate sustaining humane environments for them. ${ }^{44}$

The relationship between sociology and bio-industrial civilization is most problematic because the biocracy, neo-Darwinian in its ethos, neglects the social environment. As Michael Burawoy puts it, the regime is deeply anti-sociological in its ethos, hostile to the very idea of "society"'.45 Burawoy asserts that, as the 
biocracy threatens the survival of sociology as such, the aim is no longer to transform sociology, as Gouldner had tried with his reflexive sociology, or to adjust sociology to bio-industrial civilization as Runciman urges. The aim of sociology is nothing less than to transform bio-industrial civilization and negate and transcend the neo-Darwinian microscopic focus on life forms. ${ }^{46}$ For Burawoy, the future of sociology is inextricably linked to the uncertain fate of democratic civilization; hence, as Tocqueville had suggested, sociology must focus all its efforts upon equipping extra-parliamentary publics with sociological imagination and reflexivity. And this requires a stronger connection between sociology and the humanities, the making of a renewed sociology that is akin to philosophy, classical studies, theology, history, literature, and in which the exceptionality of humanity, of the human mind, is embraced as a democratic force.

\section{Notes}

I Raymond Aron, Main Currents in Sociological Thought: Montesquieu, Comte, Marx, Tocqueville, and the Sociologists and the Revolution of 1848 (London: Penguin, I991); Edward Shils, The Calling of Sociology and Other Essays on the Pursuit of Learning (London: University of Chicago Press, I980), 236.

2 Avner Cohen, 'Myth and Myth Criticism following the Dialectic of Enlightenment', The European Legacy I 5.5 (2010), 583-598.

3 Ernst Topitsch, 'Society, Technology, and Philosophical Reasoning', Philosophy of Science 2I.4 (I954), 275-296.

4 Max Rieser,'The Noetic Models of Mythology and Metaphysics', Journal of the History of Ideas 21.2 (1960), 300-308; Friedrich Solmsen, 'Nature as Craftsman in Greek Thought', Journal of the History of Ideas 24.4 (I963), 473-496; Herminio Martins, 'Time and Theory in Sociology', in John Rex (ed.), Approaches to Sociology: An Introduction to Major Trends in British Sociology (London: Routledge \& Kegan Paul, 1974), 246-294; Nienke Moor, Wout Ultee, and Ariana Need, 'Analogical Reasoning and the Content of Creation Stories: Quantitative Comparisons of Preindustrial Societies', Cross-Cultural Research 43.2 (2009), 9I-I22; Julián Pacho, 'The Universe as Cosmos: On the Ontology of the Greek World-Image', in Hans Ulrich (ed.), Concepts of Nature: A Chinese-European Cross-Cultural Perspective (Leiden: Brill, 2010), I36-160.

5 Topitsch, 'Society, Technology, and Philosophical Reasoning', 284; Rieser, 'The Noetic Models of Mythology and Metaphysics', 305.

6 Robert Nisbet, 'The French Revolution and the Rise of Sociology in France', American Journal of Sociology 49.2 (I943), I56-I64; Geoffrey Hawthorn, Enlightenment and Despair: A History of Sociology (London: Cambridge University Press, I976), 69.

7 Auguste Comte, The Crisis of Industrial Civilization: The Early Essays of Auguste Comte (London: Heinemann, I974), I92.

8 Comte, The Crisis of Industrial Civilization, Ior.

9 Alexis de Tocqueville, Democracy in America (London: University of Chicago Press, 2000), 6 .

Io Tocqueville, Democracy in America, 396. 
I I M.R.R. Ossewaarde, Tocqueville's Moral and Political Thought: New Liberalism (London: Routledge, 2004); Marek Tracz-Tryniecki,'Natural Law in Tocqueville's Thought', Journal of Markets \& Morality I I.I (2008), 27-40. Tocqueville, Democracy in America, 7.

H.G. Wells, 'The So-called Science of Sociology', London School of Economics and Political Science, 1906. See also Ruth Levitas, 'Back to the Future: Wells, Sociology, Utopia and Method', The Sociological Review 58.4 (2010), 530-547.

Peter J. Bowler, The Non-Darwinian Revolution: Reinterpreting a Historical Myth (London: Johns Hopkins University Press, I988), I4; Robert L. Carneiro and Robert G. Perrin, 'Herbert Spencer's Principles of Sociology: A Centennial Retrospective and Appraisal', Annals of Science 59.3 (2002), 22 I-26I; John Olfer, 'Social Change and Selectionist Thought: On Spencer, Darwin and Runciman', The Sociological Review 58.2 (2010), 305-326; Chris Renwick, British Sociology's Lost Biological Roots: A History of Futures Past (London: Palgrave Macmillan, 20I2).

5 Cristobal Young, "The Emergence of Sociology from Political Economy in the United States: I 890 to I940', Journal of the History of the Behavioral Sciences 45.2 (2009), 9I-I I6. Martin Blumer, 'Sociology in Britain in the Twentieth Century: Differentiation and Establishment', in A.H. Halsey and W.G. Runciman (eds.), British Sociology Seen from Without and Within (Oxford: Oxford University Press, 2005), 36-53; Renwick, British Sociology's Lost Biological Roots, I03, II 3 .

7 Floreal H. Forni, Ada Freytes Frey, and Germán Quaranta, 'Frédéric Le Play: A Forefather of Social Economics', International Journal of Social Economics 25.9 (I998), I380I 397.

Christian Borch, The Politics of Crowds: An Alternative History of Sociology (Cambridge: Cambridge University Press, 2012).

Victor Karady, 'The Durkheimians in Academe: A Reconsideration', in Philippe Besnard (ed.), The Sociological Domain: The Durkheimians and the Founding of French Sociology (Cambridge: Cambridge University Press, 1983), 7I-89; Hawthorn, Enlightenment and Despair, I2I, I27.

Émile Durkheim, Professional Ethics and Civic Morals (London: Routledge, I992), 84.

Raymond Aron, German Sociology (Westport, CT: Greenwood Press, I978).

Shils, The Calling of Sociology, I 85.

Charles H. Cooley, 'Reflections upon the Sociology of Herbert Spencer', American Journal of Sociology 26.2 (I920), I29-I 45 (esp. I 34).

4 Steve Fuller, Humanity 2.0: What It Means to Be Human Past, Present and Future (Basingstoke: Palgrave Macmillan, 20I I), 55.

Robert S. Lynd, Knowledge for What? The Place of Social Science in American Culture (Princeton: Princeton University Press, 1970), 2.

Craig Calhoun (ed.), Sociology in America: A History (London: University of Chicago Press, 2007).

Talcott Parsons, 'The Prospects of Sociological Theory', American Sociological Review I 5.I (1950), 3-I6 (4).

Mary Midgley, The Myths We Live By (London: Routledge, 20I I), 87.

Philip Bosserman, 'The Twentieth Century's Saint-Simon: Georges Gurvitch's Dialectical Sociology and the New Physics', Sociological Theory I 3.I (I995), 48-57.

Arnold Gehlen, Man in the Age of Technology (New York: Columbia University Press, I980), I02.

Herbert Marcuse, One Dimensional Man (London: Sphere Books, I968), I 52. 
32 Eric Dunning and Stephen Mennell, 'Elias on Germany, Nazism and the Holocaust: On the Balance between "Civilizing" and "Decivilizing" Trends in the Social Development of Western Europe', British Journal of Sociology 49.3 (I998), 339-357.

33 Shils, The Calling of Sociology, 78; Marinus Ossewaarde, "The New Welfare-Warfare State: Challenges to the Sociological Imagination', Irish Journal of Sociology I9.I (20 I I), I32-I 49.

34 Marinus Ossewaarde, 'Sociology Back to the Publics', Sociology 4I.5 (2007), 799-8 I2; Robert B. Owens 'Producing Parsons' Reputation: Early Critiques of Talcott Parsons' Social Theory and the Making of a Caricature', Journal of the History of the Behavioural Sciences 46.2 (2010), I65-I 88.

35 Ossewaarde, 'Sociology Back to the Publics'.

36 Fuller, Humanity 2.0, 35.

37 Manuel Castells, Technologies of the World: The Making of Twenty-First Century Industrial Complexes (London: Routledge, I994).

38 Anthony Giddens, Modernity and Self-Identity: Self and Society in the Late Modern Age (Cambridge: Polity Press, I99I), 2 I9.

39 W.G. Runciman, 'The Selectionist Paradigm and Its Implications for Sociology', Sociology 32.I (I998), I63-I88; Olfer, 'Social Change and Selectionist Thought'; Renwick, British Sociology's Lost Biological Roots, I 3.

40 Ivan Illich, 'Brave New Biocracy: Health Care from Womb to Tomb', New Perspectives Quarterly II.I (I994), 4-I2.

4I Ulrich Beck, Risk Society: Towards a New Modernity (London: Sage, I992), 82, 200.

42 Nancy Meyer-Emerick, 'Public Administration and the Life Sciences: Revisiting Biopolitics', Administration E Society 38.6 (2007), 689-708; Claire Blencowe,'Foucault's and Arendt's 'Insider View' of Biopolitics: A Critique of Agamben', History of the Human Sciences 23.5 (2010), II 3-I30.

43 Nikolas Rose, 'Normality and Pathology in a Biomedical Age', The Sociological Review 57.2 (2010), 66-83; Simon J. Williams, Paul Higgs, and Stephen Katz, 'Neuroculture, Active Ageing and the Older Brain: Problems, Promises and Prospects', Sociology of Health E Illness 34.I (2012), 64-78.

44 Steve Fuller, The New Sociological Imagination (London: Sage, 2006); Fuller, Humanity 2.0.

45 Michael Burawoy, '2004 American Sociological Association Presidential Address: For Public Sociology', The British Journal of Sociology 56.2 (2005), 259-294, at 263.

46 Michael Burawoy, 'The Critical Turn to Public Sociology', Critical Sociology 3I.3 (2005), 3I3-326. 


\title{
II.4 Sociology and the Proliferation of Knowledge La Condition Humaine
}

\author{
Bram Kempers
}

\section{Cognitive ambiguities and the creation of fields}

Sociology and its companion social sciences, such as cultural anthropology and psychology, enjoy ambivalent relations with one another, and with sections of the humanities, from cultural history to the study of languages. To complicate matters more, the relations with the natural sciences are ambiguous as well and subject to debate. Intellectuals never created a clear-cut and generally accepted classification of the arts and sciences concerned with human behavior. The cognitive quality of literature and the visual arts never disappeared. Literary authors still claim to enlighten la comédie bumaine, as Balzac coined the subject of his novels.

Other professionals have entered the scene and contributed their claim to the truth about humanity. None ever achieved a monopoly on wisdom. Theologians lost their position as authorities, but they still present their views in the public domain and attract followers and believers. Their role was contested more and more in European societies since the eighteenth century, yet people adhered to the religious truths, expressed in various systems of faith. The position of theologians was only partially and temporarily taken over by philosophers, who tended to focus on specific fields of knowledge and language within separate university disciplines. Their authority was challenged by sociologists and anthropologists, who formulated new claims to the truth. However, none of the new disciplines acquired a cognitive monopoly, neither on specialized knowledge nor general wisdom. Each created its own cognitive world, outside of which their authority remained contested. The emancipation of the social sciences at the American and European universities since about 1900 was an ambiguous one, since they did not substitute rival interpretations of societies and individual behavior in various historical and geographical contexts.

To understand the dynamics of knowledge, several views, concepts and classifications have been introduced. German philosophers reflected upon the differ- 
ences between Naturwissenschaft and Geisteswissenschaft, or Kulturwissenschaft, often phrased in the plural. The English novelist and physicist C.P. Snow coined his concept of two cultures and the scientific revolution; he was worried about what he saw as a gap between science and literature. ${ }^{2}$ Wolf Leppenies increased the number of cultures into three: science, literature and sociology. He linked his combination of Snow's dichotomy with German conceptualizations to the disciplinary system as it had developed at the universities. ${ }^{3}$ Models of two and three cultures are not generally accepted, and rival views emphasize the natural sciences, like Thomas Kuhn who observed a succession of paradigms. However, his attractive neologism remained ill-defined and appeared not well suited for the social sciences and the arts. ${ }^{4}$ The historical model of progress, whether seen as evolutionary or as revolutionary, has been applied to the humanities, though largely without taking sociology, literature and art into account. ${ }^{5}$ Various classifications have been proposed, different histories have been constructed; separate discourses had their own way, some of them as a narrative, modern or postmodern. Sociologists constructed historical and biographical narratives of their own. ${ }^{6}$ Sociological literature since the I97os focuses on currents, perspectives and schools, taking into account its presociological predecessors. ${ }^{7}$ Many books on sociology are at the same time faithful to sociology as an academic discipline and eclectic in their point of view and their references to predisciplinary discourses.

The French sociologist Pierre Bourdieu introduced the concept of different fields, such as education, television, literature and science, each with its own institutions, hierarchies and values. ${ }^{8}$ He linked these fields to different forms of capital (economic, cultural and social) and to various attitudes, or types of habitus. In addition he connected distinctions people made between forms of art to differences in social status. The sociological concept of fields is better suited than that of paradigm, culture, discipline or profession to understand the unity and diversity in our cognitive culture. This configuration of fields in the humanities differs from knowledge on nature, which developed a shared new language: mathematics in combination with nonpoetic English. A high degree of clarity has been attained in the scientific study of natural phenomena and the division of labor between its main disciplines. Science has substituted art, theology and philosophy with increasing success. Distinct from the natural sciences in subject, method and theory is the study of humans, which took the natural sciences as they developed since the seventeenth century as its model. Yet knowledge of human societies became divided among various fields, without clear boundaries, with partial interactions and without a dominant conceptual framework. 


\section{Continuity and innovation in artistic research and expression}

A major difference with the progress in the natural sciences concerns the authority of literary authors. No one who searches for knowledge of atoms turns to Lucretius anymore; his poem on nature falls outside any curriculum in physics. Roman and Greek authors are still read by people who want to gain insights in humans. Since the I820s a new genre emerged which communicated new contributions to understanding mankind. The novels from Stendhal to Salinger contributed to the knowledge of their contemporaries and to readers from later periods and other countries. Yet the relevant insights presented in literary works, old and modern, have hardly been incorporated into the publications of social scientists.

The same is true for the work of journalists, like Tom Wolfe, who devoted thorough research to his publications on modern art and capitalist society. Starting as a journalist, he crowned his career as an artist. The views of painters remained outside the scope of modern sociology, as did the work of pop singers. David Hockney and Jim Morrison evocatively portrayed different sections, male and female, gay and straight, of the same Californian society. Artists continued to reflect on life styles, ethics and other humanist aspects of the humanities. Successful authors experimented with different genres. Starting as a scholar, they turned to writing historical fiction, like Umberto Eco, who claimed that he could express his ideas better in fictional texts than in scientific discourse.

The variety of fields dealing with cognition of human affairs is partly dependent on a diversity of languages. After Latin lost its role in science, English became increasingly significant, yet other languages remain important in their own right, and problems of proper translation have never been absolutely solved. AngloSaxon classifications do not perfectly match French, German, Italian and Dutch concepts. There may be one human condition, but there is no unified system of knowledge, expressed in a common language. People have to cope with a wide variety of scholarly, scientific, literary, linguistic and artistic traditions that claim partial or total understanding of the human mind. Within a proliferation of fields, sociology came into being, within a wider intellectual context that includes the humanities, literature, art, journalism, theater and music.

The older fields were continuously renewed, maintaining claims to superior understanding of human emotions and interactions. They also claimed a superb way to convey insights in shorter or longer texts, ranging from epigrams to novels. From a disciplinary point of view, sociologists selectively paid attention to predisciplinary knowledge. ${ }^{9}$ While human societies converged into a complicated global network, understanding of the human condition remained divided between all sorts of genres, languages, paradigms, disciplines and professions. ${ }^{10}$ The first sociologists had a different outcome in mind. 


\section{Comte, Durkheim and the ambiguous emancipation of sociology}

In his lessons on philosophy, Auguste Comte introduced the concept of sociology as a major new branch of science. Starting in the I820s he developed his

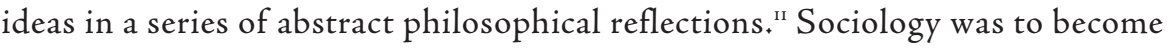
the counterpart of the natural sciences. As such sociology would complete the scientific revolution, which saw the successful emancipation of astronomy, physics, chemistry and biology. In Comte's vision, sociology embodied for human beings, what the natural sciences meant for men's natural environment: a science positive, or 'positive science'. In this way, sociologie, and its adjective sociologique became fundamental concepts, referring to the third of Comte's three historical stages of human understanding. His law of progress in three stages encompassed the first, theological, phase, a second, metaphysical, phase, and the third and final one: positive and scientific. In his philosophical lectures and publications Comte every now and then related these stages to the development of societies but these connections received little empirical or analytical attention in his extensive texts.

Sociology was not the only neologism coined by Comte. He also invented the counterpart of egoism: altruism. In his broad evolutionism Comte enjoyed some success, witness the sociological and historical ideas of the British philosopher and sociologist Herbert Spencer. ${ }^{12}$ Comte's original philosophical thought owed its importance to its positive and critical reception by Spencer and others. In his academic career, Comte was not successful. He remained a marginal figure in the university system. It was up to his fellow countryman, Émile Durkheim, to be elected to the first chair in sociology. Late in his career, Durkheim became professor of sociology at the Sorbonne in Paris, in 1912, the first sociological chair in Europe. Such a chair already existed at Chicago in the United States. In France the historians proved to be more successful institutionally, while sociologists also had to deal with other disciplines that entered the institutional arena, such as geography and anthropology.

Durkheim realized Comte's program, while abandoning his philosophical style and his broad evolutionary perspective. Durkheim abandoned abstract reasoning and historical generalizations. He advocated a sociological method on the basis of empirical research. For him this meant to collect data, guided by a repertoire of theoretical concepts. His plea for sociology was sustained by the application of statistical analysis. Durkheim raised the question what would, at first sight, look as the most individual decision a human being could take; his answer was: to end one's life. Embarking on an extensive analysis of data concerning suicide, Durkheim concluded that even that very individual deci- 
sion was determined by social factors. As part of his classification of suicides, he coined another neologism: anomy. A class of people committed suicide, because they lived within a society that lacked a system of norms and values. So, Durkheim concluded, even the most individual actions require a sociological explanation. ${ }^{13}$

Apart from suicide, Durkheim published about sociological methods and about a theme that was dealt with by specialists in political economy: the division of labor in society. ${ }^{\mathrm{I}}$ Another important domain he explored was religion, not historically like Comte, but functionally. In doing so, he was consistently expansionist, because most topics he analyzed already belonged to other disciplines. Durkheim relied on published ethnographic reports, mainly considering 'primitive' Australian societies. He sought to define the essential characteristics and social functions of religion, its symbols and rituals. Durkheim considered the usage of sacred totems as collective representations that brought individuals together in social structures of family and clan. In this way, he conducted empirical research, on the basis of descriptive publications by others who had visited small-scale communities far from Europe. In a generalizing book on the elementary forms of religious life, Durkheim covered, both empirically and theoretically, what Comte had described in very broad terms as the first stage in the development of human understanding. ${ }^{15}$ While Comte saw a one-dimensional progress in cognition from theology to metaphysics and from there to positive science, Durkheim studied religious practices and representations in a sociological way. He focused on signs, symbols, images, stories, systems, and rituals far from his familiar Christian and Jewish culture, to understand the social cohesion brought about by priests. Through collective representations (his concept), priests conveyed images of society through periodic rituals that cemented social bonds and made them visible. Durkheim practiced a comparative study of religion in a way that was fundamentally different from Comte's approach. As the one who gave a concrete adaptation of Comte's scientific model, he could hardly have been more different. So ambiguities in sociology emerged in the writings of two French authors who were later considered to be its founding fathers. They embodied different intellectual traditions, with divergent links to other disciplinary fields: theology, philosophy, geography, ethnography, anthropology and history.

Émile Durkheim became crucial in the institutionalization of sociology as a discipline within the expanding university system of disciplines and faculties. At the same time, he contributed to a falling apart of the emerging social science under the aegis of sociology. As a sociologist, he used theoretical and empirical publications that belonged to the realm of ethnography, ethnology, and anthropology. His articles and books were used by specialists in those fields, as well as 
by historians writing about culture or civilization. Durkheim's most influential pupil and colleague, Marcel Mauss, became primarily known as an anthropologist. His 'Essay sur le don' became a canonical publication in the broad field where the expansionist sociologists lost control.

\section{Interdisciplinary fusions between sociology, anthropology, history, and the arts}

The Dutch historian Johan Huizinga crossed disciplinary borders. In I9I9 he published a wide-ranging book on late medieval culture in France and the Low Countries, Herfsttij der Middeleeuwen. Huizinga focused on complex Christian ideas and images. His highly successful book was translated into many languages, in English both as The Waning of the Middle Ages and The Autumn of the Middle Ages. Huizinga, trained in languages, became a famous cultural historian, who selectively used ideas from the social sciences. Huizinga, whose ambition was to be a literary author, even an artist, rather than a scientist, became a canonical historian around the word, despite the fact that his Dutch prose was difficult to translate. As such, Huizinga contributed to the ambiguities in the fields of the arts, sciences and humanities.

In the same period this merging of ideas and genres gained an impetus due to the Belgian Arnold van Gennep, who published a book on rites de passage, or rites of passage, with which he expanded Durkheim's theory of ritual. Van Gennep provided a model for the social dynamics of coming of age in various societies. He focused on the so-called primitive societies where the rituals concerning the transformation from child to adult appeared in a more dramatic way than in European societies of the twentieth century. Van Gennep's conceptual model became part of general knowledge and was adopted by social scientists like Margaret Mead, who studied the island Samoa, and by novelists. Coming of age is a main theme in the small oeuvre by J.D. Salinger. His heroes Holden Caulfield, and Franny and Zooey Glass came of age in modern cities along America's East Coast. His invented characters for his novels and stories, published in the 1950s, highlighting the problems adolescents face when they enter a society determined by new media, a lack of solidarity, and tensions between parents and children. $\mathrm{He}$ portrays modern society and its conflicts between the generations and between insiders and outsiders, a theme that was dealt with by sociologists. So ideas developed within the social sciences became important in renewed traditions of fiction, based on accurate observation and reflection. Novelists presented their insights not in an abstract and analytical framework but in fictional stories, performed by created persons and presented without footnotes, sources and bibliography. 
The division of labor was further complicated by the rise of cultural anthropology in England and the United States. Edward Burnett Tylor published influential books on broad themes, such as culture, civilization, philosophy, religion, art and anthropology ${ }_{+}{ }^{16}$ Franz Boas, a German Jew, born in Protestant Minden, studied physics in Heidelberg before turning to historical geography and deciding in I882 to travel to the Canadian Arctic. He was the first to use the method of participant observation, which he continued in the American West, where the influence of white men remained limited. After several teaching jobs and projects at museums, in I899, Boas became professor of anthropology at Columbia University in New York. ${ }^{17}$

The success of sociological and anthropological approaches soon became one of its main risks. Concepts, methods and theories spread quickly to other disciplines, genres and languages. In translation, words acquired new meanings and produced ambiguities. Culture and civilization enjoyed highly divergent meanings in the various languages and disciplines. The rise of sociology as a scientific method became a complicated affair, because it flourished outside the domain of empirical and statistical studies. New generations of sociologists turned away from this scientific model and reoriented themselves on the humanities and the older humanist tradition, which had contributed so much to the shared knowledge of texts, words, symbols and history. In Germany several authors, for whom the identity of sociologist was important, like Mannheim and Weber, looked for the older intellectual tradition of the humanities to clarify their methods and ideas. For some of the most original scholars in the early twentieth century, sociology became a Geisteswissenschaft. When they acquired a university chair, it was often not in sociology. At the same time nonsociologists adopted some of their ideas, so the emancipating discipline lost the grasp of its own inventions and lost its coherence. On the one hand, sociologists claimed to embody the new, positive science focusing on human behavior, and on the other they had to compete with many disciplines and arts. Cultural anthropology was only one of several rival disciplines that entered the university system, alongside sociology, without any consistent division of labor between them.

Sociological and anthropological ideas influenced cultural historians, who were eclectic and flexible in their approaches as a writer and researcher. Creative fusions between history, art history, anthropology and sociology attracted many readers. The monumental books and articles by Jacob Burckhardt, Aby Warburg, Johan Huizinga, Carlo Ginzburg and Peter Burke all testify to this intellectual trend of transcending disciplinary boundaries. With or without bibliographical references in his introductions, articles and footnotes, Huizinga used ideas from the social sciences. ${ }^{18} \mathrm{He}$ did so particularly in his influential book on the civilization, or beschaving, which flourished in the Low Countries 
and the Duchy of Burgundy during the fourteenth and fifteenth centuries. Huizinga focused on religion, literature, ritual and the visual arts, within urban societies bound together by the central, though itinerant ducal court. The dukes created a territorial state, rivaling for a while the King of France and the German Emperor.

Huizinga, who had studied Sanskrit, became a highly influential author, not only in the Dutch university world, where he occupied chairs in history at Groningen and Leiden. His books were translated and he became part of an international network of scholars within the humanities and occasionally in the social sciences. At the same time, Huizinga became an opinion leader in matters of contemporary art and culture, mostly in the Netherlands. Part of his publications belonged to the genre of the essay and journalism. His native country remained the framework for another identity: his outspoken and self-conscious literary ambition, a new blurring of prose and poetry. After his death his literary writing style came to be considered outdated and unscientific, yet Huizinga's works enjoyed several renaissances. The mixed reception of his publications and his choice for different modes confirms the complicated configuration of different fields.

\section{Max Weber, Norbert Elias, and the re-establishment of sociology}

Unlike Huizinga, Max Weber aimed at sociological theory and method. He came to be recognized as one of its founding fathers, although sociology is absent in the title of his books. ${ }^{19}$ Like Durkheim, Weber turned to religion as one of his fields of interest. He did so in a historical way and with an eye for highly complicated systems of belief, in particular Protestant Christendom within capitalism, which he linked to Protestant belief. ${ }^{20}$ This was a way to criticize the approach, developed by Karl Marx and Friedrich Engels, who had presented religion (and art), as determined by the economic structures of society. Weber sought to re-evaluate religion as a force of its own, that facilitated the expansion of capitalism in Europe and the United States.

In his oeuvre, Weber added history, economics, and law to sociology as it was introduced by Comte and established by Durkheim. Using various intellectual traditions, Weber gave a decisive turn to the social sciences within the humanities in the German-speaking world. He occupied various chairs in different cities, only late in life to become professor of sociology. Methodologically, Weber turned away from the scientific approach and reorientated his language on philosophy and history. 
In the I930s, Norbert Elias synthesized the available traditions. His magnum opus, published in 1939, on the civilizing process was republished in $1969{ }^{21} \mathrm{He}$ added a dedication to his parents, Hermann Elias, who died in Breslau in 1940 and 'Sophie Elias, gest. Auschwitz 1941 (?)'. The second addition has an introductory chapter, written in 1968 while Elias was teaching at Leicester. In this introduction, Elias seeks to explain the fundamental, paradigmatic meaning of this, by then, thirty-year-old book. He criticizes the dominant American sociology. Talcott Parsons's theory is a-historical and opposes individual and society as two distinct entities. Elias distances himself from the dominant functionalist model of Parsons and Robert Merton. He argues for a reorientation on nineteenthcentury theories, such as those of Comte, Spencer and Marx. Unlike Comte and Spencer, Marx did not present himself as a sociologist; he was a journalist and a politician rather than a scientist, yet he was posthumously included in the canon of founding fathers. This was also the case with Alexis de Tocqueville, who came to be considered as sociologist only from the late i950s, due to the efforts of C. Wright Mills, Raymond Aron, and Robert Nisbet. With his 1969 introduction, Elias reshaped sociology and history, a transformation of ideas that he rendered even more explicit in his introduction under the title: What Is Sociology?

The in memoriam to his parents - victims of one of the most uncivilized regimes from human history as regards its attitude to Jewish, homosexual and other minorities - gives a short and dramatic clue to the social identity of the author. In the preface, written in 1936 , Elias had been reluctant to present anything of his persona, apart from some of his intellectual roots, an attitude to which he remained faithful for the rest of his long life. The word sociology, so important in the 1969 introduction, only occurs once in 1939. In his preface, Elias mentions psychology, philology, ethnology or anthropology as no less relevant for his theoretical questions than sociology or the various specialized branches of Geschichtsfoschung. He expressed his loyalty to sociology by references to Weber's analysis of the state and, as part of his acknowledgements, to Karl Mannheim, then established in London. There Elias had conducted most of his empirical research of books on rules for civilized behavior from the thirteenth to the late eighteenth centuries.

In his annotations, Elias illustrates his heterogeneous intellectual background. He starts with a quote from Oswald Spengler, like Huizinga a cultural critic with an outspoken ethical opinion. Apart from philosophical works, Elias pays his tribute to Mannheim, Herder and Voltaire, belonging to distinct intellectual and artistic traditions. The German translation of Huizinga's Herfsttij serves as one of Elias's sources, empirically more than theoretically. In the notes belonging to Part 2, he discusses Max Weber's 'Idealtypen'. In this way Elias addresses again the friction between social sciences and humanities. Another discussion concerns the 
role of the Italian city states in the civilizing process. Elias connects this issue not so much to the work of Jacob Burckhardt, which was discussed in depth by Huizinga. Instead, Elias links the issue of Italy to a source publication of letters by Venetian diplomats. He used both texts and images. Where Huizinga analyzed Netherlandish panel paintings, Elias analyzed German drawings in manuscripts. Entering the domain of art history meant still another blurring of boundaries.

Ambiguities in the disciplinary order abound, as Huizinga's and Elias's analyses of images are hardly taken seriously by specialists in art history. In scholarly books about the images dealt with by Huizinga and Elias, art historians do not take account of their insights or criticize them. Within modern sociology, literature and the visual arts were hardly studied, and in this respect Elias remained an isolated scholar. Because of his broad, unconventional view of history, culture, art and society, Elias late in life became an example for a specific school in sociology and for some historians. He was marginal in postwar scientific sociology. So one of the most important books in sociology hardly contained references to sociology, and enjoyed its strongest reception in a particular sociological school and in various sections of the humanities. In its cross-references, Elias's iconic book on the civilizing process shows an open mind to a wide variety of disciplines and art forms, setting it apart from the a-historical and nonliterary main stream sociology, so strongly criticized in the new introduction of 1969 .

\section{Social scientists in search for identity, style, and audiences}

Time and again, creative social scientists moved away from the models that had proven to be successful in astronomy, physics, chemistry, and biology. They returned to history, the languages and literature to collect data and to express their ideas. They often enjoyed their most prolific reception outside one of the internally divided disciplines. The experimental method existed only in a niche, such as the famous experiment in social psychology conducted by Stanley Milgram. In the early 1970s, Milgram aimed to test hypotheses on obedience to authority in an experimental setting. He owed his success both to a scholarly publication and a film, publicized on television. Mathematical models were developed and applied to data, yet they served primarily restricted issues and themes. Statistics were widely applied, in specialized fields rather than in sociology as a whole. Large scale surveys set the tone during the 1960s and 1970s, but the results were criticized from various angles. Scientific sociology, based on quantitative data and statistical analysis, became more sophisticated and less relevant to the basic social questions. The mathematization of knowledge affected sociology much less than psychology and economy. 
Critique on the primarily American paradigm went hand in hand with a reevaluation of Elias's work, especially when he moved to Amsterdam. After a difficult career, that brought him to positions in Ghana and Bieleveld, he was acknowledged as an important sociologist, first at the University of Amsterdam and hence at various German, Italian, English and American universities. Sociology and cultural anthropology became reintegrated in a renewed type of theoretically informed cultural history, with extensions into processual archeology, art history and literary studies. Sociological and anthropological concepts and methods were once again part of the humanities and the humanist traditions. Modern historical sociology interacted again with art, literature and journalism, because some of the most important social scientists embarked on writing and publishing in those domains, creatively experimenting with a wide variety of genres. This is the case in the oeuvre of Johan Goudsblom and Abram de Swaan, which is confirmed by its reception. ${ }^{22}$ Apart from a highly regarded academic reputation in sociology, they are known as literary authors and received literary prices.

This happened to be the case as well with some Dutch specialists in the history of Dutch literature who occasionally used ideas from the social sciences, like Herman Pleij and Frits van Oostrom. ${ }^{23}$ However, the artistic appraisal of their writings mainly concerned their publications in the Dutch language. Although English became the dominant vehicle for scholarship, national languages remained important. One of the reasons for this borderline is the scarcity of good translators, another that most authors express themselves best in their native language and attract the widest audience in their own country, in spite of the worldwide dominance of English.

Unlike the natural sciences, the social sciences and the humanities show complicated, eclectic and flexible patterns which extended beyond the boundaries of science. Merging with the fields of literature, art and journalism occurs in a creative and confused way; cross over is not a marginal phenomenon; many of the most widely read authors do not identify themselves with a single discipline and maintain bonds with the arts. Novels, plays, paintings and pop songs continue to flourish, converging into one culture consisting of various fields.

\section{Enduring and renewed inspiration from the arts}

Reflection on human behavior enjoyed a long history before the scientific revolution. Anachronistically, scholarly writers tend to consider these texts as prescientific. From a sociological point of view, it is possible to consider the Bible, Homer and Shakespeare to be proto-sociology, and the nonwritten ideas as presociology. Before Comte and Durkheim, a geographically and historically broad spectrum 
of texts circulated which addressed common themes. Since the making of the Hebrew Bible, the codification of the heroic battle of Troy, and the dialogues of Plato, a continuous literary tradition arose. This consisted of library inventories, commentaries, constitution of texts, translations and analyses of words. The Greek version of the Hebrew Bible was supplemented by an extensive section on the life, death and resurrection of Jesus. His actions and ideas, served to portray Hebrew society under Roman imperial rule within a Hellenistic cultural tradition. From Augustine onward, the Latin literary tradition arose reflecting on Jerusalem-centered texts in continuously expanding social and linguistic contexts.

The emancipation of what became a worldwide network of faculties of the social sciences since the I950s was complicated by the continuous interest in predisciplinary texts, not only for reasons of style but also because their content remained relevant. Texts were continuously read and interpreted, far beyond the limits of the societies they described and the audiences they originally addressed. Their wisdom concerning human behavior remained functional beyond their geographical and historical contexts. Yet they were hardly included by sociologists in their repertoire.

While the social sciences came into being, a nonscientific approach to human societies was continued and renewed. Stendhal used personal experiences and journalistic reports for modern novels, such as Le rouge et le noir. He located his plot in a village near Besançon and in Paris. The social context of his invented characters was recognizable to his readers, then and now, in France and beyond. He wrote modern literature that portrayed modern individuals. Novels were experimental in style and in ideas; they created an experiment on paper, using observations and experiences from outside the literary world. Since the I820s, the tradition of literature was renewed in vocabulary, themes, aspects of human behavior and social setting. Madame Bovary, by Gustave Flaubert, portrayed a social drama between Ry and Rouen, while other aspects of the provincial world of France were evoked by Guy de Maupassant and Alain-Fournier.

Marcel Proust described the elite society of his youth in Paris. He addressed the dynamics of coming of age and tensions between social groups: conservative aristocrats, intellectual Jews, and gays with divergent profiles. His title refers to historical research. He added new insights to the role memory played in forming a personal identity and to shifting identities in different social settings. And Proust portrayed the social usage of concepts, such as culture and mentality. French novelists addressed social phenomena that scientists failed to understand. Large sections of the human mind and heroic response to social pressures were treated in the domain of literature.

Novels, journalistic articles and plays continued to be produced outside the era of the social sciences. They continued to be read, seen and commented upon 
after the rise of disciplines and faculties. Many sections of society were enlightened by literary authors, journalists and comedians who criticized and mocked professional scientists, failing to incorporate insights from other fields. Bourdieu, who published on Flaubert, remained an exception, as he analyzed the fields of literature, art, higher education, mass media and science.

Interesting aspects of Dutch society were portrayed in novels rather than scientific publications. Willem Elsschot, Louis Couperus, Nescio and Multatuli interpreted aspects of society that were neglected by sociologists. They highlighted the role of new media in private companies at Antwerp, relations between men and women, young and old in bourgeois society of The Hague, young marginal artists in Holland and Zeeland, as well as colonial society in Asia. In the Netherlands this tradition of realistic fiction was renewed and continued, covering more recent trends in social life by authors ranging from W.F. Hermans to A.F.Th. van der Heijden. Their style of writing and method of research was less abstract and less analytic than the work of contemporary social scientists, who left large sections of human emotions, sexual relations, trade, memory, dilemmas and conflicts uncovered.

Italian society was graphically described by Giuseppe Tomasi di Lampedusa and Giorgio Bassani. The aristocrat Tomasi addressed the circulation of elites, a theme introduced by the sociologist and aristocrat Vilfredo Pareto. He did so in a less analytical way, but his portrait of the disappearing Sicilian aristocracy in the period of the formation of the Italian state perfectly fits Pareto's and Weber's models. Tomasi combined the decline of one elite and the rise of another with state formation and with Veblen's leisure class, a concept he coined in I899. His historic novel, a classic in Italian literature, and appreciated all over the world, was published posthumously in 1958 , due to Bassani, the highly esteemed chronicler of social life in Ferrara in the ig3os and i940s.

The cognitive force of fiction went far beyond Europe. This tradition of inventing personages and plots was renewed and expanded into ever increasing sections of society: Russian authors, Chinua Achebe or J.M. Coetzee, and the genre of the great American novel. Who wants to understand Californian society finds more clues in the paintings by David Hockney and in the lyrics by Jim Morrison than in publications by scientists who left these corners of society untouched. In the I960s, Hockney depicted the new Californian elite, cosmopolitan and gay, with its villas, hotels, lawns, swimming pools and connections with the New York art world. He did so consciously, later commenting that upon his arrival from London he thought: this place needs its own Piranesi. The poet and performer Jim Morrison immortalized the same region with world famous songs like 'LAmerica,'LL.A. Woman' and 'The End'. After riding the highway West, Jim Morrison introduced the black American blues and sang: 'He took a face from 
the ancient gallery/And he walked on down the hall'. He continued with the Freudian drama, modeled on the ancient tragedy of Oedipus, to conclude with: 'This is the end'.

\section{One culture, many fields}

Increase in knowledge about the human mind followed a path that differed profoundly from the better known and more widely appreciated increase in knowledge about nature. There is no such a thing like a single, one-dimensional progress. Debates linger on, concerning methods, concepts, languages, narratives, falsifications and genres of presentation, many of which function next to one another with limited communication among the fields.

The natural sciences constituted a model for a new type of inquiry of humans but this scientific approach turned out to be far less successful than in chemistry and physics. Only particular niches saw a flourishing of experiments, statistical analyses and mathematical processing of data. These niches remained isolated and limited in scope. The scientific model failed to substitute literary approaches. Boundaries between disciplines changed continuously, creating unstable citation communities, separate catalogues and bibliographies, as well as unclear divisions of labor among libraries.

Next to the scientific approach of human societies, the older paradigm of the humanities continued to exist and along these lines new insights came into being, sometimes interacting with the scientific model. This resulted in eclectic and varied mixtures of disciplines that tended to transcend the boundaries of science. The most-quoted authors moved between literary studies, philology, art history, archeology, history, sociology and anthropology, as well as theater studies, cultural studies and media studies.

These creative shifts from one genre to another extended into the realm of the arts. Works of art were studied and successful scholars choose to write fiction themselves. They considered themselves to be literary authors and sometimes even became famous authors of best sellers in the domain of literary fiction or in a mixture of art, the humanities and journalism.

Innovations in art and literature allowed for new genres to emerge in which themes were addressed that were also of interest to social scientists and those who adhered to the humanist tradition. This happened in modern painting, pop music, journalism, film and television. Sometimes artists expressed their views on human societies in a more impressive and evocative way than social scientist had done, or they observed aspects of human behavior that had escaped their attention. 
All these fields of thinking about the human race, changing, eclectic and heterogeneous as they are, at first sight suggest less order and more chaos than the setting of the natural sciences and their search for a unified theory of forces. However, the humanities embody a different order. The various fields converge into one cognitive culture concerned with human societies, global and full of niches. This multifield setting and the partial connectivity between the fields proved to be an intellectually productive way to address the complicated topic of human relations and their rich histories.

\section{Notes}

I Various authors reflected on this dichotomy. Wilhelm Dilthey rejected Comte's positivism, which was also criticized by Heinrich Rickert. Johan Gustav Droyson developed the method of 'forsehend zu verstehen'. See Pim den Boer, Beschaving. Een geschiedenis van de begrippen hoofsheid, heusheid, beschaving en cultuur (Amsterdam, 2001), 60-63. Around I900 authors tried to reestablish a link with the German intellectual tradition of idealist philosophy. For sociology, Johan Heilbron, Het ontstaan van de sociologie (Amsterdam, I990), I2-I2 and 274-28I.

2 Charles Percy Snow, The Two Cultures and the Scientific Revolution (Cambridge, I959); The Two Cultures: A Second Look (Cambridge, I963).

3 Wolf Leppenies, Die drei Kulturen. Soziologie zwischen Literatur und Wissenschaft (Munich, I985). He corrected Snow's dichotomy and amplified his portrait of disciplinary sociology, Geschichte der Soziologie. Studien zur kognitiven, sozialen und historischen Identität einer Disciplin, 4 vols. (Frankfurt am Main, 198I); Between Literature and Science (Cambridge, I988).

4 Thomas S. Kuhn, The Structure of Scientific Revolutions (Chicago, I962/1970). For an overview, see H. Floris Cohen, How Modern Science Came into the World: Four Civilizations, One 17th-Century Breakthrough (Amsterdam, 2010).

5 See Rens Bod, De vergeten wetenschappen. Een geschiedenis van de bumaniora (Amsterdam: Prometheus, 2010; 2nd rev. ed., 2012). Bod's overview of progress in the study of texts, music, architecture, theater, media, and the visual arts has appeared in English as $A$ New History of the Humanities (Oxford University Press, 2013). See also Rens Bod, Jaap Maat, and Thijs Weststeijn (eds.), The Making of the Humanities, 2 vols. (Amsterdam University Press, 2010, 2012).

6 Robert Nisbet, The Sociological Tradition (New York, 1966); Lewis Coser, Masters of Sociological Thought: Ideas in Historical and Social Context (New York, I97I); Dirk Kaser (ed.), Klassieker des soziologischen Denkens, 2 vols. (Munich, 1976); Heilbron, Het ontstaan van de sociologie; Michiel Leezenberg and Gerard de Vries, Wetenschapsfilosofie voor geesteswetenschappen (Amsterdam University Press, 200I, rev. ed., 2012). Overviews on the history of literature form a separate field, divided along lines of languages and according to views on literature. For a critical discussion, see Johan Goudsblom, Balans van de sociologie (Utrecht and Amsterdam, 1974); Sociology in the Balance (Oxford, I977). I used sociological and related theories in Painting, Power and Patronage: The Rise of the Professional Artist in Renaissance Italy (London, 1992). 
7 This approach was introduced by Raymond Aron, Main Currents in Sociological Thought (New York, I965/I968/I998). Familiar with the French tradition, Aron gave Montesqieu and Alexis de Tocqueville their due, as well as Karl Marx. On sociology and its history: E.C. Cuff, W.W. Sharock, and D.W. Francis (eds.), Perspectives in Sociology (London and New York, 1979; 3rd ed., 1990); Richard Kilminster, The Sociological Revolution: From the Enlightment to the Global Age (London, I998); Nico Wilterdink and Bart van Heerikhuizen, Samenlevingen. Inleiding in de sociologie (Groningen, 2007), and the oeuvre of Randall Collins.

8 Pierre Bourdieu, La distinction (Paris, I979), with subsequent editions and translations. His analytical framework is discussed in Michael Grenfell, Pierre Bourdieu: Key Concepts (Stocksfield, 2008).

9 Johan Heilbron, The Rise of Social Theory (Cambridge, I995); Johan Heilbron, Lars Magnusson, and and Bjorn Wittrock (eds.), The Rise of the Social Sciences and the Formation of Modernity (Dordrecht, Boston, and London, I998).

Io Pim den Boer, Geschiedenis als beroep. De professionalisering van de geschiedbeoefening in Frankrijk (1818-1914) (Amsterdam, 1986), with a focus on history as a university discipline; for geography and sociology, 257-258, 344, 404-407, 4I3, 426, 455-456. In 1902 Durkheim held the chair of the science of education, created in I 887. L'Annee sociologique existed since I898.

I I See Heilbron, The Rise of Social Theory. The fourth volume of Discours de philosphie positive saw the introduction of sociology, further developed in Système de politique positive; Comte's third group of publications on contemporary society rather than the history of ideas. Publications appeared in I822, I830, I838, I839, I84I, I842, I852, I853, I854, the later ones on social order, society, statistique sociale, social dynamics, and sociological prediction of the future of humanity. First editions of Comte and others are hard to find in libraries of departments of sociology.

I2 Herbert Spencer, The Study of Sociology (New York, I89I); The Principles of Sociology (New York, I 896). His publications also deal with philosophy, biology, and his own life.

I3 See Émile Durkheim, Le suicide, étude de sociologie (Paris, I 897); Suicide, a Study of Sociology (London, I970); Steven Lukes, Durkheim: His Life and His Work, a Historical and Critical Study (London, I973).

I4 Émile Durkheim, Les regles de la méthode sociologique (Paris, I 895); De la division du travail social (Paris, I 893); The Division of Labour in Society (London, I984).

I5 Émile Durkheim, Les formes élémentaires de la vie religieuse (Paris, I9I2); The Elementary Forms of Religious Life (London, I968).

I6 Edward Burnett Tylor, Researches into the Early History of Mankind and the Development of Civilisation (London, I865); Primitive Culture: Researches into the Development of Mythology, Pbilosophy, Religion, Art and Custom (New York, I97I); Anthropology: An Introduction to the Study of Man and Civilisation (London, I88I).

I7 For Boas, see Siep Stuurman, De uitvinding van de mensheid. Korte wereldgeschiedenis van het denken over gelijkheid en cultuurverschil (Amsterdam, 2009), 390-406.

I 8 See Johan Huizinga, Verzamelde werken, 8 vols. (Haarlem, I948-I95I).

I9 Max Weber, Wirtschaft und Gesellschaft (Tübingen, I922), published posthumously on the basis of the notes he had made for teaching; he addressed sociology as a discipline in its often-quoted first sentence.

20 Max Weber, Die Protestantische Ethik und der Geist des Kapitalismus (Hamburg, I920).

2 I Norbert Elias, Über den Prozess der Zivilisation. Soziogenetische und psychogenetische Untersuchungen, 2 vols. (Bern/Munich, I969); Norbert Elias, Was ist Soziologie? (Munich, I970). 
22 Nico Wilterdink, Johan Heilbron, and Abram de Swaan (eds.), Alles verandert. Opstellen voor en over J. Goudsblom (Amsterdam, I997); Bram Kempers,'Een geleerde op zoek naar een genre. Cultuur in het werk van Goudsblom', in Nico Wilterdink, Johan Heilbron, and Abram de Swaan (eds.), Alles verandert. Opstellen voor en over J. Goudsblom (Amsterdam, 1997); and B. Kempers, 'Secretaris van Stendhal. Kunst, geschiedenis en sociale wetenschap', in Annet Mooij, David Bos, and Sonja van't Hof (eds.), Grenzeloos nieuwsgierig. Opstellen voor en over Abram de Swaan (Amsterdam, 2007), I 2 I-I 32.

23 Bram Kempers, 'Een held staat nooit alleen. Herman Pleij en de cultuur van Nederland', in Herman Brinkman, Jeroen Jansen, and Marita Mathijsen, Helden bestaan! Opstellen voor Herman Pleij bij zijn afscheid als hoogleraar Nederlandse letterkunde aan de Universiteit van Amsterdam (Amsterdam, 2008), 275-283. 



\title{
II.5 Inhumanity in the Humanities \\ On a Rare Consensus in the Human Sciences
}

\author{
Abram de Swaan
}

A broad and strong consensus prevails in the human sciences about the personality traits that distinguish genocidal perpetrators from other human beings: there are none. A small percentage of the killers, roughly the same as in society at large, say five percent, may indeed show psychopathologies that make them impervious to the suffering of others and even cause them to enjoy it. The vast majority, however, displays the same variety of traits and in roughly the same frequencies as the population at large. There is near unanimity among scholars, a rare exception in the human sciences, that nothing in their personality predisposes the perpetrators to commit their deeds more than anyone else. In the very titles of their books, the adherents of this view announce their conclusion: the killers are ordinary men.' What must be explained is 'how ordinary people commit extraordinary evil'.

The argument follows a fixed itinerary. It begins with the psychological tests that were administered to the Nazi defendants at the Nuremberg trials by US psychologists and psychiatrists. The chiefs of the Nazi regime were rather remarkable personalities, each in his own way. The fact that psychological tests did not reflect any anomaly, to my knowledge, was never seen as a shortcoming of the tests, but rather as evidence for the mental health of the persons tested. ${ }^{2}$ They were, however, found to share high scores on certain traits that were not per se pathological: above average intelligence, high ambition, overconfidence and an 'ambient' style of problem-solving. ${ }^{3}$

\section{Eichmann in Jerusalem: The banalization of evil}

If anything focused global attention on the Nazi crimes, it was the spectacular abduction of Adolf Eichmann from his hideout in Argentina and his subsequent trial, in the spring of $196 \mathrm{I}$, before an Israeli court in Jerusalem. In most war-crime trials, the defendants had presented themselves as average citizens, not especial- 
ly motivated for their task, lukewarm at most in their ideological convictions, career-minded, maybe, but not wildly ambitious, not much given to racial or ethnic hatred, nor driven by passionate loyalties to the Leader or the Party. Strong motivations after all, might betray a personal commitment to their murderous task and bring their individual responsibility to the fore.

This camouflage strategy was brought to perfection by Eichmann's defender, Servatius, who may not have fooled the prosecution or the judge, but certainly influenced some of those who attended the trial, most notoriously Hannah Arendt ${ }^{4}$ (or the Dutch writer Harry Mulisch, for that matter). ${ }^{5}$ Even at the time, it was well-known that Adolf Eichmann had been a fanatic Jew hunter, who knew full well what fate lay in store for his prey. In interviews with Willem Sassen, his SS acquaintance in Argentina, which were published in part in Time Weekly before the trial, Eichmann had said that he regretted only one thing: that he had not caught them all'.6 Arendt mentions that Eichmann during and after the war had repeatedly boasted: 'I will jump into my grave laughing, because the fact that I have the death of five million Jews on my conscience gives me extraordinary satisfaction'.7 Arendt dismisses this rather unusual confession as rodomontade (a boast) and adds: 'Bragging was the vice that was Eichmann's undoing'. But, as a matter of fact, Eichmann was not bragging; he was more or less accurate, and it was certainly not this vice that got him in trouble, but the fact that indeed he had been instrumental in the extermination of many millions of Jews.

Arendt and many others who reported on the trial were enthralled by the fashionable notion of the time that the Nazi (and the Soviet) state were mighty machines, manned by countless, nameless, faceless bureaucrats and soldiers who were no more than cogs in the apparatus, obediently and unthinkingly doing whatever they were told, without much conviction of their own, except for loyalty to the system. But, certainly in Eichmann's case, this was an expedient masquerade, set up by the defense, and it went together very well with the spirit of the times: 'Befehl ist befehl' (Orders are orders) had become the ironic mot d'ordre of the 1960s, implying the opposite: that people should never again hide behind their superiors' commands and that they should learn to judge for themselves and heed their individual conscience. ${ }^{8}$

Arendt depicts Eichmann as a pompous idiot, 'genuinely incapable of uttering a single sentence that was not a cliché. ${ }^{9}$ Poking fun at his malapropisms, she observed with dead precision: ' $[\mathrm{H}]$ is inability to speak was closely connected with an inability to think, namely, to think from the standpoint of somebody else'.

Eichmann whose efforts to expel, deport and exterminate millions exceeded even the orders he received, who continued to the very last moment when even Himmler had changed course, who said he despised colleagues who just followed orders ${ }^{10}$ was the least apt example of an average bureaucrat, of just another number 
in the huge equation of the Nazi state. ${ }^{\text {II }}$ Eichmann was totally devoted to Hitler and national socialism, fanatically ambitious and without any trace of conscience or empathy regarding his victims even when he was directly confronted with their fate.

Were the perpetrators banal? Arendt's thesis on the 'banality of evil' does not stand critical scrutiny, certainly not as applied to Adolf Eichmann or other Nazi leaders, nor for that matter, to the rank-and-file killers. Her model might, however, fit the countless minor middlemen of the Holocaust: the administrators in the civil registry who supplied the names of the prospective victims, the local police who rounded them up, the railroad employees who transported them in cattle trains, the local contractors who built the gas chambers and supplied the extermination camps. Most of them were in some sense banal.

It was Hannah Arendt's great, albeit not unique, accomplishment that she took the idées reçues of her epoch, combined them with widespread though unrealistic notions about Adolf Eichmann, and presented these musings as profoundly innovative insights all her own. ${ }^{12}$ Her readers, being told with the seal of Arendt's authorial and philosophical rank, that what they had been thinking all along was novel and profound, piously gobbled it all up.

\section{Milgram's punishing experiment and its ambiguous outcomes}

In the meantime, and no doubt inspired by the Eichmann trial, a series of spectacular psychological experiments received rapt attention in the US and across the world. Stanley Milgram had invited volunteers to participate in what he presented to them as an educational experiment. They were told that they would be randomly assigned to the role of either teacher or student. In fact all of them were made teachers and the student was played by an actor, a 'plant'. The teachers were expected to present him with a series of random words and administer an electrical shock each time he made an error in reproducing the sequence from memory. The setup was presented as an experiment about the effects of punishment by different 'teachers' on memorizing by the 'student'. As the shocks increased in strength, the actor playing the 'student' would simulate growing discomfort, and then signal more and more intense pain, until he fell silent. The electric shocks went from hardly perceptible to 'dangerous' at 300 and beyond, up to 450 volts. Or so the subjects were led to believe.

Against all expectations, also the experimenter's, a two-thirds majority of the subjects went all the way and administered the highest and seemingly quite dangerous jolts. They did so under the adamant insistence of the researcher that they continue the experiment to the very end. Most subjects protested, visibly and audibly torn between compassion and compliance. Nevertheless they went on to 
obey the experimenter and shock the hapless 'student'. However, a considerable proportion did not obey: from one-third to four-fifths, depending on the miseen-scène of the experiment. Thus, there always remained a considerable share of naysayers.

Apparently, the general expectation at the time had been that people would not obey if it went against their individual conscience. When it turned out that many or even most did, this finding became the overriding message from the experiment. But to people who would have thought from the outset that most people will do what they are told, Milgram finally proved that among a very sizeable and varying proportion of the test population, disobedience prevailed.

It is quite customary to conclude from Milgram's results that a majority of people would collaborate with a real genocidal regime. But no one has drawn the same conclusion in the opposite direction and decided on exactly the same grounds that a very sizeable minority or even a majority under a genocidal regime would resist. Probably, the most sensible conclusion is that the outcomes of laboratory experiments must not be directly applied to real-life situations, either way.

More pertinent for the present argument is Milgram's finding that he could not find any significant difference between the compliers and the resisters. But, as we shall see, absence of evidence is not evidence of absence.

The proportions of the two categories varied considerably with the variations that Milgram introduced in the setup of the experiment: the proportion of refusers increased when the element of authority was reduced (no lab coat; an ordinary room in a plain building; no experimenter present, just 'other subjects'; the presence of other - planted - 'teachers' who would refuse to go along with the experiment or on the contrary would comply ostentatiously); or if the element of empathy was intensified (a visible 'student'; the opportunity to hold his hand). This strongly suggests that the subject's reactions in the experiment are determined by the balance between the opposing tendencies of compliance and empathy.

Milgram's own filmed account of the original experiments begins with a subject who abruptly stops sending electric shocks as he hears the 'student' scream. He turns around to face the experimenter, his arms folded over his chest. When the experimenter asserts, 'You have no choice', he responds: 'What do you mean, I have no choice? Of course I have a choice'.

Paradoxically, after having demonstrated that obedience to authority figures was much more common than many would have expected, Milgram's followers concluded that personal psychology was irrelevant in explaining compliance to authority. Supposedly, it depended on the characteristics of the situation alone. But this leaves unexplained the fact that even within one and the same experimental context, a sizeable proportion of subjects did go the other way. 
This was and still is a most revealing experiment. But what exactly it reveals is not all that clear. Did Milgram's subjects believe in the 'reality' of the punishment that they inflicted on the student? That is in itself hard to believe. Nobody in his right mind would ever accept the idea that someone, anyone, would be electrocuted deliberately and with forethought in the presence of certified researchers in the psychology lab, on the campus of Yale University (New Haven, Connecticut).

Unquestionably, there is a gamelike aspect to the situation. The experiment must have been experienced by the 'teacher' subjects as a very serious game. Apparently, the subjects were suspending their disbelief, like the participants in a serious game tend to do.

There were, moreover, some most significant ambiguities in the presentation of the experiment to the subjects: During the session, the experimenter would insist that 'no lasting damage' would result from the shocks. ${ }^{13}$ But the subjects sat in front of a machine with labels under the rightmost buttons, which explicitly mentioned just that: 'danger, severe shock'.

Does the experiment show that the majority of people in real life are ready to electrocute someone, if a person of authority tells them to? No. Does the experiment show that people can get carried away in an experimental situation and will do almost anything not to antagonize a person of authority, even act as if they were electrocuting a third person? Yes.

In other words, experiments are a kind of serious game. That somehow the setup of the experiment was not entirely real may not have eluded most participants.

Thomas Blass reviewed the many replications of the Milgram experiment. He found that some major changes in the situational setup of the experiment did not much affect the outcome. On the other hand, some personality traits did make a difference in the participants' behavior: 'authoritarianism' by one measure or another did make a difference, as did (lack of) 'empathy' and 'trust' in the experimenter. Blass proposes an 'interactionist' approach to the problem of obedience to authority, which takes into account both situational and dispositional aspects. But against his expectations, twenty years later this sensible position has by no means become predominant in the field.

Milgram himself remained rather reserved in his interpretations. ${ }^{14}$ But his experiment became an icon of modern self-consciousness: 'If the situation demands it, everyone is a murderer'. Fifty years later, what stands out most is the authority that laboratory experiments hold, most of all for scholars in the human sciences. 


\section{Ordinary men or ordinary Germans}

The third phase in the discussion on genocidal perpetrators, after Arendt on Eichmann, and Milgram on obedience to authority came when students of mass violence began to explore the judicial documents on Nazi génocidaires. The pioneering and meticulous research by Christopher Browning produced the classic in this field: Ordinary Men. That title is followed by a subtitle: Reserve Police Battalion 101 and the Final Solution in Poland. The book's message is contained in this juxtaposition: the mass executions of millions of Jews in Eastern Europe were in fact the work of 'ordinary people'. Browning makes his case most convincingly. Most of his findings have been confirmed and some vehemently criticized by Daniel Jonah Goldhagen in a study of the same Battalion IoI, Hitler's Willing Executioners: Ordinary Germans and the Holocaust.

Both authors agree that the recruits for Police Battalion Ior were quite representative of the German (male) population in its entirety. The men expected to be recruited for police duty and had no idea beforehand that they would be employed to round up Jewish men, women, and children, march them toward a killing site nearby, force them to undress, line them up on the edge of a trench that the male captives had been forced to dig, and mow them down with machine guns so that they would fall into the pit on top of the other bodies, dead or still alive. And yet, almost without exception, these ordinary German men complied and carried out their murderous duty, day after day, for months at a stretch.

Browning and Goldhagen mainly disagree whether' the men of Battalion IoI were 'ordinary 'men', as in Browning's title, or ordinary 'Germans', as in Goldhagen's subtitle.

Under police interrogation in the 1960s, long after the war, most men of Battalion Ior denied any particular animosity against Jews or a special commitment to Nazi ideals. They may well have wanted to conceal the motivations that they brought to their killing assignment. Browning, and even more so Goldhagen, have produced ample evidence of incidents of obscene and barbaric cruelty. Many men of Battalion Ior did not just follow the orders to kill by the thousands, according to schedule, but exceeded them on their own initiative. Even if later they denied strong anti-Semitic feelings, at the time these atrocities were committed with fanatic hatred and contempt of Jews. In this respect, the draftees of Battalion IoI may have not been entirely 'ordinary men'.

In these respects, they certainly were not unique. The German nation did produce genocidal perpetrators en masse, but it was not the only nation to do so in the course of the twentieth century. 


\section{History, biography, and immediate context}

'Situation' and 'disposition' are not opposites. Dispositions are shaped by situations over time, in social processes that is. Social situations, in turn, are the outcome of human interactions in the course of time, sometimes on a very large scale, prompted in part by their dispositions.

An authoritarian and a militaristic tradition, defeat in war, political violence and economic crisis, coupled with an endemic anti-Semitism that became state ideology, did affect the Germans of those days and may have rendered many among them more amenable to the massive killing of human beings whom they had been taught to consider 'nonhuman'. Yet, the difference with other nations is one of degree, and of statistical averages in a varied and changing population.

In retrospect, the controversy between Browning and Goldhagen boils down to a difference of opinion about the weight to be assigned to one of these historically shaped, cultural characteristics: German anti-Semitism.

Judicial evidence tends to reinforce the impression of depersonalization in the perpetrators. Their personalities pale in the process. In front of their judges, they minimize their initiatives, convictions, emotions, ambitions and desires. They come to look more and more like Hannah Arendt's version of Eichmann and for the same reasons he chose to present himself in that manner. What is often lost in this trial documentation is the individual variety in dealing with the genocidal situation. There was indeed a continuum of cooperation with the imposed project of extermination. Some men were 'willing executioners', volunteering for the Jew hunt, eager to join the roundups and the shootings and given to haphazard meanness (and sometimes kindness too, since unpredictable favors on a whim would even better display their supreme power over their victims). Other men limited their participation to the tasks that were explicitly demanded from them, without much enthusiasm, but without objection either. And, finally, there were men who tried to exploit what little room for maneuver they perceived in order to stay away from the roundups, forced marches and firing squads.

It is in these variations of comportment that differences in individual personalities and dispositions are revealed. But even in the rare cases that individual behavior within the genocidal context has been documented, it is hard to infer from this evidence what the individual's dispositions were, let alone to trace these personality characteristics back to prior life experiences, in early childhood or adolescence. So far, this sort of research has not even been tried, not in the case of the perpetrators of the Holocaust, nor of later instances of genocide. ${ }^{15}$

A remarkable consensus across the fields of history, political science, sociology and social psychology holds that genocidal perpetrators as a group are 
not distinct in disposition from the population at large. It is the immediate situation that turns people of diverse background and inclination into mass killers.

This apparently factual conclusion has had an enormous impact on moral thinking about 'contemporary men and modem society'. The vulgarization of the Arendt-Milgram-Browning tradition has led to the grand cliché of our times: potentially, all people are genocidal perpetrators, we just never were in a situation where that would show.

First of all, the fateful phrase: 'If you and I had been in the same circumstances...' is a counterfactual and can not be shown to be either true or false, since you and I were not in the same circumstances and they are extremely unlikely to recur. It is also counterintuitive, since people find it very hard to imagine themselves as mass executioners. Yet, the idea that in a certain social context, in a given situation, people will commit acts that they would not dream of otherwise, is quite plausible. Some people are more likely to do so than others, some will resist, even at considerable risk to themselves. Others may be willing and even eager to do what they are told to. That does not only depend on the situation of the moment, but also on their prior experience and personal history, in one word, a term that with so many words has been declared out of bounds: on their personal disposition. And in other words: on their particular personality.

'Under the same conditions, you or I might have done the same thing.... I very much doubt if $\mathrm{I}$, or most of my readers for that matter, upon being brought into the killing site would have started clubbing, knifing, shooting, gassing people to death by the thousands, for weeks and months at a stretch. It would have taken more than that, it would require deadly threats and ineluctable force to turn us into executioners.

But to make me or you into mass killers without extreme duress would require more preparation. If, for example, we had been brought up by authoritarian and unfeeling parents, as church-going anti-Semitic German Lutherans or Catholics, had survived the trenches and the mustard gas of WWI, had lived through the hyperinflation and the political chaos of the Weimar Republic, if we had lost our jobs or our business as a result of the Great Crisis, had had to adapt to the Nazi tyranny under a constant bombardment of the vilest racist propaganda, if we found ourselves in the utterly destructive battles at the Eastern Front, if this had been the course of our lives, then, yes, maybe then, some of us might have become genocidal killers. But then, you and I, we would have been someone else. 


\section{Notes}

I Cristopher Browning, Ordinary Men: Reserve Police Battalion 101 and the Final Solution in Poland (London: Penguin Books, 200I); Harald Welzer, Wie aus ganz normalen Menschen Massamörder werden (Frankfurt a. M.: Fischer Verlag, 2005); Donald Dutton, The Psychology of Genocide, Massacres and Extreme Violence: Why 'Normal' People Come to Commit Atrocities (London: Praeger Security International, 2007); Michael Mann, "Were the Perpetrators of Genocide "Ordinary Men" or "Real Nazis"? Results from Fifteen Hundred Biographies', Holocaust and Genocide Studies I 4.3 (2000), 33 I-366; James Waller, Becoming Evil: How Ordinary People Commit Genocide and Mass Killing (New York: Oxford University Press, 2002); Daniel Jonah Goldhagen, Hitler's Willing Executioners: Ordinary Germans and the Holocaust (New York: Knopf, 1996); Fred E. Katz, Ordinary People and Extraordinary Evil: A Report on the Beguilings of Evil (Albany: State University of New York Press, I993); John Conroy, Unspeakable Acts, Ordinary People: The Dynamics of Torture (New York, NY: Knopf, 2000); Hans Askenasy, Are We All Nazis? (Secaucus NJ: L. Stuart, I978); Olaf Jensen and Claus-Christian W. Szejnmann, Ordinary People as Mass Murderers: Perpetrators in Comparative Perspectives (Basingstoke: Palgrave Macmillan, 2008); Everett C. Hughes, 'Good People and Dirty Work', in The Sociological Eye: Selected Papers (New Brunswick, NJ/London: Transaction Books, 2009 [orig. 195 I]), 87-97; Philip G. Zimbardo, The Lucifer Effect: How Good People Turn Evil (London: Rider, 2007).

2 Charny agrees that 'the potential for being genociders and accomplices is in all of us', but he argues that we should revise our concept of normalcy and decide that 'wanton destruction of life is an act of madness'. He proposes to include disorders of pseudocompetence, invulnerability and doing harm to other people and the extent to which people abandon their individual identity and self to any collective process' (Israel W. Charny, 'Genocide and Mass Destruction: A Missing Dimension in Psychopathology', in Israel W. Charny (ed.), Toward the Understanding and Prevention of Genocide: Proceedings of the International Conference on the Holocaust and Genocide [Boulder and London: Westview Press, I984], I54-I74, I55).

3 Cf. Waller, Becoming Evil, 74.

4 Cf. Christopher Browning, 'Introduction' in L.S. Newman and R. Erber (eds.), Understanding Genocide: The Social Psychology of the Holocaust (New York: Oxford University Press, 2002), 4: 'Most historians would now agree, I think, that Arendt had uncritically accepted Eichmann's misrepresentation of himself, and that he was in fact a Nazi activist, motivated by both his ideological identification with the regime and his unquenchable ambition'. Yet, Browning continues, 'Arendt had arrived at a powerful insight that the ability of a state to organize mass murder owes much to the accommodation and compliance of petty and dutiful civil servants, even if she misunderstood her star example'.

5 Mulisch concludes at the end of his account of the Eichmann trial: 'He is the machine that is suitable for everything. He is the right man in every place. He is the ideal of psychotechnics. He walks the earth by the millions' (Harry Mulisch, Criminal Case 40/61, the Trial of Adolf Eichmann: An Eyewitness Account [Philadelphia: University of Pennsylvania Press, 2005]). Other writers who attended the trial, with fewer axes to grind and pet theories to launch, avoided these errors, e.g., the always perceptive Abel Herzberg, Eichmann in Jeruzalem (The Hague: Bert Bakker/Daamen, 1962), who mentions numerous instances of initiatives by Eichmann, above and beyond the call of duty. 
6 Cf. David Cesarani, Eichmann: His Life and Crimes (London: Vintage, 2005), 226.

7 Hannah Arendt, Eichmann in Jerusalem: A Report on the Banality of Evil (Penguin, I979 [orig. I963]), 46.

8 In fact, in German war crime trials, until late in the I960s, in order to get the accused convicted, the prosecutor had to prove that a particular defendant committed criminal acts above and beyond what he was ordered to do. In later jurisprudence, the plea of obedience to superior orders was no longer accepted and the defendants could be sentenced for committing criminal acts even if they had been ordered to do so. Moreover, if the evidence left room for doubt, initially the German courts decided in favor of the defendant (in dubio pro reo). Cf. Dick de Mildt, In the Name of the People: Perpetrators of Genocide in the Reflection of Their Postwar Prosecution in West Germany: The 'Euthanasia' and 'Aktion Reinhardt' Trial Cases (The Hague, London, Boston: Martinus Nijhoff, I996), 302-325.

9 Arendt, Eichmann in Jerusalem, 48.

Io Ibid., 57 Compare: '[...] Ich war kein normaler Befehlsempfänger, dann wäre ich ein Trottel gewesen, sondern ich habe mitgedacht, ich war ein Idealist gewesen'. (cf. Wikipedia.du, lemma 'Eichmann'): 'I was not an ordinary follower of orders, that would have made me a sucker, but I thought along, I was an idealist' [trans. AdS].

I I 'However, in Eichmann's case her analysis seems strangely out of touch with the reality of his historical record' (Deborah E. Lipstadt, The Eichmann Trial [New York: Nextbook/ Shocken, 20II], I69).

I 2 For an overview of intellectual opinion at the time, cf. Anita Shapira, "The Eichmann Trial: Changing Perspectives', Journal of Israeli History, special issue: 'After Eichmann: Collective Memory and the Holocaust since I96I', ed. David Cesarani, 23.I (Spring 2004), I 8-39. Among many others she quotes (on p. 28) Richard Crossman who gave an identical appraisal of Eichmann in an essay entitled 'The Faceless Bureaucrat', published in the New Statesman in 196I. Cf. also Norman Podhoretz, 'Hannah Arendt on Eichmann: A Study in the Perversity of Brilliance', Commentary 36.3 (I963), 20Iff. For an early refutation of Arendt's views on Eichmann, exhaustive, painstaking and at times nitpicking, see Jacob Robinson, And the Crooked Shall Be Made Straight: The Eichmann Trial, the Jewish Catastrophe, and Hannah Arendt's Narrative (New York and London: MacMillan, 1965).

I 3 The set phrase was: Although the shocks may be painful, there is no permanent tissue damage. So please go on'. The film that was made of the experiments under Milgram's own supervision in 1965 is instructive in every respect.

I Milgram mentions the outcome of test research by his assistant, A.C. Elms, who found that the subjects who had obeyed showed a greater degree of authoritarianism (a higher F score) than those who refused to obey', Stanley Milgram, Obedience to Authority (New York: Harper and Collins, 2004 [orig. I974]), 204. The relationship, however, was not very strong, and Milgram adds (in I974): 'It is hard to relate performance to personality because we really do not know very much about how to measure personality' (ibid., 205).

I5 Stanley Milgram, and no doubt others who replicated his experiments, regularly came across subjects who 'went all the way' without showing reluctance or even uneasiness. Afterwards one of them explained that 'I had to follow orders. That's how I figured it'. This compliant participant argued that the victim brought punishment upon himself for being 'a more or less stubborn person'. And, yes he could have stopped shocking the learner, if only the experimenter would have told him to (Milgram, Obedience to Authority, 46-47). 
What the experimenters had stumbled upon was the Rosetta Stone of genocide studies: an innocent genocidaire. Someone with the mind of a mass murderer but without any guilt, who could have answered any question without shame of the past or fear for punishment. However, after the presentation of a series of most enlightening thumbnail case descriptions, Milgram does not pursue this path further. 

XII

The Humanities

in Society
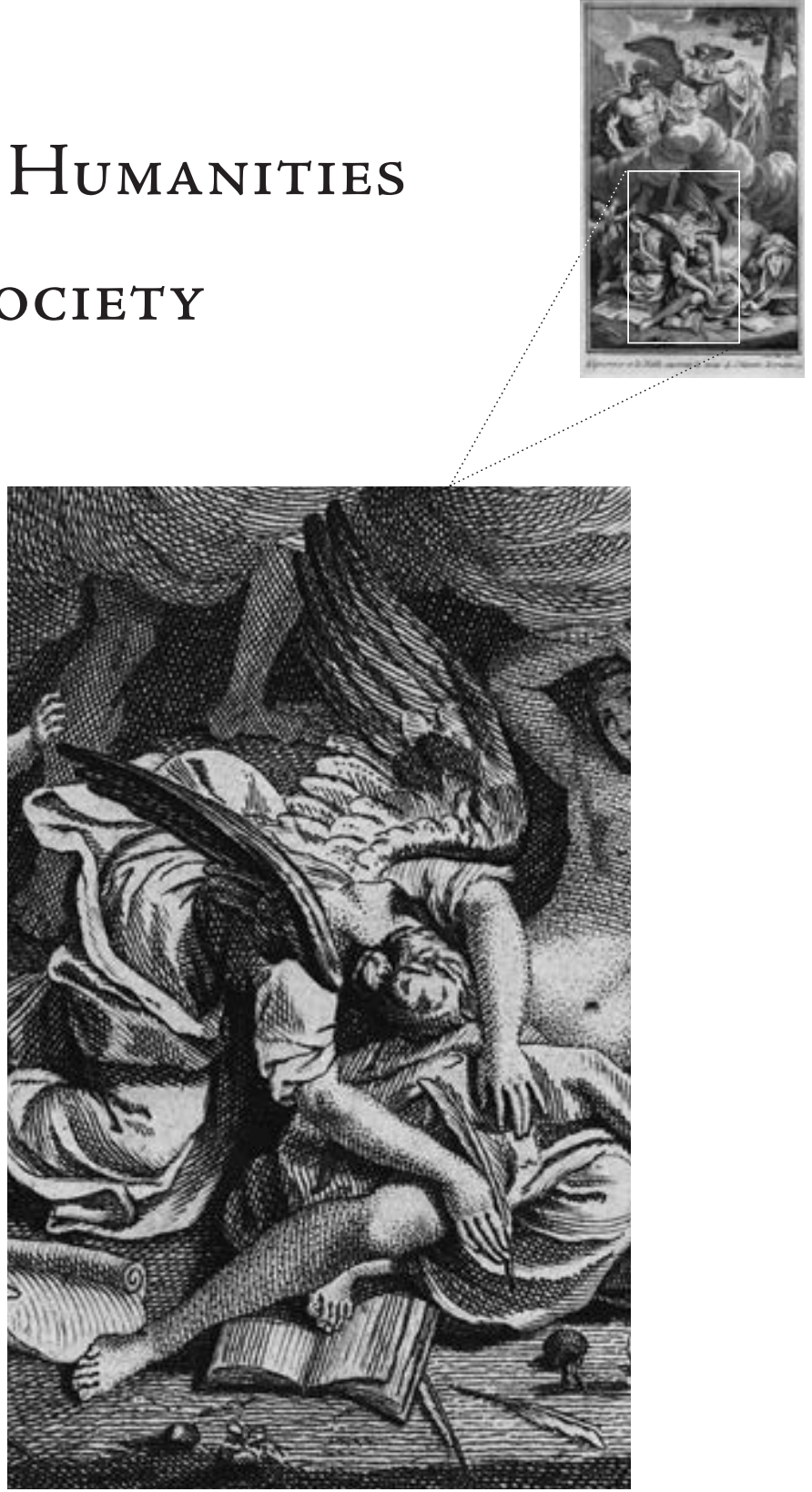



\title{
I2+I The Making and Persisting of Modern German Humanities
}

\author{
Balancing Acts between Autonomy and Social Relevance
}

\author{
Vincent Gengnagel and Julian Hamann
}

\section{Introduction}

The history of the humanities shows a constant struggle for constituting and maintaining their particular logic in relative autonomy from social influences. Understanding their emergence in the nineteenth century requires a sociological examination of how the humanities managed to maintain academic autonomy while at the same time demonstrating social relevance.

The foundation for the autonomy of the modern humanities' disciplines was formulated by Kant. He claimed that liberal arts constitute the very core of academic purity precisely because of their autonomy from any societal purpose. Declaring that 'our age is the age of criticism,', Kant at the same time wants critique to be restricted by nothing but pure reason - i.e., all knowledge has to be subjected to an academically autonomous critique. He states that

the power to judge autonomously - that is, freely (according to principles of thought in general) - is called reason. So the philosophy faculty, because it must answer for the truth of the teachings it is to adopt or even allow, must be conceived as free and subject only to laws given by reason, not by the government. ${ }^{2}$

Two hundred years later, our sociological analysis of the making of the humanities after Kant takes the idea of academic autonomy into account as the ideological groundwork that helped to form a conceptual idea of a Gelehrtenrepublik still called 'the humanities'. The emphasis is put on the notion of the humanities having a self-concept in which they conceive of themselves as free. ${ }^{3}$ In order to sketch out two centuries of development, the narrative of an overall pattern that underlies this ongoing constitution of the humanities helps to structure and understand the characteristics of the said process more precisely: following the claim of 
academic purity, each discipline defends its impartiality and objectivity while at the same time being dependent on societal constraints. With complete purity unattainable, a successful construction of any discipline within the humanities has to develop legitimate relations with its embedding society without compromising its claim for autonomy and disinterestedness. ${ }^{4}$ Since societies as well as academia are changing, the way a discipline produces knowledge and recognition thereof is problematized constantly. During this ongoing process, humanities are structured by orthodox defenders and heterodox challengers competing for legitimacy, thus shaping the potential orthodox position for future debates in symbolic struggles. ${ }^{5}$ We argue that this dynamic in itself is a constitutive element in what is conceived as 'free', that is, in the academic sphere of 'the humanities'. Applying this idea to history, a discipline traditionally in a state of precarious balance between its own academic autonomy and both societal relevance and academic relevance as defined by other disciplines, this paper contributes to a constructivist understanding of the humanities and the symbolic practices discursively establishing their autonomy.

With this groundwork in mind, we describe the subsequent balancing acts between 'pure' autonomy and 'impure' social relevance as discursive practices. We analyze two historical cases of emergence and contestation of orthodoxies within history as a German academic discipline: the orthodox positions of historicism (I87I-1945) and historical social science (1960-1979). For both cases, societal influence and academic influence are assessed as two forms of social influence, while the precarious balance is illustrated by shifts in debates about epistemological grounds of legitimate humanistic knowledge and by transformations of the ideal-typical subject position legitimately representing autonomy: the professor of history.

\section{Objectifying partiality (187I-I945)}

In the period from Germany's unification to the end of World War II, German historians, as humanists, orient themselves along the academic distinction between humanities and natural sciences, while societally being influenced by the 'belated nation's ${ }^{6}$ desire for national (or nationalistic) constructions of its collective identity. These influences favor balancing acts whose outcomes can be indicated in terms of attempts to define legitimate bumanistic knowledge and in terms of the characteristics of the ideal-typical subject position in this period of time. 


\section{Societal and academic influences}

Especially for the humanities, the relationship between state and university was crucial at the beginning of the nineteenth century. As state and university interests begin to coincide toward the end of the century, autonomy from the state is no longer seen as a pressing issue. After 1871, the demand for an interpretation of national identity calls for cultural leadership, a duty that is most eagerly accepted by historians who become advocates of a national ideology. Not only is their objective to provide canonical knowledge for civil education, but also to offer political orientation for Germany's seemingly threatened political position in Europe. ${ }^{7}$ But crucially, historians are anxious not to jeopardize their rigorous stance of academic autonomy. Reluctant to get involved in party politics, they prefer to address issues concerning the state or the nation on an abstract level and derive their political contributions from historical facts.

While this reluctance is dismissed during World War I, the belief in nonpartisan and disinterested interpretation of the weal of the nation and the state is still widespread in the Weimar Republic. Academics perceive a lack of intellectual leadership, combined with a climate of massification and industrialization of society. Historians are searching for a way of coming to terms with a German past that neither witnessed a successful bourgeois revolution nor the establishment of a parliamentary constitution, but instead is dominated by the Prussian authoritarian state and traditional elites. ${ }^{8}$ Historians deliver the interpretative tools to derive from this a unique German national heritage that assures identity while historically explaining and rationalizing Germany's role in global politics. ${ }^{9}$

With this in mind, it is not particularly surprising that historians and their works did not form a noteworthy resistance against National Socialism. But even after 1933, when the societal influence on history is most notable, a remainder of autonomy is retained as the discipline is split. Openly political propaganda, conducted by quasi-official National Socialist historians, stays away from academic research foundations like the Ethnic German Research Societies (Volksdeutsche Forschungsgemeinschaften) and thus contributes to maintaining autonomy at least as a self-conception of the academic National Socialist research taking place in these very research foundations. This is not to say that university history does not play an important role in at least intellectually legitimizing the regime. On the contrary, it is its relative academic autonomy that serves as a rational supplement. ${ }^{10}$

Summing up, even if it was minimized during war time, historians maintained their (discipline's) relative autonomy by translating the belated nation's desire for national (or nationalistic) identity and constructions of history into a humanistic logic, combining societal engagement in terms of abstract political contributions with displays of academic disinterestedness. Joined to the societal influence 
sketched so far, an academic influence on history posed another challenge for the discipline's autonomy: the last third of the nineteenth century saw notable institutional expansion and a growing self-confidence of the natural sciences, displayed exemplarily by Von Siemens's (I886) and Virchow's (1893) announcement of the 'age of natural sciences'.

This development has a twofold impact on the humanities in general and on history in particular: On the one hand, natural sciences become competitors for the prerogative of interpretation of the world that was firmly in the hand of humanistic disciplines like philosophy and history since the beginning of the nineteenth century. This becomes apparent when Max Lenz denies the claim for sole reign' of the natural sciences, stating 'that the historical sciences in no way have to fear the competition with those of nature, neither regarding their scope nor their impact.' ${ }^{\text {II }}$ On the other hand, the broad success of neo-Rankean historicism is at least partly facilitated by the rise of natural sciences that shapes an academic climate legitimating the orthodoxy's focus on objectivistic empirical research and elaborated methods. This is why Lenz's defense also conveys an acknowledgement of the legitimate research logic defined by the natural sciences. The background against which he claims the significance of history is, in fact, its disinterested research practice being similar to that of the natural sciences: 'We face the past like the natural scientist faces a plant or the history of the earth. [...] We have [...] little interest in a system and dogmatic values [...]. We want nothing but to examine and discover. ${ }^{12}$ Against this backdrop, the academic influence on bistory exerted by the natural sciences is promise and threat at the same time.

Strategies like Lenz's are exactly what ensures the persistence of the autonomy of history - and, on a broader scale, of the humanities. Representatives of the discipline, rather than subordinating themselves to the academic influences, present their own adapted research logic and even position it in contrast with the natural sciences. In this light, historicism serves as a transmitter of the influence of the research logic of the natural sciences into history. Historicism's role as a balancing act serving the persistence of humanities and history in particular is highlighted in the following section.

\section{Balancing acts of legitimate bistorical knowledge and ideal-typical subject positions}

The growing influence of the natural sciences enables historicism to shape a new orthodox position of legitimate bumanistic knowledge. Since part of establishing a new orthodoxy is to challenge and overcome the former, historicists deny that the historiography of the Enlightenment has produced genuine historical thinking and degrade it to a mere preliminary stage. Many historicists do not fully reject 
the former orthodoxy: instead, its way of interpreting and judging is seen as a discardable subjective residue of what now is perceived as a diversity of moral, religious or legal orientations. In the eyes of its main representatives, it is historicism that promoted historiography to the status of a science (Wissenschaft). ${ }^{13}$ Rediscovering Ranke, ${ }^{14}$ they define scientificity (Wissenschaftlichkeit) as sourcebased empirical research using intersubjectively reliable methods. This, and the researcher pushing back any subjectivity when conducting his research, is to ensure a seemingly disinterested objectivity. ${ }^{15}$

But the recourse to Ranke, constituting legitimate bumanist knowledge in the period investigated, means more than just striving for objectivity. It also implies the adoption of Ranke's idea of a primacy of foreign affairs, perceiving historical events from a state perspective interested in bellicose or diplomatic relations between nation-states. ${ }^{16}$ Despite disputes about methodological as well as epistemological issues, there is a rather broad agreement on basic assumptions and axioms. Among them are the conviction that history is national, entrenching the newly found national unity and argumentatively backing up the further development of the empire (Reich), and the belief that history is scientific (wissenschaftlich) in an objective, disinterested and nonpartisan way. ${ }^{17}$ Following Ranke, historians like Lenz and Marcks are convinced that we can only exert a genuine influence on the present age when we abstain from it for the time being and raise ourselves to free objective science [Wissenschaft], ${ }^{18}$

Ranke's quote suggests that the ideal-typical subject position of the professor of history is that of a mediator between party political factions on the one hand, and the greater gain of the state or Kulturnation on the other hand. ${ }^{19}$ This does not raise concerns about autonomy because the subject position unites the role of a 'critical researcher' who 'has the duty to force back his subjective moods' and of a 'political expert [Sachverständiger]', whose 'perception of the spiritual substance of the events will always be exercised by the subjective standpoint of the beholder.. ${ }^{\circ}$ Their different (but mostly conservative) political stances notwithstanding, historians look down on practical politics, although their engagement at the same time legitimizes political day-to-day business. ${ }^{21}$

The particular social position of the historian is related to a specific selfperception. Firstly, the ideal-typical subject position is occupied by an especially homogeneous group that is reproduced through a remarkable degree of self-recruitment in comparison to other professors. ${ }^{22}$ Secondly, historians do not only enjoy a high socio-structural status, their profession also has a high social prestige ensuring almost a monopoly on political resonance with the public. ${ }^{23}$ Unsurprisingly, the social prestige historians enjoy in the eyes of their contemporaries is, thirdly, matched by their self-conception and their general habitus. The feeling of dominance state-centered historicist display is partially fed by their position 
as state officials at state institutions of higher education. They see themselves not only as a meritocratic but also as a value elite, distinguished by certain moral and political norms that need to be championed and proclaimed to supervise the national unification. ${ }^{24}$

Recapitulating the balancing on the level of ideal-typical subject positions, it is striking that it is exactly the objectivity of their empirical research that enables historians to take a political stance. They introduce the claim for objectivity through source-based empirical research into the humanities via historicism, and at the same time benefit from the scientific (wissenschaftlich) prestige of the orthodoxy and the social prestige of their position when engaging for the greater good of nation and state. In the subject position, empirical research striving for objectivity, political engagement striving for national unity and the public reception of these stances are heavily intertwined.

As has been illustrated up to this point, the belated nation's demand for statist and national(ist) interpretations of history and the rise of the natural sciences exert strong influences on history. However, they are not compromising the discipline's claim for autonomy. Firstly, historicism articulates a research logic that allows combining academic purity via objectivistic research with political engagement. Secondly, the social position, prestige and self-conception of the historian allow taking a political stance not only without losing, but exactly because of his academic credibility.

\section{Reflecting partiality (1960-1979)}

Conservative orientations toward the nation remain largely unchanged and constitute a great deal of continuity from 1945 up until the I96os. However, in the I960s and I970s, societal demands for democratization, the expansion of universities as well as a relative loss of reputation of subject positions in history change the conditions for humanistic practice, while the expansion of the social sciences provides an academic influence on the discipline. ${ }^{25}$ The two-level balancing acts these influences require in history are again illustrated by the indicators legitimate bumanistic knowledge and ideal-typical subject positions.

\section{Societal and academic influences}

The general political changes embracing (West) German society since the I96os translate the topic of democratization into an academic field whose structure is shaped by newly founded universities and student protests. This societal influence on history causes an 'unprecedented atmosphere of departure. ${ }^{26}$ 
Associated with this is the need for a discussion about purpose and relevance of history for a modern society, prompting a number of contributions about the relationship between history and society ${ }^{27}$ The domestic climate of political reforms is advantageous for heterodox positions in the disciplinary discourse, conducing to an open controversy between conflicting heterodoxies. Novel positions developed in the course of these conflicts are deemed relevant to the present as they seem equipped to satisfy the demand for explanations of current problems. ${ }^{28}$ The effect the climate of democratization has on history becomes apparent in a declaration of the Association of German Historians (Verband der Historiker Deutschlands), calling for historiography to provide a 'practical service to democracy' by encouraging citizens to develop a critical understanding of the liberal-democratic constitution they are living in. ${ }^{29}$ Against the backdrop of political and societal changes like democratization and social opening of the universities, historians realize that 'they can only push their claim of relevance for society if they are prepared to enter the scientific-political and socio-political ring' ${ }^{30}$

Academically, the humanities are confronted with the growing influence of the social sciences. Similar to the way the natural sciences were acknowledged but at the same time opposed, historians try to integrate social-scientific methods and theories without losing their autonomy or even merging the discipline with the social sciences. The strategic pattern used in dealing with this academic influence on history is twofold in a way resembling the preservation of autonomy toward the natural sciences.

One the one hand, many historians oppose the pressure the social sciences are exerting. If Lenz announced in 1897 that history would not have to fear the competition of the natural sciences, Wehler's argumentation about the deficiency of sociology and economy is reminiscent of that. ${ }^{31}$ On the other hand, the newly established dominance of the social sciences makes it difficult to ignore the potential their theories, methodologies and methods have. Too big seems history's need for a renewal during the I960s and I970s, too persuasive the success of the social sciences and too wide-ranging the overlap regarding subject matter and method. Hence, the second part of the strategic pattern toward this academic influence is to acknowledge the social sciences by interdisciplinary cooperation or at least inspiration. This is why many historians, more or less programmatically, call for a sociologization of history. ${ }^{32}$

Although German historians defend their autonomy against the social sciences, they are still willingly acknowledging their legitimate influence. This balancing act becomes not least apparent in the name that is established for the new orthodoxy proving most suitable to deal with the influences sketched up to here: historical social science. While 'social science' is meant to symbolize the affinity 
to systematic social sciences, the adjective 'historical' 'emphasizes the aspiration of historical autonomy., ${ }^{33}$

\section{Balancing acts of legitimate bistorical knowledge and ideal-typical subject positions}

From the I960s onwards, societal influences as well as the growing academic influence of the social sciences challenge the legitimate bumanistic knowledge of both idealist and historicist orthodoxy. Opposed by defenders of the historicist tradition who see the danger of an instrumentalization of historical knowledge in the political discussion' ${ }^{34}$ and try to fend off 'a widespread and fundamental subjectivistic wave that has carried away history, [...] threatening to lead to a decay of thinking, ${ }^{35}$ there are heterodox attempts to provide a new foundation for objectivity. ${ }^{36}$

However, with historicism losing ground, soon enough historical social science becomes the main program of the new orthodoxy of legitimate bumanistic knowledge in history. In contrast to the political historiography of neo-Rankean historicism, it focuses on all areas of social and cultural life. Wehler, one of its main representatives, insists on history's practical relevance and emancipating mission by characterizing the discipline as a lively, political, critical social science. ${ }^{37}$ Unsurprisingly, the critical ambition toward overcome traditions is above all criticism of historicism. ${ }^{38}$ By way of example, Wehler states that 'only a historiography that is freezed in an antiquarian-esoteric self-sufficiency', inhabiting 'the ivory tower of allegedly purposeless, presuppositionless human science' would deny the practical relevance of the discipline. ${ }^{39}$

Just as historicism replaced the historiography of the Enlightenment as the orthodox tradition, this time it is the heterodox challenge of historical social science that delegitimizes historicism, either by tradition criticism or by reintegrating those historians that were excluded as outsiders by historicism..$^{40}$ While source critique still forms a core aspect of historical research, historicism's assertion that it deducts objectivity from it is now seen as a deficient antecedent. ${ }^{41}$ The new orthodoxy aims to achieve objectivity through its critical intentions and the disclosure of its own epistemological premises, allowing for an open discourse about axioms and presuppositions..$^{42}$

Therefore, for historical social science, 'the principle of objectivity of historical research is in no way obsolete. ${ }^{43}$ In Mommsen's case, it is reconciled with his moderate relativism by distinguishing illegitimate partiality and legitimate value considerations or theoretical insights. Similarly, Kocka distinguishes between legitimate practical engagement and illegitimate political instrumentalization. ${ }^{44}$ These reconciliations of objectivity and partiality - in the eyes of historicism 
a sure sign of the discipline's loss of purity - can be seen as a major feature of historical social science becoming the main approach of the new orthodoxy that is balanced by a decidedly critical and emancipative stance and by the pointedly societal involvement of its representatives.

It is not a coincidence that the success of the new orthodoxy takes place during the social opening of the university and the subsequent increase in recruitment of university personnel. The result is not only a changed age pattern of the idealtypical subject position, ${ }^{45}$ but also a crisis of succession: ${ }^{46}$ critically observed by established professors, who bemoan 'unforeseen dangers' because of 'personnel malinvestment in a partially rash and politicized phase of expansion and founding,,47 a new generation of historians can introduce heterodoxies due to the opened up personnel hierarchy. The crisis of succession also waters down the once distinctive degree of self-recruitment. Historians still enjoy a high socio-structural status, but as a group they are less homogeneous and less exclusively composed. ${ }^{48}$ This is fitting with more mundane working conditions the ideal-typical subject position of the professor is facing due to rising student numbers and the subsequent need for vocational education.

While a good deal of the historians working in the period from I87I to 1945 can safely be described as conservative, the new generation, whose 'moral profession' is characterized as 'political-societal pedagogy with emancipative intentions, ${ }^{49}$ is mostly left-liberal..$^{50}$ Attempts at democratizing the university further contribute to the politicization of the subject position. ${ }^{51}$ Similar to their predecessors described above, the historians of the I960s and I970s can still utilize their expertise for historical-political advice, but in contrast have to actively legitimize their stance in disciplinary discourse..$^{52}$ In summary, the ideal-typical subject position is occupied by historians mostly younger and less exclusively recruited than their counterparts described above. Their societal and political engagement is assuming critical and emancipative forms rather than nationalist and conservative ones, while their political stance tends to be left rather than conservative.

In the second period investigated, influences on history are exerted by democratization and expansive reforms and by the rise of the social sciences. But again, they are not compromising the discipline's claim for autonomy. Historical social science not only integrates the influence of the social sciences but also allows emancipative and critical societal engagement while preserving objectivity through an explicitly theoretical ambition and a critical-rational discourse. From a subject position that itself is a product of the social opening of the field, historians can claim autonomy by openly legitimizing their political engagement and reflecting their societal embeddedness as well as their interestedness in terms of contemporary politics. 


\section{Conclusion}

In the two cases discussed above, rules of legitimate historical knowledge are discursively established, contested or altered and broadened while historians aim for academic purity. Accordingly, subject positions allow the bearers of legitimate knowledge to orient themselves toward academic and societal relevance and toward the 'pure' academic core of their discipline at the same time. During this balancing act, former challenges can later become part of what is considered the proper discipline of history: The source critique of historicism reacts to an academic influence in order not to lose ground to the positivist natural sciences. Even for a discipline that is shaped by new orthodoxies, source critique still forms a core means to claim academic advances in historical knowledge. Societal influences such as the given form of government and its approach toward national history represent particular external needs that demand historical sense from scholars at a particular time, for example, a sense for the ideological needs of the belated nation (historicism) or postwar reeducation (historical social science). Although the social production of historical knowledge and corresponding subject positions is always subject to academic constraints and follows internal rules of cognition, a successful adaptation to such new societal needs establishes an autonomy that is always precarious. The balancing acts analyzed here involve two narratives or discursive strategies: the first as means of substantiating purity and the second as means of legitimizing societal and academic relevance.

According to the narrative of academic purity, societal and academic influences lead to history developing and broadening the concept of historical knowledge through an ongoing process in which more and more aspects of the discipline become subject to reasonable critique: initially, historicism derives abstract political stances from historical facts and rejects the knowledge produced by the historiography of the Enlightenment. Only an empirical stance toward history relying on research conducted with original sources ensures the discipline's academic autonomy from philosophy. Hence, the kind of critique historicism makes possible is focused on historical sources. While source critique forms a constitutive criterion of legitimate historical knowledge until today, its claim for objectivity and societal aloofness is questioned by a new generation of historians from the I960s onwards. ${ }^{53}$ Adding the critique of socially constructed axioms, purity of historical research now also has to be criticizable in terms of social embeddedness of the researcher him- or herself. By including critical-rational discourse as means of mutual persuasion, the production of historical knowledge becomes more transparent, open to scrutiny and therefore more societally relevant in a democratic way. This way, the democratization of postwar Germany is integrated in the discipline by being subjected to an academic critique ensuring that the 
societal demand will be met within the condition of scientific purity. The first discursive strategy depicts this balancing act as incrementally broadening the horizon of critique. While this is the narrative constituting purity as advances in knowledge, i.e., 'the power to judge autonomously' through critique of reason, ${ }^{54}$ a narrative of societal and academic impurity focuses on different aspects.

Analysis of the two historical cases reveals how, as a second narrative, the balancing acts do not only follow internal rules, but occur in different societal and academic settings. In the case of historicism, historians obediently emphasize statist and national (or nationalist) perspectives on foreign affairs and national heritage. While not involved in day-to-day politics, they are certainly committed to a national culture. At the same time, the influence of the natural sciences is absorbed and academic legitimacy is gained by a quasi-positivistic orientation on methods and sources. In reeducated Germany, the discipline once more finds an appropriate stance toward societal and academic demands. For a more democratic society, it docilely orients toward questions of civil society and educational tasks, while academic influences favor the emergence of theoretical and methodical imports from the social sciences. In contrast to substantiating purity, the second narrative is a discursive strategy paying tribute to societal and academic influences. As we have shown, both narratives, that of substantiating purity and that of legitimizing societal and academic relevance, have been balanced out under certain historical circumstances.

In both cases - historicism and historical social sciences - historians take part in a process of relatively autonomous translation of societal and academic demands into the logic of their discipline. As shown in this paper, the internalization of these challenges takes place in conflicts between orthodox stakeholders of the discipline and their heterodox counterparts. Such confrontational processes of negotiation are not conclusively solved at any given point. Instead, they are part of the permanent process of the humanities situating themselves within society and academia according to changing dominant societal and academic influences.

\section{Notes}

I Preface, in I. Kant, Critique of Pure Reason (Basingstoke, 2003 [orig. I787]).

2 I. Kant, 'The Conflict of the Faculties', in A.W. Wood and G. Di Giovanni (eds.), Immanuel Kant: Religion and Rational Theology (Cambridge, 1996, orig. I798), 225. Apart from this quote, all following quotes are translated by the authors.

3 J. Hamann, Die Bildung der Geisteswissenschaften. Zur Genese einer sozialen Konstruktion zwischen Diskurs und Feld (Konstanz, 2014).

4 P. Bourdieu,'The Specificity of the Scientific Field and the Social Conditions of the Progress of Reason', Social Science Information I4.6 (I975), I9-47. 
5 P. Bourdieu, Homo Academicus (Cambridge, I988).

6 H. Plessner, Die verspätete Nation (Stuttgart, I959).

7 F. Meinecke, Weltbürgertum und Nationalstaat. Studien zur Genesis des deutschen Nationalstaates (Munich, Berlin, 20I I), vi, challenges his colleagues to 'bathe in philosophy and politics more courageously'. H. Oncken, Historisch-Politische Aufsätze und Reden (Munich/Berlin, I9I4), vol. I., vi, asks for a 'politicisation of the nation on ground of historical education', at the same time complaining that history is out of touch with real life.

8 Cf. Fritz K. Ringer, The Decline of the German Mandarins: The German Academic Community, 1890-1933 (Hannover, NH, and London: Wesleyan University Press, I990), 200252. Exemplary for numerous contemporary references indicative of an elitist and antidemocratic view, F. Meinecke, 'Die Idee der Staatsräson in der neueren Geschichte', in H. Herzfeld (ed.), Friedrich Meinecke. Werke (Munich, I963, orig. I924), vol. I, 49 I, concedes that the moderately industrialized agrarian state with an aristocratic structure of society offered more favourable conditions to perpetuate intellectual [geistig] culture than the democratised and big capitalist industrial state. A conservative and nostalgic outlook is expressed by G. Steinhausen, Deutsche Geistes- und Kulturgeschichte von 1870 bis zur Gegenwart (Halle, I93I), II6, stating that 'after the war, facing the fiercest disruption of all conditions, even the superficial nimbus of the intellectual [geistig] strata is gone. [...] The intellectual [das Geistige], meeting no real demand, fades and with it its bearer: the educated middle class'. Cf. F. Stern, 'Die unbußfertige Nation', Die Grenzboten 80.4 (I92 I), I93-I96, esp. I94-I95.

9 Bernd Faulenbach, Ideologie des deutschen Weges: die deutsche Geschichte in der Historiographie zwischen Kaiserreich und Nationalsozialismus (Munich, 1980).

Io Schöttler, 'Geschichtsschreibung als Legitimationswissenschaft I918-I945. Einleitende Bemerkungen', in Peter Schöttler (ed.), Geschichtsschreibung als Legitimationswissenschaft 1918-1945 (Frankfurt a. M., 1997), 7-30, esp. I5-I7; S. Berger, The Search for Normality: National Identity and Historical Consciousness in Germany since 1800 (New York, Oxford, 1997), 38-40.

I I M. Lenz, 'Die Stellung der historischen Wissenschaften in der Gegenwart', in Max Lenz (ed.), Vom Werden der Nationen. Kleine historische Schriften (Berlin, Munich, 1922; orig. I 897), vol. I, 596-608, esp. 597 .

I2 Ibid., 602-603.

I 3 Cf. G. von Below, Die deutsche Geschichtschreibung von den Befreiungskriegen bis zu unsern Tagen (Munich, 1924), and F. Meinecke, Die Entstehung des Historismus, 2 Bde. (Munich, I936).

I4 For L. von Ranke, 'Englische Geschichte vornehmlich im sechzehnten und siebzehnten Jahrhundert, Bd. 7: Nebst Anhang: Analekten englischer Geschichte', in Leopold von Ranke, Sämtliche Werke (Leipzig, Berlin, I868), 4, '[e]verything is interrelated: critical studies of the real sources; impartial conception, objective presentation; the aim is bringing to mind the full truth'.

I5 R. Vierhaus, 'Rankes Begriff der historischen Objektivität', in Reinhart Koselleck, Wolfgang J. Mommsen, and Jörn Rüsen (eds.), Objektivität und Parteilichkeit in der Geschichtswissenschaft (Munich, I977), 63-76.

I6 Friedrich Jaeger, and Jörn Rüsen, Geschichte des Historismus (Munich, I992), 92-93.

I7 R. vom Bruch, 'Historiker und Nationalökonomen im Wilhelminischen Deutschland', in K. Schwabe (ed.), Deutsche Hochschullehrer als Elite: 1815-1945 (Boppard/R., I988), 105I 50, esp. I 26-I 32 . 
L. von Ranke, 'Erster Vortrag vom 25. September', in T. Schieder and H. Berding (eds.), Aus Werk und Nachlaß, Bd. 2: Ueber die Epochen der neueren Geschichte (Munich, I97I, orig. I854), 2 Io.

I9 K. Schwabe, 'Einführende Bemerkungen: Rahmenbedingungen und Selbstdeutung des beruflichen Wirkens deutscher Gelehrter', in Deutsche Hochschullebrer als Elite: 1815-1945 (Boppard/R., I988), 9-25, esp. 22.

20 H. von Sybel, 'Georg Waitz', Historische Zeitschrift 20 (I 886), 482-487, esp. 484.

2 I B. vom Brocke, 'Professoren als Parlamentarier', in Klaus Schwabe (ed.), Deutsche Hochschullebrer als Elite: 1815-1945 (Boppard/R., I 988), 55-92, esp. 62-66, 68.

W. Weber, Priester der Klio. Historisch-sozialwissenschaftliche Studien zur Herkunft und Karriere deutscher Historiker und zur Geschichte der Geschichtswissenschaft 1800-1970 (Frankfurt a. M., I984), 7I-83.

23 Vom Bruch,'Historiker und Nationalökonomen', I I6.

24 H.-U. Wehler, Historische Sozialwissenschaft und Geschichtsschreibung. Studien zu Aufgaben und Traditionen deutscher Geschichtswissenschaft (Göttingen, I980), I4; Schwabe,'Einführende Bemerkungen', I6.

25 Cf. J. Hamann, 'Bildung in German Human Sciences: The Discursive Transformation of a Concept', History of the Human Sciences 24.5 (2011), 48-72, esp. 58-60; R. Vierhaus, 'Zur Lage der historischen Forschung in der Bundesrepublik Deutschland', in Arbeitsgemeinschaft Historischer Forschungseinrichtungen in der Bundesrepublik Deutschland (ed.), Jahrbuch der historischen Forschung (Stuttgart, I974), I7-32, esp. 2 I, summarizes the situation as follows: 'The coincidence of a crisis of reputation, the expansion of the social sciences, a structural change of the epistemological interest in society and the necessity of a new theoretical foundation' has brought history in the I960s in a difficult position'. H.W. Blanke, Historiographiegeschichte als Historik (Stuttgart, Bad Cannstadt, I99I), 669. and R. Koselleck, 'Wozu noch Historie?', Historische Zeitschrift I (I97 I), I-I9.

J. Kocka,'Theorien in der Sozial- und Gesellschaftsgeschichte. Vorschläge zur historischen Schichtungsanalyse', Geschichte und Gesellschaft I.I (I975), 9-42, esp. I I-I2; Wehler, Historische Sozialwissenschaft, 32.

29 Cf. Mommsen, Die Geschichtswissenschaft, 468; I. Geiss, 'Der Ort der Geschichtswissenschaft in der Gesellschaft oder Die Funktion des Historikers', in E. Jäckel and E. Weymar (eds.), Die Funktion der Geschichte in unserer Zeit (Stuttgart, I975), I92-207, esp. I96-I 98. K.-D. Erdmann, 'Der Deutsche Historikertag in Mannheim', Geschichte in Wissenschaft und Unterricht 28 (1977), I29-130, esp. I29.

Wehler, Historische Sozialwissenschaft, 46-52, cf. E. Jäckel and E. Weymar (eds.), Die Funktion der Geschichte in unserer Zeit (Stuttgart, 1975), 9.

Geiss, 'Der Ort der Geschichtswissenschaft', 196; Wehler, Historische Sozialwissenschaft, 43.

33 Blanke, Historiographiegeschichte, 65.

34 K.-G. Faber, 'Zur Instrumentalisierung historischen Wissens in der politischen Diskussion', in Reinhart Koselleck, Hans Mommsen, and Jörn Rüsen (eds.), Objektivität und Parteilichkeit in der Geschichtswissenschaft (Munich, I977), 270-316, esp. 270.

35 D. Junker and Reisinger, 'Was kann Objektivität in der Geschichtswissenschaft heißen und wie ist sie möglich?', Historische Zeitschrift, Beibeft 3 (I974), I-46, esp. 4.

36 Programmatically: Kosellek, 'Wozu noch Historie?’.

37 Wehler, Historische Sozialwissenschaft, 9.

38 Kocka, 'Theorien in der Sozial- und Gesellschaftsgeschichte', I I. 
39 Wehler, Historische Sozialwissenschaft, 9.

40 Explicitly so. See H.-U. Wehler (ed.), Deutsche Historiker, 5 Bde. (Göttingen, I97 I-I982).

4I Cf. Mommsen, Die Geschichtswissenschaft; Wehler, Historische Sozialwissenchaft, I3-4I.

42 Blanke, Historiographiegeschichte, 673-7I2.

43 W.J. Mommsen, 'Der perspektivische Charakter historischer Aussagen und das Problem von Parteilichkeit und Objektivität historischer Erkenntnis', in Reinhart Koselleck, Wolfgang J. Mommsen, and Jörn Rüsen (eds.), Objektivität und Parteilichkeit in der Geschichtswissenschaft (Munich, I977), 44I-468, esp. 448.

44 Kocka, 'Theorien in der Sozial- und Gesellschaftsgeschichte', I I.

45 In $1973,45 \%$ of all full professors were younger than 44 . See W. Conze, 'Die deutsche Geschichtswissenschaft seit 1945: Bedingungen und Ergebnisse', Historische Zeitschrift 225-I (I977), I-28, esp. I9.

46 Bourdieu, Homo Academicus, I43-I47.

47 Conze, 'Die deutsche Geschichtswissenschaft', I 8, 20.

48 Weber, Priester der Klio, 7 I-83.

49 Kocka,'Theorien in der Sozial- und Gesellschaftgeschichte', I I.

50 Blanke, Historiographiegeschichte, 708.

5 I C. Cornelißen (ed.), Geschichtswissenschaft im Geist der Demokratie. Wolfgang J. Mommsen und seine Generation (Berlin, 2010).

52 Blanke, Historiographiegeschichte, 693.

53 The generational aspect is covered in D. Moses, German Intellectuals and the Nazi Past (Cambridge, 2007), 55-73.

54 Kant, 'Conflict of the Faculties', 225. 


\title{
I2.2 Critique and Theory in the History of the Modern Humanities
}

\author{
Paul JaY
}

What role has poststructuralist literary, critical, and cultural theory played in the making of the humanities, particularly in the period between 1968 and the present, and what role should theory have going forward as we come to terms with the corporatization of higher education, with its stress on practical skills, vocational training, and on measuring concrete learning outcomes? Exploring these questions requires confronting - and linking - two key issues currently at the core of sometimes-fierce debates about the humanities in the West, and particularly in the US.

The first issue has to do with whether or not theory since 1968 has served to undermine the traditional coherence of a humanities education, and the second has to do with how humanists and their supporters respond to assertions the humanities have little value because they do not teach students practical skills. In the US in particular these two issues have gotten intertwined.

I will be arguing that since theory has always been central to the humanities it is a mistake to argue it has somehow undermined and marginalized them. This is especially the case at a time when questions are being raised about the practical skills humanities students acquire, for the skill of critical thinking is at the very heart of an education in theory. Claims that a humanities education has no practical utility are surprisingly common. Indeed, such a claim is often worn as a badge of prestige by humanists themselves. For example, the well-known literary critic and New York Times columnist Stanley Fish has insisted that the humanities

don't do anything, if by 'do' is meant bring about effects in the world. And if they don't bring about effects in the world they cannot be justified except in relation to the pleasure they give to those who enjoy them. To the question 'of what use are the humanities?', the only honest answer is none whatsoever. ${ }^{\mathrm{I}}$ 
And Frank Donoghue, writing about the marginalization of the humanities in an increasingly vocation-centered university, surrenders to a dangerous fatalism. 'Curricula change overtime', he notes, 'and the humanities simply don't have a place in the emergent curriculum of the twenty-first century. ${ }^{2}$ With friends like this the humanities do not need any enemies.

The failure to rise to the challenge of defending the humanities in terms of the practical skills they teach is all too often a retreat into idealism. Worse still, it usually comes off as defeatist. It avoids the necessity of developing a pragmatic position in the face of realities that are not going to go away. Arguing that the humanities have gotten sidetracked by abstract, esoteric theories fails to recognize that theory is intimately related to critique, that critique has been at the center of debates about humanism since its inception, and that critique is demonstrably connected to the practical skill we sometimes too loosely call 'critical thinking'. For this reason, highlighting the role of theory as critique in the humanities is one of the best ways to highlight the practical utility of a humanities education.

\section{Critical Theory and the end/ends of the humanities}

Observers who complain theory has ruined the humanities argue that from 1850 to about 1968 the humanities developed a curricular and intellectual coherence that was successively undermined by structuralist, deconstructive, psychoanalytic, queer and Marxist theory, and later by multiculturalism, feminism, and the rise of postcolonial and cultural studies. ${ }^{3}$ This old coherence was based largely on an attitude of deference to canonical texts and traditional humanist ideals. It was connected to what the American critic Andrew Delbanco has called a curatorial model of scholarship and teaching. ${ }^{4}$ According to this narrative, the primary role of the humanities was to preserve and explore a great tradition of humanist work in literature, philosophy, the fine arts, history, and religion, encouraging students, following Matthew Arnold's ideal, to study with disinterest the best that has been thought and written.

The problem with theory, from Delbanco's perspective, is that it abandoned deference and disinterest in favor of criticism, fracturing a coherence organized around great books and the ostensible pursuit of 'universal truths' at the core of Western humanism. The complaint about theory from this perspective is that its focus on difference and diversity turned our attention away from what unites us to what divides us. According to this narrative, difference replaced universality as the key principle directing the pursuit of knowledge in the humanities. Following this new model, the humanities turned its attention to analyzing the exclusion 
of differences as a constitutive move in the construction of the very notion of a 'common humanity', and this attention led to an explosion of work across the disciplines of the humanities on the importance of particular differences related to things like culture, gender, race, and sexual orientation. It also led to what traditional humanists came to feel was a counterproductive critique of humanism itself, one that undermined the very notion of a humanities education.

Of course traditional humanists were hardly wrong in seeing theory as a threat to humanism, for theorists as varied as Michel Foucault, Jacques Derrida, and Louis Althusser (along with French feminists such as Monique Wittig, Luce Irigaray, and Hélène Cixous) often presented their work as announcing the end of humanist man. While humanism tended to see the human subject as a sovereign agent, language as a transparent medium for that agency, and truth as the product of a reason that transcended history, these theorists and their followers questioned the autonomy and agency of the subject, the transparency of language, the foundations of reason, and the whole idea that truth could stand outside history and culture as universal and foundational. The most oft-cited version of this idea is Foucault's declaration near the end of The Order of Things that 'man is neither the oldest nor the most constant problem that has been posed for human knowledge', that 'one can be certain that man is a recent invention [...] and one perhaps nearing its end'. 5 Derrida's critique of metaphysics, the questions he raises about the idea of presence, and his criticism of the equation between voice, reason, and the subject, was also framed as a frankly anti- or posthumanist approach to subjectivity. And the work of both Derrida and Foucault is consistent with that of Althusser, who insisted on the fundamentally anti-humanist orientation of Marxism and argued that the putatively autonomous humanist subject was a product of ideology and language, a being not sovereign but interpellated. From this point of view, theory's critique of humanism seemed to betray the very ideals upon which the humanities were built. ${ }^{6}$ Why? Because theory substituted ideological critique for disinterest, made it more difficult to explore our common humanity, and seemed to fracture the curricular coherence of a humanities education by marginalizing the great works of the Western tradition in favor of inferior texts by formerly marginalized writers.

While there is no denying how dramatically poststructuralist theory has transformed the humanities, it is by no means necessary to see theory as anti-humanist. Indeed, as Martin Halliwell and Andrew Mously have shown, ${ }^{7}$ humanist thought is too diverse a tradition to be reduced to a single line of thinking about human subjectivity. They question the standard narrative that contemporary critical theory constituted a 'complete rupture' with humanism. Instead, they argue that the work of thinkers like Baudrillard, Derrida, Foucault, Kristeva, Lacan, and Lyotard, ought to be seen as developing a more nuanced, self-reflexive, and 
'rigorous theory' of the human. From this point of view, contemporary critical theory 'takes the human to be an open-ended and mutable process', but this does not have to be seen as an anti-humanism. A 'postfoundationalist view of the human', suspicious of essentialist categories, is in their view an 'ethically and politically grounded humanism' ${ }^{8}$

I think they are right, and that it is important to recognize not simply how contemporary critical theory can be understood as an attempt to productively modify the substance of humanist thinking, but how the kind of critical thinking theory performs is itself central to the tradition of humanism. The danger in dismissing theory as anti-humanist is that it runs the risk of elevating subjects of knowledge (call it cultural literacy) over learning how to think critically about systems of thought, ideologies, and authority (what I would call critical literacy). One of the most significant drawbacks of this position is that it sees objects of knowledge and the practice of critique in either/or terms. This problem is exemplified by Delbanco's distinction between curation and criticism. According to Delbanco, the humanities went astray when criticism overwhelmed curation, when theory and the critique of humanism took the place of the humanities' responsibility to preserve and venerate a traditional body of knowledge (and the seemingly timeless authority it had). What this point of view misses, of course, is the reciprocal relationship between curation and criticism, for to a significant degree the act of curation requires criticism, and criticism is itself a form of curation.

A curator does not just make decisions based on quality and distinction. He or she is also critically and imaginatively involved in putting together objects in ways that produce new relations between things and new forms of knowledge. Humanities scholars and educators curate by being critical in this more capacious sense of the term. Contemporary work in the humanities is therefore curatorial in the best sense of the word. It both reorganizes old materials and gathers them together with new materials to create new perspectives on both the past and the present. This means theory is not a threat to the curatorial enterprise, but rather, is central to its intellectual and pedagogical vitality.

Because theoretical thinking has always been central in mainstream humanism, the distinction between preservation and critique simply does not hold up. Delbanco wants the great texts or art works in literature, philosophy, art history, or religious studies to be the primary focus of attention, but in a way that runs the risk of separating them off - even protecting them - from criticism. In his view the act of curation must always take precedence over what he takes to be the counterproductive practices of criticism. My point, of course, is not to argue that Delbanco gets it backwards - that the humanities ought to be all about criticism and that they ought to put curation on the back burner. My point is that the two 
activities are interdependent. When we articulate the value of the humanities we need to emphasize not only the body of knowledge they preserve but also the value of the forms of critique they teach, and to underscore that critique is a practical skill integral to both scholarly work and critical citizenship.

\section{Theory, critique, and the tradition of humanism}

Now, what do I mean when I invoke the word critique, and how has critique been central to the making of the humanities? Let me be clear: by critique I do not simply mean critical thinking. The phrase 'critical thinking' has become a terribly overused catch phrase in discussions of higher education, and it is often very loosely defined - if it is defined at all. By critique I mean the practice of systematically analyzing and interrogating the constitution of conceptual categories and the sources of their authority. Critique explores historically and conceptually the development of norms that regulate our personal, social, and political lives together (for that matter, it explores the historical constitution of the very 'we' these norms are supposed to protect).

It is important to stress here that there is such a thing as critique itself - separable from particular critiques of particular discourses. And critique can be taught, not just particular critiques, but the activity of critique per se. Indeed, this is what we teach when we teach critical theory. Judith Butler, writing about Foucault's conception of critique, has observed that critique

will be dependent on its objects, but its objects will in turn define the very meaning of critique. Further, the primary task of critique is not to evaluate whether its objects - social conditions, practices, forms of knowledge, power, and discourse - are good or bad, valued highly or demeaned, but to bring into relief the very framework of evaluation itself. ${ }^{9}$

This meta-level in critique, this bringing into relief the very framework of evaluation itself' is at the heart of the activity we call critique.

Critique is, in this sense, at the very heart of the humanist enterprise. It involves the kind of abstract, systematic thinking we associate with Kant's theory of the aesthetic, Hegel's dialectic, Marx's analysis of the class structure or the operations of ideology, Nietzsche's idea of the death of god, or Freud's work on the unconscious, or his great work, Civilization and Its Discontents. But it also involves our evaluating the very frameworks of evaluation that have been employed to think about those critiques, including our own evaluation of those evaluations. Indeed, it is quite impossible to think about humanism, and thus the humani- 
ties, without thinking of the primary role that dissent and critique played in the development of Enlightenment thought, especially in terms of its radical proposals about human liberty and agency, about the primacy and autonomy of the individual, and about the natural or human rights everyone is entitled to. All of these ideas involved a theoretical critique of the status quo. It was what humanism, at its very foundations, was all about. From this point of view, the criticism of theory's place in the humanities makes no sense. Worse still, it seems to strike at the very heart of the humanist enterprise, relegating its critical vitality to the past. Seen this way, humanism is over, fixed, curated, and sanitized. It is worthy of historical study, but not something that still lives.

One thing that is particularly interesting about Butler's discussion of Foucault's approach to critique is her focus on how he associates critique with virtue, the cultivation of which - along with an ethical sensibility - we like to associate with a humanities education. About his idea that 'there is something in critique that is akin to virtue' Foucault observes, ${ }^{\text {IO }}$

virtue is most often understood either as an attribute or a practice of a subject, or indeed a quality that conditions and characterizes a certain kind of action or practice. It belongs to an ethics which is not fulfilled merely by following objectively formulated rules or laws. And virtue is not only a way of complying with or conforming with pre-established norms. It is, more radically, a critical relation to those norms. ${ }^{\text {II }}$

This critical relation to norms, Butler emphasizes, involves 'a resistance to authority', something Butler points out Foucault saw as absolutely central to Enlightenment critiques of the status quo.

Although Butler is quick to point out that most Enlightenment thinkers would not understand the link between critique and virtue in this kind of way, she insists that 'this resistance would not invalidate' the link Foucault makes, for what he 'seeks in the characterization of the Enlightenment is precisely what remains "unthought" within its own terms: hence, his is a critical history' of critique. ${ }^{12}$ 'In his view', she concludes, 'critique begins with questioning the demand for absolute obedience and subjecting every governmental obligation imposed on subjects to a rational and reflective evaluation. ${ }^{13}$ Foucault's connection between virtue and critique, of course, is aimed precisely at exposing these operations and therefore has the potential to be liberatory.

Linking theory to critique, and considering its liberatory potential in the way I have been sketching out, underscores a key problem with conservative criticisms of theory. On the one hand, the popular idea that theory has ruined the humanities is often based on the quite accurate idea that theory has had a lot of critical 
things to say about humanism. But on the other hand, that argument misses the fact that theory's critique of humanism is thoroughly consistent with the centrality and purpose of critique in humanism itself, and that its purpose, by and large, has been to ensure the ideals of liberty and agency at the heart of humanism are extended to everyone. For this reason, contemporary theory - contemporary critique - ought not to be thought of as anti- or posthumanist, although as we have seen above, some theorists like to style it that way. In my view, such terms are quite counterproductive. In an age when the humanities are imperiled, it makes little sense to use the rhetoric of anti- or posthumanism in articulating its value. There is no reason why theory and its critique of humanism cannot be folded into a positive articulation of a twenty-first-century humanism.

Instead of seeing theory as a threat to humanism, new ways of thinking about the human subject, the role that language plays in constructing reality and shaping meaning and value, and how gender, sexual orientation, race, ethnicity, and class both shape identity and enable or circumscribe agency, ought to be seen as constructively rethinking and expanding traditional humanist claims about individuality, autonomy, liberty, and rights. In my view, contemporary forms of humanistic critique are, by and large, interested in helping to broaden, and diversify these claims, to make the discourse of humanism more, not less legitimate. Although in its most radical moments, theory seemed to be announcing the end of man or the beginning of a posthumanist age, it has actually represented constructive, forward-looking dissent from the historical limits of humanism, dissent that sought to expand, correct, and broaden humanist ideals.

Examples abound. Although, as we have seen, Foucault's remarks about the 'end of man' have often been cited as an example of the anti-humanist orientation of contemporary theory, it makes more sense to see his work on the relationship between subjectivity, discourse, ideology, and power - along with theory's general critique of the idealist human subject of eighteenth- and nineteenth-century philosophy - as a contribution to refining and clarifying our humanist understanding of subjectivity and agency. From this point of view, contemporary theory is all about insuring that the humanist guarantee of agency and rights is extended to everyone, not just the traditional human subject of 'universal man'.

Here, of course, feminist theory becomes another, crucial example of a critical theory that, while it might be presented as anti-humanist, is anything but. On the one hand, feminism dissents from humanism's notion of 'man', based as it is on the universalizing of a version of human nature derived by, and largely based on, male experience, but on the other hand feminism is linked to humanism in its insistence that women be accorded the same set of rights and the same kind of autonomy and agency associated with traditional humanism. On the critical side, of course, feminist theory and history help foreground the patriarchal orientation of 
humanism. Not simply in the trivial and quite obvious sense that virtually all of the early thinkers and writers associated with humanism were males whose status as scholars and educators was predicated on all of the privileges that came with being male in a patriarchal system, privileges that were unavailable to women (who, more often than not, were treated as the property of men). The less obvious but perhaps even more important point is that the identity category of gender is altogether absent inside humanist thinking about the human. We should not see this simply as linguistic hair splitting, believing that the great writers of Renaissance, Enlightenment, or modern humanism meant to include women when they wrote 'man'. Too often they did not. Humanist 'man' was conceptualized from the experience of male human beings; it is about forms of power, thought, agency and autonomy (not to mention access to education and therefore to the very activity of scholarship upon which humanism is founded) historically only accessible to men.

However, as critical as feminism is of how humanism's philosophy of man kept women disenfranchized, it is important to see contemporary feminist theory as part of a struggle to expand humanism's ideals with regard to individual autonomy and liberty rather than as an attempt do away with humanist ideals altogether. Like Marxism, feminism has had a double relationship to humanism, simultaneously launching a critical dissent from, and insisting on the broad legitimating and application of, its central ideals about human individuality, autonomy, and agency. This kind of work, while often cast as post-or anti-humanist, ought to be understood as part of an evolving discourse within humanism about what it means to be human, and about what ought to be included in a humanities education. It constitutes both a dissent from humanism, and an extension of its logic.

\section{Theory, critique, and critical thinking}

Linking theory to critique, and critique to critical thinking, not only makes intellectual and historical sense. It makes strategic sense as well. Critical thinking is routinely cited as the single most important practical skill the humanities teach, yet, as I indicated earlier, it is often invoked with little attempt to define it. Many of the same people who are critical of the role of theory in the humanities are the same people who emphasize the importance of critical thinking, which means they are missing the fact that critical theory courses are some of the best courses in critical thinking we have in higher education. Seeing critical theory as training in critical thinking emphasizes the general utility of such courses, but it also helps add substance to a concept that is often invoked but rarely defined in discussions about higher education. For example, The Foundation for Critical Thinking outlines an approach to critical thinking that links it to the kind of theoretical think- 
ing associated with structuralism, deconstruction, and other social, cultural, and political theories that challenge received dogmas and entrenched assumptions. ${ }^{14}$ For example, the foundation's mission statement declares that critical thinking cultivates 'intellectual discipline [...] self-reflection and open-mindedness', insisting that it requires a break with 'automation and fixed procedure' and embraces 'radically different' forms of 'thinking [...] adaptable, more sensitive to divergent points of view'. And critical thinking is also tied explicitly to social changes under globalization.

The world in which we now live requires that we continually relearn, that we routinely rethink our decisions, that we regularly reevaluate the way we work and live. In short, there is a new world facing us, one in which the power [...] to regularly engage in self-analysis, will increasingly determine the quality of our work, the quality of our lives, and perhaps even our very survival.

This approach to critical thinking underscores its foundations in theoretical thinking and critique in disciplines across the humanities, but also to challenging, resisting, and rethinking those forms in the very act of using them. From this point of view you cannot have critical thinking without theory, for what's being subjected to critical thinking here are entrenched, naturalized professionalized assumptions and protocols. Critical thinking involves asking challenging questions about ways of thinking and conceptualizing problems that have become automatic and fixed. This approach to critical thinking, which deals with received concepts 'openmindedly within alternative systems of thought, recognizing and assessing, as need be, their assumptions, implications, and practical consequences', is strikingly in sync with the shorthand definition of theory Jonathan Culler provides. 'The main effect of theory', he points out, 'is the disputing of 'common sense': common-sense views about meaning, writing, literature, experience. ${ }^{15}$ Theory, from this perspective, is a form of critical thinking that in challenging old, naturalized orthodoxies gets us to see that what we take to be 'common sense' explanations and assumptions are in fact theories. For 'theory', Culler explains, is an 'attempt to show that what we take for granted as "common sense" is in fact a historical construction, reflecting a particular theory that has come to seem so natural to us that we don't even see it as a theory." ${ }^{16}$

Theory in the humanities, then, is not a distraction from what the humanities ought to be doing. Theory is central to what everyone believes the humanities ought to be doing: teaching critical thinking. It is a way of thinking critically about humanism and the gap between what it advocates and who has benefited from what it advocates. And theory challenges students to think open-mindedly 
in the context of divergent points of view about their core beliefs, to rethink and reevaluate their positions, and to entertain radically different forms of thinking about how meaning is produced, about the relationship between art, philosophy and power, and about the relationship between class, gender, race, sexual orientation, and social justice. From this point of view theory, as it challenges traditionally entrenched ways of doing intellectual and historical business, is an important vehicle for critical thinking and is thus central to the core mission of the humanities. Indeed, it is one of the most concrete examples we have of teaching critical thinking.

\section{Conclusion}

To come back to the double argument I have been making, all of this means not only that theory ought not to be seen as a distraction from what the humanities should be doing, but even more importantly, that theory ought to be seen as central to both the history of humanism and the range of practical skills we teach in the humanities. We should not allow theory to become the scapegoat for what critics believe is wrong with the humanities. Indeed, we need to go beyond defending theory and actively argue for its centrality in the traditions of humanism we teach, and the contemporary humanities we increasingly have to defend.

\section{Notes}

I Stanley Fish, 'Will the Humanities Save Us?' The New York Times, January 6, 2008, URL: http://opinionator.blogs.nytimes.com/?s=will+the+humanities+save+us.

2 Frank Donoghue, 'Will the Humanities Survive the 2 Ist Century?', The Chronicle of Higher Education, September 5, 20 I0.

3 Leaders of the attack on theory at the height of the so-called culture wars in the US included William Bennett, Lynn V. Cheney, Dinesh D’Souza, and Roger Kimball, among others. For an interesting discussion of why they got it wrong, see Mark Bauerlein, 'The Attack on Theory', The Chronicle of Higher Education, February 9, 2013. URL: http:// chronicle.com/blogs/brainstorm/the-attack-on-theory/6I35.

4 Andrew Delbanco,'A New Day for Intellectuals', February I3, 2009. URL: http://chronicle.com/article/A-New-Day-for-Intellectuals/2 1359.

5 Michel Foucault, The Order of Things: An Archaeology of the Human Sciences (New York, Vintage Books, 1994), 386-387.

6 This was, of course, the main thrust of conservative critiques in the United Sates of contemporary theory produced by people like William Bennett, Lynn Cheney, and Dinesh D'Souza.

7 Martin Halliwell and Andy Mousley, Critical Humanisms: Humanist/Anti-Humanist Dialogues (Edinburgh: Edinburgh University Press, 2003). 
8 Halliwell and Mousley, Critical Humanisms, I-2.

9 Judith Butler, 'What Is Critique? An Essay on Foucault's Virtue', in eipcp, a publication of the European Institute for Progressive Policies, May, 200I. URL: http://eipcp.net/ transversal/o806/butler/en.

Io Quoted in Butler,'What Is Critique?'

I I Ibid.

I2 Ibid.

I3 Ibid.

I4 URL: http://www.criticalthinking.org.

I5 Jonathan Culler, Literary Theory: A Very Short Introduction (New York: Oxford University Press, 20I I), 4.

I6 Culler, Literary Theory, 4 . 



\title{
Epilogue
}

\section{Toward a History of Western Knowledges}

\section{Sketching Together the Histories of the Humanities and the Natural Sciences}

\author{
John V. Pickstone
}

In my book on Ways of Knowing: A New History of Science, Technology and Medicine (2000), I showed how a model developed from the historiography of medicine could be used to elucidate much wider histories. Since then I have published several papers refining my framework and extending its scope. ${ }^{1}$ In June 20I2, after a lecture in Utrecht, I was asked how my method might be used for the history of the humanities. This paper sketches a response. ${ }^{2}$

But why should I presume that I have something to contribute to the 'history of the humanities', especially since this category has rarely been considered by historians in Britain? Even if we agree that there might be simple ways of mapping the history of humanities as part of Western knowledge more generally, why should work on ways of knowing in science, technology and medicine (STM) be one good place to start?

In this introductory section I suggest reasons why my approach might help with this wider remit, beginning with the openness of the method as to subject matter. I then discuss questions of chronology, of theory and practice, and about combinations of ways of knowing, across that wider range. I do not attempt to define the history of humanities, any more than I have delimited the history of STM. Rather, I follow an open-ended method which may in fact serve for most of the formalized knowledges of the West since the Renaissance. Later in the essay I test that proposition by sketching a history across that range, including both natural and cultural knowledge practices. Importantly, I note ways in which issues in the history of humanities may improve our histories of STM. Questions about the ultimate scope of the approach, and of what may lie beyond, I leave for another day! 


\section{Ways of knowing in STM and beyond}

Though my book was called a history of science, technology and medicine, the approach was never defined by its sphere of application; indeed the book included some notes on social and cultural sciences. The same is true for each of my ways of knowing and ways of working taken individually as 'elements' of historical analysis. In brief, these are: reading and using meanings; describing/classifying and crafting; analysis (whether mathematical or substantive) and rationalization; and synthesis from elements. With but one partial exception, these 'working knowledges', seem applicable to the humanities, at least if we allow that mathematical analysis is similar to, or a class of, formal analysis, such as used in linguistics. We can show this by considering in turn these four kinds of working knowledges:

(A) The applicability is especially obvious for 'hermeneutics', or readings for meaning, along with its practical correlate that I provisionally called rhetoric. As an aspect of the history of STM, the reading of natural objects for meaning may be seem debatable, but reading texts for their meanings has always been central to the humanities. It is, indeed, against concerns with literary texts that historians can best consider later readings of the book of nature.

One already begins to see how including the history of the humanities might enrich the whole project. Perhaps, for example, we need to enquire how natural philosophy worked when it was no longer on the syllabus of 'science' teachers; or how classical humanities, modern languages, academic philosophy and art continue to inform our response to the world and our self-fashioning, as well as the factual content of our learning?3

(B) I have used the term 'extended natural history' for projects that describe and/ or classify any kind of object - and that must surely include books. The choice of terms is difficult: I have sometime used 'sorting' as less associated with birds' eggs and flowers. The term 'cataloguing' would stress the connection with bibliography, etc., and especially in a restaurant in Greece, 'catalogue' would lead directly to the menu - and maybe to recipes, which in turn bridge nicely from classification to crafting. Perhaps, however, as we widen the agenda and stay with Greek, techne is a better term than craft - one which can cover all knowledge-based creative practices, including the literary or political.

It is no accident, that here and elsewhere in this discussion, we meet with Aristotle, the greatest of Western systematisers and the widest in range. Perhaps recent historians of technology are too ready to focus on machines; better, with Aristotle, to include the biological and psychological as we consider ways of working that depend on knowledge of materials, tools, designs, and the needs of users. 
(C) My third primary way of knowing is 'analysis', meaning reduction of a complex phenomenon to known elements - whether mathematical, as in planetary astronomy, or substantive, as in chemical analysis. Equally, and evidently, it can characterise work in literary studies, philology or psychoanalysis, for example. Here too it seems useful to distinguish formal analyses, which tend to be very general, e.g., questions of symmetry, and substantive analysis which is more field specific, e.g, the elements of the Freudian psyche.

(D) In the early papers and the book, I used 'experimentalism' as a fourth way of knowing and working, to stress the experimental creation of systems out of known elements, especially from the nineteenth century, whether in synthetic chemistry or the experimental medicine of Claude Bernard. But this usage was problematic because I also needed to distinguish several other kinds of experimental interventions, e.g., experimental histories (a Baconian class) and experimental analysis. More recently I have used the term 'synthesis' to include both mathematical modeling and novel material constructions - made from known 'elements', whether radicals in organic chemistry or, say, endocrine glands and hormones in clinical physiology. This aspect of the model is certainly suggestive for the humanities, and I have indicated elsewhere how the analysis: synthesis distinction may prove useful in characterising 'modernism' - in the arts and in STM. ${ }^{4}$

This use of 'synthesis' also frees 'experiment' to qualify the primary working knowledges - to indicate interventions (or maybe the open-ended) across the whole range of knowledge practices.

\section{Chronologies across the knowledge practices}

Most overviews of natural sciences hinge in the mid-seventeenth century, with the first scientific revolution; but many historians of STM stress major changes in the several decades around 1800 , sometimes called the second scientific revolution, though there is little systematic exploration of its structure and dynamics, beyond individual disciplines. If we look to other kinds of knowledge practices, it is this second period, say $1776-\mathrm{I} 848$, which seems especially prominent and pregnant. Historians of technology and medicine both tend to prioritise shifts around 1800 - the Industrial Revolution and the Birth of the Clinic - without neglecting others. That has indeed been my frame for my analysis of STM generally, stressing the second scientific revolution along with the industrial and the clinical. It corresponds easily with the history of humanities, for most modern social sciences are commonly dated to the half century around 1800 , as are key shifts in studies of language and art, along with the Kantian and Romantic revo- 
lutions in philosophy and art. If we agree that all these revolutions in knowledge practices are roughly coincident, then analysis of this complex mega-revolution and its relations with political revolutions is surely a central task for any historian prepared to work on that scale; and any analysis which has proved plausible for STM in this period would seem likely to assist that wider endeavor.

\section{Theory and practice in STM and cultural work}

Many historians of the natural sciences now see themselves as also dealing with the history of technology, while historians of medicine rarely make any primary division between science and technology. They know the nineteenth-century supposition that practices stem from prior formal knowledge, but they also know, and can use even for later periods, the old model that 'sciences' were the inclusions of formal knowledge, as it were, in liberal practices. Perhaps across the whole range of what the Greeks called techne - from medicine to playwriting -we might try to recreate the knowledges at work, the 'sciences' in the arts and crafts, including (fine) art, along with the philosophies which helped place those arts in both natural and cultural worlds?

Perhaps in our world as well as Aristotle's, the sciences of languages, literature and of art might usefully be considered, in part, as technical sciences, akin to engineering sciences or some medical science - as studies of artifacts and/or modifications of nature. Thinking of technical sciences in this way may nicely approximate Bacon's claim that making is the test of our natural knowledge and Vico's subsequent, and perhaps consequent, claim that culture is more knowable than nature because it is man-made. Of course, in all such cases, the knowledge deployed by makers or analysts will not exhaust the properties of the artifact or the possibilities for improvement. It is importantly untrue that man-made objects are ipso facto fully understood: Victorian steam engines and novels were, and may remain, important objects of investigation - in natural sciences and in the humanities.

Here we may also note that technical sciences are often, but not always, normative. Practitioners usually want to know how they can do things better - whether they are doctors, engineers, orators or painters. For the sciences of culture, we know that normativity was crucial in the early modern period; some of them, e.g., art history, seem to have been relativized in the Age of Revolutions (so any remaining norms became local to particular artistic projects rather than general). These complex issues of praxis, technical science and normative need much more discussion than is possible in this essay; here I simply suggest that putting the sciences of culture (back) alongside wide views of medicine, engineering or agri- 
culture may bring advantages across the board. Medicine, as a well-studied and partly discursive art, may be especially useful as a common point of reference, not least because our bodies and our languages are each, in various measures, both inherited and created.

\section{Changes and combinations of knowledge practices}

As noted, the kinds of ways of knowing and working which I used for analysis in the history of STM are reading/rhetoric, sorting/crafting, analysis/rationalization, and synthesis. Of course, practices of each kind were not static over time. The work of sorting in a Renaissance museum was vastly different from that in a present-day text bank, but there are enough commonalities and continuities across time to make the category stable. Changes within each 'way' are a significant part of history, but so too are new discriminations and combinations. In my view most knowledge projects are combinations of 'ways'. This is hugely important, because it allows infinite variety and subtlety of analysis, perhaps more so than in the historiography which uses 'style'. Most of the work of Alistair Crombie or Ian Hacking, for example, traces particular styles through history, simply mentioning the possibility of combinations. ${ }^{5}$ My approach is analytical rather than simply taxonomic - more like chemistry than botany - and thus more openended in the treatment of any 'case' (at any level).

Certainly one can follow each kind of working knowledge, and their mixtures, but their interactions and 'compoundings' are central. For example, all syntheses depended, and in some sense incorporated prior analyses, which in turn involved prior sortings; and all projects (and their objects) have cultural and symbolic aspects. It follows from this last statement that projects which present 'natural' objects involve the cultural work of 'naturalization' which strips particular objects of their symbolical significance, for the purposes of that project. These relationships probably hold across the whole field of knowledge. We can, for example, read a book for its meaning, to check changes between editions, or to analyze sentence structure, and these activities are likely to have different histories. This essay will stress diachronic variety, interactions and compoundings across the whole range of knowledge - in ways which seem to link easily with the complexities of social history.

Again medicine is a good guide. A disease may be seen as a vital disturbance which doctors (and historians) can analyze into natural-historical and cultural components; they may see laboratory analysis added, at least after 1800; and more recently, say, genetic engineering. All these elaborations involve new cultural resonances. But common accounts of disease may be more simply understood as 'bio- 
graphical' - a term which covers both cultural and natural components. Thinking of biography can then connect medicine with the many other cultural disciplines and practices which study human conditions, goals and actions; and if we wish, these too can be similarly deconstructed for the purposes of analysis.

In what follows, I focus first on the dialectics of naturalization, disenchantment or objectification, and mention those of mathematical analysis. I look at the relations of reading, sorting and calculating, beginning with the early modern hierarchies of knowledge practices. I then focus on the decades around I80o and the dynamics of analysis and rationalization, of 'reduction' and 'holism' that were central to the politics of patients, factories or literary analysis. Here I touch on the political revolutions and the roles (especially in the humanities) of new analytical disciplines which were substantive as well as mathematical. I conclude by sketching some late-nineteenth-century formations, and then skipping toward our present.

Of course, in so short a paper one can only make patchy notes, but hopefully in a way which will map important historical and logical relations. By standing far back from the disciplines we study, we may glimpse an historical overview of Western knowledge - one that might also be useful for students and historians based in other academic traditions.

\section{The early modern conjunctures: Meanings, sortings, and calculations}

It is not easy to focus on reading meanings as a way of knowing, for it is to academics as swimming is to fish; but historical scholarship on early modern reading, writing and teaching comes to our aid. In a lovely summary, Anthony Grafton focuses on the teaching of classical texts, usually Aristotle - on the line-by-line presentation, the oral commentary, and the printed editions which left room for intertextual notes. This was the infrastructure for the high-level transmission of classical cosmologies - of philosophy and its various extensions in the professional education of theologians, physicians and lawyers whose main business was speaking and writing in that frame. ${ }^{6}$ This may seem a world away from ours, and of course, the methods and infrastructure have changed, but when we learn subjects new to us we usually read for the meaning, not to study the author; and all such learning may shape us as actors, not just as critics. Outside of religious education, we now are rarely taught cosmologies directly, but as historians we might attend more to how modern cosmologies are transmitted; and why some champions of the humanities continue to promote the role of humanities in self-creation. 
Professional education was also underpinned by the seven liberal arts, the quadrivium and the trivium. The former, including geometry, arithmetic, astronomy and music, provided mathematical literacy and an appreciation of regularities; we will return to them in discussing the development of mixed mathematics as mathematical analysis of nature and of artifacts. The latter, comprising grammar, logic and rhetoric, might also be said to deal in formal or substantive analysis, but as the basics of reading, writing, speaking and argument - the arts of discourse. As in all the liberal arts, the emphasis could be on the analysis of structures, or on norms and the improvement of practice and of character - as in renaissance rhetoric.

But as we have already suggested, there were other activities also ancillary to reading for meaning. Texts were collected and compared, catalogued and indexed; and so were words and quotations, along with the notes that scholars had made. One had to work out what was likely to be the 'best' text - not necessarily the most meaningful but the one which appeared less infected by successive copying errors or mistranslations. From classical libraries to modern databases, texts of many kinds have been assessed and prepared for use, sometimes using formal analyses.

It seems that the arts of bibliography, etc., were in some ways prior to the arts of cataloguing developed for natural and other technical objects; ${ }^{7}$ there was clearly a parallel, at least, between the searching out of new texts and the collecting of new plants. We know that in medicine, natural history and astronomy, textual criticism was then the basis for increasing reference to the 'book of nature': that corpses, for example, were used to illustrate readings of Galen, to ask questions about alternative readings, and then to question the veracity of the classical source - so that modern anatomy books were written to replace the classical (and to be taught and learned from, with more or less reference to corpses). Essentially the same story has been well-told for Dioscorides and botany, and for Pliny and natural history: commentaries on classical but perhaps marginal writers gave way to texts based on collections and observations of specimens. ${ }^{8}$

Partly because many of the new specimens did not 'come with culture', wouldbe botanists learned how to 'objectify', as anatomist learned to explore the body as if a new land. This naturalization and objectification is a key feature of Western knowledge, for objects and for texts, but in thinking across the whole range of Western knowledge we should always be aware that objectification is a process, and reversible. Birth monsters are never securely 'naturalized', even for technicians; recent Western museum displays often render ethnography as art, or natural history as culture; and the word-world of Google is wonderfully undisciplined. 
Information about bodies or plants was compiled in historia, a new genre which extended across most of knowledge. It could include the findings of crafts or systematic observation of weather, diseases or planetary motions; or legal cases and other historical documents. ${ }^{9}$ Historia literaria, of course, included classical texts and commentaries, whether they were still the foundation of didactic education or of decreasing direct interest within 'modern' fields.

One can give a similar account of the relations between texts, meanings and quantitative analysis in astronomy. Kepler was philologist enough to be able to judge the quality of texts, and he could help date texts by calculating the year of occurrences mentioned therein. He could also debate the relative merits of various classical and modern models of the heavens, guided by his cosmological preferences. ${ }^{10}$ Comparable stories can be told about mechanics and the Archimedean tradition, which, of course, interacts with astronomy through Galileo and then crucially through Newton. Mathematical analysis, in courts and universities, grew way beyond the quadrivium into a discipline often called mixed mathematics.

As most scholars seem to agree, the main frame of early modern natural knowledge was tripartite, and perhaps that model can be extended across the humanities: reading meanings continued to be central in theology and various kinds of philosophy, but the once ancillary projects of collecting information and of calculating were growing strongly and encouraging new cosmologies. The scientific revolution' can be read as shifts of world meanings based on extension and intensification of naturalization and mathematization (with some attempts to bridge them through experimental philosophy). In the humanities, in some countries, the new stress on plain speech downplayed renaissance rhetoric, and scholars attempted to understand languages by a universalist analysis, as in music. In my view this triangular interplay of meanings, information and mathematics remained the chief pattern of knowledge through much of the eighteenth century, ${ }^{\text {II }}$ and these kinds of working knowledges remain important to the present. Much of 'management science', for example, is made up of case histories, mathematics and 'philosophies' - as it must be.

It is, however, a mistake to imagine that the scientific disciplines of the nineteenth century were simply specializations or elaborations of these early modern practices. The new sciences built on the older knowledge, and in some ways incorporated them, but they involved new elements specific to each new science, e.g., chemical elements, geological strata or the elements of deductive political economy. The working knowledges of these new or reformed sciences were heterogeneous but predominantly analytical - both in natural sciences and technologies and in the disciplines related to languages and the fine arts. 


\section{The age of knowledge revolutions}

We can begin with the history of medicine, as portrayed by Michel Foucault at the start of his career. Like most historians of medicine, he saw in post-Revolutionary Paris a new form of science, based on the analysis of bodies into tissues, each of which could show characteristic lesions. But if we look more closely we will also see the continuance of older practices, including the case histories and the medical philosophies; we will indeed see a variety of 'compoundings' according to the local contexts. Historiography of medicine, including the critiques aimed at Foucault, is thereby a useful model for the continuities, uneven development and contested cumulations which are crucial to a full history of any such field, including the cultural sciences. But that is not to deny the significance of new forms of knowledge and practice circa 1800 which Foucault also noted for zoology, philology and economics. ${ }^{\mathrm{I2}}$

That significance is especially clear when we know that the tissues of Bichat's new general anatomy were in some ways modeled on the new chemical elements of Lavoisier's chemistry. These elements, unlike those of the ancients or early moderns, were field-specific and accessible: chemistry was the discipline which analyzed the stuffs of the world in terms of chemical elements; general anatomy analyzed bodies as composites of tissues. I have shown elsewhere how this kind of intellectual project can be traced across many new physical and biological sciences and technologies - in several varieties of anatomy and physiology of animals and plants, crystallography, comparative engineering, and in the stratigraphy of the new geology* ${ }^{13}$ (The range of comparability is much wider than Foucault supposed when he excluded the harder sciences.) The rest of this paper sketches some ways in which the argument can be developed across the humanities and allied practices. We begin with French and British projects which claimed kinship with comparative anatomy and chemistry, before moving to developmental analyses' and to the arts and sciences of the subjective. The latter were, of course, characteristic of German universities where the hierarchies and chronologies of knowledge practices were very different from those of Parisian museums and professional schools.

\section{Anatomies of societies and economies}

In the early nineteenth century, the headquarters of comparative anatomy was the National Museum of Natural History in Paris. The dominant author was Cuvier who contrasted four different kinds of organism, each with a distinct plan; each animal was a system of interactions between organs, and each animal 
interacted with features of its surroundings that thereby constituted its 'environment'. That model reordered zoology, but there were many other ways of analyzing biological and medical organisms, most of which could also be used on social organisms. (The direction of 'influence' here is debatable; I am not arguing for the intellectual priority of biology*) Models included the Saint-Simonian idea of parallel functional systems, the communitarian model of similar parts acting in concert, the 'economy' of material interactions between differentiated parts, or the old view of a unitary soul (remade for a context in which it was no longer hegemonic). In my view, none of these approaches or scholarly fields can be fully understood in isolation from the others or from contemporary politics, nor should they be detached from the descriptive, practical or statistical 'social sciences', which in England at least, occupied most of the enthusiasts. ${ }^{14}$ Much of the more refined sociological analysis was 'merely theoretical'; the effects in practice were chiefly through suggesting or legitimating particular modes of social action. ${ }^{15}$

Perhaps only in political economy did analytical reduction then gain much empirical traction, in interactions with other kinds of working knowledge. For example, most eighteenth-century economical writings could be classed as extensions of natural philosophy, natural history or mathematics, or as normative manuals for the management of estates; and writing of these kinds continued. But in England, and especially with Ricardo, one also sees increasingly abstract, calculative models of the economy, analyzed as the interactions of 'elements, of land, labor and capital'. According to Schabas, it was then J.S. Mill who made a strong separation between the natural sciences of agricultural or industrial production and the moral science of political economy.

This key move may perhaps be linked with then current general questions about the interrelations of the new analytical sciences. Mill was much indebted to Comte, the prime French theorist of the new configurations of science, who described a hierarchy of sciences - in which each new disciplinary layer added new understandings specific to that layer, e.g., the biologist added understandings of tissues for living bodies that also showed chemical phenomena. Comte saw social analysis as superadded to biological (and lower) analyses for any given material case; in Mill's view, political economy as a science should confine itself to the necessities caused by social arrangements'. One may see here, across the board, how questions of the organization of knowledge connected with new ontologies, including the isolation of 'the economy' from nature. ${ }^{16}$

But all such economic analyses were so obviously disputable that the British Association for the Advancement of Science, for all its stress on analytical physical sciences, preferred that would-be economists restrict themselves to the collecting of data. Similar reactions to deductive analysis were common among Ger- 
man scholars who took an interest in economics and social development. They scorned the simplifications of the British and preferred more descriptive and historical modes. ${ }^{17}$ Part of the issue here was the different philosophical underpinnings in the two countries, and the German focus on state rather than the civil society prized by the British; but the disputes also exemplify the characteristic tensions seen in many fields of knowledge between the ambitions of analysts and the caution of 'naturalists' and historians.

The centrality and range of this tension is nicely visible in the novels of George Eliot, who was closely associated both with Comteans and exponents of descriptive natural history. ${ }^{18}$ My point here is not to find influences of natural sciences in humanities or art, but to underline how creative intellects across many fields wrestled with the characteristic tensions of the age of analysis - between the surface appearances and the underlying agencies, between the taxonomies and the underlying relations, and between normative approaches to various arts (and their histories) versus the systematic study of difference. Novelists - as technologists if you like - presented their analyses by constructing 'cases' which had to be realistic, just as geologists had to reconcile stratigraphic analysis with the details of local land forms. I have suggested elsewhere how such matters may relate to important questions about 'objectivity'. ${ }^{\prime 9}$

We will return to studies of arts and art, especially in Germany, but can take here a further example from France, where mid-nineteenth-century art history was connected with comparative anatomy. After the Revolution, art had been separated from use rather literally, through the creation of museums from what were once parts or possessions of churches or palaces. In these new museums art objects' were arranged and studied historically, highlighting the classical tradition. ${ }^{20}$ But from the 1860 s, lectures in art history were introduced as part of a reform of the École des Beaux-Arts. One of the key reformers and the first lecturer was Eugène Viollet-le-Duc, a specialist in historic architecture and reconstruction who was steeped in the morphology of Cuvier's rival, Geoffroy Saint Hilaire. The environmental understandings of art pioneered by the positivist Hippolyte Taine was closely related to Cuvier's analysis of animals in their contexts, as it were. In both cases, a self-consciously scientific, comparativist approach to art history was designed to undermine the classical, normative tradition of the École - at much the same time as Manet's equally subversive explorations of different styles. ${ }^{21}$ Again we see how the historical study of similar problems across different working knowledges may allow the generalization of historiographical methods and resources. 


\section{Languages, analysis and history}

Language studies, like 'the medicine of the clinic', zoology or art history, depended on collections and on the developments in the sorting/describing arts which we have already discussed, including source-criticism. Some language scholars retained a normative commitment to the betterment of language, as some anatomists focused on improving the detailed knowledge of human anatomy for use in surgery; ${ }^{22}$ other language scholars, like comparative anatomists, concentrated on comparative analysis, which here again could take several forms.

Especially in Britain, where associationist models of mind had been boosted by the success of new analytical sciences such as chemistry, it was fashionable to focus on etymology and to analyze words as 'compounds' which tended to be abbreviated over time. Continental scholars found this approach conjectural and instead focused on closer structural analyses of particular languages, and especially Sanskrit, comparisons with which suggested new orderings of European languages. ${ }^{23}$ In philology, as in geology, comparisons of structures and functions soon opened question of historical development. In both cases, the forms of historical enquiry which proved secure depended on detailed comparative analysis based on extensive collections and careful descriptions. ${ }^{24}$

But whereas zoologists and paleontologists usually found time-series of ascending complexity, students of language envisaged primal language as fully formed, and subject to various patterns of decay. Though academic philologists learned Sanskrit from followers of the British pioneer, William Jones, and used collections in Paris, it was in German universities that structural and historical studies of language thrived. That was partly because of the strength of the mindset called Romanticism, with its elevation of the past, but it was also because of the conditions of work and especially the idea of developing knowledge though research. Indeed, it seems clear that 'seminars' and cooperative studies of text collections set the pattern for the laboratories and 'research schools' which became the glory of German natural sciences. More specifically perhaps, the model of a tree of texts with a common root may have been the basis for later zoological phylogenies. ${ }^{25}$ One notes here an important echo of the centrality of humanities in the renaissance, and a reminder that the common image of humanities disciplines following the natural sciences may be very misleading. 


\section{A new philosophy of knowing}

So far in this essay, as in my book and the work of Foucault, much of the history has been French and British. But if one wishes to include philosophy, history, and the sciences of mind and culture, or even the biological sciences of development, then Germany must be central - so too for the fine arts and their histories. Perhaps a brief outline may indicate how one may bridge the national traditions at the same time as one bridges from sciences to art.

Historians of science usually see natural philosophy declining in the nineteenth century, except for the substantial recrudescence of natural theology often regarded as a medicine for unrest in newly industrial Britain. In general, philosophical cosmologies seem to be replaced with theories of scientific method - which had a history in Britain. Neither in Britain nor France was there much endogenous change in philosophy, which tended to remain associationist. But in German states, where philosophy became a key academic discipline, a new world of knowledge was created around a new view of mind - not as a sorter and aggregator of sensations, but as a source of schema through which the world was understandable. These included principles constitutive of all knowledge and some constitutive of particular fields, e.g., the appreciation of biological systems as teleological, or the recognition of polarities and patterns in nature. It was natural to see individuals, organisms and states as developing - as our knowledge of them also developed - hence the centrality of historical approaches in all fields. Art was central because it could directly express the mind's responses. This new philosophy of mind and nature restructured German disciplines, including those constructed with some reference to new French analyses.

Characteristically these German disciplines were gathered in faculties of philosophy, by teachers who prized their new independence from the professional faculties, and their disciplines were presented as sciences that could be applied, rather than the knowledge contents of professional arts. Certainly, in some ways, the German approach can be seen as anti-analytical: the new legal studies, for example, celebrated the historical development of law in opposition to French codifications which were seen as intellectual conceits. Most Romantics saw 'dissection' as destructive, and instead sought unities beneath variety, as in the cell theory which pointed to a common mode of origin of different kinds of cells and tissues; or they composed particulars into larger entities which could be seen as systemic - e.g., the Humboldtian cosmos. ${ }^{26}$ But these views were not just an extension of older approaches, they were new; and if we compare these new forms of knowledge with natural history or with the older natural philosophies, they can be seen as an alternative form of modernity, one which cannot be dismissed as merely descrip- 
tive. It stressed the recurrence of simple patterns and especially the unfolding of underlying forms - and in that extended sense can, I think, fairly be described as analytical. We may thereby usefully broaden that term and its range; and we can begin to explore the issues by looking at German historiography.

This same concern with development which we have noted in German biology was evident, earlier, in the study of human history. Historiography depended, of course, on the developing arts of sorting and description, but also on new conceptual objects, notably the nation, and on newish 'actors' such as the common (Germanic) people. Later in the nineteenth century the study of history often became normative as well as analytic, not just for the betterment of political skills or diplomacy - the universal justification of the classical humanities - but to improve the health and strength of the nation. ${ }^{27}$

But the new history was also analytical in other ways, related to the concern with ideas. To read meanings correctly was no longer a simple task: accurate reading required knowing the whole system of which the text or action was a part. As is well-known, this view came from Vico in early-eighteenth-century Naples: 'understanding' became less a matter of correspondence with nature, and more a question of recreating perspectives. This scientific but nonnaturalistic approach to 'ideas' grew chiefly in nineteenth-century Germany where philosophy attained a new centrality alongside the history of culture and of the state.

Readings, however, also depended on the empathy of historians, who needed to internalize the societal context and rules, adding them to their own cultural understandings and repertoires. In this respect, historians claimed similarity to artists, both in registering the likely feelings of their actors and in skillfully depicting the reconstructed scenes and sequences. ${ }^{28}$ In as much as sciences could focus on ideas, there could be new introspective psychologies ${ }^{29}$; in as much as art now had new goals, it could be understood as a historical development characteristic of a new setting which was peculiarly Germanic. That outlook helped create German art history, especially when academics far from the major art collections could use that emblematic comparative device, the slide projector - or preferably two. ${ }^{30}$

\section{The decline of national difference and the challenge of natural sciences}

Through the first half of the nineteenth century, analytical science and Romantic art were held together in Germany by a common focus on the analysis of mind and history, and by the fact that the many new disciplines cohabited in reformed universities, sharing ideologies of Bildung and research. We have seen how they were characterized by new analytical formations which stressed development and 
resisted French and British reductions, as they were also related to older disciplinary practices and professional education. But by about 1850 , the great constructive period of German philosophy seemed to be over; thereafter, national differences in method diminished, even as Germany became the leading site for natural, human and cultural sciences. ${ }^{31}$ Such then were the strengths of German universities in both philosophy of mind and experimental physiology that they led the world in forms of psychology in which experimental and subjective analyses were variously opposed or compounded. Such psychologies were increasingly felt to threaten the place of philosophy and of history as the core of humanities. ${ }^{32}$

Philosophy as a discipline came in part to reflect on the successes and the relations of the natural sciences; in part it became analysis of past philosophical positions, especially German. In this latter respect it was convergent with other historical disciplines which countered the astonishing growth of natural sciences by stressing Verstehen as a method, and uniqueness as a supposed peculiarity of cultural systems. ${ }^{33}$ In many countries idealism continued to serve as a secular philosophy of societal progress (for others it could be Spencerism); thus meaning was preserved alongside the classificatory and calculative arts; but the frontier of knowledge was now made up of analytical sciences - some of which claimed to be distinctively cultural.

While German philosophers of history appealed to the re-creative analysis of ideas as distinguishing the realm of Geisteswissenchaften, roughly corresponding to later 'cultural studies', most academic promoters of history in Britain seemed happy to imitate the research schools of their colleagues in the natural sciences. Few British humanists worried publicly about the differences between academic sciences and arts - at least until the expansion of academic sciences after World War II, when some teachers of English had moved away from philology and saw their subject as a successor to classical humanities in upholding cultural values. In their case it was values evident in early modern Britain, long undermined by industrialization and now threatened by the pretensions of some scientists. ${ }^{34}$ The ensuing battle remains as the familiar question of 'two cultures' - an opposition better analyzed than assumed, as this essay may suggest. We may thus conclude by skipping to other present-day configurations - as seen across the two cultures.

\section{Coda}

Perhaps the indulgent reader may have found here enough useful frames and connections to mitigate the obvious charge of simplification across too wide a canvas. I have stressed continuities as well as reconfigurations, and the complexities within disciplines as well as the relations and the connections between them. These 
relationships between different kinds of knowledge practices operated at many levels - for micro-histories and macro-histories need not be different in kind. To analyze a small case is to reconstruct the interactions over time of differing sociocognitive traditions and thus to begin to see a larger picture, incorporating many such interactions. In such ways we can hope to work across levels and across fields which are usually considered separately.

In later work, deo volente, I hope to extend and deepen this sketch, and to bring it up to the present. But I wanted here to sketch a method and a historical frame which can include both the early modern triad and the nineteenth-century analytical additions - for humanities and social sciences/technologies as well as natural sciences and technologies.

Nowadays, across the world, governments and companies fund massive enterprises for sorting and describing - for objects, patents, texts and data; and for mathematical analysis. These now coexist with, and are partly reformulated by, new analytical sciences, as also with various forms of synthesis. All are found across the natural and social sciences and technologies, but also in the cultural sciences and humanities. They afford a huge challenge to historians, who must also include issues of shared meanings - of our changing relationships with the physical world and with each other.

We can illustrate that last point by again returning to history of medicine. Discursive arts and cultural meanings were central to its high-status early modern practice, and in some ways they remain so; discussions of how to live and die remain the core of our 'philosophies' - medical and humanistic. In modern medicine, at the limits of astonishing material technologies we still return to issues of life and death, and to sharing our readings of the world and ourselves. As a huge medico-biographical literature - professional and amateur, printed and electronic, primary and secondary - now demonstrates, humans always need more than the technicalities; they need more than the naturalized, the analyzed and the synthesized. ${ }^{35}$ That is also true, and vital, for the humanities.

One may here note the still-sharp barb directed a century ago at Germanophile modernisers of the Sorbonne. The Etude in which students had read the classics had become the Laboratoire de philologie française, where bibliography now reigned; the Sorbonne was coming to resemble a restaurant in which the only thing to eat was the menu ${ }^{36}$ We need histories that will show how the whole range of technical knowledges were successively generated and used - but ones which can also widen our appreciation of other crucial forms of 'philosophical' understanding and practice, including self-creation. 


\section{Notes}

I John V. Pickstone, Ways of Knowing: A New History of Science, Technology and Medicine (Manchester University Press, 2000, and Chicago University Press, 200I); 'Working Knowledge Before and After circa I800: Practices and Disciplines in the History of Science, Technology and Medicine', Isis 98 (2007), 489-5I6; and John V. Pickstone (ed.), 'Natural Histories, Analysis and Experimentation: Dissecting the Working Knowledges of Chemistry, Biology and Medicine since I750', special issue of History of Science 49.3 (20II).

2 I am very grateful to the Descartes Centre at the University of Utrecht for the invitation to lecture, for a fellowship in Autumn 20I2, and for introducing me to many scholars of the history of the humanities, notably Rens Bod, whose kind help included the advance use of his A New History of the Humanities: The Search for Principles and Patterns from Antiquity to the Present (Oxford: Oxford University Press, 2013). My thanks also to Jonathan Harwood, John Christie and Helen Small for reading a draft, and also to Ludmilla Jordanova, David Lomas, and Bart Karstens for suggestions. For reasons of length the notes on this preliminary essay are minimal - but they mention some wonderful books.

3 Robert E. Proctor, Defining the Humanities (Bloomington: Indiana University Press, 1998).

4 John V. Pickstone, 'Analytical Revolutions and the Syntheses of Modernism', in H. Otto Sibum and Kapil Raj (eds.), Histoire des sciences modernes, which is vol. 2 of Les sciences et la modernité (Paris, Le Seuil, forthcoming). See also the article by Robert Brain in the same volume.

5 See, for example, Ian Hacking, 'Style for Historians and Philosophers', Studies in History and Philosophy 23 (I992), I-20.

6 Anthony Grafton, 'Libraries and Lecture Halls', in Katharine Park and Lorraine Daston (eds.), Early Modern Science, vol. 3 of the Cambridge History of Science (New York: Cambridge University Press, 2006), 240-250.

7 Ann Blair, Too Much to Know: Managing Scholarly Information before the Modern Age (New Haven and London: Yale University Press, 2010).

8 Paula Findlen, 'Anatomy Theaters, Botanical Gardens, and Natural History Collections', in Katharine Park and Lorraine Daston (eds.), Early Modern Science, vol. 3 of the Cambridge History of Science (New York: Cambridge University Press, 2006).

9 Lorraine Daston and Elizabeth Lunbeck (eds.), Histories of Scientific Observations (Chicago and London: University of Chicago Press, 20II).

Io Anthony Grafton, 'Chronology, Controversy, and Community in the Republic of Letters: The Case of Kepler', in Worlds Made by Words: Scholarship and Community in the Modern West (Cambridge, MA, and London: Harvard University Press, 20 I I).

I I See H. Floris Cohen, How Modern Science Came into the World (Amsterdam: Amsterdam University Press, 2007), 723. I thank Floris for discussion of this point.

I 2 Michel Foucault, The Birth of the Clinic (London: Tavistock, I973); The Order of Things (London: Tavistock, I973).

I 3 Pickstone, Isis, 2007.

I4 Lawrence Goldmann, 'Victorian Social Sciences: From Singular to Plural', in Martin Daunton (ed.), The Organisation of Knowledge in Victorian Britain (Oxford: Oxford University Press, for the British Academy, 2005), 87-I I4.

I5 John V. Pickstone, 'How Might We Map the Cultural Fields of Science? Politics and Organisms in Restoration France', History of Science 37 (I999), 347-364. 
I6 See Margaret Schabas, The Natural Origins of Economics (Chicago: Chicago University Press, 2005). The gloss regarding Comte and Mill is mine.

I7 For summaries and references, see Pickstone, Ways of Knowing, I25-I29.

I8 Sally Shuttleworth, George Eliot and Nineteenth Century Science (Cambridge: Cambridge University Press, I984).

I9 John V. Pickstone, essay review of Daston and Galison, Ojectivity, in British Journal for the History of Science 42 (2009), 595-600; essay review of Daston and Lunbeck, Histories of Scientific Observations, in British Journal for the History of Science 45 (2012), 67I-675.

20 Francis Haskell, History and Its Images: Art and the Interpretation of the Past (New Haven and London: Yale University Press, I993), especially ch. 9.

2 I Phillip Hotchkiss Walsh, 'Viollet le Duc and Taine at the École des Beaux Arts: The First Professorship of Art History in France', in Elizabeth Mansfield (ed.), Art History and Its Institutions: Foundations of a Discipline (London and New York: Routledge, 2002), 85-99; Michael Fried, Manet's Modernism, or The Face of Painting in the 1860s (Chicago: University of Chicago Press, I996).

22 See Olga Amsterdamska, Schools of Thought: The Development of Linguistics from Bopp to Saussure (Dordrecht: D. Reidel, I987); Joep Leerssen, "The Rise of Philology: The Comparative Methods, the Historicist Turn and the Surreptitious Influence of Giambattista Vico', in Rens Bod, Jaap Maat, and Thijs Weststeijn (eds.), The Making of the Humanities, Volume II: From Early Modern to Modern Disciplines (Amsterdam: Amsterdam University Press, 2012), 23-36, and in the same volume, Bart Karstens, 'Bopp the Builder: Discipline Formation and Hybridisation: The Case of Comparative Linguistics', I03-30.

23 Hans Aarsleff, The Study of Language in England, 1780-1860 (Princeton: Princeton University Press, I967).

24 Rudwick has published exemplary accounts of how natural philosophy and natural history (including antiquarianism) were displaced (NOT replaced) by structural analyses of animals and rock formations - which were later made historical. Martin J.S. Rudwick, Bursting the Limits of Time: The Reconstruction of Geology and the Age of Revolution (Chicago: University of Chicago Press, 2005), and Worlds before Adam: The Reconstruction of Geohistory in the Age of Reform (Chicago: University of Chicago Press, 2008).

25 R.S. Turner, "The Growth of Professorial Research in Prussia, I8I8-I848: Causes and Context', Historical Studies in Physical Sciences 3 (I982), I29-I62; and see Leerssen, 'Philology', 24.

26 E.g., Michael Dettelbach, 'The Face of Nature: Precise Measurement, Mapping, and Sensibility in the Work of Alexander Von Humboldt', Studies in History and Pbilosophy of Science, Part C, 30 (1990), 473-504.

27 Of the large secondary literature on German historiography, I750-I9I4, see, for example, Georg G. Iggers, The German Conception of History: The National Tradition of Historical Thought from Herder to the Present (Middletown, CT: Wesleyan University Press, 1968), and Frederik C. Bieser, The German Historicist Tradition (Oxford: Oxford University Press, 201 I).

28 E.g., see Iggers, German Conception, I I I.

29 For this and much else, see Roger Smith, Fontana History of the Human Sciences (London: Harper Collins, I997), ch. I4.

30 Frederick N. Bohrer, 'Photographic Perspectives: Photography and the Institutional Formation of Art History', in Mansfield (ed.), Art History and its Institutions, 246-259.

3I I here follow J.T. Merz in his great survey of European Thought in the Nineteenth Century (I904 to I9I2), repr. in 4 vols. (New York: Dover Publications, I965).

32 Smith, History of the Human Sciences, ch. I4. 
33 For the romantic re-creation of science vs. art opposition as objective/general vs. subjective/particular, see M.H. Abrams, The Mirror and the Lamp: Romantic Theory and the Critical Tradition (Oxford: Oxford University Press, I953).

34 For the 'humanities side' of the 'Two Cultures' debate, see Francis Mulhern, The Moment of 'Scrutiny' (London: Verso, I98I).

35 John V. Pickstone, 'Radicalism, Neo-liberalism and Biographical Medicine', in Carsten Timmermann and Elizabeth Toon (eds.), Cancer Patients, Cancer Pathways: Historical and Sociological Perspectives (Basingstoke: Palgrave, 20I2), 230-255.

36 Wolf Lepenies, Between Literature and Science: The Rise of Sociology (Cambridge: Cambridge University Press, I988), 50. 



\section{About the Authors}

Annette M. Baertschi is Associate Professor in the Department of Greek, Latin, and Classical Studies at Bryn Mawr College. Her research interests include Roman literature, especially imperial poetry, Greek and Latin epic, ancient drama and performance as well as the reception of the classical world. She published a monograph on necromancy in Neronian and Flavian epic in 2013 and also coedited a large essay collection entitled Die modernen Väter der Antike. Die Entwicklung der Altertumswissenschaften an Akademie und Universität im Berlin des 19. Jahrbunderts (Berlin 2009).

Rens Bod is Professor of Computational Humanities (University of Amsterdam) and Director of the Center for Digital Humanities. His computational work covers several humanities disciplines - natural language processing, computational musicology, digital aesthetics and computational literary studies. His historical work focuses on the comparative history of the humanities from a global perspective. He also writes extensively in the popular press, revealing himself to be an ardent advocate for the humanities. His most recent book is A New History of the Humanities (OUP, 2013).

Jeroen Bouterse obtained his MA in Comparative History of the Sciences and Humanities at Utrecht University (both cum laude). He is currently working on a $\mathrm{PhD}$ dissertation on the philosophical foundations of the historiography of science, at the Institute for Philosophy at Leiden University (under the supervision of Dr. J.W. McAllister).

Chiara Maria Buglioni studied Foreign Languages and Cultures with a specialization in German Literature at the University of Milan, from which she graduated in June 20Ir. She is a PhD student in German Studies at the University of Milan and, through a cotutelle agreement, in Theater Studies at Ludwig-Maximilians- 
University Munich. She is currently writing her dissertation on Artur Kutscher and the foundation of the Munich Theaterwissenschaft. Her major research interests include theater historiography, German popular drama, and Weimar culture.

H. Floris Cohen is Professor of Comparative History of Science at the Faculty of Humanities, Utrecht University, and editor of the History of Science Society. He is the author of Quantifying Music: The Science of Music at the First Stage of the Scientific Revolution, 1580-1650 (Dordrecht: Reidel, 1984); The Scientific Revolution: A Historiographical Inquiry (University of Chicago Press, 1994), and How Modern Science Came into the World: Four Civilizations, One $17^{\text {th }}$-Century Breakthrough (AUP, 2010).

Lorraine Daston is Director at the Max Planck Institute for the History of Science, Berlin, and Visiting Professor in the Committee on Social Thought at the University of Chicago. Her publications include (coauthored with Peter Galison) Objectivity (2007), (coedited with Elizabeth Lunbeck) Histories of Scientific Observation (20II), and (coauthored with Paul Erikson et al.) How Reason Almost Lost Its Mind: The Strange Career of Cold War Rationality (2013). She is currently at work on a book about the history of rules.

Adi Efal is a postdoctoral researcher at the Thomas Institute of the University of Cologne. She has taught at the Universities of Tel-Aviv and Haifa, as well as at the Bezalel Academy of Art in Jerusalem. She completed a book on Panofsky and the philological tenor of art history and is now developing a project on habitude, habitus, and corporeal memory. She publishes in the domains of art theory, historiography, and the history of French philosophy.

Vincent Gengnagel is a PhD student at the University of Bamberg and member of the DFG-funded research group 'Horizontal Europeanization - Europeanization of Higher Education'.

Julian Hamann is postdoc at the Forum Internationale Wissenschaft, University of Bonn. He obtained his PhD in 2014 at the University of Bamberg with a study about the discursive transformation of the notion of 'Bildung' in the German Geisteswissenschaften.

Charles van den Heuvel is Head of the Research Group in the History of Science and Scholarship at the Huygens Institute for the History of the Netherlands of the Royal Netherlands Academy of Arts and Sciences. Furthermore, he holds the chair in Digital Methods and Historical Disciplines at the University of Amster- 
dam. He has a background in history of art. Recent research interests are digital humanities, history of science (in particular, the Republic of Letters), and the history of library and information science.

Carlo Ierna is postdoctoral researcher at Utrecht University and Visiting Fellow in Philosophy at Harvard (January to May 2014). After working at the HusserlArchives Leuven since 2004, he obtained a Dutch NWO Innovational Research Incentives Scheme VENI grant in 2012 for the project 'Philosophy as Science: The Project of the School of Brentano'. He is in the process of completing a book entitled The Beginnings of Husserl's Philosophy. For more information, see http:// blog.ierna.name.

Paul Jay is a Professor of English and a Fellow at the Center for Interdisciplinary Thinking at Loyola University in Chicago. His most recent books are Global Matters: The Transnational Turn in Literary Studies (2010) and The Humanities 'Crisis' and the Future of Literary Studies (2014). His essays on modern literature, criticism, and theory have appeared in PMLA, American Literary History, Callaloo, Cultural Critique, and Modern Fiction Studies.

Perry Johansson is a Research Assistant Professor at the David C. Lam Institute for East-West Studies at Hong Kong Baptist University and a Privatdozent affiliated with Stockholm University. He has served as Senior Research Fellow at Singapore National University and was a visiting scholar at the Center for Comparative Literature and Society at Columbia University. His book Saluting the Yellow Emperor: A Case of Swedish Sinography was published by Brill in 2012. His next book, The Libidinal Economy of China, is to appear with Lexington Books/ Rowman \& Littlefield.

Franciska de Jong has been a Full Professor of Language Technology in the $\mathrm{Hu}$ man Media Interaction Group at the University of Twente since 1992. She is also affiliated with Erasmus University in Rotterdam as Director of the Erasmus Studio. She obtained a PhD in Theoretical Linguistics at the University of Utrecht. Currently, her research interests are in the fields of text mining, information retrieval, access tools for spoken word archives, and the multimodal analysis of narratives. For more information, see her homepage at http //wwwhome.ewi. utwente, $\mathrm{nl} / \sim$ fdejong.

John E. Joseph is Professor of Applied Linguistics and Head of Linguistics and English Language in the University of Edinburgh. He is coeditor of the journals Language E Communication and Historiographia Linguistica. His most re- 
cent book, Saussure (Oxford University Press, 2012), has been widely praised and figured in the TLS Books of the Year. His earlier books include Language and Politics (2006), Language and Identity (2004), From Whitney to Chomsky (2002), and Limiting the Arbitrary (2000).

Ton van Kalmthout is a Senior Researcher in Literary Studies at the Huygens Institute for the History of the Netherlands, a research institute within the Royal Netherlands Academy of Arts and Sciences. He is member of the editorial board of Tijdschrift voor Nederlandse Taal- en Letterkunde. His research is concerned with forms of cultural transmission in national and international contexts. His main publications include articles on the history of philology and literary education, the role of translation in cultural repertoire formation, and the international circulation of literature.

Bart Karstens is Lecturer in Philosophy of Science at Leiden University. He is a $\mathrm{PhD}$ candidate on the NWO funded project 'Philosophical Foundations of the Historiography of Science' at Leiden University. Before entering this project he graduated with a Research Master's degree in the History of Science from Utrecht University (cum laude). He also acted as a teacher of historiography and the philosophy of history in the Department of History at Utrecht University. His research interests include the history of the humanities and the philosophy of historiography.

Bram Kempers is Professor of Sociology of Art at the University of Amsterdam. His PhD dissertation, Painting, Power and Patronage: The Rise of the Professional Artist in the Italian Renaissance (1987), was published in Dutch, English, German, French and Chinese. He has written articles on the art market, past and present cultural policy, as well as on various aspects of Italian art. Recently, his research has focused on the artistic life surrounding the Renaissance popes and more contemporary topics, such as art sponsorship, the art market, advertising and graphic design.

Jacqueline Klooster ( $\mathrm{PhD}$ 2009, University of Amsterdam) is a Marie Curie/ Pegasus Postdoctoral Fellow at Ghent University. She has previously published books on Hellenistic poetry (Poetry as Window and Mirror: Positioning the Poet in Hellenistic Poetry, Leiden 20II) and space in literature (The Ideologies of Lived Space in Literary Texts, with Jo Heirman, Ghent 2013), as well as various journal articles. Currently, she is writing a monograph entitled 'A Portrait of the Statesman as an Artist: The Evaluation of Writing Rulers in Antiquity'. 
José María Lanzarote-Guiral (born in Huesca, Aragon, Spain in 198I) is a LabEx HASTEC Postdoctoral Researcher at the Centre Alexandre Koyré, Paris. In January 2012 he defended his $\mathrm{PhD}$ dissertation at the European University Institute (Florence, Italy): Prehistoria Patria: National Identities and Europeanisation in the Construction of Prehistoric Archeology in Spain, 1860-1936. In 2010-2012 he worked as a research assistant for a Eunamus project ('European National Museums: Identity Politics, the Uses of the Past and the European Citizen' - FP 7), in the Universities of Bologna and Paris I-Pantheon-Sorbonne. His academic interests cover the history of human sciences, the construction of national identities, and heritage studies.

Michiel Leezenberg teaches in the Department of Philosophy and in the MA program 'Islam in the Modern World' at the University of Amsterdam. Among his research interests are the intellectual history of the modern Muslim world, the comparative study of Orientalisms, and the history and philosophy of the modern humanities. Recently, he published a new edition of a philosophy of science handbook designed specifically for the humanities, Wetenschapsfilosofie voor geesteswetenschappen (with Gerard de Vries, Amsterdam 2012).

Jaap Maat is a Lecturer in the Department of Philosophy, University of Amster$\mathrm{dam}$. His main interests are in the history of philosophy, linguistics, logic, and semantics. He has published widely on seventeenth-century artificial languages (including the monograph Pbilosophical Languages in the Seventeenth Century: Dalgarno, Wilkins, Leibniz, Kluwer 2004). Books on Wallis's logic and on teaching language to a boy born deaf (both with David Cram) and a book on Leibniz's rational grammar are forthcoming.

László Marácz is an Assistant Professor in the Department of European Studies at the University of Amsterdam. He studied general linguistics and Hungarian studies at the University of Groningen. He publishes on the history of Eastern Europe, European multilingualism, the enlargement of the European Union in Central and Eastern Europe and on the protection of minority rights. He coordinates a number of international projects, including one on 'Mobility and Inclusion in Multilingual Europe' sponsored by the European Commission's Framework Programme $7\left(\mathrm{FP}_{7}\right)$. He is visiting professor at the L.N. Gumilyov Eurasian National University and the Academy for Public Administration in Astana (Kazakhstan).

David L. Marshall is an Assistant Professor in the Department of Communication at the University of Pittsburgh. An intellectual historian of early modern and modern Europe, his first book was Vico and the Transformation of Rhetoric 
in Early Modern Europe (Cambridge: Cambridge University Press, 2010). He is currently working on a book concerned with the intrication of political and rhetorical inquiry in Weimar Germany.

Riccardo Martinelli is Associate Professor at the University of Trieste, where he has taught the history of philosophy since 2005 . He was previously an assistant professor (2000-2005) and a high school teacher (1995-2000). Higher Education: University of Bologna, University of Florence. Research abroad: Forschungsstelle für österreichische Philosophie, Graz (1998); University of Konstanz (Fellowship, A. von Humboldt Foundation, 2004, 2010); Humboldt University, Berlin (20II). Journal advisory boards: Intersezioni, Discipline filosofiche, Ethics E Politics, Jahrbuch für Europäische Wissenschaftskultur.

Steffi Marung (née Franke) is Senior Researcher at the Center for Area Studies of the University of Leipzig (CAS), where she is working on a project investigating the history of African studies in the Soviet Union and teaches at the Global and European Studies Institute. Having received her PhD in Global Studies her research includes the history of area studies, border regimes and territoriality and European integration history. Her dissertation was published in 2013 with Vandenhoeck\&Ruprecht as Die wandernde Grenze. Die EU, Polen und der Wandel politischer Räume, 1990-2010. With Katja Naumann she edited Vergessene Vielfalt. Territorialität und Internationalisierung in Ostmitteleuropa seit der Mitte des 19. Jahrbunderts, which came out in 20I4. She furthermore contributes to a handbook on the transnational history of East Central Europe being prepared at the Center for the History and Culture of East Central Europe (GWZO) Leipzig as well as to a handbook on transregional studies being prepared at the CAS.

Marita Mathijsen is Professor of Contemporary Dutch Literature at the University of Amsterdam (The Netherlands). Her specialisms are nineteenth-century literature and culture, and editorial scholarship. In 1998 she received the Prince Bernhard Fund Prize for the Humanities. A study on the nineteenthcentury state of mind, De gemaskerde eeuw (The Masked Century), appeared in 2002. She is the author of the standard Dutch introduction to textual scholarship, Naar de letter (4th ed., 2010). In 2013, she published a study, entitled Historiezucht, on how the past was opened up to everyone in the course of the nineteenth century.

Laura Meneghello, born in 1985, studied philosophy in Venice, Paris, and Utrecht. She obtained her Master's degree from Utrecht University, specializing in History of Philosophy with a thesis on Jacob Moleschott's materialist 
worldview. She is now carrying on research on scientific materialism in the nineteenth century writing her $\mathrm{PhD}$ dissertation in history on Moleschott's conception of science in its cultural and political context at the International Graduate Centre for the Study of Culture (GCSC) of Justus Liebig University, Gießen, Germany.

Birgit Mersmann is Professor of Non-Western and European Art at Jacobs University in Bremen, Germany. From 2005 to 2007 she was a Senior Researcher at the National Centre of Competence in Research (NCCR) 'Iconic Criticism' at the University of Basel, Switzerland. Research foci include image and media theory, visuality and representation, art theory and aesthetics, contemporary East Asian and Western art, global art and art history, the history of Asian biennials, transculturality, visual cultural translation, and interrelations between script and image.

Glenn W. Most is Professor of Greek Philology at the Scuola Normale Superiore di Pisa, Visiting Professor on the Committee on Social Thought at the University of Chicago, and External Scientific Member of the Max Planck Institute for the History of Science in Berlin. He has published numerous books and articles on classics, on the history and methodology of classical studies, on the classical tradition and comparative literature, on modern philosophy and literature, on literary theory, and on the history of art.

Katja Naumann studied history and philosophy in Leipzig, Edinburgh, and Vienna, and received her $\mathrm{PhD}$ with a dissertation about the formation of world history teaching and research in the US. Currently, she works at Centre for the History and Culture of East Central Europe (GWZO) at the University of Leipzig, where she studies the representation of East Central European states in international organizations and contributes to a handbook on the transnational history of the region. She is part of research group at Arhus University that deals with the development of neoliberalism in comparative and transnational perspective.

Julia Orell is Assistant in the Section for East Asian Art History, Department of Art History at the University of Zurich. She received her PhD from the University of Chicago in 2011 specializing in Chinese landscape painting of the Song and Yuan dynasties. Besides her new project on the historiography of East Asian art history, she is currently working on a book manuscript titled Landscape Painting and Geographical Knowledge in Song China. 
Marinus Ossewaarde is Associate Professor in the Sociology of Governance at the University of Twente, Netherlands. He is the author of Tocqueville's Moral and Political Thought: New Liberalism (London: Routledge, 2004) and Theorizing European Societies (Basingstoke: Palgrave Macmillan, 2013). He has published a variety of articles on topics such as Europe, cultural movements, sovereignty, subsidiarity, cosmopolitanism, publics, dialectic, and self-responsibility in journals including Current Sociology, Critical Sociology, European Journal of Social Theory, European Societies, Sociology, and The European Legacy.

Christine Ottner is Head of the Library, Archive, and Collections Department of the Austrian Academy of Sciences (ÖAW); MA-level studies in Chemistry and History, Master of Advanced Studies for Historical Research and Archival Science, DPhil; collaborator in the editorial undertakings Monumenta Germaniae Historica and Regesta Imperii (2000-2012) and at the Institute for Modern and Contemporary Historical Research and of the Institute of Culture Studies and Theater History (both ÖAW); visiting scholar at the Max-Planck-Institute for the History of Science in Berlin (20II); lecturer at the Universities of Salzburg and Vienna.

Herman Paul is Associate Professor of Historical Theory and Historiography at Leiden University, where he currently directs an NWO-funded research project on 'The Scholarly Self: Character, Habit, and Virtue in the Humanities, I860I930'. He also holds a special chair in secularization studies at the University of Groningen. His publications include Hayden White: The Historical Imagination (Polity Press, 20II), Key Issues in Historical Theory (Routledge, forthcoming) and coedited special issues of History and Theory, History of the Human Sciences, and Journal of the Philosophy of History.

John V. Pickstone was the Wellcome Research Professor and Founding Director of the Centre of History of Science, Technology and Medicine (CHSTM) at the University of Manchester. His books include Ways of Knowing: A New History of Science, Technology, and Medicine (2001), Surgeons, Manufacturers and Patients, with Julie Anderson and Francis Neary (2007), and The Quest for Public Health in Manchester, with Emma Jones (2008). His most recent work was on the history of modern medicine and medical technology, and on uniting the histories of the humanities, sciences, and technology.

Virginia Richter is Full Professor of Modern English Literature at the University of Bern. She studied English literature, comparative literature and German literature at the University of Munich. She was a Visiting Fellow at the University of Kent at 
Canterbury and at the University of Leeds, and a Visiting Professor at the University of Göttingen. Her most recent monograph is Literature after Darwin: Human Beasts in Western Fiction, 1859-1939 (Basingstoke: Palgrave Macmillan, 201I).

Jan Rock (1980) is Assistant Professor of Modern Dutch Literature at the University of Amsterdam. He obtained his $\mathrm{PhD}$ at the same university after having been trained as a cultural historian at KU Leuven. His research aims at a socially embedded history of Dutch vernacular philology from 1750 onwards, with a particular focus on nationalism and materiality. The research presented in this volume was carried out as a project of the UvA Research Priority Area 'Cultural Heritage and Identity'.

Jan-Willem Romeijn is Professor of the Philosophy of Science in the Faculty of Philosophy of the University of Groningen. His research interests include the scientific method, inductive logic, statistical inference, social epistemology, and model selection. In addition to doing systematic work in philosophy, he regularly collaborates with scholars from a wide variety of disciplines, most recently from the humanities.

Ingrid D. Rowland lives in Rome, where she is a Professor at the University of Notre Dame School of Architecture. She writes on a variety of topics for scholarly and general readers. Her books include Giordano Bruno, Philosopher/Heretic (2008), The Culture of the High Renaissance (1998), The Scarith of Scornello: A Tale of Renaissance Forgery (2004), and a collection of essays, From Heaven to Arcadia (2005), as well as translations of Vitruvius's Ten Books on Architecture, with Thomas N. Howe (1999), and Giordano Bruno's On the Heroic Frenzies (2010).

Alexis Ruccius studied musicology and art history in Berlin. Between $201 \mathrm{I}$ and 2013 he was a Research Associate at the Institute of Art and Visual History of Humboldt University in Berlin. His PhD dissertation deals with the sound sculptures of Stephan Von Huene. Since October 2013 he has been a Research Associate in the Department of Music at the Max-Planck-Institute of Empirical Aesthetics in Frankfurt am Main, where he is focusing on a project about the aesthetic threshold between noise and music.

Stef Scagliola is a Postdoctoral Researcher at the Erasmus Studio of the Erasmus University Rotterdam, specializing in digital oral history archives. She studied museology in Leiden and social history at the Erasmus University Rotterdam, where she obtained a $\mathrm{PhD}$ in history in 2002. She initiated the Dutch Veterans Oral History Project (Iooo audio interviews) and the multimedia project 
www.warlovechild.nl, and she monitored two projects in the former Yugoslavia: www.bosnianmemories.org, and www.croatianmemories.org. She is currently developing a multidisciplinary research agenda based on the data from the Balkan projects.

Eline Scheerlinck studied classics at Ghent University, where she recently defended her PhD dissertation on the classicist and historian of religions Franz Cumont: An Orient of Mysteries: Franz Cumont's views on 'Orient' and 'Occident' in the Context of Classical Studies in the Nineteenth and Early Twentieth centuries. Her work explores a post-Orientalist approach to the history of the humanities.

Maria Semi is a musicologist. Her dissertation Music as a Science of Mankind in Eighteenth-Century Britain was published in 2012 by Ashgate. In 2013 she was at the Université Paris-7, thanks to a 'Bourse de la Ville de Paris pour chercheurs étrangers', to complete her edition of Rousseau's Dictionnaire de musique (to be published by Classiques Garnier as vol. 8 of Rousseau's OEuvres complètes. Présentation chronologique, edited by J. Berchtold, F. Jacob and Y. Seité). She is currently Junior Research Fellow at the Lichtenberg-Kolleg (Göttingen), where she is working on a collective project on 'The Nature of Man in the European and Atlantic Enlightenment(s)'.

Floris Solleveld is a $\mathrm{PhD}$ student at Radboud University Nijmegen and the University of Amsterdam, working on the project 'The Transformation of the Humanities: Ideals and Practices of Scholarship between Enlightenment and Romanticism. Additionally, he has published extensively on interdisciplinary art and new music.

Johanna Sprondel studied philosophy, comparative literature and political sciences at the Universities of Oxford, Freiburg, Zurich, Basel, and Strasbourg. She received her $\mathrm{PhD}$ in $201 \mathrm{I}$ with a dissertation on myth as a narratological form (it was published as Textus - Contextus - Circumtextus: Mythos im Ausgang von Joyce, Aristoteles und Ricoeur, Berlin: Walter de Gruyter, 2013). She is an Assistant in Philosophy at the Humboldt-University of Berlin and currently a visiting scholar at Stanford University where she works on the question of the importance of practices of the humanities for an understanding of the digital. Her book entitled Humanities of the Digital will be published in Spring 2015.

Abram de Swaan is emeritus University Professor and was the cofounder and Dean of the Amsterdam School for Social Science Research (1987-1997). He taught at the Collège de France (1997) and received the Netherlands state prize 
for literature (essays) in 2008. De Swaan published Words of the World: The Global Language System (200I). His books have been translated into ten languages. His most recent book, The Killing Compartments, will appear with Yale University Press and Éditions du Seuil in 2015.

Robert Deam Tobin holds the Henry J. Leir Chair in Foreign Languages and Cultures at Clark University in Worcester, Massachusetts. In the 2013, he was the Fulbright Freud Visiting Scholar of Psychoanalysis at the Sigmund Freund Museum and the University of Vienna. He is the author of Warm Brothers: Queer Theory and the Age of Goethe, Doctor's Orders: Goethe and Enlightenment Thought, and the forthcoming Peripheral Desires: The German Discovery of Sex, as well as a coeditor of A Song for Europe: Popular Music and Politics in the Eurovision Song Contest.

Jo Tollebeek is Full Professor of Cultural History since 1750 at the University of Leuven, Belgium. He was visiting faculty at the University of Pennsylvania and a Distinguished Fellow of the KB National Library of the Netherlands. He has published work on university history, the history of historiography, and the history of the humanities in the nineteenth and twentieth centuries. His works include Writing the Inquisition in Europe and America (2004), Men of Character: The Emergence of the Modern Humanities (201I), and Henri Pirenne, Historian: A Life in Pictures, with Sarah Keymeulen (2011).

Thijs Weststeijn is Associate Professor of Art History at the University of Amsterdam. He has published on Dutch and English artistic terminology, theories of pictography, Germanic antiquity, and the reception of China in the seventeenthcentury Low Countries. His book Art and Antiquity in the Netherlands and Britain: The Vernacular Arcadia of Franciscus Junius (1591-1677) is forthcoming from Brill in 2014 . 



\section{List of Figures}

Cover image: Nikolaus Gysis, München 1892 ... VI. internationale Kunstausstellung, 1892, I892, Chromo-lithographed poster, I2I x $68 \mathrm{~cm}$, printed by Chromotypie v. Meisenbach, Riffarth \& Cie (Munich), Bibliothèque nationale de France, Paris, Département Estampes et photographie (inv.nr. EST ENT DO-I). The original oil painting is in a private collection in Athens.

I From B. Latour, We Have Never Been Modern (Cambridge, MA, I993), p. 5 I

2 Gergely Czuczor (I800-I866)

3 János Fogarasi (180I-1878)

4 P. Yver, frontispiece to Louis de Beaufort, Dissertation sur l'incertitude des cinq premiers siècles de l'histoire romaine (Utrecht, I738), engraving (C) University Library, University of Amsterdam, Special Collections)

5 Édouard Manet, Le Déjeuner sur l'herbe, I862-1863, oil on canvas, 208 x 265.5 $\mathrm{cm}$, Musée d'Orsay, Paris

6 Émile-Antoine Bayard, The Forerunners of Raphaël and Michelangelo, or the Birth of the Arts of Drawing and Sculpture in the Reindeer Age, engraving from Louis Figuier, L'Homme primitif (Paris, I870, first edition)

7 Pierre Gatier, Prehistoric Ceremony in a Decorated Cave, Related to Henri Breuil's Magic Interpretation of Prehistoric Cave Art, c. I930, drawing, Bibliothèque Centrale du Muséum d'Histoire Naturelle, Paris (Fonds BreuilBoyle, Br. 22). Reproduced in Noël Coye, Ed., Sur les chemins de la prébistoire : L'abbé Breuil du Périgord à l'Afrique du Sud. (Paris, 2006): 17I).

8 Francisco Benítez Mellado, printed poster for the Exbibition of Spanish Prehistoric art (Exposición de arte prebistórico español), May-June I921, Madrid

9 Francesc d'Assís Galí i Fabra, printed poster for the International Exhibition of Barcelona (Exposición internacional de Barcelona), Barcelona, May I929-January 1930.

Io Erasmus Darwin, Zoonomia; or, The Laws of Organic Life (London, I794) 
II Joseph Wright of Derby, An Experiment on a Bird in the Air Pump, I768, oil on canvas, $183 \times 244 \mathrm{~cm}$, National Gallery, London

I2 Georg Schünemann and Carl Stumpf Recording Tatar Singers, 19i6, photo, The Sound Archive of Humboldt University, Berlin (HZK Bilddokument ID8249, Sammlungszugehörigkeit Lautarchiv, Inventar-Nr. Sign. Pn. $1003 / 5)$

I3 From Julius Rühlmann, Geschichte der Bogeninstrumente (Braunschweig I882), p. 144 (detail)

I4 Master of the Bartholomew Altar, Bartholomew Altar, c. I500-I510, oil on oak, I29 x I6I cm, Alte Pinakothek, Munich, Nr. II863 (central panel, detail with Saint Cecilia)

I5 From Julius Rühlmann, Geschichte der Bogeninstrumente (Braunschweig, I882), p. I38-I39

I6 From Leo Schrade, Die Darstellung der Töne an den Kapitellen der Abteikirche $z u$ Cluni (1929), Fig. $2 b$

I7 Hieronymus Bosch, The Garden of Earthly Delights, c. 1500, oil on panel, 220 x $389 \mathrm{~cm}$, Museo del Prado, Madrid (right panel, detail)

I8 Soviet Orientalists Abroad

I9 Yumedono Kannon, first half of the seventh century, wood and gilt lacquer, height: $178.8 \mathrm{~cm}$, Horyu-ji, Nara prefecture (frontal view); after Karl With, Buddhistische Plastik in Japan (Vienna, I919), vol. 2, plate I5

20 Yumedono Kannon (see fig. 19) (side view); after Karl With, Buddhistische Plastik in Japan (Vienna, I919), vol. 2, plate 16

2I Head of a Buddha, c.500 AD, limestone, previously collection Von der Heydt; after Karl With, Bildwerke Ost-und Südasiens der Sammlung Yiyuan (Basel, I924), plate 20

22 Head of a Buddha, Wei Dynasty (fifth century AD), sandstone, previously collection Von der Heydt; after Karl With, Bildwerke Ost-und Südasiens der Sammlung Yiyuan (Basel, 1924), plate 22

23 Albert Renger-Patzsch, Second hall in the Folkwang Museum, Essen, view into the big gallery with paintings by Paula Modersobn-Becker and Erich Heckel, with Franz Marc's "Grazing Horses IV" and with non-European sculptures and objects, around 1930 (C) Museum Folkwang Essen)

24 Moissey Kogan, Female Figure; after Karl With, 'Kogan besucht Deutschland', Das Kunstblatt 6.II (1922)

25 Leaders of the Sino-Swedish Expedition studying a map (c. 1927-28): Xu Bingchang (also known as Xu Xusheng), professor of history and archaeology at Peking University (left), Sven Hedin, the Swedish explorer (center), and Yuan Fuli, a geologist (right). Photo at a private collection / The Bridgeman Art Library 
26 Johan Gunnar Andersson in China, 1920, photo, East Asian Museum, Stockholm

27 Visualization from Paul Otlet's manuscript Theorie schématique de la classification, 14 December 1908

28 The British historian Paul Thompson among his books

29 Home page of the Shoah Foundation Visual Archive

30 Timeline visualization of retrieved fragments in the access portal for a collection of thirty-eight interviews with Dutch survivors from Camp Buchenwald, Buchenwald, NIOD Instituut voor Oorlogs-, Holocaust- en Genocidestudies, http ///www.buchenwald.nl 



\section{Index}

A

Aarsleff, Hans 275, 279, 684

Abdel-Malek, Anouar IOI, III

Abegg, Michael 483

Abovian, Khatchatur 100

Abraham, Otto 49, 397

Achebe, Chinua 62I

Adam I6, 7I, 684

Adelung, Johann Christoph 273-275, 279

Adler, Guido I69, I7I-182, 40I, 404, 410

Adorno, Theodor 556,597

Aeschylus 6I

Aguilera y Gamboa, Enrique de 367

Ajdukiewicz, Kazimierz 549

Alcaeus 255, 258, 262-263

Alekseev, Vasilij Mikhailovich 419

Alembert, Jean-Baptiste le Rond d' 349, 392

Aletrino, Arnold 588

Alexander, Samuel 470

Algazi, Gadi 134

Alison, Archibald 382

Almirante, Giorgio 292

Alfonso xIII, King of Spain 359

Althusser, Louis 657

Anacreon 585

Anderson, Benedict Ioo, IIO

Andersson, Johan Gunnar 454-455, 46I, 701

Annunzio, Gabriele d' 29I

Antimachus 256, 257

Appia, Adolphe 315

Aquinas, Thomas 473

Arendt, Hannah 22, 556, 558-563, 566, 608, 628-629, 632-636

Aretino, Pietro 303
Arezzo, Guido of 407

Aristarchus 256-257

Aristophanes 257

Aristotle 19, 262, 347, 350-356, 395, 400, 551, $556-558,560,598,668,670,672$

Arius 48

Arndt, Wilhelm 496

Arneth, Alfred von I6I, I68

Arnim, Achim von 150

Arnold, Matthew 656

Aron, Raymond 603, 606-607, 617, 624

Astruc, Jean 210

Athanasius 48, 49

Auerbach, Erich 307, 311, 345, 355

Augustine 48, 559, 564, 620

Avenarius, Richard 55I

\section{B}

Bach, Johann Sebastian 173

Bacon, Francis 49, 77, 267, 528, 551, 553, 670

Baertschi, Annette M. 8, 18, 233, 245, 247249, 687

Bailyn, Bernard 473, 477

Bain, Alexander 466

Bakhtin, Mikhail I06, 345, 355

Balzac, Honoré de 589, 609

Barante, Prosper Amable 148

Barclay Squire, William 404, 410

Baron, Hans 556, 565

Bartol'd, Vasilij Vladimirovič 4I8

Bassani, Giorgio 62I

Baudrillard, Jean 657

Baumgarten, Alexander 380 
Bayard, Émile-Antoine 36I-362, 699

Bazermann, Charles 268

Beattie, James 38I

Beaufort, Louis de 265-267, 272, 276-279, 699

Beck, Ulrich 605, 608

Bedier, Joseph 253

Beeckman, Isaac 45

Beer, Gillian 68, 76-77, 168

Begouën, Henri 363

Bekker, Immanuel 246

Bell, Chichester 514

Bellow, Saul 516

Belting, Hans 34I, 343, 4II

Benedict, Ruth 9I

Bengel, Johann Albrecht 213

Benjamin, Walter 22, 345-346, 355, 489, 498, 556, 562-563, 566

Bennett, William 664

Benussi, Vittorio 549

Benveniste, Émile 289

Benzécri, Jean-Paul 482

Berg, Alban 173

Bergson, Henri 345, 354-355, 466

Berlinguer, Enrico $\quad 292-293$

Berlusconi, Silvio 283, 29I-293, 295, 297

Bernard, Claude 669

Bernheim, Ernst I7I, I74-I75, I78-I8I

Bessenyei, György II4

Bettelheim, Bruno 85, 93

Beveridge, William 602

Beyer, Oskar I9, 329, 335, 343

Bichat, Marie François Xavier 675

Biemans, Jos 499

Bilderdijk, Willem I46-I47, I5I

Bindseil, Heinrich Ernst 49I-492

Binet, Alfred 583

Binford, Lewis 285

Blake, Robert 422

Blass, Thomas 63I

Bliss, Henry Evelyn 465, 476

Bloch, Iwan 583

Blok, P.J. 133-134, 309

Bloor, David 194, 20I-202

Blot, Alfred 265, 267, 272, 278-279

Blüher, Hans 592, 595

Boas, Franz 394, 615

Bod, Rens 3, 7, I3, 24, 43, 5I, 75, IIO, I13, I23I25, I66, 203, 216, 355, 465, 476, 478, 528, $538,623,683-684,687$
Bodenhamer, David 474, 477

Boder, David P. 515

Boeckh, August 235-237, 239, 24I, 245, 247, 267, 490

Bohr, Niels 602-603

Boltzman, Ludwig 469

Bopp, Franz II 8, I25

Borgman, Christine 465, 475

Bos, Jacques 24

Bosch-Gimpera, Pere 372,375

Bossuet 277, 279, 599

Bouhours, Dominique 83,93

Bourdieu, Pierre I42, 610, 621, 624, 651, 652, 654

Bouterse, Jeroen I0, 22, 569, 687

Bouwman, André 503

Bowring, John II6, I24

Brahe, Tycho 246

Brahms, Johannes 173

Brand, Adolf 59I

Braudel, Ferdinand 293

Bréal, Michel 86-87, 93

Breidenstein, Heinrich Carl 410

Brentano, Clemens 150

Brentano, Franz IO, 21, 393, 400, 543, 545554,689

Breuil, Henri I9, 363-364, 373-375, 699

Breysig, Kurt 33I

Bridenbaugh, Carl 473, 477

Broglie, Louis de 602

Brooks, Philip C. 517

Brosses, Charles de 274-275, 279

Brouwer, Petra 24

Browning, Christopher 632, 635

Büchner, Ludwig 53

Buckle, Henry Herbert 32

Budenz, Josef II7

Buglioni, Chiara Maria 9, I8, 313, 687

Burawoy, Michael 605, 608

Burckhardt, Jacob 350, 615, 618

Burke, Edmund 382

Burke, Peter 523, 615

Burkert, Walter 229, 289-290, 297

Burnett Tylor, Edward 615

Burtt, E.A. I88, 196, 200

Busa, Roberto 473

Busse, Dietrich 275, 279

Butler, Judith 659, 665

Byron, George Gordon 587, 593 
C

Cai Yuanpei 453, 456, 459

Callimachus 260

Campbell, Joseph 289

Capurro, Rafael 474, 478

Carlson, Marvin 321, 324

Carlyle, Thomas 149

Carnap, Rudolf 536

Carpenter, Edward 587

Cartailhac, Émile $361,363,373$

Cassirer, Ernst I3

Castells, Manuel 604, 608

Cerquiglini, Bernard 253

Cerralbo, Enrique de Aguilera y Gamboa, Marquis of 367

Cézanne, Paul 434

Chagall, Marc 435, 446

Chambers, Robert 74

Champollion, Jean-François I48

Chen Yinke 452, 454, 456, 460

Cheney, Lynn V. 664

Chiang Kai-shek 458

Chiron, Vanna 284, 296

Chmel, Joseph I58-I6I, I66-I67

Christ 47, 49, 295, 372

Cindî, Haciyê I07

Cirillo, Ciro 296

Civilis, Claudius (Junius) 56I

Cixous, Hélène 657

Clercq, Willem de 300-30I, 307, 309

Coetzee, J.M. 62I

Cohen, Floris 7, 15, 43, 200, 203, 623, 683, 688

Cohen, Herman 544

Cohen, I.B. I84

Coleman, James Samuel 602

Coleridge, Samuel I47

Comte, Auguste 22, 183, 466, 472, 476, 597, 599, 601, 606, 612-613, 616-617, 619, 623$624,676,684$

Condillac, Étienne Bonnot de 86, 88, 93, 273

Cooley, Charles H. 60I, 607

Coolidge, Archibald 428

Coomaraswarmy, Ananda 439

Copernicus, Nicolaus 603

Coppino, Michele 64

Couperus, Louis 62I

Courbet, Gustave 352

Cousin, Victor 279

Craig, Edward Gordon 315
Cremona, Luigi 53

Croce, Benedetto $346,355,514,523$

Crombie, Alistair 76, 67I

Cruden, Alexander 480-48I, 490-492

Csernátoni, Gyula II9, I25

Culianu, Ioan 288, 297

Culler, Jonathan 663,665

Cumont, Franz 8, 17, 219-231, 696

Cutolo, Raffaele 296

Cuvier, Georges 675, 677

Czuczor, Gergely 16, I13-115, I25, 699

\section{D}

Dante $244,300,482,492$

Darwin, Charles $55,62-63,66-68,70-71$, 73-77, 373, 38I, 383, 385, 389, 607, 695

Darwin, Erasmus $19,383-384,389,699$

Daston, Lorraine 7, 14-15, 15, 27, 39, 74, 76-77, I4I, I47, I72, I80, 195, 279, 506, 683-684, 688

Deissmann, Adolf 222, 229

Delbanco, Andrew 656, 664

Delisle, Léopold 496

Derrida, Jacques 207, 345-346, 355, 549, 657

Descartes, René I5, 43, 45-46, 49, 51-52, 267, $551,553,683$

Desgouttes, François 584

Desor, Edouard 56, 63

Dewey, John 465

Dewey, Melvil 467

Diderot, Denis 348-350, 353-356, 491, 589

Diels, Hermann 37, 4I, 224, 230, 239

Dijksterhuis, E.J. I88-I89, 200

Dilthey, Wilhelm I3, 24, 27, 177, 181, 279, 315, 550,623

Dinger, Hugo 317

Dionysius 40, 262, 265

Dioscorides 673

Döbrentei, Gábor II6

Doegen, Wilhelm 515

Dolan, Jill 32I, 324

Donker Duyvis, Frits 472, 477

Donoghue, Frank 656,664

Doorenbos Willem 30I

Dousa, Janus 500

Droysen, Gustav 32-33, 39-40, 134, 180, 245 , 623

Drucker, Johanna 474,478

Dubos, Abbé Jean-Baptiste 348 
Duhem, Pierre 183,200

Dumas, Alexandre 303

Dumézil, Georges 289, 297

Dürer, Albrecht 562, 566

Durkheim, Émile 22, 88, 90, 600, 602, 607, $612-614,616,619,624$

Dvořák, Max I78, I80, I82, 447

E

Eberlein, Johann Konrad 433

Eco, Umberto 6II

Edelstein, Dan 273, 278-279

Edison, Thomas A. 514

Efal, Adi 9, 19, 345, 688

Ehrenfels, Christian von 549

Eichhorn 210, 274-275

Eichhorn, Johann Gottfried 210, 274

Eichmann, Adolf 23, 559, 627-629, 632-633, $635-636$

Einstein, Albert 602

Eisenstein, Sergej 106

Elam, Keir 319, 324

Elffers, Els 24

Eliade, Mircea I8, 226-227, 287, 289-290, 296-297

Elias, Hermann 617

Elias, Norbert 22, 202, 603, 608, 616-619, 624

Eliot, George $\quad 65,76,677,684$

Elisséeff, Serge 20, 422, 428

Ellis, Alexander 397

Ellis, Havelock 583,588

Elsner, Jas 433, 446

Elsschot, Willem 62I

Elzinga, A. I9I, 200

Engels, Friedrich 616

Enneccerus, Magda 496

Erman, Adolf 239

Ernesti, Johann August 21I, 246

Esra 210

Euler, Leonhard 392

Euripides 56I

Eusebius 48, 26I

Evola, Julius I8, 29I, 297

F

Fechner, Gustav Theodor 395

Félibien, André 348,355

Fichte, Johann Gottlieb 97
Figuier, Louis 361-362, 373, 699

Fini, Gianfranco 285

Firdowsi, Abulqasim 97

Fischer, Otto 445

Fischer, Wilhelm I77, I82

Fischer-Lichte, Erika 321, 323-324

Fish, Stanley 489, 655, 664

Fisher, Ronald A. 528

Fitzpatrick, Sheila 427, 489

Flaubert, Gustave 589, 620,62I

Fleck, Ludwik 66-69, 76

Flusser, Vilém 489

Fogarasi, János 16, II3-II5, 699

Fortuyn, Pim 539

Foucault, Michel 66, I00, I09-IIO, 388, 390, $489,539,583,586,594-595,605,608,657$, $659-66 \mathrm{I}, 664-665,675,679,683$

Fouillée, Albert 466, 468

Fournier, Alain 620

Francis I, King 295

Franco, Francisco 287

Frank, Joseph 289

Franke, Otto 452

Franssen, Gaston 24

Frazer, James 221, 228

Frederick I, Elector of Brandenburg and Duke of Prussia 240

Frederick III, Prince-Elector of Prussia 240

Fredericq, Paul I3I-I32, I34-I35, I37-I38, I40-I42

Freeman, Edward Augustus I7I

Freud, Sigmund 90, 95, 549, 587, 593, 596, 659, 697

Friedrich, Caspar David 584

Frisch, Michael $52 \mathrm{I}$

Fritzsche, Peter 153, I55

Fronto, Marcus Cornelius 238

Fruin, Robert 136, I4I-I42

Fu Sinian 450, 452, 454, 456-457, 459-462

Fuchs, Georg 315

Fuller, Steve 605, 607-608

Fustel de Coulanges, Numa Denis 29-3I, 39, 142

G

Gadamer, Hans-Georg I3

Galen 673

Galilei, Galileo $\quad 45,49$, I88, 674

Galison, Peter 39, 74, 76-77, I4I, 279, 684, 688 
Gambarota, Paola 83, 93

Gauguin, Paul 434

Gehlen, Arnold 603,607

Genette, Gérard 268, 346-347, 355

Gengnagel, Vincent II, 23, 64I, 688

Genjewi, Nizami 97

Gennep, Arnold van 6I4

Gerard, Alexander 382

Géricault, Théodore 150

Gervinus, Georg 31, 39

Ghirlandaio, Domenico 56I

Gibbon, Edward 29, 39, 273, 276, 279

Giddens, Anthony 604, 608

Giddings, Franklin Henry 600

Giesebrecht, Wilhelm von 30

Ginzburg, Carlo 286, 297, 523, 615

Goblet d'Alviella, Eugène 227

Goboulev, Victor 434, 445

Goethe, Johan Wolfgang von 75, I47, I5I-152, 299-300, 307-308, 543, 697

Goffman, Erwin 320

Gogh, Vincent van 434

Goldhagen, Daniel Jonah 632, 635

Golgi, Camillo 59

Golinski, J. I95, 20I

Gosse, Philip Henry 7, 16, 65-67, 70,-75, 77

Goudsblom, Johan 619, 623

Gouldner, Alvin Ward 604

Gourgouris, Stathis 98-I00, I08-IIO

Gouw, Jan ter I52

Graevius, Johann Georg 237

Grafton, Anthony 47, 52, 244-249, 278, 493, 672,683

Gramsci, Antonio I09, II2, 295, 298

Granet, Marcel 454, 46I

Gratian 48I, 49I

Green, John Richard 134, 226, 399

Gregory, John 38I

Grimm, Jacob Ludwig Carl 97, I00, II8, I22, 150, 273

Gronovius, Jacob 237

Grosskinsky, August 35, 40

Grotius, Hugo 500

Grünwedel, Albert $\quad 434,444,449$

Gruppe, Otto 222

Gruter, Jan 237

Gu Jiegang 45I, 459

Guimet, Émile 227

Gunkel, Hermann 222

Gunnell, John 555
Gurlitt, Willibald 407, 4II

Gurvitch, Georges 603,607

Gutenberg, Johannes 482, 492, 514

Guy de Maupassant, Henri René Albert 620

\section{$\mathrm{H}$}

Habermas, Jürgen 388

Hacking, Ian 279, 671, 683

Haeckel, Ernst 63

Haenisch, Eric 452

Hafiz 585

Hall, A. Rupert I87, 200

Halliwell, Martin 657,664

Hamann, Julian 23, 64I, 65I, 653, 688

Hamann, Richard 178,182

Hammer, Franz 47, 52

Hammerstein, Reinhold 403, 407, 410-4II

ha-Nasi, Jehuda 208

Hanslick, Eduard I73, 176, I8I

Harnack, Adolf von 239, 247

Hartley, David 380-382, 385, 389

Hatfield, Gary 380,389

Hedin, Sven $444,449,456,458$

Hegel, Georg Wilhelm Friedrich 200, 543544, 55I, 659

Heidegger, Martin 22, 493, 549-550, 556$560,562,565-566$

Heijden, A.F.Th, van der 621

Heine, Heinrich 306

Heisenberg, Werner 602

Helmholtz, Hermann 27, 59, 391-393, 395$396,399-400,551$

Hemmeler, Daniel 584

Herder, Johann Gottfried von 24, 97, II8, I42, I48-I49, I8I, 279, 6I 7, 684

Hermann, Gottfried 245

Hermans, Willem Frederik 62I

Hermogenes 93

Hernández-Pacheco, Eduardo 366, 375

Hernstein Smith, Barbara 68

Herod, King 47

Herodotus 35, 208, 512, 523

Herrmann, Max I8, 315, 318, 321, 323-324

Herzfeld, Michael 293, 297

Hess, Albert G. 404, 410

Heuvel, Charles van den IO, 20, 465, 476477,688

Heydt, Eduard von der 432, 435, 440, 446 
Heyne, Christian Gottlob 234

Higden, Ranulf 480-48I, 49I

Himmler, Heinrich 628

Hintikka, Jaakko 536

Hirschfeld, Magnus 59I

Hitler, Adolf 514, 603, 629, 632, 635

Hobbes, Thomas 597

Hobhouse, L.T. 600

Hockney, David 6II, 62I

Hoffmann, E.T.A. 593

Hogarth, William 382

Homer 84, 212, 242, 255-260, 262, 492, 619

Hooker, Joseph 73

Horace (Horatius Flaccus) 585

Horkheimer, Max 597

Hornbostel, Erich Moritz von 20, 391, 397, 401

Horton, Russell 273, 278-279

Hössli, Heinrich 584-587, 589, 591, 594-595

Hu Shi 449, 453-454

Hübschmann, Heinrich IO2

Hugo, Victor I47, 150

Huizinga, Johan 22-23, I33, I4I-I42, 614-6I8, 624

Humboldt, Wilhelm von 68, 97, 99-100, IO6, I47, 235, 684

Hume, David 380-38I, 389-390

Hunfalvy, Pál II7, I24

Husserl, Edmund 400, 545-546, 549, 552 553,689

Hutcheson, Francis 309, 380, 382

Huxley, Thomas Henry 66-67, 73-77

Huydecoper, Balthasar 500

\section{I}

Ibycus 258

Ierna, Carlo io, 2I, 543, 689

Illich, Ivan 605,608

Innis, Harold 489

Irigaray, Luce 657

\section{$\mathrm{J}$}

Jack the Ripper 285

Jackson, Noel 386, 390

Jacobson, Roman 549,589

Jaensch, Erich 544

Jäger, Gustav 587

Jay, Paul II, 23, 655, 689
Jensen, Peter 224

Jeremias, Alfred 224

Jesi, Bruno 283

Jesi, Furio 9, I8, 283, 285-286, 290, 293-297

Jesus 47, 49, 65, 211, 620

Johansson, Perry IO, 20, 449, 46I, 689

Johnson, Samuel 479, 490

Jonckbloet, Willem 500

Jones, William II7, I5I, 275, 678

Jong, Franciska de IO, 2I, 5II, 689

Jorink, Eric 43, $5 \mathrm{I}$

Joseph, John E. 7, I4, I6, 8I, 93-94, 689

Joseph, Losey 295, 298

Josephus, Flavius 47-48

Jünger, Ernst 558,565

\section{K}

Kalff, Gerrit 30I, 303, 309-310

Kalmár, György II9, I25

Kalmthout, Ton van 9, I8, 299, 307, 309, 31I, 690

Kalonymus, Isaac Nathan ben 48I

Kames, Henry Home, Lord 382

Kant, Immanuel 550-551, 641, 651, 654, 659

Karajan, Theodor von I6I, I66-I68

Karlgren, Bernhard 453-454, 456, 46I

Karstens, Bart 8, 17, 24, I25, 183, 683-684, 690

Kastil, Alfred 549

Keilson-Lauritz, Marita 593, 595-596

Kelder, Jorrit 24

Kemp, Karen 473,477

Kempers, Bram II, 22, 609, 625, 690

Kepler, Johannes I5, 43-45, 47-48, 50, 52, 674,683

Ker, W.P. 301,309

Kerenyi, Karl 286, 288, 296

Kertbeny, Karl Maria 585, 587, 591, 595

Kimball, Roger 664

Kittler, Friedrich 489

Kleist, Heinrich von 590

Klooster, Jacqueline 8, I8, 25I, 690

Knies, Karl 572

Kocka, Jürgen $275,648,653-654$

Koffka, Kurt 393, 40I, 549

Kogan, Moissey 443-444, 700

Köhler, Wolfgang 393, 395, 400, 549

Kokoschka, Oskar 173

Kolijn, Klaas 50I, 508 
Könnecke, Gustav 496

Korais, Adamantios 100

Koselleck, Reinhart 39, 152, 154, 275, 278, 652-654

Kosofsky Sedgwick, Eve 594

Kotarbinski, Tadeusz 549

Kotte, Andreas 322, 325

Koyré, Alexandre I84, I88-I89, I9I, 196, 200, 69I

Krafft-Ebing, Richard von 583, 587-588, 595

Kragh, Helge 187, 199-200

Kramrisch, Stella 445

Kranz, Walther 239

Kraus, Oskar 549, 552

Krausse, Karl 366

Kresznerics, Ferenc II8, I20, I22, I25

Kristeva, Julia 657

Krockow, Christian von 558

Kugler, Franz 350, 356

Kuhn, Thomas 43, 66, 68, 76, I93-I94, I98, 200-202, 497, 610, 623

Kümmel, Otto 43I, 445

Kunst, Jaap 397, 401

Kupffer, Elisar von 593

Kursell, Julia 24

Kurth, Godefroid I32, I35, I4I, I42

Kutscher, Artur I8, 315, 318, 688

\section{L}

La Font de Saint-Yenne, Etienne 348, 356

Lacan, Jacques 657

Lachmann, Karl I8, I50-151, 213, 215-217, 236-237, 239, 246, 252, 26I

Lamartine, Alphonse de I47, 276-277, 279

Lambert, Johann Heinrich II9

Lamont, Michèle $\mathrm{I} 32$

Lampedusa, Giuseppe Tomasi di 62I

Lamprecht, Karl 19, 174, 329, 330-331, 333, 34I-342

Langlois, Charles-Victor I7I, I75, I79, I8I

Lanzarote-Guiral, José María 9, I9, 359, 69I

Lardinois, André 259

Latour, Bruno $\mathrm{I} 6,68,76-77,8 \mathrm{I}-85,87,9 \mathrm{I}-93$, 95, 98, 20I-202, 533, 699

Laudan, Larry 180,199

Lavoisier, Antoine 675

Le Coq, Albert von 444

Lederer, Emil 600

Leeb, Susanne 342, 433, 446
Leezenberg, Michiel 7, 16, 97, I25, 623, 69I

Lehrs, Karl 2I2

Leibniz, Gottfried 49, 240

Leichtentritt, Hugo 403, 405, 410

Lenz, Max 245, 644, 645, 647, 652

Leppenies, Wolf 610

Lesniewski, Stanislaw 549

Levi della Vida, Giorgio 225, 230-231, 536

Levinas, Emmanuel 549

Levine, George 68, 76

Lévi-Strauss, Claude 46I

Lewin, Kurt 394

Li Ji 456-459, 46I-462

Liala (Amalia Liana Negretti Odescalchi Cambiasi) 292

Lichtenstein, Heinz 560

Licklider, Joseph 472

Lieftinck, Gerard Isaäc 502

Lindner, Theodor 33I

Linné, Carl von (Linnaeus) 386,584

Liu Fu 452

Livingstone, David 74, I30, 140

Livy 265

Lobeck, Christian 212

Locke, John 275, 279, 380, 382, 386

Lockhart, James 253

Logier, Johann Bernhard 410

Lope de Vega, Félix Arturo 305

Lord, A.B. 255, 262, 273

Lotze, Hermann 393

Lowenthal, David I53

Lu Xun 449

Lucian 585

Lucretius 213, 237, 252, 6II

Lukasiewicz, Jan 549

Luo Zhenyu 450, 453

Luther, Martin $56 \mathrm{I}$

Lyell, Charles 65-67, 69, 7I, 73-77

Lynd, Robert Wilson 60I

Lyotard, Jean-François $345,355,657$

Lysenko, Trofim IO2

\section{M}

Maas, Paul 25I

Maat, Jaap 3, 7, 13, 75, 125, I66, I80, 355, 623, 684,69 I

Mabillon, Jean 3I

Macaulay, Thomas 32, I48-I49, I5I, I53-155

Mach, Ernst I83, 200, 395, 400, 457 
Machiavelli, Niccolò 3I

Mackay, John Henry 592, 595

MacNair, Harley F. 424

Macpherson, James 146

Madvig, Johan Nicolai 246

Mahler, Gustav 174

Maillol, Aristide 434

Maimonides, Moses 208, 216

Malm, Mats 24, 345, 355

Mandelkern, Salomon 49I

Manet, Édouard 352, 353, 677, 684, 699

Manetho 49

Mannheim, Karl 615, 617, 653

Manovich, Lev 249, 497

Mantegazza, Paolo 588

Marácz, László 8, I6, I13, I24-I25, 691

Marbeck, John 49I

Marchand, Suzanne IIO, 222, 224, 229-230, 249, 426, 446

Marcks, Erich 645

Marcuse, Herbert 603, 607

Marez, Guillaume des 136, I42

Margadant, Steven 302-305, 309-310

Maria Theresa, Archduchess of Austria II 4

Marinis, Marco de 322, 324-325

Marr, Nikolaj Jakovlevič 7, I6, 97, I00-IO4, IO6-IO9, III-II2, 4I8

Marshall, David L. IO, 22, 355, 555, 566, 691

Marshall, S.L.A. 515

Marshall, Thomas Humphrey 602

Martinelli, Riccardo 9, I9, 39I, 400, 692

Marty, Anton 549

Marung, Steffi 9, 20, 415

Marx, Adolf Bernhard 410

Marx, Karl 200, 523, 601, 606, 616, 617, 624, 659

Masaryk, Thomas 549

Maspero, Henri 423

Mathesius, Vilem 549

Mathijsen, Marita 8, I6, I45, I54-155, 508, 625,692

Matisse, Henri 434

Mattei, Stefano 285

Mattei, Virgilio 285

Mauss, Marcel 6I4

Mayakovsky, Vladimir 106

Mayer, Julius Robert von 55

Mayo, Deborah 199

McKenzie, Jon 320, 324

McKenzie, Kenneth 482, 492
McKirahan, Richard 351, 356

McLuhan, Marshall 489, 492

Mead, George Herbert 6oI

Mead, Margaret 9I, 6I4

Medici, Lorenzo de 561-562

Meillet, Antoine I6, 83, 88-92, 94, 423

Meinecke, Friedrich 134, 652

Meinong, Alexius 180, 549, 55I, 553

Meneghello, Laura 7, 15, 53, 62, 692

Menzel, Wolfgang 584

Merleau-Ponty, Maurice 549

Mersenne, Marin 45-46, 52

Mersmann, Birgit 9, 19, 329, 693

Merton, Robert I84, 20I, 617

Meuli, Karl 289, 297

Meyer, Eduard 424

Meyerhold, Vsevolod Emilevich 106

Mialaret, Athénaïs I34

Michaelis, Johann David 210

Michel, Charles 220

Michelangelo 361-362, 587, 699

Michelet, Jules 32-33, I34, I48-I49, 265, 267, 279

Michels, Robert 600

Miert, Dirk van 24

Milgram, Stanley 23, 618, 629-632, 634, 636

Miliband, Sofia 418

Mill, John Stewart 582, 676

Mirandola, Giovanni Pico della 209

Moleschott, Jacob 7, 16, 53-63, 692-693

Mommsen, Theodor 29-30, 38-4I, I47, I49, 228, 238-242, 244, 246-248, 265, 580, 648, $652-654$

Monboddo, James Burnett, Lord 386

Monod, Gabriel I34

Montesquieu, Charles-Louis de Secondat, Baron de La Brède et de 273, 279, 597, 606,624

Montezemolo, Luca Cordero di 292

Moravia, Sergio 159, 380, 389-390

Moreno, Manuel Gómez 366, 372

Moretti, Mauro I34, 273

Morgenstern, Oskar 602

Moro, Aldo 284, 296

Morrison, Jim 6II, 62I

Mortillet, Gabriel de 36I

Moses 49, 84, 208, 210, 216, 275, 654

Mosso, Angelo 59

Most, Glenn W. 8, I4, I7, 207, 216, 26I, 244$248,273,693$ 
Mostern, Ruth 473, 477

Mously, Andrew 657

Mozart, Wolfgang Amadeus I75, 295

Mueller, Friedrich W.K. 452

Mulisch, Harry 628, 635

Müller, Friedrich Max 85-86, II8, I25, I4I, 212, 219, 223, 226-227, 245-246, 400

Multatuli (Eduard Douwes Dekker) 62I

Musil, Robert 394

Mussolini, Benito 291, 292, 514

\section{$\mathrm{N}$}

Nagel, Thomas 129

Nagy, Gregory 289

Nain, Louis Le 348

Naumann, Katja 9, 20, 415, 693

Needham, Joseph 199

Nescio (Jan Hendrik Frederik Grönloh) 621

Nettement, Alfred 276-277, 279

Neumann, Carl $\quad$ 178, I82

Neumann, John von 602

Nevins, Allen 516

Newton, Sir Isaac 15, 43-44, 47-52, 77, 133, 603,674

Nichanian, Marc 98-IOI, IO8-III

Nicole, Jules 224

Niebuhr, Barthold Georg 31-32, I47, 246, 265,273

Niessen, Carl 315, 317-318, 324

Nietzsche, Friedrich 27-28, 3I, 36, 38-39, 4I, I74, 2I6, 60I, 659

Njegos, Petar 97

Noah 49, 5I, 70, 274

Nolde, Emil 434

Noorden, Carl von 138

Novick, Peter I79, I82

\section{O}

Oberg, Barbara Bowen 38I, 389

Obermaier, Hugo 19, 364, 374-375

Odescalchi Cambiasi, Amalia Liana Negretti 292

Ol'denburg, Sergej Fedorovič 4I8

Ol'derogge, Dmitrij Alekseevich 420

Olson, Richard 273, 379, 389-390

Oostrom, Frits van 619

Oostveldt, Bram van 24
Oppenheimer, Franz 600

Orell, Julia IO, 20, 43I, 693

Orelli, Johann Caspar von 246

Origen 26I, 49I

Ossewaarde, Marinus II, 22, 597, 608, 694

Ossian 84, I46-I47, I54

Osthaus, Karl Ernst 432, 434, 443, 446

Ostwald, Wilhelm 469, 476

Otlet, Paul 466-477, 70I

Otrokócsi, Fóris Ferenc II9, I25

Ottner, Christine 8, I7, I57, I66-168, 694

Ovid 56I

Owens, Jack 474

\section{$\mathbf{P}$}

Padua, Antony of 49I

Palacký, František 159, 167

Paley, William 69-70, 74, 77

Palladio, Andrea 295

Panini 84

Panofsky, Erwin $354,357,444,507,566$

Pareto, Vilfredo 62I

Park, Robert Ezra 6oI

Parker, Theodore 56-57

Parry, Milman 255, 262

Parsons, Talcott 602, 607-608, 617

Pascal, Blaise I5, 43-44, 45, 49, 5I, 599

Pasteur, Louis 68

Patocka, Jan 549

Patzer, Harald 35,40

Paul, Herman 8, I7, I7 I, I80, 694

Peeren, Esther 24

Pelgrom, Jeremia 24

Pelliot, Paul 423, 444, 449, 452, 456, 46I

Percy, Thomas 24, I46-I47, 610, 623

Perdrizet, Paul 230

Perrot, Georges 224

Pertz, Heinrich 133

Petrarch 482, 492

Petronius (Gaius Petronius Arbiter) 589

Pickstone, John V. 5, II, I4, 23-24, 667, 683685,694

Piles, Roger de 348,356

Pindar 245, 262

Pirchegger, Hans 139

Pirenne, Henri I32-I34, I36, I40-I42, 697

Planck, Max 602, 688, 693

Platen, August von 593

Plato 93, 208-209, 230, 551, 560, 620 
Pleij, Herman 619, 625

Pliny (Plinius Major) 673

Pocock, John 276

Pohlenz, Max 35, 40

Politian (Angelo Ambrogini) 209, 213

Polivanov, E.D. I06-I08, II2

Innocent IV, Pope 49I

Popper, Karl 528,602

Porciani, Ilaria I29, I40-I42

Posnett, Hutcheson Macaylay 30I, 309

Potekhin, Ivan Izosimovich 42I

Pott, August Friedrich II3, II8, I24

Poulsen, Valdemar 514

Prévost, Abbé (Antoine François Prévost d'Exiles) 590

Priebke, Erich 294

Prometheus 61, 308, 538, 623

Propp, Vladimir 106

Proust, Marcel 620

Pythagoras 392

\section{Q}

Qian Xuantong 454

Quine, Willard Van Orman 198

Quinet, Edgar 279

\section{$\mathrm{R}$}

Raimondi, Ruggero 295

Ramdohr, Friedrich Wilhelm Basilieus 584

Rameau, Jean-Philippe 392-393, 399

Ranganathan, Shiyali 470, 477

Ranke, Leopold von 30-4I, 97-98, 134-I50, I66, I74, I80, 273, 33I, 333, 512, 523, 652

Raphael (Raffaello Sanzio) 39, I68, 36I, 404

Rayward, Boyd 472, 476-477

Réau, Louis 178, I82

Regusa, John of 492

Reich, Hermann 317

Reichenbach, Hans 536

Reinach, Théodore 224

Reinach, Salomon 363, 374

Reinhardt, Max 315

Reischauer, Edwin 424

Reitzenstein, Richard 222, 229

Rembrandt van Rijn 56I

Renan, Ernest 6I

Réville, Albert 227

Ricardo, David 676
Ricci, Matteo 449

Richter, Virginia 7, 16, 65, 76-77, 694

Rickert, Heinrich $\quad 13,22,569-572,575,578-$ 580, 582, 623

Ricoeur, Paul 549

Riegl, Alois I9, I72-I73, I76, I80, 329-330, 34I, 433, 444-446

Riemann, Hugo I76, I8I

Rigney, Ann 276, 278

Ritschl, Friedrich 21I, 213, 217, 246

Robertson Smith, William 221, 228

Robida, Albert 514

Rock, Jan IO, 2I, 495, 695

Rohlf, Christian 434

Romeijn, Jan-Willem Io, 2I, 527, 695

Roosevelt, Franklin Delano 516

Roscher, Wilhelm 572

Rose, Nikolas 605, 608

Rostovtzeff, Michael 424

Rothacker, Erich 39, 178, I82

Rouse, M.A. 199, 479-480, 490-49I

Rousseau, Jean-Jacques 393, 597, 696

Rowland, Ingrid I8, 695

Roy Ladurie, Emmanuel Le 473, 477

Rozen, Viktor Romanovič 418

Ruccius, Alexis 9, 20, 403, 695

Rühlmann, Julius 403-405, 407, 410, 700

Rumohr, Carl Friedrich von 339

Runciman, W.G. 604, 607-608

Russa, Ignazio La 29I

Russell, Bertrand 202, 278, 470, 472

Rustaveli, Shota 97

\section{S}

Sa'di 585

Sacher-Masoch, Leopold von 589

Sachs, Eduard 423

Said, Edward 97-IOI, IIO, 427, 460

Saint Hilaire, Geoffroy 677

Saint-Cher, Hugh of 480-48I, 49I

Salinger, J.D. 6II, 6I4

Salmony, Alfred 445

Sand, George 590

Sapir, Edward 9I

Sappho 212, 248, 255, 258-260, 262-263, 59I

Sarton, George 184-193, 199, 200

Sartre, Jean-Paul 549

Sassen, Willem 628

Sauppe, Hermann 246 
Saussure, Ferdinand de 16, 83-84, 86-91, 9395, 106, 125, 275, 279, 684, 690

Sauter, Willmar 314, 323

Sautuola, Marcelino Sanz de 360, 370, 373

Saxe, Christoph 278

Scagliola, Stef IO, 21, 5II, 524, 695

Scaliger, Josephus Justus 47, 48, 49, 50, 52, 261

Schabas, Margaret 676,684

Schäfer, Dietrich 174

Schaffer, Simon 98

Schaffner, Anna Katharina 583,594

Schechner, Richard 319-320, 324

Scheerlinck, Eline 8, 17, 219, 230, 696

Scheler, Max 600

Schelling, Friedrich Wilhelm Joseph 58, 63

Schiller, Friedrich von ${ }_{152}$

Schleiermacher, Friedrich 65, 226-227, 235, 279

Schlosser, Julius von 172

Schmitt, Carl 555, 558, 565

Schnasse, Karl 350

Schönberg, Arnold I73-174, I76

Schrade, Leo 20, 406, 409-410, 700

Schrödinger, Erwin 602

Schultens, Hendrik Albert II9

Schulz, Franz 174

Schünemann, Georg 392, 397, 700

Scott, Sir Walter I47-I48, I50-I5I

Scribe, Eugène 303

Scriverius, Petrus 500

Seebaß, Tilmann 403

Segovia, John of 492

Seignobos, Charles I7I, I75, I79, I8I, 46I

Sellars, Wilfrid 279

Semi, Maria 9, 19, 379, 390, 696

Servantsdiants, Karekin Ioo

Servatius, Saint 628

Shakespeare, William 244, 300, 487, 489, $492,507,587,589,593,619$

Shapin, Steven 98, 190, 200-20I

Shemo, Ereb 107

Sickel, Theodor I59, I62-163, I66, I68

Siemens, Werner von 644

Simmel, Georg 600

Simplicius 239

Skyrms, Brian 536

Small, Albion Woodbury 600

Smedt, Charles de I7I

Smith, Adam 28, 34, 39-40, 76-77, I4I, 20I, $228,380-381,553,684$

Snow, C.P. I3, 200, 610
Socrates 6I, 92-93, 59I

Solleveld, Floris 8, I8, 265, 696

Solon 258

Sombart, Werner 600

Sophocles 245, 593

Souza, Dinesh D' 664

Spencer, Herbert $63,302,466,468,472$, 476, 599-602, 607, 612, 617, 624

Spengler, Oswald 285,617

Spinoza, Benedictus de 6I, 210, 216

Spitta, Philipp I73, I80

Spitzer, Leo 354-355

Sprondel, Johanna Io, 21, 355, 479, 493, 696

Stael von Holstein, Alexander, Baron 52

Stechow, Wolfgang 348, 356

Stein, Aurel 444, 449, 458, 462

Stein, Edith 549

Steinbeck, John 516

Steiner, Rudolf 549

Stendhal 6II, 620, 625

Sterne, Laurence 386

Stopford, Alice 134

Stradivari, Antonio 406, 410

Strauss, Leo 216, 556, 565

Strauss, David Friedrich 65

Strzygowksi, Josef 178, I82, 431-436, 438440, 445-448

Stumpf, Carl 19, 391-393, 399-40I, 549, 552553,700

Sumner Tainter, Charles 514

Sumner, William Graham 600

Svenbro, Jesper 289

Swaan, Abram de II, 22, 619, 625, 627, 696

Swift, Jonathan 386,389

Sybel, Heinrich von 31, 33, 39, 137, 653

Symonds, John Addington 587

Széchenyi, István I15-I16, I24

\section{$\mathrm{T}$}

Tacitus 28-29

Taine, Hyppolite 265,677

Tartini, Giuseppe 392

Terkel, Louis 'Studs' 516

Thausing, Moritz 173

Theocritus 585

Theognis of Megara 258

Thierry, Augustin I48, I50

Thomas, William I. 60I

Thomson, Derick 146 
Thorndike, Lynn 200

Thucydides 28, 33-36, 40, 252, 512-513

Tietze, Hans I7I-I82

Titmuss, Richard 602

Tobin, Robert Deam II, 22, 583, 697

Tocqueville, Alexis de 22, 597, 599-601, 603604, 606-607, 617, 624, 694

Tollebeek, Jo 8, I4, I6, 24, 98, I29, I54, I68, I80, 697

Tolz, Vera IOI, III, 427

Tönnies, Ferdinand 600

Topitsch, Ernst 597,606

Tormo, Elías 366, 368, 370

Tosh, John 138

Tótfalusi Kis, Miklós II9

Toulmin, Stephen 201

Toutain, Jules 220-221, 227-228

Treitschke, Heinrich von 3I-33, 39, I3I

Trevisa, John of 480-48I, 49I

Troeltsch, Ernst 600

Trubetzkoy, Nikolai I00-I04, I08, III

Tuchman, Barbara 518

Twardowski, Kazimierz 549

\section{$\mathrm{U}$}

Ullrich, Franz Wolfgang 34, 40

Ulrichs, Karl Heinrich 585-587, 591, 593-595

Unamuno, Miguel de 366, 374

Usener, Hermann 220, 227

\section{V}

Varnhagen, Rahel 559

Vasari, Giorgio 337

Velde, Henry van 434

Verlaine, Paul 593

Vernes, Maurice 220

Versluys, Miguel-John 24

Verwijs, Eelco 50I

Vico, Giambattista 13, 75, I48, 279, 670, 680, 684, 69I

Vida, Giorgio Levi della 225, 230

Vigny, Alfred de 148

Vilanova, Juan de 360-361, 370

Villari, Pasquale 64

Virchow, Rudolf 55I, 644

Virgil 585

Virilio, Paul 498

Vogelweide, Walther von der 253, 256, 260
Vogt, Carl 53

Voloshinov, V.N. 106, II2

Voltaire II4, 273, 277, 617

Vonwiller, Oskar 435, 445-446

Vossius, Gerard 49, 5 I

Vreese, Willem de 2I, 495, 497, 506-507

Vuillard, Édouard 352

\section{W}

Wagenaar, Jan 152, 155, 500

Wagner, Richard 174, 315

Waitz, Georg I33-135, 138, 397, 40I, 653

Walch, Jan I8, 303-307, 310-3II

Wallace, Alfred Russel 74

Wang Guowei 460

Warburg, Aby 19-20, 22, 329, 333-335, 340, $342,354,403,406,444,556,560-564$, 566,615

Warner, Langdon 462

Watelet, Claude-Henri 349

Watson, Thomas J. 473

Weber, Alfred 600

Weber, Ernst Heinrich 395

Weber, Max 22, 8I, 85, 92, I42, I88, 396, 400, $523,555,565,569-570,572-577-582,600$, 6I6-6I7, 62I, 624, 653-654

Weber, Wilhelm 393, 395

Webern, Anton 173

Wehler, Hans-Ulrich 647-648, 653-654

Welcker, Friedrich 212

Wells, H.G. 599, 607

Wertheimer, Max 397, 393, 40I, 549

Westerman, Diedrich 420

Westfall, Richard S. 47, 49, 52

Westphal, Carl 586

Weststeijn, Thijs 3, 7, 13, 75, I25, I66, I80, $355,623,684,697$

Whewell, William I83, 200

Whitehead, Alfred North 47I-472

Whiting Bishop, Carl 456-457

Whitney, William Dwight 85-86, 91, 93, 95, 690

Whorf, Benjamin Lee 9I

Wick, Gian Carlo 296

Wickhoff, Franz I72-173, 444

Wiese, Leopold von 600

Wilamowitz-Moellendorff, Ulrich von 222, 229, 240-24I, 247-249, 26I

Wilberforce, Samuel 67,74

Wilbrandt, Adolf 589 
Wilbur, Martin C. 424

Willems, Jan Frans 500

Winckelmann, Johann Joachim 580, 587

Winckler, Hugo 224

Windelband, Wilhelm 22, 27, 569-573, 578580,582

Witasek, Stephan 549

With, Karl Io, 20, 43I-448, 700

Witter, Henning Bernhard 210

Wittgenstein, Ludwig 198, 202,55I

Wittig, Monique 657

Wolf, Friedrich 7, 17, 8I, 210, 212, 234-236, 239, 244, 254-255, 26I, 523, 566, 623, 685

Wolfe, Tom 6II

Wolff, Eugen 315

Wölfflin, Heinrich I77-I78, 444-445

Wolin, Sheldon 555, 565

Wordsworth, William 386

Wright Mills, Charles 603, 617

Wright, Joseph 386-387, 700

X

Xu Xusheng (Xu Bingchang) 452-453, 457, 460

Y

Yao Congwu 452

Yuan Fuli 450

Z

Zarlino, Gioseffo 392

Zenodotus 257

Zevi, Shabbatai 289-290

Zilsel, Edgar 199

Zimmermann, Johann Georg 584

Zimmermann, Otto 590

Zola, Emile 589

Zschokke, Heinrich 584

Wundt, Wilhelm 59, 334, 342, 466, 544, 55I, $572-573,580$

Zückert, Johann Friedrich 584

Zumpt, Karl Gottlob 246 


\section{Table of Contents}

Table of Contents

Introduction

The Making of the Modern Humanities

The history of the humanities comes of age

The papers in this book

Acknowledgements

Notes

I

The Humanities and the Sciences

I.I

Introduction: Objectivity versus Justice

Impartiality

Objectivity

Thucydides at the bar

A new religion

Conclusion: Intensely disinterested

Notes

I.2

Notes

I.3

The interaction between arts and sciences: The idea of 'humanity' and the role of history

The 'Philosophical Faculty' and the 'Unity of Science'

Classical culture and the roots of the Tree of Knowledge

Notes

$\mathrm{I} .4$

I

II

III

Notes

II

The

Science

of Language

$2 . \mathrm{I}$

Weber's antimodernism and Latour's symmetrical anthropology

The 'genius of a language' as natural and irrational Linguistics and the Nature vs. Subject/Society polarization 
The evolution of Meillet

Conclusion

Notes

2.2

The universalization of the philological humanities

Russian and Soviet Orientalism: Marr and Trubetzkoy

Marr and early Soviet nationality policies

Some Gramscian conclusions

Notes

2.3

Contextualizing the first Hungarian academic dictionary

Searching for roots

Patterns in the $\mathrm{CzF}$ Dictionary

Discussion and outlook

Notes

III

Writing History

$3+1$

The garret: The rhetoric of modesty

The study: The rituals of intimacy

The laboratory: The representation of modernity

Epilogue

Notes

3.2

Scholarly standards for history writing, and an appeal to the imagination

Editors as historians

Literary authors as history writers

Transgression and expansion

Urgency

Notes

$3 \cdot 3$

Introduction

A historical repertory: Der österreichische Geschichtsforscher A printed archive: The Archiv für Österreichische Geschichte Promoting professional auxiliary sciences of history: The Mitteilungen des Instituts für Österreichische Geschichtsforschung

Conclusion

Notes 


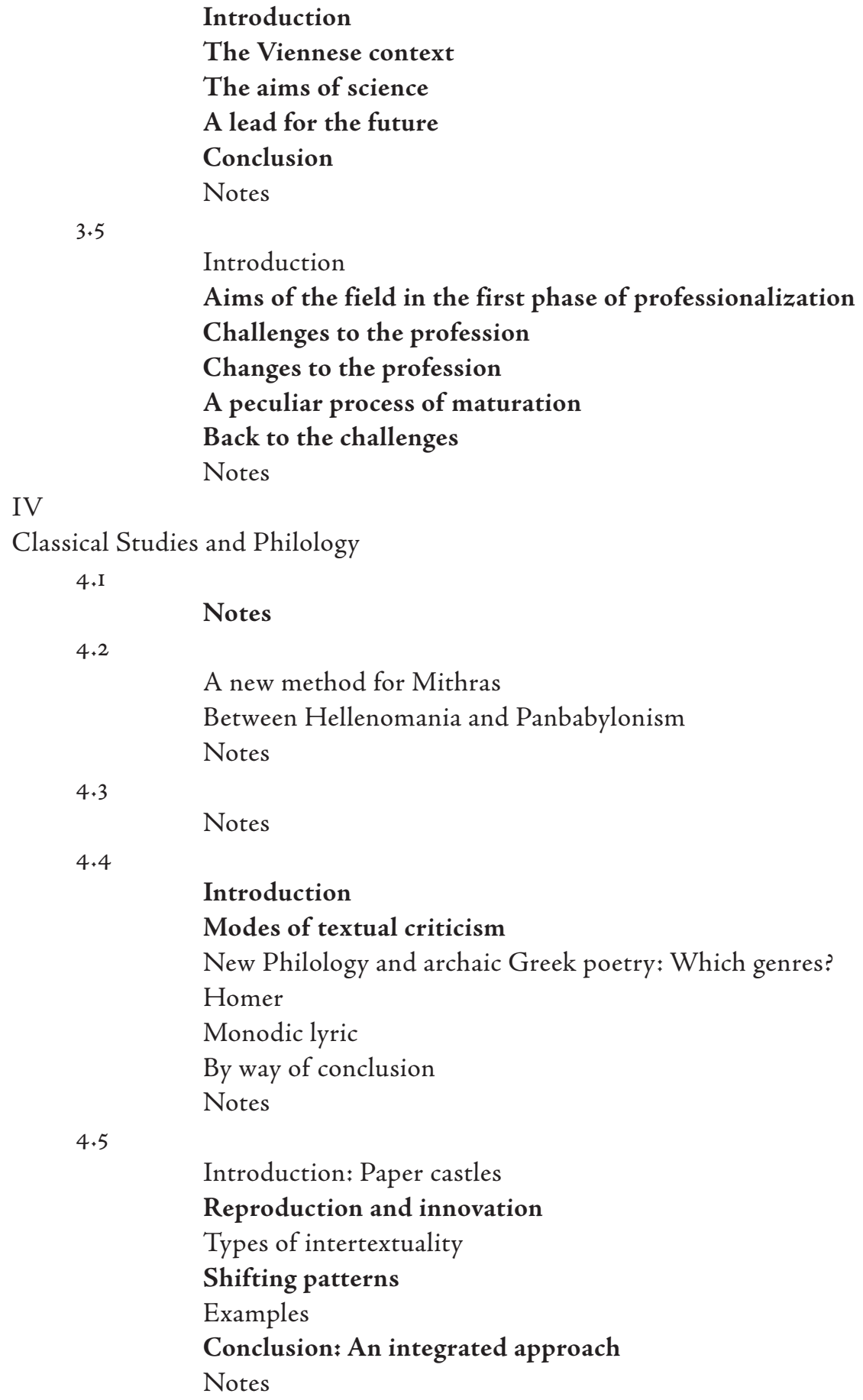


V

Literary

and

Theater Studies

$5+1$

Notes

$5 \cdot 2$

Introduction

Scientification

Popularization

Jan Walch's book on world literature

Conclusion

Notes

$5 \cdot 3$

A young discipline fighting for independence and recognition

Approaches to theater studies: Relationships to the other humanities

Epilogue

Notes

VI

Art History and Archeology

6.I

Art history and universal history: New linkages

Universal history as cultural history: A new concept and methodology of historical research

Cultural history of images: The emergence of image studies in the work of Aby Warburg

The universalist concept of modern world art history

Modern global humanities and the making of image studies

Notes

6.2

\section{Genre: Critics and defenders}

Literary genres and their Aristotelian origins

Peintres de genre and habitual subject matter

Generic classification and genre as the 'matter' of forms

Genre painting and the subject matter of modern art

Genre and philological habitude

Notes

$6+3$

The question of cave art and the making of prehistory

Searching for the origins of Spanish art 


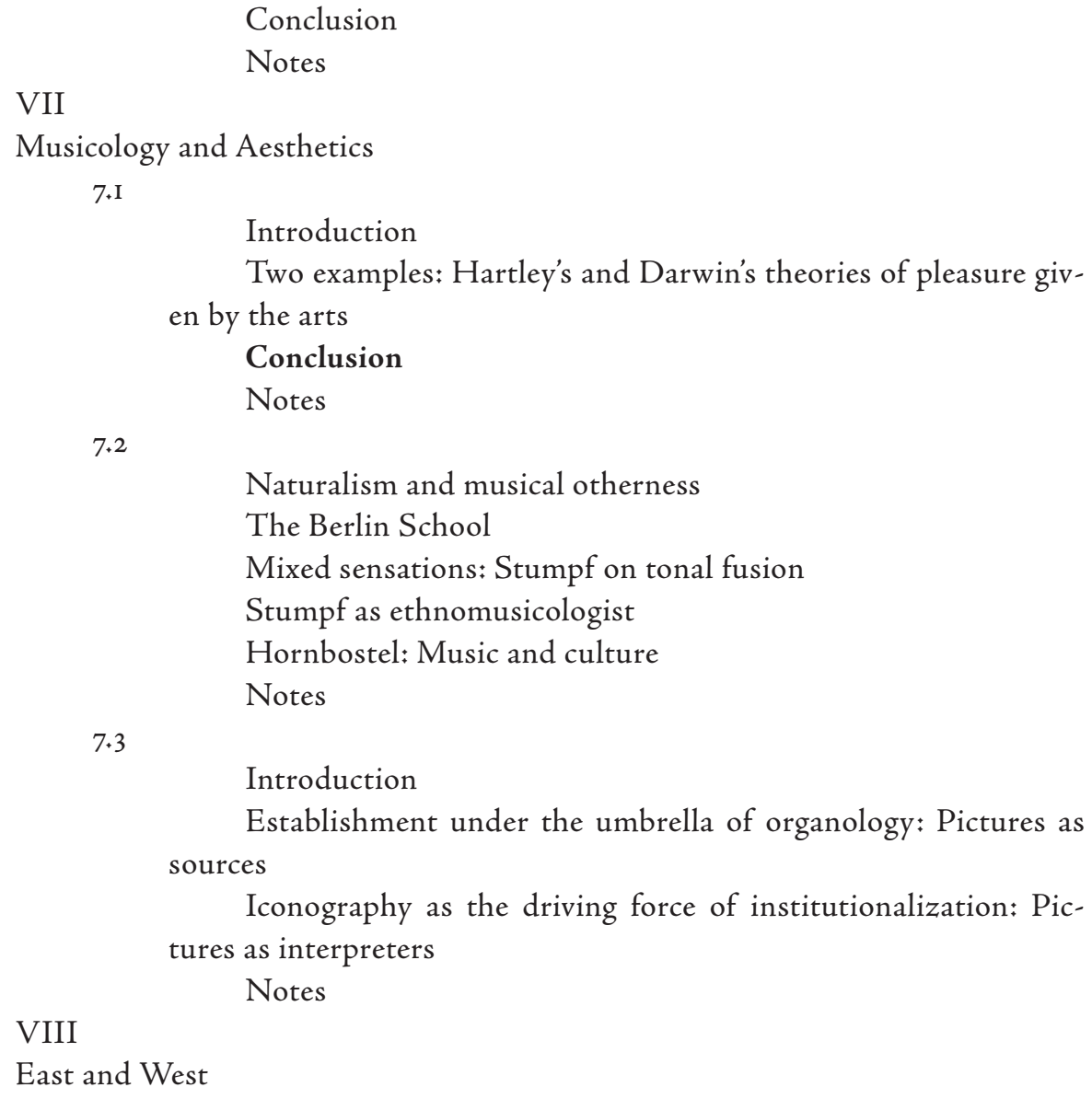

Iconography as the driving force of institutionalization: Pictures as interpreters

Notes

VIII

\section{East and West}

8.1

Soviet Orientalists

Oriental studies in the United States

Conclusion

Notes

8.2

East Asian art and art history

Josef Strzygowski and non-European art

Karl With's career in art history, work for private collectors, and museums

With's dissertation on Japanese Buddhist art under Strzygowski

The problem of Gandhara

Notes 
$8+3$

Introduction

From European sinology to national studies

The Chinese humanities

Conclusion

Notes

IX

Information Science and Digital Humanities

9.1

Introduction: The making of library and information sciences Classification of the sciences

Paul Otlet: Knowledge organization of ideas and retrieval of facts

Dimension reduction: Multidimensional thought and one-dimensional search

Denial of philosophical conceptions of classification

Dimension reduction in the humanities

Epilogue: Digital hermeneutics and the making of e-humanities Notes

$9 \cdot 2$

Introduction

Concordance and the idea of harmony

Searching the Web: Index, corpus and engine ${ }^{21}$

Same but different: Retrieving knowledge, scraping information and sorting data

The potential of reading search engines as a concordance

Notes

$9+3$

A paper database between new and old media

The database in national thought and philological epistemology (I895-I938)

The database in Leiden, a scholarly metropolis (1939)

An automated database (I99I-I995)

Conclusion

Notes

$9 \cdot 4$

Introduction

Text defeats spoken word

Capturing the voice

Personal experience with war and crisis 
Pioneers in archives and academia

The memory boom, the cultural turn, and the digital turn

Immediacy and hidden layers

Notes

$9 \cdot 5$

\section{Introduction}

New methods and missing methodology

Case study: The Drents Museum

Exploring the relation between visitor data and heritage studies

Fuzzy evidence and incompatible conceptual schemes

Some first steps in confirmation theory

Conclusion

Notes

$\mathrm{X}$

Philosophy and the Humanities

IO.I

Notes

10.2

Notes

XI

The Humanities and the Social Sciences

II.I

Windelband and Rickert: Expelling psychology from the humanities

Weber and the explicability of human action

Interpretation as explanation

Conclusion

Notes

II +2

The I830s: Heinrich Hössli and the truth of literature

Mid-nineteenth-century homosexual emancipationists

Richard von Krafft-Ebing and the late-nineteenth-century sexologists

The masculinists and the early twentieth century

Conclusion

Notes

II.3

Notes

II. 4

Cognitive ambiguities and the creation of fields 
Continuity and innovation in artistic research and expression

Comte, Durkheim and the ambiguous emancipation of sociology

Interdisciplinary fusions between sociology, anthropology, history, and the arts

Max Weber, Norbert Elias, and the re-establishment of sociology

Social scientists in search for identity, style, and audiences

Enduring and renewed inspiration from the arts

One culture, many fields

Notes

II. 5

Eichmann in Jerusalem: The banalization of evil

Milgram's punishing experiment and its ambiguous outcomes

Ordinary men or ordinary Germans

History, biography, and immediate context

Notes

XII

The Humanities in Society

I2.I

Introduction
Objectifying partiality (I87I-I945)
Reflecting partiality (I960-I979)
Conclusion
Notes

12.2

Critical Theory and the end/ends of the humanities

Theory, critique, and the tradition of humanism

Theory, critique, and critical thinking

Conclusion

Notes

Epilogue

Ways of knowing in STM and beyond

Chronologies across the knowledge practices

Theory and practice in STM and cultural work

Changes and combinations of knowledge practices

The early modern conjunctures: Meanings, sortings, and calculations

The age of knowledge revolutions

Anatomies of societies and economies

Languages, analysis and history 
A new philosophy of knowing

The decline of national difference and the challenge of natural sciences Coda

Notes

About the Authors

List of Figures

Index 